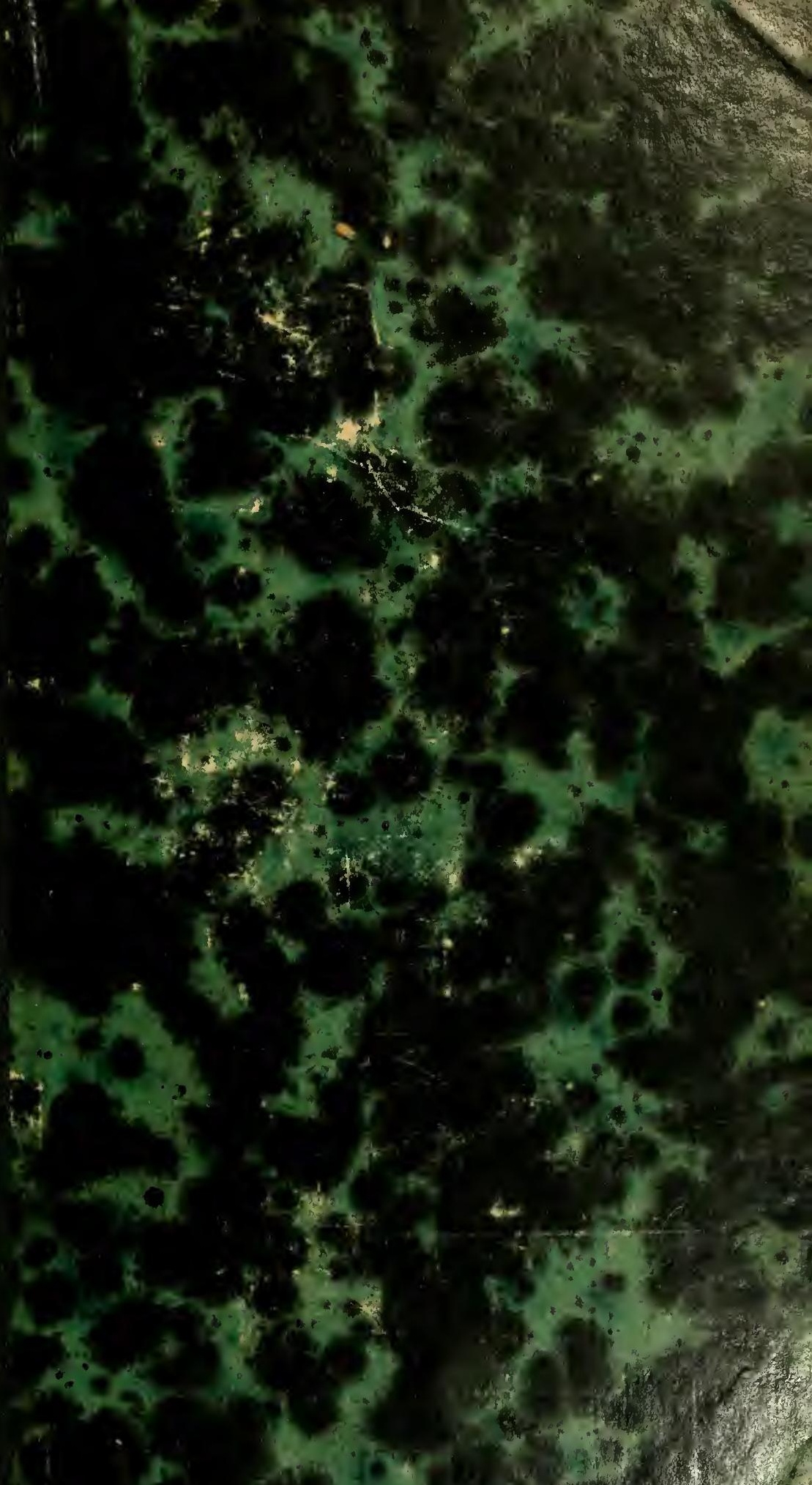




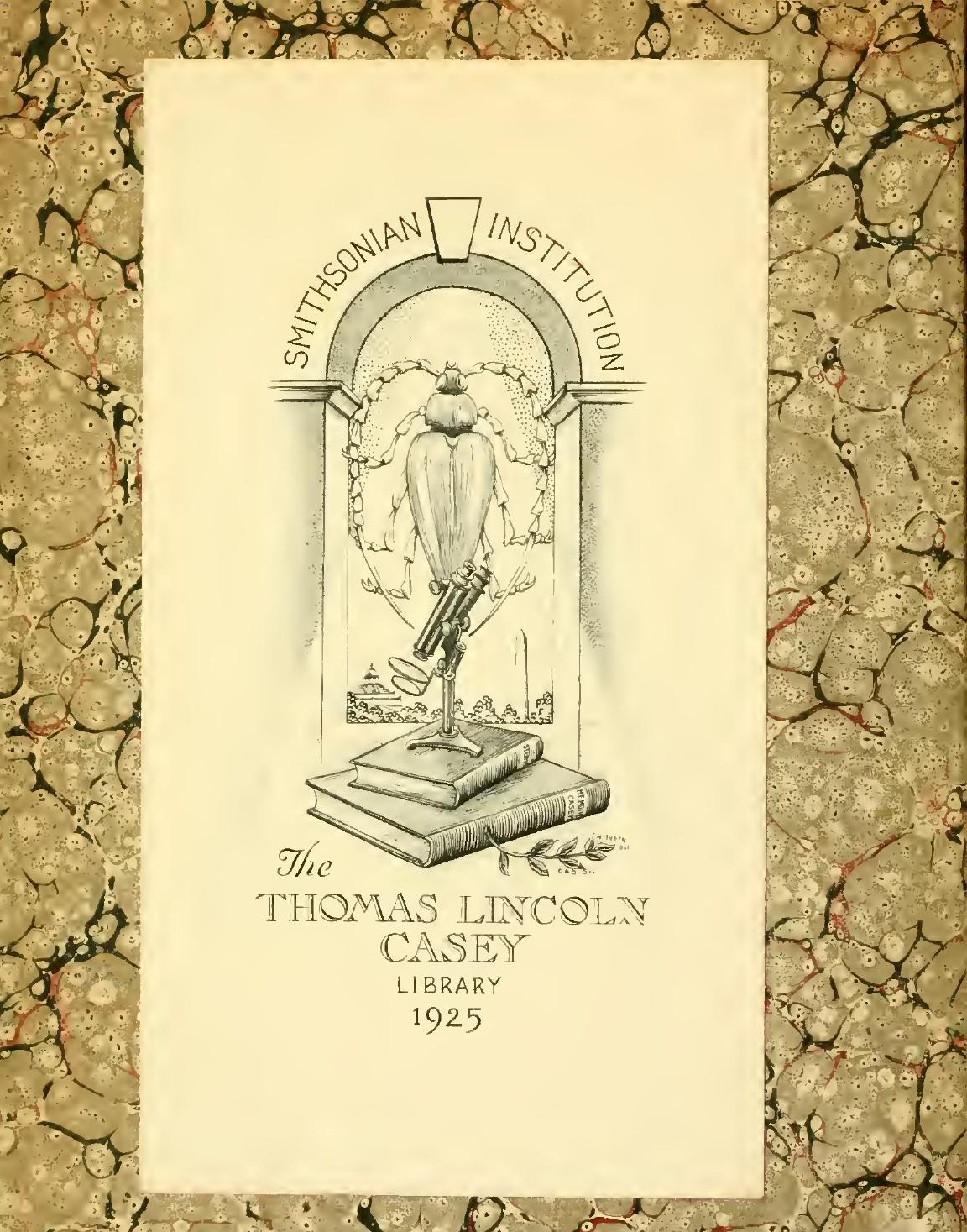




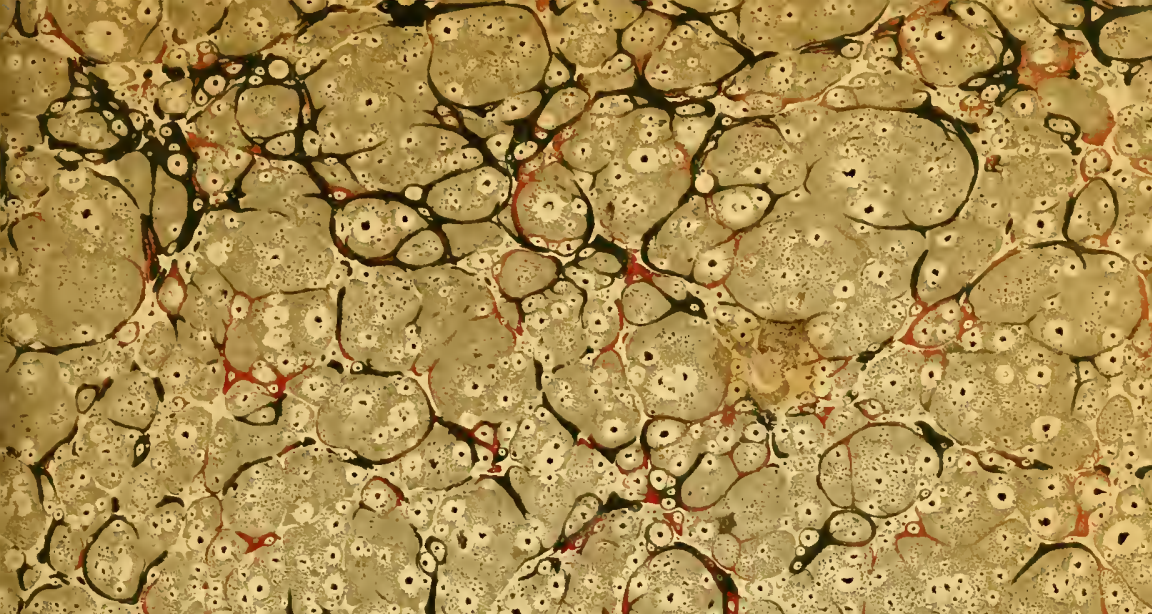

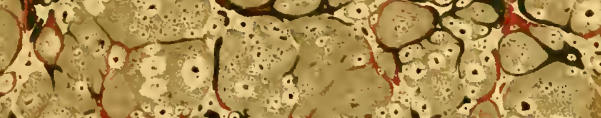

1 ......

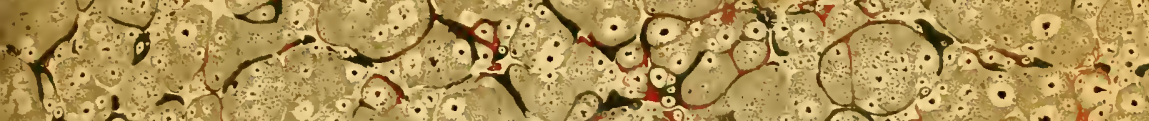
If $60.020 \%$

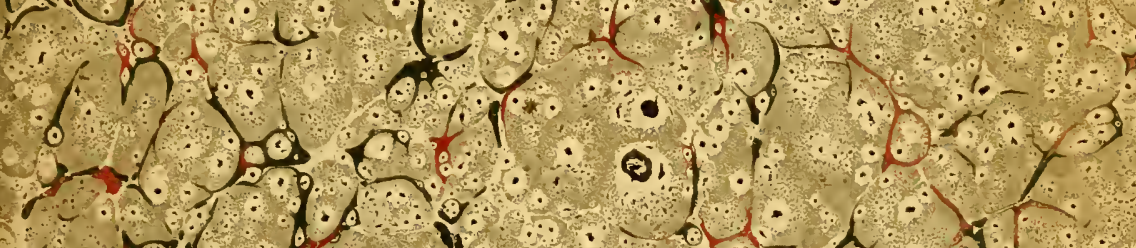

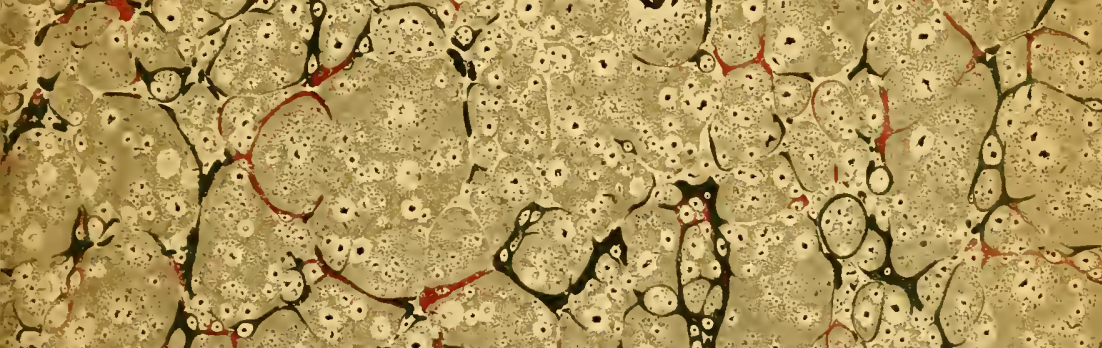

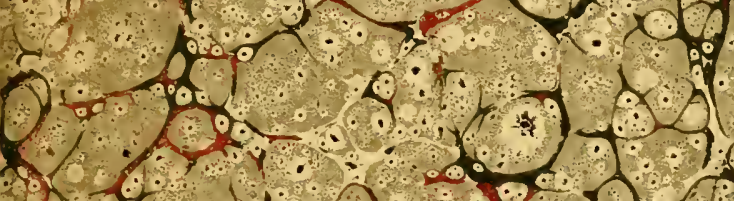

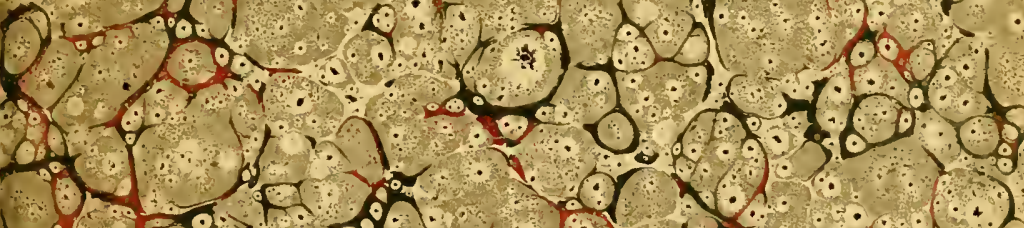
- T. 2 . . . .

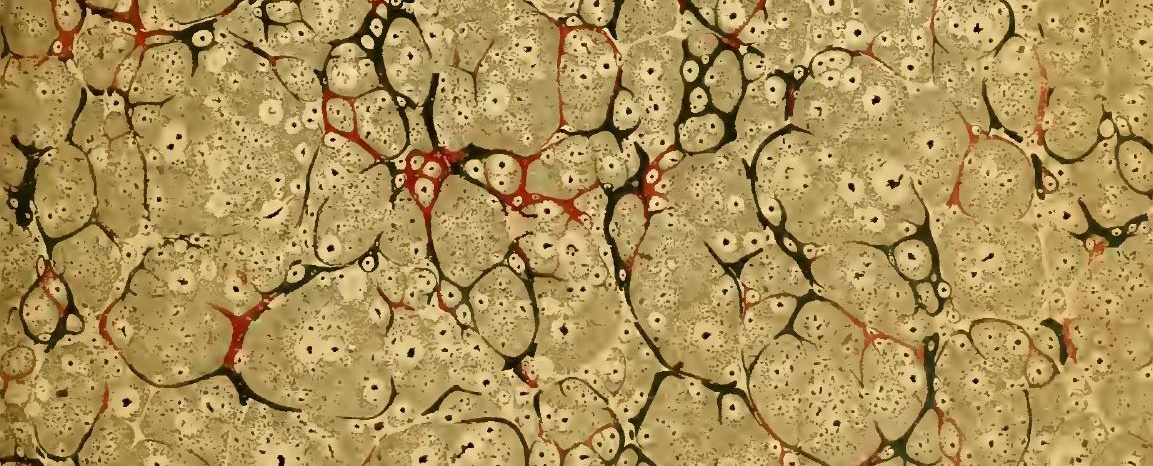

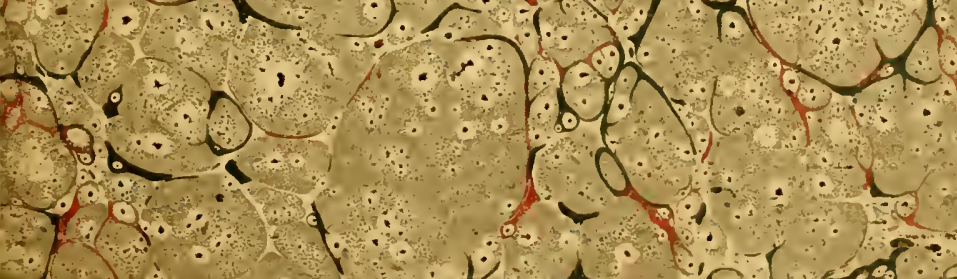





C.2 Ent. ESSA NONOGRAPHIOLE

SWR I, 1

\section{FIVILLE DES IISTÉRIIDES,}

I.U IIPRENANT

LA DESCRIPTION E'T LA FIGURE AU TRAIT

DES LETHES ET DIS ESPÈCES, LEUR DISTRIBUTION MÉPHODIQUE,

AIEC I R RESUME DE LEIRS WOEURS ET DE LEUR A TATOMIE,

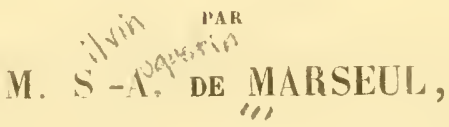

Vrubre de l'Institut des Provinces; de la Société Entoutologique de France; Correspondant des Societés Entomologique de Stettin;

limuéenne de Iyon; d'Agriculture, Sciences et Aris dı Mans, etc.

Extrail des Innales de la Sociele Entomologiyue de trance.

\section{PARIS。}

IMPRIMLIIE ET IITHORRAPHE FELIX MALTESTE ET CIF,

RUE IFS NEUX-PORTES-SAINT-SAUVEUR, 22.

1855. 



\section{ESSAI MONOGRAPHIQUE \\ SUR LA FAMILLE DES HISTÉRIDES.}

Par M. S. A. de MARSEUL.

(Séance du 9 Février 1853.)

\section{AVANT-PROPOS.}

En commençant cette publication, il m'a semblé nécessaire d'exposer en peu de mots mon but, le plan que j'ai suivi et les ressources qui m'ont permis d'entreprendre une monographie si étendue et si difficile.

Depuis longtemps, séduit par les formes si variées et si bizarres des IIistérides, frappé du mystère qui enveloppe la vie si peu explorée des espèces les plus répandues, je m'étais senti un goût prononcé pour l'étude de cette famille et je m'en occupais arec prédilection. Aussi les instances de mes savants amis, MM. Guérin-Méneville et Chevrolat, m'ont-elles déterminć sans peine à produire sur ce sujet un travail sérieux et aussi complet que le comporte l'état actuel de la science. Paykull avait ouvert la marche en 1811 par une monographie remarquable, mais il n'avait connu que quatre-vingt treize espèces. En 1834, Erichson en avait ajouté quatre-vingt dix-sept, et en même temps portant le flambeau de l'analyse dans ce groupe déjả nombreux, il l'avait de main de maître distribué en vingt et une coupes génériques. Dans ces derniè- 
res années, M. Le Conte et quelques autres entomologistes sont venus décrire encore de nouvelles espèces. Mais il en reste un nombre considérable à publier, et il est temps de réunir et de coordonner tous ces travaux épars. C'est ce corps de doctrine que j'ai offert à la Société entomologique de France, et c'est sans doute la difficulté et l'importance de la tâche plus que la valeur intrinsèque de l'œuvre qui m'ont valu, de la part de mes savants collègues, un suffrage si bienveillant, un accueil si empressé et si encourageant pour moi.

De nombrcux matériaux m'ont été communiqués de tous côtés. Gràce à l'obligeance de l'éminent professeur d'entomologie M. Milne Edwards, si zélé pour les progrès de la science, et de MII. Blanchard, Lucas et Boulard, qui ont sccondé ses intentions avec la plus aimable prévenance, il m'a été permis d'examiner à loisir la magnifique collection du Jardin des Plantes. J'ai reçu en communication celle de M. le Marquis de Laferté-Sénectère, si considérable, et où j’ai pu vérifier toutes les espèces du fameux catalogue de la collection Dejean qui en fait le noyau, et beaucoup de types de Paykull, GyHlenhal, Say, Le Conte, etc; celle de M. Chevrolat, riche en types d'Olivier; celles de MM. Guerin-Méneville, Deyrolle, L. Buquet, et d'autres entomologistes distingués.

Tant de richesses mont permis de doubler et au delà le nombre des espèces connues. Je ne me suis pas borné à de simples descriptions. Dans une famille d'insectes de couleur uniforme et ordinairement sombre, il m'a paru indispensable de faciliter l'étude par tous les moyens : tableaux synoptiques conduisant aux espèces par des caractères toujours appréciables; rappel fréquent des différences essentielles qui distinguent les plus voisines; figures au trait de chacune en 
particulier, représentant avec une sévère exaclitude toute ces stries si régulières et si constantes qu'on y remarque.

Dans l'établissement des coupes génériques, j'ai consulté avant tout la forme générale ou facies, vrai miroir de l'ensemble, et ce n'est qu'après avoir groupé les espèces, en rassemblant celles qui ont un air de parenté, si je puis parler ainsi, que j'ai cherché des notes distinctives; car les caractères du genre ne sont pas constants comme le genre luimême. Tout le monde sait que souvent une nouvelle espèce vient renverser l'économie du groupe auquel elle appartient et dont elle porte évidemment le cachet. De même je ne saurais me persuader que tel système d'organes déterminé fournisse toujours des caractères plus importants que tel ou tel autre; chaque forme n'est-elle pas stable dans une famille et variable dans une autre? Mais quand bien mème j'eusse admis ce principe exclusif, je me serais vu forcé de chercher mes caractères ailleurs que dans les parties de la bouche, sous peine de rendre impossible l'étude des Histérides, et d'obliger l'amateur à classer au hasard ou à faire un travail de dissection ardu et le plus souvent impraticable. Aussi, tout en étudiant avec soin et en figurant même les parties de la bouche, j’ai préféré recourir à des organes plus visibles et d'un examen moins difficile.

A la description des genres et des espèces vient se joindre une étude d'ensemble sur les caractères de la famille, sur sa distribution en sections et en genres, accompagnée d'un résumé de l'anatomie et des mœurs, de l'historique de science et d'une table alphabétique des auteurs. Naturellement cette partic devrait précéder; mais la publication de cette monographie, qui se fera par mémoires separés, devant durer assez longtemps, à cause de sa longueur, il serait à rraindre que de nouvelles découvertes ne vinssent. 
modifier mes idées et rendre mon essai disparate ou incomplet. On me permettra done de ne la donner qu'en dernier lieu.

Je ne terminerai pas ees courtes réflexions sans témoigner ici publiquement ma reconnaissanee à toutes les personnes qui m'ont aidé de leurs livres, de leur collection ou de leurs conseils. A ceux que j’ai déjả nommés j'ajouterai les suivants: pour la France : MII. L. Fairmaire, Jaequelin-Duval, Javet, Jekel, Percheron, Reiche et Auguste Sallé, à Paris ; Mulsant, á Lyon; Gélin et Bellevoye, à Metz; Mocquerys, à Rouen ; Pilate, à Wazemmes; Blisson, au Mans; Perris, à Montde-Marsan; pour l'étranger : MM. T. Lacordaire, à Liège; Saunders et Waterhouse, à Londres; Dohrn, à Stettin.

Explications de quelques termes partieuliers employés.

Le pronotum désigne la partie dorsale du prothorax; le prosternum, le milieu de sa partie pectorale, entre les hanches antérieures, ordiuairement un peu saillant, terminé en devant par une avance (lobe prosternal) plus ou moins forte, séparée par une ligne transversale. Le pronotum est marqué d'une ou plusieurs stries; la plus rapprochée du bord est appelée marginale, les autres, latérales.

Les élytres ont une partie abaissée (bord infléchi ou repli latéral) enserrant l'abdomen, avec une fossetle subhumérale et une ou plusieurs stries marginales. En dessus, on remarque presque toujours une petite strie (humérale) qui coupe obliquement l'épaule; en dehors de laquelle, une ou deux subhumérales; en dedans les dorsales, ordinairement au nombre de cinq, qui se comptent à partir de l'épaule, et le long de la suture, la suturale.

L'abdomen laisse voir en dessus ses deux segments extrêmes; le dernier est le pygidium, et l'avant-dernier le propygidium. 
Inutile d’insister sur ces dénominations, dont on se rendra compte aisément en étudiant deux ou trois espèces sur la description confrontée avec la figure.

Nota. La longueur indiquée par une ligne dans les planches va, non d'une extrémité à l'autre, mais du bord antérieur du pronotum à l'extrémité de la suture.

\section{HOLOLEPTA.

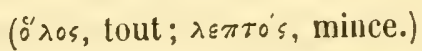

Soc. Ent. $3^{\mathrm{e}}$ série, T. 1 (1853), pl. 1v. - Molı. pl. ${ }^{\text {ro }}$. Genre I, f. 1-31.

Hister, Linné (1746). Mololepta, Paykull. Mon. Hist. p. 101. T. 1 (1811). - Erichson, in Jalur. 1, 87, I (1834). - Le Conte, N. Amer. Hist. 6 (1S45).

Corpus planum.

Caput exsertum.

Mandibulce porrectie, requales.

Labrum purvum, bilobum.

Maxille pone mentum insertce, prorsus coopertie.

Prosternum latum, planum, parum elevatum, lobo truncato. Tibice extus dentate, subtus inermes, antice intus dente basali.

Propygidium lalum horisontale, hexagonum; pygidium breve, perpendiculare.

Corps aplati, déprimé, plus ou moins allongé.

Tête saillante, ne pouvant pas s'enfoncer dans le prothorax; front sans strie, ou seulement avec une courte strie transversale de chaque côté, non distinct de l'épistome, avec une dent au devant des yeux, au-dessus de l'insertion des antennes. Labre court, échancré. Mandibules saillantes, plus ou moins longues, légèrement courbées vers la pointe, 
égales entr'elles, ordinairement inermes, creusées en dedans pour loger le lobe et le palpe maxillaire.

Antennes (f. 6 a) insérées sous le rebord du front, entre les yeux et les mandibules; scape allongé, légèrement courbé et épaissi au bout, logé dans une rainure de la partie inférieure de la tête; funicule de sept articles; premier un peu plus long que les suivants, qui s'élargissent un peu vers le bout; massue ovale comprimée, de quatre articles, placée sous le bord antérieur du prothorax, au devant des hanclies, sans fossette bien accusée.

Menton (f. $10 f, q)$ coupé droit à sa base, plus ou moins excavé, échancré en devant; languette (f. $6, c)$ cachée par le menton. Paraglosses membraneuses, courbées, garnies de poils en dedans, insérées derrière le menton. Palpes labiaux tri-articulés, troisième article plus long que le deuxième. Mâchoires (f. $6 b$ ) à lobes étroits, garnis de poils en dedans, l'externe corné, allongé, l'interne beaucoup plus court, membraneux. Palpes maxillaires de la longucur du lobe maxillaire externe, premicr article très petit, deuxième et troisième cylindriques, allongés, quatrième bcaucoup plus court, obtus. Ils sont logés, ainsi que les lobes maxillaires, dans une coulisse pratiquée dans l'épaisseur des mandibules.

Pronotum sub-bisinué à la base, plus ou moins arrondi sur les côtés, et fortement échancré en devant, plus large que long. Strie marginale plus ou moins forte. Prosternum peu élevé, large, arrondi à la base, un peu rétréci au milieu, séparé par une strie transversale d'un lobe prostcrnal court, droit ou échancré en devant. Mésosternum court, échancré en devant, pour recevoir la base du prosternum. Pièce humérale visible en dessus. Ecusson petit, triangulaire. Elytres courtes, coupées obliquement au bout: une strie sub-humérale alteignant rarement la base; pas d'humérale. 
et quelques rudiments des premières dorsales soit à la base, soit au bout.

Abdomen de cinq segments, dont le premier, plus large, est marqué de chaque coté d'une strie sinueuse. La partie supérieure des deux derniers est visible en dessus: le propygidium est horizontal et en hexagone; le pygidium, court et perpendiculaire.

Cuisses postérieures renflées, fort distantes à leur insertion. Jambes antérieures (f. $6 d$ ) garnies de quatre dents sur l'arête du dessus, lisses ou légèrement dentées sur l'inféricure du bord externe, avec une dent à la base du bord interne, lequel vient se loger dans une coulisse de la cuisse; terminées par deux épitues inégales. Fossette tarsale courbée, profonde, bien limitée de toutes parts. Jambes moyennes et postérieures (f. 6,e) terminées par deux épines, et armées au bord externe de dents sur l'arête supérieure, l'inférieure lisse. Tarses filiformes et minces, avec les quatre premiers articles garnis chacun de deux petites soies.

Ce genre est le premier qui ait été démembré du grand genre Hister de Linné. Paykull l'a caractérisé en 1811 dans son remarquable ouvrage, Monographia histeroidum ; mais il y fait entrer avec les vraies Hololeptes toutes les autres espèces aplaties, soit qu'elles puissent ou non enfoncer la tête dans le prothorax, soit qu'elles aient une dent à l'origine en dedans des jambes antérieures, et des dentelures sur l'arête inféro-externe des postérieures, ou qu'elles en soient dépourvues, soit que le prosternum s'élève en carène saillante, appointie au bout antérieur, ou se montre élargi, peu saillant et tronqué, soit enfin qu'elles aient le labre court ou allongé, et les mâclıoires articulées au dessus ou en deliors du menton,

Erichson, qui a sérieusement remanié cette famille dans 
le Jahrbucher, publié en 1834, tout en conservant le genre Hololepıa, pour les espèces dont la tète est dégagée du prothorax, le labre court, les mâchoires insérées au-dessus du labre, et les jambes antérieures munies en dedans à l'origine d'une petite dent, a réparti les autres dans les genres Phylloma, Oxysternus, Platysoma et Paromalus.

En adoptant les bases de ce travail, admis dans la science, j'ai cru devoir, à l'exemple de Dejean dans son Catalogue (1837), séparer encore du genre Hololepta les espèces dont le prosternum en carène saillante, s'avanceen pointe plus ou moins arrondie sous la bouche et dont les jambes postérieures ont l'arête inférieure dentelée. Ainsi le genre se trouvera composé de trente et une espèces, H. plana, F.; humilis, Pkl.; fossularis, Say; Indica, bractea, Cubensis, aradiformis, procera, clongata, Er.; lucida, Le Conte, attenuata, Blanch., et vingt nouvelles.

Elles sont répandues, inégalement il est vrai, sur tout le globe: une vient d'Europe, cinq d'Asie, trois d'Afrique, vingt et une d'Amérique, et une de la Nouvelle-Hollande.

Elles vivent sous les écorces des arbres abattus, dans le terreau humide qui s'y forme. Leurs métamorphoses sont inconnues. La larve que Paykull figure et decrit est celle d'un Diptère.

Le $\sigma^{*}$ a le pronotum dilaté en devant, les mandibules plus allongées, droites et arquées au bout; sauf une ou deux espèces, une profonde excavation bien limitée sous le menton, prolongée angulairement au devant du prosternum; souvent une échancrure ou une fossette à l'angle antérieur du pronotum. La + a les mandibules plus courtes, arquées dès la base, ordinairement le menton obsolètement impressionné, et l'angle antérieur du pronotum sans dilatation, échancrure, ni fossette $(f, 10 f, q)$. 

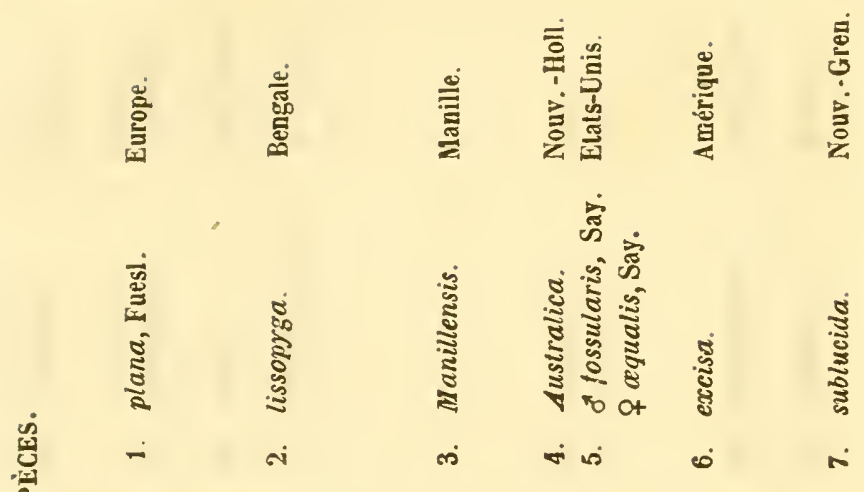

点

彭受

1 要

เ

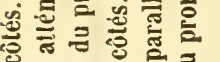

国 号

\&

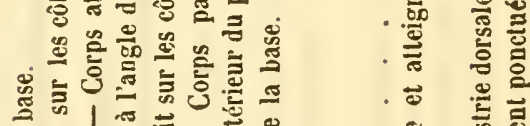

हूँ

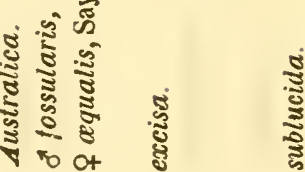

ङ

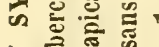

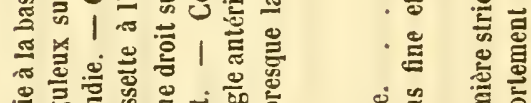

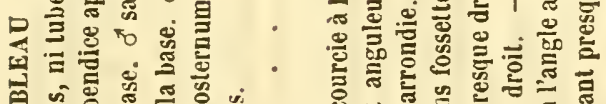

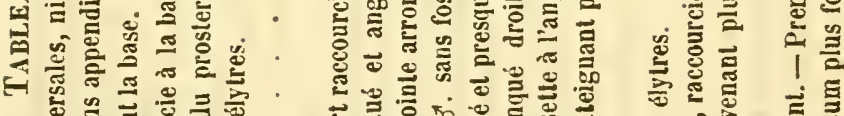

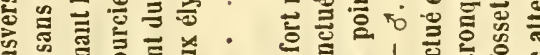

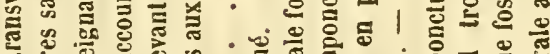

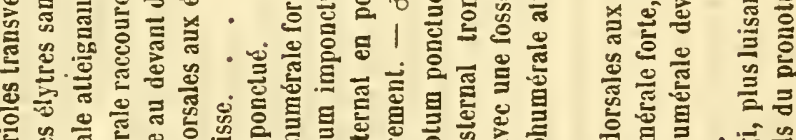

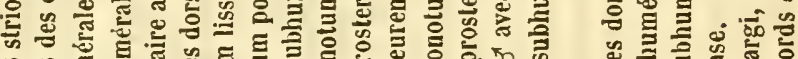

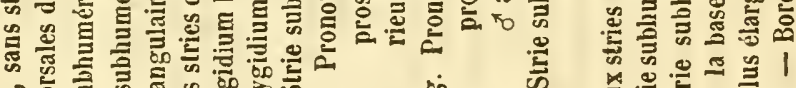

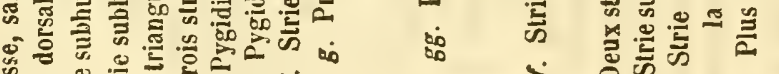

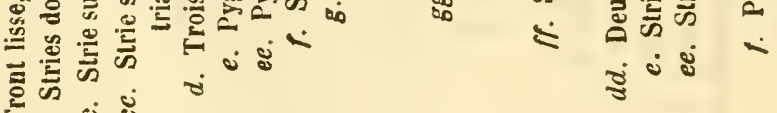




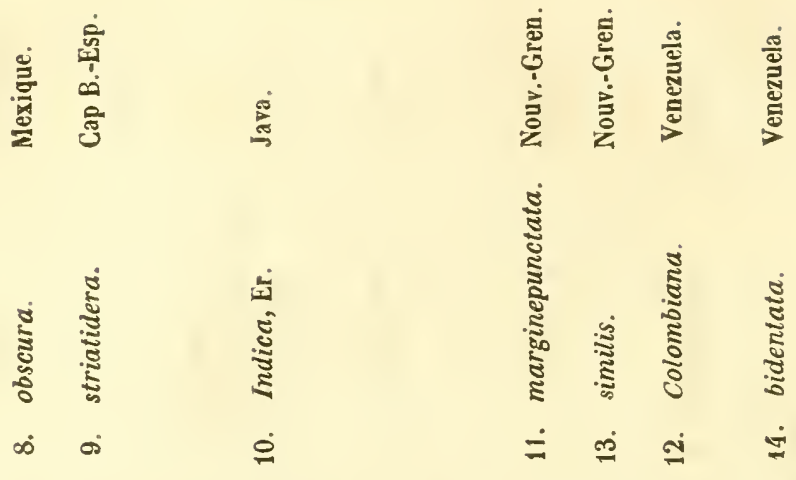

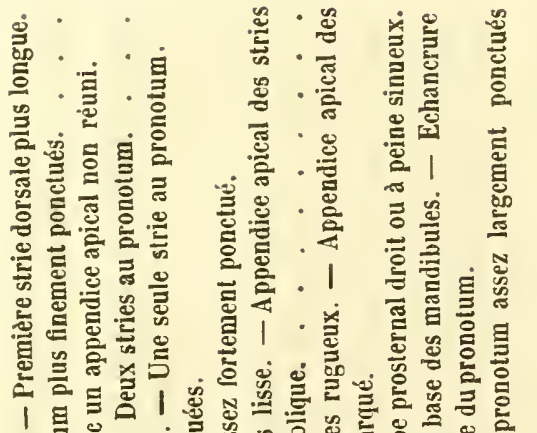

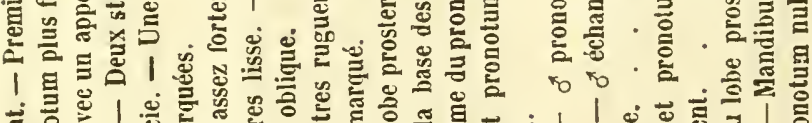

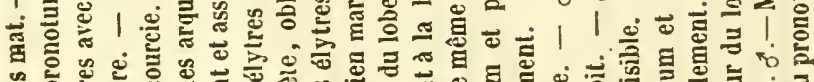

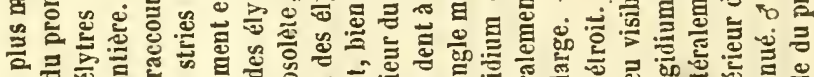

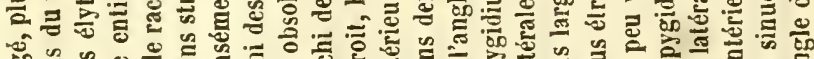

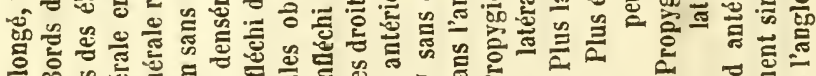

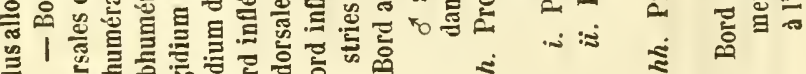

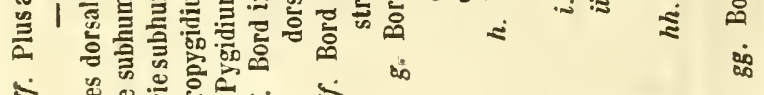

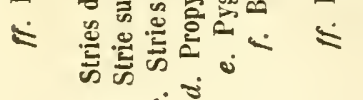
sis 


\section{Hololepta.}

离

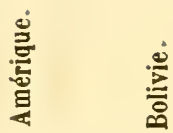

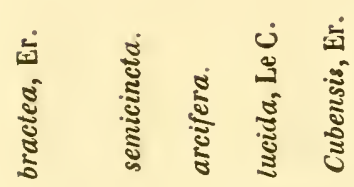

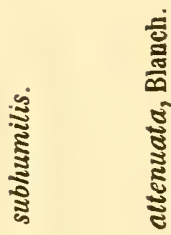

i $\quad \therefore \quad \infty \quad \infty$

त तี

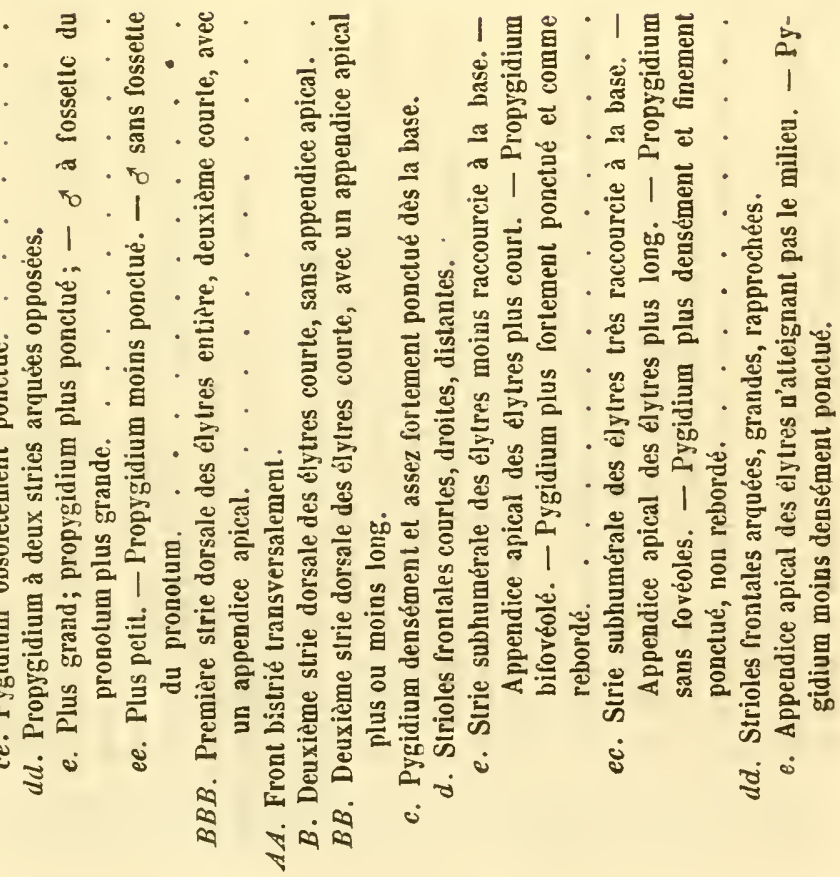




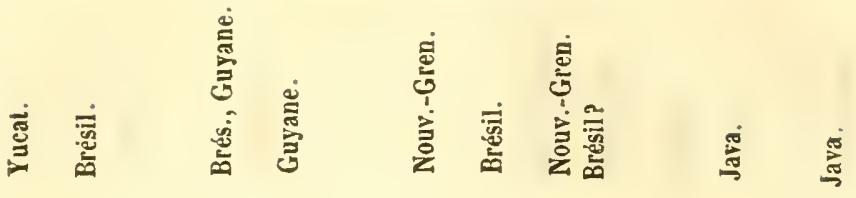

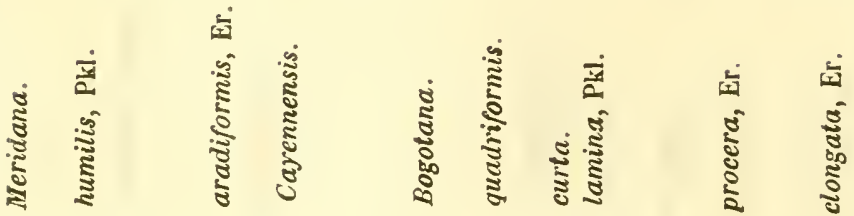

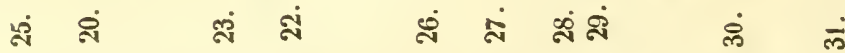

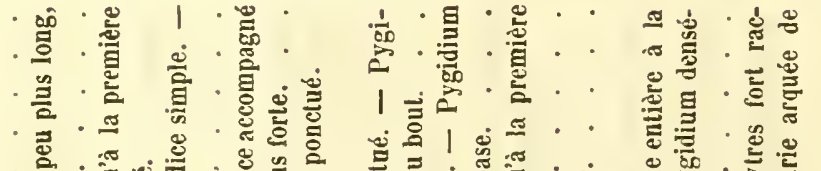

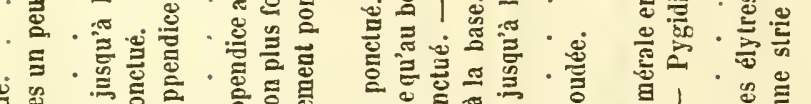

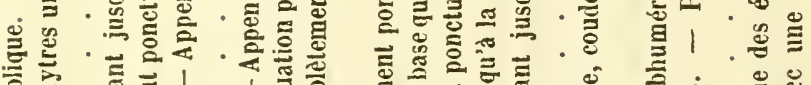

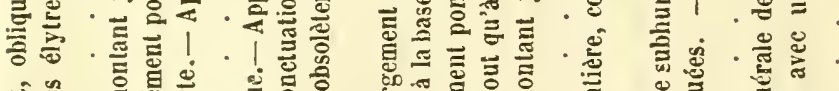

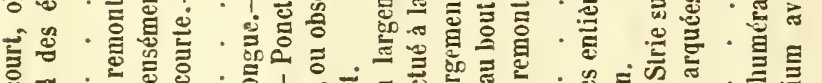
ठี.

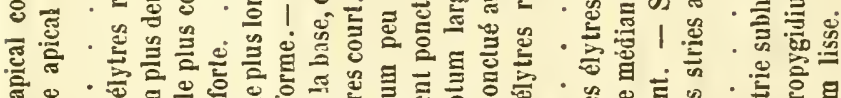

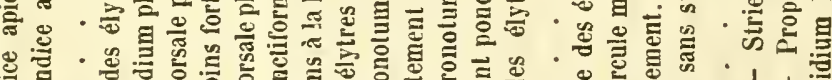

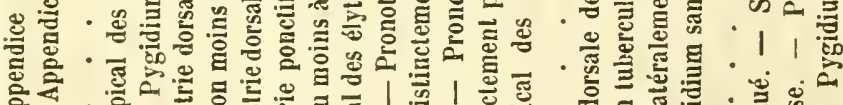

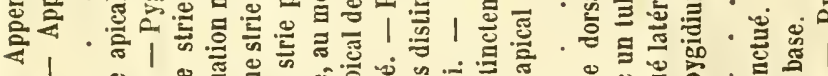
।

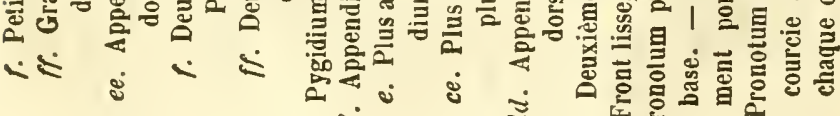

$$
\begin{aligned}
& \text { डं }{ }^{\circ} \text { \& } \\
& \text { बत्ष बं }
\end{aligned}
$$


A. Front sans stries, ni tubercule (1-18).

B. Stries dorsales des élytres sans appendice apical (1-8).

\section{H. Plana,}

Nigra nitida, depressa; fronte aquali; pronoto stria marginali tonuissima; clytris stria humerali basim attingente, 2 dorsalibus abbreviatis ; pygidio subimpunctato. Long. 6-7 mill.; larg. 4 mill.

Hister planus, Fuesl. 5, 68 (1775). - F. Mant. 1, 32, 5. - Ent. Syst. 1, 73, 7. - Syst. El. 1, 90, 36. - Ol. Ent. 1, 8, 15, 16, pl. 3, 22. - Herlsst. Nat. Syst. Ins. 4, 33, 8, pl. 35, 8. - Panz. Ent. Germ. 1, 21, 6. xcII, 4. - Illig. Kaf. pr, 1, 65, 25. - Sturm. Deut. 1. 244, 28.

Hololepta plana, Payk. Mon. Hist. 107, 5, T. Ix, f. 3. - Gyll. Ins. Suec. Iv, 272, 3. - Küst. Kxf. Eur. 1II, 32.

Allongé-parallèle, Irès aplati, d'un noir luisant. Front plan, sans strioles transversales, ni tubercule; dent préoculaire peu saillante; antennes d'un noir de poix, massue grise; mandibules saillantes, sans dents, légèrement courbées. Pronotum plus large que long, légèrement bisinué à la base, arrondi et faiblement anguleux sur les côtés, échancré en devant, avec les angles un peu obtus; strie marginale fine, rapprochée du bord. Ecusson petit, triangulaire. Elytres de la largeur du pronotum, et à peu près de sa longueur, parallèles sur les côtés, obliques au bout, et formant un angle sutural bien prononcé ; strie subhumérale forte, plus fine vers la base, qu'elle atteint: deux dorsales raccourcies, première à peine du tiers de la longueur totale, deuxième presque réduite à un point; bord infléchi imponctué. Propygidium bordé de points épars; pygidium à peine distinctement pointillé. Jambes antérieures garnies en de- 
hors de quatre dents obtuses, postérieures de trois fortes dents sur l'arête supérieure.

Le $\sigma^{\pi}$ se distingue de la + par le pronotum plus élargi en devant, les mandibules plus droites et l'échancrure du menton plus profonde.

Cette espèce se trouve dans plusieurs contrées de l'Europe centrale et méridionale : France, Allemagne, Suisse,Autriche, Styrie, Carinthie, Silésie, Hongrie, Russie méridionale, Caucase, Turquie; dans l'Arménie, et même dans l'Amérique septentrionale, d'après le témoignage de Paykull. Elle vit sous l'écorce des arbres morts, et elle est peu commune.

\section{H. LISSOPYGA.}

Latior, planiuscula, nigra nitida; fronte tovi; pronoto stria marginali valida, lateribus punctato; clytris striis a dorsalibus brcvissimis, subhumerali forti, abbreviata, margine inflexo lavi; propygidio latcribus punctato, pygidio impunctalo. Long. 12 mill.; larg. 6 mill.

Ovale élargi, aplati, d'un noir luisant. Front lisse, sans stries, ni tubercule; antennes d'un noir de poix, funicule brun, massue grise. Mandibules allongées, sans dents, droites 8 , et un peu courbées au bout; dent préoculaire saillante. Pronotum court et large, bisinué à la base, avec une fine strie raccourcie au devant de l'écusson, légèrement dilaté au-delà du milieu, largement échancré en devant, avec les angles arrondis, un peu échancrés dans les deux sexes; lisse sur toute sa surface, avec des points assez gros le long des côtés; strie marginale forte (terminée à l'angle antérieur en une fossette grosse et profonde $\sigma^{*}$ ). Ecusson petit, triangulaire. Elytres de la largeur du pronotum à la base, de salongueur à la suture, coupées obliquement au bord apical, 
et formant une échancrure semi-circulaire; strie subhumérale large, profonde, raccourcie en devant; trois dorsales courtes, obliques, sans rudiment apical, première forte, à peu près de la longueur du tiers des élytres, loord infléchi imponctué. Propygidium entouré de points, plus gros latéralement. Pygidium lisse. Echancrure du menton daus les deux sexes, sans tubercule médian, avec une double rainure à l'angle prosternal. Jambes antérieures armées de quatre dents, postérieures de trois, les apicales rapprochées.

Le mâle se reconnaît à la fossette du pronotum.

Bengale.

\section{II. Manillensis.}

Postice angustior, complanata; fronte ctquali; pronoto stria marginali integra angulata; clytris margine inflexo lovi, stria subhumerali abbreviata, $1^{\mathrm{a}}$ dorsali brevi, $2^{\mathrm{a}}$ vix conspicua; propygidio lateribus sparsim, pygidio dense et fortiter punctatis. Long. 11 mill.; larg. 6 mill.

Ovale allongé, rétréci postérieurement, aplati. Front uni, sans stries, ui tubercule; antennes brunes, massue grise. Dent préoculaire saillante. Pronotum beaucoup plus large que long, bisinué à la base, avec une demi-strie longitudinale au devant de l'écusson, dilaté angulairement sur les côtés, échancré en devant, avec les angles obtus, non échancrés ơ ; strie marginale entière, anguleuse. Ecusson petit, triangulairc. Elytres de la longueur du pronolum, de sa largeur à la base, légèrement élargies sur les côtés, rétrécies et obliques au bord apical, formant un angle sutural très ouvert; bord infléchi lisse; strie subhumérale forte, raccourcie à la base; première dorsale oblique, du quart de la longueur, deuxième et troisième peu visibles. PropygiЗе Série, томе I. 
dium couvert de points peu serrés dans son pourtour. Pygidium densément et fortement ponctué. Forte excavation au devant du prosterium, avec un tubercule alıngé au milieu. Jambes inermes sur l'arête inférieure, et armées sur la supérieure, les antérieures de quatre dents, les postérieures de trois.

Je n'ai vu qu'ui seul individu de cette espèce; il fait partie de la riche collection du Muséum, et vient de Manille.

\section{H. Australica.}

Oblongu depressa, nigra, nitida: fronte atquali; pronoto lateribus punctato, antice utrinque fovcolato, stria marginati validu, vix angulata; rlytris striu subhumerali valida, ubbreviata, 3 dorsalibus brecissimis, 1 a longiori ; propygidio latoribus parce, pygidio dense menctutis. Long. 13 mill.; larg. 7 mill.

Allongẻ, presque parallèle, quoique un peu rétréci postérieurement, déprimé, d'un noir luisant. Front lisse, sans stries, ni tubercule; dent préoculaire peu saillante; mandibules fortes; antennes d'un brun de poix roux, massue velue. Pronotum bisinué à la base, avec une demi-strie longitudinale au milieu, à peine arqué et bordé de points sur les còtés, bisinueusement échancré en devant, avec les angles étroitement découpés; strie marginale forte, à peine coudée et terminće par une profonde fossette arrondie, un peu arant l'angle antérieur. Ecusson petit, triangulaire. Elytres le la largeur du pronotum à la base, et à peu près de sa longueur à la suture, droites sur les côtés, obliques au bout, et formant un angle sutural peu profond; bord infléchi lisse; strie subhumérale fort raccourcie à la base, premiere dorsale du tiers environ de la longueur, denxième et troisième tout 
à fait rudimentairss. Propygidium bordé latéralement de gros points espacés; pygidium assez densément ponctué. Jambes antérieures quadri-dentées, arec quelques dentelures en dessous : postérieures armées de trois fortes épines.

Celte espèce est assez répandue dans les collections de Paris, sous le nom d'H. Australica, que M. Reiche lui assigna lorsque, le premier, il la reçut de Swan-River (NouvelleHollande). Dans tous les individus on retrouve l'excavation du menton et la fossette arrondie de l'angle antérieur du pronotum, qui caractérisent le $\sigma^{x}$. Quelques-uns ont les mandibules plus courbées, moins fortes, et le pronotum moins dilaté en devant; je n'ai pas pu m'assurer directement si ce sont des $q$.

\section{H. FOSSULARIS.}

Elongata, complanata, nigra nitida; frontc aipuali; monoto lateribus vix punctato, stria marginali angulata; elytris stria sublumerali basin subattingente 3 dorsalibus brevissimis, margine inflexo lovi; propygidio lateribus parce, pygidio sat dense punctatis. Long. 8 mill.; larg. $41 / 2$ mill.

Hololepta fossularis ơ. Say, Phil. Soc. $\mathrm{v}, 1,47,2$ (1825). II. cequalis ㅇ. Say. Plil. Soc. v, 1, 47, 1.

Assez allongé, aplati, d'un noir luisant. Front plan, lisse, sans stries, ni tubercule; dent préoculaire peu saillante; mandibules grandes; antennes brun de poix. Pronotum court, bisinué à la base, avec une demi-stric longitudinale au milieu, anguleux et bordé de quelques points sur les côtés, échancré en devant, avec les angles peu aigus; strie marginale bien marquée, coudíe an milieu. Ecusson petit, triangulaire. Elytres de la largeur du pronotum à la base, de sa longueur à la suture, à peine courbées sur les côtés, 
obliques au bout et formant un angle sutural peu profond; strie subhumérale à peine raccourcic à la base; première dorsale forte, moins longue que le tiers des élytres, deuxième et troisième fort raccourcies; bord infléchi non ponctué. Propygidium bordé latéralement de quelques points espacés. Pygidium assez densément ponctué. Jambes antérieures armées de qualre dents obtuses: postérieures de trois fortes épines.

Le $\sigma^{*}$ se reconnaît à l'excavation du menton, à la fossette du pronotum accompagnée d'une petite échancrure dans l'angle méme, lesquelles n'existent pas dans la + .

Say a fait une deuxième espèce de la + , sous le nom d'Hol. aqualis. Cet insecte vit sous l'écorce des arbres morts, et en particulier du Robinia pseudo-acacia, L., dans l'A mérique septentrionale.

\section{H. ExCISA. (F. 6, $a, b, c, d, c$.)}

Latior, subdcpressa, nigra nitida; fronte cequali; monoto lateribus punctulato, stria marginali vix angulata; clytris margine inflexo rugoso, stria subhumerali antice parum abbreviata, 2 dorsalibus brevissimis; propygidio latcribus parce, pygidio dense et grosse punctatis. Long. 10 mill.; larg. 5 1/2 mill.

Oblong, un peu plus large, subdéprimé, noir luisant. Front plan, très finement pointillé, sans stries, ni tubercule; dent préoculaire assez saillante; mandibules grandes, fortes; antennes noir de poix, massue velue, grise. Pronotum court, très élargi, bisinué à la base, arec une demi-strie fine longitudinale au milieu, dilaté anguleusement et bordé de points peu nombreux sur les cỏtés, bisinueusement échancré en devant, avec les angles peu avancés; strie marginale rapprochée du bord et bien marquée. Ecusson petit, triangu- 
laire. Elytres de la largeur du pronotum à la base, et de sa longueur à la suture, obliques au bout et formant un angle sutural bien marqué; bord infléchi fortement rugueux ; strie marginale forte, rugueuse, un peu raccourcie à la base; deux dorsales très rudimentaires. Propygidium bordé de points espacés. Pygidium densément et fortement ponctué. Jambes antérieures armées de quatre dents obtuses : postérieures de trois épines longues.

Le $\sigma^{*}$ est caractérisé par l'excavation du menton et par une échancrure dans l'angle même du pronotum.

Cette espèce est répandue en Amérique, depuis les EtatsUnis jusqu'au Brésil. J'en ai vu des exemplaires provenant des Etats-Unis, du Mexique, du Venezuela, de la NouvelleGrenade et du Brésil.

\section{H. SEBLUCIDA.}

Oblonga, complanata, nigra nitida; fronte aquali; pronoto latcribus punctato, stria marginali tonui angulata; clytris stria sublumerali forti antice attenuata, subintegra, 2 dorsalibus brevibus; margine inflexo rugoso; propygidio punctis parcis cincto, mygidio dense et fortiter punctato. Long. 9 mill.; larg. 5 mill.

Ovale, aplati, noir luisant. Front uni, sans stries, ni tubercules; antennes brun de poix, massue cendrée. Pronotum court, large, subbisinué à la base, avec une demistrie longitudinale très fine au milieu, anguleusement dilaté sur les côtés, largement échancré en devant (avec les angles antérieurs échancrés $\sigma^{x}$, aigus $\%$ ), ponctué le long des bords latéraux; strie marginale fine, rapprochée du bord, anguleuse et atteignant l'angle antérieur. Ecusson peiti, triangulaire. Elytres de la largeur du pronotum à la base, et 
de sa longueur à la suture, légèrement dilatées à l'épaule, coupées obliquement au bord apical, angle sutural très obtus; bord infléchi rugueus ; strie sublıumérale forte, deveuant plus fine à la base, et presque entière, deux dorsales obliques fort courtes. Propygidium ceint de points épars peu nombreux. Pygidium densément et assez fortement ponctué. Jambes antérieures armées de quatre dents, les deux apicales n'en formant souvent qu'une seule obtuse : postérieures de trois épines.

Le o differe de la $q$ par l'excavation anguleuse du menton et par l'échancrure du pronotum.

Très voisin de l'Ilol. excist, il s'en distingrue par la strie subhumérale qui, au lieu d'ètre fort raccourcie à la base conme dans celui-ci, devient très fine et paraît l'atteindre.

Carthagène, Nouvelle-Grenade.

\section{II. OBSCURA.}

Oblongo-ovata, depressa, atra subnitida; fronte cequali: monoto lateribus temissime et marec munctato, stria marginali subangulata; elytris margine inflexo mgoso; stria subhumerali forti, antice attemata, sub integra, 2 dorsalibus, $1^{\text {a }}$ sat clongata; propygidio circum parce, pygidio densissime punetatis. Long. 8 mill.; larg. $41 / 2$ mill.

Ovale allongé, rétréci postérieurement, aplati, d'un noir presque mat. Front lisse, sans stries, ni tubercule; antennes d'un brun de poix, massue grise. Pronotum court, transversal, bisinué à la base, légèrenent dilaté sur les côtés, avec quelques points, échancré en derant, et les angles entiers faiblement impressionnés: strie marginale fine, angruleuse, atteignant l'angle antérieur. Ecusson pelit, triangulaire. Elytres de la longueur di pronolum, et de sa 
largeur à la base, légèrement arquées sur les còtés, coupées obliquement au bord apical, et formant une échancrure semi-circulaire; bord infléchi rugueux à l'épaule ; strie subhumérale forte, devenant plus fine à la base, et presque entière; deux dorsales; première atteignant presque la moitié de l'élytre. Propygidium ceint l'une ponctuation peu serrée et assez large. Pygidium très densément et asse fortement ponctué. Excavation du menton bien marquée dans le malle. Jambes antérieures armées de quatre dents, les deux apicales n'en formant qu'une seule obtuse, à peine divisée : postérieures tri-dentées.

Je n'ai vu qu'un seul individu provenant de Mexico. (Collection du Muséum.)

BB Stries dorsales des élytres arec un appendice apical non réuni $(9-17)$.

\section{H. STRLATIDERA.}

Ovata lata, subdepressa, nigra nilida; fronte cequali; pronoto lateribus punctato, striis marginali et laterali, utraque in angulo antico desinente; elytris margine inflexo locvi, stria subhumerali integra, validissima; 2 dorsalibus validis latis, $1^{\text {a }}$ subintegra, $2^{\text {a }}$ parvo appendice ancta: propygidio punctis parcis cincto, apice bifoveolato, mygidio dense munctato. Long. 9 mill.; larg. 6 mill.

Ovale, très large, subdéprimé, d’un noir très luisant. Front légèrement fovéolé, sans stries, ni tubercule; antennes d'un brun de poix, massue grise. Pronotum court, très large, bisinué à la base, avec une demi-strie longitudinale au milieu, curvilinéairement dilaté sur les côtés, largement écliancré en devant, avec les angles arrondis ; finement 
pointillé, avec de forts points le long des bords latéraux; strie marginale très fine, peu distante postérieurement, latérale bien marquée, l'une et l'autre atteignant l'angle antérieur. Ecusson très petit, triangulaire. Elytres de la largeur du pronotum à la base, de sa longueur à la suture, à peine dilatées sur les côtés, coupées obliquement au bout, angle sutural bien prononcé; repli latéral lisse; strie subhumérale très forte, entière, mais un peu moins grosse à la base; première dorsale très large d'abord, à peine interrompue au milieu, deuxième plus courte, avec un court appendice apical fort éloigné. Propygidium ceint de points épars, peu serrés, et bifovéolé. Pygidium densément ponctué. Excavation du menton profonde $\sigma^{*}$, prolongée en queue. Jambes antérieures armées de quatre dents, postérieures de trois, les deux apicales rapprochées.

Je n’ai vu qu'un individu de cette espèce (coll. Laferté). Il provient du cap de Bonne-Espérance.

\section{II. INDICA.}

Lata, subdcpressa, nigra nilida; fronte apquali: pronoto latcribus dilatatis, impunctatis, stria marginali angulata; clytris margine inflexo tavi, stria subhumerali lata, antice abbreviata, 2 dorsalibus brevissimis, $1^{\text {a }}$ appendice acula; propygidio parce circum, pygidio dense munctatis. Long. 9 mill.; larg. 4 mill.

Hololepta Indica, Erichs. Jahr. 90, 3 (1834).

Elargi, subdéprimé, noir luisant. Front lisse, sans stries, ni tubercule; dent préoculaire saillante; antennes brun de poix, massue grise. Pronotum court, bisinué à la base, arrondi et imponctué sur les côtés, profondément échancré en devant, avec les angles obtus ; strie marginale bien marquée, anguleuse. Ecusson petit, triangulaire. Elytres de la 
largeur du pronotum à la base, de sa longueur à la suture; obliques au bord apical; angle sutural peu marqué; repli latéral impunctué; strie subhumérale grosse, peu amincie, mais raccourcie à la base; première dorsale forte, courte et très oblique, deuxième encore beaucoup plus courte, avec un petit appendice apical oblique. Propygidium légèrement bifovéolé au bout, avec quelques points peu nombreux sur les côtés. Pygidium densément ponctué. Jambes antérieures armées de quatre dents obtuses : postérieures tri-épineuses.

Le $\sigma^{*}$ différe de la $\&$ par l'excavation du menton seulement (f. 10, $f, g)$.

Java.

\section{II. MARGINEPUNCTATA.}

Oblonga, planiuscula, nigra nitida; fronte aquali; pronoto lateribus fortiter punctato, stric marginali angulata; clytris margine inflexo rugoso, stria subhumerali forti abbreviata, 1 a dorsali brevi, 2 a breviori, appendiculata; propygidio punctis sparsis cincto, pygidio donse punctato. Long. 12 mill.; larg. 6 mill.

Ovale allongé, assez aplati, noir luisant. Front uni, sans stries ni tubercule; antennes noir de poix, massue cendrée. Pronotum court, large, bisinué à la base, avec une demi-strie médiane au devant de l'écusson, dilaté angulairement aux deux tiers sur les côtés, et bordé d'une ponctuation forte et assez large, bisinueusement échancré en devant, avec les angles arrondis (échancrés dans le $\sigma^{*}$ ); strie marginale assez fine, anguleuse, atteignant l'angle du devant. Ecusson triangulaire, très petit. Elytres de la longueur du pronotum, de sa largeur à la base, légèrement dilatées sur les côtés, obliques au bord apical, avec un angle sutural bien pro- 
noncé; repli latéral rugueux ; strie subhumérale forte, raccourcie à la base, dorsales olliques, première du tiers de la longueur, deuxième deux fois plus courle, avec un court appendice apical. Propygidium largement ceint de points épars assez forts. Pygidium densément ponctué. Excavation triangulaire du menton forte dans le $c^{*}$. Jambes antérieures armées de quatre dents, postérieures de trois, les deux apicales rapprochées.

Le seul exemplaire de cette espèce que j'aic eu sous les yeux fait partie de l'ancienne collection Dejean; il est de Carthagène (Nouvelle-Grenade).

\section{II. Coloniana.}

Oblongo-ovalis, subdepressa, nigra subnitida; fronte cequali; monoto latcribus parce punctato, stria marginali tenui, angulata; clytris margine inflexo rugoso, stria subhumerali forti abbreviata, dorsalibus obliquis, $2^{\text {a }}$ brevissima, appendicata: propygidio munctis raris cincto, pygidio dense punctato. Long. 11 mill.; larg. 6 mill.

Ovale allongé, légèrement aplati, noir, assez luisant. Front uni, sans stries, ni tubercule; antennes brun de poix, massue grise. Pronotum court, large, bisinué à la base, avec une demi-strie longitudinale très fine au devant de l'écusson; légèrement dilaté au milieu et bordé de points rares sur les côtés, largement échancré en devant, avec les angles arrondis (échancrés dans le $c^{*}$ ); strie marginale finc, anguleuse, cessant à l'angle antérieur. Ecusson triangulaire, très petit. Elytres de la longueur du pronotum, de sa largeur à la base, légèrement dilatées sur les côtés, obliques au bord apical, avec un angle sutural bien prononcé; repli latéral rugueux ; strie subhumérale forte, profonde, raccourcie à la base; 
deus dorsales obliques, première forte à la base, du quart de la longueur, deuxième très courte, avec un petit appendice apical arqué. Propygidium entouré de quelques points peu nombreux, serrés sur un petit espace de chaque côté. Pygidium densément ponctué. Excavation du menton profonde dans le $c^{\star}$. Jambes antérieures armées de quatre lents, les deux apicales à peine séparées, et n’en formant qu'une obtuse : postérieures tri-dentées.

Un peu moins grand que l'Il. marginepunclata, il s'en distingue surtout par la ponctuation du pronotum et du propygidium beaucoup moins étendue que dans ce dernier, et par la deuxième stric dorsale proportionnellement plus courte. Le of réunit l'excavation da menton et l'échancrure de l'angle du pronotum.

Caracas, dans le Venezuela.

\section{H. SIMILIS.}

Oblonga, subdepressa, nigra nitida; fronte ctquali; pronoto lateribus punctato, stria marginali angulata; elytris margine inflexo rugoso, stria subhumerali antice abbreviata, 2 dorsalibus obliquis brevibus, 2 a panlo breviose appendiculata; promygidio sat late sparsim, pygidio dense punctatis. Long. \& mill.; larg. 4 1/2 mill.

Oblong, subdéprimé, noir luisant. Front lisse, sans stries, ni tubercule; dent préoculaire saillante; antennes brun de poix, massue grise. Pronotum bisinué à la base, avec une demi-strie longitudinale fine au devant de l'écusson, curvilinéairement dilaté et bordé de points sur les côtés, échancré en devant, avec les angles obtus (très étroitement échancrés dans le $\sigma^{*}$ ); strie marginale anguleuse. Ecusson petil, triangulaire. Elytres de la largeur du pronotum à la base, de sa 
longueur à la suture, à peine arquées sur les côtés, obliques au bord apical, formant un angle sutural bien marqué; repli latéral ponctué; strie sublıumérale gl’osse, raccourcie en devant; deux dorsales obliques, première forte, du tiers de la longueur, deuxième à peine moitié plus courte, avec un appendice apical presque droit et assez long. Propygidium largement entouré de points épars. Pygidium densément ponctué. Jambes antérieures quadri-dentées, postérieures tri-épineuses.

Le $\sigma^{*}$ est distinct par l'échancrure du pronotum et par l'excavation du menton.

Il diffère de l'Hol. marginepunctala par sa forme plus allongée, par l'appendice des élytres plus long et plus droit, et par l'exiguité de l'échancrure du pronotum dans le $\delta$; de l'Hol. similis par l'étendue de la ponctuation du pronotum et du propygidium, et par la longueur de la deuxième strie dorsale des élytres.

Carthagène (Nouvelle-Grenade).

\section{II. BIDENTATA.}

Lata subdepressa, nigra nitida; fronte aquali; mronoto latcribus vix punctato, stria marginali angulata; elytris margine inflexo rugoso, strice sublumerali antice tenui, abbreviata,

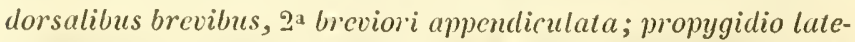
ribus parce, pygidio dense punctatis; prosterno antice emarginato. Long. 7 mill.; larg. 3 mill.

Elargi, subdéprimé, noir luisant. Front lisse, sans stries, ni tubercule; dent préoculaire obtuse; antennes brun de poix, massue grise. Pronotum bisinué à la base, avec une demi-strie longitudinale au devant de l'écusson, curvilinéairement dilaté sur les côtés, avec quelques points peu 
nombreux; bisinueusement échancré en devant, avec les angles assez aigus; strie marginale anguleuse. Ecusson petit, triangulaire. Elytres de la largeur du pronotum à la base, de sa longueur à la suture, à peine arquées sur les côtés. obliques au bord apical, et formant un angle sutural bien marqué; repli latéral rugueusement ponctué; strie subhumérale un peu amincie et raccourcie à la base; deux dorsales obliques, courtes; première assez forte, du tiers de la longueur, deuxième fort courte, avec un appendice apical droit. Propygidium bordé de points épars. Pygidium densément ponctué. Lobe prosternal plus ou moins profondément échancré. Jambes antérieures garnies de quatre dents obtuses : postérieures de trois.

Le $\sigma^{*}$ se fait remarquer, outre son excavation du menton, par des mandibules très fortes et très élargies à la base, armées d'une longue dent interne; il a l'angle du pronotum entier, mais précédé d'une légère sinuosité.

M. Sallé a trouvé cette espèce aux environs de Caracas (Venezuela), en avril et en juillet, sous les écorces des arbres morts en décomposition. Le $\sigma^{*}$ paraît beaucoup plus rare que la + .

\section{I. BRACTEA.}

Oblonga, complanata, nigra nitida; fronte cequali; pronoto antice lateribus punctato, stria marginali subangulata; elytris margine inflexo laci, stria subhumerali abbreviata, 2 dorsalibus brevibus, 2a appendiculata; propygidio parce circum, pygidio obsolete punctatis. Long. 5 1/2 mill.; larg. $23 / 4$ mill.

Hololepta bractea, Erichs. in Jahr. 1, 91, 4 (1834). - H. populnea, Le C. Col. Calif. Lyc. (18á1), 39, 3.

Oblong, aplati, noir luisant. Front lisse, sans stries, ni tubercule; dent préoculaire courte; antennes brun de poix, 
massue grise. Pronotum bisinué à la base, avec une demistrie longitudinale au milieu, curvilinéairement dilaté sur les côtés, avec quelques poiuts seulement en devant, échancré au bord antérieur, avec les angles obtus; strie marginale fine, à peine coudée. Ecusson petit, triangulaire. Elytres de la largeur du pronotum à la base, de sa longueur à la suture, parallèles sur les côtés, obliques au bord apical. avec un angle sutural peu profond ; repli latéral imponctué; strie subhumérale raccourcie à la base, sans être amineie; dorsales peu obliques, première du quart de la lougueur, deuxième de moitié plus courte, avec un appendice plus on moins distiuct. Propygidium bordé de quelques gros points épars sur les côtés. Pygidium assez densément, mais faiblement ponctué. Jambes antérieures quadri-dentées : postéricures tri-épineuses.

Le $\delta^{*}$, outre son excavation du menton, a une très petite échancrure dans l'angle même du pronotum.

J'ai dù rapporter cette espèce à l'H. bractea, Er., quoique l'auteur ne mentionne pas l'appendice apical des élytres; car la description s'y rapporte du reste de point en point, ainsi que la patrie. D'ailleurs, cette petite stric est parfois peu visible, et sans doute Erichson n'y aura pas fait attention, comme il le fait pour l'Indica, où cependant elle est toujours bien marquée; je n'ai pu consulter les types d'Erichson, malgré mes instantes demandes au docteur Kilug. Je me suis convaincu que l'llol. populnea, décrite dans le Lyceum d'hist. nat. de New-York, appartient à cette espèce, par un individu femelle communiqué par Le Conte à M. Th. Lacordaire.

Nouvelle-Grenade (Caracas). Californie, bords du rio Colorado, sous l'écorre de penplier. 
16. H. SEIICINCTA

Oblongo-ovata, subdcpressa, nigra nitida, puncticulata; fronte aquali; pronoto stria marginali valida; elytris margine inflexo lavi, stria subhumerali antice abbreviata, 3 dorsalibus brcvibus, $2_{2}$ appendiculata; propygidio arcu utrinque ct punctis sparsis cincto, pygidio dense punctato. Long. 7 1/2 mill.; larg. $31 / 2$ mill.

Orale oblong, subdéprimé, noir luisant, entièrement couvert d'un pointillé très fin. Front lisse, sans stries, ni tubercule; dent préoculaire assez saillante; antennes noir de poix, massue grise. Pronotum bisinué à la base, avec une demi-strie longitudinale au milieu, curvilinéairement dilaté, avec quelques rares points sur les cotés, bisinueusement échancré en devant, avec les angles peu saillants; strie marginale coudée, forte. Ecusson petit, triangulaire. Elytres de la largeur du pronotum à la base, de sa longueur à li suture, légèrement arquées sur les côtés, obliques au bord apical, avec un angle sutural bien marqué; repli latéral lisse; strie sublumérale raccourcie ì la base; trois dorsales fortes, courbées, première du tiers de la longueur, deuxième avec un appendice apical arqué, assez long. Propigidium entouré de points peu serrés, assez nombreux, avec une rainure profonde de chaque coté, en forme de parenthèses. Pygidium densément ponctué. Jumbes antérieures quadridentées : postérieures tri-épineuses.

Le $o^{*}$ se reconnaît à l'excavation du menton et à une fossette arrondie à l'angle antérieur du pronotum.

Cette espèce, rare dans les collections, est particulière an Sénégal.

\section{H. ARCIFEMA.}

Oblongo ovata, complanata, nigra nilide; fronte cequali; monoto stria manginali angulata; rlytris margine inflexo latri, 
stria sublumerali abbreviata, 3 ulorsalibus obliquis, $2_{\mathrm{a}}$ appendiculata; propygidio punctis sparsis, 2 que striis oppositis arcuatis cincto; pygidio punctatissimo. Long. 6 1/2 mill.; larg. $31 / 2$ mill.

Ovale allongé, aplati, noir assez luisant. Front très finement pointillé, uni, sans stries, ni tubercules; antennes d'un brun de poix rougeâtre, massue grise. Pronotum court, large, légèı'ement bisinué à la base, avec une demi-strie fine longitudinale au devant de l'écusson; angulairement dilaté sur les côtés, sans ponctuation distincte; éclıancré en devant, avec les angles entiers dans les deux sexes, un peu impressionnés seulement; strie marginale anguleuse, atteignant l'angle antérieur. Ecusson triangulaire, très petit. Elytres de la longueur du pronotum, de sa largeur à la base, légèrement dilatées sur les côtés, obliques au bord apical, avec un angle sutural bien prononeé; repli latéral lisse; strie subhumérale forte, raccourcie à li base; trois dorsales obliques, courtes; première du quart de la longueur des élytres, deuxième plus courte, avec un appendice apical à peine plus long qu'elle ; troisième accompagnée d'une petite lossette superficielle. Propygidium ceint de quelques points peu serrés, avec deux stries arquées opposées. Pygidium densément ponctué. Excavation du menton bien marquée dans le $\sigma^{\star}$, forte, avec un tubercule médian allongé. Jambes antérieures armées de quatre dents obtuses : postérieures de trois, les deux apicales rapprochées.

Cette espèce a les plus grands rapports avec l'H. semicincta; elle en diffère par sa taille plus petite, moins élargic, par le pronotum moins visiblement pointillé et par le propygidium dont la ponctuation est moius étendue. Le $\sigma^{*}$ n'a pas de fossette à l'angle antérieur du pronotum.

Sénégal (MM. de Laferté et Géhin). 
BBB. Ire stric dorsile des élytres entière, $2^{2}$ appendiculée (18).

\section{II. LUCIDA.}

Oblonga, depressa, nigra, nitida, fronte cquali; pronoto latcribus dilatato, punctato; stria marginali valida; clytris margine inflexo plicato, stria subhumerali antice abbreviata, $1^{\text {a }}$ dorsali integra, 2a brevissima appendiculata; mopygidio bifoveolato, circum grosse, mygidio dense punctatis. Long. 8 mill.; larg. 4 mill.

Hololepta lucida. Le Conte. Mon. N. Am. Hist. 7,2 (IS45).

Oblong, aplati, noir luisant. Front uni, sans stries, ni tubercule; dent préoculaire peu saillante. Antennes brun de poix, massue rousse. Pronotum court, bisinué à la base, avec une demi-strie longitudinale au milieu, fortement dilaté et ponctué sur les côtés, échancré en devant, avec les angles obtus ; strie marginale forte, coudéc. Ecusson petit, triangulaire. Elytres de la largeur du pronotum à la base, et de sa longueur à la suture, à peine arquées sur les côtés, obliques au bout, arec un angle sutural large; repli latéral légèrement plissé ; strie sublıumérale forte, raccourcic à la base; première dorsale entière un peu sinueuse, deuxième fort courte, munie d'un petit appendice apical. Propygidium bifovéolé, bordé d'une forte ponctuation. Pygidium densément el grossièrement ponctuć. Jambes antérieures quadridentées, postérieures tri-épineuses.

Le $\sigma^{*}$ a une fossette profonde à l'angle antérieur du pronotum, outre l'excavation du menton.

Cette espèce se rencontre aux Etats-Unis : j'en ai sous les yeux deux exemplaires, l'un de New-York, l'autre du Texas (MM. Chevrolat et Pilate). M. Le Conte l'a décrite comme étant l'H. Lucila de Dejean; mais l'H. lucida de cet auteur est tout autre chose. 


\section{$A A$. Front bistrié (19-29).}

\section{H. Cunensis.}

Oblonga, depressa, nigra, nitida; fronte puncticulata, 2 striis transversis brevibus; pronoto vix lateribus punctato, stria marginali angulata; elytris margine inflexo lavi, stria subhumerali abbreviata, 2 dorsalibus brevibus; propygidio parce lateribus, pygidio levissime punctulato. Long. 7 mill.; larg. 3 mill.

Hololepta Cubcnsis, Erich. in Jahrb. 93.8 (1834).

Allongé, déprimé, noir luisant. Front finement pointillé, avec deux courtes stries transversales écartées, obliques; dent préoculaire saillante. Antennes brun de poix, massue grise. Pronotum bisinué à la base, avec une demi-strie longitudinale au milieu, curvilinéairement dilaté et à peine ponctué sur les côtés, échancré en devant, avec les angles peu avancés; strie marginale légèrement coudée. Ecusson petit, triangulaire. Elytres de la largeur du pronotum à la base, de sa longueur à la suture, uu peu courbées sur les côtés, obliques au bord apical, avec un angle sutural bien marqué; repli latéral imponctué; strie subhumérale raccourcie à la base; dorsales obliques, première à peine du quart de la longueur, deuxième ponctiforme, sans appendice. Propygidium couvert latéralement de quelques points rares et épars. Pygidium presque lisse dans le $\sigma^{*}$, et légèrement ponctué dans la + . Jambes antérieures armées de quatre dents obtuses, postérieures de trois.

Le $o^{*}$ diffère de la + par l'excavation du menton et la orme des mandibules.

Se trouve à Cuba et à Saint-Domingue, dans le suc des arbres en fermentation putride. 


\section{H. HUMILIS.}

oblonga, subdepressa, nigra, nitida; fronte puncticulata, striis 2 arcuatis magnis; pronoto puncticulato, latcribus punctato, stria marginali valida, angulata; elytris margine inflexo lavi, stria subhimcrali abbreviata; 2 dorsalibus sat longis, appendice recto magno ; propygidio circum parce, pygidio dense punctatis. Long. $81 / 2$ mill.; larg. 4 1/2 mill.

Hololepta humilis, Payk. Mon. Hist. 109,7. T. xu1, f. 3 (1811).

Oblong, légèrement aplati, noir luisant. Front finement pointillé, avec deux stries transversales, arquées, grandes et assez rapprochées; dent préoculaire saillante. Antennes brun de poix, massue grise. Pronotum finement pointillé, bisinué à la base, avec une demi-strie longitudinale au milieu, curvilinéairement dilaté et ponctué sur les côtés, échancré en devant, avec les angles obtus; strie marginale forte et coudée. Ecusson petit, triangulaire. Elytres de la largeur du pronotum à la base, de sa longueur à la suture, droites sur les côtés, obliques au bout, avec un angle sutural bien marqué; repli latéral sans points; strie subhumérale grosse, aiguisée et raccourcie à la base; première dorsale dépassant le tiers de la longueur, deuxième moitié plus courte, munie d'un appendice long et droit. Propygidium entouré de points espacés, oblongs. Pygidium densément ponctué. Jambes antérieures armées de quatre dents, postérieures de trois.

Le $\sigma^{A}$ présente une excavation au menton et une échancrure à l'angle même du pronotum.

Brésil.

\section{H. SUBHUMILIS.}

Ovalis, subdepressa, nigra, nitida; fronte puncticulata, utrinque stria brevi; monoto lateribus parce punctato, stria mar- 
ginali tenui angulata: elytris margine inflexo lavi, stria subhumerali subintegra, 2 dorsalibus obliquis, 2a brevissima, appondiculata; propygidio late punclis distantibus cincto, apice bifoveolato; pygidio donse et fortiter punctato, margine reflexo. Long. 7 mill.; larg. 4 mill.

Ovale, très légèrement convexe, noir luisant. Front finement pointillé, avec une très petite strie de claque côté. Antennes brunes, massue grise. Pronolum court, assez large, bisinué à la base, arec une demi-strie longitudinale très fine au devant de l'écusson, anguleusement dilaté sur les côtés et bordé de quelques points, échancré en devant, avec les angles arrondis, abaissés; strie marginale fine, anguleuse, se terminant à l'angle antérieur. Elytres un peu plus longues que le pronotum, de sa largeur à la base, légèrement dilatées sur les côtés, obliques au bord apical et formant un angle sutural bien prononcé; repli latéral lisse; strie sublumérale forte, sinueuse, atteignant presque la base, et accompagnce d'une double striole; première dorsale forte, oblique, du quart de la longueur des élytres; deuxième fort petite, avec un appendice apical court. Propygidium couvert dans tout son pourtour de gros points espacés, et bifovéolé postéricurement. Pygidium fortement et densément ponctué, avec la marge un peu relevée. Jambes antérieures armées de quatre dents, postéricures de trois, les deux apicales rapprochées.

Un seul exemplaire + de cette espèce dans la collection de M. Chevrolat, sans indication de patrie.

\section{H. Cayennensis.}

Ovata, subdlepressa, nigra, subnitida; fronte utrinque stria lata arcuata; pronoto lateribus punctato, stria marginali angulata; elytris margine inflexo impunctuto, stria subhumerali abbre- 


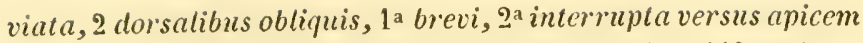
arcuata; mopygidio punctis sparsis cincto, leviter bifoveolato, pygidio dense punctato. Long. 6 1/2 mill.; larg. 4 mill.

Ovale, subdéprimé, d'un noir peu brillant. Front avec deux stries transversales, arquées, assez longues et assez rapprocliees. Antennes brunes, massue grise. Pronotum court, assez large, légèrement bisinué à la base, avec une demi-strie longitudinale très fine au devant de l'écusson, angulairement dilaté sur les côtés et bordé de points peu nombreux, échancré en devant, avec les angles arrondis (entaillés $\sigma^{*}$ ); strie marginale anguleuse, très près du bord, dépassaut l'angle antérieur. Elytres de la longueur du pronotum, de sa largeur à la base, légèrement dilatées sur les côtés, obliques au bout, formant un angle sutural très prononcé; repli latéral à peine visiblement ponctué; strie subhumérale forte, raccourcie à la base; deux stries dorsales courtes, obliques; première du tiers de la longueur de la strie humérale; deuxième un peu plus courte, mais presque réunie postérieurement à un long appendice arqué. Propygidium couvert dans son pourtour de gros points espacés, bifovéolé au bout, et divisé longitudinalement par une ligne élevée, lisse, peu visible. Pygidium densément, mais peu fortement ponctué. Excavation du menton ơ profonde. Jambes antérieures armées de quatre dents obtuses; postérieures de trois aiguës, les deux apicales rapprocliées.

$c^{*}$. Excavation triangulaire du menton; angle antérieur du pronotum écliancré.

†. Menton et angle antérieur du pronotum entiers.

Cayenne (Guyane). (MM. de Laferté et Géhin.)

23. H. ARADIFOHNIS.

Oblonga, depressa, nigra, nitida; fronte striis 2 arcuatis 
foveolaribus; pronoto lateribus punctato, stria marginali angu. lata; clytris margine inflexo sublovi, stria sublumerali abbre-

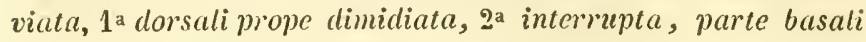
brevissima; propygidio bifoveolato lateribus parce, pygidio dense punctatis. Long. 7 mill.; larg. 4 mill.

Hololepta aradiformis, Er. in Jahrb. 93,9 (1834).

Oblong, légèrement aplati, noir luisant. Front lisse, à deux fossettes limitées par une strie arquée; dent préoculaire obtuse. Antennes brun de poix, massue grise. Pronotum bisinué à la base, avec une demi-strie longitudinale au milieu, dilaté et ponctué sur les côtés, échancré en devant, avec les angles arrondis, peu saillants; strie marginale anguleuse, bien marquée. Ecusson petit, triangulaire. Elytres de la largeur du pronotum à la base, de sa longueur à la suture, presque droites sur les cotés, obliques au bout, avec un angle sutural bien marqué; repli latéral paraissant lisse; strie subhumérale forte, sinueuse, raccourcie à la base; première dorsale large, dépassant le tiers de la longueur, deuxiène interrompue, composée d'un rudiment basal très court et d'un apical très long remontant jusqu'à la première đorsale. Propygidium légèrement bifovéolé, entouré de gros points espacés; pygidium densément ponctué. Jambes antéricures armées de quatre dents obtuses, postérieures de trois aiguës, les deux dernières rapprochées.

$\sigma^{*}$. Menton avec une excavation triangulaire, angle antérieur du pronotum légèrement sinué.

Brésil (Para); Guyane (Cayenne).

\section{IJ. ATTENUATA.}

Oblongo-ovata, subdepressa, nigra, nitida; fronte utrinque stria recta; pronoto lateribus parce punctato, stria marginali tonui, angulata; elytris margine inflexo lovi, stria ubhumerali 
antice abbreviata; 2 dor'salibus obliquis, 2 a breviori, appendiculata; propygidio punctis sparsis late cincto, pygidio leviter punctato. Long. 6 mill.; larg. 3 nill.

Hololepta attenuata, Blanch. Voy. Amér. mer. de d’Orbigny, $68,246$.

Ovale allongé, rétréci postéricurement, légèrement déprimé, noir luisant. Front pointillé, avee une strie transversale droite, assez longue, de chaque côté. Antenues d'un brun de poix, massue grise. Pronotum court, assez large, bisinué à la base, avec une demi-strie très fine, longitudinale, au devant de l'écusson; légèrement dilaté en angle et bordé de points peu nombreux sur les côtés, échancré en devant, avec les angles arrondis, étroitement entaillés $\sigma^{*}$; strie marginale fine, rapprochée du bord, anguleuse, terminée à l'angle antérieur. Elytres de la longueur du pronotum, de sa largeur à la base, légèrement rétrécies postérieurement, obliques au bord apical, formant un angle sutural très prononcé; repli latéral lisse; strie subhumérale raccourcie à la base; deux stries dorsales obliques, première du quart de la longueur, deuxième plus courte, mais terminée par un long appendice presque droit. Propygidium légèrement convexe, presque tout couvert de points peu serrés et assez forts. Pygidium assez faiblement ponctué. Excavation du menton $o^{*}$ profonde, avec un tubercule médian oblong. Jambes antérieures armées de quatre dents obtuses, postérieures de trois, les deux apicales rapprochées.

Un seul exemplaire o venant de Santa-Cruz (Bolivia), de Ja collection du Muséum, décrit par M. Blanchard dans l'entomologie du Voyage de M. d'Orbigny dans l'Amérique méridionale. 


\section{H. MERIDANA.}

Oblongo-ovata, subdepressa, nigra, nitida; fronte puncticulata, striis 2 grossis arcuutis; pronoto lateribus punctato, stria marginali angulata; clytris margine inflexo lovi, stria subhumerali abbreviata, 2 dorsalibus obliquis, brevibus, $2^{\text {a }}$ breviter appendiculata; propygidio late et parce, pygidio dense punctatis. Long. 6 mill.; larg. 3 1/2 mill.

Ovale oblong, subdéprimé, noir luisant. Front pointillé, avec deux stries arquées, courtes; dent préoculaire assez saillante. Antennes brun de poix, massue grise. Pronotum bisinué à la base, avec une demi-strie longitudinale fine, au milieu, curvilinéairement dilaté et ponctué sur les côtés, échancré en devant, avec Ies angles arrondis, obtus; strie marginale anguleuse. Ecusson petit, triangulaire. Elytres de la largeur du pronotum à la base, de sa longueur à la suture, courbées sur les còtés, obliques au bout, avec un angle sutural bien marqué; repli latéral lisse; strie subhumérale raccourcie en devant; dorsales obliques, première large, du quart de la longueur, deuxième très courte, avec un fort petit appendice. Propygidium largement couvert de points espacés; pygidium peu densément ponctué. Jambes antérieures armées de quatre dents obtuses, postérieures de trois pointues, les deux dernières rapprochées.

$\sigma^{A}$. Excavalion triangulaire du menton et échancrure à l'angle antérieur du pronotum,

Yucatan (Mérida), (MM. Pilate, Chevrolat).

\section{II. BogotaNi.}

Oblonga complanata, nigra, nilida, munctulata; fronte leviter bistriata; monoto lateribus marginato, punctato; elytris stria 
subhumerali antice abbreviata, 1' dorsali brevi, 2a late interrupta; propygidio parce lateribus, mygidio leviter punctatis. Long. 6 1/2 mill.; larg. 3 1/2 mill.

Oblong, aplati, d'un noir luisant, pointillé sur toute la surface. Front plan; stries transversales fines ; dent préoculaire assez saillante. Antennes d'un noir de poix, massue grise. Pronotum court, bisinué à la base, avec une demistrie longitudinale anté-scutellaire, curvilinéairement dilaté sur les côtés, largement échancré en devant, avec les angles obtus (légèrement échancrés $\sigma^{*}$ ), lisse, avec quelques points peu serrés le long des bords latéraux; strie marginale entière jusqu'à l'angle antérieur, à peine coudée. Ecusson très petit, triangulaire. Elytres de la largeur du pronotum à la base, de sa longueur à la suture, obliques au bord apical; repli latéral lisse; strie subhumérale assez forte, raccourcie à la base; première dorsale oblique, n'atteignant pas le tiers, deuxième très courte, avec un appendice assez long, droit. Propygidium largement couvert de points espacés dans son pourtour. Pygidium avec quelques points obsolètes à la base (plus visibles dans la \&). Jambes antérieures armées de quatre dents fortes, postérieures de trois, les deux dernières rapprochées.

$\sigma^{*}$. Se reconnaît à la longueur des mandibules, à l'angle antérieur du pronotum légèrement échancré, à la profonde excavation triangulaire du menton, et à son pygidium qui paraît lisse.

Trouvé par M. A. Sallé dans les arbres en fermentation, en mai, sur les bords du lac Izabal, daus le Guatemala, et en juillet, à Caracas, dans le Venezuela. 


\section{II. QUADRIFORMIS.}

Ovata, lata, complanata, nigra, nitida; fronte stria utrinque arcuata; pronoto brcvi lato, latcribus punctulato; clytris margine inflexo lcevi, stria subhumerali forti abbreviata, 2 dorsalibus obliquis, 2a breviter appendiculata; propygidlio punctis sparsis cincto, apice bifovcolato; pygidio sublocvi. Long. 6 1/2 mill.; larg. 4 mill.

Ovale élargi, aplati, d'un noir luisant. Front pointillé, avec deux stries transversales, légèrement arquées, assez distantes; dent préoculaire saillante. Antennes d'un brun de poix, massue grise. Pronotum large et court, bisinué à la base, avec une demi-strie longitudinale très fine au devant de l'écusson, dilaté curvilinéairement sur les côtés, et bordé assez largement de points épars; échancré en devant, avec les angles arrondis ; strie marginale atteignant l'angle antérieur. Elytres un peu plus longues que le pronotum, de sa largeur à la base, légèrement dilatées sur les côtés, obliques au bord apical, et formant un angle sutural assez prononcé ; repli latéral lisse; strie subhumérale forte et raccourcie en devant; deux dorsales obliques; première large, du tiers à peu près de la longueur; deuxième plus fine, plus courte, avec un appendice apical court. Propygidium ponctué peu densément dans son pourtour, bifovéolé au bord postérieur. Pygidium presque lisse, un peu infléchi et ponctué au bout. Jambes antérieures armées de quatre dents obtuses, postéricures de trois, les deux apicales rapprochées.

đ". Excavation du menton, et angle antérieur du pronotum légèrement échancré.

Brésil. 


\section{H. CURTA.}

Ovata, brevis, complanata, nigra, nitida; fronte striis 2 transversis, arcuatis, distantibus; pronoto lateribus late punctato, stria marginali tonui; clytris margine inflexo locvi, stria subhumerali valida abbreviata, 2 dorsalibus, $1_{a}$ lata brevi, $2^{a}$ integra bissubintcrupta, apice punctis adancta; propygidio punctis sparsis latc cincto, apice bifovcolato; pygidio inflexo apice punctato. Long. 71/2 mill.; larg. 4 1/2 mill.

Ovale court, aplati, noir luisant. Front avec deux stries transversales assez longues, légèrement arquées, distantes. Antennes d'un noir de poix, massue grise. Pronotum court, large, bisinué à la base, arec une demi-strie longitudinale très finc au devant de l'écusson, curvilinéairement dilaté et largement ponctué sur les côtés, échancré en devant, arec les angles arrondis, abaissés; strie marginale assez fine, rapprochée du bord, atteignant l'angle antérieur. Elytres à peu près de la longueur du pronotum, de sa largcur à la base, élargies latéralement, coupées obliquement au bord apical et formant un angle sutural assez prononcé; repli latéral lisse; strie subhumérale forte, raccourcie à la base ; deux stries dorsales obliques, première forte, du tiers de la longueur, deuxième fine, entière, interrompue en un ou deux endroits, accompagnée postérieurement de quelques points. Propygidium largement ponctué dans son pourtour, bifovéolé au bord postérieur, avec une ligne élevée, lisse, longitudinale au milieu. Pygidium infléchi, ponctué postérieurement, lisse à la base. Jambes antérieures armées de quatre dents obtuses; postérieures de trois, les deux apicales rapprochées.

Nouvelle-Grenadc. 
29. H. LAMINA.

Ovala, subdepressa, nigra, nitida, fronte striis 2 arcuatis, subapproximatis; monoto lateribus punctato, stria marginali subangulata; clytris margine inflexo lavi; stria sublumerali forti abbreviata; 2 dorsalibus, 1 a brevi, 2a integra angulata; mopygidio munctis sparsis fortibus cincto; pyyidio sat dense punctato. Long, 7 mill.; larg. 4 1/2 mill.

Hololepta lamina, Payk. Mon. hist. 108, 6. T. Ix, pl. 6. (1811).

Ovale, légèrement convexe, noir luisant. Front avec deux stries transversales, fortes, arquées, assez rapprochées. Antennes d'un brun de poix, rougeâtres en quelques endroits, massue grise. Pronotum court, assez large, bisinué à la base, avec une demi-strie longitudinale très fine au devant de l'écusson; dilaté et bordé de points sur les côtés; échancré en devant, avec les angles arrondis, abaissés; strie marginale à peine anguleuse. Elytres de la longueur du pronotum, à peu près aussi larges à la base, à peine élargies latéralement, obliques au bord apical, formant un angle sutural très prononcé; repli latéral lisse; strie subhumérale forte, large, raccourcie à la base; deux dorsales, première forte, du tiers de la longueur, deuxième entière, coudée au milieu à la hauteur de l'extrémité postérieure de la première. Propygidium sans fossettes, ponctué dans son pourtour, et sillonné dans son milieu par une ligne lisse, élevée, longitudinale. Pygidium ponctué assez fortement. Pattes d'un brun de poix : lianches antérieures et tarses, roussâtres; jambes antérieures armées de quatre dents, postérieures de trois, les deux apicales rapprochées.

Un seul individu + provenant d'Amérique, je ne sais de quelle contrée, peut-être du Brésil. 
AA. Front avec un tubercule médian (30-31).

\section{H. PROCERA.}

Elongata, complanata, nigra, nitida; fronte unituberculata, pronoto lateribus parce punctato, stria marginali tomi angulata; elytris margine inflexo lavi, stria subhumerali integra, 2 dorsalibus brevibus; propygidio lateribus pasce, pygidio parum dense punctatis. Long. 11-15 mill.; larg. 6 mill.

Hololepta procera, Erichs. in Jahrb. 91, 5. (1834).

Allongé, aplati, noir luisant. Front lisse, avec un tubercule médian plus ou moins élevé; dent préoculaire médiocre. Antennes d'un brun de poix, massue grise. Pronotum large, bisinué à la base, avec une demi-strie longitudinale fine au milieu, curvilinéairement dilaté et bordé de quelques points sur les côtés, écliancré en devant, avec les angles obtus; strie marginale assez fine et légèrement coudée. Ecusson petit, triangulaire. Elytres de la largeur du pronotum à la base, de sa longueur à la suture, arquées sur les côtés, obliques au bout, avec l'angle sutural peu profond; repli latéral lisse; strie subhumérale entière; première dorsale large, du tiers de la longueur, deuxième fort raccourcie, sans appendice. Propygidium bordé latéralement de points espacés. Pygidium assez fortement, mais peu densément ponctué. Jambes antérieures armées de quatre dents, postérieures de trois, les deux dernières rapprochées.

Les deux sexes ont le front tuberculé, l'angle antérieur du pronotum sans échancrure, et une profonde excavation au menton. Le $\sigma^{*}$ ne diffère de la $\&$ que par l'élargissement du pronotum, par la longueur et la forme des mandibules.

Java. 


\section{H. ELONGATA.}

parallela, complanata, nigra, nitida, lcovissima; fronte unituberculata; pronoto lateribus subrectis, stria marginali tenui; elytris margine inflexo lavi, stria subhumerali utrinque valde abbreviata, dorsalibus brevissimis, $2^{\text {a }}$ appendiculata; propygidio utrinque sulco semi-circulari postice appendiculato, pygidioque impunctatis. Long. 8 mill.; larg, 3 mill.

Hololepta elongata, Erichs. in Jahrb. 92, 6. (1834).

Etroit, allongé, parallèle, très aplati, noir luisant, sans points en dessus. Front unituberculé ; dent préoculaire médiocre. Antennes d'un brun-rougcâtre, massue grise. Pronotum presque carré, à peine bisinué à la base, presque droit sur les côtés, largement échancré en devant, avec les angles assez aigus ; strie marginale fine, légèrement coudée. Ecusson petit, triangulaire. Elytres de la largeur du pronotum à la base, de sa longueur à la suture, droites sur les côtés, obliques au bout, avec un angle sutural assez marqué, repli latéral lisse; strie sublumérale faible, fortement raccourcie de part et d'autre; première dorsale très courte, deuxième ponctiforme, avec un très petit appendice oblique. Propygidium bordé de chaque côté d'un sillon demi-circulaire, accompagné au bout d'une courte strie en dedans; pygidium petit. Jambes antérieures armées de quatre dents obtuses, postérieures de trois aiguës, les deux dernières rapprochées.

Dans les deux sexes, on retrouve le tubercule frontal, l'angle antérieur du pronotum entier, et dans l'excavation, qui ne s'ètend pas au-delà du menton, deux tubercules saillants; le $\delta$ ne diffère de la $q$ que par la dilatation du pronotum et la forme des mandibules.

Cette espèce, provenant de Java, est rare dans les collections. 


\section{PHYLLOMA.}

(

3o Série, 'T. 1 (1853), pl. v. - Mon. pl. 2. Genre II, f. 1-3.

Hololepta. Paykull Mon. Hist. p. 101 (1811). - Phylloma.

Erichson. in Jahrb. p. 96.2 (1834).

Corpus planum. Caput exsertum.

Mandibulce porrecte, aquales, dentate.

Labrum longum, bilobum.

Maxillo juxta mentum insertce, basi conspicuce.

Prosternum latum, plamum, lobo truncato.

Tibice antice intus dente basali.

Propygidium latum, horizontale, hexagonum; pygidium breve inflexum.

Corps aplati, ovale allongé.

Tête saillante, dégagée du prothorax. Front uni, sans strie qui le sépare de l'épistome, avec une dent de chaque côté, au-dessus de l'insertion des antennes. Labre (f. $1 e$ ) à deux lobes allongẻs. Mandibules (f. $1 e$ ) saillantes, assez courtes, légèrement courbées, unidentées en dedans, égales entre elles.

Antennes (f. 1 h) iusérées sous un rebord du front, au devant des yeux : scape allongé, renflé au bout, courbé, logé dans une coulisse pratiquée sous la tête; funicule de sept articles, premier et deuxième obconiques, plus longs, celuici un peu moins, 3-7 croissant en largeur ; massue ovale. comprimée, de quatre articles, velue.

Mâchoires (f. $1 \mathrm{~g}$ ) visibles à la base, entre le menton et la base des mandibules; à deux lobes, garnis de poils en dedans; externe long, étroit, colné; interne court. Palpes 
maxillaires de quatre articles ; premier court, deuxième un peu plus long, troisième et quatrième subcylindriques, égaux entre eux. Menton (f. $1 f$ ) court, coupé droit à la base, relevé en haut, cachant la lèvre et échancré au bord antérieur. Lèvre membraneuse, échancrée au milieu, avec les paraglosses barbues en dedans, sinuées. Palpes labiaux de trois articles, deuxième et troisième ovalaires, à peu près égaux.

Fossette antennaire, nulle ou peu distincte. Prosternum peu élevé, large, rétréci au milieu à l'insertion des pattes ; arrondi à la base, distinct du lobe antérieur par une strie transversale. Mésosternum large, court, échancré en devant pour recevoir la base du prosternum; strie marginale interrompue au devant de l'échancrure. Pièce humérale visible en dessus. Ecusson très petit, triangulaire. Elytres courtes, coupées obliquement à l'extrémité, arec une strie subhumérale n'atteignant pas la base, dilatée au milieu et prolongée en une ligne droite, fine; pas d'humérale.

Abdomen de cinq anneaux : premier segment ventral plus al!ongẻ que les autres, avec une ligne sinueuse de chaque côté; propygidium hexagonal, presque circulaire, horizontal; pygidium triangulaire, infléchi.

Pattes courtes : cuisses ovales, comprimées ; jambes (f. 1 $a, b, c$ et $d$ ) élargies vers le bout, logées dans une coulisse du bord de la cuisse, terminées par deux épines inégales; les antérieures avec une dent basilaire en dedans, quadridentées en dehors, avee une fossette tarsale profonde et bien limitée; tarses de cinq articles, le premier plus long et plus fort que le deuxième, et celui-ci plus que les suivants.

Le genre Phylloma a été établi par Erichson (Jahrb. der 
Insect, p. 96, 11), en 1834, sur l'Hister corticalis, Fabr. J'y ai réuni deux espèces inédites, l'une de Cayenne, et l'autre du Brésil. Sa forme aplatie annonce qu'il vit sous l'écorce des arbres. Sa larre est inconnue. Il est propre au Brésil et à la Guyane, et peu répandu dans les collections.

Ce genre se distingue aisément des Hololepta et des Lcionota arec lesquels il a les plus grands rapports, par la longueur du labre profondément bilobé, par l'insertion des màchoires en dehors du menton, ce qui les laisse voir dans une échancrure entre ce dernier et la base des mandibules, et par la strie subhumérale dilatée à l'épaule, linéaire et très fine postérieurement. Le pygidium infléchi et la dent des mandjbules, caractères fort rares dans les autres genres, peuvent aussi servir à le reconnaitre.

\section{P. conticale.}

Valde complanatum, nigrum, nitidum; fionte cequali ; pronoto stria marginali tenui brevi in angulo antico; elytris stria sub. humerali antice abbreviata, postice recta, temi. Propygidio circum parce, pygidioque inflexo punctulatis; tibiis posticis spinulosis. Long. 6 1/2 mill. Larg. $31 / 2$ mill.

Hister corticalis, F. Syst. El, 1, 91, 38 (1801).

Hololepta corticalis Payk. Mon. Hist. 106, 4, T. 9, f. 2.

Ovale allongé, très aplati, noir luisant. Front uni, sans stries, ni tubercule. Antennes brunes, massue velue, grise. Pronotum plus large que long, bisinué à la base, avec une courte strie longitudinale très fine au devant de l'écusson, arrondi sur les côtés, échancré en devant, avec les angles entiers, peu saillants; strie marginale courte, trìs fine, visible seulement dans l'angle antérieur. Ecusson petit, triangulaire. Elytres un peu plus longues que le pronotum, de sa 3e Série, тоne 1. 
largeur à la base, subparallèles sur les côtés, obliques au borl apical, formant un angle sutural très ouvert; repli latéral ponctué ; strie subhumérale fine, raccourcie à la base, presque entière, droite et linéaire postérieurement; première dorsale du tiers de la longueur, deuxième uulle. Propygidium sub-octogonal, entouré de points fins; pygidium infléchi, ponctué. Jambes antérieures quadri-dentées ; postérieures garnies d'épines en lessus et en dessous, et surtout au bout, où elles sont très serrées.

Brésil (Sainte-Catherine et Para); Cayenne.

\section{P. OBLITCM.}

Subdemessum, nigrum nitidum ; fronte ctquali; pronoto stria marginali integra, angulata; elytris margine inflexo plicato, stria sublumerali postice filiformi recta, 2 dorsalibus brevibus; momygidio bifoveointo, circum munctuto; mygidio inflexo dense punctuto; tibiis posticis 3 dentatis. Long. 6 1/2 mill. Larg. $32 / 3$. mill.

Ovale, légèrement convexe, noir luisant. Front uni, sans stries ni sillon en dedans des yeux; labre à deux lobes, assez grands. Antennes d'un brun de poix, massue grise, velue. Pronotum plus large que long, arqué à la base, dilaté angulairement sur les côtés, échancré en devant, avec les angles entiers, obtus; strie marginale fine, entière, anguleuse. Ecusson très petit, triangulaire. Elytres un peu plus longues que le pronotum, de sa largeur à la base, a peine élargies sur les côtés, obliques au bord apical, formant un angle sutural très ouvert; repli latéral plissé; strie sublumérale raccourcie à la base, très fine et Iroite postérieurement, et prolongée presque jusqu'au bout; trois dorsales courtes, obliques; première du tiers de la longueur, deuxième plus 
courte, troisième à peine visible. Propygidium entouré d'un cercle de points et biforéolé au bont; pygidium inlléchi, ponctué. Jambes denticulées en dessous; antérieures armées en dessus de quatre dents, postérieures de trois.

Nourelle-Grenade (Carthagène), (M. de Laferté).

Un peu plus épais que le $P$. corticale, il s'en distingue encore par les fovéoles bien marqués du propygidium, la ponctuation plus forte du pygidium, la deuxième strie dorsale des élytres, le prosternum plus étroit, etc.

\section{P. HANDIBULARE.}

Subdenressum, nigrum, nitidum; frontc cequali; mandibulis latioribus; pronoto stria marginali integra, angulata; clytris margine inflcxo sublcevi, stric subhumcrali postice filiformi recta, a dorsalibus brevibus; propygidio bifoveolato, circum menctalo; pygidio inflexo dense menctato; tibiis posticis 3-dentatis. Long. 8 mill. Larg. 4 mill.

Orale oblong, légèrement convere, noir luisant. Front convexe, sans stries ni sillon en dedans des yeux; labre à deux lobes médiocres. Mandibules élargies, coudées, proéminentes, dentées en dedans. Antennes brun de poix, massue grise, velue. Pronotum plus large que long, arqué à la base, avec une strie médiane courte au devant de l'écussun, dilaté sur les côtés, échancré en devant, avec les angles obtus, abaissés; strie marginale entière, bien marquée, anguleuse. Ecusson très petit, triangulaire. Elytres de la longueur du pronotum, de sa largeur à la base, obliques au bord apical, formant un angle sutural bien marqué; repli latéral à peine pointillé; strie subhumérale subitement dilatée et prolongée linéairement de chaque côté; trois dorsales courtes. Propygidium entouré d'un cercle de points, 
bifovéolé. Pygidium infléchi, ponctuée à la base. Pattes antérieures quadri-dentées, postérieures tri-dentées.

Cette espèce remarquable, de Cayenne (Guyane), est une forme intermédiaire, peut-être digne de constituer un nouveau genre: elle a le labre avancé, l'insertion latérale des mâchoires et la forme de la strie subhumérale des autres Plylloma; sa forme est un peu convexe, et ses jambes postérieures sont dentées comme dans le $P /$. oblitum. Elle rappelle le genre Leionola par son prosternum; les Oxystermus par son menton biforéolé et ses mandibules dilatées, saillantes, quoique égales entre elles.

\section{LEIONOTA.}

$$
\text { (A Eĩos, lisse. - vĩos, dos.) }
$$

30 Série, 'T.1 (1853), pl. v. - Mon. Pl. 2. Genre III, f. 1-15.

Corpus planiusculum.

Caput exsertum. Mandibule porrectee, requales. Lubrum parvum, bilobum.

Maxille pone nentum inscrte, prorsus cooperle.

Prosternum constrictum, prominens, lobo plus minusve aculo.

Tibice extus dentate, infra sape denticulate; antice inlus dente basali.

Propygidium latum, horizontale, hexagonum; pygidium obliqunm.

Corps plus ou moins aplati, en ovale allongé.

Tête saillante, dégagée du prothorax. Front sans strie qui le sépare de l'épistome (quelques espèces seulement ont de chaque côté une courte strie transversale), avec une dent 
au-dessus de l'insertion des antennes; quelquefois un sillon longitudinal en dedans des yeux. Labre court, échaneré. Mandibules saillantes, légèrement courbées vers la pointe, égales entre elles, ordinairement inermes, plus longues dans le $\sigma^{*}$ que dans la $\&$, creusées en forme de coulisse, pour y loger les mâchoires.

Antennes (f. $10 \mathrm{c}$ ) insérées sous un rebord du front: scape allongé, légèrement courbé et épaissi vers le bout, logé dans une rainure de la partie inférieure de la tête; funicule de sept articles : premier plus long que les suivants, ceux-ci à peu près d'égale longueur vont en s'élargissant vers le bout; massue ovale, comprimée, quadri-articulée, révêtue d'un duvet épais, gris, placée sous le bord antérieur du prothorax au-devant des hanches, sans fossette bien accusée.

Mâchoires (f. 10 a) à lobes étroits, garnis de poils en dedans : l'interne court, membraneux, l'externe très allongé, membraneux en dedans, corné en dehors. Palpes maxillaires de quatre articles, plus longs que le lobe maxillaire externe; cylindriques; premier article beaucoup plus court que les autres, deuxième et troisième égaux entre eux, quatrième un peu plus court. Menton (f. 10 b) coupé droit à la base, plus ou moins sillonné et excavé, échancré en devaut, couvrant toute la bouclse. Paraglosses membraneuses, allongées, courbées en dedans, et garnies de poils. Palpes labiaux de trois articles, troisième le plus long.

Pronotum transversal, bisinué à la base, avec une fine strie longitudinale qui remonte jusqu'an milieu, plus ou moins arrondi sur les côtés, fortement échancré en devant. Strie marginale plus ou moins forte, ordinairement terminée à l'angle antérieur. Prosternum assez éleré, rétréci, arrondi à la base, terminé en devant en pointe plus ou moins saillante. Mésosternum échancré en devant pour recevoir la 
base du prosternum, bordé d'une strie interrompue à l'échancrure prosternale. Pièce liumérale visible en dessus. Ecusson petit, triangulaire. Elytres courtes, coupées obliquement au bout, formant un angle sutural, plus ou moins profond. Strie humérale nulle; une subhumérale raccourcie ordinairement à la base. Deux dorsales : première raccourcie, deuxième entière, coudée, interrompue dans quelques espèces.

Abdomen de cinq anneaux : premier segment inférieur plus long que les autres et marqué de chaque côté d'une ligne sinueuse. Propygidium horizontal et en hexagone. Pygidium court et perpendiculaire, quelquefois rebordé.

Pattes postérieures fort distantes à leur insertion: cuisses renflées; jambes triangulaires, aplaties, logées dans une coulisse de la cuisse, avec une double arête sur le bord externe, terminées par deux épines inégales : antérieures armées en dedans d'une dent basilaire, et en dehors de quatre dents sur l'arête supérieure, avec une fossette tarsale profonde et bien limitée de clıaque côté, les quatre postérieures munies de trois dents fortes, aiguës. Tarses filiformes et minces, quatre premiers articles garnis en dessous chacun de deux petites soies.

J'ai réuni, dans ce genre démembré des Hololepta d'Erichson, quinze espèces du continent ou des illes d'A mérique, dont trois seulement avaient été décrites. Dejean, dans la 3e édition de son Catalogue, en 1837, avait indiqué cette division, et dans sa collection se trouvaient réunis sous ce nom l'II. minuta d'Erichson, qu'il rapporte faussement à l'II. Lamina de Paykull, et les deux autres qu'il confond, et dont il indique le $\sigma^{*}$ sous le nom de $L$. quatrilentuta, F., ct la \& sous celui de $L$. Lovicollis, avec une quatrième, rap)portée de Cayenne par M. Lacordaire, sous le nom de $L$. 
cerdo. Quoiqu'il m’ait été impossible de trouver un ou deux caractères saillants, tirés soit des parties de la bouche, soit du sternum ou des pattes, de ceux en un mot qu'on est convenu d'appeler importants, qui s'appliquent à toutes les espèces de ce genre, l'ensemble des caractères m'a paru si tranché que je n'ai pas balancé à les séparer des Hololepıa, devenus déja trop nombreux.

On reconnaitra toujours les Leionola au prosternum saillant, rétréci et terminé en pointe antérieurement, aux jambes postérieures dont l'arête du dessous est dentelée, et à la deuxième strie dorsale des élytres entière. Si dans quelqques espèces le prosternum, un peu plus large et moins appointi, laisse quelque doute, les deux autres caractères viennent lever toute difficulté.

Les preniers états des Lcionola sont inconnus. Leur genre de vie est le mème que celui des Hololepta; leur forme aplatie indique qu'ils vivent sous les écorces des vieux arbres morts, dans le terreau humide qui s'y forme. La seule espèce un peu répandue, $\boldsymbol{L}$. quadridentata, F., a été trouvée dans ces conditions à diverses époques de l'année (janvier, avril, octobre).

Le seul caractère sexuel qui paraisse général est la forme des mandibules plus droites et plus allongées dans le ơ que dans la ․ La plupart des espèces ont une fossette à l'angle antérieur du pronotum; est-ce un caractère exclusivement propre au ${ }^{A}$ ? Les $L$. quadridenlala, devia, interrupla, Rei hii, sont les seules espèces où j'aie pu m'en assurer. Quant à l'excavation en $\mathrm{M}$ du menton, on la retrouve également dans les deux sexes.

Le $L$. strigicollis, par son sternum, fait le passage aux Oxystermus, et le $L_{\text {. }}$ confusa aux Hololepta. 

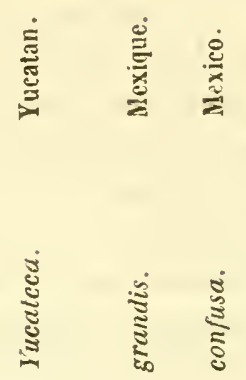

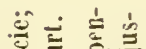

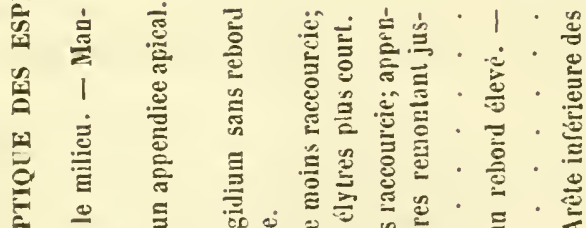

है।

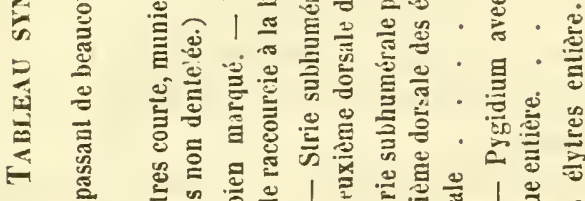

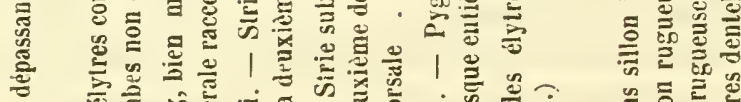
范

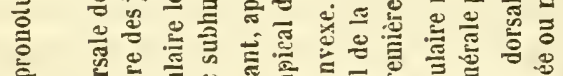

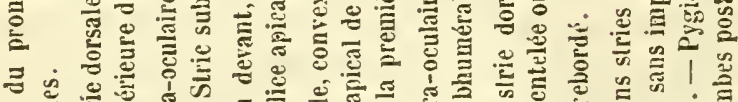

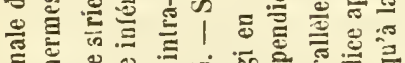

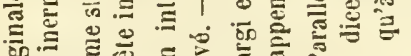

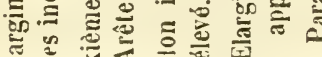

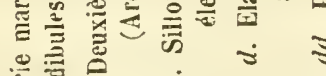

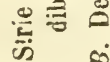


$\frac{\dot{d}}{2}$

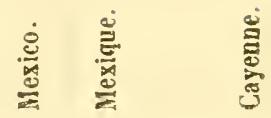

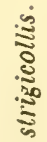

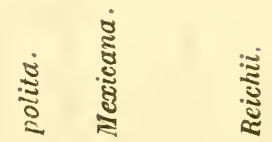

4

$\dot{0} \infty \dot{\infty}$

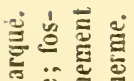

总芯怘

ఏ

을 일

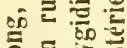

드을 융

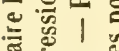

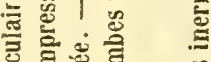

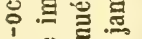

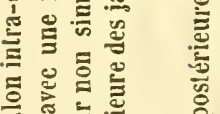

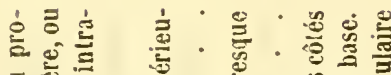

푤 :

-

ठ

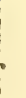

๘

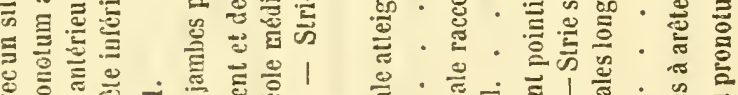

仓

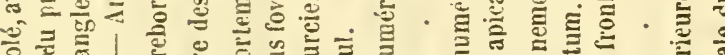

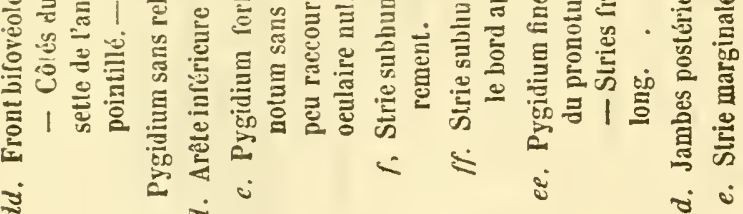

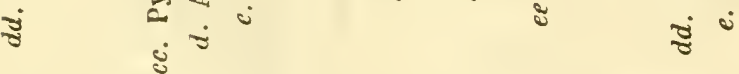

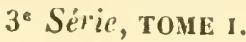




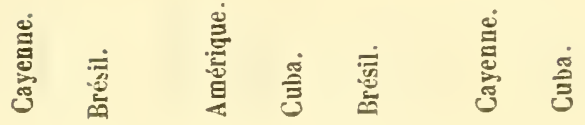

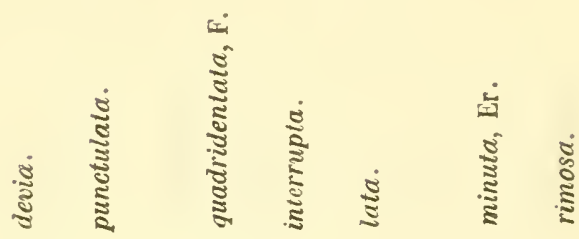

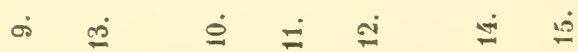

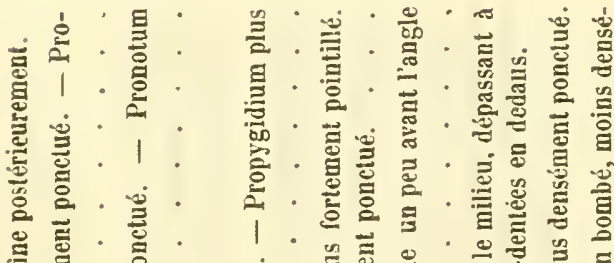

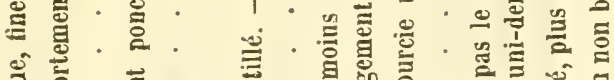

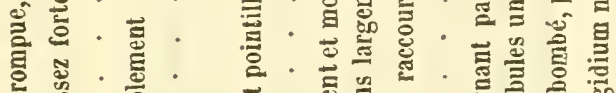

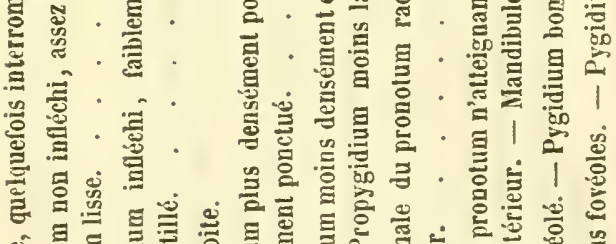

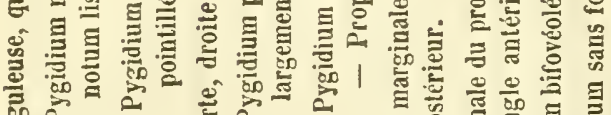

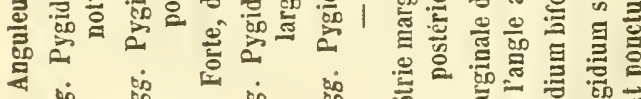

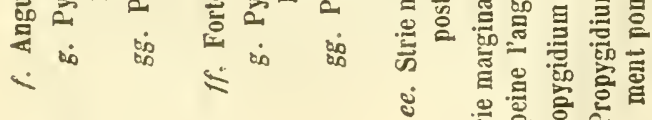

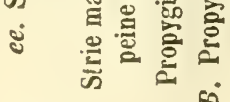
दो 
A. Strie marginale du pronotum dépassant le milieu. Mandibules inermes (1-13).

$B$. Deuxième strie dorsale des élytres courte, avec un appendice plus ou moins long. - Arête inféricure des jambes non dentelée (1-3).

\section{L. Yucateca.}

Lata, postice attenuata, deplanata, puncticulata, nigra nitida; fronte striis 2 obsoletis, sulco intra-oculari longo; pronoto lateribus recto, stria marginali valida, basi continuata; elytris margine inflexo rugoso, stria subhumerali antice parum abbreviata, $1^{2}$ dorsali dimidiata, 2a valde interrupta; propygidio lateribus parce, pygidio dense punctatis. Long. 18 mill. Larg. 8 mill.

A plati, oblong, élargi en devant, noir luisant. Front finement pointillé, arec deux stries obsolètes, et un sillon entier et profond en dedans des yeux ; dent préoculaire saillante; antennes brunes, massue grise. Pronotum transversal, finement pointillé, plus distinctement sur les bords latéraux. bisinué à la base, avec une demi-strie longitudinale fine au milieu; droit sur les côtés, largement échancré en devant, avec les angles arrondis, obtus; stric marginale forte, droite, continuée à la base, interrompue un peu après l'angle antérieur. Ecusson triangulaire, très petit. Elytres de la largeur du pronotum à la base, de sa longueur à la suture, rétrécies postérieurement, obliques au bord apical, avec un angle sutural très prononcé; repli latéral rugueux; strie subhumérale très large, atteignant presque la base; première dorsale forte, dépassant le tiers de la longueur; deuxième très courte, avec un appendice droit, remontant à peine au tiers. Propygidium couvert de points espacés sur les côtés; pygi- 
dium densément et assez fortement ponctué. Menton large, pointillé, obsolètement rebordé; prosternum en carène étroite, saillante. Jambes antérieures garnies de quatre dents, postérieures de trois, avec l'arête inférieure inerme.

Yucatan (M. Pilate).

\section{L. GRANDIS.}

Elongata parallelu, subconvexa, nigra nitida; fronte sulcis 2 integris; monoto lateribus rectis, stria marginali basi contimuata, antice interrupta; elytris margine inflexo rugoso, stria subhumerali magis abbreviala, $1^{\text {a }}$ dorsali dimidiata, 2a parum interrupla; propygidio parce lateribus, pygidio densc punctatis. Long. 15 mill. Larg. 7 mill.

Allongé, parallèle, légèrement convexe, noir luisant. Front lisse, sans stries, avec un sillon entier en dedans les yeux; dent préoculaire saillante. Pronotum bisinué à la base, avec une demi-strie longitudinale fine au milieu, droit sur les cotés, largement échancré en devant, avec les angles obtus; strie marginale forte, droite, continuée à la base, interrompue un peu après l'angle antérieur. Ecusson triangulaire, très petit. Elytres de la largeur du pronotum à la base, de sa longueur à la suture, obliques au bord apical, avec un angle sutural assez marqué; repli latéral rugueux; strie subhumérale inoins large et plus raccourcie à la base que dans le $L$. Iucaleca; première dorsale forte, du tiers de la longueur, deuxième fort courte, arec un appendice qui remonte jusqu'à la première dorsale. Propygidium bordé de points espacés. Pygidium densément et assez fortement ponctué, sans rebord. Menton pointillé, à peine rebordé, sans carènes. Prosternum en carène saillante. Jambes antérieures garnies de qnatre dents, postérieures de trois, avec l'arète inférieure inerme. 
Se distingue aisément du $L$. Yucateca par sa forme plus parallèle, plus convexe, sa strie subhumérale plus raccourcie et sa deuxième dorsale beaucoup moins interrompue.

Mexique (Mexico, Oaxaca), (MM. de Laferté et Chevrolat).

\section{L. Confusi.}

oblongo-ovata, subdepressa, nigra nitida; fronte cequali; pronoto in angulo antice muctato, stria marginali angulutu, basi continuata; elytris margine inflexo lavi; stria subhumerali subintegra, $1_{a}$ clorsali lata, $2^{a}$ brevissima appendiculata; propygidio apice bifoveolato, lateribus punctis arcuatis rugoso; pygidio temiter marginato, grosse et dense punctato. Long. 10 mill. Larg. 5 mill.

Ovale oblong, subdéprimé, d'un noir luisant. Front uni, sans stries, ni sillon en dedans des yeux; antennes brunnes, massue grise. Pronotum bisinué à la base, avec une demistrie longitudinale au devant de l'écusson; curvilinćairement dilaté sur les côtés, échancré en devant, avec les angles obtus, ponctués; strie marginale entière, fine, anguleuse. Elytres un peu plus longues que le pronotum, de sa largeur à la base, presque droites latéralement, obliques au bord apical, et formant un angle sutural très ouvert; repli latéral lisse; strie subhumérale forte, plus fine et presque entière à la base; première dorsale forte, du tiers de la longueur; deuxième très courte, avec un assez long appendice. Propygidium avec deux impressions de chaque côté, et couvert dans son pourtour de gros points arqués, pres-

- que rugueux. Pygidium étroitement rebordé, fortement et densément ponctué. Menton non rebordé, carènes longiludinales obsolètes. Prosternum en carène saillante. Jambes 
inermes en dessous; armées en dessus, les antérieures de quatre dents, les portérieures de trois, les deux apicales rapprochées; tarses bruns.

Mexique (M. Chevrolat).

BB. Deuxième strie dorsale des élytres entière (4-13)

c. Pygidiun rebordé (4-5).

\section{L. CERDO.}

Oblonga, subdepressa, nigra subnitide: fronte cequali; monoto stria marginali angulata subinterrupta, antice sinuatim foveolata; elytris margine inflexo lavi, stria sublumerali abbreviata, $1^{\text {a }}$ dorsali brevi; propygidio apice bifoveolato, lateribus grosse; mggidio dense et fortiter punctatis, tibiis infru denticulatis, Long. 10 1/2 mill. Larg. 5 mill.

Allongé, légèrement déprimé, noir assez luisant. Front uni, sans stries, arec un sillon court en dedans des yeux; antennes brunes, massue grise; mandibules creusées en dessus d'une gouttière oblique. Pronotum plus large que ong, bisinué à la base, arec une demi-strie longitudinale au devant de l'écusson; angulairement dilaté sur les côtés, échancré en devant avec les angles obtus; strie marginale fine postérieurement, interrompue à la dilatation, plus forte et terminée à l'angle antérieur dans une fossette sinuée, profonde. Elytres un peu plus longues que le pronotum, de sa largeur à la base, à peine élargies sur les côtés, obliques au bord apical, formant un angle sutural très ouvert; repli latéral lisse; strie subhumérale forte, raccourcie; première dorsale forte, du tiers de la longueur; deuxième entière, se rapprochant de la première en faisant un coude. Propygidium bifovéolé au bout et couvert de gros points peu serrés 
dans son pourtour. Pygidium bombé, densément et fortement ponctué, bordé postérieurement. Excavation présentant une $\mathrm{II}$ en relief sur le menton, et derrière un W. Jambes antérieures armées de quatre dents : postérieures de trois, les deux apicales rapprochées, arête inférienre dentelée.

Le seul individu $\sigma^{*}$ que j'aie sous les yeux a été rapporté de Cayenne, sous ce nom, par M. Lacordaire, et fait partie de la collection de M. de Laferté.

\section{L. STRIGICOLLis.}

Elongata, convexiuscula, nigra nitida; fronte bifoveolata, sulco utrinque intra oculos; pronoto latcribus punctato, in medio rugoso, stria marginali forti basi molongata, antice in fossa lata desinente; elytris margine inflexo punctato, stria subhumerali lata subintegra, $1^{\text {a }}$ dorsali brevi; propigidio parce et sat fortiter, pygidio tenuissime punctatis, tibiis infra inermibus. Long. 11 mill. Larg. 6 mill.

Allongé, assez convexe, noir luisant. Tront plan, biforéolé; avec un sillon en dedans des yeux, de chaque côté; dent préoculaire saillante; antennes brunes, massue grise. Pronotum bisinué à la base, arec une demi-strie longitudinale fine au milieu, curvilinéairement dilaté et ponctué sur les côtés, avec une large impression rugueuse, largement échancré en devant, avec les angles obtus; strie marginale forte, arquée, prolongée à la base, terminée en devant dans une large et profonde fossette. Ecusson triangulaire, très petit. Elytres de la largeur du pronotum á la base, un peu plus longues, droites sur les côtés, obliques au bout, avec l'angle sutural peu marqué; repli latéral ponctué, strie subhumérale forte, rugueuse, amincie et arquée en devant, raccourcie; première dorsale large, du tiers de la longueur; deuxième entière, légèrement coudée, bordée au bout de 
points irréguliers. Propygidium couvert de gros points peu serrés ; pygidium fortement rebordé, pointillé. Menton rebordé, bicaréné. Prosternum élevé, étroit, fort aiguisé. Jambes antérieures armées de quatre dents : postérieures de trois, arète inférieure inerme.

Cette espèce, dont je n'ai vu qu'un individu o , vient du Mexique (M. Cherrolat).

cc. Pygidium non rebordé (6-13).

d. Jambes postérieures inermes sur l'arête iıférieure $(6 \cdot 8)$.

\section{L. POLITA.}

Oblonga subconvexa, nigra nitida; fronte obsoletissime bistriata; pronoto lateribus munctato, stria marginali basi continuata; clytris margine inflexo punctato; stria subhumerali integra; propygidio latcribus parce, pygidio dense punctatis. Long. 10 mill. Larg. 6 mill.

Allongé, légèrement convexe, noir luisant. Front avec deux strioles indistinctes; dent préoculaire saillante. Antennes brunes, massue grise. Pronotum court, bisinué à la base, avec une demi-strie longitudinale fine au milieu, curvilinéairement dilaté et ponctué sur les côtés, échancré en devant, arec les angles obtus; strie marginale légèrement coudée, continuée à la base, et terminée antérieurement dans une fossette arrondie, profonde. Ecusson triangulaire, très petit. Elytres de la largeur du pronotum à la base, un peu plus longues que lui a la suture, droites sur les côtés, obliques au bout, avec l'angle sutural peu profond; repli latéral arec quelques points; strie subhumérale forte au milieu, devenant plus fine à la base, qu'elle atteint; première 
dorsale forte, du tiers de la longueur; deuxième entière, courbée. Propygidium largement couvert de points arqués; pygidium densément ponctué, sans rebord. Menton obsolètement rebordé, sans trace de carènes. Prosternum étroit, éleré. Jambes antérieures armées de quatre dents : postérieures de trois, les deux dernières rapprochées, inermes à l'arête inférieure.

Mexique.

J'ai décrit cette espèce sur un individu de la collection de M. de Laferté, type du $L$. polita Sturm.

\section{L. MexiCANA.}

Oblonga subconvexa, puncticulata, nigra nitida; fronte leviter bistriata; pronoto lateribus punctato, stria nurginali angulata basi continuata: clytris margine inflexo punctato, stria subhumcrali antice abbreviata; propygidio bifoveolato, lateribus parce, pygidio dense punctatis. Long. 9 mill. Larg. $51 / 2$ mill.

Allongé, légèrement convexe, pointillé, noir luisant. Front faiblement bistrié; dent préaculaire saillante. Antennes brunes, massue grise. Pronotum court, bisinué à la base, avec une demi-strie longitudinale fine au milieu, arrondi et ponctué sur les côtés, échancré en devant, avec les angles obtus ; strie marginale forte, coudée, continuée à la base, et terminée antérieurement par une fossette arrondie, profonde. Ecusson triangulaire, très petit. Elytres un peu plus longues que le pronotum, de sa largeur à la base, droites sur les côtés, obliques au bout, avec un angle sutural assez profond; repli latéral arec quelques points ; strie subhumérale grosse au milieu, amincie aux deux bouts, raccourcie a la base; première dorsale dépassant le tiers de la longueur : 
deuxième entière, courbée. Propygidium légèrement bifovéolé au bout, largement bordé de points peli serrés; pygidium densémen: ponctué, sans rebord. Mienton pointillé, non rebordé. Prosternum en carène ćlroite, saillante. Jambes antérieures armées de quatre dents : postérieures cie trois; arêle inférieure inerme.

Mexique.

\section{I. Reichir.}

Oblonga, convexa, nigra nitida; fronte 2 striis arcuatis, inter oculos utrinque bisulcalu; pronoto stria marginali valida recta, basi continualu, foveolu parva laterali; clytris margine inflexo levi, stria subhumerali antice valde abbreviata; $2^{2}$ dorsali appendiculata; propmgidio sparsim, mygidio dense tenuiteryue menctatis. Long. 9 mill. Larg. 5 mill.

Allongé, convexe, noir luisant. Front avec deux larges stries arquées, transversales, rapprochées, et un sillon de chaque côté en dedans des yeux; dent préoculaire saillante. Antennes brun de poix, massue grise. Pronotum court, fortement bisinué à la base, avec une demi-strie longitudinale au milieu, légèrement courbé sur les côtés, avec une petite fossette au milieu, bisinueusement ćchancré en devant, avec les angles obtus; strie marginale forte, droite, prolongée à la base. Ecusson triangulaire, très petit. Elytres un peu plus longues que le pronotum, de sa largeur à la base, droites sur les côtés, obliques au bout, avec l'angle sutural assez marqué ; repli latéral lisse ; strie subhumérale fort raccourcie à la base; première dorsale grande, arquée, dépassant le tiers de la longueur; deuxième entière, arquée, accompagnéc au bout d'une petite stric et de quelques points. Propygidium couvert de points espacés, plus gros sur les 
côtés. Pygidium densément et finement poictuć. Menton fortement rebordé et bicaréné. Prosternum saillant, étroit Jambes antéricures armées de quatre dents: nostérieures de trois; arête inférieure inerme.

Cette remarquable espèce faisait partie de la collection de M. Reiche, sans désignation de patrie. Je l’ai dédiéc, comme un faible témoignage de ma gratitude, à cet entomologiste distingué, qui ın’a communiqué avec empressement sa collection et ses livres. Depuis j'en ai vu un exemplaire $\sigma^{*}$ provenant de Cayenne.

d. Jambes portérieures à arête inférieure dentelće (9-13).

\section{L. DEVIL.}

Elongata, subconvexa, nigra nitida; fronte utrinque inter oculos sulcata; pronoto lateribus angulato, stric marginati postice attcunata; elytris margine inflexo lari, stria subhumerati antice abbrcviata; promygidio bifovcolato, lateribus parce, pygidio sat dense punctutis. Long. 10-11 1/2 mill. Larg. 5-6 1/2 mill.

Hololepta quadridentata, Er. Jahrb. 95, 11. (1834).

Allongé, légèrement convexe, noir luisant. Front lisse, avec un sillon de chaque côté en dedans des yeux; dent préoculaire saillante. Antennes brun de poix, massue grise. P'ronotum bisinué à la base, avec une demi-strie longitudinale fine au milieu, fortement dilaté sur les côtés, largement échancré en devant, arec les angles obtus; strie marginale anguleuse, plus fine et plus rapprochéc du bord postérieurement, prolongée à la base. Ecusson triangulaire, très petit Elytres de la longueur du pronotum, et de sa largeur à la base, à peine arquées sur les côtés, obliques au bout, arec l'angle sutural peu profond; repli latéral lisse; strie sub- 
humérale fort raccourcie en devant ; première dorsale forte, dépassant le tiers de la longueur; deuxième entière, coudée. Propygidium légèrement bifovéolé, couvert largement de gros points espacés dans soll pourtour. Pygidium fortement et assez densément ponctué. Menton rebordé seulement au milieu du bord antérieur, et bicaréné. Prosternum saillant et étroit. Jambes antérieures armées de quatre dents : postérieures de trois; arète inférieure dentelée.

$\sigma^{\star}$. Une fossette arrondie, profonde à l'angle antérieur du pronotum; + sans fossette.

Brésil, Guyane (Cayenne).

Ericlıson, loc. cit., a cru, d'après l'inspection d'un individu provenant de Fabricius, que cet ancien auteur avait décrit une espèce différente de celle de Paykull, et il a, en conséquence, appelé Hololepta plalysma l'espèce si bien décrite et figurée par ce dernier, réservant à l'autre le nom de $H$. quadrilenlata. Notre savant entomologiste a dù supposer que Fabricius s'est trompé sur la patrie, et il s'est mis en contradiction avec tous les auteurs, et en particulier avec Paykull et Schœnherr, qui ont dù connaître mieux que nous la collection de Fabricius. N'est-il pas bien plus simple de supposer que le célèbre disciple de Linné, dont les travaux superficiels ont été cause de tant d'erreurs et de difficultés, a rapporté faussement à cette espèce l'individu comparé par Erichson, ou qu'il a confondu les deux espèces? Dejean, dans sa collection, les avait également réunies; il donnait au * le nom de L. 4-dentala, et à la + celui de L. lavicollis.

\section{L. QUADRIDENTATA.}

Ovalis subconvexa, nigra nitida; fronte absque striis et sulcis: pronoto stric marginali valida recta, basi continuata; elytris margine inflexo levi, stria subhumerali abbreviata; propygidio 
parce lateribus, pygidio dense, tenuiter punctatis. Long. 8-11 mill. Larg. 5-6 mill.

Hister 4-dentatus, F. Ent. S. 1, 74, 11 (1792). - F. Syst. El, $1,91,39$.

Hololepta 4-dentata, Payk. Mon. Hist. 109. 8, T. Ix, f. 4. H. platysma Er. Jahrb. 95, 11.

Ovale, légèrement convexe, noir luisant. Front sans stries transversales, ni sillon en dedans des yeux; dent préoculaire assez saillante. Antennes brunes, massue grise. Pronotum court, bisinué à la base, avec une demi-strie longitudinale fine au milieu, à peine courbé sur les côtés, bisinueusement échancré en devant, avec les angles obtus; strie marginale forte, presque droite, sans coude, prolongée à la base, terminée à l'angle antéricur, se perdant $\sigma^{*}$ dans une fossette profonde, oblongue. Ecusson triangulaire, petit. Elytres de la largeur du pronotum à la base, de sa longueur à la suture, légèrement courbées sur les côtés, obliques au bout. avec un angle sutural très profond; repli latéral lisse; strie subhumérale très raccourcie en devant; première dorsale forte, dépassant le tiers; deuxième entière, coudée. Propygidium couvert latéralement de gros points espacés. Pygidium densément et peu fortement ponctué. Menton rebordé et bicaréné. Prosternum étroit, saillant. Jambes antérieures armées de quatre dents:postérieures de trois; arête inférieure dentelée. $\sigma^{7}$. Une fossettc oblongue, arquée, plus ou moins forte à l'angle antérieur du pronotum. o sans fossette.

Cette espèce, assez commune, est répandue dans une grande partie de l'Amérique : Etats-Unis (Nouvelle-Orléans), Texas, Saint-Domingue, Nouvelle-Grenade, Venezuela, Guyane, Brésil, Bolivie. On la trouve sous les écorces du bois mort et en voie de décomposition, dans les mois de janvier, avril et octobre. 


\section{L. INTERRIPTA.}

Ovala, subconvexa, nigra, nilida; fronte aquali; monoto stria marginali forti subrectu integra; elytris margine inflexo lovi, stria subhmmerali antice valde abbreviala, 1a dorsali brevi, 2a parum intermpla; propygidio latcribus parce, mygidio minus dense el obsolete punclatis. Long. 9 mill.; larg. $51 / 2$ mill.

Ovale, assez couvexe, noir luisant. Jont uni, sans stries, ni sillons en dedans des yeux. Antennes brunes, massue grise. Pronotum court, beaucoup plus large que long, bisinué à la base, arec une demi-strie longitudinale très fine au devant de l'écusson, légèrement arqué sur les côtés, échancré en devant, avec les angles arrondis, entiers; strie marginale entière, presque droite, forte, prolongée à la base, aboutissant à une fossette profonde, allongée o à l'angle antérieur. Elytres plus courtes que le pronotum, de sa largeur à la base, légèrement dilatées sur les côtés, obliques au bord apical, et formant un angle sutural profond; repli latéral lisse; strie subhumérale fort raccourcie à la base; première dorsale forte, oblique, du tiers de la longueur; deuxième arquée, ordinairement un peu interrompue au-delà du milieu. Propygidium avec des points épars, peu nombreux sur les côtés. Pygidium moins densément et plus obsolètement ponctué que dans le L. 4-dentala. Excavation du menton en M. Jambes antérieures armées de quatre dents : postérieures de trois en dessus; arête inférieure dentelée.

* Fossette allongée, profonde à l'angle antérieur du pronotum. ㅇ saus fossette.

Cette espèce a les plus grands rapports avecle $L$. 4-dentala. mais la ponctuation du pygidium, faible, espacée, et la deuxième dorsale interrompue l'en séparent suffisamment. Elle est propre à l'île do Cuba. 


\section{I. LATA.}

Ovato-lata, subdcpressa, nigra, nitida; fronte aquati; pronoto latcribus punctato, stria marginali basi abbreviata; elytris margine inflexo lavi; stria subhumerali lata profunde

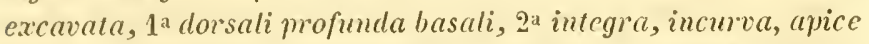
foveolata; propygidio circum punctato, apice subvifoveolato; pygidio levi. Long. 9 1/2 mill.; larg. $61 / 2$ mill.

Ovale très élargi, déprimé, noir assez luisant. Front uni, avec un petit point de chaque côté en devant; dent préoculaire saillante. Antennes d'un brun de poix, massue d'un roux-cendré. Pronotum court, large, fortement bisinué à la base, arec une demi-strie longitudinale très fine au devant de l'écusson, curvilinéairement dilaté sur les côtés et bordé de points, largement échancré en devant, avec les angles entiers dans les deux sexes, abaissés, obtus; strie marginale forte, ne partant pas tout à fait de la base, et dépassant un peu l'angle antérieur. Ecusson très petit, triangulaire. Elytres un peu plus longues que le pronotum, de sa largeur à la base, fortement dilatées sur les côtés, obliques au bord apical, arec un angle sutural peu profond; repli latéral lisse; une profonde et large excavation sous l'épaule, dans laquelle est creusée la strie subhumérale, raccourcie à la base; première dorsale forte, du tiers de la longueur; deuxième entière, coudée, et terminée par une fossette. Propygidium bordé d'une ponctuation peu serrée, assez étendue, légèrement bifovéolé au bord postérieur. Pygidium lisse. Menton rebordé, légèrement caréné. Prosternum un peu élargi. Jambes antérieures armées de quatre dents : postérieures de trois, les deux apicales rapprochées; arête inférieure dentelée.

o Mandibules allongées, renflées à la base; une échancrure du menton bifide au derant du prosternum.

Brésil. 


\section{L. Peyctelata.}

Oblonga, dcpressa, nigra, nitida, puncticulata; fronte bistriata, utrinque intra oculos sulcala; pronoto lateribus punctato, stria marginali angulata postice attcmuata, basi continuata; elytris margine inflexo lavi, stria subhumerali abbreviata, $1^{\text {a }}$ dorsali brevi; mropygidio bifovcolato, parce; pygidio inflexo punctatis; tibiis infra denticulatis. Long. 7 mill.; larg. 4 mill.

Allongé, déprimé, noir luisant, finement pointillé. Front plan, largement bistrié, arec un sillon en dedans des yeux, séparant tout à fait la dent préoculaire. Antennes ferrugineuses, massue grise. Pronotum bisinué à la base, avec une demi-strie longitudinale fine au milieu, dilaté et ponctué sur les côtés, largement échancré en devant, avec les angles obtus; strie marginale coudée, forte en devant, fine par derrière et prolongée à la base. Ecusson triangulaire, petit. Elytres de la largeur du pronotum à la base, de sa longueur à la suture, droites sur les côtés, obliques au bout, avec l'angle sutural assez marqué; repli latéral lisse; strie subhumérale fort raccourcie en devant; première dorsale forte, du tiers de la longueur; deuxième entière, coudée. Propygidium biforéolé, entouré de points espacés. Pygidium infléchi, faiblement ponctué au bout. Menton rebordé. Prosternum assez étroit, peu saillant en derant. Jambes antérieures armées de quatre dents : postérieures de trois; arête inférieure dentelée.

Brésil; Guyane (Cayenne). 
AA. Strie marginale n'atteignant pas le milieu du pronotum. Mandibules unidentées (14-15)

\section{L. MINUTA.}

Oblonga, subdepressa, nigra, subnitida; fronte sulcis intra oculos parvis; pronoto in medio subtiliter carinato; elytris margine inflexo subpunctato: stria subhumerali abbreviata, dorsalibus validis, $1^{\text {a }}$ brevi, $2^{\text {a }}$ integra; propygidio bifoveolato grosse at parce; mygidio sat dense punctatis; tibiis subtus dentatis. Long. 6 mill.; larg. 3 mill.

IIololepta mimuta, Er. Jahrb. 96, 13 (1834).

Oblong, légèrement déprimé, noir assez luisant. Front pointillé, sans stries, avec un petit sillon court derric̀re les ycux. Antennes ferrugineuses, massue grise; dent préoculaire saillante. Pronotum bisinué à la base, avec une petite ligne élevée entière au milieu, angulairement dilaté sur les côtés, échancré en devant, avec les angles obtus; strie marginale très courte dans l'angle antéricur même. Ecusson triangulaire, petit. Elytres de la largeur du pronotum à la base, de sa longueur à la suture, droites sur les côtés, obliques au bout, avec un angle sutural bien marqué; repli latéral avec quelques points peu profonds; strie subhumérale fort raccourcie; dorsales bien marquées, première du tiers de la longueur, deuxième entière, coudée. Propygidium bifovéolé au bout, couvert de gros points oblongs. espacés. Pygidium bombé, grossièrement et assez densément ponctué. Mienton rebordé et bicaréné. Prosternum élevé, étroit. Jambes antérieures armées de quatre dents : postérieures de trois; arête inférieure dentelée.

Brésil.

3e Séric, Tome 1. 


\section{L. RIMOSA.}

Oblonga, subdepressa, nigra, subnitida ; fronte ctquali ; pronoto stria marginali brevissima, in angulo antico tantum conspicua; elytris margine inflexo subpunctato; stria subhumerali abbreviala, $1^{\text {a }}$ dorsali brevi, $2^{\mathrm{a}}$ integra angulata ; promygidio hand foveolato, lateribus parce; pygidio minus dense punctatis; tibiis subtus denticulatis. Long. 6 mill.; larg. 3 1/4 mill.

Oblong, subdéprimé, noir assez luisant. Front uni, sans stries, avec un sillon court derrière les yeux; mandibules uni-dentées. Antennes brunes, massue grise. Pronotum plus large que long, bisinué à la base, avec une strie longitudinale fine, entière au devant de l'écusson, arrondi sur les côtés, échancré en devant, avec les angles obtus; strie marginale très courte, ne dépassant guère l'angle antérieur. Elytres de la longueur du pronotum, de sa largeur à la base, parallèles sur les côtés, obliques au bord apical, formant un angle très ouvert ; repli latéral presque lisse; strie subhumérale raccourcie; première dorsale dú quart de la longueur; deuxième forte, rapprochée de la première, coudée, entière. Propygidium sans fossettes postérieures, couvert de points assez espacés, avec le milieu lisse. Pygidium assez fortement, mais peu densément ponctué. Menton rebordé, excavé en M. Prosternum élevé. Jambes antérieures armées de quạtre dents : postérieures de trois; arête inférieure denticulée.

Très voisin du L. minuta, il s'en distingue par la figure du propygidium, qui n'a pas de fossettes séparées par une petite carène postérieurement, et qui est lisse au milieu, et par la ponctuation moins serrée du pygidium.

Cuba. 
Espèces des auteurs que je nai pas vues, et qui se rapportent ì l'un des trois premier's genres.

Erichson, Jahr. p. 94, 10.

Hololepta Caffra. Fronte ulvinque striola impressa, pronoto lateribus rugoso-punetalo, unistriato; elytris stria lorsali interiore subintegra. Long. 11 mill. - Caffraria.

Front inégal, de chaque côté avec une impression oblique qui s'abouchent en devant, et au fond desquelles il y a une striole transversale; il est couvert de petits points, et dans les impressions de quelques points plus gros. Les mandibules sont plus longues que la tête, droites, et légèrement courbées en dedans a la pointe. Les antennes sont couleur de poix : le premier article du funicule est un peu allongé. Le pronoturn est parsemé de points très fins et espacés au milieu, gros, serrés, rugueux sur les côtés; au milieu de ces poirts on remarque une strie longitudinale, parallèle à la marginale; de plus, entre ces deux stries, une troisième très courte, qui n'atteint pas l'angle antérieur, et par derrière ne s'avance pas au-delà du milieu; et au milieu une autre très fine. Les élytres sont ponctuées sur les bords, mais à peine visiblement au milieu. La strie subhumérale devient plus fine en devant et atteint la base; les dorsales sont interrompues au milieu, l'externe beaucoup plus que l'interne; cette dernière, dans quelques individus, est entière sur l'une des élytres : l'avant-dernier segment supérieur de l'abdomen est couvert de quelques points, qui deviennent plus fins au milieu. Postérieurement s'élève une légère carène longitudinale. Le dernier segment est profondément et très densément ponctué.

Cette espèce rappelle la forme de l'Ilol. striatidera, qui vient du cap de Bonne-Espérance. 
Le Conte, Coléop. N. Calif. p. 38.

1. Hol. Cacti. Fronte utrinque striola obliqua, thorace lateribus antice rotundatis, parce punctatis, margine medio interrupto, elytris stria interna integra, lateribus postice parce punctatis; tibiis posticis dentibus 3 æequaliter distantibus; mandibulis capite longioribus, mento utrinque carinato. Long. 0,58. San Diego, in cactis putridis. Mas, thorace ad angulos anticos fovea maxima excavato; variat stria externa fere integra.

2. Hol. vicina. Fronte utrinque stria horizontali curvata, thorace lateribus antice rotundatis, parce punctatis, margine integro; clytris stria interna integra, externa postice in lineam punctorum fracta; tibiis posticis dentibus tribus, intermedio apicali propiore; mandibulis capite longioribus, mento concavo. Long. 0,33. San Diego, cum priore minus frequens.

\section{OXYSTERNUS.}

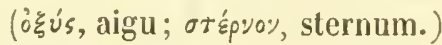

3e Série, T. 1 (1853), pl. v. - Mon. pl. 2. - Genre Iv, f. 1.

IIister. Linné (1746). - Fabr. Syst. EI. (1801).

Hololepta. Paykull. Mon. Hist. p. 101 (1811).

Oxystcrmus. Erichson, Jahr. 98, 3 (1834).

Corpus oblongum, crassum, subdepressum.

Caput exsertum.

Mandibula porrecter, intus dentata, incequales.

Maxilla juxta mentum inserte.

Prosternum compressum, prominulum, lobo acuminato.

Tibice antice intus edentala: posticae extus integree seriatim spinosulce.

Propygidium obliquum, transversum; pygidium devexum . 
Corps grand, épais, ovale, allongé, légèrement convexe sur le dos, et rétréci postérieurement.

Tête saillante, dégagée du prothorax. Epistome en pointe, enfoncé, non séparé du front par une strie transversale. Yeux réniformes, perpendiculaires, peu saillants; un sillon sinueux en dedans des yeux de chaque côté. Labre aliongé, arrondi au bout, avec une impression étroite. Mandibules fortes, très saillantes, courbées, dentées au bord interne, gauche plus large et plus longue que la droite.

Antennes (f. 1, 6) insérées sous le rebord du front, au devant des yeux. Scape allongé, courbé, épaissi vers le bout, logé dans une coulisse oblique, pratiquée au-dessous de la tête; funicule de sept articles, qui vont en s'élargissant; massue comprimée, ovale-allongée, de quatre articles coupés obliquement.

Mâchoires (f. 1, a) insérées à la base, entre le menton et les mandibules, a deux lobes linéaires, garnis de poils serrés en dedans, l'externe fort long, logés, ainsi que les palpes, dans une coulisse des mandibules. Palpes maxillaires filiformes, allongés, de quatre articles, le premier court, deuxième et troisième beaucoup plus longs et égaux entre eux, le quatrième plus court que le précédent. Menton court, transversal, perpendiculaire, coupé droit à la base et échancrẻ au bord opposé. Paraglosses cachées par le menton. Palpes labiaux courts, tri-articulés, troisième article plus long que le deuxième.

Pronotum plus large que long, semi-lunaire : la base formant un demi-cercle avec les côtes, sans angle postérieur, le bord antérieur profondément échancré ; cotés bordés par une strie marginale profonde, se terminant de cliaque côté à l'angle interne des yeux. Fosselte anteunaire peu pro- 
fonde et mal limitée, placée au devant des hanches, sous le bord antérieur et inférieur du prothorax. Prosternum élevé, élargi, et terminé en pointe à la base, rétréci en devant et terminé en pointe saillante; lobe prosternal à peine distinct. Mésosternum court, profondément échancré, jusqu'au métasternum, pour loger la base du prosternum, sans strie marginale. Pièce humérale triangulaire et forte. Ecusson très petit, triangulaire. Elytres assez courtes, rétrécies vers le bout et arquées, avec une strie liumérale et quelques dorsales distinctes.

Abdomen 5-articulé; premier segment ventral plus long que les autres, avec une strie sinuée de cliaque côté. Propygidium en hexagone transversal, incliné; pygidium également abaissé, triangulaire, rebordé.

Pattes fortes, la deuxième paire très rapprochée de la première, les postérieures distantes à leur insertion. Cuisses allongées, avec une coulisse dans le sens de la flexion pour recevoir les jambes. Jambes terminées par deux épines inégales; les antérieures fortement élargies, sans dent basilaire en dedans, hordées de soies courtes et serrées, bidentées au dehors, fossette tarsale profonde et bien limitée; les postérieures sont coudées au tiers de leur longueur, et garnies en dehors, dans leur dernière moitié, d'une triple série de soies serrées. Tarses courts, les quatre premiers articles égaux entre eux, serrés, garnis en dessous d'une double rangée de soies, cinquième assez court, armé de deux crochets.

Le genre Oxysternus, établi par Erichson, Jahrb. (1834), we renferme qu'une seule espèce, IIister maximus, L., maxillosus F., rangée par Paykull, en 1811 , parmi les Hololepta. Il se lic au genre Ilister par la 
forme de son abdomen, de ses élytres, et la disposition des stries; mais il tient aux Leionota par la forme de son prosternum et par sa tête avancée, qui ne s'enfonce pas dans le prothorax. Il s'en distingue par plusieurs caractères remarquables : absence de dent à la base des jambes antérieures, mandibules inégales; jambes antéricures bidentées, et les postéricures ciliées.

Les métamorphoses et le genre de vie de cet insecte sont inconnus.

\section{O. MAXIMUS.}

Elongatus, convexus, niger, nitidus; fronte intra oculos bisulcata; pronoto semi-circulari, stria marginali antice interrupta; elytris stria marginali unica, humerali obliqua, dorsalibus 1 et 2 antice abbreviatis, $3^{a}$ integra, $4^{\text {a apicali; }}$ propygiclio pygidioque marginato parce punctatis. Long. 16-22 mill.; larg. 9-13 mill.

Hister maximus, L. Syst. nat. 1, 2, 566, 1 (1746). - 11. maxillosus, F. S. El. 1, 91, 40. (1801).

Allongé, convexe, noir luisant. Front bombé, finement pointillé, avec un sillon en $S$ en dedans des yeux de cliaque côté ; labre allongé, sillonné ; mandibules longues et fortes, dentées, gauche plus forte, plus allongée, et passant sur la droite. Antennes brun de poix, massue grise, velue. Pronotum court, semi-lunaire, avec un point anté-scutellaire, les angles antérieurs obtus, abaissés, et une strie marginale bien marquée sur les côtés. Ecusson très petit, triangulaire. Elytres de la largeur du pronotum à la base, un peu plus longues, dilatées à l'épaule, rétrécies postéricurement, obliques au bout, avec un angle sutural à peine marqué; strie marginale entière, humérale, oblique, bien marquéc; 
première et deuxième dorsales un peu raccourcies à la base, troisième entière, quatrième tout à fait rudimentaire. Propygidium bordé de points assez espacés, et d'un pointillé plus fin dans les intervalles. Pygidium assez finement ponctué et rebordé. Jambes antérieures armées de deux larges dents, postérieures de trois rangs de soies serrées.

Guyane (Cayenne); Brésil ; Bolivie.

$$
\begin{aligned}
& \text { V. PLASIUS. } \\
& \text { ( } \pi \lambda \text { nøios, voisin.) }
\end{aligned}
$$

$3^{e}$ série. T. 1 (1853), pl. vi. - Mon. pl. 3. - G. v. f. 13. Erichson, Jahr. 101, Iv. Pl. 2, f. 1 (1834).

Corpus oblongum, subdepressum. Caput retractum, fronte stria sinuala interrupta.

Mandibulce aquales dentate.

Antennce funiculo scnsim incrassalo, clava ovali, compressa, foveole antennalcs subangulo antico prothoracis.

Prosternum basi rotundalum, in mesosterni sinu receptum, lobo lato valde producto.

Tibice anlice intus inermes, extus obtuse bidentate, fovcola tarsali distincte exarala; postice integrce 3-scriatim spinosule.

Propygidium declive; pygidium perpendiculare.

Corps ovale-allongé, rétréci postérieurement, peu convexe en dessus.

Tête grande, s'enfonçant dans le prothorax. Yeux réniformes, peu saillants. Strie frontale irrégulière, interrompue au milicu. Epistome avec une impression; labre transversal et légèrement sinué. Mandibules courbées, unidentées, égales entre clles, saillantes.

Antennes (f. a insérées sous un rebord arrondi du front, au devant des yeux : scape allongé, courbé, renflé vers le bout, 
logé dans une coulisse pratiquée sous la tête; funicule de sept articles, premier obconique, allongé; les autres vont successivement en augmentant de largeur; massue ovalaire, comprimée, composée de quatre articles taillés obliquement et velus. Fossette antennaire large, peu profonde, placéc sous l'angle antérieur du prothorax, l'antenne y pénètre par une profonde coulisse pratiquée dans le bord pectoral antérieur.

Mâchoires(f.c.) cornées, à deux lobesbarbus en dedans; l'externe long, l'interne beaucoup plus court. Palpes maxillaires de quatre articles; premier étroit; deuxième obconique; troisième plus long que le deuxième; quatrième ovalaire, allongé.Menton (f. b) coupé carrémentà la base, transversal, un peu bombé et relevé, légèrement tri-sinué au bord antéricur. Languette cacliée par le menton; paraglosses allongées, velues en dedans, arrondies au bout. Palpes labiaux de trois articles, deuxième obconique, troisième deux fois plus long, tronqué au bout.

Pronotum légèrement arqué à la base, presque parallèle sur les côtés, fortement échancré en devant. Strie marginale fine, latérale forte et bien marquée, interrompue en devant. Prosternum peu élevé, assez étroit, un peu plus large à la base, qui est arrondie et profondément enfoncéc dans le mésosternum; lobe antérieur large, distinct par une strie transversale, fortement avancé, arrondi cn avant, et bordé d'une stric. Mlésosternum transversal, profondément échancré en devant, pour recevoir la base du prosternum ; strie marginale interrompuc. Pièce humérale visible en dessus. Ecusson petit, triangulaire. Elytres peu convexes, rétrécies et coupées droit à l'extrémité, avec une ou deux stries subhumérales, unc humérale et quelques dorsales. deux marginales, evterne continuéc le lonğ du bord apical. 
Abdomen de cinq anneaux; premier segment ventral allongé, bistrié entre les pattes postérieures. Propygidium en hexagone, transversal, court, oblique; pygidium triangulaire, légèrement bombé, presque perpendieulaire.

Pattes fortes, médiocrement distantes à leur insertion. Cuisses allongées, avec une coulisse pour recevoir les jambes, plus ou moins comprimées. Jambes fortement élargies vers le bout, terminées par deux épines inégales; antérieures creusées en dessus d'une fossette tarsale nette et profonde, bidentées; les postérieures garnies d'un triple rang de soies; épineuses en dessus. Tarses courts, à articles serrés, égaux, excepté l'ongulifère qui est plus long, quoique assez court, et garni de deux crochets.

Ce genre a été créé en 1834 par Erichson, sur une espèce de Java, que cet auteur a déerite et figurée dans le Jahrbucher, 1,101, IV, T. 2, sous le nom de Javanus, et que Dejean a nommée, dans son eatalogue, Platysoma orthogonium, sans tenir compte du travail du savant naturaliste allemand.

Il contient trois espèces, qui toutes viennent de Java. Leurs mœurs et leurs métamorphoses sont inconnues.

Elles ont quelque ressemblance avec les genres Placodes, Platysoma, Aulacosternus et Macrosternus, qui ont, comme elles, la fossette antennaire sous l'angle antérieur du prothorax, une fossette tarsale bien limitée aux jambes antérieures, mais il est aisé de les distinguer par leurs jambes antérieures obtusément bidentées, et les postérieures garnies d'un triple rang d'épines serrées, sans échancrure au bout.

\section{P. Javanus.}

Oblongns, postice attenuatus, niger, nitidus; fronte utrinque stria sinuata obsoleta; pronoto stria marginali subintegra, 
luterali forti utringue arcuata; elytris margine inflexo punctato, 3-striato, stria interiori fore mediam attingente suturam; subhumerali cxterna integra, interna abbreviata; dorsali $1^{\text {a }}$ integra, 2-4 sensim brevioribus; pygidio propygidlioque grosse punctatis ; prosterno bistriato. Long. 13 mill.; larg. 7 mill.

Plcesius Javanus, Erichs. Jahr. 1, 102, 1, pl. 2, f. 1 (1834).

Oblong, peu convexe, rétréci postérieurement, noir luisant. Front plan, lisse; strie obsolète, courte, sinueuse de chaque côté; épistome et labre impressionués. Antennes brun de poix, massue grise. Pronotum court, arqué à la base, avec un point anté-scutellaire, à peine courbé sur les côtés, largement échancré en devant, avec les angles obtus, abaissés; strie marginale fine, interrompue au milieu ; latérale forte, arquée à la base, élargie à l'angle antérieur et ne dépassant pas les yeux. Ecusson petit, triangulaire. Elytres beaucoup plus longues que le pronotum, de sa largeur à la base, dilatées à l'épaule, rétrécies postérieurement, et droites au bord apical; repli latéral ponctué, avec trois stries marginales, interne rebordant toute l'élytre, presque jusqu'au milieu de la suture; strie subhumérale externe forte, entière; interne remontant jusqu'au milieu, oủ elle s'évanouit insensiblement; première dorsale entière, $2-4$ raccourcies de plus en plus. Propygidium bifovéolé, fortemert ponctué, ainsi que le pygidium. Prosternum brièvement bistrié; mésosternum profondément échancré; strie marginale interrompue.

Java.

\section{P. ellipticis.}

Ellipticus, narum convexus', niger, nitidus; fronte stria sinuata vix interrupta; pronoto stria marginali antice interrupta, basi continuata, laterali in angulo desinente; chytris 
margine inflexo punctulato, 2 striato, interna suturam tantum attingente; subhumerali externa brevi, interna et 1-4 dorsalibus antice abbreviatis; propygidio bifoveolato, pygidioque punctatis ; prostemo haud striato. Long. 15 mill.; larg. 7 mill.

Elliptique, légèrement convexe, noir luisant. Front plan, finement pointillé, avec une impression commune sur l'épistome et le labre; strie sinueuse, forte, à peine interrompue en devant. Antennes brunes, massue grise. Pronotum court, arqué à la base, avec un petit point anté-scutellaire, courbé sur les côtés, largement échancré en devant, avec les angles abaissés, obtus; strie marginale fine, continuée à la base, dépassant le bord antérieur de l'œil; latérale plus forte, terminće à l'angle antérieur sans élargissement. Ecusson triangulaire, petit. Elytres plus longues que le pronotum, de sa largeur à la base, rétrécies postérieurement, droites au bord apical; repli latéral pointillé, avec une double strie, dont l'interne se continue jusqu'à l'angle sutural; subhumérale externe très courte; interne forte, composée de points, et raccourcie en devant comme les dorsales, celles-ci 1-4 de plus en plus courtes. Propygidium bifovéolé, couvert de forts points latéralement. Pygidium bombé, densément ponctué. Prosternum sans stries. Mésosternum à strie marginale interrompue.

Java.

\section{P. LeVigatus.}

Ovalis, subdepressus, niger, nitidus; fronte strie sinuatu subinterrupta; pronoto stria marginali antice juncta, latcrali valida utringuc arcuata; elytris margine inflexo punctulato, 2 striis marginalibus, interna ad suturam desinente; $1^{\text {a dorsati }}$ integra, 2-5 scnsim et subhumeralibus 2 ubbreviatis punctatis; propygidio bifoveoluto, mygidiogne munctatis; mosterno bistriato, mesostrino stria marginati integra. Iong. 1/4 mill.; larg. 7 mill. 
Ovale, faiblement convexe, noir luisant. Front finement pointilié, avec une impression prolongée sur l'épistome; strie arquée, à peine interrompue au milieu. Antennes brunes, massue grise. Pronotum arrondi à la base, avec un petit point anté-scutellaire, arqué sur les côtés, échancré en devant, avec les angles abaissés, obtus; stric marginale fine, s'arretant à la base, et non interrompue au bord antérieur ; latérale forte, recourbée en crochet aux deux bouts. Ecusson petit, triangulaire. Elytres plus longues que le pronotum, de sa largeur à la base, presque droites sur les côtés, à peine rétrécies et pointillées au bord apical ; repli latéral pointillé, arec deux stries, dont l'interne longe le bord postérieur et remonte un peu le long de la suture; deux sublımérales bien marquées, externe raccourcie par derrière, interne par devant, réunie avec la première dorsale; celle-ci entière, 2-5 de plus en plus courtes, obsolètes, toutes formées de points plus ou moins liés entre eux. Propygidium bifovéolé, grossièrement ponctué, ainsi que le pygidium. Prosternum longuement bistrié; mésosternum bordé d'une strie profonde et non interrompue.

Java (MM. Chevrolat et de Laferté).

\section{PLACODES. \\ ( $\pi \lambda \alpha x \omega \dot{d n s}$, plat.)}

3e Série, T. 1 (1853), pl. v. - Mon. pl. 2, genre vi, f. 1.

Erichson, Jahrb. 1, 103, v (1834). pl. II, f. 2.

Corpus crassum, subdepressum. Caput retractum; fronte stria integra profunda.

Mandibule cequales, dentatce.

Antenne funiculo sensim incrassato, clava orbiculari. Foveole antemales subangulo antico mothoracis. 
Prostcrmum basi rotundatum, in mesosterni sinu receptum, lobo lato valde producto.

Tibie antice cxtus bidentate, foveola tarsali distincte exarata, postice ante apiccm emarginate, biseriatim spinosulce.

Propygidium transversum, valde inclinatum; mygidium subinflexum.

Corps ovale-allongé, peu convexe en dessus.

Tête assez grande, s'enfonçant dans le prothorax. Stric frontale forte, bien marquée, bisinuée. Epistome distinct du front, avec une impression qui se continue sur le labre; ce dernier transversal, légèrement échancré en devant. Mandibules arquées, d'égale longueur, bifides au bout, peu saillantes.

Antennes (f. 1, d) insérées sous un rebord arrondi du front, au devant des yeux, pénétrant dans la fossette par une coulisse profonde, entre l'angle antérieur du prothorax et le lobe prosternal; scape allongé, courbé, épaissi au bout, logé dans une rainure pratiquée sous la tête; funicule de sept articles, premier obconique plus long que les autres, 2-7 croissant en largeur; massue orbiculaire, comprimée, de quatre articles velus, serrés. Fossettc antennaire large, superficielle, placée sous l'angle antérieur du prothorax.

Mâchoires (f. 1, b) à deux lobes cornés, garnis en dedans de longs poils serrés, interne très court, cxterne assez long. Palpes maxillaires de quatre articles, premier mince, deuxième gros, obconique, troisième plus court, cylindriquc, et quatrième ovalaire, presque aussi long que les deux précédents réunis. Menton (f. 1, a) coupé droit à la base. Languette nulle, paraglosses membraneuses, linéaires, assez allongées, garnies en dedans de poils scrrés, asscz longs. Palpes Iabiaux de trois articles, premier court, deuxième 
long, obconique, troisième encore plus long, ovalaire.

Pronotum peu convexe en dessus, transversal, arqué à la base et sur les cotés, rétréci et fortement échancré en devant; strie marginale entière; latérale interrompue en devant. Pièce humérale peu visible en dessus. Ecusson petit, triangulaire. Elytres presque planes, rétrécies et coupées carrément au bout, avec deux stries marginales, deux sublıumérales, une humérale et toutes les dorsales. Prosternum assez saillant, arrondi à la base, rétréci vers le lobe, dont il est très distinct; ce dernier très saillant sur la bouche, bordé d'une strie sur les côtés, et dépassant les angles antérieurs du prothorax. Mésosternum court, large, profondément échancré pour recevoir la base du prosternum, avec une double strie de chaque côté, laquelle ne se continue pas autour de l'échancrure.

Abdomen de cinq anneaux; premier segment ventral, allongé, bistrié. Propygidium trapézoïde, bifovéolé, oblique. Pygidium triangulaire, infléchi.

Pattes médiocres, rapprochées plus ou moins, les antérieures beaucoup plus que les autres.

Cuisses comprimées, peu dilatées au milieu, bordées d'une rainure sur leur bord interne. Jambes (f. 1, c) antérieures fort dilatées, terminées par deux épines inégales, creusées d'une fossette tarsale profonde, bien limitée des deux côtés, inermes en dedans, avec une seule arête en dehors, fortement bidentée; quatre postérieures légèrement dilatées vers le bout, avec une double rangée d'épines ou dentelures en dehors, sinuées avant l'extrémité, et terminées par une dent large, garnie de cinq ou six épines courtes. Tarses courts, à quatre premiers articles comprimés, garnis en dessous de deux épines chacun; l'article onguli!ère seulement un peu plus long. 
Ce genre, créé par Erichson (Jahrb. 103, v, T. 2,6 (1834)) pour une scule espèce de Caffrerie, a les plus grands rapports avec les Plcesius; c'est la même forme, la même sculpture, la même disposition du sternum, de la fossette antennaire, des jambes antérieures, etc. II n'en diffère que par la massue des antennes, qui est orbiculaire et beaucoup moins allongée, par les pattes postérieures échancrées un peu avant l'extrémité et terminées par une dent obtuse fort avancée, garnies en deliors de deux rangs seulement d'épines courtes et peu serrées. La strie frontale, en outre, n'est pas interrompue, et le prosternum est dépourvu de strie.

Il se compose de deux espèces, l'une, P. Caffer, décrite et figurée comme type du genre, et l'autre, Hister Senegulensis de Paykull, inconnue à l'auteur. Il est donc propre à l'Afrique, tandis que les Plcesius appartiennent à l'île de Java.

Mœurs et métamorphoses inconnues.

\section{P. Senegalevsis.}

Ovalis, parum convexus, niger nitidus; frontc impressa, stria sinuata integra; pronoto stria marginali tonui haud interrupta, laterali valida, utrinque uncinate; elytris margine inflexo punctato, 2 striis, interna ad suturam prolongata; snbhumcrali externa posticc, interna antice abbreviatis, dorsalibus 1-3 integris, ccteris apicalibus, punctatis; propygidio bifoveolato, pygidioque punctatis.

Hister Senegalensis. Payk. Mon. hist. 13, 5, pl. 4, 5 (1811).

Ovale, peu convexe, noir luisant. Front large, légèrement impressionné au milieu, séparé de l'épistome par une strie forte, cntière, tri-sinuée, formant un angle rentrant. Antennes brunes, massue grise. Pronotum court, arrondi à la 
base, arec un petit point anté-scutellaire, à peine arqué sur les côtés, échancré en devant, avec les angles abaissés, obtus, strie marginale fine, terminée à la base, entière, et un peu plus éloignée au bord antérieur; latérale forte, recourbée en crochet aux deux bouts. Ecusson petit, triangulaire. Elytres plus longues que le pronotum, de sa largeur à la base, faiblement dilatées à l'épaule, pointillées et droites au bord apical; repli latéral fortement et densément ponctué. avec deux ou trois stries marginales, l'interne longeant le bord postérieur jusqu'à l'angle de la suture; strie humérale très fine, oblique; les autres assez étroites, ponctuées ; subhumérale externe raccourcie par derrière, interne par devant, 1-3 dorsales entières, quatrième, cinquième et suturale courtes, apicales. Propygidium bifovéolé, ponctué fortement, ainsi que le pygidium. Mésosternum profondément échancré en devant, bordé d'une double strie incomplète.

Sénégal, Guinée.

\section{P. Cafffer}

Ater, nitidus, thorace unistriato, clytris striis dorsalibus 4 interioribus cxolctis, marginali interiore abbreviata. Long. 14 mill.

Placodes Gaffer, Er. Jahr. 105, 1, pl. 2, 2 (1834).

Front faiblement impressionné au milieu, avec une strie sinuée, non interrompue. Pronotum un peu rétréci en devant, légèrement arrondi sur les côtés, dessus très peu convexe, poli; strie marginale assez profonde; latérale profonde, suit de près le bord latéral, se contourne en dedans à l'angle antérieur et se termine bientôt. Les élytres sont de moitié plus longues que le pronotum, un peu courbées laté3c Série, TOME I. 
ralement, et faiblement impressionnées derriêre l'épaule, densément ponctuées au bout; les quatre stries intérieures sont obsolètes, les extérieures entières, fines; la strie subhumérale interne est raccourcie au milieu par devant, l'externe entière. Le repli latéral est densément couvert de gros points, rugueux çì et là, avec deux stries marginales. Propygidium et pygidium grossièrement ponctués.

Caffrerie.

\section{AULACOSTERNUS.

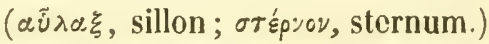

Soc, Ent. 3e Série, tome 1 (1853), pl. 6. - Mon. pl. 3, genre VII.

Caput retractile, mandibulis exsertis, dentatis, requalibus, fronte plana, stria transversa antice tantum interrupta.

Antenne sub frontis margine inserte, fossa antennali sub angulo antico prolhorcteis profunda.

Prosternum elevatum bistriatum, basi roturdatum in mesosterno receptum, antice lobo valde prominulo.

Tibice antica fossa tarsali concinne exarata, extus dentate, postica biseriatim denticulate.

Corps plan, assez épais, en ovale allongé.

Tête médiocre s'enfonçant dans le prothorax, avec une strie semi-circulaire sur le vertex, laquelle s'arrête à l'angle antérieur de l'œil sans séparer le front de l'épistome. Labre (f. 1,b) transversal, légèrement échancré en devant. Mandibules (f. 1,b) égales entre elles, fortes à la base, dentées en dedans, courbées et terminées en pointe aiguë.

Antennes (f.1, e) insérées sous le rebord du front, en devant des yeux; scape fortement courbé, épaissi au bout, 
logé dans une rainure pratiquée sous la tête; funicule de sept articles: premier obconique, ainsi que le deuxième, mais plus allongé, les autres croissant en largeur vers le bout; massuc ovale, comprimée, de quatre articles velus.

Mâchoires (f. $1, d)$ à deux lobes garnis le poils en dedans, l'externe corné en dehors, beaucoup plus long que l'interne. Palpes maxillaires de quatre articles; premier très court, deuxième plus long que le troisième, mais beaucoup plus court que le quatrième. Menton $(\mathbf{f} .1, c)$ cylindrique, droit à la base, bisinué en devant ; languette linéaire, velue ; paraglosses allongées, courbées et velues en dedans. Palpes labiaux de trois articles; deuxième obconique, troisième fusiforme, plus long que le précédent.

Pronotum transiersal, légèrement convexe, arqué à la base, presque droit sur les côtés, et échancré en devant. Fossette antennaire profonde, creusée sous l'angle antérieur du prothorax. Prosternum saillant, étroit, bordé d'une strie longitudinale de chaque côté, arrondi à la base, et séparé par une strie transversale du lobe antérieur, qui est convexe et fortement avancé sur la bouche. Hésosternum court, échancré en devant pour recevoir la base du prosternum, et bordé d'une strie forte dans tout son pourtour antérieur. Pièce lumérale à peine visible en dessus. Ecusson très petit, triangulaire. Elytres planes, coupées droit à l'extrémité, avec une stric humérale, une subhumérale et quelques dorsales.

Cuisses dilatées, comprimées, bordées en dedans d'une gouttière; jambes épaissies vers le bout, avec une double arête denticulée sur le bord externe; antérieures avec une fossette tarsale hien limitée.

Abdomen de cinq anneaux; premicr segment veutral, 
plus long que les suivants et marqué de chaque côté d'une strie en $S$. Propygidium court, transversal, incliné; pygidium triangulaire, presque rertical.

Ce genre, établi sur deux espèces, l'une de Madagascar, et l'autre de la Nouvelle-Zélande, répandue dans les collections sous le nom de llister Zelandicus, rappelle le faciès de certains Platysoma et de quelques Pachycrerus. Il a la fossette tarsale antérieure bien limitée, le lobe prosternal large et saillant, la fossette antennaire creusée à l'angle antérieur, et découverte au-dessus du bord pectoral antérieur, la forme déprimée, ovalaire et assez épaisse des uns et des autres; son front dépourvu de strie transversale et son prosternum bistrié le distinguent des premiers; son prosternum arrondi à la base, pénétrant dans le mésosternum, ne permet pas de le confondre avec les seconds. - Mœurs et métamorphoses inconnues.

\section{A. Zelandicus}

Ovalis, supra subdepressus, niger, nitidus; antennis brunneis; fronte stria semi-circulari postice cineta; pronoto ante scutellum foveolato, stria laterali externa interrupta, interna tractu punctorum figurata; chytris subhumerali externa $1^{\text {a }}$ que lorsali integris, 2-3 basi apiceque brevissimis ; pygidio dense punctato; prosterno bistriato; mesosterno stria marginali integra; tibiis anticis quadridentatis, posticis biseriatim spinosulis. Long. 8 mill.; larg. 5 1/2 mill.

Ovale, déprimé en dessus, noir luisant. Front lisse, légèrement convese, non séparé de l'épistome, entouré par derrière d'une strie semi-circulaire qui s'arrête à l'angle antérieur de l'œil. Antennes brunes, massue grise. Pronotum plus large que long, légèrement bisinué à la base, avec une 
forte fossette au devant de l'écusson, presque droit sur les côtés, arrondi seulement aux angles antérieurs, rétréci et échancré en devant; strie latérale externe fine, rapprochée du bord, interrompue en devant; latérale interne visible seulement au bord antérieur, et comme continuée latéralement par une traînée de points. Elytres une fois et demie plus longues que le pronotum, de sa largeur à la base, cur. vilinéairement dilatées sur les côtés, rétrécies et coupées droit au bord apical; strie humérale bien marquée ; subhumérale externe presque entière, interne nulle. Première dorsale à peine raccourcie à la base, 2-3 représentées par deux courtes stries, une apicale, l'autre basale; repli latéral sillonné de deux marginales entières, l'interne se continue au bord apical, et d'une foule de petites stries obliques. Propygidium bifovéolé, assez fortement ponctué; pygidium plus densément. Prosternum étroit, saillant, bistrié, arrond i à la base, avec un lobe antérieur infléchi, arrondi, ponctué, bien distinct; mésosternum échancré en devant et entièrement rebordé. Jambes antérieures quadri-dentées : postérieures garnies en dessus de quatre ou cinq épines, et en dessous de très petites dentelures.

Nouvelle-Zélande.

\section{A. Edwarsit.}

Ovatus, subdepressus, niger, nitidus, antennis brunneis; fronte impressa, stria semi-circulari postice cincta; pronoto stria laterali cxterna tenui integra, interna sulciformi, interrupta; elytris postice impressis punctatis, striis 4-5 marginalibus, 1-3 dorsalibus integris punctatis, $4^{\mathrm{a}}$, suturali et subhumerali abbreviatis; mygidio grosse punctato; tibiis multidenticulatis. Long. 8 mill.; larg. 5 mill. 
Ovale, peu convexe, noir luisant ; antennes brunes. Front lisse, impressionné, bordé sur les côtés d'une strie qui s'avance jusqu'à l'angle antérieur de l'œil, et qui est reliće par une strie transverse par derrière. Pronotum beaucoup plus large que long, bisinué à la base, arrondi sur les côtés, rétréci fortement et échancré en devant, avec les angles obtus; strie latérale externe fine, très rapprochée du bord latéral, non interrompue cn devant; interne formant un sillon profond, large, cessant à l'angle antérieur. Ecusson très petit, triangulaire. Elytres beaucoup plus longues que le pronotum, de sa largeur à la base, dilatées curvilinéairement sur les côtés, rétrécies postérieurement, et droites au bord apieal, bombées au milieu, avec unie impression subapicale fortement et densément ponctuée; strie humérale fine, oblique; subhumérale raccourcie en devant; dorsales fortes, avec quelques points, 1-3 entières, quatrième et cinquième rudimentaires, suturale, un peu raccourcie; bord infléchi sillonné de cinq stries marginales, rugueuses. Propygidium et pygidium couverts de gros points serrés. Prosternum rétréci en devant, stries convergentes; mésosternum légèrement sinué, entièrement rebordé. Jambes antérieures garnies de six ou sept denticules : postérieures épineuses.

Cette remarquable espèce, de Madagascar, fait partie de la collection du Muséum de Paris : je l'ai dédiée, comme marque de ma gratitude, à M. Milne Edwards, toujours si zélé pour les progrès de la science. 


\section{MACROSTERNUS.}

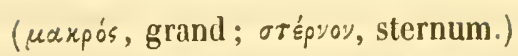

Soc. Ent. $3^{\circ}$ Série, T. 1 (1S53), pl. 6. - Mon. pl. 3, genre VIII.

Hololepta, Payk. Mon. Hist. (1811).

Corpus complanalum.

Caput retractile, mandibulis exsertis, dentatis, requalibus; fronte plana vel depressa, stria transversa antice deficienti (excepto M. foliaceo).

Antennce sub frontis margine inserta, fossa antennali profunda sub angulo prothoracis.

Prosternum latum, plamum, sœpius bistriatum, basi rectum aut sinualum in mesosterno receptum; lobo antico valde prominulo.

Tibice antica dentatce, fossa tarsali distincte exarata; postica uni-seriatim denticulate.

Corps aplati, mince, plus ou moins ovale.

Tête grande, assez enfoncée dans le prothorax. Front avec une légère impression en devant, ordinairement sans strie qui le distingue de l'épistome. Labre (f. a) court, transversal, sinué. Mandibules (f. $a$ ) saillantes, égales entre elles, courbées et en pointe très aiguë, dentées en dedans.

Antennes (f. b) insérées sous le rebord du front, au devant des yeux : scape fortement courbé, logé dans une rainure de la partie inférieure de la tête ; funicule de sept articles : premier obconique, plus long que le deuxième, les autres vont en s'élargissant vers le bout; massue ovale-allongée, velue, de quatre articles.

Mâchoires (f. $d$ ) cornées, à deux lobes barbus en dedans, externe allongé, obtus au bout, interne court. Palpes maxillaires de quatre articles : premier court, deuxième renflé, 
troisième obconique, quatrième beaucoup plus long, ovalaire, tronqué. Menton (f. $c$ ) corné, court, transversal, tri-sinué en devant; lèvre membraneuse ; paraglosses arquées, assez longues, frangées; languette courte, échancréc. Palpes labiaux de trois articles: premier court, leuxièmc assez lonğ, reuflé au milieu, un peu sinué en dedans, troisième long, ovalaire.

Pronotum transversal, coupé presque droit à la base, légèrement arqué sur les còtés, profondément échancré ell devant, bordé d'une strie marginale très fine. Fossette antennaire très profonde, sous l'angle antéricur du prothorax, au-dessus du bord pectoral, découverte. Prosternum large et peu élevé, bordé d'une strie de chaque côté; légèrement échancré à la base, et s'eufonçant néanmoins dans le mésosternum, avec un lobe antérieur distinct par une petite strie transversale, horizontal, fortement avancé, et circonscrit par une strie fine et bien marquée. Mésosternum très court, largement échancré en devant pour recevoir la base du prosternum; avec le fond de l'échancrure plus ou moins avancé. Pièce humérale à peine visible en dessus. Ecusson triangulaire. Elytres coupées à peine obliquement au bout, avec une strie humérale, une subliumérale, et quelques dorsales plus ou moins complètes.

Abdomen de cinq anneaux : premier segment ventral, plus long que les autres, et marqué de chaque coté d'une ligne sinueuse ; propygidium transversal, horizontal; pygilium triangulaire, légèrement incliné.

Patles très distantes à leur insertion. Cuisses larges, aplaties, creusées en dedans d'unc rainure pour receroir la jambe. Jambes aplaties, dilatées vers le bout, avec deux épines terminales, inégales; uné seule arête garnie de 
dents sur le côté extcrne : antérieures (f.e) creusées d'une fossette tarsale bien limitée, sans dent basilaire en dedans. Tarses filiformes, de cinq articles, garnis chacun de deux soies en dessous, triangulaires; premier et deuxième plus longs, troisième plus court, quatrième très petit, cinquième allongé, renflé au bout, avec deux crochets.

Ce genre, que j'ai formé pour le M. Lafertei, espèce remarquable découverte par M. Bocandé dans le Sénégal portugais, et pour quelques autres de Madagascar, a les plus grands rapports avec les espèces aplaties de Platysoma; mais il s'en distingue aisément par son prosternum plus élargi, moins saillant, légèrement sinué ou droit à la base, pénétrant néanmoins dans le mésosternum, bordé de chaque côté d'une petite strie longitudinale, par son front sans strie transversale ( $\boldsymbol{M}$. foliaceus excepté), et par son pronotum dépourvu de strie latérale. J'y ai rapporté l'Hololepta foliacea, Payk., méconnu par Erichson, qui a, du reste, tous les caractères du genre, sauf les stries marginales du prosternum. Les mours et les premiers états de ces insectes sont incounus, mais la forme aplatie de leur corps indique assez qu'ils vivent sous les écorces, à la manière des Hololepla, Paromalus et Platysoma. 


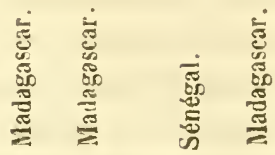

हैं

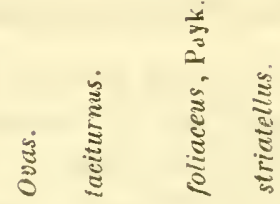

舀

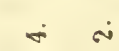

cis

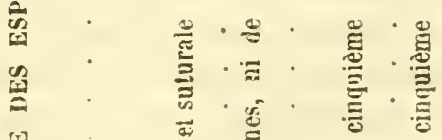

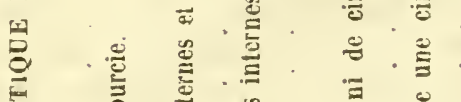

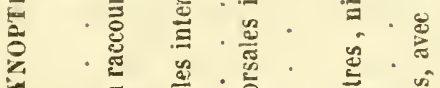

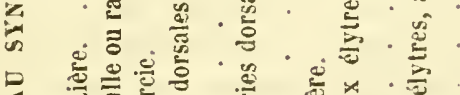

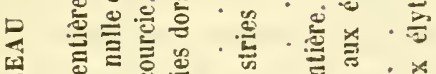

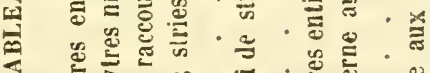

ए

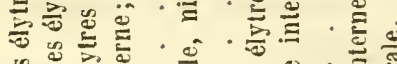

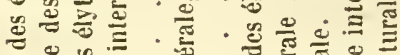

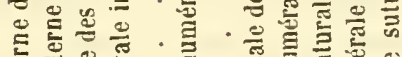

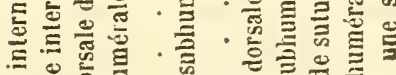

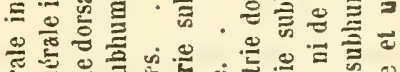

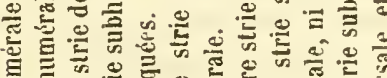

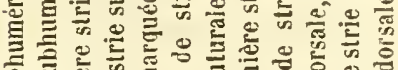

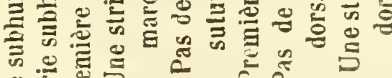

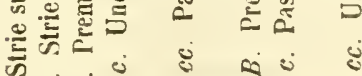

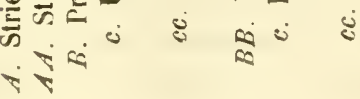




\section{M. LAFERTEI.}

Ovatus lutior, valde complanatus, nitidus, supra nigro-caruleus; fronte concava, stria transversa nulla; pronolo lateribus punctulato, stria marginali intcrupta; clylris stria utraque subhumerali integra, dorsuli $1^{\text {a }}$ integra, $2^{\text {a }}$ antice abbreviatu, $3^{a}$ tatc intcrrupta; pygidio punctato utrinque fovcolato; tibiis anticis queudridentatis. Long. 7 1/2 mill.; larg. 4 mill.

Ovale élargi, fort aplati, d'un noir luisant, bleu foncé en dessus. Tête large, front pointillé, un peu concave, avec une petite dent au-dessus de l'insertion des antennes; strie marginale fine, courte, ne séparant pas le front de l'épistome. Antennes brunes. Pronotum court, très large, coupé droit à la base, arqué sur les côtés, rétréci et largement échancré en devant, avec les angles abaissés, obtus; lisse sur toute sa surface, si ce n'est le long des bords latéraux; strie marginale fine, rapprochée du bord, cessant au niveau des yeux. Ecusson petit, triangulaire. Elytres courtes, un peu plus longues que le pronotum, de sa largeur à la base, arquées sur les côtẻs, rétrécies et coupées obliquement au bord apical, de manière à former un angle sutural très obtus ; strie humérale presque droite, bien marquée, deux subhumérales entières, interne assez rapprochée de la première dorsale, externe reportée sous le bord infléchi; première dorsale entière, deuxième raccourcie à la base, troisième largement interrompue. Propygidium court, ponctué, en hexagone transversal, presque horizontal; pygidium triangulaire, oblique, ponctué, bombé au milieu, fovéolé de chaque côté à la base. Prosternum large, bistrié, sinué à la base, muni en devant d'un lobe horizontal, long. Mésosternum ion bordé, présentant en devant une large échancrure bisinuéc, où s'enfonce la base du prosternum. 
Pattes d'un noir de poix. Jambes antérieures quadridentées; intermédiaires garnies de quatre denticules; postérieures de trois, les deux extrêmes rapprochés.

Sénégal portugais.

\section{M. Taciturnos.}

Oblongo-ovatus, complanatus, nigro-piceus, nitidus; fronte convexiuscula munchulata, stria transversa nulla; pronoto stria marginali interrupta; elytris striis 2 et 3 dorsalibus integris; 1 a postice subabbreviata; pygidlo convexo marginato punctato; abdominis segmentis ventralibus transversim striatis; tibiis anticis quadridentatis. Long. 5 1/2 mill.; larg. $21 / 4$ mill.

Ovale-oblong, aplati, d'un noir de poix luisant. Front légèrement convexe, pointillé, strie fine, s'arrêtant à l'insertion des antennes. Pronotum transversal, coupé droit à la base, légèrement arrondi vers les angles antérieurs, échancré en devant; strie marginale interrompue. Ecusson petit, triangulaire. Elytres plus longues que le pronotum, de sa largeur à la base, parallèles sur les côtés, à peine rètrécies et presque droites au bord apical; stries dorsales bien marquées, première un peu raccourcie vers le bout, deuxième et troisième entières; les autres nulles, ainsi que les subhumérales. Propygidium transversal, court, peu densément ponctué. Pygidium fortement et peu densément ponctué, bombé, avec un rebord élevé. Prosternum court, assez large, bistrié, sinué à la base, et muni en devant d'un lobe fort long, saillant, horizontal. Mésosternum sans strie marginale, avec une échancrure antérieure bisinuée, oủ pénètre la base du prosternum. Segments ventraux de l'abdomen striés transiersalement. Jambes antérieures quadridentées, intermédiaires garnies de quatre denticules.

Madagascar (M. Guérin-Méneville). 


\section{M. Foliaceus.}

Oblongo-ovalis, complanatus, rufo-brunneus nitidus; fronte convexa, stria transversa distincta; pronoto lavi, stria laterali interrupta; elytris striis 3 primis dorsalibus validis, integris; pygidio grosse punctato, marginato; prostcrno lato, basi simuato, haud striato; tibiis anticis quadidentatis. Long. 4 1/2 mill.; larg. 2 1/2 mill.

Hololepta foliacca, Payk. Mon. Hist. 106, 3, T. 1x, f. 5 (1811).

Ovale-oblong, aplati, d'un brun-ferrugineux luisant, lisse. Front à peine déprimé, bordé d'une strie derrière les yeux, et distinct de l'épistome par une strie transversale bien marquée. Pronotum coupé droit à la base, arrondi sur les côtés vers les angles antérieurs, un peu rétréci et fortement échancré en devant; strie marginale cessant à l'angle antérieur; latérale plus forte et plus longue, interrompue. Ecusson petit, triangulaire. Elytres plus longues que le pronotum, de sa largeur à la base, rétrécies et coupées droit au bout; stries dorsales fortes, bien marquées, 1-3 ordinairement entières, quatrième quelquefois représentée par un court rudiment vers le bout. Propygidium transversal, ponctué. Pygidium bombé, fortement rebordé et couvert de gros points peu serrés. Prosternum peu élargi, sans stries, sinué à la base, muni en devant d'un lobe horizontal bien distinct. Mésosternum avec une échancrure bisinuée au milieu, et une courte strie marginale de chaque côté. Pattes antérieures quadri-dentées; intermédiaires garnies de quatre denticules; postérieures de trois, les deux apicaux rapprochés.

Sénégal.

4. M. Ovas.

Ovalis, subdepressus, nigro-piceus, nitidus; fronte punctulata, subconcava, inter oculos marginata; pronoto stria laterali 
integra; elytris striis validis, sublumerali intorna $1^{a}$ que dorsali postice in medio abbreviatis, $2^{a} 3^{a} q u e$ integris, $4^{a}$, 5a et suturali antice abbrcviatis; mygidio marginato punctatoque; prosterno lato bistriuto basi simuato, mesosterno antice bisimeatim emarginato stria utrinque interrupta; tibiis anticis quadridentatis. Long. 3 mill.; larg. 2 1/4 mill.

Ovale, déprimé, d'un noir de poix luisant et lisse. Front pointillé, légérement concave au milieu, bordé d'une strie qui s'arrête au-dessus de l'insertion des antennes. Pronotum court, assez large, coupé droit à la base, arrondi sur les côlés, rétréci et fortement éclıancré en devant, avec les angles abaissés, obtus; strie latérale entière. Ecusson petit, triangulaire, allongé. Elytres courtes, un peu plus longues que le pronotum, de sa largeur à la base, curvilinéairement dilatées sur les côtés, rétrécies et coupées droit au bout; stries fortes, bien marquées; deuxième et troisième dorsales entières, première partant de la base et descendant jusqu'au milieu, ainsi que la subhumérale interne; quatrième, cinquième dorsales et suturale courtes, apicales. Propygidium court, transversal, ponctué. Pygidium bombé, ponctué, avec un rebord élevé. Prosternum large, bistrié, très distinct du lobc antérieur, sinué à la base; mésosternum (f. f) échancré au milicu du bord antérieur, avec une stric transversale derrière l'échancrure, et une marginale de chaque côté, qui se continuent. Pattes rouges; jambes antérieures quadri-lentées; intermédiaires garnies de cinq denticules, postérieures de quatre, les deux extrêmes rapprochés.

Madagascar (Muséum).

\section{M. STRHATELLIS.}

Ovatus, subdepressus, nigı o-piccus, nitidus, munctulatus, amtenmis pedibustue rufo-brameis; fronte leviler concara, stria 
interrupta; pronoto stria marginali integra; clytris striis validis crenatis; 4 primis dorsalibus integris, $5^{2}$ suturalique antice abbreviatis, subhumerali interna basali; mygidio punctato, utrinque subimpresso; prostcrno lato, bistriato; mesosterno loviter cmarginato, stria hand interrupta; tibiis quadridenticulatis. Long. 2 3/4-4 mill.; larg. 11/2-2 mill.

Ovale, déprimé, d’un noir de poix luisant. Tête ponctuée; front concave, avec une dent au-dessus de l'insertion des antennes, bordé d'une strie sur les côtés, jusqu'à cette dent; antennes d'un brun-ferrugineux, massue testacée. Pronotum court, plus large que long, légérement arqué à la base, avec un point anté-scutellaire, presque droit sur les côtés, échancré en devant, avec les angles antérieurs abaissés, obtus; finement ponctué; strie marginale entière. Ecusson petit, en triangle allongé. Elytres une fois ef demie plus longues que le pronotum, de sa largeur à la base, légèrement rétrécies au bout, pointillées assez densément; stries bien marquées, ponctuées, quatre premières dorsales entières, cinquième et suturale raccourcies à la base, sublhumérale interne occupant la moitié antérieure, externe nulle. Pygidium peu convexe, ponctué, avec une légère impression de chaque côté de la base. Prosternum large, bistrié, avec un lobe antérieur allongé, à peine sinué à la base. Mésosternum largement échancré, et bordé d'une strie entière. Pattes d'un rouge ferrugineux; jambes antérieures intermédiaires et postéricures, garnies de quatre denticules.

Madagascar (Muséum). 


$$
\begin{aligned}
& \text { IX. PLATYYSOMA. }
\end{aligned}
$$

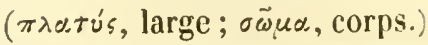

Soc. Ent. $3^{\mathrm{c}}$ série, T. 1 (1853), pl. 7. - Mon. pl. 4, Gente IX. Hister, F. Mant. (1787). - Payk. Mou. Hist. (1811).

Ilololepta, Payk. Mon. Hist. (1811).

Platysoma, Leach, Zool. Misc. (1817).

Corpus oblongo-oyalum vel cylindicum.

Caput retractile, fronte stria integra, antentis sub marginc insertis, funiculo sensim crassiori, clava ovala, compressa; mandibulis exsertis, cequalibus, unidentatis.

Prosternum compressum, basi rolundalum, in mesostcrno receplum; lobo lato, ultra angulum prolhoracis prominenti; fossa antennali profunda in angulo, supra pectoris marginem.

Tibice intus inermes, cxtus uni-serialim dentate; foreola tarsali recte exarata.

Pygidium propygidiumque declivia.

Corps tantôt ovale-allongé, plus ou moins aplati, tantôt cylindrique.

Tête large, assez forte, pouvant s'enfoncer dans le prothorax. Front formant un angle saillant au-dessus de l'insertion des antennes, distinct de l'épistome par une strie transversale ordinairement entière, se rattachant quelquefois à unc strie latérale. Epistome très rétréci en devant, trapézoïdal, avecune excavation plus ou moins profonde qui s'étend même au-delà. Labre court, élargi, sinuć. Mandibules saillantes, égales, armées d'une petite dent interne.

Antennes (f. 1 a) insérées sous un rebord anguleux du front, dans une fossette entre les yeux et les mandibules : scape fortement courbé ; funicule de sept articles, serrés, comprimés, s’élargissant peu à peu; massue ovalaire, com- 
primée, garnie d'un duvet court el serré, et, en outre, de plus longs poils, de quatre articles.

Mâchoires (f. 1 c) à deux lobes barbus intérieurement; externe assez long, corné; interne court, membraneux. Palpes de quatre articles : premier petit, deuxième obconique, troisième cylindrique, un peu plus court, quatrième ovalaire, presque aussi long que les deux précédents réunis. Menton (f. 1 b) corné, semi-circulaire, quelquefois échancré au milieu; lèvre membraneuse, peu avancée; paraglosses ciliées en dedans, assez longues. Palpes labiaux de trois articles, deuxième obconique, troisième ovalaire, à peu près égaus.

Pronotum ordinairement transversal, quelquefois presque carré, presque droit à la base et sur les côtés, largement échancré en devant, avec les angles peu saillants, abaissés, plus ou moins obtus; une strie latérale externe bien marquée, rarement une interne, la marginale n'est visible, le plus souvent, que dans l'angle antérieur. Fossette antennaire arrondie, bien marquée, creusće sous l'angle antérieur du protlıorax, au-dessus du bord pectoral. Prosternum peu saillant, rétréci et arrondi à la base; lobe antérieur large, un peu incliné et séparé par une ligne transversale, bordé d'une strie, arrondi en devant et dépassant les angles prothoraciques. Mésosternum échancré pour recevoir la base du prosternum, bordé d'une strie souvent interrompue. Pièce humérale à peine visible en dessus. Ecusson petit, triangulaire. Elytres de la largeur du pronotum, plus ou moins allongées, parallèles, coupées droit au bout, sans angle sutural; repli latéral sans fossette, à deux sillons; stries subhumérales presque toujours nulles, suturale et dorsales en nombre variable.

3e Série, Tome I. 
Pattes assez longues, distantes à leur insertion, deuxième paire éloignée de la troisième. Cuisses bordées en dedans. Jambes (f. $2 d, e, f$ ) triangulaires, terminées par deux épines inégales, bistriées en dedans, et à deux arêtes, dont la supérieure est seule dentée; antérieures creusées d'une fossette tarsale nettement limitée. Tarses assez grêles, de cinq articles, 1-4 courts, garnis d'une petite soie, cinquième presque aussi long que les autres réunis, armé de deux crochets.

Abdomen de cinq anneaux : premier segment ventral long, bistrié entre les hanclıes, les autres courts. Propygidium en hexagone fortement transversal. Pygidium triangulaire, fortement incliné.

Ce genre, créé en 1817 par Leach, dans le Zool. Misc., adopté ensuite par Erichson, dans sa Revue des Histérides (1834), réunit des espèces appartenant les unes aux Hister de Paykull, les autres à ses Hololepta. Il a des représentants sur tout le globe. Des vingt-cinq espèces qui le composent, six se trouvent en Europe, trois en Afrique, huit en Asie ou dans l'Archipel Indien, trois daus l'Océanie, et cinq en Amérique. Paykull n'en avait connu que cinq; Erichson en porta le nombre à quinze, dont le $\boldsymbol{P}$. rimariun nous est seul inconnu. Depuis, cinq autres espèces ont été publiées dans différents recueils; sept seulement sont nouvelles.

Les métamorphoses et les mœurs d'une espèce de ce genre, le $\boldsymbol{P}$. oblongum, inconnues jusqu'à ce jour, comme celles de la plupart des autres Histérides, ont été étudiées avec soin par un excellent observateur, M. E. Perris, de Mont-de-Mlarsan, qui les fait connaître avec d'intéressants détails dans son remarquable mémoire sur les Insectes din Pin. Notre savant confrère veut bien me permettre d'user de sa découverte, qui ne sera publiée que plus tard. 
Lave (l. i.) (long. 9-10 mill.).Charnue, déprimée, linéaire. Tête plate, cornée, ferrugineuse, marquée sur le front de quatre sillons longitudinaux, deux intermédiaires convergents, raccourcis, arec l'intervalle relevé en crête, et deux externes à double courbure, s'étendant d'un angle à l'autre, et de quelques gros points écartés sur les côtés, creusée en dessous de quatre fossettes oblongues bien marquées, ne dépassant pas le milieu. Epistome soudé au labre, bord antérieur dentelé. Nandibules (f. $k$.) longues, acérées, étroites, arquées en faucille, se croisant complètement, d'un brun-ferrugineux, munies en dedans, vers le milieu, d'une dent assez saillante, surmontée d'un petit tubercule. Mâchoires (f. $m$.) très longues, cylindriques, étruites, de deux articles : premier muni en dedans d'un long pinceau de poils roux à la base, et d'une soic un peu épaisse près de l'extrémité, en dehors de deux plus fines et plus courtes; deuxième quatre fois plus court, portant une petite soie externe et un lobe interne grêle, court, papilliforme, sétifère. Palpes maxillaires de trois articles; premier et deuxième à peu près égaux, un peu renflés en dedans; troisième une fois et demie aussi long que les précédents, plus étroit, cylindrique, obtus au bout, et couronné de très courtes spinules. Lẻvre partant de la base des mâchoires, élargie et coupée droit à l'extrémité, droite sur les côtés; palpes labiaux plus grêles que les autres, de deux articles, deuxième un peu plus long que le premier, couronné de tris petits cils. Antennes (f. l.) de quatre articles : premier très court et rétractile, deuxième renflé en dedans vers le bout, troisième légèrement en massue, tronqué, terminé en dehors par un très petit rudiment épineux, et en dedans par une petite spinule; quatrième étroit, cylindrique, subtronqué, avec trois petites soies. Yeux muls. 
Thorax de la longueur de la tête, garni de poils rares sur les côtés; prothorax grand, presque semi-discoïdal, blanchâtre en dessous, ferrugineux et corné en dessus, avec un sillon médian; mésollorax et métathorax de moitié plus courts, charnus et d'un blanc légèrement roussâtre. Pattes (f. $n$.) courtes, assez grèles, de quatre articles ; cuisses ciliées en dessous; jambes arec un poil de chaque côté; crochet pelit, subulé.

Abdomen blanc-roussâtre, de neuf segments, 1-8 de la longueur du prothorax, munis de poils et d'une fossette formant un bourrelet latéral, et en dessus de trois plis transversaux; neuvième segment un peu plus long que les précédents, arrondi sur les côtés, un peu échancré postérieurement, terminé par deux longs appendices, de deux articles chacun, avec deux longs poils, muni en dessous d'un petit mameion rétractile, au milieu duquel est l'anus. Neuf paires de stigmates elliptiques, premier près du bord antérieur du mésothorax, 2-9 au quart antérieur des huit premiers segments de l'abdomen.

Nymphe (f. j.). Prolhorax carré. bordé de cils; abdomen bordé sur les côtés de courtes soies, dernier segment muni de deux appendices très divergents.

Cette larve est exclusivement carnassière. En mai, le Plutysoma of suit le Tomicus stenographus, qui perfore l'ècorce du Pin, dépose ses œufs dans les galeries et entre les œufs de celui-ci. La larve parasite qui en éclot dévore ses hơtes, et au bout de cinq mois environ, ses évolutions achevées, elle s'enfonce, en septembre et octobre, au milieu des détritus, se courbe et se roule en serpentant jusqu'à ce qu'elle se soil formé une cellule elliptique, très lisse en dedans, dont elle vernit les parois avec un nucilage incolore 
déversé par la bouche, et dont elle forme une coque solide. Après quoi elle se plie en arant, de manière que la tête et le thorax soient couchés sur le ventre, et demeure ainsi quatre ou cinq jours immobile jusqu'a son entier développement.

Un faciès propre distingue aisément les Platysoma des genres avec lesquels ils ont des affinités. Le lobe antérieur large et allongé de leur prosternum; la fossette antennaire placée à l'angle antérieur du prothorax, un peu au-dessus du bord pectoral, el visible en dessous; la base du prosternum arrondie, assez comprimée et sans stries, pénétrant dans une échancrure du mésosternum; la fossette tarsale des jambes antérieures, profonde, bien limitée; l'absence de dent basale interne; les deux arètes, dont la supérieure seule est dentée; le front ordinairement impressionué, distinct de l'épistome par une strie transversale; enfin, la strie latérale du pronotum et les stries dorsales des élytres, forment autant de caractères saillants qui ne laissent pas le moindre doute.

Quoique ce genre soit parfaitement homogène, il se laisse diviser en deux groupes tranchés, les uns sont plus ovales, plus aplatis; les autres sont cylindriques, allongés. J’ai préféré ici ce caractère, tiré de la forme générale du corps, moins bien limité que ceux dont je me suis servi d'ordinaire, parce qu'il me donne un groupement en parfaite harmonic avec l'ordre naturel que brisait l'emploi de tout autre caractère.

Erichson ne m’a pas semblé lıeureux dans ses divisions fondées sur les denticules des jambes, dont le nombie est fort rariable. 
है
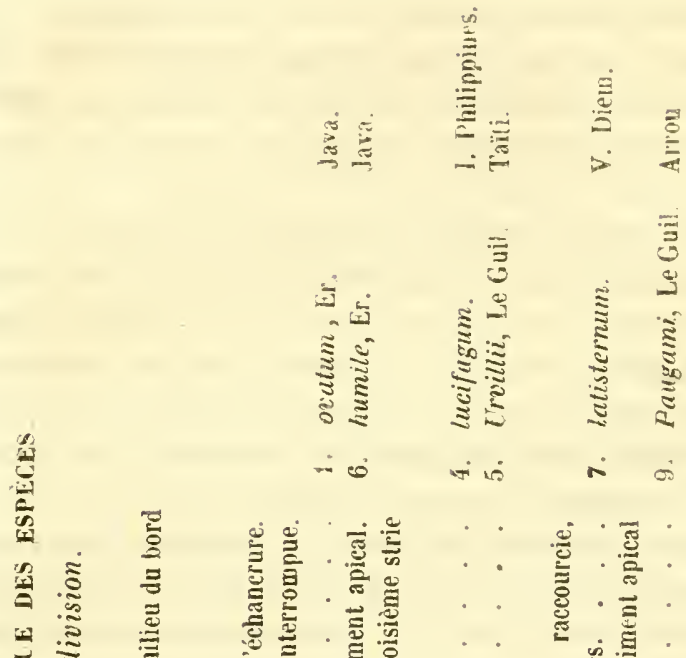

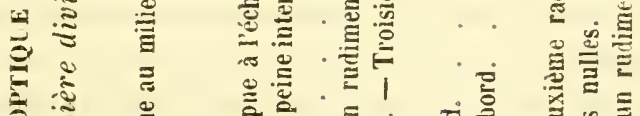

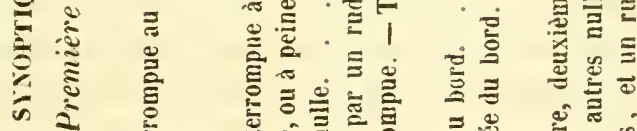

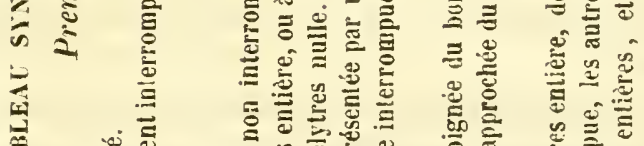

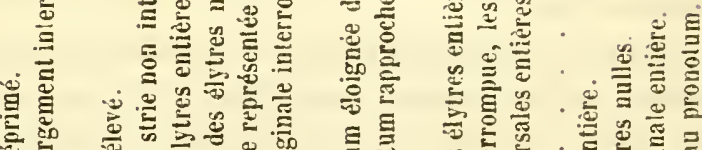

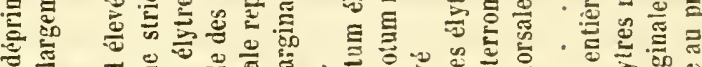

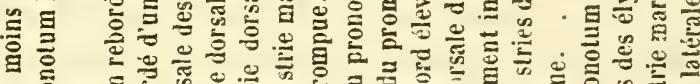
है

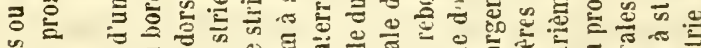

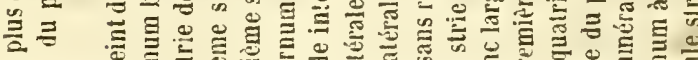

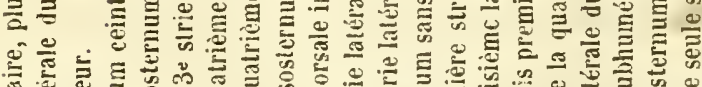

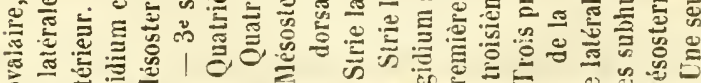

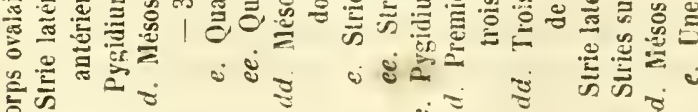
i i i ن च के

50 
IX. Platysoma.

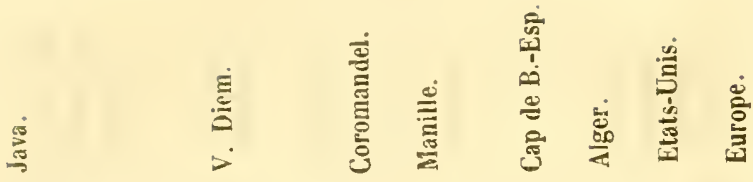

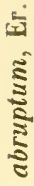

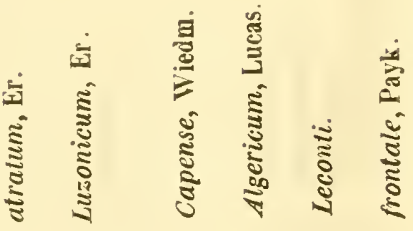

$-i$

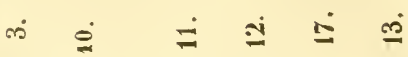

节.

(1)

$\stackrel{5}{\infty}$

$$
\text { 苋 } \cdots
$$

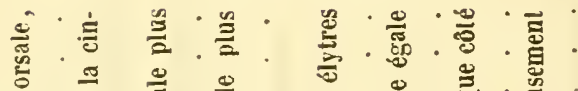

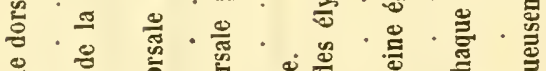

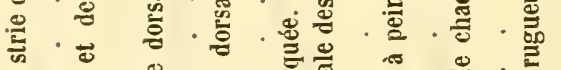

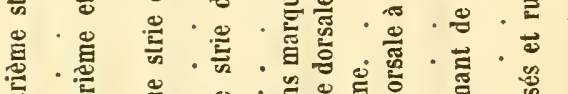

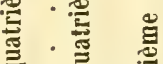

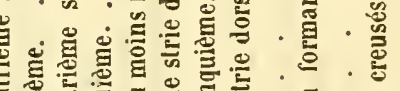

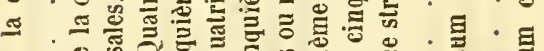

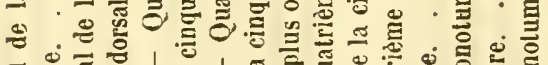

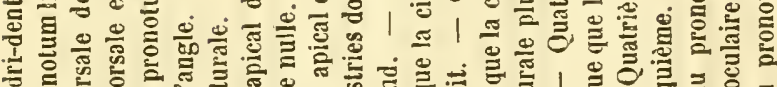

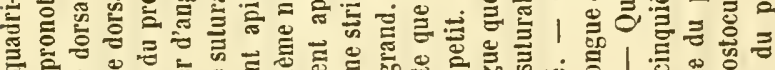

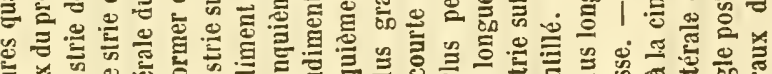

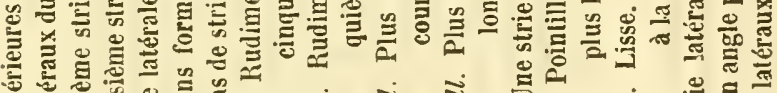

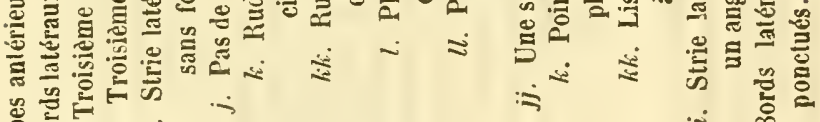

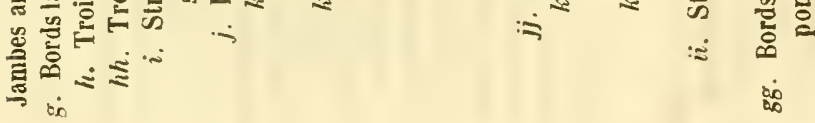




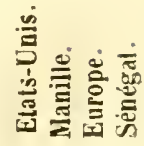

莺 总

宝

$\stackrel{ }{\circ}$

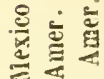
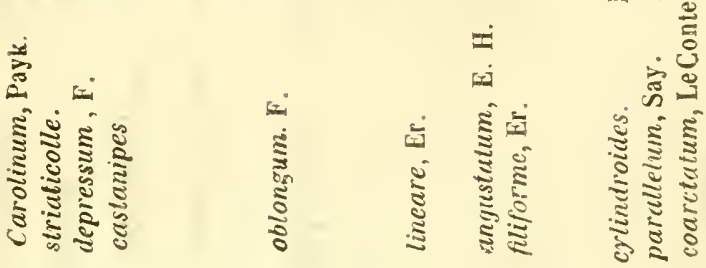

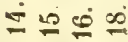

$\stackrel{2}{2}$

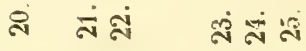

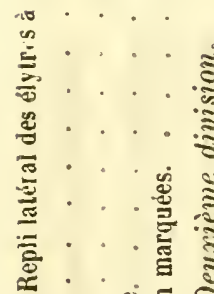

I.

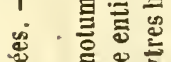

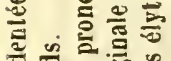

กั่

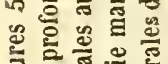

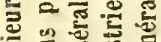

可言的

สิ

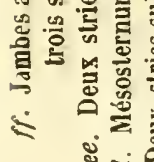

芯

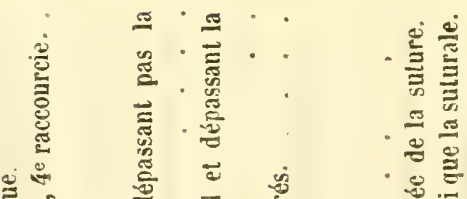

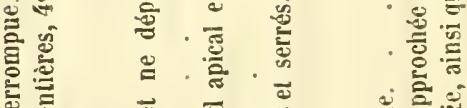

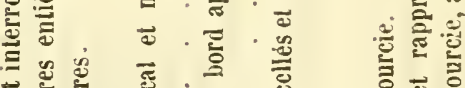

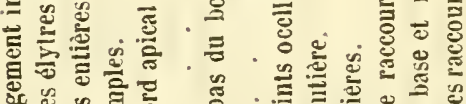

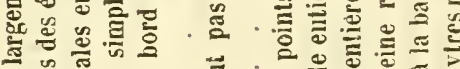

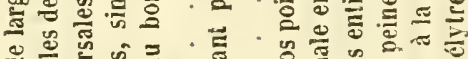
สี \%

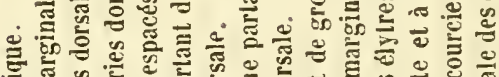

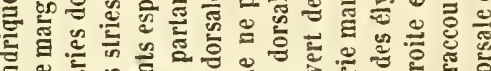
․ㅗㄴ

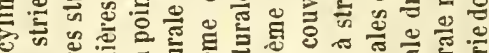

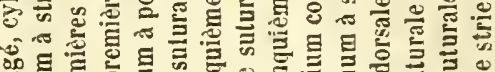

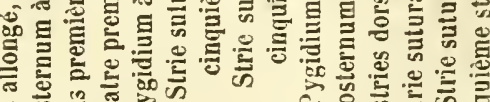

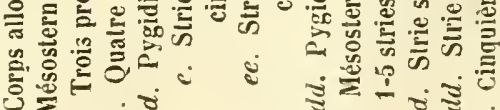
今

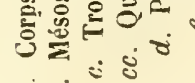

$\infty$ $\square \infty$

$\infty$

i -8 ن 


\section{Première division.}

Corps déprimé en dessus, assez large, en carré oblong $(1-18)$.

\section{P. ovaten.}

Oblongo-subquadratum, subdcpressum, nigrum nitidum; fronte concava, stria temui subsinuata; pronoto stria laterali late intcrupta; clytris dorsalibus $1-3$ integris; pygidio dense punctato, margine reflexo; mesosterno stria integra; tibiis anticis et intermediis quadri-, posticis tridentatis. Long. 7-6 mill.; larg. 4-3 1/2 mill.

Platysoma ovatum, Er. Jahrb. 10S, 3 (1834),

En carré oblong, légèrement déprimé, lisse, noir luisant. Antennes brunes, massue roussâtre. Tête large, finement pointillée; front et épistome concaves, séparés par une stric transversale fine, sinuée à l'angle oculaire. Pronotum court, large, à peine bisinué à la base, droit sur les côtés, éclrancré en devant, avec les angles arrondis, abaissés; strie latérale forte, bien marquée, interrompue au bord antérieur. Ecus. son triangulaire, petit. Elytres plus longues que le pronotum, de sa largeur à la base, légèrement rétrécies et coupées droit au bord apical; repli latéral à deux stries, humérale fine, oblique, 1-3 dorsales entières, troisième souvent un peu interrompue, les autres nulles. Propygidium très court. ponctué et incliné; pygidium rebordé, fortement couvert de points ocellés très serrés. Mésosternum avec une strie entière. Jambes antérieures et intermédiaires armées de quatre dents : postérieures de trois, les deux apicales rapprochées.

Java.

\section{P. ABRUPTUM.}

Oblongo-ovatum, subdepressum, niginm, nitidum, subtilissime muncliculatum ; fromle concava, stria transver:sa subrecta; 
pronoto stria laterali integra; clytris striis 2 primis dorsalibus integris, $3^{\mathrm{a}}$ interrupta, $4^{\mathrm{a}}$ apicali, obsolet, ; mygidio marginato, sat dense punctato; mesostermo marginato; tibiis anticis et intcrmodiis quadri-, posticis tridentutis. Long. 6 mill.; larg. 3 1/2 m.

Platysoma abruptum, Er. Jahrb. 109, 4 (1834).

Ovale allongé, d'un noir de poix luisant, lisse (très finement ponctué au microscope). Tète large; front légèrement concave, distinct de l'épistome; strie bien marquéc, droite et entière au milieu, brièvement interrompue de chaque côté, au-dessus des yeux. Antenues brunes. Pronotum beaucoup plus large que long, à peu près droit à la base, légèrement arqué sur les côtés, rétréci et échancré en devant, avec les angles abaissés, obtus; strie latérale forte et non interrompue en devant. Ecusson petit, triangulaire. Elytres une fois et demie plus longues que le pronotum, de sa largeur à la base, à peine rétrécies et coupées droit au bout; strie lıumérale bien marquée; sublıumérales nulles; deux marginales fortes et entières; première et deuxième dorsales entières, troisième largement interrompuc au milieu; quatrième courte, obsolète, représentée par quelques points apicaux; les autres nulles. Propygidium court, bifovéolé, ponctué ; pygidium triangulaire, avec un rebord élevé, couvert d'une ponctuation profonde, ocellée et assez serrée. Mésosternum échancré au bord antérieur, complètement rebordé. Jambes antérieures quadri-dentées; intermédiaires garnies également de quatre dents; postérieures de trois, les deux apicales fort rapprochées.

Il se distingue du P.ovatum, outre les stries des élytres et du pronotum et la tailie, par la strie frontale plus forte, moins sinueuse; par le pygidium plus profonclement, mais moius densément ponctué.

Java (M. de Laferté). 


\section{P. ATRATU.}

Oblongo-ovatum, subdepressum, nigrum, nitidum; clava fretuginea, fronte subconcava, stria rectu; monoto stria laterali integra; clytris $1-3)$ dorsalibus integris, $4^{\text {a }}$ et $5^{\text {a }}$ valde abbreviatis, suturali nulla; mygidio grosse munctato; mesosterno stria integra ; tibiis quadridentatis. Long. 6 mill.; larg. $31 / 2$ mill.

L'latysomut atratum, Er. Jahrb. 110, 6 (1834).

Ovale-allongé, légèrement déprimé, noir, lisse, luisant. Antennes brunes, massue ferrugineuse. Front à peine impressionné au milieu; strie bien marquée, presque droite. Pronotum plus large que long, bisinué à la base, à peine arqué sur les côtés, échancré en devant, avec les angles arrondis, abaissés; strie marginale bien marquée; latérale forte, entière, continuée à la base. Ecusson petit, triangulaire. Elytres plus longues que le pronotum, de sa largeur à la base, un peu rétrécies et coupées droit au bout; repli latéral sillonné de deux stries entières, l'interne se prolongeant jusqu’à la suture le long du bord apical; humérale fine, oblique ; 1-3 dorsales entières, quatrième et cinquième fortement raccourcies; les autres nulles. Propygidium court, légèrement bifovéolé, ponctué, mais moins densément que le pygidium. Lobe prosternal ceint d'une strie circulaire; mésosternum entièrement rebordé. Jambes quadri-dentées.

Coromandel.

\section{P. LCCIFUGUN.}

Oblongo-ovatum, smbderressum, nigro-nitidum; antenuis brumncis; fromle leviler impressa, stria integra; monoto stria. faterati a magine remola rentice intervumta; elytris striis dor- 


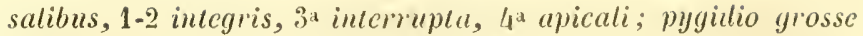
punctato margine elevato; mesostono stria valde interrupta; tibiis anticis et intcrmediis quadri-, posticis tridentatis. Long. 7 mill.; larg. 3 1/2 mill.

Ovale-allongé, aplati, noir luisant. Antennes brunes. Front lisse, à peine concave, strie entière, bien marquée. Mandibules creusées en dessus. Pronotum lisse, beaucoup plus large que long, arqué à la base, droit sur les côtés, échancré en devant, avec les angles abaissés, assez aigus; strie latérale forte, bien marquée, assez distante du bord latéral, surtout au milieu, un peu interrompue en devant. Ecusson petit, triangulaire. Elytres de la largeur du pronotum à la base, beaucoup plus longues que lui, un peu rétrécies par derrière, droites au bord apical; deux stries marginales entières; première et deuxième dorsales entières, troisième interrompue, quatrième courte, apicale. Propygidium court, impressionné, ponctué ; pygidium densément et fortement ponctué, entouré d'un rebord élevé, très saillant. Mésosternum à strie marginale largement interrompue. Jambes antérieures quadri-dentées; intermédiaires garnies de quatre denticules; postérieures de trois, les deux apicaux rapprochés.

Iles Philippines.

\section{P. URThlit.}

Ovatum depressum, lave, piccum, nilidum; antonnis pedibusque brunncis; fronte conceva, stria integra; pronoto stria laterali intcrupta; dytris striis dorsalibus 2 primis intcgris, $3^{\text {a }}$ late intorrupta margini moxima, cateris nullis; mygillo punctato, margine reflexo; mesosterno antice stria interrupta; tibiis anticis 5-, posticis quadri-dentatis. Long. 5 mill.; larg. 2 4/5 mill.

Hololepia Imillci, Le Guill. Rev. 7ool. (1894), 223, 12. 
Ovale, déprimé, presque lisse, d'un brun de poix írès luisant. Antennes brunes. Front légèrement excavé, distinct de l'épistome par une strie transversale bien marquée, entière. Pronotum court, beaucoup plus large que long, presque droit à la base, avec un point anté-scutellaire, très légèrement arquué sur les côtés, à peine rétréci et fortement échancré en devant, avec les angles abaissés, obths; strie latérale rapprochée du bord, interrompue derrière la tête. Ecusson petit, triangulaire. Elytres une fois et demie plus longues que le pronotum, de sa largeur à la base, parallèles sur les còtés, un peu rétrécies et coupées droit au bord apical; deux premières stries dorsales entières, troisième largement interrompue; les autres nulles. Propygidium court, impressionné, ponctué. Pygidium triangulaire, peu densément, mais assez fortement ponctué, avec les bords relevés. Prosternum arrondi à la base, avec un lobe antérieur long; mésosternum échancré en devant pour recevoir la base du prosternum, avec une strie marginale interrompue. Pattes d'un rouge-brun; jambes antérieures et intermédiaires garnies de cinq dents : postérieures de quatre, les deux apicales rapprochées.

Taïti, Vavao.

\section{P. HUMILE.}

Ovatum, demessum, nigro-piccum, nitidum, lске ; antennis pedibusque rufis; fronte concava, stria transversa integra recta; monoto stria lalcrali interrupta; elytris striis dorsalibus 3 primis integris, $4^{\text {a }}$ valde abbreviata; pygidio marginato munctatoque; mesosterno stria marginali integra; tibiis quadridcntatis, Long. 5 mill.; larg. $23 / 4$ mill.

Platysoma humile, Er. Jahrb. 109, 5 (1834). 
Ovale, aplati, d'un noir de poix luisant, lisse. Front distinct de l'épistome par une strie bien marquée, fortement concave. Antennes d'un brun-rouge. Pronotum court, transversal, coupé droit à la base, légèrement arqué sur les còtés, largement et bisinueusement échancré en devant, avec les angles abaissés, obtus, assez saillants; strie latérale bien marquée, ainsi que la marginale, assez distante du bord, s'en rapprochant derrière les yeux, oủ elle se termine de chaque côté. Ecusson petit, triangulaire. Elytres une fois et un tiers plus longues que le pronotum, de sa largeur à la base, légèrement arrondies sur les côtés vers le bout, rétrécies et coupées droit au bord apical; stries dorsales bien marquées, trois premières entières, troisième quelquefois un peu plus fine au milieu et comme brièvement interrompue; quatrième fortement raccourcie; les autres nulles. Propygidium avec une bande transversale de gros points peu nombreux. Pygidium triangulaire, avec un rebord élevé, couvert de gros points espacés. Prosternum court, assez large, sans stries, arrondi à la base, avec un lobe antérieur bieu distinct, allongé, horizontal; mésosternum court, légèrement échancré en devant pour recevoir le prosternum, bordé d'une strie entière, bien marquée. Pattes rousses jambes antérieures quadri-dentées; postérieures garnies de quatre denticules.

Java.

\section{P. LATISTERNIM.}

Ovatum, complanatum, brunneum, nitidum, lave, pedibus antennisque rufis; fronte tevissime concruva, stria integra; monoto slria laterali temi breviter intermpta; clytris striis dorsalibus, $1^{\mathrm{a}}$ integra, 2a basi abbreviata, $\mathrm{s}^{\mathrm{a}}$ late interrupla; catcris mullis; mgidio menctato; mostermo lato, basi rolundato; mesostemo antice simuato marginatoqur; tiliis anticis quadridemlatis. I.omg. 1 mill.: larg.g. 2 1/2 mill. 
Uvale, aplati, d'un brun luisant, lisse. liront très légèrement concave, distinct de l'épistome par une strie transversale bien marquée, non interrompue. Antennes brunes, massue testacée. Pronotum court, transversal, droit à la base, arqué sur les côtés, rétréci et échancré en devant; strie latérale fine, très rapprochée du bord, brièvement interrompue. Ecusson petit, triangulaire. Elytres une fois et demie plus longues que le pronotum, de sa largeur à la base, rétrécies postérieurement, épaules légèrement saillantes; stries dorsales fines, première entière, deuxième raccourcie à la base, troisième composée d'une strie basale oblique et d'un rudiment apical plus court. Propygidium transversal, légèrement ponctué. Pygidium un peu convexe, sans rebord élevé, finement ponctué. Prosternum court, large, arrondi à la base, muni en devant d'un lobe court, bombé, très distinct; mésosternum largement sinué en devant, avec une strie marginale entière, rapprochée du bord. Pattes rousses; jambes antérieures obtusément quadri-dentées, ou mieux, armées de deux dents obtuses, géminées : intermédiaires garnies de quatre denticules.

Van Diemen (Muséum).

\section{P. LEVE.}

Ovatum, depressum, piceum, nitidum, Icte ; antonnis pedibusquer ufis; fronte lexiter concava, stria utrinque recurva, interrupta; pronoto stria laterali integra; clytris striis dorsa libus 3 mimis integris, $4^{a}$ apricali ; mygidio punctulato; mesosterno marginuto; libiis 4 anticis quadri-, posticis tridentatis. Long. 3 1/2 mill.; larg. $14 / 5$ mill.

Orale, aplati, d'un brun de poix luisant, lisse. Front légèrement concave; strie interrompue, recourbce de chaque 
côté. Antennes rougeâtres, massue testacée. Pronotum court, droit à la base, légèrement arqué sur les côtés, rétréci et bisinueusement échancré en devant, avec les angles abaissés, peu saillants; strie latérale fine, entière. Ecusson petit, triangulaire. Elytres assez courtes, plus longues que le pronotum, de sa largeur à la base, légèrement rétrécies au bout; stries fines, 1-3 dorsales entières, quatrième courie, apicale. Pygidium triangulaire, finement pointillé. Prosternum saillant, étroit, arrondi à la base, muni en devant d'un lobe étroit, allongé; mésosternum échancré au milię du bord antérieur, bordé d'une strie entière. Pattes d'un rouge-brun; jambes antérieures quadridentées : intermédiaires garnies de quatre denticules; posiérieures de trois, les deux apicaux rapprochés.

Van Diemen (Muséum).

\section{P. Patganil.}

Ovato-parallehm, subdepressum, lave, nigro-nitidum; antennis pedibusque rufo-brumeis; fronte concava, stria transversa integra; pronoto stria laterali valida, intorrupta; clytris striis 3 mimis torsalibus integris, $4^{\mathrm{a}}$ apicali; mygidio punctato; mesostcrno emarginato, stria integra; tibiis anticis 4-, posticis 3-dentatis. Long. 4 1/2 mill.; larg. 2 1/2 mill.

Hololepta Paugumi, Le Guill. Rev. Zool. (1844), 223, 13.

Ovale, presque parallèle, déprimé, lisse, d'un noir luisant. Front concave, distinct de l'épistome par une strie transversale bien marquée, entière. Antennes brunes. Pronotum court, large, coupé droit à la base, avec un point antéscutellaire, arrondi sur les côtés aux angles antérieurs, largement et profondément échancré en devant; stric latérale forte, se contournant a l'angle antéricur, s'interrompant, 
puis semblant recommencer de nouveau plus fine, plus rapprochée du bord, pour cesser bientôt. Ecusson petit, triangulaire. Elytres courtes, un peu plus longues que le pronotum, de sa largeur à la base, parallèles; 1 -4 stries dorsales entières, sinuées, fortes, première et troisième plus larges à la base, quatrième fortement raccourcie. Pygidium ponctué. Prosternum large, court, sans stries, arrondi à la base, avec un lobe antérieur listinct, horizontal. Mésosternum échancré au milieu et distinctement rebordé sans interruption. Pattes brunes; jambes antérieures obtusément quadri-dentées; intermédiaires garnies de quatre denticules; postérieures de trois.

Iles Aroë (Muséum).

\section{P. Luzonicun.}

Oblongo-ovatum, subdepressum, nigro-piccum, nitidum ; antemis pedibusque fermgineis; fronte vix excavata, stria integra, recta; pronoto stria laterali haud interrupta; elytris striis 3 primis dorsalibus integris, $4^{\text {a }}$ et $5^{2}$ valde abbreviatis; mygiclio grosse munctato; mesosterno antice cmarginato, stria integra; tibiis 4 anticis 4-, posticis 3-dentatis. Long. 4 mill.; larg. $21 / 3$ mill.

Platysoma Luzonicum, Er. Jahrb. 111, 7 (1834).

Ovale-oblong, subléprimé, d'un noir de poix luisant, ponctué si finement qu'on a peine à distinguer les points. Front presque plan; strie transversale entière, bien marquéc et droite au milieu. Antennes brunes, massue d'un rouge-brun. Pronotum beaucoup plus large que long, droit à la base, faiblement arqué sur les côtés, légèrement rétréci et fortement échancré en devant, avec les angles obtus, abaissés et assez avancés ; strie lalérale forte, entière. Ecus- 
son petit, triangulaire. Elytres une fois et demie plus longues que le pronotum, parallèles; stries dorsales droites, fortes, 1-3 entières, quatrième et cinquième très raceoureies, à peu près égales. Propygidium et pygidium couverts de gros points assez serrés. Prosternum assez saillant, étroit, muni d'un lobe antérieur bordé d'une strie, arrondi à la base, et s'enfonçant dans le mésosternum; ce dernier échancré en devant, avec une strie marginale bien marquée, entière. Pattes d'un rouge-ferrugineux: jambes antérieures quadri-dentées; intermédiaires garnies de quatre dentieules; postérieures de trois, les deux extrêmes rapprochés.

Iles Philippines, Manille (M. de Laferté).

\section{P. Cipense.}

Oblongo-ovaum, subdepressum, piceum, nitidum, punctulatum; antonnis forrugineis; fronte concava, stria integra; pronoto stria latcrali tonui haud intorrupta; elytris dorsalibus 1-3, stope $4^{a}$, integris, 5a et suturali apicalibus; mygidio punctato; mesostcrno stria integra; tibiis quadridentatis. Long. 5-4 1/2 mill.; larg. 3-2 mill.

Hololepta capensis, Wiedm. in Germ. Mag. 4, 127, 32 (1821).

H. Hemingii, Sturm. Cat. p, 62. pl. 2, 11 (1S43).

Platysoma capense, Bohem. Ins. Caffr. 1, 555, 606.

Ovale-allongé, déprimé, d'un noir de poix luisant, avee le bord apical des élytres et celui des segments abdominaux rougeâtres, finement et densément pointillé. Antennes ferrugineuses, seape brun. Front avee une cxcavation peu profonde, et une strie arquée, entière, peu nettement accusée. Pronotum court, plus fortement ponctué sur les côtés, bisinué à la base, arrondi aux angles antérieurs, et écliancré en devant; strie latérale fine, rapprochée du bord, non interrompue. Ecusson petic, triangulaire. Elytres beau- 
coup plus longues que le pronotum, de sa largeur à la base, un peu saillantes à l'épaule, rétrécies et coupées droit au bout; repli latéral rugueux, les deux stries fortes; subhumérales très obsolètes; 1-3 dorsales entières, quatrième entière aussi quelquefois, mais peu marquée; cinquième et suturale courtes. Propygidium court; pygidium convexe, assez densément et fortement ponctués. Mésosternum entièrement rebordé. Pattes brunes; jambes garnies de quatre dents

Cap de Bonne-Espérance, Natal.

\section{P. Alginicon.}

Ovatum, parum convexum, nigro-picenm, nitidum; antennis pedibusque rufo-brumeis; fronte plana, stria transversa incegra; monoto stria laterali hand interrupta a margine remota; elytris striis 3 primis dorsalibus integris, 4a, 5a suturalique abbreviatis; pygidio punctato; mesosterno marginato; tibiis omnibus 4-dentatis. Long. 4 mill. Larg. 2 3/4 mill.

Platysoma Algiricum, Lucas. Exp. Sc. en Algerie, 231, 606, pl. 22, f. 10 (1849).

Ovale, peu convexe, d'un noir de poix luisant ef lisse. Front légèrement convexe, séparé de l'épistome par une strie forte, entière. Antennes brunes, massue rougeatre. Pronotum court, transversal, coupé droit à la base, légèrement arqué sur les côtés, vers les angles antérieurs, fortement échancré en devant; strie latérale forte, entière, éloignée du bord. Ecusson petit, triangulaire. Elytres courtes, plus longues que le pronotum, de sa largeur à la base, légèrement rétrécies et coupées droit au bord apical; stries fortes et bien marquées ; 1-3 dorsales entières, première et troisième plus profondes à la base, quatrième, cinquième et suturale occupant le tiers postérieur, égales entre elles, mais commençant plus loin du bord apical à 
mesure qu'elles s'approchent de la suture. Pygidium assez fortement ponctué. Prosternum assez saillant, étroit, arrondi à la base, muni en devant d'un lobe distinct et assez large. Mésosternum échancré au milieu du bord antérieur, avec une strie marginale entière. Pattes d'un brun-rouge: jambes antérieures quadri-dentées; postérieures armées de quatre denticules, les deux extrêmes rapprochés.

M. H. Lucas a trouvé cet insecte en juillet, sous l'écorce d'un frêne abattu, dans la province d'Alger.

\section{P. Froxtale.}

Ovatum, subquadratum, nigrum, nilidum; antomis pedibusque rufo-brumeis; stria frontali valida, clypeo impresso ; pronoto latcribus imprcssis, rugoso-punctatis, margine clevato, stria integra; clytris margine inflexo 3-sulcato; 1-3 dorsalibus integris, cateris brevibus obsoletis; mesostcrno stria haud interrupta; tibiis anticis 4-, intermediis 6-, posticisque 5-dentatis. Long. 4 mill.; larg. 2 1/2 mill.

Hister frontalis, Payk. Fn. Suec. 1, 40, 7 (1798), - Mon. Hist. 44, 31, T. Ix, f. 8. - Ent. Hefte 1, 96, 22. - Sturm Deuts. Fn. 1, 237, 24. T. 18, f. a. - Gyll. Ins. Suec. 1, 84. 12. - Duft. Fn. Austr. 1, 219, 15.

Platysoma frontale, Er. Kæf. Brand. 1, 651, 1. - Redt. Fin. Austr. 231. - Küst. Kaf. Eur. 20,1.

Ovale presque carré, légèrement convexe, noir luisant. Antennes ferrugineuses, scape brun. Front finement pointillé, à peu près plan; épistome concave; strie profonde, entière. Pronotum court, à peine bisinué à la base, avec un point anté-scutellaire, droit sur les côtés, avec une impression longitudinale rugueusement ponctuée, qui forme un bourrelet assez marqué, échancré en devant, avec les angles abaissés, obtus; strie latérale fine, entière. Ecusson petit, 
triangulaire. Elytres plus longues que le pronotum, de sa largeur à la base, fortement rétrécies au bout; bord infléchi ponctué, avec trois sillons; stries dorsales 1-3 entières, bien marquées; les autres courtes et obsolètes. Propygidium court; pygidium bombé, couverts l'un et l'autre de gros points ocellés, espacés. Prosternum obsolètement bistrié à la base; mésosternum entièrement rebordé. Pattes ferrugineuses; jambes antérieures quadri-dentées; intermédiaires garnies de six denticules; postérieures de cinq, les deux derniers rapprochés.

$V a r$. Strie suturale réduite à quelques points qui finissent par disparaître.

Cette espèce, peu commune, vit sous les écorces des arbres morts. Elle est répandue dans une grande partie de l'Europe : Angleterre, Suède, Finlande, France, Allemagne, Autriche, Espagne, Italie, Russie, Turquie.

\section{P. Carolinum.}

Ovatum, subdepressum, piceum, nitidum; antennis pedibusque rufis; fronte clypeoque concavis, stria transversa separatis; pronoto stria laterali antice ambiente; elytris a striis marginalibus, 1-3 dor'salibus integris, $4^{a}, 5^{\text {a }}$ el suturali abbreviatis; mygidio punctato; tibiis 4 vel 5-denticulatis. Long. 3 1/2-3 mill. Larg. 2 1/3-1 3/4 mill.

Hisler Garolinus, Payk. Mon. Hist. 45, 32. T. 10, f. 2 (1811).

H. sordidus, Say. Soc. Phil. v, 44, 17 (1825).

Platysoma Carolinum, Le Conte. Mon. N. Amer. Hister. 9, 1, pl. 1, f. 3.

Ovale, peu convexe, brun de poix luisant, quelquefois ferrugineux. Antennes roussâtres. Front et épistome avec une impression médiane assez marquée, séparés par une stric entière. Pronotum court, à peine bisinué à la base, 
avec un point anté-scutellaire, faiblement arqué sur les cotés, écliancré en devant, avec les angles abaissés, peu aigus; strie latérale entière. Ecusson petit, triangulaire. Elytres un peu plus longues que le pronotum, de sa largeur à la base, courbées sur les côtés, rétrécies et coupées droit au bout; repli latéral ponctué, avec trois sillons entiers; 1-3 stries dorsales entières; quatrième, cinquième et suturale raccourcies au milieu, interstries sillonnés le long du bord apical.Propygidium bifovéolé, ponctué un peu plus fortement que le pygidium. Mésosternum entièrement rebordé. Pattes ferrugineuses; jambes antérieures 4 ou 5-dentées; intermédiaires et postérieures garnies de quatre à cinq denticules.

Etats-Unis (Caroline), sous l'écorce des arbres morts.

\section{P. Striatiderum.}

Oblongo-ovatum, parum convcxum, nigro-piceum, nitidum, lave; antennis pedibusque brunncis; fronte concava, stria transversa integra; pronoto 2 striis lateralibus, cxterna integra; elytris striis dorsalibus 3 primis integris, $4^{\mathrm{a}} 5^{\mathrm{a}} \mathrm{et}$ suturali abbrcviatis; pygidio marginato, grosse munctato; mesosterno marginato; tibiis anticis 4-, posticis 3̈-denticulatis. Long. 4 mill.; larg. 2 mill.

Ovale, peu convexe, d'un noir de poix luisant, lisse. Front fortement concave, distinct de l'épistome par la strie transversale, non interrompue. Antennes brunes. Pronotum court, presque droit à la base, arrondi sur les côtés antérieurement, largement et bisinueusement échancré, avec les angles abaissés, obtus, assez saillants ; strie latérale externe entière, interne fort distante du bord latéral, finissant aux angles antérieurs. Ecusson petit, triangulaire. Elytres courles, un peu plus longues que le pronotum, de sa largeur à la base, fortement striées; repli latéral imponctuć, 
avec deux sillons entiers, bien marqués, l'interne remonté presque à la place de la sublumérale externe; 1-3 stries dorsales entières, les autres raccourcies, quatrième et suturale vers le milieu, cinquième bien avant. Propygidium court, ponctué, bifovéolé. Pygidium couvert de gros points ocellés, assez espacés, avec un rebord éleré. Prosternum étroit, arrondi à la base, muni en devant d'un lobe distinct, long. Mésosternum légèrenient échancré en devant, bordé d'une strie non interrompue. Pattes brunes : jambes antéricures quadri-dentées; intermédiaires garnies de quatre denticules; postérieures de trois, les deux extrêmes rapprochés.

Manilie.

\section{P. DEPRESSUM.}

Oblongo-ovatum, depressum, migrum, nitidum; antennis pedibusque brumeis; fronte leviter concava, stria integra; pronoto lateribus punctulato, stria laterali integra; clytris striis 1-3 dorsalibus integris, ccteris abbreviatis ant mullis; pygidio grosse muctato; mesostcrno stria late interrupta; tibiis 4 anticis 4-, posticis 3-denticulatis. Long. 4 mill. Larg. 2 mill.

Hister depressus, F. Mant. 1, 32, 8 (1787). - Ent. Syst. 1, 74, 10 (1792). - Syst. El. 1, 91, 37. - Ol. Ent. 1, 8, p. 15, 17. T. 2, f. 9. - Rossi. Fn. Etr. 1. 29, 68. - Herbst. Nat. Syst. 4, 34, 9, pl. 35, f. 9. - Schneid. Mag. 1, 303, 10.- Panz. Ent. Germ. 1, $21,9$. - Germ. Fu. T. 80, f. 6. - Ilig. Kxf. Prus. 1, 64, 23. - Thunb. Ins. Suec. 63. - Payk. Fn. Suec. 1, 41, 8. - Ent. Hefte 1, 98, 23. - Sturm. Deuts. Fn. 1, 239, 25. - Gyll. Ins. Suec. 1, 559, 13-14.

H. deplanatus, Gyll. Ins. Suec. 1, 85, 13 (1808).

Hololepta depressa, Payk. Mon. Hist. 103, 1. T. S, f. S.

Platysoma depressum, Er. Jahr. 1, 111, 8. - Kæe. Brand. 1, 651, 2. - Heer. Fn. Helv. 1, 452, 2. - Küst. Kææ. Eur. 8, 68. Redt. Faun. Austr. 31. 
Ovale-oblong, déprimé, noir luisant. Antennes brunes. Tête très finement pointillée. Front légèrement concave, strie entière. Pronotum beaucoup plus large que long, assez court, Jroit à la base, ainsi que sur les côtés, échancré en devant, avec les angles abaissés, obtus, pointillé sur le bord latéral; strie latérale bien marquée, entière, formant un petit angle de claque côté derrière les yeux. Ecusson petit, triangulaire. Elytres près de deux fois plus longues que le pronotum, de sa largeur à la base, un peu rétrécies postérieurement, droites au bord apical; stries dorsales 1-3 entières, quatrième raccourcie, quelquefois entière, cinquième et suturale nulles, ou très courtes. Propygidium court, transversal, bifovéolé, grossièrement ponctué. Pygidium sans rebord, fortement ponctué. Mésosternum(f.g)largement sinué en devant, bordé d'une strie qui cesse de chaque côté à l'angle antérieur. Pattes brun de poix; jambes antérieures quadri-dentées; intermédiaires garnies de quatre denticules; postérieures de trois, les deux derniers rapprochés.

Var. A. Quatrième strie dorsale courte, cinquieme nulle, ainsi que la suturale. Er. Jahr. var. $a$.

$V a r . B$. Quatrième et cinquième stries dorsales raccourcies, suturale nulle. Er. Jahr. var. 6.- Payk. Mon. var. $\beta, \gamma$.

Var. C. Quatrième strie dorsale entière, cinquième raccourcie, suturale nulle. Er. Jahr. var. c. - Payk. Mon. var. $\delta$, T. vili, f. 8. - deplanati, Gyll, Faun. Suec. 1, 85, 13.

Var. D. Quatrième strie dorsale entière, cinquième et suturale raccourcies. Er. Jahr. var. $d$.

Cette espèce vit sous les écorces des arbres, tels que le Bouleau, le Chène, le Hêtre.... Elle se rencontre daus presyue toute l'Europe : Angleterre, Suède, France, Allemagne, 
Autriche, Espagne, Italie, Suisse, Turquie, Russie, Caucase. La var. $A$ est celle qui se trouve d'ordinaire en Allemagne et en France. Les var. $C$ et $D$ ne se trouvent guère qu'en. Suède, et sont rares.

\section{P. LECONTI.}

Ovato-subquadratum, depressum, nigrum, nitidum; antermis pedibusque rufo-brumneis; fronte conctuva, stria integra; pronoto latcribus punctatis, stria laterali integra, pone oculos utrinque angulata; clytris striis 1-3 dorsalibus integris, 4-5 abbreviatis; mygidio parum fortiter munctuto; mesosterno stria integra; tibiis 4 anticis 4-, posticis 3-dcnticulatis. Long. 3 mill. Larg. 2 mill.

Platysoma depressum, Le Conte. Mon. Hist. 10, 2. T. 1, f. 4. (1845).

Ovale, court, presque carré, déprimé, noir luisant. Antennes rousses. Front très finement pointillé, légèrement concave, strie bien marquée, entière. Pronotum court, beaucoup plus large que long, droit à la base et bordé de points, arqué sur les côtés et assez fortement rebordé, profondément échancré en devant, subbisinué au fond de l'échancrure, avec les angles abaissés, assez aigus, assez fortement ponctué latéralement; strie latérale bien marquée, entière, formant derrière les yeux une légère échancrure de chaque côté, et souvent un peu interrompue en ce point. Ecusson petit, triangulaire. Elytres beaucoup plus longues que le pronotum, de sa largeur à la base, parallèles sur les côtés, un peu rétrécies postérieurement, droites au bord apical; stries dorsales 1-3 entières, 4-5 raccourcies, suturale rudimentaire, sourent nulle. Propygidium bifovéolé, ponctué, ainsi que le pygidium, peu densément et beaucoup moins fortemeut que dans le $P$. depressum. Mésosternum (f.h) 
échancré; strie marginale distincte, entière. Pattes d'un rouge-brun. Jambes antérieures quadri-dentées; intermédiaires garnies de quatre denticules, postérieures de trois, les deux extrêmes rapprochés.

Cette espèce, confondue avec le $P$. depressum, Payk., par M. Le Conte, dans sa Monographie des Histérides des EtatsUnis, prise pour une de ses variétés par Erichson (Jahr. 1. c.), et sans doute réunie aussi par Paykull lui-même, en diffère par un caractère constant. Tous les individus d'Amérique, à pygidium moins fortement ponctué, à pronotum plus arqué sur les bords, ont la strie marginale du mésosternum entière et bien marquée en devant, tandis que dans tous les Européens cette strie s'arrête à l'angle antérieur, et est largement interrompue.

Etats-Unis, sous les écorces des arbres.

\section{P. Castanipes.}

Oblongo-ovatum, depressum, brumeum, nitidum; antennis pedibusque rufis; fronte concava, stria integra; pronoto lateribus punctato, stria latcrali haud interrupta; elytris postice punctatis, striis 2 marginalibus, 2 subhumeralibus, 1-3 dorsalibus integris, $4^{\mathrm{a}}, 5^{\mathrm{a}}$ suturalique sensim brevioribus; pygidio grosse punctato; tibiis anticis 4-, posticis 3-denticulatis. Long. 3 1/2 mill. Larg. 1 2/3 mill.

Ovale-oblong, déprimé, d'un brun luisant. Antennes ferrugineuses, massue plus claire. Tête finement pointillée; front concave, séparé de l'épistome par une strie entière, bien marquée. Pronotum court, presque droit à la base, légèrement arqué et bordé d'une ponctuation assez étendue, bisinueusement échancré en devant, avec les angles abaissés, obtus; strie latérale entière. Ecusson très petit. Elytres plus longues que le pronotum, de sa largeur à la base, à peine 
rétrécies au bout, ponctuées et rougeâtres au bord apical; repli latéral pointillé, avec deux forts sillons entiers; strie subhumérale externe fort raccourcie postérieurement, interne fine, presque entière ; 1-3 dorsales entières, quatrième à peine raccourcie, cinquième et suturale de plus en plus courtes. Propygidium court, marqué de gros points espacés, ainsi que le pygidium. Mésosternum échancré largement, entièrement rebordé. Pattes ferrugineuses. Jambes antérieures quadri-dentées; intermédiaires garnies de quatre à cinq denticules, postérieures de trois.

Sénégal.

\section{Deuxième division.}

Corps allongé, cylindrique (19-25).

A. Mésosternum à strie marginale interrompue (19-22).

\section{P. OBLONGUM.}

Elongatum, subcylindricum, nigrum, nitidum; antennis pedibusque brunneis; fronte impressa; pronoto lateribus punctulato, striu latevali integra; clytris $1-3$ dorsalibus integris, $4^{a}$, $5^{\text {a }}$ suturalique antrorsum abbreviatis; pygidio dense punctato; mesosterno stria late interrupta; tibiis anticis 4-dentatis, posticis 3-denticulatis.

Hister oblongus, F. Ent. Syst. 1, 75, 13 (1792). - Syst. El. 1. 92, 41. - Panz. Ent. Germ. 1, 29, 11. - Fu. Germ. 93, 5, - Payk. Fn. Suec: 1, 42, 9. - Mon. Hist. 93, 77. T. 10, f. 3. - Ent. Hefte 1, 100, 24. - Sturm. Deuts. Fn. 1, 241, 26. T. 18, f. b. - Gyll. Ins. Suec. 1, 86, 14.

Hister clongatus, OI. Ent. 1, 8, p. 16,18. T. 2, f. 14. - Thunb. Ins. Succ. 63.

Platysoma oblongum, Er. Kæf. Brand. 1, 652, s̊. - Küst. Kæf. Eur. 20, 3.

Allongé, cylind̉rique, d'un noir luisant. Antennes brunes. 
massue ferrugineuse. Tète finement pointillée; front légèrement concave, distinct de l'épistome par une strie droite, entière. Pronotum plus large que long, ponctué latéralement, presque droit à la base, ainsi que sur les côtés, profondément échancré en devant, avec les angles abaissés, aigus ; strie latérale entière, anguleuse derrière les yeux. Ecusson petit, triangulaire. Elytres beaucoup plus longues que le pronotum, de sa largeur, parallèles, rougeâtres et ponctuées au bord apical; repli latéral à deux sillons entiers, rapprocliés; 1-3 stries dorsales entières, quatrième, cinquième et suturale raccourcies au milieu. Propygidium bifovéolé et grossièrement ponctué. Pygidium couvert de gros points ocellés, un peu plus serrés. Mésosternum étroit, profondément échancré en devant; stric marginale largement interrompue. Pattes brunes; jambes antérieures quadri-dentées; intermédiaires garnies de quatre denticules; postérieures de trois, les deux extrèmes rapprochés.

Il vit dans le terreau qui se forme sous les écorces des arbres morts, en particulier du Pin, du Hètre.....; il est répandu dans une grande partic de l'Europe : Suède, France, Allemagne, Autriche, Suisse, Portugal, Espagne, Italic.

\section{P. Lineare.}

Elongatum, subcylindricum, nigro-piceum, nilidum, pedibns antennisque ferrngincis; fronte concava, stria simual a integra; monoto lateribus pmonchlato, stria laterali integra; elytris 1-4 dorsalibus integris, $5^{\text {a }}$ el suturali cequaliter abbreviatis; pygidlio parce munctulato; mesosterno stria interrupta; libiis unticis 4dentatis, posticis 3̈-denticulatis. Long. 4 mill. Larg. $12 / 3$ mill.

Hister oblongus, Illig. Kix. Pr. 1, 63, 22 (1798). 
11. angustatus, Payk. Mon. Hist. 92, 76. T. x, f. 4 (1811).

Platysoma lineare, Er. Jahrb. 1, 113, 11 (1834). -- Kxf. Brand. 1, 653, 4. - Küst. Kæf. Eur. 20, 4.

Allongé, subcylindrique, brun de poix luisant. Antennes ferrugineuses. Tête finement pointillée; front concave, séparé de l'épistome par une strie sinueuse, entière. Pronotum beaucoup plus large que long, droit à la base et sur les côtés, fortement échancré en devant, avec les angles abaissés, pcu saillants; couvert d'une ponctuation fine, plus forte le long de la base et des bords latéraux; strie latérale entière. Ecusson petit, triangulairc. Elytres beaucoup plus longues que le pronotum, de sa largeur à la base, parallèles, rougeâtres et ponctuées au bout; repli latéral à deux sillons complets; stries dorsales 1-4 entières, cinquième et suturale raccourcies au milieu, partant toutes les deux du bord apical et s'arrêtant au même point. Propygidium bifovéolé, couvert de points espacés assez forts, non ocellés. Pygidium un peu plus faiblement ponctué. Mésosternum largement échancré en devant, avec une strie marginale interrompue. Pattes ferrugineuses; jambes antérieures quadri-dentées; intermédiaires garnies de quatre denticules, et postérieures de trois, les deux extrêmes rapprochés.

Il vit sous l'écorce des arbres, surtout du Pin. Commun en Suède, il est plus rare en Allemagne et en Suisse. On le rencontre aussi en Portugal.

\section{P. ANgustatum.}

Elongatum, cylindricum, nigrum, nitidum; nedibus antermisque brunncis, clava rufa; fronte subconcava, stria temi simuata; pronoto brcvi, transverso, latcribus punctuto; stria laterali integra; elytris $1-4$ dorsalibus integris, $5^{\text {a }}$ et suturali abbreviatis incequaliter ascendentibus; mopygidio ocellato, 
pygidio parce punctatis; mesosterno stria interrupta; tibiis anticis $4^{-}$, posticis 3-dentatis. Long. 3 mill. Larg. 1 1/4 mill.

Hister angustatus, Ent. Hefte 1, 102, 25 (1803). - Sturm. Deutsch. Faum. 1, 242, 27. T. 18, f. c. - Gyll. Ins. Suec. 1, S6, 15.

Platysoma angustatum, Er. Jahr. 1, 113, 12. - Kxf. Brand. 1, 654, 5. - Heer. Fn. Helv. 1, 452, 4. - Küst. Kæf. Eur. 20, 6.

Allongé, cylindrique, peu convexe, noir luisant. Antennes brunes, massue roussâtre. TCie finement pointillée; front et épistome légèrement concaves, séparés par une strie fine, sinueuse. Pronotum court, élargi, finement pointillé, avec des points latéraux plus forts, droit à la base et sur les côtés, largement échancré en devant, avec les angles abaissés, obtus ; strie latérale entière, formant un angle post-oculaire. Ecusson petit, triangulaire. Elytres deux fois plus longues que le pronotum, de sa largeur à la base, parallèles, ponctuées et rougcâtres au bord apical; repli latéral à deux sillons complets; stries dorsales $\mathbf{1 - 4}$ entières, cinquième raccourcie au milieu, suturale remontant un peu plus haut, mais ne partant pas tout à fait du bout. Propygidium bifovéolé, couvert de gros points ocellés, peu serrés. Pygidium assez fortement ponctué, les points simples et espacés. Mesosternum assez fortement échancré, strie interrompue. Pattes ferrugineuses : jambes antérieures quadri-dentées ; intermédiaires garnies de quatre denticules; postérieures de trois, les deux extrêmes rapprochés.

Vit sous l'écorce des arbres, particulièrement dı Chêne. Suède, France, Suisse, Allemagne, Autriche.

\section{P. FILIFOR NIE.}

Elongatum, cylindricum, piccum, niticlum; antennis pedibusque rufis; fronte impressa, stria integra; pronoto subquadrato, 
punctato, versus latera validius, stria laterali antice ambiente; elytris 1-4 dorsalibus integris, 5a suturalique ctque abbrcviatis; propygidio bifoveolato, mygidioque sat dense ocellato-punctatis, mesosterno stria interrupta; tibiis anticis 4-, posticis 3-denticulatis. Long. s mill. Larg. 1 1/2 mill.

platysoma filiforme, Er. Jalır. 114, 13 (1834).

P. dalmatinum, Küst. Kxf. Eur. 20, 5 (1850).

Allongé, cylindrique, luisant, brun, plus ou moins rougeâtre. Antennes ferrugineuses, massue testacée. Tête densément pointillée; front et épistome concaves, distincts par une strie transversale bien marquée, entière. Pronotum presque carré, ponctué, plus fortement dans son pourtour, droit à la base et sur les côtés, largement échancré en devant, arec les angles peu saillants, abaissés; strie latérale non interrompue, mais formant un angle post-oculaire. Ecusson très petit, triangulaire. Elytres une fois et demie plus longues que le pronotum, de sa largeur à la base, parallèles, ponctuées et rougeâtres au bout; repli latéral à deux sillons complets; stries dorsales crénelées, 1-4 entières, cinquième raccourcie au milieu, suturale plus courte encore. Propygidium bifovéolé, assez densément courert de gros points ocellés, ainsi que le pygidium. Mésosternum échancré, strie marginale interrompue. Pattes ferrugineuses; jambes antérieures quadri-dentées; intermédiaires garnies de quatre denticules; postérieures de trois.

Cette espèce différe du $P$.oblongum par sa taille beaucoup plus petite, sa forme moins déprimée, plus cylindrique, et surtout par sa quatrième strie entière; du $P$. angustatum par sa forme plus cylindrique, son pronotum presque carré, la ponctuation du pygidium plus forte, plus serrée et ocellée, et par sa strie suturale; enfin, du $P$. lineare par sa taille plus 
petite, sa forme moins aplatie, son pronotum moins transversal, et par la ponctuation du pygidium.

France méridionale, Portugal, Dalmatie, Volhynie.

B. Mésosternum à strie marginale entière. (23-25.)

\section{P. CYLIYiroides.}

Oblongum, cylindricum, nigro-piceum, nitidum, puncticulatum; antennis pedibusque brunneis; fronte concava. stria integra; pronoto stria laterali valida integra; elytris humeris elcvatis, striis dorsalibus et suturali integris; mygidio punctulato; tibiis anticis 4-, posticis 3-denticulatis. Long. 4 mill.; larg. 1 1/2 will.

Allongé, cylindrique, d'un noir de poix luisant. Antennes brunes. Front pointillé, séparé de l'épistome par une strie transversale bien marquée, non interrompue; ce dernier concave. Pronotum en carré plus large que long, bombé, coupé droit à la base, avec une légère impression antéscutellaire, échancré en devant, avec les angles saillants, abaissés, finement pointillé; strie latérale profonde, non interrompue en devant, anguleuse derrière les yeux. Ecusson petit, triangulaire. Elytres une fois et demie plus longues que le pronotum, de sa largeur à la base, parallèles, à épaules saillantes; stries dorsales entières, ainsi que la suturale, cependant la cinquième est légèrement interrompue à la base; subhumérales nulles. Pygidium ponctué, mais moins fortement. Prosternum saillant, étroit, arrondi à la base, terminé en devant par un lobe avancé, bien distinct et réfléchi. Mésosternum fortement échancré en devant, bordé d'une strie non interrompue. Pattes brunes; jambes antérieures quadri-dentées; intermédiaires garnies de quatre denticules; postérieures de trois, les deux derniers rapprochés.

Mexico. 


\section{P. PARALELUN.}

Elongatum, cylindricum, piccum, nitidum, punctatum, antcmuis pedibusque rufis; fronte concava, stria tenui transversa; pronoto stria marginali antice subinterrupta; clytris stria marginali interna profunda, subhumerali obsolcta, dorsalibus integris, suturali abbreviata antice et ibi suturce propiore; pro. mygidio mygidioque parce ocellato-pnnctatis; tibiis anticis 4-, posticis 3-denticulatis. Long. 2 1/2 mill. Larg. 1 1,4 mill.

Ilister parallehes, Say. Sc. Phil. v, 1, 42, 15 (1825).

Platysoma parallelum, Le Conte. Hon. N. Amer. Hist. 10, 3. T. 1, f. 5.

Allongé, cylindrique, d'un brun de poix luisant. Antennes ferrugineuses, massue plus claire. Front pointillé, légérement concave, séparé de l'épistome par une strie transversale entière. Pronotum presque carré, arrondi à la base, droit sur les côtés, largement échancré en devant, avec les angles abaissés, peu saillants, ponctué sur toute sa surface, mais plus fortement dans son pourtour ; strie latérale faiblement interrompue. Ecusson petit, triangulaire. Elytres beaucoup plus longues que le pronotum, de sa largeur à la base, parallèles, finement pointillées; repli latéral à deux stries, l'externe fine, l'interne très forte et très profonde; subhumérale interne obsolète; dorsales entières, crénelées; suturale se rapprochant en devant de la suture et n'atteignant pas la base. Propygidium couvert de gros points ocellés, peu serrés, ainsi que le pygidium. Mésosternum profondément échancré en devant, entièrement rebordé. Pattes ferrugineuses; jambes antérieures quadri-dentées; intermédiaires garnies de quatre denticules; postérieures de trois, les deux extrèmes rapprochés.

Etats-Unis, dans les provinces méridionales.

3e Série, tome i. 


\section{P. confctatun.}

Cylindricum, elongatum, nigro-piccum, nitidum; antermis pedibusque rufis; fronte subtiliter punctulata, stria integra, clypeo concavo; pronoto munctulato, stria laterali integra; elytris striis $1-4$ dorsalibus integris, $5^{2}$ suturalique parum abbreviatis; pygidlo punctulato; mesosterno integre marginato; tibiis anticis 4-, posticis 3̈-denticulalis. Long. $21 / 2$ mill. Larg. 1 mill.

Platysoma coarctalum, Le Conte. Mon. N. Amer. Hist. 11, 4. T. 1, f. 6 (1845).

Allongé, cylindrique, d'un noir de pois luisant. Front pointillé, distinct de l'épistome par une strie bien marquée, entière, ce dernier concave. Antennes rousses. Pronotum en carré plus large que long, coupé droit à la base, avec un point anté-scutellaire, parallèle sur les côtés, largement échancré en devant, avec les anģles abaissés, obtus; fincment pointillé; stric latérale non interrompue en devant, anguleuse derrière les yeux. Ecusson petit, triangulaire. Elytres une fois et demie plus longues que le pronotum, de sa largeur à la base, parallèles; stries fines, externes droites, internes rapprochées de la suture à la base; quatre premières dorsales entières, cinquième plus fine, raccourcie un peu, avec un point basal, suturale également raccourcic; pas de subhumérale. Pygidium assez finement ponctué. Mésosternum fortement échancré au milieı du bord antérieur pour recevoir la base du prosternum, qui s'y enfonce, burdé d'une strie entière. Pattes roussâtres ; jambes antérieures quadri-dentées; intermédiaires garnies de quatre denticules, postérieures de trois, les deux derniers rapprochés

Il se trouve arec le $P$. parallelum, dont il diffère par sa taille plus petite, sa forme plus étroite et plus allongée, par 
la strie latérale du pronotum entière, la ponctuation du pygidium moins forte, et par les stries des élytres.

Espèces que je n'ai pas vues.

26. P. Rimariun. Er. Jahrb. 1, 112, 9 (1834).

Oblongum, piceum, uitidum; pronoto lateribus punctato; elytris stria suturali nulla, $4^{\mathrm{a}} 5^{\mathrm{a}}$ que dorsalibus antrorsum abbreviatis. Long. fere 2 lin. - Indes.

Un peu plus étroit que le $\boldsymbol{P}$. depressum, très aplati, noir de poix. Antennes et pattes rougeatres. Front excavé, densément ponctué. Pronotum très faiblement arrondi sur les côtés, un peu avancé au milieu de l'échancrure antérieure, grossièrement ponctué sur les côtés, très lisse au milieu; strie latérale profonde sur les bords latéraux, fine et un peu interrompue en devant. Elytres également larges avant le milieu, légèrement enfoncées sur les côtés; suturale nulle, quatrième dorsale raccourcie au milieu, cinquième un peu avant, les trois extérieures fortes, entières. Propygidium couvert de plus ou moins gros points. Pygidium densément et grossièrement ponctué au milieu, lisse et relevé en bourrelet sur les bords.

27. P. Gracile. Le Conte, N. Amer. Hist. 11. T. 1. f. 7. (1845).

Hister frontalis, Say. Sc. Phil. v, 43, 16 (1825).

Elytris striis dorsalibus omnibus integris, cequalibus, suturali antice paulum abbreviata. Long. 4 mill. - In provinciis Australibus.

Noir ou noir de poix. Tête ponctuée, front concave, ligne transversale légèrement imprimée. Antennes brunes, massue plus pâle. Pronotum ponctué, rebordé; strie latérale inter- 
rompue en devant. Elytres pointillées, stries ponctuées, toutes les dorsales entières, suturale un peu raccourcie à la base, subhumérale obsolète, à peine visible, humérale distincte; deux marginales, l'interne large et profonde en devant. Corps entièrement ponctué en dessous. Propygidium et pygidium grossièrement ponctués. Jambes antérieures quadri-dentées, intermédiaires tri-dentées, postérieures bi-dentées.

28. P. attenuatum. Le Conte, N. Amer. Hist. 12, 7, T. 1, f. 9 (1845).

Fronte excavala; elytris striis clorsalibus 4 primis el suturali integris, 5a serie punctorum constituta. Long. 3 mill. - In provinciis Australibus.

Cylindrique, noir ou brun de poix. Tête ponctuée; front fortement échancré, très excavé; strie transversale nulle. Antennes ferrugineuses. Pronotum ponctué, rebordé; strie latérale non interrompue. Elytres peu distinctement pointillées, stries ponctuées, quatre premières dorsales et suturale entières, cinquième formée d'une séric de points, raccourcie un peu au-delà du milieu, suturale arquée en dehors à la base, humérale distincte, deux latérales, l'inférieure à peine visible. Tout le dessous du corps ponctué. Propygidium et pygidium ponctués. Pattes noir de poix; jambes antérieures quadri-dentées, intermédiaires tridentées, postérieures bi-dentées

29. P. LAvicolle. Küst. Kæf. Eur, 20, $2(1850)$.

Oblongum, subdepressum, nigrum, nitidum, capite punctulato, thorace transverso, lateribus impunctato; clytris striis 2 imtimis abbreviatis; tibiis 4-dentatis. Long. $13 / 4$ lin. Larg. 4/5 lin. - Sardinia. 
Cefte espèce, facile à distinguer des espèces voisines du mênı genre par l'absence de ponctuation au pronotum, forme une coupe particulière par ses jambes quadri-dentées. Elle se rapproche, pour la forme, du $P$. depressum, mais elle est un peu plus grande, plus parallèle, et ses élytres ont des stries autrement disposées. Corps allongé, en carré arrondi, très légèrement convexe, noir luisant. Antennes d'un brun-rouge brillant, massue rougeâtre, grise, velue. Tête fiuement ponctuée, concave en devant; strie transversale un peu anguleuse. Pronotum une fois et demie plus large que long, échancré en devant, avec les angles triangulaires, saillants, cotés droits, arrondis à l’angle antérieur, base à peine visiblement bisinuée; surface légèrement convexe, lisse, luisante; à un très fort grossissement, on apercoit une fine ponctuation sur les còtés; strie latérale profonde, l'intervalle entre elle et le bord est plus large vers le milieu. Ecusson triangulaire, poli, luisant. Elytres de la largeur du pronotum à la base, visiblement rétrécies par derrière, presque droites au bout, légèrement convexes; quatre stries extérieures entières, les deux internes n'atteignant pas tout à fait le milieu, la suturale ne part pas du bord apical, toutes indistinctement ponctuées au fond; stries subhumérales nulles. Propygidium ponctué d'une manière peu serrée, pygidium densément et légèrement. Dessous de l'abdomen finement et irrégulièrement ponctué. Pattes brun-rouge, toutes les jambes quadri-dentées, aux quatre postérieures les deux dents extrêmes rapprochées.

30. P. sculptum. Bohem. Ins. Caffr. 1, 554, 605 (1851).

Subdepressum, nigrum, nilidissimum, capiluto antennarum flaco; fronte immessu; stria transversa, flexuosu, terminata; 
pronoto fere lavi, lateribus distinctius punctatis; elytris 1-4 dorsalibus integris, 5a et suturali antice posticcque obliteratis, pedibus piceo-ferrugineis; tibiis anticis dentibus 5, posterioribus 3 armatis. Long. 4 1/2 mill. Larg. 2 1/2 mill. - Hab. in tractibus fluvii Limpoponis (Cafliaria).

Noir luisant, excepté les pieds et les antennes. Tête rétrécie antéricurement, pointillée, vertex aplati, front impressionné, strie flexueuse, complète. Antennes assez courtes, ferrugineuses, massue flave. Pronotum deux fois plus large que long à la base, rétréci en devant, assez profondément échancré; angles subacuminés, abaissés, un peu avancé au milieu à la base; peu convexe en dessus, presque lisse sur le dos, ponctué distinctement, mais moins densément sur les côtés, strie latérale entière. Ecusson triangulaire, poli. Elytres de la largeur du pronotum à la base, formant ensemble un léger angle sutural, un peu dilatées près de la base, se rétrécissant vers le bout, tronquées au bord apical, deux fois plus longues que le pronotum, faiblement convexes en dessus; stries dorsales obsolètement ponctuées, 1-4 entières, cinquième et suturale disparaissant avant le milieu, un peu raccourcies postérieurement; còtés impressionnés et marqués d'un sillon oblique avant le milieu; repli latéral sillonné de deux stries arquées. Pygidium convexe et arrondi au bout, profondément ponctué de toutes parts. Dessous du corps lisse au milieu et distinctement ponctué dans son pourtour. Pattes médiocres, comprimées, d'un brun de poix ferrugineux; jambes dilatées, armées en dehors; les antérieures de ciuq dents, les intermédiaires et les postérieures de trois. 


\section{CYlistus.}

(кuגistós, roulé.)

Soc. Ent, $3{ }^{\circ}$ série, T. 1 (1853), pl. 7. - Mon. pl. 4, genre X.

Hister. Payk. Mon. Hist. (1811).

Platysoma. Erichs. in Jahrb. (1834).

Corpus elongatum, cylindricum.

Caput rctractile, fronte profunde excavata, ante oculos utrinque in dentem prominula, mandibulis exsertis, cequalibus, dentatis.

Antenne sensim incrassate, clava ovato-acuminata; foveolis in angulo profundis, margine pectorali velatis;

Pronotum stria laterali inlegra; elytris 6-striatis.

Prosternum marginatum, basi constrictum rolundatum in mesosterno receptum, lobo lato spatuliformi, valde prominente.

Pedes approximali, femoribus incrassalis, tibiis extus uniseriatim dentatis, unticis intus basi armatis, fovea tarsali intus tanlum recle limitata.

Pygidium semicirculare convexum, propygidium subtrigonum declivia.

Corps allongé, cylindrique.

Tête grosse, médiocrement enfoncée dans le prothorax. Front profondément excavé, avec un rebord élevé et une petite dent saillante au devant des yeux; épistome séparé du front par une strie transversale fine, interrompue. Labre court, légèrement écliancré. Mandibules fortes, saillantes, recourbées, avec une pelite dent au bord interne.

Antennes (f. $1 a$ ) insérées sous le rebord du front, an devant des yeux; scape allongé, courbé, épaissi au bout, logé dans une rainure pratiquée au-dessous de la tête; 
funicule de sept articles, premier obconique, beaucoup plus long que le deuxième, celui-ci un peu plus long que les autres, qui vont en s'élargissant ; massue ovale, peu abrupte, velue, terminée en pointe, de quatre articles.

Mâchoires (f. $1 c$ ) à deux lobes barbus en dedans, l'externe long, l'interne très court. Palpes maxillaires de quatre articles : premier petit, deuxième assez long, obconique, troisième plus court, quatrième ovalaire, plus long que le précédent. Menton ( . 1, b) corné, trapézoïdal, légèrement échancré en devant; lèvre profondément bifide; paraglosses frangées en dedans, étroites, de la longueur des palpes; ceux-ci de trois articles, deuxième obconique, troisième ovalaire, à peu près d'égale longueur.

Pronotum convexe, allongé, légèrement arqué à la base, à côtés parallèles, largement échancré en devant, arec une strie latérale bien marquée et non interrompue en avant. Fossette antennaire profonde, creusée sous l'angle antérieur du prothorax, presque entièrement cachée en dessous par le bord pectoral qui, en se réunissant à l'angle antérieur du pronotum, forme une sorte de pli pour loger la massue. Prosternum rebordé, saillant, étroit, arrondi à la base, distinct par une strie transversale du lobe antérieur, qui s'élargit, se recourbe en haut sur la bouche, et forme une sorte de spatule arrondie el entourée d'une strie. Mésosternum étroit, échancré profondément pour recevoir la base du prosternum, et bordé d'une strie bien marquée. Pièce humérale visible en dessus. Ecusson petit, triangulaire. Elytres convexes, parallèles coupées droit au bout, avec toutes les stries marquées, excepté les subhumérales.

Pattes (f. $1 d, c, f)$ fort rapprochées à leur insertion; paire postéricure fort distante le l'intermédiaire; cuisses 
courtes, renflées, surtout les antérieures, bordées en dedans. Jambes presque cylindriques, terminées par deux épines inégales, avec une seule arête garnie de dents sur le bord externe; antérieures avec une petite dent basilaire interne et une fossette tarsale bien limitée en dedans. Tarses filiformes, 1-4 articles courts, garnis de deux soies, einquième long, mince, avec deux crochets.

Abdomen de cinq anneaux : premier segment ventral plus long que les autres et marqué d'une strie sinueuse de chaque côté. Propygidium allongé, convexe, presque triangulaire, incliné ; pygidium semi-circulaire, bombé, abaissé.

A l'exemple de Dejean dans son Catalogue de 1837, j'ai formé un genre de l'llister cylindricus, Payk., espèce singulière rangée par Erichson parmi les Platysoma, et j'ai conservé le nom qui lui avait été assigné. Ces insectes ont en effet les plus grands rapports avec les espèces cylindriques de ce genre, mais ils ont le menton transversal et plus court, Ia fossette antennaire presque entièrement cachée, le Iobe prosternal plus avancé, les palpes moins allongés et à dernier article plus court. On les reconnaît surtout aisément à la dent basilaire interne des jambes antérieures, caractère qui les rapproche des Trypanceus, à leur front profondément excavé et à leur prosternum rebordé.

\section{Cylistus cylindricus.}

Cylindricus, elongatus, nigro-piceus, nitidus, punctulatus; pedibus antemisque ferrugineis; fronte profunde excavata, stria transversa intermpta; pronoto punctato, stria laterali integra; clytris stria marginali profunda, dorsalibus 1-4 et suturali integris, 5a vi.e abbreviala; mygidio parce fortiter munctato; tibiis anticis 4-, posticis 3-dentatis. 
Hister cylindricus, Payk. Mon. Hist. 91, 75. T, x, f. 5 (1811). Platysoma cylindricum, Le Conte. N. Amer. Hist. 12, 6. T. 1, f. 8 .

Allongé, cylindrique, noir de poix luisant, finement pointillé. Antennes ferrugineuses, massue plus claire. Front profondément excavé, avec les bords de la concavité irréguliers, et une dent au-dessus de l'insertion antennaire; strie transversale, fine, interrompue. Pronotum en carré long, droit à la base, parallèle et même sinué sur les côtés, largement échancré en devant, avec les angles abaissés, peu saillants, ponctué plus fortement dans son pourtour, avec une impression inédiane forméc de points remontant jusqu'au tiers; strie latérale entière, bien marquée. Ecusson petit, triangulaire. Elytres un peu plus longues que le pronotum, de sa largreur à la base, parallèles sur les côtés, droites au bord apical; repli latéral bombé, à deux sillons, dont l'interne est très profond, entier; stries subhumérales nulles; 1-4 dorsales entières, cinquième un peu raccourcie à la base, suturale entière, arquée en dchors ì la base. Prom pygidium et pygidium bonbés, couverts de points gros, espacés. Pattes ferrugineuses; jambes antérieures quadridentées; intermédiaires garnies de quatre denticules; postérieures de trois, les deux extrèmes rapprochés.

Cette espèce, propre aux provinces méridionales de l'Union-Américaine, vit sous les écorces des arbres morts : elle paraît rare.

\section{CRYP'TURUS.}

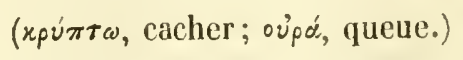

Soc. Ent. 3e série, T. 1 (18ร̌3), pl. 7. - Non, pl. 4. Genre XI.

Corpus ovatum, crassum. 
Caput retractile, fronte plana, stria transversa; mandibulis requalibus, dentalis.

Antennce sub frontis margine inserto, sensim incrassuta, clava orbiculari; foveolis in angulo prothoracis, detectis.

Pronotum stria marginali; elytris 7-striatis.

Prostermum basi incisum, marginatum, lobo brevi inflexo; mesosternum in medio productum, receptum.

Tibice anticce extus uniseriatim dentate, fossa tarsali subrecta profunda, posica biseriatim spinosulet.

Propygidium longum hexagonum; pygidium convexum, circulare, subinflexum.

Corps ovale allongé, convexe, densément pointillé, noir métallique luisant.

Tête arrondie, assez grande, s'enfonçant dans le prothorax; front plan, entouré d'une strie; épistome distinct par une petite arête, transversal ; labre court, légèrement sinué au bout; mandibules égales, unidentées en dedans; yeux latéraux, triangulaires.

Antennes $(f .1, d)$ insérées sous un rebord du front, au devant des yeux; scape courbé, fortement épaissi au bout, logé dans une coulisse pratiquée sous la tête, entre les yeux et les mandibules; funicule de sept articles, premier un peu plus long, obconique, les autres élargis graduellement, serrés; massue orbiculaire, de quatre articles, velus, coupés droits. Fossettes antennaires bien marquées sous l'angle antérieur du prothorax, découvertes.

Mâchoires (f. 1, c) insérées en dehors du menton, cornées, à deux lobes barbus en dedans, externe beaucoup plus long, à peine dépassé par le palpe. Palpes maxillaires de quatre articles courts et assez gros ; deuxième obconique, troisième 
cylindrique, plus court, quatrième ovalairc, deux fois plus long que le précédent. Menton (f. 1 b) corné, quadrangulaire, légèrement siuué en devant; languette membraneuse, peu saillante; paragl ssses ciliées en dedans, assez longues; palpes labiaux de trois articles, deuxième obconique, troisième plus long, ovalaire.

Pronotum légèrement convexe, trapézoïde, arrondi à la base, obliques sur les côtés, échancré en devant, avec les angles abaissés, aigus ; strie marginale fine, rapproclıée de la marge, continuée au bord antérieur. Ecusson visible, petit, triangulaire. Pièce humérale à pcine perceptible. Elytres assez courtes, légèrement convexes, de la largeur du pronotum à la base, rétrécies postérieurement, arquées au bout et formant un angle sutural assez profond; bord infléchi étroit, sans fossette humérale, avec une strie marginale non prolongée au bord apical; cinq stries dorsales, une suturale, une humérale et une sublıumérale, presque toutes entières. Prosternum peu élevé, échancré à la base, bordé sur les côtés d'une stric, fermée en devant, avec un lobe prosternal assez court, distinct par une strie transversale, finement rebordé. Mésosternum assez grand, limité derrière par une fine strie, armé en devant d'une pointe qui pénètre dans la base du prosternum; strie marginale entière. Métasternum assez long, légèrement concave, avec une strie médiane longitudinale.

Pattes (f. $1 e, f$ ) assez longues; les deux prenières paires rapprochées; celles du côté droit de plus en plus distantes de celles du côté gauche. Cuisses légèrement dilatées; antéricures creusées d'une coulisse pour loger les jambes, rebordées en dedans. Jambes laiblement élargies, terminées par deux épines inégales; antérieures inermes en dedans, 
garnies en delıors de 6-7 denticules, creusées en dessus d'une fossette tarsale droite, bien limitée; postérieures garnies de deux rangs de petites épines peu nombreuses. Tarses de cinq articles : quatre premiers égaux entre eux, courts, triangulaires, garnis de cils en dessous; cinquième plus long, terminé par deux croclicts.

Abdomen de cinq anneaux; premier segment ventral long, bistrié; deuxième et troisième égaux et plus courts, quatrième ne paraissant que sur les côtés, cinquième très étroit. Propygidium convexe, hexagonal, très grand. Pygidium bombé, arrondi, infléchi et invisible en dessus.

Ce genre, créé par Erichson en 1834, sur une seule espèce, se reconnait surtout au prosternum rebordé, échancré à la base pour recevoir la pointe du mésosternum, au propygidium grand, hexagonal, convexe, et au pygidium en forme de calotte sphérique, fortement infléchi.

Il habite l'Indoustan, au pied de l'Himâlaya. Møurs et métamorphoses inconnues.

\section{IENESCENS.}

Ovalis, oblongus, convexus, ceneo-niger, punctatissimus; fronte plana rugosa; mronoto stria marginali integra; elytris stria subhumerali obsolcte $5^{a} q u e$ dorsali antice abbrcviatis, cateris integris; prosterno stria marginali antice arcuata; tibiis anticis 7-denticulatis. Long. 6 mill. Larg. 3 1/2 mill.

Crypturus anescens, Er. Jahrb. 1, 126, 1 (1834), pl-2, f. 3.

Ovale allongé, assez convexe, d'un noir métallique assez luisant, très densément pointillé sur toute sa surface. Front plan, rugueux, bordé d'une strie en devant et sur les còtés, séparé de l'épistome par une petite arête transversale. Pronotum courbé a la base, oblique et rugueux sur les 
côtés, échancré en devant, avec les angles aigus, abaissés; strie marginale fine, non interrompue. Ecusson petit, triangulaire. Elytres assez courtes, de la largeur du pronotum à la base, rétrécies postérieurement, avec le bord apical arqué, formant un angle sutural assez profond; repli latéral étroit, sans fossette humérale, avec une forte strie marginale; humérale oblique; subhumérale obsolète, raccourcie en devant; 1-4 suturales entières, cinquième raccourcie en devant; suturale entière, arquée à la base vers la quatrième dorsale, rapprochée de la suture postérieurement. Propygidium et pygidium très densément pointillés. Prosternum bordé d'une strie, réunie en arc en devant; mésosternum entièrement rebordé. Jambes antérieures bordées de sept dentelures; postérieures de quelques rares épines sur chaque arête.

Quelques individus présentent une forte impression rugueusement ponctućc au milieu du pygidium. C'est sans doute un caractère sexuel, et d'après l'analogic, probablement, celui de la $q$.

Pondichery, Neelgherries (Indes). 


\title{
ESSAI MONOGRAPHIQUE
}

\section{SUR LA FAMILLE DES HISTERIDES.}

\author{
(Suite) (1).
}

par M. S. A. de MARSEUL.

(Séance du 9 Février 1853.)

\section{PACHYCR ERUS.}

$$
\text { ( } \pi \alpha \text { xن̀s, épais; xpaĩpa, tête.) }
$$

Soc. Ent. $3^{3}$ série, T. 1 (1853), pl. 14. - Mon. pl. 5. Genre XII. Hister. Er. Jahrb. (1834). - Platysoma, Boh. Ins. Caffr. (1851).

Capul retractile, epistomo excavato, à fronte distincto, marginato, mandibulis cequalibus, dentatis.

Antennce sub frontis margine insertce, clava ovali, articulis transverse parallelis, foveolis in angulo prothoracis detectis.

Pronotum stria marginali, elytris 7 vel 8 striatis.

Prosternum basi incisum marginatum, lobo lato inflexo; mesosternum in medio productum, receptum.

Tibice extus uniseriatim, anticce dentatis, posticis spinulosis, foveola tarsali concinna.

Propygidium hexagonum trunsversum, mygidium semicirculare declive.

(1) Voyez ce volume, page 131. 
Corps plus ou moins cylindrique, luisant, ordinairement orné de couleurs métalliques.

Tête grosse, élargie; front bombé, transversal, faiblement déprimé au milieu; épistome excavé au milieu, relevé dans son pourtour, séparé du front par un sillon plus ou moins distinct de chaque côté, l'un et l'autre ceints d'une strie forte, entière; labre court, sinué en devant; mandibules saillantes, courbées, unidentées en dedans, terminées en pointe longue, aiguë; yeux ovalaires, assez saillants.

Antennes (f. $2 d$ ) insérées sous un rebord du front, entre les yeux et la base des mandibules; scape long, coudé, renflé au bout, logé dans une coulisse pratiquée sous la tête; funicule de sept articles, progressivement élargis, premier obconique, les autres à peu près d'égale longueur'; massue ovale, comprimée, velue, de quatre articles coupés droit. Fossettes antennaires arrondies, profondes, dans l'angle même du prothorax ; le bord pectoral antérieur n'est pas entaillé pour le passage des antennes.

Máchoires (f. $2 c$ ) larges, cornées, insérées en dehors du menton, composées de deux lobes barbus; externe ovalaire, plus long; palpes de quatre articles, premier petit, deuxième obconique, troisième cylindrique, plus court, quatrième long, ovalaire. Menton (f. 2 b) corné, transversal, court, largement sinué en devant; lèvre échancrée; paraglosses membraneuses, ciliées en dedans, assez longues, étroites, un peu recourbées; palpes de trois articles, premier petit, denxième obconique, et troisièmeovalaire, d'égale longueur.

Pronotum beaucoup plus large que long, légèrement bisinué à la base, presque droit sur les côtés, à peine rétréci en devant, mais largement échancré, avec les angles bien marqués, abaissés; une seule strie marginale, fine, très 
rapprochée du bord. Pièce humérale visible ell dessus. Ecusson petit, triangulaire. Elytres beaucoup plus longues que le pronotum, de sa largeur à la base, presque droites sur les côtés, à peine rétrécies et tronquées au bord apical, avec un petit angle sutural; repli latéral sans fossette humérale, sillonné de deux fortes stries marginales; strie humérale fine, oblique; une ou deux subhumérales, cinq dorsales, internes raccourcies, ainsi que la suturale. Prosternun assez saillant, étroit, profondément incisé à la base, bistrié, muni en devant d'un lobe distinct, large, dépassant les angles du pronotum, arrondi en devant, sans strie marginale, s'abaissant doucement jusqu'à la fossette antennaire. Nésosternum large, limité postérieurement par une petite strie obsolète, bisinué en devant avec une pointe médiocre qui pénètre dans la base du prosternum, bordé d'une strie ordinairement interrompue en devant.

Paltes allongées; cuisses comprimées, rebordées en dedans et creusées d'une gouttière pour loger les jambes; celles-ci tcrminées par deux épines inégales; antérieures dentées en dehors, avec une fossette tarsale bien limitée; postérieures faiblement élargies au bout, avec quelques rares épines sur un seul rang; tarses de cinq articles, 1-4 ciliés en dessous, Iriangulaires, égaux; cinquième un peu plus long, garni de rleux crochets.

Abdomen de cinq auneaux; premier segment ventral asse $z$ long, bistrié ; les autres plus ou moins courts; propygidium oblique, en hexagone court; pygidium presque en demi-cercle, peu bombé.

Ce genre, remarquable par son énorme tête et pour l'ordinaire par ses couleurs métalliques, est composé de huit espèces qui appartiennent toutes à l'Afrique, depuis le 3e Série, Tome 1. 
Sénégal jusqu'en Cafrerie. Deux espèces seulement avaient été décrites; l'une par Erichson en 1834, dans la troisième famille de son genre Hister, dont j'ai fait celui de Phelister; l'autre par Fischer, dans l'Ins. Caffr. de Boheman (1851), sous le nom de Plalysoma chalybaum; toutes les autres sont nouvelles. En général ces insectes sont peu répandus dans les collections. Leurs métamorphoses et leurs mœurs sont inconnues.

Les Pachycrcerus se rapprochent de quelques autres genres par plusieurs points de contact, mais il sera toujours aisé de les en distinguer par leur tête large et leur épistome excavé, entourés par une strie marginale commune, par leur fossette tarsale bien accusée, par leur prosternum profondément incisé à la base, recevant une pointe du mésosternum. Les Crypturus ont l'épistome bombé et le front arrondi, plan, avec la strie passant entre les deux, et les pattes postérieures garnies d'un double rang d'épines; les Platysoma ont le front et l'épistome impressionnés, mais séparés par la strie, et la base du prosternum arrondie, pénétrant dans le mẻsosternum; les Phelister, en général arrondis, ont la tête petite, l'épistome sans ligne marginale, et la fossette tarsale mal arrêtée en dehors. 


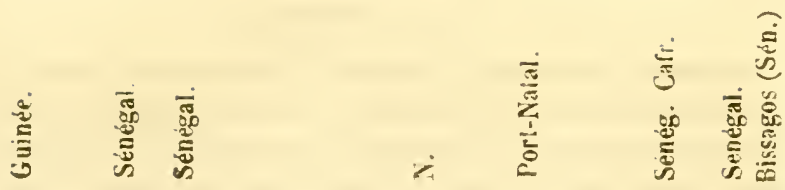
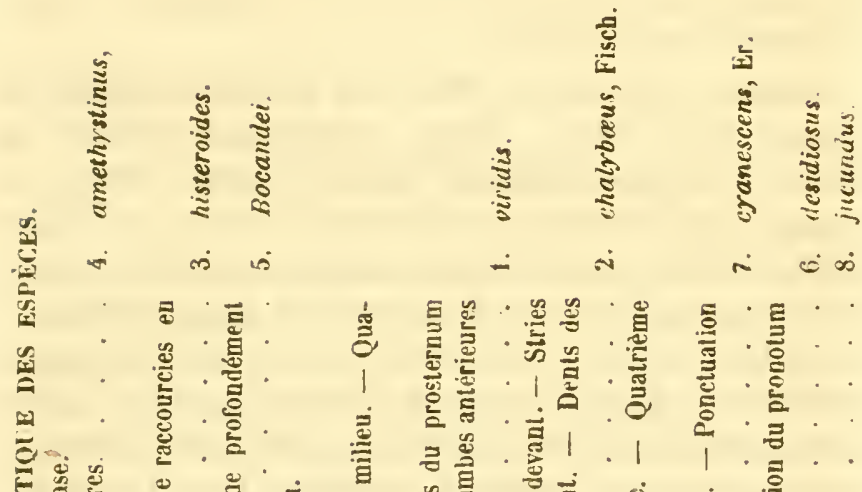

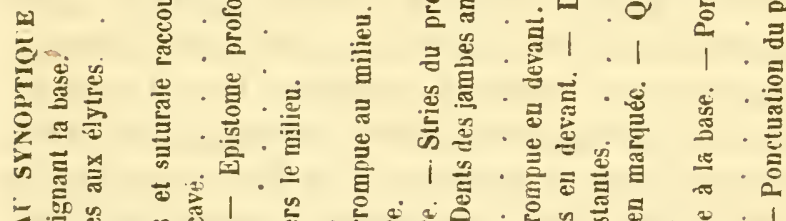

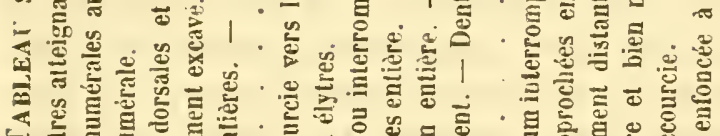

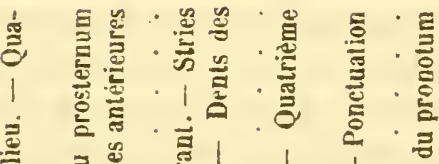

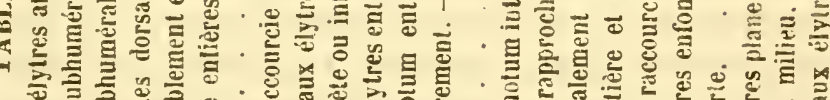
क \%

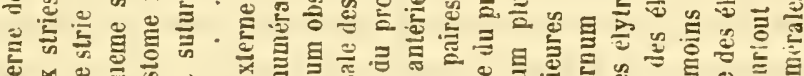

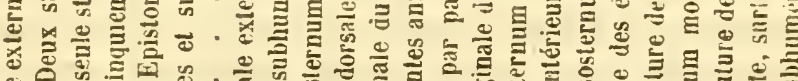

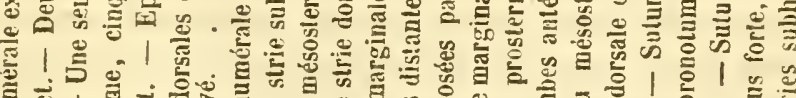

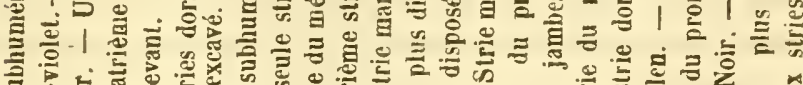

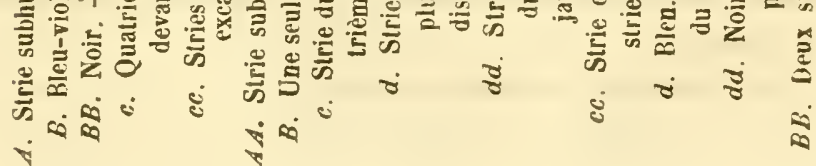




\section{P. VIRIDIS.}

Oblongus, cylindricus, virescens, punctulatus; pronoto lateribus punctato, stria marginali integra; elytris striis dorsalibus 1-4 integris, $5^{a}$ brevissima, subhumerali externa suturalique dimidiatis; propygidio pygillioque sat dense punctatis; mesosterno stria late interrupta; tibiis denticulatis. Long. 7 1/2 mill.; larg. 3 1/2 mill.

Oblong, cylindrique, d'un vert métallique luisant en dessus. Iront large, bombé, obsolètement sillonné au milieu; épistome fortement rebordé, excavé, distinct de chaque côté du front, strie marginale commune bien marquée, entière; antennes brunes, massue plus claire, velue. Pronotum beaucoup plus large que long, largement bisinué à la base, droit, un peu sinué sur les côtés, largement échancré en devant, avec les angles abaissés obtus, couvert d'une ponctuation assez serrée, plus forte dans le pourtour ; strie marginale fine, rapprochée du bord, non interrompue. Ecusson petit, triangulaire. Elytres beaucoup plus longues que le pronotum, de sa largeur à la base, droites sur les côtés et au bord apical; repli latéral bisillonné; strie subhumérale externe raccourcie au milieu, ainsi que la suturale; dorsales fortes, crénelées, 1-4 entières, cinquième réduite à un rudiment apical obsolète. Pygidium bombé, bifovéolé, assez fortement et densément ponctué, ainsi que le propygidium. Mésosternum à strie marginale interrompue en devant. Pattes brunes: jambes antérieures armées de cinq dents, intervalle de la deuxième à la troisième plus grand; intermédiaires garnies de cinq épines, postérieures de quatre.

M. Chevrolat; patrie inconnue. 


\section{P. ChalYBAUS,}

Cylindricus, subconvexus, viridi-metullicus, nitens; untennis tarsisque fulvis; fronte epistomoque marginatis, distinctis, hoc excavato; monoto versus latera fortius punctato, stria marginali antice interrupta, stria subhumerali suturatique in medio abbreviatis, 4 primis dorsalibus integris, 5a apicali, sape nulla; pygidio punctato; mesosterno immarginato. Long. 7 mill.; larg. $31 / 4$ mill.

Platysoma chalybceus, Fisch. in Boh. Ins. Caffi. 1, 553,604 (185̆1).

Cylindrique, peu convexe, à côtés parallèles, d'un vert métallique brillant en dessus, obscur en dessous. Front à peine pointillé, bordé d'une strie bien marquée, se continuant autour de l'épistome; ce dernier avec une excavation, distinct du front par un commencement de strie transversale de chaque côté; antennes brunes, arec le funicule et l'extrémité de la massue roussâtres. Pronotum court, très légèrement arqué à la base, à peine rétréci en devant, avec l'échancrure large et les angles obtus; pointillé, avec une ponctuation plus forte latéralement, et un point antéscutellaire; strie marginale interrompue au milieu du bord antérieur. Ecusson petit, triangulaire. Elytres une fois et demie plus longues que le pronotum, de sa largeur à la base, subparallèles, à peine rétrécies et droites au bord apical, avec les angles arrondis; repli latéral bisillonné; quatre premières stries dorsales entières, bien marquées, cinquième apicale, obsolète; suturale dépassant á peine le milieu, ainsi que la subhumérale externe. Propygidium et pygidium assez densément pointillés. Prosternum bistrié. étroit, échancré à la base, muni en devant d'un lobe infléchi, peu avancé, mésosternum bisinué, avec une pointe médiane saillante; 
strie marginale interrompue au bord antérieur. Pattes d'un noir métallique : tarses bruns; jambes antérieures armées de cinq dents; intermédiaires garnies de six épines, postérieures de quatre.

Port-Natal (Cafrerie).

\section{P. HISTEROIDES.}

Oblongo-ovalis, partm convexus, niger, nitidus, clava urumea; fronte punctulata marginataque, epistomo impresso; pronoto lateribus fortius punctato, stria murginali integra; elytris stria subhumerali externa 3que primis dorsalibus integris, $4^{\text {a }} 5^{\text {a }}$ que et suturali abbrcvialis; propygidio bifoveolato, pygidio dense munctatis; tibiis anticis extus 5-dentatis, intermediis 6-, posticis 4-spinosis. Long. 7 mill.; larg. 5 mill.

Ovale-allongé, peu convexe, noir, luisant. Tête pointillée; front convexe, bordé d'une stric bien marquéc, se continuant saus interruption autour de l'épistome; ee dernier excavé el sans ligne de démarcation. Antennes d'un noir de poix, inassue brunc. Pronotum transversal, bisinué à la base, avec un point antéseutellaire, oblique sur les côtés et un peu arrondi aux augles antérieurs, largement échaneré en devant, finement ponctué sur toute sa surface, avec qunelques points plus gros et moins serrés sur les côtés; strie marginale bien marquée, plus fine, non interrompue en devanl. Ecusson petit, triangulaire. Elytres plus longues que le pronotum, un peu plus larges à la base, légèrement arrondies sur les còtés, rétrécies et droites au bord apical, avec les angles arroudis, a peine visiblement pointillées; repli latéral arec deux sillons profonds; stries liues, ponctuées; trois premières dorsales entières, quatrième racrourcie an milicu, ainsi que la suturale, cinquiime encore 
plus courte; subhumérale interne nulle, externe entière. Propygidium avec une fovéole de chaque côté du bord postérieur, densément et fortement ponctué, ainsi que le pygidium. Prosternum bistrié, étroit, presque parallèle, fortement échancré à la base, avec un lobe antérieur infléchi. Mésosternum en pointe, à peine distinctement rebordé. Jambes garnies d'une seule rangée de dentelures; antérieures 5-dentées; intermédiaires garnies de six épines; postérieures de quatre.

Sénégal.

\section{P. AMETHYSTINUS.}

Cylindricus, convexus, nigro-violaceus, nitidus; antennis pedibusque rufo-brunncis; fronte stria subintegra, clypeo impresso; pronoto punctulato, strighaudinterrupta; elytris margineinflexo 3-sulcato; stria subhumerali interna dimidiata, externa et 1-4 dorsalibus integris, 5a apicali, suturali abbreviata; propygidio mygidioque punctatis; mesosterno stria marginali integra. Long. 6 mill.; larg. 3 mill.

Cylindrique, convexe, d'un noir-violet, luisant. Antennes rousses. Front finement pointillé; épistome impressionné ; strie commune un peu obsolète en devant. Pronotum bisinué à la base, courbé sur les côtés, rétréci el largement échancré en devant, avec les angles abaissés assez aigus, couvert d'une ponctuation fine, assez espacée, plus visible vers les bords; strie marginale entière. Ecusson petit, triangulaire. Elytres plus longues que le pronotum, de sa largeur à la base, un peu rétrécies, légèrement arquées et pointillées au bord apical; repli latéral avec trois sillons; strie subhumérale externe entière, interne raccourcie par derrière, coupée obliquement par l'humérale ; dorsales crénelées, peu 
fortes, 1-4 entiéres, cinquième apicale, rudimentaire ; suturale remontant jusqu'au milieu. Propygidium bifovéolé, couvert, ainsi que le pygidium, de points peu serrés. Prosternum étroit, bistrié, fortement incisé à la base, avee un lobe antérieur large, arrondi, avancé. Mésosternum bisinué, avec une pointe médiane fort longue, bordé de deux stries, externe interrompue, interne entière, en ogive. Pattes rouge-brun, jambes élargies : antérieures 5-dentées, intermédiaires armées de quatre épines, postérieures de deux ou trois.

Guinée (M. de Laferté).

\section{P. Bocandei.}

Cylindricus, subconvexus, nigro-picens, nitidus; antennis pedibusque. brunneo-rufis; clypeo profunde excavato, stria. integra; pronoto sat fortiter punctato, stria marginali integra; elytris striis subhumerali, 1-5 dorsalibus suturalique integris : pygidio munctuto, mesosterno stria marginali late interrupta. Long. 5 mil.; larg. 2 mill.

Subeylindrique, peu convexe en dessus, d'un noir de poix brunâtre sur les bords, luisant. Tête pointillée; épistome profondément excavé, bordé d'une strie, ainsi que le front. dont il n'est pas distinctement séparé, antennes brunes, massue rousse. Pronotum court, transversal, faiblement arqué à la base, droit sur les côtés, avec une faible sinuosité au milieu, largement éclancré en devant, avec les angles arrondis; ponctuation asse $z$ forte; strie marginale entière. Ecusson petit, triangulaire. Elytres une fois un tiers plus longues que le pronotum, de sa largeur à la base, subparallèles, à peine rétrécies et droites au bord apical, avec les angies arrondis; repli latéral bistrié; stries fortes, crénelées. 
1-5 dorsales, saturale et subhumérale externe entières. Propygidium peu densément et assez fortement porıctué ; pygidium pointillé. Dessous finement pointillé. Posternum étroit, histrié, légèrement échancré à la base, muni en devant d'un Iobe large, arrondi, peu saillant; mésosternum bisinué en devant, sans strie marginale. Pattes d'un brunroussâtre; jambes antérieures à cinq dents, intermédiaires garnies de quatre épines, et postérieures de trois.

Sénégal (M. de Laferté).

\section{P. DESIDIOSUS.}

Ovalis, parum convexus, niger, nitidus, punctulatus; autennis pedibusque rufo-brumneis; fronte clypeo impresseque marginatis; monoto fortiter punctato, stria marginali antice interrupta; elytris apis punctatis, striis 3 primis dorsalibus integris, 4a interrupta, 5a suturali subhumeralique abbreviatis; pygidio punctato; mesosterno stria integra. Long. 41/2 mil.; larg. 2 1/2 mill.

Ovale, peu convexe, d'un noir métallique, luisant. Tête pointillée; front convexe, bordé d'une strie qui se prolonge autour de l'épistome; ce dernier excavé et séparé du front par un commencement de sillon de chaque côté. Antennes brunes, massue ferrugineuse. Pronotum court, transversal, à peine arqué à la base, presque droit sur les côtés, légèrement rétréci et largement échancré en devant; couvert de gros points médiocrement serrés; strie marginale interrompue au milieu du bord antérieur. Ecusson petit, triangulaire. Elytres une fois et demie plus longues que le pronotum, de sa largeur à la base, à peine rétrécies au bout, très finement pointillées, avec quelques points apicaux bien marqués; repli latéral bisillonné; stries fortes, profondes ; 
1-3 dorsales entières; quatrième interrompue dans le tiers de la base; cinquième raccourcic au milieu, suturale et subhumérale externe un peu plus longues. Propygidium et pygidium assez fortement, mais peu densément ponctués. Prosternum bistrié, assez court et moins étroit, fortement échancré à la base, avec un lobe infléchi en devant; mésosternum distinctement rebordé. Pattes brunes; jambes antérieures 5-dentées, intermédiaires garnies de cinq épines, postérieures de trois.

Sénégal.

\section{P. Cyanescens.}

Ovalis, supra parum convexus, cceruleus seu viridis metallicus, nitidus; antennis pedibusque rufo-brunneis; clypeo impresso a fronte distincto, stria integra; pronoto lateribus fortius punctato, stria marginali interrupta; elytris striis 1-3 dorsalibus integris, $4^{\mathrm{a}}$, $5^{\mathrm{a}}$, suturali et subhumeruli externa dimidiatis; mesosterno antice marginato. Long. 4 mill.; larg. $24 / 5$ mill.

Hister cyanescens, Es. Jahrb. 155. 72 (1834). - Boh. Ins. Caffr. $1,538,585$.

Ovale, peu convexe, luisant, bleu ou vert métallique en dessus, noir en dessous. Front convexe, finement pointillé, avec une impression médiane, distinct de l'épistome par un commencement de sillon transversal de chaque côté; ce dernier excavé; strie entière, bien marquée. Antennes brunes. Pronotum court, transversal, presque droit à la base, avec une ligne de points et une impression antéscutellaire, légèrement rétréci et largement échancré en devant, avec les angles assez aigus; finement pointillé, avec les cotés largement couverts d'une ponctuation plus forte. Ecusson triangulaire. Elytres une fois et demie plus longues que le 
pronotum, un peu plus larges à la base, légèrement arrondies sur les côtés, rétrécies et coupées droit au bord apical; repli latéral bisillonné; stries fortes, bien marquées, 1-3 dorsales entières, quatrième et cinquième, suturale et subhumérale externe à peu près égales entre elles, et raccourcies vers le milieu. Propygidium et pygidium couverts de points espacés. Prosternum moins étroit, bistrié, légèrement échancré à la base, terminé par un lobe antérieur infléchi; mésosternum bisinué en devant, avec une pointe qui s'enfonce dans la base du prosternum; bordé d'une strie cntière. Pattes d'un brun-ferrugineux; jambes antérieures quadridentées, intermédiaires garnies de cinq épines, postérieures de trois.

Sénégal, Guinée, Cafrerie.

\section{P. Jicundus.}

Ovalis, parum convexus, viridi-cyaneus, nitidus, subtus niger, pedibus antennisque rufo-brumneis; clypeo excavato fronteque marginatis; pronoto lateribus forlius punclato, stria marginali interrupta; elytris sutura impressa, striis 1-3 dorsalibus integris, $4^{\mathrm{a}}, 5^{\mathrm{a}}$, suturali 2 que sublumeralibus dimidiatis; pygidio punctato, mesosterno stria integra. Long. 3 1/2 mill.; lárg. 2 1/2 mill.

Orale, peu convexe, luisant, d'un vert-bleuàtre en dessus, noir en dessous. Tète très finement pointillée; front bombé, avec une légère impression longitudinale, bordé d'une strie bien marquée qui se continue autour de l'épistome; ce dernier excavé, et distinct du front par un commencement de sillon transversal; antennes roussâtres. Pronotum court, presque droit à la base, avec une bordure de points, légèremont arqué sur les côtés, largement échancré et rétréci en 
devant, avec les angles abaissés, bien marqués, assez densément ponctué, beaucoup plus fortement vers les bords latéraux; strie marginale fine, interrompue au bord antérieur. Ecusson petit, triangulaire. Elytres une fois et demie plus longues que le pronotum, de sa largeur à la base, à peine ćlargies latéralement, ponctuées et droites au bord apical, fort enfoncées le long de la suture; repli latéral à deux sillons; stries bien marquées, crénelées, 1-3 dorsales entières, quatrième munie d'un point basal, raccourcie au milieu, ainsi que la suturale, cinquième un peu avant; deux subhumérales courtes, interne plus obsolète. Propygidium avec une fossette de chaque côté, assez fortement ponctué, ainsi que le pygidium. Prosternum peu saillant, assez étroit, bistrié, échancré à la base, terminé par un lobe antérieur assez long; mésosternum bisinué en devant et entièrement rcbordé. Pattes brunes: jambes antérieures armées de quatre dents ; intermédiaires de quatre épines, postérieures de trois.

Archipel de Bissagos, près des côtes du Sénégal (M. de Laferté).

Espèce que je n'ai pas vue.

9. Pachycrkos (Hister) cyanipennis, Fisch. in Boh. Ins. Caffr. 1, 539 (1851).

Sublinearis, subtus niger, antennarum apice tarsisque ferru. gineis, thorace nigro-ceneo, lateribus punctato, haud striato; elytris caruleis, striis 7 punctulatis insculptis, suturali longe ultra medium dorsi producta, $5^{\mathrm{a}}$ dorsali medio abbreviata, reliquis subintegris; pygidio profunde et sat crebre punctato; tibiis omnibus 4-dentatis. Long. 4 mill.; larg. 2 1/2 mill.

$H$. in tractibus flwvii Gariepis superioribus (Caffraria). 
Tête transversale, sinuée de chaque côté en devant, très finement pointillée, noire, luisante, avec une teinte bronzée vers le bout; front obsolètement impressionné, strie semicirculaire ordinaire entière, envoyant en dedans de chaque côté un faible rameau; épistome transrersalement sublinéaire, brun de poix. Antennes un peu plus longues que la tête, obscures à la base; massue en ovale court, ferrugineuse. Pronotum de moitié plus large que long, linéaire sur les côtés de la base jusqu'au-delà du milieu, ensuite rétréci, assez profondément échancré en devant, avec les angles abaissés, presque tronqué a la base, ou seulement légèrement arancé au milieu, légèrement et uniformément convexe en dessus ; bronzé obscur, luisant, pourtour latéral et antérieur distinctement, mais moins densément ponctué, lisse à la partie postérieure du disque. Ecusson en triangle allongé, bronzé, lisse. Elytres fortement appliquées contre le pronotum, de sa largeur, linéaires de la base jusque bien au-delà du milieu, tronquées au bout, avec les angles arrondis, néanmoins presque deux fois plus longues que le pronotum, peu convexes en dessus, bleues, luisantes, avec sept stries ponctuées, suturale se prolongeant jusqu'au-delá du milieu, cinquième dorsale raccourcie au milieu, les autres à peu près entières; en outre, deux stries submargiuales ponctuées. Pygidium obtus; bronzé obscur, assez densément et profondément ponetué, avec le bout lisse. Dessous du corps noir, lisse au milieu, ponctué latéralement; prosternum avancé vers la bouche, arrondi au bout, ponetué. Pattes assez fortes, légèrement comprimées, brun de poix ; tarses moins foncés, toutes les jambes 4-dentées en dehors. 


\section{PHELISTER.}

$$
\text { (фйлos, trompeur; Hister.) }
$$

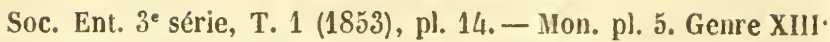
Hister. Say. Sc. Phil. (1825). - Erichs. Jahrb. - Le Conte, N. Amer. Hist.

Corpus globosum.

Caput parvum rolundatum retractile, fronte stria interjecta a clypeo distincta, sæpius concava, mandibulis cequalibus, dentatis.

Antennce subfrontis margine inserte, clava ovali articulis parallelis, foveolis in angulo prothoracis detectis.

Pronotum stria quandoque laterali, elytris 7 vel 8 striatis.

Prosternum basi sinuatum, bistriatum, lobo brevi, inflexo; mesosternum bisinualum, striis 2 narginatum.

Tibice antica extus dcnticulatce, foveola tarsali vaga; postice parum dilatatce biseriatim spinosule.

Propygidium transversum, pygidium semicirculare, declivia.

Corps arrondi, plus ou moins globuleux, d'un noir de poix, quelquefois rougeâtre; rarement métallique vert-bleu ou violet.

Tête (f. 11, 11 a) médiocre, arrondie, s'enfonçant dans le prothorax. Front entouré d'une strie semi-circulaire, ordinairement sinuée en devant et souvent interrompue; presque toujours fortement saillant sur l'insertion des antennes, et concave au milieu; labre court, transversal, échancré en devant, non rebordé; mandibules courbées en pointe aiguë, uni-dentées en dedans; yeux semi-lunaires, peu saillants. 
Antennes (f. $11 d$ ) insérées sous un rebord du front, eutre les yeux et la base des mandibules; scape courbé, épaissi au bout, logé dans une coulisse sous la tête ; funicule de sept articles, élargis progressivement vers le bout, assez serrés; premier obconique, plus long, les autres à peu près d'égale longueur; massue comprimée, sphérique, velue, de quatre articles coupés droit. Fossettes antennaires profondes, creusées sous l'angle antérieur du prothorax, le bord pectoral n'est pas entaillé pour que l'antenne y pénètre.

Màchoires (f. $11 c$ ) insérées en dehors du menton, cornées, à deux lobes, barbus en dedans, externe beaucoup plus long; palpes de quatr'e articles, premier très petit, deuxième obconique, assez long, troisième cylindrique, deux fois plus court, quatrième ovalaire, aussi long que les deux précédents réunis. Menton ( $\mathbb{f} .11 b$ ) corné, en carré transversal, faiblement échancré en devant; lèvre allongée, membraneuse; paraglosses allongẻes, ciliées en dedans; palpes de trois articles, deuxième obconique, troisième un peu plus long, en ovale allongé.

Pronotum trapézoïdal, bombé, arqué à la base, avec une. petite impression antéscutellaire, arrondi plus ou moins sur les côtés, rétréci, abaissé et fortement échancré en devant, avec les angles assez aigus; une strie marginale fine rapprochée du bord, entière ordinairement; quelquefois une latérale plus forte, plus ou moins raccourcie. Ecusson petit, triangulaire. Pièce humérale à peine visible en dessus. Elytres plus ou moins bombées au milieu, de la largeur du pronotum, beaucoup plus longues que lui, plus ou moins arrondies sur les côtés, coupées droit au bord apical, sans angle sutural; repli latéral sans fosselte à l'épaule, strié; strie humérale fine, oblique; tantôt une ou deux sublumé- 
rales, tantot aucume; cinq dorsales et une suturale plus ou moins racourcies en devant. Prosternum assez étroit et

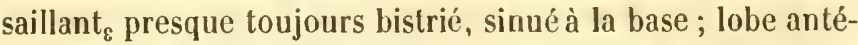
rieurbien distinct, ne dépassant pas les angles antérieurs du pronotum, arrondi et rebordé en devant, infléchi. Mésosternum court, transversal, bisinué en devant, avec une petite pointe médiane qui répond à l'échancrure de la base du prosternum; bordé d'une strie d'ordinaire entière, avec une deuxième strie forte, arquée, paraissant distincte de sa limite postérieure.

Pattes assez allongćes : cuisses comprimées, rebordées et creusées en dedans d'une gouttière pour loger les jambes; jambes effilées, un peu élargies au bout, terminées par deux épines inégales; anterieures garnies d'une série de denti. cules aigus, également espacés, avec une fossette tarsale mal limitée; postérieures garnies en dehors d'une double rangée de petites épines rares; tarses de cinq articles, menus; quatre premiers triangulaires, égaux, ciliés en dessous; cinquième un peu plus long, avec deux crochets.

Abdomen de cinq anneaux; premier segment ventral long, bistrié: deuxième beaucoup plus court, et les trois autres très serrés et étroits. Propygidium hexagonal, oblique; pygidium presque vertical, semi-circulaire.

Les espèces conıues de ce genre avaient été réunies pai Erichson dans une famille à part de son grand genre Hister. La forme générale, la disposition des stries du pronotum, et surtout l'articulation du prosternum et du mésosternum en forment un groupe effectivement bien distinct. II serait à désirer que des caractères d'égale valeur permissent de diviser ce qui reste d'espèces en trois ou quatre coupes aussi naturelles. 
Ces insectes appartiennent presque tous à l'Amérique, où ils sont répandus depuis les Etats-Unis jusqu'en Bolivie. Ils vivent dans les bouses et aussi sous les détritus des végétaux : on les trouve de janvier en mai et juin. La larve est inconnue.

Nota. Je dois à l'obligeance de M. Auguste Sallé, jeune voyageur intelligent et instruit, un bon nombre d'espèces rares du Venezuela, de la Caroline, du Mexique et des $\Lambda$ ntilles, et des détails précis et intéressants sur leurs mœurs. 

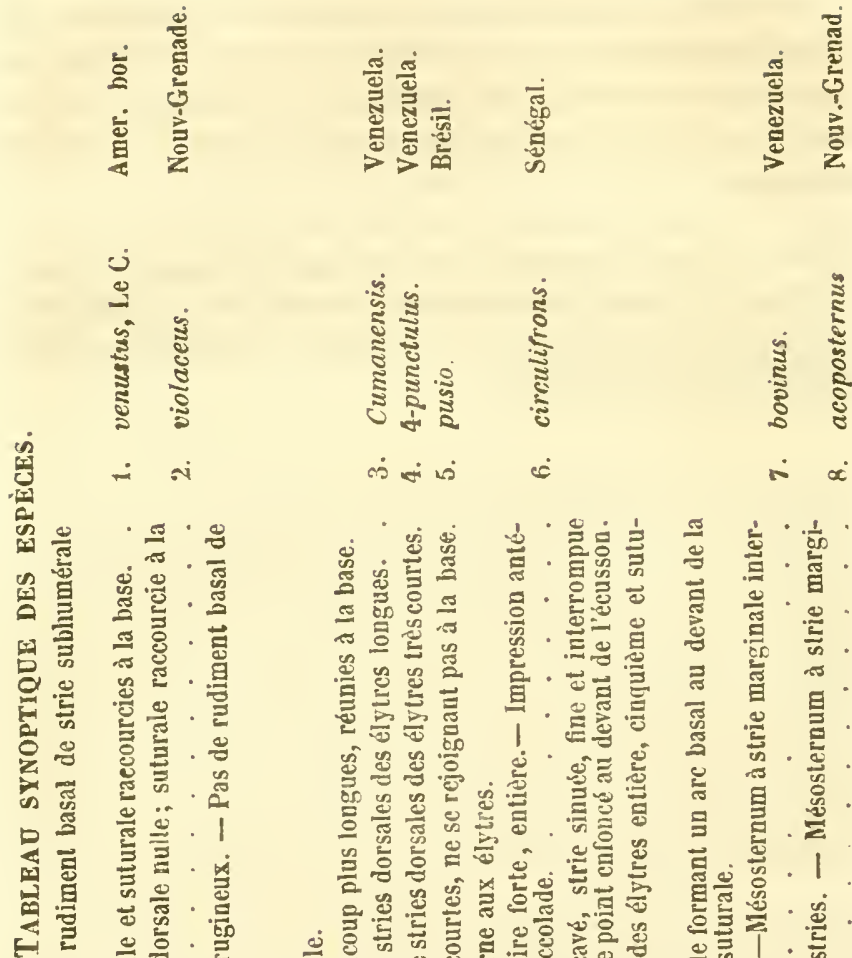

$\dot{-i}$

نे

$\dot{c}$

$\therefore \quad x$

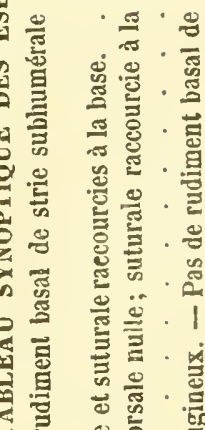

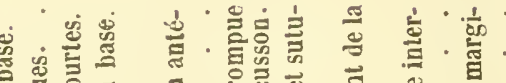
ธ

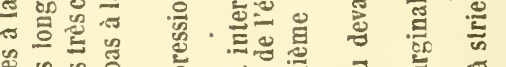

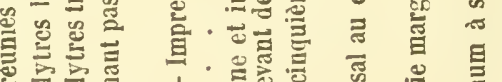

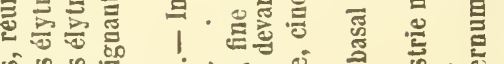

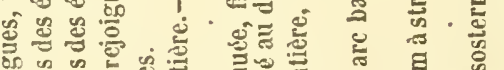

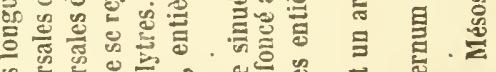

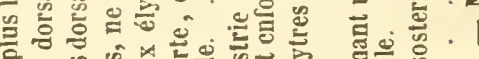
․ ङ क्ष 1

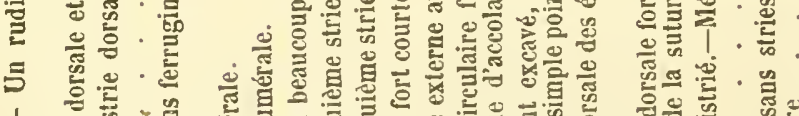

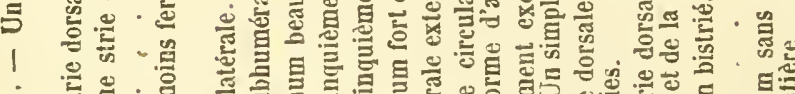

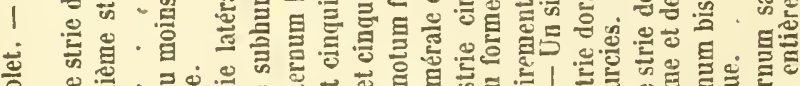
\%

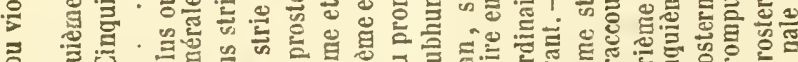

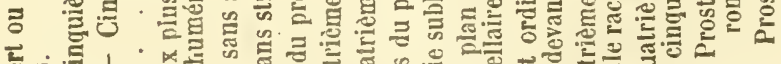

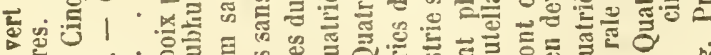
। $\dot{0}$.

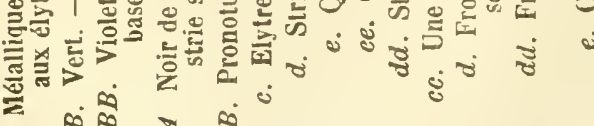




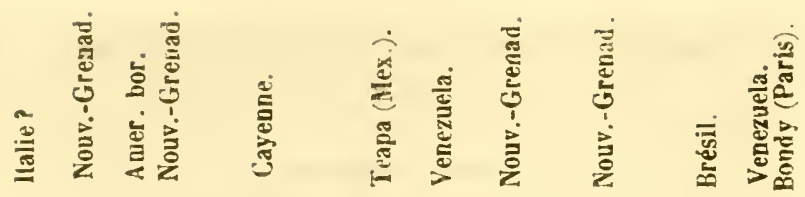

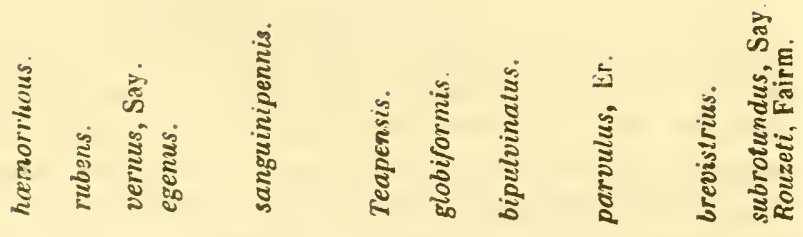

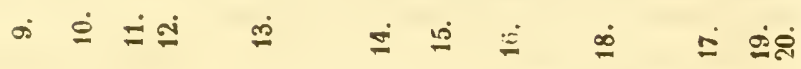

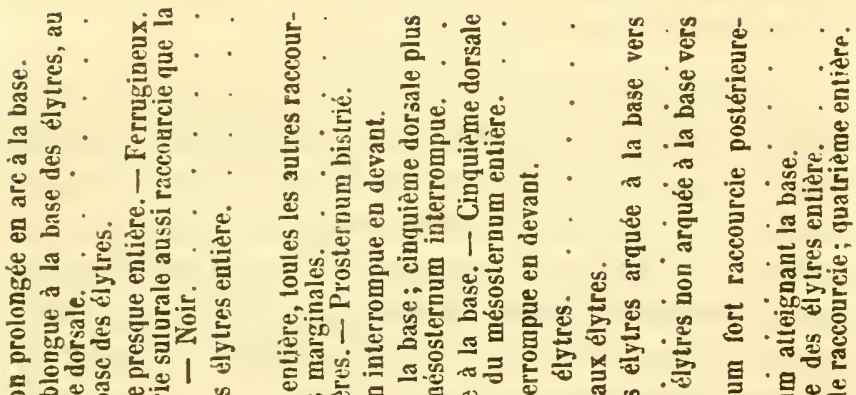

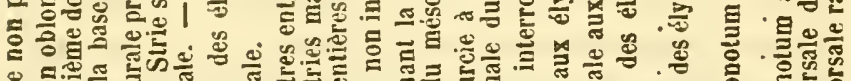

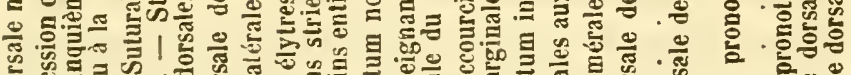

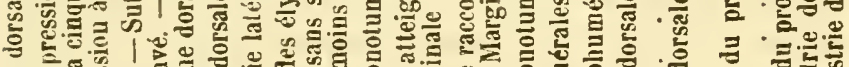

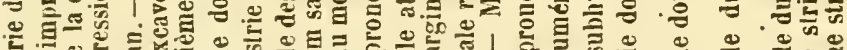
以

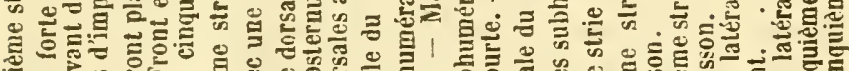
屯

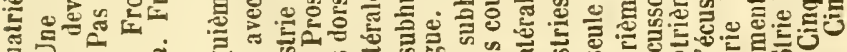

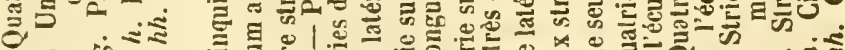

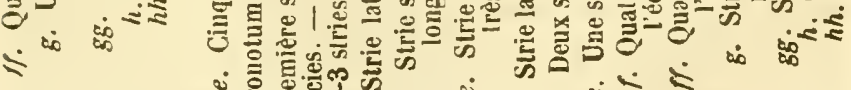
\& si $\dot{0} 0$ 
A. Métallique. - Rudiment basal de strie subhumérale aux élytres (1-2).

\section{P. venostus.}

Breviter ovulis, parum convexus, viridi-caruleus, nitens; antemnis pedibusque rufo-brunneis; fronte concava, "grosse el parce punctata, stria simuata integra; pronoto lateribus parce punctato, impresso, stria marginali integra; elytris apice punctatis; striis 4 primis dorsalibus integris, $5^{\text {a }}$ et suturali antice abbrevialis, subhumerali bascos; mesosterno stria marginali intcrrupta. Long. 3 mill.; larg. 2 mill.

Platysoma venustum, Le Conte, N. Aner. Hister. 56, 6 (1845). - New Sp. Calif. col. 39.

Ovale arrondi, peu convexe, d'un vert-bleuâtre métallique, luisant. Tête couverte de gros points épars peu nombreux; front concave, relevé au-dessus des yeux, entouré d'une strie semi-circulaire, profonde, non interrompue, qui le sépare de l'épislome. Antennes brunes; funicule ferrugineux. Pronotum court, beaucoup plus large que long, arqué à la base, avec un point antéscutellaire, arrondi sur les côtés, échancré et rétréci en devant, avec les angles abaissés, obtus, lisse au milieu, assez fortement ponctué sur les côtés, avec unc impression oblongue qui les fait paraître relevés ; strie marginale entière. Ecusson petit, triangulaire. Elytres légèrement convexes, plus longues que le pronotum, de sa largeur à la base, dilatées sur les côtés, rétrécies, ponctuées et coupées droit au bout; repli latéral fortement bistrié; stries fortes, crẻnelées, dorsales raccourcies un peu à l'extrémité, cinquième interrompue à la base, suturale raccourcie au tiers antéricur; subhumérale interne réduite à un court rudiment basal. Propygidium et pygidium 
assez fortement, nais peu densément ponctués. Dessous du corps noir. Prosternum bistrié, assez large, court, sinué à la base, avec un lobe antérieur court, à peine infléchi. Mésosternum bisinué en avant, bordé d'une strie interrompue au milieu, traversé par un arc crénelé. Pattes d'un brun-ferrugineux; jambes antéricures quadri-dentées; intermédiaires garnies de deux épines; postérieures d'une seule apicale.

Amérique boréale, dans les provinces méridionales (Caroline, Géorgie), sous l'écorce des arbres; très rare.

\section{P. VIOLACEUS.}

Breviter ovatus, parum convexus, violaccus, nitidus; pedibus antennisque brunneis; fronte excavata, punctata, stria semicirculuri integra; mronoto latcribus clevatis, punctatis, stria marginali integra; elytris striis postice abbreviatis, dorsalibus 4 primis antice integris, $4^{a}$ arcuata, $5^{a}$ mulla; suturali antice abbreviata, subhumerali basali; mesosterno stria marginali integra. Long. 2 1/2 mill.; larg, 1 2/3 mill.

Ovale court, peu convexe, d'un violet luisant. Tête ponctuée; front concave, avec les angles oculaires élevés, séparé de l'épistome par une strie scmi-circulaire, entière, moins marquée au fond de l'excavation; antennes brunes, massue plus roussâtre. Pronotum court, transversal, légèrement bisinué à la base, arrondi sur les côtés, échancré en devant, avec les angles abaissés, obtus, ponctué sur les cotés, avec une impression longeant le bord latéral, ce qui le fait paraître relevé; strie marginale entière. Ecusson petit, triangulaire. Elytres plus longues que le pronotum, de sa largeur à la base, dilatées latéralement, rétrécies et 
coupées droit au bord apical, entièrement lisses, avec de gros points épars ; stries fortes, crénelées, s’avançant seulement jusqu'à cette ponctuation, quatre premières dorsales entières, quatrième recourbée à la base, cinquième nulle, suturale raccourcie, cependant on trouve un point basal audessus de ces deux dernières; subhumérale interne courte, basale, externe nulle; repli latéral fortement bistrié. Propygidium ponctué; pygidium finement pointillé. Prosternum assez large, bistrié, sinué à la base, muni d'un lobe antérieur court, infléchi ; mésosternum bisinué en devant, bordé d'une strie entière, traversé d'une strie arquée, crénelée. Pattes brun-roussâtre; jambes antérieures quadri-dentées; intermédiaires munies de deux épines, postérieures mutiques.

Nouvelle-Grenade.

$A A$. Noir de poix. - Pas de rudiment hasal de strie suhhumérale $(3-20)$.

B. Pronotum sans strie latérale (3-12).

C. Elytres sans strie subhumérale (3-5).

\section{P. Cumaneisis.}

subglobosus, convexus, piceus, nitidus, subtilissime punctulatus; fronte concava, stria interntpta; pronoto lateribus punctato, stria marginali integra; elytris striis crenatis, dorsalibus 4 primis integris, 5a valde abbreviata puncto basali ancta, suturali tantum basi; prosterno striis postice coёuntibus; mesosterno stria marginali integra. Long. 212 mill.; larg. $11 / 2$ mill.

Sphérique, convexe, d'un noir de poix luisant, tinement pointillé. Front concave, avec une strie fine, largement 
interrompue; antennes rougeatres. Pronotum beaucoup plus large que long, arqué à la base, avec une bordure de points et une fossette anté-scutellaire, légèrement arrondi et ponctué sur les côlés, rétréci et échancré en devant, avec les angles abaissés, obtus; strie marginale entière. Leusson petit, triangulaire. Elytres un peu plus longues que le pronotum, de sa largeur à la base, curvilinéairement dilatées sur les cotés, légèrement rétrécies et coupées droit au bout; stries fortes, crénelées; quatre premières dorsales entières, cinquième fort raccourcie, arec un point basal; suturale plus longue, subhumérales nulles; repli latéral bistrié. Prosternum étroit, allongé, avec un lobe antérieur étroit, et deux stries fortes, rapprochées, réunies; échancré à la base. Mésosternum bisinué en devant, bordé d'une strie entière. Pygidium couvert, ainsi que le propygidium, de gros points espacés. Pattes d'un rouge-brun; jambes antérieures peu dilatées, armées de cinq dents; postérieures garnies de quelques épines.

Cumana (Venezuela). (M. de Laferté.)

\section{P QUADRI-PUNCTULUS.}

Sphericus, convexiusculus, puncticulatus, piceus, nitidus; antennis pedibusque rufis; fronte impressa stria late interrupta; pronoto lateribus punctalo, stria marginali integra; clytris striis dorsalibus 1-3 integris, 4-5̃ puncto basali auctis et suturali abbreviatis; prosterno striis postice junctis; mesostemo stria integra. Long. 3 mill.; larg. 2 mill.

Sphérique, assez convexe, d'un noir de poix luisant, finement pointillé. Front concave, strie fine, Jargement interrompue; antennes rousses. Pronotum court, arqué à la base, avec un point anté-scutellaire, courbé et bordé de 
points espacés sur les côtés, fortement rétréci et échancré en devant, avec les angles abaissés médiocrement aigus. Ecusson petit, triangulaire. Elytres un peu plus longues que le pronotum, de sa largeur à la base, arrondies sur les côtés et droites au bord apical; repli latéral fortement sillonné; strie subhumérale nulle, humérale oblique, très fine; dorsales 1-3 entières, 4-5 apicales marquées d'un point chacune à la base ; suturale raccourcic en devant, se rapprochant peu à peu de la suture postérieurement. Propygidium couvert de points espacés, ainsi que le pygidium. Prosternum assez saillant, rétréci, bordé de stries réunies à la base, avec un lobe antérieur étroit, à peine creusé. Mésosternum très faiblement bisinué, avec les deux stries distantes, entières, droites. Pattes rouge-brun; jambes antérieures garnies de cinq dents; postérieures de quelques soies fines.

Caracas (Venezuela).

\section{I. I'ESTO.}

Rotundatus, convexiusculus, puncticulatus, piccus, nitidus ; antennis pedibusque rufis; fronte concava, stria semi-circulari

- interrupla; pronoto latcribus punctato, stria marginali intcgura; ante scutellum impresso; elytris striis dor'salibus 3

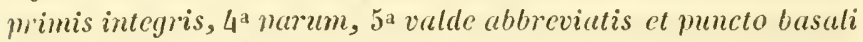
anctis, suturali $4^{\text {ac }}$ cequali; mygidio parce munctulato; mosterno breviter bistriato. Long. 3 mill.; larg. 2 mill.

Suborbiculaire, assez convexe, d'un noir de poix luisant, finement pointillé sur toute sa surface, avec une ponctuation peu serréc et visible sur les côtés du pronotum et sur le propygidium et le pygidium. Front concave au milieu et relevé au-dessus de l'insertion des antennes; strie semicirculaire interrompue à peine au milieu, entre le front et 
l'épistome; antennes brunes, massue rousse. Pronotum beaucoup plus large que long, arqué à la base, avec une impression anté-scutellaire, légèrement arrondi sur les côtés, échancré et fortement rétréci en devant, avec les angles abaissés, obtus; strie marginale entière. Ecusson petit, triangulaire. Elytres un peu plus longues que le pronotum, de sa largeur à la base, curvilinéairement dilatées sur les côtés, très rétrécies, coupées droit et rougeâtres au bord apical; repli latéral fortement sillonné; stries fortes, bien marquées, crénelées ; subliumérales nulles ; trois premières dorsales entières, quatrième raccourcie, ainsi que la suturale, dans le premier tiers; cinquième courte, apicale, surmontées chacune d'un point basal. Prosternum court, sinué à la base, muni d'un lobe antérieur assez étroit, sans ligne de démarcation, avec deux stries courtes. Mésosternum court, transversal, bisinué et entièrement rebordé en devant, traversé d'une strie anguleuse au milieu. Pattes d'un rouge-brun; jambes antérieures à cinq dentelures; intermédiaires garnies de cinq épines; postérieures de trois.

Bahia (Brésil). (M. de Laferté.)

CC. Elytres avec une strie subhumérale (6-12).

\section{P. circulifrons.}

Suborbicularis, convexus, nigro-piceus, nitidus; antennis pedibusque brunneis; fronte planu, stria semi-circulari integra; pronoto stria marginali integra, versus latera punctato, ante scutellum rugose impresso; clytris striis 3 primis dorsulibus integris, $4^{\mathrm{a}} 5^{\mathrm{a}} q u e$ apricalibus, muncto busali auctis, suturali subhumcralique parum abbreviatis; prostemo lato bistriato; tibiis posticis biseriatim spinosis. long. 3 1/2 mill.; larg. 21/2 mill. 
Suborbiculaire, convexe, d'un noir de poix luisant. Front plan, pointillé, ceint d'une strie bien marquée, semi-circulaire, non interrompue; antennes brunes. Pronotum plus large que long, arqué à la base, avec une impression sigmoïde, rugueuse au devant de l'écusson, arrondi sur les côtés, rétréci et échancré en devant, avec les angles abaissés, obtus; fincment pointillé, avec des points plus gros latéralement; strie marginale entière. Ecusson petit, triangulaire. Elytres une fois et demie plus longues que le pronotum, de sa largeur à la base, curvilinéairement dilatées sur les côtés, plus étroites et coupées droit au bord apical, à peine visiblement pointillées; repli latéral bisillonné; stries bien marquées, ponctuées; trois premières dorsales entières, quatrième et cinquième très courtes, apicales, chacune avec une impression bașale, l'une oblique, l'autre arquée, transversale; suturale et subhumérale externe raccourcies aux deux tiers. Propygidium et pygidium densément pointillés. Prosternuin large, court, bistrié, échancré à la base; mésosternum bistrié et bordé entièrement en devant, limité du côté du mésosternum par une strie transversale presque droite. Pattes rougeâtres; jambes postérieures garnies d'un double rang d'épines.

$$
\text { Sénẻgal (M. de Laferté). }
$$

\section{P. Bovinus.}

Suborbicularis, convexus, piceus, nitidus, punctulatus; antennis pedibusque rufis; fronte concava, stria interrupta; pronoto lateribus punctato, stria marginali integra; elytris margine inflexo sulcato, stria subhumerali dislocata, dorsalibus 1-4 integris, 4a antice arcuata, 5a apicali, suturali abbreviata; propygidio parce, pygidio temiter punctatis; prosterno lato bistriato; mesostemo stria interrupta. Long. 2 mill.; larg. 1 1/2 mill. 
Orbiculaire, assez convexe, d'un noir de poix luisant, finement pointillé. Front fortement excavé et saillant au devant des yeux; strie largement interrompue; antennes rouge-brun. Pronotum assez court, arqué à la base, avec un point anté-scutellaire, courbé et ponctué sur les côtés, rétréci et fortement échancré en devant, avec les angles abaissés, assez marqués; strie marginale entière. Ecusson petit, triangulaire. Elytres un peu plus Iongues que le pronotum, de sa largeur à la base, courbées sur les cotés, droites au bord apical; repli latéral profondément sillonné; strie subhumérale assez longue, décomposée, humérale fue, oblique; dorsales fortes, crénelées, quatre premières entières, quatrième terminée en arc vers l'écusson, cinquième très courte, apicale; suturale un peu raccourcie. Propygidium couvert d'assez gros points espacés. Pygidium plus finement ponctué. Prosternum large, bistrié, lobe étroit, court, arrondi en devant. Mésosternum bordé en devant d'une strie interrompue, postérieurement d'une entière, arquée. Pattes rouge-brun; jambes antérieures garnies de six ou sept denticules; postérieures de quelques soies.

Caracas (Venezuela), dans les bouses; avril.

\section{P. Acoposternes.}

Suborbicutaris, convexiusculus, nigro-piceus, nitidus; antennis pedibusque rufo-brumeis, punctulatns; fronte concava, stria late interrupla; pronoto lateribus punctuto, stria marginali integra; clytris striis 4 primis dorsalibus intcgris, $4^{a}$ arcuatubusi, כ̆a, suturati et subhumerali abbreviatis; prosterno lato haul striato. Long. $21 / 2$ mill.; larg. 1 1/2 mill.

Suborbiculaire, assez convexe, d'un noir de poix luisant, 
pointille sur toute sa surface. Front légèrement concave; strie semi-circulaire cessant au niveau de l'insertion des antennes sans se fermer entre l'épistome et le front; antennes brun-rouge. Pronotum plus large que long, arqué à la base, avec une bordure de gros points et une impression anté-scutellaire, arrondi et ponctué sur les côtés, rétréci et échancré en devant, arec les angles abaissés, obtus; strie marginale entière. Ecusson petit, triangulaire. Elytres plus longues que le pronotum, de sa largeur à la base, curvilinéairement dilatées sur les côtés, rétrécies et coupées droit au bord apical; repli latéral sillonné; stries fortes, crénelées, quatre premières dorsales entières, quatrième recourbée en arc à la base vers l'écusson, cinquième raccourcie au milieu, suturale et subliumérale externe un peu au-delà. Prosternum plan, assez large, sinué à la base, plus étroit en devant, sans stries; lobe antéricur étroit, à peine concave. Mésosternum bistrié et complètement rebordé en devant, traversé par une strie créneléc, presque droite. Pattes roussâtres; jambes antérieures garnies de cinq dents; intermédiaircs de cinq épines; postérieures de deux.

Carthagène (Nouvelle-Grenade).

\section{P. henorkious.}

Ovalis, subconvexus, brunneus, postice, antennis pedibusque ferrugineus, nilidus, puncticulatus; fronte concava, stria late interrupta; pronoto lateribus punctato, stria marginali integra; elytris margine inflexo sulcato, striis crenatis, dorsalibus 4 primis integris, $5^{2}$, suturali subhumeralique abbrevialis, fovcola basali; propygidio punctato; prosterno bistriato. Long. 3 mill.; larg. 1 1/2 mill.

Ovale, assez convexe, d'un hrun de poix, passaut an rouge 
postérieurement, luisant, finement pointillé sur toute sa surface, et de plus couvert de gros points dans l'intervalle, sur les côtés du pronotum et sur le propygidium. Front peu profondément concave, strie semi-circulaire, cessant à l'angle interne des yeux; antennes rougc-brun, massue testacée. Pronotum plus large que long, arqué à la base et bordé de points, avec une fossette anté-scutellaire, légèrement arrondi sur les cotés, rétréci et échancré en devant, avec les angles obtus et abaissés; strie marginale entiére. Ecusson petit, triangulaire. Elytres une fois et demie plus longues que le pronotum, de sa largeur à la base, curvilinéairement dilatées sur les côtés, rétrécies et coupées droit au bord apical; repli latéral sillonné; stries fortes, crénelées; quatre premières dorsales entières, cinquième raccourcie aux deux tiers antérieurs, un peu plus que la suturale, avec un petit point basal caché dans une inpression oblongue placée au devant de ces deux stries; subhumérale externe assez courtc. Prosternum étroit, allongé, sinué à la base, bistrié, plus étroit au milieu, terminé par un lobe antérieur légèrement infléchi ; mésosternum bisinué et entièrement rebordé en devant, traversé par une strie un peu sinueuse. Pattes rouge-brun; jambes antérieures munies de sept denticules; intermédiaires de cinq épines ; postéricures de trois.

M. Dupont m'a vendu cet insecte comme venant d'Italie ; n’est-ce pas une indication erronée?

\section{P. RUBENS.}

Suborbicularis, convexiusculus, rufo-ferrugincus, nitidus, fronte plana, stria utrinque arcuata, nec in medio juncta; pronoto latcribus punctato. stria marginali integra: clytris 
striis crenatis, 4 primis dorsalibus integris, $5^{\mathrm{a}}$ in medio abbre. viata puncto basali auctu, suturali subhumeralique vix abbreviatis; prosterno bistriato, angustato; tibiis posticis biseriatim spinulosis. Long. 2 1/2 mill.; larg. 1 1/2 mill.

Ovale, assez convexe, d'un rouge-ferrugineux luisant, à peine visiblement pointillé. Front plan, strie arquée de chaque côté, ne se joignant pas derrière l'épistome. Pronotum beaucoup plus large que long, arqué à la base, avec un point anté-scutellaire, arrondi sur les côtés, rétréci et échancré en devant, avec les angles abaissés, obtus; strie marginale entière. Ecusson petit, triangulaire. Elytres une fois et demie plus longues que le pronotum, de sa largeur à la base, curvilinéairement dilatées sur les côtés, rétrécies et coupées droit au bord apical; repli latéral sillonné; stries profondes, crénelées; quatre premières dorsales entières, cinquième raccourcie au milieu, réunie avec la quatrième postérieurement, et surmontée d'un fort point basal; suturale rapprochée de la suture vers l'extrémité, et á peu près continuée jusqu'à la base; subhumérale remontant jusqu'à l'épaule. Prosternum allongé, étroit, bistrié, muni d'un lobe antérieur étroit, ponctué, à peine échancré et dilaté à la base. Mésosternum à peine bisinué et rebordé antérieurement, séparé du métasternum par une strie droite transversale. Jambes antérieures garnies de denticules nombreux; postérieures de deux rangs de soies peu serrées.

Carthagène (Nouvelle-Grenade). (M. de Lalierté.)

\section{PERNIS.}

Suborbicularis, convexiusculus, nigro-piceus, nitidus; antennis pedibusque rufo-brunneis; fronte concava, stria semicirculari late interrupta; monoto dense punctulato lateribus 
punctis sparsis, stria marginali integra; elytris striis validis crenulatis, dorsalibus 1 primis integris, $5^{2}$, suturali et subhumerali antice abbreviatis; prostcrno bistriato, mesostcrno bimarginato. Long. 2 mill.; larg. 1 1/2 mill.

Hister vermus, Say. Soc. Phil. v, 40,11 (1825). - Le Conte. N. Amer. Hist. 30,28, T. 4, f. 3 .

Suborbiculaire, médiocrement convexe, d'un noir de poix luisant. Front fincment pointillé, avec une concavité peu profonle; strie semi-circulaire s'arrêtant de chaque côté à l'angle antérieur des yeux sans traverser entre le front et l'épistome; antennes brunes, massue fauve. Pronotum court, beaucoup plus large que long, arqué à la base, avec une bordure de gros points et une impression anté-scutellaire; légèrement arrondi sur les côtés, rétréci ct échancré en devant, avec les angles obtus, abaissés ; densément pointillé arec des points espacés, latéraux; strie marginale fine, entière. Ecusson petit, triangulaire. Elytres plus longues que le pronotum, de sa largeur à la base, curvilinćairement dilatées sur les côtés, rétrécics et coupées droit au bout; repli latéral sillonné; stries bien marquées, crénelées: quatre premières dorsales entières, cinquième raccourcie un peu au-delà du milieu, avec un petit point basal, suturale et subhumérale externe à peu près de la même longueur. Propygidium ponctué et finement pointillé dans les intervalles, ainsi que le pygidium. Prosternum assez long, étroit, un peu échancré à la basc, avec deux stries rapprochées ell devant, muni d'un lobe antérieur étroit; mésosternum bisinué et rebordé el devant, traversé par unc strie presque droite. Pattes d'un rouge-brun; jambes antérieures garnies de six dentelures; internédiaires de six épines, et postérieures de deux. 
Cetle espèce est assez répandue dans les Etats-Unis, surtout dans les provinces méridionales; comme la NouvelleOrléans, où elle a été recueillie abondamment dans les bouses, au mois de février.

\section{P. Egenus.}

Ovalis, parum convexus, niger, nitidus, antennis, pedibus, elytris postice pygidioque rufis; fronte puncticulata, concava, stria late intorrupla; pronoto lateribus punctalo, stria marginuli integra; clytris striis cremulatis, dorsatibus integris, suturali parum subhumcralique valde ubbreviatis; prosteruo bistriato. Long. 2 1/4 mill.; larg. 1 1/2 mill.

Ovale, peu convexe, d'un noir luisant. Front pointillé, légèrement concave au milieu, avec les angles oculaires relevés, strie largement interrompue; antennes brun-rouge. Pronotum beaucoup plus large que long, arqué à la base, avec un point anté-scutellaire, légèrement arrondi sur les côtés, rétréci et échancré en devant, avec les angles abaissés, obtus; finement pointillé sur toute sa surface, et peu densément ponctué sur les bords latéraux; strie marginale entière. Ecusson petit, triangulaire. Elytres une fois et demie plus longues que le pronotum, de sa largeur à la base, curvilinéaires sur les côtés, légèrement rétrécies au bout, fincment pointillées, rouges à l'angle postérieur externe; repli latéral sillonné; stries assez fortes, crénelées, dorsales entières, suturale à peine raccourcie à la base, subhumérale beaucoup plus courte, apicale. Propygidium et pygidium rouges, finement pointillés, avec quelques points plus gros. Prosternum étroit, bistrié, sinué à la base, muni en devant d'un lobe infléchi, court. Mésosternum bisinué, hordé d'une double strie transversale. Pattes rouge-brun; 
jambes antérieures 6-denticulécs; postérieures garnies de petites épines.

Carthagène (Nouvelle-Grenade); Caracas (Venczuela), dans les bouses, au mois de janvier.

B. Pronotum avec une strie latérale (13-20).

\section{P. SANGUINIPEINIS.}

Ovalis, parum convexns, niger, nitidus ; elytris, antennis: pedibusque rufis; fronte excavata, stria valde recurva interrupta; pronoto stria laterali antice haud ambiente; elytri: stria dorsali $1^{\text {a }}$ integra, cateris abbreviatis; prosterno absqu. striis; propygidio bifoveolato pygidloque grosse punctatis. Long. 4 mill. larg. 2 1/2 mill.

Ovale, peu convexe, d'un noir lisse et luisant, avec les élytres, les pattes et les antennes rouges. Tête finement pointillée, profondément excavée, strie frontale recourbée très loin sur le vertex, interrompue à l'angle rentrant. Pronotum court, arqué à la base, ainsi que sur les côtés, avec un! point anté-scutellaire, bisinueusement échancré en devant. avec les angles abaissés obtus; finement pointillé, avec un petit groupe de points latéraux; strie marginale fine, entière . s'éloignant un peu plus de la marge à l'échancrure; latérale forte, cessant à l'angle antérieur. Ecusson petit, triangulaire. Elytres un peu plus longues que le pronotum, de si largeur à la base, arquées sur les côtés, rétrécies et coupées droit au bord apical, ponctuées; une seule marginale fine; humérale à peine visible; subhumérale courte; premièr dorsale entière, 2-4 fort raccourcies ; cinquième et suturalc un peu moins. Propygidium bifovéolé, fortement ponetuci, ainsi que le pyogidium. Prosternum fort élargi à la basc, 
sans stries ; mésosternum bordé d'une seule strie non interrompue. Jambes antérieures garnies de quatre à cinq denticules; postérieures de deux rangées de spinules.

Cayenne.

\section{P. Teapensis.}

Ovalis, subconvexus, brunneus, nitidus, puncticulatus; fronte planiuscula stria integra antice recta; pronoto lateribus punctato, stria marginali interrupta, laterali integra; elytris margine inflexo bisulcato, stria subhumerali et 1-4 clorsalibus integris, $5^{a}$ et suturali abbreviatis; mesosterno stria antica. interrupta, postica arcuata, valde approximatis. Long. 3 mill.; larg. 2 mill.

Ovale, assez peu convexe, brun, luisant, finement pointillé. Front à peu près plan, strie entière, bien marquée et droite au devant de l'épistome ; antennes brunes. Pronotum court, arqué à la base, avec un point profond, anté-scutellaire, ponctué et courbé seulement en devant sur les côtés, échancré en devant, avec les angles abaissés, bien marqués : strie marginale fine, interrompue; latérale forte, entière. Ecusson petit, triangulaire. Elytres une fois et demie plus longues que le pronotum, de sa largeur à la base, dilatées à l'épaule, droites au bord apical; repli latéral bisillonné; stries fortes, crénelées, subhumérale et $\mathbf{1 - 4}$ dorsales entières; cinquième et suturale un peu raccourcies. Propygidium couvert de points espacés, ainsi que le pygidium. Prosternum assez étroit et allongé, bistrié, sinué à la base, muni d'un lobe antérieur assez infléchi. Mésosternum bordé antérieurement d'une strie interrompue, et traversé par une autre entière, arquée, fort rapprochée au milieu. Jambes antérieures assez dilatées, quadri-dentées; postérieures garnies de soies assez rares.

Téapa (Mexique) (M. Pilate). 
15. P. GLOBHORHIS.

Suborbicularis, globosus, brunneo-piceus, nitidus; untenni. pedibusque rufis, puncticulatus; fronte concava, stria interrupta; pronoto lateribus parce punctato, stria marginali lat: interrupta, laterali integra; clytris striis crenatis, 4 primis dorsalibus integris, $5^{\mathrm{a}}$ apicali brevi, linea basali aucta, suturali et subhumerali abbreviatis; prosterno bistriato; mesosterno sinuatim bimarginato. Long. 2 1/4 mill.; larg. 1 3/4 mill.

Suborbiculaire, globuleux, d'un brun de poix luisant. Tête finement pointillée ; front concave, strie semi-circulaire interrompue au milieu, distinguant le front de l'épistome : antennes rousses, massue plus claire. Pronotum plus large que long, arqué à la base, avec une fossette anté-scutellaire et une bordure de points, arrondi sur les côtés, rétréci et échancré en devant, avec les angles abaissés et obtus ; finement pointillé, avec quelques gros points latéraux; strie marginale fine, ne dépassant pas les yeux; latérale forte, non interrompue en devant. Ecusson petit, triangulaire. Elytres une fois et demie plus longues que le pronotum, de sa largeur à la base, curvilinéairement dilatées sur les côtés, rétrécies et coupées droit au bord apical, très bombées, plus finement pointillées encore que le pronotum; repli latéral sillonné; stries bien marquées, ponctuées; quatre premières dorsales entières, cinquième courte, apicale, avec un arc transversal à la base ; suturale beaucoup plus longue, raccourcie d'un tiers; subhumérale assez longue. Pygidium pointillé, avec quelques gros points, ainsi que le propygidium. Prosternum assez long, bistrié, élargi et sinué à la base; mésosternum bisinué en devant, traversé par deux lignes sinuées et assez rapprochées. Pattes rougeâtres ; jambes antérieures munies de six denticules; intermédiaires 
de cinq ou six petites épines, et d'un deusième rang de plus petites encore.

Caracas (Venezuela), région froide, dans les détritus, en mai.

\section{P. Biplevinatus.}

Suborbicularis, sat convexus, nigro-picens, nitidus; antennis pedibusque rufo-brunneis, dense punctulatus; fronte leviter. concuva, stria semi-circulari interrupta; pronolo utrinque fovcolato, stria marginati integra, laterali interrupta ; elytris striis crenatis, 1-4 dorsalibus integris, 4a basi arcuatu, $5^{\text {a }}$, suturali et subhumerali utraque antice abbreviatis; mosterno striis approximatis; mesosterno bistriato. Long. $23 / 4$ mill.; larg. 2 mill.

Suborbiculaire, assez convexe sur les élytres, avec lit suture déprimée, d'un noir de poix luisant, finement et densément pointillé. Front légèrement concave, ceint d'une strie semi-circulaire, interrompue au milieu, et par lá distinct de l'épistome; antennes d'un brun-ferrugineux. Pronotum court, beaucoup plus large que long, arqué à la base. avec une bordure de points et une fossette anté-scutellaire, légèrement arrondi sur les côtés, rétréci et échancré en devant, avec les angles abaissés, obtus et marqués d'une légère impression; strie marginale fine, entière ; strie latérale forte, se terminant en arc à l'angle antérieur. Ecusson petit, triangulaire. Elytres une fois et demie plus longues que le pronotum, de sa largeur à la base, curvilinéairement dilatées sur les côtés, rétrécies et coupées droit au boụt, légèrement bombées en dessus, avec la suture dépriniée; repli latéral sillonné; stries fortes, bien marquées, crénelées; quatre premières dlorsales entières, quatrième arquée à la base, accompagnée d'un point à gauche; cinquième. sutu- 
rale, subhumérales interne et externe raccourcies un peu à la base. Prosternum étroit, échancré à la base, muni d'un lobe étroit, bien distinct, sillonné de deux stries longues, parallèles, rapprochées. Mésosternum transversal, bisinué en devant et rebordé entièrement, traversé d'une strie postérieure presque droite. Pattes d'un rouge-brun; jambes antérieures 6-denticulées; postérieures garnies de quelques épines.

Nouvelle-Grenade.

\section{P. BREVISTHIUS.}

Rotundatus, convexiusculus, piceus, nitidus, puncticulatus ; antermis pedibusque rufis; fronte concava, stria interrupta; monoto lateribus punctuto, stria marginali integra, laterali brevissima; elytris margine inflexo sulcato, striis 1-3 integris, 1.5 muncto basali auctis, suturali et sublumerali abbreviatis; mosterno bistriuto; mesosterno transversis 2 striis integris. Long. $23 / 4$ mill.; larg. 1 4/5 mill.

? Hister prmilus, Er. Jahrb. 155, 74 (1834).

Arrondi, assez convexe, noir de poix luisant, finement et densément pointillé sur toute sa surface. Antennes rousses. Front excavé, strie sinuée, entière. Pronotum court, arrondi ì la base arec un point anté-scutellaire; courbé sur les côtés, arec quelques points espacés, rétréci et échancré en devant, avec les angles abaissés, obtus; strie latérale fine, entière, rapprochée du bord latéral, un peu plus éloignée de l'antérieur; latérale réduite à un petit arc dans l'angle. Ecusson petit, triangulaire. Elytres plus longues que le pronotum, de sa largeur à la base, curvilinéaires sur les côtés, rétrécies et droites au bord apical; repli latéral fortement sillonné; stries fortes, crénelées, 1-3 dorsales entières, 4-5 avec chacunc un point basal, racrourcies, l'une an milieu, ainsi que 
la subhumérale et la suturale, l'autre bien avant. Propygidium couvert de points gros, espacés; pygidium pointillé. Prosternum assez large, bistrié, lobe peu distinct, presque droit. Mésosternum bisinué, rebordé entièrement, traversé par une strie forte, crénelée, arquée. Pattes roussas ; jambes antérieures garnies de cinq denticules; postérieures de quelques soies fines.

Brésil.

Je suis porté à croirc que cette espèce n'est autre chose que l'Hister pumilus d'Erichson, quoique cet auteur dise que celui-ci manque de strie latérale; cette strie est ici en effet si rudimentaire, qu'il est difficile de la voir à la simple loupe. Mais dans la crainte d'attribuer faussement le nom de pumilus à cette espèce, je lui ai donné un autre nom, qui rappelle son caractère tout particulier.

\section{P. Parvulus.}

Breviter ovatus, sat convexus, puncticulatus, nigro-piceus, nitidus; antennis pedibusque rufis; fronte concava, stria integra; pronoto lateribus punctato, stria marginali integra, laterali interrupta, postice abbreviata; elytris margine inflexo sulcato, striis crenatis, 1-4 dorsalibus integris, $4^{\mathrm{a}}$ versus scutellum arcuata, $5^{\mathrm{a}}$, suturali sublumeralique abbreviatis. Long. 2 1/4 mill.; larg. 1 1/2 mill.

Hister parvulus, Er. Jahrb. 156, 75 (1834).

En ovale court, assez convexe, d'un noir de poix luisant, très finement pointillé. Front légèrement concave, stric semi-circulairc, entière, sinuée derrière l'épistome; antennes rouge-brun. Pronotum court, arqué à la base, avec un point anté-scutellaire, arrondi et ponctué sur les côtés, rétréci et échancré en devant, avec les angles abaissés, 
obtus; strie marginale fine, entière; latérale bien marquée, raccourcie à la base, arquée à l'angle antérieur et interrompue. Ecusson petit, triangulaire. Elytres une fois et demie plus longues que le pronotum, de sa largeur à la base, dilatées curvilinéairement sur les côtés, rétrécies et coupées droit au bord apical; repli latéral fortement sillonné; stries bien marquées, fortes, crénelées; 1-4 dorsales distantes, entières, quatrième arquée vers l'écusson à la base; cinquième apicale, fort courte, suturale et subhumérale externe raccourcies vers la base. Propygidium ponctué et finement pointillé dans l'intervalle, ainsi que le pygidium. Prosternum assez long, avec deux stries sinuées, échancré à la base, muni en devant d'un lobe assez étroit, bien distinct; mésosternum bisinué et entièrement rebordé, traversé par une strie sinuée. Pattes rougeâtres; jambes antérieures garnies de cinq dents; postérieures de trois petites épines.

Nouvelle-Grenade.

\section{P. Subrotundus.}

Ovalis, parum convexus, piceus, nitidus, subtilissime punctulatus; antennis pedibusque rufis; fronte leviter excavata, stria interrupta; pronoto basi et versus latera punctato, stria marginali integra, laterali interrupta, antice arcuata; elytris striis dorsalibus integris, suturali et subhumerali abbreviatis. Long. $14 / 5$ mill.; larg. 4/5 mill.

Hister subrotundus, Say. Soc. Phil. v, 39, 10 (1825). - Le Conte, N. Amer. Hist. 30, 27, T. 4, f. 2.

Ovale, médiocrement convexe, d'un noir de poix luisant. Tête finement pointillée; front avec une légère excavation, strie semi-circulaire, interrompue au milieu entre le front et l'épistome; antennes rougeâtres. Pronotum court, plus 
large que long, arqué à la base, avec un point anté-scutellaire, arrondi latéralement, échancré el rétréci en devant, très finement pointillé, avec des points épars, bien marqués sur les côtés; strie marginale fine, entière; latérale plus forte, arquée à l'angle antérieur et interrompue. Ecusson petit, triangulaire. Elytres une fois et demie plus longues que le pronotum, de sa largeur à la base, légèrement dilatées sur les côtés, rétrécies au bout, plus on moins rouges; repli latéral sillonné; stries bien marquées, crénelées; 1-5 dorsales entières; suturale raccourcie vers la base, subhumérale externe courte, apicale. Pygidium pointillé; propygidium ponctué. Prosternum assez allongé, échancré à la base, avec denx stries rapprochées en devant, lobe antérieur distinet, infléchi; mésosternum bisinué et rebordé en devant, traversé d'une strie droite. Pattes rougeâtres; jambes antérieures garnies de six denticules; postérieures de six ou sept épines.

Rtats-Unis ; Nouvelle-Grenarle; Venezuela; dans le's housts.

\section{P. ROIZETI.}

Breviter ovatus, parume convexus, nitidus, nigro-piceus; clytris, antennis pedibusque rufis; fronte leviter concuva, stria interrupta; pronoto lateribus parce munctulo, stria marginati integra temi, laterali antice arcuata, interrupta; elytris striis 1-4 dorsalibus integris, $5^{\text {a }}$, sumrali et subhumerali abbreviatis. L̇ong. $13 / 4$ nill.; larg. 1 1/5 mill.

Paromalus Rouzeti, Fairm. Soc. Ent. (1849) 421.

Ovale court, peu convexe, luisant, d'un noir de poix, avec les élytres rouges en grande parlie. Front légèrement concare, distinct de lépistome par une strie semi-circulaire interrompue; antennes hrunes, massue testacéc. Pronotum 
court, plus large que long, arqué à la base, avec de gros points et une fossette anté-scutellaire, légèrement arrondi sur les côtés, échancré et rétréci en devant, avee les angles abaissés obtus; couvert latéralement de points, très espacés; strie marginale fine, entière; latérale bien marquée, terminée en are à l'angle antérieur. Ecusson petit, triangulaire. Elytres une fois et demie plus longues que le pronotum, de sa largeur à la base, curvilinéairement dilatées sur les côtés, rétrécies et coupées droit au bord apical; stries bien marquées, 1-4 dorsales entières, einquième avee un petit point basal, raccourcic en arant, ainsi que la suturale et la subhumérale. Pygidium pointillé. Prosternum bistrié, échancré ì la base, plus étroit en levant, et bien distinct du lobe antérieur; mésosternum bisinué en devant et rebordé, traversé d'une deuxième stric presque droite. Pattes d'un rouge-ferrugineus; jambes antérieures denticulées; postérieures épineuses.

Un individu de cette espèce a été trouvé à Boudy, près de Paris, dans une fourmillière, par M, Rouzet (M. Fairmaire).

\section{SPHYRACUS.}

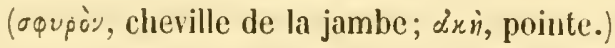

Soc. Ent. 3̊ série, T. 1 (1853), pl. 14. - Mon. pl. 5. Genre XIV.

Corpus glohosum.

Capue retractum, rotundatum; fronte clypeoque concavis, stria interjecta; mandibulis requalibus, dentatis.

Antemuse sub fromlis margine inserte, scapo contorto, funiculi arliculo primo longiori, clava ovali arliculis angmlatim reserlis, foreulis sub proborecis amgulo deectis. 
Pr: notum striu laterali integra; elytris 4-5 striatis.

Prostermum bistriatum, basi sinuatum, lobo brevi rotundato marginato; mesosternum marginatum, bisinuatum.

Tibice antice extus apicali unco et denticulis armate, foveola tarsali parum profunda, postica biseriatim spinosulce.

Propygidium declive, hexagonum; pygidium semi-ellipticum valde inflexum.

Corps ovale, plus ou moins bombé en dessus, noir luisant. Tête (f. 1 b) arrondie, médiocre, s'enfonçant dans le prothorax; front concave, ainsi que l'épistome, avancé en pointe obtuse, élevée au-dessus de l'insertion des antennes, entouré d'une strie circulaire, sinuée en devant; labre court, légèrement sinué au bout; yeux déprimés, semilunaires; mandibules assez saillantes, arquées, uni-dentées en dedans, terminées en pointe aiguë.

Antennes (f. $1 d$ ) insérées sous un rebord du front entre les mandibules et les yeux; scape tordu, épaissi au milieu, logé dans une faible coulisse; funicule de sept articles, premier obconique, plus long, les autres à peu près d'égale longueur, croissant successivement en diamètre; massue ovalaire, allongée, comprimée, velue, de quatre articles taillés anguleusement. Fossettes antennaires assez profondes, arrondies, dans l'angle même du prothorax, audessus du bord pectoral, non entaillé pour le passage de l'antenne.

Máchoires (f. $1 c$ ) à deux lobes cornés, barbus en dedans, premier plus long que le deuxième; palpes maxillaires de quatre articles, deuxième obconique, troisième beaucoup plus court, eylindrique, quatrième ovalaire, plus long que 
les deux autres. Menton corné, presque carré, sinué en devant; lèvre peu suillante; paraglosses membraneuses, ciliées en dedans, arquées. Palpes labiaux de trois articles, deuxième obconìue, troisième ovalaire, à peu près d'égale longueur.

Pronotum arrondi a la base, avec une légère impression anté-scutellaire, oblique sur les côtés, puis subitement coudé en dedans, avec l'angle même aigu et abaissé; fortement échancré en arc antérieurement; strie marginale fine, rapprochée du bord, terminée en devant au niveau des yeux; latérale forte, éloignée du bord à l'angle antérieur et rejoignant celle du côté opposé. Pièce humérale à peine visible en dessus. Ecusson petit, triangulaire. Elytres bombées, plus longues que le pronotum, de sa largeur à la base, courbées sur les côtés, rétrécies et droites au bord apical; repli latéral strié, sans fossette humérale; une demi-strie subhumérale, une humerale oblique, très fine, et quelques dorsales. Prosternum assez élevé, plan en dessous, légèrement sinué à la base, bistrié, muni d'un lobe arrondi et rebordé en devant, très distinct. Mésosternum court, transversal, légèrement bisinué en devant, bordé d'une strie entière dans tout son pourtour.

Pattes assez allongées; cuisses comprimées, creusées en dedans d'une coulisse pour loger les jambes, et bordées d'un sillon; jambes en triangle très allongé, terminées par deux épines inégales, obliques; antérieures (f.1 $e$ ) sans dent à l'origine de l'arête interne, dentées en dehors, avec une avance terminale, séparée, fort longue; fossette tarsale bien marquée, limitée seulement en dedans; postérieures (f.1f) garnies d'un double rang d'épines. Tarses de cinq articles triangulaires, à peu près égaux, quatre premiers garnis au bout 
de longues soies, cinquième portant deux courts crochets.

Abdomen de cinq articles : premier segment ventral bistrié, fort long, les autres fort courts, très serrés, et en partic invisibles au milieu. Propygidium hexagonal, fort penché. Pygidium ogival, infléchi.

J'ai cru devoir former ce genre pour une jolie espèce de Caracas (Venezuela), dont le facies est celui d'un petit Omalodes, et dont les vrais caractères sont ceux des Phelister. Elle a du premier le pronotum et les élytres, avec leurs stries, l'abdomen, tout en un mot, excepté les jambes et la base du pronotum. Comme dans le deuxième, le prosternum est bistrié, le mésosternum bisinué en devant, avec une faible pointe au milieu répondant à l'échancrure du prosternum; bordé d'une strie entière; le front est concave, séparí de l'épistome par une strie sinueuse. Nais il s'en distingue par la massue des antennes dont les articles sont coupés angulairement, par une strie latérale du pronotum entière, par les jambes postérieures garnies de deux rangées d'épines, et surtout par la forme des antéricures terminées en dehors par une longue avance, distante des autres dents. Cette disposition remarquable m'a fait lui adjoindre une autre espèce de Bolivie, quoiqu'elle en diffère un peu par le lobe du prosternum. Les mœurs et métamorpłsoses de ce genre sont entièrement inconnues.

\section{S. OMALONELLUS.}

Ovalis, converus, niger, nitidus; fronte stria integra; pronoto tavi; clytris margine inflexo 1-striato, stiiis dorsalibus 1-3 tenuibus, cuteris nullis; propygidio pygidioque punctatis; pros. terno striis ablmeviatis, lobo convexo; tihiis anticis ante apierm livilmatis. Jong. $/$ mill.: larg. $91 / 2$ mill. 
Ovale, assez hombé, nuir luisant. Front concave, stric frontale entic̀re, avec un angle rentrant au milieu; antennes brunes, massue grise, velue. Pronotum arrondi à la base, avec un point anté-scutellaire, oblique sur les côtés, rétréci et échancré en devant, avec les angles assez marqués et abaissés; strie marginale fine, rapprochée du bord, terminée derrièe les yeux; latérale forte, assez peu distante du bord latéral, arquée et éloignée à l'angle antérieur, et se continuant en devant sans interruption. Ecusson petit, triangulaire. Elytres plus longues que le pronotum, de sa largeur à la base, courbées sur les cotés, rétrécies et droites au bord apical, bombées au milieu; repli latéral lisse, sans fossette a l'épaule, 1-sillonné, strie humérale oblique, très fine; une subhumérale remontant jusłu’d l'épaule; dorsales fines; 1-2 entières, troisième raccourcie par derrière, les autres nulles, ainsi que la suturale. Prop̣gidium abaissé, ponctué, ainsi que le pygidium, fortement infléchi. Prosternum à deux stries raccourcies, lobe bombć. Jambes antérieures armées avant l'avance apicale de deux dents seulement.

Cette espèce, qui a les plus grands rapports avec certains Onialodes pour la forme et la disposition des stries, a été découverte à Caracas (Venezuela) par M. Sallé.

\section{S. UNCIPbS.}

Ovatus, subcomrexus, niger, nitidus, antennis pedibusque brunneis; fronte concuva, stria sinuata, integra; pronoto lateribus punctato, stria marginali intormupla, laterali distanti, valida, integra; chytris striis dorsalibus 1-3 integris, $4^{a}$, suturali et subhumerali abbrevialis; propygidio mygidioque punctatis; tibiis anticis ante apicem 3-dentatis. Long. 4 mill.; larg. $21 / 2$ mill.

Orale, assez convex', noir luisant. Front concave, forte- 
ment relevé sur les yeux; strie entière, bisinuée en devant ; antennes brunes, massue grise. Pronotum court, arqué à la base, avec un point anté-scutellaire, arrondi sur les côtés, avec de gros points espacés en dedans des stries, rétréci et fortement échancré en devant, avec les angles aigus et abaissés ; strie marginale fine, rapprochée du bord, cessant derrière les yeux; latérale forte, distante, sans interruption. Ecusson petit, triangulaire. Elytres beaucoup plus longues que le pronotum, de sa largeur à la base, bombées, abaissées le long de la suture, à peine courbées sur les côtés, rétrécies et droites au bord apical ; repli latéral bistrié; strie humérale fine, oblique; subhumèrale courte,1-3 dorsales entières, quatrième fort courte, cinquième nulle; suturale remontant jusqu'au milieu, mais ne partant pas tout à fait du bout. Propygidium couvert de points ocellés, peu serrés. Pygidium plus densément ponctué. Prosternum entièrement bistrié, lobe court, infléchi, arrondi au bout. Pattes brunes; jambes antérieures garnies avant la pointe apicale de trois ou quatre dents aiguës.

Bolivie.

\section{RHYPOCHARES.}

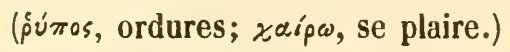

Soc. Ent. $3^{e}$ série, T. 1 (1853), pl. 16. - Mon. pl. 7. Genre XV, fig. 1.

Hister. Erich. Jahrb. (1834).

Corpus convexum, ceneo-nigrum, puncticulatum

Caput rolundum, retractum; fronte plana, stria clypro interjecta; mandibulis cequalibus. 
Autenna sub frontis margine insorlte, cluva ovata, recle resecta, foveolis sub angulo prothoracis delectis.

Pronotum stria marginali; elytra 3 vel \& obsulete striata.

frosicrnum basi rolundatum, haud striatum, lobo brevi; mesosternum emarginatum, striı integra.

Tibice antice dentalte, postice biseriatim spinosula, fovea tarsali obsoleta.

Propygidium hexagonum; pygidium trigonum, convexodeclivia.

Corps ovale, convexe, noir métallique luisant, densément pointillé en dessus.

Tête médiocre, arrondie, pouvant s'enloncer dans le prothorax : front plan, entouré d'une strie bien marquée, formant en devant un angle rentrant; épistome court, trapézoïdal, sinué en devant; labre petit, échancré; mandibules courbées, aiguës, avec une dent obsolète; yeux ovalaires, peu saillants.

Antennes (f. 1 b) insérées sous un rebord du front entre les yeux et les mandibules; scape long, coudé, épaissi au bout, logé dans une coulisse du dessous de la tête; funicule de sept articles élargis progressivement, premier et deuxième obconiques, plus longs, les autres égaux; massue ovale, comprimée, de quatre articles velus, coupés droit. Fossette antennaire arrondie, bien marquée, dans l'angle antérieur même du prothorax; bord pectoral non entaillé pour le passage de l'antenne.

Mâchoires (f. $1 c$ ) insérées en dehors du menton, cornées, à deux lobes barbus en dedaus, externe beaucoup plus long; palpes de quatre articles, premier très petit, deuxième long, obconique, troisième court, cylindrique, quatrième 
ovalaire, deux fois plus long que le précédent. Míenton en trapize court, plus étroit en devant; lèvre menbraneuse; paraglosses ciliées, arrondies; palpes de trois articles, premier petit, leuxième obconique, renllé au bout, et troisième ovalaire, d'égale longueur.

Pronotum court, bombé, arrondi à la base, sinué sur les côtés, fortement rétréci et échancré en devant, avec les angles abaissés, peu aigus; une strie marginale entière, bien marquée. Ecusson triangulaire petit. Pièce humérale invisible en dessus. Elytres courtes, de la largeur du pronotum à la base, dilatées à l'épaule, rétrécies, droites au bord apical; repli latéral sans fossette, avec deux stries assez fines; humérale oblique, peu marquée; subhumérale raccourcie au milieu; dorsales réduites à trois, plus ou moins entières, les autres nulles ou obsolètes. Prosternum assez saillant, sans stries, arrondi à la base, avec un lobe antérieur très court, un peu infléchi, bordé et arrondi en devant; mésosternum sinué en devant pour recevoir la base du prosterıum, bordé d'une strie entière.

Pattes assez minces; cuisses comprimées, creusées en dedans d'une coulisse pour loger les jambes; celles-ci en triangle peu élargi au bout, terminées par deux épines inégales; antérieures fortement dentées sur les côtés, avec une fossette tarsale obsolète; postérieures garnies d'un double rang d'épines; tarses de cinq articles, quatre premiers triangulaires, garnis en dessous de soies; à peu près égaux entre eus; dernier un peu plus long, avec deux crochets.

Abdomen de cing anneaux; premier seginent ventral fort long, bistrié; deusième et troisième courts; quatrième visible seulement sur les cotés. Propygidium en hexagone, 
très court, oblique. Pygidium en triangle curviligne, peu bombé, perpendiculaire.

L'espèce unique de ce genre a été décrite pour la première fois par Erichson (Jahrb. p. 146. 48), sous le nom de Hister saprinoides. Ses couleurs métalliques, la forme et la sculpture des élytres, en effet, lui donnent l'aspect d'un Saprinus. Cette conformation, jointe à la disposition du pronotum et du front, m'ont engagé à la séparer des Hister dont elle n'a en aucune manière le faciès, quoiqu'elle ait le sternum et la fossette antennaire disposés comme dans ce genre. Elle vit dans les ordures. Ses métamorphoses sont inconnues.

\section{R. SAPRINOIDES}

Ovalis, convexus, niger ceneus, nitidus, puncticulatus ; pedibus piceis antennis rufis; fronte plana, stria in medio angulata; pronoto lateribus punctato, stria marginali integra; elytris margine inflexo bistriato subhumerali dimidiat $\iota, 1-3$ dorsalibus plus minusve postice abbreviatis, ceteris sapius nullis; tibiis anticis 4-dentatis, posticis biseriatim spinosulis. Long. 5 mill.; larg. 3 1/2 mill.

Hister saprinoides, Er. Jahrb. 1, 146, 48 (1834).

Ovale, convexe, noir métallique luisant, densément pointillé sur toute sa surface. Front plan, strie entière, formant au milieu un angle rentrant; épistome légèrement impressionué. Antennes rousses. Pronotum arrondi à la base, avec une impression anté-scutellaire, sinué et ponctué sur les côtés, rétréci et éclıancré en devant, avec les angles abaissés, obtus; strie marginale entière, assez marquée. Ecusson petit, triangulaire. Elytres courtes, de la largeur du pronotum à la base; dilatées à l'épaule, rétrécies et droites au bord apical; repli latéral bistrié, sans fossette; strie subhu$3^{\text {e Série, TONe } 1 .}$ 
mérale raccourcie au milieu; dorsales fines, première entière, 2-3 raccourcies plus ou moins par derrière, les autres nulles ou fort obsolètes. Propygidium pointillé, ainsi que le pygidium. Pattes brunes; jambes antérieures armées de quatre dents, les deux dernières fort longues; postérieures garnies de deux rangées d'épines.

Cap de Bonne-Espérance; M. Mocquerys l'a trouvé au Havre, dans de vieilles laines apportées de ce pays.

\section{OMALODES.

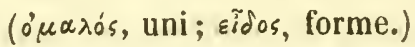

3. série, T. 1 (1853), pl. 15 et 16. - Mon. pl. 6 et 7. Genre XVI, f. 1-30.

Hister. F. Syst. El. (1801). - Payk. Mon. Hist. (1811)

Omalodes. Er. in Jahr. 114, 7 (1834).

Corpus ovalum, crassum.

Caput rolundatum, parvum, retractum; fronte stria circulari, sapius impressa; mandibulis 1-dentatis requalibus.

Antennce sub frontis margine inserte, clava ovali compressa, foveola subprolhoracis angulo profunda.

Prosternum elevalum, basi rotundatum, in mesosterno receptum, lobo subinflexo, longo, anterius rotundato.

Pronotum antice valde angustatum, stria laterali integra margini proxima.

Elytra striis dorsalibus scepius $21 / 2$ levibus, subhumerali externa angulo externo circunducta.

Tibia anticce extus dentate, foveola tarsali distincte exarata, posticce extus uni-seriatim spinose.

Propygidium hexagonum declive; pygidium perpendiculare. 
Lorps ovale, épais, plus ou moins convexe.

Tête (f.1 a et 3 e) petite, très enfoncée dans le prothorax; front ordinairement ceint d'une strie bien marquée, tantot plan, tantot marqué d'une impression profonde; épistome en trapèze, plus ou moins distinct du Pront; labre presque aussi long que large, arrondi au bout. Yeux réniformes. Mandibules fortes, légèrement arquées au bout, et unidentées en dedans.

Antennes (f. $1 d$ ) insérées sous un rebord du front, au devant des yeux; scape épais, contourné, logé dans une coulisse sous la tête; funicule de sept articles serrés : premier obconique, plus long que les suivants, 2-7 comprimés, croissant en largeur; massue suborbiculaire, comprimée, de quatre articles velus et serrés, le dernier à peine sensible. Fossettes antennaires profondes, creusées sous l'angle antérieur du prothorax.

Mâchoires (f. 1c) à deux lobes cornés, garnis en dedans de longs poils serrés; l'interne court, l'externe allongé, atteignant presque l'extrémité du palpe. Palpes maxillaires de quatre articles; premier petit, deuxième obconique, troisième cylindrique, un peu plus court; quatrième ovalaire, aussi long que les deux précédents réunis. Menton (f. 1 b) en trapèze, subsinué à la base, rétréci et échancré en avant; lèvre membraneuse, terminée par une languette courte, conique, et par deux paraglosses allongées, linéaires, ciliées en dedans de longs poils. Palpes labiaux de trois articles: premier court, deuxième obconique, troisième ovalaire, égaux en longueur.

Pronotum transversal, convexe, plus ou mois arrondi à la base, oblique sur les côtés, ordinairement fort rétréci en devant, avecles angles aigus abaissés, et l'échancrure cépliali- 
que profonde. Une strie marginale fine, qui n'est bien visible qu'à l'angle antérieur; une latérale ordinairement entière. Pièce humérale visible en dessus. Ecusson petit, triangulaire. Elytres plus ou moins bombées, élargies à la base, arrondies à l'angle postéro-externe, et coupées obliquement au bout, avec un angle sutural. On y remarque une strie marginale entière, une subhumérale externe s'arrondissant autour de l'angle postérieur, accompagnée parfois d'un rudiment de subhumérale interne; une humérale fine, oblique; quelques dorsales, souvent à peine marquées. Prosternum saillant, ordinairement sans stries, élargi et arrondi à la base, lobe prosternal court, bien distinct et arrondi au bout; cachant toute la bouche; bord pectoral non entaillé pour le passage des antennes. Mésosternum large, court, profondément échancré en devant pour recevoir le prosternum; strie marginale interrompue d'ordinaire à l'échancrure. Métasternum long, avec une strie médiane longitudinale.

Pattes robustes, assez allongées, fort distantes à leur insertion. Cuisses comprinées, assez élargies, avec une coulisse pour loger les jambes, et une strie marginale en dedans. Jambes triangulairement élargies au bout, terminées par deux épines inégales, rebordécs en dedans, avec une seule arête sur le côté externe, qui est armé de dents; antérieures creusćes d'une fossette tarsale bien marquée et nettement limitée de part et d'autre. Tarses courts, à quatre premiers articles triangulaires, comprimés, courts, ciliẻs en dessous; cinquième plus long, avec deux crochets égaux.

Abdomen de cinq anneaux : premier segment ventral grand, bistrié ; quatre suivants très courts, égaux entre eux; antépénultième segment dorsal en partie découvert, avec une carène visible dans l'angle sutural des élytres. Propygi- 
dium hexagonal, oblique; pygidium en triangle curviligne, bombé, vertical.

Ce genre, établi par Erichson dans le Jahrbucher en 1834, sur les Hister angulatus, F.; omega. Kby., et lovigatus, Schh., se compose d'espèces très voisines et difficiles à distinguer les unes des autres, mais d'une forme toute particulière, d'un cachet propre qui les sépare à la première vue de tous les autres genres de la famille. La tête arrondie, s'enfonçant dans le prothorax; le front ordinairement impressionné au milieu, entouré d'une strie circulaire, fermée par derrière, et formant souvent un angle antérieur rentrant; le pronotum rétréci fortement et échancré en devant; bordé d'une petite strie marginale, qui n'est visible qu'd l'angle antérieur, et d'une latérale entière, bien marquée et fort rapprochée du bord; les élytres avec une strie subhumérale externe, arquée autour de l'angle postérieur, et trois dorsales plus ou moins fines et raccourcies, les autres obsolètes ou nulles; le repli latéral sans fossettes à l'épaule et avec une seule strie marginale; le prosternum assez élevé, élargi et arrondi à la base, muni d'un lobe distinct et assez saillant; la fossette des antennes sous l'angle antérieur du prothorax; le mésosternum court, fortement échancré pour recevoir le prosternum, bordé d'une strie interrompue; les jambes antérieures garnies d'une rangée de dents, avec une fossette tarsale bien limitée, et les postérieures avec une seule arête épineuse : tels sont les principaux caractères.

Ils habitent tous les parties chaudes de l'A mérique, depuis le Texas jusqu’à la Plata, excepté l'O. Marquisicus qui paraît appartenir à l'Océanie. Ils vivent dans les bouses, les végétaux en décomposition, quclquefois dans les charognes. Leurs métamorphoses sont inconmues. 
密

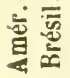

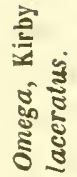

兽

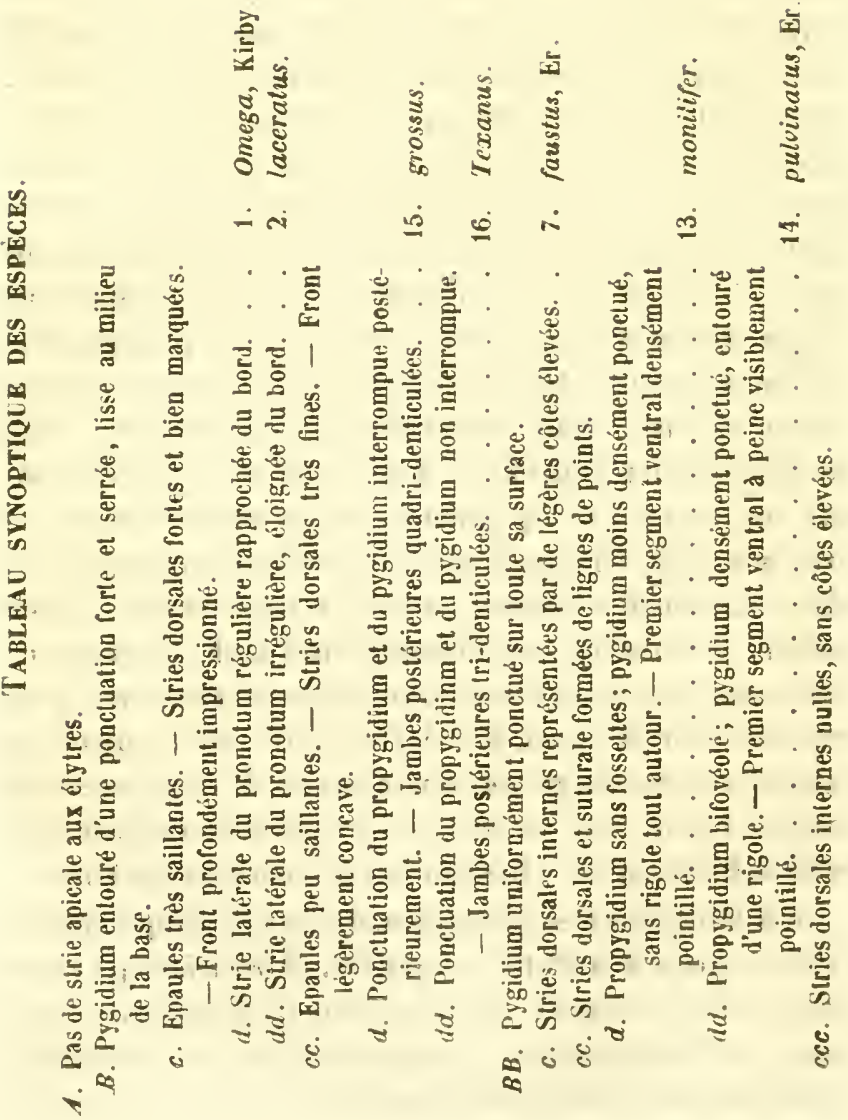

ำ 


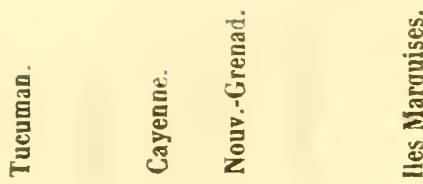

ङัँ

苞

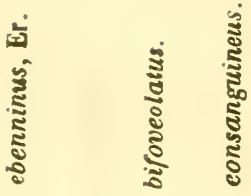

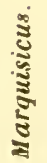

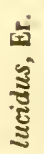

కัँ

ส่

ม่ สิ

$\circ$

in

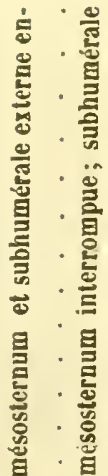

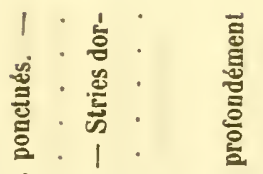

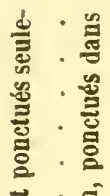

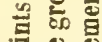

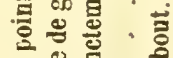

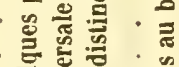

등

.

产䓌: 离: 苛

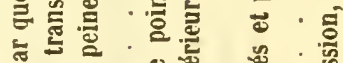

. ฮ

का . क्ष

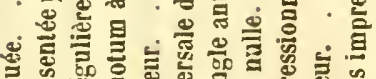

总.

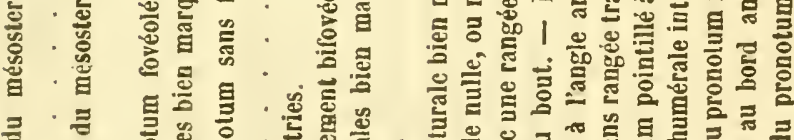

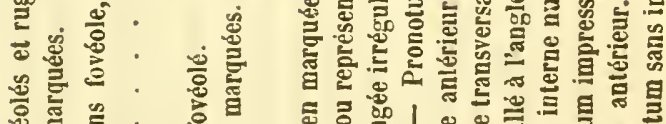

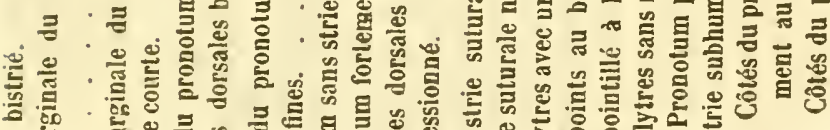

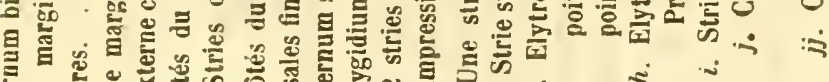

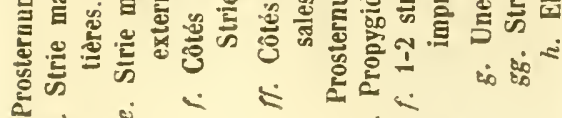
2 
音

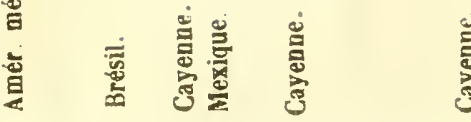

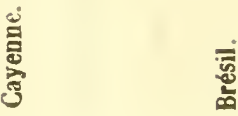

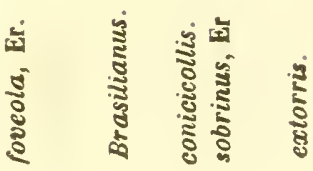

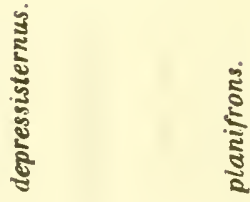

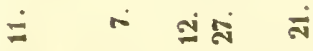

คे

$\frac{5}{2}$

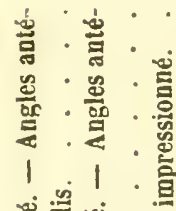

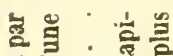

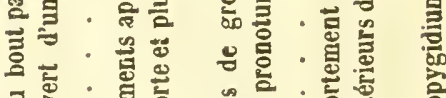

สี

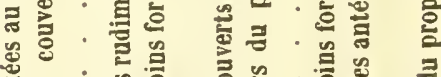

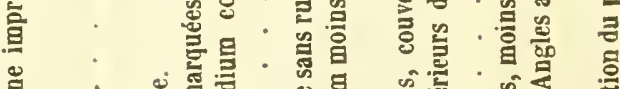
ن

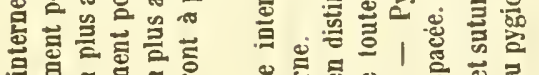

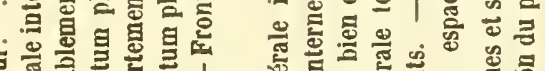

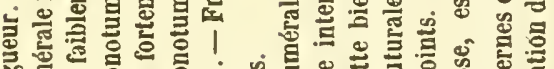

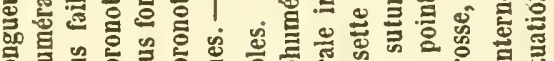

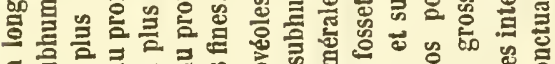

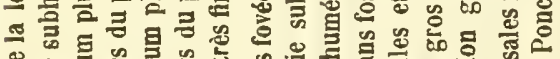

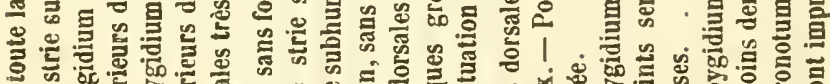

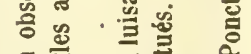

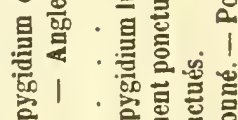

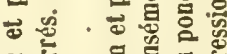

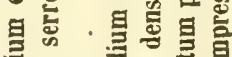

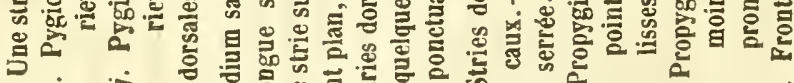

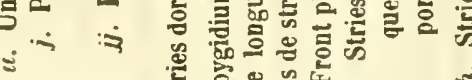

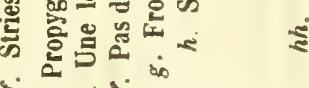

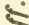
घं $<$ 
XVI. Omalodes.

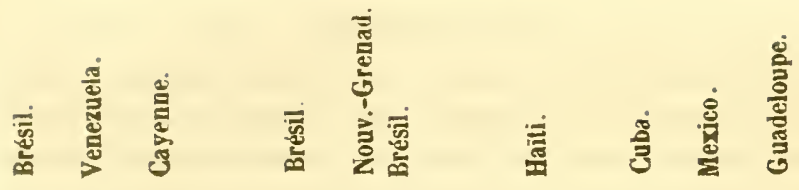

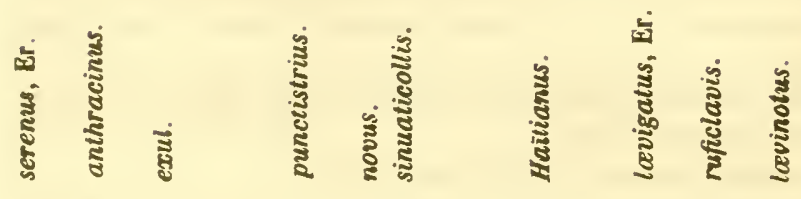

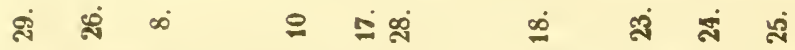

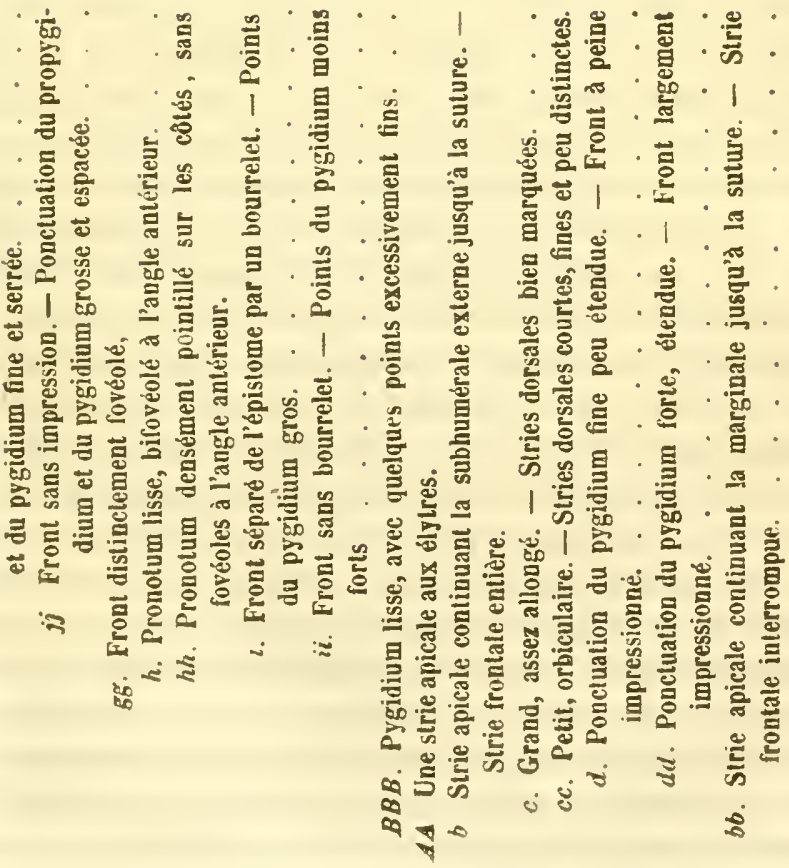




\section{O. OUEGA.}

Ovalis, subquadratus, parum convexus, niger, nitidus; fronte profunde impressa, stria antice retro acuminata, impressione longa; pronoto lateribus usque ad basim punctatis; elytris humeris valde prominulis, sutura depressa, striis $21 / 2$ dorsalibus, subhumerali abbreviata; propygidio pygidioque dense circumpunctatis; tibiis anticis 4-dentatis. Long. 13 mill.; larg. 8 mill.

Hister omega, Kirby. Cent. d'Insect. In Lin. Trans. xi, 394, 26. - Id. Leq. 20, 26 (1817).

Omalodes omega, Erich. in Jahr. 1; 117, 1.

? O. borealis, Le Conte. N. Amer. Hist. 14, 1. T. 1, f. 10. (1845).

Ovale, presque carré, épais, peu convexe en dessus, noir luisant. Tête finement pointillée; front creusć d'un sillon longitudinal profond, ceint d'une strie circulaire, forte, entière, formant un angle aigu rentrant dans le sillon médian ; épistome légèrement concave. Antennes d'un brun de poix, massue grise. Pronotum court; fort large, bisinué à la base, avec une fovéole au devant de l'écusson; très rétréci et échancré en devant, avec les angles aigus et abaissés ; oblique sur les côtés, avec une strie latérale fine, rapprochée du bord, entière, et une bordure de points serrés, rugueux, presque aussi large à la base qu'en devant: Ecusson petit, triangulaire. Elytres une fois et demie plus longues que le pronotum, de sa largeur à la base, dilatées sur les côtés, avec les épaules très saillantes, rétrécies et légèrement arquées au bord apical, formant un petit angle sutural; creusées le long de la suture; première strie dorsale fine, terminée par des points; deuxième entière, forle, recourbée en dedans, creusée dans un sillon bien marqué; troisième faible, raccourcie au milieu; les autres nulles; subhumérale externe ne remontant pas au-delà du tiers postéricur, et ne 
se continuant pas le long du bord apical. Prosternum saus stries; mésosternum à strie marginale interrompue: Frofygidium et pygidium: avec une impression de chaque côté, densément et fortement ponctués dans leur pourtolir. Jambes antérieures armées. de quatre dents; intermédiaires: de cinq épines; postérieures de quatre, la. dernière-kifide.

Brésil, sous les pierres, dans les bouses un peu vicilles, pendant la sécheresse.

\section{O. LACERATUS.}

Ovalis, parum convexus, niger, nitidus, clava rufo-brunnea; fronce in medio longitudinaliter profunde excavata, stria valida antice retro acuminala, clypeo subimpresso; pronoto lateribus rugoso, stria laterali irregulari a margine distanti; elytris humero prominulo, $1_{\mathrm{a}}$ dorsati integra, tenui; $2^{\mathrm{a}}$ forti basi abbreviata, $3^{\text {a }}$ postice in medio; propygitlio bifoveolato, pygidioque dense et fortiter punctatis antice lavibus; libiis anticis 4-dentatis. Long. 9 mill.; larg. 6 1/2 mill.

Ovale, peu convexe en dessus, noir, luisant. Tête finement pointillée; front convexe, creusé dans son milieu d'un profond sillon longitudinal ; strie circulaire forte, entière, formant en devant un angle rentrant aigu dans le sillon; épistome légèrement impressionné. Antennes d'un noir de poix, massue d'un rouge-brun. Pronotum court, très large et bisinué à la base, avec un point anté-scutellaire, légèrement arqué sur les côtés, très rétréci et échancré en devant; avec les angles aigus; rugueusement ponctué le long des côtés; strie latérale irrégulière, éloignée du bord, non interrompue. Ecusson petit, triangulaire. Elytres une fois et demie plus longues qus le pronotum, de sa largeur à la base, dilatécs sur les côtés, avec l'épaule saillante, rétrécies 
postérieurement, creusées dans le sens de la suture; strie subhumérale courte; première dorsale obsolète, ponctuée postérieurement; deuxième forte, arquée en dedans, au fond d'une impression, l'une et l'autre entières; troisième raccourcie au milieu. Propygidium bifovéolé, fortement et densément ponctué, presque lisse au milieu dı bord antérieur. Pygidium ponctué encore plus fortement, avec le milieu de la base lisse. Prosternum lisse, sans stries. Mésosternum à strie marginale interrompue. Jambes antérieures armées de quatre dents, l'apicale bifide; intermédiaires de cinq, et postérieures de trois épines.

Cette espèce a les plus grands rapports avec l'O. omega, cependant elle a les épaules un peu moins saillantes, la suture moins enfoncée, le propygidium bifovéolé, et un nombre d'épines différent aux jambes postérieures; la structure de la strie latérale du pronotum pourrait être une anomalie individuelle. Je n'ai vu qu'un seul exemplaire provenant du Brésil (M. Chevrolat).

\section{O. ANgulatis.}

Ovatus subconvexus, niger, nitidus, clava brunnea; fronte convexa in medio sulco longitudinali profundo exarata, stria que circulari haud retrorsum acuminata, clypeo subimpresso; pronoto lateribus antice punctato impressoque; elytris pulvinatis circumque impressis, humeris prominulis, stria $1^{\text {a }} 2^{a} q u e$ dorsali integris, $3^{\mathrm{a}}$ abbreviata ; propygidio bifoveolato, circum, pygidioque toto punctatis; tibiis anticis 4-dentatis. Long. 9 mill.; larg. $61 / 2$ mill.

Hister angulatus, F. S. El. 1, 85, 8 (1801). - Payk. Mon. Hist. 42,30, t. 4, f. 4 ,

Omalodes angulatus, Er. in Jahr. 1, 118, 3, (1834). 
Ovale, assez convexe, d'un noir luisant. T'ete densément pointillée; front convexe, creusé d'un sillon profond dans sa longueur, et ceint d'une forte strie, sans angle rentrant; épistome légèrement impressionné. Antennes noires, massue brune. Pronotum court, fort large et bisinué à la base, avec un point anté-scutellaire, légèrement arqué sur les côtés, très rétréci et échancré en devant, avec les angles aigus, abaissés, impressionnés et une bordure de points très courte; strie latérale entière, rapprochée du bord. Ecusson petit, triangulaire. Elytres une fois et demie plus longues que le pronotum, de sa largeur à la base, rétrécies postérieurement, bombées et entourées d'une impression distincte, avec les épaules assez saillantes; strie subhumérale courte, première et deuxième dorsales entières, bien marquées, troisième fue, raccourcie au milieu. Propygidiun ponctué dans son pourtour, peu densément, mais assez fortement, presque lisse dans son milieu, bifovéolé au bout, souvent impressionné entre les deux fossettes. Pygidium bombé, couvert entièrement de points forts et peu espacés. Prosternum large, sans stries. Mésosternum court, à strie marginale interrompue. Jambes antérieures quadri-dentées; intermédiaires garnies de cinq, et postérieures de quatre épines.

Brésil, Guyane (Cayenne).

Paykull, dont je n'ai pas vu le type, a sans doute confondu plusieurs espèces sous ce nom.

\section{0 . Lucidus.}

Ovatus, convexus, niger, nitidus, antennis piceis; fronte punctulata in medio sulcata, stria circulari haud retrorsum angulata; pronoto tateribus vix punctulato; elytris humeris parum 
prominulis, sutura convexa, striis 3 primis dorsulibus tenuissimis postice obsoletis, punctis 5 ante apicem transversis; propygidio bifoveoluto pygidioque parce et fortiter punctatis; tibiis anticis 4-dentatis. Long. 8 mill.; larg. 7 mill.

Omalodes lucidus, Er. in Jahr. 1. 120, 4 (1834).

Ovale court, convexe, d'un noir luisant. Tête densément pointillée; front convexe, creusé au milieu d'un sillon assez profond; strie circulaire sans angle rentrant; épistome légèrement impressionné. Antennes brunes. Pronotum court, très large et bisinué à la base, légèrement arqué sur les côtés, échancré et fort rétréci en devant, avec les angles aigus; étroitement rebordé de points peu marqués jusqu'aux deux tiers postérieurs; strie latérale forte, entière. Ecusson petit, triangulaire. Elytres une fois et demie plus longues que le pronotum, de sa largeur à la base, fortement dilatées sur les côtés, rétrécies au bout; épaules d̀ peine marquées, suture plane; strie subhumérale courte ; première et deuxième dorsales fines, obsolètes postérieurement; troisième encore plus fine et plus courte, avec une rangée transversale, irrégulière de cinq ou six gros points, un peu avant le bord apical. Propygidium peu densément. surtout au milieu et assez fortement ponctué, avec deux fossettes peu profondes. Pygidium bombé, un peu plus densément et aussi fortement ponctué, creusé dans son pourtour. Prosternum déprimé et densément pointillé. Mésosternum très court, avec des points sur les côtés et la strie marginale interrompue. Jambes antérieures quadri-dentées ; intermédiaires garnies de quatre épines; postérieures de trois.

Brésil (Bahia et Para).

\section{O. BifOVEOLATUS.}

Ovatus, subconvexus, niger, nitidus ; fronte punctuluta profunde sulcala, stria circulari profunda, clypeo separato; 
pronoto lateribus dense et late munctuto, utrinque foveolato; elytris humero prominulo, stria 1a dorsali integra, 2a basi . parum, 3 a in medio abbreviatis, sutura subdepressa; mropygidio bifoveolato grosse et parce, in medio mrcesertim, pygidioque punctatis; prosterno bistriato, mesosterno lateribus punctulalo; tibiis anticis 4-dentatis. Long. 9 mill.; larg. 7 mill.

Ovale oblong, peu convexe, noir, luisant. Tete densément pointillée; front convexe, creusé au milieu d'un sillon profond, longitudinal, qui passe sur le rebord élevé qui l'entoure; strie circulaire profonde, sans angle aigu rentrant; épistome bombé, bien séparé du front. Antennes noir de poix, massue brune. Pronotum court, bisinué et fort large à la base, avec un point antẻ-scutellaire, droit sur les côtés, arrondi sur ses angles, avec une bordure entière assezlarge de points serrés, presque rugueux, etun fort point au milieu ; très rétréci et échancré en devant; strie marginale entière, rapprochée du bord. Ecusson petit, triangulaire. Elytres plus longues que le pronotum, de sa largeur à la base, fortement dilatées et assez saillantes à l'épaule, rétrécies au bout, déprimées sur la suture; strie subhumérale atteignant presque le milieu; première dorsale entière, deuxième raccourcie à la base, bien marquées; troisième fine, raccourcie au milieu; quelques gros points apicaux entre la deuxième et la suture. Propygidium bifovéolé, fortement ponctué, mais peu densément, surtout au milieu. Pygidium bombé, couvert de gros points espacés. Prosternum pointillé, bistrié. Mésosternum ponctué sur les côtés, avec une strie marginale interrompue. Jambes antérieures quadridentées; intermédiaires garnies de quatre épines; postérieures de trois.

Guyane (Cayenne) 


\section{O. MarQuisicus.}

Ovatus, convexiusculus, niger, nitidus; antemis brunneis; fronte profunde et late sulcata, stria circulari antice retrorsum haud acuminata; pronoto lateribus punctulato; elytris striis 2 primis dorsalibus integris, $3^{\mathrm{a}}$ antice suluralique postice dimidiatis; propygidio bifoveolato pygidioque margine elevato, punctatis; tibiis anticis 4-dentatis. Long. 8 mill.; larg. 6 mill.

Ovale, légèrement convexe, noir luisant. Front convexe, avec un sillon médian longitudinal, profond, entier, élargi en devant et pointillé; strie circulaire complète, profonde et forte, sans angle aigu rentrant; antennes brunes, massue roussatre. Pronotum court, beaucoup plus large que long, légèrement bisinué à la base, avec un point anté-scutellaire, un peu arqué sur les côtés, largement échancré et rétréci en devant, avec les angles abaissés et aigus; strie latérale forte, bien marquée, entière, avec un petit espace ponctué aux angles antérieurs. Ecusson petit, triangulaire. Elytres une fois un quart plus longues que le pronotum, un peu plus larges à la base, dilatées sur les côtés, rétrécies et presque droites au bord apical, formant un petit angle sutural; épaules saillantes, suture élevée; strie subhumérale forte, raccourcie en devant et ne se continuant pas au bout; première dorsale entière, bien marquée; deuxième un peu raccourcie à la base, plus forte, surtout par derrière, où elle est dans un enfoncement; troisième obsolète, raccourcie au milieu, avec quelques points apicaux; suturale bien marquée dans la moitié postérieure. Propygidium bifovéolé, couvert de points peu serrés, surtout au milieu; pygidium ponctué de la même façon, mais un peu plus densément, presque plan, avec le rebord légèrement relevé. Prosternum 
sans stries. Mésosternum avec une strie interrompue. Jambes antérieures armées de quatre dents très petites; intermédiaires garnies de six épines; postérieures de quatre.

Cette espèce est établie sur un seul individu de la collection de M. Feisthamel, indiqué comme provenant des îles Marquises.

\section{O. Brasiliants.}

Breviter ovatus, convexiusculus, niger, nitidus; fronte media profunde sulcata, stria circulari valida integra, retrorsum haud acuminata; pronoto lateribus punctato; clytris mulvinutis circiterque depressis, humeris prominulis; striis 2 subhumeralibus abbreviatis, dorsalibus 2 primis integris, 3a postice abbreviata; propygidio bifovcolato parce, pygidio sat dense punctatis; tibiis anticis 4 -dentatis. Long. 8 mill.; larg. 6 mill.

Ovale arrondi, assez convese, noir, luisant. Front convexe, pointillé, parcouru dans toute sa longueur par un fort sillon médian; strie circulaire forte, entière, sans angle antérieur rentrant ; épistome bombé, plus visiblement pointillé. Antennes brun de poix, massue ferrugineuse. Pronotum court, très large et bisinué à la base, avec un point anté-scutellaire; subsinué et bordé de points sur les côtés ; fortement rétréci et échancré en devant, avec les angles aigus, abaissés et impressionnés; strie latérale bien marquée, entière. Ecusson petit, triangulaire. Elytres une fois un quart plus longues que le pronotum, de sa largeur à la base, dilatées sur les côtés, avec l'épaule saillante, rétrécies et presque droites au bord apical, avec un angle sutural peu profond; bombées au milieu, la partic convexe entourée par une espèce de fossé très distinct, qui passe sur les stries dorsales en dedans de

$3^{\circ}$ Série, tome I. 
l'épaule et sur la suture, et longe le bord apical; strie subhumérale externe raccourcie au milieu, interne bien marquée, plus ou moins courte, réunie postérieurement avec la première dorsale, qui est entière, ainsi que la deuxième; troisième fine, raccourcie au milicu, avec quelques points apicaux. Propygidium bifovéolé, presque lisse, avec des points épars sur ses bords. Pygidium légèrement convexe, sans rebord élevé, également ponctuć sur toute sa surface. Prosternum sans stries. Mésosternum assez court, avec une strie marginale interrompue. Jambes antérieures armées de quatre dents, la dernière bifide; intermédiaires de cinq petites épines; postérieures de quatre.

Brésil.

\section{O. EXUL.}

Oulongus convexus, niger, nitidus; fronte clypeoque valde concavis, stria obsoleta, in medio retrorsum acminata; pronoto antice utrinque bifoveolato; elytris striis 1-2 dor'salibus integris, $3^{\text {a }}$ et subhumerali dimidiatis, ceteris postice munctis indicatis; propygidio pygidiogue marce punctatis; tibiis anticis 5-dentatis. Long. 7 mill.; larg. $41 / 2$ mill.

Allongé, presque cylindrique, assez convexe, noir lnisant. Antennes brunes. Tête finement pointillée; front avec une large impression qui s'étend sur l'épistome; strie peu marquée, formant en devant un angle rentrant. Pronotum court, bisinué à la base, oblique sur les côtés et presque sans points, rétréci et échancré en devant, avec les angles aigus, marqués d'une fossette profonde, divisée par la strie latérale. Ecusson petit, triangulaire. Elytres beaucoup plus longues que le pronolum, de sa largeur à la base, presque droites sur les côtés, avec les épaules peu saillantes; rétré- 
cies et un peu oblipues au borl apical, avec un angle sutural bien marqué; bombées au milieu et ceintes d'une rigole bien visible; strie subhumérale atteignant l'épaule, première et deuxième dorsales entières, bien marquées; troisième courte, marquée au bout de points, ainsi que les stries intéricures. Propygidium et pygidium couverts de points espacés, réguliers. Prosternum pointillé, sans stries. Mésosternum un peu plus long que dans les autres espèces, pointillé de même, avec une strie marginale interrompue. Jambes antérieures 5-dentées; intermédiaires garnies de cing petites épines; postérieures de quatre.

Cette espèce, provenant de Cayenne (MM. Gehin, de la Ferté), a les plus grands rapports avec l'O. fausius, mais elle n'a pas, comme lui, les côtes élevées des élytres en guise de stries intérieures.

\section{O. FACSTIS.}

Oblongus, parum convexus, niger, nitidus; fronte foveolata, stria circulari retrorsum acuminata, clypeo impresso ; pronoto latcribus vix punctuluto; elytris stria subhumerali externa ad munerum producta, interna brevi, 1-2 dorsalibus integris, $3_{2}$ dimidiate, intus lincolis levibus clevatis; promygidio postice utrinque subimpresso pygidioque parce muncticulatis; tibiis anticis 4-dentatis. Long. 6 mill.; larg. 4 1/2 mill.

Omalodes faustus, Er. in Jahr. 1,124,10 (1834.)

Oblong, presque parallèle, peu convexe, d'un noir luisant. Front convexe, à peine visiblement pointillé, avec une fossette médiane pas très profonde; strie circulaire entière, formant en devant un angle rentrant, aigu, trìs long; épistome légèrement impressionné. Antennes d'un brun de poix, massue ferrugineuse. Pronotum court, transversal, à 
peine bisinué à la base, légèrement sinué et à peine pointillé sur les côtés; rétréci et échancré en devant, avec les angles aigus, abaissés; strie latérale entière, formant au bord antérieur, derrière les yeux, un angle bien marqué, surmonté d'un petit point. Ecusson petit, triangulaire. Elytres plus longues que le pronotum, de sa largeur à la base, subparallèles latéralement, obliques au bord apical, formant un angle sutural peu sensible; strie subhumérale externe sinueuse, remontant jusqu'à l'épaule, interne courte; première et deuxième dorsales entières, troisième raccourcic au milieu et souvent continuée par des points; les autres, ainsi que la suturale, représentées par quelques points. On aperçoit, mais seulement à un certain jour, le long des trois dorsales internes, de légères côtes longitudinales, lisses. Propygidium légèrement bi-impressionné sur le bord postérieur, presque lisse, avec quelques petits points épars; pygidium ponctué de même, avec un point à l'angle antérieur de chaque côté. Prosternum sans stries. Mésosternum assez long, imponctué; strie marginale interrompue. Jambes antérieures armées de quatre dents, apicale bifide; intermédiaires de cinq fortes épines; postérieures de quatre.

Brésil, Guyane (Cayenne).

\section{O. Punctistrius.}

Ovatus, convexiusculus, niger, nitidus; fronte punctulata, sulco medio longiludinali profonde cxarata, stria circulari valida, iterum a clypeo distincta; pionoto lateribus antice rugose punctato et impresso; clytris stria subhumerati abbreviala, 1a $2^{a} q u c$ dorsati integris, $3^{\text {a }}$ dimidiata posticc punctatis; propygidio sparse, pygidio requatiter punctatis; tibiis anticis 4-dentatis. Long. 7 mill.; larg. $51 / 2 \mathrm{mill}$. 
Ovale, asse $\iota$ convexe, noir luisant. Front convexe, peu densément ponctué, sillonné longitudinalement au milieu d'une impression entière; strie cireulaire, forte, entière, entourée d'un rebord élevé, un peu abaissé en devant, mais non interrompu, séparé de l'épistome par une strie transversale; ce dernier à peine impressionné, plus densément pointillé. Antennes d'un brun de poix. Pronotum court, à peine bisinué à la base, avec un point oblong anté-seutellaire, oblique sur les côtés, bordé de points, avec un enfoncement rugueusement ponctué vers les angles antérieurs, rétréei et échancré en devant; strie latérale entière, bien marquée, sans angles bien arrêtés derrière les ycux. Ecusson petit, triangulaire. Elytres plus longues et aussi larges que le pronotum à sa base, dilatées sur les côtés, rétrécies et presque droites au bord apical, angle sutural peu profond, strie sublumérale externe raccoureie, interne nulle; première et deuxième dorsales entières, terminées par un ou deux points; troisième raccoureie au milieu et continuée jusqu'au bout par une série de points; les deux autres, ainsi que la suturale, représentées par quelques points apicaux. Propygidium sans fossettes bien marquées, ponetué, mais très vaguement. Pygidium ponctué d'une manière plus régulière, mais peu serrée. Prosternum sans stries. Mésosternum court, avec une strie marginale interrompue. Jambes antérieures armées de quatre dents; intermédiaires de quatre épines assez fortes; postérieures de trois.

Brésil (M. Deyrolle).

\section{O. FOVEOLA.}

Subrolundalus, concerus, niger, nitidus; fronce mofunde sulcata, stria rirculari integra forti, antice haud retrorsum acumi- 
"uala; clypeo subimpresso; pronoto lateribus muclato, elytris pulvinatis, stria sublumeraliabbreviata, $1_{\text {a }}$ et $2_{\text {a }}$ dorsali integris 3a dimidiata, suturali sapius indicuta; propygidio mofunde bifoveolato, lateribus parce, pygidio sat dense punctatis; tibiis anticis 5-denticulatis. Long. 5 mill.; larg. 4 mill.

Omulodes foveola. Er. in Jalır. 1, 120,5 (1834).

Ovale arrondi, assez convexe, noir luisant. liront convexe, pointillé, avec une impression médiane élargic en devant et assez profonde; strie circulaire entière, forte; épistome légèrement impressionné. Antennes d'un brun de poix. Pronotum court, élargi à la base et à peine bisinué, avec un point oblong anté-scutellaire; légèrement arqué et bordé de points sur les còtés, échancré et rétréci eı devant, avec les angles antérieurs aigus, abaissés et impressionnés; stric latérale bien inarquée, entière, sans angles derrière les yeux. Ecusson petit, triangulaire. Elytres une fois et demie plus longues que le pronotum, aussi larges à la base, dilatées latéralement, avec les épaules assez saillantes, rétrécies et à peu press droites au bol'd apical, formant un angle sutural assez saillant, bombées, avec une rigole circulaire; strie sublıumérale externe raccourcie en devant; interne nulle; première dorsale entière; deuxième à peine raccourcic à la base, plus forte, surtout par derrière; troisième oblique. moins marquée, raccourcic au milieu; quelquefois une légère trace de la suturale. Propygidiuın fortement bifovéolé, lisse au milieu, avec quelques points épars. Pygidium légèrement convexe, assez régulièrement ponclué. Prosıernum sans stries. Mésosternum court; strie marginale interrompue. Jambes antérieures armées de cinq dents; intermédiaires to cinq pelites épines; postérieures de quatre.

Guyane (Caycunr); Rrósil 


\section{O. CONICICOLLIS.}

Oealus, conexiusculus, niger, nitidus; frome media foveolata, stria circulari integra, retrorsumhand acuminala, clypeo"ule depresso punctulatis, pronoto lateribus punctato, unticis angulis impresso; clytris humeris elcvatis, striis 2 subhumeralibus abbreviutis, 1a 2aque dorsuli integris, $3_{\mathrm{a}}$ dimidiutu, muctis apicalibus sumuralibusque; promygidiovage munctuto, bifoveoluto, pygidio pulvinato cyualiter punctato; tibiis anticis 4-dentatis. Long. 5 1/2 mill.; larg. 4 1/2 mill.

Ovale, assez convexe, noir luisant. Front convexe, pointillé, sillonné dans sa longueur d'une fossette médiane peu profonde; strie circulairc cutière, sans angle rentrant, avec un rebord élevé derrière l'épistome même, quoiqu'un peu plus bas; ce dernier peu convexe, pointillé. Antennes d'un brun de poix. Pronotum court, beaucoup plus large que long, élargi et bisinué à la base, avec un point anté-scutellaire; oblique et subsinué sur les côtés, avec une bordure entière de points; éclıncré et fort rétréci en devant, avec les angles abaissés, aigus, impressionnés. Elytres une fois et demie plus lougues que le pronotum, de sa largeur à la base, dilatées sur les côtés, rétrécies et presque droites au bout, bombées, avec les épaules saillantes et la suture abaissée; strie subhumérale externe atteignant presque la strie humérale; interne plus courte; première et deuxième dorsales entières, fortes; troisième fine, raccourcie au milieu, arec quelques points apicaux; suturale représentéc par quelques points. Propygidium biforéolé, couvert de points épars, presque lisse au milieu. Pygilium bombé, assez également ponetuć. Prosternum sans stries. Mésosternum long, à stric marginale interrompue. Jambes antérieures armées de quatre dents: intermédiaires de quatre ŕnines, et postérieures de trois. 
Guyane (Cayenne); Brésil (r. negro); dans les bouses, en janvier, et dans les charognes en mai et juin.

\section{0. MONILIFEK.}

Rotundatus, convexus, niger, nitidus, puncticulatus, clava brunnea; fronte clypeoque concavis, stria circulari antice vetrorsum breviter acuminata; pronoto lateribus punctato; elytris stria subhumerali ad humcrum producta, dorsalibus punctorum lineis compositis, 3 primis integris, ceteris abbreviatis, $5^{\text {a }}$ gemina; propygidio pygidionte et $1^{\circ}$ ventrali abdominis scgmento punctatis ; tibiis anticis 4-dentatis. Long. 6 mill.; larg. 5 mill.

Arrondi, convexe, noir luisant. Tête pointillée; front concave, ainsi que l'épistome; strie circulaire forte, entière, avec un angle rentrant très court. Antennes brunes. Pronotum court, très large et bisinué à la base, avec un point allongé au devant de l'écusson; oblique et sinué sur les côtés, échancré et fortement rétréci en devant, avec les angles aigus, abaissés, impressionnés ; couvert d'une très fine et très dense ponctuation, et d'une bordure latérale de points plus forts. Ecusson petit, triangulaire. Elytres pointillées comme le pronotum sur toute leur surface, une fois et demic plus longues et aussi larges que lui à la base, curvilinéairement dilatées sur les côtés; strie subhumérale externe bien marquéc, raccourcie ả l'épaule; interne représentéc par des points presque imperceptibles; dorsales formées de lignes de points réguliers, les trois premières entières et liées, quatrième plus fine, un peu raccourcie à la base, cinquième géminée, n'atteignant pas le milieu; suturale plus longue. Propygidium vaguement ponctué, ans fovéoles; pygidium un peu plus densément et plus for- 
tement. Prosternum sans stries. Mésosternum court, à strie marginale interrompue; premier segment ventral très densément pointillé. Jambes antérieures armées de quatre dents; postérieures de trois ou quatre petites épines.

Mexique (Mexico, Téapa). (MM. Chevrolat et Pilate).

\section{O. pulvinatus.}

Rotundatus, pulvinatus, niger, nitidus; fronte media profunde foveolata, stria circulari, retrorsam acuminata, clypeo impresso; pronoto latcribus parce punctulato; elytris humeris prominulis stria subhumerali extus ad humerum producta, interna breviori, punctorum lineis formata sicut ceterce, 3 primis dorsalibus integris, 4a, $5^{\mathrm{a}}$ geminata suturalique abbrcviatis; propigidio bifoveoluto sublcevi, pygidio dense punctulato ; tibiis anticis 5-dentatis. Long. 4 mill. 1/2 ; larg. 3 mill. 1/2.

Omalodes pulvinatus Er. in Jahr. 1,123,9 (1834).

Arrondi, assez convexe, noir luisant. Tête finement pointillée; front convexe, avec une fossette médiane arrondic, très profonde, continuée en devant par un sillon; strie circulaire entière, formant un angle aigu rentrant; épistome impressionné. Antennes brunes. Pronotum lisse sur toute sa surface et finement ponctué latéralement, court, beaucoup plus large que long et bisinué légèrement à la base, oblique et subsinué sur les côtés, échancré et fortement rétréci en devant, avec les angles antérieurs aigus et abaissés; stric latérale entière. Ecusson petit, triangulaire. Elytres plus longues que le pronotum et aussi larges à la base, dilatées sur les côtés, avec les épaules très saillantes, rétrécies et légèrement arrondies au boul, formant un angle sutural assez prononcé; bombées et entourées d'une espèce de rigole; suture légèrement carénée; strie sublıumérale externe assez bien marquée, atteignant l'épaule, mais si- 
uneuse et interrompue leux fois; interne plus courte, formée de points réguliers comme toutes les autres; $1-3$ dorsales entières, quatrième à peine raccourcie, cinquième géminée et suturale raccourcies vers le milieu. Propygidium profondément bifovéolé, couvert d'un pointillé très fin. Pygidium bombé, faiblement et peu densément ponctué. Prosternum sans stries. Mésosternum ponctué, à stric marginale interrompue. Premier segment ventral à peine visiblement poinlillé. Jambes antérieures armées de cinq petites dents; intermédiaires de cinq petites épines; postéricures de quatre.

Brésil ; Guyane (Cayenne).

\section{O, GROSSES.}

Ovatus, latus, convexiusculus, niger, nitidus, clavabrunnea; fronte parnu convexa, leviter in medio foveoluta, stria circulari artice subinterrupta, clypeo subimpresso; rronoto latcribus antice punctato; clytris striis levibus, $1^{\text {a }}$ dorsali integra, 2+ utrinque abbreviau, 3a subhumeralique externa dimidiatis; mropygidio pygidioque lateribus impressis muctatisque; libiis anticis 4-dentatis. Long. 10 mill.; larg. 8 mill.

Ovale très élargi, assez convexe, noir, luisant. Tête finement pointillée; front légèrement convexe, avec une fossette médiane peu profonde; strie circulaire peu marquéc en devant; épistome subimpressionné. Antrunes d'un brun de poix, massue rousse. Pronotum court, très large et légèrement bisinué à la base, oblique et à peine sinué avec une bordure de points sur les côtés, échlancré et fort rétréci en devant, avec les anģles aigus et abaissés; strie latéralc entière. Ecusson petit, triangulaire. Elytres une fois et demie plus longues et un peu plus larges que ie prouolum 
à la basc, dilatées sur les cotés, rétrécies au bout; épaules à peinc saillantes; suture un peu déprimée; strie subhumérale cxterne raccourcic; trois dorsales fines : première entière, deuxième raccourcie de part et d'autre, troisième encore plus courte. Propygidium avec deux impressions larges et superficielles, fortement ponctuées. Pygidium impressionné et fortement ponctué dans tout son pourtour, excepté au milieu. Prosternum sans stries. Mésosternum court, à strie interrompue. Jambes antérieures armées de quatre dents, l'apicale bifide; postérieures de quatre épines.

Mexique (MII. de la Ferté et Chevrolat).

\section{O. Texanis.}

Ovatus, subconvexus, niger, nitidus, clava urunnea; fronte punctulata leviter in medio foveolata, stria circulari integra, antice retrorsum brevitcr acuminata; clypeo subimpresso; pronoto lateribus tenuiter punctulato; clytris stria subhumerali abbreviata, 1-3 dorsalibus obsoletis postice evanescentibus: mopygidio pygidioque utrinque impressis punctatisque circum; tibiis anticis 4-dentatis, Long. 9 mill.; larg. 7 mill.

Ovale, légèrement convexe, noir luisant. Front légèrement bombé, pointillé, avec une fossette médiane peu profonde; strie circulaire entière, avec un angle rentrant très court; épistome légèrement impressionné. Antennes brunes, massue roussâtre. Pronotum court, très large et subbisinué à la base, oblique sur les côtés et bordé de petits points assez serrés; fortement rétréci cl échancré cn devant, avec les angles aigus et abaissés; strie latérale entière. Ecusson petit, triangnlaire. Elytres une fois et demie plus inngues et aussi larges que Ir pronotum ì la base, dilatées 
sur les côtés, rétrécies et presque droites au bout; épaules peu saillantes, suture subdéprimée; strie subhumérale externe raccourcie; 1-3 dorsales obsolètes, raccourcies un peu au-delà du milieu. Propygidium légèrement bifovéolé, couvert latéralement d'une ponctuation forte et serrée, qui se réunit au milieu du bord postérieur. Pygidium lisse au milieu, ponctué et impressionné dans son pourtour. Prosternum sans stries. Mésosternum très court, à strie marginale interrompue. Jambes antérieures armées de quatre dents; intermédiaires de quatre fortes épines; postérieures de trois plus petites.

Il se distingue du $O$. grossus par sa forme plus allongée et un peu moins convexe, sa strie frontale réunie ell angle rentrant, et l'espace ponctué de chaque côté du propygidium et lu pygidium réuni postérieurement.

Etats-Unis (Texas).

\section{O. Noves.}

Ovatus, subconvexus, niger, nitidus, clava brunnea; fronte clypeoque foveolatis, stria circulari integra retrorsum acuminata; pronolo lateribus punctato; elytris striis validis, subhumerali abbreviata basali rudimento ancta, 2 primis

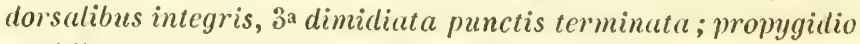
pygidioque parce punctulatis; tibiis anticis 4-dentatis. Long. 9 mill. ; larg. 6 mill.

Ovale, assez allongé, légèrement convexe. Tête finement pointillée; front peu convexe, avec une fossette médiane arrondie; strie circulaire bien marquée, entic̀re, formant un angle rentraıt assez aigu; ćpistome subimpressionné. Antennes brunes, massue rousse. Pronotum court, très large et subbisinué à la base, avec un point au devant de. 
l'écusson, oblique et bordé de points très serrés sur les côtés, échancré et rétréci en devant, avec les angles aigus et abaissés. Ecusson petit, triangulaire. Elytres une fois et demie plus longues, aussi larges que le pronotum à la base, peu élargies sur les cotés, droites au bord apical; stries fortes et bien marquées; subhumérale externe atteignant presque dorsales entières, troisième raccourcie au milieu et continuée par une ligne de points. Propygidium couvert de points réguliers, peu serrés, assez fins; sans fossettes. Pygidium ponctué de même. Prosternum sans stries. Mésosternum profondément éclıancré, à strie marginale interrompue. Jambes antérieures armées de quatre dents; intermédiaires de cinq épines; postérieures de trois.

Nouvelle-Grenade (Carthagène).

\section{O. Hä̈thants.}

Ovalus oblongus, subconvexus, niger, nitidus; fronteclypeoquc late et parum profunde impressis, muncticulatis, stria integra, vix retrorsum acuminata; pronoto lateribus punctulato; elytris stria subhumerali ab humero ad suturam continuata;

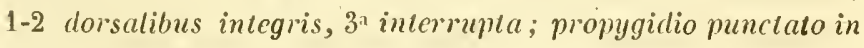
medio lavi, pygidio densius; tibiis anticis 4-dentatis. Long. 10 mill.; larg. 7 mill.

Ovale allongé, légèrement convexe, noir luisant. Front et épistome pointillés, avec une impression large et superficielle; strie circulaire assez marquée, entière, avec un angle rentrant à peine saillant. Antennes brunes. Pronotum court, large et bisinué à la base; oblique, légèrement sinué et bordé de points sur les côtés; échancré et rétréci en devant, avec les angles abaissés, aigus; strie latérale 
entière, fortement anguleuse derrière les yeux. Ecusson petit, triangulaire. Elytres beaucoup plus longues et aussi larges que le pronotum à la base, légèrement arquẻes sur les côtés, rétrécics et presque droites au bout, formant un angle sutural assez profond, strie subhumérale externe atteignant d'une part l'humérale, et se continuant de l'autre le long du bord apical jusqu'à la suture; interne nulle ; 1-2 dorsales entières, troisième interrompue. Propygidium sans fossettes bien accusées, ponctué assez densément et peu fortement sur les côtés, lisse au milieu; pygidium plus également ế plus fortement ponctué sur toute sa surface. Prosternum sans stries. Mésosternum court, profondément échancré et rebordé d'une strie interrompue. Jambes antérieures armées de quatre dents; intermédiaires de cinq épines fortes; postérieures de quatre.

Haïti (S.-Domingo), dans les végétaux charnus en décomposition, tels que le Palmier, le Papayer, elc; octobre.

19. O. PLANIFRONS.

Ovalus, subconvexus, niger, nitidus; fronte plana, stria circulari antice subintervupta; monoto stria laterali forti; elyıris stria subhumerali inlegra ad humerum disjuncta; 1-2 dorsalibus integris, $3^{a}$ dimidiata, punctis continuata; pygidio propygidioque fortiter et dense punctutis; tibiis anticis 4-dentatis. Long. 8 mill.; larg. 6. mill.

Ovale, assez convexe, noir, luisant. Front légèrcment convexe, sans fossette ni points; stric circulaire un peu interrompue en devant. Antennes d'un brun de poix. Pronotum court, élargi et bisinué à la base, avec un point 
anté-scutellaire, oblique sur les côtés, rétréci et échancré en devant, avec les angles aigus, abaissés; imponctué sur les còtés; strie latérale forte et entière. Ecusson petit, triangulaire. Elytres une fois et demie plus longues et aussi larges que le pronotum à la base, dilatées latéralement, droites au bout, un peu bombées, avec une espèce d'impression tout autour et les épaules saillantes; stries fortes, bien marquées; subhumérale externe entière, décomposée à l'épaule; première et deuxième dorsales entières, troisième raccourcie au milieu, continuée par des points; quatrième, cinquième et suturale représentées par quelques points apicaux. Propygidium et pygidium densément et fortement ponctués sur toute leur surface. Prosternum large, sans stries. Mésosternum court, à strie très grosse, interrompue. Jambes antérieures armées de quatre dents obtuses; postéricures de cinq ou six petites épines.

Brésil (Sainte-Catherine).

\section{O. Consanguinets.}

Ovatus, couvexiusculus, niger, nitidus; fronte plana in medio anguste sulcata, stria circulari antice retrorsum angulata; pronoto lateribus impunctatis; elytris sub humeroimpressis, striis tenuibus, $1^{\text {a }}$ dorsali integra, $2^{\text {a }} 3^{\mathrm{a}} q u e$ postice abbreviatis; propygidio sparsin, pygidio dense punctatis; prosterno breviter bistriato; tibiis anticis 5-dentatis. Long. 9 mill.; larg. 7 mill.

Ovale, assez convexe, noir, luisant. Front plan, lisse, creusé dans sa longueur par un sillon médian, étroit, assez profond; strie circulaire bien marquée, entière, formant un angle antérieur rentrant, peu aigu; épistome plan. Antennes brunes. Pronotum court, large et subbisinué à la base, avec un point anté-scutellaire, oblique sur les côtés, 
rétréci et échancré en devant, avec les angles aigus ot abaissés; imponctué sur toute sa surface; strie latérale forte, entière, sans angles derrière les yeux. Ecusson petit, triangulaire. Elytres une fois et demie plus longues, aussi larges que le pronotum à la base; légèrement bombées, et enfoncées sur la suture et dans leur pourtour, avec une impression assez profonde sous l'épaule, ce qui la rend plus saillante; strie subhumérale externe raccourcie en derant ; dorsales fines, obsolètes, première entière, deuxième et troisième raccourcies. Propygidium assez vaguement ponctué; pygidium un peu plus densément et assez régulièrement. Prosternum aplati à la base, avec deux courtes stries. Mésosternum très court, strie marginale interrompue. Jambes antérieures armées de cinq ou six dents; postérieures de cinq ou six petites épines.

Nouvelle-Grenade (Bogota). (M. Chevrolat.)

\section{O. EXTURRIS.}

Oblongo-ovatus, convexiusculus, niger, nitichs, fronte clypeoque subdepressis punctulatis, stria circulari integra, vix retrorsum angulata; pronoto lateribus antice impressis punctatisque; elytris striis validis, subhumerali externa integra, interna humerum jungente, 1-3 dorsalibus integris, $3^{\text {a }}$ postice punctis formata; propygidio pygidioque dense et aquatiter punctatis; tibiis anticis 4-dentatis. Long. 9 mill.; larg. 6. mill.

Ovale un peu oblonğ, légèrement convexe, noir, luisant. Antennes brunes. Front pointillé et légèrement déprimé, ainsi que l'épistome, avec une légère trace de sillon médian; strie circulaire entière et presque sans angle rentrant. Pronotum court, large et arqué à la base, avec une petite impression anté-scutellaire, oblique sur les côtés, et bordé 
d'une ponctuation serrée, assez large, qui s'arrete au milieu, rétréci et échancré en devant, avec les angles abaissés, aigus et imprensionnés; strie latérale forte, entière. Ecusson petit, triangulaire. Elytres une fois et demie plus longues, aussi larges que le pronotum a la base, bombées et entourées d'une dépression assez marquée; stries fortes et bien marquées; subhumérale externe atteignant la base, interne montant jusqu'à l'humérale; première dorsale entière, deuxième un peu raccourcie à la base, troisième formée de points à partir du milieu. Propygidium couvert d'une ponctuation assez serrée, assez forte, un peu plus fine au milieu du bord antérieur. Pygidium ponctué un peu plus densément. Mésosterıum court; strie marginale interrompue. Jambes antérieures armées de quatre dents; postérieures de quatre épines.

Guyane (Cayenne).

\section{0. EBENNINTS.}

Oblongus, parum convexus, niger, nitidus, puncticulatus; fronte depressa, stria circulari subintegru, retrorsum angulatu; pronoto luteribus tate densius punctato; clytris stria externa subhumerati integra, interna brevi; $1-3$ dorsalibus integris, ceteris apiculibus; propygidio pygidioque dense punctatis; mosterno bistriato, mesosterno marginato; ribiis anticis j̃-denticulatis. Long. 9 mill. larg. 6 mill.

Omalorles cbenninus. Er. in Jahr. 1, 118. 2 (1834).

Plus allongé que tous ses congénères, peu convexe, noir luisant, finement et densément pointillé sur toute sa surface, couvert, en outre, d'une ponctuation plus forte et serrée sur la tête, sur les bords du pronotım, et surtout sur le propygidium et te pygidium. Antennes brunes. Front зе Série, томе 1. 
déprimé, ainsi que l'épistome, avec une légère trace de sillon médian; strie circulaire bien marquée, entière, formant un angle antérieur rentrant, peu prononcé. Pronotum court, large et subbisinué à la base, arrondi sur les côtés, rétréci et écliancré en devant, avec les angles aigus et abaissés. Ecusson petit, triangulaire. Elytres deux fois plus longues, et aussi larges que le pronotum à sa base, peu élargies sur les côtés, légèrement rétrécies, droites et sillonnées sur le bord apical, formant un angle sutural bien marqué; épaules peu saillantes, suture assez dépriméc; stries fortes et bien marquées; subhumérale externe entière; interne courte, décomposée; première et deuxième dorsales entières, troisiène raccourcie, mais continuée par des points, quatrième, cinquième et suturale représentées par quelques points apicaux. Propygidium couvert d'une ponctuation forte et serrée, ainsi que le pygidium. Prosternum étroit, bistrié. Mésosternum ponctué, avec une strie marginale non interrompue derrière l'échancrure céphalique Jambes antérieures armées de cinq ou six denticules; intermédiaires de cinq fortes épines; postérieures de quatre à cinq petites.

Chili, Montevideo, Tucuman.

\section{O. LAvigatus.}

Rotundatus, convexiusculus, niger, nitidissimus; fronte levissime subimpressa, stria circulari retror sum subangulata; pronoto stria laterali pone oculos angulata; elytris 3 striis dorsalibus brevibus obsoletis, subhumeruli externa antice abbreviata usque ad suturam continuata; propygidio pygidioque versus latera tenuissime punctulatis; tibiis anticis 4-dentatis. Long. 7 mill.; larg. 6 mill.

Histerlacvigatus. Quens, in Schh. Syn. Ins. 1,90,15 note T. 2 f. 3. (1806)-Angulatus var, Payk. Mon. Hist. 43,30 (1834). 
Arrondi, convexe, d'un noir très luisant et sans points, si ce n'est aux angles antérieurs du pronotum et sur les côtés du propygidium et du pygidium, encore sont-ils très fins et obsolètes. Antennes d'un brun de poix. Front à peu près plan, avec une très légère impression; strie circulaire bien marquée, entière, formant un angle rentrant antérieur à peine sensible. Pronotum court, large et légèrement arrondi à la base, avec un point anté-scutellaire; subarrondi sur les côtés, rétréci et échancré en devant, avec les angles aigus et abaissés; stric latérale forte, entière, avec des angles assez marqués derrière les yeux. Ecusson petit, triangulaire. Elytres plus longues et un peu plus larges que le pronotum à la base, curvilinéairement dilatées sur les côtés, rétrécies et droites à l'extrémité; stries fines: 1-3 dorsales courtes, obsolètes ; subhumérale externe raccourcie en devant et prolongée le long du bord apical jusqu'à la suture. Propygidium et pygidium avec quelques points épars, obsolètes dans leur pourtour. Prosternum large, sans stries. Mésosternum court, profondément échancré ; strie marginale interrompue. Jambes antérieures armées de quatre petites dents; intermédiaires de quatre épines, et postérieures de trois.

Haïti (Santo-Domingo), dans les végétaux charnus en décomposition, tels que Palmier, Papayer, etc. Octobre.

\section{G. RUFicla Vis.}

Subrotundatus, convexus, niger, nitidus; fronte clypeoque depressis puncticulatis, stria integra retrorsum antice subangulata; pronoto lateribuspuncticulato, stria pone oculos angulata; elytris stria subhumerali, apice continuata, 3 dorsalibus 
tenuissimis; propygidio mygidionue marce punctatis; tibiis anticis 4-dentatis. Long. 9 mill.; larg. 7 mill.

Omalodes levigalus, Er. in Jahr. 1,121, 6 (1834).

Ovale, arrondi, convexe, noir luisant. Antennes noires, massue brune. Front déprimé, ainsi que l'épistome, pointillé; strie entière, peu profonde, formant un angle rentrant en devant. Pronotum court, bisinué à la base, avec un petit point anté-scutellaire, oblique et pointillé sur les cotés, rétréci et échancré en devant, avec les angles abaissés, peu aigus; strie latérale forte, entière, anguleuse derrière les yeux. Ecusson petit, triangulaire. Elytres bombées, plus larges et aussi longues que le pronotum à la base, arrondies sur les côtés, sans épaules saillantes, obliques et rétrécies au bord apical, avec un petit angle sutural; strie subhumérale fort courte antérieurement, prolongée au bord apical jusqu'à la suture; dorsales très fines, 1.2 entières, ponctuées, troisième courte. Propygidium couvert de points espacés. Pygidium régulièrement ponctué. Prosternum sans stries. Mésosternum fort court, profondément échancré; strie marginale interrompue. Jambes antérieures quadridentées; intermédiaires garnies de quatre épines fortes; postérieures de quatre petites.

Mexique, Cuba, Ilaïti, dans les végétaux charnus en décomposition, comme Palmier, Papayer, etc. Octobre.

\section{O. LEVINOTUS.}

Rotundato-ovatus, convexiusculus, niger, nitidissimus, impunctatus; fronte plana stria late intorrupta; elytris striis obsoletis, tenuibus, 3 dorsalibus, subhumeralique externa abbreviatis, marginali apice usque ad suturam continuata; pygidio propygidioque omnino levibus; tibiis anticis 4-dentatis. Long. 7 mill.; larg. 6 mill. 
Ovale arrondi, assez convexe, lisse et sans points, noir très luisant. Antennes brunes. Front plan, sans fovéole distincte; strie fortement interrompue cessant à l'angle antérieur de l'œil; on apercoit néanmoins comme une légère trace du reste de la strie. Pronotum court, large et légèrement bisinué à la base, avec un point anté-scutellaire, suharrondi sur les côtés, rétréci et échancré en devant, avec les angles aigus, abaissés; strie latérale entière, bien marquée, sans angle sensible derrière les yeux. Ecusson petit, triangulaire. Elytres plus longues et à peu près aussi larges que le pronotum à la base, curvilinéairement dilatées sur les côtés, rétrécies et droites au bout; stries très fines et obsolètes; 1-3 dorsales fort courtes; subhumérale externe raccoureie de part et d'autre; marginale se continuant jusqu'à la suture, le long du bord apical. Propygidium et pygidium entièrement lisses. Prosternum sans stries. Mésosternum court, strie marginale interrompue. Jambes antérieures armées de quatre petites dents; quatre postérieures de cinq ou six épines.

Guadeloupe.

\section{0. ANTIRACINIS}

Oblongus, convexiusculus, niger, nitidissimus, cleva brunnea; fronte plana, striacirculari integra, retrorsum subangulata; monotolatcribusmencticulato; elytris stria subhumerali 3que primis dorsalibus abbreviatis tenuissimis; mopygidio sparsin, pygidio puulo densius punctatis; tibiis anticis l-dentatis. Long. 7 mil.; larg. 6 mill.

Ovale, assez convexe, noir, lisse, luisant. Antennes hrun de poix, massue moins foncéc front plan, strie circulaire bien marquéc, formanl un angle antérieur rentrant, court, 
un peu interrompu. Pronotum court, large et bisinué faiblement à la base, avec un point anté-scutellaire, courbé et pointillé sur les côtés, rétréci et échancré en devant, avec les angles aigus, abaissés et impressionnés; strie latérale entière, bien marquée, assez profonde, arrondie et éloignée du bord aux angles antérieurs, à peine anguleuse derrière les yeux. Ecusson petit, triangulaire. Elytres plus longues et un peu plus larges que le pronotum à la base, curvilinéairement dilatées sur les côtés, rétrécies et droites au bout; stries fines, obsolètes, trois premières dorsales raccourcies ; sublıumérale externe n'atteignant pas l'épaule et ne se continuant pas le long du bord apical, non plus que la marginale. Prosternum élargi à la base, suns stries. Mésosternum court, échancré; strie marginale interrompuc. Propygidium couvert de points espacés; ponctuation du pygidium un peu plus serrée. Jambes antéricures armées de quatre dents; postérieures épineuses.

Ces quatre espèces, très voisines de taille et de forme, se distinguent aisément les unes des autres par le propygidium et le pygidium imponctués dans l'(). lavinotus, á peine pointillés latéralement dans l'O. lavvigatus, tandis qu'ils sont assez également et assez fortement ponctués dans les deux autres; surtout par la strie apicale qui vient de la subhumérale dans celui-ci comme dans l'O. ruficlavis, de la marginale dans celui-là, et qui manque dans l'O. anthracinus.

Nouvelle-Grenade (Carthagène); Venezuela (Caracas), dans les bouses en janvier, région froide.

\section{O. SOBRINIS.}

Ovarms, convexiusculus, niger, nitidus; fronle plana, in medio leviter impressa, stria riventari antice retronsum acuminata: 
pronoto angulis unticis subtiliter puncticulatis; elytris stria subhumerali humerum jungente; 1-3 dorsalibus tonuissimis, ulimidiatis; propygidio iateribus subimpresso et parce, mygidio validius untice punctato; tibiis anticis 5-dentatis. Long. 5 1/2 mill.; larg, 4 1/2 mill.

Omalodes sobrimus, Er. in Jahr. 1,122, 7 (1834).

Ovale, assez convexe, noir luisant. Antennes brunes. Front plan, lisse, avec une impression médiane très faible; strie circulaire bien marquée, entière, formant un angle antérieur rentrant. Pronotum court, large et faiblement bisinué à la base, avec un point anté-scutellaire, courbé sur les côtés et finement pointillé vers l'angle antérieur, qui est aigu et abaissé, échancré et fortement rétréci en devant; strie latérale bien marquée, entière, sans angle derrière les yeux. Ecusson petit, triangulaire. Elytres beaucoup plus longues et aussi larges que le pronotum à la base, dilatées latéralement, rétrécies et droites au bord apical; strie subhumérale remontant jusqu'à l'humérale ; 1-3 dorsales très fines, raccourcies au milieu. Propygidium assez fortement mais vaguement ponctué, et superficiellement impressionné sur les cotés. Pygidium aussi fortement et plus densément ponctué antérieurement. Prosternum sans stries, élargi à la base. Mésosternum court, profondément échancré, strie narginale interrompue. Jambes antérieures armées de cinq petites lents ; intermédiaires de quatre épines; postérieures de trois.

Mexique; Nouvelle-Grenade (Bogota); Venezucla (Caracas), dans les bouses, région froide, janvier; Bolivia.

\section{O. STNTATICOLLIS}

Rotundatus, convcrinsculus, niger, nilidus; fronle clypeoque lale impressis. srria cirrulari antior relrorsmm armminala : 
monoto lateribus simuato, angulis anticis anctis foveola carina transversali divisa; elytris humeris clevatis, circum impressis ; stria subhumerali brevi, 3 primis dorsalibus postice abbrevialis, linea punctornm suturali; propygidio mygidioque parce puncticulatis; tibiis antiris obtuse 5-dentutis. Long. 7 mill.; larg. 6 inill.

Arrondi, assez convexe, noir luisant. Antennes brunes. Front largement et peu profondément impressionné, ainsi que l'épistome; strie circulaire entière, assez marquée, formant un angle antérieu rentrant, assez avancé. Pronotum court, large et faiblement bisinué à la base, avec un point anté-scutellaire à peine visille, oblique et sinué sur les côtés, avec le rebord élevé, échancré et rétréci en devant, avec les angles aigus, abaissés, creusés chacun d'une fossette divisée en deux par une carène transversale; strie latérale entière et anguleuse derrière les yeux. Ecusson petit, triangulaire. Elytres plus longues et aussi larges que le pronotum à la base, légèrement dilatées sur les côtés, rétrécies et droites au bout, bombées au milieu et bornćes par une dépression latérale; épaules saillantes; strie subhumérale courte, 1-3 dorsales fines, raccourcies; suturale représentée par une ligne de points peu marqués. Propygidium et pygidium presque lisses, avec quelques points obsolètes. Prosternum sans stries, élargi à la base. Mésosternum assez long, strie marginale interrompue. Jambes antérieures garnies de cinq petites dents; postérieures faiblement épincuses.

Bresil (Sainte-Catherine).

\section{0. SELENUS.}

brevirer ovatus, subromiralus, niger, nitidus; fromte plama subelepressa, stria rireruluri integla, reborsum subangulata; 
clytris striis 3 dorsalibus, utrinque abbreviatis, subhumerali extcrna humerum jungentc, ungulo suturali plica brevi marginato; propygidio utrinque subfoveolato, sparsim, mygidiofortius et densius punclatis; tibiis anticis 4-dentatis Long. 7 mill.; larg. $51 / 9$ mill.

Omalodes serenus. Er. in Jalur. 1, 123, 8 (1834).

Ovale court, assez convexe, noir luisant. Antennes brunes. Front plan, avec une faible impression au milieu; strie circulaire bien marquée, entière, formant un angle antérieur rentrant à peine sensible. Pronotum court, élargi et subbisinué à la base, avec un point anté-scutellaire, oblique sur les côtés, échancré et rétréci en devant, avec les angles aigus, abaissés ; strie latérale entière, rapprochée partout de la marginale. Ecusson petit, triangulaire. Elytres plus longues et aussi larges que le pronotum à sa base, légèrement dilatées sur les côtés, rétrécies et presque droites au bord apical, et formant un angle sutural assez prononcé, avec un petit pli court à la suture; strie subhumérale externe assez marquée, remontant jusqu'à l'épaule; 1-3 dorsales moins fortes, surtout les internes, plus ou moins raccourcies à leurs deux extrémités. Propygidium faiblement bifovéolé et couvert de points espacés. Pygidium légèrement convexe, plus fortement et plus densément ponctué. Jambes antếrieures garnies de quatre dents, assez obtuses; intermédiaires de quatre épines; postérienres de deux.

Rrésil, Guyane (Cayenne).

30. ก. HER ESSISTERNUS.

Ovatus, comeriussulus, miger, nitidus; fronte clypeoqur mumcrulatis subimmrsssisque, stria rirculari integra, refrorsum 
subangulala; pronoto lateribus puncticulato; clytris striis 3 dorsalibus apice punctisterminatis, $4^{\mathrm{a}}$, $5^{\mathrm{a}}$, suturali subhumeralique interna punctis apicalibus indicatis, externa antice abbreviata; prosterno basi depresso; propygidio subfoveolato, pygidioque parce et grosse punctatis; tibiis anticis 5-clentatis. Long. 7 mill.; larg. 5 1/2 mill.

Ovale, assez convexe, noir luisant. Antennes brunes. Front plan, faiblement impressionné et pointillé, ainsi que l'épistome; strie circulaire bien marquée, entière, formant un angle antérieur rentrant à peine sensible. Pronotum court, large et légèrement bisinué ả la base, avec un point anté-scutellaire peu distinct, oblique sur les côtés, échancré et rétréci en devant, avec les angles aigus, abaissés; strie latérale bien marquée, entière. Ecusson petit, triangulaire. Elytres plus longues et aussi larges que le pronotum à la base, légèrement dilatées sur les côtés, rétrécies et droites au bord apical; strie subhumérale externe bien marquée, ne remontant pas jusqu'à l'humérale; interne obsolète, formée d'une ligne de points; première el deuxième dorsales assez fortes, troisième fine, toutes trois terminées par des points; quatrième et cinquième représentées par quelques points apicaux ; suturale presque entière, formée d'une ligne de points obsolètes. Propygidium faiblement bifovéolé, couvert de points épars assez forts. Ponctuation du pygidium aussi forte et plus serrée. Prosternum finement et densément pointillé, avec une large impression superficielle à la base. Mésosternum court, strie marginale interronpuc. Jambes antérieures garnies de quatre à cinq dents; postérieures épineuses.

fuyane (Cayenne). 


\title{
XVII. PSILOSCELIS.
}

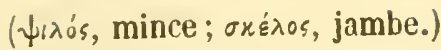

Soc. Ent. 3e série. T. 1 (1853), pl. 16. - Mon. pl. 7. Genre XVIl.

Omalodes. Le Conte. N. Amér. Hist. (1845).

Corpus crassum, oblongo-ovatum.

Caput retractum, stria frontali integra, labro minuto, mandibulis requalibus, palporum subsecuriformi ultimo articulo.

Antennce sub frontis margine inserter, clava orbiculari, foveola profunda, detecta, sub angulo prothoracis.

Pronotum subquadratum, lateribus pluri-sulcatum, angulis anticis rotundatis.

Elytra striala margine inflexo foveolato.

Prostermum elevatum, basi rotundatum, receptum, lobo valde prominulo.

Propygidium transversum declive; pygidium perpendiculare.

Tibice latce, compresse, extus uniseriatim denticulate vel spinose, foveola tarsali antica rectc parum exarata.

Corps ovale, légèrement convexe en dessus.

Tête médiocre, arrondie, s'enfonçant dans le prothorax; front plan, entouré d'une strie forte, bien marquée, entière, qui le distingue de l'épistome; labre arrondi, sillonnẻ; yeux ovalaires, peu saillants. Mandibules larges, courbées, terminées en pointe, inermes en dedans, égales entre elles.

Antennes (f. $1 c$ ) insérées sous un rebord du front, au devant des yeux; scape fort, assez court, épaissi au bout, contourné, logé dans une coulisse pratiquée au-dessous de la tête; funicule de sept articles : premier obconique, allongé, les autres serrés, s'élargissant graduellement; massue orbi- 
culaire, à peine plus large que le dernier article du funicule ; de quatre articles, velus, comprimés. Fossette antennaire profonde, pratiquée sous l'angle du prothorax, visible en dessous; bord pectoral fortement échancré, mais non entaillé.

Mâchoires (f. 1 b) cornées, garnies de longues soies, à deux lobes larges, velus èn dedans, l'externe très long. Palpes maxillaires larges, de quatre articles; premier petit, deuxième obconique, troisième de même forme, un peu plus court; quatrième plus fort, plus long, élargi, tronqué au bout et comme sécuriforme. Menton étroit, hérissé de soies longues, sinué en devant ; paraglosses courtes, arrondies au bout, ciliées en devant. Palpes labiaux de trois articles : premier très court, deuxième obconique, plus long, troisième allongé, subsécuriforme, tronqué et élargi au bout.

Pronotum transversal, un peu arqué à la base, presque droit sur les côtés, échancré en devant, avec les angles arrondis; une strie marginale, deux latérales, l'interne forte, entière, non interrompue en devant comme les deux autres, fort rapprochées sur les côtés, un peu plus éloignées aux angles antérieurs. Ecusson très petit, ponctiforme. Elytres peu convexes, de la largeur du pronotum à la base, légèrement arrondies sur les cotés, un peu obliques au bord apical, angle sutural à peine sensible; repli latéral avec urıe fossette humérale, sillonnć par deux stries marginales, plus profondes sous l'épaule; strie humérale peu distincte, une subhumérale externe, cinq dorsales et une suturale entières. Prosternum étroit, assez court, convexe, plus saillant à la base, arrondi et rebordé, pénétrant un peu dans le mésosternum; muni en devant d'un lobe infléchi, arrondi et 
rebordé. Mésosternum court, assez large, échancré en devant, uni-strié au milieu, bistrié sur les côtés.

Pattes courtes et larges. Cuisses creusées en dedans d'une coulisse pour loger les jambes. Jambes très larges, minces, tranchantes, à une scule arête externe, munies au bout de deux épines inégales; antérieures triangulaires, quadridentées, avec une fossette tarsale droite, mal limitée en dehors; intermédiaires et postérieures dilatées dès la base et presque parallèles, creuses en dessus, un peu convexes en dessous, garnies d'un seul rang d'épines. Tarses comprimés, logés sur la jambe, de cinq articles : 1-4 triangulaires, garnis en dessous de deux soies, à peu près égauxen longueur, mais diminuant d'épaisseur, dernier un peu plus long et portant deux petits crocliets inégaux.

Abdomen de cinq anncaux; premier segment ventral, très long, 2-strié; les quatre autres très courts et serrés. Propygidium en hexagone transversal, abaissé. Pygidium triangulaire, vertical.

Ce genre est établi pour une seule espèce des Etats-Unis, qui II'a nul rapport de forme et de caractères avec les Omalodes, avec lesquels $\mathbf{M}$. J. Le Conte la range dans sa Monographie des Histérides des Etats-Unis. M. J.-L. Le Conte, son fils, dans l'Essai de classification des Histérides qu'il vient de publier dans les Proceedings de l'Académie des sciences naturelles de Philadelphie, tout en réunissant au genre Hister les Omalodes Er., aussi bien que les Platysoma Leach, forme une division à part pour l'O Harrisii, entre les Omalodes et l'Hister arcuatus Say. On le reconnait d ses jambes extrêmement ininces et aplaties, garnies d'une seule rangée d'épines ou de dents, à ses fossettes tarsales droites et mal limitées, à ses fossettes antennaires plus enfoncées 
et découvertes, à la profonde échancrure du bord pectoral antérieur, enfin, au dernier article des palpes sécuriforme. II est rare dans les collections; ses mours et ses métamorphoses sont inconnues.

\section{P. Harrisil.}

Ovatus, parum convexus, niger, obscurus, rugosus punctatissimus, antennis oreque rufis, pedibus piceis: fronte subplana, stria integra, pronoto striis marginuli et laterali $1^{a}$ inter $u p t i s$, 2 a integra; elytris stria subhumerali postice abbreviata, dorsalibus 5 et suturali integris; pygidio fortius punctato; tibiis anticis 4 -dentatis. Long. 8 mill.; larg. 5 mill.

Hister planipes. J.-L. Le Conte, class. Hist. (1852) 39.

OmalodesHarrisii. J. Le Conte, N. Amér. Hist. 14, 2; Pl. 1, 11 (1850).

Ovale, peu convexe, d'un noir mat, rugueux, densément ponctué. Front plan, séparé de l'épistome par une forte strie bisinuée, non interrompue en devant. Antennes d'un rouxbrun, massue gris-roussâtre. Pronotum court, transversal, légèrem̉ent arqué à la base, droit sur les côtés, échancré en devant, avec les angles antérieurs arrondis; strie marginale fine, cessant derrière les yeux, ainsi que la première latérale, deuxième plus forte, non interrompue: ces trois stries, rapprochées sur les côtés, s’éloignent à l'angle antérieur. Ecusson très petit, ponctiforme. Elytres une fois et demie plus longues que le pronotım, de sa largeur à la base. élargies à l'épaule, coupées un peu obliquement et rétrécies au bord apical; strie subhumérale externe raccourcie postérieurement, interne nulle, dorsales et suturale entières, mais un peu irrégulières dans leur direction; repli latéral sillonné de deux stries plus profondes, et fovéolé sous l'épaule. Pygidium plus grossièrement ponctué. Prosternum arrondi 
et rebordé à la base, lobe antérieur infléchi. Mésosternum échancré et rebordé d'une strie entière. Jambes antérieures élargies, quadri-dentées; postérieures élargies en rames aplaties, garnies en dehors d'un rang de huit à neuf épines.

Amérique boréale (Pensylvanie). (MM. de Laferté et Chevrolat.)

\section{CONTIPUS.}

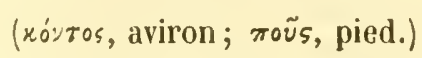

Soc. Ent. 3 série. T. 1 (1S53), pl. 16. - Mon. pl. 7. Genre XVIII.

Corpus ovatum, subglobosum.

Caput retractum, stria frontali integra, labro mimuto; mandibulis cequalibus, palporum ultimo articulo longo fusiformi.

Antenne sub frontis margine inserte, clava vix a funiculo distincta, foveola sub angulo prothoracis detecta.

Prosternum carinaium, basi rotundatum receptum, lobo inflexo prominulo.

Pronotum antice angustius, depressum, striis 2 lateralibus.

Elyıra brevia, striis 2 subhumeralibus a basi incipientibus humerali oblique sectis, margine inflexo foveolato.

Propygidium hexagonum declive; pygidium perpendiculare.

Tibice latce, triangulares; antica dentatce, foveola tarsali extus inexarata, postice biseriatim spinosula.

Corps ovale, épais.

Tete arrondie, petite, fortement enfoncée dans le prothorax. Front transversal, ceint d'une strie qui le sépare de l'épistome; labre court, arrondi au bout. Yeux réniformes, 
peu saillants, perpendiculaires sur les côtés. Mandibules fortes, ordinairement rebordées en tessus, courbées en une pointe aiguë, dentées en dedans.

Anteunes (f. $3 d$ ) insérées sous un rebord du front; scape assez long, courbé, renflé au bout, logé dans une fosselte creusée sous la tête, entre les yeux et la base des mandibules; funicule de sept articles : premier obconique, plus allongé; les autres serrés, à peu près de même longueur, croissant graduellement en largeur, mais surtout à partir du cinquième; le septième est presque de la largeur de la massuc et parait en faire partie, mais il est glabre; massue arrondie, serrée, comprimée, couverte d'une pubescence bien fournie, de quatre articles. Fossette antennaire creusée sous l'angle antérieur du prothorax, visible derrière le bord pectoral antéricur.

Mâchoires (f. $3 b$ ) cornées, à deux lobes garnis en dedans de longrs poils serrés; externe étroit, très allongé, interne très court. Palpes maxillaires de quatre articles, premier petit, deuxième obconique, troisième cylindrique, court; quatrième fusiforme, presque cylindrique, trois fois plus long que le précédent. Menton ( $f .3 c$ ) corné, en trapèze, à peine rétréci en devant, subsinué; lèvre membraneuse, bifide; paraglosses longues, arrondies et larges, barbues en dedans. Palpes labiaux de trois articles : premier petit, deuxième obconique, troisième fusiforme, plus long.

Pronotum bombé, beaucoup plus large que long, arrondi il la base, légèrement arqué sur les côtés, arec une stric marginale et deux latérales; rétréci et échancré en devant. pièce humérale visible en dessus. Ecusson triangulaire, petit. Elytres courtes, un peu plus longues que le pronotun, de sa largeur à la base, curvilinéairement dilatées à l'épaule, 
rétrécies et à peine arquées au hord apical ; fossette sublumérale bien marquée, avec deux stries marginales; humérale fine, oblique, croisant les deux subhumérales ; cinq dorsales et une suturale entières. Prosternum court, en carêne assez saillante, arrondi à la base et s'enfonçant à peine dans le mésosternum, sans stries; lobe assez court, infléchi, rebordé et arrondi en devant. Mésosternum en trapèze, sinué en devant, avec les angles arrondis, bistriés ; une seule des stries se continue autour de la sinuosité.

Pattes longues, aplaties, larges. Cuisses dilatées, rebordées de chaque cóté, avec une coulisse pour recevoir les jambes. Jambes anterieures très larges, en triangle, armées de trois ou quatre fortes dents et terminées par deux épines inégales ; fossette tarsale droite, peu profonde, étroite, mal limitée extérieurement. Intermédiaires et postérieures dilatées dès le genou, minces, tranchantes, en forme de rames, garnies en dehors de sept ou huit paires d'épines courtes; terminées par des épines inégales. Tarses courts, comprimés, de cinq articles, garnis chacun en dessous de deux soies, égaux entre eux, serrés; le cinquième plus mince et à peine plus long, armé de deux crochets courts, égaux, et saillant entre eux comme un troisième crochet.

Abdomen de cinq anneaux; premier segment ventral assez long, bistrié ; deuxième un peu moins long, cependant beaucoup plus que les trois derniers. Propygidium en hexagone, plus large que long, abaissé; pygidium en triangle curviligne, vertical.

Ce genre, remarquable par ses jambes très larges et aplaties, a beaucoup de rapport avec les Psiloscelis : il s'en distingue par les épines des jambes postérieures rangées par paires, par la massue moins abrupte et de la largeur du 3. Série, Tоме I. 
septième article du funicule, par les palpes allongés, dont le dernier article est fusiforme, et surtout par la disposition des stries subhumérales de ses élytres bien marquées à la base, l'interne entière, l'externe raccourcie. Il se compose de trois espèces, deux du Sénégal et une du Yucatan, dont les mœurs me sont inconnues.

\section{C. Didymostrius.}

Ovalus, comexus, niger, nitidus, mandibulis bidentatis marginatis; frontestriasemicirculariintegra; pronoto striistemuibus, marginali integra, 2 lateralibus ad angulum anticum evanescontibus, altcrntra in medioredintegrata; clytris striis didymis, suturali, 5 dorsalibus, subhumerali interna integris, externa abbreviata; tibiis anticis 3-dcntatis. Long. 10 mill.; larg. 7 1/2 mil.

Ovale, très convexe, d'un noir lisse ct luisant. Front pointillé finement, plan, ceint d'une strie semi-circulaire, qui le sépare de l'épistome ; mandibules rebordées, bidentées en dellans. Antennes brunes, massue velue, grise. Pronotum plus large que long, arrondi à la base, à peine arqué sur les côtés, fortement rétréci et échancré en devant, visiblement et très finement pointillé sur les côtés ; stries fines, marginale entière; deux latérales cessant à l'angle antérieur, mais l'une ou l'autre reparaît au devant de l'échancrure céphalique. Ecusson petit, triangulaire. Elytres courtes, cependant plus longues que le pronotum, de sa largeur à la base, fortement dilatées à l'épaule, rétrécies au bord apical; stries géminées, composées chacuue de deux petites stries parallèles, fort rapprochées; dorsales et suturale entières, subhumérale interne également entière, plus profonde postérieurement, externe raccourcie au milieu, l'une et l'autre traversées obliquement par l'lıumérale ; fosseltc subhumérale 
profonde, sillonnée par deux marginales, bien marquées, entières. Mésosterıum faiblement sinué en devant, strie marginale entière. Propygidium hexagonal, oblique, lisse, bifovéolé; pygidium rebordé étroitement à la base de clıque côté. Jambes antérieures fortement tri-dentées; postérieures garnies en delıors d'une double série d'épines courtes.

Sénégal (M. de Laferté).

\section{C. mgitatus.}

Ovalis, subdepiessus, niger, nitidus; mandibulis marginatis, edentatis; pronoto striis 2 lateralibus, interna integra, externa abbreviata; elytris margine inflexo 3-sulcato, striis dorsalibus 1-3) et subhumerali intema integris, coleris abbreviatis; momygidio lateribus, mygidio tolo dense punctalis; mesosterno emarginato; tibiis anticis 4-dentatis. Long. 8 mill.; larg 5 mill.

Ovale, légèrement déprimé, noir luisant. Antennes brunes, massue roussâtre. Front large, plan, pointillé ; strie bien marquée, entière, droite en devant; mandibules courbées, bombées en dessus, rebordées et sans dents. Pronotum court, à peine arqué à la base, droit sur les cotés, échancré fortement en dedans, avec les angles saillants, arrondis; strie latérale interne entière, forte, en crochet à la base, externe raccourcie postérieurement. Ecusson petit, triangulaire. Elytres beaucoup plus longues que le pronotum, de sa largeur à la base, arrondies à l'épaule, rétrécies et droites au bord apical, sans angle sutural; repli latéral avec une fossette profonde sous l'épaule et trois forts sillons; stries bien marquées, 1-3 dorsales cntières, 4-5 très courtes, apicales, suturale raccourcie au milieu; sublıumérale externe cessant à l'épaule, interne entière, traversées obliquement l'une et l'autre par l'lumérale. Propygidium bifovéolé, 
ponctué sur les cotés, pygidium à la base. Mésosternum échancré, bordé d'une strie entière. Jambes antérieures bordées de quatre fortes dents; postérieures d'une double rangée de petites épines.

Sénégal (M. de Laferté).

\section{C. subquadatus.}

Ovatus, convexiusculus, niger, nitidus; mandibulis subrectis, denticulatis, immarginatis; pronotostriis 2 dorsalibus antice coalescentibus integris; elytris striis 1-4 dorsalibus integris, $5^{\mathrm{a}}$, suturali jet utraque subhumerali abbreviatis; propygidio bifoveolato pygidioque dense puncutis, mesosterno emarginato, tibiis anticis 3-rlentatis. Long. 6 mill.; larg 4 mil.

Ovale court, assez convexe, noir luisant. Antennes brunes. Front pointillé, assez bombé, eutouré d'une strie droite en devant, entière; mandibules courbées seulement au bout, arrondies, sans rebord, garnies de deux denticules obtus en dedans. Pronotum court, arqué et bordé de points à la base, courbé et bordé de cils sur les côtés, rétréci et échancré en devant, avec les angles abaissés, assez saillants; stries latérales parallèles, entières, réunies en une seule au bord antérieur. Ecusson petit, triangulaire. Elytres pointillées, un peu plus longues et aussi larges que le pronotum à la base, curvilinéairement dilatées sur les côtés, droites et un peu rétrécies au bord apical, avec un petit angle sutural; repli latéral avec deux sillons profonds et une fossette à l'épaule; stries dorsales fortes, 1-4 entières, cinquième raccourcie an milieu, suturale un peu au-delà, subhumérale externe au tiers de la base, interne presque entière. Propygidium hifovéolé, ponctuć sur toute sa surface; pygidium 
seulement à la base. Iésosternum échancré en devant, bordé d'une strie entière. Jambes antérieures faiblement tri-dentées; postérieures garnies de deux rangées de petites épines.

Yucatan (M. Pilate).

\section{MARGARINOTUS.}

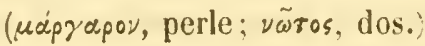

Soc. Ent. $3^{\circ}$ série, T. 1 (1853), pl. 16. - Mon. pl. 7. Genre XIX.

Hister. Fabr. Ent. Syst. (1792), - Payk. Mon. (1811).

Corpus ovatum convexum, rugoso-punctalum, dorso tuberculis nilidis lavibus sparso.

Caput parvum retrachum, fronte stria circulari, mandibulis cequalibus. Palpi maxillares crassi, arliculis 2-3 securiformibus, 30 ovuto, cequalibus; labiales articulo 30 elongato.

Antennce breves, sub frontis murgine inserte, funiculo tenui, clava magna ovali abrupla.

Prosternum elevatum, bistriatum, basi rolundatum, receptum, lobo brevi inflexo.

Elytra postice arcuala, angustala, margine inflexo foveoluto.

Tibice antice extus dentalce, foveolu lursali huud exarala, postica tuberculis bispinosis armalce.

Corps ovale, convexe, ponctué-rugueux sur toute sa surface, avec des plaques lisses, luisautes en dessus.

Tête petite, s'enfonsant dans le prothorax; front entouré d'un rebord élevé, qui le sépare de l'épistome, également rebordé et excavé; labre un peu plus long que large, sillonné dans sa longucur; yeux ovalaires, aplatis, obliques 
sur les còtés. Mandibules recourbées au bout en pointe aiguë, garnies en dedans à la base de poils serrés, inermes.

Antennes $(f .1 d)$ insérées sous un rebord du front, au devant des yeux; scape court, courbé, renflé au bout, logé dans unc coulisse du bord inférieur de la tête; funicule court, de sept articles peu serrés : premier un peu plus long, obconique; les autres vont en diminuant de longueur et en augmentant de largeur vers la massue; celle-ci abrupte, ovalaire, en pointe, revêtuc de poils serrés, de quatre articles distincts, inégaux. Fossette antennaire visible en dessous, arrondie, bien linitée sous l'angle antéricur du prothorax, entre deux feuillets du bord pectoral antéricur, le supérieur est traversé par l'antenne, l'inférieur est sinué, abaissé peu à peu.

Màchoires (f. 1 b) cornées, sur les còtés du menton, bordées de longues soies; à deux lobes frangés en dedans; exterue étroit, fort long; interne court. Palpes maxillaires épais, de quatre articles : premier petit, deuxième gros, sécuriforme, troisième de mème forme et aussi long, quatrième à peine plus long, ovalaire, terminé en pointe obluse. Menton (f. $1 c$ ) presque carré, échancré en devant, hérissé de longues soies; lèvre échancrée, avec deux paraglosses en lanières, ciliées, membraneuses, terminées en pointe. Palpes labiaux de trois articles allongés : premier petit; deuxième deux fois plus long, obconique; troisième presque cylindrique, en pointe obtuse, aussi long que les deux premiers réunis.

Pronotum court, élargi postérieurement, légèrement bisinué à la base, confusément 3 -strié sur les côtés, échancré en devant. Pièce humérale visible en dessus. Ecusson petit, triangulaire. Elytres plus longues gue le pronotum, de sa 
largeur à la base, curvilinéairement dilatées sur les côtés, rétrécies et arquées au bord apical; repli latéral creusé sous l'épaule; on ne remarque que quelques stries rudimentaires irrégulières. Prosternum assez saillant, convexe, arrondi à la base, rétréci et bistrié au milieu, muni d'un lobe antérieur, infléchi, étroit, arrondi en devant et rebordé. Mésosternum en trapèze, échancré en devant et bordé d'une strie non interrompue, séparé du métasternum par une strie transversale.

Pattes assez allongées, étroites. Cuisses renflées, creusées d'une coulisse pour loger les jambes, et rebordées en dedans. Jambes étroitement triangulaires, avec une seule arête externe, et au bout deux courtes épines presque égales; antérieures obtusément tridentées, et creusées en dessus d'une fossette tarsale droite, mal limitée en dehors: postérieures garnies de quatre tubercules bi-épineux, et. en outre, ciliées. Tarses de cinq articles comprimés, garnis en dessous de deux soies, égaux entre eux, cinquième un peu plus étroit et plus long, armé de deux courts et fins crochets.

Abdomen de cinq anneaux : premier segment ventral plus long; les quatre autres égaux et plus courts en dessous. Propygidium oblique, en hexagone transversal; pygidium en triangle curviligne, convexe, abaissé.

J'ai cru devoir établir ce genre pour l'Hister scaber $\mathbf{F}$., qui n'est pas mentionné dans le travail important d'Erichson, quoique parfaitement figuré et décrit dans Paykull. Cette remarquable espèce n'a pas, il est vrai, de différence importante dans le sternum, la tète, les pattes, le pronotum, qui la sépare nettement du grand genre Hister; néanmoins la forme des antennes et relle des palpes se joignent, pour Ic 
distinguer, à cette configuration singulière du dos, où les stries semblent remplacées par des rangées de tubercules luisants et saillants, en guise de perles sur un fond obscur et rugueux.

\section{SCABEl.}

Ovalis, convexus, niger, obscurns, ore antennisque rufis, punctatissimus rugosus, tuberculis rotundatis lavibus nitidis; pronoto, triplici serie transversa 4, 4, 6, elytris lineis longitudinallbus irregularibus, propygidtio 5, pygidlio 4; tibiis anticis 4-dentatis, posticis biscriatim spinosulis. Long. 7 mill.; larg. 5 mill.

Hister scaber. F. Ent. Syst 1, 73, 5 (1792), - F. Syst. EI. 1, 86, 12. - Payk. Mon. Hist. 83, 66. T. vII, f. 4.

Ovale, convexe, d'un noir obscur, rugueusement ponctué en dessus et en dessous, et couvert de plaques arrondies, élevées, lisses, luisantes. Front couvert d'impressions irrégulières, entouré d'un rebord élevé, étroit, ainsi que l'épistome, dont il est distinct par une crête transversale; labre étroit, sillonné longitudinalement; yeux roux, aplatis. Antennes rouge-brun, scape plus obscur, massue velue, grisâtre; bouche ferrugineuse. Pronotum convexe, beaucoup plus large que long, subbisinué à la base, presque droit sur les cotes, échancré et fortement rétréci en devant; deux ou trois stries fines, irrégulières, peu distinctes latéralement; tubercules larges, irrégulièrement arrondis, disposés sur trois rangées transversales, 4, 4, 6; la paire médiane réunie souvent avec la paire correspondante des autres rangées. Ecusson petit, triangulaire, sillonné. Elytres convexes, une fois et demie plus longues que le pronotum, de sa largeur à la base, curvilinéairement dilatées sur les 
cótés, rétrécies et arrondies au bord apical; angle sutural marqué, mais petit; on aperçoit quelques rudiments de stries obsolètes; elles semblent remplacées par des rangées longitudinales de plaques élevées, lisses; ces rangées irrégulières, au nombre de six, ell contiennent chacune de cinq à huit; repli latéral creusé sous l'épaule. Propygidium couvert de cinq tubercules, et pygidium de quatre. Prosternum arrondi à la base, rétréci au milieu, bistrié; lobe antérieur infléchi, étroit, peu allongé. Jambes antérieures armées de quatre dents obtuses, l'apicale bifide; postérieures garnies de quatre tubercules épineux et de soies assez longues.

Portugal, Espagne, Algérie, sous les pierres, dans des matières animales en putréfaction.

Nors. Le Pachycrerus viridis, décrit p. 452, dont la patrie n'a pas été indiquée, vient du pays des Hottentots, et l'Hololepta subhumilis, lécrit p. 163, est du Mexique. 



\title{
ESSAI MONOGRAPHIQUE
}

\section{SUR LA FAMILLE DES HISTERIDES.}

\author{
(Suite) (1).
}

Par M. S. A. de MARSEUL.

(Séance du 9 Février 1853.)

\section{HISTER.}

(Hister, mot étrusque, histrion (2).

Soc. Ent. $3^{\text {e }}$ série, T. 2 (1854), pl. vi à x. - Moı. pl. viIxil. Genre XX.

Hister. L. Syst. nat. (1735); Fabr. Payk. Gyll. Erichs. etc.

Corpus ovalum, crassum.

Caput retractile; fronte stria integra; antennis sub margine insertis, funiculo plus minusve incrassuto, clava ovali 4-articulata; mandibulis exsertis, ot leva scepe longiori.

Prosternum compressum, basi rolundalum, lobo incurvo prominulo, margine pectorali emarginato, fossa antennali scepius vaga sub angulo prothoracis. Mesostermum aut simuatum aut rectum, marginatum.

(1) Voyez $3^{e}$ série, t. I, p. 131 et 447.

(2) Suivant les auteurs qui se sont occupés de l'étynologie du nom Hister, ces insectes ont été ainsi appelés, parce qu'ils ressemblent à un histrion, soit par leurs élytres courtes et bariolées de rouge, soit par leur habitude de se tenir immobiles et de faire le mort.

3e Série, tome 11. 
Pronotum trapezoïdale, convexum, antice emarginatum, stria marginali et 1 vel 2 lateralibus. Elytra striis 5 dorsalibus, internis et suturali scepius abbrevialis, quandoque obsolctis, margine inflexo sulcalo.

Propygidium hexagonum, pygidium semi-circulare, deelivia.

Tibice intus incrmes, anticce extus dentatce, fossa tarsali recta, parum exarala; posticce extus biseriatim spinosulce.

Corps épais, ovalaire, allongé ou raccourci, plus ou moins bombé.

Tête plus ou moins large, s'enfonçant dans le prothorax et s'inclinant en avant. Front en ovale transversal, plan, légèrement bombé, rarement impressionné, entouré d'une strie semicirculaire, quelquefois interrompue en devant; épistome distinct du front; yeux réniformes, peu saillants. Labre tantôt ovalaire échancré, tantôt triangulaire, à lobe moyen avancé dans le $\sigma^{*}$ et de formes diverses; ordinairement court, transversal. Mandibules saillantes, de forme variable.

Antennes (fig. $1 a$ et 91 d) insérées sous un rebord du front : scape assez long, courbé, épaissi au bout, logé dans une gouttière pratiquée entre les yeux et la base des mandibules; funicule de sept articles : premier obconique, plus long que les suivants, 2-6 courts, á peu près égaux, septième beaucoup plus large, appliqué contre la massue; celle-ci de quatre articles coupés plus ou moins obliquement, velus. Fossette antennaire plus ou moins bien limitée; l'antenne est logée dans l'intervalle compris entre la tête et le prothorax. Souvent le bord pectoral ne présente qu'un simple pli dans lequel passe le scape, d'autres fois une fossette se forme entre ce pli et l'angle antérieur. 
Menton (f.91 d) presque carré, petit, plus ou moins échancré dans le milieu. Lèvre membraneuse, saillante : languette courte, paraglosses linéaires beaucoup plus longues, ciliées. Palpes labiaux de trois articles : deuxième obconique et troisième fusiforme, obtus, à peu près d'égale longueur. Mâchoire (fig. $91 d$ ) à lobes membraneux, barbus en dedans; externe long, terminé par un croclet, interne court. Palpes maxillaires de quatre articles; premier court, deuxième et troisième obconiques, égaux entr'eux, quatrième ovalaire, en pointe obtuse, souvent plus long que les précédents.

Pronotum plus large que long, légèrement arqué à la base, quelquefois bisinué; plus ou moins retréci et échancré en devant; bordé sur les côtés d'une fine strie marginale toujours visible au moins dans l'angle antérieur; en outre d'une strie latérale interne, rarement interrompue au milieu du bord antérieur, et souvent d'une externe plus ou moins raccourcie. Ecusson très petit, triangulaire. Pièce humérale visible. Elytres ordinairement plus larges que longues, plus ou moins convexes, de la largeur du pronotum a la base, dilatées à l'épaule, rétrécies et coupées obliquement au bout, où elles forment un angle sutural plus ou moins marqué; bord infléchi avec une fossette subhumérale plus ou moins profonde, traversée d'un ou de plusieurs sillons; strie humérale fine, courte, oblique; subhumérales quelquefois nulles; cinq dorsales dont les internes sont raccourcies ou nulles, ainsi que la suturale. Prosternum saillant, arrondi à la base, terminé en devant par un lobe peu avancé, rabattu, rebordé. Mésosternum transversal, échancré en devant et bordé d'une strie sourent interrompue à l'échancrure; quelquefois à peine sinué et même droit.

Pattes plus ou moins allongées; cuisses ovalaires, renflées 
au milieu, creusées d'une coulisse et rebordées en dedans. Jambes triangulaires, comprimées, terminées par deux épines inégales : antérieures dentées sur le bord externe, creusées en dessus d'une fossette tarsale, droite, limitée seulement en dedans; intermédiaires et postérieures garnies en dehors d'un double rang de dentelures plus ou moins serrées, émettant des épines. Tarses de cinq articles comprimés, garnis chacun de deux soies; premier à peine plus long que les suivants; cinquième armé de deux crochets.

Abdomen de cinq segments : premier plus long que les autres, bistrié en dedans des cuisses; 2-5 allant en diminuant de longueur; propygidium court, en hexagone transversal, arrondi en devant, coupé droit par derrière, incliné; pygidium semicirculaire, plus ou moins abaissé.

I.e genre Hister, créé par Linné dans son Systema naturœ, a longtemps compris toutes les espèces de la famille à laquelle il donne son nom. Paykull le premier, en 181I, en a séparé les espèces aplaties sous le nom de Hololepta. Plus tard, Leach a formé les genres Platysoma, Abrceus, Dendrophilus, et Onthophilus (Zool. Miscel. 3, 76. 1817). Enfin, Erichson a divisé le reste en coupes bien tranchées, lesquelles ont été adoptées par la plupart des entomologistes. Partant de ce point, j'ai séparé, du genre tel que cet auteur l'a constitué, d’abord les espèces à mésosternum en pointe s'enfouçant dans une incision de la base du prosternum, pour en former les genres Pachycrarus et Phelister, ensuite les $H$. saprinoides et scaber, qui ont une forme très différente des autres; mais malgré mes efforts, je me suis vu obligé de conserver tout le reste.

Ainsi réduit à cette limite étroite, le genre renferme encore un trop grand nombre d'espèces. J'en ai étudié et 
figuré cent quarante-huit, qui sont distribuées dans les diverses contrées de la manière suivante : Europe, vingtcinq; Afrique, quarante-cinq; Asie, trente; Amérique, trente-six; deux répandues par toute la terre, six dans toutes les parties de l'ancien continent, trois communes à la fois à l'Europe et à l'Afrique, et deux à l'Europe et à l'Asie.

Pour Linné il n'y avait que quatre espèces d'Hister; Fabricius, Olivier, Herbst, Illiger et plusieurs autres entomologistes en publièrent successivement de nouvelles, et le groupe s'était grossi de dix-neuf, lorsqu'en 1811 Paykull fit paraitre sa monographie. Ce travail ne le dota pas de nombreuses espèces, puisqu'il le porta seulement à trente-trois ; mais il en réunit tous les fragments épars, le fixa d'une manière stable et le rendit abordable par ses descriptions claires et ses figures bien caractérisées. Dans les vingt années qui suivirent, quelques espèces furent encore découvertes, et à l'époque de la classification d'Erichson (1834), le nombre total, qui était de quarante-huit, s'enrichit encore de trente-trois. Enfin dans ces dernières années, M. Le Conte en a publié dix et divers auteurs à peu près autant, de sorte que la totalité des espéces décrites se monte aujourd'hui à cent-douze, dont vingt-trois me sont inconnues.

Quoique le genre Hister éprouve quelques légères variations dans la forme de ses principaux organes, si stables dans les autres groupes, il a un faciès tellement caractéristique qu'on ne peut hésiter un seul instant à le distinguer des genres voisins. On le reconmaîtra sans peine aux caractères suivants : corps trapu, épais et ovalaire; pygidium semicirculaire, et propygidium hexagonal, l'un et l'autre obliques ; tête petite, fortement enfoncée, front séparé de l'épistome par une strie circulaire; antennes insérées sous un rebord 
du front, logées derrière le bord pectoral, où la fossette antenuaire, quand elle existe, est vague et placée sous l'angle; pronotum toujours ceint au moins d'une strie latérale, assez éloignée du bord; élytres, souvent creusées sous le bord infléchi d’une fossette sillonnée, à cinđ stries dorsales dont les internes sont souvent raccourcies ou obsolìtes; jambes antérieures à fossette tarsale droite et mal limitée en dehors, postérieures garnies d'épines sur plusieurs rangs; enfin prosternum comprimé, arrondi à la base, muni en devant d'un lobe assez court, rabattu, et mésosternum droit ou sinué, mais jamais en pointe.

Les différences sexuelles sont diverses et en général peu saillantes. Le $\sigma^{t}$ est plus luisant, plus lisse et moins arrondi que la 9 . Dans beaucoup d'espèces, surtout du deuxième groupe, il est remarquable par le prolongement extraordinaire soit du labre, soit de la mandibule gauche.

Ces insectes vivent dans les bouses et autres matières excrémentitielles, dans les fumiers, ordures, végétaux en décomposition, dans les charognes, dans les champignons pourris et dans le suc qui suinte des vieux arbres. Ils commencent à paraitre dès le premier printemps. On en rencontre encore en automne, mais en petit nombre. Certaines espèces indigènes sont fort communes et très abondantes. Cependant on les a peu étudiées, et on ne possède que des détails incomplets sur leurs mœurs. Les larves sont carnassières et ont à peu près le même genre de vie que l'insecte parfait. Elles se nourrissent volontiers de petits animaux crevés, tels que rats, taupes, etc. Elles se dévorent les unes les autres. Un II. merdarius trouvé, avec une larve et une nymphe, par M. Bellevoye, dans une pomme de terre malade, semblerait annoncer que cette espèce du 
moins peut faire sa nourriture d'une pareille substance. Mais une expérience de M. Bazin, notre collègue, prouve que les larves n'y touchent pas. Ces larves passent à l'état de nymphe vers le commencement de mai et accomplissent promptement leur dernière évolution. Néanmoins j'ai trouvé vers la fin d'août des larves paraissant appartenir å l'H. carbonarins et parvenues pour ainsi dire au terme de leur croissance. Passent-elles l'hiver dans cet état, ou bien y a-t-il deux éclosions par an? C'est ce que je ne saurais assurer, n'ayant pas réussi à les élever. Ce que Paykull dit des métamorphoses de l'H. mérdarius semblerait appuyer la dernière lyypothèse. La description de la larve de cette espèce est la seule qui ait été publiée, avec celle du $\boldsymbol{H}$. cadaverinus. Je la donnerai de préférence, parce que la description de Paykull n'est pas exacte en tout point, et que je suis certain de l'espèce de l'individu qui est sous mes yeux. Je connais néanmoins celle du $H$. unicolor, qui paraît n'en différer que par la dent des mandibules plus obtuse.

Larve (fig. 91 f). (Long. 15-18 mill.) Charnue, linéaire, subdéprimée. Tête cornée aplatie; front terminé en devant par quatre dentelures, creusé en dessus de quatre sillons longitudinaux : deux profonds médians, irréguliers et comme formés chacun de deux fossettes réunies, et deux autres courbés circonscrivant la bosse où sont ordinairement les yeux, qui ici paraissent nuls. Mandibules fortes, longues, courbées en pointe aiguë, unidentées au milieu du bord interne. Mâchoires (fig. 91, g, $h$ ) longues, de deux articles, premier trois fois plus long que le deuxième; celui-ci terminé par un palpe 3-articulé et émettant en dedans un petit lobe papilliforme, sétifère. Menton partant de la base entre les mâchoires; lèvre un peu élargie et sinuée en devant ; 
palpes labiaux bi-articulés. Antennes de quatre articles: premier court et rétractile ; deuxième assez long, renflé en dedans vers le bout, troisième un peu plus court, tronqué et élargi au bout, et garni en dehors de quelques épines; quatrième linéaire, inséré sur le côté interne du précédent.

Prothorax corné, un peu plus large et aussi long que la tête, ciliẻ sur les côtés, avec trois sillons, un longitudinal médian entier, et deux latéraux profonds, arqués en devant et n'occupant guère que la moitié postérieure. Mésothorax et métathorax charnus et d'un blanc roussâtre, très courts et plus larges que le prothorax. Pattes (fig. $91 e$ ) courtes, assez grêles, de quatre articles, crochet subulé.

Abdomen blanc roussâtre, de 9 anneaux ; 1-8 chacun de la longueur du prothorax, garnis de poils et présentant en dessus des plis transversaux; neuvième un peu plus long que les précédents, atténué et coupé droit au bout, terminé par deux appendices composés de deux articles biciliés au bout; anus placé en dessous dans un petit mamelon; neuf paires de stigmates, placés sur les côtés au quart antérieur du mésothorax et des huit premiers anneaux.

Nymphe (fig. 91 i). Cette larve forme dans la partie desséchée de la bouse de vache une cellule très lisse, où elle se transforme. Elle ne forme pas de coque. La nymple est d'uu brun pâle; elle ne rejctte pas entièrement la peau de la larve, qui reste adhérente à son extrémité et empêche de bien distinguer les deux filets qui persistent quelque temps. Parvenue à un certain degré de développement, clle laisse entrevoir la forme de toutes les parties de l'insecte parfait. 


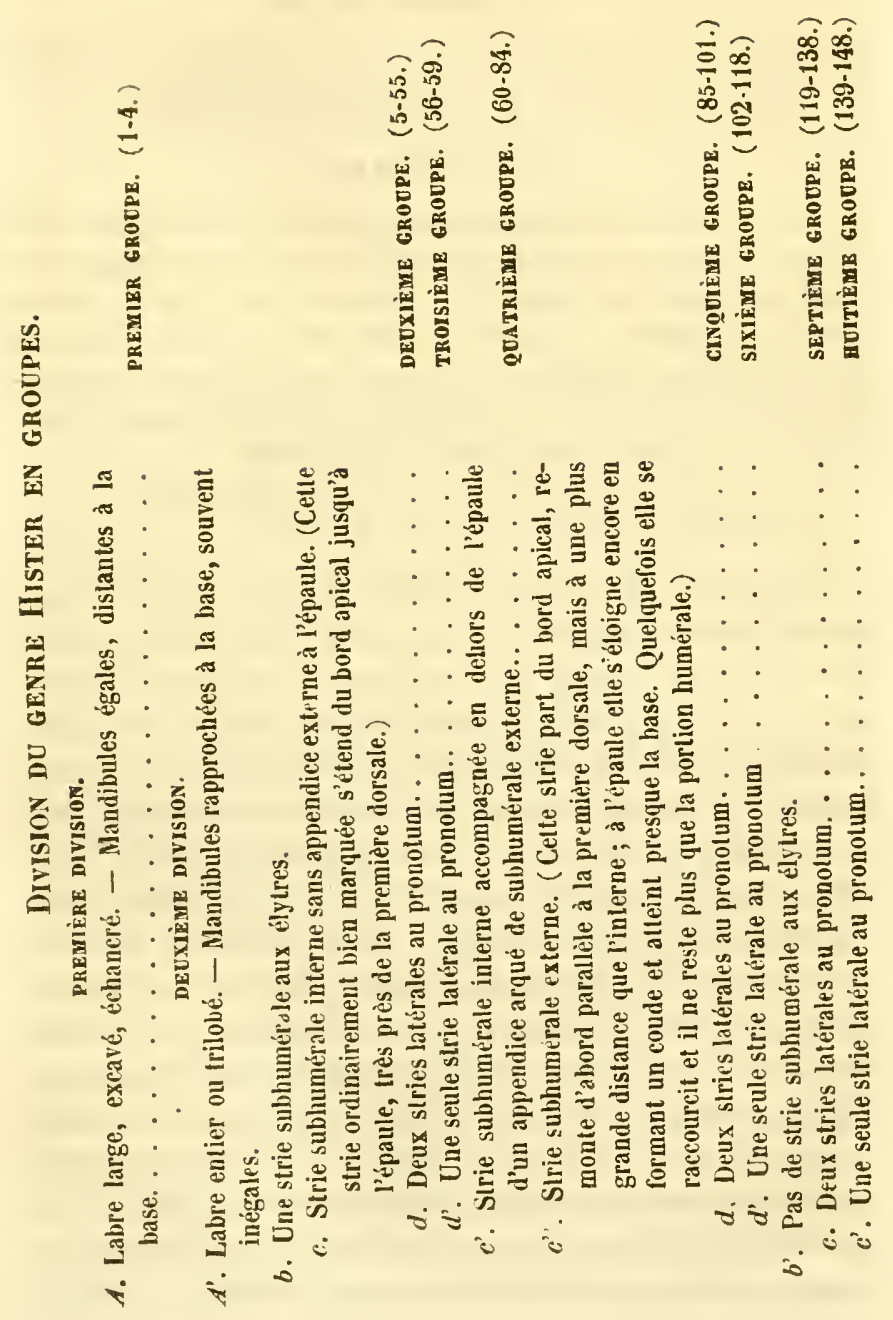


1 re Division.

1er Groupe (1-4).

A. Labre large, excavé, échancré. - Mandibules égales, distantes à la base. - Lobe maxillaire très saillant.

\section{H. GIGAS.}

Ovalis, subconvexus; niger, nitidus; stria frontall antice recta integra; pronolo brevi nigro-ciliato, stria laterali interna interrupta, utraque basi integris approximatis; elytris striis dorsalibus 1-4 integris, 5a et sulurali abbreviatis, foveola humerali levi; pygidio propygidioque punctatis; mesosterno valde emarginato, stria interrupta; tibiis anticis 3-dentatis, posticis 5-tuberculato-spinosis. Long. 20 mill.; larg. 15 mill.

Hister gigas. Payk. Mon. Hist. 9, 1. T. 11, f. 1 (1811).

H. maximus. Ol. Ent. 1, 8, p. 5, 2. Pl. 95, 5.

Ovale assez élargi, peu convexe, d'un noir luisant. Antennes brunes, massue petite, cendrée. Tête grosse, large; front convexe, séparé de l'épistome par une strie entière, droite par devant; labre semicirculaire, enfoncé, échancré; mandibules étroites, longues, arquées, unidentées en dedans, terminées en pointe obtuse. Pronotum court, bisinué et bordé de points à la base, avec une impression antéscutellaire; cilié et oblique sur les côtés, un peu rétréci, largement échancré en devant, avec les angles obtus, abaissés, saillants, présentant une apparence de fossette; strie latérale interne forte, interrompue au milieu, externe entière fine, presque réunie à l'interne aux deux bouts; écusson petit, triangulaire. Elytres un peu plus longues et aussi larges que le pronotum à la base, dilatées à l'épaule, rétrécies et obliques au bord apical; bord infléchi bisillonné et creusé d'une fossette imponctuée; stries fortes, ponctuées ; subhumérale entière, accompagnée quelquefois d'un rudiment externe, 1-4 dorsales 
entières, ciuquième et suturale plus ou moins raccourcies. Propygidium et pygidium couverts d'assez gros points serrés. Prosternum élevé, arrondi à la base, lobe rebordé peu saillant, bord pectoral avec un léger pli, sans fossette antennaire. Mésosternum profondément échancré, à strie interrompue. Jambes antérieures fortement tridentées; postérieures garnies de 5-6 tubercules épineux.

Sénégal.

\section{H. validus.}

Parallelo-ovatus, convexus, niger, nilidus; stria frontali antice subsinuata; pronoto basi punctato, nigro ciliato, stria laterali interna interrupta, externa postice abbreviata, antice parallela; elytris striis dorsalibus $1-4$ integris, $5^{\text {a }}$ suluralique abbreviatis; foveola humerali lcevi; pygidio dense punctato; mesosterno valde emarginato, stria interrapla; tibiis anticis 3-dentalis, posticis 5-tuberculato-spinosis. Long. 18 mill.; larg. $13 \mathrm{~m}$.

IIister validus. Er. in Jahrb. 1, 130, 2 (1834). - Fahr. in Boh. Ins. Cafr. 1, 529, 572.

II. Walkeri. Reiche. Voy. Abyss. 298, 1 (1851).

H. ponderosus. Fahr. in Bohem. Ins. Cafr. 1, 529, 573 (1851).

Ovale oblong, assez convexe, d'un noir lisse et luisant. Front large, convexe; strie fine entière, subanguleuse au milieu du bord antérieur; labre fortement excavé, mais faiblement échancré en devant. Mandibules faiblement unidentées au milieu, distantes, recourbées, terminécs en pointe obtuse. Antemnes d'un noir de poix. Pronotum très court, bisinué et ponctué à la base, avec un trait au devant de l'écusson, presque droit et cilié de noir sur les côtés, largement échancré et à peine rétréci en devant, avec les angles saillants, obtus, marqués d'une impression superficielle; strie latérale interne forte, interrompue au milieu du bord antérieur, entière; exterıc raccourcie au milieu, ne se joignant pas à l'interne à l'angle antérieur, mais le dépas- 
sant et suivant quelque temps le bord antérieur parallèle à sa congénère. Ecusson petit, triangulaire. Elytres de la largeur du pronotum à sa base, à peine dilatées, un peu plus courtes, rétrécies et à peine obliques au bord apical; bord infléchi creusé d'une fossette subhumérale et bisillonné, strie subhumérale atteignant l'épaule, première dorsale coudée à la base, entière, ainsi que les $2-4$; cinquième raccourcie au milieu, suturale moitié moins grande. Pygidium densément ponctué. Prosternum arrondi à la base, lobe rebordé peu saillant; mésosternum profondément échancré, strie marginale interrompue. Jambes antérieures fortement 3-dentées; postérieures garnies de 5-6 rangs de tubercules épineux.

Cette espèce a les plus grands rapports avec la précédente dont elle paraît différer par sa taille plus petite, sa forme plus convexe et plus parallèle, ses épaules moins saillantes et son pronotum encore plus court par rapport aux élytres. On la trouve en Cafrerie, au Sénégal et au Sennaar (Nubie).

\section{H. RoBtstus.}

Ovatus convexus, lavis parum nitidus ; labro brevi excavato, subemarginato; stria; frontali obsoleta; pronoto lateribus ciliato, stria laterali interna interrupta, externa levissima; ely. tris striis tenuissimis punctatis, 1-3 integris, 4-5 et suturali obsoletis; fossa subhumerali punctata, bisculcata; pygidio dense punctulato; prosterno lobo brevi acuminato; tibiis unticis 3-dentatis, posticis 7-8 tuberculato-spinosutis. Long. $18 \mathrm{~m}$. ; larg. $9 \mathrm{~m}$.

Hister robustus. Er. in Jahr. 130, 3 (1834). - Fahr. in Bohem. Ins. Cafr. 530, 57.

H. obscurus. Reiche. Voy. Abyss. 300, 2 (1851).

H. gravis. Fahr. in Bohem. Ins. Gafr. 1, 532,577 (1851).

Ovale court, bombé, d'un noir lisse, presque mat. Front peu convexe; strie entière, mais peu marquée. Labre court, impressionné, peu profondément échancré en devant. Mandibules courtes, assez fortes, faiblement unidentées en 
dedans. Antennes brun de poix, massue velue, grise. Pronotum court, bisinué à la base, droit sur les côtés, fortement échancré en devant, avec les angles saillants, obtus, marqués d'une fossette oblique superficielle. Strie latérale interne partant de la base, continuée au bord antérieur, interrompue au milieu; externe fine, plus ou moins entière. Ecusson petit, triangulaire. Elytres de la largeur du pronotum à la base, une fois et demi plus longues que lui; dilatées et arrondies à l'épaule, rétrécies postérieurement; fossette subhumérale avec deux sillons bien marqués, bordés de points; strie subhumérale fine, ponctuée, ainsi que les dorsales; dont les trois premières sont entières, les quatrième, cinquième et suturale obsolètes. Propygidium et surtout pygidium densément ponctués. Prosternum arrondi à la base; lobe court, rebordé, pointu; mésosternum écliancré, rebordé d'une marginale interrompue. Jambes antérieures assez fortement 3-dentées; postérieures garnies de 7-8 tubercules épineux. - Cap de B.-Espérance; Cafrerie; Abyssinie.

\section{H. MAJOR.}

Ovato-subquadratus, convexiusculus, niger, nitidus; fronte lata, stria sinuata integra, labro inciso; pronoto fulvo longius cincto, striis lateralibus integris pone oculos interruptis; elytris margine inflexo bisulcato, subhumerali interna et 1-3 dorsalibus integris, ccteris brevibus seu obsoletis; pygidio dense punctato; prosterno lobo brevi acuminato; tibiis anticis 3-dentatis, posticis tuberculato-longius spinosis. Long. 13-10 ; long. 9-7.

Hister major. Lin. Syst. nat. 1, II, 566, 3 (1735). - F. Syst. ent. 52, 1. - Spec. 1, 60, 1. - Mant. Ins. 1, 32, 1. - Ent. Syst. 1, 72, 1. - Syst. El. 1, 83, 1. - Ol. Ent. 1, 8, p. 6, 3, pl. 1, 4. Rossi. Mant. Fn. Etr. 1, 11, 18. - Panz. Ent. Germ. 1, 20, 1. Fn. Germ. 1, 43, 7. - Sturm, Deuts. f. 1, 190, 2. - Dufts. Fn. Austr. 1, 200, 2. - Payk. Mon. Hit. 11, 3, pl. 2, 3. - Heer, Fn. Helv. 1, 452, 1. - Küist. Kaf. Eur. 3, 33.

Ovale presque carré, légèrement convexe, noir luisant. 
Antennes brun de poix, massue petite, grise, velue. Tête grosse; front large, convexe, séparé de l'épistome par une fine strie entière, sinueuse; labre arrondi, fortement et plus ou moins largement incisé; mandibules assez courtes, arquées, assez aiguës, dentées en dedans. Pronotum bordé dans tout son pourtour de longs poils jaunes serrés, épais; transversal, court, bisinué à la base, oblique sur les côtés avec deux stries latérales, sinuées, parallèles, partant de la base et cessant au même point derrière les yeux, largement échancré en devant avec les angles saillants, obtus, abaissés. Ecusson petit, triangulaire. Elytres un peu plus longues que le pronotum, de sa largeur à la base, un peu rétrécies et coupées droit au bout; bord infléchi bisillonné avec une fossette sous l'épaule; stries fines, subhumérale interne et 1-3 dorsales entières, les autres courtes, obsolètes ou nulles. Pygidium et propygidium fortement ponctués, le premier plus densément. Prosternum élevé, arrondi à la base, lobe court, aigu, rebordé. Mésosternum profondément échancré, strie marginale interrompue. Jambes antérieures armées de trois fortes dents; postérieures de 6-7 tubercules garnis de longues épines, ainsi que les tarses.

Cette espèce vit dans les matières stercorales; elle est commune dans le sud de l'Europe et dans le nord de l'Afrique. On la trouve également en Syrie.

\section{$2^{e}$ Division.}

A'. Labre entier ou trilobé. - Mandibules rapprochées à la base, souvent inégales. - Lobe maxillaire non saillant.

B. Une strie subliumérale interne sans appendice aux élytres.

C. Deux stries latérales au pronotum.

2e Groupe (5-55). 


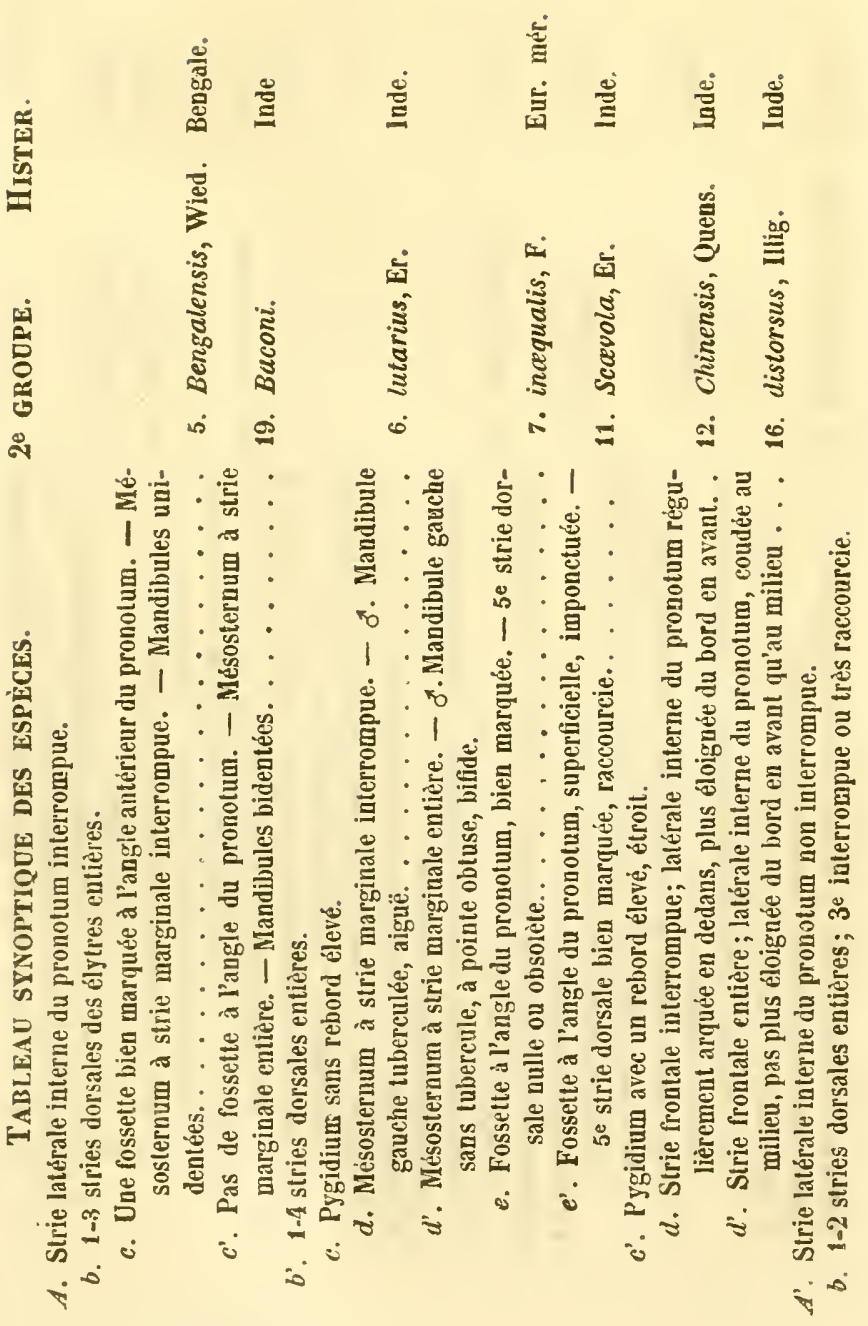




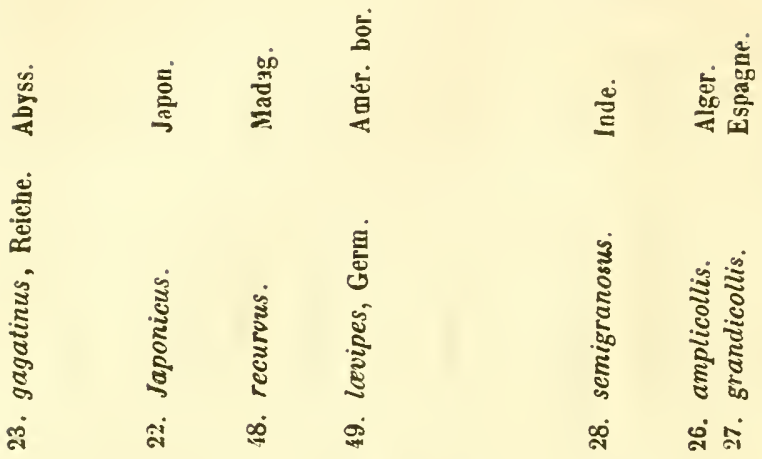

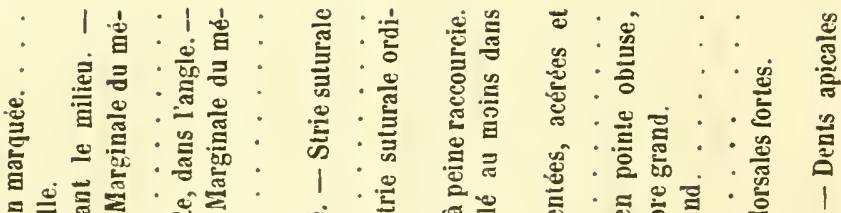

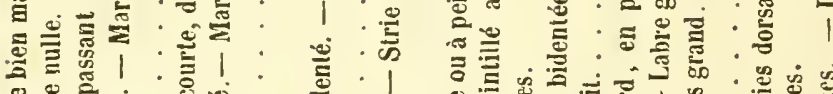

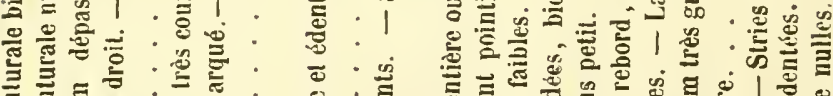

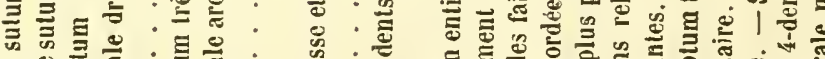

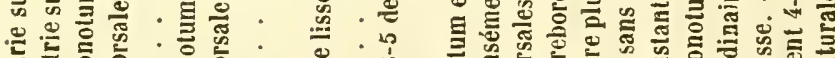

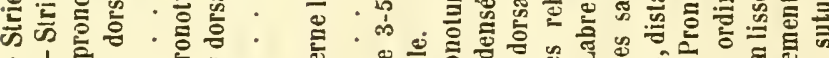

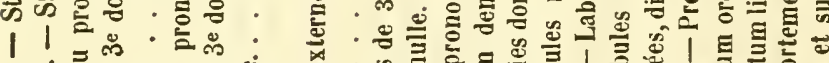

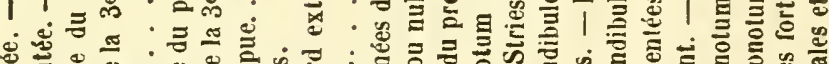

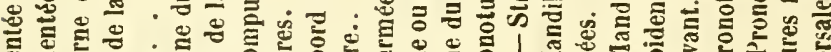

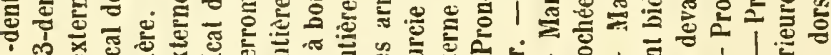

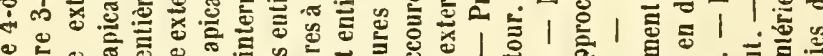

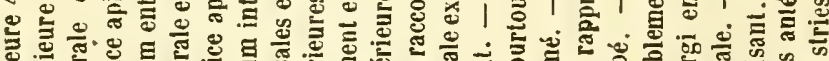

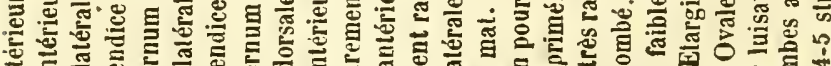

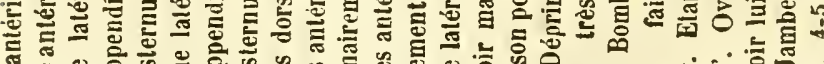

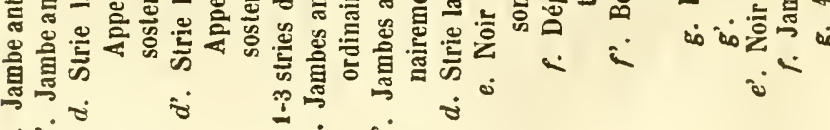


XX. Ilister.

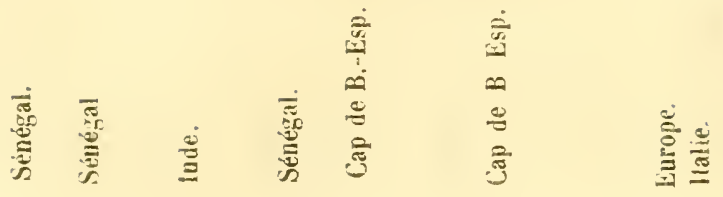

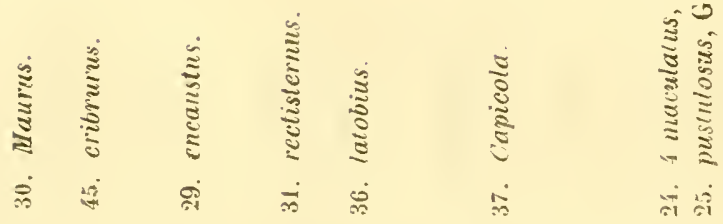

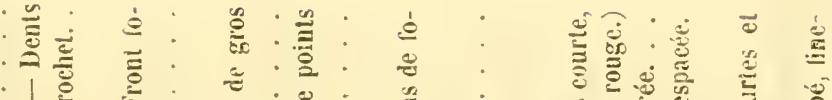

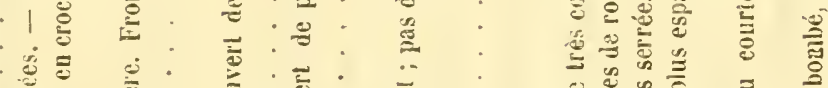

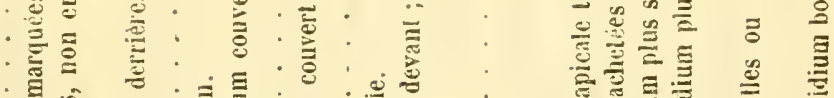

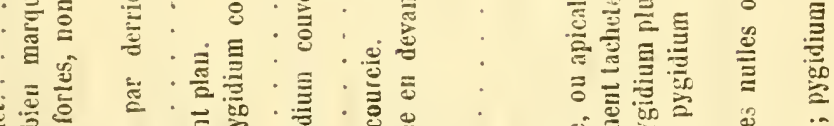

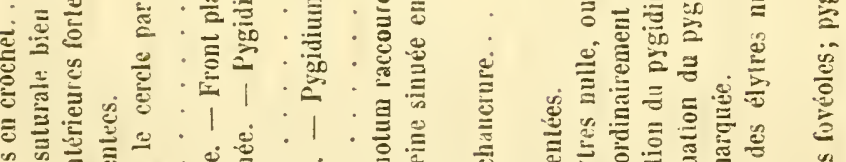

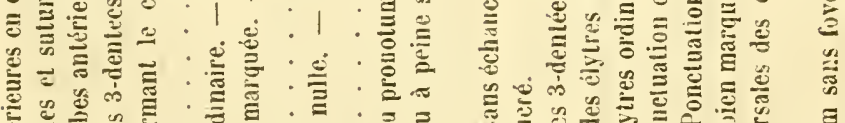

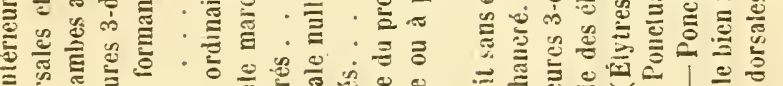

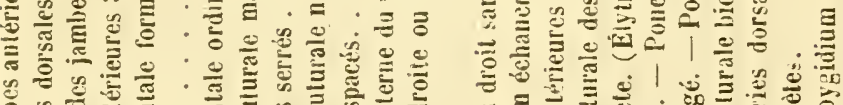

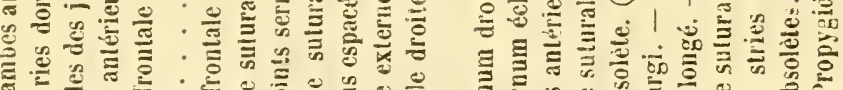

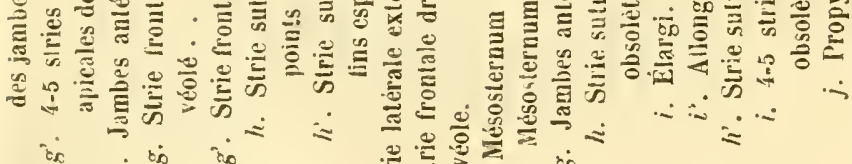

3e Sérir, TOME 11. 


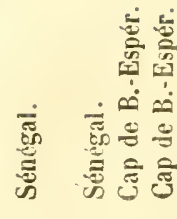

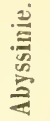

永

语莒

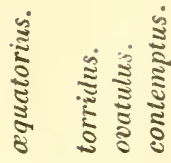

ณำ

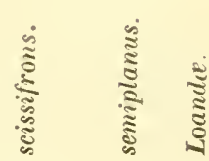

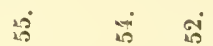

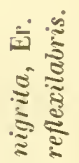

$\infty \dot{0}$

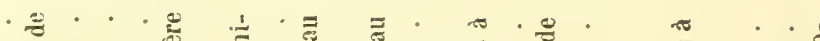

$:$ : $\cdot$.

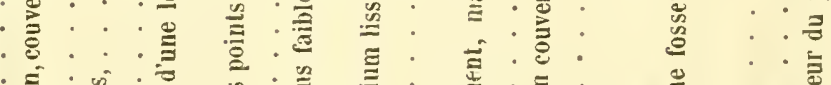

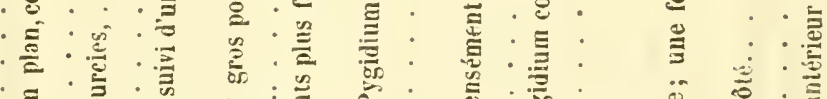

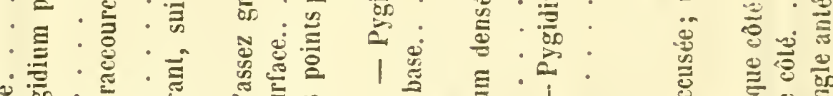

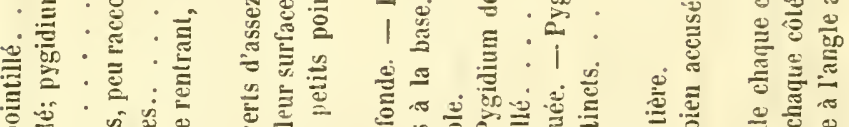

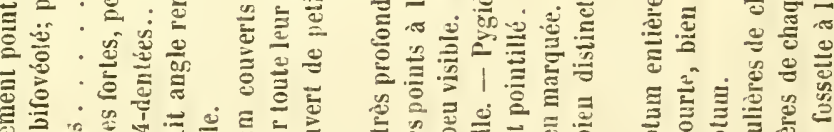

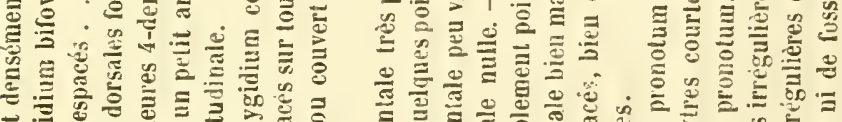
ะ

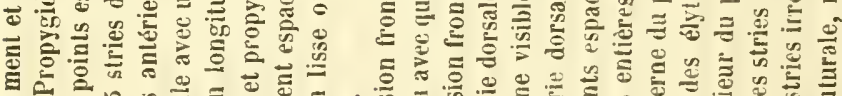

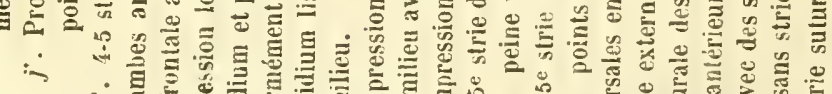

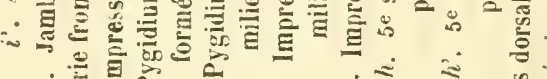

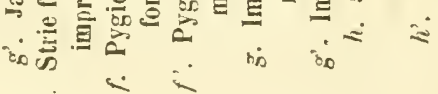
एँ

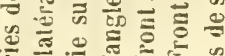

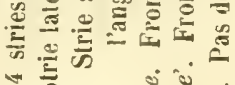

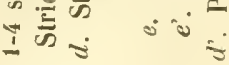
$\therefore$ is 
XX. Ilister.

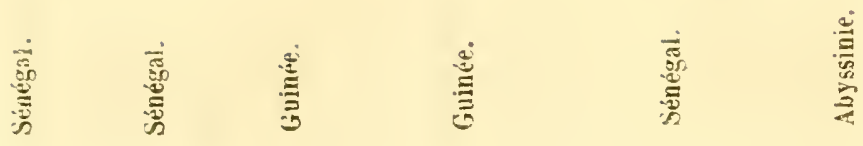

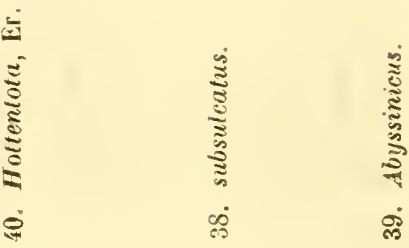

ลิ่

$\frac{\sqrt{2}}{8}$

\%

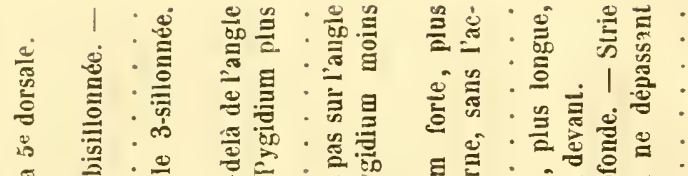

$\stackrel{\circ}{\circ}$

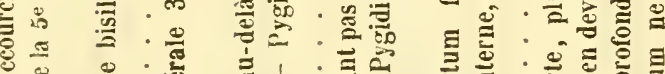

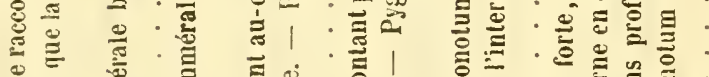

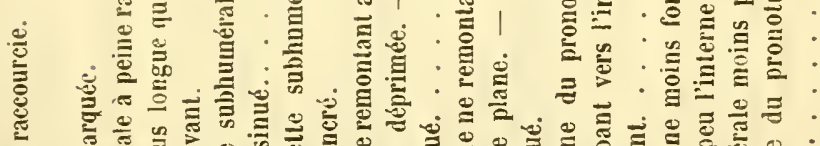

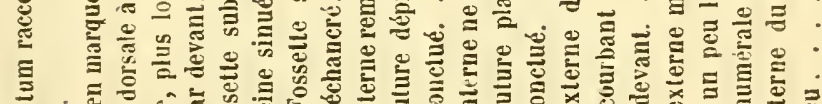

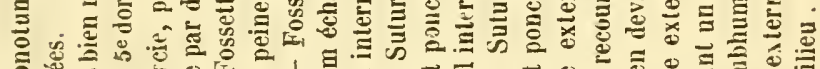

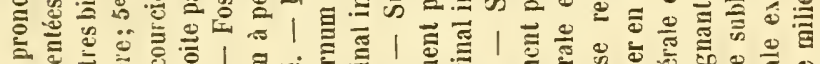
उ ฏ

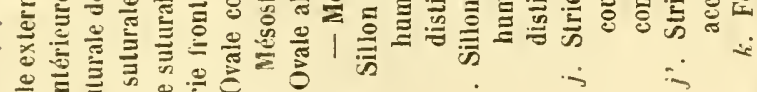

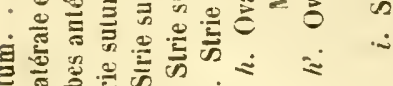

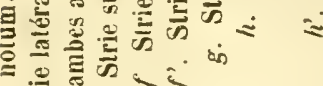

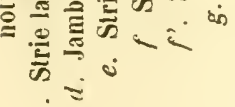




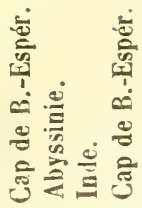

$\stackrel{\stackrel{0}{\Xi}}{\frac{0}{6}}$
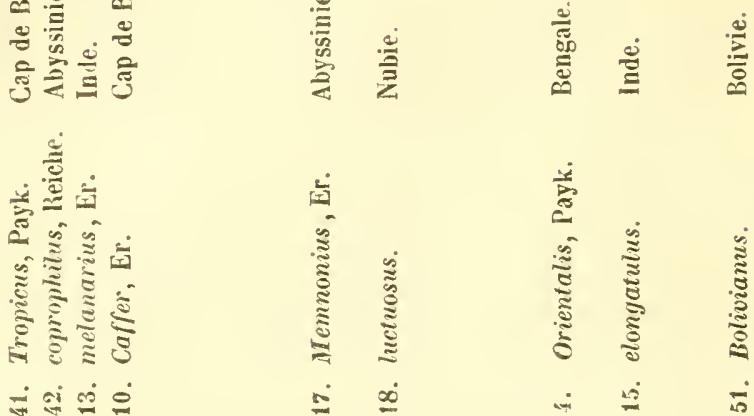

$=-i \stackrel{0}{\circ}$

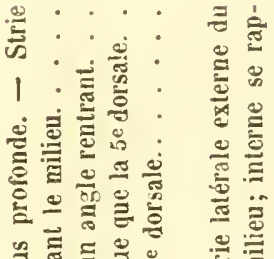

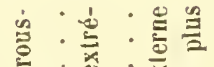

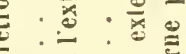

$-1$

is

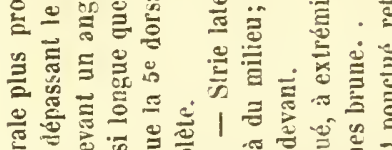

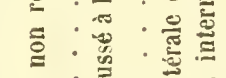

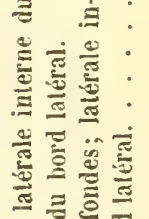

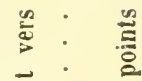

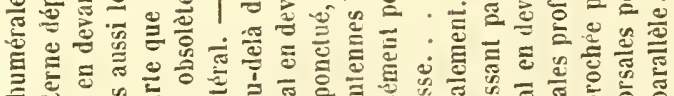

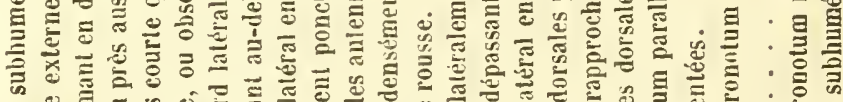

Ð

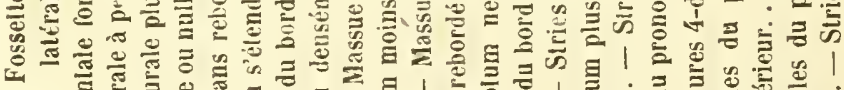

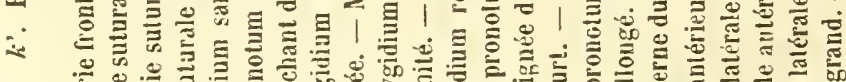

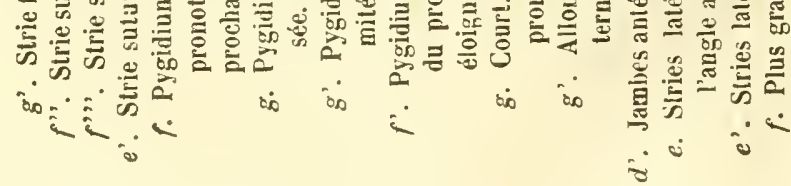


XX. Hister.

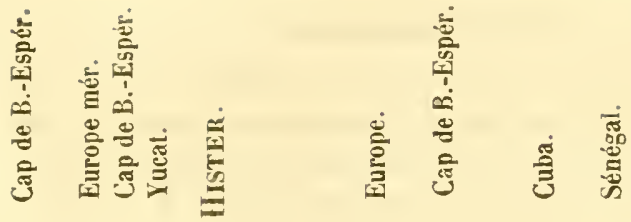

至

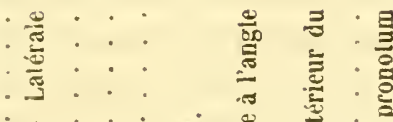

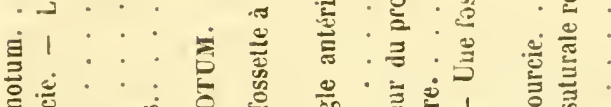

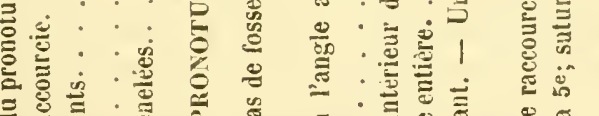

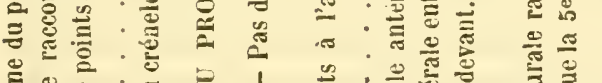

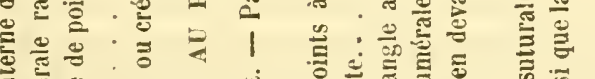

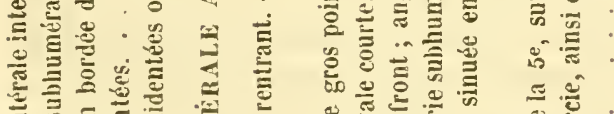

ธี

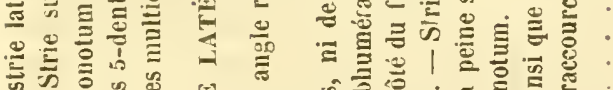

का

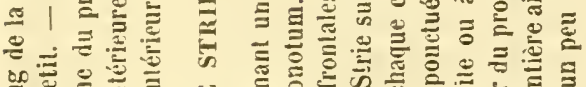

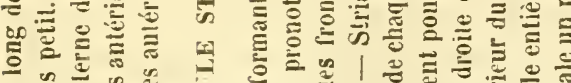

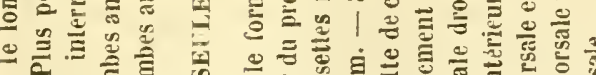

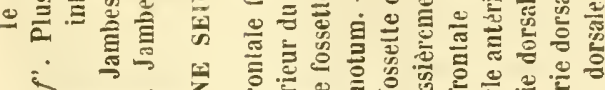
된

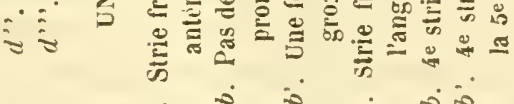
सं $\rightarrow$ i $\therefore \rightarrow \infty$ 


\section{H, BeNGALENSIS.}

Ovalis, convexinsculns, niger, nitidus; fromte impressu, stria iutegra; pronoto ciliato, utrinque foveolato, stria utraque laterali interrupta; clytris sub apicem impressis, margine inflexo 1-sutcuto, fovcolato; striis 1-3 dorsalibus integris, $4^{\mathrm{a}}$ late interrupta; mopygidio pygidioque munctatis; prosterno lobo lato; mesosterno emarginato, stru interrupta; tibiis anticis valide 3-ılentutis, posticis 8-9 alenticulato-spinosis. Long. 15 mill.; largeur 11 mill.

Ilister Bengulensis, Wiedm. in Germ. Mag. Ent. 4, 126. 31 (182i). - Er. in Jahr. 1, 131, 6.

II. grandis. Germ. Sp, 147, 86. (1824).

Ovale, élargi, assez convexe, noir, luisant. Antennes noir de poix, massue grise, velue, comprimée. Tête grosse; front bombé, avec une légère impression médiane, séparé de l'épistome par une stric entière en demi hexagone; labre triangulaire; mandibules saillantes, dentées en dedans, rapprochées à la base. Pronotum cilié, court, bisinué à la base arec un point anté-scutellaire, droit sur les côtés avec les angles arrondis, rétréci et échancré en devant avec les angles abaissés, obtus, saillants, surmontés d'une fossette imponctuée; stries latérales un peu raccourcies à la base, se rapprochant graduellement, suivant quelque temps le bord antérieur et s’interrompant, l'externe plus tôt. Ecusson petit, triangulaire. Elytres un peu plus longues et aussi larges que le pronotum à la base, dilatées à l'épaule, rétrécies et obliques au bout avec une impression transversale; bord infléchi 1-sillouné avec une fossette sous l'épaule sans ponctuation apparente; stries fortes, ponctuées, subhumérale interne et 1-3 dorsales entières, quatrième largement interrompue, les a utres nulles. Propygidium bifovéolé, couvert d'assez gros points espacés. Pygidium ponctué de mêmè 
mais plus densément. Prosternum saillant, arrondi à la base, lobe large, infléchi, rebordé et arrondi. Mésosternum échancré, strie marginale interrompue. Jambes antérieures garnies de trois fortes dents; postérieures de 8-9 denticules épincux.

Le $\sigma^{*}$ se distingue par ses mandibules plus longues, inégales, tuberculeuses, unidentées en dedans, et par son labre en còne élevé et allongé.

Inde (Bengale).

\section{H. LUTARILS.}

Ovalis convexinsculus, niger, nitidus; stria frontali profunda, antice obsoteta; pronoto fulco ciliato bifoveoiato, stria laterali utraque hinc inde abbreviata; elytris striis dorsatibus 1-4 integris, 5a suturatique obsoletis; pygidio lavi; prosterno carinato, lobo acuto, mesosterno emarginato stria interrupta; tibiis anticis 3-dentatis, posticis biseriatim multispinosis. Long. 14-12 mill.; larg. 9-8 mill.

Hister lutarius, + , Er. in Jahr., 1, 133, 10 (1834).

Ovale, peu convexe, d'un noir luisant; très finement et peu visiblement poiıtillé en dessus. Front inégal; strie semicirculaire profonde en dedans des yeux, interrompue au milieu; épistome concave; labre trilobé, court; mandibules à peu près égales, à côtes aiguës, uni-dentées en dedans (dans le $\sigma^{*}$ un tubercule saillant au dessus de la dent de la mandibule gauche). Antennes d'un noir de poix, massue grise. Pronotum court, plus large que long, garni de poils jaunàtres, bisinué à la base avec une courte ligne anté-scutellaire; oblique, à peine arqué sur les côtés, échancré et rétréci en devant, avec les angles abaissés, aigus, marqués en dessus d'une large fossette; strie latérale interne raccourcie à la base et remontant plus ou moins, mais ne se 
contournant pas autour du bord antérieur; externe remontant plus haut et ne descendant pas aussi bas que l'interne. Ecusson petit, en triangle aigu. Elytres courtes, aussi larges que le pronotum à la base, dilatées à l'épaule, rétrécies et légèrement abliques au bord apical, avec une légère impression transversale; bord infléchi lisse, 1-sillonué, creusẻ d'une fossette; strie subhumérale atteignant l'épaule; 1-4 dorsales assez forles, ponctuées, entières; cinquième et suturale obsolètes, représentées par des points, plus ou moins longues. Pygidium subbifoveolé, lisse ainsi que le propygidium. Prosternum arrondi à la base, sailiant, caréné; lobe arrondi, largement rebordé. Mésosternum échancré, bor lé d'une strie iuterrompue. Jambes antérieures fortement 3-deutées; postérieures garnies de dix à douze dentelures bi-épineuses.

Erichson n'a connu que la femelie de cette espèce, autant que j'en puis juger par sa description. Le $\delta^{x}$, dont les mandibules offrent une particuliarité si bizarre que j'aurais pu la prendre pour une monstruosité, si je n'arais eu sous les yeux plusieurs individus identiques, portait le nom de H. Indus dans la collection Dejean.

Inde (Silhet, Ilimalaya, Bengale); Timor (Malaisie).

\section{H. INEQUALIS.}

Ovalis, subconvexus, niger, nitidus, stria fromtali amice obsoleta, labro 3-lobo; pronoto ciliato, foveola utrinque munctata, stria latcrali interna interrupta, externa abbreviata; clytris margine foveolato punctato 1-sulcato, striis 1-4 dorsalibus integris, $5^{\text {a }}$ et suluerali nullis; promggidio mygidioque punctulatis ; mesostemo stria integra; tibiis anticis : d-dentatis, poslicis biscriatim multispinosis. Long. 12 mill.; larg. 9. mill.

Hister incequalis, OI. Ent., 1, 8, p. 7, 4 pl. 1, :3 (1789). F. Sแp. ent., 37. 1-2. - Syst. El. 1, 84, 2. - Stmm. Deuts., fir, 1. 
S6, 1. - Dufts., fin. Austr., 1, 209, 1. - Payk., Mon. hist., 10, 2, 1. ı, fig. 2.- Heer., fin. Helv., 1, 453, 2. - Küst. Kæf., Eur., 6, 52. - Redt., fil. Austr., 233.

H. Lews, Rossi, fn. Etr., 1, 28, 63, pl. 1, lig. 1, ? (1790). Panz., fir. Germı., xlı1, 8.

Orale, assez convexe, noir, luisant. Antemes brunes, massue velue, cendrée. Tête médiocre, arrondie; front à peine visiblement pointillé; strie circulaire, profonde de chaque côté, obsolète au milieu; labre trilobé; mandibules saillantes, peu acérées, gauche unidentée, droite bidentée. Pronotum court, large, bisinué et bordé de points à la base, arec un point anté-scutellaire, arqué et cilié sur les côtés, rétréci et échancré en devant avec les angles obtus, abaissés, marqués d'une fossctte large, ponctuée; strie latérale interne interrompue, externe faible, raccourcie. Ecusson triangulaire, petit. Elytres plus longues que le pronotum, de sa largeur à la base, dilatées à l'épaule, très rétrécies et droites au bord apical, avec une légère impression transversale; bord infléchi 1-sillonné, creusé d'une fossette ponctuée; stries assez fortes, crénelées. 1-4 dorsales entières, cinquième et suturale nulles. Propygidium couvert de petits points serrés, ainsi que le pygidium. Prosternum en carène assez. élevée, arrondi à la base, lobe court, infléchi, rebordé. Mésosternum échancré avec une strie entière. Jambes antérieures armées de trois fortes dents; postérieures d'une double série de nombreux denticules épineux.

Le o se distingue par la mandibule gauche dépassant la droite, terminée par une double pointe obtuse, et par le lobe médian du labre très allongé.

On le trouve au printemps dans les bouses: Europe méridionale : France méridionale. Corse. Allemagne, Autriche, 
Suisse, Espagne, Italie, Illyrie, Turquie, Russie, Caucase ; nord de l'Afrique.

\section{H. NIGRITA.}

Ovalis, subconvexus, niger, nitidus, antennis brunneis; fronte utrinque multistriolata; promoto ciliato bifoveolato, striis 2 lateralibus integris, interna haud internupta; elytris margine 1-sulcato, fovea impunctata, striis validis punctatis, 1-4 dorsalibus integris, $5^{\mathrm{a}}$ et suturali abbreviatis; propygidio pygidioque punctutis; mesosterno stria integra; tibiis anticis 3-dentatis, posticis biseriatim multispinosis. Long. 18-12 mill.; larg. 11-9 mill.

Hister nigrita, Er. in Jahr., 1, 131, 7 (18;4).

11. Guffer., Fahr. in Bohem,, Ins. Cafr., 1, 5331, 575 (185̌1).

Ovale, légèrement convexe, noir, luisant. Antennes brunes, massue grise, velue. Tête médiocre, arrondie, front plan, distinct de l'épistome, couvert de plus ou moins nombreuses petites stries irrégulières en dedans des yeux; stric ordinaire bieı marquée de chaque côté, mais souvent obsolète au milieu; labre concave, 3 -lohé, assez grand; mandibules longues, armées la gauche d'une dent, la droite de deux, toujours terminées en pointe aiguë, inégales dans le $\approx$. Pronotum court, bisinué à la base avec un point scutellaire, oblique et cilié sur les còtés, rétréci et échancré en devant avec les angles obtus, abaissés, marqués d'une légère fossette; stries latérales fortes, parallèles, rapprochées, entières; interne non interrompue, externe suivant le bord antérieur pour cesser bientôt. Ecusson petit, triangulaire. Elytres une fois et demi plus longues que le pronotum, de sa largeur à la base, dilatées à l'épaule, fort rétrécies et obliques au bord apical avec une légère impression transversale; bord infléchi l-sillonıé, imponctuć, fossette humérale peu profonile. 
stries fortes, ponctuées, 1-4 dorsales entières, cinguième raccourcie vers la base, suturale au milieu. Propygidium couvert ainsi que le pygidium de points assez forts el serrés. Prosternum saillant, arrondi et élargi à la base, lobe infléclıi court, rebordé. Mésosternum échancré et entièrement rebordé. Jambes antérieures armées de trois fortes dents; postérieures de deux séries de 10-12 dentelures épineuses.

Sénégal; Guinée; Cafrerie (Natal).

\section{H. REFLEXILABRIS.}

Ovalis, convexiusculus, niger, nitidus; stria frontali integra; pronoto ciliato, bifoveolato, strice laterali utraque integra; e'ytris striis 4 dorsalibus integris, $5^{\text {a }}$ suturalique abbreviatis, fovcola subhumerali punctata; pygidio punctato; mesosterno utrinque bistriato; libiis anticis 3-dentatis, posticis wulti-denticulato-spinosis. Long. 19 mill.; larg. 13 mill.

Ovale allongé, assez convexe, noir, luisant, lisse. Front plan, strie semicirculaire entière bien marquée, droite en devant; labre indistinctement trilobé, large et réfléchi $\sigma^{*}$; mandibules 1-dentées en dedans, droite à dent large, obtuse, gauche plus longue ${ }^{*}$. Antennes hrunes, massue grise, velue. Pronotum court, large, cilié de jaune, bisinué à la base, légèrement arqué sur les côtés, rétréci et échancré en devant, avec les angles abaissés, aigus, marqués en dessus d'une fossette arrondie; stries latérales partant de la base à peu près, assez rapprochées, interne se continuant en devant sans interruption, externe s'y joignant à l'angle antérieur. Ecusson très petit, triangulaire. Elytres aussi larges et plus longues que le pronotum à la base, dilatées à l'épaule, rétrécies et coupées obliquement au bout avec une impression transversale subapicale; subhumérale interne remontant 
jusqu'à l'épaule; quatre premières dorsales fortes, entières, équirlistantes; cinquième et suturale courtes, obsolètes. Bord infléchi bisillonné, fossette subhumérale assez profonde, ponctuée. Pygidium assez densémeut ponctué et un peu plus fortement que le propygidium. Mésosternum échancré et rebordé de deux fortes stries interrompues au milieu. Jambes antérieures fortement 3-dentées; postérieures garnies d'une double rangée de denticules épineux au nombre de dix à douze.

Inde, côtes de Malabar (M. de Laferté)

10. H. Caffer.

Ovalus, convexiusculus, niger, mitidus; frontati stria integra; monoto ciliato, stria latcrali interna haud interrupla, externa abbreviata; elytris striis crentlatis, 1-4 dorsalibus integris, $5^{a}$ vix suturalique in medio abbrcviatis; margine 1-sulcato, foveola punctata; pygidio submarginato punctulato; mesosterno stria integra; tibiis amticis 3-dentatis, posticis biseriatim multispinosis. Long. 13 mill.; larg. 9 mill.

Hister Caffer, Er. in Jahr., 1, 132, \& (1834).

II. severus, Fahr. in Bohem., Ins. Caflr., 1, 531, 576 (1851).

Ovale, assez convexe, noir, luisant. Antennes brunes; massue velue, grise. Tête médiocre, arrondie; front plan, strie entière, sinuée sur les côtés; labre trilobé; mandibules fortes, saillantes, armées la gauche d'une large dent aiguë, la droite d'une avance tronquée et comme bifide. Pronotum court, large, bisinué à la base avec un petil point anté-scutellaire, à peine arqué sur les côtés, rétréci et échancré en devant, avec les angles obtus, abaissés, pour ainsi dire sans fovéole; stric latérale interne non interrompue, externe forl raccourcie. Ecusson petit, triangulaire. 
Elytres plus longues et aussi larges que le pronotuın à la base, dilatées à l'épaule, fortement rétrécies et obliques au bout avec les angles arrondis et une impression subapicale; bord infléchi fortement 1-sillonné, arec une fossette ponctuée; stries larges, profondes, crénelées, 1-4 dorsales entières, cinquième à peine raccourcie, suturale deux fois plus courte. Pygidium étroitement rebordé, couvert de points assez serrés, ainsi que le propygidium. Prosternum en carène tranchante, élargi et arrondi à la base, lobe court, rebordé, abaissé; mésosternum échancré, strie entière. Jambes antérieures armées de trois fortes dents; postérieures d'une double série de denticules épineux en grand nombre.

Le $\delta^{*}$ est distinct par sa mandibule gauche, beaucoup plus longue que la droite, obtuse, et par le lobe médian du labre prolongé en pointe relevée.

Cap de Bonne-Espérance; Cafrerie.

\section{H. SC.EVOLA.}

Subovalis, convexiusculus, ater, subnitidus ; frontali stria in medio tenuissima; pronoto ciliato, utrinque impresso, stria laterali interna interrupta, externa vix abbreviata; elytris margine inflexo 1-sulcato, fovea punctulata, striis $1-4$ dorsatibus intcgris, 5a suturalique brevissimis; pygidio obscuro punctulato; mesosterno marginalo; libiis anticis 3-dentatis: posticis biseriatim mullispinosis. Long. 9 mill.; larg. 6 mill.

Hister Scctvolı, Er. in Jahr., 1, 1334, 12 (1834).

Ovale, allongé, assez peu convexe, noir, luisant. Antennes brunes; massue grise, velue. Tête assez grosse; front plan, strie entière mais très fue au milieu; Iabre triangulaire, relevé au bout. Mandibules fortes, saillantes, dentées en 
dedans, creusées d'une gouttière: gauche beaucoup plus longue, terminée par une pointe tuberculée $\sigma^{*}$. Pronotum cilié de roux, court, large, bisinué à la base avec un point antéscutellaire, faiblement arqué sur les côtés, rétréci et échancré en devant avec les angles obtus abaissés, marqués d'une fossette lisse, superficielle; stries latérales bien marquées; interne interrompue, externe à peine raccourcie. Ecusson très petit, triangulaire. Elytres plus longues que le pronotum, de sa largeur à la base, rétrécies et droites au bout avec une impression subapicale et l'angle arrondi; repli latéral 1-sillonné, fossetteà peine pointillée; stries bien marquées, ponctuées, 1-4 dorsales entières, cinquième et suturale courtes, obsolètes. Propygidium et pygidium obscurs, à peine visiblement pointillés. Prosternum étroit, arrondi à la base, lobe court, bordé. Mésosternum échancré, strie entière. Jambes antérieures armées de trois fortes dents: postérieures d'une double série de nombreux denticules épineux.

Inde (Pondichery); Chine.

\section{H. Coinensis.}

Ovalis, parum convexus, niger, subnitidus; stria frontali subintegra; pronoto ciliato, vix bifoveolato, striis lateralibus anterius magis remotis, interna interrupta, externa abbreviata; elytris margine unisulcato, foveola subpunctulata, striis 1-4 dorsalibus integris, $5^{a}$ brevi, suturali nulla; pygidio marginato deuse punctato; prosterno carinato, mesosterno emarginato, stria integra; tibiis anticis 3-dentatis, posticis biseriatim multispinosis. Long. 10-8 mill.; larg. 7-5 mill.

IIister Chinensis, Quens. in Schh. Syn., 1, 88, 5, pl. 2, 2 (1806). - Payk., Mo». Hist., 16, 7, pl. 2, f. 5. - Er. in Jahı., 1, 135, 14. 
Orale, peu convexe, noir, peu brillant surtout sur les élytres. Antennes brunes, massue grise, velue. Tête petite, arrondie ; front plan, strie forte, obsolète en devant; labre obtusément 3-Iobé, court, plus long o ; mandibules creusées d'un sillon, saillantes, courbées : droite, unidentée en dedans, gauche bidentée, beaucoup plus longue que celle-ci et terminée en pointe précédée d'un tubercule. Pronotum court et large, bisinué à la base, cilié et arqué sur les côtés, rétréci et échancré en devant avec les angles obtus, abaissés, à peine distinctement impressionnés; stries latérales bien marquées: externe raccourcie, interne partant de la base, s'éloignant graduellement du bord et s'interrompant derrière les yeux. Ecusson petit, triangulaire. Elytres obscures, plus longues que le pronotum, de sa largeur à la base, à peine curvilinéaires sur les cotés, arrondies à l'angle postérieur, obliques au bout avec une faible impression subapicale et un angle sutural ; bord infléchi uni-sillonné, fossette à peine pointillée; stries bien marquées, ponctuées : sublumérale interne atteignant l'épaule, 1-4 dorsales entières, rapprochées par paires, quatrième un peu plus courte que la troisième, cinquième très petite, suturale nulle. Propygidium couvert de points épars, avec un fin pointillé dans les intervalles. Pygidium obscur, rebordé et densément ponctué. Prosternum en carène tranchante, arrondi à la base, lobe court rebordé. Mésosternum échancré, strie non interrompue. Jambes antérieures armées de trois fortes dents : postérieures d'une double série de nombreux denticules épineux.

Chine; Inde; Malaisie (Manille).

\section{H. MELANARIUS.}

Ovatus, parum convexus, niger, opacus ; capite puncticulato, stria integra, monoto cilinto, stiva taterali imerna imegra, 
externa parum abbreviata; chtris striis $1-1$ dorsalibus inte-

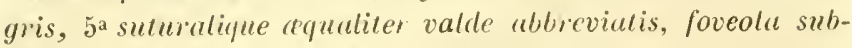
humerali punctulata; propygidio sparsim, pygidio parce punctatis; mesosterno sinuato, stria integra; tibiis anticis 3-dentatis, posticis'biseriatim dense spinosis. Long. 9 mill.; largeur 5 1/2 mill.

Hister melanuritus, El. in Jahr., 1, 135, 15 (1834).

Ovale, peu convexe, d'un noir mat. Antennes d'un brun de poix, massue velue, grise. Tête fortement pointillée; front plan, large; strie subsinuée; labre court; mandibules bidentées, creusées en goutière. Pronotum court, assez large, cilié de gris, légèrement bisinué à la base, oblique sur les côtés, rétréci et échancré en devant, avec les angles abaissés, obtus ; strie latérale interne entière, externe rapprochée du bord, un peu raccourcie à la base. Ecusson petit, triangulaire. Elytres un peu plus longues que le pronotum, de sa largeur à la base, arquées légèrement sur les còtés, árrondies à l'angle postérieur, presque droites au bout, sans impression; rossette subhumérale bisillonnée, pointillée; stries fines, assez bien marquées, crénelées; subhumérale atteignantl'épaule, quelquefois accompagnée d'un court rudiment externe; $\mathbf{1 - 4}$ dorsales entières, cinquième et suturale raccourcies également et bien avant le milieu. Propygidium légèrement bifovéolé, couvert de petits points épars; pygidium assez deusément ponctué. Prosternum élevé, arrondi à la base, lobe assez saillant, rebordé. Mésosternum légèrement échancré, bordé d'une strie entière Jambes antérienres dilatées, 3-dentées, postérieures garnies de six ou sept paires de denticules épineux.

inde, Bengale. 


\section{H. OHENTALIS.}

Ovatus, convexiusculus, niger, subnitidus, antemnis rufobrumcis; fronte latiori, stria integra, valida ; pronoto ciliato, stria laterali cxterna abbreviata, interna hand interrupta, postice marginis mopiori; clytris fossa marginali sulcata, punctulata, striis dorsalibus 1-4 intcgris profundis, $5_{a}$ brevi; pygidio marginato, parce punctato; mosterno carinato, mesosterno cmarginato stria integra; tibiis anticis 3-dentatis, posticis biseriatim multispinosis. Long. 7 mill.; larg. 4 1/2 mill.

Hister Oricntalis, Payk., Mon. Hist., 17, 8, pl. 13, f. 7 (1811).

Ovale, faiblement convexe, noir, assez luisant. Antennes d'un brun ferrugineux; massue velue, grise. Tête large; front bombé, séparé de l'épistome par une forte strie arquée; labre court, ovalaire; mandibules assez fortes, bidentées, terminées en pointe, gauche dépassant la droite $\sigma^{*}$. Pronotum court, bisinué à la base, cilié et arqué sur les côtés, profondément échancré et retréci en devant avec les angles obtus, abaissés, peu distinctement impressionnés; stries latérales fortes, interne entière s'éloignant graduellement de la marge, externe s’étendant du milieu à l'angle. Ecusson petit, triangulaire. Elytres courtes, un peu plus longues que le pronotum, de sa largeur à la base, courbées légèrement sur les còtés, arrondies à l'angle postérieur, obliques au bout; bord infléclii presque bisillonné; fossette ponctuée, assez marquée; stries furtes, ponctuées, subhumérale interne atteignant l'épaule, 1-4 dorsales entières, rapprochées par paires à la base, cinquième très courte, suturale nulle. Propygidium bifovéolé, couvert de points épars. Pygidium étroitement rebordé, peu densément ponctué. Prosternum en carène, arrondi à la base, lobe court, incliné, rebordé ; mésosternum échancré, strie entière. Jambes antérieures

3c Série, тоне 11. 
fortement 3-dentées; postérieures garnies d'un double rang de nombreux denticules épineux.

Chine; Inde (Pondichery).

\section{H. ELoxgatilis.}

oblongo-ovatus, subdepressus, miger, nitidus; stria frontali integra recta; pronoto ciliato, stria taterali intema integra margini parallela, externa dimieliata; clytris fossa subhumerali bisulcuta, punctuluta, subhumerali stria brevi, 1-4 dorsalibus integris, perum profundis, 5 ante medium abbrcviata, suturali nulla; propygidio indistincte punctulato; pygidio punctato; mesosterno emarginato stria intcgra; libiis anticis 3-dentatis, posticis biseriatim niultispinosis. Long. 8 mill.; larg. 5 mill.

Ovale allongé, subdéprimé, d'un noir luisant. Antennes brunes. Pronotum beaucoup plus large que long, légèrement bisinué à la base, cilié et à peine arqué sur les côtés, rétréci et échancré en devant, avec les angles abaissés, obtus; strie latérale interne entière, mais n'atteignant pas tout à fait la base, parallèle à la marge ; l'externe fort distante de l'interne et rapprochèe du bord, raccourcie au milieu. Ecusson petit, triangulaire. Elytres plus longues que le pronotum, de sa largeur à la base, à peine rétrécies par derrière, arrondies à l'angle postérieur, angle sutural bien marqué; fossette subhumérale bistriée, ponctuée; strie subhumérale fine, n'atteignant pas l'épaule; dorsales peu profondes, crénelées, 1-3 entières, quatrième un peu raccourcie à la base, cinquième n'atteignant pasle milieu; suturale nulle. Propygidium paraissant lisse. Pygidium rebordé sur les côtés, densément ponctué. Prosternum en carène, arrondi à la base, lobe court, peu abaissé, rebordé. Mésosternum échancré et bordé d'une strie entière. Jambes antérieures fortement 3-dentées; postérieures garnies de nombreuses paires de denticules épineux.

Inde (Dekkini). 
16. H. UISTURSLS.

Ovatus, subconvexus, niger, nitidus; striu frontuli integru: pronoto ciliato, lerissime biforeolato, stria laterali interna sinuata, antice late interrupta, externa valde abbreviata; elytris striis 1-14 dorsalibus integris, 5a abbreviata, suturali nulla; foveola subhumerali punctulata; propygidio parum dense, pygidio densius punctuluto, marginato; mesosterno stria marginali integra; tibiis anticis 3-dentatis. Long. 9 mill. ; larg. 71/2. Hister distorsus, Illig. Mag., $\mathrm{II}_{\mathrm{I}}, 29$ note $(1 \mathrm{~S} 0 \mathrm{~T}) .-\mathrm{E}$. in Jahr., 13ㄹ, 9 (1834).

H. major., Herbst. Col., 4, 4S, 21, pl. 36, f. 10 (1792).

Ovale, assez convere, d'un noir luisant, lisse. Front plan, large; strie entière bien marquée; labre ovalaire; mandibules fortes, inégales $z^{x}$, en pointe aiguë, creusées en gouttière en dessus, bidentées en dedans, la gauche plus fortement. Antennes diun brun ferrugineux; massue velue, grise. Pronotum plus large que long, cilié, bisinué à la base, légèrement arrondi sur les cơtés, échancré et rétréci en devant arec les angles aigus, abaissés, marqués d'une fossette très superficielle; strie latérale interne partant de la base, coudée, interrompue avant de se réfléchir, externe. raccourcie avant le milieu. Ecusson petit, triangulaire. Elytres une fois et demi plus longues que le pronotum, de sa largeur à la base, curvilinéairement dilatées sur les còtés, arrondies à l'angle postérieur, rétrécies et obliques au bout avec une impression subapicale et un angle sutural bien marqué; stries crénelées, fortes, subhumérale atteignant l'épaule, dorsales 1-4 entiẻres, rapprochées par paires à la base, quatrième à peine raccourcie, cinquième avant le milieu, suturale nulle; bord infléchi parcouru par un sillon profond accompagné d'un autre plus petit au milieu, fossette subhumérale pointillée. Propygidium couvert de points épars. 
Pygidium rebordé, densément ponctué. Prosternum en carène tranchante, arrondi à la base, lobe court, rebordé, non incliné. Mésosternum échancré, strie marginale entière. Jambes antérieures garnies de trois fortes dents, postéricures de deux rangées de dentelures épineuses nombreuses.

Inde (Coromandel, Sillıet).

\section{H. MEMronius.}

Ovatis, subconvexus, niger, nitidus, stria frontali integra; monoto ciliato, stria intema integra, externa margini valde approximata subintegra, a marginali vix distincta; clytris striis 1-4 dorsalibus integris, 5a basi abbreviata, suturali obsoleta; marginis fovcola bisulcata, punctata; propygidio leviter subfoveolato, parce, mygidio marginato dense punctatis; mesostorno stria marginali integra; tibiis anticis 3-dentatis, posticis biscriatim multispinosis. Long. 12 mill.; larg. 8 mill.

Hister Memnonius, Er. in Jahr., 134, 11 (1834).

Ovale, subconvexe, noir, luisant. Antennes d'un brun de poix rougeàtre; massue velue, grise. Front plan, large; strie forte, entière; épistome concave; labre court, transversal; mandibules fortes, courtes, canaliculées en dessus, armées en dedans cliacune de deux dents, celles de la droite plus rapprochées. Pronotum court, large et bisinué à la base, cilié et oblique sur les côtés, très rétréci et échancré en devant, avec les angles obtus et abaissés; strie latérale externe raccourcie un peu à la base, très rapprochée du bord, à peine distincte de la marginale qui est courte et visible seulement dans l'angle antérieur, interne entière, avec des impressions légères sur son trajet, plus fine et plus rapprochée du bord en devant Ecusson petit, triangulaire. Elytres une fois et demie plus longues et anssi larges que le pronotum à la base, 
fortement dilatées à l'épaule, rétrécies et presque droites au bout, avec l'angle postérieur arrondi et une impression subapicale; stries fortes, crénelées; subluumérale atteignant l'épaule; dorsales 1-4 entières, cinquième raccourcic au milieu, suturale très courte, obsolète ; bord infléchi bisillonné, fossette sublumérale pointillée. Propygidium bifovéolé, couvert de points fins espacés; pygidium opaque, beaucoup plus densément ponctué. Prosternum en carène, arrondi à la base, lobe court rebordé, à peine incliné; mésosternum échancré et bordé d'une strie eutière. Jambes antérieures garnies de trois fortes dents; postérieures de deux séries de nombreux denticules épineur.

Abyssinie; Nubie.

\section{H. Luctuosus.}

Rotundato-ovalis, parum convcxus; untennis rufis; striu frontali subsinuata; pronoto ciliato, striis lateralibus interna hand interruptu, externa subintegra; clytris striis crenatis, 14 dorsalibus integris, 5a dimidiata, suturali nulla; fossa subhumerali 3-sulcala; mesosterno emarginato, stria integra; pygidio propygidioque purum dense punctatis; tibiis anticis 3dentatis, posticis biseriatim multispinosis. Long. $10 \mathrm{mil}$; largeur 7 mill.

Ovale arrondi, peu convexe, noir, luisant. Antennes rousses. Tête large; front plan, strie entière sinuée en dedans; épistome court, arrondi en devant; mandibules fortes, bidentées, creusées en gouttière, à pointe recourbée aiguë. Pronotum beaucoup plus large que long; subbisinué à la base, oblique, à peine arqué et cilié sur les côtés, fortement rétréci et échancré en devant, avec les angles obtus; strie latérale interne entière, forte, parallèle au bord latéral avec une lrace légère de fossettes en devant. 
non interrompue au bord antérieur; externe très rapprochée du bord, complétée à la base par un point, ne remontant pas plus haut que l'interne, sans la joindre ou l'accompagner. Ecusson petit, triangulaire. Elytres une fois et demie plus longues que le pronotum, de sa largeur à la base, fortement dilatées aux épaules, très retrécies et un peu obliques au bout avec une impression subapicale ; stries bien marquées, fortes, crénelées; subhumérale et $\mathbf{1 - 4}$ dorsales entières, cinquième raccourcie au milieu, suturale nulle; fossette subhumérale 3-striée, ponctuée. Propygidium couvert de points espacés; pygidium subbifovéolé, peu densèment ponctué. Prosternum en carène, arrondi à la base, lobe court, rebordé, abaissé. Mésosternum échancré, bordé d'une strie entière et d'une autre interrompue.Jambes antéricures fortement tridentées ; postérieures garnies de huit à dix paires de denticules épineux.

Très voisin du précédent, il est cependant plus petit; son pygidium est moins densément ponctué, la fossette subhumérale inoins profonde, couverte de points plus gros et espacés, enfin les stries dorsales sont plus grosses et mieux crénelées, troisième rapprochée au bout de la quatrième.

Nubie.

\section{H. Baconi.}

Ovatus, parum convexus, niger, subnitidus; frontis stria integra; pronoto ciliato, sliva laterali interna ad angulum subfoveolata intermpla, extenna integra; elytsis margine 2-sulcato, foveola humerali punctata, striis validis, crenatis, subhumerali humerum attingente, 1-3 dorsalibus integris, $4^{\mathrm{a}}$ arcuala ubinque abbreviala, cateris nullis; promygidio pygidioque subtiliter punctulatis; mesosterno stria marginali integra ; tibiis anticis, B.dentatis, posticis biseriatim multispinosis, Long. 10 mill.; larg. 7 mill. 
Ovale, peu convexe, noir, assez luisant. Front plan, large, ceint d'nne strie fine et entière; labre court; mandibules fortes, canaliculées en dessus, bidentées. Antennes brunes; massue velue, grise. Pronotum cilié, large, court, bisinué à la base, oblique et à peine arqué sur les côtés, rétréci et échancré en devant, avec les angles abaissés, obtus; strie latérale interne forte sur les cotés, légèrement impressionnée, arrondie à l'angle antéricur, suivant le bord et s'interrompant bientôt; externe entière. Ecusson petit, triangulaire. Elytres plus longues et aussi larges que lc pronotum à la base, un peu rétrécies au bord apical, avec une impression subapicale; stries fortes, crénelées ; subhumérale atteignant l'épaule, 1-3 dorsales entières, quatrième arquée, raccourcie de part et d'autre, cinquième et suturale nulles; bord infléchi bisillonné, fossette subhumérale pointillée. Propygidium finement et peu densément pointillé ainsi que le pygidium. Prosternum en carène, arrondi à la base, lobe court, rebordé, à peine infléchi. Mésosternum échancré, bordé d'une strie entière. Jambes antérieures armées de trois fortes dents; postérieures garnies de deux séries de denticules épineux serrés et nombreux.

Inde boréale ( $M$. de Laferlé).

\section{H. SPINIPES.}

Ovalis, subdepressus, niger, nitidus; antennis brunneis; stria frontali integra; pronoto ciliato, striis lateralibus integris, inter'na haud interrupta; elytris margine bisulcato, striis dorsalibus $1-4$ integris, $5^{\text {a }}$ brevi; propygidio pygidioque parce punctatis; mesosterno marginato; tibiis anticis valide 3-dentatis, posticis biseriatim multispinosis. Longneur 10 mill.; largeur 8 mill. 
Ovale, assez allongé, pei convexe, noir, luisant. Antenncs brunes; massue velue, grise. Front large, à peine distiuctement pointillé, entouré d'une strie entière; épistome concave; labre court; mandibules fortes, crénelées, recourbées, en pointe aiguë, bidentées en dedans, égales. Pronotum beancoup plus large que long, bisinué à la base, avec un point antéscutellaire, oblique et cilié sur les côtés, rétréci et éclıancré en devant, avec les angles abaissés, obtus; stries latérales sinueuses, parallèles, interne partant de la base et se continuant sans interruption, externe un peu raccourcie, cessant à l'angle antérieur. Ecusson petit, triangulaire. Elytres plus longues que le pronotum, de sa largeur à la base, légèrement curvilinéaires sur les côtés, arrondies à l'angle postérieur, presque droites au bout; repli latéral bisillonné, fossette très étroite, sans points; stries fortes, crénelées, subhumérale atteignant l'épaule, dorsales 1-4 entières, cinquième raccourcie au milieu, suturale nulle. Propygidium bifovéolé, couvert de points épars. Pygidium un peu plus densément ponctué. Prosternum en carène, arrondi à la base, lobe court, rebordé, à peine abaissé. Mésosternum faiblement écliancré et rebordé. Jambes antérieures armées de trois fortes dents, postérieures d'un double rang de denticules épineux en grand nombre.

Sénégal.

\section{H. STRIOLATUS.}

Ovatus, subdepiessus, niger, nitidus; antennis rufo-brunneis; stria frontali integra; pronoto ciliato, stria laterali interna integra forti, cxierna brevi temai; clytris striis fortibus crenatis, sulurali et 1.4 dorsalibus integris, $5^{\text {a }}$ vix abbreviata, margine inflexo bisulcato, fossa muctnlata; mopygidio mygi- 
dioque punctulatis; mesosterno stria marginali integra; tibiis anticis 3-dentatis, posticis biseriatim multispinosis. Long. 11 mill.; larg. 7 mill.

Ovale, déprimé, noir, lisse et luisant. Antennes rougebrun; massue velue, grise. Front plan, large, strie bien marquée, entière, droite en devant; épistome bombé; labre court, linéaire; mandibules fortes, concaves en dessus, bidentées en dedans; recourbées en pointe aiguë. Pronotum ciiié, court, large et à peine bisinué à la base, peu arqué sur les côtés, rétréci et échancré en devant; strie latérale interne forte, non interrompue; externe fine, rapprochée du bord et raccourcie avant le milieu. Ecusson petit, triangulaire. Elytres une fois et demi plus longues et aussi larges que le pronotum à la base, curvilinéaires sur les côtés, arrondies à l'angle postérieur, fortement rétrécies et droites au bout; stries fortes, profondes, crénelées, subhumérale atteignant l'épaule, suturale et 1-4 dorsales entières; cinquième un peu raccourcie à la base; bord infléchi parcouru par deux sillons voisins de la marge, fussette subhumérale pointillée. Propygidium et pygidium assez densément pointillés, avec des points plus fins encore dans les intervalles. Prosternum en carène, arrondi à la base, lobe très court, rebordé, à peine abaissé. Mésosternum assez légèrement échancré, strie marginale entière. Pattes d'un brun de poix. Jambes antérieures armées de trois fortes dents; postérieures de nombreux denticules épineux disposés sur deux lignes.

Sénégal.

22. II. JAPONICIS.

Ovatus, convexinsculus, niger, lavis, nitidus; stric frontali 
integra; pronoto ciliato, stria interna integra, externa pone medium abbreviata; elytris striis $1-2$ dorsalibus integris; $3^{\text {a }}$ late interrupta, 4-5 apicalibus; margine inflexo bisulcato, fossa punctata; propygidio pygidioque punctulatis; mesosterno emarginato stria haud interrupta; tibiis anticis 3-dentatis, posticis biseriatim multispinosis. Long. 11 mill.; larg. 8 mill.

Ovale, assez convexe, noir, luisant, lisse, Antennes brunes. Front plan, strie entière, bien marquée; labre court; mandibules concaves en dessus, bidentées, recourbées en pointe. Pronotum cilié, plus large que long, légèrement bisinué à la base, arqué sur les côtés, échancré et rétréci en devant avec les angles abaissés, aigus; strie latérale interne forte, non interrompue; externe raccourcic un peu au-delà du milieu. Ecusson petit, triangulaire. Elytres courtes, un peu plus longues que le pronotum, de sa largeur à la base, curvilinéairement dilatées sur les côtés, arrondies à l'angle postérieur, droites au bout avec une impression subapicale; strie subhumérale atteignant l'épaule, 1-2 dorsales entières; troisième largement interrompue, rudiment basal plus long que l'apical, quatrième et cinquième apicales, fort courtes; bord infléchi, bisillonné, fossette large, profonde, ponctuće. Propygidium et pygidium couverts de points peu serrés. Prosternum en carène, arrondi à la base, lobe court rebordé, horizontal. Mésosternum échancré, bordé d'une strie entière. Pattes brunes. Jambes antérieures 3-dentées; postérieures garnies de nombreux denticules épineux, serrés, disposés sur deux séries.

Japon (H. Guérin).

23. H. GAGATINUS.

obovatus, subglobosus, niger, lavissimus, nitidus; frontalt 
stria levi in medio interrupta; mandibulis subunidentatis; pronoto stria laterali interna integra, exierna abbreviata; elytris murgine inflexo bisulcato, fossa profunda, 1-2 dorsalibus integris, $3^{\text {a }}$ late interrupta, suturati utrinque abbreviata cateris obsoletis; propygidio bifoveolato, pygidioque lavigatis; mesosterno subsinuato, bimarginato; tibiis anticis 4-clentatis; posticis biseriatim multispinosis. Long. 9 mill.; larg. 7 mill.

Hister gagatiuus, Reiche, Voy. Abyss., 301, 3 (1851).

Ovale, bombé, noir, lisse et très luisant. Antennes brunes; massue grise, velue. Front plan, strie obsolète, interrompue en devant; labre court; mandibules fortes, courtes, à peine unidentées en dedans, recourbées en pointe. Pronotum plus large que long, légèrement arqué à la base, avec une ligne antéscutellaire, arrondi sur les côtés, échancré en devant, avec les angles abaissés et obtus; strie latérale interne entière et non interrompue; externe raccourcie au milieu. Ecusson petit, triangulaire. Elytres un peu plus longues et aussi larges que le pronotum à la base, curvilinéaires sur les côtés, arrondies à l'angle postérieur, obliques ả l'extrémité, avec une impression subapicale à peine sensible; repli latéral bisillonné, fossette profonde, pointillée, traversée par l'un des sillons; stries fines, subhumérale atteignant l'épaule, 1-2 dorsales entières, troisième largenent interrompue, 4-5 représentées par de très courts rudiments apicaux, suturale raccourcie de part et d'autre. Propygidium bifovéolé, lisse ainsi que le pygidium. Prosternum en carène, arrondi à la base, lobe court, rebordé, horizontal ; mésosternum à peine légèrement échancré, bordé de deux stries, dont l'une est entière, l'autre interrompue. Jambes antérieures armées de quatre dents apicales assez fortes; postérieures assez allongées, garnies de deux séries de denticules épineux serrés et nombreux.

Abyssinic. 


\section{II. QUADRIMACULATUS.}

oblongo-subquadratus, parum convexus, niger, nitidus; stria frontali integra; pronoto stria laterali interna haud intermupta, externa brevi; elytris scepius rubro maculatis, margine inflexo bisulcato, fossa punctulata, striis tenuibus, 1-3 dorsalibus scepius integris; propygidio bifoveolato circum, pygidio dense punctatis; mesosterno emarginato stria integra; tibiis anticis 3-dentatis, posticis biseriatim multispinosis. Long. 10-8 mill.; larg. 8-6 mill.

Hister 4-maculatus, L., Syst. nat., 2, 567, 6 (1735). - Fn. Suec., 4, 143. - Illig. Kæf., pr. 1, 56, 8. - E. H., 1, 41, 4 et 2, 121. - Dufts., Fn. Aust., 1, 210, 3. - Gyll., Ins. snec., 1, 77, 4. - Payk., Mon. Hist., 14, 6, t. xı1, f. 1. - Fisch., Ent. Russ., 1, 205, 1. - Steph., Illıst。 Brit. Ent., 3, 146, 5. - Heer., Fn. Helv., 1, 454, 4. - Küst. Kæf. Eur., 4, 66. - Redt., Fn. Anstr., 232. Bach. Kæ. Prus., 1, 300, 2.

H. simuatus, Thunb., Ins. snec., v, 66 (1784). - Herbst, Nat。 Syst., 4, 43, 18.

H. reniformis, Ol. Ent., 1, 10, 8, pl. 1, 5 (1789).

H. lunatus, Rossi, F. Etr., 1, 28, 64 (1790). - F. Syst. El., 1, 86, 16. - Sturm. Deuts., Fn., 1, 198.

H. Gagates, Illig. Mag., vi, 31, 3 (1807).

H. Marshami, Stepl. Ill. Brit. Ent., 3, 144, 1, pl. 18, 5 (1830). H. Ethiops, Heer, Fn. Helv., 1, 453, 3 (1847).

Ovale, presque en carré allongé, peu convexe, noir, luisant. Antennes brunes; massue velue, grise. Tête assez grosse; front large, plan, séparé de l'épistome par une strie entière, droite en devant; labre court, arrondi ; mandibules recourbées, en pointe plus ou moins obtuse, bidentées en dedans, égales. Pronotum court, droit et crénelé à la base avec une ligne antéscutellaire, un peu oblique sur les côtés, rétréci et échancré en devant avec les angles abaissés, obtus; strie latérale externe entière, coudée derrière Ies yeux; externe réduite d'ordinaire à un court rudiment antérieur. 
Ecusson petit, triangulaire. Elytres un peu plus longues que le pronotum, de sa largeur à la base, arrondies à l'angle postérieur, à peine rétrécies et droites au bout; repli latéral bisillonné, fossette assez large, pointillée; stries fincs, coudées en divers sens, ponctuées, sublumérale atteignant l'épaule; 1-3 dorsales entières, les autres nulles et obsolètes. Propygidium bifovéolé, ponetué dans son pourtour. Pygidium couvert de points serrés et assez gros. Prosternum en carène assez aiguë, arrondi à la base, lobe court, rebordé, infléchi ; mésosternum échancré, rebordé. Jambes antériẹres armées de trois fortes dents; postérieures garnies d'un double rang de nombreuses dentelures épineuses.

Cette espèce, l'une des plus répandues et des mieux caractérisées, est sujette à de nombreuses variations. La strie latérale externe du pronotum est plus ou moins longue, quelquefois presque entière; dans un seul individu noir, elle avait complètement disparu, encore restait-il une empreinte légère. L.es stries dorsales quatrième et cinquième et la suturale, ordinairement nulles, apparaissent souvent au moins en partie, et quelquefois sont bien marquées. Quant a la coloration des élytres, on trouve tous les passages; on peut répartir les variétés de la manière suivante :

Var. $\propto$. Tache rouge couvrant toute l'élytre à l'exception de la suture.

๖. Tache rouge semilunaire étendue, laissantà découvert le bout et la portion suturale qui présente la figure d'une croix noire. H. humeralis, Fisch.II. 4-maculalus, var. a. Payk. I. c.

7. Tache rouge occupant les trois quarts de la largeur, envoyant un prolongement le long lu bord latéral, et un inciiian se détachant dans le pre- 
mier interstrie (quelquefois isolé) et se recourbant vers la suture. H. 4-maculatus, var. $\beta$. Payk. I. c.

$\delta$. Comme dans $\gamma$, sans prolongement latéral.

є. Trois taches rouges séparées, deux basales ot une apicale. II. scapularis, Fisch.

$\zeta$. Deux taches rouges ponctiformes, l'une au tiers, l'autre aux deux tiers plus rapprochée de la suture.

". Comme ל, mais l'une des deux taches disparaît. H. 4 maculatus, var. $\gamma$. Payk. I. c.

๑. Elytres noires sans taches rouges. H.4-maculalus, var. d. Payk. l. c. - H. cethiops, Heer. l. c.

Cette espèce vit dans le fumier. Elle est répandue dans toute l'Europe et sur le littoral de la Méditerranée, soit africain, soit asiatique; plus commune dans les parties méridionales. Les variétés noires ou peu colorées sont plus particulières au Nord. J'en ai vu des exemplaires provenant de Suède, Angleterre, France, Belgique, Allemagne, Suisse, Autriche, Russie, Portugal, Espagne, Italie, Algérie, Syrie, Caucase.

\section{H. Pustulosus.}

Oblongo-ovalus, convexus, niger, nitidus, lavis; stria frontali integra; pronoto basi punctato stria laterali interna integra, externa valde abbreviata; clytris margine inflexo bisul. cato, fossa plicata; stria subhumerali abbreviata, 1-3 dorsalibus levibus, integris, cateris mullis; 2 maculis rubris basali et apicali; promygidlio mygidioque parce munctatis; mesosterno marginato; tibiis anticis 3. dentatis, posticis biseriatim multispinosis. Long. 10 mill.; larg. 5 mill.

Hister pustulosus, Géné. in Mrm., Acarl. Turin (1838). 
Ovale allongé, convexe, d'un noir lisse et luisant. Antennes brunes; funicule rouge. Front plan, large, finement pointillé; strie entière à peine sinuće au milieu; labre court, arrondi; mandibules bidentées. Pronotum plus large que long, coupé droit et ponctué à la base, à peine arqué sur les côtés, un peu rétréci et fortement échancré en devant, avec les angles abaissés, obtus; strie latérale interne forte, entière, coudée derrière les yeux, externe raccourcie avant le milieu. Ecusson petit, triangulaire. Elytres plus longues et aussi larges que le pronotum à la base, presque parallèles sur les côtés, arrondies à l'angle postérieur, obliques au bord apical; strie subhumérale plus ou moins courte, dorsales 1-3 à peu près entières, deuxième cependant un peu raccourcie à la base, quelquefois même fines et très obsolètes, quatrième, cinquième et suturale nulles; deux taches rouges, ovales, l'une au milieu de la base, l'autre un peu avant le bord apical; bord infléchi bisillonné, fossette subhumérale étroite sans points distincts. Propygidium couvert de points épars à la base et sur les côtés; pygidium un peu plus densément ponctué. Prosternum en carène sinuée, arrondi à la base; lobe rebordẻ très aigu, abaissé, mésosternum échancré, bordé d'une strie non interrompue. Jambes antérieures armées de trois fortes dents; postérieures de six ou sept paires de denticules épineux.

Cette espèce se distingue de la précédente, même des variétés à deux petites taches, par sa taille plus petite, sa forme plus allongée et subcylindrique, ses stries dorsales plus profondes.et parallèles, et par la ponctuation du pygidium plus espacée.

Sardaigne. 


\section{IJ. AMPLICOLLIS.}

Ovalus, gibbus, niger, subnitidus; capite punctulato, frontali stria intcgra; pronoto subtilissime puncticulato, ciliato, striis latcralibus intcgris; elytris brevibus, margine b̈-sulcato, vix foveolato, striis tenuissimis, 1-3 dorsalibus integris irregularibus; propygidio bifoveolato mygidioque dense munctulatis; mesosterno emarginato, stria completu; tibiis punctutis, anticis 3dentatis, posticis biseriatim multispinulosis. Long. 12-10 mill.; larg. 9-S mill.

Hister amplicollis, Er. in Wagn. Voy. Alg., 169 (1840).

Ovale, gibbeux, noir, luisant, un peu mat sur les élytres. Antennes brunes; massue grise, velue. Tête grosse, densément pointillée sur toute sa surface, front large; strie profonde, entière; labre siuué; mandibules un peu concaves en dessus, armées en dedans de deux dents obsolètes. Pronotum grand, élargi, cilié, finement pointillé, plus distinctement sur les bords, coupé droit à la base avec une strie antéscutellaire; droit sur les côtés, à peine rétréci et profondément échancré en devant, avec les angles arroudis, abaissés; stries latérales fines, entières, distinctes, l'interne coudée vers la base. Ecusson petit, triangulaire. Elytres aussi larges, pas plus longues que le pronotum à la base, rétrécies et coupées droit au bord apical; stries fines; subhumérale atteignant l'épaule, rapprochée de la première dorsale, quelquefois obsolète, remplacée par des points; 1-3 dorsales entières, sinueuses, irrégulières dans leur direction ; les autres tout à fait obsolètes, fossette subbumérale superficielle, traversée par trois replis. Propygidium bifovéolé, densément pointillé, ainsi que le pygidium. Prosternum en carène, arrondi à la base, lobe court, rebordé, horizontal; mésosternum échancré et bordé d’une strie entière. Jambes 
antérieures dilatées, fortement 3-dentées, ponctuées en dessus, granulées en dessous; postérieures pointillées, garnies de deux séries de denticules épineux, au nombre de sept ou huit paires.

Algérie; Espagne (Cordoue), mai, dans les bouses.

\section{H. GRANDICOLLIS.}

Ovalis, convexus, niger, subnitidus, antenmis brunneis; fronte puncticulata bifovcolata, stria antice recta; mandibutis vix dentatis; pronoto lateribus ciliato punctulatoque, striis lateralibus integris sat approximatis; clytris striis 1-3 dorsalibus validis integris, 4.5 et suturali obsoletis; fossa subhumerali punctata b-striata; propygidio mygidioque sat dense punctatis; tibiis anticis 3-dentatis, posticis biseriatim 7-spinosulis. ong. 9 mill.; larg. $61 / 2$ mill.

Hister grandicollis, Illig. Mag., vi, 30, 2 (1807).

Ovale, convexe, noir, peu luisant. Antennes brunes; massue grise. Tête grande, front large, finement pointillé, légèrement bifovéolé, strie forte, entière, droite par devant; labre court, arrondi. Mandibules allongées, non canaliculées, en crochet obtus, très faiblement bidentées en dedans loin du bout. Pronotum beaucoup plus large que long, droit à la base, avec une petite strie antéscutellaire; arqué et cilié sur les côtés, échancré et rétréci en devant, avec les angles abaissés. obtus; stries latérales bien marquées, externe presqu'entière, interne entière, bisinuée sur les côtés, non interrompue au devant avec les angles postoculaires arrondis. Ecusson petit, triangulaire. Elytres courtes, un peu plus longues que le pronotum, de sa largeur à la base, un peu dilatées à l'épaule, rétrécies et obliques au bout; stries bien marquées, crénelées; sublıumérale atteignant l'épaule, rap3e Série, Tove II. 
prochée de la première dorsale; 1-3 dorsales entières, presque parallèles, 4-5 et suturale raccourcies, obsolètes ; fossette subhumérale bien marquée, ponctuée, 3-sillonné. Propygidium couvert de points assez serrés; pygidium beaucoup plus densément et un plus fortement ponctué. Prosternum court, en carène peu élevée, arrondi à la base, lobe court bien distinct, rebordé, infléchi et terminé en pointe; mésosternum échancré, bordé d'une strie entière, et d'une autre largement interrompue. Jambes antérieures fortement 3-dentées; postérieures garnies de sept paires de denticules épineux.

Tous les caractères rapprochent cette espèce de l' 1 . amplicollis, mais il a un faciès très différent; plus ovale, moins bossu et moins dilaté en devant, il est aussi plus luisant, moins pointillé; ses stries sont plus parallèles et plus fortes, et sa fossette subhumérale est mieux marquée.

Portugal (Lisbonne).

\section{H. SEMigranosus.}

Ovalis, marum convexus, niger, obscurus; capite, pronoto pygidioque dense punctutis; stria frontali integra, pronoto ciliato, stria utraque laterali integris; clytris striis $1-3$ dorsalibus integris, 4-5 et suturali punctiformibus brevibus, fossa subhumerali 3-sulcata punctata; mesosterno vix sinuato, stria murginali integra recta; tibiis anticis 3.dentatis; posticis biseriatim multispinosulis. Long. 10 mill.; larg. 7 mill.

Ovale, peu convexe, noir mat. Antennes brunes; massue grise. Tête densément ponctuée, strie frontale profonde eutière; labre court; mandibules bidentées, rebordées, recourbées en pointe aiguë. Pronotum large, court, coupé droit à la base, pas sensiblement arqué et cilié sur les côtés, 
échancré et à peine rétréci en devant, avec les angles abaissés, obtus; couvert d'une ponctuation fine, serrée, plus granuleuse sur les bords; stries latérales parallèles, entières. Ecusson petit, triangulaire. Elytres un peu plus longues, et aussi larges que le pronotum à la base, dilatées légèrement à l'épaule, rétrécies vers le bout, avec une faible impression sub-apicale; stries assez fines, bien marquées, subhumérale atteignant l'épaule, 1-3 dorsales entières, quatrième, cinquième et suturale formées de points, courtes, apicales obsolètes; bord infléchi parcouru par trois sillons garnis de plis et de points, fossette subhumérale bien marquée. Propygidium avec une impression de chaque côté, entièrement ponctué ainsi que le pygidium, mais moins densément. Prosternum en carène peu élevée, arrondi à la base, lobe peu avancé, presque horizontal, bordé de deux ou trois stries sur les côtés; mésosternum faiblement éclıancré, bordé de deux stries, l'une interrompue, l'autre entière, droite. Jambes antérieures fortement 3-dentées; postérieures garnies de deux rangées de nombreux denticules épineux. Inde.

\section{H. ENCAUSTUS.}

Ovalis, subdepressus, niger, nitidus; fronte munctulata, trifoveolala, stria profunda, integra, postice continuata; mandidulis canaliculatis, fossa clavali profunda; pronoto ciliato; stria interna sinuata externaque integris ; elytris foveola subhumerali bisulcata, striis 1-3 dorsalibus validis integris, catcris mullis; mopygidio bifoveolato pygidioque dense ocellato. punctatis; mesosterno subsinuato stria integra; tibiis anticis 3-dentatis, posticis biseriatim multispinosulis. Long. 9 mill.; larg. 6 mill.

Ovale, peu convexe, noir, très luisant. Antennes brunes; 
massue velue, plus rousse; fossette antennaire profonde el bien limitée. Front finement pointillé, entouré d'une strie profonde entière, continuée même par derrière, marqué de trois fossettes peu profondes, deux en devant et une par derrière; labre court, infléchi. Mandibules fortes, larges, bidentées en dedans, terminées en pointe acérée, creusées en gouttière. Pronotum beaucoup plus large que long, cilié, coupé droit à la base, légèrement arqué sur les côtés, rétréci en devant, avec les angles obtus et abaissés, et le fond de l'échancrure subsinué; strie latérale interne forte, profonde, entière, coudèe au milieu du bord latéral et derrière les yeux, externe entière longeant le bord. Ecusson petit, triangulaire. Elytres plus longues que le pronotum, de sa largeur à la base, curvilinéaires sur les côtés, arrondies à l’angle postérieur et rétrécies au bout avec une impression subapicale et un angle sutural; stries fortes, crénelées, profondes; subhumérale atteignant l'épaule; 1-3 dorsales entières; les autres nulles, cependant on retrouve quelques points rudimentaires de la quatrième; bord infléchi 3-sillonné, fossette ponctuée. Propygidium bifuvéolé, couvert de points ocellés, serrés, ainsi que le pygidium. Prosternum bombé, arrondi à la lsase , lobe incliné, étroit, bi-marginé ; mésosternum légèrement sinué, bordé d'une strie entière et d'une strie interrompue. Jambes antérieures dilatées, 3-dentées; intermédiaires plus courtes que les postérieures, garnies de nombreux denticules épineux, disposés par paires.

Inde (Pondichery) (M. Guérin).

\section{H. Maurus.}

Oealis, subconvexus, niger, nitidus ; fronte plant, stria integra; monoto riliato, striis integris, ad latere rectis, basi ap- 
moximatis; clytris margine bisulcuto, foveolato; striis 1-3 dorsalibus integris, $4^{a}, 5^{2}$ et suturali vix apice indicatis ; momygidio bifoveolato pygidlioque punctatis; mesosterno subsinuato marginuloque; tibiis anticis valide 4-dentatis; posticis biscriatim multispinosis.Long. 8 mill.; larg. 6 mill.

Ovale, légèrement convexe, noir, luisant, lisse. Antennes brunes; front plan, strie Iroite, entière; labre très petit; mandibules fortes, bidentées en dedans, creusées d'une gouttière, à pointe acérée. Pronotum plus large que long, cilié, coupé droit à la base, oblique sur les côtés, rétréci et échancré en devant, avec les angles abaissés, obtus; strie latérale interne entière, sans angles postoculaires, forte et droite sur les côtés, ainsi que l'externe; rapprochées l'une de l'autre à la base. Ecusson petit, triangulaire. Elytres plus longues que le pronotum, de sa largeur à la base, curvilinéaires sur les côtés, rétrécies et arquées au bout avec une impression subapicale, et un angle sutural bien marqué; stries fortes, profondes; subhumérale atteignant l'épaule; 1-3 dorsales entières, quatrième, cinquième et suturale à peine indiquées par des points; fossette subhumérale bistriée, pointillée. Propygidium bifovéolé, assez densément ponctué, ainsi que le pygidium. Prosternum en carène, peu arrorıdi à la base, lobe court, infléchi, rebordé; ınésosternum à peine sinué, bordé d'une stric entière et d'une strie interrompue. Jambes antérieures garnies de quatre dents arrondies, dont les deux apicales sont fort grandes; postérieures garnies de six ou sept paires de denticules épineux. Sénégal (M. de Laferté).

\section{H. RECTISTERNIS,}

Ovalis, conecxus, niger, niridus ; strie frontali inteyra; wronato ciliato striis :alidis approximatis simuatis integris : elytri.s 
1-3 dorsalibus integris, 4-5 brevissimis, suturali utrinque abbreviata; margine in/lexo 3-sulcato, fossa sat profunda; propygidio bifoveolato pygidioque dense punctutis; mesosterno subrecto marginato; tibiis anticis 3 -dentatis, posticis biscriatim spinosulis. Long. 8 mill.; larg. $51 / 2$ mill.

Ovale, assez convexe, noir, luisant. Antennes brunes, massue velue, grise. Front plan, finement pointillé ; strie bien marquée, entière; labre court, infléchi; mandibules assez fortes, creusées en gouttière, bidentées en dedans, terminées en pointe aiguë, arquée. Pronotum plus large que long; subarqué et bordé de points à la base, oblique et cilié sur les côtés, rétréci et échancré en devant avec les angles abaissés, peu aigus; stries latérales fortes, sinuées, parallèles, rapprochées, entières. Ecusson petit, triangulaire. Elytres plus longues que le pronotum, de sa largeur à la base, dilatées à l'épaule, rétrécies et droites au bord apical; fossette subhumérale assez profonde, à peine distintement pointillée, 3-sillonnée; stries 1-3 dorsales fortes, entières, crénelées, rapprochées, presque parallèles, quatrième et cinquième très courtes, obsolètes, suturale bien marquée, raccourcie de part et d'autre, subhumérale atteignant l'épaule. Propygidium bifovéolé, densément et assez fortement ponctué, ainsi que le pygidium. Prosternum en carène, élargi à la base, lobe court, abaissé, rebordé; mésosternum droit, bordé d'une strie entière et d'une interrompue. Jambes antérieures dilatées, armées de trois fortes dents; postérieures garnies de sept on huit paires de denticules épineux.

Sénégal.

\section{H. helluo.}

Ovalis, parmm conexus, mitidus; antennis rufo-brunncis; frontali stria integra; monoto lateribus per loca munctatis, stria 
Laterati externa dimidiuta, interna integra; clytris fossu subhumerali punctuluta, bisulcata; stria subhumerali brevi obsoleta; 1-4 dorsalibus integris, $5^{\text {a }}$ suturalique abbreviutis; mopygidio bifoveoluto, purum dense, mygidio subtilius muctutis; mesostcrno emarginato stria integra; tibiis anticis 4-denticulatis, postiris biscriatim multispinosis. Long. 5 mill.; larg. 4 mill.

Hister helluo. Truq. in Soc. ent. Fr. (1852) 61, 1, pl. 2, n. 2, 4.

Ovale, peu convexe, noir, luisant. Antennes brunes; massue rougeàtre. Tête petite, subarrondie; front plan; strie entière; labre court, très petit; mandibules à peine visiblement dentées. Pronotum beaucoup plus large que long; légèrement arqué à la base, oblique, puis arrondi sur les côtés, rétréci et échancreé en devant, avec les angles abaissés, obtus; strie latérale externe n'atteignant pas tout á fait le milieu; interne bien marquée, entière, bordée gà et là de gros points irréguliers disposés par groupes. Ecusson petit, triangulaire. Elytres plus longues que le pronotum, de sa largeur à la base, légèrement arquées sur les côtés; droites et rétrécies au bout avec une faible impression subapicale; bord infléchi bisillonné. fossette pointillée; strie subhumérale courte, obsolète; 1-4 dorsales fines, imponctuées, entières, subparallèles; cinquième courte, formée de points, suturale un peu moins raccourcie. Propygidium bifovéolé, couvert de points ocellés peu serrés; pygidium aussi densément, mais beaucoup plus finement ponctué. Prosternum peu élevé, élargi à la base, lobe court, incliné, rebordé; mésosternum échancré, bordé d'une strie entière ; jambes antérieures armées de quatre dents très fines, l'apicale bifide; postérieures de sept à huit paires de denticules épineux.

France; Piémont. 


\section{II. NonAS.}

Ovalis, subconvexus, niger, nitilus, temissime puncticulatus; stria frontali profunda integra; monoto stria laterali interna integva, externu mox abbreviata; elytris mangine bisulcato, fossa sat profunda, panctulala, striis 1-1, dorsatibus integris, $5^{\text {a }}$ in medio, suturuli ultra abbreviatis; mopygidio subbifoveolato sparsim, pygidio subtilius punctulatis; mesosterno subsinuato stria integra; tibiis anticis 4-dentatis, posticis biscriatim multispinosis. Long, 7 mill.; larg. 5 mill.

Hister nomus. Er. in Jahr. 137, 23 (1834).

Ovale, assez convexe, noir, luisant, couvert d'une ponctuation très fine et peu visible. Antennes brunes; massue velue, grise. Tete petite, arrondie; front plan, strie forte, entière, semicirculaire; labre court, bombé; mandibules inermes. Pronotum court, assez large, droit à la base, arqué sur les côtés, rétréci et échancré en devant, avecles angles abaissés, obtus; strie latérale externe très raccourcie, interne entière, n'atteignant pas tout à fait la base. Ecusson triangulaire, petit. Elytres plus longues que le pronotum, de sa largeur à la base, légèrement curvilinéaires sur les côtés, rétrécies et arquées au bord apical; fossette marginale pointillée, bisillonnéc; strie subhumérale touchant à l'épaule, 1-4 dorsales entières, fortes, crénelées, cinquième raccourcie au milieu, prolongée par des points; suturale plus longue. Propygidium légèrement bifovéolé, couvert de petits points espacés; pygidium plus densément pointillé. Prosternum peu élevé, élargi à la base, lobe court, reborué, presque horizontal; mésosternum à peine bisinué, étroitement rebordé. Jambes antérieures dilatées, armées de quatre dents; postérieures garnies de cinq ou sept paires de denticules épineux.

Cap de Bonne-Espérance; Cafrerie (Natal); $\Lambda$ byssinie. 


\section{H. Tropicilis.}

Ovalis, convexiusculus, niger, niticus; stria frontali integra; pronoto ciliuto, stria luterali internu valida haud interrupta, externa brevi; elytris sub apicem impressis, margine inflexo bisulcato, fossa punclulata; striis sulciformibus crenatis, 1-4 integris, 5 et suturati abbreviatis; propygidio bifoveolato pygidiogne parce punctulatis; mesostemo subrecto, marginato; tibiis anticis 3-dlontatis, posticis biscriatim multispinosis. Longueur 8 mill.; larg. 6 mill.

Ovale, assez convexe, noir, luisant. Antennes brunes, massue d'un roux cendré. Tête petite, arrondie; front plan, séparé de l'épistome par une strie semicirculaire forte; labre court; mandibules bidentées, terminées en pointe recourbée. Pronotum cilié, court, Jroit à la base, à peine arqué sur les côtés, très rétréci et échancré en devant avec les angles abaissés, obtus; strie latérale interne profonde et non interrompue, externe courte, rapprochée du bord. Ecusson petit, triangulaire. Elytres plus longues que le pronotum, de sa largeur à la base, curvilinéairement dilatées sur les côtés, arrondies à l'angle postérieur, rétrécies et obliques au bout, avec une forte impression subapicale; suture enfoncée, bord infléchi bisillonné, fossette peu marquée, pointillée; stries profondes, fortes, crénelées, subhumérale atteignant l'épaule, 1-4 dorsales entières, cinquième raccourcie au milieu, suturale arquée en dehors, plus longue. Propygidium bifovéolé, couvert de points espacés, ainsi que le pygidium. Prosternum à peine élargi à la base, lobe court, rebordé, infléchii; mésosternum peu visiblement sinué, bordé de deux stries, l'unc entière, l'autre interrompue. Jambes antérieures bidentées; posté- 
rieures garnies d'un double rang de nombreux denticules épineux.

Séuégal.

\section{H. Nigrines.}

Breviter ovalus, convexiusculus, niger, nitidus; frontali stria profunda, integra; pronoto stria laterali interna integra, externa brevi, didyma; clytris fossa subhumerali punctulata bisulcata, striis $1-4$ dorsalibus integris, $5^{\text {a }}$ ante medium suturalique ultra abbreviatis; momygidio bifoveotato, pygidio bipunc. tato punctulatis; mesostcrno sinuato, marginato; tibiis anticis 5-dentatis, posticis biscriatim spinosis. Long. 7 mill.; largeur $51 / 2$ mill.

Hister nigrinus, Fahr. in Boh. Ins. Cafr. I, 533, 578 (185̌1).

Ovale arrondi, assez convexe, noir, luisant. Antennes brunes, funicule et extrémité de la massue rouges. Tête petite, arrondie; front plan, strie profonde entière, sinuée ; labre court infléchi ; mandibules à peine dentées. Pronotum plus large que long, droit à la base, arqué sur les côtés, échancré et très rétréci en devant, avec les angles abaissés, obtus; strie latérale interne entière, droite sur les côtés; externe n’atteignant pas le milieu, accompagnée d'une striole supplémentaire. Ecusson petit, triangulaire. Elytres plus longues que le pronotum, de sa largeur à la base, curvilinéairement dilatées sur les côtés, rétrécies au bout avec une impression subapicale; fossette subhumérale pointillée, bisillonnée; strie sublıumérale atteignant l'épaule; 1-4 dorsales fortes, crénelées, entières, cinquième droite raccourcie au milieu, suturale remontant bien au-delà. Propygidium finement et peu densément ponctué, légèrement bifovéolé. Pygidium avec un gros point enfoncé de chaque côté de la base, finement ponctué. Prosternum en carène, 
élargi à la base, lobe court, bordé de deux stries, abaissé; mésosternum faiblement sinué, bordé d'une stric entière et d'une interrompue. Jambes antérieures dilatées, armées de cinq dents; postérieures garnies de sept ou huit paires de denticules épineux.

Cap de Bonne-Espérance; Cafrerie (II. de Laferté).

\section{H. LAtobius.}

Ovalis, convexiusculus, niger, nitidus, clava brumnea ; stria frontali antice recta, mandibulis bidentatis; pronoto ciliato striis 2 lateralibus integris; clytris margine inflexo, foveolato, bisulcato, stria subhmerali et $1-3$ dorsatibus integris, catcris mullis; mygidio propygidioque punculatis; mesosterno recto stria integra; tibiis anticis 3.dentatis, posticis longius multispinosis. Long. 8 mill.; larg. 6 mill.

Ovale, assez convexe, noir, luisant. Antennes noires, massue brune. Front large, plan, à peine visiblement pointillé, séparé de l'épistome par une strie entière, droite en devant, bianguleuse de clıque côté; mandibules égales, courtes, recourbées, fortement bidentées. Pronotum beaucoup plus large que long, arqué à la base avec une bordure de points et une ligne antéscutellaire, oblique et cilié de noir sur les côtés, un peu rétréci et profondément échancré en devant, avec les angles saillants, obtus et abaissés ; strie latérale interne non interrompue, externe à peine raccourcie à la base, ne cessant qu'au niveau des yeux. Ecusson petit, triangulaire. Elytres plus longues que le pronotum, de sa largeur à la base, courbées légèrement sur les côtés, arrondies à l'angle postérieur et droites au bord apical, un peu enfoncées sur les stries et d'un mat qui contraste avec le brillant général; bord infléchi bisillonnẻ, avec une 
fossette à peine pointillée; stries assez fines, quoique bien marquées, subhumérale interne remontant jusqu'à la base, 1-3 dorsales entières, les autres nulles. Pygidium obscur, pointillé; propygidium couvert de points plus gros et espacés. Prosternum étroit, en carène, arrondi à la base, lobe court rebordé, infléchi; mésosternum droit, à strie entière. Jambes antérieures armées de trois dents fortes; postérienres garnies d'une double rangée de longues et nombreuses épines.

Cap de Bonne-Espérance.

\section{H. Capicola.}

Ovatus, convexus, niger, subnitidus; frontali stria integra; mandibulis bidentatis; canaliculatis; monoto ciliato, stria intcrna integra, externa mox abbreviata; clytris fossa subhumerali bistriata vix punctuluta, striis dorsalibus 1-3 integris,

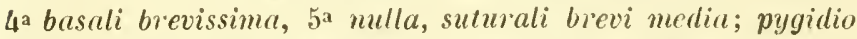
mopygidioque punctatis; mesosterno recto marginato; tibiis anticis 3-dentatis, posticis biseriatim multispinosis. Long. $8 \mathrm{~m}$. ; larg. 6 mill.

Ovale, assez convexe, noir, luisant. Antennes brunes, funicule rougeâtre, massue velue, grise. Front très finement pointillé, large, pian ; strie entière subsinuée en devant; labre court, transversal; mandibules fortes, bidentées en dedans, creusées en gouttière, terminées en pointe acérée. Pronotum plus large que long, coupé droit à la base, cilié et légèrement arqué sur les côtés, fort rétréci et échancré en devant, avec les angles abaissés, moins obtus; strie latérale interne forte, entière; externe raccourcie avant le milieu. Ecusson petit, triangulaire. Elytres plus longues que le pronotum, de sa largeur à la base, curvilinéairement dilatées sur les côtés, rétrécies postérieurement; fossette sub- 
humérale pointillée, bisillonnée; strie subhumérale atteignant l'ćpaule; 1-3 dorsales fines, entières, quatriẻme basale très courte, suturale raccourcie de part et d'autre. Propygidium peu densément ponctué, arec de plus petits points dans les intervalles; pygidium couvert d'une ponctuation encore plus espacée. Prosternum élevée, élargi à la base; lobe court, abaissé, bordé de deux stries; mésosternum droit, avec une stric entière. Jambes antérieures dilatées, armées de trois lortes dents; postérieures garnics de sept ou huit paires de denticules épineux.

Cap de Bonne-Espérance.

\section{H. subsulcitus.}

Ovatus, subdepressus, niger, nilidus; stria frontali integra; pronoto ciliato, stria interna inteyia, cxterna ante medium abbreviatu; clytris striis fortibus, crenulatis, 1-4 dorsalibus integris, 5a medio, sulurali arcuata ultra abbreviatis; fossa subhumerali lavi, 3 sulcis ultra humerum haud productis; propygidio bifoveolato parce punculuto, mygidio sublavigato; mesosterno cmarginalo stria integra; tibiis unticis 3-dentalis, posticis biscriatim multispinosis. Long. 8 mill.; larg. 6 mill.

Ovale, déprimé, noir, luisant, lisse. Antennes d'un brun de poix, massue velue, d'un gris roussàtre. Front large, plan, strie bien marquée, droite par devant, non interrompue; labre court, infléchi; mandibules fortes, acérées, bidentées en dedans, creusées en gouttière. Pronotuın beancoup plus large que long, cilié, coupé droit à la base, oblique sur les côtés, échancré en devant, arec les angles abaissés obtus; strie latérale interne entièrc, forte, coudée au milieu, courbéc en dedans à la base; externe également forte, rapprochée de l'interne, raccourcie avant le 
milieu. Ecusson petit, triangulaire. Elytres une fois et demie plus longues que le pronotum, de sa largeur à la base, légèrement arquées sur les côtés, rétrécies et coupées droit au bord apical; fossette subhumérale profonde, avec trois sillons ne remontant qu'à l'épaule; stries fortes, profondes, subhumérale atteignant l'épaule; 1-4 dorsales entières, rapproclıćes par paires à la base, les autres raccourcies, cinquième vers le milieu, suturale arquée, au delá du milieu. Propygidium bifovéolé, couvert de points peu serrés; pygidium lisse arec quelques petits points aux angles antérieurs. Prosternum en carène, à peine ćlargi à la base, lobe lıorizontal, rebordé; mésosternum échaneré, boldé d’une strie entière. Jambes antérieures 3-dentées; postérieures garnies d'un grand nombre de denticules épineux disposés par paires.

Sénégal; cap de Bonne-Espérance.

\section{H. Abyssinicus.}

Ovalis, subconvexus, niger, nitidus, clava rufu; frontali stria antice recta mandibulis bidentutis, canaliculatis; monoto ciliato stria laterali interna integra, externa timidiala; elytris striis validis crenatis, 1-4 dor'salibus integris, 5a ante et suturuli in nedio abbreviatis; fossu subhumerali 3-sulcis ultru humerum non productis; mopygidio bifoveolato parce, mygidio vix punctulato; mesosterno emarginato, stria integra; libiis anticis 3-rlentratis, posticis biseriatim multispinosis. Longueur 10 mill.; larg. 7 mill.

Ovale, peu convexe, noir, luisant. Antennes brunes, massue velue, rousse. Tête forte; front presque plan, large, stric bien marquée entière, droite par devant; labre court, arrondi en devant. Mandibules fortes, larges, bidentées. 
creusées en gouttière en dessus, à pointe aiguẻ, recourbée. Pronotum plus large que Iong, presque droit à la base. cilié et arqué légèrement sur les côtés, échancré et retréci ell devant, avec les angles abaissés obtus; strie latéralc interne entière, recourbée en dedans à la base, bisinuée sur les côtés, avec une légère fossette au quart, non interrompue en devant sans coudes derrière les yeux; externe raccourcie au milieu, suivant un peu le bord antérieur. Ecusson petit, triangulaire. Elytres plus longues que le pronotum de sa largeur à la base, curvilinéairement dilatées sur les côtés, rétrécies et un peu obliques au bout; stries fortes, bien marquées, crénelées; subhumérale atteignant l'épaule, 1-4 dorsales entières, rapprochées par paires, cinquième raccourcie avant le milieu, suturale arquéc au milieu; fossette subhumérale peu profonde, avec 3 sillons qui ne s'étendent pas au-delà de l'épaule. Propygidium bifovéolé, couvert d'une ponctuation peu serrée; pygidium presque lisse avec quelques points latéraux à la base. Prosternum en carène, peu arrondi à la base, lobe infléchi, bimarginẻ; mésosternum éclancré, bordé d'une strie entière, et d'une interrompue. Jambes antérieures fortement 4-dentées; postérieures garnies de neuf ou dix paires de denticules épineux.

Abyssinie.

\section{H. Hottentota.}

Obtongo-ovatus, subconvexus, niger, nitidus; fromtali stria integru, mundibulis bidentatis, canuliculatis; pronoto ciliato, stria interma integra, cxterna dimidiata; clytris fossa subhumerali, 3-sulcis ultra humerum moductis, punculatu; stris crenatis, dorsalibus 1-4 imegris, basi per paria upprorimatis, $5^{3}$ ante ef suturati in medio abbreviatis; momggidio bifoveolate 
pygidioque parce panclatis; mesosterno emarginato, stria integra; tibiis anticis 3-dentatis, posticis tiscriatim multispinosis. Long. 8 mill.; larg. 5 mill.

Hister Hottentota, Er. in Jahr. 136, 17 (1834). - Fahr. in Bohem. Ins. Cafr. I, 534, 580.

Ovale allongé, légèrement convexe, noir, luisant. Antennes brunes, massue rousse. Front plan, large ; strie forte, entière, droite en devant; labre court, transversal; mandibules fortes, bidentées en dedans, à pointe acérée, creusées cı gouttière. Pronotum beaucoup plus large que long, coupé droit et bordé de points à la base, à peine arqué et cilié sur les côtés, échancré et rétréci en devant, avec les angles abaissés, saillants, obtus; strie latérale interne entière, sinuée sur les côtés, externe raccourcie vers le milieu. Ecusson petit, triangulaire. Elytres plus longues que le pronotum, de sa largeur à la base, légèrement curvilinéaires sur les côtés, un peu obliques au bord apical, sans impression; fossette sublıumérale pointillée, à trois sillons, dont l'interne remonte sur l'épaule; stries fortes, crénelées, 1-4 dorsales entières, rapprochées par paires à la base, cinquième droite, raccourcie un peu avant le milieu; suturale arquée, un peu plus longue. Propygidium bifovéolé, ponctué peu densément, lisse au milieu. Pygidium un peu moins distinctement pointillé. Prosternum en carène, à peine élargi à la base, lohe peu abaissé, binarginé ; mésosternum échancré, bordé d'une strie entière. Jambes antérieures 3-dentées; postérieures garnies de luuit à dix paires de denticules épineux.

Cap de Bonne-Espérance : Calierie ; Ahyssinie. 


\section{1. Н. Tropicus.}

Oblongo-ovatus, parum convexus, niger, nitidus; frontc transversa, stria integra; mandibulis bidentatis, canaliculatis; pronoto ciliato, stria interna intcgra, externa vix abbreviata; elytris striis crenatis, 1-4 dorsalibus integris, 5 a in medio, suturali ultra abbreviatis, fossa subhumcrali 3-sulcata; pygidio bifoveolato pygidioque subtiliter punctulatis; mesosterno emarginato, stria integra; tibiis anticis jo-dentatis, posticis biseriatim multispinosis. Long. 9 mill.; larg. 6 mill.

Histcr Tropicus, Paykl. Mon. 19, 9, pl. 2, fig. 4 (1811).

Ovale allongé, peu convexe, noir, luisant. Antennes brunes, massue gris-roux ; front large ; strie entière, forte, droite en devant; labre court, infléchi. Mandibules larges, courtes, à pointe acérée, fortement bidentées, creusées en gouttière. Pronotum beaucoup plus large que long, droit et bordé de points à la base, à peine arqué et cilié sur les côtés, échancré et rétréci en devant, avec les angles abaissés, obtus; strie latérale interne entière, non interrompue ; externe peu raccourcie à la hase. Ecusson petit, triangulaire. Elytres plus longnes que le pronotum, de sa largeur à la base, à peine dilatées sur les côtés, et subarquées au bord apical; fossette latérale assez profonde, pointillée, à trois sillons, dont l'interne ne remonte pas l'angle huméral; stries fortes, crénelées; subhumérale, atteignant l'épaule, 1-4 dorsales entières, cinquième raccourcie au milieu, suturale arquée en sens inverse, plus longue. Propygidium bifovéolé, couvert de points peu serrés, et daus l'intervalle, de points plus petits; pygidium plus finement pointillé, presque lisse au milieu. Prosternum en carène, peu élargi à la base, lobe court, rebordé, à peine abaissé. Mésosteruum enhaneré, bordé d'une strie entière. Jambes antérieures 
armées de trois dents; postérieures garnies de huit ou dix paires de denticules épineux serrés.

Guinée; Nubie.

\section{H. COPROPHILUS.}

Oblongo-ovatus, subdepressus, niger, nitidus; antemis rufobrunncis'; fronte subimpressa, stria integra retrorsum angutata; pronoto stria interna integra, externa in medio abbreviata; elytris fossa subhumerali bistriala; striis dorsalibus 1-4 iutegris, 5 a ante medium, suturali ultra abbreviatis; mromygidio bifoveolato pygidioque punctatis; mesosterno sinuato, stria integra; tibiis anticis 3-dentatis, posticis biseriatim spinosis. Long. $61 / 2$ mill.; larg. $31 / 2$ mill.

Ilister coprophilus. Reiche, Voy. Albyss. p. 302, 4 (1851).

II. tumidus. Fahr. in Bohem. Ins. Cafr. 1, 537, 581 (1851).

Ovale allongé, subdéprimé, noir-brun, lisse, luisant. Antennes brun-rouge. Front très finement pointillé, avec une légère impression longitudinale; strie entière, bien marquée, avec un angle rentrant très petit; labre court, arrondi ; mandibules faiblement bidentées en dedans, creusées en gouttière, à pointe acérée. Pronotum plus large que long, légèrement arqué et bordé de points à la base, oblique sur les côtés, rétréci et échancré en devant, avec les angles abaissés, assez aigus ; strie latérale interne entière, légèrement sinuée sur les côtés; externe raccourcie au milieu. Ecusson petit, triangulaire. Elytres plus longues que le pronotum, de sa largeur à la base, curvilinéaires sur les côtẻs, rétrécies et coupées droit au bout; fossette latérale, bisillonnée, pointillée, strie sublıumérale atteignantl'épaule ; 1-4 dorsales entières, parallèles, ponctuées, cinquième raccourcic au milieu, suturale bien au-delà. Propygidium bifovéolé, couvert ainsi que le pygidium d'une ponctuation 
peu serrée. Irosternum en carène, élargi à la base, lobe court, reborlé, infléchi ; mésosternum légèrement échancré, bordé d'une strie entière. Jambes antéricures dilatées, 3-lentées; postérieures garnies d'un double rang de dentelures épincuses inégales et serrẻes.

Abyssinic ; Cafrerie.

\section{H. AEQATORIUS.}

Ovalis, subconvexus, niger, nitidus; antennis brunneis, stria frontali intcgra antice recta, mandibulis bidentatis, canaliculatis; pronoto ciliato, stria externa pone medium abbreviata, intorna valida, sinuata, integra; clytris fossa subhumerali bisulcata, striis crenatis, 1-3 dorsalibus integris, 4-5 mullis, suturali brevi media; mopygidio punctato, pygidio convexo: mesosterno emarginato, stria integra; tibiis anticis 3dentatis; nosticis biseriatim multispinosis. Long. 6 mill.; largeur 4 mill.

Ovale, peu convexe, noir, luisant. Antennes brunes. Front plan, large ; strie entière, forte, droite par devant; labre court ; mandibules fortes, courtes, bideutées en dedans, à pointe acérée, légèrement creusées en gouttière. Pronotum plus large que long, coupé droit et bordé de points à la base, cilié et à peine courbé sur les côtés, rétréci et échancré en devant, avec les angles abaissés, assez aigus ; strie latérale externe raccourcie au milieu, forte; interne entic̀re, plus forte encore, sinueuse latéralement. Ecusson petit, triangulaire. Elytres un peu plus longues que le pronotum, de sa largeur à la base, curvilinéairement dilatées sur les côtés, droites et un peu plus étroites au bord apical; fossette latérale 2-sillonnée; stric subhumérale atteignant l'épaule, 1-3 dorsales entières, fortes, profondes; quatrième et cinquième nulles; suturale médiane, bien marquée, raccourcif 
de part et d'autre. Propygidium court, ponctué légèrement sur les côtés. Pygidium convexe, à peine visiblement pointillé. Prosternum en carène, à peine élargi à la base, lobe court, rebordé, peu abaissé; mésosternum légèrement sinué, bordé d'une strie entière et d'une autre interrompue. Jambes antérieures 3-dentées; postéricures garnies de liuit ou neul' paires de denticules épineux.

Guinée; Sénégal.

\section{H. OVATULES.}

Ovalis, convexiusculus, niger, nitidus; antenuis rufobrunneis; stria frontuli integra; mandibulis bidentatis, cunaliculatis; monoto ciliato, stria laterali intorna integra, externa dimidiata; elytris fossa 3-sulcata, striis crenatis integris, $5^{\text {a }}$ dorsali et suturuli parum abbreviatis; propygidio bifoveolato pygidloque parce punctatis; mesosterno emarginuto, stria haud interrupta; tibiis anticis 3̈-dentatis, posticis biscriation multispinosis. Long. 6 mill. ; larg. 4 mill.

Ovale, peu convexe, noir, luisant. Antennes brunes, massue velue, gris-roux. 'Tête large ; front plan, pointillé, strie forte, entière, droite par devant ; labre court ; mandibules bidentées, canaliculées, recourbées en pointe aiguë. Pronotuın court, droit et bordé de points à la base, cilié et arqué sur les côtés, rétréci et échancré en devant avec les angles abaissés, obtus ; strie latérale interne forte, entière, bisinuée latéralement, externe raccourcie au milieu. Ecusson petit, triangulaire. Elytres plus longues que le pronotum, de sa largeur à la base, curvilinéaires sur les côtés, arrondies à l'angle postéricur, et rétrécies au bout ; tossette latérale 3-sillonnée; stries fortes, crénelées, subhumérale atteignant l'épaule, 1-3 dorsales entières, quatrième à peine 
raccourcie, cinquième et suturale égales, un peu plus courtes. Propygidium bifovéolé, couvert de points espacés; pygidium un peu plus densément ponctué. Prosternum en carène, peu élargi à la base, lobe court, bimarginé, infléchi ; mésosternum échancré, rebordé. Jambes antérieures armées de trois dents, postérieures garnies d'un double rang de nombreux denticules épineux.

Cap de Bonne-Espérance (II. Deyrolle).

\section{II. CRibrurus.}

Ovalis, convexiusculus, niger, nitidus ; clava rufo-grisea; fronte concavu; stria integru; mandibulis bidentatis, canuliculatis; pronoto striu laterali vatida haud interrupta, externa vix abbreviata; chytris fossa laterali bisulcata, striis crenatis, 1-3̊ dorsalibus integris, 4-5 et suturali abbreviatis; propygidio bifoveolato mygidioque dense et grosse munctatis; mesosterno recto, marginato; tibiis anticis 3-dentatis, posticis biscriatim multispinosis. Long. 7 mill.; larg. 5 mill.

Ovale, peu convexe, noir, luisant. Antennes brunes, massue d'un gris roux. Front élargi, concave, entouré d'une forte strie non interrompue; mandibules canaliculées, bidentées, courbées en pointe aiguë. Pronotum court, arqué et bordé de points à la base, oblique sur les côtés, rétréci et échancré en devant avec les angles abaissés, presqu'aigus ; strie latérale interne forte non interrompue, externe peu raccourcie. Ecusson petit, triangulaire. Elytres un peu plus longues que le pronotum, de sa largeur à la base, curvilinéaires sur les côtés, arrondies à l'angle postérieur, rétrécies et droites au bord apical ; fossette bien marquée, 2-sillonnéc; stries fortes créuelées, subhumérale atteignant l'épaule, 1-3 dorsales entières, quatrième, cinquième et suturale 
raccourcies au milieu un peu plus, un peu moins. Propygidium bifovéolé, couvert de gros points assez serrés, ainsi que le pygidium. Prosternum en carène, un peu élargi à la base, lobe infléchi, ponctué, rebordé; mésosternum droit, bordé de deux stries, dont l'interne seule entière. Jambes antérieures armées de trois dents, l'apicale bifide; postérieures garnies d'un double rang de nombreux denticules épineux.

Sénégal.

\section{H. TORRIDEs.}

Brcviter ovatus, parum convexus, niger, mitidus; stria frontali recta integia; promoto ciliato, striis 2 validis, interna simata haud interrupta, externa ultra medium abbreviata; clytris fossa subhumerali 3-sulcula, striis 1-3 ylorsalibus intcgris, $4^{\mathrm{a}}$ in medio, 5a apice, suturati ulle medinm abbreviatis; mopygidio bifoveolato mygidioute plano parce punctutis; mesosterno emarginato, stria integra; tibiis anticis 3-dentatis, posticis biscriatim multispinosis. Long. 6 mill.; larg. 4 1/2 mill.

Ovale arrondi, peu convexe, noir, luisant. Antennes brunes, massue gris-roux. Front large, plan, stric entière, bien marquée, droite par devant ; labre court, transversal ; mandibules fortes, larges, bidentées en dedans, courbées en pointe aiguë, faiblement canaliculées. Pronotum plus large que long, droit et bordé de points à la base, oblique et cilié sur les côtés, rétréci et échancré en devant, avec les angles abaissés, obtus; stries fortes, profondes, interne, sinueuse latéralement, non interrompue, externe droite, raccourcie au-delà du milieu. Ecusson petit, triangulaire. Elytres un peu plus longues que le pronotum, de sa largeur à la basc, curvilinéaires sur les côtés, rétrécies et presque droites au bord apical ; fossette subhumérale 3-sil- 
lonnée, strie subhumérale atteignant l'épaule; 1 -3 dorsales forles, entières ; quatrième plus finc, raccourcie vers le milieu, einquième courte, apicale ; suturale arquée remontant au-delả du milieu. Propygidium bifovéolé, ponetué dans son pourtour. Pygidium plan, couvert de points fins et espacés. Prosternum en carène obtuse, peu élargi à la base, lobe court, abaissé, bimarginé ; mésosternum éehancré et étroitement rebordé. Jambes antérieures dilatées, armées de trois dents; postérieures garnies de sept ou huit paires de denticules épineux.

Sénégal.

47. II. CONTEMPTUS.

Ovalis, subconvexus, niger, nitiches, frontali stria integra, recta; mandibulis bidentatis, concavis; pronoto ciliato, stria interna integra bisimeate, externa dimidiata; elytris fossa sublumerali 3-sulcata; striis 1-3 dorsalibus integris, $4^{\text {a }}$ apicis munctiformi; propygidio subbifoveolato myidioque munctatis; mesosterno sinuato marginato; tibiis anticis 4-clentatis, posticis biseriatim multispinosis. Long. 7 mill.; larg. 5 1/2 mill.

Ovale, peu convexe, noir, luisant. Antennes brunes, massue gris-roux. Front large, plan, strie bien marquée, entière, droite par devant ; labre court infléchi ; mandibules bidentées, courbées en pointe aiguë, légèrement concaves. Pronotum plus large que long, droit à la base, cilié et légèrement arqué sur les côtés, rétréci et échancré en devant, avec les angles abaissés, obtus; strie latérale interne forte, entière, bisinuée latéralement, externe plus fine, raccourcie au milieu. Ecusson petit, triangulaire. Elytres plus longues que le pronotum, de sa largeur à la base, curvilinéaires sur les eôtés, rétrécies et obliques au bord apical; fossette laté- 
rale, peu marquée, 3-sillonıée; strie subhumérale atteignant l'épaule, rapprochée de la première dorsale ; 1-3 dorsales entières, quatrième représentée par quelques points obsolètes apicaux, les autres nulles. Propygidium subbifovéolé, couvert de points peu serrés. Pygidium assez densément ponctué. Prosternum en carène, élargi à la base, lobe court, infléchi, bimarginé ; mésosternum échancré, bordé d'une strie entière. Jambes antérieures dilatées, armées de quatre dents, les deux extrêmes assez fortes; postérieures garnies de sept ou huit paires de denticules épineux.

Cap de Bonne-Espérance.

\section{H. RECURVUS.}

Breviter ovalis, subconvexus, niger, nitidus; fronte lata stria integra, labro quadrato; mandibulis bidentatis; pronoto stria interna integra, cxtema mox abbreviata; clytris fossa laterali bisulcata, stria subhumerali dimidiata, 1-2 dorsalibus

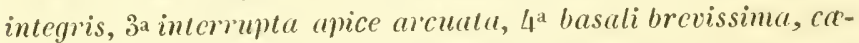
teris nullis; propygidio bifoveolato pygidioque grosse munctatis; mesosterno emarginato stria interrupta; tibiis anticis 3-dentatis, posticis biscriatim 5-spinosis. Longueur 6 mill.; largeur 4 1/2 mill.

Ovale court, assez convexe, noir, luisant. Antennes brunes, massue grise, velue. Front plan; strie entière subsinuée ; labre presque carré; mandibules bidentées, concaves, courbées en pointe acérée. Pronotum court, beaucoup plus large que long, légèrement arqué à la base, oblique sur les côtés, rétréci et échancré en devant, avec les angles antérieurs obtus; strie latérale interne bien marquée, entière, touchant à la base; externe très courte dans l'angle. Ecusson petit, triangulaire. Elytres un peu plus Inngues que le pro- 
notum, de sa largeur à sa base, curvilinéaires sur les côtés, rétrécies et obliques au bord apical; fossette subhumérale bisillonnée; strie subhumérale atteignant l'épaule, très rapprochée de la première dorsale ; celle-ci et la deuxième entières; troisième interrompue, rudiment basal très fort à la base, puis très fin et obsolète, apical court, bien marqué, arqué en dedans; quatrième représentée par un seul point basal, les autres nulles. Propygidium bifovéolé, fortement et densément ponctué, ainsi que le pygidium. Prosternum en carène obtuse, peu élargi à la base, lobe court, infléchi, bimarginé ; mésosternum fortement échancré, avec une strie marginale interrompue. Jambes antérieures dilatées, armées de trois dents, apicale bifide; postérieures garuies de cinq ou six paires de denticules épinenx.

Madagascar (M. Chevrolat).

\section{H. IAVIPES.}

Suborbicularis, comvexus, niger, nitidus; antemis brmmeis; fronte plana, stria integra; pronoto ciliato, stria laterali externa dimidiat, interna hand interrupta; elytris fossa marginali 3-sulcata, striis suturali et 1-3 dorsalibus integris, $4^{\mathrm{a}}$ brevissima basali; mopygidio parce punctato, pygidio lavi; mesosterno emarginato, stria integra; tibiis anticis edcntatis, posticis biseriatim multispinosis. Long. 6 mil.; larg. 5 mill.

Hister lcevipes, Germ. spec. nov. 148, 87 (1824). - Le Conte, N. Amér. Hist. 20, 8, pl. $2,7$.

Suborbiculaire, convexe, noir, Juisant. Antennes brunes, massue gris-roux. Front un peu bombé, pointillé, entouré d'une strie forte semicirculaire ; mandibules concaves, bidentées, courbées en pointe aiguë ; labre court. Pronotum court, arqué et bordé de points à la base, avec une ligne anté-scu3e Série, TOne II. 
tellaire, cilié et oblique sur les côtés, rétréci et échancré en devant avec les angles abaissés, aigus; strie latérale interne non interrompue, exterue dépassant un peu le milieu. Ecusson petit, triangulaire. Elytres à peine plus longues que le pronotum, de sa largeur à la base, curvilinéaires sur les côtés, arrondies au bout, avec un angle sutural assez profond; fossette latérale ponctuée, 3-sillonnée; stries fortes, crénelées, subhumérale atteignant l'épaule, suturale et $\mathbf{1 . 3}$ dorsales entières, quatrième courte, basale. Propygidium ponctué dans son pourtour, légèrement bifovéolé; pygidium lisse. Prosternum en carc̀ne obtuse, élargi à la base, lobe court, abaissé, hi-marginé ; mésosternum échancré, rebordé de deux stries, l'une interrompue, l'autre entière, éloignée du bord. Jambes antérieures sans dents; postérieures garnies d'une double rangée de nombreuses dentelures épineuses.

Amérique : Ĺtats-Unis ; Mexique; Brésil; dans les bouses.

\section{II. Panamensis.}

Ovalis, subconvexus, niger, nitidus, sumra subtilissime punctulatus; stria frontuli sinuata; mandibulis edentatis ; mronoto stria interna integra, cxterna dimidiata; clytris fossa laterali bisulcata, striis 1-4 dorsalibus integris, $5^{\text {a }}$ in medio, suturali ultra medium abbreviatis ; mopygillio bifoveolato; mesosterno emarginato, stria integra; tibiis anticis 6-8 denticulatis, posticis biseriatim spinosis, Long. 6 mill.; larg. 4 1/2 mill.

Ovale, peu convexe, noir, luisant, très finement pointillé sur toute sa surface. Antennes brunes, massue grise, velue. Front arrondi, plan en dessus, strie profonde, sinuée en devant; labre court, arrondi; mandibules courbées en pointe aiguë, subdentées. Pronotum court, beaucoup plus large 
que long, arqué à la base et sur les côtés, échancré et très rétréci en devant, avec les angles abaissés, obtus; strie latérale interne assez fine, entière, externe rapprochée du bord, raccourcic au milieu. Ecusson petit, triangulaire. Elytres courtes, plus longues que le pronotum, de sa largeur à la base, curvilinéaires sur les côtés, rétrécies postérieurement; fossette marginale bisillonnée; strie sublımmérale atteignant l'épaule souvent accompagnée d'un point, rudiment de subhumérale externe; 1-4 dorsales entières, fortes, crénelées; cinquième sinueuse, raccourcie avant le inilieu; suturale partant un peu avant le bord apical et dépassant le ınilieu. Propygidium bifovéolé, avec des points plus forts en devant. Pygidium n'ayant pas d'autres points que la ponctuation générale. Prosternum en carène obtuse, élargi à la base, lobe court, presqu'horizontal, rebordé ; mésosternum échancré, bordé d'une strie entière. Jambes antérieures dilatées, crénelées de six ou huit petits denticules; postérieures garnies de sept ou huit paires de denticules épineux.

Amérique centrale; Mexique (Vucatan), Nouvelle-Grenade (Panama).

\section{H. Bolivianus.}

Elongato-ovatus, subconvexus, niger, nitidus; antemis pedibusque rufo-brunneis; stria frontali integra retrorsum acuminata; mandibulis subdentatis; pronoto stria interna integra valde obliqua, externa dimidiata; elytris fossa subhumerali bisulcata, 1-4 dorsalibus integris, $5^{\mathrm{a}}$ apicali brevissima, suturali abbreviata; propygidio pygidioque punctatis; mesosterno emarginato, stria integra; tibiis anticis valde dilatatis, obtuse 4-dentatis, posticis biseriatim multispinosis. Long. 7 mill.; larg. 4 mill.

Ovale allongé, peu convexe, pointillé sur toule sa sur- 
lace, noir, luisant. Antennes d'un brun ronx, plus clair à la massue. Tete assez large; front plan, strie fine, entière, formant un petit angle rentrant. Labre court, arrondi, mandibules à peine dentées en dedans, courbées au bout en pointe aiguë. Pronotum plus large que long, légèrement arqué à la base et sur les côtés, à peine rétréci, échancré en devant, - avec les angles peu abaissés, obtus; strie latérale externe raccourcie au milien, fine, plus rapprochée du bord postérieurement; interne non interrompue, oblique sur les côtés et dans l'angle très éloignée du bord. Ecusson petit, triangulaire.Elytres un peu plus longues que le pronotum, de sa largeur à la base, à peine arquées sur les côtés, obliques et peu rétrécies au bord apical; fossette subhumérale bisillonnée; stries fines ponctuées, $1-4$ dorsales entières, cinquième fort courte, apicale; suturale et subhumérale remontant au milieu. Propygidium très finement pointillé ainsi que le pygidium. Prosternum en carène, élargi à la base, lobe court, rebordé, infléchi; mésosternum échancré, bordé d'une strie entière. Jambes antérieures fortement dilatées au bout, armées de quatre dents très obtuses, hors l'apicale qui est large et saillante; postérieures garnies de cinq à six paires de denticules épineux.

Bolivic.

\section{H. LOAVDE.}

Oblongo-ovatus, subconvexus, niger, mitilus; antennis pedibusque rufo-brumeis; fronte impressa, striu retrorsum angulata; mandibulis bidentatis, canaliculatis; pronoto stria laterali interna haud internpla, externa brevi; clytris fovea marginali 1-sulcata, striis dorsalibus 1-3 integris, $4^{a}$ interrupla, 5. abbreviala, sulurali dimidiata; mopygialio bifovcolato 
pygidioutue parce punctatis; mesosterno recto, marginuto; tibiis unticis 3-dentutis, posticis biseriatim multispinosis. Long. 4 3/4 mill.; larg. 2 3/4 mill.

Ovale allongé, peu convexe, noir, luisant. Antennes brunes, massue gris-roux. Front convexe, faiblement impressionné, strie forte, bisinuée, formant un angle rentrant au milieu; épistome concave; labre petit; mandibules dentées, concaves, courbées en pointe aiguë. Pronotum court, presque droit à la base, oblique sur les côtés, rétréci et échancré en devant avec les angles abaissés obtus; strie latérale interne forte, entière, droite, non interrompue; externe très courte. Ecusson petit, triangulaire. Elytres un peu plus longues que le pronotum, de sa largeur à la base, à peine arquées sur les côtés, arrondies à l'angle postérieur, obliques el rétrécies au bout; fossette marginale unisillonnée; strie subhumérale atteignant l'épaule; dorsales crénelées, bien marquées, 1-3 entières, quatre et cinq raccourcies avant le milieu, suturale un peu au-delà. Propygidium bifovéolé, couvert de points espacés; ponctuation du pygidium également espacée, presqu'effacée au milieu. Prosteruum en carène, peu élargi à la base, lobe assez long, ponctué, incliné, rebordé, en pointe; mésosternum droit à strie entière. Pattes ferrugineuses; jambes antérieures armées de trois dents, extrême bifide; postérieures garnies d'un double rang de dentelures épineuses.

Guinée; Angola (Loanda) (M. Guérin).

\section{H. Niloticis.}

Ovalis, subconvexus, niger, nitidus; clava Mro-grisea; fronte impressa, stria reororsum angulata; mundibulis canaliculatis; pronoto stria laterali interna incgra, externa dimidiata: 
elyeris strits crenatis, 1-4 dorsalibus integris, 4-5 ante medium, sulurali nll'a mellium ablreviatis, fossa laterali menctata bisulcalu; mromygidio bifoveolate pygidioque sat dense menctutis, mesosterno vix sinnalo, marginato; tibiis anticis b̈-dentatis, posticis biseriatim multispinosis. Longueur 5 1/2 mill.; largeur 3 3/4 mil!.

Ovale, assez convexe, noir, luisant: Antennes brunes, massue gris-roux. Tète médiocre; front plan, très finement pointillé, avec une légère impression longitudinale au milieu; strie profonde, entière, bisinuée, formant au milieu un angle rentrant court; labre petit, arrondi ; mandibules fortes, bidentées en dedans, creusées en gouttière, à pointe recourbée, aiguë. Pronotum plus large que long, finement ponctué, plus fortement sur les côtés et à la base; à peine arquélatéralement, assez rétréci et échancré en devant, avec les angles abaissés, obtus; stries latérales fortes, crénelées; externe entière, droite, non interrompue en devant avec des angles post-oculaires; externe s'arretant au milieu et accompagnant un peu l'interne en devant. Ecusson petit, triallgulaire. Elytres un peu plus longues que le pronotum, de sa largeur à la base, curvilinéaires sur les côtés, droites et rétrécies au bout; stries bien marquées, crénelées ; sublımérale atteignant l'épaule; 1-3 dorsales entières, quatrième raccourcie avant le milieu, cinquième encore plus, suturale dépassant le milieu; fossette subbumérale ponctuée, bisillonnce. Propygidium bifovéolé, couvert d'une ponctuation forte, assez serrée. Pygidium plus densément ponctué. Prosternum court, en earène mince, peu élargi à la base, lobe ponctué, rebordé, en pointe inclinée; mésosterıum à peine sinué. bordé d'une strie entière et d'une autre interrompue. Jambes antéricures dilalées, armées de trois dents, externe 
bifide; postérieures garnies de luuit à dix paires de dentelures épineuses.

Abyssinie.

\section{H. SEMiplanus.}

Ovalis, convexiusculus, niger, nilidus; anlcunis pedibusque rufis; fronte subimpressa stria retrorsum vix angulalu; mandibulis bidentatis, canaliculatis; pronoto stria latcrali interna haud internpta, cxterna dimidiata; clytris fovea marginati bisulcala, striis crenulis, dorsalibus 1-3 integris, 4a obsoleta, sulurali urimque abbreviala; mopygidio bifoveolalo circum purce, pygidio suttilissime muctulutis ; mesosterno recto, marginato; tibiis anticis 3-dentatis, posticis biseriatim multispinosis. Long. 5 1/2 mill.; larg. 4 mill.

Ovale, assez convexe, noir-brun, luisant. Antennes ferrugineuses. Front faiblement bombé et impressionné, entouré d'une stric forte, bisinuée de chaque coté, formant un petit angle rentrant; épistome concave; labre petit; mandibules bidentées, canaliculées, courbées en pointe aiguë. Pronotum court, pointillé sur toute sa surface, presque, droit et bordé de points à la base, oblique sur les côtés, rétréci et échancré en devant, avec les angles abaissés, obtus; strie latérale interne forte, sinuée, non interrompue; externe raccourcie au milieu. Ecusson petit, triangulaire. Elytres une fois et demie plus longues que le pronotum, de sa largeur ì la base, curvilinéairement dilatées sur les còtés, rétrécies et droites au bord apical; fossette subhumérale ponctućc, bisillonnée; stries crénelées, bien marquées, sub. humérale atleignant l'épaule, 1-3 dorsales entières, quatrieme courte, obsolète, sulurale médiane raccourcie de part et d'autre. Propygidinm biforéolé, fincment pointillé. ainsi que le pygidium, avec des points plus gros de chayue 
còté, mésosternum à peine sinué, bordé d'une strie entiẻre, et d'une interrompue. Prosternum court, en carine aiguë, yeu ćlargie, lobe ponctué, reborté, en pointe inclinée. Jambes antéricures armées de trois forles lents; postérieures garnies d'une double rangée de nombreuses dentelures épineuses.

sénégal.

\subsection{Scissintions}

Ovalis, subconvexus, niger, nilidus; antennis rufo-brunneis: fronte sulcalo-impressa, stria retrorsum angulala; mandibulis bidentatis, canaliculatis; pronoto antice bisinuato; stria intorna integra, externa mox abbreviata; elytris fossalaterati punctuto-3-sulcala; striis $1-3$ clorsalibus integris, $4^{\text {a }}$ et sulurati rimidiatis, 5a brevi, apracali; promygidio mygidioque basi sparsim munctatis; mesosterno subrecto, stria integra; libiis anticis 3-dentatis, posticis biseriatim multispinosis. Long. 5 1/2 mill.; larg. $31 / 2$ mill.

Ovale, assez convexe, noir, luisant. Antennes brunes, funicule et massue rougeàtres. Front finement pointillé, transversal, avec une impression médiane en forme de sillon profond; strie entière formant un angle rentrant; labre court, infléchi; mandibules fortes, billentées en dedans, courbées en pointe acérée, creusées en gouttière. Pronotum plus large que long, droit à la base, légèrement arqué sur les côtés, rétréci et échancré en devant, bisinué au fond de l'échancrure, avec les angles abaissés, asse\%. aigus ; strie latérale interne entière, cxterne très raccourcie. Ecusson petit, triangulaire. Elytres plus longues que le p!onotum, de sa largeur a la base, curvilinéaires sur les. cotés, rétrécies et roupées droit au borl apical ; fossette latriale ponctuéc, hisillonnée; strie subhumérale atteignant 
l'épaule; 1-3 dorsales entières; quatrième raccourcic au milieu, avec quelques vestiges de points en devant; cinquième courte, apicale, décomposée; suturale arquée remontant au-delà du milieu. Propygidium subbifovéolé, avec quelques points épars dans son pourtour. Pygidium bombé, bordé en devant de quelques points légers. Prosternum en carène, peu élargi à la base, lobe court, ponctué, rebordé, incliné; mésosternum coupé droit, strie marginale entière, accostée sur les côtés d'une deuxième stric. Jambes antérieures dilatées, armées de trois dents, apicale bifide; postérieures garnies de six à sept paires de denticules épineux.

Inde (Kurmaul) (M. Deyrolle).

Espèces que je n'ai pas vues.

20. 11'. II. Ixcists. Er. in Jalır. I, 134, 13 (1834).

Orbicularis, ater, opacus, mandibulis dentatis, pronoto utrirque sesquistriato, elytris striis dorsalibus 1-4 integris, 5a abbreviata, suturali obsoleta, tibiis antıcis 3-dentatis. Long. 9 mill. - Amér. bor.

Très voisin du $H$. Sccevola, d'un luisant terne comme lui, mais moins obscur sur les élytres. Mandibules de la longueur de la tête, bidentćes au milieu; labre presque plus long que large dans le $\sigma^{*}$, arrondi, court chez la + , faiblement bilobé. Front uni, strie profonde, obsolète au milieu. Massue des antennes noire. Pronotum fortement rétréci en devant, légèrement arrondi sur les côtés et garni de poils jaunes; strie latérale exterme un peu raccourcie en devaut, ainsi que l'interne qui ne suit pas le bord antérieur; fossettes a l'angle antérieur assez marquées. Elytres assez arrondies sur les côtés, très peu ronvexes ; 1 - 1 stries dorsales entières. 
cinquième raccourcie un peu avant le milieu, suturale uulle; fossette subhumérale légèrement ponctuée. Propygidium densément et finement ponctué, couvert en outre de plus forts points espacés; pygidium densément ponctué. Jambes antérieures armées de trois fortes dents.

20. 12'. H. Heros. Er. Beil. Fn. Angola, 226, 42 (1842).

Ater, nitidus, suborbicularis, mandibulis dentatis, pronoto utrinque bistriato stria exteriore abbreviata, dense punctuluto: clytris stria dorsali $5^{\text {a }}$ abbreviata, suturuli obsolescente; tibiis anticis 3-dentalis. Long. 14 mill. - Angola (Afrique).

20. 24'. H. chuentu's. Er. in Jahr. 1, 137, 21 (1834).

Subovalis, ater, nitidus, mandibulis dentatis, pronoto utrinque sesquistriato, elytris sanguineis, striis dorsalibus 1-3 integris, 4-5 et suturali mullis; tibiis anticis 4-dentatis. Long. 8 mill. - Calraria.

De la forme du $\boldsymbol{I}$. simuatus. Front légèrement convexe, finement ponctué; strie profonde non interrompue. Labre court. Mandibules courtes, bidentées. Pronotum modérément rétréci en devant, faiblement arrondi sur les côtés ; strie latérale externe brisée au milieu, interne entière. Elytres faiblement arrondies sur les côtés; stries dorsales, 1-3 entières, quatrième, cinquième et suturale nulles; fossette subhumérale superficielle, ponctuée. Propygidium densément et fortement ponctué, ainsi que le pygidium. Corps d'un noir luisant, avec une lache d'un rouge de sang foncé sur le métasternum; élytres également rouges desang, avec une étroite bordure noiràtre, qui s'élargit en une grande lache autour de l'écusson; antennes rougeàtres, massuc brune. Cuisses noires; jambes rougeatres; tarses 
rouges; jambes antérieures arnées de quatre dents, la supérieure peu distincte.

2o. 26'. Н. тнокасісыs. Payk. Mon. Ilist., 20, 11 (1811), pl. 2, fig. 5 .

Ater; pronoto elytrorum longitudine, margine omni punctulato, elytris striis 4 levissimis; thiis anticis 4-dentatis. Longueur 9 mill. - Amér. septentr.

Tout noir, peu luisant. Tête finement pointillée; strie frontale entière; mandibule gauche un peu plus longue que la droite; massue foncée. Pronotum antérieurement aussi large que long, à peine moitié plus large à la base, convexe; strie latérale externe raccourcie au milieu, interne entière, marge sans cils, mais très densément pointiliée. Elytres de la longueur du pronotum et de sa largeur à la base, rétrécies postérieurement; convexes, lisses à l'œil nu, strie subhumérale interne atteignant l'épaule, 1-3 dorsales presqu'entières, arquées en dedans, toutes obsolètes, très légères; fossette latérale imponctuée. Lobe prosternal avancé, arrondi au bout. Propygidium et pygidium pointillés. Jambes dilatées, postérieures très épineuses, antérieures 4-dentées.

Cette espèce est très voisine de l'H. amplicollis.

2o. 30'. H. ignaves. Fahr. in Boh. Ins. Cafr., I, 533, 579 (1851).

Subrotundutus, ater, nitidus, capite pronotoque tavissimis, hoc striis 2 lateralibus integris, adjecta striola arcuata in angulo antico utrinque, elytris stria subhumerali interma abbreviata, 1-3 don sulibus integris, crteris obsolrtis, fossula inflexi matginis 3-sulceta punctata; tibiis anticis 4-dentatis, subtus munctulatis. Larg. 6 1/2-9) mill.; larg. 5 1/2-7 mill.

Noir, luisant. Tête transiersale, strie frontale distincte, 
épistome très court, linéaire transversalement. Antennes courtes, massue ovale, velue. Pronotum tronqué à la base et là deux fois plus large que long, rétréci en devant et profondément échancré, avec les angles assez proéminents, également convexe en dessus, lisse, deux stries latérales entières très distinctes, interne non interrompue; dans l’angle même on aperçoit une petite striole arquée, qui cesse avant le milieu. Ecusson triangulaire, lisse. Elytres deux fois plus longues que le pronotum, arrondies, tronquées à la base, arquées au bout, médiocrement convexes en dessus, lisses ; stries dorsales 1-3 a peine ponctuées, entières, 4-5 et suturale ordinairement nulles, représentées quelquefois par des rudiments à la base et au bout; subhumérale interne raccourcie, rapprochée de la première dorsale ; repli latéral 3 -sillonné, avec une fossette ponctuée. Pygidium obtus, assez profondément et densément ponctué; propygidium avec un espace triangulaire lisse au bout. Dessous convexe, grossièrement ponctué latéralement, très lisse au milieu; prosternum arrondi à la base, avancé jusqu'à la bouche. Pattes fortes; jambes postérieures garnies de beaucoup d'épines; antéricures ponctuées en dessous, 4-dentées, dent basale obsolicte.

Cafrerie.

2. 33'. H. pullatus. Er. in Jahr., 1, 138, 24 (1834).

Orbiculuris, ater, nilidus, mandibulis subdenutis, pronoto sesqui striato, elytris striis dorsalibus $1-4$ integris, 5a ot sulurali abbreviatis; tibiis unticis 3-dentutis. Longnenr 6 mill. Indes or.

Noir uniforme, inédiocrement luisant. Front légèrement ronvexe, avec une profonde impression longitudinale; strie 
formant un angle rentrant au milieu. Jabre arrondi, élevé au milieu en arète transversale, s'abaissant en toît de chaque coté. Mandibules courtes et fortes, unidentées au milieu. Antennes brun de poix, massue rougeatre. Pronotum fortement rétréci en devant, légèrement arrondi sur les côtés ; stries latérales raccourcies, externe au milieu, interne près de la base. Stries dorsales des élytres profondes et larges, 1-4 entières, cinquième raccourcie bien avant le milieu, suturale au-delà et quelquefois postérieurement. Propygidium légèrement bifovéolé, couvert d'une ponctuation forte, mais espacée. Pygidium ponctué fortement, seulement à la base, finement vers le bout. Jambes antérieures 3-dentées. Mésosternum légèrement échancré en devant.

Très voisin de l'H. coprophilus, auprès duquel il peut se placer.

20. 36’ H. vilıs. Fahr. in Boh. Ins. Cafr., I, 536, 582 (1851).

Breviter ovalis, ater, nitidus, antennarum clava apice rufescente; capite pronotoque lavibus, hoc utrinque mrofunde bistriato; clytris stria subhumerali, 1-3 dorsalibus integris, vix punctatis, disco interiore lavi; tibiis anticis :-dentatis. Longueur 6-7 mill.; larg. 4 1/2-5 mill. - In tractibus fluvii Limpoponis, Cafr.

Noir, luisant. Tete transversale, lisse, strie frontale distincte, entière; labre transversal, obtusément arrondi en devant; mandibules courtes, fortement dentées, légèrement rebordées; antennes courtes, massue ovale, roussâtre au bout. Pronotum tronqué à la base, deux fois plus large que long, assez rétréci et échancré en devant avec les angles abaissés, convexe et lisse en dessus, stries latérales profondes, interne entière, non interrompue, externe n'attei- 
gnant pas la base, recourbée en dedans. Ecusson petit, triangulaire, lisse. Elytres dilatées, tronquées obliquement au bout, lisses sur le disque intérieur; stries profondes, imponctuées, 1-3 dorsales entières, les autres nulles; subliumérale interne rapprochée de la première dorsale. Pygidium obtus, assez densément et fortement ponctué. Propygidium lisse au milieu du bord postérieur. Corps convexe en dessous, lisse au milieu, inégalement ponctué sur les cotés. Pieds robustes, comprimés; jambes dilatées, quatre postérieures épincuses, antérieures fortement 3-dentées, rugueusement ponctuées en dessous.

2o. 43'. H. Guinensis. Payk. Mon. Hist. 26, 15, pl. 3, fig. 2 (1811).

Ater, elytris striis 3 dor salibus integris, 2a, $3 \mathrm{~g}$ que commexis; tibiis anticis 4-dentatis. Long. 5 1/2 mill. - Guinée.

Noir, luisant en dessus, brun en dessous. Front plan, strie bien marquée. Pronotum aussi long que large en devant, moitié plus long et plus par derrière, convexe, impouctué; stries latérales rapprochées, interne entière, externe raccourcie au-delà du milieu. Elytres pas moitié plus longues que le pronotum, de sa largeur à la base, à peine plus étroites au bout, dilatées au milieu; strie subhumérale interne atteignant l'épaule; 1-2 dorsales entières, la troisième commence à la base, s'oblique avant le milieu vers la deuxième et s'y réunit, à une petite distance elle s'en sépare de nouveau et descend au bord apical ; 45 nulles, suturale peu marquée, raccourcie au milieu; fossette latérale imponctuée. Pygidium pointillé. Pattes noir de poix; jambes postérieures très dilatées, épineuses; antérieures encore plus larges, armées de quatre dents, basale très petite. 
Cette espèce se rapproche du $H$. requatorius; la singulière conformation des stries dorsales me paraît accidentelle, comme l'a soupçonné Paykull lui-même : j'en ai vu des exemples dans plusieurs espèces d'Hister.

$2^{0} .45^{\prime}$. H. vindes. Fahr. in Bohem. Ins. Cafr., 1, 535, 581 (1851).

Breviler ocalis, ater, nitidus, capile medio munctato, pronoto utrinque profunde bistriato, interstitio antice rugoso mnctato, ulisco lcovi; clylris 1-4 dorsalibus inlegris, 5a ct suturali obritcralis; subhnmerali inlerna antice abbreviala, fossula infra marginali 3̈-sulcata, menclala; libiis anticis valide Bo-dentalis, inferne munctulatis. Long. 8 mill.; larg. 6 mill. - In tractibus lluvii Limpoponis. Cafr.

Noir, luisant. Tête courte, ponctuée au milieu, strie frontale distincte, flexueuse; épistome petit, transversal ; mandibules de la longueur de la tête, dentées, rebordées. Antennes courtes, massue ovale, d'un ferrugineux de poix au bout. Pronotum tronqué à la base, deux fois plus large que long, assez rétréci et largement échancré en devant, avec les angles aigus, abaissés ; assez convexe en dessus, très lisse sur le disque; deux stries latérales profondes, entières, interne non interrompue, intervalle couvert de rides et de quelques points. Ecusson triangulaire, lisse. Elytres à peine deux fois plus longues que le pronotum, dilatées lẻgèrement, médiocrement convexes; strie subhumérale raccourcie, dorsales profondes, crénelées, 1 -3 entières, les autres faibles, quatrième raccourcie en devant, cinquième rudimentaire, suturale atteignant à peine le milieu; fossette submarginale ponctuée, 3-sillonnée. Pygidium obtus densément et profondément ponctué. Corps convexe en dessous, rugueuse. ment pnnctué sur les cotés, lisse au milieu; prosternum 
comprimé, très saillant. Pattes robutes ; jambes comprimées, dilatées, postérieures multiépineuses, antérieures fortement tridentées, pointillées en dessous.

d'. Une seule strie latérale au pronotum.

$$
\text { ge Groupe (56-59) (1). }
$$

\section{H. 14-STRIATUS.}

Ovalis, convexiusculus, niger, nilidus, antemnis rufis; stria frontali integra, antice simuatu; monoto stria tateruli interna hand intervuptu; chloris marginis fossu munctulata, bisulcata, striis crenatis, dorsatibus integris, 5a curn suturali connexa, subhunerali breci, obsoleta; mopygidio purce munctato, pygi. dio subtilissime puncticulato; mesostcrno recto, marginato; tibiis anticis 3-dentatis, posticis biseriatim multispinosis. Longueur 4 mill.; larg. 3 mill.

Hister 14-striatus. Gyll. Ins. suec, 1, 83, 11 (1808). - Er. in Jahr., 1, 152, 67. - Redt. Fn. Austr. 234.

Ovale, assez convexe, noir, luisant. Antennes ferrugineuses. Front plan, à peine visiblement pointillé; strie entière, sinuée en devant; labre petit; mandibules dentées, canaliculées, courbées en pointe aiguë. Pronotum court, droit et bordé de points à la base, arqué sur les côtés, rétréci et échancré en đevant, avec les angles abaissés, obtus; strie latérale interne unique, non interrompue. Ecusson petit, triangulaire. Elytres plus longues que le pronotum, de sa largeur à sa base, curvilinéaires sur les côtés, rétrécies et droites au bord apical; fossette marginale, pointillée, faiblement bisillonnée; stries crénelées, dorsales et suturale entières, les deux internes réunies à la base, subhumérale courte, souvent obsolète. Propygidium couvert de points

(1. Voyez le tablean des espèces, page 181. 
épars; pygidium bombé à peine distinctement pointillé. Prosternum en carène, peu élargi à la base, lobe court, ponctué, rebordé, infléchi ; mésosternum droit, bordé d'une strie entière accompagnée d'une petite striole de chaque côté. Jambes antérieures 3-dentées; postérieures garnies d'uı double rang de denticules épineux.

Cette espèce est propre aux contrées boréales de l'Europe (Suède, Finlande, Russie); elle se rencontre dans le fumier. Elle a les plus intimes rapports avecle $\boldsymbol{H}$. 12 -striatus, dont le système artificiel que j'ai employé pour faciliter l'étude de ce genre si nombreux, l'éloigne tant. La strie subliumérale courte et souvent rudimentaire, et les autres différences, telles que la forme plus courte et plus convexe, la coloration des pattes, etc., ne seraient pas pour moi un obstacle à la réunion de ces deux espèces, sans l'autorité de Gyllenhall, qui assure qu'en Suède, où les deux espèces sont communes, elles vivent toujours isolées; que dans le fumier des jardins il a trouvé celle-ci en abondance, sans jamais y rencontrer celle-là. Je laisserai donc la solution de cette question à des entomologistes assez heureux pour éundier les métamorphoses de ces deux espèces.

\section{H. CONFORMIS.}

Suborbicularis, convexiusculus, niger, nitidus; antennis pedibusque rufis; fronte bifoveolata, stria retrorsum acuminuta ; pronoto stria laterali unica integra, in angulo antico muntato; elytris margine sulcato; striis integris, dorsali 5a et suturali basi arcnatim junctis; propygidio sparsim punctulato; pygidio subtilius puncticulato; mesosterno haud sinuato mar. ginato; tibiis anticis 3-dentatis, posticis biseriatim multispinosis. Long. 5 mill.; larg. $31 / 2$ mill.

Hister conformis. Er. in Jahr., 153, 68 (1834).

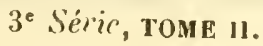


Ovale, court, légèrement convexe, noir, assez luisant. Antennes roussâtres. Front pointillé, bifovéolé, strie entière formant un angle rentrant entre les fossettes; labre court; mandibules concaves subdentées, courbées en pointe aiguë. Pronotum beaucoup plus large que long, droit à la base, à peine courbé sur les côtés, rétréci et échancré en devant; strie latérale interne unique, entière, non interrompuc, bordée de points, sans fossette à l'angle antérieur. Ecusson petit, triangulaire. Elytres courtes, plus longues que le pronotum, de sa largeur à la base; courbées sur les côtés, rétrécies et légèrement arquées au bord apical; fossette subhumérale peu marquée, bisillonnée; la deuxième strie remontant en dessus et s'interrompant; stries fortes, crénelées; subhumérale atteignant l'épaule; dorsales entières, cinquième réunie à la base avec la suturale. Propygidium couvert de points fins, épars ; pygidium paraissant lisse. Mésosternum coupé droit en devant, borlé d'unc strie entière. Jambes antérieures armées de trois dents; postérieures garnies de cinq ou six paires de denticules épineux.

Cap de Bonne-Espérance.

\section{H. CoNFinis.}

Suborbicularis, convexiusculus, niger, nitidus, antemnis pedibusque rufis; frontali stria subsinuata; pronoto puncticulato, ad angulum punctato, foveolato, stria laterali unica hand interrupta; elytris margine bisulcato, striis crenatis, 5 a dorsali suluralique junctis antice; mopygidio parce punctulato, pygidio sublavi; mesosterno vecto, marginato; tibiis anticis 3-dentatis, posticis biscriatim 5-6 spinosis. Long. 4 mill.; larg. 3 mill.

Ilisler confinis. Er. in Jahr. 1, 154, 69 (1834).

Suborbiculaire, assez convexe, noir, luisant. Antennes 
rouges. Front arrondi, légèrement concave, ainsi que l'épistôme, strie entière à peine sinuée; labre petit; mandibules lentées, concaves, courbées en pointe aiguë. Pronotum beaucoup plus large que long, finement pointilié, arqué et bordé de points à la base, courbé sur les côtés, rétréci et échancré en devant, avec les angles abaissés, aigus, marqués d'une fovéole ponctuée; strie latérale interne, unique, forte, non interrompue. Ecusson petit, triangulaire. Elytres un peu plus longues que le pronotum, de sa largeur à la base, curvilinéaires sur les côtés, rétrécies et droites au bord apical; fossette subhumérale bisillonnée; stries fortes, crénelées; 1-5 dorsales et suturale entières, celle-ci réunie à la base arec la cinquième; quatrième un peu raccourcic à la base; subhumérale atteignant l'épaule. Propygidium couvert de points épars. La ponctuation du pygidium est si fine qu'il paraît lisse. Prosternum en carène, à peine élargi à la base, lobe ponctué, rebordé, incliné. Mésosternum droit et bordé d'une strie entière. Pattes ferrugineuses; jambes antérieures 3-dentées, postérieures garnies de 5-6 paires de denticules épineux.

Antilles (Cuba).

\section{H. GEMINIS.}

Ovalis, subconvexus, nitidus; antcnnis pedibusque rufo-brun. neis; stria frontali recta, integra; pronoto stria unica laterali integra, angulo antice foveolato punctato; elyuris fossa latcrali obsoleta, lavi, striis validis crenatis, subhumerali dimidiata, 1-3 dorsalibus integris, catcris subabbrcviatis, $5^{\text {a }}$ sutualique antice comnexis; propygidio smarsim munctato; pygidio lavi; mesosterno recto stria integra; tibiis anticis 3-dentatis, postiris biseriatim multispinosis. Long. 3 1/2 mill.; larg. 2 1/2 mill.

Hister gemimus. Er. in Jahr., 154, 70 (1834). 
Ovale, assez peu convexe, noir, luisant. Antennes et pieds d'un brun r'ouge. Front à peu près plan; strie bien marquée, entière, droite par devant; labre court, arrondi ; mandibules subdentées, concaves, courbées en pointe aiguë. Pronotum beaucoup plus large que long, droit á la base, courbésur les côtés, rétréci et échancré en devant, avec les angles abaissés et obtus; strie latérale externe nulle, interne entière; une fossette arrondie, ponctuée de cliaque côté à l'angle antérieur. Ecusson petit, triangulaire. Elytres beaucoup plus longnes que le pronotum, curvilinéairement dilatées sur les côtés, rétrécies et obliques au bord apical ; fossette subhumérale peu profonde, bisillonnée, imponctuée ; stries fortes, profondes, crénelées; subhumérale atteignant l'épaule; 1-3 dorsales entières, quatrième un peu raccourcie à la base; cinquième réunie à la base avec la suturale. Propygidium couvert de points épars; pygidium paraissant lisse. Prosternum en carène, à peine élargi ì la base, lobe conrt, infléchi, rebordé; mésosternum coupé droit en devant, bordé d'une strie entière. Jambes antéricures dilatées au bout et armées de trois dents; postérieures garnies de paires de denticules épineux en petil nombre.

Cap de Bonne-Espérance. 


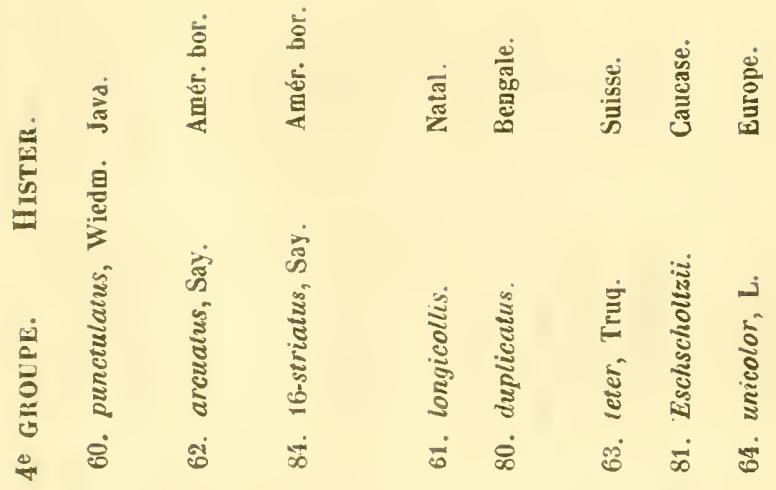

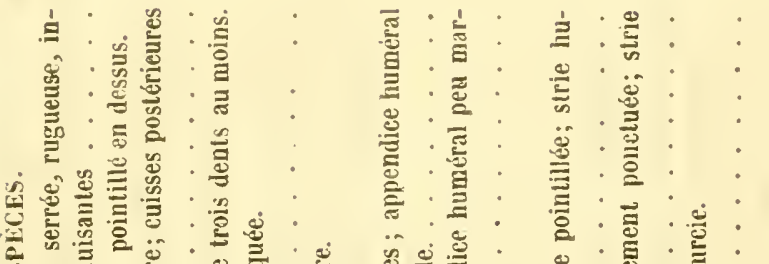

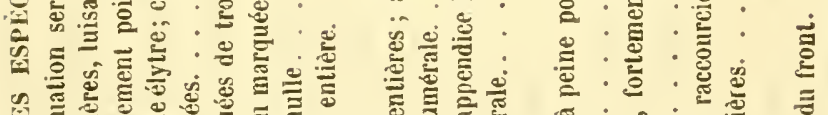

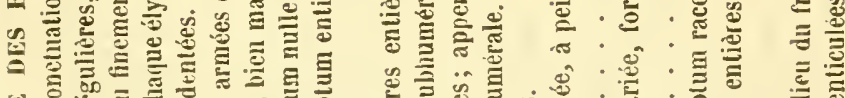

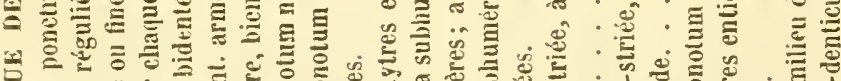

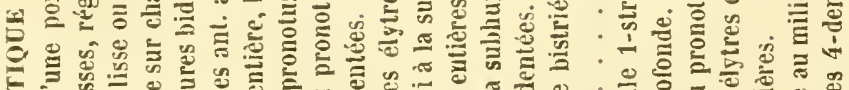

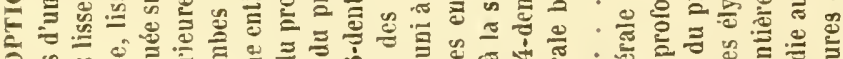

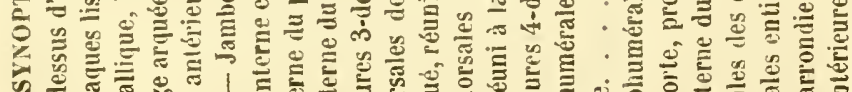

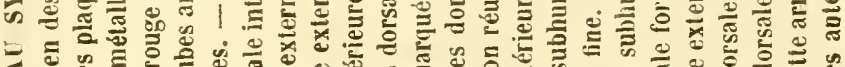

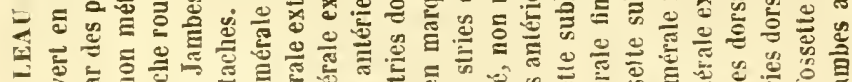

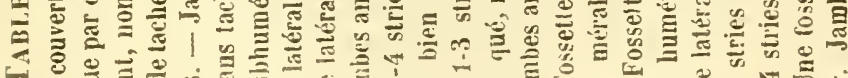

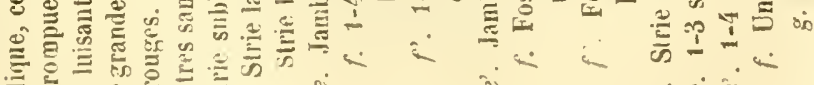

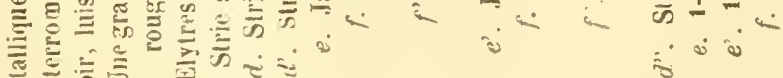

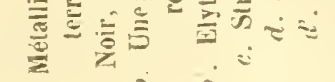




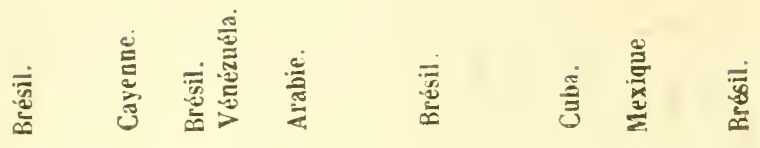

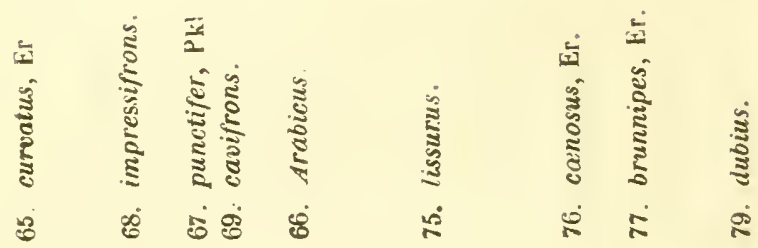

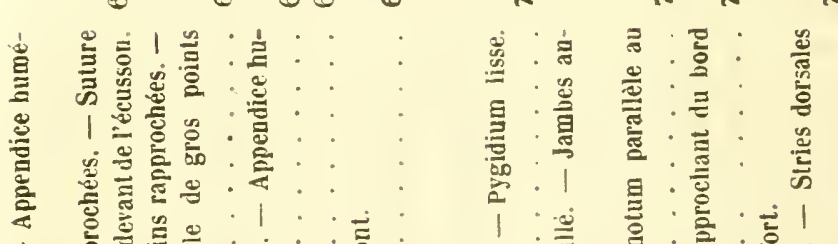

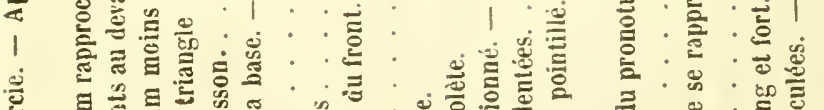

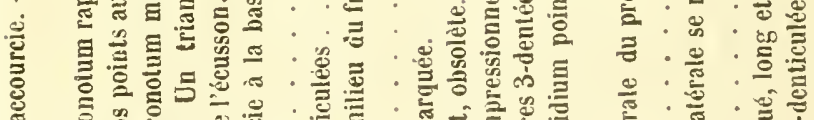

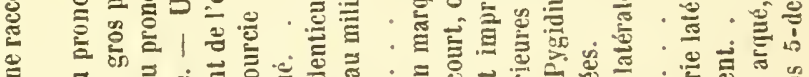
引 \%

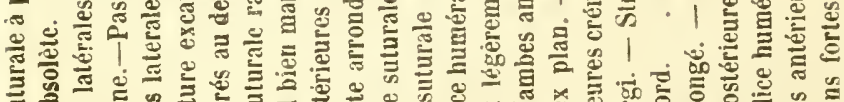

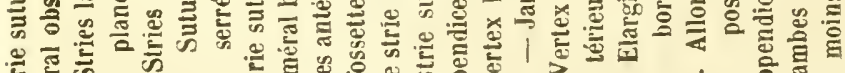

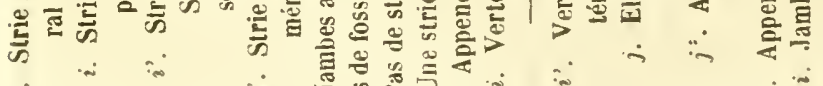




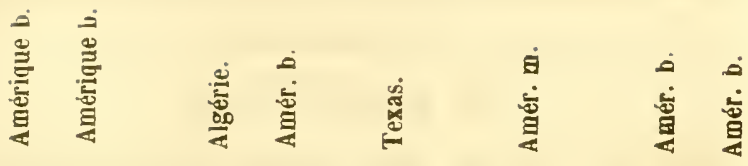

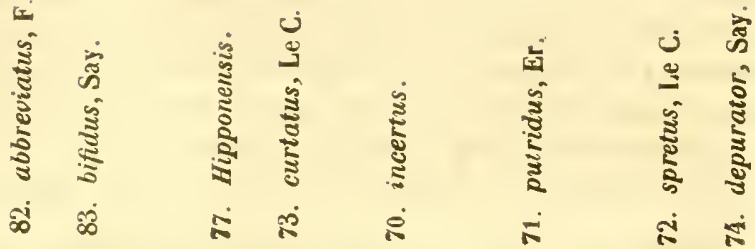

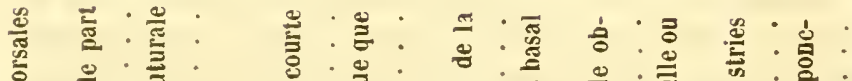
总 离 1 出: $:$ :

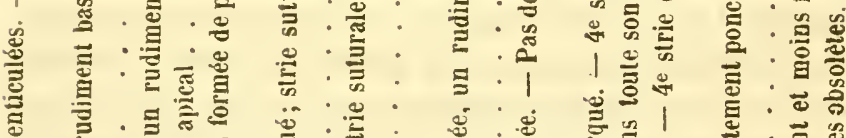

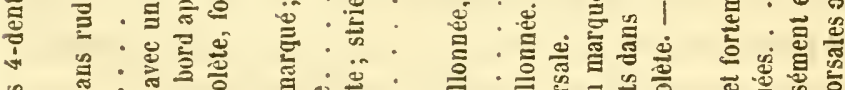
山

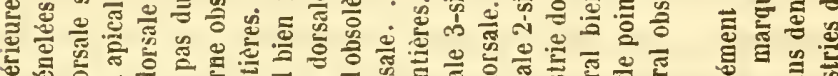

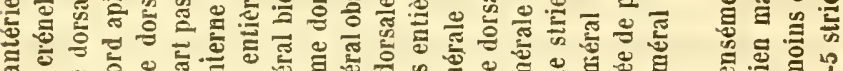

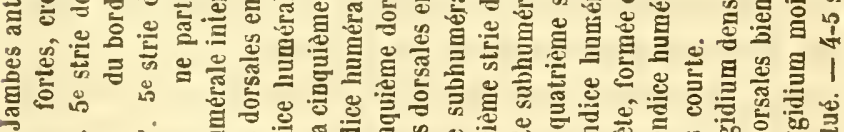

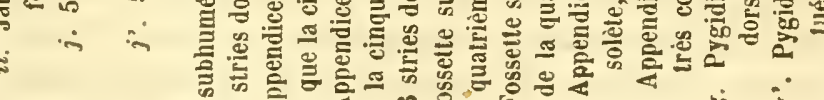
के 
¿'. Strie subhumérale interne accompagnée d'un appendice. $4^{\circ}$ Groupe (60-84).

\section{II. punctulatus.}

Oblongus, convexus, supra nigro-ceneus, rugoso-punctutus, spatiis levibus nitidis, subtus piceus; frontali stria integra; pronoto ciliato, stria laterali utraque integra; clytris stria laterali interna integra, externa brevi, humero interruptis, dorsalibus 1-4 integris, $5^{\text {a }}$ et suturali abbrcviatis; mesosterno emarginato stria integra; tibiis anticis 3-dentatis, posticis biseriatim spinosis. Long. 8 mill.; larg. 5 mill.

Hister punctulatus. Wierlm. in Zool. mag. , 1, 3, p. 162, 8 (1817).

Allongé, convexe, noir métallique en dessus, brun en dessous. Antennes brunes, massue velue, gris-roussâtre. Tête grande, rugueusement ponctuée; front plan, entouré d'une strie entière, droite par devant, avec le rebord élevé; épistome impressionné; labre court; mandibules larges, creusées en gouttière, dentées, courbées en pointe aiguë. Pronotum plus large que long, droit à la base avec une ligne antéscutellaire, un peu oblique et cilié sur les côtés, rétréci et fortement échancré en devant avec les angles saillants et abaissés, ponctué, plus rugueux latéralement avec la marge extérieure, une large plaque triangulaire au devant de l'écusson et deux petites irrégulières de chaque côté, disposćes transversalement, lisses et luisantes; stries latérales Iroites, entières, assez distantes. Ecusson petit, triangulaire. Elytres courtes, de la largeur du pronotum à la base. à peine rétrécies et obliques au bord apical, rugueusement ponctuées avec un grand nombre de plaques lisses et luisantes : une grande auprès de l'écusson, quatre petites irréyulières, unc sur le premier interstice, deux sur le deuxième et une au bout du quatrième; stries subhumérales interrom- 
pues à l'épaule, externe courte; 1-4 dorsales entières, cinquième et suturale raccourcies. Propygidium grossièrement ponctué, avec une impression apicale de chaque côté et une petite plaque lisse, luisante, triangulaire ; pygidium également ponctué avec une plaque allongée. Prosterium en carène, sans stries, arrondi á la base; mésosternum échancré et rebordé. Pattes brunes. Jambes antérieures 3-dentées, postérieur'es garnies d'un double rang de nombreux denticules épineur.

Inde ; Bengale; Malaisie (Java).

\section{H. LONGICOLLIS.}

Oblongo-ovatus, convexus, niger, nitidus; fronte puncticulata, bifoveolata, stria profunda integra; mandibulis canaliculatis; pronoto ciliato, striis integris, approximatis, parallelis, profundis, intus ad angulum punctis paucioribus laceris; elytris striis 2 subhumeralibus junctis, 1-4 dorsalibus integris, $5^{a}$ pone medium, suturali ante abbreviatis; propygidio pygidioque grosse et parce punctatis; mesosterno emarginato, stria integra; tibiis anticis 3-dentatis, posticis biseriatim 5 ou 6 spinosulis. Long. 7 mill.; larg. 4 1/2 mill.

Ovale allongé, bombé, noir, luisant. Antennes brunes, moins foncées. Front large, finement et densément pointillé, bifovéolé, strie profonde, entière ; labre très court ; mandibules larges, bidentées, creusées en gouttière, courbées en pointe aiguë. Pronotum assez long, bombé, cilié; coupé droit à la base avec une strie antéscutellaire, oblique et subsinué sur les côtés, rétréci et fortement échaucrè en devant, avec les angles abaissés, assez aigus ; stries latérales fortes, entières, parallèles, et ıpprochées sur les côtés, arec des points lacérés à l'angle antérieur. Ecusson pelit, triangu- 
laire. Elytres de la largeur du pronotum à la base, pas plus longues que lui, très rétrécies au bout ; fossette subhumérale ponctuée, 3-sillonnée; stries fortes, bien marquées, crénelées, subliumérale interne remontant au-delà de l'externe, qui lui est unie; 1-4 dorsales entières, subparallèles, cinquième raccourcie avant le milieu, suturale plus longue. Pygidium fortement, mais peu.densément ponctué, ainsi que le propygidium. Prosternum en carène, élargi à la base, lobe court, ponctué, bimarginé, incliné ; mésosternum échancré, bordé d'une strie entière et d'une autre interrompue. Jambes antérieures armées de trois fortes dents; postéricures garnies de cinq à six paires de dentelures épineuses.

Cafrerie (Natal) (II. de Laferté).

\section{H. ARCUATIS.}

Ovalis, convexus, niger, nitidus; antennis rufis; stria frontali integra; pronoto flavo ciliato, striis 2 lateralibus integris postice approximatis; elytris fossa subhumerali lcevi bisulcala, stria subfumerali interna irregulari, cxterna humerali separata adaucta; 1-3 dorsalibus integris, $4^{\text {a }}$ late interrapta, $5^{a}$ nulla vel brevissima obsoleta, sulurali subintegra; macula magna rufa arcuata; pygidio propygidioque parce munctatis; mesosterno emarginato, stria integr'e, femoribus 4 posticis rufis; tibiis anticis bidentatis, posticis multispinosis. Long. 8 mill.; larg. 6 mill.

Hister arcuatus. Say. in Soc. Philad., t. v, p. 34, 3 (1825). Le Conte, N. Amér. Hist., 16, 1, pl. 1, fig. 12.

Ovale, très convexe, noir, luisant. Antennes rouge-brun, massue velue, gris-ferrugincux. Tête large; front plan; stric bien marquée, entière, semicirculaire. Labre petit; mandibules sublentées en rledans, courbées en pointe aiguë. 
Pronolum plus large que long, bordé de poils jaunes longs et serrés, droit à la base, avec une strie antéscutellaire, un peu courbé sur les côtés, rétréci et fortement échancré en devant, aree les angles abaissés et obtus ; stries latérales entières, assez distinctes, rapprochées à la base, souvent ponctuées dans l'intervalle. Ecusson petit, triangulaire. Elytres courtes, plus longues que le pronotum, de sa largeur à la base, dilatées à l'épaule, rétrécies et curvilinéaires au bout, avee une impression subapicale et un petit angle sutural; fossette marginale, assez profonde, imponctuée, bisillonnée; strie subhumérale interne large, irrégulière, avec une externe disjointe; 1-3 dorsales entières, quatrième obsolète largement interrompue; cinquième ou nulle ou très courte; suturale presque entière; une grande tache rouge arquée, occupant à la base les trois premiers interstries, se contournant en dedans jusqu’à la suturale. Propygidium légèrement biforéolé, couvert de points épars, presque lisse au milieu. Pygidium un peu plus densément ponctué. Prosternum en carène, élargi et arrondi à la base, lobe court, ponctué, rebordé, incliné; mésosternum assez profondément échaneré, bordé d'une strie entière. Cuisses postérieures renflées, rouges au milieu; jambes antérieures larges, fortement bidentées; postérieures garnies de sept on liuit paires de denticules épineux.

Etats-Unis, dans les cadarres, sur le bord de la mer.

\section{II. TETER.}

Ovatus, subcomecus, niger, nilidus; fronle impressa, stria integra; pronoto strice externa integra, interne subintcgra; elylris fossa subhumciali hisulialu, heri, shiu subhumerali interna arcuatim apmendiculata, 1 -h rensulibus inlegris, $5^{3}$ su- 
neralique dimidiutis; propygidio mygidioque punctulatis; mesosterno emarginalo, stria integra; tibiis anticis 4-dentatis, posticis biseriatim spinosis. Long. 9 mill.; larg. 6 mill.

Hister teter. Truq. in Soc. Ent. Fr. (1852), 62, 2, pl. 2, no 2, fig. $\mathbf{1}$.

Ovale, élargi, assez convexe, noir, luisant. Antennes brunes, funicule rougeâtre; fossette antennaire bien limitéc. Tête arrondie, médiocre; front finement pointillé avec une impression médiane, strie assez fine, droite par devant; labre court, arrondi ; mandibules subbidentées, courbées en pointe aiguë. Pronotum court, beaucoup plus large que long, arqué et ponctué à la base avec une strie antéscutellaire, courbé sur les côtés avec un étroit rebord élevé, échancré et fortement rétréci en devant, avec les angles abaissés, un peı obtus; strie latérale externe entière, bien marquée, rapprochée du bord, interne non interrompue, mais n'atteignant pas tout à fait la base. Ecusson petit, triangulaire. Elytres plus longues que le pronotum, de sa largeur à la base, curvilinéairement dilatées sur les côtés, rétrécies et obliques au bord apical ; fossette marginale assez profonde, bisillonnée, imponctuée; strie subhumérale interne bien marquée, atteignant l'épaule, accompagnee d'une externe arquée disjointe remontant presque jusqu'à la base; 1-4 dorsales entières ponctuées; cinquiène et suturale raccourcies au milieu, relle-ci un peu plus longue. Propygidium à peine visiblement bifovéolé, couvert, ainsi que le pygidium, de points ćpars, et d’un pointillé plus fin dans les intervalles. Prosternum en carène obtuse, élargi à la base, lobe court, ponctué, reborlé, abaissé; mésosternum échancré, borlé l'une stric cntiere. Jambes antóricures dilatíes au bout, 
armées de quatre deuls, l'extrême bifide; postérieures garnies de sept ou huit paires de denticules épineux.

Suisse; Piémont.

\section{H. UNICOLOR.}

Rotundato-ovatus, convexiusculus, nigcr, nitidus, antomis brunncis; stria frontali integra; pronoto stria laterali externa valde, interna vix abbreviatis; elytris fossa marginali punctulata, bisulcata, striis munclatis, subhumciali externa obsoleta, 1-3 dorsalibus integris, 4-5 et suturali brevibus; propygidio bifoveolato mgidioque muctatis; mesosterno cmarginato, stria integra; tibiis anticis 3-dentatis, posticis biseriation multispinosis. Larg. 10-8 mill.; larg. 7-6 mill.

Hister unicolor. Lim. Syst. 11at. 1, 2, 567, 3 (1735), - Fn. Suec. 1, 440. - - F. Syst. ent. 1, 52, 2. - Spec. Ins. 1, 60, 2. Mant. 1, 32, 2. - Ent. Syst. 1, 92, 2. - Syst. El. 1, 84, 3. Ol. Ent. 1, 8, 7, 5, pl, 1, 1. - Ros. Fu. Etr. 1, 27, 62. - Herbst. nat. Syst. 4, 22, 1, pl. 35, 1. - Panz. Ent. Germ. 1, 20, 2. Illig. Kæf., Pr. 1, 52, 1.-Payk., Fu. Suec, 1, 35, 1 ;-Mon. Hist., 19, 10, pl. 2, 7. - E. H., 1, 31, 1, pl.1, 1. -- Sturm. Deuts. Fn. 1, 192, 3, pl. 16. - Dufts. Fu. Austr. 1, 213, 7. - Gyll., Fn. suec., 1, 74, 1. - Steph., Illust. Brit. 3, 145, 3. - Er. Kæf. Brand. 1, 655, 1. - Heer, Fn. Helv. 1, 453, 3. - Küst. Kæf. Eur. 6, 53. - Redt. Fn. Austr. 233. -- Bach. Fu. Pruss, 1, 301, 4.

Ovale arrondi, assez convexe, noir, luisant. Autennes brunes, massue grise, velue. Tête petite, arrondie; front légèrement concave, pointillé, strie forte, entière, sinuée en devant; labre court; mandibules à peine bidentées, courbées en pointe. Pronotum court, large, droit d̀ la base avec quelques points et une ligne antéscutellaire, courbé sur les cotés, très rétréci et échancré en devant, avec les angles abaissés, aigus; stries latérales raccourcies, inlerne vers la base, cxterue au milieu. Ecusson petit, triangulaire. Elytres 
plus longues yue le pronotum, de sa largeur à la base, curvilinéairement dilatées sur les còtés, rétrécies et arquées au bout avec une impression subapicale et un angle sutural; fossette marginale pointillée, bisillonnée; strics crénelées, subhumérale interne atteignant l'épaule avec un rudiment externe très obsolète, dorsales 1-3 entières, 4-5 et suturale très raccourcies. Propygidium bifovéolé, couvert de points espacés; pygidium un peu plus densément ponctué. Prosternum en carène obtuse, élargi ả la base, lobecourt, incliné, rebordé; mésosternum échancré, avec deux stries, l'une entière, l'antre interrompue. Jambes antérieures garnies de trois dents, l'extrême bifide; postérieures d'un double rang de nombreus denticules épineux.

Commun dans toute l'Europe, depuis l'Angleterie et la Laponie jusque sur le littoral de la Méditerranée. Il vit dans le fumier, les cadavres, le suc qui découle des plaies des arbres, etc.

\section{H. CuRvatus.}

Ovalis, subconvexus, subtiliter punctulatus, niger, nilidus ; fronte impressa, stria subrccta; pronoto striis lateralibus approximatis, cxterna parum abbreviata, interna subintegra; elytris fossa Laterali punctala bisulcata, stria subhumerali ap. pendice obsolelo, suturali arcuata el 1-4 dorsalibus integris, $5^{\mathrm{a}}$ in medio abbreviala ; propygidio bifoveolato pygidioque punctatis; mesostcrno profunde cmarginalo stria integra; libiis anticis 4-dentatis, posticis biseriatim multispinosis. Longueur 8 mill.; larg. 6 mill.

Hister curvalus. Er. in Jahr. 1, 139, 26 (18;4).

Ovale, subconvexe, noir, luisant, finement pointillé sur toute sa surface, plus distinctement sur la tête, le pronotum 
et lescotés des élytres. Antennes brunes, funicule rougeâtre. Front largement impressionnć au milieu, strie entière bien marquée, légèrement sinuée en devant ; labre petit ; mandibules sans dents, courbées en pointe aiguë. Pronotum beaucoup plus large que long, arqué à la base, courbé sur les cotés, rétréci et échancré en devant, avec les angles abaissés, assez aigus ; stries bien marquées, crénelées, rapprochées ; externe un peu raccourcie, interne non interrompue, n'atteignant pas tout a fait la base. Ecusson petit, triangulaire. Elytres courtes, plus longues que le pronotum, le sa largeur à la base, curvilinéairement dilatées sur les cotés, rétrécies et arquées au bout avec une impression subapicale et un angle sutural prononcé ; fossette marginale bisillonnce, pointilléc; stries bien marquées, crénclées; subhumérale atteignant l'épaule, accompagnée d'un appendice court, très obsolète; 1-4 dorsales entières, cinquième raccourcie au milieu; suturale arquée en dehors, entière. Propygidium bifovéolé, couvert de points peu serrés, entremêlés de plus petits points; pygidium avec les deux espèces de ponctuation, mais plus serrées. Prosternum en carène obtuse, élargi à la base, lobe court, rebordé, infléchi; mésosternum fortement écluancré, bordé de deux stries, une entière, l'autre interrompue. Jambes antérieures dilatées au bout, armées de quatre dents, l'extrême bifide, la première très petite; postéricures garnies de six ou huit denticules épineux.

Brésil.

66. H. Arabicus.

Ovalus, convexiusculus, niger, nitidus; stria fromtali integra; pronoto ciliato, leviter bifoveolato, stria laterali interna 
integra, exlerna subabbreviala; elytris striis 1-4 dorsalibus integris, 5 a in medio abbrcviata, suturali nulla; fossa laterali punctulata; propygidio bifoveolato parce, pygidio densius punctatis; mesosterno emarginato, stria integra; libiis anticis 3. dentatis, posticis biseriatim multispinosis. Longueur 8 mill.; larg. 6 mill.

Ovale, légèrement convexe, d'un noir très luisant, lisse; cependant on aperçoit des points fins et légers sur la tête et le pronotum. Strie frontale entière, bien marquée, subsinuée en derant, labre court; mandibules fortes, aiguës, bidentées. Antennes brunes, funicule rougeâtre, massue grise. Pronotum court, large et légèrement bisinuć à la base, oblique et presque droit sur les côtés, très rétréci et échancré en devant, avec les angles abaissés, assez aigus, cilié sur les bords, superficiellement fovéolé aux angles antérieurs; stries latérales droites, parallèles, interne non interrompue, externe un peu raccourcie. Ecusson petit, triangulaire. Elytres courtes, plus longues que le pronotum, de sa largeur à la base, dilatées à l'épaule, rétrécies au bout avec une impression subapicale; strie subhumérale remontant jusqu'à l'épaule; dorsales bien marquées, fines, 1-3 entières, quatrième raccourcie un peu à la base, cinquième atteignant le milieu, suturale nulle; fossette subhumérale ponctuée. Propygidium bifovéolé, ponctué plus fortement sur les côtés, presque lisse au milieu. Pygidium assez densément ponctué. Mésosternum échancré et bordé d'une strie complète. Jambes antérieures armées de 3 fortes dents; postérieures de nombreux denticules épineux disposés sur une double ligne.

Arabie (Muséum). 


\section{II. PVICTIFEN.}

Ovalis, convexinsculus, niger, nitidus, mucticulutus; fronte. impressu, stria integra; monolo striis proximis, exlcona dimidiule, interme hend intermetla ; clytris fovea marginali bisulcalu, striis crenatis, apmendice subhumerati brevi, 1-4 dorsalibus integris, $5^{a}$ el suturali abbrevialis; promygidio bifoveoluto mygidiogue munculatis; mesostcrno emarginato, stria altorutra integra; libiis anticis 4-denticulatis, posticis biseriatim mullispinosis. Long. 7-5 mill.; larg. 5-3 1/2 mill.

Hister munclifer. Payk., Mon. Hist., 25, 14, pl. 4, 1. 1 (1811). - Er. in Jahr., 1, 140, 29. - Lec. N. Amér. Hist. 21, 10, pl. $2,9$.

Ovale arrondi, assez convexe, noir, luisant, pointillé sur toute sa surface. Antennes brunes, massue gris-cendré. Tète petite, arrondie; front fovéolé, stric circulaire entière, sinuée en derant; labre petit; mandibules faiblement dentées, courbées en pointe aiguë. Pronotum court, arqué à la base arec un point antéscutellaire, courbé sur les côtés, rétréci et échancré en devant, avec les angles abaissés, aigus; stries latérales crénelées, rapprochées, intel'ne no॥ interrompue, externe raccourcie au milieu. Ecusson petit, triangulaire. Elytres it peine plus longues que le pronotum, de sa largeur à la base, curvilinéairement dılatees sur les cotés, rétrécies et obliques au bout, avec une impression subapicale et un angle sutural; fossette latérale lisse, bisillonnéc; stries crénclées, subhumérale interıe atteignant l'épaule, appendice court, bien marqué, 1-4 dorsales entières, cinquième courte, sulurale un peu raccourcie aux deux bouts. Propygidium bifovéolé, couvert, ainsi que le pygidium, de points espacés et dans l'intervalle d'une ponctuation très fine. Prosternum en rarène obtuse, élargi à la base, lobe court, rebordé, incliné; mésostermun échancré, horlé d'une

3r Série, Tove II. 
strie entière el d'une autre inlerrompue. Jambes antérieures garnies de quatre denticules, extrême bifide; postérieures d'une double rangée de nombreuses dentelures épincuses.

Brésil; Bolivie; dans les bouses, en janvier, et dans les charognes, en mai et juin.

\section{II. IMPRESSIFRONS.}

Ovatus, subconvexus, pumticulatus, niger, nitidus; fronte foveolatu, stria integra; pronoto ante scutellum rugose punctato, stria laterali interna integra, externa abbreviata; elytris sutura impressa; margine inflexo bisulcato, stria subhumcrali internu, appendice obsolcto; 1-4 dorsalibus integris, $5^{\text {a dimi- }}$ diata, suturali subintegra; propygidio bifoveolato pygidioque punctulatis; mesosterno cmarginato, striu integra; tibiis anticis 4-denticulatis, posticis biseriatim multispinosis. Longuem $61 / 2$ mill.; larg. 5 mill.

Ovale, assez convexe, très finement pointillé sur toute sa surface, noir, luisant. Têle petite, arrondie; front creusé d'une fossette profonde; strie circulaire cntière, sinuée en devant; labre petit; mandibules subdentées en dedans, courbées en pointe aiguë. Pronotum court, pius large que long; arqué et ponciué à la hase, avec une petite surface triangulaire rugueusement ponctuée au devant de l'écusson, courbé sur les côtés, échancré et fortement rétréci en devant, avec les angles abaissés, assez aigus; strie latérale interne entière, crénelée, recourbée en dedans à la base ; externe rapprochée du bord, raccourcie au-delà du milieu. Eeusson petit, triangulaire. Elytres plus longues que le pronotum, de sa largeur à la base, curvilinéairement dilatées sur les côtés, rétrécies et à peine obliques au bout, avec un angle sutural bien marqué, déprimées le long de la suture; bord infléchi finement pointillé, hisillonné, sans fossette; 
subhumérale interne, accompagnée d'une courte strie externe très obsolele; 1-4 dorsales entières, fortes, crénelées, cinquième raccourcie au milieu: suturale arquée en sens inverse, à peine raccourcie aux deux bouts. Propygidium légèrement bifovéolé, couvert ainsi que le pygidium, d'une ponctuation assez régulière et assez serrée, entremêlée de points plus petits. Prosternum en carène obtuse, élargi à la base, lobe court, rebordé, incliné ; mésosternum échancré, bordé d'une strie entière et d'une interrompue. Jambes antérieures garnies de quatre petites dents, extrême bifide; postérieures de sept on huit paires de denticules épineux.

Cette espèce diffère du II. punctifer par la fossette du îront plus profonde, la strie latérale externe du pronotum plus longue, les points antéscutellaires, la fossette subhumérale nulle, les épaules plus saillantes, la suture enfoncée, les stries plus fortes, plus crénelées, la suturale plus allongée, la subhumérale externe plus obsolète et le propygidium plus entièrement ponctné.

Guyane (Cayenne).

\section{H. CAVIFRONS.}

Ovalis, parum convexus, puncticulatus, niger, nitilus; fronte foveoluta, stria intrgia; monoto stria laterali interna hand interrupta, externa ante modium abbreviala; elytris margine inflexo bisulcuto, striu subhumerati untice bifurcatu; 1-4 dorsalibus integris, 5a ante medium, suturali ultra medium abbreviatis; promygidio bifovcolato mygirlioque munctulatis; mesosterno emarginato, striu alterutra integra; tibiis anticis 5-denticulatis, posticis biscriatim multispinosis. Longueur 6 mill.; larg. 5 mill.

Ovale, peu convexe, très finement pointilté, peu visible- 
ment sur les élytres, noir, assez luisant. Antenucs brunes, massue grise, velue. Tête assez petite, arrondie; front creusé d'une fossette médiane assez profonde, strie entière ; labre petit; mandibules subdentées courbées en pointe aiguë. Pronotum court, bcaucoup plus large que long, arqué et nonctué à la base, courbé sur les côtés, fortement rétréci et échancré en devant, avec les angles antérieurs aigus et abaissés; strie latérale interne non interrompue, recourbée en dedans à la base, externe raccourcie avant le milien. Ecusson petit, triangulaire. Elytres courtes, plus longues que le pronotum, de sa largeur à la base, curvilinéairement dilatées sur les côtés, rétrécies et obliques au bout, avec un angle sutural; bord infléchi fiuement pointillé, bisillonné, sans fossette bien marquée; strie subhumérale interne inégalement bifurquée à l'épaule, c'est-à-dire qu'une courte strie externe vient joindre l'interne avant sa terminaison ; 1-4 dorsales assez fines, ponctuées, entières, cinquième n'atteignant pas le milien; suturale remontant bien au-rlelà. Propygidium couvert de gros points épars, avec une ponctuation plus fine et plus serrée dans les intervalles. Pygidium punctué à peu près de même. Mésosternum échancré, bordé d'une strie entière et d'une interrompue. Jambes antérieures garnies de cinq petites dents, extrême bifide; postéricures de sept ou huit paires de denticules épincux.

Cette espèce diffère du $H$. impressifrons par ses stries moins fortes, par sa suturale moins longue, sa suture non impressionnée; du H. punctifer, par son bord infléchi sans fossette; de l'un el de l'autre par ses jambes antérieures à cinq denticules, ses stries subhumérales jointes, sa latérale externe du pronotum plus courte, et son manque de points antéscutellaires. 
Ltats-Unis; Venezuela (Caracas), montagnes, en janvier, dans les bouses, et en mai et juin, dans les charognes.

\section{H. INCERTUS.}

Ovalis, convexiusculus; antcnnis rufo-brunneis; stria frontali scmicirculari; stria laterali cxterna abbreviata, interna haud interrupta; elytris margine inflexo 3-sulcato, striis 1-3 dorsalibus intcgris, $4^{\text {a }}$ basali, postice punctis obsoletis continuata, 5a inconspicua, suturali urrinque vix abbreviata; subhumcrali punctiformi vix conspicua; propygidio bifoveolato parce, pygidio subtilius punctulatis; mesosterno sinuter, marginuto; libiis anticis 3̈-dentatis, posticis biseriatim multispinosis. Longueur 7 mill.; larg. $5 \mathrm{I} / 2$ mill.

Ovale, assez convexe, noir, luisant, paraissant lisse. Antennes brunes, funicule rougeâtre, massue grise. Tête arrondie, médiocre. Front plan; strie semicirculaire entière, bien marquée; labre petit; mandibules édentées, courbées en pointe. Pronotum beaucoup plus large que long, légèrenıent arqué à la base, avec un point antéscutellaire, courbé sur les côtés, fortement rétréci et échancré en devant arec les angles abaissés, assez aigus; stries latérales assez distantes, non réunies en devant, raccourcies, externe au milicu, interne ver's la base; celle-ci arrondie à l'angle antéricur, non interrompue en devant et sans sinuosités. Ecusson pelit, triangulaire. Elytres plus longues que le pronotum, de sa largeur à la base, curvilinéairement dilatées sur les côtés, retrécies et droites postéricurement avec une légère impression subapicale; strie sublımérale externe très obsolète, composée de petits points et accompagnée à l'épaule d'une trace de subhumérale esterne; 1-3 dorsales entières, bien marquées, à peine crénclées ; quatrième très 
courte, basale, continuée par des points obsolètes, einquième indistincte; suturale presque entière, mais n'atteignant ıi la base, ni l'extrémité ; fossette subhumérale 3-sillounće, imponctuée. Propygidium bifovéolé, couvert de points assez espacés en devant; pygidium plus densément, mais très finement pointillé. Prosternum en carène obtuse, élargi à la base, lobe court, rebordé, ponctué, infléchi ; mésosternum échancré, bordé de deux stries, l'une entière, l'autre à peine interronıpue. Jambes antérieures dilatées, armées de 3 dents, extrême bifide; postérieures garnies de huit à dix paires de denticules épineux.

Etats-Unis; Texas.

\section{H. pethidus.}

hotundato-ovatus, convexus, niger, nitidus ; antennis ferrugineis; fronte pianu, stria circulari integra; pronoto stria laterali externa subabbreviata, interna haud interrupta; elytris margine punctato bisulcato, striu subhumerali obsoleta, appendice brevi, dorsulibus 1-3 inteyris crenatis, $4^{\mathrm{a}}$ integra punctis composita, sulurali dimidiula; momygidio bifovcolato pygilioque punclulatis; mesostcrno simuato, marginulo; tibiis anticis 3-dentatis, posticis biscriatim 5-6 spinosis. Long. 7 mill.: larg. 5 1/2 mill.

llister putridus. Er. in Jahr., 1, 140, 28 (1834).

Ovale, arrondi, convexe, noir, luisant. Antennes bıuncs, funicule ferrugineux, massue roux-cendré. Têle médiocre, arrondie; front un peu bombé, strie forte, entière, semirirculaire; labre petit; mandibules édentées, courbées cu pointe. Pronotum court, arqué et bordé de points à la base, avec une strie antéscutellaire, oblique sur les cotés, échanrré et fort rétréci en devaut, arec les anghles abaissés, obtus: stries latérales bien marquéce, externe à peine racenurcie, 
interne non interrompue. Ecussun petit, hriangulaire. Elytres plus longues que le pronolum, de sa lirgeur à la base, curvilinéairement dilitées sur les côtés, arrondies à l'angle postérieur, droites et rétrécies au bout avec une impression subapicale bien marquée; bord inflécli creusé de 2 sillons pointillés; strie snbhumérale interne formée d'une ligne obsolète de petits points, appendice court, mais distinct; dorsales 1-3 entières, fortes, crénelées, quatrième entière, remplacée par une ligne de points, cinquième ì peine rudimentaire, suturale raccourcie de part et d'autre. Propygidium subbifovéolé, couvert de points assez serrés. Pygidium plus finement ponctué. Prosternum assez 'large, arrondi à la base, lobe très court, ponctué, rebordé, abaissé; mésosternum sinué et bordé d'une strie entière et d'une largement interrompue. Jambes antérieur'es 3 -dentées; postérieures garnies de cinq ou six paires de denticules épineux.

Amérique méridionale.

\section{II. SPRETUS.}

Ovalis, convexiusculus, niger, nitidus; amennis rufis; fion. tali stria arcuata inlegra; pronoto stria laterali cxlerna ultra medium, interna basi abbrevialis; elylris stria sublamerali inlernu obsoletu, aren munclormm adaucla; 1-3 dorsalibus punctatis integris, $4^{\mathrm{a}}$ suluralique in inelio, $5^{\text {a }}$ upice abbreviatis; propiygidio subfovcolato pygidioquc alense punclatis; mesosterro emaryinato, sura inteyra ; libiis unticis s-dentutis, poslicis biscriatim multispinosis. Long. 7 mill.; larg. 5 mill.

Ilister spretus. Le Conte, N. Amẻr., Hist. 23, 14, pl. 3, lig. 1 $(1845)$.

Ovale, assez convexe, noir, hisant, presque lisse et peu distinctement pointillé. Antennes rousses. Tête médiocre, arrondie. Front pilan, strie plus fine et mesque droite en 
devant ; labre pelit; mandibules édentées, à pointe recourbée, assez aiguë. Pronotum beancoup plus large que longr, légèrement arqué et bordé de points à la base arec une petite impression antéscutellaire, courbé sur les côtés, très rétréci et échancré en devant avec les angles abaissés, obtus; stries latérales disjointes en devant; externe raccourcie audelà du milieu, interne presque entière, non interrompue en devant et à peine sinuée à l'angle postoculaire. Ecusson petit, triangulaire. Elytres beaucoup plus longues que le pronotum, de sa largeur à la base, curvilinéairement dilatées sur les côtés, rétrécies et obliques au bout, avec une impression subapicale bien marquée; stric subhumérale interne accompagnée d'un arc huméral externe, fine, composée de points obsolètes; 1-3 dorsales fortes, ponctuées, entières; quatrième raccourcie vers le milicu, ainsi que la suturale; cinquième courte, apicale, souvent obsolète; fossette mar-ginale bisillonnée, pointilléc. Propygidium légèrement bifovéolé, couvert ainsi que le pygidium de points serrés et assez. forts. Prosternum assez large, arrondi à la base, lobe court, abaissé, rebordé; mésosternum échancré, bordé de deux stries, l'une entière, l'autre interrompue. Jambes antérieures armées de trois dents obtuses, apicale bifide; postérieures garnies de huit on dix paires de denticules épineux.

Btals-Unis; Georgie, Louisiane; dans les bouses.

\section{H. CURTATIS.}

Brevilet otalis, comvexiusculus, niger, nitidus; antemms brunmeis; strin frombuli scmicirculat; monolo strin latcruli

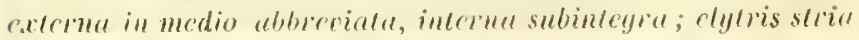
suhhumeralio muntis obsoletis are"l adruncta; 1-4 dorsulibus 
integris, 5, ante medium, sulurali in matio abbreviatis, margine inflexo munctulato bisulcuto; mopygidio bifoveolato py. gidioque sul dense punclulutis; mesosterno emarginato, stria integra; tibiis anticis :3-dentatis, posticis biseriatim multispinosis. Long. 6 mill.; larg. $41 / 2$ mill.

Hister curtatus. Le Conte, Mon. Hist. 24, 15, pl. 3, f. 2 (1845).

Ovale arrondi, assez convexe, noir, luisant. Antennes brunes, massue gris-roux. Tête médiocre, arrondie; front plan; strie entière, bien marquée, semicirculaire; labre pelit; mandibules édentées, ̀̀ pointe recourbée, assez aiguë. I'ronotum beaucoup plus large que long, légèrement arqué à la base, courbé sur les côtés, rétréci et échancré en de. vant, avec les angles abaissés, assez aigus; stries fortes, parallèles, assez distantes, non réunies en devant, externe rapprochée du bord, raccourcie au milieu, interne entière, non interrompue en devant et sans sinuosités. Ecusson petit, triangulaire. Elytres plus longues que le pronotum, de sa largeur à la base, curvilinéairement dilatées sur les côtés, rétrécies et un peu obliques au bout, avec une impression subapicale; strie subhumérale obsolète, formée de points, ainsi que l'are luméral externe; 1-4 dorsales enlières, bien marquées, ponctuées, cinquième raccourcie avant le milieu, suturale au milieu; fossette sublıumérale lisillonnée, pointillée. Propygidium légèrement bifovéolé, couvert, ainsi (jue le pygidium, d'une ponctuation faible et assez serrée. Prosternum en carène obtuse, élargi à la base, lolve très court, rebordé, incliné; mésosternum échancré, bordé d'une strie entière el d'une iıterrompue. Jamhes anlérieures dilatées, anmées dle lrois dents, extrême bifide ; postérieures garnies de huil à dix paires de denticules épiIIEU.

Etals-Iuis. 


\section{H. DEPURATOR.}

Suborbicularis, convcxus, niger, nitidus, puncticulatus; an= tennis brunneis; fronte plana, stria semicirculari; pronoto stria laterali interna haud interrupta, externa dimidiata; elytris margine bisulcato, stria subhumerali obsoletissima, dorsalibus crenatis validis, 1-3 integris, 4" punctis composita, suturali abbreviata; propygidio subfovcolato sat fortiter, pygidio sublilius punctatis; mesostcrno emarginato, stria integra; tibiis unticis e.dentatis, posticis biscriatim multispinosis. Longueur 8 mill.; larg. 6 mill.

Hister depurator. Say. Soc. Phil., v, 33, 2 (1825). - Le Conte, N. Amér. Hist. 24, 16, pl. 3, fig. 3.

Ovale arrondi, convexe, noir, luisant, pointillé. Antennes brunes, massue velue, gris-roux. Tête médiocre, arrondie; front plan, strie forte, semicirculaire ; labre petit ; mandibules dentées, courbées en pointe aiguë. Pronotum court, arqué et bordé de points à la base, courbé sur les côtés, rétréci et échancré en devant, avec les angles abaissés, obtus; strie latérale externe raccourcie vers le milieu, interne forte, non interrompue. Ecusson petit, triangulaire. Elytres beaucoup plus longues que le pronotum, de sa largeur à la base, curvilinéairement dilatées sur les côtés, obliques au bout avec un angle sutural et une impression subapicale; bord inlléchi parcouru par deux sillons ponctués, sans fossette; sirie subhumérale obsolète, ainsi que l'arc huméral, composée de points; dorsales fortes, crénelées, 1-3 entières, quatrième représentée par une ligne de points peu marqués, suturale raccourcie de part et d'autre. Propygidium à peine bifovéolé, couvert de points assez serrés et médiocres. Ponctuation du pygidium plus finc et un peu plus dense. Prosternum assez large, arrondi à la base, lobe très court, rebordé, peu abaissé ; mésostcrnum échancré, bordé d'une 
strie entière et d'une interrompue. Janbes antérieures arncées de trois dents, extrême bifide; posiérieures garnies de sept ou huit pairés de dentelures épineuses.

Etats-Unis, assez commun dans les bouses et les bolets pourris.

\section{H. LISsUinus.}

Ovalis, subconvexus, miger, nitichs; fronte teviter impressa, stria semicirculari; pronoto stria laterali interna subintegra, externa dimidiata; elytris fossu marginali 3-sulcala, striis 1-4 dorsalibus integris, 5 ante, suturaii ultra medium abbre. viatis; propygidio basi subpunctula:o; pygidlo lavi; mesosterno simulo marginaloque; tibiis anticis 3-dentatis, posticis biseriatim 6-spinosis. Long. $51 / 2$ mill.; larg. 5 mill.

Ovale, peu convere, noir, luisant, Antennes hrunes, massue gris-roux. Tête large, arrondic; front légèrement impressionné å milieu, strie forte, bien maiquée, semicirculaire; låore petit; mandibules non canaliculées, sans dents internes, à pointe courbée, assezaignue. Pronotum beaucoup plus large que long, arqué et bordé de points à la base, courbé sur les côtés, échancré et rétréci en devant, avec les angles abaissés et assez aigus; stries latérales bien marquées, erénelées, interne à peine raccourcie, un peu oblique vers l'angle de la base, non interrompue et droite en devint, exteme raccourcic avant le milieu, recourbée cn dedans antérieurement. Ecusson petit, triangulaire. Elytres courtes, un peu plus longues que le pronotum, de sal largeur à la base, curvilinéairement dilatées sur les côtés, rétrécies et obliques au hout; stric subhumćrale avec un appendice lıuméral obsolète, très court; 1 - 1 dorsales entières, bien marquées, rénclées ; rinquièun rarcourcic avant le milieu, 
suturale au-delà; fossette latérale bisillonnée, pointillée. Propygidium lisse avec quelques points fins dans son pour tour. Pygidium entièrement imponctué. Prosteruum en carène assez aiguë, élargi à la base, lobe court, rebordé, peu incliné; mésosternum échancré, bordé d'une seule stric entière. Jambes antérieures armées de trois dents; postérieures garnies de cinq à six paires de denticules épineux.

Brésil.

76. II. CoEnosus.

Suborbicularis, convexiusculus, niger, nitidus, punticulatus; fronte plana, stria integra, simuata; pronoto stria laterali externa dimidiata, interna hand internupt, margini parallela; elytris margine inflexo bisulcuto, striis crenutis, subhumeralis "tppendice brevi, dorsalibus 1-4 integris, $5^{2}$ et suturali abbreviatis; propygidio bifoveolato parce, pygidio dense et subtilius punctulato; mesosterno sinuato, marginato; tibiis anticis multidenticulatis, posticis biseriatim multispinosis. Long. 5 1/2 mill.; larg. 4 1/2 mill.

Hister conosus. Er. in Jalır. 1, 140, 30 (1834).

11. decisus. Le Conte, N. Amér. Hist. 21, 11, pl. 2, f. 10 (1845).

Ovale, arrondi, assez convexe, noir, luisant, finement pointillé. Antennes brunes, massue velue, grise. Tête petite, arrondie; front plan, strie entière, sinuće; labre petil; mandibules à peine dentées, à pointe courbée et assez aiguë. Pronotum court, arqué et bordé de points à la base avec une ligne antéscutellaire, courbé sur les cotés, rétréci el échancré en devant, avec les angles abaissés, obtus; stries latérales crénelées, exterue raccourcie au milieu, interne non interrompue, paraltèle au bord latéral. Ecusson petit, triangulaire. Elytres plus longues que lepronotum, de sa lar- 
geur à la bisce, curvilinéairement dihatées sur les còtés, obliques au bout; bord inlléchi ponctué, bisillonné; stries forles, crénelées, subhumérale atteignant l'épaule, avec un court appendice, dorsales $\mathbf{1 - 4}$ entières, cinquième et suturale raccourcies au milieu. Propygidium bifovéolé, couvert de points espacés et d'un pointillé fin dans les intervalles. Pygidium ponctué de même, mais plus finement et plus densément. Prosternum en carène très obtuse, élargi ả la base, lobe court, ponctué, rebordé, incliné; mésosternum échancré, bordé d'une strie entière et d'une interrompue. Jambes antérieures garnies de 5-7 denticules, postéricures de 8 à 10 paires de dentelures épineuses.

Etats-Unis; Antilles (Cuba ; Saint-Domingue); Guatemala (Nicaragua), de aoùt à décembre, dans les bouses et les charognes.

\section{H. BRENIPES.}

Oblongo-ovalis, parum convexus, niger, nitidus, unternis pedibusque brumeis; fronte planu, stria simuata; pronoto stria latcrali externa dimidiata, interna hand interrupta, postice margini approximata; clytris fovea laterali bisulcata, striis crenatis, subhumeralis appendice brevi, dorsalibus 1-4 integris, $5^{\text {a }}$ et suturali abbreviat is, mopygidio vix bifoveolato mygidioque densius punchulatis; mesosterno cmarginato, stria integra; tibiis anticis denticulatis, posticis biseriatim multispinosis. Long. 6 mill.; larg. 4 mill.

Ilister brumipes, Er. in Jahr. 1, 141, 31 (1834).

Orale allongé, peu convexe, noir, luisant. Antennes brunes, massuc grise. Tête petite, arrondie; front plan, strie entière, sinuée ; labre petit ; mandibules a peine dentées, a pointe courbée, peı aiguë. Pronotum court, arqué et borlé de points à la base, aver une ligne antéscutellaire, 
courbé sur les cotés, rétréri et échancré en devant, avec les angles abaissés, aigus; stries latérales bien marquées, externe raccourcie au milieu, interne non interrompue, rapprochée du bord postérieurement. Ecusson petit, triangulaire. Elytres plus longues que le pronotum à la base, curvilinéaires sur les côtés, peu rétrécies et obli(jues au bout; fossette latérale bisilionnée; stries crénelées, sublıumérale atteignant l'épaule avec un court appendice, dorsales 1-4 entières, rapprochées par paires, cinquième raccourcie, suturale un peu plus longue. Propygidium à peine bifovéolé, couvert de petits points épars; pygidium densément pointillé. Prosternum en carène assez aiguë, arrondi à la base, lobe court, rebordé, peu infléchi ; mésosternum échancré, strie entière. Pattes brunes; jambes antérieures multidenticulées, postérieures garnies d'une double rangée de nombreuses dentelures épineuses.

Mexico.

\section{H. Hipponensis.}

Ovalis subparullelus, parum convexus, puncticulatus ; «ntennis rufis; stria frontuli antice recta; mandibulis concavis; pronoto stria laterali interna integra; elytris apice rufis, stria subhumerali interna obsoleta postice abbreviata, appendice aucta; 1-4 dorsalibus integris, $5^{\text {a }}$ el sulu ali dimidiatis; fossa subhumerali 3̈-sulcata punctulata; propygidio bifovcolato mygidioque densius grosse muctatis; mesosterno subsinnato; tibiis anticis 4-dentatis, posticis biseriatim 7.8 spinosis. Longueur 5 1/2 mill.; larg. 4 mill.

Ovale presque parallèle, peu convexe, noir, luisant, linement pointillé en dessus. Antennes rouge-brun. Tête large, assez grande. Front plan; strie entière, droite par devant; labre petit; mandibules subdentées en dedans, légèrement creusées, à pointe courbée, oltuse. Pronotum beaucoup 
plus linge que long; presque iroit et ponclué à la base, arqué sur les colés, échancré el rétréri en devant avec les angles abaissés et assez aigus ; strie latérale interne entière. non interrompue en devant, assez rapprochée lu bord, un rudiment court, obsolète de latérale externe. Ecusson petit. triangulaire. Elytres courtes, un peu plus longues que le pronotum, de sa largeur à la base, subparallèles sur les côtés, rétrécies, obliques et rouges au bout, sans impression subapicale; stric subhumérale interne obsolète, raccourcie postérieurement, accompagnée d'un rudiment externe, arqué, assez long ; 1-4 dorsales crénelées entières, cinquième et suturale raccourcies au-delà du milieu, à peu près égales ; fossette subhumérale pointillée, 3-sillonnée. Propygidium biforéolé, convert d'une forte ponctuation espacée; pygidium aussi fortement, mais beaucoup plus densément ponctué. Prosternum court, peu élevé, à peine élargi à la base, lobe ponctué, rebordé, peu incliné. Mésosternum légèrement sinué, bordé d'une strie entière et d'une autre interrompue. Jambes antérieures dilatées, armées de quatre dents; postérieures garnies de sept ou liuit paires de denticules épineux.

Algérie (MM. Guérin et Reiche).

\section{H. DUBILS.}

Ovalis, parum convexus, nitidus, puncticulatus; fronte plana, stria integra subsinuata; monoto stria laterali interna integra, externa versus medium abbreviata; clytris fossa marginati bisulcata; stria subhumerali interna appendiculata, 1-4 dorsalibus crenatis integris, 5a paulo ante, suturali ultra medium abbreviatis; propygidio bifoveolato pygidioque puncticulatis; mesosterno emarginuto, stria integra; tibiis anticis 5-denticulatis, posticis biseriatim multispinosis. Long. 6 1/2 mill.; larg. $41 / 2$ mill. 
Ovale, un peu allongé, légèrement conveve, noir, luisant, très finement pointillé. Antennes brunes, massue grise. Tête petite, arrondie; front plan, strie entière, légèrement sinuée en devant; labre petit; mandibules sans dents, à pointe courbée, aiguë. Pronotum beaucoup plus large que long, arqué à la base, avec la marge ponctuće et une strie antéscutellaire ; courbé sur les côtés, rétréci et échancré en devant, avec les angles abaissés, aigus ; strie latérale interne entière, sinuée au bout, n'atteignant pas tout à fait la base, externe rapprochée du bord, raccourcie an-defà du milieu. Ecusson petit, triangulaire. Elytres plus longues que le pronotum, de sa largeur à la base, légèrement arquées sur les côtés, rétrécies et obliques au bout; fossette subhumérale bien marquée, bisillonnée ; strie subhumérale accompagnée d'un rudiment de strie externe assez long, disjoint. 1-5 dorsales entières, bien marquées, crénelées, cinquième courte, I’atteignant pas le milieu, suturale le dépassant. Propygidium bifovéolé, couvert de points assez espacés, et dans l'intervalle, de points plus petits et plus serrés; pygidium ponctué à peu près de même, seulement la différence des deux sortes de points est moins sensible. Prosternum en carène, élargi à la base, lobe court, rebordé, ponctué, peu abaissé; mésosternum échancré, strie entière. Jambes antérieures garnies de cinq denticules, extrême bifide; postérieures de sept ou huit paires de denticules épineux.

Brẻsil ; Montevideo.

\section{H. DEPLICATES.}

Ovalis, subconvexus, niger, nitidus, puncticulalus; fromte 3-foveolata, stria integra valde simuata; mandibulis canaliculatis; pronoto amlice bisinuato, ciliato, stria lateiali utraque integra, interna bisimuata; clytris fossa maiginali 3-sulcata; 
stria sublumerali brevissime apmendiculata, 1-3 dorsalibus integris, 4-5 apicalibus, sumerali dimillata; mopygidio bifoveolato mygidiogue dense punctatis; mesosterno simuato, marginato; libiis amtiris 3-dematis, posticis biseruttim multi-spinosis. Long. 6 mill.; larg. 4 1/2 mill.

Orale, assez convexe, noir, luisant, très finement pointillé, plus distinctement sur le pronotum. Antennes brunes, massue grise. Front large 3-fovéolé, strie entière, profonde, formant un angle rentrant au milieu. Labre petit. Mandibules bidentées, à pointe courbée et aiguë, légèrement canaliculées. Pronotum court, beaucoup plus large que long, légèrement bisinué à la base, peu courbé sur les côtés, rétréci et échancré en devant, bisinué au fond de l'échancrure, avec les angles abaissés, assez aigus; stries latérales fortes, entières, externe rapprochée du bord et formant un bourrelet, interne bisinuée, latéralement rapprochée à la base de l'externe, formant de chaque côté un angle postoculaire arrondi, bien marqué, au devant duquel se trouve un point isolé. Ecusson triangulaire, petit. Elytres plus longues que le pronotum, de sa largeur à la base, curvilinéaires sur les côtés, rétrécies et légèrement arquées au bout, avec un angle sutural bien prononcé; fossette subhumérale 3sillonnée; stries profondes, fortes; subhumérale atteignant l'épaule, accompagnée d'une courte strie séparée; 1-3 dorsales entières, la dernière fortement enfoncée à la base, quatrième et cinquième apicales, très courtes, obsolètes; suturale raccourcie un peu au-delà du milieu. Prosternum peu élevé, élargi à la base, lobe rebordé, en pointe abaissée; mésosternum légèrement sinué, bordé d'une strie entière. Propygidium légèrement bifovéolé, couvert ainsi que le pygidium de gros points serrés, entremélés d'une ponc-

3e Série, Tone 11. 
tuation plus line. Jambes antérieures 3-dentées; postérieures garnies de neuf ou dix paires de denticules épineux.

Bengale (M. Cherrolat).

\section{II. Eschischoltzil.}

Ovalis, convexiusculus, puncticulatus; stria frontali temi, subsimuatu; pronoto striis lateralibus integris; elytris margine inflexo munctato subunistriato; stria humerali profunda, subhumerali appendice longo, 1-4 dorsalibus per paria approximatis, basi alternis mrofundioribus, 5a et suturali apicalibus obso letis; mesostcrno emarginato, stria integra; propygidio subbifoveolato myidlinque dense munctulatis; libiis anticis 4-dentatis, posticis biscriatim multispinosis. Long. 5 mill. ; largeul 4 mill.

Ovale, assez convexe, noir, luisant, finement pointillé. Antennes brunes, funicule rouge, massue grise. Tête petite, arrondie ; front plan, strie assez fine, légèrement sinuée en devant; labre aplati, assez long; mandibules inermes, à pointe courbée, aiguë. Pronotum court, beaucoup plus large que long, légèrement arqué à la base, avec une strie antéscutellaire, courbé sur les côtés, rétréci et échancré en devant, avec les angles abaissẻs, assez aigus ; stries latérales bien marquées, crénelées, à peine raccourcies à la base, interne non interrompue. Ecusson petit, triangulaire. Elytres plus longues que le pronotum, de sa largeur à la base, dilatées à l'épaule, un peu rétrécies postérieurement, et avec une impression subapicale ; bord infléchi unisillonné et fortement ponctué daus la fossette; strie humérale oblique, très profonde, unie avec la première dorsale, subhumérale assez éloignéc de la première dorsale, presque réunie à cette stric et à un rudiment externe assez long, lesquelles semblent en être les bifurcations: $1-4$ dorsales rapprochées par paires, 
entières, alternativement très enfoncées à la base (2 $2^{\circ}$ et 4e), cinquième obsolète raccourcic avant le milieu; suturale un peu plus longue. Propygidium légèrement bilovéolé, couvert d'une ponctuation assez espacée, entremelée de points plus petits; pygidium un peu plus densément ponctué. Prosternum large bombé à lá base et séparé du lobe par un profond enfoncement (disposition qui peut tenir à un vice de conformation dans le seul individu à ma disposition); mésosternum échancré, bordé d'une strie entière. Jambes antérieures armées de quatre petites dents, extrème bifide ; postéricures garnies de sept ou huit rangées de denticules épineux.

Sibérie, liamschatka. (M. de Laferté).

\section{H. ABIREVIATIS.}

Suborbicularis, comvexiusculus, niger, nitidus, puncticula:tus; stria frontali subrectu; promoto stria laterali interna integra, externa dimidiata; clytris striis valialis, crenatis, subhumerali appendice areuato forti oblongo, 1-4 dorsulibus int'gris, 5a unte merlium, suturali ultru ubbreviutis, margine inflexo muntato, bisulcato; propygidio bifoveolato marce, mygidio vix distincte muctulatis; mesosterno emarginato, stria integra; tibiis anticis 4-denticulutis, posticis biscriatim multispinosis. Long. 5-4 mill.; larg. 4-3 mill.

Hister abbreviatus F. Syst. Ent. 53. 6 (1775). - Spec. Ins. 1, 61, 6. - Mant. 1, 32, 9. - Ent. Syst. 1, 75, 14. - Syst. El. 1, 89, 29. - Herbst. Nat. Sysı. 4, 55, 28. - Er. in Jahr. 142, 32. l.e Conte, Mon. His?. 22, 12, pl. 2, 11.

Ovale arrondi, assez convexe, trèsfinement pointillé, noir, luisant. Antennes brunes, funicule rougeâtre. Tête petite, arrondie; front plan, strie entière, subsinuée en devant: labre petit; mandibules inermes en dedans, à pointe courbée, 
aiguë. Pronotum court, beaucoup plus large que long, arqué à la base, avec une rangée de points sur la marge, légèrement courbé sur les côtés, échancré et rétréci en devant, avec les angles abaissés, assez aigus; stric latérale interne crénelée, presque entière, non interrompue; externe se rapprochant peu à peu du bord, raccourcie au milieu. Ecusson petit, triangulaire. Elytres courtes, plus longues que le pronotum, de sa largeur à la base, curvili néairement dilatées sur les côtés, rétrécies et obliques au bout avec un angle sutural bien marqué; bord infléchi pointillé, profondément bisillonné; stries fortes, profondes, crénelées; sublıumérale entière, accompagnée d'un rudiment externe arqué, fort, crénelé, atteignant presque la base; 1-4 dorsales entières, cinquième n'atteignant pas le milieu, suturale le dépassant. Propygidium bifovéolé, couvert de points espacés, plus fins au ınilieu; pygidium très finement et densément pointillé. Prosternum en carène obtuse, arrondi à la base, lobe rebordé, très incliné ; mésosternum échancré, bordé d'une strie entière. Jambes antérieures garnies de quatre petits denticules, extrême 3-fjde; postérieures garnies de cinq ou six denticules épineux.

Etats-Unis, fort commun dans les bouses.

\section{H. BIFIDUS.}

Ovalis, subconvexus, puncticulatus; stria frontali antice sub. simuata; pronoto stria laterali externa ante medium, interna basi abbreviatis; elytris striis validis, crenatis; sublumerali appendice arcuato longo, 1-4 dorsalibus integris, 5a late interrupta, suturali utrinque valde abbreviata; propygidio munctato, pygidio dense puncticulato; mesosterno emarginato, stria integra; tibiis anticis 4-denticulatis, posticis biseriatim multispinosis. Long. 5 mill.; larg. 4 mill. 
Hister bifictus. Say, in Soc. Philitl. v, 34,4 (1825). - Le Conte, N. Amér. Hist. 22, 13, pl. 2, 12.

Entièrement semblable àl'II. abbreviatus, un peu plus ovale; strie latérale externe du pronotum plus raccourcie, cinquième dorsale munic à la base d'un rudiment oblique, profond ; suturale ne partant pas du bord apical et beaucoup plus courte. Serait-ce une simple variété de l'II. abbrevialus?

Etats-Lnis, daus les bouses et les bolets en putréfaction.

\section{H. 16-striatis.}

Snborbicnlaris, convexinsculns, niger, nitidus; antemis pedibusque ferrugineis; frome plana, stria semicirculari validu; monoto stria laterali interma unica hand interrupta; elyt is apice munctatis, margine bisulcato, punctato, striis validis cre. nutis integris, 2 subhumeralibus, 5 a dorsuli et suturali junctis ; propygialio mnctulato, mygidio sublavi; mesosterno recto, marginato; tibiis anticis 4-dentatis, posticis biseriatim multispinosis. Long. 5 mill.; larg. :3 1/2 mill.

Hister 16-striutus. Say, in Soc. Phil. v, 1, 36, 6 (1825). - Le Conte, N. Amér. Hist. 27, 22, pl. 3, f. 9.

Ovale arrondi, assez convexe, noir, luisant. Antemmes ferI’ugineuses. Tête médiocre, arrondie; front plan, strie bien marquée, cutière, droite en devant; labre petit; mandibules bidentées, concares, à pointe courbée. Pronotum court, arqué et bordé de points á la base, courbé sur les côtés, rétréci et échancré en devant arec les angles abaissés, aigus; strie latérale interne unique, non interrompue. Ecusson petit, triangulaire. Elytres un peu plus longues que le pronotum, de sa largeur à la base, curvilincairement dilatées sur les còtés, droites, ponctuées et rétrécies au bout; borl infléchi, ponclué, bisillomó; stries grosses, crénelées, sub- 
humérale interne atteignant l'épaule, accompagnée d'un appendice externe très fort et très long, dorsales et suturale entières, les deus plus près de la suture réunies à la base. Propygidium couvert de points assez espacés; pygidium paraissant lisse. Prosternum en carène aiguë, à peine élargi à la hase, lobe court, rebordé, incliné; mésosternum droit et bordé d'une strie entière et d’une interrompuc. Pattes ferlugineuses; jambes antérieures garnies de quatre dents obtuses, extrême bifide; postérieures de six à sept paires de dentelures épineuses.

Etats-Unis; dans les bouses.

Espèce que je n'ai pas vue.

40 7I'. H. Pavkuli, Kirby Fn. bor. Amer. 123, $172(1837)$.

Ater, nitidus; tibiis anticis 3-dentatis, dente exterior i fisso; mronoto utrinque bistriato; stria cxleriori abbreviata; elytris striis dorsalibus 1-3̊ distinctis integris, 4-5 et suturali ex punctis conflatis, abbreviatis. Long. 8 mill. - Amérique boréale.

Noir, poli. Strie frontale profonde. Antennes noir de poix, massue pâle. Mandibules plus longues que la tête. Pronotum très élargi par derrière, paraissant lisse, mais couvert réellement de très petits points peu marqués et serrés; strie latérale interne profonde, externe raccourcie, moins marquée. Outre la subhumérale courte et formée de points, il y a sur les élytres 1-3 dorsales entières, quatrième interrompue, à peine distincte, cinquième apicale, suturale obsolète, raccourcie au milieu; dessus couvert de petits points fins à peine distincts. Jambes antéricures armées de trois dents, apicale bifide.

Voisin de l'II. unicolor, il en diflere par sa ponrtuation ef ses stries prothoraciques. 
IX. Hister.

善

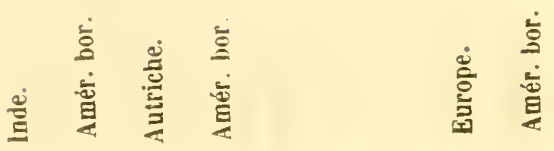
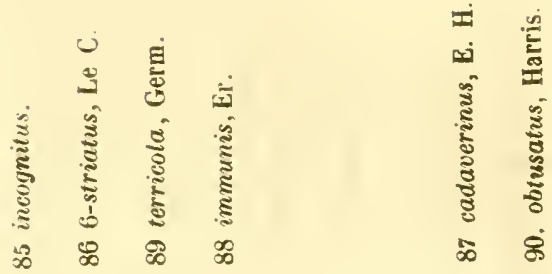

ำ

in

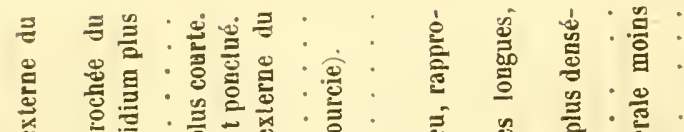

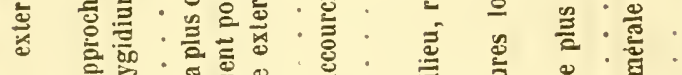

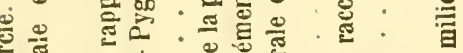

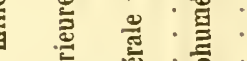

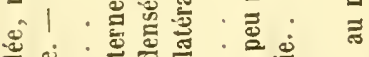

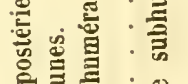

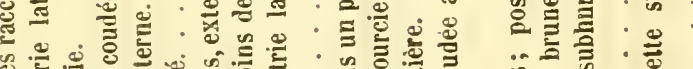
凹 ङ

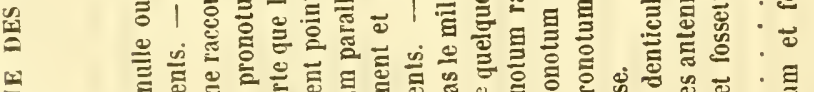

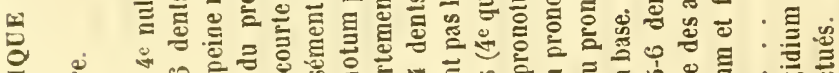
过

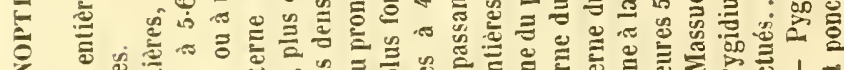
¿

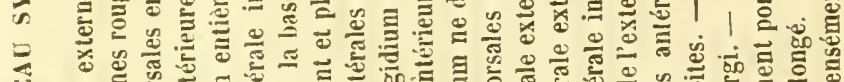

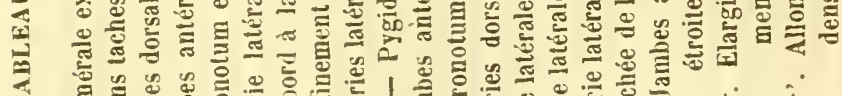

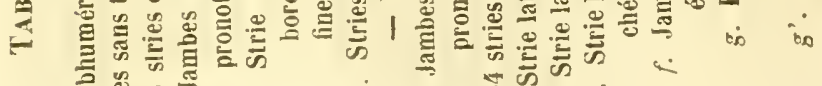

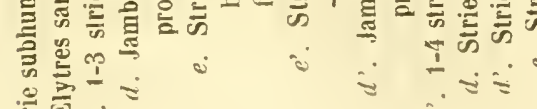
$\frac{2}{n} i$ 


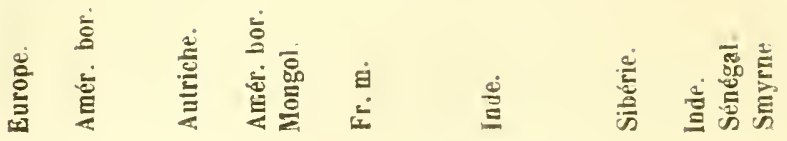
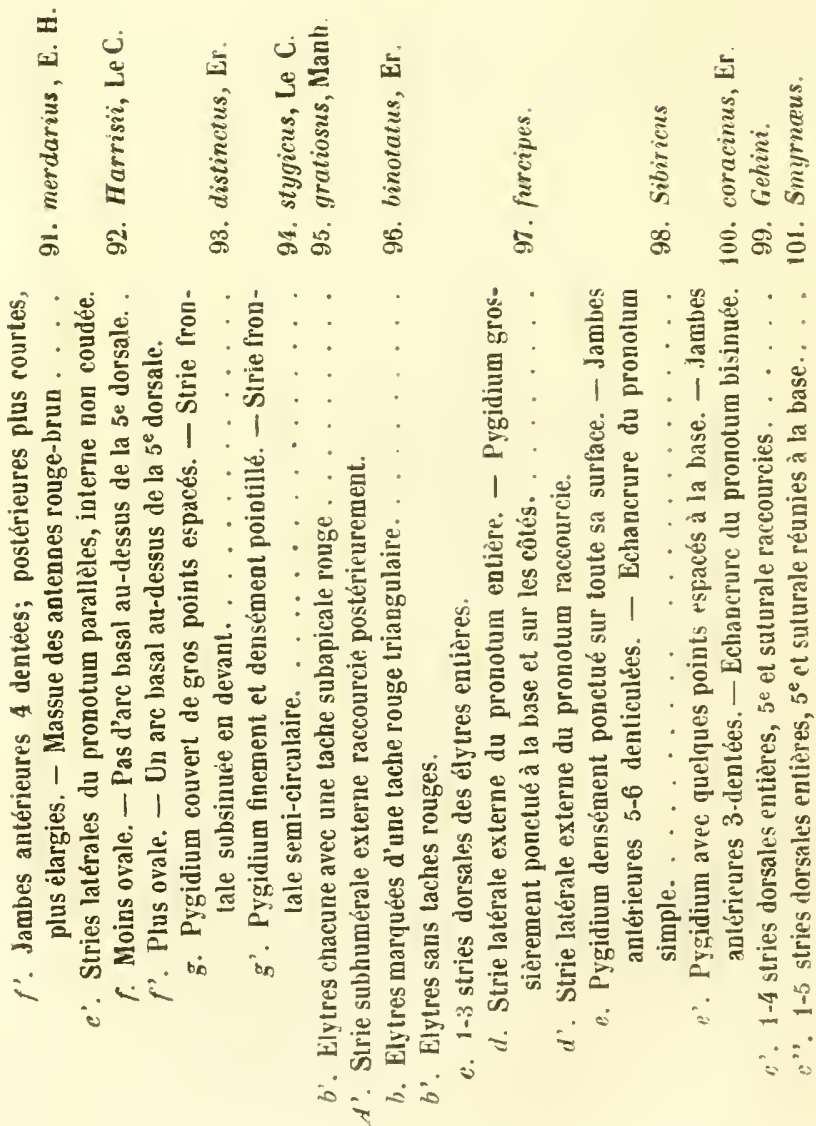
C." Strie sublımmétale externe.

1). 2 stries latérales au pronotum.

$$
5 \text { e Groupe }(85-101) \text {. }
$$

\section{H. INCOGNitIS.}

Ovalus, subconverus, niger, militus; stin fromali levi, retrorsum angulatu subinterrupta; pronoto striis lateralibus anlice junclis, postice approximatis, intcrua breviori; clytris margine inflexo 1-sulcato, punctuto, stria subhumerali externa basi ubbreviulu, 1-3̈ tlorsulibus temuibus integris, La 5a el sulurali apicalibus, obsoletis; mopygidio pygidioque dense muclatis; mesosterno emaryinuto, striu integral ; tibiis anticis 6-denliculatis, posticis biseriatim multispinosis. Longueur 10 mill.; larg. 6 mill.

Ovale allongé, peu convexe, noir, luisant. Antennes brunes, massue grise, funicule rougeàtre. Tête petite, arrondie; labre court, sinuć; mandibules édentées, à pointe aiguë, courbée. Pronotum plus large que long, presque droit à la base, avee une strie antéscutellaire, arqué sur les côtés, échancré et fortement rétréci en devant, avec les angles antérieurs abaissés, assez aigus ; stries latérales fines, réunies en devant, rapprochées à la base et raccourcies, l'interne un peu plus courte. Le seul individu à ma disposition présente deux points isolés derrière le bord antérieur (ce qui me semble un vice de conformation). Ecusson petit, triangulaire. Elytres plus longues que le pronotum, de sa largeur à la base, dilatées à l'ćpaule, rétrécies et légèrement arquées au bout, avec une légère impression subapicale; bord infléchi ponctué assez fort et 1-sillonué; strie sublıumérale seulement un peu raccourcie à la base, 1-3 dorsales fiues, entières, quatrième, cinçuième et suturale courtes, obsoletes, apicales. Propygidium rouvert d'une ponetuation 
assez serrée, avec des points plus petits dans les intervalles; pygidium encore plus densément ponctué. Prosternum en carène très obtuse, peu élargi à la base, lobe court, bordé, ponctué, incliné; mésosternum profondément échancré avec une strie marginale entière et une interrompue. Jambes antérieures armées de six petites dents, extrême bifide ; postérieures garnies de sept ou huit paires de denticules épineux.

Inde.

\section{H. 6-STRIATUS.}

Oblongo-ovatus, subconvexus, niger, nitidus; stria frontali retrorsum anyulata; pronoto striis lateralibus antice haul interruptis, cxtcrna parum abbreviata; clytris stria subhumerati basi vix abbreviata, 1-3 dorsalibus integris, cateris obsolctis apicalibus, fossa laterali munctulata; propygidio bifoveolato pygidtioque dense punctatis; tibiis anticis 5-dentatis, posticis biseriatim 4-5 spinosis

Hister 6-striatus, Le Conte, N. Col. Calif. 39, 1 (1851).

Ovale allongé, subconvexe, noir, luisant. Antennes brunes, massue cendrée. Tête large, finement pointillée; front plan, strie entière avec un angle rentrant en devant; labre subsinué ; mandibules inermes, à pointe aiguë. Pronotum beaucoup plus large que long, presque droit à la base, avec une strie courte antéscutellaire, arqué sur les côtés, rétréci et éclıancré en devant, avec les angles abaissés, assez aigus; stric latérale interne entière, externe un peu raccourcie à la base, continuées sans interruption toutes deux au bord antérieur. Ecusson petit, triangulaire. Elytres allongées, de la largeur du pronotum à la base, légèrement courbées sur les côtés, rétrécies et presque droites au bout, avec une légère impression subapicale; fossette marginale bisillonnée, nointillee; stric subhumérale légèrement recourbée à 
l'epaule, un peu raceourcie à la base, 1-3 dorsales crénelées, entières, 4-5 et suturale très obsolètes, formées de points apicaux confus. Propygidium légèrement bifovéolé, fortement ponctué sur toute sa surface, ainsi que le pygidium. Mésosternum profondément échancré, avec une strie marginale entière. Jambes antéricures dilatées, armées de cinq dents, extrême bifide; postérieures garnies de quatre ou cinq paires de denticules épineux.

Amérique boréale; Californie.

\section{H. CADAVERINUS.}

Ovalis, con:exiusculus, niger, nilidus, mucticulutus; clava grisea; stria frontali sape interrupta, sinuula; pronoto striis lateralibus integris, postice approxinatis; clytris margine 1sulculo, muctalo, striis 4 dorsalibus integris, 5a el suturali abbreviatis; mopygidio bifoveolato pygidionue dense munctatis; mesosterno cmurginato, stria integra; tibiis anticis 5-dentatis, posticis biseriatim spinosis, elongatis. Long. 9-6 mill.; larg. 6-4 nill.

Hister calaverinus E. H. 1, 34, 2, pl. 1, f. 2 (1803). - Sturu, Deuts. Fu. 1, 194, 4.-Payk. Mon. Hisı. 21, 12, pl. 2, f. 8.-Steph. Illust. Brit. 3, 145, 4.-Er. Kaf. Brand. 1, 656, 3.-Héer, Fn. Helv. 1, 454, 6. Küst. Kæf. Eur. 6, 54.-Redt. Fı. Austr. 2, 33.-Bach. Kirf. Pl'ts. 1, 302, 8.

II. brunneus, Illig. Kael. Pr. 5̌̉, 4 (1798). - Gyll. Ins. snec. 1. 75,2 .

11. immessus, F. Syst. El. 1, 85, 6 (1801).

11. transversulis, Dufts. Fu. Austr. 1, 214, 8 (1805).

Ovale, assez comvere, noir, luisant, pointillé. Antenucs brun de poix, massue grise. Tete petite, arrondic; frout plan, strie sinuée en devant et quelquefois interrompuc; labre petit; mandibules sausdents, courbées en pointe. Pronotum court, courbe à la base aree une ligne antéseutellaire; 
arqué sur les côtés, échancré et rétréci en devant, avec les angles abaissés, assez aigus; stries latérales presque entières, interne coudée légèrement et rapprochée de l'externe, non interrompue. Ecusson petit, triangulaire. Elytres beaucoup plus longues que le pronotum, de sa largeur à la base, dilatées à l'épaule, droites et peu rétrécies au bout, avec une impression subapicale; bord inlléchi 1-sillonué, fortement ponctué; stries ponctuées peu régulières, subhumérale externe raccourcie, dorsales $\mathbf{1 - 4}$ entières, rapprochées par paires, cinquième et suturale obsolètes, courtes. Propygidium bifovéolé, couvert de points serrés; pygidium encore plus densément, mais moins fortement ponctué. Prosternum en carène très obtuse, peu élargi à la base, lobe court, bordé, incliné. Mésosternum échancré, rebordé. Jambes antérieures garnies de cinq dents, l'extrême bifide; postérieures garnies de $7-8$ paires de denticules épineux, étroites et allongées.

l.'llister brunneus de Fabricius est un mélange d’individus appartenant à plusieurs espèces dont la coloration est incomplète. Cet auteur a donné le nom de $\boldsymbol{H}$. impressus à certains individus de l' $\boldsymbol{H}$. cadaverinus dont la taille est plus petite, et qui ont denx petites impressions sur le pronotum.

Cette espèce est commune et très répandue dans toutes les contrées de l'Europe. Elle vit dans les fumiers, les charognes, les champignons pourris; dans le suc qui suinte des plaies des arbres.

\section{H. FOEDATUS.}

Brevitcr ovalis, mornm convexus, niger, nilidus; antennis rufis; stria fromtali subsinuulu; monoto stria luterali crternu in medio, interna basi abbreviatis; elylris margine inflero 1sulcato pare munctalo; stria subluumerati profunda, 1-3 dorsa- 


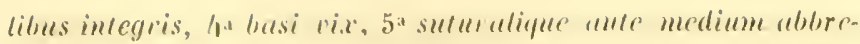

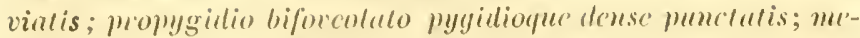
sosterno simunto, maryimuto; tibiis unticis 6-dentutis, posticis biscrutim mullisprimosis. Long. 6 mill.; larg. / 1/2 unill.

Hister foctutus, Le Conte, N. Amér. Ilist. 20, 9, pl. 2, tig. 8 $(1845)$.

Ovale court, pen convexe, d'un noir de poix luisant, finement pointillé, plus distinctement dans son pourtour. Antennes brunes, funicule plus clair, massue grise. Tête petite, arrondie; front plan; stric entière subsinuée en avant; labre petit, subsinué; mandibules édentées, à pointe aiguë. Pronolum court, beaucoup plus large que long, arqué à la base arec une petite strie antéscutellaire, courbé sur les cơtés, rétréci et échancré en devant, avec les angles abaissés, assez aigus; stries latérales bien marquées, ponctuées: externe rapprochée du bord, courte ; interne presque entière, arrondie à l'angle antérieur, non interrompue en devant. Ecusson petit, triangulaire. Elytres courtes, un peu plus longues que le pronotum, de sa largeur à la base, curvilinéaires sur les côtés avec les épaules un peu saillantes, rétrécies et un peu obliques au bout, avec une impression subapicale superficielle; fossette sublumérale distinctement, mais peu densément ponctuée, 1-sillonnée; strie subhumérale crénelée, lorte, recourbée et plus large sous l'épaule, atteignant presque la base; 1-3 dorsales entières, crénelées et très fortes, première et deuxième arquèes l'une vers l'autre à la base et se joignant presque, troisième plus profonde a la base, quatrième un peu raccourcie; cinquième et suturale n'alteignant pas le milieu, celle-ci un peu plus longue que celle-là. Propygidium bilovéolé, fortement et densément ponctué, comme le pygidium. Prosternum en carène obtuse, élargi à la basse, lohe court, reborlé, 
incliné; mésosternum légèrement échancré, avec une stric marginale entière. Jambes antérieures dilatées, garnies de cinq ou six petites dents, extrême bifide; postérieures de sept ou huit paires de denticules épineux.

Etats-Unis; partout dans les bouses.

\section{H. TERRICOLA.}

Oblongo-ovalis, subconvexus, niger, nitidus; umemis mfis; stria frontali subsinuata; pronoto striis luteralibus antice jumetis, externa in medio, intcrna basi abbreviatis, hac interrupta; clytris fossa marginali 1-sulcata impunctata, striis subhumerali, 1-3 clorsalibus integris, 4-5 et suturali valde abbrevintis; mopygidio subbifoveoluto mygidioque densius punctatis; mesostemo emarginato, stria integra; tibiis anticis 3-dentatis, noslicis biscriatim 4-spinosis. Long. 8 mill.; larg. 5 mill.

Hister tericola, Germ. Sp. S7, 149 (15:4). - Er. Kaf. Brand. 1, 658, 5.-Heer, Fu. Helv. 1, 453, 9. - Redt. Fn. Austr. 233. Bach. Kæf. Pruss. 1, 301, 5.

Ovale allongé, assez convexe, noir, luisant. Antennes roussâtres, scape obscur. Tête médiocre, arrondie: front plan, finement pointillé ; strie entière, bien marquée, subsinuée en devant ; labre transversal, légèrement sinué ; mandibules édentées, à pointe courbée, aiguẻ. Pronotum beaucoup plus large que long, faiblement arqué à la base, avec un point antéscutellaire, courbé sur les côtés, rétréci et échancré en devant, avec les angles obtus, abaissés ; stries latérales réunies en devant, externe rapprochée du bord, raccourcie au milieu, interne coudée latéralement, n’atteignant pas tout à fait la base, interrompue au milieu du bord antéricur. Ecusson petit, triangulaire. Elytres allongées, de la largeur du pronotum à la base, à peine curvilinéaires sur les côtés, épaules saillantes, peu rétrécies au bout, avec une 
lrès légire trace d'impression subapicale; lossette latérale 1-sillonnée, presque lisse; strie subhumérale coulée i l'épaule, un peu raccourcic à la base et terminée en crochet, 1-3 dorsales entières, première et troisième plus fortement enfoncées ì la base; quatrième et cinquième réduites à quelgues points apicaux; suturale ne partant pas toul a fait dı bord apical et ne remontant pas jusqu'au milieu. Propygidium légèrement bifovéolé, couvert d'une ponctuation assez serrée; pygidium plus densément ponctué. Prosternum en carène obtuse, plus dilatíe à la base, lobe court, rebordé, incliné ; mésosternum profondément échancré arec une stric entière. Jambes dilatées, ar'mées de quatre dents assez fortes, extrême bifide; postérieures garnies de quatre ou cinq paires de denticules épineux.

Suisse: Allemagne; Autriche, très rare.

\section{II. INTERRLTUS.}

Oblongo-ovulus, subconvexus, puncticulutus, niger, nitidus ; stria frontuli subsimuata; monoto striis lateralibus untice alisjunctis, postice apmoximatis, cxterma paulo breviori; elytris stria subhumeruli vix abbreviata, 1-4 torsalibus crenatis integris, $5^{\mathrm{a}} \mathrm{ct}$ suturuli upicalibus munctis obsotetis contimuatis, illu busi rudimento anctu, fossu subhumerali munctulatu 1-sulcula; propygidio indistincte bifoveolato mygidiorne sal dense munctatis ; mesosterno emarginato, stria integra; tibiis anticis 6-denticulatis, posticis biseriution multisprinosis. Long. 7 mill.; larg. 4 $1 / 2$ mill.

Hister interruptus, ['alis.-Beauv. 180, pl. 6 b, 8 (1805).

H. obcusulus, Harris. in Trans. Soc. Hartf. $1^{\circ}$ 1. - Le Conte, 17. $3, p$. 2, f. 2.

Ovale allongé, presque parallèle, nédiocrement convexe, noir, luisant, finement pointillé. Antennes brunes, massue 
gris-roussâtre. Tête assez large; front plan; strie entière. subsinuée en devant; labre presque carré; mandibules édentées, à pointe aiguë. Pronotum plus large que long, faiblement arqué et bordé de points à la base, avec une strie courte, antéscutellaire, presque droit sur les côtés, échancré et rétréci en devant, avec les angles abaissés, un peu aigus ; stries latérales séparées en devant, assez peu distantes, rapprochées à la base, externe un peu raccourcie, interıe entière, non interrompue en devant. Ecusson petit, triangulaire. Elytres assez longues, de la largeur du pronotum à la base, légèrement saillantes et dilatées à l'épaule, rétrécies et arquées au bord apical; strie sublımérale coudée à l'épaule, atteignant presque la base: 1-4 dorsales entières, rapprochées par paires à la base, cinquième et suturale raccourcies avant le milieu, mais contiuuées par des points obsolètes, la première en outre avec un rudiment basal; fossette subhumérale 1-sillonnée, pointillée. Propygidium saus fossettes distinctes, couvert d'une ponctuation assez serrée; pygidium encore plus densément ponctué. Prosternum en carène obtuse, élargì à la base, lobe pouctué, bordé et incliné; mésosternum échancré, bordé d'une strie entière. Jambes antérieures dilatées, armées de six dents, extreme bifide, les deux premières très petites; postérieures garnies de luit à dix paires de denticules épineux.

Nota. Un individu présente sur le pronotum deux paires de fossettes bien marquées et régulièrement disposées, ce qui n'est évidemment qu'uıe évolution individuelle, puisque cette disposition ne se retrouve pas daus les autres individus que j’ai pu étudier. L'apparition de ces fossettes disposées même régulièrement se retrouve souvent dans ectlé 
famille, ainsi que te changenent de couleur de noir en ferrugineux.

Etats-Unis, dans les bouses.

\section{H. IERUARIUS.}

Ovalis subparallelus, convexinsculus, niger, nitilus; clavu rufa; stria fromtali simuata; pronoto striis lateralibus integris, postice appraximatis, intervallo punctato, intema profundiare bisinuata; elytris margine inflexo vix munctulato i-sulcato; stria subhumerali et 1-4 torsalibus integris, 5a suturalique dimidiatis; propygidio pygidioque dense punctatis; mesosterno entarginato, stria subinterrupta; tibiis anticis 4-denticulatis, posticis brevioribus dilatatis biseriation multispinosis. Long. 6 mill.; larg. 4 mill.

Hister merdarius, Ent. Hefte, 1. 39, 3, pl. 1, 3 (1803).-Sturn, Deuts. Fn. 1, 179, 5.-Ghl. Ins. suec. 1, 76, 3 - Paykl. Mon. Hist. 22, 13, pl. 3, 1. - Steph. Illust. Brit. 4, 144, 2. - Er. Kæf. Brand. 1, 657, 4.-Heer, Fn. Helv. 1, 455, 8. -.-Le Conte, N. Amér. Hist. 17, 2, pl. 2, f. 1.-Redt. Fn. Austr. 233.-Bach. Fn. Pruss. 1, 302, 9.

H. memnonius, Say. in Soc. Phil. v, p. 32, 1 (1825).

Ovale allongé, presque parallèle, peu convexe, noir, luisant, finement pointillé. Antennes brunes, massue gris-fauve. Tête assez large; front plan; strie entière, bien marquée, sinuée ; labre court subsinué; mandibules édentées, à pointe aiguë. Pronotum beaucoup plıs large que long, légèrement arqué a la base, arec une strie courte antéscutellaire. courbé sur les côtés, rétréci et échancré en devant, aver les angles abaissés, assez aigus; stries latérales entières, rapprochées à la base, recourbées en dedans, interne forte, bisinuée, non interrompue en devant, intervalle ordinairement ponctué. Ecusson petit, triangulaire. Elytres plus longues que le pronotum, de sa largeur à la hase, presque parallèles sur les 3e Série, Tome II. 
côtés, épaules saillantes, un peu rétrécies et obliques au bout avec une légère impression subapicale ; fossette latérale à peine pointillée et unisillonnée; strie subhumérale externe coudée à l'épaule, n'atteignant pas tout à fait la base; 1-4 dorsales bien marquées, légèrement crénelées entières, cependant denxième et quatrième un peu plus courtes à la base, cinquième el suturale raccourcies au milieu. Propygidium couvert de points assez serrés, mais moins encore que ceux du pygidium. Prosternum en carène obtuse, élargi à la base, lobe court, rebordé, infléchi; mésosternum échancré avec une strie presque entière. Jambes antérieures dilatées, armées de quatre dents, extrème bi ou trilide; postérieures courtes, assez larges, garnies de sept ou huit denticules épineux.

Cette espèce se distingue de l'H. cadaverinus par la massue de ses antennes presque toujours rousse, ses jambes antérieures 4-dentées, ses stries protlioraciques plus fortes et leur intervalle plus ponctué, sa fossette subhumérale moins ponctuće, ses jambes postérieures courtes et élargies et par sa forme moins ovale et plus parallèle.

Cet insecte, qui n'est pas commun, se rencontre non seulement en Europe, mais encore dans les autres parties du monde : j'en ai vu des exemplaires de France, d'Allemagne, d'Autriche, des Etats-Unis, et même de Natal. Il vit dans le fumier de poule, dans les excréments de l'homme, rarement dans les bouses; M. Bellevoye m'a remis des individus à tous les degrés de développement trouvés par lui dans des pommes de terre malades. Grâce à cette communication, j’ai pu décrire et figurer de nouveau la larve de cette intéressante espèce, la seule décrite par Paykull. 
92. H. HIRKISH.

Ovalis, frorum convexus, brumneus, furtum nitilus, undique ingose punctulatus; striu frontali subsinunta; monoto striis lateralibus approximatis, utrimpue junctis, subintegris ; elytris fossa taterali muctulate, 1-sulcate; stria subhumerali antice subabbretutu, 1-4 dorsalibus integris, $5^{\text {a }}$ suturalique dimillutis; monygidio mygidioune dense munctulis; mesosterno emarginuto, stria integra; tibiis anticis 5-dentatis, nosticis biseriatim 6-spinosis. Long. 5 mill. ; larg. \& $1 / 2$ mill.

IIister Harisii, Kirlny, Fu. boreali Amer. 15, 124, 173, 2 (1837). - I.e Conte, V. Amér. IIist. 19, 6, pl. 2, f. 5.

Orale, peu convexe, brun, peu luisant, couvert entièrement d'une ponctuation fine et serrée. Antemnes brunes. Tète petite, arrondie; strie entière, sinuée; labre court; mandibules édentées, à pointe acérée. Pronotum court, plus large que long, légèrement, arqué à la base, avec un gros point antéscutellaire, courbé sur les côtés, échancré et rétréci en devant, avec les angles abaissés et assez aigus, stries latérales éloignées du bord, très rapprochées l'une de l'autre, se joignant aux deux extrémités, à peine raccourcies à la base, interne non interrompue, marginale se joignant presque avec celle du côté opposé. Ecusson petit, triangulaire. Elytres plus longues que le pronotum, de sa largeur à la base, à épaules saillantes, rétrécies et presque droites au bord apical; stric subhumérale coudée, raccourcie à la base ; 1-4 dorsales entières, cinquième raccourcie ainsi que la suturale vers le milieu, celle-ci cependant un peu plus longue. Fossette subhumérale unie, sillonnée, ponctuée. Propygidium et pygidium très densément et assez fortement ponctués. Prosternum en carène obtusc, élargi à la base, lobe ponctué, court, rehordé, incliné; inésosternum échancré, bordé d'une strie entière. Jambes antérieures dilatées, 
armées de cinq dents assez aiguës, extrême bifide; postérieures garnies de sept ì huit paires de denticules épineus.

Etats-Unis, dans les bouses.

\section{H. Distixctus.}

Ovalis, convexus, niger, nitidus; antemis pedibusque brun-" neis; fronte plana puncticulata, stria semicirculari; pronoto striis dor sulibus validis integris; elytris margine inflexo 1-sulcato; subhumerali et $1-4$ dorsalibus crenutis integris, $5^{\mathrm{a}}$ brevi, suturali dimidiata; promygidio bifoveolato myidioque parce punctatis; mesosterno simuto, marginato; tibiis anticis 5-6 dentatis, posticis biseriatim 6-7 spinosis. Long. 6 mill.; largeur 4 mill.

Hister distinctus, Er. in Jahr. 1, 143̊, 41 (1834). - Heer, Fn. Helv. 1, 455, 7. - Redt. Fn. Austr. 233. - Bach. Kæf. Pruss. 1, 302,7 .

Ovale, convexe, noir, luisant. Antennes et pattes brunes. Téte petite, arrondie; front plan, pointillé ; strie semicirculaire; labre court; mandibules à peine dentées, courbées en pointe. Pronotum court, arqué a la base, avec un point antéscutellaire, courbé sur les côtés, rétréci et échancré en devant, avec les angles abaissés, assez aigus; stries latérales fortes, entières, parallèles, rapprochẻes, interne non interrompue, ainsi que la marginale. Ecusson petit, triangulaire. Elytres plus longues que le pronotum, de sa largeur à la base, dilatées à l'épaule, rétrécies et obliques au bout, avec une impression subapicale; fossette latérale pointillée, 1-sillonnée; stries fortes, crénelées, subhumérale et 1-4 dorsales entières, quatrième avec un rudiment basal arqué, cinquième très courte, suturale raccourcie au milieu. Propygidium bifovéolé, couvert dle gros points épars, ainsi que lc lygidium. Prosternum assez élevé, élargi à la base, lohe 
court, ponctué, rebordé et abaissé; mésosternum sinué et rebordé. Jambes antérieures garnies de 5-6 dents, extrême bifide; postérieures garnies de 6-7 rangées de denticules épineux.

Autriche; Allemagne; Suisse; très rare.

\section{II. STrgiles.}

Ocalis, subcomrexus, niger, nilidus; stria fromtali mrofunda arcuata, clypeo impresso; pronoto striis sulpuralletis, validis, integris, interna punctis marginatu; chytris fossa marginali 1 sulcate, stria subhmmesuli via abbreviuta, 1-4 dorsalibus integris, à basuli rudimento anctu, ame medium, sulurali in medio ubbreviatis; pronygidio pygidiorpe sat dense punctatis; mesosterno simualo marginatoque; libiis unticis b̆-denticulatis, posticis biscrialim mullispinosis. Long. 4 mill.; larg. 8 mill.

Ilister slygicus, I.e Conte, 入. Amér. Hist. 18, 5, pl. 2, f. 4 (1845).

Ovale, assez convexe, noir, luisant. Antennes brunes. Tête petite, arrondie ; front plan, pointillé, strie semi-circulaire profonde ; épistome impressionné ; labre court, arrondi; mandibules édentées, à pointe aiguë. Pronotum court, heaucoup plus large que long, arqué à la base arec un petit point antéscutellaire, courbé sur les côtés, rétréci et échancré en devant, avec les angles abaissés, obtus; stries latérales fortes, presque parallèles, entières, interne recourbée en dedañs à la base et bordée de points, non interrompue, ainsi que la marginale. Ecusson petit, triangulaire. Elytres plus longues que le pronotum, de sa largeur à la base, curvilinéairement dilatées sur les côtés, rétrécies et obliques an hout, avec une impression subapicale: stries fortes, crénelées, subhumérale un peu raccourcie à la base, 1-4 dorsales entières; cinquieme n’atteignant pas le milieu, avec une 
petite strie basale; suturale un pen plus longue; fossette subhumérale 1-sillonnée, presque lisse. Propygidium fortement et assez densément ponctué, ainsi que le pygidium. Prosternum en carène assez aiguë, peu élargi à la base, lobe courl, rebordé, incliné; mésosternum échancré, bordé I'une strie entière. Jambes antérieures dilatées au bout, armées de cinq petites dents, l'apicale bifide; postérieures garnies de sept ou huit paires de denticules épineux.

Etats-Unis, dans les provinces méridionales.

\section{H. GRATIOSIS.}

Oblongo-ovatus, convexns, niger, nitilus; stria frontuli subsimual $x$; pronolo cilialo, striis lateralibus inteyris; clylris stria subhumeruli purum abbreviala, 1-3 dorsalibus inlegris, 4-5 unte, suturali in medio abbrevialis, postice dilatatu magnu rubra macula; fossa subhumerali mmctulata bisulcala; propygidio pygidiogne dense punclatis muctirnlatisque; mesosterno cmarginato, stiva integra; lubiis anticis b-tlentatis, posticis 4-5 biscriutim spinosulis. Longueur 6 mill.; larg. 3 3/4 mill

Ovale oblong, convese, noir, luisint. Antennes brunes, funicule rouge. Tête assez grande ; front large, plan, pointillé, strie forte, entière, subsinuée; labre court; mandibules subdentées en dedans, arquées et aiguës au bout. Pronotum plus large que long, légèrement arqué à la base, avec un point antéscuteliaire, courbé sur les côtés, rétréci et échancré en devant, avec les angles abaissés, obtus, cilié de poils jaunes longs et serrés ; stries latérales entières bien marquées, assez distantes. Ecusson petit, triangulaire. Elytres plus longues que le pronotum, le sa largeur à la base, dilatées à l'épaule, un peu rétrécies el coupées droit au boul; strie subhamérale coudée el un peu raccourcie à Ia base ; $1-3$ dorsales entières, fortes el crénelées, quatrième 
raccourcie avant le milieu, cinquième un peu plus courte; suturale atteignant le milieu; une tache rouge, elargie postérieurement, occupe tout le milieu de l'élytre de la première dorsale à la suturale et du tiers aux $5 / 6$ de la longueur; fossette sublumérale bisillonnée, ponctuée. Propygidium couvert d'une ponctuation forte, assez serrée et entremêlée de points plus petits. Pygidium ponctué de même. Prosternum court, arrondi à la base, lobe allongé, rebordé et abaissé; mésosternum profondément échancré, bordé d'une strie entière. Jambes antérieures dilatées et armées de cinq dents larges et assez fortes; postérieures garnies de quatre à cinq paires de lenticules épineux, terminées en dessous par une couronne serrée de courtes épines.

Mongolie; Sibérie (Kiatka).

\section{H. Bivotatis.}

Oblongus, subcylindricus, niger, nilidus; strie frontali subsinnatu; monoto stive lateruli externu abbieviata, interna haul intermpta; elytris muryine inflero 1-sulcato tevi, stria subhumerali abbreviala, 1-3 dorsalibus el sulurali inlegris, 4-5 brevibus, mucula lriangulari rubra; mopygidio yrosse, pygidio densius muctutis; mesosterno enarginato, striu integra; libiis unlicis 4-tentulis, posticis biscriatim 4-spinosis. Long. 5 mill.; larg. 3 mill.

Hister binolutus, Er. in Jahr. I, 145,45 (1834). - Heer, Fn. Helv. 1, $15.5,10$.

Oblong, subcylindrique, noir, luisant. Antennes brunes. Tête assez grosse, pointillée; front plan, assez large; strie forte, entière, sinuée ; labre petit ; mandibules subdentées, courbées en pointe. Pronotum plus large que long, presque droit à la base, avec un point antéscutellaire, peu arqué sur les rôtés, rétréci et échancré en devant arec les angles 
abaissés, assez aigus; strie latérale externe raccourcie au milieu, interne entière, non interrompue. Ecusson petit, triangulaire. Elytres beaucoup plus longues que le pronotum, de sa largeur à la base, Aroites et peu rétrécies au bout, avec une faible impression subapicale; bord infléchi imponctué, 1-sillonné, sans fossette; strie subhumérale externe un peu raccourcie par derrière, 1-3 dorsales entières, 4-5 très courtes, suturale n'atteignant pas tout à fait la base; taclıe rouge triangulaire au milieu traversant les 1-5 interstries. Propygidium couvert de gros points espacés; pygidium densément et finement ponctué. Prosternum en carène étroite, élargi à la base, lobe court, rebordé, peu abaissé; mésosternum échancré, strie entière. Jambes antérieures 4-dentées; postérieures garnies de 4-5 paires de denticules épineux.

France méridionale; Espagne; Suisse; très rare.

\section{H. FURCIPES.}

Ovalis, convexintsculus, niger, nitidus, antemis fulvis; fronte plana, stria recta integra; pronoto striis 2 lateralibus integris, moximis; elytris fossa marginali 3-sulcata, stria subhumerali brevi, 1-3 alorsalibus integris, $4^{\text {a }}$ apicali, ceteris mullis; propygidio mygidioune basi parce ocellato-punctatis; mesosterno emarginato, stria obsoleta; tibiis anticis valide 3-dentatis, posticis hiseriatim 5-6 spinosis. Long. 10 mill.; larg. 7 mill.

Ovale, assez convexe, noir, luisant. Antennes brunes, massue gris-roux. Tête grosse; front large, plan, strie entière, bien marquée, droite; labre arrondi; nandibules dentees, courbées en pointe aiguë. Pronotum court, bisinué à la base avec une ligne antéscutellaire, oblique sur les côtés, très rétréci et échancré en devant, avec les angles abaissés, aigıs: stries ldtéralcs fortes, entières, parallèles, 
rapprochées du bord et l'une de l'autre, interwe non interrompue. Ecusson petit, triangulaire. Elytres à peine plus longues que le pronotum, de sa largeur à la base, curvilinéairement dilatées à l'épaule, rétrécies et droites au bout, avec une impression subapicale; Cossette marginale profonde, 3-sillonnée; strie subhumérale très courte ; 1-3 dorsales entières, quatrième très petite, les autres nulles. Propygidium bifovéolé, courert à la base, ainsi que le pygidium, de gros points ocellés éfrars. Prosternum assez large, lobe court, rebordé, peu abaissé; mésosternum échancré, bordé d'une stric obsolète au milieu. Jambes antéricures armées de trois dents, dont les deux terminales forment de longs crochets; postérieures garnies de 5-6 paires de denticules épineux.

Inde?(M. Deyrolle).

\section{H. Sibiricis.}

Ovalus, subconvexus, niger, nitidus; antemis rufis; striu frontali simuata integra; pronoto striis lateralibus abbreviatis; elytris stria subhumerali utrinque valde abbreviata, dorsalibus 1-3 crenatis integris, 4-5 suturalique brevissiuis, margine inflexo bisulcato; mesostcrno emarginato, stria integra; propygidio bifoveolato sparsim, myidio dense punctatis; tibiis anticis 5-6 denticulatis, posticis biseriatim multispinosis. Iong. 8 mill.; larg. 6 mill.

Orale, assez convexe, noir, luisant. Antennes brunrouge, massue plus claire. Tête assez grande, arrondie; front plan, stric bien marquée, entière, sinuée; labre très petit. Yandibules larges, bidentées, concaves, à pointe courbe, aiguë. J'ronotum beaucoup plus large que long, presque droit et bordé de points à la base, avec une ligne antéscutellaire, légèrement arqué sur les cotés, rétréci et 
échancré en devant avec les angles assez aigus, abaissés; stries latérales fortes, externe assez rapprochée du bord, raccourcie; interne presque entière, non interrompue en devant. Ecusson petit, triangulaire. Elytres beaucoup plus longues que le pronotum. de sa largeur à la base, curvilinéaires sur les côtés, rétrécies et coupées droit au bout, avec une légère impression subapicale; strie subhumérale très courte, 1-3 dorsales entières, crénelées, 4-5 très courtes apicales; suturale plus longue, n'atteignant pas le milieu; fossette latérale bisillonnée, sans points. Propygidium faiblement bifovéolé, couvert de points espacés; pygidium plus densément ponctué. Prosternum en carène étroite, peu élargi à la base, lobe court, ponctué, rebordé et peu abaissé ; mésosternum échancré, bordé d’une strie entière doublée sur les côtés d'un court rudiment de deuxième strie. Jambes antérieures dilatées, armées de 5-6 petites dents, extrêne bifide; postérieures garnies de huit à dix paires de denticules épineux.

Sibérie ; Daourie.

\section{H. GeIIINI.}

Ovalis, subconvexus, niger, nitidus; stria frontali profunda semicirculari; pronoto stria laterali externa busi abbreviata, interna subintegra; elytris stria subhumerali brevi, 1-4 dorsalibus integris, crenulis, 5a ante medium, sulurali versus busim abbreviatis, fossa laterali -sulcala punctuta; mopygidio tifoveolato pygidioque pare punctato; mesosterno emurginato, stria integra; tibiis anticis 3-dentatis; posticis biseriatim multisprinosis. - Long. 6 1/2 mill.; larg. $43 / 4 \mathrm{mill}$.

Ovale, assez convexe, noir, luisant. Antennes brunes, massue roussâtre. Tête grande, large; front plan, pointillé: strie forte, entiere, semi-rirculaire: labre court, arrondi. 
Mandibules subdentées, courbées en pointe aiguë. Pronotum beaucoup plus large que long, presque droit et hordé de points à la base, oblique sur les côtés, échancré et fort rétréci en devant, avec les angles abaissés et aigus. Stries latérales fortes, crénelées, interne à peine raccourcie, non interrompue, externe un peu plus courte. Ecusson petit, triangulaire. Elytres plus longues que le pronotum, de sa largeur à la base, dilatées à l'épaule sur les còtés, rétrécies et arquées obliquement au bout avec une impression subapicale; stric subhumérale externe très courte; dorsales fortes, crénclées, 1-4 entières, cinquième très courte apicale, suturale dépassant le milieu; fossctte latérale bisillonnée, assez fortement ponctuée. Propygidium bifovéolé, couvert de points forts, espacés ; pygidium un peu plus faiblement et aussi plus deusément ponctué à la base, presque lisse au bout. Prosternum en carène très obtuse, peu élargi à la base, lobe court, rebordé, peu incliné; mésosternum échancré, bordé de deux stries, l'une entière, l'autre interrompue. Jambes antérieures, armées de trois fortes dents; postérieures garnies de sept ou huif denticules épineux.

Sénégill.

\section{H. Coracinus.}

Ovalis, subroncerus, niger, nilidus; amlemmis brunneis, funiculo rujo; stria fromlali antice recta; mowoto antice bisinualo, stria laterali inerna integra, externa ame metium abbreviata; elylris stria subhumerali brevi, 1-ỏ dorsatibus integris, Ца lale interruplu, ju suturalique brevissimis; fossa lalerali 3-sulcata; postermo bistriuto; mesosterno sinuato murginutoque; mropygidio bifoveolato mygidioqur basi furce munclatis ; libies antiris 3-tenlalis, postiris hiseralim multispimosis, Long. s mill.; larg. $31 / 2$ mill.

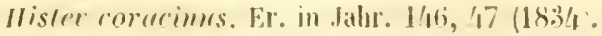


Ovale, assez convexe, noir, luisant. Antennes brunes, funicule roussâtre. Tête assez grande, arrondie; front plan; strie bien marquée, entière, droite en devant; labre court; mandibules édentées, à pointe recourbée, aiguë. Pronotum beaucoup plus large que long, droit à la base, légèrement arqué sur les còtés, rétréci et échancré en devant, bisinué dans l'échancrure, avec les angles abaissés, peu aigus; strie latérale interne non interrompue, externe n’atteignani pas le milieu. Ecusson petit, triangulaire. Elytres plus longues que le pronotum, de sa largeur à la base, dilatées à l'épaule, rétrécies et obliques au bout avec une impression subapicale ; fossette marginale 3 sillonnée ; strie subhumérale arquée, très raccourcie surtout par derrière; 1-3 dorsales entières, quatrième largement interrompue, ou plutôt conıposée de deux courts rudiınents, l'un basal, l'autre apical, cinquième très courte, suturale un peu plus longue, ne partant pas du bord apical. Propygidium couvert de points très espacés, bifovéolé; pygidium ponctué à la base, lisse sur le reste de sa surface. Prosternum en carène très obtuse, élargi à la base, lobe court, rabattu et rebordé; mésosternum échancré, bordé d'une strie entière. Jambes antérieures armées de trois dents assez fortes: postérieures garnies de sept ou huit paires de denticules épineux.

Inde : Pondichéry.

\section{H. Silnnels.}

Ovalis, subparallelus, depressiusculus, brumeus; fromtuli stria recta; pronoto lateralibus integris; elytris subhumerali utrinque value abbreviata, cateris integris, 5 a dorsali cum suturali busi junctu; fossu luterali i-suleate, muctulula; propygidio mygidioque munctulatis; messosterno subsimnato: tibiis an- 
licis 4-elentutis, mosticis biseriatim 7-8 sprinosis. 1.0ng. 3 mill.; larg. I $2 / 3$ mill.

Ovale parallèle, légèrement déprincé, brun, luisant. Antennes brunes. Tête assez grande; front plan; strie frontale entière bien marquée, droite par devant; labre court; mandibules bidentées, creusées en goutiière, à pointe recourbée, aiguë. Pronotum plus large que long, coupé droit à la base, arqué sur les côtés, échancré et rétréci en devant, arec les angles abaissés, obtus; stries latérales entières, parailèles, distantes, externe rapproclıée du bord. Ecusson petit, triangulaire. Elytres plus longues que le pronotum, de sa largeur à la base, ì peine arquées sur les côtés, droites et peu rétrécies au bord apical; strie subhumérale courte, arquée, raccourcie de part et d'autre, mais surtout postérieurement; toutes les stries bien marquées, entières, suturale réunie à la base à la cinquième dorsale ; fossette latérale 3-sillonnée, ponctuée. Mésosternum à peine sinué, bordé d'une strie entière. Jambes antérieures 4-dentées, aplaties, dilatées; postérieures garnies de 7-8 paires de denticules épineux.

Turquie d'Asie (Smyrne) (M. Cherrolat).

Espèces que je n'ai pas vues.

5o. 89'. H. mis-5-strintus. Germ. Mag. Ent. 1 a, 120,8 (1813).

Pronoto lateribus sesqui striatis, ater, nitidus; elytris extrotsum 5-striatis; tibiis anticis dilatatis, 3-striatis. - Amérique.

strie frontale semi-circulaire. Pronotum fort rétréci par devant, strie latérale interne entière, non interrompue en devant, externe raccourcie au milieı. Strie sublıumérale des 
élytres raccourcic par derrière, humérale fine, oblique, 1-4 dorsales obliques, cinquième et suturale très courtes; dessus lisse, noir, luisant. Pygidium fortement et vaguement ponctué. Jambes antérieures très comprimées, garnies de trois dents aiguës.

Très voisin du $H$. carbonarius par la taille et le faciès.

50. 90'. H. Refletus. Le C. N. Amer. Hist. 19, 7, pl. 2,6 (1845).

Punclatus; monoto striis integris, requalibus, interstitio angusto; elytris striis ommibus dorsulibus el suturali integris, huc antice incmevata, subhumerati postice abbteviata; tibiis anticis 5-dentatis. Long. 7 mill. - Etats-Unis, provinces méridionales.

Noir de poix, luisant, très pâle en dessons, ponctué dessus et dessous. Front avec une strie sinuée en devant. Pronotum avec les deux stries latérales rapprochées du bord, entières, interne courbée par derrière, intervalle étroit. Elytres à 1-4 dorsales entières, cinquième courbée en devant, réunie postérieurement quelquefois arec la précédente, un peu raccourcie à la base, ainsi que la suturale, deux latérales. Bord antérieur du mésosternum profondément échancré. Pattes noires, jambes antérieures armées de cinq dents, l’antérieure obtuse, plus grande.

$$
5^{\circ} 91 \text {. H. LIMUNis. }
$$

Subdepressus, ater, nitidus; pronoto ulrinque bistriato; clytris striis dorsalibus 1-4 integris, 5ّa el sumbli abbreviatis, subhumerali subintegia; tibiis anticis subserratis. Long. 7 mill. - Amérique boréale.

Hister immunis, Er. in Jahr. 1, 148, 39 (1834).-Le C. 1. Amél. Hisı. 18, 4, pl. 2, 3.

Tris voisin du H. merdarius, mais plus court, plus aplati, 
arec les épanles moins saillantes. Pronotum un peu plus rétréci en devant, avec les angles antérieurs un peu moins saillants. Sur les élytres la strie suturale est plus raccourcie que la troisième dorsale. Les pattes sont d'un brun rouge; les jambes antérieures larges, arrondies avec six ou sept denticules obtus.

50. 98'. H. Catugrousts. Steph. lil. Brit. Ent. 3, 152, 21 (1830).

Snboblongus, atcr, nilidus; clytris striis 3 intcgris, 3 abbreviatis; tibies anticis ö-dentalis, dente extimo bifido, antennarum clava ferruginea. Long. 6 mill.

Plus long, d'un noir foncé, très luisant. Pronotum avec une strie latérale plus forte, ponctuée, et un court rudiment à l'angle antérieur. Il y a à la base et sur la marge latérale des petits points espacés. Elytres avec une strie subhumérale courte, basale, 1-3 dorsales entières, 4-5 réunies postérieurement très raccourcies, suturale un peu moins. Pattes noires; jambes antérieures avec cinq dentelures, extrême bifide. Antennes d'un noir de poix, massue ferrugineuse.- Urı seul exemplaire trouvé près de Londres. 



\section{ESSAI MONOGRAPHIQUE}

\section{SUR LA FAMILLE DES HISTERIDES.}

(Suite) (1).

Par M. S. A. de MARSEUL.

(Séance du 9 Février 1853.)

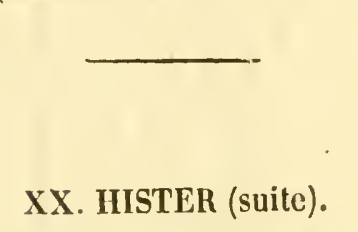

Soc. Ent. , 3e Série, T. 2 (1854), pl. VI à X. - Mon. pl. VIII à XII. Genre XX.

(1) Voyez $3^{3}$ Série, T. I (1853), p. 131 et 447, et T. II (1854), p. 161. 


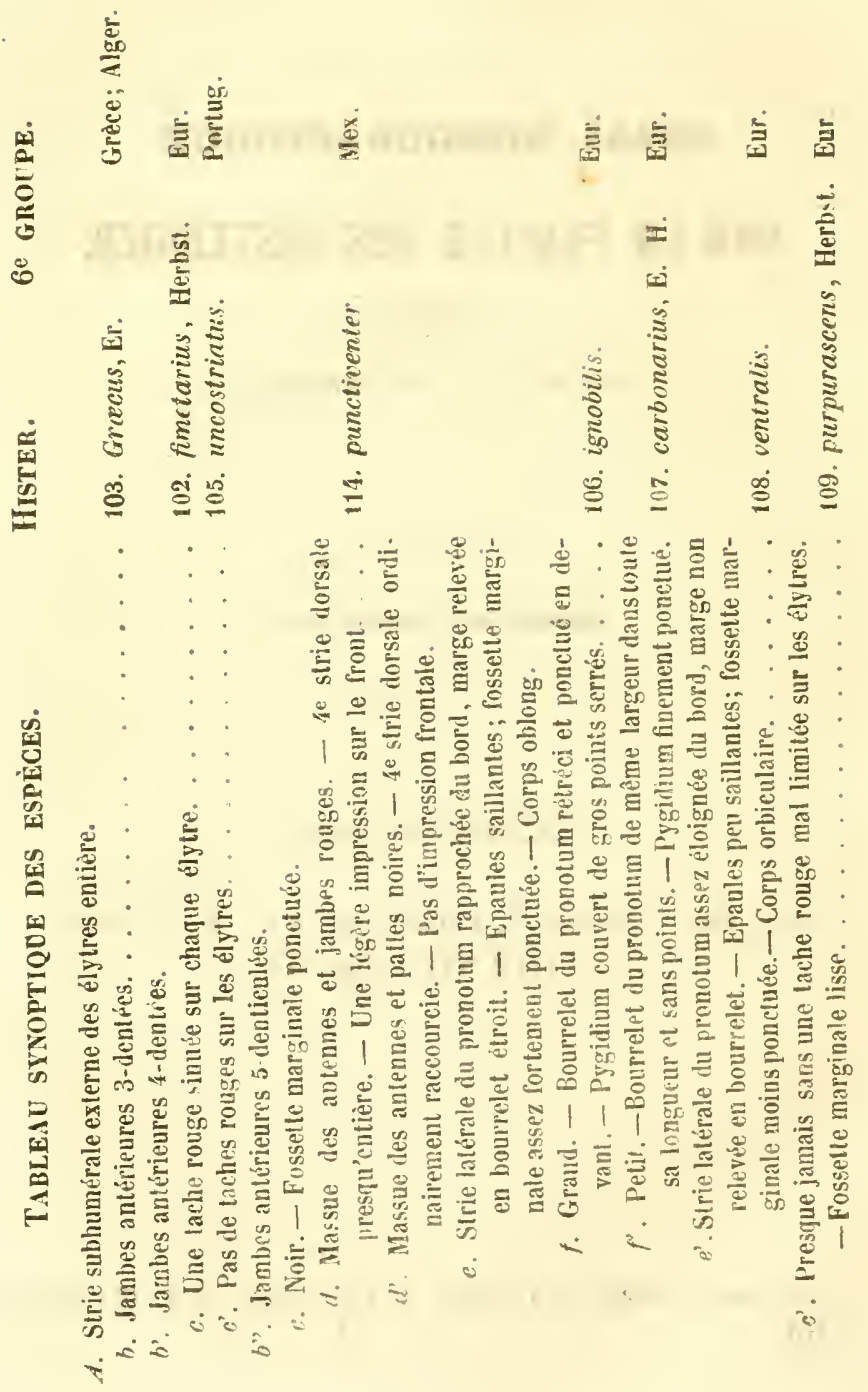




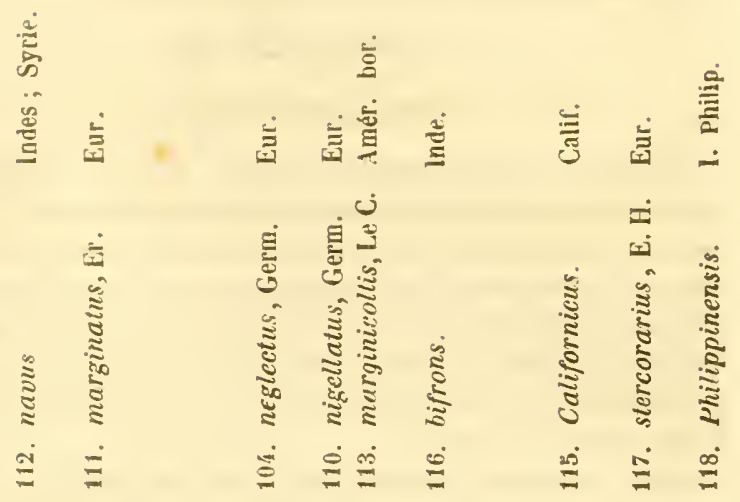

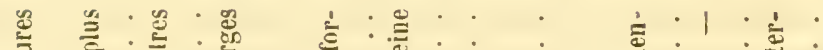

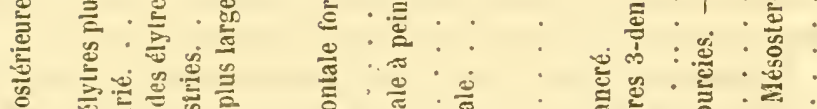
总

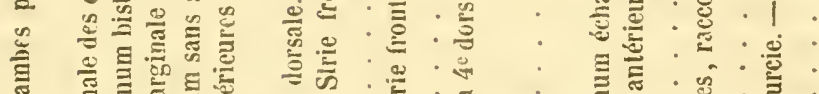

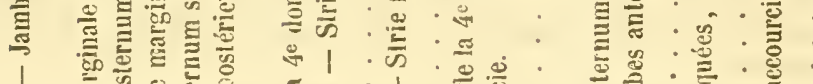

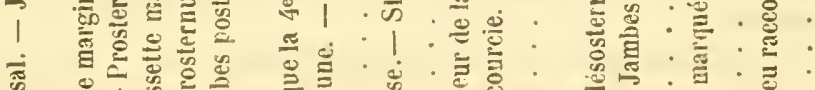

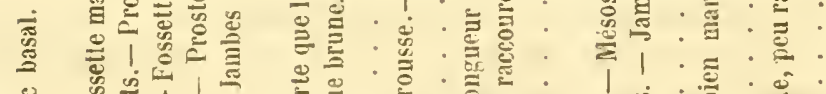

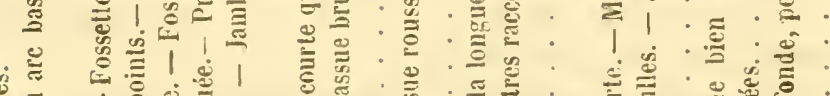

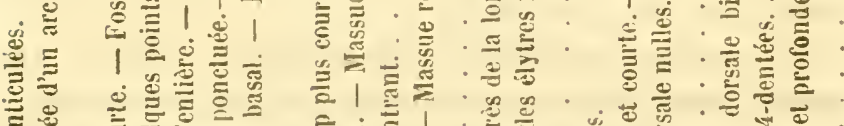

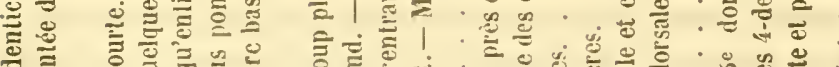

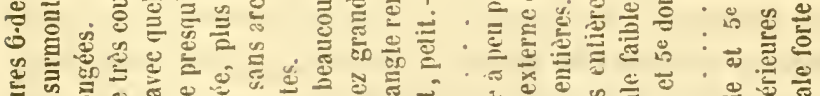

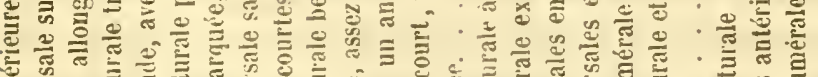

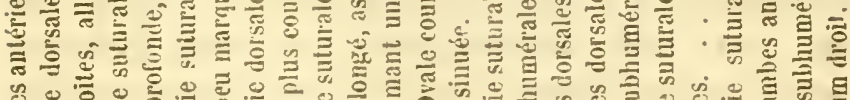

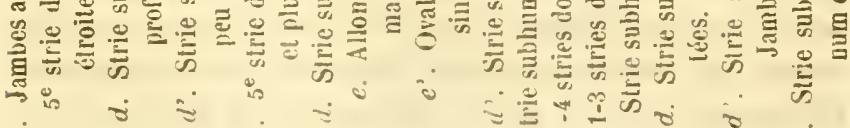


b'. Une seule strie latérale au pronotum.

$$
\text { 6e Groupe (102-118). }
$$

\section{H. FIMETARIUS.}

Oblongus, converiusculus, nigor, nitidus, puncticutatus; stria frontuli integra; pronoto stria laterali integra, basi arcuata; elytris margine inflexo 1-sulcato, punctulato, stria subhumerali et 1-3̊ dorsalibus integris, $4^{\text {a }}$ et suturali abbreviutis, macula obliqua utrinque sinuata rubra; propygidio pygidioque sat dense punctatis; mesostcrno profunde emarginato, stria integra; tibiis anticis 4-dentatis, posticis biseriatim 5-6 spinosis. Long. (j. mill.; larg. 4 1/2 mill.

Hister fimetarius, Herbst, Nat. Syst. 4. 27, pl. 35, f. 3 (1791). - E. H. 1. 48, 7. - Sturm, Deut. Fiı. 1, 205, 9. - Payk. Mon. Hist. 41, 29, pl. 12, f. 6.- Fiscl. Ent. Russ. 1, 206, 6.

H. sinuatus, F. Ent. Syst. 1, 75, 15 (1792). Syst. El. 1, 87, 17. - Illig., Mag., 1, 317, 27.-Er. Kæf., Brand., 1, 658, 6. - Dufts., Fu., Aust., 1, 212 , 5. - Heer, Fu., Helv., 1, 455, 12. - Küst.,

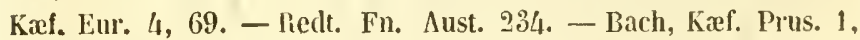
$303,12$.

II. Illigeri, Duft. Fn. Aust. 1, 213, 6 (1805).

II. bipustulatus, Ol. Ent. 1, 10, 9, pl. 2, 19. - Panz. Ent. Germ. 1, 23, 19. - Fu. 80, 3.

Ovale oblong, assez convexe, noir, luisant, pointillé. Antennes brunes. Tete grosse ; front large, plan, strie entic̀re, bien marquée, droile en devant; labre arrondi; mandibules dentées, courbées en pointe. Pronotum plus large que long, presque droit à la base, avec un point antéscutellaire, oblique sur les côtés, échancré et un peu rétréci en devant, avec les angles abaissés, oblus; strie latérale interne unique, entière, en crochet à la base. Ecusson petit, triangulaire. Elytres plus longues que le pronotum, de sa largeur à la base. curvilinćaires sur leś côtés, rétrécies et droites au 
bout avec une faible impression subapicale; fossette marginale 1-sillonnée, pointillée; strie subhumérale et 1-3 dorsales entières, quatrième apicale, suturale raccourcie au milieu; tache rougc orale, hisinuée, comme composée de deux accolées dont l'interne un peu plus basse, s'étendant sur les 1-5 interstries. Propygidium couvert de points ŕpars; pygidium asșez densément ponctué. Prosternum en carène obtuse, élargie à la base, lobe court, rebordé, un peu alıaissé; mésosternum profondément échancré, strie entière. Jambes antérieures armées de quatre dents, extrême bifide; postérieures garnies de 5-6 paires de denticules épineux.

France, Belgique, Suisse, Allemagne, Autriche, Volhynie, Russie; dans les bouses, le crottin etles charognes; assez rare.

Erichson, dans sa faune d'Allemague, a cru devoir changer le nom de $H$. fimetarius donné à cette espéce par Herbst en 1791 et admis depuis lors par Paykull et les autres entomologistes et adopter celui de H. simuams publié par Fabricius, dans son Entomologie systémalique en 1792. Mais je n'ai pu me ranger à cet avis, puisque ce dernier nom est postérieur au premier.

\section{H. GR ECES.}

Oblongus, comvexus, niger, nitidus; mncticulatus; fronte latu, stria integra; mronoto stria laterali unica integra; clytris margine inflexo 1-sulcato, stria sublumneruli et 1-3 dorsulibus integris, coteris obsoletis brevibus; mopygidio mygidioque sat dense mmetatis; mesosterno emaryinato, stria integra; tibie anticis 3-dentatis, posticis biscriatim 5-6 spinosis. Jong. 12-9 mill. ; larg. S-6 nill.

Ilister grocus, Brul. Expéd. Joríe. 157, 2/2, pl. 36, 10 (1899). - Er. iı Jahı. 1, 192, 35.

Allongé, convexe, noir, luisint, pointillé. Antemen 
brunes, massue grise. Tète grosse ; front large, plan, strie entière, subsinuée, labre semicirculaire, enfoncé; mandibules fortes, dentées, courbćes en pointe. Pronotum plus large que long, arqué à la base, avec une ligne antéscutellaire, courbé à peine sur les côtés, échancré et un peu rétréci en devant, avec les angles abaissés obtus; strie latérale interne unique non interrompue et coudée derrière les yeux. Ecusson petit, triangulaire. Elytres à peine plus longues que le pronotum, de sa largeur à la base, parallèles, rétrécies et droites au bout; bord infléchi 1-sillonné, sans fossette; stries plus ou moins obsolètes, peu régulières, subhumérale et 1-3 dorsales entières, les autres courtes ou nulles. Propygidium et pygidium couverts $s_{d}^{\natural}$ de forts points serrés. Prosternum assez large, arrondi à la base, lobe court, large, ponctué, rebordé, presqu'horizontai; mésosternum échancré, bordé d'une strie entière et d'une interrompue. Jambes antérieures armées de trois fortes dents, extrême bifide; postérieures garnies de 5-6 paires de denticules épineux.

Il se trouve de mars en juin dans les bouses, sur tout le littoral de la Méditerranće : Grèce (Corfou, Morée); Syrie (Smyrne, Beyrouth); Algérie (Alger, Oran, Médéah, Boghar); Tripoli; Tanger.

\section{H. NEGLECTIS.}

Oblongo-ovatus, subconvexus, niger, nitirlus; striu fromali simuata; monoto striu laterali internt integra; clytris striis 1-3 dorsalibus integris, subhumerali el $4^{a}$ dorsali vix basi, $5^{\text {a }}$ ante medium et suturali uttra medium abbreviatis, fossu marginali 1-sulcate, munctata; mesostermo simuato marginato; tibiis anticis 6-denticulutis, postiris biseriatim 6-7 spinosis. Loug. 6 mill. ; larg. \& $1 / 2$ mill. 
Hister neglectus, Germ. Mag. Ent. 1, 120, 7 (1813). - Steph. III. Brit. EIt. 3, 150, 14. - Heer, Fn. IIelv. 1, 456, 12. - Küist. Kaf. Eur. 13, 19. - Fedt. Fu. A ust. 234. - Bach, Kæf. Prus. 1, 303, 14.

II. Leachii, Stephl. Ill. Brit. Ent. 3, 150, 15 (1830).

Ir. quisquilius, Steph. 13l. Brit. Ent. 3, 151, 17 (1830).

Ovale allongé, peu convexe, noir, luisant. Antennes brunes, funicule rouge. Téte médiocre, arrondic; front plan, finement pointillé; strie entière, bien marquée, sinuée en devant; labre petit presque carré; mandibules édentées, presque droites. Pronotum beaucoup plus large que long, légèrement arqué à la base, avec une petite strie antéscutellaire, courbé sur les côtés, rétréci et échancré en devant avec les angles abaissés, peu aigus; une seule strie latérale intcrne entière, non interrompue en devant, éloignée du bord latéral. Ecusson petit, triangulaire. Elytres plus longues que le pronotum, de sa largeur à la base, légèrement dilatées sur les côtés, rétrécies et coupées droit au bout; stries fines, ponctuées, bien marquées, subhumérale externe coudée à l'épaule et raccourcie à la base, 1-3 dorsales entières, quatrième atteignant presque la base, cinquième raccourcie avant le milieu, suturale au milieu; fossette marginale 1-sillounée, bien ponctuée. Propygidiun bifovéolé, couvert de points assez scrrés; pygidium encore plus densément ponctué. Prosicrnum cu carène obtuse, élargi à la base, lobe pointillé, rchordé, abaissé ; mésosternum sinué, avec une strie entièrc. Jambes antérieures armées de six petitesdents, extreme bifide; postérieures garnies de sept à huit paires de denticules épineux.

Angleterre, Suèle, France, Allemagne, Suisse, Alger. J'ai vu quelques individus provenant des Indes ct ru Kamsrhatka (Sibérie). 


\section{II. uncostriatus.}

Ovalis, subconvexus, niger, nitidus; stlia frontali semi-circulari; pronoto stria laterali interna unica integra; elytris fossa marginali 1-sulcala, vix punctulata, stria subhumerulict 1-3 dorsalibus integris, 4-5 ct suturali abbreviatis; mopiygidio bifoveolato mygidioque sat dense punctatis; mesosterno simuato marginatoque; tibiis anticis 4-rlentatis, posticis biseriatim 5-spinosis. Long. 4 1/2 mill.; larg. 4 mill.

Ovale, peu convexe, noir, luisant. Antemnes brunes, massue grise. Tete petite, arrondie; front plan, strie semicirculaire, entière ; labre petit. Mandibules subdentées, courbées en pointe. Promotum beaucoup plus large que long, arqué à la base, avec un point antéscutellaire, courbé sur les côtés, rétréci et échancré en devant, avec les angles abaissés assez aigus; strie latérale interne unique entière, assez rapprochée du bord, non interrompue. Ecusson petit, triangulaire. Elytres plus longues que le pronotum, de sa largeur à la base, dilatées à l'épaule, rétrécies et droites au bout avec une impression subapicale; fossette marginale bien marquée, 1-sillonnée, avec quelques petits points; strie subhumérale recourbée en crochet et n'atteignant pas la base, 1-3 dorsales entières, quatrième et cinquième courtes irrégulières, suturale raccourcie au milieu. Propygidium bifovéolé, couvert, ainsi que le pygidium, de points assez serrés. Prosternum en carène obtuse, élargi à la base, lobe court, rebordé et incliné. Mésosternum sinué et bordẻ d'une strie entière. Jambes antérieures 4-dentées, postérieures garnies de .5-6 paires de denticules épineux.

Espagne, Portugal.

106. H. IGNOBIIS.

Ovalis, subcomrems, nigfi, milides ; frome plana, stria sub- 
sinuatu; monoto stria laterali profundu, antice margini elcvatu propiore, in spatio menctato obsoletiore; chylris humcris elcvatis, sub apicem impressis, striis 1-3 dorsalibus integris, 5a apicali, $4^{\text {a }}$ suturalique dimialiatis, fossu marginalil-sulcata, valide munctala; mrorygidio bifoecolato mygidioque fortiten et dense munctatis; mesostcrno emarginato, stria integra; libiis anticis 5-dentalis, posticis biscriatim mullispinosis. I.ongueur $61 / 2$ mill.; larg. $42 / 3$ mill.

Ovale, légèrement convexe, noir, assez luisant. Antenues brunes, funicule rouge. Tìte assez petite arrondic; front plan, stric assez légère, sinuée en devant, entière, quelquefois un peu interrompue; labre petit, arrondi; mandibules sans dents, sans goultière, à pointe courbée, peu aiguë. Pronotum court, beancoup plus large que long, arqué à la base avec un point antéscutcllaire, peu courbè et relevé en bourrelet sur les côtés, rétréci et échancré en rlevant, aver: les angles abaissés, aigus, couverts en dessus d'un espace ponctué ; strie latérale interne unique profonde postérieurement, obsolète et très rapprochée dlu bord antéricurement, non interrompue. Ecusson petit, triangulaire. Elytres une fois et demic plus longues que le pronotum, de sa largeur à la base, fortement saillantes et dilatées à l'épaule, rétrécies et droites postérieusement, avec une impression subapicale; stries ponctuées assez bien marquées, subliumérale à peinc raccourcic à la base, 1-3 dorsales entières, quatrième raccourcie au milieu ainsi que la suturale, cinquième bien plus courte; fossette marginale bien marquée, ponctuée fortement, 1-sillonnée. Propygidium bifovéolé, densément et fortement ponctué, ainsi que le pygidium. Prosternum en carène obtuse, élargi à la base, lobe court, rebordé et infléchi. Mésosternum échancré, bordé d'une strie cntière, et d'une autre interrompue. Jambes antéricures armées de cinq 
dents, cxtrène bifide; postérieures garnies de 5 ou 6 paires de denticules épineux.

France; dans les cadavres, en juin et juillet.

\section{H. CARBONARIUS.}

Ovalis, convexiusculus, niger, nitidus; strice frontali semicivculari; pronoto nurgine angusto lineari clevato, stria laterali intema integra; clytris fossa marginali 1-sulcala, monctata; striis subhumerali el dorsulibus 1-s̀ integris, $4^{a}$ et sulurali ultra medium, 5a ante abbreviatis; propygidio mygidioque sut dense punctatis; mesostorno sinualo marginatoque; tibiis unticis 5-dcnticulatis, posticis biscrialim š-6 spinosis. Larg. 5 mill., larg. 4 mili.

Hister carbonarius, Illig. Kx.. Prus. 1, 53, 3 (1798). - E. H. 1, 54, 10, pl. 1, f. 4. - Sturm, Deuts. Fn. 1, 210, 12. - Gyll. Ins. Suec. 1, 82, 10. - Payk. Mon. Hist. 39, 27, pl. 3, f. 8. - Steplı. Ill. Brit. Ent. 3, 150, 16. - Er. Kie., Brand. 1, 660, 8. - Hcer, Fn. Helv. 1, 456, 13.-K Küst. Kief. Eur. 8, 69.-Redt. Fn. Aust. 23̋4, 16. - Bach, Kæi. Frus. 1, 303, 15.

II. 12-striatus, Fab. S. El. 1, 85, 5 (1801). - Illig. Mag. 6, 33, 6. - Dufts. Fn. Austr. 1, 216, 10.

Ovale, assez convexe, noir, luisant. Antennes brunes, massue grise. Tête petite, arrondie; front plan, strie bien marquée, entière, semicirculaire; labre petit; mandibules subdentées, courbées en pointe. Pronotum court, arrondi à la base avec une ligne antéscutellaire, arqué sur les côtés, rétréci et échancré en devant, avec les angles abaissés, aigus; strie latérale interne unique non interrompue, entière, rapprochée uniformément du bord latéral, sans points en dedans ni à l'angle, marge relevée en bonrrelet. Ecusson petit, triangulaire. Elytres plus longues que le pronotum, de sa largeur à la base, dilatées à l'épaule, curvilinéairos sur les còtés, 
rétrécies et droites an bout, avec une impression subapicale, fossette marginale assez profonde, 1-sillonnée, asfez fortement ponctuće; strie sublıumérale et 1.3 dorsales entières, quatrième raccourcie à la base, ainsi que la suturale, cinquième très courte. Propygidium faiblement bifovéolé, couvert, ainsi que le pygidium, de points peu serrés. Prosternum en carène obtuse, élargi à la base, lobe court, bordé et incliné; mésosternum sinué, bordé d'une strie entière. Jambes antérieures garnies de cinq petites dents, extrême bifide; postérieures de 5-6 paires de denticules épineux.

Cette espèce, très commune dans toutes les contrées de l'Europe, se rencontre dans les fumiers, les charognes et autres immondices. Les auteurs ont confondu sous ce nom plusieurs espèces que j’ai cru devoir séparer. Le H. carbonarius se distingue surlout du $\boldsymbol{H}$. ventralis par sa petite taille, sa forme moins ventrue, l'étroit bourrelet de son pronotum, ses épaules saillantes et sa fossette marginale plus profonde et plus fortement ponctuée; lu II. ignobilis par la largeur uniforme du bourrelet du pronotum, jar l'absence de points à l'angle antérieur et par les points moins serrés et moins forts du pygidium; du II. nigellatus par cette mème ponctuation, par l'absence de stries au prosternum, et par la quatrième dorsale raccourcie.

\section{H. Ventialis.}

Suborbicularis, convcriusculus, niger, nitidus; frontulistriu vix simuata; pronoto stria integra, margine lato, atquali, haud clevalo; elytris humeris hand momimalis, striis 1-3 dorsulibus integris, 4a ultru, $5^{\text {a }}$ ante suluraliyue circa medium abbreviatis; fossu murginali 1-sulcatu pare' munctutu; propigydio pygidioque parmm dense punclutis; tibiis anticis 5-dcnlatis, posticis biscriatim multispinosis. Long. 5 mill.; larg. 4 mill. 
Suborbiculaire, assez convexe, noir, luisant. Antennes brunes, funicule rouge. Tête assez petite, arrondie; front plan, strie entière, bien marquée, à peine sinuée en devant; labre presque carré ; mandibules fortes, sans dents, ni gouttière, à pointe recourbée, aiguë. Pronotum court, beaucoup plus large que long, arqué à la base arec un point antéscutellaire, courbé sur les côtés, avec une marge large, de même diamètre dans toute son étendue et non relevée cn bourrelet, fort rétréci et échancré en devant, avec les angles abaissés, peu aigus ; strie latérale un peu raccourcie à la base, forte, crénelée, parallèle au bord latéral, non interrompue en devant, formant un petil coude postoculaire. Ecussoı petit, triangulaire. Elytres courtes, un peu plus longues que le pronotum, le sa largeur à la base, curvilinéairement dilatées sur les côtés, rétrécies et droites au bout avec une légère impression subapicale; stries bien marquées, crénelées; subhumérale externe à peine coudée à l'épaule, touchant presque la base; 1 -3 dorsales entières, quatrième dépassant un peu lc milieu ainsi que la suturale, cinquième plus raccourcie; fossette marginale parcourue par un sillon, ponctuéc. Propygidium sans fovéoles distinctes, peu densément et peu fortement ponctué, ainsi que le pygidium. Prosternum en carène obtuse, élargi à la base, lobe court, rebordé, infléchi; mésosternum échancré, avec une strie entière Jambes antérieures armées de cinq dents, extrême bifide, postérieures garnies de 5 à 6 paires de denticules épineux.

France, dans les bouses ot les famiers.

109. H. PuRpurascens.

Ovalis, subconvexus, niger, nitilus; fronte stria integra; 
pronoto stria laterali profinuta integra; elytris fossa marginali 1 -sulcutu, leri; striis $1-3$ dorsulibus integris, $4^{\text {a }}$ et subhumerali snbintegris, 5" et suturali versus medium abbreviatis; scepius muculu indeterminata rubra; mropygidio mygidioque dense punctutis; mesosterno sinuato marginatoque; pedibus rufo-brumeis, tibiis anticis 5-denticnlatis, posticis biseriatim mullispinosis Long. 5 mill.; larg. 3 1/2 mill.

Hister murpurascens, Herbst, Nat. Syst. 4, 42, 17, pl. 36, f. 6 (1791). - Pauz., Ent. Germ. 1, 23, 18. - Illig., Kæf. Pr. 1, 54, 5. - Payk. Fu. suec. 1, 38, 4; Hou. Hist. 38, 26, t. 11, f. 7. - F. Syst. El. 1, 87, 18. - Ent. Hefte, 1, 51, 9. - Sturm., Deut. Fn. 1, 208, 11.- Dufı. Fn. Austr. 1, 217, 11.- Gyl., Ins. suer. 1, 81, 9. Steph. Ill. Bril. Ent. 3, 152, 19. -- Er. Kæe. Brand. 1, 661, 10. Heer, Fn. Helv. 1, 45้6, 15. - Küst. Kæf. Eur. 4, 71. - Redt. Fn. Austr. 2333.- Bach., Kxf. Pr. 1, 302, 10.

H. castanipes, Steph. Illust. Brit. Ent. 3, 152, 20 (1830).

Ovale, légèrement convexe, noir, luisant. Antennes brunes arec l'extrémité de la massue roussìtre; front plan à peine distinctement pointillé ; strie bien marquée, entière, subsinuéc en devant. Pronotum court, plus large que long, arrondi à la base, oblique et arqué sur les côtés, rétréci et échancré en devant avec les angles abaissés et assez obtus, finement ponctué surtout latéralement; strie latérale entière, forte, assez rapprochée du bord qui est relevé en bourrelet. Ecusson petit, triangulaire. Elytres une fois et demie plus longues et aussi larges que le pronotum à la base, curvilinéairement dilatées sur les côtés, rétrécies et coupées droit au hout avec une légère impression subapicale; strie subhumérale externe atteignant presque la base; $\mathbf{1 - 3}$ dorsales entières, quatrième ordinairement à peine raccourcie, cependant quelquefois un peu plus courte et d'autres fois entière, cinquième n'atteignant pas le milieu, suturale un plus longue; tache rouge médiane triangulaire, mal terminéc, se 3e Série, Towe 11. 
fondant insensiblement avec la couleur du fond. Dans la var. $\mathbf{A}$, elle s'étend de manière à couvrir toute l'élytre; dans la var. B, elle disparaît complètement; fossette marginale sous le bord infléchi distincte, mais peu profonde, 1-sillonnée et imponctuée. Propygidium et pygidium assez fortement et densément ponctués. Prosternum en carène assez aiguë, élargi à la base, lobe élroit, rebordé, abaissé; mésosternum sinué, strie entière. Pattes d'un brun rouge plus ou moins clair. Jambes antérieures garnies de cinq denticules, postérieures d'une double rangée de nombreux denticules épineux.

Var. A. Tache rouge épanouie et couvrant presque toute la surface de l'élytre.-Hister brunneus, Herbst, Nat. Syst. 4, 35, 10, pl. 35, 10 (1791). - H. castanipes, Steph. Illust. Brit. 4, 38, 4 (1830).

B. Elytres entièrement noires.

Cette dernière variété a les plus grands rapports avec le H. Carbonarius, mais elle s'en distingue aisément par la fossette marginale imponctuée.

Il se rencontre assez communément dans les bouses, fumiers et ordures quelconques, en Angleterre, Suède, Allemagne, France, Suisse, Autriche, Espagne, Portugal et dans la plupart des contrées de l'Europe.

\section{H. NIGELLATLS.}

Suborbicularis, convexỉuseulus, niger, nitidus; clava rufa; stria frontali semicirculari; pronoto margine laterali elevato, stria laterali integra intus punctata; elytris humeris prominulis; fossa marginali 1-sulcata punctata; striis 1-4 dorsalibus integris, 5a ante suturalique paulo ultra abbreviatis; mopygidio bifoveolato pygidioque sat dense et valide muctatis; prosterno basi bistriato, mesosterno sinuato marginatoque; tibiis anticis 6-denticulatis, posticis biseriatimmultispinosis. L. 4 mill.; $1.3 \mathrm{~m}$.

IIister nigellatus, Germ. Spec. Ins. 88, 150 (1824). 
Suborbiculaire, assez convexe, noir, luisant. Antennes brunes, massue rousse. Tete petite, arrondie; front plan, strie bien marquée entière, semicirculaire; labre court, arrondi. Mandibules fortes, sans lents, ni gouttière, à pointe courte, arquée, peu aigguë. Pronotum court, plus large que long, arqué ì la base avec un point antéscutellaire, courbé et relevé en bourrelet sur les còtés, échancré et rétréci en devant, arec les angles obtus; stric latérale forte, entière, non interrompue en devant, parallèle au bord et sans coude postoculaire, bordée en dedans latéralement de quelques points épars, strie marginale à peine interrompue. Ecusson petit, triangulaire. Elytres plus longnes que le pronotum de sa largeur à la base, fortement dilatées et un peu saillantes à l'épaule, rétrécies et obliques au bout, avec une légère impression subapicale; stries bieu marqquées, pnuc:uées; subhumérale externe à peine raccourcie, faibiement arquée à l'épaule; 1 -4 dorsales entières, cinquième raccourcie au milieu, suturale un peu au-delà; fossette marginale 1-sillonnée, distinctement ponctuée. Propygidium bifovéolé, peu densément mais assez fortement ponctué, ainsi que le pygidium. Prosternum en carène obtuse, élargi et bordé d'une petite strie de chaque côté à la base; mésosternum sinué, bordé d'une strie entière et d'une interrompue. Jambes antérieures garnies de six petites dents, extrême bifide; postérieures de 6-7 paires de denticules épineux.

France et Allemagne, dans les bolets pourris.

\section{H. MARGINATLS.}

Ovalis, convexus, niger, nitidus; stria frontali semicirculari; monoto lateribus munctalo, stria integra, margine angusto laterati elevato; elytris mulvinatis ante apicem transverse impressis, striis subhumerali, suturali ct 1-4 dorsalibus integris, $5^{\mathrm{a}}$ in medio abbreviata, fossa marginali punctata, 1-sulcatu; 
propygidio bifoveolato mygidioque farce punctatis; mesosterno sinuato marginatoque; tibiis anticis 6-denticulatis, posticis biseriatim 6-spinosis. Long. 4 1/2 mill.; larg. 3 1/2 mill.

Hister marginatus, Er. in Jahr. 144, 43 (1534); Kæf. Brand. 1, 660. 9. - Heer, Fn. Helv. 1, 456,14. - Küst. Kæf. Eur. 13, 20. - Redt. Fn. Ausır. 234. - Bach, Kæf. Pruss. 502, 13.

Ovale, assez convexe, noir, luisant. Antennes brunes, funicule fauve. Tête petite, arrondie; front plan, avec une trace d'impression longitudinale superficielle, strie semicirculaire; labre assez allongé; mandibules aiguës, édentées en dedans. Pronotum beaucoup plus large que long, arqué à la base, oblique d'abord sur les cotés, puis arrondi, échancré et fort rétréci en devant, avec les angles abaissés, peu aigus; strie latérale interne unique, entière, bien marquée, rapprochée du bord qui est relevé en bourrelet, bordée en dedans de gros points irréguliers. Ecusson petit, triangulaire. Elytres plus longues que le pronotum, de sa largeur à la hase, bombées, avec une inpression subapicale; curvilinéairement dilatées sur les côtés, rétrécies et coupées droit au bout; strie sul)humérale esterne coudée ì l'épaule, àpeine raccourcie à la base, 1-4 dorsales entières ainsi que la suturale, cinquième raccourcie au milieu, avec un petit arc basal ; fossette marginale peu profonde, 1-silonnée, ponctuée. Propygidium très légèrement bifovéolé, couvert d'une ponctuation espacée. Pygidium un peu plus densément pouctué. Prosternum en carène obtuse, élargi à la base, lobe court, rehordé et abaissé; ınésosternum légèrement échancré, bor'dé d'une strie eritière. Jambes antérieures dilatées, armées de six petites dents, apicale bifide; postérieures uninces, allongées, garnies de sept ou huit paires de denticules épineux.

Autriche, Allemagne, Suisse, France, forêt de SaintGermain, sous des fenilles sèches, en mai; très rare. 


\section{H. NAVUS.}

Ovalis, converiusculus, niger, nitidus; striu frontull semicirculari; pronoto stria laterali interna unica integra; elytris fossa murginali 1-sulcula parce punclalata, striis 1-4 dorsalibus integris, 5a urcu basali munitu ct sulurali in medio, subhumerali vix abbreviatis; propygidio bifoveolato pygidioque sat dense punctatis ; prosterno bistriato, mesosterno subrecto marginato; tibiis anticis 6-denticulatis, posticis biseriatim 6-7 spinosis. Long. 4 mill. ; larg. 3 mill.

Orale, assez convexe, noir, luisant. Antennes brunes, massue gris-roussìtre. Tùte petite, arrondic; front plan, strie entière, semicirculaire; labre petit; mandibu'es édentées, recourbées en pointe. I'ronotum courl, arqué à la base, arec un point antéscutellaire, courbé sur les côtés, rétréci et échancré en devant, arec les angles antérieurs abaissés, assez aigus ; strie latérale interne scule, rapprochée du bord, entière, non interrompuc. Ecusson petit, triangulaire. Elytres beaucoup plus longues que le pronotum, de sa largeur à la base, curvilinéairement dilatées sur les côtés, rétrécies et droites au bout avec une impression subapicale; fossette marginale 1-sillonnée, pointillée; strie subhumérale légèrement arquée et forte à l'épaule, n’atteignant pas la base; 1-4 dorsales entières, paralleles, cinquiense raccourcie vers le milieu, surmontée d'un petit are basal fort rapproché de la quatrième, suturale un peu moins courte. Propygidium bifovéolé, couvert de points assez serrés, ainsi que le pygidium. Prosternum en carène obtuse, élargi et bistrié à la base, lobe court, rebordé et abaissé ; mésosternum à peine sinué, rebordé. Jambes antérieures garnies de six petites dents, postérieures de six à sept paires de denticules épineux.

Indes; Syrie (Damas), (MI. de Laferté et Truqui). 


\section{II. hiAkgINICOLLIS.}

Oblongus, subconvexus, niger, nitidus; antennis medibusque rufo-brunneis; stria frontali subsinutu; pronoto subtiissime punctulato, ad latera fortius; strialaterali interna forli integra, margine elevato; elytris stria subhnmerali exteria subintegra, 1-3 clorsatibus integris, $4^{\text {a }}$ suturaliquo in medio, 5a ante medium abbrevialis ; fossa maryinali punctulata 1-sulcala ; propygidio leviter bifoveolato mgidioune sut dense punctatis; mesosterno sinuato; libiis anticis 6-denticulatis; posticis biseriatim multispinosis. Long. 4 mill. ; larg. 3 mill.

Hister marginicollis, Le Conte, Mon. Hist. 28, 2\%, pl. 3, f. 11 $(1845)$.

Ovale allongé, légèment convexe, noir, luisant. Antennes rouge-brun. Tète petite, arrondie; front plan, strie forte, entièı’e, á peine sinuée en devant; labre arrondi ; mandibules édentées, à pointe recourbée, aiguë. Pronotum plus large que long, légèrement arqué à la base, courbé sur les côtés, échancré et rétréci en devant, avec les angles aigus, abaissés, couvert d'une ponctuation très fine, avec des points plus gros sur les côtés; strie latérale interue profonde, enlière, non interrompue en devant, sans angles postoculaires, assez rapprochée du bord latéral. Ecusson petit, triangulaire. Elytres beaucoup plus longues que le pronolum, de sa largeur à la bise, àpeine dilatées sur les côtés, droites au bout, avec une légère impression subapicale; stric latérale externe légèreInent coudéc à l'épaule, n’atteignant pas la base, 1-3 dorsales entières, quatriène raccourcie un peu au-delà du milien, ainsi que la suturale, cinquiène beaucoup plus courte; fossette marginale 1-sillommée, finement pointillée, peu profonde. Propygidium bifovéolé, assez densément pouctué, ajusi que le pygidium. Prosterumm en carène obtuse, élargi à la base, lohe court, jebordé. incliné; mésosternum sinué, bordé 
d'une strie entière. Jambes antérieures dilatées, armées de six petites dents, extrême bifide; postérieures garnies de six ou sept paires de denticules épineux.

Ėtats-Unis (Nouvelle-Orléans), dans les bouses.

\section{II. PLNCTIVENTER.}

Breviter ovalis, subconverus, miger, nitilus ; untennis rufobrunneis ; stria frontali subsinuala; pronoto stria lalerali interna integra; clytris stria subhumerali subintegra, 1-3 dorsali-

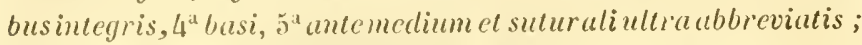
fossa marginali grosse punctata, 1-sulcuta; propygidio bifoveolato pygidiogue alcuse el grosse munctatis; mesosterno sinuato marginatoque; tibiis anticis 5-denticulatis, posticis biseriatim 6-spinosis. Longueur 5 mill. ; Jarg. $31 / 2$ nill.

Ovale court, légèrement convexe, noir, luisant, pointillé linement. Antennes rouge-brun. Tète petite, arroudic; front plan, strie entière, forte, sinuée en devant ; labre court arrondi; mandibules presque droites, édentées en dedans, à pointe recourbée et assez aiguë. Pronotum pointilié, court, beaucoup plus large que long, arqué à la base, courbé sur les côtés, rétréci et échancré en devant, avec les angles abaissés, assez aigus; strie latérale interne forte, entière, assez rapprochée du bord, recourbée en dedans à la base, non interrompue en devant. Ecusson petit, triangulaire. Elytres beaucoup plus longues que le pronotum, de sa largeur à la base, curvilinéairement dilatées sur les côtés, rétrécies et droites aı bout, avec une impression subapicale et les épaules assez saillantes; strie subliumérale coudéc à l'épaule, n'atteignant pas la base, 1-3 dorsales crénelées, entières, quatrième presque entière, cinquième contournée, raccourcie au milieu, suturale plus longue; fossette mar- 
ginale fortement ponctuée et dissimulant le sillon unique qui la traverse. Propygidium bifovéolé, couvert ainsi que le pygidium de points ocellés assez scrrés. Prosternum en carc̀ne obtuse, élargi à la base, lobe court, bordé et presque horizontal; mésosternum sinué, bordé l'une strie entière. Jambes antérieures armées de cinq petites lents, extrême bifide; postérieures garnies de cinq ou six paires de denticules épineux.

Mexique (M. de Laferté)

\section{H. Callforicus.}

Ovalis, parum convexus, niger, nitidus; fronte puncticulata, subdepressa, stria antice subsinuata; pronoto stria laterali interna integra; elytris fossa marginali 3-sulcata, stria subhumerali postice valde abbreviata, 1-3 dorsalibus integris, 4a upicali obsoleta, cateris mullis; propygidio mygidioque dense punctatis; mesosterno enarginato, stria integra; tibiis anticis 3-clentatis, posticis biseriatim 7-8 spinosis. Longueur 6 mill.; larg. 4 1/2 mill.

Ovale, peu convexe, noir, luisant. Antennes brunes. Tête assez grande; front large, finement pointillé, légèrement déprimé ; strie entière, bien marquée, subsinuée en devant; labre court, arrondi ; mandibules légèrement creusées en dessus, édentées, à pointe obtuse. Pronotum beaucoup plus large que long, presque droit à la base, courbé sur les côtés, rétréci et échancré en devant, avec Ics angles assez aigus, abaissés; strie latérale interne unique bien marquée, entière quoi(jue ne joignant pas la base, non interrompue en devant et sans angle postoculaire. Ecusson petit, triangulaire. Elytres plus longues que le pronotum, de sa largeur à la hase. curvilinéaires sur les côtés, rétrécies et presque droites au bout; strie subhumérale externe arquée, raccourcic à la 
base et beaucoup plus encore postérieurement, 1-3 dorsales entières crénelées, quatriène représentée par quelques points obsoletes apicaur, les antres nulles; fossette marginale à peine visiblement ponctuée, trisillonnée. Propygidium densément ponctué, ainsi que le pygidium. Posternum en carène obtuse, peu élargi à la base, lobe court, ponctué, rebordé et infléchi; mésosternum échancré, bordé d'une strie entière avec un rudiment court de chaque côté d'une deuxième marginale. Jambes antéricures très dilatées, armées de trois dents, extrême bifide; postérieures garuies de six à huit paires de denticules épineux.

Californic.

\section{H. BIFRONS.}

Ovalis, subconvexus, niger, nitidus; antennis rufis; fronte biloba, stria antice vix sinuata; monoto antice emarginato bisinuatoque, stria laterali intema snbintegra, basi lateri approximata; elytris subhumerali arcuatu, postice valde abbreviata, 1-4 dorsalibus integris, 5a suturalique dimidiatis, fossa marginalibisulcata punctuluta; mopyyidio mygidioque sat dense punctutis; mesosterno recto marginato; tibiisanticis 4-dentatis, posticis biseriatine multispinosis. Long. 4 1/2 mill.; larg. 3 1/4 mill.

Ovale, légèrement convexe, noir, luisant. Antennes rousses. Tête assez grande; front divisé en deux bosses par une impression longitudinale médiane; strie entière, à peine sinuée en devant; labre court, transversal; mandibules presque droites, édentées, à pointe à peine courbée. Pronotum plus large que long, arqué à la basc, presque droit sur les côtés, bisinueusement échancré et rétréci en devant, avecles angles abaissés, obtus; strie latérale interne entière, cependant un peu raccourcie et rapprochée du bord à la base. Ecusson petit, triangulaire. Elytres courtes, un peu plus longues que 
le pronotum, de sa largeur à la base, curvilinéaires sur les côtés, rétrécies et droites au bord apical; strie subliumérale externe arquée, un peu raccourcie par devant et beaucoup par derrière, 1-4 dorsales fortes, crénelées, entières, cinquième racourcie au milieu, suturale un peu plus longue; fossette marginale bien marquée, pointillée, bisillonnée. Propygidium assez densément ponctué, ainsi que le pygidium. Prosternum en carène aiguë, peu élargie à la base; lobe re: bordé et abaissé ; mésosternum droit, bordé d'une strie marginale entière. Pattes d'un brun rouge. Jambes antérieures, armées de quatre petites dents, extrême bifide; postérieures garnies de sept à huit paires de denticules épineux.

Inde (II. Deyrolle).

\section{H. STERCORARIIS.}

Oblongus, convexus, niger, nitidus; stria frontuli antice subsimuata; pronoto stria laterali interna integra, basi recurva; elytris stria subhumerali utrinque abbreviata, 1-3 dorsalibus integris, 4-5 brevissimis, suturali ante medium abbrcviata; fossamurginali impunctata, 1-sulcata; propygidio subbifoveolato pygidioque fortiter punctatis; mesostcmo emarginato, stria int'gra; tibiis anticis 4-dentatis, posticis biseriatim 7-8 spinosis. Long. 5 mill.; larg. 3 1/2 mill.

Hister stercorararius, Ent. Hefte, 1, 57, 11, pl. 1, f. 5 (1803).Sturm, Deuts. Fu. 1, 112, 13. - Payk. Act. Holm (1809), p. 229, pl. 7, f. 1. ; Mon. Hist. 48, 28, pl. 4, f. อे. - Duft. Fn. Austr. 1, 218, 14. - Gyll. Ins. suec. Iv, 265, 11-12. - Steph. Ill. Brit. Ent. 3, 149, 13. -- Er. Kæf. Brand. 1, 662, 11. - Heer, Fn. Helv. 1, 457, 16. - Küst. Kæf. Eur. 9, 51. - Redı. Fn. Austr. 23\%. Bach, Kæf. Pruss. 1, 303, 11.

Ovale allongé, convexe, noir, luisant. Antennes brunes, funicule roussatre. Tète assez grande, large; front plan, 
strie entière, bien marquée, sintée en devant ; labre arrondi ; mandibules fortes, édentées, à pointe courbe, assez aiguë. Pronotum beaucoup plus large que long, légèrement arqué à la base et sur les cotés, rétréci et échancré cu devant, avec les angles abaissés, obtus; strie latérale interne, non interrompue en devant, entière, bisinuée sur les côtés et recourbée en delans à la base. Ecusson petit, triangulaire. Elytres beaucoup plus longues que le pronotum, de sa largeur à la base, presque parallèles sur les côtés, à peine rétrécies et obliques au bout; strie subhumérale externe arquée, raccourcie de part et d'autre ; 1-3 dorsales entières crénelées, quatrième et cinquiène apicales très courtes, suturale un peu plus longue, n’atteignant cependant pas le milieu; fosselte marginale superficielle, à peine ponctuée, 1 -sillonnée. Propygidium subbifovéolé, assez densément et fortement ponctué, ainsi que le pygidium. Prosternum en carène obtuse, élargie à la base, lobe rebordé et infléchi ; mésosternum échancré, bordé d'une strie entière. Jambes antérieures dilatées, armées de quatre dents; postérieures garnies de sept ou huit paires de denticules épineux.

Cette espèce, assez peu commune, vit dans les bouses et les fumiers. On la trouve dans la plupart des contrées de l'Europe: Angleterre, Suisse, France, Allemagne, Autriche, Dalmatie, Russie, et aussi en Suède, mais très rarement.

\section{H. Philippivensis.}

Ovalis, demessus, niger, nitidus; fromle pluna, stria semicirculari; pronoto stria lalerati interna hand interrupta basi ablreviala; elytris fossa marginali bisulcuta, sublavi; stria subhumerali utrinque parum abbreviata, mofunda, 1-3 dorsa-

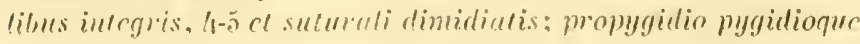


sat dense punctatis; mesosterno recto marginatoque; tibiis anticis 5-denticulatis, posticis biseriatim mullispinosis. Longueur 5 1/2 mill.; larg. 3 1/2 mill.

Ovale, aplati, noir, luisant. Antennes brunes, massue grise. 'Tète médiocre; front plan, assez large, strie semicirculaire, bien marquée, entière; labre petit; mandibules édentées, courbées en pointe mousse. Pronotum beaucoup plus large que long, droit à la base avec une ligne antéscutellaire, arqué sur les côtés, rétréci et échancré en devant, avec les angles abaissés, obtus; strie latérale interne seule, non interrompue, rapprochée du bord et un peu raccourcie postérieurement. Ecusson petit, triangulaire. Elytres un plus longues que le pronotum, de sa largeur à la base, curvilinéaires sur les côtés, très rétrécies et courbées au bout; fossette marginale presqu’imponctuée, bisillonnée; strie subhumérale très forte, à peine raccourcie; dorsales crénelées, 1-3 entières, 4-5 et suturale raccourcies au milieu. Propygidium couvert de points espacés ; pygidium plus densément ponctué. Prosternum en carène tranchante, peu élargie à la base, lobe rebordé et incliıé ; mésosternum droit, bordé d'une strie entière. Jambes antérieures garnies de cinq petites dents, postérieures d'une double rangée de nombreux denticules épineux.

Malaisie (îles Philippines).

Espèces que je n'ai pas vues.

6o 114'. H. cognatus.

Pronotolateribus punctutis, stria laterali postice abbreviatu; elytris striis $1-4$ dorsalibus integris, $5^{\text {a }}$ et suturali antice abbreviatis; tibiis anticis 5-dentatis. Long. 5 1/4 mill. - NouvelleOrléans.

Hister rogmalus, If C. X. Amér. Hisı. 28, 23, pl. 3, $10(1845)$. 
Noir, luisant. Strie frontale sinnée. Pronotum ponctué sur les côtés; strie latérale un peu raccourcie postérieurement. Stries dorsales des élytres 1-4 cntières, quatrième cependant un peu plus courte que les autres, cinquième raccourcie avant le milieu, suturale au milieu, deux latérales, interne raccourcic postérieurement. Prosternum ponctué; mésosternum lisse, échancré, ponctué sur les côtés. Segments inférieurs de l'abdomen ponctnés excepté le premier et le dernier. Jambes antéricures 5-dentées.

La quatrième dorsale est parfois entière et unie à la suturale, mais cetle réunion est toujours peu distincte.

\section{$6^{\circ} 117^{\circ}$. H. EXARATIS.}

pronoto stria inlegra; elytris striis 1-3 dorsalibus integris, $4^{\mathrm{a}}, 5^{\mathrm{a}}$ cum suturali anlice subconnexa, paulum abbreviatis cequalibus; tibiis anticis 3-denutis. Long. 5 1/4 mill. - EtatsUnis (Georgie et Garoline).

Hister exaratus, Le C. N. Amér. Hist. 29, 25, pl. 3, 12 (1845).

Noir, luisant. Strie frontale droite en devant. Pronotum pointillé; strie latérale entière. Elytres à stries dorsales 1-3 entières, les autres un peu raccourcies en devant, égales, cinquième et suturale réunies par un arc basal peu distinct, quatrième et cinquième quelquefois réunies aussi par derrière; subhumérale très obsolète, à peine visible, formée d'une série de points; humérale très superficielle et à peine visible ; deux latérales, dont l'inféricure raccourcic antérieurement. Prosternum ponctué au bout; mésosternum droit. Segments inférieurs de l'abdomen ponctués sur les côtés. Pattes brun de poix. Jambes antérieures 3-dentées; dent autérieure grande. 


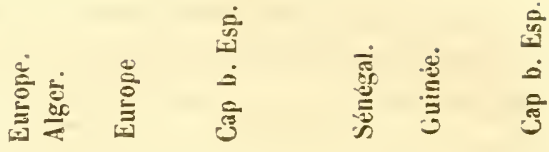

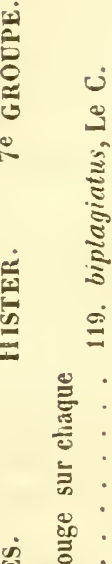

蓠

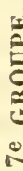

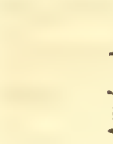

jo

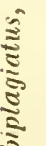

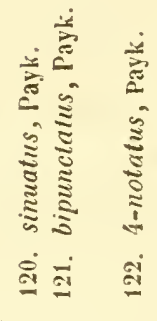

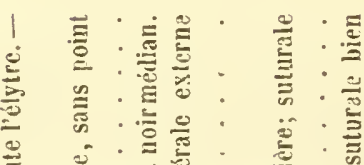

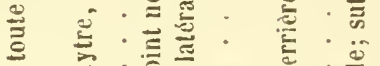

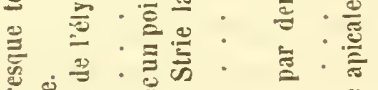

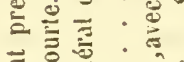

콩

旅

总芒

葛言总:

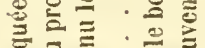

营: : $:$

ำ

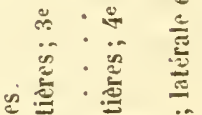

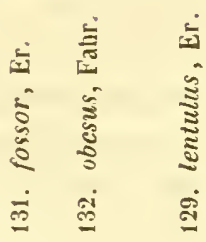

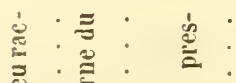

苋:

白

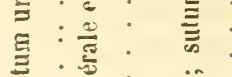

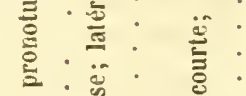

$2 \cdot \dot{0}$

zำ

跣:

密

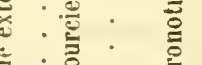

: 言:

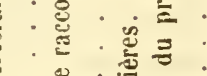

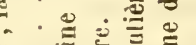

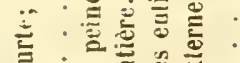

.

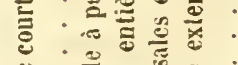

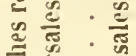

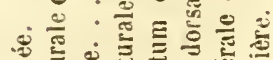

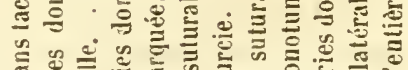
홍

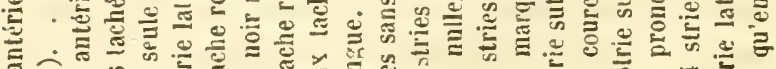

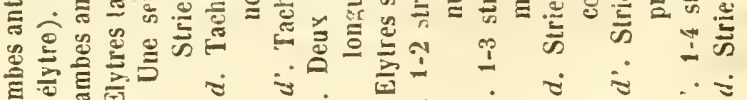

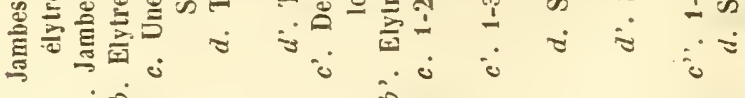
$\rightarrow+\infty$ 
XX. Hister.

551

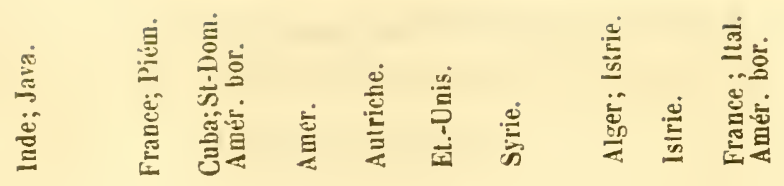

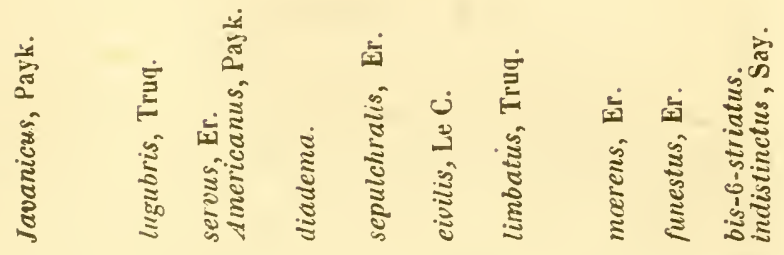

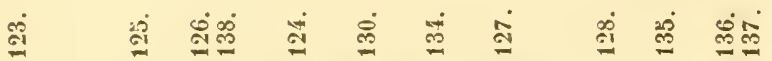

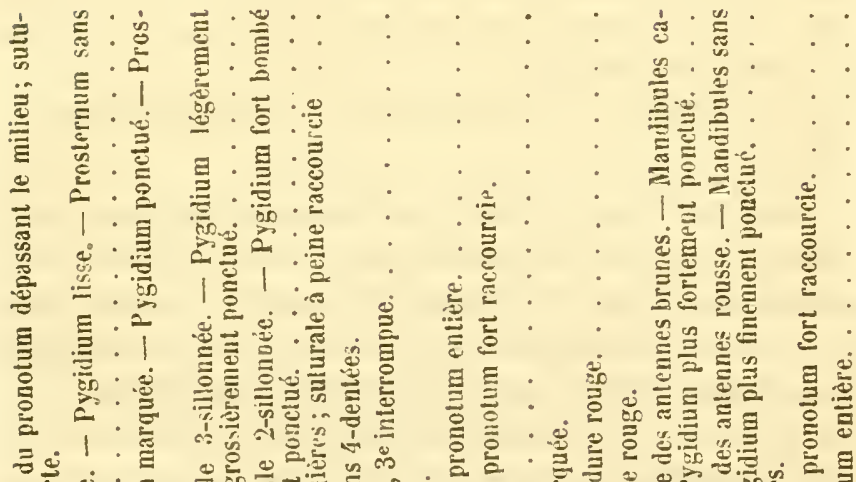

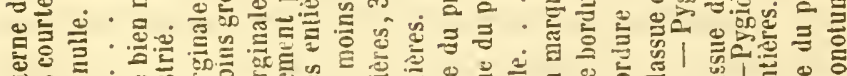

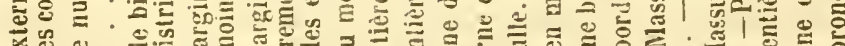

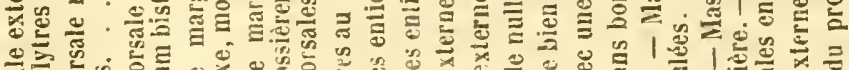

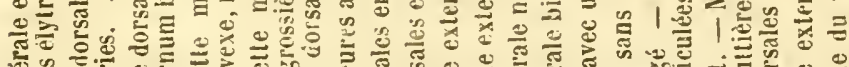

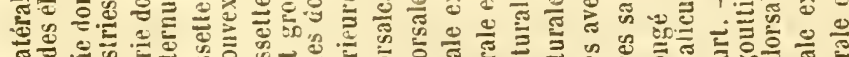

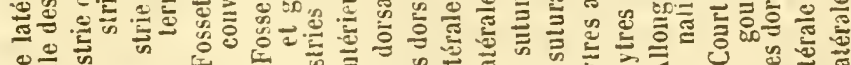

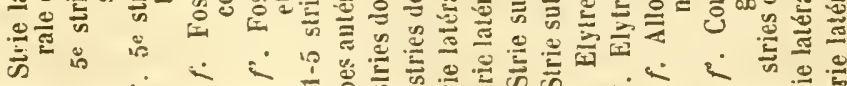

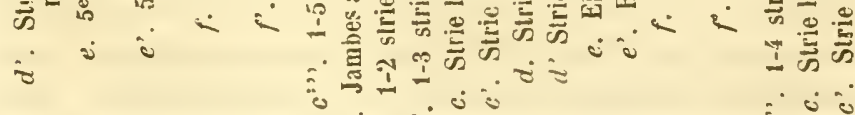

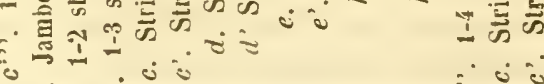

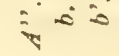


B' Pas de strie subhumérale aux élytres.

C. Ieux stries latérales au pronotum.

$$
7^{e} \text { Groupe (119-13S). }
$$

\section{H. BIPLAGIATIS.}

Ovalis, couvexiusculus, niger, mitidus; antennis rufis; stria frontali semicirculari, pronoto fulvo ciliato, striis 2 lateralibus integris distantibus, subparallelis; clytris striis $1 . .3$ dorsalibus integris, $4^{\text {a }}$ et $5^{\text {a }}$ apicalibus obsoletis, suturali utrinque abbreviata; macula magna rubra; fossa marginali punctata bisulcata; propygidio bifoveolato parce punctulato, pygidio basi densius, postice subtilius; mesosterno cmarginato, stria integra; tibiis anticis bidentatis, posticis biseriatim 7-8 spinosis. Long. 6 1/2 mill.; larg. 4 1/2 mill.

Hister biplagiatus, Le Conte, N. Amér. Hist. 25, 17, pl. 3, f. 4 (1845).

Ovale, assez convexe, noir, luisant. Antennes brun-rouge, massue plus claire. Tête assez grande; front large, plan; strie entière, bien marquée, faiblement arquée en devant; labre pelit; mandibules édentées, à pointe recourbée, assez aiguẻ. pronotum beanconp plus large que long, cilié de jaune, arqui à la base, avec un point antéscutellaire, courbé sur les côtés, rétréci et échancré en devant, avec les angles abaissés, assez aigus; stries latérales entières, distantes, presque parallèles, touchant la base et ne se réunissaut pas en devant, axterne rapprochée du bord, interne non interrompue, coudée derrière les ycux. Ecusson petit, triangulaire. Elytres plus longues que le pronotum, de sa largeur à la base, curvilinéaires sur les côtés, rétrécies et obliques au bout, avec une impression subapicale; stries 1-3 dorsales entières, parallèles, bien marquées, 4-5 apicales ohsolètes, suturale 
raccourcie de part et d'autre; une tache rouge occupant les premier, deuxième et troisième interstries sans atteindre la base, ni le bord apical, recourbée par derrière jusqu’à la strie suturale; bord infléchi parcouru par deux sillons, ponctué. Propygidium bifovéolé, couvert de points espacés, entremêlés de points plus petits; pygidium plus densément ponctué, et aussi fortement en devant, mais très finement sur le reste de sa surface. Prosternum en carène obtuse, élargie à la base, lobe rebordé et incliné; mésosternum éclıancré, bordé d'une forte strie entière et sur les côtés d’une deuxième strie. Jambes antérieures dilatées, bidentées; postérieures garnies de sept ou huit paires de denticules épineux.

je possède un individu de celte espèce, d'un brun plus ou moins ferrugineux, dont la strie suturale est entière et recourbée en crochet à la base et qui présente un petit rudiment desublsumérale interne. Ce qu'il a de plus remarquable, c'est une monstruosité de la jambe antérieure droite dont le côté externe est divisé en deux arêtes exactement semblables et fortement bidentées. Il me vient du savant professeur d'anatomie comparée à l'Université de Jiège, M. Théodore Lacordaire, qui l'avait reçu de M. Le Conte.

États-Unis, plus rare dans les provinces médionales.

\section{H. Sinuatus.}

Ovalis, convexus, niger, nitidus; stria frontali semi-hexagona; pronoto stria laterali interna integra, haud interrupta, externa brevi; elytris margine bisulcato, striis dorsalibus 1-3 integris, 4-5 et suturali brevibus obsoletis, macula rubra arcuata marginem haud coopericnte; propygidio parce, pygidio sat dense punctatis; mesosterno cmarginato, stria integra; tibiis anticis 
3-dentatis, posticis biseriatim muttispinosis. Long. $61 / 2$ mill.; larg. 5 mill.

Hister sinuatus, Illig. Kæe. Pruss. 57, 9 (1798). - Payk. Fu. suec. 1, 37. 3 ; Hon. Hist. 29, 18, pl. 12, f. 2.- E. H. 1, 44, 5.-Sturm, Deut. Fn. 1, 201, 7, pl. 17, f. A. - Duft. Fn. Austr. 1, 212, 5. Gyll. Ins. suec. 1. 78, 5.-Fisch. Ent. Russ., 1, 205, 亿.- Steph. Ill. Brit. Ent. 3, 146, 6.

H. uncinatus, Illig. Mag. vi, 32, 5 (1807). - Er. Kxf. Brand. 1, 662, 12. - Heer, Fn. Helv, 1, 457, 17. - Küist. Kif. Eur. 4, 68. Redt. Fu. Austr. 233. - Bach, Kæf. Pruss. 1, 301, 3.

H. humeralis, Fisch. Ent. Russ. 1, 205, 4 (1823).

Ovale, convexe, noir, luisant. Antennes brunes. Tète assez grosse; front large, pointillé, plan, strie forte, entière, semihexagonale; labre petit; mandibules édentées, courbées en pointe aiguë. Pronotum pointillé, plus large que long, presque droit à la base avec un point antéscutellaire, arqué sur les còtés, rétréci et échancré en devant avec les angles abaissés et obtus; strie latérale interne entière, non interrompue, externe très courte. Ecusson petit, triangulaire. Elytres plus longues que le pronotum, de sa largeur à la base, curvilinéaires sur les côtés, rétrécies et obliques au bout avec une impression subapicale; fossette marginale lisse, bisillonnée; 1-3 stries dorsales entières, deuxième coudée en delıors, 4-5 obsolètes très courtes, suturalc raccourcie avant le milieu, une grande tache rouge occupant l'épaule, mais sans s'étendre sur la marge, rétrécie et recourbé aux deux tiers vers la suture. Propygidium bifovéolé, couvert de points espacés dans son pourtour; pygidium assez densément ponctué. Prosternum en carène obtuse, arrondi à la base, lobe étroit, rebordé et abaissé; mésosternum échancré, bordé d'une strie entière et d'une interrompue. Jambes antérieures armées de trois dents, extrème bifide; postérieures garnies de six à sept paires de denticules épineux. 
Suèle, France, Suisse, Allemagne, Autriche, Espagne, Russic, Caucase; Algérie; dans les bouses et les fumiers.

\section{II. Biplictates.}

Ovalis, subconvexus; frontali striu antice recta; pronoto stria latcrali interna integra, externa brevi; clytris rubris basi, apice suturaque, magna scmi-circulari ad sculcllum parvaque ulrinque mucula nigris, fossa marginuli bisulcata, striis 1-3 dorsulibus integris, $4-5$ ct suturali obsoletis; propygidio bifoveolato, purum donse, mygidio basi subtiliter menctulatis; mesosterno emarginato, stria integra; tibiis anticis 3-(lentatis, posticis biscriatim 6-7 spinosis. Long. S mill.; larg. 5 mill.

Hister bipunctutus, Payk. Mon. Hist. 27, 10, pl. xı, f. 4 (1811).

Orale, assez convexe, noir, luisant. Antennes brunes, funicule rouge. Tête grande, large, finement pointillée; front plan; strie entière, droite par devant; épistome impressionné; labre arrondi; mandibules dentées en dedans, à pointe recourbée, assez aiguë. Pronotum court, beaucoup plus large que long, presque droit à la base, courbé sur les côtés, rétréci et échancré en devant, avec les angles abaissés, obtus; strie latérale externe raccourcie avant le milieu, interne entière, non interrompue en devant, bisinuée sur les côtés. Ecusson petit, triangulaire. Elytres plus longues que le pronotum, de sa largeur à la base, curvilinéaires sur les cotés, rétrécies et coupées droit au bord apical, rouges avec la base très étroitement, l'extrémité postérieure, la suture, une large tache commune scutellaire et une plus petite sur le deuxième interstrie de chaque côté noires; fossette marginale pointillée, bisillonnée ; stries 1-3 dorsales entières, fines, ponctuées, deuxième coudée au milieu, 4-5 et suturale nulles ou obsolètes, courtes. Propygidlium légèrement 
bifovéolé, couvert d'une ponctuation peu serrée; pygidium finement ponctué en devant. Prosternum en carène obtuse, peu élargi à la base, lobe court, rebordé et incliné ; mésosternum échancré, bordé d'une strie entière. Jambes antérieures armées de trois dents, extrême longue et bifide, postérieures garnies de six ou sept paires de denticules épineux.

Cette espèce assez répandue en Algérie n’a pas été mentionnée par Erichson dans le Jahrbücher. Il est difficile de croire qu'elle ne fit pas partie de la collection du musée de Berlin. Cet auteur l'aurait-il considérée comme une variété du $\boldsymbol{H}$. sinuatus ou du $H$. 4.-maculatus? Alors il eût dù la rappeler dans sa synonymie. Pour moi, il m’a été impossible de constater le passage entre ces deux espèces, quoique j'en aie examiné un nombre considérable d'individus.

\section{H. 4-NOTATLS.}

Ovalis, subconvexus, niger, nitidus; stria frontali semicirculari; pronoto striis lateralibus postice approximatis, vix abbreviatis; elytris fossa marginali bisulcata, striis dorsalibus 1-2 integris, 3a postice obsoleta, suturali brevissima, maculis 2 rubris obliquis; propygidio bifoveolato parce punctato, pygidio sublavi; mesosterno sinuato, marginato; tibiis anticis 3.dentatis, posticis biseriatim multispinosis. Long. 8 mill. ; larg. 6 mill.

Hister 4-notatus, Scriba, Beytr. 1, 47, 12, pl. 5, f. 5 (1790). - Illig. Kæl. Pruss. 1, 58, 10. - E. H. 1, 46, 6. - Sturm, Deuts. Fn. 1, 203, 8. - Dut ts. Fn. Austr. 1, 211, 4. - Gyll. Ins. suec. 1, 78, 6. - Payk. Mon. Hist. 28, 17, pl. 12, f. 3. - Steph. Ill. Brit. Ent. 3, 146, 7. - Er. Kæf. Brand. 1, 656, 2. - Heer, Fn. Helv. 1, 45h, 5. - Küst. Kæf. Eur. 4, 67. - Redt. Fn. Austr. 232. - Bach, Kief. Pruss. 1, 300, 1.

H. 4-maculatus, Ol. Ent. 1, 8, p. 9, 7, pl. 3, 18 (1789). - 
Herbst, Nat. Syst. 4, 26, 2, pl. 35, 2 et 36, 12. - Pauz. Eut. Germ. 1, 24, 20.- Fn. 6, 80, 2.- Payk. F॥. suec. 1, 36, 2.

Ovale, assez convexe, noir, luisant. Antennes brunes, massue gris-roux. Tete assez grosse; front large, plan, strie forte, semicirculaire, entière; labre petit; mandibules dentées, courbées en pointe assez aiguë. Pronotum beaucoup plus large que long, presque droit à la base avec une ligne antéscutellaire, arqué sur les côtés, rétréci et échancré en devant avec les angles abaissés assez aigus; stries latérales rapprochées et un peu reccourcies à la base, interne non interrompue. Ecussou petit, triangulaire. Elytres plus longues que le pronotum, de salargeur à la base, curvilinéaires sur les côtés, droites et rétrécies au bout; fossette marginale bisillonnée, lisse; strie subhumérale quelquefois marquée par un rudiment obsolète ; 1-3 dorsales entières, troisième. obsolète par derrière, 4-5 nulles, suturale très courte; deux taches rouges sur chaque élytre, une à l'épaule, l'autre ovalaire dirigée obliquement au milieu, quelquefois réunies.Propygidium bifovéolé, couvert de points épars; pygidium à peine poiıtillé en devant. Prosternum en carène obtuse, peu élargi à la base, lobe court, rebordé et rabattu ; mésosternum sinué et bordé d'une strie entière. Jambes antérieuresarmées de trois dents, extrêne bifide; postérieures garnies de sept à huit paires de denticules épineux.

Angleterre, Suède, France, Suisse, Allemagne, Autriche, Italie.

\section{H. JAVANICLS.}

Ovalis, convexiusculus, niger, nitidus; stria frontali semicirculari; pronoto antice emarginato bisinuatoque, stria laterali interna integra, externa versus basim abbreviata; elytris 
striis 1-4 dor'salibus crenatis validis integris, 5a apicali brevissima, suturali utrinque vulde abbreviata; fossamarginali 3-sutcata; mesosterno sinuato marginatoque; mropygidio subbifoveolato antice sparsim, mygidio vix basi munctatis; tibiis anticis 3-dentatis, posticis biseriatim multispinosis. Long. $61 / 2$ mill. ; larg. 4 1/2 mill.

Hister Javanicus, Payk. Mon. Hist. 30, 10, pl. 4, 2 (1811).

Ovale, assez convexe, noir, luisant. Antennes brunes, funicule rougeâtre. Tête assez grande; front plan, strie bien marquée, entière, droite par devant; labre court, arrondi ; mandibules édentées, à pointe recourbée, assez aiguë. Pronotum court, beaucoup plus large que long, très légèrement arqué à la base et sur les côtés, rétréci et échancré en devant, échancrure bisinuée, avec les angles abaissés, obtus; stries non réunies, externe raccourcie au-delà du milieu, interne entière, recourbée à la base, non interrompue en devant, avec des angles postoculaires arrondis. Ecusson petit, triangulaire. Elytres courtes, un peu plus longues que le pronotum, de sa largeur à la base, curvilinéairement dilatées sur les côtés, rétrécies et assez droites au bout, avec une impression subapicale ; strie subhumérale nulle, 1-4 dorsales entières, fortes, crénelées, (quatrième quelquefois interrompue postérieurement), cinquième représentée par que'ques points apicaux, suturale courte raccourcie de part et d'autre; fossette marginale imponctuée, 3-sillonnée. Propygidium ponctué à la base et dans les fossettes, lisse sur le reste de la surface, ainsi que tout le pygidium. Prosternum assez large, peu saillant, arrondi à la base, lobe rebordé et un peu abaissé; mésosternum sinué, bordé de deux stries, l'une entière, l'autre interrompue. Jambes antérieures armées de trois dents assez fortes; postérieures garnies de sept à lıuit paires de denticules épineux.

Inde: Bengale, Coromantel (Tranguchar); Malaisie (Java) 


\section{H. DIADEMA.}

Ovalis, convexiusculns, niger, nitidus; fronte subimpressa, stria forli trisinnata; pronoto striis 2 latcralibus approximatis, margine propinquis, externa valde abbreviata, interna profunda integra; clytris striis 1-2 dorsalibus profundis integris, $3^{\mathrm{a}} 4^{\mathrm{a}} q u c$ late intcrruptis, 5a upicali, suturali ultra medium abbrcviata; fossa marginali bisulcata impunctata; propygidio bifovcolato pygidioque mulvinuto grosse munctatis; mosterno bistriato, mesostemo simnato marginatoque; tibiis amticis 5-dentatis, posticis biscriatim multispinosis. Longueur 6 1/2 mill.; larg. 4 1/2 mill.

Ovale, assez convere, noir, luisant. Antennes brunes, massue d'un gris roussatre. Tête assez grande; front large, impressionné dans sa lougueur, strie forte, entière, arrondie en devant, sinuée sur les côtés ; labre court, arrondi ; mandibules fortes, creusées en dessus, à pointe courbe, aiguë. Pronotum court, beaucoup plus large que long, arqué et ponctué à la base, courbé légèrement et relevé en bourrelet sur les côtés, rétréci et échancré en devant, avec les angles assez aigus et abaissés; stries latérales profondes, très rapprochées du bord et peu distantes l'une et l'autre, externe plus fine, largement interrompue, interne très forte et très profonde, entière, non interrompue en devant avec les angles postoculaires arrondis. Ecusson petit, triangulaire. Elytres plus longues que le pronotum, de sa largeur à la base, curvilinéairement dilatées sur les côtés avec les épaules saillantes, rétrécies et obliquement arquées postérieurement, avec une impression subapicale; stries subhumérales nulles, 1-2 dorsales entières, profondes, troisième et quatrième interrompues, celle-ci plus largement, cinquième courte apicale, suturale remontant au-dela da milieu; bord infléchi imponctué, bisillonné. Propygidium bifinfóolé, couvert d'une ponc- 
tuation forte et régulière, en forme de couronne à triple fleuron, lisse dans son pourtour; pygidium bombé, grossièrement ponctué sur toute sa surface. Prosternum bistrié, élargi à la base, lobe court, horizontal, rebordé; mésosterum échancré, bordé de deux stries, l'une entière, l'autre interrompue. Jambes antérieures dilatées, armées de cinq petites dents, extrême hifide; postérieures garnies de luit à dix paires le denticules épineux.

Guyane (Cayenne), Bolivie.

\section{H. LLGLBRIS.}

Oblongus, subconvexus, nigro-brumens, nitidus, puncticulatus; fronte plana, rugosulu, stria antice rectu; monoto striis lateralibus validis approximatis, externa parum abbreviata, interna haud interrupta; elytris fossa marginali 3-sulcala, 1-4 dorsalibus integris, $5_{\text {a }}$ et suturali dimidiatis; propygidio pygidioque sat dense ocellato-punctulis; prosterno bistriato; mesosterno sinnato marginatoque; tibiis anticis 3-dlentatis; posticis biseriatim 7-8 spinosis. Long. 6-5 mill. ; larg. 4-3 mill.

Hister lugubris, Truq. in Soc. Ent. (1852), 63, 3, pl. 2, n² 2, f. 2.

Ovale allongé, assez convexe, noir-brun, luisant, finement pointillé. Antennes ferrugineuses, massue gris-roussâtre. Tête assez grosse; fronit plan, large, rủgueux, strie entière, droite en devant; labre court; mandibules bidentées, courbées en pointe aiguë. Pronotum court, arqué à la base avec un point antéscutellaire, presque droit sur les cotés, un peu rétréci et profondément échancré en devant, avec les angles abaissés, assez aigus; stries latérales profondes, rapprochées, parallèles, externe un peu plus courte, interne non interrompue, coudée derrière les yeux. Ecusson petit, triangulaire. Elytres plus longues que le pronotum, de sa largeur à la base, curvilinéaires sur les cotés, 
obliques et rétrécies au bout avec une impression subapicale; fossette marginale 3-sillonnée ; stries dorsales 1-4 entières, cinquiène et suturale raccourcies, celle-ci un peu plus tôt que celle-ià. Propygidium á peine bifovéolé, couvert de points ocellés assez serrés, ainsi que le pygidium. Prosternum étroit, bistrié, à peine élargi à la base, lobe rebordé et infléchi; mésosteruum échancré et bordé d'une strie entière et d'une interrompue. Jambes antérieures armées de trois dents, extrême bilide; postéricures garnies de sept a huit paires de denticules épineux.

France (Nantes), Piémont.

\section{H. SERVLS.}

Ovalis, subconvexus, niger, nitidus, muncticulatus; antemis rufo-brumneis; fronte impressa, stria semicirculari; pronoto lateralibus parallelis, interna haud interrupta, externa abbreviata; elytris $1-4$ dorsulibus integris, 5a ante, suturali in medio abbreviatis, margine inflexo bisulcuto; mopygidio bifoveolato mygidioque grosse et dense punctatis; mosterno bistriato, mesosterno subrecto marginato; tibiis anticis 3-dentatis, posticis biseriatim multispinosis. Long. 5 mill. ; larg. $33 / 4$ mill.

Hister screus, Er. in Jahr. 147, 51 (1834).

Ovale, légèrement convexe, noir, luisant, finement pointillé sur la tête et le pronotum. Antennes d'un brun roussâtre. Tête médiocre, arrondie; front légèrement impressionné, entouré entièrement d'une strie arquée en devant ; labre assez long presque carré; mandibules fortes, bidentées, légèrement concaves, à pointe recourbée, aiguë. Pronotum beaucoup plus large que long, arqué et ponctué à la base, avec un point antéscutellaire, oblique sur les côtés, rétréci et échancré au devant, avec les angles antérieurs abaissés, un peu obtus; stries assez rapprochées, parallèles, externe un peu raccour- 
cie, interne entière, non interrompue en devant, sinuée derrière les yeux. Ecusson petit, triangulaire. Elytres courtes, un peu plus longues que le pronotum, de sa largeur à la base, curvilinéairement dilatées sur les côtés, légèrement rétrécies et arquées au bout avec une légère impression subapicale; stries subhumérales nulles; $\mathbf{1 - 4}$ dorsales entières, fortes, ponctuées, cinquième raccourcie avant le milieu, suturale à peu près au milieu; bord infléchi avec deux sillons ponctués. Propygidium bifovéolé, fortement et densément ponctué ainsi que le pygidium. Prosternum bistrié, arrondi à la base, lobe rebordé, un peu incliné; mésosternum subsinué, bordé de deux stries, l'une entière, l'autre interrompue. Jambes antéricures dilatées, armécs de trois dents, extrême bifide, postérieures garnies de 7-8 paires de denticules épineux.

Autilles (Cuba, Saint-Domingue); dans les charognes, en septembre.

\section{LIMBATCS.}

Oblongus, subdepressus, niger, nitidus; antennis pedibusque ferrugineis; stria frontali integra; pronoto stria taterali externa brevissima, interna haud interrupta; elytris fossa marginali impunctata, bisulcata; striis 1-3 dorsalibus integris, 4-5 et suturali abbreviatis, macula laterali rubra; propygidio sparsim, mygidio busi tenuiter punctatis; tibiis anticis 3-dentatis, posticis biseriatim multispinosis. Long. 3 1/2 mill.; larg. 2 1/2 mill.

Hister limbatus, Truq. in Soc. Ent. (18522), 64, 4, pl. 2, n² f. 5 .

Ovale allongé, peu convexe, noir, luisant. Antennes brunes, massue gris-ferrugineux. Front large, plan; strie bien marquée, entière, légèrement sinuée. Pronotum court, étroit et bordé de points à la base, arqué sur les cotés, 
rétréci et échancré en devant, avee les angles abaissés, assez aigus; strie latérale externe fort raccourcie, interne entière, bien marquée, assez éloignée du bord latéral en devant. Ecusson petit, triangulaire. Elytres une fois et demie plus longues que le pronotum, de sa largeur ì la base, presque parallèles, un peu rétrécies et droites au bout; fossette marginale imponctuée, bisillonnće; stries 1-3 dorsales entières, parallèles, les autres raccourcies, quatrième vers le milieu, cinquième un peu plus tôt, suturale aux deux tiers; tache rouge couvrant toute la margye jusqu'à la première dorsale, et s'élargissant en are vers la suture aux trois quarts de la longueur, ou plutôt enroyant un prolongement arqué, aminci graduellement et s'arrêtant à la suturale; cette tache conjointement arec celle du côté opposé forme un grand arc qui s'étend l'une épaule à l'autre. Propygidium couvert de points épars; pygidium très finement et un peu plus densément ponctué à la base. Pattes ferrugineuses; jambes antérieures armées de trois dents, extrême bifide; postérieures garnies d'une double rangée de nombreux denticules épineux.

Syrie (Mont-Liban).

128. H. HOERENS.

Oblongus, subconvexus, niger, nitidus; antemis rufo-brunneis; fronte muncticulata, stria antice simuala; mandibulis canaliculatis; pronolo stria latcrali interna integra, extorna ante medium abbreviata; clytris 1.3 dorsalibus crenatis integris, 4-5́ apicalibus brcvissimis, suturali dimidiata; fossa murginali bisuleata, punclulata; mopygidio pygidloque sat dense punctatis; mesosterno emarginato, stria integra; tibiis anticis 4-dentatis, posticis biscriatim 6-7 spinosis. Longueur 5 1/2 mill.; larg. $31 / 4$ mill.

Hister merens, Er. in Jahr. 150.57 (183亿). 
Ovale allongé, légèrement convexe, noir , luisant. Antennes brun-rouge, plus ou moins clair. 'Tête assez grande, arrondie; front à peu près plan, finement pointillé, strie entière, forte, sinuée en devant; labre court, arrondi ; mandibules courtes, bidentées en dedans, canaliculées, à pointe recourbée et aiguë. Pronotum finement pointillé, beaucoup plus large que long, presque droit et bordé de points à la base, arqué sur les côtés, rétréci et échancré en devant, avec les angles abaissés assez aigus. Ecusson petit, triangulaire. Elytres une fois et demie plus longues que le pronotum, de sa largeur à la base, presque parallèles, à peine raccourcies et droites au bout; stries 1-3 dorsales bien marquées, ponctuées, entières, 4-5 très courtes, apicales, suturale remontant jusqu'au milieu; fossette marginale pointillée et bisillonnée. Propygidium couvert de forts points assez serrés, ainsi que le pygidium. Prosternum en carène étroite, arrondi à la base, lobe court, rebordé, incliné ; mésosternum échancré, bordé d'une strie entière et d'une autre interrompue. Jambes antérieures garnies de quatre petites dents, extrême bifide; postérieures de cinq ou six paires de denticules épineux.

Istrie; Alger.

\section{H. LeNTules.}

Ovalis, convexiusculus, niger, niticlus; fronte plana, stria semicirculari; pronoto subciliato, stria laterali externa brevi, interna haudinterrupta; elytris fossa marginali punctata bisulcata; stria suturali et dorsalibus 1-4 crenatis integris, 5 a dimidiata; propygidio bifoveolato pygidioque basi fortius, apice subtilius parce punctatis ; mesosterno sinuato marginatoque; tibiis anticis 3-dentatis, posticis biseriatim multispinasis. Longueur 6 mill.; larg. 5 mill.

Hister lentulus, Er. in Jahr. 1, 149, $5 \mathbf{5}$ (1834). 
Ovale, assez convexe, noir, luisant. Antennes brun-ferrugineus, massue grise. Tete grande; front plan, large, strie bien marquée, entière, semicirculaire; labre court; mandibules bidentées, courhées en pointe aiguë. Pronotum court, cilié, droit et bordé de points à la base, avec une ligne antéscutellaire, arqué sur les côtés, rétréci et échancré en devant avec les angles abaissés, assez aigus; strie latérale externe courte, interne entierc, non interrompue en devant. Ecusson petit, triangulaire. Elytres un peu plus longues que le pronotum, de sa largeur à la base, curvilinéairement dilatées sur les côtés, rétrécies et obliques au bout; fossette marginale bisillonnée, ponctuée; stries fortes, crénelées, 1-4 dorsales et suturale entières, cinquième raccourcie vers le milieu. Propygidium bifovéolé, couvert, ainsi que le pygidium, de points espacés, obsolètes au bout. Prosternum en carène obtuse, arrondi à la base, lobe court, rebordé et incliné; mésosternum sinué et bordé d'une strie entière. Pattes ferrugineuses; jambes antérieures tridentées; postérieures garnies d'une double rangée de nombreux denticules épincux.

Cap de Bonne-Espérance.

130. H. SEPLLCHRALIS.

Ovalis, subconvexus, niger, nitidus, puncticulatus; antennis brunneis, clava rufa; fronte bi-impressa, stria profunda antice recta; monoto striis lateralibus integris; elytris 1-3 dorsalibus integris, $4^{a}$ interrupta, suturali basi abbreviata, fossa murginali levi 3-sulcata; propygidio grosse mygidioque sat dense punctatis; tibiis anticis obtuse 5-dentatis, posticis biseriatim multispinosis. Long. $61 / 2$ mill. ; larg. 4 mill.

His'er sepulchralis, Er. in Jahr. 149, 56 (1834).

Orale, légèrement convexe, noir, luisant, finement poin- 
tillé, plus distinctement sur la tête et le pronotum. Antennes brunes, massue rousse. Tête assez grande; front large, légèrement bifovéolé en devant ; strie entière forte, droite en devant; épistome subimpressionné; labre petil, arrondi; mandibules assez fortes, dentées en dedans, canaliculées, avec le bord tranchant, à pointe courbée, acérée. Pronotum beaucoup plus large que long, arqué et bordé de points à la base, avec une petite impression antéscutellaire, presque droit sur les côtés, mais arroudi antérieurement, rétréci et échancré en devant, avec les angles abaissés, obtus; stries latérales entières assez distantes, externe rapproclsée du bord, interne non interrompue en devant, obtusément anguleuse derrière les yeux. Ecusson petit, triangulaire. Elytres plus longues que le pronotum, de sa largeur à la base, curvilinéairement dilatées sur les còtés, rétrécies et droites à l'extrémité, impression subapicale à peine sensible; stries 1-3 dorsales fortes, entières, quatrième obsolète, largement interrompue, cinquième peu visible, représentée par un ou deux points apicaux; suturale bien marquée remontant au-delá du milieu; fossette marginale bisillonnée, imponctuée. Propygidium et pygidium couverts d'une ponctuation assez dense, plus forte sur celui-ci. Mésosternum échancré, bordé d'une strie entière. Jambes antérieures armées de cinq dents obtuses, extrême bifide; postérieures garnies de 7-8 paires de denticules épineux.

Autriche; Hongrie.

\section{H. FOSSOR.}

Ovalis subcomvexus, niger, nitidus; antennis rufis; stria fromlali arcuata; pronoto striis lateralibus parallelis approximatis, interna integra, externa parum abbreviata; slytris 1-3 
dorsalibus integr is, 4-5 apicalibus suturalique mediabrevissimis; fossa marginali munctata bisulcuta; mopygidio sat fortitcr pygidioque subtiliter perce munctulatis; mesosterno sinuato, striat subintcruptu; libiis anticis vuliule 3-dcntatis, posticis biseriatim longius multispinosis. Long. 5 mill.; larg. $31 / 2$ mill.

Hister fossor, Er. in Jahr. 148, 54 (1834).

Ovale, assez convexe, noir, luisant. Antennes et pattes rouges. Tète grande; front large, plan, strie entière, forte et arquée en devant; labre court, arrondi ; mandibules dentées en dedans, à pointe recourbée, assez aiguë. Pronotum court, beaucoup plus large que long, presque droit et ponctué à la base avec une ligne antéscutellaire, courbé sur les côtés, échancré et rétréci en devant, arec les angles abaissés, obtus ; stries latérales fortes, profondes, rapprochées, subparallèles; cxterne un peu raccourcie, interne entière, non interrompue en derant. Ecusson petit, triangulairc. Elytres courtes, un peu plus longues que le pronotum, de sa largeur à la base, curvilinéairement dilatées sur les côtés, fortement rétrécies et un peu obliques au bout, formant un angle sutural bien marqué, avec une impression subapicale; stries 1-3 dorsales fortes, profondes, crénelées, entières, $4-5$ réduites à de courts rudiments apicaux, suturale courte, médiane; fossette marginale pointillée, bisillonıée. Propygidium couvert de points assez forts et espacés. Pygidium très finement et peu densément pointillé. Prosternum en carène obtuse, élargi à la base, lobe court, rebordé et rabattu ; mésosternum sinué, bordé d’une strie obsolète au milieu et d'une interrompue. Pattes roussâtres ; jambes antérieures armées de trois dents, les deux apicales fort longues; postérieures de dix à douze paires de denticules garnis de longues épines.

Sénégal. 


\section{H. OBESUS.}

Ovalis, parum convexus, niger, nitidus; fronte plana, stria semicirculari; pronoto striis 2 lateralibus parallelis, integris; elytris 1-3 dorsalibus intcgris, postice approximatis, 4 a $5^{\mathrm{a}} q u$ c apice, suturali basiabbreviatis, fossa marginali punctata; propygidio mygidioque parce punctatis; mesosterno vix sinuato; tibiis anticis 3-dentatis, apicalidente immani; posticis biscriatim multispinosis. Long. 5 mill.; larg. $31 / 2$ mill.

Hister obesus, Fahr. in Boh. Ins. Cafr. 1, 537, 583 (1851).

Ovale, peu convexe, noir, luisant. Antennes brunes, funicule rouge. Tête assez grandle; front plan, strie forte, entière, bien marquée, semicirculaire; épistome légèrement impressionné; labre très court; mandibules fortes, bidentées en dedans, sans gouttière, à pointe recourbée, assez aiguë. Pronotum court, beaucoup plus large que long, peu arqué et ponctué à la base, avec un point autéscutellaire, courbé sur les côtés, rétréci et échancré en devant, avec les angles abaissés, assez aigus ; stries latérales bien marquées, profondes, entières, rapprochées, parallèles sur les côtés, interne non interrompue en devant, coudée derrière les yeux; marginale bien marquée fine, se continuant le long du bord antérieur avec celle du côté opposé. Ecusson petit, triangulaire. Elytres courtes, à peine plus longues que le pronotum, de sa largeur à la base, curvilinéairement dilatées sur les côtés, rétrécies et arquées au bout, avec une légère impression subapicale; stries subhumérales nulles, 1-3 dorsales entières, fortes, crénelées, rapprochées au bout, quatrième et cinquième apicales, courtes, suturale à peine raccourcie au bout; fossette marginale bisillonnée, ponctuée. Propygidium couvert de points espacés forts, ainsi que le pygidium. Mésosternum à peine sinué, bordé 
d'une strie cntière. Jambes antérieures dilatées, armées de trois dents, extrème très grande; postéricures garnics de six ou sept paires de denticules épineux.

Guinée ; Cafrerie.

\section{H. 3-STRHACS.}

Oealis, convexus, niger, nitidus; stria frostuli integru; mandibulis dentatis; monoto stive interna integra, exterma dimidiala ; chytris fossa marginali punclulata, bisulcata; dossalibus 1-2 integris, $3^{\text {a }}$ dimidiatabuscos, ceteris mullis ; mopygidio mygidioque pare basi munctatis ; mesosterno subrecto maryinatoque; tibiis anticis 3-dentatis; posticis biscriatim multispinosis. Long. 7 mill.; larg. $31 / 2$ mili.

Ovale, assez convexe, noir, luisant, lisse. Antennes brunes. Tête assez grande, arrondie ; front plan, strie entière, droite par devant; labre court; mandibules faiblement dentées en dedans, à pointe courbée, acérée. Pronotum plus large que long, coupé droit et bordé de points à la base, à peine arqué sur les cùtés, échancré et rétréci en devant, avec les angles abaissés, obtus; strie latérale interne entière, largement arrondie en devant, externe raccourcie avant le milieu et se rapprochant de l'interne. Ecusson petit, triangulaire. Elytres un peu plus langues que le pronotum, de sa largeur à la base, légèrement dilatées à l'épaule, peu rétrécies vers le bout; fossette marginale pointillée, bisillonnée; 1-² stries dorsales entières, bien marquées, troisième allant de la base au milieu, quatrième, cinquième et suturale nulles. Propygidium couvert dans son pourtour de points espacés, lisse au milieu. Pygidium un peu plus densément mais moins fortement ponctuć dans sa partie antérieure. Prosternum en carène obtuse, élargi à la base, lobe court, rebordé et rabattu; mésosternum à pcine siıué, 3e Séric, томе II. 
bordé d'une strie forte et entière. Jambes antérieures armées de trois dents, extrême bifide; postérieures garnies le huit à neuf paires d'épines serrées.

Cap de Bonne-Espérance.

\section{H. CIVILIS.}

Ovalis, convexiusculus, niger, nitidus ; antemnis rufis; frontali stria biimpressa antice subarcuata; monoto laterali interna integra, externa mox abbreviata; elytris 1-3 dorsatibus integris validis, cetcris nullis; fossa marginali munctata bisulcata; propygidio subfoveolato, sat fortiter at parum dense, mygidio subtilius punctatis; mesosterno emarginato, stria inte. gra; tibiis anticis rulde dilatatis, 5-denticulatis, posticis biseriatim multispinosis. Long. 5 1/2 mill.; larg. $32 / 3$ mill.

Hister civilis, Le Conte, N. Amér. Hister. 25, 18, 11. 3, f. 5 (1845).

Ovale, légèremont convexe, noir, luisant. Antenne: rousses. Tête assez grande, arrondie; front à peu près plan, finement pointillé, strie forte, entière, presque semicirculaire; labre courl, arrondi; mandibules fortes, à pointe obluse. Pronotum finement pointillé, beaucoup plus large que long, légèrement arqué et bordé de points à la base, avec une petite impression antéscutellaire, à peine courbé sur les cótés, rétréci et échancré en devant, avec les angles abaissés, assez aigus; strie latérale interne entière, forte, non interrompue et sans angles postoculaires, un peu rapprochée par derrière du bord latéral et recourbée en dedans, externe raccourcie bien avant le milieu. Ecusson petit, triangulaire. Elytres courtes, plus longues que le pronotum, de sa largeur à la base, curvilinéaires sur les côtés, légèrement rétrécies et droites au bout, avec une impression subapicale; stries 1-3 dorsales fortes, ponctuées, 
entieres, coutes les autres stries nulles; fosselle marginale bisillonnée, avec quelques points. Propygidium bifovéolé, couvert d'une ponctuation assez forte; pygidium plus linenent ponctué. Prosteruum en carène, élargi à la base, lobe rebordé et rabatlu. Mésosternum échancré, bordé d'une strie entière et d'une autre interrompue. Jambes antérieures très élargies, armées de quatre dents très obsolètes; postérieures garnies de huit à dix paires de denticules épineux.

Etats-Unis. (Massachusetts ef Pensylvanie.)

\section{i35. I1. Fi NESTS.}

Ovalis, subcomvexus, niger, nitidus; antennis rufis ; fronte puncticulala, stria antice subrectu; pronoto laterali interna integra, cxterna mox abbreviala; clyuris 1-?) lor'sulibus integris, 4-j upraculibusbrevissimis, sulurali ultra medium extensa; fossa marginuli punclula bisulcuta; propygidio pygilioque parce munclulatis; mesosterno emarginato, striatulcgra ; tibiis anticis 1-rlentulis; posticis biseriutine multispinosis. Long. 4 mill.; larg. $21 / 4$ inill.

Hister funestus, Er. in Jahr. 151, 58 (1834).

Uvale, peu conrexe, noir, luisant. Antemnes rousses. Téte médiocre arrondie, finement pointillée; front plan; strie forte, entière, droite par derant; labre court, arrondi; mandibules fortes, non creusées en desşus, courbées en pointe. Pronotum beaucoup plus large que long, presque droit et ponctué à la base, à peine courbé sur les côtés, rétréci et échancré en devant, avec les angles abaissés, obtus; strie latérale interne entière, non interrompue en derant, coudée au milieu du bord latéral et un peu arquée en dedans à la base, exterue très courte. Ecusson petit, triangulaire. Elytres beancoup plus longues que le pro. 
notum, de sa largeur à la base, presque parallèles sur les côtés, à peine rétrécies et droites au bout; stries 1-3 dorsales bien marquées, ponctuées, entières, quatrième et cinquième apicales courtes, suturale remontant au-delà du milieu; fossette marginale bisillonnée, pointillée.Propygidium couvert de points esparés et assez forts. Pysgidium ponctué de même, mais plus finement, surtout au milieu. Prosternum en carèue, arrondi à la base, lobe abaissé, rebordé. Mésosternum échancré, bordé d'une strie entière et d'une autre interrompue. Jambes antérieures dilatées, armées de quatre petites dents, extrême bifile; postéricures garnies de sept ou huit paires de denticules épineux.

Voisin de l'H. moerens, il en diffère par sa forme plus conrte, sa strie frontale droite par devant, ses mandibules non canaliculées, sa strie suturale beaucoup plus longue, sa fossette marginale ponctuée, la ponctuation du pygidium moins forte et moins serrée.

France; Autriche; Dalmatie; Espagne.

\section{H. BISSEXSTRIATIS.}

Ovalis, parzm convexus, niger, nitidus, antemnis pedibusque bramneis; fronte plana, stria integra untice reclu; monoto stria laterali externa brevissima, interna hand internpta; elytris fossa marginali bisulcata, dorsalibus 1-4 integris, 5 a ante medium, sutmali ultra abbreviatis; promygidio bifoveolato sparsim, pygidio densins punctatis; mesostcrno sinuato marginatoque; tibiis anticis 4-dentatis, posticis biseriutim multispinosis. Long. 5 mill.; larg. $21 / 2 \mathrm{mill}$.

Hister bissexstriatus, F. Syst. El. 1, 84, 4 (1801). - Payk. Non. Hist. 32, 21, pl. 3, f. 3. - Er. Kaf. Brand. 1, 663, 13. Heer, Fn. Helv. 1, 457, 18. - Küst. Kax. Enr. 13, 21.- Redt. Fn. Austr. 233.- Bach, Kaf. Pruss. 1, 301, 6. 
11. marvus, Gyl. Ius. suec. 1, 79, 7 (180S). - Steph. Illust. Brit. Ent. $3,148,10$.

II. 12-striutus, vur, b. E. H. 1, 59, pl, 1, f. 7. - Sturm, Deuts. Fin. 1, 214.

Ovale, peu convexe, noir, luisant. Antemes brunes, massue gris-roux. Tête médiocre, arrondie; front plan, strie entière, droite en devant, anguleuse de chaque côté; labre petit; mandibules concaves, dentées et courbées en pointe. Pronotum court, droit et bordé de points à la base, arqué sur les côtés, rétréci et échancré en devant, avec les angles abaissés et assez aigus; strie latérale externe très courte, interne entière, non interrompue, coudée derrière les yeux. Ecusson petit, triangulaire. Elytres plus longues que le pronotum, de sa largeur à la base, curvilinéaires sur les côtés, rétrécies et presque droites au bout; fossette marginale bisillonnée, pointillée; stries dorsales $1-4$ entières, cinquième raccourcic au milieu, suturale un peu plus longue. Propygidium bifovéolé, couvert de points épars. Pygidium plus densément pointillé. Prosternum court, en carène obtuse, arrondi à la base, lobe rebordé et rabattu. Mésosternum à peine sinué, bordé d'une strie entière et d'une interrompue. Pattes d'un brun-ferrugineux. Jambes antérieures garnies de quatre pelites dents, extrême bifide; postérieures garnies de nombreuses paires de denticules épineux.

Presque toute l'Europe: Suède; Finlande; Angleterre; France; Suisse; Allemagne; Autriche; Espagne; Italie. Assez commun rans les funiers.

\section{3\%. II. IN⿴)ISTINCTIS.}

Ovalis, ronvexus, niger, nitidus; antennis pedibusque rufo- 
brumneis; stria frontali antice subrecta; monoto striis laterclibus parallelis, integris; elylris 1-4 dorsalibus integris validis, 5a ante medium, suturali utrinque abbreviatis; margine inflexo punctuto bisulculo; promygidio fortius mygidioque subtilius munctatis; prosterno bistriato, mesosterno simualo marginatoque; tibiis anticis 1-denticulatis, posticis biserintim multispinosis.

IIister indistinctus, Say, in Soc. Philad. V. 35, 5 (1825). - Le Conte, Mon. Hist., 26, 19, pl. 3, f. 6.

Ovale, convexe, brun-noir, luisant. Antennes brun-roussâtre, massue plus claire. Tête assez grande; front plan, stric: entière, bien marquéc, semicirculaire ; labre court; mandibules édentées, à pointe obtusc, courbée. Prorıtum court, beaucoup plus large que long, légèrement arqué et ponctuć à la base, oblique sur les côtés, échancré ct rétréci en devant, avee les angles abaissés, un peu obtus; stries latérales fortes, parallèles, rappprochées, entières, interne non iuterrompue en devant, à peine sinuéc derrière les yeux. Ecusson petit, triangulaire. Elytres courtes, un peu plus longues que le pronotum, de sa largeur à la base, curvilinéairement dilatées sur les côtés, rétrécies et un peu obliques au bout; stries 1-4 dorsales fortes, crénelćes, entières, cinquième raccourcie avant le milieu, suturale remoutant au-delà, mais ne partant pas du bort apical; bord infléchi ponctué, bisillonné. Propygidium couvert d'une ponctuation forte et assez serrée; pygidium plus légèrement ponctué. Prosternum bistrić, un peu élargi à la base, lohe rebordé et faiblement incliné; mésosternum échancré, bordé de deux stries, l'unc entière, l'autre interrompue. Jambes antéricures armées de quatre petites dents, extrème large et bifide; postéricures garnies de sept ou huit paires de denticules érineux.

États-Unis, dans les excréments. 


\section{II. Anericanes.}

Suborbiculuris, convexiusculus, niger, nitidus; antemis pedibusque rufis; fronte plana, stria semicirculari; mronoto stria laterali externu brevi, interma hund interrupta; clytris murgine inflexo bisulcato, striis dorsalibus 1-5 integris, suturali setpe $5^{\text {te }}$ comere; propyyuliu parce, mygilio subtilissime munctatis; mesosterno recto marginatoque; tibiis unticis 3-alentatis, posticis biscriutim multisprinosis. I.ong. 3 1/2 mill.; larg. 2 1/2 mill.

IIster Amcricamus, Payk., Mon. Hist., 31, 20, pl. 9, f. 1 (1811). - Le Conte, N. Amér. Hist., 26, 20, pl. 3, f. 7.

Orale ariondi, assez convexe, noir, luisant. Antennes ferrugineuses. Tête médiocre; front plan, strie bien marquée, senuicirculaire entière; labre petit; mandibules concaves, dentées, courbées en pointe aiguë. Plonotum court, presque droit et bordé de points à la base, arqué sur les côtés, rétréci et échancré en devant, avec les angles abaissés obtus; strie latérale externe très courte, interne entière, non interrompuc. Ecusson petit, triangulaire. Elytres un peu plus longues que le pronotum, de sa largeur à la base, curvilinéaires sur les côtés, rétrécies et droites au bord apical, bord infléchi parcouru par deux sillons ponctués; stries dorsales et suturale crénelées entières, Ies deux internes souvent réunies à la base. Propygidium couvert de points espacés; pygidium finement pointillé. Prosternum court, en carène, à peine élargi à la base, lobe rebordé et abaissé ; mésosterunm droit, bordé d'une stric entière et d'une interrompue. Pattes rouges; jambes antérieures èlargies, garnies de trois petites dents, extrême large, bifide; postérieures d'une double série de nombreux denticules épineux.

États-Unis, commun parinut dans les bouses. 
Espèces que je n'ai pus vues.

70 123' H. secanous, Er. in Jahr, 1, 148, 53 (1834).

Ater, nitidus, pronoto utrinque sesquistriato; elytris striis. "lorsalibus $1-4$ intcyris, $5^{\text {a }}$ et suturali abbreviatis, tibiis anticis 3-dentatis. Long. 5 1/2 mill. - Chine.

De la structure du $\boldsymbol{H}$. carbonarius et très voisin du $\boldsymbol{H}$. $\boldsymbol{J}_{\boldsymbol{a}}$ vanicus. Front plan, assez fortement et densément ponctué, strie arquée sur les côtés, droite par devant; scape des antennes noirâtre ainsi que la massue, funicule rouge. Pronotum fortement rétréci en devant, faiblement arrondi sur les côtés, bisinué au fond de l'éclıancrure antérieure, densément et distinctement ponctué en dessus; strie latérale externe raccourcie au milieu; élytres arrondies sur les côtés, finement pointillées, stries dorsales fortes, 1-4 entières, cinquième raccourcie vers le milieu, suturale de part et d'autre; fossette marginale inégale, mais imponctuée. Propygidium très grossièrement ponctué ainsi que le pygidium. Jambes antérieures 3-dentées.

7` 129'. II. nISPAn, Le C. N. Amér. Hist. 27, 21, pl. 3, 8 (1845).

pronoto striis incequalibus, extcriore brevissima; clytris striis dorsalibus 1-3 et suturali integris; tibiis anticis 3-dentatis. Long. 4 mill. - Etats-Unis (Géorgie), rarius.

Noir, luisant. Tête avec la strie frontale șinuée. Pronotum à stries latérales inégales, externe très courte, rapprochée de la marge, interne entière. Elytres bordées de roux au bout, stries suturale et 1-3 dorsales entières, quatrième largement interrompue au milieu, avee les deux portions réunies par une ligne de points, cinquieme pelite, raccour- 
cie de part et d'autre, quelquefois obsolete. Prosternum ponctué au bout; mésosternum droit, segments intérieurs de l'abdomen lisse, avec quelques points sur les côtés. Pattes brun de poix; jambes antéricures armées de trois dents grandes, obtuses.

70 136'. II. sondids, Aubé in Soc. Ent. (1850), 322, 30.

oblongns, niger; monoti latcribus bistriatis; clytrorum striis dorsalibns 1-4 integris, $5^{a}$ et suturali abbreviatis, subhnmerali mulla, exterins late rubro maculatis; tibiis anticis 4dentatis, dente extremo bifido, intimo vix conspicuo. Longueur 4 mill.

Taille, forme, couleur du $\boldsymbol{H}$. binaculalus. Tête avec la strie ordinaire. Pronotum ayant la strie latérale interne assez éloignée du bord externc, avec une autre petite strie vers les angles antérieurs. Les élytres sont marquées de cinq stries dorsales dont la cinquième est abrégée en avant, ainsi que la suturale et moins qu'elle; la strie subhumérale manque entièrement, et la fossette inférieure du repli latéral est traverscé dans toute son étendue par un sillon marginal; elles sont ornées d'une tache rouge irrégulièrement triangulaire, qui part de l'angle huméral, se dirigeant vers l'angle sutural postérieur, en occupant toute la partie cxterne. Le pygidium, les côtés de la poitrine et de l'abdomen sont fortement ponctués. l'attes ferrugineuses; jambes antérieures fortement dilatées, arec quatre dents, la dernière très large et bifide, la première et la deuxième très petites, la première surtout est presqu'imperceptible.

Espagne méridionale. 
帘

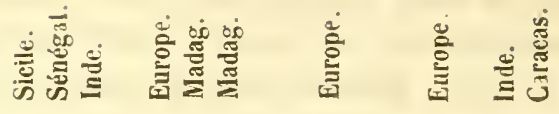

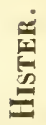
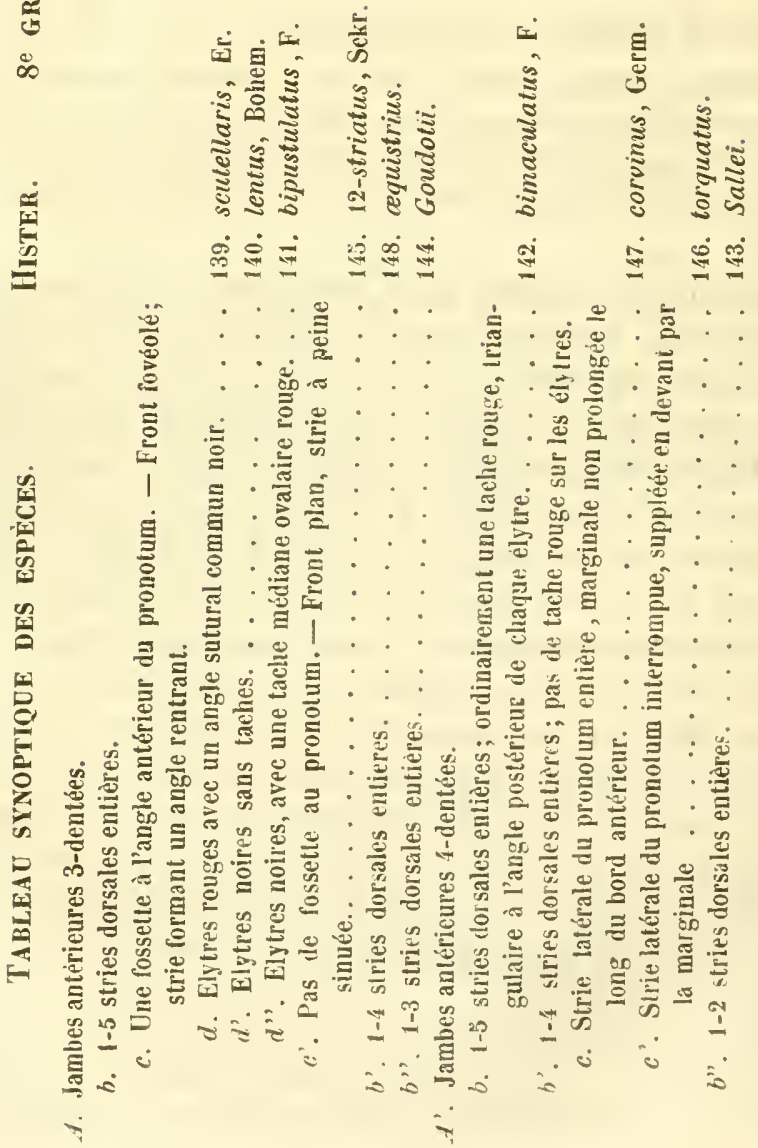
c'. Une senle strie latérale au pronotums.

$$
\text { se Groupe (139-148). }
$$

\section{H. SCITELIARIS.}

Ovalis, convexiusculus, niger, nitilus, fmncticulatus ; antemis rufis; fronte impressa, striu retro acuminata; momoto utrinque fovcolato, shia laterali interna subabbreviata, utrinque simnata, haud intermpta; elytris rubris, macula communi angulala nigra, margine inflexo bisulcato, striis dorsalibus 1-5 crenatis integris, suturali dimidiata; propyyidio perce, mygidio subtilitor mnctalis; mesosterno recto marginatoque; tibiis anticis 3-dentatis, postiris biscriatim 6-7 spinosis. Long. 7 mill.; larg. 5 mill.

IIster scutellaris, Er. in Jahr., 1, 152, 62 (1834).

Ovale, assez convexe, noir, luisaut, pointillé. Antennes rousses. Tête assez grande; front large, strie entière forunant un angle rentrant, impression bien marquée s'étendant sur l'épistone; labre petit; mandibules forles, canaliculées, dentées, courbées en pointe aiguë relevée. Pronotum court, droit et bordé de points à la base, arrondi sur les côtés, échancré et fortement rétréci en devant, avec les angles abaissés, assez aigus, marqués en dessus d'une fovéole ponctuée; strie latérale interne raccourcie, sinueuse daus l'angle, nou interrompue. Ecusson petit, triangulaire. Elytres à peine plus longues que le pronotum, de sa largreur à la base. dilatées ì l'épaule, fortement rétrécies ct arquées au bord apical; ronges avec une grande tache noire triangulaire commune à la base de la suture; bord infléchi parcouru par deux sillous ponctués; stries crénelées, 1-5 dorsales entières, cinquième recourbée vers la suture à la base, suturale raccourcic. Propygidium couvert de points entremêlés, d'autres très fins. Pygidium bombé 
finement pointillé. Prosternum court, en carène obtuse, à peine élargi à la base, lobe court, large, rebordé et abaissé. Mésosternum droit, bordé de deux stries, l'une entière, l'autre interrompue. Pattes brunes. Jambes antérieures armées de trois fortes dents ; postérieures garnies de 6-7 denticules épineux.

Sicile; Dalmatie ; Syrie (Smyrne)

\section{II. LENTUS.}

Ovalis, convexus, niger, nitidus; antennis rufis ; fronte impressa, stria retrorsum angulata; mandibutis canuliculat is ; monoto bifovcolato, stria laterali interna integra; elytris

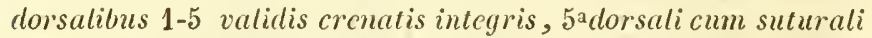
arcuatim connexa; propygidio bifovcolato pygidioque parum dense munctatis; mesosterno subsinuato, stria subinterrupta; tibiis anticis 3-dentatis, posticis biseriatim 6-spinosis. Longueur 7 mill.; larg. 4 1/2 mill.

Ovale, convexe, noir de poix, luisant. Antennes rousses. Tête grosse, front large, bombé postérieurement, avec une fossette large profonde au milicu; strie entière, bien marquée au fond de la fossette et $\mathrm{y}$ formant un angle rentrant bien prononcé; labre court; mandibules fortes, inégales, dentées en dedans, creusées en gouttière, à pointe recourbée, obtuse. Pronotum finement pointillé, court, large ; droit et bordé de points à la base, avec une petite impression antéscutellaire, courbé sur les côtés, rétréci et échancré en devant, avec les angles abaissés, obtus, marqués en dessus d'une fossette arrondie; strie latérale interue cntière, oblique, non interrompue en devant. Ecusson petit, triangulaire. Elytres un peu plus longues que le pronotum, de sa largeur à la base, curvilinéairement dilatees sur les côtés, fort rétrécies et légèrement arqqućes postérieure- 
ment; quelquefois une strie subhumérale interne obsolète, réduite is un court rudiment, et accompagnée d'une autre courte strie externe; dorsales et suturale entières, fortes , crénelées, cinquième et suturale réunies ensemble à la base, quelquefois obsolètes; bord infléchi bisillonné, sans points. Propygidium bifovéolé, assez fortement ponctué mais peu densément, ainsi que le pygidium. Prosternum en carène, pen élargi à la basc, lobe rebordé, abaissé. Mésosternum légèrement sinué, strie obsolète au milieu. Pattes brunes; jambes antérieures dilatées, armées de trois fortes dents; postérieures garnies de cinq ou six paires de denticules épineur.

Sénégal.

\section{H. BIPISTCLATIS.}

Ovalis, convexus, niger, nitidus; antemis brumneis; fronte impressa, stria retrorsum acuminata; mandibulis canalirulatis; monoto utrinque foveolato-punctaio, stria lateruli haud interrupta, basi adunca; elyeris macula media mubra, margine inflexo bisulcuto, dorsulibus 1-5 crenatis integris, suturati subabbreviata; mopygidio mygidioque parce munctutis; mesosterno subsimulo marginutoque; libiis unticis 3-dentatis, posticis biseriatim multispinosis. Long. 5 mill.; larg. 3 1/2 mill.

Hister bipustulutus, F. Ent. Syst., Suppl., 38, 16-17 (1798); S. El. 1, 87, 20. - Payk., Mon. Hist. 33, 22, pl. 13, 1.

Orale, convexe, noir, luisant. Antennes brunes, massue grise. Tête grosse; front large, arec une impression qui s'étend sur l'épistome; stric bien marquée, formant un angle rentrant; labre court; mandibules canaliculées, dentées, courbées en pointe obtuse. Pronolum court, droit et bordé de points à la base, arrondi sur les cô'és, fort rétréci et bisinueusement échancré en derant, arec les angles abaissés, 
obtus, et une fossette ponctuée en dessus; strie laterale interne unique, presqu'entière, en crochet à la base, sinueuse a l'angle et non interrompue. Ecusson petit, triangulaire. Elytres à peine plus longues que le pronotum, de sa largeur à la base, dilatées à l'épaule, très rétrécies et arquées au bout, bord iıfléchi bisillonné; stries fortes, créuelées, 1-5 dorsales entières, suturale raccourcie; une tache rouge petite, ovalaire au milieu de chaque élytre. Propygidium et pygidium couverts de points espacés, assez gros. Prosternum en carène très obtuse, peu élargi à la base, lobe rebordé, infléchi. Nésosternum à peine sinué, bordé d’unc strie entière. Jambes antérieures armées de trois fortes dents; postéricures garnies de 7-8 paires de denticules épineux.

Inde (Pondichéry); Malaisie (Ceyłan).

\section{H. HIMACTLATES.}

Ovalis, parum comvexus, niger, nitidus; antemis pedibusyuc rufts; strin frontali retrorsum angulatu; monoto bifovcolato, striu laterali subablreviatu, haul internuta; elytris nargine 1-sulcuto, dorsulibus crenutis, 1-5 imegris, suturati ubbreviatu, sctpius macula briungulari externa rubra; mromygidio subti. liter punctulato; pygidio sublavi; mesosterno recto marginatoque; libiis anticis 4-rlentatis, posticis biscriatim multispino. sis. Long. 412 m ill. : larg. 3 mill.

Ilister bimaculntus, L. Syst. Nat. 1, 11. p. 567, 5 (1735); Fn.

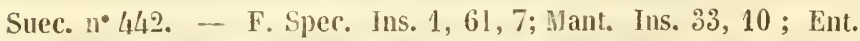
Syst. 1, 76, 17 ; Syst. El. 1, 88, 23. - 01. Ent. 1, 8, p. 11, 10. pl. 2, 12. - Rossi, Fn. Etr. 1, 31, 72. - Panz. Ent. Germ. 1. 23, 17; F.. G. 80, 4. - E. H. 1, 50, 8. - Stum, Deuts. En. 1, 206, 10. -Duft. Fn. Aust. 1, 218. 13.-Illig. Kæf. Prus. 1, 54, 6.-Gyll. Ins. Suec. 1, S0, 8.-Payk. Mnn. Hist. 3̆4, 23, pl. 3, f. 6; Fn. Suec. 
1, 38, 5.- Le Conte, N. Amér. Ilist. 29, 26, pl. 4, l. 1. - Li. Kief. Brand. 1, 66!1, 14. - Steph. 1ll. Brit. Ent. 3, 148, 9. - Ileer, Fn. Helv. 1, 458, 20. - Küist. Kief. Eur. 4, 70. - Redı. Fu. Austr. 234. - Bach, Kàf. Pius. 1, 304, 16.

11. eryutropterns, F. Ent. Supl). 38, 16 (179S) ; Syst. El. 1, SS, 22. - Ol. Ent. 1, 8, pl. 2, f. 12.

11. obliquns, Say, iı Soc. Phil. v, 37, 7 (1825).

II. apicatus, Schrank, Fu. Boic. 1, 11, 452 (179S).

Ovale, peu convexe, noir, luisant. Antennes rouges. Tête médiocre; front large, plan; strie entière formant un angle rentrant; labre petit; mandibules dentées, courbées en pointe aiguë. Pronotum court, droit et bordé de points à la base, arrondi sur les côtés, rétréci et échancré en devant, avec les angles abaissés, obtus, marqués en dessus d'une fossette ponctuée; stric latérale interne unique, raccourcie à la base, non interrompue. Ecusson petit, triangulaire. Elytres un peu plus longues que le pronotum, de sa largeur à la base, curvilinéaires sur les côtés, arquées ct rétrécies au bout, divisées par une diagonale, de l'épaule à l'angle sutural, en deux parties égales, l'une noire, l'autre rouge; borl infléchi 1-sillonnė; stries fortes, crénelées, 1-5 dorsales entières, les deux premières un peu plus rapprocliées, suturale faiblement raccourcie. Propygidium finement ponctué. Pygidium paraissant lisse. Prosternum court en carène étroite, élargi à la base, lobe rebordé et rabattu. Mésosternum droit, bordé d'une strie entière et d'une interrompue. Pattes ferrugineuses; jambes antérieures garnies de quatre petites dents, extrème bifide; postérieures de 7-8 paires de denticules épineux.

Répandu dans presque toutes les parties du globe : Angleterre, Suède, France, Suisse, Allemagne, Autriche, Espagne, Italie; Caucase: Algérie; Syrie (Beyrouth); Inde; 
Amérique boréale, il n'est commun nulle part. Il vit daus les fumiers.

\section{II. Sallei.}

Suborbiculuris, convexinsculus, niger, nitidus; antemis brunneis; fronte concava; stria scmihcxagona; pronoto laterati interna integra ; elytris apice transversim impressis punctatisque; 1-2 dorsalibus integris, 3-4 late interuptis, salrevissimaupicali, suturali in medio abbreviata; margine inflexobisulcato propygidio bifovcolato pygidioque parce munctatis; prostcrno bistriato; mesostemo simuato marginatoque; tiniis anticis 4-dentatis; posticis biseriutim multispinosis. long. 6 mill.; larg. 4 1/2 mill.

Ovale arrondi, assez convexe, noir, luisant. Antennes rougebrun, scape plus foncé. Tête assez grande; front concave, strie entière bien marquée, semihexagonale; labre allongé ; mandibules fortes, à pointe peu courbée, obtuse. Pronotum plus large que long, arqué et ponctué à la base, avec une petite impression antéscutellaire, courbé légèrement sur les côtés, rétréci et échancré en devant, avec les angles abaissés, assez aigus; strie latérale interne unique, droite sur les côtés, entière, interrompue en devant ; marginale fine sur les côtés, distincte jusqu’ả la base et se continuant derrière le bord antérieur sans interruption. Ecusson petit, triangulaire ; élytres bombées, plus longues que le pronotum, de sa largeur à la base, curvilinéairement dilatées sur les côtés, avec l'épaule saillante, rétrécies, ponctuées et obliquement arquées au bout, formant un angle sutural bien marqué et une impression subapicale; stries 1-2 dorsales entières fortes, crénelées , 3-4 largement interrompues avant le milieu, cinquième réduite à un court rudiment apical, suturale atteignant le milieu ; bord infléchi plan, bisillonné, à peu près lisse. Propygidium bifovéolé, couvert d'une ponc- 
tuation forte et espacée, ainsi que le pygidium. Prosternum bistrié, à peine élargi à la base, lobe rebordé, rabaltu. Mésosternum échancré et bordé d'une strie entière. Jambes antéricures dilatées, armées de quatre dents très obtuses; postérieures de huit ou dix paires de tubercules épineux.

Cette espèce rare a été trouvée en janvier, sous les bouses dans les montagnes, aux environs de C'aracas (Venezuela), par M. A. Sallé, qui a bien voulu me la céder.

\section{H. GovDotir.}

Ovalis, convexus, niger, nitidus; fronte biimpressa, stria antice simuta; pronoto laterali interna integra, bisinnata; elytris 1-3 dorsalibus integris, crenatis, $4^{\text {a }}$ late interupta, $5^{a}$ nulla, suturali abbreviata; fossa marginali vix punctulata; propygidio bifoveoluto mygidioque densins grosse punctatis; mesosterno recto, marginato; tibiis anticis 3-dentatis; posticis biscriutim 5̆-6 spinosis. Long. 5 1/2 mill.; larg. 4 mill.

Ovale, légèrement convexe; noir, luisant. Antennes d'un brun-ferrugineux. Tête assez grande; front large, biimpressionné, strie forte, entière, sinuée en devant ; labre court, arrondi ; mandibules fortes, édentées, canaliculées, à pointe arquée, aiguë. Pronotum beaucoup plus large que long, presque droit et bordé de points à la base, courbé sur les côtés, rétréci et échancré en devant, avec les angles abaissés, un peu obtus; stric latérale interne forte, à peu près entière, sans toucher cependant la base, coudée sur les côtés, non interrompue en devant, sans angles postoculaires. Ecusson petit, triangulaire. Elytres courtes, un peu plus longues que le pronotum, de sa largeur à la base, curvilinéairement dilatées sur les côtés, rétrécies et légèrement arquées au bout; stries 1-3 dorsales entières, fortes, cré3e Série, Tone II. 
nelées, quatrième composée de deux courtes stries, uıc basale, l'autre apicale, cinquième nulle, suturale raccourcie de part et d'autre; fossette marginale bisillonnéc, peu distinctement pointillée. Propygidium bifovéolé, couvert de points forts, espacés. Pygidium plus densément et aussi fortement ponctué. Prosternum en carène aiguë, à peine élargi à la base, lobe rebordé et abaissé. Mésosternum droit et bordé d'une forte strie. Jambes antérieures armées de trois dents; postérieures garnies de 5-6 paires de denticules épineux.

Madagascar.

\section{H. 12-STRIATUS.}

Oblongo-ovatus, convexus, niger, nitidus; fronte subimpressa, stria integra angulata; mandibutis canaliculatis; pronoto stria laterali sutintegra hand interrupta, clytris margine bisulcato, striis crenatis, 1-5 dorsalibus intcgris, $5^{\text {a }}$ cum suturali conjuncta; propygidio parce, pygidio vix punctulatis; mesosterno recto marginatoque; tibiis anticis 3 -dentatis, posticis biseriatim 5-6 spinosis. Long. 5 mill. ; larg. 3 mill.

IIister 12-striatus, Schrank, Enum. Insect . Austr. 39, 70 (1781). - Payk. Fn. Suec. 1, 39, 6; Mon. Hist. 36, 25, pl. 3, f. 5. - Gyll. Ins. Suec. Iv, 263, 11-12. - Steph. Ill. Brit. Ent. ', 147, 8. - Er. Kæ. Brand. 1, 665, 16. - Heer, Fn. Helv. 1, 458, 22. - Küst. Kæf. Eur. 6, 56. - Redt. Fn. Austr. 234. - Bach, Kæf. Pruss. 1, 304, 18.

II. 12-striatus, var, $a$. E. H. 1.58, 12. pl. 1, 6 (1803).-Sturm. Deuts. Fn. 1, 213, 14.

H. bissexstriatus, Duft. Fn. Aust. 1, 215, 9 (1805). - Illig. Mag. vi, 34, 7 (1807).

Ovale allongé, assez convexe, noir, luisant. Antennes d'un brun-roux. Front large, pointillé, un peu impressionné, stric entière formant un angle rentrant; labre petit; man- 
dibules dentées, canaliculées, courbées en pointe obtuse. Pronotum court, droit et échancré en devant avec les angles abaissés, obtus; stric latérale interne unique, crénelée, non interrompue, n'atteignant pas tout à fait la base. Ecusson petit, triangulaire. Elytres plus longues que le pronotum, de sa largeur à la base, curvilinéaires sur les côtés, un peu rétréeies et obliques au bout; fossette marginale bisillonnée; stries fortes, crénelées, toutes entières, cinquième dorsale et suturale réunies à la base. Propygidium couvert de petits points espacés. Pygidium paraissant lisse. Prosternum en carène aiguë, ćlargi à la base, lobe court, rebordé et rabattu. Mésosternum droit bordé d'une strie entière et d'unc interrompue. Pattes bruncs. Jambes antérieures garnies de trois dents, extrême bifide; postérieures de 5-6 paires de denticules épineux.

Angleterre, Suède, France, Suisse, Autriche, Allemagne, Dalmatie, Illyrie, Espagne, Russie; Syrie; Algérie. Assez commun dans les bouses, le fumier, le bois pourri.

\section{H. TORQUATUS.}

Suborbicularis, convexus, niger, nitidus, puncticulatus; fronte biimpressa, stria semihexagona; pronoto laterali interna unica, antice interrupta, marginali cjus tocum excipiente; cly. tris dorsalibus 1-4 integris, $5^{\text {a }}$ et suturali dimidiatis, crenatis, fossa marginali bisulcata; propygidio bifoveolato parce, pygidlo vix punctulatis; mesosterno recto marginatoque; tibiis anticis 4.5 dentatis, posticis biseriatim multispinosis. Long. 4 3/4 mill. ; larg. $31 / 2$ mill.

Suborbiculaire, convexe, noir, luisant, pointillé. Antennes brunes. Tête médiocre; front large, avec une double impression ; strie profonde, entière, semihexagonale; labre petit; mandibules édentées, courbées en pointe aiguë. 
Pronotum court presque droit et bordé de points à la base, arrondi sur les cötés, rétréci et bisiuueusement échancré en devant, avec les angles abaissés. obtus; strie latérale interne unique, un peu raccourcie a la base et cessant à l'angle antérieur, marginale la remplaçant en devant. Ecusson petit, triangulaire. Elytres un peu plus longues que le pronotum, de sa largeur à la base, curvilinéaires sur les cotés, rétrécies et droites au bout; fossette marginale lisse, bisillonnée ; stries bien marquées, crénelées, 1-4 dorsales entières, cinq̨uième raccourcie au milieu, suturale un peu au-delà. Propygidium couvert de points espacés. Pygidium à peine visiblement pointillé. Prosternum en carènc obtuse, tronqué et peu élargi à la base, lobe rebordé et abaissé. Mésosternum droit et rebordé. Jambes antérieures garnies de 4.5 petites dents, extrême trifide; postérieures de 7-8 paires de denticules épineux.

Inde.

\section{H. CORvinus.}

Ovalis, convcxiusculus, niger, nitidus; untemis pedibusque ferrugineis; stria frontali valida semicirculari; monoto laterali interna unica bisinuata hand interrupta; elytris fovea marginali bisulcuta, 1-4 dorsalibus integris, $5^{\text {a }}$ et suturali dimidiatis; propygidio bifoveolato punctato, pygidtio puncticulato; mesosterno recto marginatoque; tibiis anticis 4-dentatis, posticis biseriatim multispinosis. Long. 4 mill.; larg. 3 mill.

Hister corvinus, Germ. Reis. Dalm. 85.37 (1817). - Gyll. Ins. Suec. 4, 262, 7-8. - Er. Kæf. Brand. 1, 664, 15. - Stejh. Iil. Brit. Ent. 3, 148, 11. - Heer, Fn. Helv. 1, 458, 21. - Küst. Kæf. Ëur. 6, 55. - Redl. Fn. Austr. 23\%. - Bach, Kix. Pruss. 1, $304,17$.

11. bisscxstrintns, var. Payk. Mon. Hist. 32, pl, 3, f. 4 (ISI1). 
Ovale, peu convexe, noir, luisant, pointillé. Antennes ferrugineuses. Tete médiocre, arrondie; front plan, strie semicirculaire forte, entière; labre très petit; mandibules dentées, canaliculées, courbées en pointe. Pronotum court, droit et bordé de points à la base, arqué sur les côtés, rétréci et échancré en devant, avec les angles abaissés, obtus; strie latérale interne unique, entière, sinuée, non interrompue. Ecusson petit, triangulaire. Elytres un peu plus longues que le pronotum, de sa largeur à la base, presque parallèles et à peine rétrécies au bout arec une faible impression subapicale; fossette marginale bisillonnée; stries 1-4 dorsales entières, cinquième raccourcie au milieu, suturale un peu au-delà. Propygidium bifovéolé, couvert de points espacés; pygidium très finement pointillé. Prosternum en carène, droit et peu élargi à la base, lobe court, rebordé et rabattu. Pattes ferrugineuses, jambes antérieures garnies de quatre petites dents, extrême bifide; postérieures de nombreuses paires de denticules épineux.

France, Allemagne, Autriche.

\section{H. EQTISTRIIS.}

Breviter ovatus, convexiusculus, niger, nitidus ; untennis rufis; fronte plana, striu integra subsinuata; pronoto laterali integra; elylris striis vulidis crenatis, 1-4dorsalibus integris, 5 a ante, suluruli in medio abbreviutis, fossa luterali 1-sulcata; propygidio punctis sparsis, mygidio sublavi; mesosterno recto marginutoque; tibiis anticis 3 -dentatis; posticis biseriatim multispinosis. Long. 3 1/2 mill.; larg. 2 1/2 mill.

Orbiculaire, assez convexe, noir, luisant, finement pointillé. Antennes rousses. Tète assez grande; front large, plan, strie forte, entière, légèrement sinuée en devant; labre court, 
arrondi; mandibules fortes, creusées en dessus, à pointe aiguë. Pronotum beaucoup plus large que long, presque droit et bordé de points à la base, courbé sur les côtés, échancré et rétréci en devant, avec les angles antérieurs abaissés, assez obtus; strie latérale interne unique, bien marquée, entière. non interrompuc en devant. Ecusson petit, triangulaire. Elytres un peu plus longues que le pronotum, de sa largeur à la base, curvilinéairement dilatées sur les côtés, rétrécies et un peu obliques au bout; stries fortes, crénelées; 1-4 dorsales entières, cinquième raccoureje un peu avant le milieu, suturale au-delà ; fossette marginale 1-sillonnée , peu distinctement pointillée. Propygidium avec quelques points épars; pygidium paraissant imponetué. Prosternum court, en carène assez aiguë, droit et peu élargi à la base, lobe court, rebordé et rabattı; mésosternum arqué en devant, bordé d'une strie entière. Jambes antérieures armées de trois petites dents, extrême bifide; postérieures garnies de six ou sept paires de denticules épineux.

Madagasear (M. de Laferté).

Espèces que je n'ai pas vues.

8o 147'. H. Puncticollis, Redt. Fn. Austr. 782 (1849.)

Mésosternum légèrement échancré pour recevoir la base obtuse du prosternum. Noir, luisant, tarses rouge-brun, palpes et massue des antennes rouges. Pronotum deux fois aussi large que long, un peu rétréei par devant et profondément échancré, fortement et densément ponctué sur les côtės avec une strie latérale profonde. Elytres avec six stries, dont les trois externes entières, imponetuées, les trois autres interncs avec quelques points, atteignant à peine le milieu; 
repli latéral ponctué. Jambes antérieures garnies de quatre à cinq dents graduellement plus fortes. - L. 4 mill. - Uu seul individu des environs de Vienne (Autriche).

Il doit se placer auprès dı H. corvinus, el si l'on ne tient pas compte de la petite strie latérale externe du pronotum, la description se rapporte bien au 11 . morens ou au funestus.

80 147". I. puxcticolus, Heer, Fn. Helv. 1, 459, 19 (1841).

Oblongo-ovalis, pronoto lateribus confertim punctato; clytris striis 1-3 dorsalibus integris, 4-5 ct suturati abbreviatis, tibiis anticis 3-dentatis. Long. 5 mill.

Front déprimé, lisse; pronotum un peu rétréci en devant, uni-strié latéralement, strie latérale rapprochée du bord, lisse sur le disque, densément et assez profondément ponctué sur les côtés; élytres dilatées au milieu, stric suturale très raccourcie, cinquième dorsale un peu plus longue, quatrième atteignant le milieu, 1-3 entières, sublıumérales nulles; bord infléchi avec 3 stries ponctuées. Propygidium et pygidium densément et profondément ponctués. - Suisse, très rare.

80 147"'. H. NigriTA, Steph. Ill. Brit. Ent. 3, 149, 12 (1830)

Suboblongus, atcr, clytris 6-striatis, 2 interioribus abbrcviatis, libiis anticis 5.dentatis, dente extimo bifudo. Long. 4 1/2 mill.

Oblong, noir foncé, assez lisse ; strie latérale droite et rapprochée du bord. Elytres chacune arec une strie suturale raccourcie au milieu; dorsales $1-4$ entières, cinquième très courte, du tiers de la suturale; subhumérale nulle. Paltes noires; jambes antérieures garnies de cinq dentelures, la dernière bifide. Antennes noires; bouche noir de poix. 
Le manque de strie subhumérale le distingue du $I I$. carbonarius, qui lui ressemble un peu. - Londres, un seul exemplaire.

Espèce dont la place est incerlaine.

? H. Afer, Payk. Mon. Hist. 12, 4. T. xil, f. 6 (1811). Ater vitidus, pronoto striis 2, elytris 9 integris. Long. 9 mill. -. Guinée.

Front sans fossette, à strie bien marquée, finement pointillé ; mandibules égales, aussi longues que celle du $\boldsymbol{H}$. unicolor, armées d'un denticule assez fort; massue des antennes noir de poix. Pronotum aussi large que long par devant, et deux fois plus par derrière, convexe; stries latérales entières, à peu près droites, rapprochées un peu postéricurement, externe assez éloignée du bord, très pointillé comme dans 11. punctiger. (Plus tard ce nom est remplacé dans Paykul, p. 25, par punctifer). (Un seul individu m'a présenté des poils marginaux.) Elytres à peine deux fois plus longues que le pronotum, de sa largeur à la base, un peu dilatées au milieu, retrécies au bout, convexes; suturale, 1-5 dorsales, subluumérale et deux marginales, distantes entre elles également, entières, suturale et 4-5 dorsales cependant un peu plus courtes que les autres; interstries finement pointillés. Dessous noir de poix peu profondément ponctué, lobe prosternal avancé, arrondi au bout. Pattes noir de poix; jambes postérieures dilatées épineuses; antérieures encore plus larges, armées de trois dents entières, première plus petite. Taille du $H$. unicolor.

Cette espèce me parait devoir se rapprocher du Contipus digilatus. 


\section{ESSAI MONOGRAPHIQUE}

\section{SUR LA FAMILLE DES HISTERIDES.}

(Suite) (1).

Par M. S. A. de MARSEUL.

(Séauce du 9 Février 1853.)

\section{EPIERUS.}

(ย̉mínpos, gracieux).

Soc. Ent. 3e série, t. 11 (1854), pl. 10. - Mon. pl. xı, G 21.

Hister, F. Illig. Ros. Payk. Say.

Epierus, Er. in Jahr. 1, 158, xı (1834); Le Conte.

Corpus ovatum, parvum.

Cuput convexum, stria frontuli nulla, mandibulis retractis, cequalibus; antennee sub frontis margine inserte, foveola sub angulo prothoracis margine pectoris obtceta.

P'ronotum trapezoidale, stria marginali.

Elytra striala, apice truncata, maryine inflexo haud foveo lato, striato.

Prupygidium transerersum, pygidium trigonum, declivia.

Prosternum elevatum, busi subtruncutum haud receptum, bistriatum, lobo antico mediocri; mesosternum antice vix sinuatum, marginatum.

Tibice unticu setulis breviter serrata, foveola tarsali levi.

(1) Voyez $3^{e}$ Série, T. I (1853), p. 131 et 447, et T. II (1854), p. 161 et 525 . 
Corps en ovale plus ou moins allongé, médiocrement convexe en dessus, quelquefois aplati, ordinairement d'un noir de poix luisant.

Tête petite, enfoncée dans le prothorax; front bombé, sans strie qui le distingue de l'épistome; labre court, arrondi au bout ; mandibules courbées, peu saillantes, terminées en pointe avec une dent subapicale interme.

Antennes (f. $2 c$ ) insérées sous un rebord du front un peu au-dessus des mandibules; scape presque droit, assez long, plus ou moins élargi au bout; funicule de sept articles, premier obconique, aussi long que les trois suivants réunis; 2-7 serrés, à peu près égaux, seulement les premiers tant soit peu plus longs que les derniers; massue ovalaire comprimée.Fosseties antennaires profondes, creusées sois l'angle antérieur du prothorax, au-dessus du bord pectoral, qui les recouvre et n'est pas entaillé pour le passage de l'antenne.

Nàchoires (f. $2 b$ ) élargies, cornées, à 2 lobes membraneux, l'exterme arrondi, beaucoup plus large et plus long, barbu au bout, l'interne cultriforme, barbu en dedans, plus court et plus étroit. Palpes maxillaires forts, de quatre articles; premier petit, deuxième obconique, assez long, épais et renflé au bout; troisième court, cylindrique; quatrièmc long, ovalaire, obtus au bout. Menton (f. 2 a) corné, beaucoup plus large que long, plus étroit en devant, avec une double échancrure de chaque còté; lèvre membraneuse, échancrée, paraglosses allongées, frangées. Palpes labiaux Je trois articles; premier petit, deuxiènı obconique et troisième ovalaire, à peu près d'égale longueur.

Pronotum trapézoïde, arrondi à la base, fortement appliqué contre les élytres, arqué sur les côtés, rétréci et fortement échancré en devant, avec les angles antéricurs saillants 
et abaissés; une strie maıginale line, pas de latérale. Ecusson très petit, triangulaire. Elytres plus longues que le pronotum, de sa largeur à la base, courbées latéralement, rétrécies et coupées ciroit au bord apical; rebord infléchi sans fossette humérale, sillonné d'une ou deux stries marginales; strie humérale fine, oblique, une sublumérale externe, rarement une interne; une suturale el cinqdorsales, dont les plus rapprochées de la suture manquent quelquefois. Prosternum ( fig. $d, e, f, g, h, i, j, h, l, m, n, p, r, s, \imath, u$ ) légèrement saillant, plus long que large, bistrié, droit ou faiblement sinué à la base, terminé en devant par un lobe court, arrondi en devant. Mésostermum court, légèrement bisinué ou droit en devant, distinct du métasternum par une strie très fine, rebordé d'une strie marginale et dans plusieurs espèces traversé en outre par une autre strie semi-circulaire plus forte.

Pattes allongées, assez distantes à leur insertion. Cuisses dilatées au milieu, comprimées, rebordées en dedans. Jambes aplaties, légèrement élargies au bout, terminées par deux épines inégales; antérieures courbées, plus larges, garnies d'épines courtes, serrées, et comme pectinées, avec une rainure oblique superficielle, pour recevoir le tarse; intermédiaires garnies de petites épines; postérieures ciliées au bout seulement. Tarses menus, de cinq articles, dont les quatre premiers sont garnis en dessous chacun de deux soies; premier beaucoup plus court que le deuxième; le dernier beaucoup plus long, terminé par deux crochets.

Abdomen de cinq anneaux; premier segment ventral beaucoup plus long que les quatre autres, ceux-ci très courts. - Propygidium court, hexagonal, pygidium triangulaire, l'un et l'autre.inclinés. 
Le genre Epierus a été créé en 1834, par Erichson (Jahrbuch. 1, p. 158), pour trois espèces d'Hister, décrites par Paykull dans sa monographie (H. retusus, comptus, Illig. et fulvicornis), auxquelles il en joint six autres nouvelles, passant sous silence le $\boldsymbol{H}$. nigrellus, publié par Say dès 1825. Il s'appuie principalement sur la forme des jambes antérieures garnies en dehors d'une rangée de courtes épines serrées, sans fossette tarsale bien marquée; sur le prosternum élevé, tronqué à la base, garni en devant d'un lobe assez court; sur la fossette antennaire creusée sous l'angle du prothorax, un peu recouverte par le bord pectoral ; enfin sur l'insertion des antennes sous un rebord du front, au devant des yeux. Ces caractères bien tranchés, parfaitement d'accord avec la forme, font de cette coupe générique une des plus homogènes et des mieux établies. Depuis, M. Le Conte a décrit deux autres espèces, l'une dans ses Hislérides de l'Amérique du Nord (1845), l'autre, dans les Insectes de Californie :(1851). J'ai pu augmenter le nombre de seize nouvelles espèces.

Ces insectes, sauf le $\boldsymbol{E}$. Watcrhousii, ont tous une livrée sombre, noire ou brune. Ils vivent tous dans cette décomposition putride qui se forme sous l'écorce des arbres morts. Ils sont répandus sur le sol de l'Amérique, tant dans les îles du golfe du Mexique que sur le continent, depuis les EtatsUnis jusqu'au Brésil. Trcis seulement se retrouvent en Europe.

Ils ont quelques points de contact, soit pour le facies, soit pour la forme, avec certaines espèces de Carcinops, d'Hister et de Phelister. Leurs jambes antérieures étroites, garnies de soies courtes, serrées, égales, les distinguent tout d'abord de tous les autres. Leur prosternum bistrié, tronqué à la 
base et leur fossette antennaire un peu couverte par le bord pectoral les séparent des Hister; la base du prosternum non pénétrée par une pointe du mésosternum, le défaut de fossette tarsale et de strie frontale, des Phelister; enfin la fossette bien marquée dans l'angle même du prothorax, des Carcinops. 

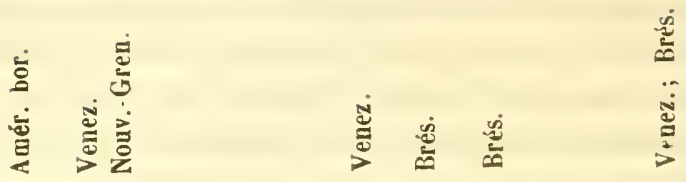

a
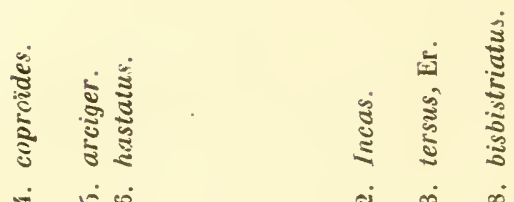

¿ุ

$$
\text { - } \therefore 0^{\circ}
$$

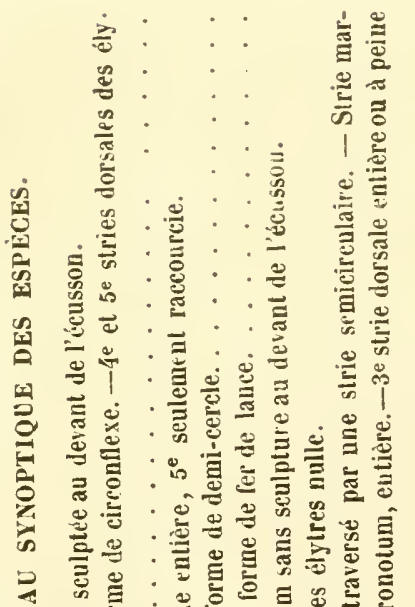

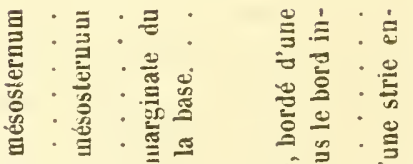

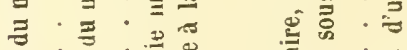

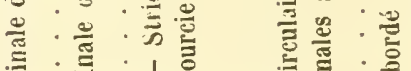

.

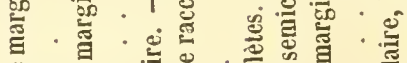

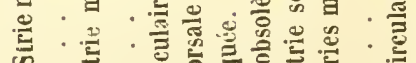

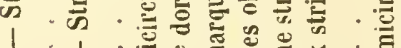
1. 1. ह

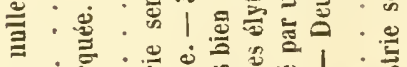

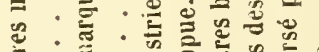

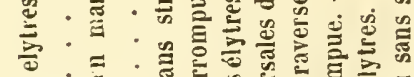

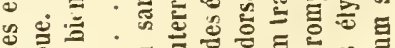

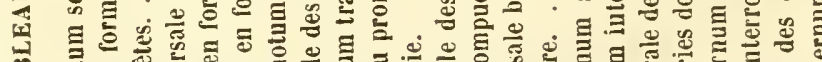
ᄂ 山

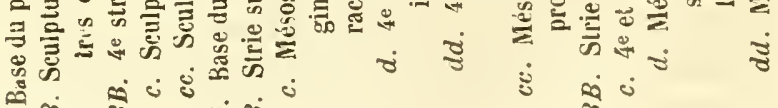

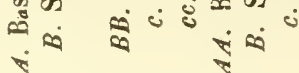


XXI Epierus.

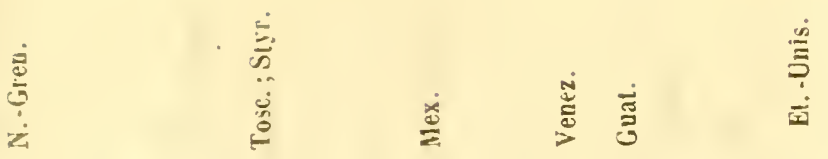

$\stackrel{\substack{3 \\ \frac{3}{3}}}{\frac{3}{3}}$

这

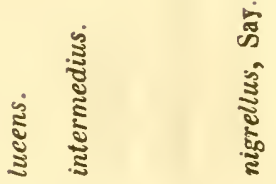

$\therefore \quad \dot{0} \quad \dot{0}$ व

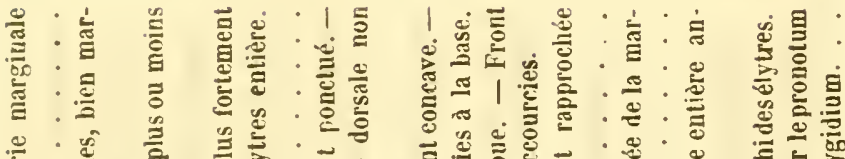

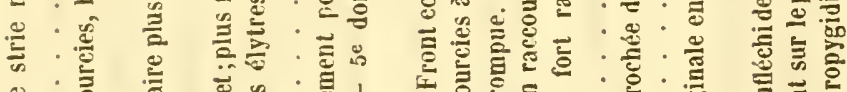

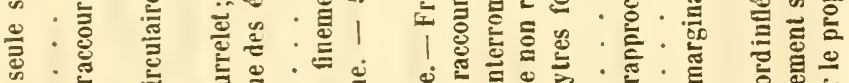

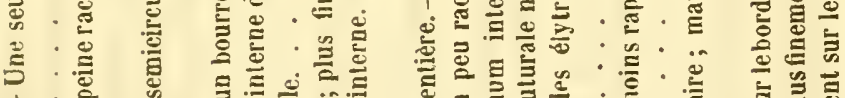

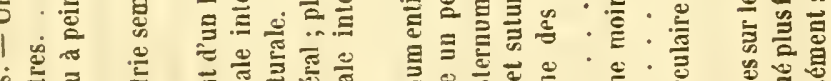

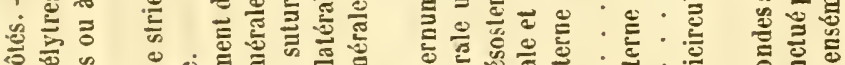

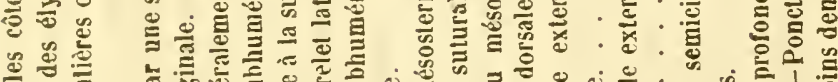

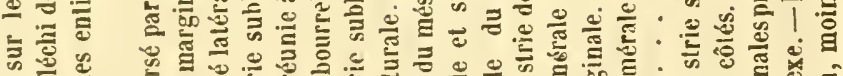

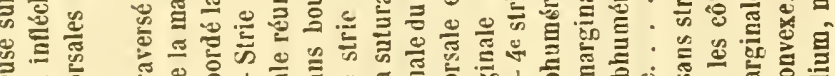

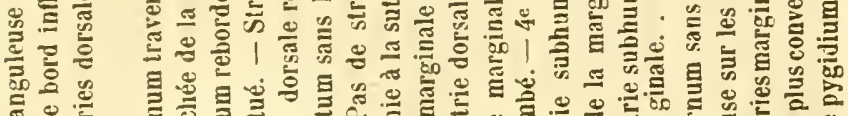

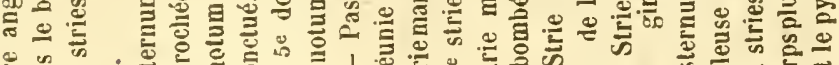

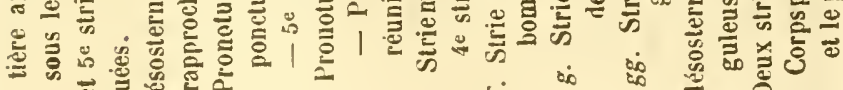

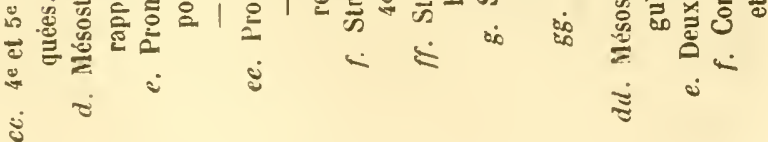


Ð $\frac{8}{\circ}$

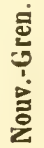

릉

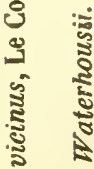

$\stackrel{\dot{1}}{\dot{2}}$
ํㅓㄴ

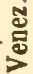

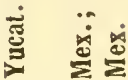

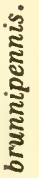

$\infty$

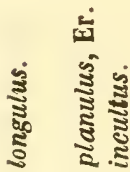

这

वं

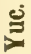

$\stackrel{d}{2}$

㐫

گำ

สี สี่

:

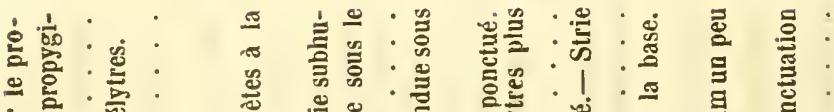

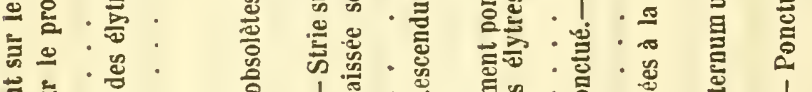

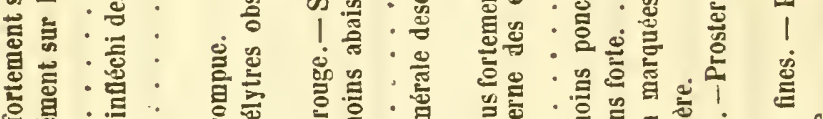

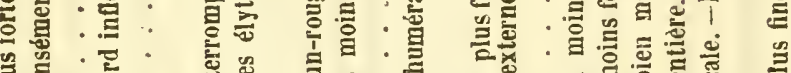

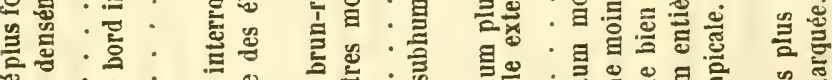

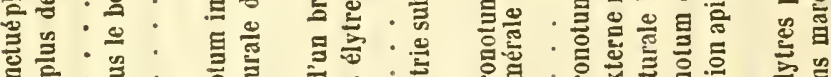

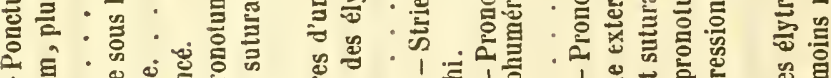

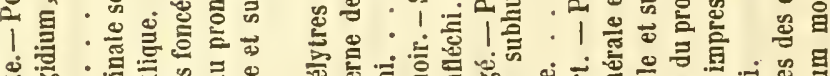

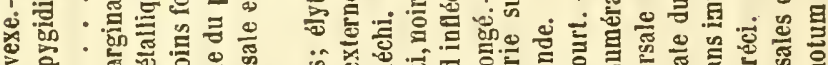

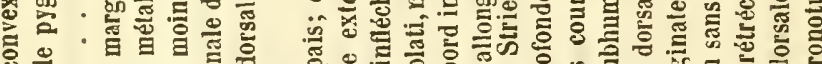

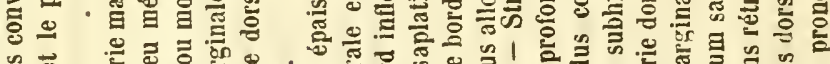
ฯ

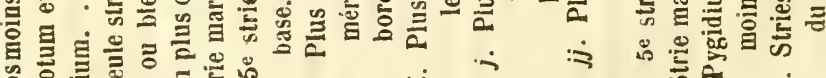

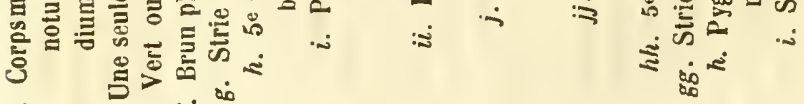
$<\quad \dot{0}<$ 


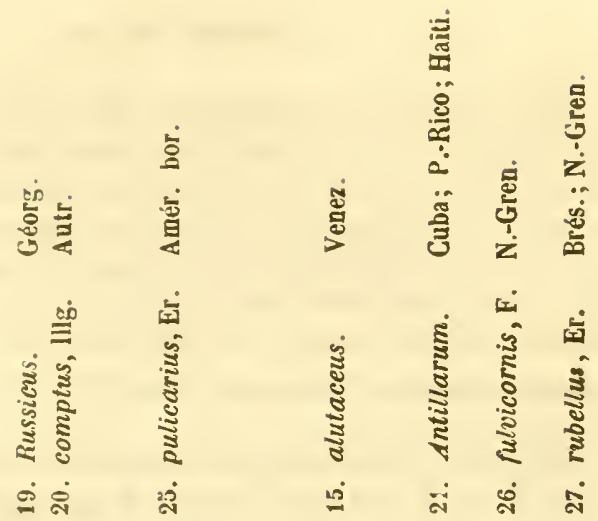

플
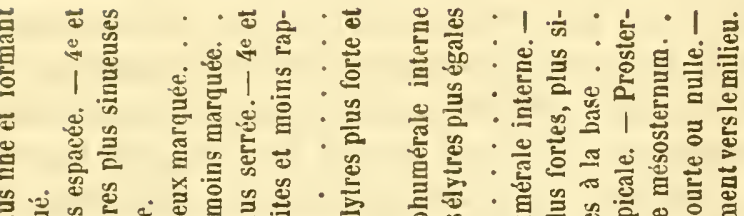

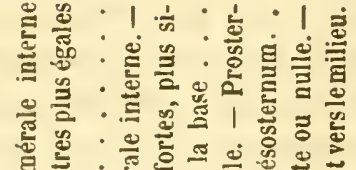

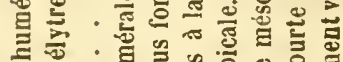

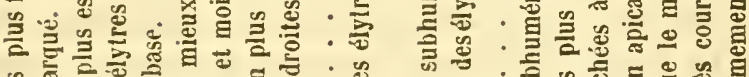
\&. 凹 छ 응

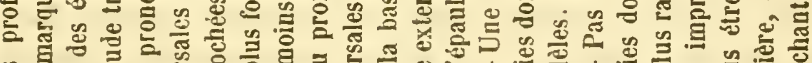

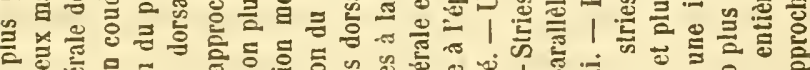
๓

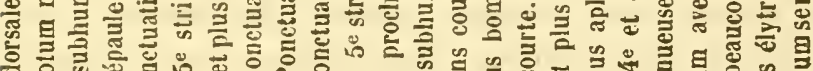

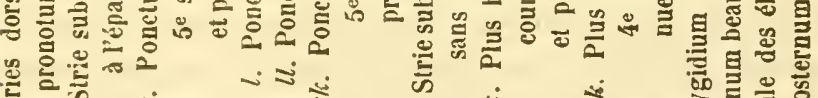

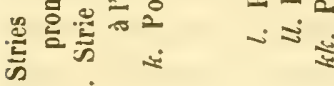
$: \approx$ $: \dot{>}$ i

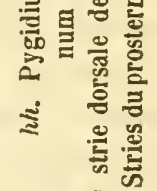

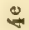
ยुं 


\section{Epierus mundus.}

Ovalis, in merlio convexiusculus, niger nitidus, antennis rufis, pedibus brumeis; pronoto lateribus distinctius punctulato, stria marginali integra; clyuris "stria subhumerali externa et 1-2 dorsatibus integris, 3a suturalique abbreviatis, 4-5a obsoletis, margine inflexo bistriato; pygidio puncticulato; prosterno lato; mesosterno stria marginali interrupta, intermedia arcuat, distante. Long. 4 1/2 mill.; larg. 3 mill.

Epierus mundus, Er. in Jahr. 1, 160, 2 (1834).

Ovale, légèrement convexe, noir luisant. Antennes rouges, scape bruı. Front lisse, bombé. Pronotum finement pointillé, mais plus distinctement sur les côtés, arrondi à la base, rétréci et profondément échancré en devant avec les angles aigus, abaissés; strie marginale entière. Ecusson triangulaire, très petit. Elytres deux fois plus longues que le pronotum, de sa largeur à la base, subitement dilatées sur les côtés, rétrécies et droites au bord apical, bombées au milieu et concaves dans leur pourtour; bord infléchi large, pointillé, bistrié; strie subhumérale externe fine, peu coudée, dans le bord même, interne nulle; dorsales crénelées, 1-2 entières, troisième n'atteignant pas tout à fait la base, 4-5 obsolètes; suturale bien marquée, raccourcie aux deux extrémités. Propygidium couvert de points espacés, pygidium d'un pointillé plus fin et plus serré. Prosternum (f. 1 a) large, à stries presque parallèles, sub. sinué à la base; lobe court, presque sur le même plan. Stric marginale du mésosternum interrompue, intermédiaire arquée, forte, très peu avancée vers le milieu du bord antérieur. Pattes brunes.

Cayenne (Guyane); Para (Brésil). 
2. E. Incias.

Ovalis, subcomvexus, nilidns, niger; antennis pedibusque brunneis; pronolo subtilissime munctulato, stria murginali integra; clylris margine inflearo unistrialo, stria subhumerali externu, 1. 2* que dorsali integris, $3^{\text {a }}$ antice abbreviala, sutura clevata; prosterno bistriuto subpurallelo, antice lobato, mesosterno stria marginali interm)ta, intermedia scmi-circulari. Long. 3 1/2 mill. ; larg. 2 3/4 mill.

Ovale, moins allongé que l'E. mundus, peu convexe en dessus, d'un noir luisant. Tète finement pointillée; front convexe. Antennes brunes, massue rousse. Pronotum beaucoup plus large que long, arrondi à la base, à peine arqué sur les côtés, fortement rétréci et échancré en devant, avec les angles aigus, abaissés; très fuement pointillé sur toute la surface; strie marginale fine, entière. Elytres à peu près aussi larges que longues, de la largeur du pronotum à la ba e, deux fois plus longues que lui, légèrement dilatées au milieu, avec la suture un peu élevée; bord infléchi presque lisse, étroit, unistrié; subhumérale externe bien marquée, fort abaissée et coudée à l'épaule; première et deuxième dorsales fines, entières, troisième un peu raccourcie à la base, avec une trace basale de la quatrième; les autres nulles. Propygidium court. Pygidium pointillé. Prosternum (f. $d$ ) beaucoup plus long que large, bistrié, à peine élargi à ses deux extrémités, avec un lobe antérieur court, faiblement infléchi. Mésosternum presque lisse, légèrement bistrié en devant, traversé par une strie semicirculaire, rapprochée du bord antérieur, et bordé d'une marginale interrompue. Pattes brunes; tarses roux.

Caracas (Venezuela); en avril et juillet, sous les écorces des arbres morts et déjà en décomposition.

зе Série, томе 


\section{E. TEISUS.}

Oblongo-ovatus, convexiusculus, niger nitidus; clava rufa, pedibus brunneis; pronoto lateribus punctato, stria integra; elytris striis subhumerali externa et 1-2 dorsulibus integris, 3-4 antice abbreviatis, ceteris nullis, margine inflexouni-striato; mesosterno stria marginali integra, intermedia arcuata sat approximata. Long. 4 1/2 mill.; larg. : mill.

Epierus tersus, Er. in Jahr. 1, 161, 3 (1834).

Ovale allongé, faiblement convexe, noir luisant. Antennes brunes; massue rousse. Front bombé, finement pointillé. Pronotum arrondi à la base, rétréci et échancré en devant arec les angles abaissés, peu aigus, pointillé sur toute sa surface, plus fortement sur les côtés; strie marginale entière. Ecusson très petit, triangulaire. Elytres deux fois plus longues que le pronotum, de sa largeur à la base, curvilinéaires sur les côtés, rétrécics et droites au bord apical, régulièrement convexes; bord infléchi assez étroit, ponctué, unistrié ; strie subhumérale externe très abaissée, assez forte, dorsales bien marquées, ponctuées, 1-2 entières, 3-4 raccourcies à la base, cinquième et suturale nulles ou représentées par un court rudiment apical. Propygidium et pygidium finement pointillés. Prosternum (f. $3, e)$ droit à la base, assez allongé, fortement bistrié. Mésosternum entièrement rebordé; strie intermédiaire très rapprochée du bord antérieur. Pattes brunes.

Brésil.

\section{E. COPROÏDES.}

Ovalis, convexus, nigernitidus; antennis pedibusque brunneis; fronte concava supra oculos elcvata; monoto lateribus punctato, stria marginali integr a, ante scutellum sinuatim striato; 
elytris levibus, striis 1-3 dorsalibns et suturali integris, ccteris obsolctis, abbreviatis, snbhumerali sulmissa; mgidio subtilitcr. punctulato; monoto bistriato; mesostcmo stria semicirculari et marginali interruptis. Long. 3 mill. ; larg. $21 / 4$ mill.

Orale, convexe, d'un noir luisant. Tête lisse; front concave, releré fortement au-dessus des yeux. Antennes brunes; massue ferrugineuse. Pronotum plus large que long, arrondi à la base et sur les côtés, abaissé, échancré et rétréci en devant avec les angles antérieurs aigus, couvert de points épars, plus forts latéralement ; strie marginale entière, avec une petite stric en forme d'accolade au devant de l'écusson. Elytres très convexes, une fois et demie plus longues que le pronolum, de sa largeur à la base, fortement arrondies et dilatées sur les côtés, rétrécies et droites au bout; stries dorsales intérieures obsolètes; première et deuxième entières, fortes, ponctuées, troisième un peu raccourcie, quatrième et cinquième apicales, suturale presque entière; subhumérale externe abaissée, jnterne nulle; bord infléchi creux, avec quelques points épars, 1-strié. Pygidium peu densément et finement ponctué. Prosternum (f. $4, f$ ) beaucoup plus long que large, bistrié, subsinué à la base, muni en devant d'un lobe infléchi. Mésosternum beaucoup plus large, bisinué en devant, bordé d'une strie marginale non interrompue et traversé d'une intermédiaire semicirculaire, rapprochée de la première. Pattes d'un brun-rouge.

Diffère de l' $E$. arciger, par sa forme plus élargie, ses stries dorsales internes obsolètes et peu raccourcies, la ponctuation du pronotum plus forte et plus serrée, celle du pygidium beaucoup plus fine.

Anérique boréale (M. de Laferté). 


\section{E. $\triangle R C I G E R$.}

Ovalis, convexus, lavissimus, nigro-piceus nitidus; antennis pedibusque rufis; fronte concava, supra oculos elcvata; pronoto lateribus parce punctato, stria marginali integra, arcuata alia ante scutellum; clytris striis punctatis, 1-4 dorsalibus integris, 5 a et suturali antice abbreviatis, subhumerali valde demissa, margine inflexo unistriato; mygidio munctato; prosterno bistriato; mesosterno stria marginali et intermedia completis. Long. 3 mill. ; larg. 1 4/5 mill.

Orale, convexe en dessus, très lisse, d'un noir de poix luisant. Front concave, relevé de chaque côté en tubercule au-dessus des yeux. Antennes l'un brun-rouge; massue testacée. Pronotum court, plus large que long, arrondi à la base, avec une ligne semicirculaile au devant de l'écusson, fortement rétréci et échancré en devant, avec les angles abaissés, aigus; quelques points épars visibles sur les côtés; strie marginale entière. Ecusson triangulaire, très petit. Elytres bombées, de la largeur du pronotum à la base, une fois et demie plus longues que lui, fortement dilatées et arrondies latéralement, rétrécies et coupées droit au bout; stries ponctuées, $1-4$ dorsales entières, cinquième remontant un peu au-delà du milieu, ainsi que la suturale; subhumérale externe fine, abaissée et coudée à l'épaule; interne nulle; bord infléchi, ponctué, étroit, 1-strié. Propygidium couvert ainsi que le pygidium, d'une ponctuation assez forte et assez serrée. Prosternum (f. 5, g) assez court, à deux stries légèrement divergentes aux deux extrémités, trouqué à la base, avec un lobe large et assez long en devant. Mésosternum beaucoup plus large, subsinué en devant; strie marginale entière ; intermédiaire semicirculaire, rapprochée de la première au milieu. Pattes d'un rouge-brun; tarses plus clairs.

Cumaua (Venezuela). (M. de Laferté.) 


\section{E. mastatis.}

Ovatus, convexiusculus, rufo-brunneus nitidus, tevis; fronte concava; pronoto lateribus punctato, ante scutellum impressione hastiformi; elytris stria sublumerali externa demissa, dorsalibus 1-4 integris punctatis, $5^{4}$ suluralique abbreviatis, mygillio dense punctato; mesosterno stria marginali integra, intermediaque semicirculari. Long. 2 1/2 mill.; larg. 1 1/2 mill.

Ovale arrondi, assez convexe, d'un rouge-brun luisant, entièrement lisse, avec quelques points sur les bords latéraux du pronotum. Front concave, relevé au-dessus des yeux. Antennes testacées. Pronotum court, beaucoup plus large que long, arrondi a la base, arqué sur les côtés, mais seulement vers les angles antérieurs, rétréci et échancré en devant; strie marginale entière; on aperçoit au devant de l'écusson une impression peu profonde en forme de fer de lance, circonscrite par une strie anguleuse en devant et bien accusée. Elytres courtes, aussi larges que longues, de la largeur du pronotum à la base, fortement dilatées latéralement, coupées droit au bout; stries dorsales bien marquées crénelées; 1-4 entières, cinquième raccourcie au milieu, suturale un peu au-dlelà; strie subhumérale interne nulle, externe entière coudée, abaissée sous le bord infléchi, qui est unistrié. Propygidium et pygidium densérnent ponctués. Prosternum (f. $6, h$ ) bistrić, allongé, un peu élargi en devant, subsinué à la base. Mésosternum deux fois plus large que la base du prosternum, traversé de deux stries rapprochées au milieu, entières, l'une parallèle au borl, l'autre semicirculaire. Pattes d'un rouge testacé.

Diffère du $E$. coproüdes et du $E$. arciger par la forme de l'impression antéscutellaire, par sa couleur plus brune; en nutre ilu premiel, par sa quatrième strie dorsale entière et sal 
cinquième plus allongée, et du deuxième par sa surface moins ponctuée.

Carthagène ( Nouvelle-Grenade).

\section{E. LEVISTRIES.}

Ellipticus, parum convexus, nigro-piccus, nitidus; antennis pedibusque rufo-brumeis; fronte plana; pronoto subtilissime munctulato, stria murginali integra; elytris margine inflexo umistriato; striis dorsalibus 1-3 integris, 4 a $5^{2}$ que in medio valde obsoletis, subhumerali cxterna depressa; prostcrno clongato valde angustato; mesosterno stria marginati integra. Long. 2 1/\% mill. ; larg. 1 1/2 mill.

Elliptique, peu convexe, d'un noir de poix brillant. Front légèrement convexe, sans élévation au-dessus des yeux. Antennes brunes; massue fauve. Pronotum plus large que long, arrondi à la base, presque droit sur les côtés, échancré, rétréci en devant, avec les angles aigus et abaissés, finement pointillé sur les côtés; strie marginale entière. Elytres une fois et demie plus longues que le pronotum, de sa largeur à la base, peu dilatées sur les côtés, rétrécies et coupées droit au bout ; stries dorsales peu fortes, ponctuées, 1-3 entières, quatrième obsolète au milieu, cinquième largement interrompue, suturale entière; subhumérale interne nulle, externe entière abaissée sous le bord infléchi, qui est unistrié et pointillé. Pygidium ponctué. Prosternum ( $f .7, i$ ) allongé, fort étroit, bistrié, arrondi à la base, élargi aux deux extrémités. Mésosternum deux fois et demie plus large que la base du prosternum, court, échancré en devant, avec une seule strie marginale entière suivant le bord latéral. Pattes d'un rouge-brun.

Outre les stries dorsales bien moins marquées, il diflère 
du $L$. lucidulus iar sa taille plus petite, sa forme plus parallibe et surtout par le bord inllechi élroit et sa strie subhumérale plus abaissée et plus coudéc.

Carthagène (Nouvelle-Grenade). (MI. Deyrolle.)

\section{E. BISISISTRIATIS.}

Ovalis, subdepressus, levissimus, nigur nitidus; antemis pedibusque rufo-ferrugineis; fronte plana; pronoto lateribus punctulato, stria maryinali interrupta; clytris striis dorsalibus 2 1/2, subhumerali externa temissima valde angulata ct depressa; prosterno lato brevi bistriato; mesostemo fere prosterni latitudine, stria marginali integra. Long, 3 mill.; larg. 2 mill.

Orale, presque plan en dessus, d'un noir très luisant. Tête lisse. Front plan. Antennes brunes; massue testacée. Pronotum plus large que long, arrondi à la base, à peine arqué sur les côtés, échancré et rétréci en devant avec les angles abaissés, aigus; lisse, arec quelques points sur les côtés; strie marginale cessant derrière les yeux. Elytres une fois et demie plus longues que le pronotum, de sa largeur à la base, élargies latéralement, rétrécies et tronquées au bord apical, élevées sur la suture, entièrement lisses; bord infléchi unistrié, pointillé; stries dorsales entières, troisième raccourcie au milieu, les autres, ainsi que la suturale, nulles; sublıumérale exterue fine, coudée, abaissée; interne nullc. Pygidium lisse. Prosternum (f. $8, j$ ) court. large, bistrié, coupé droit à la base, avec un lobe antérieur assez long. Mésosternum court, à peine plus large que le prosternum à sa base, strie marginale entière. Paltes d'un brun-roussàtre.

Sainte-Catherine ( Brésil). (M. lle Iaferts.) 


\section{E. Retusus.}

Ovatus, convexus, nitidus, piceus; antennis pedibusque rufobrumneis; pronoto dense munctato, stria laterali valida abbreviatu, marginali integra, interstitio elcvato; elytris punctulatis, striis omnibus integris, 2 subhumeralibus, 5a dorsali cum suturali conjuncta; mygidio busi tantum punctato; prosterno antice latiori; mesosterno stria intermedia arcuata, marginali interrupta. Long. 3 mill.; larg. 2 mill.

Hister retusus, Illig. Mag. vi, p. 36 (1807).

11. Italicus, Payk. Mon. hist. 47, 35, t x, 7 (1811).

Epierus retusus, Er. Jahr. 1, 160, 1.

Ovale arrondi, convexe en dessus, d'un noir de poix luisant. Tête finement pointillée. Front légèrement concave et relevé au-dessus de l'insertion des antennes; strie frontale obsolète. Epistome bombé. Mandibules et bouche ferrugineuses. Antennes roussâtres, avec la massue plus claire. Pronotum plus large que long, bisinué à la base, à peine arqué sur les côtés, fortement rétréci et échancré en devant, avec les angles aigus; couvert d'une ponctuation assez forte et assez serrée; strie marginale fine, entière, latérale forte, s'arrêtant aux angles antérieurs, avec leur intervalle relevé. Elytres de la largeur du pronotum à la base, deux fois plus longues, dilatées sur les côtés, coupées carrément et rétrécies au bout, finement pointillées, avec les stries à peine ponctuées, toutes entières, suturale réunie avec la cinquième dorsale à la base, humérale peu marquée, 2 subhumérales; bord infléchi ponctué très visiblement, avec une seule marginale. Propygidium court, transversal, avec quelques gros points. Pygidium triangulaire, ponclué senlement à la base, lisse au bout avec une faible impression. Prosternum (f. 9, $k$ ) légèrement élevé, assez large, coupé 
droit à la base, bistrié, plus long que large, dilaté antérieurement et terminé par un lobe court, arrondi en devant. Mésosternum légèrement bisinué en devant et bien distinct du métasternum, bordé d'une strie marginale interrompue et traversé par une strie arquée rapprochée au milieu du bord antérieur. Pattes d'un rouge-brun.

Malgré l'autorité du savant Erichson, j'ai dù rapporter le II. Italicus de Paykull à cette espèce: le bourrelet du pronotum et les sept stries des élytres indiquées dans la figure et dans la description, ne permet pas de le confondre avec le $\boldsymbol{E}$. comptus.

Toscane, Styrie.

\section{E. LUCENS.}

Ovalis, convexiusculus, niger nitidus; antemnis pedibusque rufo-brunneis; fronte convexa; pronoto versus later a subtiliter punctulato, stria marginali integra; clytris striis dorsalibus suturalique integris punctatis parallelis, parum profundis; subhumerali externa tam marginali proxima ut mulla esse vidcatur; pygidlio apice impresso; prostcrno brevi, antice latiori; mesosterno lato, stria semicirculari marginali integra «pproximata. Long. 2 1/2. mill.; larg. 2 mill.

Ovale, légèrement convexe, d'un noir de poix luisant. Tête à peine visiblement pointillée; front convexe, sans tubercules au-dessus des yeux. Antennes rousses; massue dun testacé pâle. Pronotum beaucoup plus large que long, arrondi à la base, rétréci, échancré en devant, avec les angles aigus et abaissés; ponctué finement sur les bords latéraux; stric marginale entière. Elytres de moitié plus longues que le pronotum, aussi larges à la base, arrondies et dilatées latéralement, rétrécies et coupées droit au bout; 
stries ponctuées, peu profondes; première dorsale plus fine, toutes entières, ainsi que la suturale, presque parallèles; interstries plans, à peu près égaux; sublumérale interne nulle; externe tellement près de la marginale, sous le bord infléchi, qu'clle semble être elle-même la marginale interne. Pygidium finement ponctué, avec une impression apicale. Prosternum (f. 10,l) assez court, plus long que large, pres que droit à la base, légèrement élargi en devant et muni d'un lobe infléchi. Mésosternum beaucoup plus large, court, bordé seulement sur les côtés, traversé par une strie arquée, fort rapprochée du bord antérieur. Pattes d'un rougebrun ; tarses testacés.

Sa strie subhumérale externe si rapprochée de la marginale et la disposition de ses dorsales entie̊res, assez fines, presque parallèles le distinguent, au premier abord, de tous ses congénères.

Caracas (Venezuela), en février, sous les écorces des bois morts commençant à tomber en putréfaction.

\section{E. FRATER.}

Ovalis, convexus, picens nitidus, punctulatus; antennis pedibusque rufis; fronte plana; pronoto stria haud interrupta; clytris margine iuflexo unistriato, subhumerali externa valde demissci, 1-4 dorsalibus integris, $5_{\mathrm{a}}$ suturatique basi obsolctis ; pygidio impresso ; prosterno brevi lato ; mesosterno striis marginali intermediuque completis. Long. 2 mill.; larg. 1 1/2 mill.

Ovale, convexe, noir de poix luisant, couvert en dessus et en dessous d'une ponctuation bien marquée, peu serrée. Anterınes rouges; massue testacée, scape brun. Front légèrement concave, saillant au devant des yeux. Pronotum court, arrondi à la base, à peine arqué sur les côtés, rétríci 
et échancré en devant, avec les angles aigus, abaissés, un peu plus fortement ponctué que le reste du corps; strie marginale non interrompue. Ecusson triangulaire, très petit. Elytres bombées, deux fois plus longues que le pronotum. de sa largeur à la base, curvilinéairement dilatées sur les cotés, fortement rétrécies et droites au bord apical ; repli latéral unistrié; strie subhumérale externe très abaissée, coulée à l'épaule ; dorsales bien marquées, ponctuées, 1-4 entières, cinquième et suturale un peu obsolètes à la base. Pygidium impressionné au bout. Prosternum (f. $11, m)$ court, large, sinué à la base, bistrié. Mésosternum à stries marginale et intermédiaire complètes. Pattes ferrugineuses.

Téapa, Opelouzas (Mexique). (M. Pilate.)

\section{E. INTER MEDIUS.}

Ovalis, convexiusculus, nitidus, piceus ; antennis rufis pedibusque ferrugineis; fronte convexa; pronoto munctulato, stria integra; elytris striis crenatis validis, subhumerali externa 4 quedorsalibus integris, $5^{a}$ suturulique antice paululum abbreviatis, margine inflexo unistriato punctato; pygidio punctuto impresso; mosterno angustato, bistrialo; mesosterno stria marginali interrupta, intermedia semicirculari. Long. 2 1/2 mill.; larg. 1 1/2 mill.

Ovale, peu convexe, d'un noir de poix luisant. Tête finement pointillée; front convexe. Antennes roussâtres; massue d'un testacé pâle. Pronotum plus large que long, arrondi à la base, avec une légère impression au devant de l'écusson, légèrement arqué sur les côtés, rétréci, échancré en devant avec les ingles abaissés, aigus ; couvert de points serrés; strie marginale entière. Elytres de la largeur du 
pronotum à la base, une fois et demie plus longues, peu dilatées sur les côtés, droites et rétrécies au bout; stries fortes, crénelées, 1-4 dorsales entières, cinquième et suturale un peu raccourcies à la base; subhumérale externe très abaissée, interne nulle; bord infléchi 1-strié, creusé et fortement ponctué. Pygidium finement ponctué, avec une légère impression apicale. Prosternum (f. 12, $u$ ) beaucoup plus long que large, bistrié, subarrondi à la base, rétréci au milieu, avec un lobe antérieur court, infléchi. Mésosternum légèrement échaneré en devant, plus large que le prosternum, court, traversé par une strie arquée assez rapprochée du bord antérieur; marginale interrompue. Pattes d'un roux testacé, avec les tarses plus pâles.

Il se distingue du $\boldsymbol{E}$. frater avec lequel il a les plus grands rapports, par ses élytres moins bombées et moins visiblement pointillées, par son front convexe et surtout par la strie mésosternale interrompue.

Guatemala.

\section{E. NIGRELLUS.}

Ellipticus, subconvexus, nitidus, nigro-picens; antennis pedibusque rufo-brunneis; pronoto dense et sat fortiter punctulatus, stria marginali integra; elytris punctulatis, margine inflexo sulcato; subhumerali externa, 5 dorsalibus et suturali integris, cremulatis, validis; propygidio parce, pygidio subtilissime punctulatis; mosterno angusto, bistriato; mesosterno stria marginali integra. Long. 3 mill.; larg. 1 2/3 mill.

Hister nigrellus, Say in Soc. phil. v, p. 38, 8 (1825).

Epierus nigrellus, Le Conte, N. Amér. Hist. 32, 1, t. 4, 5 (1845).

Elliptique, médiocrement convexe, d'un noir de poix luisant. Tête finement pointillée; front convexe. Antennes 
d'un brun-ferrugineux; massue testacée. Pronotum beaucoup plus large que long, arrondi à la base, avec une impression antéscutellaire, légèrement arqué sur les cotés, fortement rétréci et échancré en devant, avec les angles abaissés, aigus; couvert d'une ponctuation serrée et assez forte; "strie marginale entière. Ecusson très petit, triangulaire. Elytres de la largeur du pronotum à la base, une fois et demie plus longues que lui, dilatées et arrondies sur les côtés, plus étroites et coupées carrément au bord apical, finement et assez densément ponctuées; bord infléchi (f.o), sillonné de deux stries marginales fortes, profondes, ponctuées; strie subhumérale externe entière, bien marquée, légèrement coudéc à l'épaule et rapprochée de la marginale interne ; dorsales et suturale entières fortes, crénelées ; les trois plus voisines de la suture rapprochées entre elles à la base. Propygidium couvert de petits points peu serrés. Pygidium très finement pointillé. Prosternum (f. 13, p) étroit, allongé, bistrié, légèrement arrondi à la base, muni en devant d'un Jobe court infléchi, arrondi au bout. Mésosternum court, beaucoup plus large que le prosternum, échancré en devant et bordé d'une strie entière, densément pointillé. Pattes ferrugineuses.

Union américaine; répandu partout.

\section{E. vicives.}

Ellipticus, narum convexus, munctulatus, nigrc-piceus nilidus; antemis pedibusque ferrugincis; fronte comvexa; monoto stria hand internupta; clytris margine imflexo bisulcato, stria subhumerali externa valida subreclu, dorsulibus suturalique validis crenatis integris, interioribus basi magis apmroximatis; momygidio densins, mygirlio fortius punctulatis; mesosterno stria marginali completa. Long. 2 1/3 mill. ; larg. 1 1/2 mill.

Epierus vicinus, Le Cont. Calif. Col. 40, 2 (1851). 
Ovalaire elliptique, faiblement convexe, noir de poix luisant. Antennes ferrugineuses; massue d'un rouge testacé. Front bombé, finement pointillé. Pronotum court, arqué à la base, avec une impression antéscutellaire, rétréci et échancré en devant avec les angles abaissés, aigus; ponctuation uniforme, assez forte et serrée; strie marginale non interrompue. Ecusson en triangle très petit. Elytres plus longues que le pronotum, de sa largeur à la base, curvilinéaires sur les côtés, rétrécies et droites au bord apical; très finement pointillées; repli latéral (f. $o$ ) rugueux, bisillonné; strie subhumérale externe forte, presque droite; dorsales 1.5 et suturale profondes, crénelées, entières, les trois plus voisines de la suture un peu plus rapprochées que les autres à la base. Propygidium couvert d'une ponctuation assez marquée et passablement serrée. Pygidium distinctement pointillé, ainsi que le dessous du corps. Prosternum (f. $p$ ) étroit, allongé, tronqué à la base ; stries légèrement divergentes à leurs deux extrémités. Mésosternum faiblement sinué elı devant, entièrement rebordé. Pattes ferrugineuses.

Très voisin du $E$. nigrellus, il ne s'en distingue qu'avec peine. Cependant il est un peu moins ovalaire, ponctué plus distinctement sur le pronotum, plus densément sur le propygidium et plus fortement sur le pygidium. La strie subhumérale externe est aussi plus forte et plus droite à l'épaule.

Commun sur les bords du Colorado (Californie).

\section{E. ALUTACEUS.}

Ellipticus, subconvexus, piceus, nitidus, dense punctulutus; antennis pedibusque rufo-brumeis; pronoto striu marginali in- 
tegra; elytris striis dorsalibus suluraligue mrofundis crenulatis incgris, subhumerali cxterna integra subrecta, interna brevi basuli; mrosterno elongato bistriato, medio angustato; mesostcrno lato, brevi, anticc subsimuto, marginato. Long. 3 mill.; larg. $14 / 5$ mill.

Elliptique, médiocrement convexe, d'un noir de poix luisant. Tête pointillée; front bombé, élevé au-dessus des yeux. Autennes d'un rouge-brun; massue testacée. Pronotun assez court, plus large que long, arrondi à la base, légèrement arqué sur les côtés, rétréci en devant, échancré, avec les angles abaissés, aigus ; couvert de petits points serrés; strie marginale non interrompue. Elytres de la largeur du pronotum à la base, une fois et demie plus longues, presque parallèles sur les côtés, un peu rétrécies et droites au bord apical, couvertes de points fins et peu serrés ; stries dorsales et suturale fortes, crénelées, assez régulières ; subhumérale externe entière, interne courte, placée à la base ; bord infléchi creux, ponctué, avec une seule marginale. Pygidium ponctué. Prosternum (f. $p$ ) allongé, étroit, bistrié, légèrement arrondi à la base, rétréci au milieu, avec un lobe antérieur, arrondi en avant, penché en bas. Mésosternum deux fois plus large que le prosternum, court, légèrement sinué en devant, bordé d'une strie marginale; l'un et l'autre densément ponctués. Pattes d'un rouge-brun.

Cumana (Venezuela).

\section{E. Lucimults.}

Oblongo-ovatus, subconvexus, niger niticlus; antemis peclibusque rufo-brumeis; pronoto punctuluto, stria integra; clytris margine inflexo uni-striato, subhumerali externa, dorsulibus 5 et suturali integris; mopygidio mygidioque parce 
punctulatis; mesosterno stria marginali integra, utrinque angulata. Larg. 3 1/2 mill.; larg. 2 1/2 mill.

Epierus lucidulus, Er. in Jahrb. 1, 161, 4 (1834).

Ovale-oblong, peu convexe, noir luisant. Antennes brunes; massue rousse. Front bombé, lisse. Pronotum arrondi à la base, rétréci et échancré en devant, avec les angles abaissés, assez aigus, pointillé sur toute sa surface; strie marginale non interrompue. Ecusson triangulaire très petit. Elytres beaucoup plus longues que le pronotum, de sa largeur à la base, courbées sur les côtés, rétrécies et droites au bord apical; stries crénelées, un peu moins profondes, quoique bien marquées, dorsales, suturale et subhumérale externe entières; cette dernière forte et presque droite; bord infléchi ponctué, assez large, avec une seule strie. Propygidium assez bien ponctué, mais peu densément. Pygidium couvert de points un peu plus fins. Prosternum (f. $p$ ) assez allongé, droit à la base, un peu rétréci au milieu, bistrié. Mlésosternum à strie marginale entière, anguleuse sur les côtés. Pattes ferrugineuses.

Mexique; Yucatan ; Nicaragua ; Carthagène, Cumana (Nouvelle-Grenade); Caracas (Venezuela); Sainte-Catherine (Brésil); dans les matières putrides qui se forment par la décomposition, sous les écorces du bois mort, en février.

\section{E. Waterhoush.}

Ovalis, parum convexus, viridi vel corrulco-metallicus nitens, antcnnis tibiisque ferrugincis; fronte plana; pronoto punctuto, stria haud interrupta; elytris margine inflexo punctato, unistriato; 5 dorsalibus, suturali et subhumerali integris; mopygidio parce, mygidio subtilissime punctatis; mesosterno stria marginali completa. Long. 2 3/4 mill. ; larg. 1 3/4 mill. 
Ovale, peu convexe, bleu ou vert métallique luisant. An teunes brunes; massue ferrugineuse. Front plan, finement pointillé. Pronolum court, arrondi à la base, un peu courlé sur les cotés, rélréci et échancré en devant avec les angles abaissés, aigus; densément pointillé sur tonte sa surface; strie marginale non interrompue. Ecusson très petit, triangulaire. Elytres une fois et demie plus longues que le pronotum, de sa largeur à la base, rétrécics postérieurement et tronquées au bord apical; bord inflérhi unistrié, pointillé; strie subhumérale exterue bien marquée, dans le bord même de l'élytre, à peine coudée; dorsales fortes, crénelées, entières, ain.i que la suturale, les trois intérieures plus rapprochées entre elles à la base que les autres. Propygidium couvert de points bien marqués, espacés; pygidium de beaucoup plus fins et plus serrés. Prosternum (f. $p$ ) assez étroit, tronqué à la base, stries bien marquées, parallèles. Mésosternum sinué en devant, borié d'une seule strie complète. Cuisses métalliques; jambes el tarses ferrugineux.

Cette espèce, découverte par M. Sallé, à st-l)omingo (Haïti), se trouve sous les écorces des arbres morts déja en putréfaction, en avril et juillet. Je l’ai dédiée à II. Waterhouse, entomologiste anglais, aussi instruit qu'obligeant.

\section{E. BRENNIPENYIS.}

Oblongo-ovutus, parum convexus, niger nitidus; elytris, antennis pedibnsque rufis; fronte subconcava, pionoto munctulato, stria interrupta; clytris murgine inflexo angusto unistriato, stria subhumerali demissa, angulata, 1-4 dorsalibus integris, 5. suturalique breviatis, interstitio tertio basi latiori; pygidio vix puncticulato; moslcrno lato, bistriato, mesosterno bisi-

Sérice, gone 11. 
nuato, stria marginali completa. Longuenr 2 1/2 mill.; larg. $13 / 4$ mill.

Ovale-oblong, peu convexe, noir luisant. Antennes ferrugineuses; front faiblement concave. Pronotum court, arrondi à la base, arqué sur les côtés, rétréci et échancré en devant, avec les angles aigus, abaissés; pouctué assez densément; strie marginale interrompue. Ecusson triangulaire très petit. Elytres ferrugineuses, pointillées, beaucoup plus longues que le pronotum, de sa largeur a la base, arquées sur les côtés, rétrécies et coupées droit au bout; repli latéral étroit, ponctué, unistrié; strie suhhumérale externe bien marquée, abaissée, coudée à l'épaule; dorsales crénelées, profondes, 1-4 eritières, cinquième et suturale un peu obsolètes à la base, commencement du troisième interstrie beaucoup plus large que les autres. Propygidiun couvert de points espacés. Pygidium un peu plus densément pointillé. Prosternum (f. 18, q) large, court, sinué à la base, à stries subparallèles. Mésosternum bisinué, entière. ment rebordé. Pattes d'un rouge-brun.

Carthagène ( Nouvelle-Grenade).

\section{E. Russicus.}

Subellipticus, parum convexus, nitidus, piceus; antennis pedibusque brumncis; pronoto grosse punctato, stria marginali integra; elytris subtilissime purctulatis, striis validis erenatis, dorsatibus, suturali, subhumerali externa angulata integris, interna rudimento basuli, margine inflexo 1-striato pygidioque punctatis; prosterno utrinque latiori, mesosterno bisinuato, marginalo. Long. 3 mil.; larg. 2 mill.

Subelliptique, peu convexe en dessus, d'un noir de poix luisant. Tête finement pointillée; front plan, élevé au- 
dessus des yeux, pointillé. Antennes brunes. Pronotum plus large que long, arrondi à la base, avec une impression antéscutellaire, légèrement arqué sur les côtés, rétréci et échnncré en devant, avec les angles aigus, abaissés; couvert d'une ponctuation très forte, espacée; strie marginale non interrompue. Elytres de la largeur du pronotum à la base, une fois et demie plus longues, légèrement dilatées sur les côtés, plus étroites et coupées droit au bord apical; très finement pointillées; stries dorsales entières, fortes, crénelées, 4-5 plus rapprochées à la base, suturale à peine raccourcie; subhumérale externe bien marquée, abaissée. coudée à l'épaule; liumérale accompagnée d'un rudiment basal représentant l'interne ; bord infléchi lortement et grossièrement ponctué, avec une seule strie. Propygidium couvert ainsi que le pygidium, de points assez forts, espacés. Prosternum ( f. $p$ ) bistrié, étroit, assez long, subsinué à la base, un peu élargi aux deux extrímités, muni d'un lobe antéricur cuurt, arrondi, subinfléchi. Mlésosternum transversal beaucoup plus large, bisinué en devant, bordé d'une strie marginale sinuée, entière. Pattes d'un noir de poix ; tarses bruns.

Fort semblable au $\boldsymbol{E}$. comptus, Illig, il en diffère par sa taille plus grande, sa ponctuation plus forte sur le pronotum et le pygidium, le rudiment de strie subhumérale interne, et les points des élytres.

Batoum (Géorgie).

20. E. conptus.

Ovalis, parum convexus, nigro-piceus nilidus; antennis pedibusque ferrugineis; pronoto parce sed sat forliter punctato, 
strit hand interrupta; elytris margine inflexo punctato, 1striato, subhumerali exterma angulosa, dorsalibus et suturali mofundis crenalis, 3 inlerioribus basi conniventibus, cunctis integris; propygidio mygidionne punctatis; mesosterno stria rompleta. Long. 3-2 1/2 mili. ; larg 2 1/4-1 1/2 mill.

Hister complus, Illig. Mag. 6, 36, note (1807).

Epierus comptus, Er. in Jahrb. 1, 162, 6 (1834).

Uvale peu convexe, d'un noir de poix luisant. Antennes ferrugineuses. Front lisse, bombé. Pronotum arrondi à la base, rétréci et échancré en devant avec les angles abaissés, aigus; couvert sur toute sa surface d'une ponctuation asse' forte, peu serrée; strie marginale entière. Ecusson très petit, triangulaire. Elytres beaucoup plus longues que le pronotum, de sa largeur à la base, courbées sur les côtés, rétrécies et droites au bord apical; bord :infléchi ponctué avec une seule strie; subhumérale externe entière, bien marquée, coudée à l'épaule, assez distante de la marginale, interne nulle; dorsales ct suturale fortes, profondes, crénelées, entières, les trois plus rapprochées de la suture courbes, rapprochées entre elles a la base. Propygidium et pygidium peu densément ponctués. Prosternum (f. $p$ ) étroit, un peu plus large et tronqué à la base, bistrié. Mésosternum bordé d'une strie bien marquée, non interrompue. Paltes ferrugineuses.

Autriche, sous l'écorce des bois morts.

\section{E. Antillarta.}

Ellipticus, dep "essus, picens, mitidus; antennis pedibusque rufo-brunncis; fron." plana; monoto dense munctulato, stria marginali integra; cly 'ris margine inflexo 1-strialo, striis amnitus infogris cremulatr; subhumerali externa valida recta; 
propygidio pygidioque punctatis; prosterno bistriato, angusto, subparalleto; mesostcrno marginuto. Long. 2 1/? mill.; larg. $11 / 2$ mill.

Elliptique, déprimé, d'un noir de poix luisant. Tête finement pointillée; front légèrement convexe, à peine relevé au-dessus des yeux. Antennes brunes; massue testacée. Pronotum beaucoup plus large que long, arrondi à la base, légèrement arqué sur les côtés, rétréci ct échancré en devaut, avec les angles aigus et abaissés; couvert d'une ponctuation assez serrée; strie marginale non interrompue en devant. Elytres de la largeur du pronotum à la base, une fois et demie plus longues, à peine arrondies sur les còtés, rétrécies et coupées droit au bord apical, très finement pointillées; stries fortes, crénelées, dorsales entières ainsi que la suturale, les trois intérieures plus rapprochées entre elle 3 ì la base; subhumérale interne nulle, externe sur le bord mème, profonde, presque droite; bord infléchi creux, pointillé, avec une seule marginale. Propygidium et pygidium ponctués. Prosternum (f. $p$ ) étroit, bistrié, arrondi à la base, subparallèle, avec un lobe antéricur court, infléchi. Iésosternum court, trois fois plus large que la base du prosternum, légèrement sinué en devant, strie marginale complète. Pattes d'un rouge-brun ; tarses plus clairs.

Très voisin des $E$. planulus, incultus et longulus dont il a la forme aplatie, il en differe par la strie marginale du pronotum entière, la subhumérale des élytres moins abaissée et plus droite; en outre du prenuier par ses stries et sa suturale entières, du deuxième, par la ponctuation du pronotum moins forte et muins serrée, et du troisième, par son corps moins allongé.

Il parait propre aux Antilles, tandis que les trois autres 
espèces appartiennent aux parties voisines du continent américain.

J'en ai vu des exemplaires de Cuba, Porto-Rico, SaintDomingue.

\section{E. Planules.}

Ovalis, depressus, niger nitidus, puncticulatus; antennis rufis, pedibus brunneis; pronoto stria interrupta; clytris margine inflexo unistriato, subhumerali externa angulata submissa, 1.4 dorsalibus integris, 5a suturalique abbreviatis; prosterno sat lato, striis validis antice divergentibus, mesosterno stria completu.

Epicrus planulus, Er. in Jahrb. 1, 162, 8 (1834).

E. decipiens, Le C. Californ. Col. 40, 1 (1851).

Ovalaire, déprimé, d'un noir de poix luisant, finement pointillé. Antennes rousses; massue plus claire. Front bombé. Pronotum très court, arqué à la base, presque droit sur les côtés, rétréci et fort échancré en devant, avec les angles aigus, abaissés; strie marginale interrompue. Ecusson triangulaire, très petit. Elytres beaucoup plus longues que le pronotum, de sa largeur á la base, curvilinéairement rétrécies jusqu'au bout et droites au bord apical ; repli latéral unistrié, étroit, ponctué; strie subhumérale externe fortement coudée à l'épaule et descendue sous le bord; dorsales ponctuées, bien marquées, quoique fines, 1-4 entières, cinquième et suturale raccourcies à la base. Propygidium et pygidium assez bien pointillés. Prosternum (f. $p$ ) assez large, tronqué à la base, avec les stries bien marquées, divergentes antérieurement. Mésosternum complètement rebordé. Pattes brunes.

Caracas (Venezuela), avril et juillet; sous l'écorce des 
arbres inorls; T'éapa; II. Leconte l'a trouvé communément sous l'écorce du peuplier, sur les bords du Colorado (Californie).

\section{E. incultus.}

Ellipticus, supra depressus, nitidus, piceus; antennis pedibusque rufo-brunneis, undigue punctulatus, pronoto fortius; stria marginali interrapta; elytris striis profundis integris crenatis, basi interioribus approximatis; subfumeraii externa subtus, interna mulla; prosterno brevi, striis 2 antice divergentibus, busi mesosterni subaquati, hoc marginato. Long. 2 mill.; larg. 1 1/2 mill.

Elliptique, déprimé, d’un brun de poix brillant. Tête ponctuée; front plan au milieu et relevé en tubercule au devant des yeux. Antennes d'un brun ferrugineux; massue testacée. Pronotum court, plus long que large, arrondi à la base, légèrement arqué sur les côtés, rétréci et échancré en devant, avec les angles aigus ; densément ponctué, avec une impression au-dessus de l'écusson; strie marginale cessant derrière les yeux. Elytres deux fois plus longues que le pronotum, de sa largeur à la base, légèrement rétrécies vers le bout; suture relevée; stries fortes, ponctuées, entières; intérieures irrégulières, rapprochées à la base; interstries finement ponctués; subhumérale interne nulle, externe forte, abaissée; rebord latéral étroit, unistrié. Pygillium ponctué. Prosternum (f. 23, q) court, large, bistrié, légèrement arrondi à la base, rétréci au milieu, élargi en devant avec un lobe large. Mésosternum légèrement échancrí en devant, bordé, l'un et l'aulre deosément ponctués. Pattes ferrugineuses.

Nexico. 


\section{E. LONGULUS.}

Elongatus ellipticus, depressus, nigro-picens, nitidus, punctutatus; antennis pedibusque brunneis; fronte supra oculos elevata; pronoto stria marginali interrupta; elytris striis cremulatis, 1-4 dorsalibus integris, 5a et suturali antice obsoletis, subhumerali externa demissa, interna nulla; margine inflexo tistriato; prosterno bistriato, antice latiori, lobato; mesosterno lato antice sinuato, margirato. Long. 2 3/4 mill.; larg. 1 1/2 mill.

Eu ellipse allongée, aphati en dessus, d'un noir de poix luisant. Tête finement poinillée ; front élevé au-dessus des yeux. Antennes brunes, massue rougeâtre. Pronotum plus large que long, arrondi à la base et sur les côtés, rétréci et échancré en devant, avec les angles aigus, abaissés, couvert de points serrés, et silionné au milieu d'une légère impression longitudinale visible au devant de l'écusson; strie marginale se continuant au bord antérieur, mais interrompue entre les yeux; quelquefois deux légères impressions obliques de chaque côté. Elytres de la largeur du pronotum à la base, subparallèles, longues, un peu rétrécies et droites au bord apical; finement pointillées; stries dorsales bien marquées, crénelées; quatre premières entières, cinquième et suturale un peu raccourcies à la base; strie subhumérale interue nulle, externe reportée sur le bord infléchi, qui est ponctué et sillonné de deux marginales profondes. Pygidium pointillé, avec une légère impression de chaque côté. Prosternum (f. 24, s) assez large, bistrié, subarrondi à la base, plus large en devant, avec un lobe assez long et infléchi. Mésosternum sinué en devant, court et très large, bordé d'une strie eotière. Pattes brumes; larses plus clairs.

Yucatan. 


\section{E. PILCARUIS.}

Oblongo-ovalus, convexiusculus, brumeus, nilidus punctulatus; antennis pedibusque rufis; pronoto stria integra; clytris striis integris, 1-5 dorsalibus ct suturali subrectis, subhumerali externa tenui angulosa, margine inflexo punctato unistriato, pygidio apice levi ; prosterno angusto ; mesosterno stria marginali haud interrupta. Long. 2 1/4 mill.; larg. 1 1/2 mill.

Epierus pulicarius, Er. in Jahrb. 1, 162, 5 (1834).

E. minor, Le Conte, N. Amér., Hist. 33, 2, t. Iv, f. 6 (1845).

Orale-oblong, assez convexe, brun de poix luisant, plus ou moins rouge. Antennes ferrugineuses; massue plus claire. Front bombé, lisse. Pronotum arrondi à la base, rétréci et échancré en devant, avec les angles aigus, abaissés; densément pointillé sur toute sa surface; strie marginale entière. Ecusson très petit, triangulaire. Elytres beaucoup plus longues que le pronotum, de sa largeur à la base, courbées sur les côtés, rétrécies et droites au bord apical, couvertes d'une ponctuation un peu plus tine que le pronotum; repli latéral convexe, ponctué, unistrié ; strie subhumérale externe fine, abaissée, coudée à l'épaule, dorsales fortes, crénelées, presque droites, entières, ainsi que la suturale. Propygidium pointillé comme la base du pygidium. Prosternum (f. $p$ ) étroit, rétréci en devant, assez long, bistrié. mésosternum pointillé, légèrement bisinué, bordé d'une strie entière, anguleuse sur les côtés. Pattes rouges.

C'est à tort que M. Le Conte rapporte, au $E$. nigrellus de Say, le $E$. pulicurius d'Erichson. La collection Dejean, citée par ces deux auteurs, renfermait, sous le mème nom de Dendrophilus pulicarius, six individus provenant de l'entomologiste américain, et se rapportant à deux espèces différentes. Que l'individu communiqué par Dejean à Erichson, 
soit le $\boldsymbol{E}$. minor de Le Conte, et non le $\boldsymbol{E}$. nigrellus de Say, l'inspection de types authentiques des deux espèces ne laisse pas plus de doute que l'étude de la description.

Cette espèce, assez répandue dans les provinces méridionales de l'Union américaine, vit sous l'écorce des arbres morts entrant en décomposition.

\section{E. FULVICORNIS.}

Oblongo-ovalis, subconvexus, piceus nitidus; antennis pedibusque ferrugincis; pronoto stria marginali haud interrupta; elytris margine inflexo 1-striato, stria subhumerali externa angulata, dorsalibus et suturali subrectis, integris, punctulatis; pygidio impresso; prosterno valde angustato; mesosterno stria completa. Long. 2 1/4 mill.; larg. 1 1/4 mill.

Hister fulvicornis, F. Syst. El. 1, 90, 35 (1801).— Payk. Mon. Hist. 45,33, t. $10,6$.

Epierus fulvicomis, Er. in Jahrb. 162, 7.

Ovale-oblong, peu convexe, brun de poix luisant. Antennes ferrugincuses; massue plus clairc. Front bombé, lisse. Pronotum lisse, arrondi à la base, rétréci et échancré en devant, avec les angles aigus, abaissés; strie marginale non interrompue. Ecusson très petit, triangulaire. Elytres plus longues que le pronotum, de sa largeur à la base, rétrécies postérieurement, droites au bord apical, pointillées sur leur surface; repli latéral ponctué, unistrié; strie subhumérale externe fine, à peine coudée à l'épaule; dorsales ponctuées droites, bien marquées, ainsi que la suturale, toutes entières. Propygidium couvert d'un pointillé fin. Pygidium ponctué de même et impressionné au bout. Prosternum (f. 26, $t$ ) bistrié, très étroit à la basc. Mésosternum trois fois plus large, strie marginale complète. Pattes ferrugineuses.

Nouvelle-Grenade (M. de Laferté). 


\section{E. ROBELLUS.}

Oblongo-ovalis, subparallelus, convexiusculus, rufus; pronoto Icevi, stria marginali interrupta; elytris juxta suturam punctatis, striis 4 dorsalibus integris, $5^{\text {a }}$ obsolcta, suturali breviata, subhumerali interna postica; prosterno elongato, 2 striis in medio valde approximatis; mesosterno stria marginali integra, intermedia scmicirculari. Long. 2 mill. ; larg. 1 1/5 mill.

Epicrus rubcllus, Er. iu Jahr. 1, 168, 9 (1834).

Ovale-allongé, presque cylindrique, assez convexe, d'un rouge plus on moins ferrugineux. Antennes ferrugineuses; massue testacée. Tête lisse ; front légèrement concave. Pronotum très indistinctement pointillé, plus large que long, arrondi à la base, avec un point antéscutelláire, presque dioit sur les côtés, échancré et à peine rétréci en devant, arec les angles aigus; strie marginale cessant au niveau des yeux. Elytres un peu plus longues que le pronotum, de sa largeur à la base, presque parallèles, ponctuées vers la suture postérieure; stries fines; quatre premières dorsales entières, obliques, cinquième représentée par un rudiment court, obsolète, postérieur et un autre en arc à la base; suturale courte, médiane; subhumérale externe entière, un peu abaissée obliquement par derrière et formant à la base un bourrelet élevé, interne raccourcie; bord infléchi fine. ment pointillé, 1-strié. Propygidium couvert de gros points espacés. Pygidium finement pointillé. Prosternum (f. 27, $u$ ) long, plus large et subsinué à la base; stries arquées, rapprochées au milieu de manière à se toucher presque par leur convexité ; lobe antérieur réfléchi. Mésosternum légèrement bisiuué en devant, étroitement rebordé, traversé au milieu par une forte ligne semicirculaire. Pattes d'un testacé ferrugrineux.

Carıhagène (Nouvelle-Grenade); Brésil. 



\section{ESSAI MONOGRAPHTUE SUR LA FAMILLE DES HISTERIDES.}

(Suite) (1).

Par M. S. A. de MARSEUL.

Séance du 9 Février 1853.)

XXII. CARCINOPS.

( xa.pxívoe, crabe; $\ddot{\psi} \psi$, figure.)

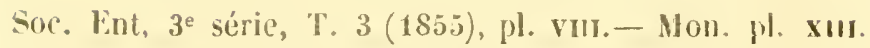
Genre XXII.

Hister. Paykull, Mon. Hist. (1811); Say.

Paromalus, Erichs. in Jahrb. (1834). - Le Conte; Aubé.

Corpus ovalum, subdepressum; purvum.

Caput retractum, parvum, orbienlare; fronce plana clypeoque marginatis, antemice sub frontis margine insertce, foveola ante coxus anticus in medio obsoleta, margine pectorali profunde inciso.

Pronotum trapesoidale; stria tenui marginali. Scutellum. parvum.

Elytra apice truncata, striis validis punctatis, margine inflexo striato hand foreolato.

Propygillium hexagonm ; pygidium in utroque sexu simplex, declivia.

Prostermum elevatum basi rotundaum. bistriatum, lobo

(1) Voyez 3 e Séric, T. I (1553), p. 131 et 447, et T. II (1854), p. 161, 525 et 671 . 
prominulo; mesosterno cmarginatum, stria marginali antice approximata.

Tibie antice arcuate, dilatale subdenticulate, foveola iarsali obsoleia.

Corps ovale, aplati ou légèrement convexe, noir luisant. Tête petite, arrondie, s'enfonçant dans le prothorax; front plan, non séparé de l'épistome, entouré d'une strie marginale fine qui s'avance plus ou moins et quelquefois reborde entièrement l'épistome. Labre court, transversal. Mandibules assez fortes, courbées, acérées et unidentées en dedans.

Antennes (f. 4, d) insérées sous 111 rebord du front, entre les yeux et les mandibules. Scape assez eourt, peu courbé, épaissi au bout, logé dans une rainure pratiquée sous la tête. Funicule de sept articles à peu près égaux, courts : premier obconique, un peu plus long, ainsi que le dernier. Massue ovalaire, comprimée, velue, de quatre articles dont le dernier est petit et peu distinct. Fossette antennaire peu profonde, placée sous le bord latéral du prothorax au devant des hanehes.

Mâchoires cornées ( $f .4, c)$, insérées en dehors du menton, à deux lobes membraneux, barbus en dedans; l'externe beaueoup plus grand que l'interne. Palpes maxillaires de quatre articles assez grêles et allongés : premier article très petit; deuxième obconique, allongé ; troisième eylindrique, court; quatrième ovalaire, trois fois plus long. Menton (f. 4, b) corné, en carré, un peu plus long que large, subsinué en devant, tronqué à la basc. Lèvre membrancuse saillante; languette nulle; paraglosses étroites, cilićes en dedans; palpes labiaux, de trois articles, premier très petit, deuxième obconique, troisième ovalaire, égaux entre eux. 
Pronotum plus large que long, peu convexe, faiblement arqué à la base et sur les côtés, rétréci et échancré en devant aree les angles abaissés, aigus, peu saillants; strie marginale fine, rarement interrompue. Ecusson très petit, mais toujours visible. Elytres un peu plus longues que le pronotum, le sa largeur à la base, peu convexes, curvilinéairement élargies sur les cotés, tronquées au bout; repli latéral sans fossette humérale, avec deux ou trois stries, dont quelquefois l'interne pourrait être regardée comme une subhumérale externe fort abaissée aiusi qu'on en voit dans certains Epierus. Stries dorsales profondes, ponctuées, ordinairement au nombre de cinq; suturale entiere ou un peu raccourcie.

Prosternum (f. $10 h$ ) assez élevé, beaucoup plus long que large, arrondi à la base, bordé d'une strie forte sinuée; lobe antérieur très distinct, un peu abaissé, dépassant un peu l'angle du prothorax, arrondi en devant et rebordé; bord pectoral profondément incisé pour le passage des antenues. Mésosternum plus large que long, très légèrement sinué en devant, bordé d'une strie non interrompue, rapproclı́e du bord antérieur (excepté le C. Dominicanus) toujours bien séparé du métasternum.

Pattes ( $f$. $4, c, f, g$ ) médiocrement distantes à leur insertion; cuisses ovalaires, comprimées, creusées en dedans d'une coulisse; jambes antérieures arquées, élargies vers le bout, terminées par un fort crochet recojurbé en dehors, bi ou tridentées en dehors, arec une fossette tarsale mal limitée : postérieures élargies au bout, un peu contournées, garnies de deux rangées de proils ou spinules; tarses de cinq articles : 1-4 courts, égaux, triangulaires, ciliés pll dessous; cinquième assez long, armé de deus crochets. 
Abdomen de cinq anneaux; premier segment ventral assez long, bistrié cntre les hanches, 2-5 courts, à peu près d'égale longueur. Propygidium hesagonal. Pygidium triangulaire, convexe; l'un ol l'autre inclines.

Les espèces de ce genre, qui n'est qu'un démembrement du genre Paromalus d'Erichson, ont un faciès uniforme et particulier d'oủ ils tirent leur nom. Ils ont des rapports avec quelques Epierus et Phelister; mais deux caractères tranchés les en séparent du premier coup d'ocil, leurs jambes contournées, terminées par un crochet arqué en dehors, et la fossette antennäire peu profonde, placée au milieu du bord latéral au devant des hanches, dans laquelle l'antenne vient se loger en passant par une fente du bord pectoral. Quant aux vrais Puromalus, auxquels on les avaient accolés, on les en distinguera aisément par leu's élytres régulièrement et fortement striées, leur prosternum toujours reborlé et pénétrant plus avant dans le mésosternum; enfin par la strie marginale de ce dernier cntière, sans strie biangulaire.

La plupart des espèces ont un genre de vie analogue a celui des Paromalus; on les trouve sous les écorces des arbres morts, en décomposition. Une seule espèca propre a l'Europe méridionale et au Nord de l'Afrique, le C. minimus se trouve sous les pierres et dans les matières animales desséchées. M. Le Conte dit avoir rencontré le C. mumilio dans les excréments. I a larve est inconnue.

Ce genre renferme douze espèces dont la moitié sont nouvelles. Répandu dans plusicurs pays du globe, il se rén partit de la manière suivante: Lurope, 1 ; Amérique, 8; Afrique 2; commune aux trois parties, 1. 
XXII. Carcinops.

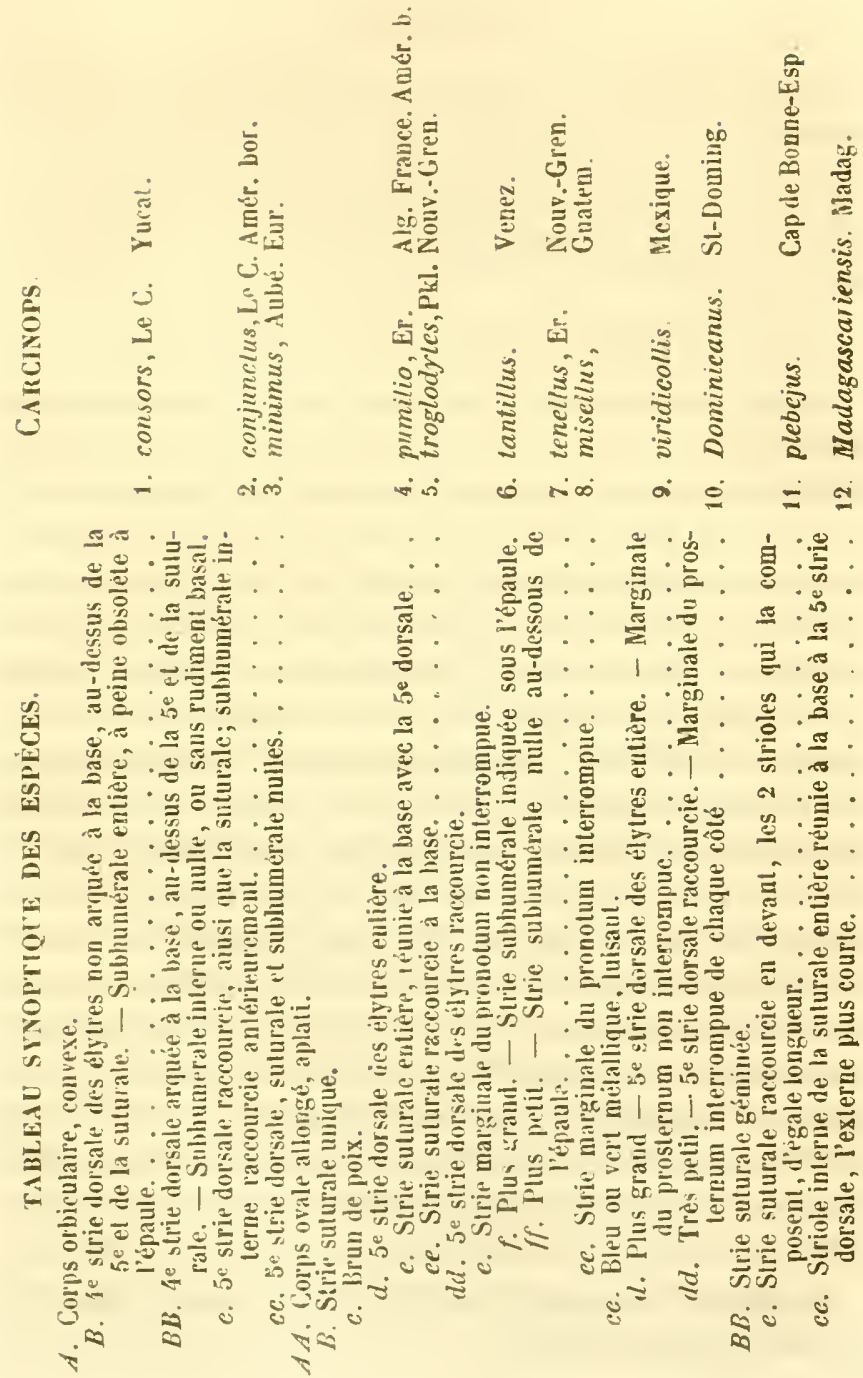




\section{C. Consons.}

Ovalis convexiusculus, picens nitidus, antennis pedibusque testaceis ; fronte punctulata ; pronoto stria marginali integra, versus lalcra sparse punctato; elytris striis punctatis, 4 primis dorsalibus integris, 5a ct suturali antice abbreviulis, illa basi fovcoia auctu; sublumerali interna interrupta. Long. 2 1/2 nill.; larg. $13 / 4$ mill.

Paromalus consors, Le Conte, Calif. Col. 40, 2 (1852).

Ovale, assez convexe, d'un brun de poix luisant. Front rebordé sur les côtés, convexe, finement ponctué. Antennes d'un brun testacé. Pronotum beaucoup plus large que long, arrondi à la base, bordé d'une série de gros points avec unc impression antéscutellaire, arrondi sur les côtés, rétréci el échancré en devant avec les angles aigus; ponctué très finement sur toute sa surface, avec de gros points peu serrés sur les bords ; strie marginale entière. Ecusson court, triangulaire. Elytres plus longues que le pronotum, de sa largeur à la base, arrondies sur les côtés, rétrécies et coupées droit au bout, à peine ponctuées sur la suture et à l'extrémité; stries fortes, bien marquées, arquées, crénelées, quatre premières dorsales entières, cinquième raccourcie au tiers antéricur, ainsi que la suturale, avec un gros point basal; strie subhumérale interne coupée par l'lıuméralc et interrompue en cet endroit ; externe courte, rudimentaire; deux marginales fortes et entières. Pygidium ponctué. Prosternum arrondi à la base, entouré d'une strie sinucuse. Mésosternum sinué en devant, à peine échancré. Pattes brunes; jambes antérieures bidentées au bord exterme.

Campêche (Mexiçue); San-1)iego (Californie); daus les Opmontia en putréfiction. 


\section{C. Conjunctus.}

Oralis converiusculus, picens mitielus, antennis pedibusque brunneis; undique geminntis pumctidis coopertus; fronte ad oculos tuntum marginata, sat comexa; pronoto stria marginali incyra; clytris striis validis crenatis, 4 mrimis torsalibus integris, hil al suturam arcuata, $5^{\text {a }}$ suturatipne subtumeralique externa amice valele abbreviatis ; tibiis anticis bidentatis. Long. 2 1/2 mill.; larg. 1 1/2 mill.

Hister coujunctus, Say. Soc. Phil. 38, 8 (1825).

Paromalus conjunctus, Le Conte, N. Amer., Hist. 3S, 5, pl. v, fig. 1.

Orale assez convexe, d'un noir de poix luisant; couvert sur toute sa surface de petits points disposés par rangées de deux ou trois. Tête avec un gros point sur le vertex. Front bordé d'une strie latérale qui s'arrête aux yeux, convexe. Antennes brunes, à massue plus claire. Pronotum plus large que long, arrondi à la base et sur les côtés, rétréci et échancré en devant, avec les angles aigus; avec de gros points épars sur les côtés et une rangée basale de points semblables. Ecusson court, triangulaire. Elytres plus longues que le pronotum, de sa largeur à la base, arrondies sur les côtés, rétrécies au bout; stries fortes, crénelées, quatre premières dorsales entières ; quatrième recourbée en haut, à la base, jusqu'àl'écusson, passant au devant de la cinquième et de la suturale, qui sont raccourcies à la base; une seule sublıumérale occupant le tiers postérieur. Pygidium ponctué. Prosternum arrondi à la base, entourée d'une strie sinuée. Mésosternum éclancré en devant et se laissant pénétrer par le prosternum. Pattes brunes; jambes antérieures bidentées, avec quelques denticules après la deuxième dent.

L'auteur annéricain cite à tort comme synonymes, les 
Paromalus pumitio. Er., Abreus irylhrocerus, Dej. Cat. La figure présente les jambes antéricures d'un Epicrus, une ponctuation trop marquée el la cinquième strie dorsale réunie à la suturale, ce que je n'ai remarqué dans ancun des nombreux exemplaires qui m’ont passé sous les yeux.

Union américaine, surtout dans les provinces méridionales, dans les excréments, selon M. Le Conte; Caracas (Venezuela).

\section{C. MINIMUS}

Breviter ovalis, convexiusculus, munctatus, piceus mitidus, antemens pedibusyme rufo testaceis; pronoto stria maryinuli

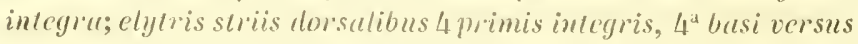
scucllum arcuala, coteris mullis; tibiis anticis 3 denticulatis. Long. 1 1/4 mill. ; larg. 4/s mill.

Paromulus minimus Aubé, Soc. ent., $2^{\mathrm{e}}$ série, $8,322,31$ (1850).

En ovale court, assez convexe, ponctué, d'un noir de poix luisant. Front convexe. Antennes rousses; massue testacée. Pronotum plus large que long, arrondi à la base, avec le rebord plus fortement ponctué, arqué latéralement, rétréci, échancré en devant, avec les angles antérieurs aigus; strie marginale entière. Ecusson petit, triangulaire. Elytres plus longues que le pronotum, aussi larges à la base, arrondies sur les côtés, rétrécies et coupées droit au bout, couvertes d'une ponctuation assez forte, surtout sur le dos, moins serrée que sur le pronotum, devenant plus fine sur les bords; stries peu fortes, ponctuées, quatre premières dorsales entières; qualrième arquée à la base, vers l'écussou; cinquième suturale et subhumérale nulles. Pattes l'un brun-testacé arec les tarses plus pales. Prosternum arrondi à la base, pénétrant daus le mésosternum, ceint d'une strie eliptique sinueuse, profonde. 
Cette espece peu commme se trouve dans presque toutes les contrées de l'Lurope et du littoral de la Méditerranée. Elle vil dans les matières animales desséchées.

\section{C. PIIIII6}

Oblongo ceutus, parum comverus, nigropicens, nitidns, peulibus anlemistue brumneis, punctulatus; fronte plana, capile marginuto; monoto ante sculellum impresso, striu marginati inceyra; clytris striis cremulis, profundis, dorsalibus integris arcuatis, sulureli rectu subintegra, antice cmm 5a junctu; striu subhumerati internu integra, culerna brevi obsolved libiis anticis bidenticulatis. Long. 2-2 1/2 mill.; larg. 1 1/2 mill.

Paromalus mumitio, Er. in Jahr., 1, 169, 1 (1834).

Ovale, allongé, peu convexe, d'un noir de poix luisant. 'Tìte finement ponctuée ; front peu élevé, ceint en devant ct sur les cotés d'une strie obsolète. Antennes brunes, avec la massue testacée. Pronotum ponctué. 'ransrerse, arrondi à la base, avec une impression au devant de l'écusson, légèrement arqué sur les côtés, rétréci et échancré en devant, avec les angles aigus; strie marginale entière. Ecusson petit, triangulaire. Elytres beaucoup plus longues que le pronotum, le sa largeur à la base, un peu rétrécies au bout, avec la suture relevée, pointillées; stries bien marquées, crénelées; dorsales entières, arquées; la suturale droite, se joignant à la base avec la cinquième dorsale; sublıumérale interne entière, traversée par l'humérale ; externe obsolète, très courte. Ilyperpyge densément et fortement ponctué ; pygidium densément et finement. Prosternum arrondi à la base, leint l'une strie sinuée. Mésosternum légèrentent sinteé en devant. Pattes d'un brun-rouge; jamber antérienes anmes de tleur dents, avec plusieurs denticules apres la deuxiemes 
Cette espèce est répandue sur toutes les parties du globe. J'ai sous les yeux des individus de Rouen et de Marseille, d'Espagne, d'Alger, d'Egypte, de la Nouvelle-Orléans (Etats-Unis ) oủ il a été trouvé en octobre, sous l'écorce des arbres.

\section{C. TROgLODYTES.}

Subovatus, parum convexus, piceus nitidus, antennis pedibusque brunneis; capite punctuto, undique marginuto, fronte convexu; monoto versus latera muctis sprersis, stria margimali integra; elytris apice tantum punctatis, striis punctatis,

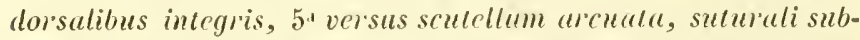
abbreviata, recta, sublumeralibus 2, cxterna abbreviata; mesosterno antice sinuato. I.ong. $21 / 2$ mill.; larg. $11 / 2$ mill.

Ilister "roglodytes, Payk. Mon. Hist. 46, 34, t. x. f. 1 (1811).

Paromalus troglodytes, Er. Jahr. 169, 2.

Ovalaire, peu convexe, d'un noir de poix luisant. 'T'ête ponctuée, avec un rebord étroit non interrompu sur l'épistome; front convexe. Antennes rousses. Pronotum beaucoup plus large que long, arrondi à la base, bordé d'une rangée de gros points, avec une impression au devant de l'écusson, arrondi sur les côtés, rétréci et échancré en devant, avec les angles aigus; couvert d'une ponctuation fine, peu serrée, invisible à la loupe, avec de gros points épars sur les côtés; stric marginale entière. Ecusson petit, triangulaire. Elytres plus longues que le pronotum, de sa largeur à la base, arrondies sur les côtés, rétrécies et coupées droit au bord apical, presque lisses, avec quelques points épars au bout, relevées sur la suture; stries fortes, crénclées, dorsales arquées, entières, cinquième se terminant droite, au-dessus de la suturale qui ne l'atteint pas; 2 subhumérales, interne entière coupéc obliquement par l'humérale, 
externe courte, finc. Pygidium ponctué. Prosternum arronti a la base, reint d'une stric elliptique sinuée. Mésosternum légírement échancré en derant, strić. Pattes d'un brun-ferrugineux; jambes antérieures armées de deux dents avec quelques denticules an-delà de la denxième.

Carthagène (Nouvelle-Grenade); Cuba ; St-I)omingue, sous les écorces, en octobre ; Paykull lui assigne pour patrie les Indes orientales.

\section{C. ravtilles.}

Oblongo-ovalis depressus, piceus nitidus; pronoto lateribus pmetuto, striu hand intermulu; clytris striis crenatis, $1-4$ dorsulibus integris, oّ" suturatique abhreviutis, subhumerali inierna vix intermpea; rropygidio pygidioque punctatis. Long. 2 mil.; larg. 1 1/4 mill.

Orale, oblong, déprimé, rétréci postérieurement, d'un noir de pois luisant. Antennes brunes; massue testacée. Front plan, finement pointillé, entièrement rebordé. Pronotum court, arqué à la base, avec un point antéscutellaire, presque droit sur les côtés, un peu rétréci et échancré en devant, avec les angles obtus, abaissés, peu saillants, couvert de points très fins et serrés, un peu plus grand latéralement; strie marginale non interrompue. Ecusson ponctiforme. Elytres plus longues que le pronotum, de sa largeur à la base, rétrécies et tronquées au bout, élevées légèrement à la suture; repli latéral bistrié ; stries dorsales profondes, crénelées, 1-4 entières, cinquième raccourcie, suturale encore plus courte; subhumérale interne entière, profonde à la base, plus fine au-dessous de l'humérale, comme interrompue. Pygidium un peu plus finement ponctué que le propygidium. Prosternum assez étroit, en- 
tièrement rebordé. Mésosternum pointilié, à strie non interrompue, sinué en devant. Pattes brunes: jambes antérieures tridenticulées, crénelées à la base; postérieures garnies de ı̨uelques épines.

Il se distingue du $P$. lencllus, qui a comme lui le pronotum entièrement rebordé, par la strie subhumérale interne bien marquée postérieurement et par sa taille plus grande.

Caracas (Venezuela), région chaude; en mars, sous l'écorce d'une tigge d'Agave Americana en décomposition.

\section{C. TENELLUS}

Ovalis, depressus, aler submitidus; antennis nelitusque ferrugineo-piccis; fronle punctulata, nec striuta, nec impressa; prothorace transverso antice angustato, stria marginali antice ambiente; scutello ronspricuo; clytris subquadrutis, striis 4-primis dorsalibus intogris, 5 ot 6 antice abbrevialis; mosterno bistriulo; tibiis antiris contortis dilutatis, extusque sublititer dentatis, intermaliis et postiris subspinosulis. Long. 2 mill.; larg. 1 1/2 mill.

Puromalus tonellus, Er, in Jahrl)., !, 170, 3 (1854).

P. gilensis, Le Conte, Calif., Col. 40, В (1852).

Ovale, apłati, d'un noir assez brillant. Antennes d'un brun de poix, avec la massue plus clairc. Tête très finement ponctuée; front sans strie transverse, ni impression. Prothorax beaucoup plus large que long, arqué à la base, arrondi sur les còtés, fortenent rétréci et échancré antérieurement, angles aigus abaissés; strie marginale non interrompue en devant. Ecusson très petit. Elytres de la largeur du prothorax à la base, presque carrées, à peine plus longues que larges; subhumerale interne fine, fortement raccourcie; dorsales ponctuées postéricurement, les quatre 
premières attcignant la base, les bs et suturale un peu raccourcies. Hyperpyge grossièrement ponctué ; ponctuation du pygidium plus fine et plus serrée. Prosternum bistrié. Pattes d'un brun-ferrugineux; jambes antérieures contournées et fortement dilatées, avec denx dents très petites; intermédiaires et postérieures presque linéaires et garnies de quelques épines.

Carthagène (Nouvelle-Grenade); Caracas (Venezuela), région chaude; en mars, sous une écorce d'Agave Americana eu décomposition, sur les bords du fleuve Grila, dans un Cereum giganteum pourri.

\section{8. (. MisELLUS.}

Subovalis, depressus, ni(pro-piccus nitidus, antennis pedibusque brunne forragineis; lecvissimus cxeontis plamoti luteribus; capite marginato; pronoto stria manginali in medio interrupla; elyu is sulura clevuta, striis punctatis, 4 primis dorsulibus inlegris, 5' basi, sulurali in medio incrruptis, sublumeruli interna integra, cxterna brevi.

Ovale, à côtés presque parallèles, déprimé, d’un noir de poix Iuisant. Tête bordéc dans son pourtour ; front assez. convexe, finement pointillé. Antennes d'un brun-ferrugineux. Pronotum plus large que long, arrondi i la base, arqué latéralement, échancré et légèrement rétréci en devant, avec les angles aigus, ponctué sur les côtés; strie marginale forte, interrompue en devant. Ecusson petit, triangulaire. Elytres plus longues que le pronotum, de sa largeur à la base, presque parallèles, relerées sur la suture, lisses, arec quelques points apicaux : stries bien marquées, ponctuées, dorsales presifue droites, rapprochies, 4 premières entières, cinquième raccourcie à la base. suturale 
au milieu; subhumérale externe courte, fine, postérieure ; interne entière coupée obliquement par l'humérale. Pygidium lisse. Prosternum large, ceint d'une stric. Mésosternum légèrement échancré en devant. Pattes brunes; jambes antérieures avec deux dents, et au-dessus de petites dentelures.

Excessivement petit el très aplati, il se reconnait des deux espèces précédentes par la strie margoinale du pronotum interrompue, le prosternum plus large et du P. tenellus, par sa strie subhumérale marquée postérieurement.

Guatemala.

\section{C. vinidicollis.}

Oblongo-ovalis, depressiusculus, aneo viridis, nilidus, untennis pedibusque rufo-brunncis; cupite monotoque marginatis, sat fortiter punctutis; clytris striis crenatis, dorsalibus, suturali et subhumerali interna integris; mesosterno antice cmarginato, striu integra. Long. 2 mill.; larg. 1 1/2 uill.

Ovale, allongé, assez peu convexe, d'un vert bronzé luisant. Tête ponctuée, avec un rebord entier ; front convexe. Antennes d'un brun testacé. Pronotum plus large que long, arrondi à la base, bordé d'une rangée de gros points, avec une impression antéscutellaire, arqué sur les côtés, rétréci et échancré en devant, avec les angles aigus, couvert d'une ponctuation assez forte; stric marginale entière. Ecusson petit, triangulaire. Elytres plus longues que le pronotum, de sa largeur à la base, presque droites sur les côtés, rétrécies et tronquées au bout, relevées sur la suture, finement pointillées sur toute lcur surface et fortement ponctuées postérieurement ; stries fortes, crénelées; dorsales entières, arquées; suturale fort rapprochée à la base de la cinquième ; 
subhumérale interne eutière. I'ropygidium ponctué, ainsi que le pygidium. Prosternum arrondi à la base, bordé d'une strie elliptique sinné. Mlísosternum bordé d'une strie.complète, et assez profondément échancré en devant. Pattes d'un brun ferrugineux; jambes antérieures armées de deux dents et de plusieurs denticules à la base, au-delà de la deuxiène dent; postérieures épineuses.

Hexico ( M. de Laferté).

\section{C. Domivicanes.}

Oblongo-ovalis, valde complanatus, viridi aneus, nitidus munctulatus; antemis pedibusqu'rufo brumeis ; monoto marginato; elytris striis cremulatis 1-4 dorsulibus integris, 5a suturalique abbreviatis, subhumerali intrma tenui; mesosterno striu utrimque interruptu. Long. 1 1/5 mill.; larg. 3/4 mill.

Très petit, ovale allongé, très aplati, d'un bleu métallique, plus vert sur le pronotum, luisant. Antenries brunes; massue ferrugineuse. Front pointillé, rebordé. Pronotum court, faiblement arqué à la base avec un point antéscutellaire, rétréci et échaneré en devant, avec les angles obtus, abaissés, pointillé, un peu plus fortement sur les côtés; strie entière. Ecusson ponctiforme. Elytres deux fois plus longues et aussi larges que le pronotum, impressionnées transversalement à la base, faiblement rétrécies et tronquées au bout; repli latéral sillonné; stries dorsales crénelées, 1-4 entières, cinquième raccourcie un peu moins que la suturale; subhumérale interne assez forte à la base, fine après l'épaule. Propygidium ponctué, ainsi que le pygidium. Prosternum assez large, resserré au milieu, fortement rebordé. Mésosternum à strie marginale interrompue à l'angle

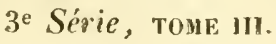


de chaque coté. Pattes brunes; jambes antérieures bidentées et crénelées; postérieures cilićes.

Il ne peut être confondu avec le $C$. viridicollis, qui est plus grand, plus épais, el n’a pas comme lui la strie marginale du mésosternum interrompue.

Ce joli pygmée du genre a été trouvé à St-Domingue, sous les écorces, en juillet, par M. Aug. Sallé, qui a bien voulu me le sacrifier, quoique uniq̧ue dans sa collection.

\section{C. Plebejts.}

Ovalis, depressus, nigro-piceus silidus, antemis pedibusque brunncis; fronte dense muctulata, marginatape; pronolo stria marginali integra, fortiter, at parce punctalo; elytris striis dorsalibus inlegris, 5a arcuala; suturati gemina antice abbreviata, 2 sulihumeralibus; mesostcrno stria haud interrupte. Long. 1 1/2 mill. ; larg. 1 mill.

Ovale, déprimé, d'un noir de poix luisant. Tête densément pointillée, rebordée; front convexe. Antennes d'un brun ferrugineux. Pronotum plus large que long, arrondi à la base, bordé d'une rangéc de poiıts, arec une impression antéscutelhaire, arqué sur les côtés, rétréci et échancré en devant, avec les angles aigus; couvert de points peu serrés, très fins au milien et assez gros vers les bords; strie marginale entière. Ecusson très petit, triangulaire. Elytres à peine pointillées, plus longues que le pronotum, de sa largrcur à la base, curvilinéairement dilatées sur les côtés, légèrement rétrécies et ironquées au bout; stries dorsales bien marquées, ponctuées, entières, cinquième arquée vers l'écusson. Suturale géminée, raccourcie en devant, un peu au-delà du milieu; subhumérale exlerne fine, raccourcie; interne entière, coupéc bliquement par l'humérale. Pygi- 
dium presque lisse. Prosternum arrondi a la base, ceint d’une strie elliptique. Mésosternum légèrement sinué en devant, entièrement rebordé. Pattes d'un brun ferrugineux; jamlẹes antérieures 4-dentées; postérienres ciliées.

Calp le Boune-Espérance.

\section{C. HADAGASCAMIENSIS.}

Oblongo-ovalis, subcomvexus, nigro piceus, nilidus, antemis peclibusque brammeis; fronte muctulata, temiter marginata; pronoto parce punclulato, interstities muctulatis, stria murgimali integra; clytris striis muncitis, subhumerati intema dorsalibusque inteyris, $5^{\text {a }}$ cum suturali busi conjunctu, hac gemimata. Long. 1 1/4. mill.; larg. 3/4 mill.

Ovale, allongé, assez convexe, presque cylindrique, d'un noir de poix luisant. Tête pointillée; front peu convexe, étroitement rebordé d'une strie non interrompue. Antemnes brunes; massue plus pâle. Pronotum plus long que large, arqué à la base, presque droit sur les côtés, légèrement rétréci et échancré en devant, avec les angles aigus ; couvert de petits points épars, peu nombreux, avec des points encore beaucoup plus petits dans les intervalles; strie marginale non interrompue. Ecusson très petit, triangulaire. Elytres plus longues que le pronotum, de sa largeur à la base, presque parallèles, à peine raccourcies au bout; stries réunies à la base, avec la suturale; celle-ci accompagnée d'une deuxième suturale qui remonte jusqu'au milieu seulement. Pygidium peu densément pointillé, rẹ̣li latéral bistrié. Prosternum court, étroit, arrondi à la base, ceint d'une strie ellipsoïde. Hésosternum transversal fortement échancré au milieu du bord antérieur pour recevoir la base du prosternum ; bordé d'une strie dans tout son pourtour. Pattes brunes; jambes antérieures contournées, dilatées au 
bord externe, 4-denticulées et finement crénclécs vers le genou; intermédiaires garnies de quatre spinules, postérieures de deux.

Madagascar. (M. de Laferté.)

Espèce que je n'ai pas vue.

paromalus opuntio, Le Conte, Calif. Col., 40, 1 (1852).

Oblong, subdéprimé, pronotum densément pointillé, ponctué sur les côtés. Elytres ponctuées au bout; stries profondes, fortement ponctuécs, les 2 internes obsolètes, composées de points; subhumérale nulle ou très courte, avec un rudiment basal. Long. 0,11 .

San-Diégo (Californie), dans les Opuntia en putréfaction.

\section{Genre PAROMALUS.}

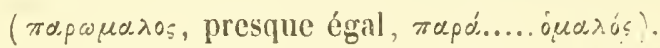

Soc. Ent. 3e séric, T. 3 (1855), pl. vill. - Mon. pl. xill. Genre XXIII.

Hister, Linn., Syst., 7 (1746). Herbst. Payk. et auct.

Holotepta, Payk. Mon. (1811).

Paromalus, Er. in Jahr. (1834); Le Conte; Heer; Redtenb., etc.

Corpus oblongo-ovatum, subdepressum, parvum.

Caput retractum orbiculare; fronte plana clypeoque stria commeni marginatis.

Antenne sub frontis maryine inserle, foveola obsoleta ante coxas anticas in medio margine pectorali, profundè inciso.

Pronotum subtrapesoidule, stria tenuimarginali. Scütcllum inconspicuum.

Elytra punctulata, striis value obsoletis, apice truncatis, margine inflexo haud fovcolato, striato. 
Propygidium trunsversum, mgidimm in altero sexu inse'ulptum, declivia.

Prosternum elevatum busi rotundatum, ruro bistriatum, lobo valde prominulo; mesostcrmem untcrius emarginatum, stria marginali valida intermpta.

Tibie untice contortue, dilutate subelenticulate'; fossa tursali obsoletu excavata.

Corps ovale allongé, plus ou moins aplati, noir luisant, pointillé assez uniformément en dessus.

Tête (f. 2 l) petite, arrondie, enfoncée dans le prothorax; front plan, non séparé de l'épistome, ceints tous les deux d'une stric fine, commune. Labre court, transversal. Mandibules assez fortes, égales, courbées, acérées à la pointe et unidentées en dedans. ..

Antenues ( . 2 f) insérées sous un rebord du front, entre les yeux et les mandibules. Scape assez long, légèrement courbé et épaissi au bout, logé dans une rainure pratiquée sous la tête; funicule de sept articles, premier obconique, beaucoup plus grand que les suivants, $2-7$ à peu près égaux entre cux. Massue ovalaire, comprimée, velue, de quatre articles dont le dernier est fort court et peu distinct. Fossette antenmaire peu profonde, placée sous le bord latéral du prothorax au devant des hanches.

Màchoires ( $1.2 e$ ) assez larges, en dehors du menton à deux lobes barbus, externe corné, interne membraneux, beaucoup plus court. Palpes maxillaires de quatre articles, premier très petit, deuxième obconique, renflé au bout, troisième subcylindrique, quatrième oralaire, plus long que le précédent. Menton corné, semicirculaire, arrondi en devant, coupé droit à la base. Lère membraneuse; languette an pointe obluse velue. Paraglosses arrondies, bar- 
bues. Palpes labiaux de trois articles; premier très petil, deuxième obconique, troisième ovalaire, d'égale longueur.

Pronotum plus large que long, peu convexe, faiblement arqué à la base, bisinueusement échancré en devant, avec les angles abaissés, peu aigus, presque droit sur les còtés, mais un peu arrondi antérieurement, bordé d'une seule strie marginale fine. Ecusson tellement petit qu'on ne peut l'apercevoir à l'origine de la suture. Elytres ordinairement planes, plus longues que le pronotum, de sa largeur à la base, dilatées à l'épaule avec le repli latéral étroit, strié, sans fossette humérale, un peu rétrécies et tronquées au bout sans angle sutural; stries réduites à deux ou trois lignes obliques, fines, courtes, obsolètes. Prosternum étroit, médiocrement saillani, avec ou sans stries marginales, arrondi à la base ; lobe antérieur, très distinct, un peu abaissé, avancé au-delà de l'angle prosternal arrondi, bordé sur les côtés; hord pectoral profondément incisé pour le passage des antennes. Mésosternum un pen plus large que long; échancré en devant pour recevoir la base du prosternum, avec un sillon latéral profond, qui cesse à l'angle antérieur sans se continuer en devant, réuni ordinairement par une strie transversale bianguleuse.

Paltes (f. $3 i, j, k$ ) médiocrement distantes à leur insertion ; cuisses ovalaires, comprimées, creusées d'une conlisse en dedans. Jambes antérieures coudées fortement au tiers, élargies au bout en spatule concave, à fossette tarsale mal limitées, terminées par une forte épine tournée en lehors, armées de trois ou quatre denticules; postérieures grêles, peu élargies au bout, un peu contournées, terminces par deux épines courtes, et gán'nies en dehors de deux rangées de spinules. Tarses de cing articles: 1-4 triangulaires, 
égaux, biciliés; cinquième beancoup plus longg, armé de deux crochets.

Abdomen de cinq anneaux; premier segment ventral assez long, bistrić; 2-5 égaur, assez courts. Propygidium en large hexagone. Pygidium semicirculaire bombé.

Dans l'un des sexes, probablement la entamé par des gerçures sans ordre, plus ou moins profondes, qui affectent des formes particulières selon les espèces.

Le genre Paromalus, tel qu'Erichson l'a établi dans le Jahrbucher en 1834, renferme deux groupes d'espèces si lisparates pour le faciès, que j’ai toujour's cru nécessaire de le décomposer. Mlais dis fois j'ai cherché inutilement des caractères pour les séparer. Ce n'est encore aujourd'hui qu'arec une certaine hésitation que je me décide à élever ces deux types à l'état de genres. Je conserve l'ancien nom de Paromalus pour les espèces sans stries et comme unies, et je replace dans le genre Carcinops, Ies espèces aplaties, fortement striées, à pattes antéricures contournées fortement coudées, qui ont, à cause de cela, quelque grossière ressemblance arec certains Crabes.

Quoiqu'il n’y ait pas ici de ces caractères tranchés qu'on rencontre dans certains autres genres de la mome famille, je ne pouvais négliger cette disposition singulière des pattes antérieures; cetle sculpture du pygilium (f. $a, e, h, m)$, dans les deux sexes, qui se trouve exclusicment dans les Paromalus; le mésosternum profondément échancré pour recevoir la base du prosternum, et si singulièrement strié : ce menton semicirculaire, etc. Ces caractères, ainsi que l'absence de stries dorsales bien arrêtées, les feront toujours recomaitre au premier abord. 
Ainsi constitué, le genre Paromalus se compose pour moi de douze espèces, dont trois appartiennent à diverses contrées de l'Europe, un aux îles Philippines, et huit à l'Amérique. Herbst, Paykull, Say, Erichson et Le Conte en avaient publié successivement sept.

Ces insectes vivent sous l'écorce des arbres morts. On les rencontre au printemps ou à la fin de l'été. Les métamorploses du $\boldsymbol{P}$. flavicomis ont été soigneusement étudiées par l'auteur des Insectes du Pin maritime. La larve vit absolument dans les mêmes conditions que celle du Platysoma oblongum, et lui ressemble extraordinairement. Elle en diffère par sa taille, qui n'est que de 6-7 millim.; par ses mandibules dépourvues de tubercule au-dessus de la dent interne, par ses mâchoires et les deux premiers articles des palpes maxillaires un peu plus courts et plus régulièrement dilatés; par le troisième article des antennes terminé par deux petites papilles en delıors et deux spinules en dedans; par le devant de la tête, prolongé en une dent tronquée; enfin, par les appendices abdominaux, un peu plus gros et terminés par des poils plus longs.

La nymple ne se distingue de celle du Plegaderus discisus que par sa taille plus grande, sa forme plus ovale, les crochets abdominaụx moins arqués et les poils plus courts. 


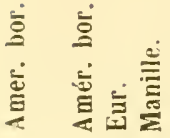
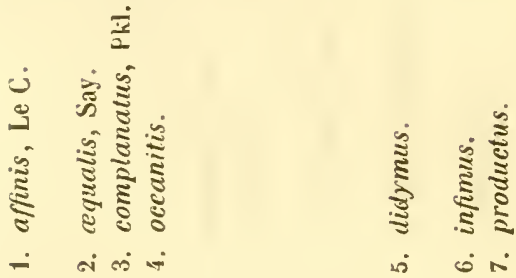

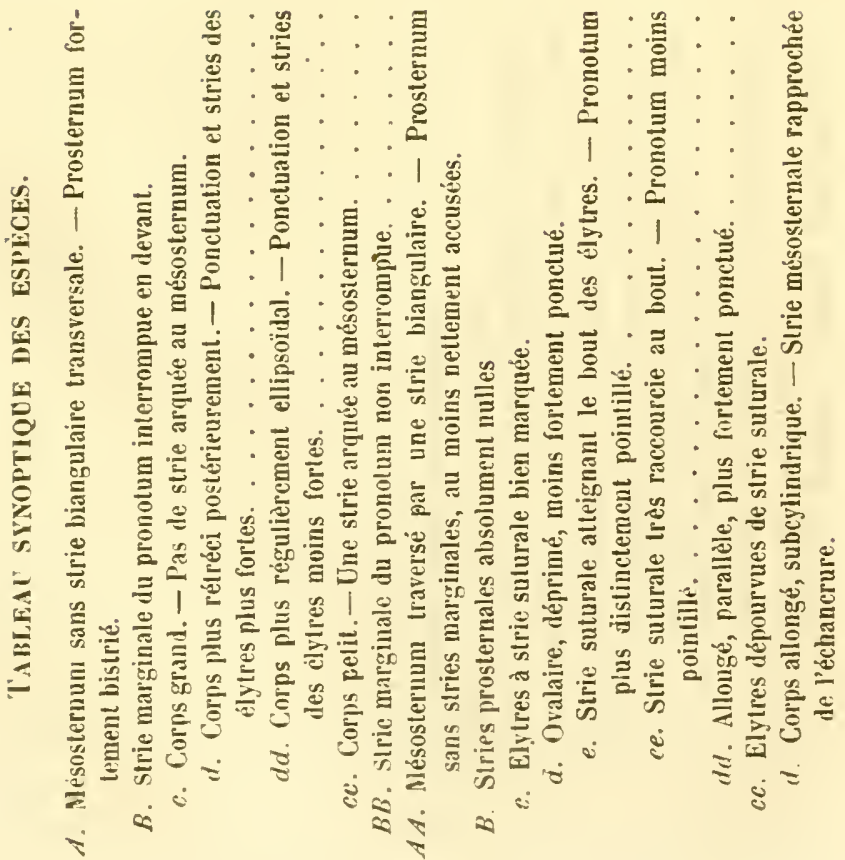




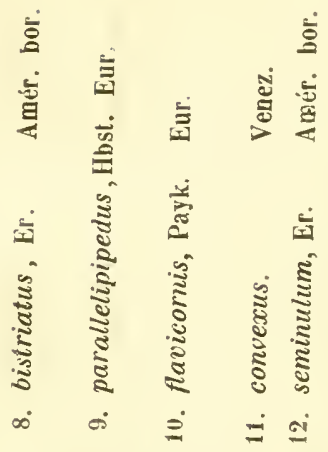

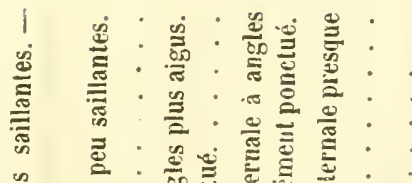

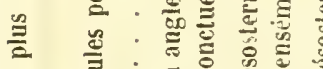
ڤ.

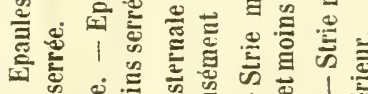

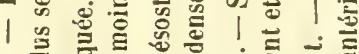
๑ 屯屯

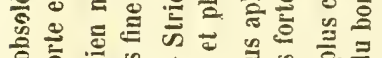

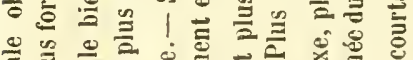

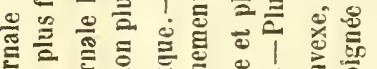

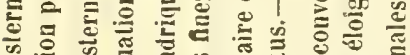
\%

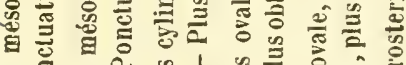
竞总

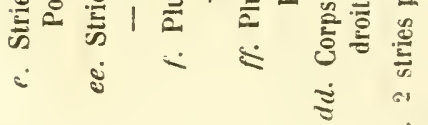




\section{P. AFEINIS.}

Ovatns, postice ingustior depressus, obsolete munctulutus; nigro piccus nilidus, antemis brunneis; pronoto stria marginali interrupta ; elytris stria dorsuli da ulinque abbreviatu, cetcris brevibus, basulibus, humerali et subhumerali distinctis. Long. 3 1/2-4 mill.; larg. 1 1/2-2/3 millim.

Paromalus uffinis, Le Conte, N. Amér. Hist., :37, 2, pl. 4, 10 (1S45).

Ovale, fortement rétréci postérieurement, depuis le premier tiers antéricur, déprimé, couvert d'une ponctuation très fine et obsolète; d'un noir de poix luisant. Front plane, avec une strie marginale derrière les yeux. Antcunes d'un brun-rouge. Pronotum beaucoup plus large que long, presque droit à la base, arec une ligne antéscutellaire, à pcine arqué sur les côtés, arrondi aux angles antéricurs, séparés par une échancrure assez profonde, dont le fond est bisinué. Elytres plus longues que le prosternum, aussi larges à la base, rétrécies vers le bout, couvertes d'une ponctuation plus distincte; première strie dorsale raccourcie de part et d'autre, les autres rudimentaires, courtes, placées à la base, l'une d'elles, plus longue et plus forte; humérale et subhumérale distincles; deux marginales, l'interne plus forte. Pygidium pointillé. Prosternum (f. 16) arrondi à la base, bistrié, étroit. Mésosternum 3-sinué en devant, avec une forte strie de chaque côté. Pattes brunes; antérieures 4-denticulées, intermédiaires garnies de quatre spinules, postérieures de trois.

* plus pelit, plus allongé, avec le pygidium (f: 1 a) couvert de gergures plus on moins profondes et compliquées.

liflère ale l'requalis par sa forme beaucoup plus élargie 
en devant, plus elliptique, par la ponctuation plus forte, les antennes plus rouges et les stries des élytres plus nombreuses et mieux marquées.

Nouvelle-Orléans (Etats-Unis ); Texas, très rare, sous l'écorce des arbres morts.

\section{P. EQUaLIS.}

Subellipticus, depressus, tonuissime punctulatuspiceo, nitidues, pedibus antemisque brunneis, clava testacea; pronoto stria marginali interrupta; elytris striis dorsalibus $1^{\mathrm{a}}$ utrinque abbreviata, interrupta, 2a brevi oblique basuli; humerali et subhumerali distinctis. Long. 3 mill. ; larg. 1 1/2 mill.

Hister arqualis, Say, Soc. Phil. v, 41, 18 (1825).

Paromalus aryulis, Le Conte, N. Amér. Hist., 36, 1, pl. 4, 9.

$\Lambda$ peu près elliptique et aussi large postérieurement qu'en devant; plane, finement et peu densément pointillé, un peu plus fortement dans le $\sigma^{*}$. D'un noir de poix luisant. Front plane, avec une stric marginale fine derrière les yeux. Antennes d'un brun-rouge, avec la massue plus pâle. Pronotum beaucoup plus large que long, à peine arqué à la base, presque droit sur les côtés, arrondi aux angles antérieurs avee une échancrure bisinuée derrière la tête; strie marginale interrompue au milieu du bord antérieur. Elytres un peu plus longues que le pronotum, de sa largeur à la base, subparallèles, à peine rétrécies au bout; deux stries dorsales; première fine, raccourcie aux deux bouts, interrompue au milieu; deuxième basale courte, oblique; humérale et subhumérale obsolètes, mais ordinairement distinctes; deux marginales, interne plus forte. Prosternum assez long, étroit, bistrié, arrondi au bout. Mésosternum trisinué en devant, avec une strie marginale forte 
de chaque coté. Pattes hrunes; jambes antérieures armées de quatre petits denticules; intermédiaires de quatre spinules, et postérieures de deux ou trois.

$\sigma^{*}$ plus fortement ponctué et distinctement strié d'une tache ordinairement plus forte, avec le pygidium ( f. $2 d$ ) profondément sculpté, tandis que celui de la + est simple.

Cette espèce est répandue partout dans les Etats-Unis : Alabama, Texas.... Elle vit sous l'écorce des arbres morts.

\section{P. Conplanatis.}

Oblongo-ovalis, depressus, piceus; antennis pedibusque forrugincis; capile lavigato; molhorace transverso antice cix angustato, subtilissimi muctulato, stria marginali antice ambiante; scutcllo mullo; elytris molhoracis basi latiludine versus apicem basim angustalis, sumna planis absque striis dorsulibus, muctulatissimis; tibiis anticis in medio dilatatis, brevissime 4-dentatis intermediis el posticis vix apice latioribus, his 2-illis 4-spinosulis. Long. 3 mill.; larg. 1 1/2 mill.

Hister complamalus, Illig. Kief. Pr. 1, 64, 24 (1798).-Duft. Fn. Aust., 1, 232, 33. - Panz. Fn. Germ. 37, 7. - Sturm, Dents. Fn. 1. $246,29, \mathrm{pl} .18, \mathrm{D}$ d.

11. nassatus, Panz. Fu. Germ., 67, 8 .

Hololepta complenala, Payk. Mon. Hist., 105, 2, pl. 8, 7 (1811).

Paromalus complanatus, Heer, Fn. Helv., 1, 439, 1. - Bach. Fn. Pr., 1, 306, 1.- Relt. Fn. Ausı., 236, 1.

En ovale peu allongé, aplati, brun de poix avec les antennes et les yattes ferrugineuses. Tête imponetuée, front uni sans strie transverse, rebordé daus tout son pourtour, ni impression. Prothorax transverse, coupé droit à la base, échancré en devant arec les angles antérieurs aigus et abaissés, cotés légèrement arrondis ; très finement pointillé sur 
toute sa surface, avee, un point enfoncé au devant de la place scutellaire; strie marginale non interrompue en devant. Écusson nul, (tellement petit qu'on ne peut le distinguer à un assez fort grossissement). Filytres aplaties, de la largeur du prothorax à la base, rétrécies vers l'extrémité, coupées droit et sans angle rentrant à la suture; deuxièmes stries dorsales nulles obsolìtes; première fine, raccourcie, interrompue au milieu; deuxième oblique basale; humérale courte visible; subhumérale obsolète ou nulle; deuxième marginale interne plus grosse; ponctuées plus fortement sur les côtés et partout plus distinctement que sur le prothorax. Pygidium ( $f .3-4)$ à peu près lisse, avec quelques points à peine visibles à un fort grossissement. Quelques individus ont en outre un espace circonscrit par une ligne circulaire peu profonde et sillonné par d'autres lignes anastomosées. $\left(\sigma^{*}\right)$ - Jambes antérieures contournées et dilatées fortement, garnies de quatre denticules peu marquées; les intermédiaires et postérieures étroites et garnies; celles. ci de 2 épines et celles-là de 4 environ.

Ericlıson a réuni à cette espèce le $P$. cequalis, Say, qui en diffère essentiellement par la strie mésosternale arquée et la marginale du pronotum non interrompue.

France; Allemagne; Autriche; Suisse; sous l'écorce des arbres morts, tels que chêne, hêtre, bouleau, peuplier. Rare.

\section{P. OCEANITIS.}

Ovalis, planiusmlus, niger nitidus, antemis pedibusque brunneis; menctatus; fromle undique marginata; monoto stria marginali internmtn; clyn is striis 2 dorsalibus, $1^{\text {a }}$ antice ${ }^{2}$ postice abbreviutis; mosterno stria clliplice marginali. Wong. $21 / 5$ mill.; larg. $11 / 5$ mill. 
Ovale, plane en dessus, d'un noir luisant. Tête finement pointillée, bordée d'une strie marginale entière. Antennes brunes, ì massue plus claire. Pronotum plus large que long, arqué à la base, presque droit sur les côtés, arrondi aux angles antérieurs, échancré et à peine rétréci en devant; finement pointillé, presque lisse au milieu; strie marginale longeant le bord antérieur et s'arrètant à l’œil. Ecusson tellement petit qu'on ne le peut apercevoir à la loupe. Elytres un peu plus longues que le pronotum, de sa largeur à la base, légèrement rétrécies au bout, assez fortement ponctuées; 2-stries dorsales; première un peu raccourcic à la base; deusième raccourcie vers le milieu postérieurement. Hyperpyge ponetué. Pygidium (f. $4 \mathrm{~m}$ ) presque lisse (avec des gerçures irrégulières $\sigma^{\star}$ ). Prosternum (f. $4 l$ ) arrondi à la base, bordé d'une strie subelliptique analogue à celle des espèces de la première division. Mésosternum fortement échancré en devant, bordé de chaque côté d'un fort sillon, et postérieurement d'une strie transverse, bisinuéc et avancée au milieu, vers l'échancrure prosternale. Pattes brunes; jambes antéricures dilatées, 4-dentées; intermédiaires armées de quatre denticules, postérieures deux.

Janille (Iles Philippines).

\section{P. DinYuus.}

Ovalis depressiusculus, niger mitidus, munctulatus; clava rufa; pronoto stria hand interrupta; clytris fortius mmctatis, stria suturali antice abbreviata, postice terminata; mosterno integro; mesosterno stria transversa biangulata, margini approximalu. Long. 2 mill. ; larg. 1 mill.

Ovale, déprimé, noir luisant. Antenues brunes; massue 
ferrugineuse. Front plane, densément pointillé ; strie entière, obsolète. Pronolum court, à peine arqué à la base, un peu arrondi sur les côtés antérieurement, bisinueusement échancré el devant, avec les angles peu saillants, abaissés, pointillé sur toute sa surface; strie marginale non interrompue. Elytres un peu plus longues que le pronotum, de sa largeur à la base, peu rétrécies et tronquées au bout, fortement ponctuées; repli latéral bisillonné ; traces des stries obliques à peine sensibles; suture relevée, avec une strie suturale partant du bord apical et atteignant le tiers antéricur. Propygidium pointillé. Pygidium pointillé de même, avec un double relief limité par un sillon profond, dans l'un des sexes. Prosternum sans stric. Mésosternum à strie transversale assez rapprochée du bord antérieur, à deux angles aigus. Pattes brunes; jambes antérieures garnies de trois ou quatre denticules; postérieures ciliées vers le bout.

Caracas (Venezucla), sous les écorces des arbres morts en octobre.

\section{P. INFINICS.}

Subeilipticus, parum convexus, piceo nitidus, pedibus antennisque brunneis, subtilissimè punctulatus; pronoto stria marginali integra; clytris striis 2 dorsalibus brevibus obsoletis, suturali utrinque abbreviatu; monoto simplici; mesostcrno stria transversa bisinnuta. Long. 2.1/5 mill.; larg. 1 1/4 mill.

Subelliptique, peu convexe, d'un noir de poix luisant; très finement et peu densément pointillé, un peu plus visiblement sur les élytres. Front peu convexe, bordé étroitement d'une strie non interrompue en devant. Antennes brunes; massue plus claire. Pronotum beaucoup plus large 
que long, arqué ì la base, légèrement arrondi sur les cotés, rétréci et échancré en devant, avec les angles aigus; strie marginale entière. Ecusson invisible à la loupe. Elytres une fois et demie plus longues que le pronotum, de sa largeur à la base, légèrement rétrécies à l'extrémité; stries dorsales obliques, basales fort raccourcies; suturale raccourcie en devant, au milieu, et n'atteignant pas le bord apical. Pygidium gercé irrégulièrement dans le 8 . Prosternum sans strie, arrondi à la base el pénétrant dans le mésosternum ; ce dernier fortement échancré en devant, bordé de chaque côté d'une forte strie, et postérieurement d'une autre strie transverse, bisinuée et rapprochée de l'échancrure au milieu. Pattes brunes; jambes antérieures contournées, dilatées et garnies de quatre denticules; intermédiaires de quatre et postérieures de deux.

Très distinct du $P$. didymus, par sa taille un peu plus grande, ses élytres moins fortement ponctuées, et surtout par sa strie suturale qui est fort raccourcie au bout.

Caracas (Venezuela), région chaude, en mars, sous des écorces d'Agave Americana en décomposition.

\section{P. PRODuctes.}

Elongato subcllipticus, parum convexus, sat densè et fortites. punctulatus, nigro piccus nitidus, antcnnis pedibusque brunneis; fronte pronotoque stria marginali integra; elytris striis 2 primis dorsalibus abbreviatis, suturali antice abbreviata, postice punctis cum apicali juncta; mesosterno stria transversa in medio mofundè bisinuata. Long. 21/4 mill. ; larg. 1 1/4 mill.

Subelliptique, allongé, peu convexe, d'un noir de poix luisant. Front peu convexe, finement pointillé, étroitement rebordé d'une strie non interrompue. Antennes brunes; 
massue moins olsscure. Pronotum plus large que long, arqué à la base, peu rétréci, échancré en devant, arec les angles aigus; finement et assez densément pointillé; strie marginale entière. Ecusson invisible. Elytres deux fois plus longues que le pronotun, de sa largeur à la base, presque arallèles, peu rétrécies et coupées droit au bout; un peu plus visiblement, mais moins densément pointillées; deux stries dorsales obliques, fort raccourcies, deuxième plus marquée, basale; suturale presqu'entiere, raccourcie à la base et un pen obsolète au bord apical, oú clle se continue par des points, avee la marginale qui longe le bord postérieur. Pygidium très finement pointillé sillonné de gercures fortes, peu nombreuses ơ . Prosternum étroil, sans stries, arrondi à la base et pénétrant assez avant dans le mésosternum ; celui-ci profondément échancré au milieu, et bordé postérieurement d'une forte strie transverse, anguleusement bisinuée, et avancée au milieu vers l'échancrure. Pattes brunes; jambes antérieures contournées, dilatées au bord externe, 4-denticulées; internédiaires garnies de quatre spinules, et postérieures de deux.

Nouvelle-Grenade; Cuba.

\section{P. Bistihatus.}

Elongatus, subcomvcxiusculus, fortins punctulatus, niger mitidus, antennis pedibus que brumeis; momoto striu marginalia imegra; clytris striis mofundis, abbreviatis, 2 primis dorsalibus, marginuli apicem usque ad suluram cingemti, sutmrali mulla; mesosterno stria transversa gemina simuata. Long. 2 1/4 mill.; larg. 1 mill.

Paromalus bistriutus, Er. in Jahr., 1, 171, 7 (1934). - Le Conte, N. Amér. Hisı., 37, 3, pl. 4, 11 (1845)? 
Allongé, presque cylindrique, faiblement convexe en Łessus; d'un noir de poix luisant. Frout presque plane, finement jointillé, bordé étroitement d'une strie non interrompue. Antenues brunes; massue plus claire. Pronotum plus large que long, légèrement arqué il la base, presque parallèle sur les côtés, échancré et à peine rétréci en devant, avec les angles aigus; assez densément el assez fortement pointillé; strie marginale non interrompue. Ecusson imperceptible. Elytres deux fois plus longues que le pronotum, de sa largeur à la base, subparallèles, à peine rétrécics postérieurement, plus fortenent, mais moins densément ponctuées; suture légèrement relevée; stries fortes, obliques; première dorsale raccourcie aux deux bouts, la deuxième seulement par derrière; suturale nulle; marginale externe coudée à l'épaule, longeant le bord apical jusqu'à la suture. Pygidium finement pointillé. Prosternum (f. $8 n$ ) arrondi à la base, sans stries. Mésosternum échancré en devant, bordé d'une strie longitudinale de chaque côté, avec uıe autre transversale sinueuse, géminée, peu marquée, un peu rapprochée de l'échancrure au milieu. Pattes brunes; jambes antérieures contournées, dilatées et 4-denticulées au bord externe; intermédiaires garnies de quatre spinules, postérieures de deux.

Cette espèce, très voisine du $P$. productus, s'en distingue par sa strie suturale nulle, celle du mésosternum peu nettement accusée, gémincée, à angles peu aigus. Ce dernier caractère empèche également de le confondre avec les $P$. parallelipipedus et flavicornis, avec lesquels il a quelques rapports de forme; en outre, sa ponctuation est plus forte. Un type de Le Conte, que j'ai sous les jeux, n'offre pas trace de la strie sulurale mentionnée daus la description et 
dans la figure de cet auteur, lesquelles semblent se rapporter à une tout autre espèce.

Etats-Innis. Mlexique: sous l'écorce des arbres morts.

\section{P. Parallelipipenus.}

Elongatus, subcylindricus, supra planus, piccus, pedibus et antennis picco-ferrngincis, undique punctatissimis clytris validis; prothorace transverso, antice angustiori, stria marginali antice intcruptu; clytris prothoracis basi latitudine, subparalletis, vix ad apicem attemuatis, stria laterali interna integra, cxterna obsoleta, $2 \mathrm{vel} 3$ dorsalibus basi obliquis valdè abbreviatis et obsoletis; tibiis anticis dilutatis, 4-denticulatis; intermediis et posticis ungustatis, his 1-, illis 3-spinulosis. Longueur $21 / 5$ mill. ; larg. 1 mill.

Hister paralletipipedus, Herbst. Nat. Ins., 4, 37, 11 (1791).

II. picipes, Duft. Fu. Ausı, 1, 232, 32 (1805).- Sturm. Deuts. Fn. 1, pl. 19.

Paromalus parallelipipedus, Er. in Jahr., 1, 170, 5. - Kæf. Brand., 1, 669, 1.- Heer, Fn. Helv. , 1, 460, 5. - Bach, Kæf. Pr., 1, 306, 2. - Redt. Fn. Aust., 236, 2.

Allongé, subdéprimé, presque cylindrique, d'un brun de poix, avec les antennes et les pattes plus claires. Tête pointillée, sans excavation ni strie transversale. Prothorax transversal, légèrement arrondi à la base et sur les côtés, rétréci en devant avec les angles abaissés et une échancrure assez large, couvert d'une ponctuation fine et assez serrée; strie marginale distincte, seulement sur les côtés. Ecusson nul. Elytres de la largeur du prothorax à la base, presque parallèles, rétrécies seulement un peu à l'extrémité, à peu près planes, avec la suture relevée postérieurement, couverte d'une ponctuation en général plus forte que sur le prothorax, mais moius près de la sutnre que vers les 
côtés. Strie marginale interne hien marquee; externe obsolète; dorsales très peu marquées, réduites à deux ou trois petites lignes obliques à la base. Pygidium légèrement pointillé, avec deux lignes arquées adossées et se réunissant par derriere dans l'un des sexes. Prosternum (f. 9 o) sans stries longitudinales. Jambes antérieures contournées el fortement dilatées, avec quatre très petites dents; intermédiaires et postérieures à peine élargies vers l'extrémité, les unes garnies de trois spinules, les autres d'une seule apicale.

France; Allemagne; Autriche; Suisse. Sous l'écorce des arbres. Rare.

\section{P. FLAVICORNIS.}

Ovalis, subdcpressus, picens, antonnis pedibusque dilutioribus; capite tenuissime punctulato, fronte nec impressa, nec striata; prothorace transverso latcribus rotundatis, antice angustiori, emarginato, angulis depressis et acutis; marginato, munctulatoque; scutello mullo; clytris prothoracis basi latitudine, mox dilatato posticeque arcuatim angusto, supra punctato ; mygidio tenuissime punctulato; prosterno haud striato; tibiis anticis valdè dilatatis; extus 4 -denticulatis; intermediis 4 et posticis apice uni-spimulosis, vix dilatatis. Long. 2 mill.; larg. 1 1/4 mill.

Hister flavicornis, Herbst, Nat. Ins., 4, 40, 13, pl. 36, 2 (1791). - E. H., 1, 106, 27. - Sturm. Deuts., F'n., 1, 249, 31. - Gyll., 1, 96, 27. - Payk., Mon. Hist., 90, 74, pl. 8, 6. - Dıft., Fn. Aust., 290, 31. - Illig. Kief., pr. 62, 20.

H. picipes, Pkl., Fu. suec, 1, 52, 21.

Paromalus flavicornis, Er. in Jahrl)., 1, 171, 6 (1798). Kal. Brand., 1, 669, 2. - Heer., Fn. Helv., 1, 459, 2. - Bach, Kief. Prus., 1, 306, 2. - Redt., Fn. Anst., 236, 3.

Ovale, subdéprimé, d'un noir de poix, avec le dessous des pattes, et surtout les anteunes, d'une couleur moins foncée. 
Tête finement pointillée, avec le front sans impression ef sans strie transversale. Prothorax transverse, légèrement arqué à la base, arrondi sur les côtés et fortement rétréci antérieurement, avec une échancrure assez profonde et les angles abaissés et aigus; légèrement et assez densément ponctué sur toute sa surface; strie marginale distincte sur les côtés seulement. Elytres assez planes en dessus, avec la suture relevée, de la largeur du prothorax à la base, assez fortement dilatées vers l'épaule, puis se rétrécissant progressivement vers l'extrémité qui est coupée droit; couvertes sur toute leur surface d'une ponctuation beaucoup plus forte que sur le prothorax, éparse et irrégulière, quelquefois rugueuse; strie marginale externe obsolète, interne bien marquée; dorsales représentées par deux ou trois lignes obliques très courtes à la base. Pygidium très finement pointillé, avec les deux lignes arquées réunies postérieurement dans l'un des sexes. Prosternum (f. $10 p$ ) sans stries. Jambes antérieures dilatées et contournées, avec quatre dentelures peu marquées; intermédiaires garnies de quatré spinules et postérieures de trois, les unes et les autres ì peine élargies vers le bout.

Diffère du parallelipipedus, par sa forme plus ovale, ses élytres plus élargies, la strie transversale du mésosternum à angles obtus et simplement sinueuse.

Assez commun au printemps et en été, sous l'écorce des arbres morts, en Europe: France; Suède; Allemagne; Italie.

\section{P. CONVEXts.}

Ovalis, convexiusculus, niyro-piceus, nitidus, sal fortiter punctulatus; antrmmis pelibusque lmrumeis; fromer stria inte- 
gra; monoto stria merginuli hued intermente; elytris striis 2 rrimis dorsalibus obliquis, abbreviulis, marginuli apicis ad mediun continuata; prosterno lutiori; mesosterno antice leviter. emarginato posticis striu subbisinuata. Long. $21 / 5$ mill.; larg. $11 / 2$ mill.

Ovale, issez comrese, d'un noir de poix luisant. Téte finement pointillée ; front légèrement convexe, bordé d'une strie fine, non interrompue. Antemnes brunes; massue moins sombre. Pronotum beaucoup plus large que long, assez lortement pointillé, arqué à la base, avec une bordure de points plus forts, légèrement arrondi sur les côtés, rétréci et échancré en devant, avec les angles antérieurs aigus; strie marginale entière. Ecusson invisible à la loupe. Elytres une fois et demie plus longues que le pronotum, de sa largeur à la base, légèrement arquées latéralement, rétrécies et coupées droit au bout; aussi fortement pointillées que le pronotum; deux premières stries dorsales obliques courtes, assez marquées; suturale nulle; marginale forte, coudée à l'épaule et continnée le long du bord apical, au-delà du milieu. Pygidium finement pointillé, sillouné $\sigma^{*}$ de nombreuses gerçures irrégulières. Prosternum un peu plus large que dans les autres espèces, sans stries, et arrondi à la base. Mésosternum peu profondément échancré en devant, bordé d'une strie de chaque côté, et en arrière, d'une autre transverse, fine, bisinuée et à peine rapprochée de l'échancrure au milieu. Pattes brunes; jambes antéricures contournées, dilatées, 4-denticulées; intermédiaires garnies de quatre épines, et postérieures de deux.

Venezucla. 


\section{P. SEMINLUM.}

Ovalis, subconvexus, piccus nitidus, pedibus antennisyne rufis, punclatus; pronoto stria marginali, haud interrupta; elytris striis 2 dorsulibus brevibus, suturalipme antice abbreviata; prosterno bistriato, stria mesosterni bisinuata. Long. $15 / 6$ mill. ; larg. 1 mill.

Paromalus seminulum, Er. in Jahrb., 1, 171, \& (1834). -- Le Conte, N. Amér. Hist. , 37, 2, pl. 4, 12.

Ovale, assez convexe, d'un brun de poix luisant, assez fortement et peu densément pointillé. Tête avec une strie marginale non interrompue; front peu convexe. Antennes ferrugineuses; massue testacée. Pronotum plus large que long, arqué à la base, légèrement arrondi sur les còtés, échancré et rétréci en avant, avec les angles aigus et abaissés; strie marginale non interrompue au milieu du bord antérieur. Ecusson invisible à la loupe. Elytres plus longues que le pronotum, de sa largeur à la base, arrondies sur les cotés, rétrécies et coupées droit au bout; deux stries dorsales obliques raccourcies, et une suturale bien marquée, raccourcie à la base. Pygidium finement pointillé ; gercé dans le $\delta^{*}$. Prosternum (f. $12 q$ ) finement bistrié, arrondi à la base et pénétrant avant dans le mésosternum; ce dernier fortement échancré en devant, avec une strie longitudinale de chaque côté, et une transverse, presque droite, bisinuée. Pattes d'un brun testacé; jambes antérieures dilatées, intermédiaires garnies de quatre denticules, postérieures de deux.

Louisiane; Caroline (Ltats-Unis): Téapa (Menique). 


\section{Espèce que je n'ai pas vue.}

paromalns exiguns, Falhr. in Bohem. Ins. Calli., 1, 552, 60: (1851).

Ovalis acpressus, niger, nitichs, vage muctulatus, antennarum capitulo flavescente, thoracis lateribus murginatis; elytris stric infia marginali, absque dorsalibus; pealibus forrugineis; tibiis anticis 3-denticnlatis, intermediis bispinosis. Longueur 1 2/3-2 mill; larg. 1-1 1/4 mill.

Entièrement noir, à l'exception des antennes et des pieds, très luisant. Tête transversale, ponctuée; front rebordé eu devant. Antennes assez courtes, noires de poix à la base; massue flavescente. Pronotum tronqué à la base, presque deux fois plus large que long, un peu rétréci en devant, avec les angles légèrement saillants, subacuminés, étroitement rebordé sur les côtés; déprimé en dessus, et vaguement pointillé de toutes parts. Ecusson nul. Elỵtres plus de deux fois plus longues que le pronotum, de sa largeur à la base, un peu rétrécies vers le bout, bord latéral infléchi; subtronquées au bout, avec les angles postérieurs arrondis, déprimées en dessus, vaguement pointillées sur toute leur surface ; repli latéral avec une petite strie arquée. Pygidium obtusément arrondi, pointillé à la base, lisse au bout; dessous du corps peu convexe, vaguement pointillé. Pattes médiocres, ferrugineuses; jambes antérieures dilatées en demi-lune, munies en dehors vers le bout, de trois denticules quelquefois obsolètes, intermédiaires peu dilatées, armées de deux spinules postérieures simples, mutiques.

Natel (Cafrérie). 


\section{MONOPILIUS.}

$$
\text { ( }
$$

Soc. Ent, 3 e série, T. 3 (1855), pl. vil.- Mou. pl. xur. Genre XXIV.

Corpus supru vulde ronvexum, orbiculare, nigrum, reticulatmm.

Caput parvum, rolundutum; fronte plama, stria integra i clypeo distincta.

Antennce scapo contorlo, funiculo 6-articul:nto, clave ovatu solicla; foveola subprolhoracis angulo antico detecta.

Pronotmm antice emarginatum, depressum, stria marginali integra.

Elytra striis levibus, suturali angulo.

Propygidium hexagonnm declive; pyyidium orbiculars convexum inflexmm.

Prosternum brele, angustum, bistriatum, busi incisum. lobo parum prominulo; mesostermum murginalum semicirculare, untice receptum.

Poles longe ciliati; tibiis anticis 1-scriatim dentatis, foveolu tarsali parum distincta; posteriores biseriatim denticulati; tarsis compressis, unianyulatis.

Corps orbiculaire, très bombé en dessus, noir terne, couvert d'une ponctuation très serrée, fine et confluente.

Tête (f. b) petite, arroudie, s'enfonçant dans le prothorax; front plan, ceint d'une strie qui le sépare de l'épistome. Labre court, transversal, sinuc; mandibules courbées, égales, unidentées en dedans; yeux semiovalaires, peu apparents.

Antennes (f. e) courtes, insćrées sons un rebord du front, entre les yeux af les mandibules; scape trapu, contourné, 
logé dans une coulisse, sous la tète, avec quelques grosses soies longues, rebroussées; funicule de six articles, premier plus long, obconique, les autres cylindriques, à peu près égaux; massue velue, solide, oralaire, altachée au funicule, un peu arant l'une des extrémités. Fossette antennaire arrondie, creusée à l'angle antérieur du prothorax, découverte; bord pectoral s'abaissant sans ètre traversé par l'antenne.

Màchoire f. $c$ ) cornée, à deux lobes membraneux, barbus au bout; externe long, dilaté au bout; interne court. Palpes maxillaires de quatre articles, riliés; premier très petit, deuxième obconique, troisième cylindrique, quatrième subovalaire; tous les trois à peu près d'égale longueur. Menton ( $f$. $d$ ) corné, en carré plus large que long, garni de longues soies; lèvres membraneuses, courtes; paraglosses courtes, ciliées en dedans; languette nulle. Palpes labiaux de trois articles; premier très petit, deuxième obconique, troisième ovalaire, égaux.

Pronotum court, avancé angulairement sur les élytres, arqué sur les côtés, abaissé et très rétréci en devant, avec une éclıancrure profonde, assez étroite; strie marginale fine, très rapprochée du bord, entière. Ecusson petit, triangulaire. Elytres courtes, hombées, arrondies au bout et formant un angle sutural très marqué; repli latéral très étroit, bistrié; lobe court, rabattu, arroudi en devant. Mésosternum semicirculaire, entièrement reboldé, pénétrant dans la base du prosternum. Métasternum concave; strie au milieu.

Pattes (f. f) distantes à leur insertion, assez longrues et grèles. Cuisses bordées en dedans et creusées d'un canal. Jambes en triangle très étroit, terminées par deux épines 
inégales; antérieures avec une large fossette tarsale mal arrètée, fortement dentées en dehors; postérieures à deux arêtes denticulées. Tarses comprimés, de cinq articles triangulaires; premier plus petit, 2-4 plus gros, garnis de deux soies en dessous, cinquième un peu plus long, plus étroit, terminé par un seul crochet.

Abdomen de cinq anneaux: premier segment ventral long, bistrié entre les pattes, échancré au bont; deuxième et troisième très courts, quatrième entièrement caché. Propygidium bombé, en hexagone, incliné. Pygidium bombé, suborbiculaire, tout à fait inférieur.

Ce genre remarquable ne renferme qu'une seule espèce du cap de Bonne-Espérance, dont les mœurs sont inconnues. Elle fait partie de l'ancienne collection Dejean, et elle est désignée dans la 3 e édition de son catalogue, sous le nom que je lui ai conservé.

\section{Moxoplius inflatis.}

Orbicularis, sumra valdè convexus, niger obscurus, strigosim dense punctatus; fionte planu, stria integra; pronoto stria marginali integra punctisque 8 juxta positis; elytris margine inflexo bistriato, 2 subhumeralibus, 1-4 dorsalibus postice abbreviatis; pedibus ciliatis; tibiis anticis 5-, intermcdiis 3̈-, posticis 1-dentatis, subtics spinosis.

Orbiculaire, très convexe en dessus, noir mat, couvert d'une ponctuation très serrée, souvent conlluente, et formant de petites lignes serrées. Antennes brunes; funicule rougeAtre. Front plane, entouré d'une strie entière qui le sépare de l'épistome. Pronotum bombé, court, large, avancé angulairement sur l'écusson, arrondi sur les còtés, abaissé 
et fortement échancré en devant, avec les angles obtus; strie marginale bien marquée, approchée du bord, non interrompue, avec huit gros points juxta-posés, trois sur chaque côté et un à l'angle postoculaire. Elytres un peu plus longues que le pronotum, de sa largeur à la base, presque droites sur les côtés, arrondies au bout, avec un angle sutural profond; bord infléchi, étroit, bistrić ; stries dorsales 1-4 fines, droites, parallèles, raccourcies postérieurement; deux subhumérales fines, l'externe sous le repli latéral. Prosternum court, peu saillant, assez étroit, fortement échancré à la base, lobe court, rabattu; stries parallèles raccourcies en devant. Mésosternum semicirculaire, à pointe antérieure reçue dans la base du prosternum, entièrement rebordé, concave ainsi que le métasternum. Pattes ciliées de longues soies peu serrées. Jambes antéricures 5-dentées; intermédiaires armées de trois dents en dessus, postérieures de deux, denticulées en dessous.

Cap de Bonne-Espérance.

\section{PEIORUS.}

$$
\text { ( } \pi \dot{\varepsilon} \lambda \omega \text { osos, monstrueux.) }
$$

Soc. Ent. $3^{\text {e }}$ série, T. 2 (1854), pl. viır. - Mon. pl. xıII. Genre XXVI.

Caput parvum, retractum; fronte plana, stria scmicirculari parcè clypeum interrupta; mandibulis validis edentatis. Antenna sub frontis margine insertu, clava compressa suborbiculari. Foveole subangulo prothoracis rolunde, detecte.

Pronotum trapezoïdale, stria marginali imegra.

Elytra striis profundis geminis, extìs completis.

Prosternum bistriutum, basi emarginatum, lobo brevi ro- 
lumdato, margine pectorali integro; mesosterno untice bisimuato, marginato, compresso.

Tibice unlice foveola vage insculpta extits dentalce, postices semiseriatim spinulosee.

Propygidium dective, hexagonum; mygidium trigonum, breve.

Corps ovale, épais, plane en dessus, noir.

Tète petite, arrondie, s'enfonçant daus le prothorax, entourée d'une strie semicirculaire, cessant à l'angle antérieur de l'œil. Front plane, non séparé de l'épistome. Labre court, transversal. Mandibules fortes, recourbées, terminées en pointe inermes en dedans. Yeus planes, arrondies, latéraux.

Antennes (fo d) insérées sous un rebord frontal à la partie supérieure de l'espace, entre les yeux et les mandibules; scape gros, contourné; funicule court, de sept articles: premier plus long et plus fort que les autres; 2-7 serrés, courts, presqu'égaux entr'eux; massue suborbiculaire, comprimée, velue, de (juatre articles. Fossette antennaire profonde, arrondie, creusée sous l'angle antérieur du prothorax, découverte.

Màchoire (f. b) à deux lobes membraneux, barbus au bout; l'externe beaucoup plus long que linterne. Palpes maxillaires de quatre articles : premier trés petit; deuxième obconique, assez long; troisiène court, cylindrique ; quatrième ovalaiı'e, le plus long. Menton (f. $c$ ) corné, quadrangulaire; lìre courte, nembraneuse; paraglosses ciliées, arrondies. Palpes labiaux de trois articles; premier très petit; Jeuxième obconique; troisième ovalaire, à peu près égaux.

Pronotum court, trapézoïde, avancé angulairement à la 
base sur l'écusson, faiblement arqué sur les cotés, fortement échancré et très rélréci en devant, avec les angles abaissés, ohtus; stric marginale entière, bien marquée. Ecusson ponctiforme. Elytres un peu plus Iongues que le pronotum, de sa largeur à la base, ì peine arquées sur les côtés, droites au bout, avec un angle sutural bien marqué, bord infléchi, étroit, sillonné, sans fossette subhumérale; stries dlorsales bien marquées, aiusi que la suturale et les sublıumérales; extérieures géminées. Prosternum assez large, échancré à la base pour recevoir une pointe du mésosternum; stries parallèles : lobe court, arrondi et rebordé en devant; bord pectoral étroit, bisinué. Mésosternum court, fort large, entièrement rebordé, bisinué en devant.

Pattes (f, e) assez distantes à leur insertion; cuisses creusées d'une coulisse et rebordées ell dedans; jambes assez grêles, rebordées en dedans et garnies de cils, arec une seule arète externe dentée ou épineuse, terminćes par deux épines inégales; antérieures à fossette tarsale mal arrêtée. Tarses à quatre premiers articles égaux garnis de soics; cinquième un peu plus long, avec deux crochets.

Abdomen de cinq anneaux : premier segment ventral assez long, bistrié cntre les pattes, les autres courts, à peu près d'égale longueur. Propygidium en hexagone, assez long, aplati, abaissé. Pygidium eu triangle à trois faces courbes, deux en dessons et une en dessus, seule visible, de sorte qu'il parait triangulaire, très petit et oblique.

Ce genre est établi sur une seule espèce du Sénégal, qui fait partie de la collection de M. de La Ferté. Cet insecte, singulier parmi ses congénères, a quelque vague ressemblance avec les Bruchus. Le nom dont je l'ai gratifié, fait 
allusion à cette disposition. Il conserve d'ailleurs toutes les allures d'un llistéride. A la forme naviculaire du Tribalus, il joint la disposition du sternum qu'on retrouve dans les Epierus, les mandibules et antennes des Hister. On le reconnaitra toujours au premier abord, à son propygidium en hexagone très allongé et à son pygidium en triangle, à trois faces convexes, dont la supérieure seule est visible, et à ses stries dorsales en sillons géminés.

\section{PELORIS BRLCHOIDES.}

Naviculuris, mger nitidus, antennis pedibusque brunncis; fronte planu munctulatu, striu utrinque ad oculum deficiente, pronoto lateribus punctato, striu integra; elytris margine inflexo bisulcato, 2 striis subhumeralibus, dorsalibus 1-3 profundis geminis, integris, $4^{\mathrm{a}}$ et suturali integris, 5a abbreviata; mopygitio munctuculato; tibiis anticis 6-dentalis, posticis s/ $i$ nulosis. Long. 5 mill. ; larg. 3 mill.

Ovale, mavieulaire, plane en dessus, noir luisant. Antennes brunes; funicule ferrugineux. Tête pointillée, ceinte d'une strie qui s'arrête à l'angle oculaire de chaque côté, sans se prolonger entre le front et l'épistome. Pronotum court, avancé anguleusement au devant de l'écusson, arqué sur les côtés, fort rétréci et échancrẻ en devant, avec les angles obtus, ponctué sur les côtés; strie marginale entière, un peu plus éloignée du bord vers la base. Ecusson ponctiforme. Elytres un peu plus longues que le pronotum, de sa largeur à la base, beaucoup plus courtes à la suture qu'au bord externe, tronquées au bout, repli latéral étroit, fortement bisillonné, deux stries subhumérales entières, humérale très rudimentaire, dorsales 1-3 en sillon profond, géminées, entières, ainsi que la quatrième et la suturale; 
cinquième raccourcie au milieu. Propygidium finement pointillé. Dessous du corps convert latéralement de gros points espacés. Prosternum bistrié, ćchancré à la base, lobe court. Mésosternum bisinué en devant, entièrement rebordé, avec une avance qui pénètre dans la base du prostermum. Pattes brunes; tarses ferrugineux; jambes antérieures garnies de six à sept denticules; postérieures d'une seule rangée d’épines plus ou moins nombreuses.

Sénégal.

\section{SCAPOMEGAS.

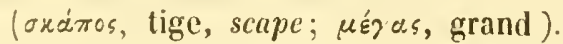

Soc. Ent. 3e série, T. 3 (1855), pl. Ix.-Mon. pl. XI. Genre XXVI.

Corpus globosum, nigrum.

Caput elougatum, vetractum; fronte à clypeo haud disjzncta; stria brevi intra-oculari; mandibulis detectis.

Antennce subfrontis margine inserte, scapo magno, clava ovali compressa; foveola subangulo prothoracis, detecta.

Pronotum antice sinuato emarginatum, angustatum, stria marginali lateralique ambiente.

Elytra globosa, striata, maryine sulcato, haud foveolato.

Prosternum bistriatum, basi cmarginatum; lobo brevi acuto; mesosternum breve, lutum, receptum.

Tibice antice extus bistratim dentieulate, posteriores spinosule.

Propygidium hexagonum, dcelive; pygidium trigonum subinflexum.

Corps orbiculaire, globulcux, noir.

Tête petite, allongée, s'enfonçant dans le prothorax : 3e Séric, Tome 11 . 
front convexe, avancé en saillie vers les antennes, avec une courte strie de chaque cóté, entre les yeux, sans ligne de démarcation qui le distingue de l'épistome. Mandibules allongées, presque droiles, fortement serrées l’une contre l'autre, découvertes.

Antennes (f. d) insérées dans une profonde cavité, entre les yeux et les mandihules, sous le bord du front; scape formant une masse d'une grosseur démesurée, logé dans une coulisse pratiquéc sous la tête; funicule de sept articles : premier allongé, 2-7 croissant en diamètre, et dinninuant de longueur; massue ovalaire, comprimée, velue. de quatre articles. Fossette antennaire creusée sous l'angle du prothorax, découverte.

Máchoires ( $\mathrm{f} . c$ ) à deux lobes membraneux, barbus, externe beaucoup plus long que l'interne. Palpes maxillaires de quatre articles: premier très petit; deuxième obconique; troisième eylindrique, égaux; quatrième ovalaire, de la longueur des deux précédents réunis. Menton ( $f_{\text {. b }}$ ) corné, sinué en devant. Lèvre courte, inembraneuse; paraglosses ciliées, arrondies. Palpes labiaux de trois articles: deuxième obconique; troisième ovalaire, d'égale longueur.

Pronotum en trapèze, fortement arrondi à la base, rétréci, abaissé en devant, avec une échancrure bisinuée au fond; strie marginale visible seulement dans l'angle antérieur, latérale non interrompue en devant. Ecusson triangulaire, très petit. Elytres un peu plus longues que le pronotum, de si largeur à la base, bombées au milieu, enfoncées dans leur pourtour; épaules saillantes; repli laléral sillonné, quelques stries bien marquées. Prosternum plane, saillant, élargi et échancré à la base; stries réunies en devant; lobe court, en pointe rabattue; bord pectoral très étroit, 
entier. Mésosternum très large et très court, bisinué en devant, avec une pointe médiane reçue dans la base du prosternum.

Pattes assez fortes, les quatre postérieures très distantes à leur insertion. Cuisses courtes, ovalaires, bordées et creusées d'une coulisse en dedans. Jambes triangulaires, terminées par deux épines inégales, garnies de deux rangées, les antérieures de denticules, lespostérieures d'épines. Tarses courts, comprimés, de cinq articles presque égaux, 1-1 garnis de soies en dessous, cinquième biangulé.

Abdomen de cinq anncaux : premier segment ventral long, bistrié entre les pattes ; $2-4$ plus ou moins rentrées, de manière à disparaitre les uns ou les autres au milieu. Propygidium en triangle sphérique, tout à fait en dessous.

Ce genre, dont le nom rappelle la disposition singulière du scape des antennes, se présente avec un faciès à lui, qui ne laisse aucun doute sur son identité. Il suffit, pour le reconnaître, d'avoir remarqué une fois sa tête fortement enfoncée dans le prothorax, avec ses mandibules serrées, formant une espèce de bec, encadrée entre ses énormes scapes, son pronotum bisinué dans l'échancrure, et bordé de sa strie latérale qui en suit les contours, ses élytres bombées et leurs stries dorsales, son prosternum échancré à la base et bistrié, son mésosternum si court et si large qui déjette fortement en dehors ses pattes; il a même plus de dissemblance avec les autres genres, que les genres Monoplius, Hclcerius, Pelorus, si tranchés néanmoins.

Il ne renferme que deux espèces, toutes deux comme coulées au même moule, et de l'Aınérique méridionale. 


\section{Scapomegas auritus.}

Globosus, niger nitidus, antennis pedibusque piceis; fronte impressa; pronoto stria laterali integra; elytris margine inflexo bisulcato, striis 1 a dorsali et suturali integris, subhumerali externa dimidiata, 2-5 dorsalibus apicalibus; propygidlio basi punctato, transversim carinato; pygidio bifoveolato.

Ovale, globuleux, d'un noir luisant. Antennes brunes; funicule ferrugineux. Front impressionné. Pronotum court, anguleusement avancé sur l'écusson à la base, avec une impression antéscutellaire, arqué sur les côtés, rétréci et bisinueusement échancré en devant, avec les angles abaissés, bien marqués; strie marginale bicn marquée dans l'angle, ne rejoignant pas le rudiment du côté opposé ; latérale forle, partant de la base et suivant le contour du bord antérieur. Ecusson petit, triangulaire. Elytres plus longues que le pronotum, de sa largeur à la base, dilatées à l'épaule, tronquées au bout, bombées au milieu, et creusées dans leur pourtour et sur la suture; repli latéral à deux sillons serrés, entiers; stries profondes, subhumérale externe raccourcie en devant, suturale entière, ainsi que la première dorsale, accompagnée d'une striole le long de la suture; 2.4 dorsales courtes, apicales. Propygidium ponctué à la base, élevé transversalement en carène. Pygidium pointillé dans son pourtour, bombé au milicu. Mésosternum avec une courte strie marginale. Pattes brunes.

Cayenne (Guyane).

\section{Scaponegas gibBus.}

Globosus, niger nitidu , ante inis pedibusque brunneis; fronte plana; pronoto stria laterali postice abbreviata; elytris mar- 
gine inflexo bisulcato, stria subfumerali dimidiata, suturali $1^{\text {a }}$ que dorsali integris, $2^{2}$ parum abbreviata, 3-5 apicalibus, propygidio basi punctato, haud curinato; mesosterno validius marginato.

Ovale, globuleux, noir luisant, très finement pointillé. Antennes brunes; scape noir. Front plane, sans impression, avec une courte strie oblique de chaque côté, entre les yeux. Pronotum court, largement anguleux à la base, avec une strie antéscutellaire, arqué sur les côtés, fortement rétréci en devant, avec une échancrure bisinuée et les angles abaissés. saillants; stric marginale, fine, bien marquée en devant, interrompue au milieu; latérale raccourcie postérieurement. Ecusson triangulaire, petit. Elytres plus longues que le pronotum, de sa largeur à la base, dilatées à l'épaule, tronquées au hout, moins bombées et moins creusées dans leur pourtour que dans le $S$. auritus; repli latéral à deux sillons serrés, entiers; suturale entière ; première humérale aussi entière, deuxième un peu raccourcie, ainsi que la subhumérale externe ; 3-5 rudimentaires, apicales. Propygidium ponctué à la base, sans carène transversale. Pygidium bombé, avec une petite impression médiane. Mésosternum presque entièrement rebordé. Pattes brunes.

Rio-Janeiro (Brésil).

XXVII. NOTODOMA.

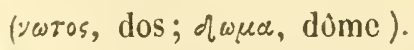

Soc. Ent. $3^{\text {e }}$ série, T. 3 (1855), pl. Ix. - Molı. pl. xiv. Genre XXVII.

Corpus globosum, suborbiculare, parvum.

Caput retrachum, oblongum; fronte à clypeo haud dis- 
tineta, utrinque striata; mandibulis clongatis inermibus; palpi maxillares 3·articulati.

Antenme sub frontis margine inserte, clava 4-articulata; margine pectorali integro; for eola antennali in angulo antico prothoracis.

Pronotum anterius angustatum, angulis demissis parum promimulis; stria marginali integra tenui.

Elytra apice subarcuata, angulo suturali, striis distinctis; margine inflexo bistriato, haud foreolato.

Propygitium hexagonum declive; pygidium trigonum, inferum.

Prostermum latum, basi incisum, lobo brevi, recurvo; mesosternum receptum, marginatum.

Pedes longe distantes, graciles; tibice anticce extus spinose, foveola tarsali obsoleta.

Corps globuleux, suborbiculaire, ferrugineux, luisant.

Tète (f. $b$ ) petite, allongée, s'enfonçant dans le protholax. J'ront plane, rebordé latéralement, mais sans strie qui le sépare de l'épistome. Labre arrondi. Mandibules saillantes, droites à la base, courbées brusquement au bout, terminćes en pointe aiguë, et inermes en dedans. Yeux latéraux, semilunaires, assez saillants.

Autennes (f. c) insérées sous un rebord du front, entre les yeux et les mandibules : scape assez long, courbé, peu épaissi au bout, logé dans une fossette creusée sous la tête; funicule submoniliforme, de sept articles; premier obconique, beaucoup plus grand que les suivants ; dernier un peu plus large. Massue en pilon, cilice, ıle quatre articles. Fossette antennaire profonde, un peu allongée, dans l'angle antérieur du prothorax.

Machoires (f. „l) larges, cornées, insérées en dehors du 
menton; lobes barbus en dedans, externe assez long, interne court. Palpes maxillaires épais, de trois articles; 1-2 courts, cylindriques; troisième ovalaire aussi long que les deux premiers. Menton (f. $e$ ) en trapèze, presque régulier, corné. Lèvre membraneuse; languette nulle; paraglosses arrondies, ciliées en dedans. Palpes labiaux de trois articles : premier petit; deuxième obconique; troisième ovalaire, égaux entre cux.

Pronotum très large, convexe, arrondi à la hase, avec une avance angulaire sur l'écusson, arqué sur les côtés, très rétréci, abaissé et échancré en devant, avec les angles aigus, peu saillants, avec une seule strie marginale. Ecusson petit, triangulaire. Elytres bombées au milieu, abaissées dans leur pourtour et le long de la suture, plus longues que le pronotum, de sa largeur à la base, dilatées à l'épaule, rétrécies postérieurement, subarrondies au bord apical, avec un angle sutural aigu; bord infléchi, strié, sans fossette lıumèrale; stries subliumérale, dorsale et sulurale bien marquées. Prosternum peu saillant, élargi à la base et échancré, sans stries; lobe antérieur distinct, court, fortement recourbé en bas, arrondi au bout, ne dépassant pas les angles prothoraciques; bord pectoral entier. Mésosternum court et large, bisinué en devant, avec une avance médiane qui pénètre dans le prosternum, bordé de stries fines ponctuées.

Pattes (f. $\imath, g$ ) allongées, grêles, très distantes à leur insertion; cuisses creusées d'une coulisse et rebordées en dedans; jambes linéaires à peine élargies au bout, terminées par une ou deux épines, garnies en dehors de spinules ou de cils; antérieures sans fossette tarsale bien arrêtée. Tarses grêles, de cing articles, $1-4$ couts, égaux entre eux, 
garnis de cils en dessous; cinquième plus long, portant deux crochets.

Abdomen de cinq anneaux; premier assez long, bistrié; 2-5 courts, disparaissant au milieu dans la flexion. Propygidium en hexagone grand, convexe, incliné. Pygidium en triangle sphérique, entièrement inférieur.

Ce genre, établi pour une seule espèce de l'Indoustan, est voisin du genre IJetcerius, et semblerait, au premier coup d'œil, devoir s'y rattacher, mais des différences importantes s'y opposent, et en font un groupe bien caractérisé. La principale est la conformation des antennes et des palpes.

\section{NOTODONA GLOBATUN.}

Suborbiculare, globosum, rufo castaneum, nitidum punctatum ; fronte subdepressa utrinque striata; pronoto stria marginali integra, bifoveolato; elytris margine inflexo bistriato; sutura depressa; stria subhumerali postice cum suturali conjuncta; dorsalibus 1-2 et 4 integris, 3-5 obsoletis approximatis; mesosterno marginato; tibiis spinulosis. Long. 3 mill.; larg. 2 mill.

Suborhiculaire, globuleux, d'un rouge ferrugineux luisant, avec les antennes et patles plus claires. Tête petite, allongée; front un peu déprimé, non séparé de l'épistome, strié de chaque côté, couvert de gros points espacés; yeux noirs, assez saillants. Pronotum fort large et court, anguleusement avancé sur l'écusson à la base, arqué et bifovéolé sur les côtés, abaissé, rétréci et échancré en devant, avec les angles assez aigus, peu saillants, assez fortement ponctué sur toule sa surface; strie marginale fine, non interrompue, rapprochée du bord. Ecusson petit, triangulaire. Elytres 
bombées au milieu, et déprimées dans leur pourtour et le long de la suture, plus longues que le pronotum, de sa largeur à la base, dilatées sur les côtés, rétrécies postéricurement, faiblement arquées au bout, avec un petit angle sutural aigu; pointillées dans leur dernière moitié; stries dorsales fines, arquées; 1-2-5 entières; troisième et quatrième obsolètes, très raccourcies, rapprochées; suturale entière, fort éloignce au milieu de la cinquième dorsale, arec laquelle elle se réunit pour ainsi dire à la base; subhumérale interne fine, courte, mais se continuant le long du bord apical, et rejoignant la suturale; repli latéral bistrié. Propygidium pointillé, ainsi que le pygidium. Mésosternum bordé en devant de deux très petites stries. Jambes antérieures garnies de huit denticules, postérieures ciliées.

Indoustan ( I. de Laferté).

\section{HET ERIUS.

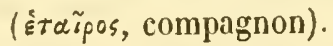

Soc. Ent. T. 3 (1855), pl. Ix.-Mon. pl. XIV. Genre XXVIII.

Hister. Kug. in Schn. Mag., 519, 21 (1791). - Sturm; Payk.

Hetcerius. Er. in Jahr., 1, 156, X (1834).

Cormus globosum, sphcericum.

Cuput parvum, retractum; fronte marginata, a clypeo hand distincta; mandibulis exsertis, intus dentatis.

Antennce sub frontis margine inserte, scapo grosso, funiculo 2-7 sensim incrassalo, clava articulo unico cylindrico, levi truncalo; fossa antennali in angulo prothoracis, pectore integro.

Pronotum antice angnstalum et emarginatum, lateribus latc clevato-marginatis; elytra pulvinatu, striis 1-subinumerali et 1-3 dorsalibus integris, seriatim hirta. 
Promgidium hexagonum inelinutum; mygitium semicireu= lare, inflexum.

Prosternum bistriatum, antice lobalum, basi subsinualum ; mesostermum leviler bisinualum, medio prominulum.

Tibice late, compressa, exlus anyulato-dilatate, supra tarsali foveola vage excavata; antice serrulatce, postica spinosule.

Corps globuleux, court, sphérique.

Tête petite, s'enfonçant dans le prothorax ; front bombé, èlevé sur les yeux, rebordé sur les còtés, et sans strie qui le sépare de l'épistome ; labre arrondi ; mandibules rétractiles, courbées, visibles, sans dent.

Antennes ( f. $1 e$ ) insćrées sous un rebord du front, logées derrière le bord pectoral, qui n'est pas entaillé, et se renfermant dans une fossette antennaire superficiellement creusée dans l'angle même du prothorax : scape globuleux, très gros; funicule inséré en dessous, de sept atticles ; premier gros, épaissi ; 2.7 à peu près d'égale longueur, croissant graduellement en largeur; massue de la largeur du précédent article, composée d'un seul article cylindrique, assez long, lıonqué au bout, lisse, sans autre villosité qu'une double ceinture de soies peu serrées, et quelques-unes au bout : il semblerait que les autres articles ordinaires de la massue sont rudimentaires et enroulés comme dans un cornet.

Mâchoires (f. $1 b$ ) cornées, insérées en dehors, de deux lobes, barbus en dedaus, externe dépassant de beaucoup l'interne; palpes maxillaires de quatre articles: premier petit; deuxième obconique; troisième cylindrique, court; quatrième fusiforme, aussi long que les deux suivants. Menton plus large que longr, échancré elı devant; lèvre 
membraneuse, bifide; paraglosses courtes, ciliées; palpes labiaux de trois articles; premier petit; deuxième et troisième égaux.

Pronotum bombé, trapézoïdal, échancré et très rétréci en devant, fortement sillonné de chaque côté, avec un large rebord relevé en bourrelet. Ecusson petit, triangulaire. Elytres plus longues que le pronotum, bombées, saillantes à l'épaule, arrondies sur les côtés, rétrécies et tronquées droit au bout, avec un repli latéral sillonné, une strie subhumérale et les premières dorsales entières. Prosternum large, bistrié, sinué à la base, muni d'un lobe antérieur court, arrondi, peu avancé. Mésosternum bisinué en devant, proéminent, avec une profonde impression de chaque côté, peu distinct du métasternum.

Abdomen court, de cinq articles pressés l'un contre l'autre; premier segment ventral, plus long que les quatre autres réunis, bistrié. Propygidium hexagonal incliné. Pygidium semicirculaire, rabattu en dessous.

Pattes assez grandes, élargies, comprimées, troisième paire distante à son iusertion. Jambes aplaties, fortement dilatées, en angle obtus en dehors, creusées en dessus d'une fossette tarsale mal limitée; antérieures crénelées; postérieures ciliées. Tarses de cinq articles munis en dessous de poils; cinquième armé de deux crochets.

Le genre Hetcrius avait été publié en 1832, dans le catalogue de Dejean, mais Erichson est le premier qui en ait donné les caractères distinctifs dans le Jahrbucher, en 1834. C'est un des plus singuliers de cette famille. La structure de ses antennes et celle de ses pattes se joignent au faciès pour le séparer et le faire reconnaître sans lósitation de tout autre. 
La seule espèce dont il se forme est propre à l'Europe et vit dans les nids de fourmis. On ne connait rien autre chose de ses mœurs, non plus que de ses divers états.

\section{H. Quadratus.}

Globulosus, rufo-fermigineus, levis, nitidus, supra seriatohispidus; fronte lateribus striata, pronoto utrinque bisulcato, margine late incrassato; elytris pulvinatis, humeris prominulis, striis sublumerali el 1-4 dorsalibus integris, parallelis; prosterno bistriato; tibiis obtuse angulato-dilatatis, anticis serratis, posticis parce ciliatis. Long. 1 1/3 mill.; larg. 1 1/4 mill.

Hister quadratus, Kugel. in Schn. Mag. 1, 519, 21 (1791). Panz. Ent. Germ. 1, 25, 24. - Fn. Germ. 37, 5. - Ill. Kæf. Pruss. 1, 58, 11. - Ent. Hefte. , 1, 63, 13. - Sturm. Deuts. Fn., 1, 216, 15, pl. 17, f. B. - Duft. Fn. Austr., 1, 217, 12.-Payk. Mon. Hist., 96,81, pl. $11,3$.

II. ferrugineus, Oliv., Ent., 1, 8, 19, 24, pl. 1, 7 (1789).

Iletcrius quadratus, Er. in Jahr., 1, 158, 1 (1834). - Kæf. Brand., 1, 666, 1. - Küst. Kxf. Eur., 10, 51. - Redt. Fn. Aust. 235. - Bach., Kæf. Pruss., 1, 305, 1.

Arrondi, globuleux, lisse, rouge-ferrugineux, clair, luisant, couvert en dessus de plusieurs rangées de soies jaunes espacées. Tête petite; front légèrement bombé, bordé d'une strie en dedans des yeux. Pronotum court, arrondi à la base, oblique sur les côtés, avec un large rebord en bourrelet, limité en dedans par un profond sillon, terminé à la base par un large enfoncement et accompagné en dehors d'une strie, échancré et rétréci en devant, avec les angles obtus. Ecusson très petit. Elytres plus longues que le pronotum, de sa largeur à la base, bombées, curvilinéaires sur les côlés, rétrécies et tronquées, droit au bout, épaules saillantes; 
repli latéral sillonné; stries fines; subhumérale entière, ainsi que 1-4 dorsales, les autres nulles. Pygidium plus clair et très lisse. Prosternum assez long, plan, bordé d'une strie, avec un lobe court, arrondi, sinué à la base. Mésosternum bisinué en devant, saillant au milieu, ct limité latérillement par un enfoncement. Pattes grandes; jambes creusées en dessus d'une large fossette tarsale, élargies en angle obtus latéralement; antérieures garnies de denticules, postérieures, de quelques cils.

France; Belgique, Autriche; sous les écorces et dans le nid des Formica rufa et fusca, dans la société desquelles il vit.

\section{ERETMOTUS.}

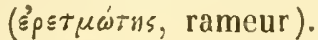

Soc. Ent. $3^{\text {e }}$ série. T. 3 (1855), pl. 20. Mon. pl. 19. Genre XXIX.

Orbiculuris, comcxus.

Caput retractum; fronte concava, stria mulla; mandibulis prominentibus; palpis maxillaribus arto 30 brevi, 40 longo, subcylinulrico.

Antemee sub frontis maryine inserte, funiculo sensim in. crassato, clava cylindricu, 1-arliculata, truncata, glabra, fossa parva in angulo antico prothoracis, margine pectorali integro.

Prosternum latum, breve, bistriatum, basi cmarginatum, lobo brevissimo; mesosternum bisinuatum, utrinque impressum.

Pronotum stria unica marginali; elytra stria subhumerali integra et 1-3 dorsalibus obliquis, brevibus.

Propygidium hexagomum, valde inclinalum; pygilium 
semicireulare, dejectum inferius; pedes basi distantes, libia omnes compressa, valde dilatato-angulata.

Corps orbiculaire, convexe, lisse.

Tête petite, enfoncée dans le prothorax ; front faiblement concave, avec un étroit rebord élevé, sinué sur les côtés, sans strie qui le sépare de l'épistome, fortement rétréci en avant; labre sinué; yeux ovalaires, peu saillants; mandibules courbées, en pointe aiguë, inermes, rétractiles.

Antennes (f. $1 c$ ) courtes, insérées sous un rebord du front au devant des yeux; scape courbé, fortement dilaté au milieu; funicule croissant progressivement, de sept articles, dont le premier un peu plus long que les suivants, est attaché au-dessous du scape ; 2-5 courts, transversaux, à peu près d'égale longueur, serrés, 6-7 plus allongés; massue solide, cylindrique, de la largeur du dernier article du funicule, et deux fois de la longueur, tronqué au bout , glabre, sans autre villosité que des poils espacés au bout. Fossette antennaire petite, creusée dans l'angle mème du prothorax, dans le pli formé entre la lame dorsale et la pectorale.

Machoires à deux lobes barbus, l'externe plus long, en partie corné, l’interne membraneux. Palpes maxillaires (f. 1 b) de quatre articles; premier petit; deuxième obconique, assez long; troisième très court, transversal ; quatrième allongé, fusiforme, de la longueur des deus précédents réunis. Menton large, corné, arqué à la base, légèrement bisinué en devant; lèrre membrancuse; paraglosses courtes, en lobe arrondi. Palpes labiaux de trois articles : premier très petil; deuxième obconique; troisième ovalaire, le plus long. 
Pronotum heaucoup plus large que long, bombé, avancé en pointe obtuse au devant de l'écusson et sinué de chaque colé, fortement rétréci et abaissé en devant, avec les angles arrondis et une échancrure assez marquée ; côtés arrondis, bordés d'une strie marginale. Ecusson petit, triangulaire. Elytres deux fois plus longues que le pronotum, plus larges que Ini à la base, arrondies sur les côtés, rétrécies au bout; suture carénéc; épaules saillantes; une strie subhumérale et quelques rudiments de stries dorsales obliques à la base. Prosternum médiocrement saillant, large, presque carré, bistrié ; légèrement échancré à la base, terminé en devant par un lobe court, transversal, sinué au bout. Mésosternum court, transversal, en pointe saillante arrondie, pénétrant dans la base du prosternum, à peine distinct du métasternum qui présente une strie médiane, et de clıque côté une large fossette.

Pattes larges, déprimées, très distantes à leur insertion, surtoul les quatre postérieures; cuisses courtes, élargies, creusées en dedans d'une coulisse pour loger les jambes: celles-ci grandes, aplaties, fortement dilatées en triangle sur le bord externe; antérieures denticulées ; postérieures sans dents, ni fortes épines. Tarses grêles, comprimés, repliés sur la jambe dans une fossette mal limitée, de cinq articles, les quatre premiers garnis de soies en dessous, à peu près d'égale dimension, cinquième plus long, armé de deux crochets.

Abdomen de cinq anneaux : premier segment ventral, bistrié, beaucoup plus long que tous les autres réunis. Propygidium convese, hexagonal très incliné. Pygidium bombé, semiclliptique, renversé. 
Le genre Eretmotus, créé pour une petite espèce découverte en Algérie, par M. Lucas, à qui je l'ai dédiée, tire son nom de l'aspect que lui donnent ses jambes étendues à l'instar de trois paires de rames. En dessus, il rapelle la forme de certaines petites espèces d'Omalodes et des Sphyracus, mais il s'en éloigne entièrement par tous les détails de son organisation. Il se rapproche des Dendrophilus, par la forme générale du corps, par la dilatation des jambes et par l'insertion des antennes; des Tribalus, par la largeur et par la base de son prosternum, par son front, son pronotum et ses élytres, par son propygidium hexagonal et par sa fossette antennaire; des Hetcrius, par la structure de ses antennes et de sol sternum. Mais des caractères saillants le distinguent aisément; il diffère du premier par son prosternum court, large, sinué à la base, avec un lobe très court, la fossette antennaire à l'angle antérieur, les stries de ses élytres; du deuxième par ses pattes postérieures fortement dilatées, son mésosternum biimpressionné et le lobe prosternal tris court; de l'un et de l'autre surtout par ses antennes, enfin du troisième par son pronotum sans large bourrelet latéral, et les stries irrégulières des élytres.

La seule espèce connue de ce genre vit sous les pierres, où elle a été trouvée aux environs de Médéah (Algérie), en avril 1851 .

\section{ERetmotus Lucasil.}

Orbicularis, convexus, niger, nitidus, lcevissimus; pedibus , ore antcnnisque rufo-piccis; fronte cxcavata margine elevato; monoto antice depresso angustiore, lateribus rotundato et marginato, ad 4 angulos impresso; elytris pronoto latioribus, ad basin breviter striatis, versus humerum impressis, sutura elevata. Long. 3 mill. ; larg. 2 1/2 mill. 
Orbiculaire, convexe, noir Juisant, lisse, avec la bouche, les antennes et les pieds d'un rouge de poix. Tête fortement enfoncée dans le prothorax ; front déprimé, avec un rebord éleré ; labre sinué antérieurement. Antennes insérées au devant des yeux, sous un rebord du front, logées entre les deux lames du bord antérieur du protlorax; yeux bruns, peu saillants. Pronotum court, bombé, transverse, bisinué à la base, fortement rétréci et abaissé en devant, avec une échancrure assez forte et les angles arrondis ; une strie marginale fine et terminée à l'angle antérieur, avec une assez forte impression à chaque angle du pronotum. Ecusson petit, triangulaire. Elytres deux fois plus courtes que le pronotum, un peu plus larges que lui à la base, rétrécies et obtuses au bout, avec les épaules saillantes et la suture relerée. La base est marquée de quelques traces courtes de stries obliques; une subhumérale assez marquée et plus longue, avec deux submarginales. Prosternum large, assez court, bistrié sur les côtés, échancré à la base, muni en avant d'un lobe court échancré. Mésosternum peu distinct du métasternum, transverse, avec une impression profonde de chaque côté et une pointe arrondie saillante qui pénètre dans la base du prosternum. Jambes aplaties, largement dilatées sur le bord externe: antérieures denticulées; tarses comprimés, logés dans une fossette, sur la jambe. Propygidium de forme hexagonale, convexe, incliné. Pygidium semi-elliptique, infléchi.

Médéah (Algérie); sous les pierres. 


\section{DENDROPHILUS.}

(d'́) dpo\%, arbre; фínos, ami).

Soc. Ent. 3e série, T. 3 (1855), pl. 1x. - Mon. pl. xiv. Genre XXX.

Hister, Linné; Payk., Gyll. Er.

Dendrophilus, Leach, Zool. Misc., 3, 76 (1817); Er. Steph., etc.

Corpus ovalum, subconvexum.

Caput parvum, retractum, stria frontali nulla; mandibulis prominentibus, intus obluse dentatis.

Antennce sub frontis margine insertce, funiculi art $1^{\circ} \mathrm{cras}$. siori, clava ovali 4 articulata; fossa antennali in medio latere pectoris antice incisi sila.

Pronotum stria marginali tenui. Elytra oblonga, margine et dorso obsolcte striatis.

Propygidium suboblectum, breve; mygidium semicirculare, inflexum.

Prostcrnum latum, bistriatum, basi rolundalum, lobo antico inclinalo; mesostermum simuatum.

Tibice omnes extus valdè dilalatce, subspinose, foveis tarsalibus pamm excavatis.

Corps ovale, épais, légèrement convexe en dessus.

Tête assez petite, s'enfonçant dans le prothorax; front peu convexe, non séparé de l'épistome par une strie trans. versale ; labre court, arrondi ; mandibules saillantes, courtes, obtuses, avec une dent interne: yeux latéraux, peu saillants.

Antennes (f. $1 d$ ) insérées sous un rebord du front, au devant des yeux; scape assez long, courbé, épaissi au bout; funicule de sept articles: premier beaucoup plus long et plus épais que les suivants ; ceux-ci à peu près égaux, ce- 
pendant lescinquiène, sixième sont plus longs, et le septième plus large; massue abrupte, 4-articulée, orbiculaire, comprimée, obtuse, garnie de poils. Fossettes antennaires creusées sous le bord latéral du prothorax au devant des hanches ; pour y arriver, l'antenne passe dans une coulisse du bord antérieur de la poitrine.

Mâchoires (f. 1 c) à deux lobes membraneux, barbus, arrondis, épais, l'externe beaucoup plus long que l'interne. Palpes maxillaires de quatre articles, épais ; premier petit; deuxième obconique, long et gros ; troisième court, large ; quatrième deux fois plus long que le précédent, ovalaire, obtus au bout. Menton (f. 1 b) court, avancé au milieu; languette bifide, courte ; paraglosses membraneuses, ciliées, arrondies. Palpes labiaux, fort courts, de trois articles: premier très petit; deuxième subobconique; troisième ovalaire.

Pronotum court, arrondi à la base et bisinué, avec les angles aigus, appliqués contre les élytres, légèrement arqué latéralement, très rétréci et échancré en devant, sans autre strie que la marginale. Ecusson triangulaire, étroit. Elytres légèrement convexes, très allongées, couvrant le propygidium presqu'en entier, rétrécies et coupées droit à l'extrémité, avec une strie subhumérale et quelques dorsales plus ou moins obsolètes. Prosternum assez saillant, peu élargi . beaucoup plus long que large, bistrié, arrondi à la base, muni en devant d'un lobe court, rabattu, arrondi au bout. Mésosternum court, large, sinué en devant pour recevoir la base du prosternum, parfaitement distinct du métasternum.

Pattes assez distantes à leur iusertion; cuisses larges, comprimées, avec une coulisse interne pour loger les jambes; 
celles-ci aplaties, diiatées en angles au milieu du bord externe, arrondies au bout, garnies de petites dentelures, avec deux épines courtes au bout, celles des antérieures obliques, fortes et allongées; toutes creusées en dessus d'une fossette tarsale mal limitée. Tarses repliés sur les jambes au repos, de cinq articles, assez longs ; premier plus long que les suivants; cinquième muni de deux crochets.

Abdomen de cinq anneaux : premier segment ventral très long, les quatre autres très courts et pressés l'un contre l'autre. Propygidium très court, transversal, caché en graude partie sous les élytres. Pygidium grand, semi-elliptique, perpendiculaire.

Ce genre, créé par Leach en 1817, dans les Zool. Miscellamy, adopté et limité par Erichson, se compose de deux petites espèces européennes qui vivent sous les écorces des arbres morts, dans les plaies des arbres, les champignons, et dont les métamorphoses sont encore inconnues. Ces insectes se rapprochent des Hetcerius pour la forme générale, surtout pour la configuration de leurs pattes, mais la fossette antennaire et la massue en diffèrent essentiellement. Leurs rapports avec certains Tribalus sont aussi très visibles : mais les jambes sont différentes, ainsi que la fossette antennaire et la massue.

\section{Dexdrophilus pinctates.}

Oblongo-ovalis, subconvexus, piceus subnitidus, ore, antcmis pedibusque brumnco-forrugincis, punctatissimus; fromte convexa, supra oculos clevata; pronoto marginato; clytris stria submarginali profunda, dorsalibus 5, internis obsoletis; tibiis cxtus angulato-dilatatis, subinermibus. Longueur. 3 mill. ; larg. $21 / 4$ mill. 
Hister punctatus, Herbst., Nat. Syst., 4, 41, 16, pl. 36, f. 5 (1/91). - Illig. kxf. Prus., 1, 60, 15. - E. H., 1, 92, 21, pl. 1, f. 12. - Gyll. Ins. Suec., 1, 93, 24. - Payk., Mon. Hist., 79, 62 pl, 7, f. 5.

II. pygmacus, F. Syst. Ent., 1, 53, 5 (1775). - Spec., 1, 61, 5. - Mant., 1, 32, 7. - Ent. Syst., 1, 74, 9. - Syst. El. 1, 29, 30 (1801). - St. Deuts. Fn., 1, 235, 28.

I1. corticalis, Pkl. Fn. Suec., 1, 50, 19 (1798).

Dendrophilus munctatus, Steph. Ill. Brit. Ent., 3, 159, 13 (1830). - Er. Kx. Brand., 1, 667, 1. - Heer, Fn. Helv., 1, 459, 1.

Ovale, un peu allongé, obtus postérieurement, assez convexe, d'un noir de poix, médiocrement luisant, avec la bouche, les antennes et les pattes d'un rouge-brun. T'ête finement ponctuée; front relevé au-dessus des yeux, sans strie qui le distingue de l'épistome. Antennes insérées sous un rebord au devant des yeux; scape allongé, renflé au bout; funicule à premier article plus long que les suivants ; deuxième et troisième plus courts que les $4-7$; ce dernier plus large; massue ovale, obtuse au bout. Pronotum beaucoup plus large que long, bisinué à la base, anguleux et un peu déprimé au devant de l'écusson, légèrement arqué sur les côtés, avec une strie marginale entière, fortement rétréci et échancré en devant, avec les angles aigus ; couvert d'une ponctuation fine et assez serrée. Ecusson petit, en triangle allongé. Elytres deux fois plus longues que le pronotum, un peu plus larges que lui à la base, presque parallèles au milieu, un peu plas étroites et coupées droit au bout, légèrement relevées sur la suture, et couvertes d'une ponctuation assez serrée et plus forte que celle du pronotum, avec une stric sublumérale forte, entière, formant comme un rebord latéral ; et 5 -dorsales parallèles, un feu arquées en dedans; les deux premières presque entières, 
les autres plus ou moins raccourcies postérieurement, les internes obsolètes. Pygidium droit, semielliptique, densément ponctué, dessous ponctué. Prosternum parallèle, bombé au milieu, bistrié. Pattes épaisses; jambes fortement dilatées en angles, au milieu du bord externe, à peine denticulées.

Angleterre; France; Suisse; Allemagne; Autriche; Suède, dans les plaies des arbres.

\section{Dendrophilus pyguzus.}

Oblongo-ovalis, subconvexus, lievis, nigro-piceus, parum nitidus, ore, antennis pedibusque brunneis; fronte supra oculos elevata; pronoto marginato, angulis anticis impressis; elytris stria submarginali integra, dorsalibus temissimis elevatis; tibiis externe valde ditatatis, Long. 3 mill.; larg. 2 1/5 mill..

IIsster pygmceus, L. Syst. Nat., 1, 2, 567, 4 (1735). - Fu. Suec., 441. - Gyll. Ins. Suec., 1, 94, 25. - Payk. Fu. Suec., 1, 51, 20. - Mon. Hist., 81, 64, T. 7, f. 6.

H. formicetorum, Aubé, Soc. Ent., 2, 95, pl. 5, 2 (1833).

Dendrophilus pygmaeus, Stepl. Ill. Brit. Ent., 3, 159, 4 (1830).

- Er. Kixf. Brand.. 1, 668, 2. - Heer. Fn. Helvet., 1, 459, 9.

D. Sheppardi, Curt. Brit. Ent., 3, 131 (1830).

D. Cooperi, Steph. Ill., Brit. Ent., 3, 159, 2 (1830).

Ovale allongé, peu convexe en dessus, lisse, avec les interstries des élytres à peine visiblement pointillées, d'un noir de poix presque mat. Front relevé sur les yeux, sans strie qui le distingue de l'épistome. Antennes d'un brunrouge. Pronotum beaucoup ply yarge que long, entièrement lisse, bisinué à la base, avec un angle obtus impressionné au devant de l'écusson, d'oú part une ligneélevéc presqu'imperceptible, qui semble la continuation entière de la suture: 
légèrement arrondi sur les côtés, bordé d'une strie marginale fortement échancrée, et échancré en devant, avec les angles moins aigus et une impression sur chacun d'eux. Ecusson petit, triangulaire. Elytres au moins deux fois plus longues que le pronotum, un peu plus larges que lui à la base, un peu dilatées sur les côtés, puis rétrécies vers le bout, qui est coupé carrément; on voit une strie submarginale entière, forte, une humérale, deux premières dorsales presqu'entières, mieux marquées que les autres, trois internes et une suturale très fines, et plus ou moins raccourcies postérieurement, bordées d'une fine côte qui disparait au bout, suture fortement carénée ; les interstries paraissent lisses, mais au microscope on voit une ponctuation très fine. Propygidium très court, entièrement couvert par les élytres. Pygidium triangulaire, densément et finement ponctué, avec une impression de chaque côté. Prosternum bistrié, peu allongé, dilaté à la base. Pattes d'un brunferrugineux; jambes fortement dilatées au milieu du bord externe, et à peine denticulées.

Suède ; Angleterre; France; Allemagne ; Suisse, dans le nid de la Formica rufa; rare.

\section{TRIBALUS.}

(tṕ́̈́cios, usé).

Soc. Ent. 3e série. T. 2 (1854), pl. Ix. - Mon. pl. xiv. Genre XXXXI.

Hister, Illg. Rossi. Payk.

Saprinus, Lucas, Expéd. Alg.

Epierius, Er. in Jahrb. (1834). - Le Conte, N.-Amér. Hist.

Carostermus et Tribalus, Le Conte, Hist. rlassif. 39 (1852). 
Corpus ovatum, leve aut puncticulatum.

Caput retractum, fronte suprı oculos clevata, à clypeo haud distincta, mandibulis 'atis.

Antenne, sub frontis margine inserta, clava orbiculari truncata; foveola in angulo prothoracis, plus mimuste margine pectorali operta.

Pronotum antice valde angustutum; stria marginali integra. Elytra margine inflexo, striato, dorso substriato obsoletè.

Pygidium perpendiculare.

Prosternum latum bistriatum, basi truncalum, lobo brevi lato; mesosternum indistincte marginatum.

Pedes tenues, tibiis anticis extus dilatalis, serrulatis, posticis parce uniseriatim ciliatis.

Corps naviculaire, toujours bombé en dessous, souvent peu convexe en dessus, arqué sur les côtés.

Tête (f. $b, j$ ) médiocre, s'enfonçant dans le prothorax; front concave, fortement saillant au-dessus des yeux, saus strie qui le distingue de l'épistome; labre semicirculaire; mandibules ( $f$. $h$ ) rétractiles, larges, courbées, terminées en pointe aiguë, avec une dent au bord interne. Yeux latéraux allongés, peu saillants.

Antennes (f. a) insérées sous un rebord élevé du front, au devant des yeux; scape allongé, légèrement épaissi au bout; funicule de sept articles : premier beaucoup plus gros et plus long que les autres; $2-5$ petits, courts, égaux entre eux; six et sept plus grands et surtout plus larges. Massue de quatre articles, inégaux; abrupte, orbiculaire, comprimée, tronquée au bout. Fossettes antennaires creusées sous l'angle antérieur du prothorax, dans un pli formé par le bord dorsal et le pectoral.

Máchoires ( $f . e$ ) cornées, à deux lobes barbus, l'externe 
plus large et beaucoup plus long que l'interne. Palpes maxillaires de quatre articles: premier petit; deuxième contourné, long. très épais au bout ; troisième court, cylindrique ; quatrième allongé, ovalaire, obtus au bout. Menton (f. f) en trapèze, coupé droit en devant et en arrière ; languette nulle; paraglosses courtes, arrondies; palpes labiaux de trois articles : premier petit; deuxième obconique ; troisième ovalaire, tronqué, égaux en longueur.

Pronotum beaucoup plus court que large, fortement rétréci et échancré en devant, sans autre stric que la marginale. Ecusson petit, ponctiforme. Elytres plus ou moins convexes en dessus, arrondies sur les côtés et fortement rétrécies au bout; on y remarque deux stries marginales, une subhumérale et quelques dorsales très obsolètes. Prosternum assez saillant, bistrié longitudinalement, convexe dans le seus transversal, plus long que large, tronqué et plus large à la base, avec un lobe antérieur court, abaissé, arrondi; bord pectoral non fendu, pour le passage des antennes, plus ou moins avancé sur la fossette antennaire. Mésosternum court, large, droit postérieurement et bien distinct du métasternum. Métasternum bombé, sillonné au milieu.

Pattes (f. $c, d, e, i)$ assez distantes à leur insertion, les antérieures un peu moins; assez allongées et grêies; cuisses subcylindriques, creusées en dedans d'une coulisse pour loger les jambes; jambes antérieures aplaties, élergies fortement et peu à peu vers le tarse, lisses ou garnies en dehors de denticules nombreux, et creusécs en dessus d'une fossette tarsale peu nettement tranchée; intermédiaires légèrement dilatées; postérieures filiformes, garnies de quelques spinules. Tarses courts, de cinq articles; $\mathbf{1 - 4}$ trian- 
gulaires, égaux entre eux; cinquième à peine plus long que les autres et armé de deux crochets.

Abdomen de cinq anneaux: premier segment ventral long, bistrié entre les pattes : 2-5 de plus en plus courts. Propygidium en hexagone transversal. Pygidium triangulaire, l'un et l'autre inclinés.

Les espèces du genre Tribalus ont un faciès qui leur est propre : leur corps trapu, souvent naviculaire; leur sternum élargi, qui déjette fortement leurs pattes grêles en dehors; la largeur de l'ouverture antérieure du prothorax où la têtes'enfonce profondément; leur fossette antennaire creusée dans l'angle du protlıorax, fermée en dessous par le bord pectoral comme entre deux lances; leur massue orbiculaire et tronquée au bout ; leur front élevé au-dessus des yeux, sans strie qui le sépare de l'épistome; leur pronotum très rétréci, abaissé en devant, avec une scule strie marginale; leurs élytres sans fossette subhumérale et arec quelques stries obliques, courtes et obsolètes; enfin tout se réunit pour en faire un genre bien caractérisé. Le T. lavigatus, il faut l'avouer, vient nuire un peu par sa forme giobuleuse à la symétrie, quoiqu'il ait tous les caractères des autres espèces.

Ce genre, admis par tous les entomologistes, est dû au clairvoyant Erichson, qui l'a fondé en 1834, dans le Jahrb., p. 164, pour trois espèces connues avant lui : T. Capensis Payk., scaphidiformis Illig., et minimus Rossi, décrit de nouveau sous le nom de Saprimus mauritanicus. En 1845, M. Le Conte a fait connaitre le T. Americanus. Enfin j'y ai réuni le $H$. levevigahus Payk, dont lirichson ne s'était pas occupé. 
Ces deux dernières espèces viennent d'ètre démembrées du Tribalus, par M. Le Conte, dans un Essai de classification lles IIistérides, et reportées dans un nouveau genre qu'il nomme Coerosternus. La fossette antennaire est en effet plus recouverte dans ces deux espèces, la lame pectorale moins arancée et moins sinuée; le mésosternum plus arqué en devant; les pattes plus déliées et les jambes presque inermes. Malgré ces caractères, je n’ai pas cru devoir adopter cette coupe peu homogène et qui me semble inutile, puisque tout rapproche l'Americanus des autres espèces, et que la conséquence naturelle serait d'en séparer le $T$. lavigahus, que je ne réunis du reste qu'avec peine à ce genre. Quoiqu'il ne puisse se confondre avec aucun autre genre, il rappelle, par ses stries dorsales, certains Saprimus, tels que le piceus, quelques Abrœus, par sa forme naviculaire, les Epierus mundus, similis, et les genres suivants.

$\boldsymbol{A}$. Fossettes antennaires découvertes, bord pecioral abaissé à l'angle antérieur du prothorax.

B. Elytres rebordées latéralement par une strie subhumérale entière.

\section{T. Agrestis.}

Orbicularis, convexus, nigm, nilidus; antennis pedibusque ferrugincis; fronte concava, puncticulala; pronoto munctis marcis et tennibus, stria marginali interrupta; clytris margine inflexo, bistriato, 2 strïs subhumcralibus integris, dorsali unica media brevi, obsoleta, grosse ct raro punctutis. Long. 3 mill.; larg. 2 mill. 
Orbiculaire, bombé, noir, luisant. Front convexe, poilitillé. Antennes ferrugineuses. Pronotum avancé en angle obtus à la base, oblique sur les côtés, échaneré et fort rétréei en devant, avec les angles aigus; strie marginale fine, interrompue au milieu du bord antérieur; ponctuation espacée, fine, un pen mieux marquée sur les côtés et plus serrée à la base. Ecusson petit, en triangle allongé. Elytres beaucoup plus longues que le pronotum, de sa largeur à la base, curvilinéairement dilatées sur les côtés, très rétrécies et coupées droit au bout, sans angle sutural; couvertes de gros points espacés, et dans l'intervalle d'un fiu pointillé, visible seulement à la loupe; stries dorsales réduites à un seul rudiment oblique, médian, obsolète; deux subhumérales entières, parallèles, bien marquées; repli latéral sans fossette, bisillonné. Pygidium finement pointillé, ainsi que le propygidium. Prosternum large, bistrié. Mésosternum rebordé seulement sur les côtés. Pattes ferrugineuses; jambes antérieures dilatées au bont, à peine ciliées.

Sénégal.

B'.-Elytres sans rebord latéral ; strie subhumérale nulle ou obsolete.

\section{T. CAPENSIS.}

Ovalis, supra subdepressus, niger subuneus, munctatissimus ; antennis pedibusque brumeis; fromle concava, supra oculos clevala; pronoto angulis anticis immessis, stria marginali integra; elytris striis obsoletis 2 marginalibus, subhumerali cxterna simuata, 1.3 dorsalibus obliqnis mevilus; mosterno striis antice divergentibus, Long. 3 mill.; larg. 2 mill.

Hister Capensis, Payk. Mon. Hist., 80, 53, t. v111, 3 (1811).

Tribalus pricipes, Falır. in Boh. Ius. Cafr., 1, 545, 595 (1851), 
Ovale, épais, peu convexe en dessus, d’un noir métallique luisant, densément pointillé sur toute sa surface. Antennes brunes. Front concave, relevé en bourrelet en dedans des yeux. Pronotum court, subtrapézoïde, anguleusement avancé à la base, oblique sur les côtés, fortement échancré et rétréci en devant, avec les angles aigus, abaissés, impres. sionnés; strie marginale fine, noı interrompue. Ecusson ponctiforme. Elytres deux fois plus longues que le pronotum, de sa largeur à la base, curvilinéairement dilatées sur les cotés, rétrécies et conpées droit au bout; suture relevée; stries 1-3 dorsales obliques, courtes, obsolètes ; subhumérale externe fine, sinueuse; bord inflécli, bistrié. Propygidium pointillé, ainsi que le pygidium; inclinés l'un et l'autre. Prosternum large, court, convexe, tronqué ì la base, à deux stries divergentes antérieurement. Mésosternum à peine distinctement rebordé. Pattes ferrugineuses; jambes antérieures crénelées, dilatées au milieu.

Cap de Bonne-Espérance; Cafrerie.

\section{T. SCAPHIDIFOR HIS.}

Ovalis, supr 'a subconvexus, piceo-reneus nitidus, ore, antennis pedibusque fermgineis, undique sat dense punctulatus; fronte ad oculos elevata; pronoto antice valde angustato, margine striato basi ante scutellum grosse punctato; elytris postice angustioribus, basi striis obliquis obsoletis; tibiis anticis extus dilatatis denticulatisque. Long. 2 mill.; larg. 1 1/2 mill.

Hister scaphidiformis, Illig. Mag. 6, 47, 24 (1807).

Saprinus Mauritanicus, Lucas, Exp. Sc. Alg., 230, 603, pl. 22, 9 (1849).

Ovale, peu convexe en dessus, d'un brun de poix luisant, un peu métallique. Tête densément pouctuée; front avec 
une impression médiane, relevé sur les côtés, suıtcut aıdessus des antennes, sans strie qui le distingue de l'épistome. Antennes ferrugineuses. Pronotum courl, beaucoup plus large que long, arrondi à la base, légèrcment arqué sur les côtés, fortement rétréci et échaucré en arant, avec les angles aigus et abaissés; ponctuation forte et assez scrrée; strie marginale bien marquée, entière. Elytres plus longues que le pronotum et ponctuées comme lui, de sa largeur à la base, fortement rétrécies postérieurement, avec quely'ues stries dorsales obliques, courtes, obsolites. Pygidium ponctué. Prosternum un peu plus long que large, bistrié, légèrement arrondi à la base et muni en devant d'un lobe court, arrondi. Pattes ferrugineuses, avec les tarses plus clairs ; jambes antérieures dilatées et denticulées; postérieures presque linéaires.

Algérie; Portuga!.

\section{T. MINIMUS.}

Ovalis, parum convexus, piceo-ferrugincus, nitidus dense punctulatus; ore, antennis pedibusque rufis; fronte ad oculos clevala ; pronoto stria marginali integra ; clytris basi obsolctissime extus striatis; tibiis anticis dilatato-rolundatis, cxtus denticulatis. Long. $13 / 4$ mill. ; larg. 1 1/4 mill.

Hister minimus, Rossi, Fn. Etr. 1, 30, 71 (1790).

Tribalus minimus, Er. in Jahrb., 1, 165, 3. - Heer, Fn. Helvet. 1, 458, 1 (1841).

Ovale, médiocrement convexe en dessus, d'un brun de poix ferrugineux, très luisant, couvert d'une ponctuation trìs fine et assez serrée. Téte petite, enfoncée dans le prothorax; front légèrement convexe, un peu relevé sur les yeux. Antennes ferrugineuses; massue testacée, velue. 
Pronotum légèrement convexe, beaucoup plus large que long arrondi à la base, faiblement arqué sur les côtés, fortement rétréci et échancré en devant, avec les angles antérieurs avancés; ponctuation fine et serrée; strie marginale entière. Ecusson petit, triangulaire. Elytres peu convexes, une fois et demie plus longues que le pronotum, de sa largeur à la base, arrondies sur les côtés, rétrécies au bout, couvertes d'une ponctuation un pen moins serrée que le pronotum, arec quelques rudiments obsolètes de stries obliques à la base. Pygidium brun, presque lisse. Prosternum assez large, un peu plus long que large, arrondi transversalement, bistrić, plus étroit et tronqué à la base, terminé antérieurement par un lobe court, infléchi, arrondi, dont le bord latéral s'avance sous forme de lobe au devant de la fossette antennaire. Pattes ferrugineuses ; jambes antérieures légèrement dilatées au milieu, garnies de poils en dedans et de denticules nombreux en dehors.

Diffère du $T$. scaphidiformis, non seulement par sa taille plus petite, mais encore par son pronotum moins fortement ponctué, et dépourvu de cette ligne transversale de gros points oblongs au devont de l'écusson.

Dalmatie; Toscane; Suisse.

$A^{\prime}$. (Coorostermus, Le C.) Fossettes antennaires cachées par le bord pectoral qui s'élève au devant de l'angle antérieur du pronotum.

\section{T. Americanus.}

Ovatus, subconvexus, migro-piceus, parum nitidus, dense for. titcrque punctatus; antcmis pedibusque forrugincis; fionte in medio et ad oculos elevala; pronoto antice valde angustato. 
margine laterali reflexo; elytris convexinsculis, apice angustatis, suturacarimata, margine laterali reflexo, striisdorsalibus obliquis, 4 abbreviatis obsoletis; tibiis anticis apice rotundatodilutatis. Long. 2 1/2; larg. 2 mill.

Tribalus Americanus, Le Conte, N. Amér. Hist., 34, 1, t. Iv, f. $7(1845)$.

Corostermus Americamus, Le Conte, Hister. Classif. 40 (1852).

Ovale, presque arrondi, légèrement convexe en dessus, d'un noir de poix, ferrugineux à l'extrémité des élytres, peu luisant. Tête très densément ponctuée; front convexe, fortement relevé sur les yeux, sans stries qui le séparent de l'épistome. Antennes à premier article fortement dilaté, brun; funicule d'un testacé ferrugineux. Pronotum court, beaucoup plus large que long, légèrement convexe, avancé angulairement à la base sur l'écusson, oblique et fortement rebordé sur les côtés, avec une strie marginale non interrompue, fortement échancré et rétréci en devant, avec les angles très aigus, abaissés. Elytres bombées, une fois et demie plus longues que le pronotum, de sa largeur à la base, arrondies et dilatées sur les côtés, rétrécies au bout, avec la suture fortement relevée, ainsi que le bord latéral; couvertes d'ure ponctuation forte et serríe, avec une strie humérale et quatre dorsales obliques, obsolètes, raccourcies, surtout les intérieures ; bord infléchi ponctué, avec deux sillons. Pygidium ponctué. Prosternum large, court, bistrié, légèrement sinué à la base, élargi et terminé antérieurement par un lobe incliné, arrondi au bout; bord pectoral s'avançant au devant de la fossette antennaire, ponctué ainsi que le mésosternum et le métasternum, séparés par une strie de points transversale. Pattes brunes; jambes ferrugineuses, inermes; antérieures dilatées au bout; postérieures simples.

Etats-Unis. 


\section{T. LAVIGates.}

Orbiculato-globosus, niger nitidus, impunctatus; antennis pedibusque rufis; fronte plana, marginata; pronoto lateribus simuatis, stria haud interrupta ; elytris margine inflexo angusto 3-striato, dorsalibus 2 vel 3 obsoletissimis; abdomine perpendiculari, vix clytra cxcedente; prosterno bistriato; foveola antennali subtus inconspicua. Longueur $13 / 4$ mill.; largeur $11 / 4$ mill.

Hister lavigatus, Payk. Mon. Hist., 84, 68, 1. 2, f. 7 (1811).

Cœrostermus lcevissimus, Le Conte, Classif. Hist. 40, 2 (1852).

Orbiculaire, globuleux, oir luisant, imponctué. Antennes ferrugineuses. Front plane, rebordé dans son pourtour. Pronotum court, arrondi à la base, oblique sur les côtés, dont la marge semble se diviser en deux lames, formées l'une par le pronotum, l'autre par la poitrine, entre lesquelles est logée la massue, échancré et très rétréci en devant avec les angles abaissés, aigus; strie marginale entière. Ecusson ponctiforme. Elytres deux fois plus longues que le pronotum, arrondies sur les côtés, rétrécies et tronquées au bout; stries dorsales très obsolètes, 1-3 courtes, obliques; subhumérale bien marquée, fort abaissée sous l'épaule; repli latéral étroit, bistrié. Propygidium et pygidium perpendiculaires, dépassant à peine les élytres. Mésosternum arrondi en devant. Prosternum large, sinué á la base, bistrié; lobe court, incliné, large, formant avec le bord pectoral antéricur un are régulier, cachant entièrement la fossette antennaire. Pattes ferrugineuses, linéaires; jambes antérieures à peine dilatées.

Etats-Unis; Yucatan ; Carthagène (Nouvelle-Grenade) ; зе Série, томв 11. 
Caracas (Venezuela), Cuba et St-Domingue, sous les écorces des arbres morts, en juillet.

\section{SPHEROSOMA.}

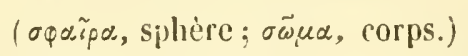

Soc. Ent. 3e série, T. 3 (1855), pl. 1x. - Mon. pl. xıv.

\section{Genre XXXII.}

Corpus orbiculare, globosum.

Caput parvum, retractum; fronte convexa à clypco haul distincta.

Antennce sub frontis margine inserte, scapo longiori, clava abrupta orbiculari; foveola rotunda latcrali, margine pectorali inciso.

Pronotum antice valdc angustalum, stria marginali integra ; elytra haud striata, lateribus margine elevato.

Prostermum latum, breve, bistrialum, basi subsinuatum, lobo antico rotundato inflexo; mesosternum à metasterio haud distinctum.

Propygidium transversum obliquum; pygidium semiellipticum, perpendiculare.

Pesles valde distantes; tibiis anticis subdenticulatis ct parum dilatatis, fovea tarsali parum excavata; posticis elongatis.

Corps orbiculaire, globuleux.

Tête (f. 1 b) enfoncée dans le prothorax; front convere, sans strie qui le sépare de l'épistome; labre court, semi-lu. naire; mandibules rétractiles; yeux ovalaires, peu saillants.

Antennes (f. I c) insérées au devant des yeux, sous un rebord peu avancé du front; scape long, fort, épaissi au bout; funicule grele, de sept articles : premier cylindrique, beaucoup plus long que les suivants; 2-6 courts, trans- 
versaux, égaux entre eux ; massue abrupte, ovalaire, velue, de quatre articles peu serrés.

Pronotum plus court que large, convexe, avancé en angle obtus, légèrement arqué sur les côtés, échancré et fort rétréci en devant; une seule strie marginale entière. Ecusson très petit, triangulaire. Elytres deux fois plus longues que le pronotum, convexes, arrondies latéralement, avec un rebord élevé, rétrécies et tronquées au bout, sans stries. Prosternum court, plus large que long, bistrié, légèrement sinué à la base, muni en devant d'un lobe arrondi, court, infléchi et rebordé, dont il est parfaitement distinct. Mésosternum large, arrondi en devant, étroitement appliqué contre la base du prosternum, sans ligne de démarcation du côté du métasternum.

Pattes (f. $1 d, e$ ) grêles, fort distantes à leur insertion, surtout les deux dernières paires; cuisses allongées, à peine dilatées au milieu, creusées d'une gouttière pour loger les jambes; celles-ci à peine élargies vers le bout, à l'exception des antérieures qui sont denticulées en dehors; tarses courts, logés, au repos, dans une fossette pratiquée à la face supérieure des jambes, de cinq articles : premier plus long que le deuxième; 3-4 égaux entre eux, courts ; cinquième médiocrement allongé, bionguiculé.

Abdomen de cinq anneaux : premier segment ventral bistrié, assez allongé, plus long que les autres réunis; ceuxci serrés les uns contre les autres, linéaires. Propygidium abaissé, court, transversal. Pygidium semielliptique,vertical.

Le type de ce genre est une petite espèce de Madagascar, qu'on prendrait au premier abord pour le $\boldsymbol{T}$. Americanus. Il a en effet de si grands rapports avec les Tribalus, que j'ai été tenté de l'y réunir ; d'autant mieux que je n'ai pu suffi- 
samment en étudier les organes buccaux, daus lá crainte d'endommager l'individu unique du Museum du Jardin-desPlantes, le seul qui m'ait passé sous les yeux. Mais, comme il s'en éloigne beaucoup par la fossette antennaire, creusée sous le bord latéral du prothorax, dans laquelle l'antenne ne pénètre qu'en passant par une coulisse entaillée dans le bord antérieur de la poitrine, et aussi par la massue ovalaire, à articles moins inégaux, je n'ai pu me dispenser d'établir une nouvelle coupe générique.

\section{SPHEROSOMA OVUM.}

Orbiculare, convexum, brunnco-piceum nitidum, dense ct fortiter punctatum; capite convexo, labro scmicirculari; monoto basi arcuato, lateribus obliquis, antice valde angustato, stivia marginali integra; clytris utrinque lateratiter et alte marginatis; pedibus basi distantibus, tibiis modice dilatatis, tarsis brevibus articulo $1^{\circ}$ elongato.

Sphérique, d'un brun de poix luisant, avec la bouche, les antennes et les pattes rousses; il est parsemé de gros points plus ou moins serrés, dans l'intervalle desquels d'autres petits points visibles seulement au microscope. Tête petite, enfoncée dans le prothorax ; front convexe, relevé ì l'angle interne de l'œil, sans strie qui le distingue de l'épistome ; labre court, semicirculaire; mandibules cachées sous la bouche. Antennes insérées sur le front, au dedans des yeux ; scape épais; funicule de sept articles lenticulaires , égaux; massue abrupte. Pronotum court, subsinué à la base, fortement rétréci et échancré en avant, avec les angles assez aigus; strie marginale bien marquée, continuée en devant sans interruption; ponctuation plus serrée et un peu moins forte que celles des élytres. Ecusson très petit, trian- 
gulaire. Elytres de la largeur du pronotum à la base, deux fois plus longues que lui, rétrécies et obtuses au bout; bord latéral relevé, formant une carène marginale plus prononcée à la base; la ponctuation devient plus serrée dans le sillon qui la borde. Prosternum court, médiocrement élevé, plus large que long, avec un lobe réfléchi, bien distinct. Mésosternum dépourvu de gros points. Métasternum et premiersegment de l'abdomen très fortement ponctués. Pattes très distantes; jambes antérieures dilatées, crénelées sur les bords; quatre postérieures à peine élargies vers le bout. Pygidium densément ponctué.

Madagascar (Musée). 



\title{
ESSAI MONOGRAPHIQUE SUR LA FAMILLE DES HISTERIDES.
}

(Suite) (1).

\author{
bir II. S. A. de IARSEUL.
}

(Séance du 9 Février 1853.)

XXXII. SAPRINUS.

$$
\text { (oompós, pourri.) }
$$

Soc. Ent. 3e série, T. 3 (1855), pl. 16 à 20.-Mon.

pl. 15 ì 19 . Genre XXXIII.

Hister. Fab. Syst. Ent. 2, 52 (1775). - F. Payk; Gyll.

Saprimus. Er. in Jahrb. 1, 172, xv (1834). - Heer, Fu. JIelv. Le Conte. - Redt. Fu. Austr.

Corpus crassum, ovatum, nitidum, seepe metallicum.

Caput retractile; fronte stria tenui, antice phs minusve obsoleta; clypco constricto; antennis frontis sub margine insertis ante oculos; funiculo brevi sensim incrassato, clava 4-articulata abrupla, rolundala.

Prostermum breve compresso-carinalum, bistriatum, basi

(1) Voyez $3^{e}$ Série, T. I (1853), ए. 131 et 4'47; T. II (1854), p. 161,525 et 671 ; et T. 111 ( 1855$)$, p. 83 . 
subsinuatum, lobo antico mullo; cui fossa antennali insculptu ante coxus, margine pectorali inciso. Mesosternum subsimuatum, maryinatum.

Pronotum trapezoidale, breve, stria murginali unica; elytra apice truncata, margine inflexo bisulcato, striis 4-dorsalibus obliquis, postice abbreviatis, humerali tenui.

Propygidium breve, transversum; pygidium triangulare plus minnsve inflexum.

Tibice anticce dilatate, extus denticulate; postice biseriatim spinostilce.

Corps épais, en ovale plus ou moins raccourci, plus bombé en dessous qu'en dessus.

Tête assez petite, s'inclinant en devant et peu enloncée dans le prothorax. Front en ovale transversal, peu bombé, entouré d'une stric souvent en devant, presque toujours réunie par derrière; épistome beaucoup plus étroit; yeux réniformes, obliques; labre court, échancré en devant. Mandibules assez saillantes, courtes, se croisant, recourbées en pointe acérée.

Antennes insérées sous le rebord du front, dans une des petites fossettes, à l'augle intérieur de l'œil; scape court, épaissi au front; funicule de sept articles ; premier beaucoup plus grand que les suivants; $\mathbf{2 - 6}$ courts, serrés, grossissant progressivement; septième court et très large; massue de 4 articles plus ou moins épaisse, arrondie. Fossette antennaire assez profonde, arrondie, au devant des hanches antérieures contre le prosternum; l'antenne y arrive par une fente du bord antérieur.

Menton petit, ell carré, court, à borl antéricur concave ; lèvre membraneuse ; paraglosses elliptiques, frangées eṇ 
dedans, n'arrivant pas tout à fait ì la base du troisième article des palpes; palpes labiaux 3 -articulés; deuxième obconique ; troisième ovalaire, tronqué au bout, un peu plus long. Màclsoires cornées, assez fortes, à deux lobes barbus en dedans; interne étroit, externe gros, arrondi, beaucoup plus grand; palpes maxillaires, assez forts, de quatre articles: premier très petit; deuxième obconique, assez grand; troisième court, subcyliıdrique; quatrième cylindrique, beaucoup plus long, tronqué au bout.

Pronotum en trapèze, beaucoup plus large que long, bisinué a la base, avec les angles aigus, serrés contre les élytres, ne laissant pas saillir en dessus la pièce mésostènale, rétréci en derant, arec les angles arrondis, bordé d'une seule strie (marginale) non interrompue en devant, rarement un feu raccourcie à la base, rapprochée du bord (conncclens excepté) ponctué assez ordinairement au moins en partie. Ecusson visible, mais triangulaire, très petit. Elytres ordinairenent plus larges que longues, de la largeur du pronotum à sa base, dilatées à l'épaule, rétrécies, coupées droiles par derrière, sans angle sutural, presque toujours ponctuées, au moins daus la partie postérieure; bord infléchi, sans fossette à l'épaule, avec deux stries marginales, rarement trois; strie suturale se continuant souvent le long du bord apical, jusqu'à ce qu'elle forme la marginale, tantôt raccourcie à la base, tantôt réunie par un arc à la quatrième dorsale; dorsales obliques, partant de la base et raccourcies par derrière, au nombre de quatre (rarement la cinquième existe); l'humérale fine, oblique, rapprochée de la première dorsale, souvent jointe à la subhumérale interne; la sublıumérale externe, quand elle existe, est réluite à un court rudiment basal. Prosternum 
saillant, plus ou moins étroit, un peu arqué à la base, sans pénétrer profondément dans le mésosternum; droit ou légèrement concave', ne dépassant pas les angles antérieurs du pronotum; bordé latéralement de deux stries longitudinales, limitées par un relıord qui en rencontre un plus extérieur, partant des hanches et bordant la fossette antennaire. Mésosternum trapézoïde, sinué en devant, séparé du métasternum par une strie transverse, bordé d'une strie rarement interrompue.

Pattes médiocres; cuisses ovalaires, creusées en dessus d'une coulisse pour la réception des jambes; jambes élargies en triangle, minces, avec de courtes épines terminales: antérieures creusées en dessus d'une fossette tarsale, large et mal limilée; bordées extéricurement d'un rang de dellticules plus ou moins forts ; quatre postérieures garnies d'un double rang d'épines; tarses de cinq articles; quatre premiers triangulaires, garnis au bout d'une épine en dehors, et de deux en dedans; dernier un peu plus long, à deux crochets.

Abdomen de cing articles; premier arceau ventral long, avec deux stries divergentes entre les pattes; les autres courts. Propygidium court, transrerse, oblique. Pygidium plus ou moins vertical, grand, en ogive.

Le genre Saprimus, créé par Erichson, en 1834, a été depuis adoplé par lous les entomologistes. C'est, en effet, l'un des plus naturels et des micux caractérisés: sa forme, celle de son pronotum et de ses élytres surtout, aux stries obliques, raccourcies par derriere; son prosternum comprimé en carène, bistrié, sans lobe antérieur, avec la fossette antennaire creusée en devant des hanches sur ses côtés; le bord pectoral entaillé pour que l'antenne puisse s'y rendre; enfin, ses jambes postérieures garnies de leux rangs 
d'épines et rarement de trois au bout, sont autant de marques qui le distinguent aisément.

Les différences sexuelles ne sont pas partout les mêmes, souvent elles sont peu perceptibles, et se réduisent à quelque chose de plus trapu et de plus luisant dans le mâle que dans la femelle; quelquefois l'un présente une excavation sur le métasternum ou même deux petits tubercules au bout du même segment; d'autres fois le pygidium du ơ est bombé á l'extrémité, aree une impression, tandisque dans la $q$ on remarque diverses sculptures.

Les métamorphoses sont encore très imparfaitement connues. La larve, si les individus que je présume être des Saprinus en sont réellement, diffère très peu de celle des Itister. A l'état parfait, ils vivent dans les fumiers, bouses , charognes, létritus, et autres matières en putréfaction. On les trouve pendant toute la belle saison, mais surtout au printemps.

Ce genre, dans lequel l'auteur de la Révision des Histérides avait réuni vingt-neuf Hister, décrits et figurés dans la Monographie des Histérides de Paykull, et trente nouvelles, s'est accru depuis lors considérablement, surtout depuis la publication des espèces d'Amérique par M. Le Conte, et j'ai pu compulser dans les auteurs cent vingt-deux espèces de Saprinus, dont quarante-quatre ne me sont pas connues de visu. Malgré cette lacune, j’en ai décrit et figuré cent soixante-trois. Dans l'ètude d'un si grand nombre d'espèces si rapprochées, souvent si petites, j’ai dû recourir à des divisions artificielles, qui laissent quelquefois à désirer sous le rapport de la rigueur, mais qui me semblent faciliter singulièrement les recherches. Je n'ai rien trouvé de mieux, dı reste, que de marcher sur les traces d'Erichson, dont je n'ai fait que développer le système. 


\section{DIVISION DU GENRE SAPRINUS EN GROUPES.}

$\boldsymbol{A}$. Tête sans carène entre le front et l'épistome.

$B$. Ely tres ornées de taches bien limitées. 1er GroupE. 1.

$B$ '. Elytres sans taches bien limitées.

C. Fossettes antennaires ne remontant pas jusqu'au bord antérieur du prosternum et séparées par un assez large intervalle. - Stries suturale entière ou à peine raccourcie postérieurement.

$D$. Strie suturale non réunie à la $4^{\mathrm{e}}$ dorsale par un arc basal. . . . . . . 2e GROUPE. 18.

$D^{\prime}$. Strie suturale réunie à la $4 \mathrm{e}$ dorsale par un arc basal. ......... 3e Groupe. 45.

$C^{\prime}$. Fossettes antennaires remontant jusqu'au bord antérieur du prosternum, et séparé par une lame étroite. - Strie suturale nulle ou fort raccourcie par derrière. . . . . . 4 4e Groupe. 119.

$A^{\prime}$. Front séparé de l'épistome par une carène.

$B$. Front sans sillon transversal en forme de chevron ou d'accolade. . . . . . . . 5 grodpe. 121.

$B$ ' Front avec un ou deux sillons en forme de chevron ou d'accolade.......... 6e Groupe. 140. 
XXXIII. Saprimus.

है

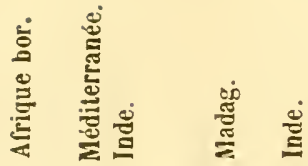

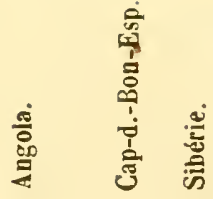

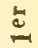
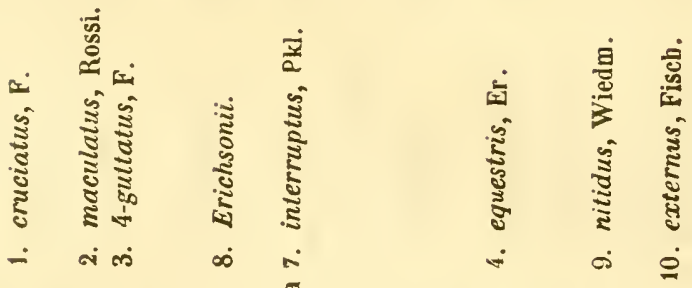

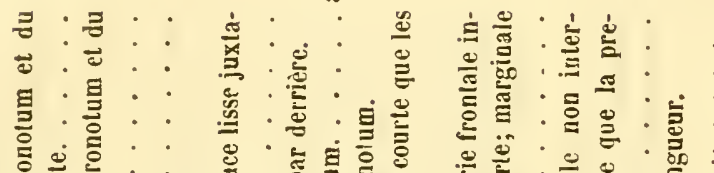

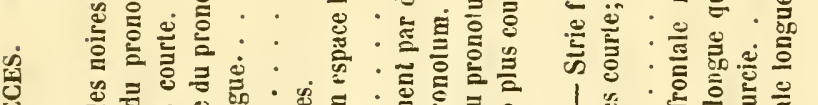

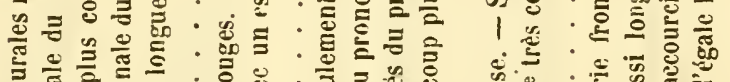

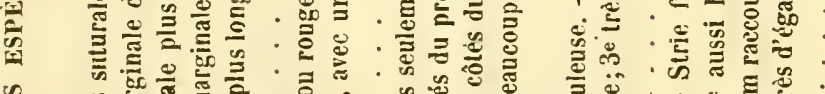
प के

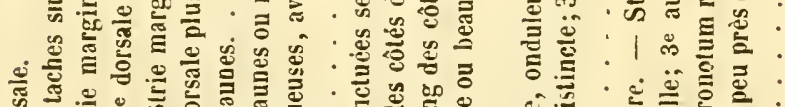

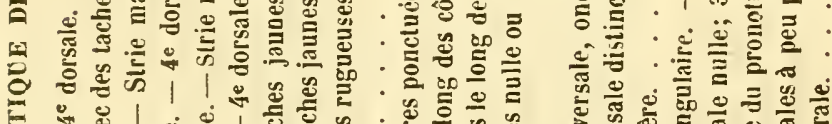

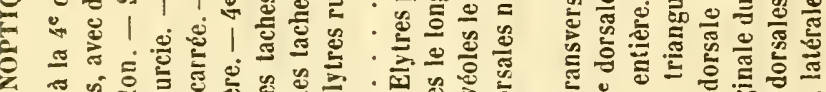

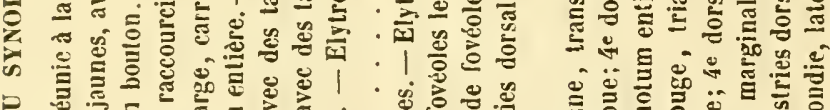

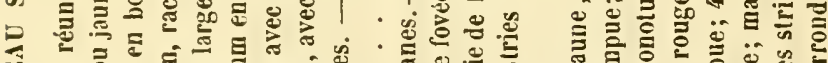

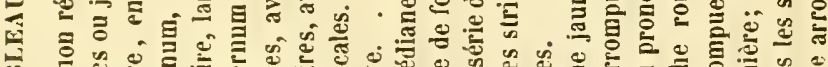

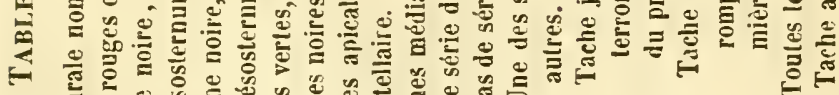

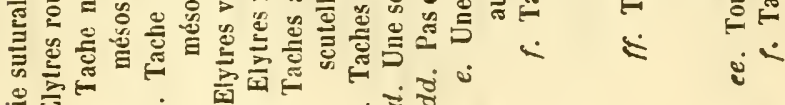

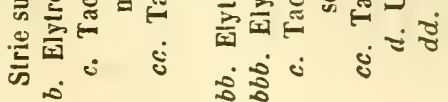


范

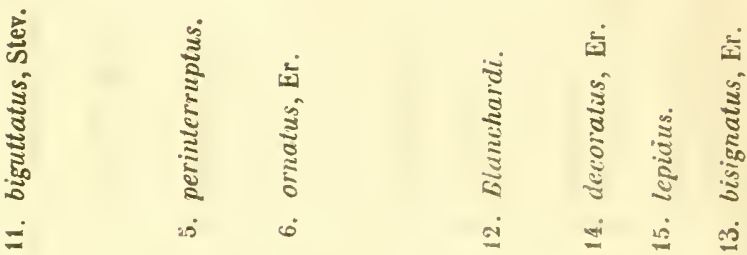

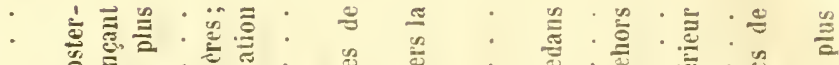

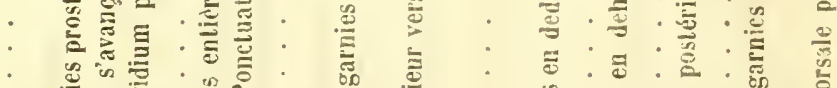

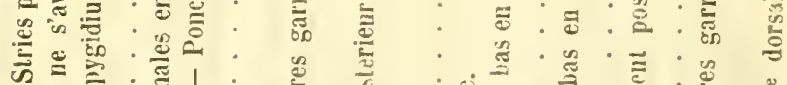
| 气 ₹.

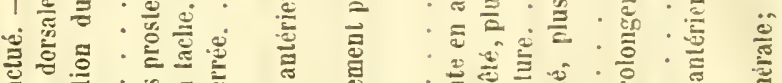

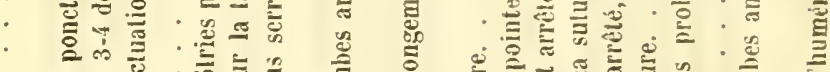

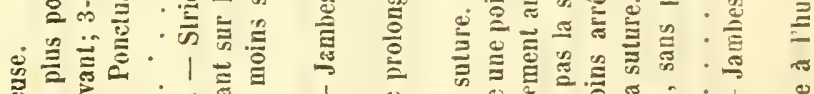

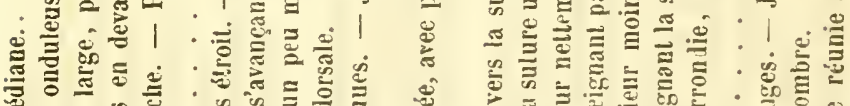
क ⿻ 丨

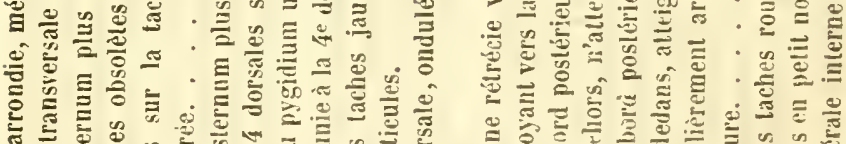
๑

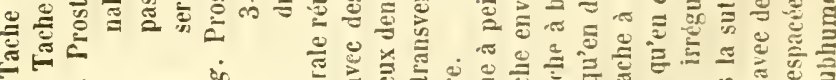
$\dot{s} \dot{\infty}$

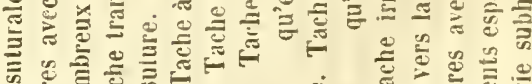

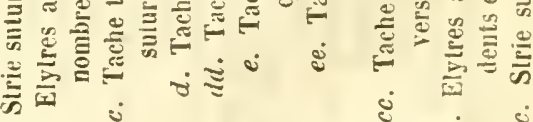

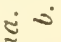


XXXIIf. Suprinus.

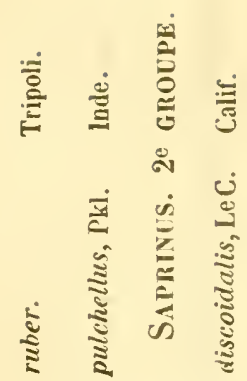

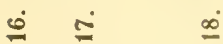

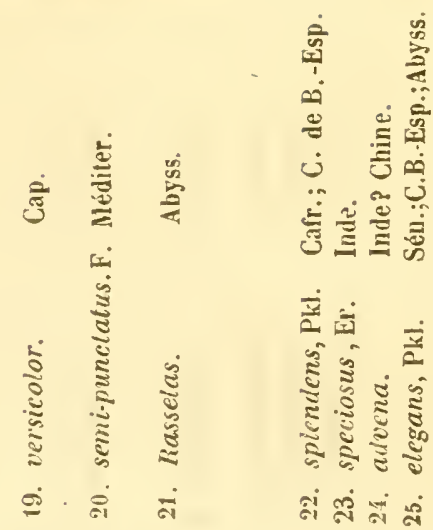

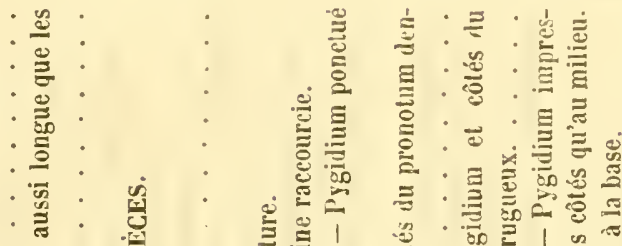

:

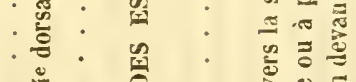

(1)

害

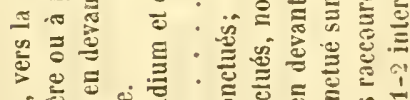

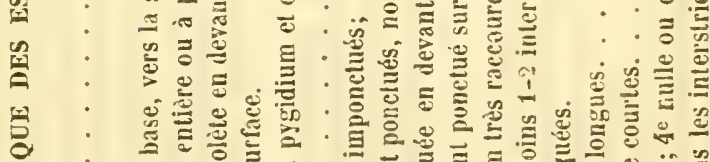

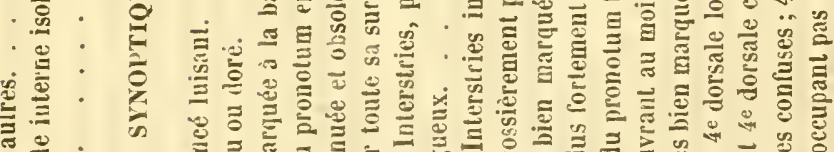

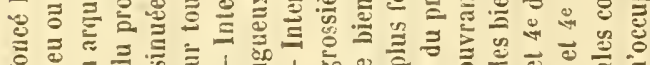

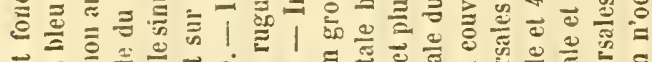

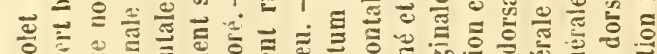

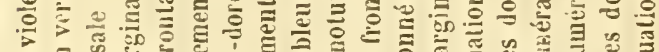

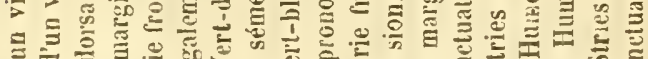

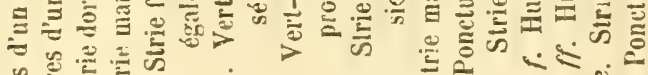

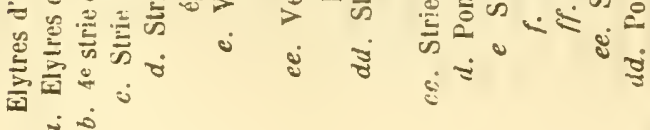
¿ं 


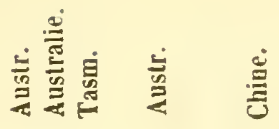

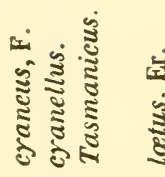

क्षेत สं के

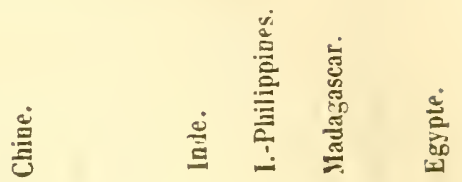

홈 $\frac{0}{2}$

ले ले बुं लें

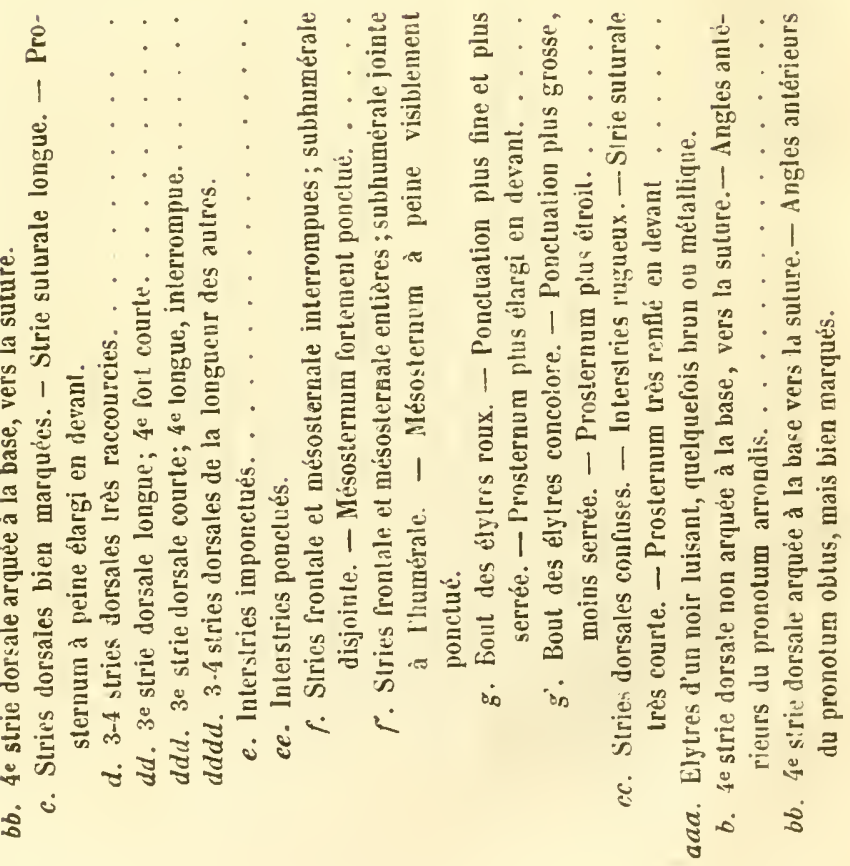


XXXIII. Saprimus.

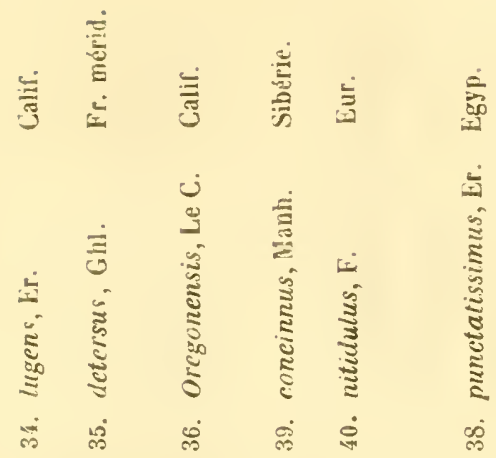

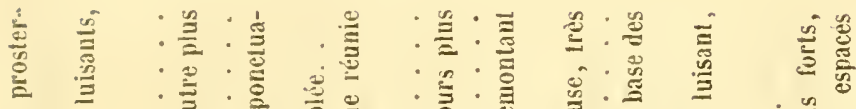

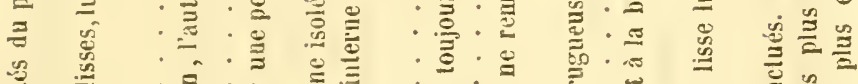

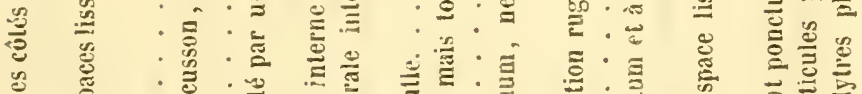

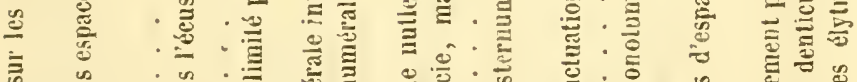

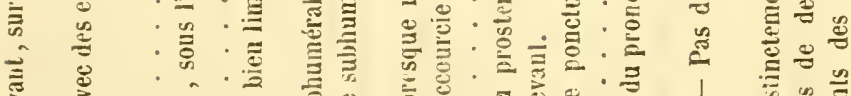

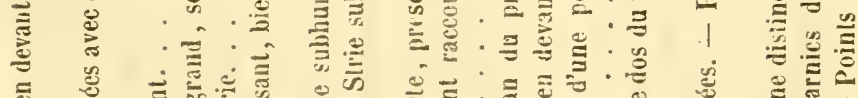

घ

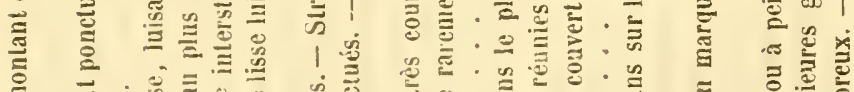

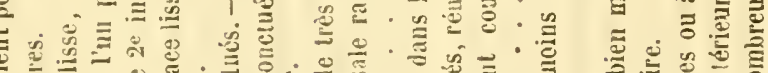

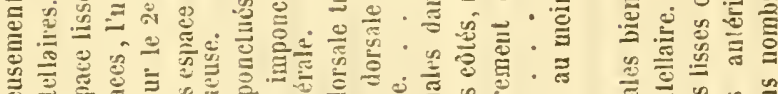

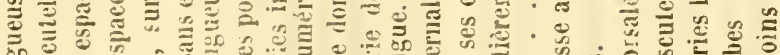

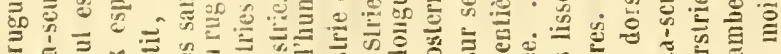

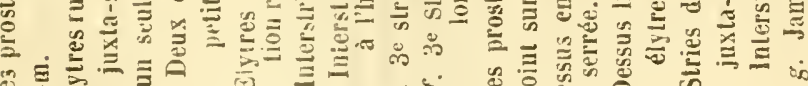

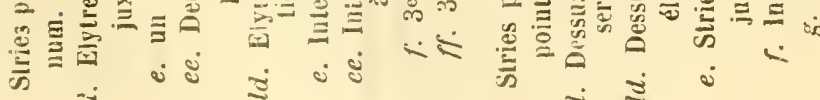

3. Série, Toms: 1!!. 

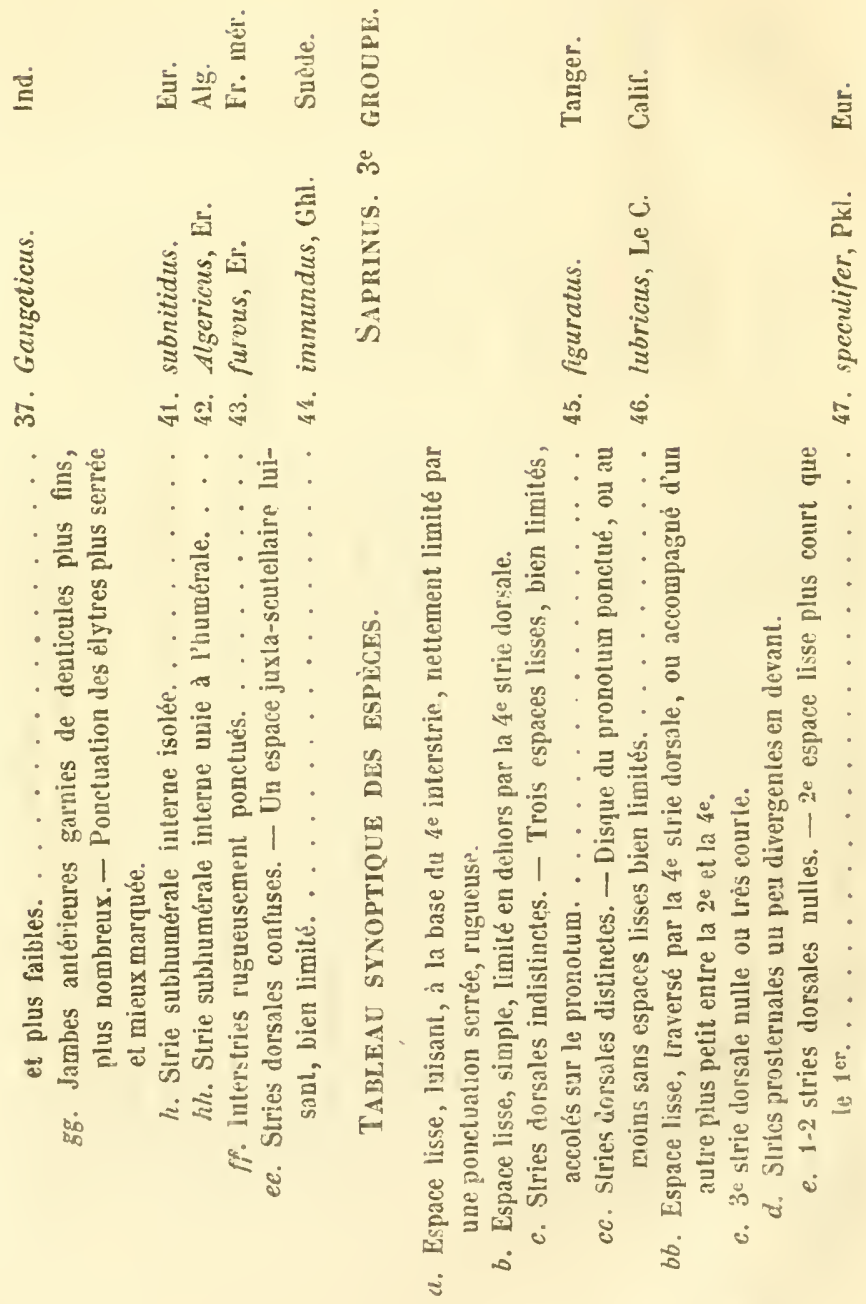


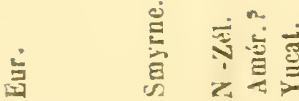

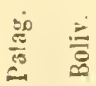

焗

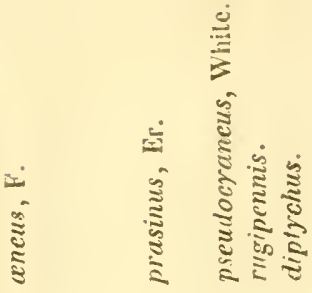

蒠

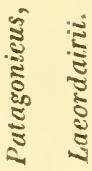

हैं

$\stackrel{\infty}{\infty}$

बें $\dot{\mathrm{s}}$ i

ชं

$22^{\circ}$

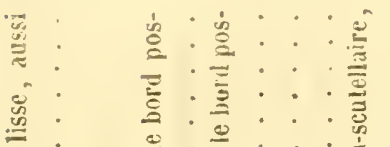

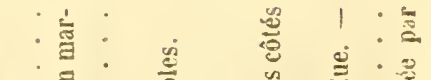

总: 竞

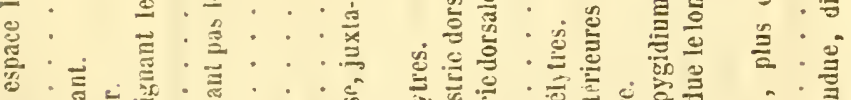

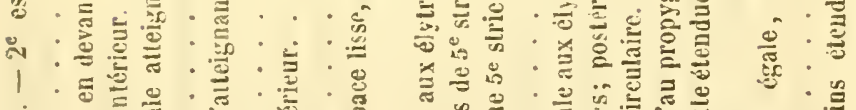

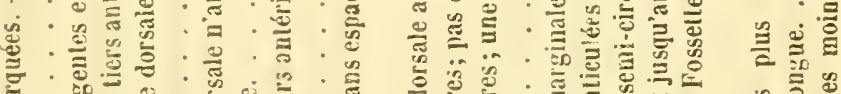
苟: : ప艹 娄

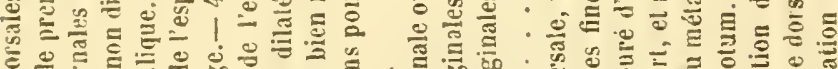
亏

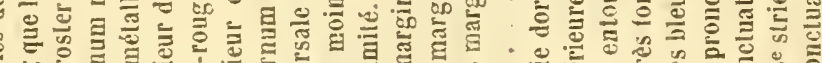

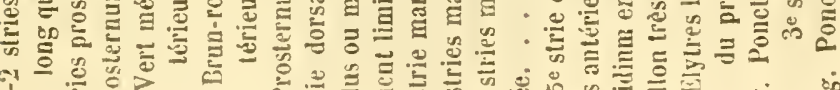
I ஓं क्ष 


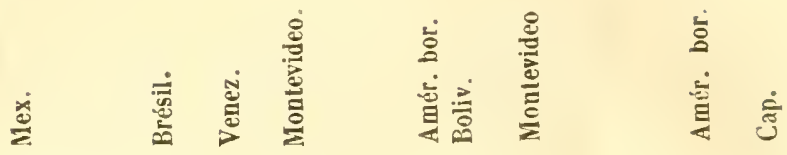
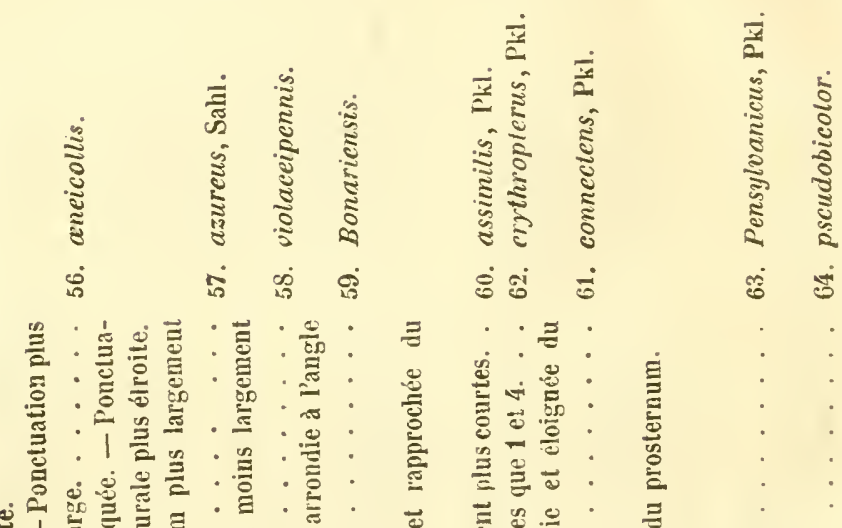

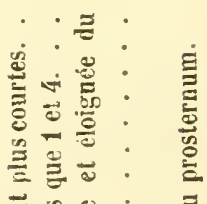

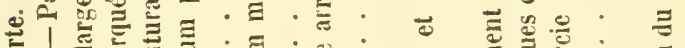

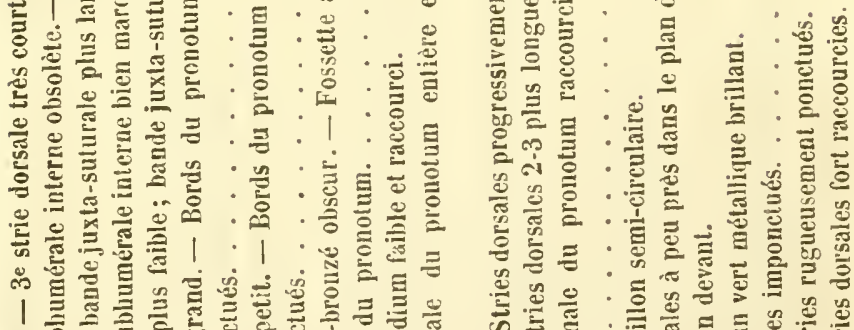

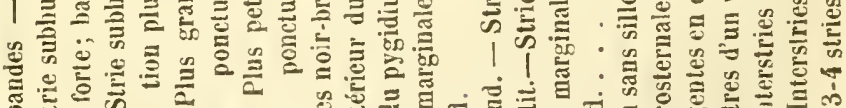

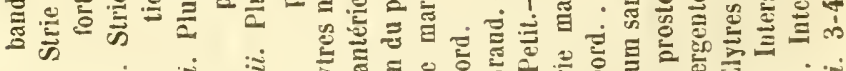

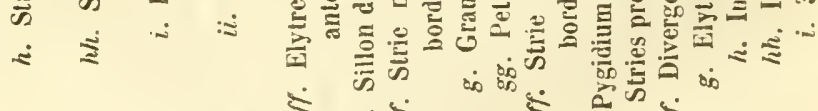

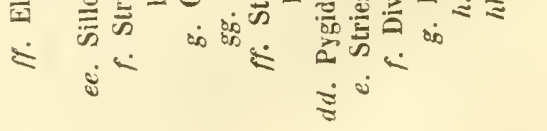


害苛言
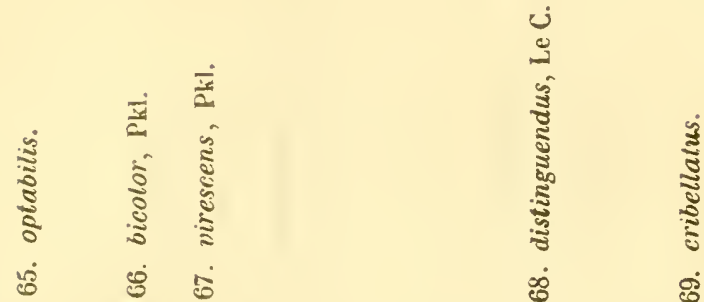

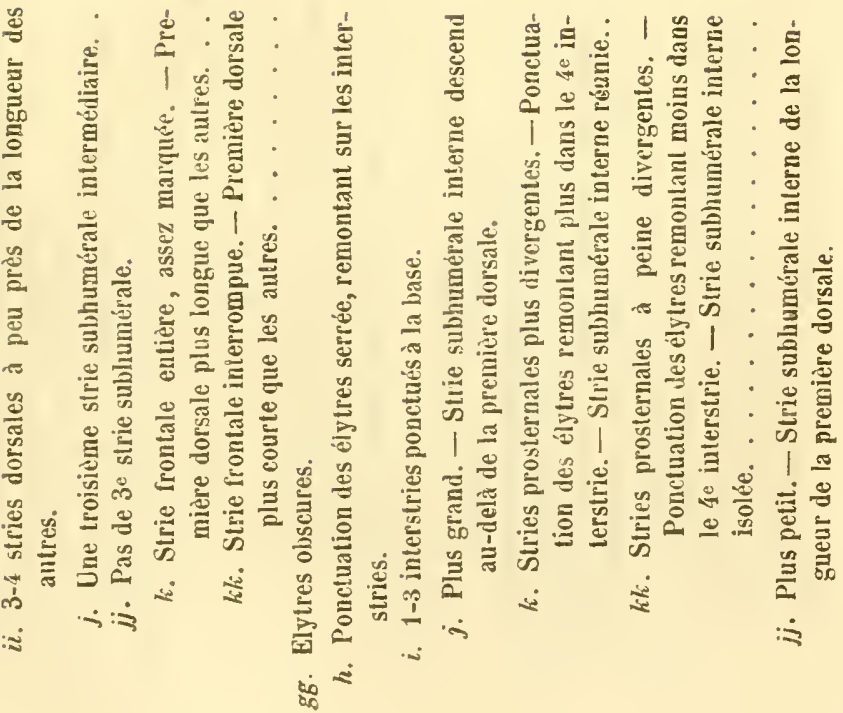


$\stackrel{\infty}{2} \stackrel{5}{\infty}$

ङँ

岕

递

章

हึ

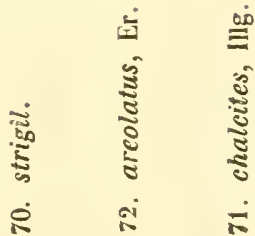

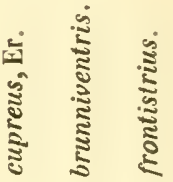

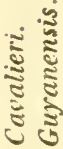

i

is

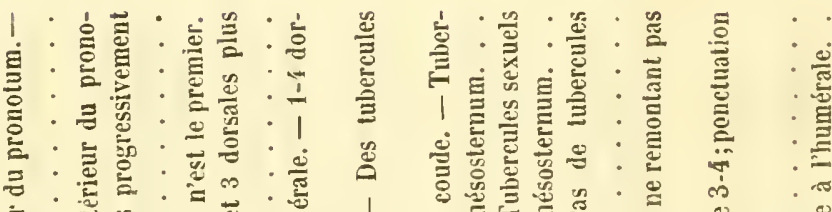

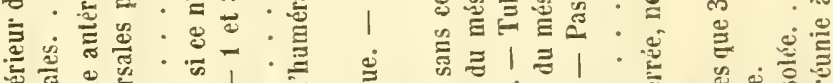

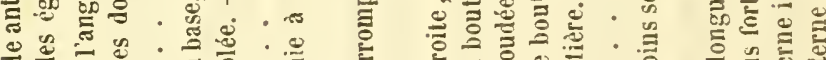

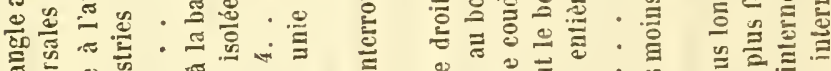

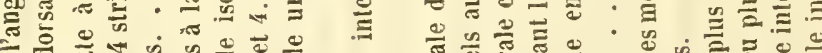

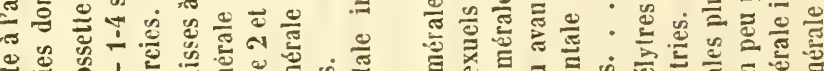

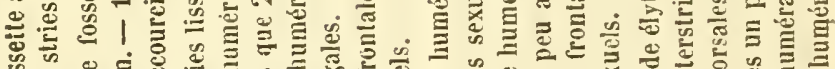

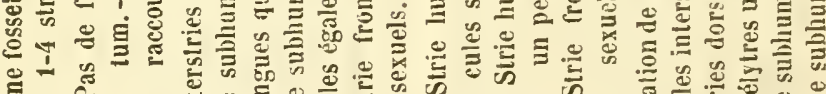

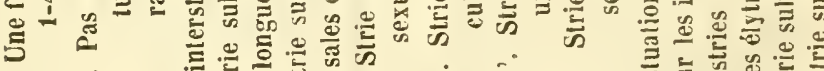

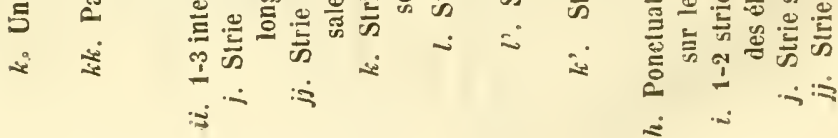


XXXIII. Saprinus.

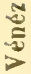

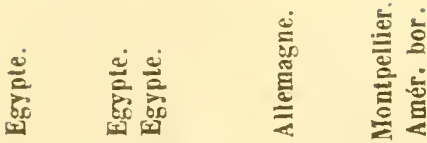

$\frac{4}{2}$

i

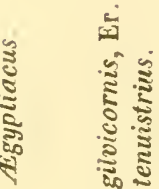

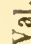

ב

வ

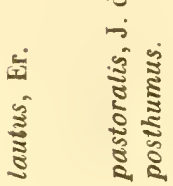

$\frac{0}{0}$

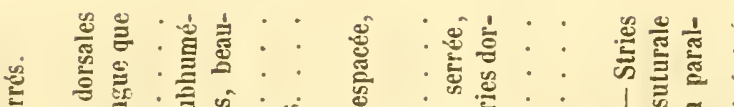

$\dot{\mathscr{S}} \quad$ in

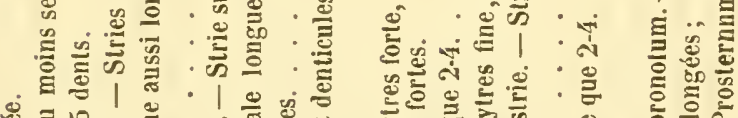

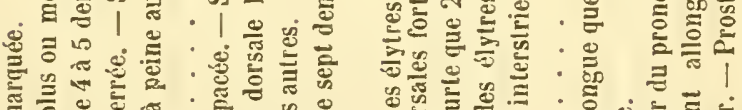

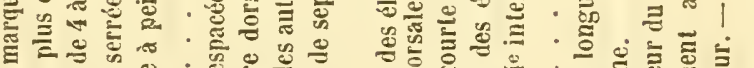

밀

क w

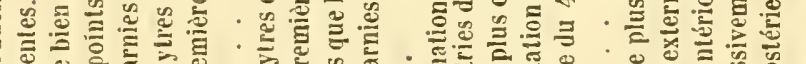

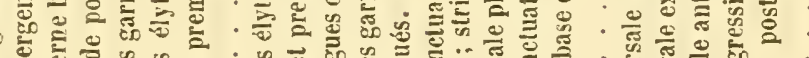

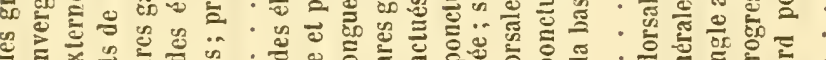
范

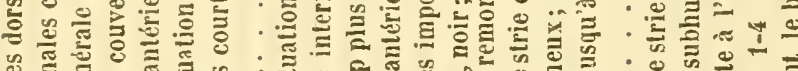

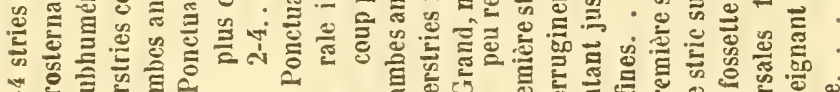

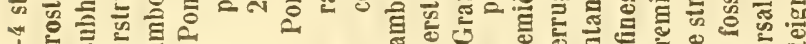

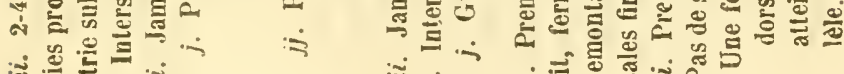
का ए $\therefore$

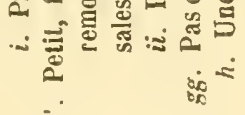




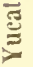

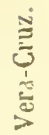

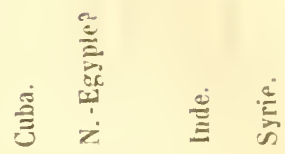

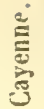

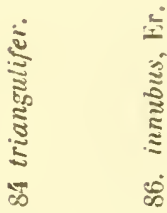

空

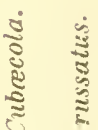

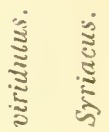

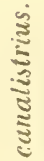

क ळं

க்

$\bar{c}$

$1 \ddot{m}$

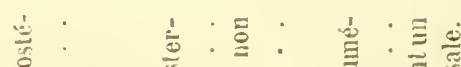

芗导

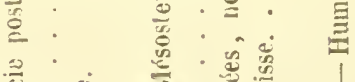

焉: 药

三 $\cong \cdot$

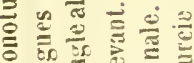

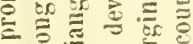

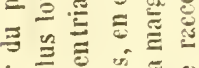

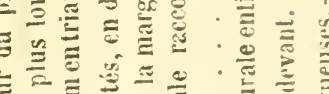

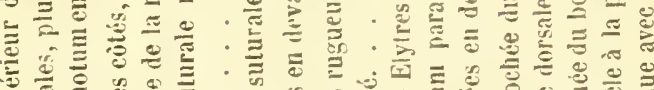

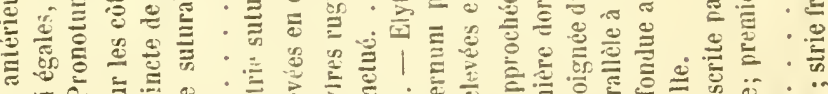
Ð

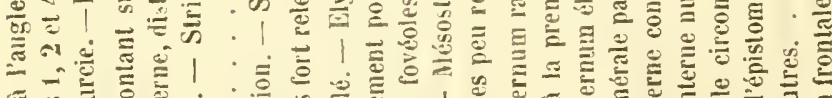

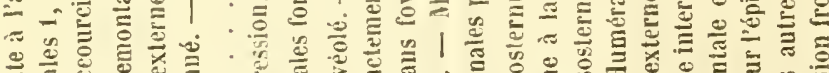

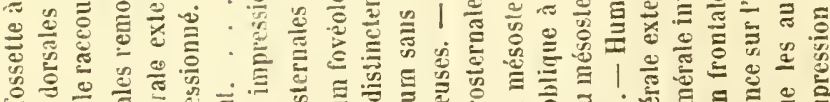

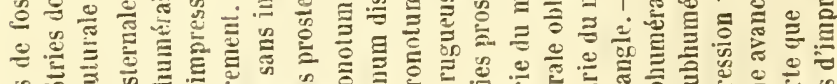

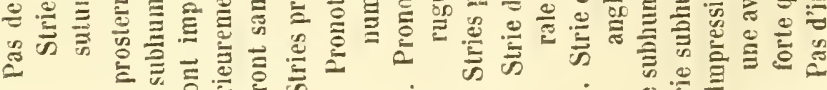

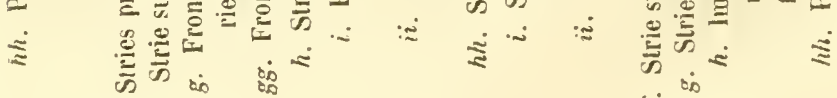
\& 
XXIII. Saprinus.

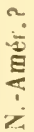

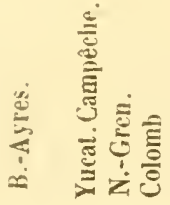

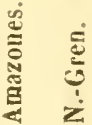

ปัँ

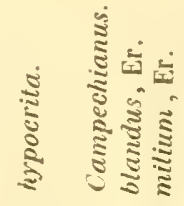

ภู่

भ

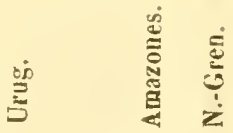

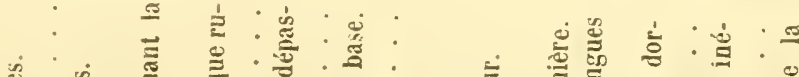

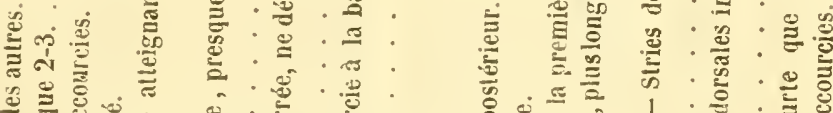

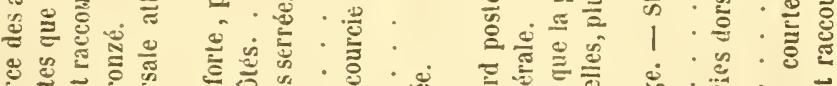

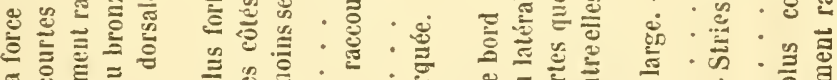
๘

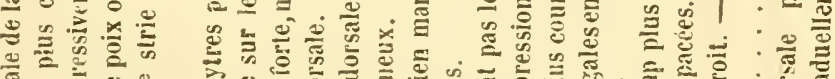
เ

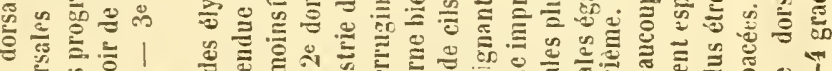

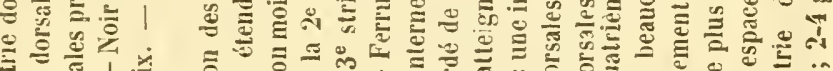
के ।

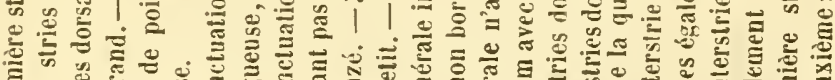

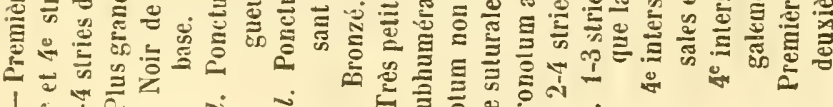
1

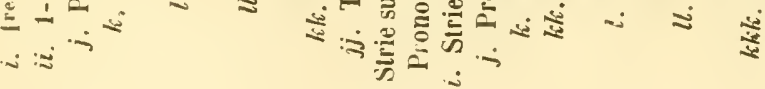
$\dot{s i}=$ 

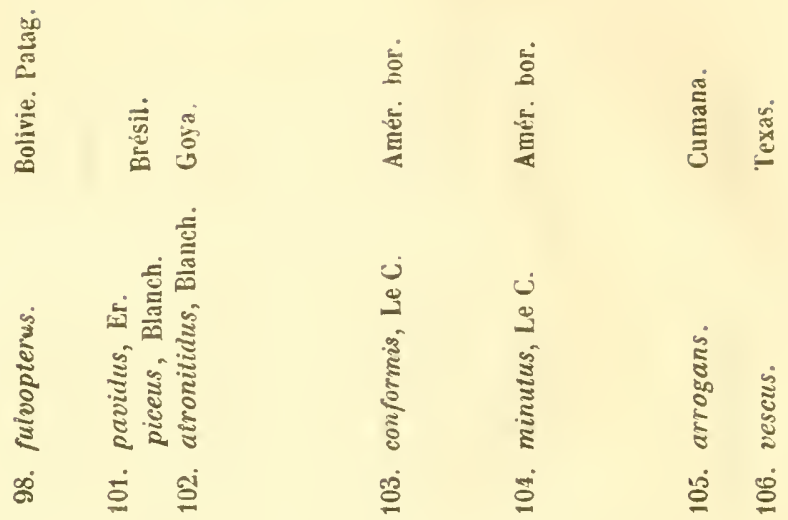

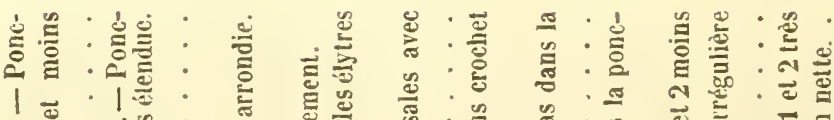

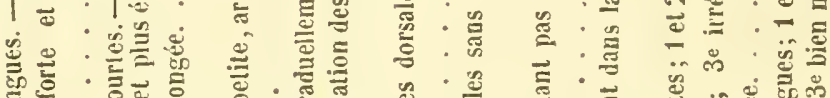

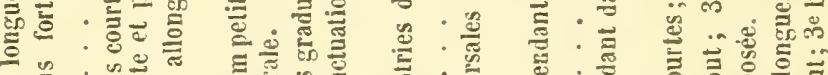

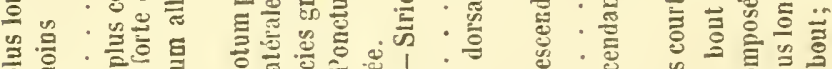

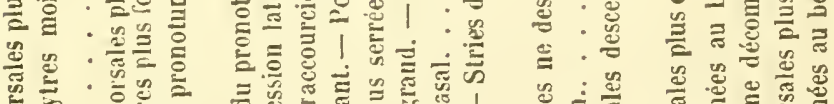

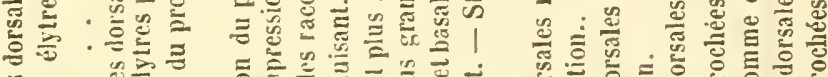

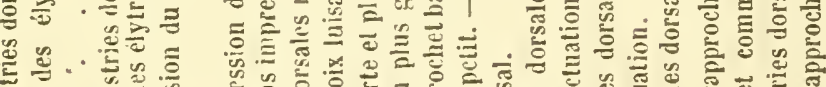
ผ

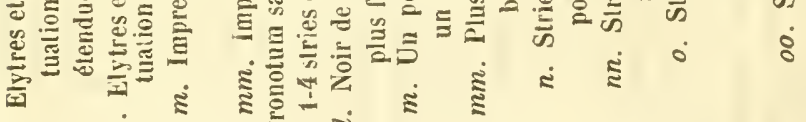
हं 
XXXIII. Saprinus.

䈉

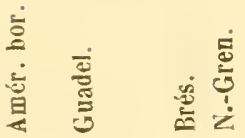

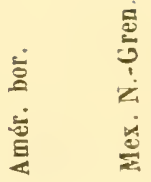

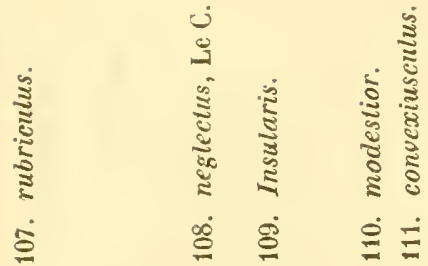

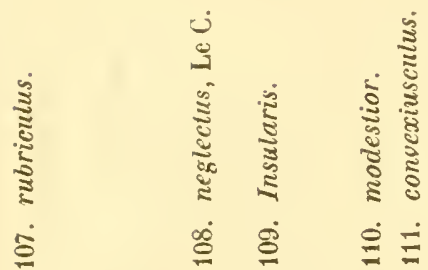

j

9

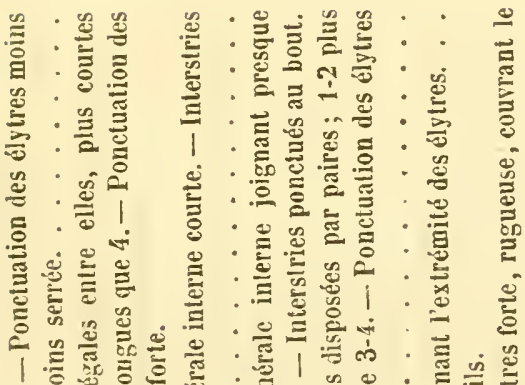

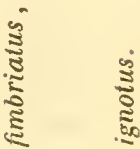

-

号: 造怘:

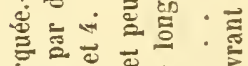

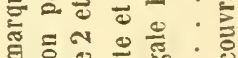
घ.气巳巳

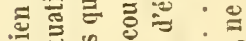

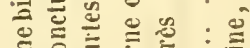

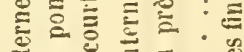

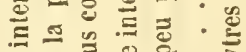

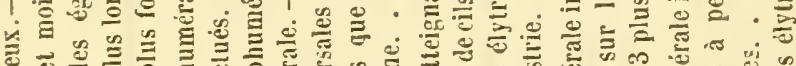

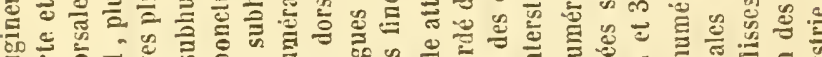

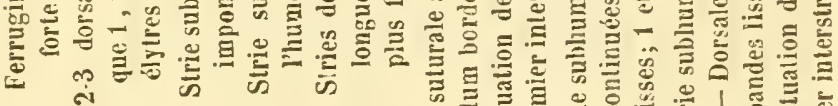

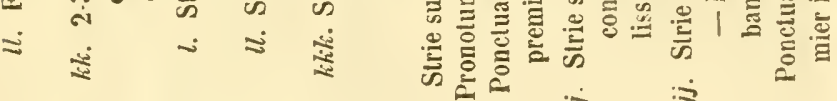

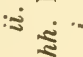


[ึ]

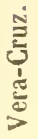

ङ艹

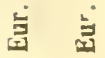

$\frac{5}{3}$

$\frac{2}{2}$ i

$\pm$

is $\doteq \div$

$\stackrel{0}{\approx} \dot{\mathcal{B}}$

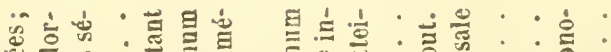

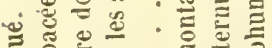
¿

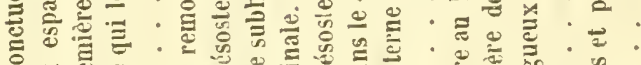

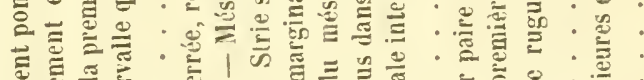
톨

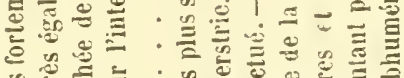

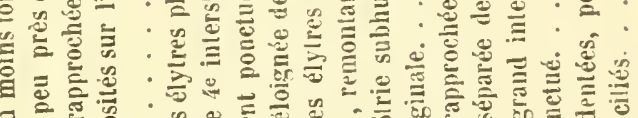

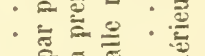
: $气 \Xi$

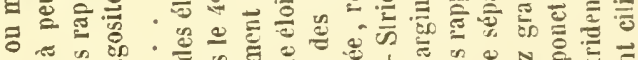

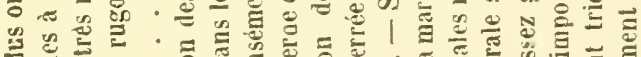

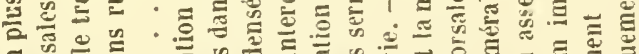

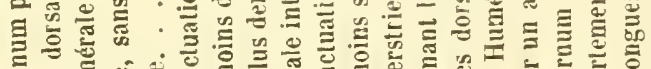

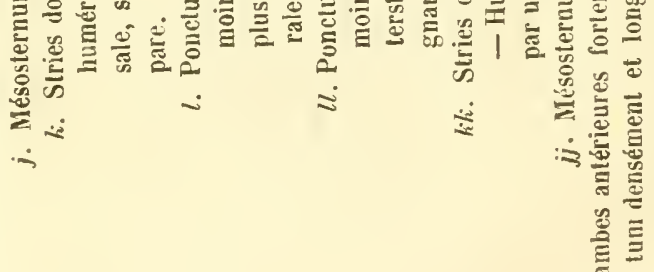

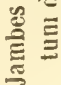

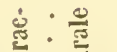

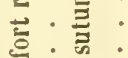

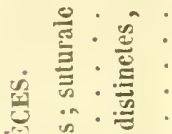

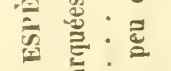
क छ. छ - $\cong$ E. $\frac{2}{6} \stackrel{0}{\frac{2}{5}}$

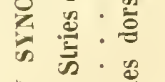
$=1 \cdot \frac{2}{n}$

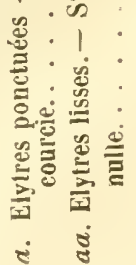



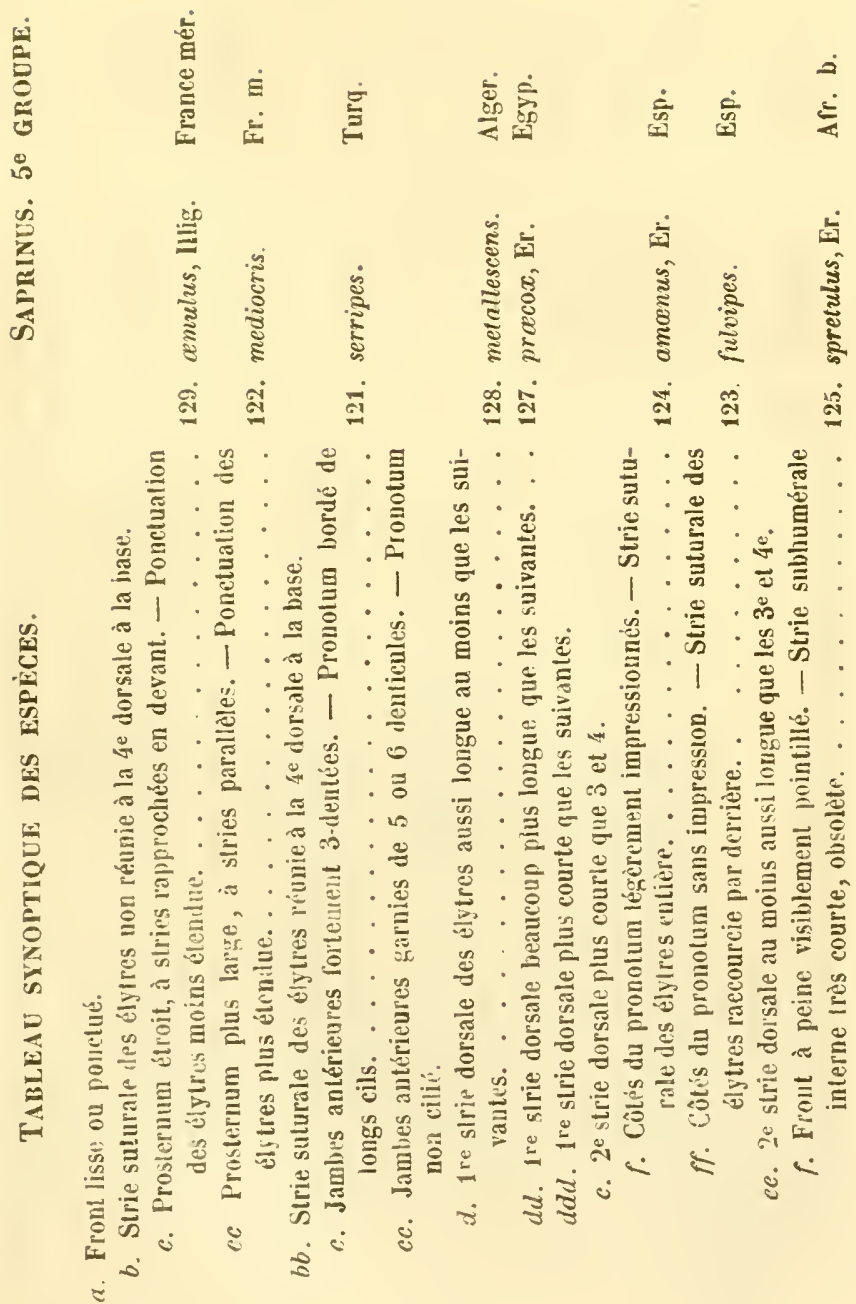


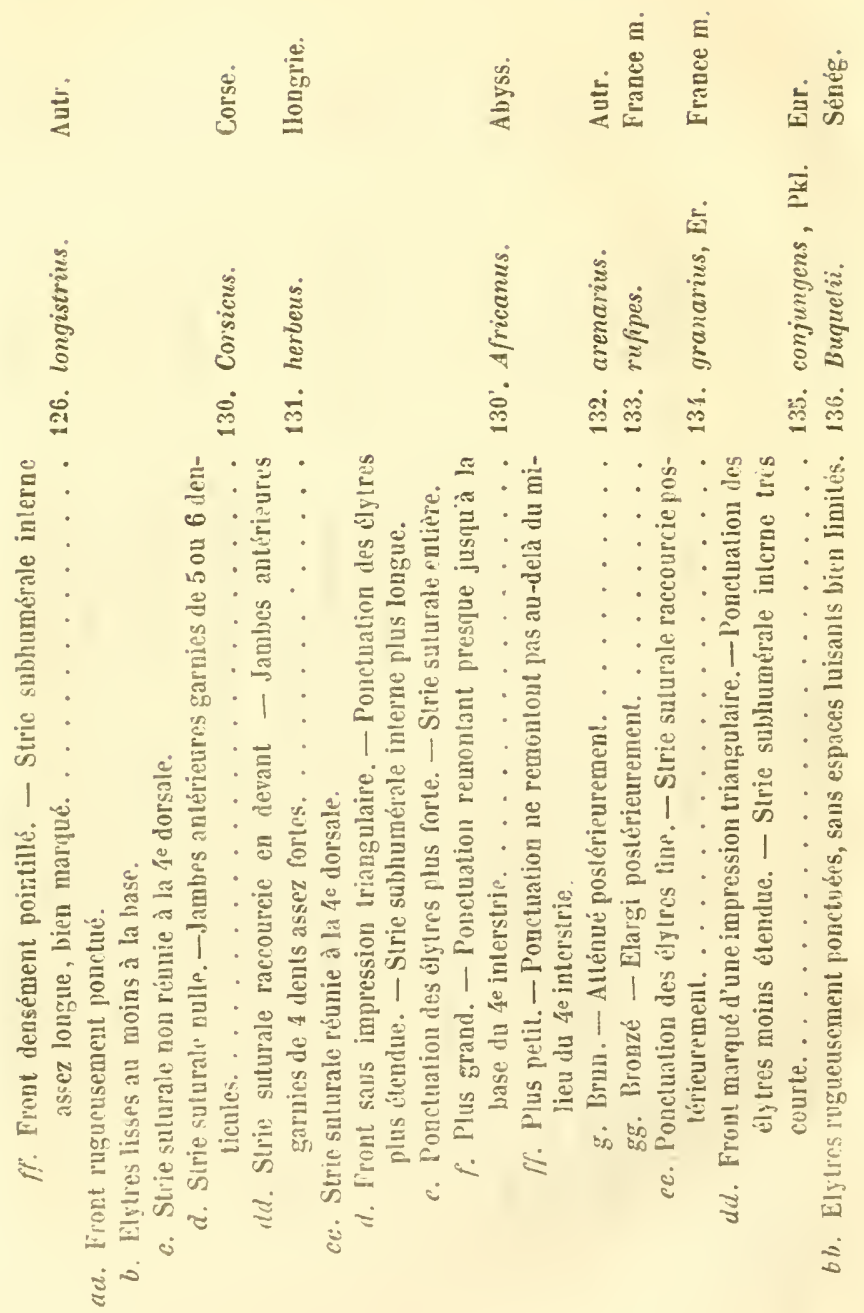


XXXIII. Saprinus.

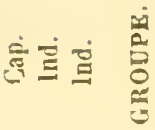

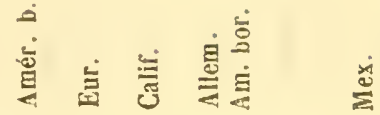

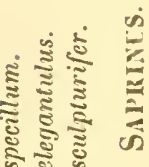

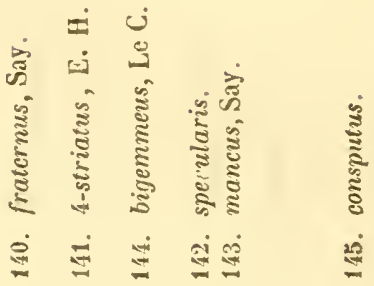

需

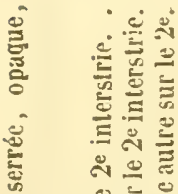

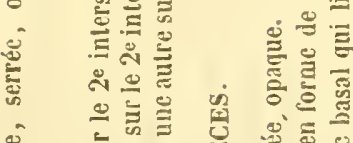

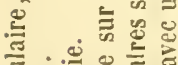

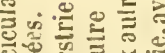

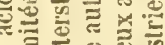

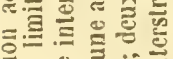

을

픈?

唯言

政

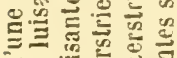

-

\&

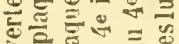

䚺部를

8.

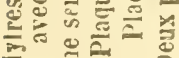

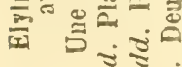

i

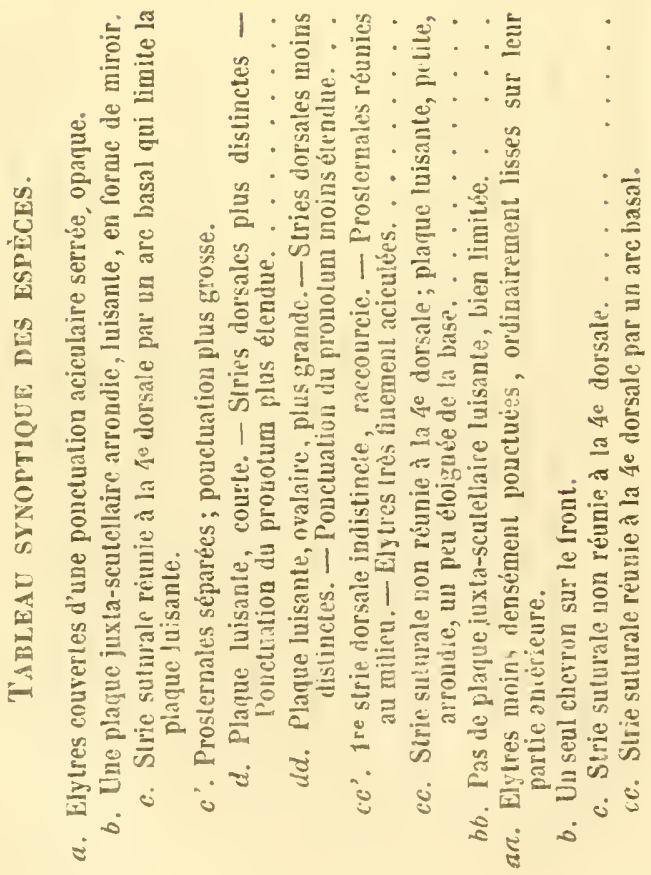




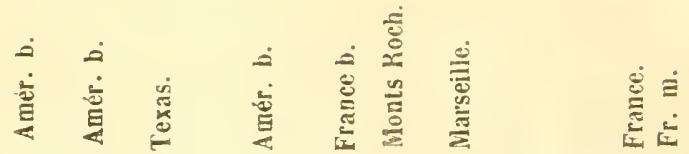

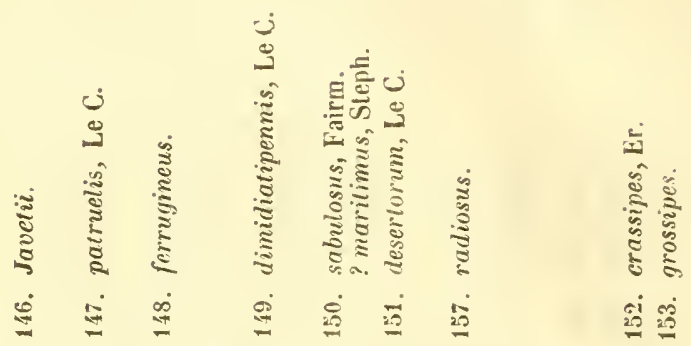

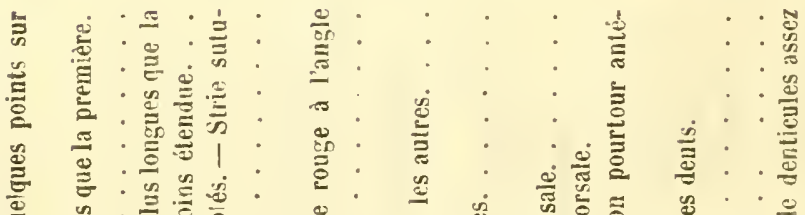

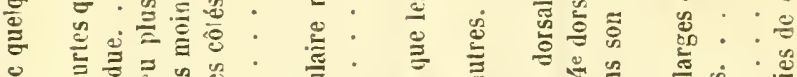

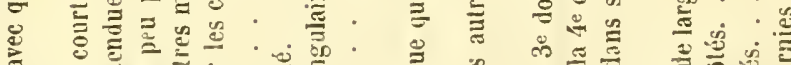

ส

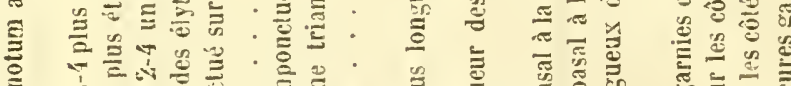

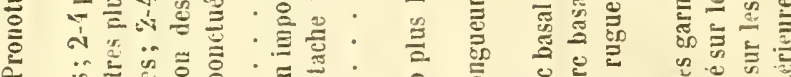

ㄴ.

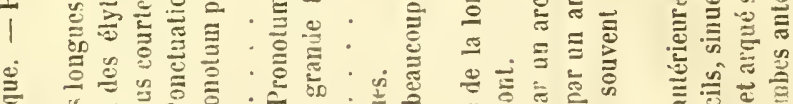

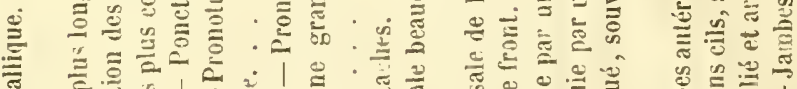

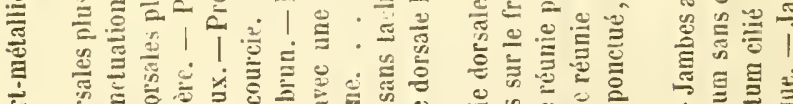
突.

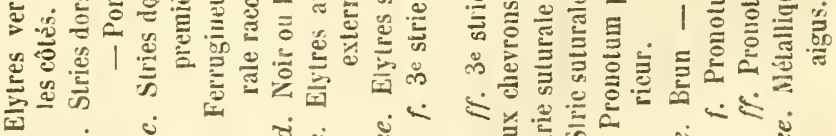

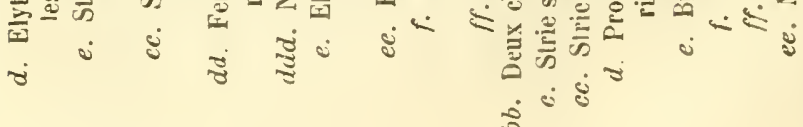




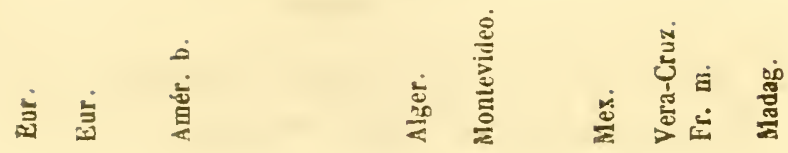

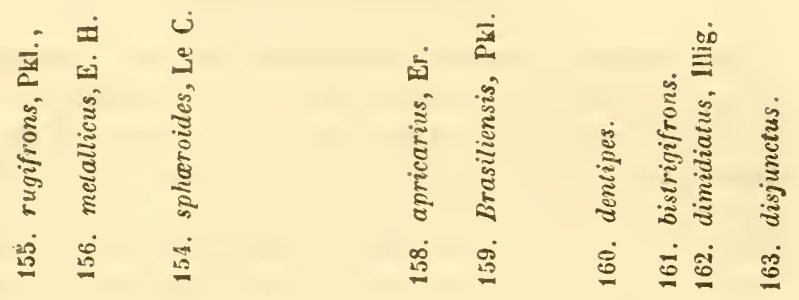

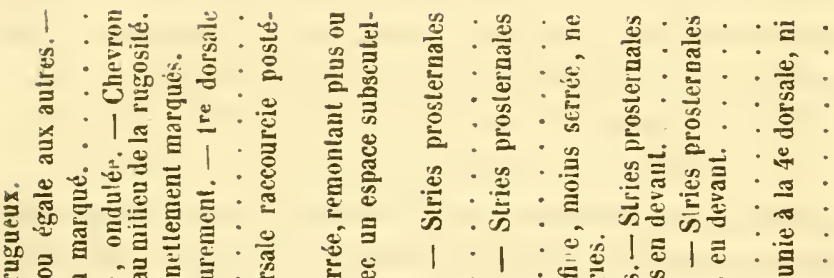

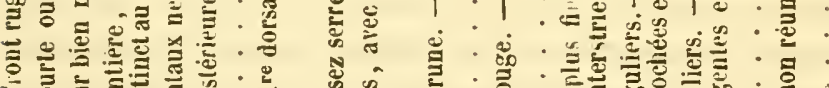

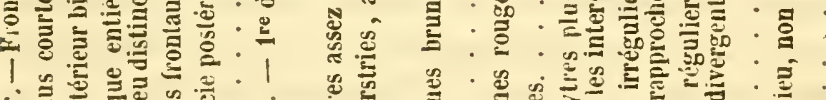

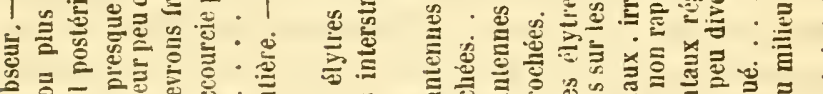

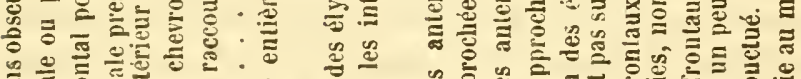

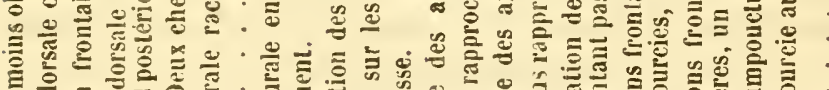

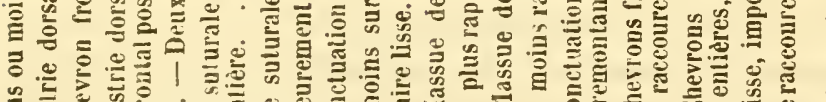

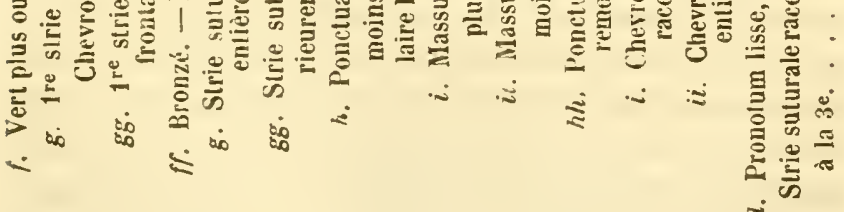
उี่ ¿ 
1er Groupe.

A. Tête sans carène, entre le front et l'épistome (1 -

B. Elytres ornées de taches bien tranchées. $(1-17$.

\section{Saprinus crctatus.}

Niger nitidus; pedibus antennisque brunneis, clava rufa; elytris rufo'flavis, margine omni maculaque subscutellari communi biloba nigris; fronte rugosa, stria temuissima; pronoto punctulato lateribus impresso rugosis, stria paulumabbreviata; elytris subrugosis, striis dorsalibus medio abbreviatis, 4" parva scepe obsoleta, suturali subintegra, marginati integra antice nulla, subhumerali utroque brevissimis; propygidio utrinque impresso punctis elongatis; mesosterno stria interrupta; tibiis anticis 6-denticulatis. Long. 7 mill.; larg. 4 1/2 mill.

Hister cruciatus, F. Ent. Syst., 1, 75,16 (1792). - Syst. El. 1, 87, 19. - Payk. Mon. Hist. 48, 36, pl. 12, f. 7.

Ovale, peu convexe, noir, luisant. Antennes brunes; massue roussatre; front légèrement convexe, rugueux, avec un point médian; strie très fine, sinuée et peu distincte en devant. Pronotum beaucoup plus large que long, largement bisinué à la base, oblique sur les côtés, rétréci, échancré en devant, avec les angles arrondis, finement pointillé sur le disque, plus fortement ponctué dans le pourtour, avec une impression rugueuse de chaque côté, en devant; strie ınarginale fiue, non interrompue, un pen raccourcie à la base. Ecusson très petil, triangulaire. Elytres plus longues que le pronotum, de sa largeur à la base, dilatées à l'épaule, rétrécies ct coupées droit à l'extrémité, pointillées, un pell plus forlement, et presque rugueusement sur les interstries, d'un jaune-rouge pâle, rebordées étroitement de brun dans tout leur pourtour, avec une tache 
noire, subscutellaire, commune, en forme de bouton de sonnette, formée l'une tète elliptique, transversale, puis rétrécie et terminée par une base appliquée contre le pronotum; stries dorsales atteignant à peine le milieu; première un peu plıs longue; quatrième très courte, raccourcie aussi à la base, souvent obsolète ; suturale presque entière; marginale interne disparaissant vers la base; subhumérales très courtes; interne confondue avec l'humérale. Propygidium peu densément ponctué. Pygidium couvert de points forts, allongés, avec une impression de chaque côté de la base, et une bande lisse, longitudinale, médiane. Prosternum à stries parallèles très fines, souvent raccourcies. Mésusternum bordé d'une strie fine, interrompue. Pattes brunes; jambes antérieures garnies de cinq à six denticules.

Il diffère du $S$. maculatus Rossi, par la forme de la tache subscutellaire en bouton, la strie marginale du pronotum raccourcie, la marginale interne des élytres raccourcie à la base, leur poncluation rugueuse, leur couleur plus jaune, et la strie du mésosternum interrompue.

Nord de l'Afrique; Alger; Tripoli; Tanger; se retrouve au Sénénal.

\section{S. maculates.}

Niger, nitidus; elytris rufis, margine, sutura, macula parva humeri, magna subquadrata utrinque cinuat a communinigris : pronoto stria marginali integra, lateribus impresso-rugosis; elytris punctatis, striis dorsalibus postice abbreviatis, 1-2 ultra, 3-4 ante medium, suturali et $4^{\mathrm{a}}$ dorsali antice nomihil abbreviatis, subhumerali utraque brevi; nuesosterno marginato, prosterni striis parallelis completis; tibiis anticis 6-denticulatis. long. 7 mill. : larg. 5 mill. 
Hister maculatus. Rossi Fn. Etr. Mant., 1, 12, 20 (1792). App. 2, 128, pl. 11.

H. personatus. Fisch. Ent. Russ., 2, 206, 5, pl. 25, 5 (1824).

Saprimus maculalus. Küst. Kaf. Eur., 4, 72 (1846).

Ovale, peu convese en dessus, noir, luisant. Antennes ferrugineuses, scape brıı. Front légèrement convexe, rugueusement ponctué: strie line, entière, formant sur l'épis. tome une sinuosité profonde. Pronotum beaucoup plus large que long, largement bisinué à la base, oblique sur les cotés, échancré en devant, avec les angles obtus, arrondis; ponctué sur toute sa surface, mais plus fortement dans son pourtour, avec une impression longitudinale rugueuse de chaque côté; strie marginale fine, entière. Ecusson très petit, triangulaire. Elytres plus longues que le pronotum, de sa largeur à la base, dilatées à l'épaule, rétrécies et coupées droit au bout, assez densément ponctuées ; ponctuation plus forte au milieu; jaune-rouge, avec le bord latéral et apical, et la suture noirs, ainsi qu'une tache subscutellaire commuic, large, presque carrée, comme formée de deux paires de taches; on trouve souvent, en outre, une lache brunc à l'épaule et une bordure de méme couleur à la base; stries dorsales bien marquées, raccourcies postérieurement; 1 - ¿2 au-delà du milieu ; $3-4$ un peu avant; quatrième recourbée en devant, vers la suturale, raccourcie, ainsi que cette der. nière; humérale bien marquée, parallèle à la première dorsale, aussi longue qu'elle, avec la subhumérale interne qui n’en est pas ordinairement séparée; subhumérale externe, courte, basale; marginales entières, bien marquées. Propygidium assez densément et assez fortement ponctué. Pygidium moins densément, mais aussi fortement ponctué, avec une légère impression de chaque côté de la 
base. Stries du prosternum entières, parallèles. Mésosterum entièrcment robordé; pattes brunes; jambes antérieures garnies de cinq à six denticules.

Var. . - La paire de taches noires postérieure se détache entièrement de la suture. La ponctuation des élytres est beaucoup moins forte.

Var. 6. - La paire de petites taches noires disparaît entièrement.

Cette espèce parait répandue sur tout le littoral du bassin de la Méditerranée: France méridionale; Italie; Turquie d’Asie ; Caucase; Sibérie; Russie méridionale ; Grèce ; les variétés $a$ et $b$ sont exclusivement propres à la Russie.

\section{S. 4-guttatus.}

Ovalis, viridi-cyaneus, metallicus; clava rufa; capite punctato stria tenui antice obsoleta; pronoto utrinque impresso, lateribus punctato, stria abbreviuta; etytris in medio strigosopunctatis, striis ante medium desinentibus, $4^{\text {a }}$ dorsuli suturalem haud attingeute, subhumerati interna mulla, externa paı va, maculis 2 flavis albis, mugna media latcrali, parva subapicali, quandoque mullu; pygidio cequuliter punctato; prosterno striis subpurallelis, mesosterni integra; tibiis brumeis, anticis 8-9 rlenticutatis. Long. 5 1/2 mill.; larg. 4 mill.

Hister 4-guttat us. F. Ent. Suppl., 39, 18-19 (1798). - Syst. El., 1, 89, 27. - Payk. Mon. Hist., 52, 38, pl. 13, 2.

Var. a. - H. lateralis. Illig., Mag., 6, 36, note (1807).

Ovalaire, peu convexe en dessus, d'un vert bleuatre, métallique, luisant. Anteunes ferrugineuses, scape brun. Front convexe, assez densciment ponctué; strie fine, sinuée et obsolète derrière l'épistome. Pronotum plus large que long, bisinué à la base, oblique sur les côtés, rétréci et échancré 
en devant, avec les angrles arrondis et marquẻs d'une légère impression, couvert largement dans son pourtour de points qui deviennent forts et presque rugneux dans le voisinage de l'impression. Ecusson très pelit. Elytres de la largeur du pronotum à la base, dilatées à l'épaule, rétrécies et coupées droit au bout, couvertes d'une strigosité serréc qui se réduit en un pointillé très fiu dans le pourtour; strie suturale entière, dor'sales n'alteignant pas le milieu; quatrième non réunie avec la suturale; lumérale parallèle à la première dorsale, éloignée, bien marquée; sublumérale interne paraissant nulle; externe très courte; une assez grande tache d'un jaune pale, arrondie vers le milieu du bord latéral, une autre très petite, ovalaire, subapicale, disparaissant quelquefois. Propygidium et pygidium fortement et également ponetués. Brosternum large, à stries subparallèles, réunies en derant. Mésosternum entièrement rebordé. Jambes avec une transparence brune; antéricures garnies de 8-9 petits denticules.

Var. a. Tache subapicale des élytres nulle. H. lateralis, Illig. Hag.

Inde; Bengale; Pondichéry ; Kurmaul.

\section{S. EQIESTRIS.}

Niger, nitidus; antermis pedibusque fuscis ; fronte munctata, stria antice interrupta; pronoto punctulato, latcribus rugosoimpresso, puncto antescutcllavi; etytris postice parum dense punctatis, macula flava transversa in medio 3-toba, striis dorsalibus brevibus 3-4 obsolctis, suturali vix abbreviata, subhumevali utraque brevi; mygidio dense munctato; mosterno striis integris utrinque divergentibus; tibiis anticis multi denticulatis. long. 6 mill.; larg, 4 mill.

saprinus rquest is. Erich. Beyt. Lus. Angola, 226. 4.3 (1848). 
Noir, luisant, peu convexe. Antennes brun de poix; funicule rougeâtre. Front légèrement convexe, densément ponctué; strie peu marquée, interrompue. Pronotum beaucoup plus large que long, bisinué à la base, avec un point antéscutellaire, oblique sur les còtés, rétréci et échancré en devant, avec les angles arrondis, couvert d'une ponctuation fine et serrée sur le disque, plus forte à la base et rugueuse sur les còtés: une fossette de chaque côté, derrière les yeux; strie marginale entière. Ecusson très petit, triangulaire. Elytres plus longues que le pronotum, de sa largeur à la base, dilatées à l'épaule, rétrécies et droites au bord apical, couvertes de points fins et espacés dans leur moitié postérieure, ainsi que sous le bord infléchi ; une tache jaune transversale au milieu, s'étendant de la subhumérale interne à la quatrième dorsale, paraissant composée de trois taches arrondies, accolées; strie suturale un peu raccourcie à la base; margrinales entières; subhumérales très courtes; interne non distincte de l'humérale; 4-dorsales fines, fort raccourcies, obsolètes, surtout les 3-4. Pygidium densément ponctué. Prosternum assez large, bordées de deux stries divergentes à chaque extrémité. Mésosternum ponctué, bordé d'une strie entière. Pattes brunes; jambes antérieures 8-9 denticulées; postérieures garnies de deux rangs de faibles épines.

Angola; Benguéla ; Iles du Cap-Vert.

\section{S. PERINTERRUPTUS.}

Niger, niticlus; antennis rufis, scapo brumeo; fronte rugosa, stria intcrupta; pronoto lateribus impressis, late punctatorugosis, disco sublavi; elytris postice et extus parum dense punctulatis, stria suturali antice, dorsalibus medio postico abbreciatis, 1-3 brevioribus; subhumerali externa brevi interna 
obsoleta; macula transversn merlia triloba rufa; pygidio dense punctato; prosterno striis intorruptis, mesostornoqucmarginato, punctatis; tibiis anticis 6-7 obtuse denticulatis. Long. 6 mill.; iarg. 4 mill.

Ovale, peu convexe, noir, luisant. Antennes rougeâtres; scape brun. Front presque plan, rugueux; strie indistincte. Pronotum beaucoup plus large que long, bisinué à la base, oblique sur les côtés, rétréci et échancré en devant, avec les angles arrondis; ponctué dans son pourtour, étroitement à la base, presque lisse au milieu, avec une forte impression rugueuse le long du bord latéral; strie marginale entière. Ecusson très petit, triangulaire. Elytres plus longues que le pronotum, de sa largeur à la base, à peine dilatées à l'épaule, rétrécies et coupées droit au bout, finement et peu densément ponctuées sur les côtés et dans leur moitié postérieure; strie suturale ne remontant pas jusqu'à la base; dorsales raccourcies vers le milieu, 1 et 3 un peu plus courtes ; marginales entières ; humérale contournée; sublıumérale externe, basale courte; interne obsolète; tache rouge médiane, transversale ondulée, s'arrêtant entre la suturale et la quatrième dorsale, paraissant formée de trois taches accolées. Pygidium peu convexe, densément ponctué. Prosternum pointillé, assez large, rétréci au milieu; stries fines, très courtes. hiésosternum avec de gros points épars et une strie marginale entière. Pattes brunes; jambes antérieures garnies de 6-7 denticules obtus.

Sénégambie portugaise ; îles du Cap-Vert.

6. S. ORNATLS.

Atro, nitilus, antennis rufo-brunneis, marula triloba transuresa moliu flava; fronte rugosula, stria subsimuata; monoto 
utrinque rugoso impresso, basi ct lateribus punctato; etytris postice punctulatis, striis dorsulibus 1. - ultra, 3-4 versus medium abbreviatis; suturali subintcgia, subhumerali utraque brevissima; pygidio dense punctalo; mosterno angusto, striis integi ${ }^{\circ}$; mesosterno punctato maryinuto; tibiis anticis 7 obtuse denticulutis. Long. 6 mill.; larg. 4 mill.

Suprinus ornatus. Er. in Jahrb., 176, 4 (1834).

Hister interruptus. Fisch., Ent. Ross., II, 207, 7, pl. 25, f. 7 (1824).

Ovale, peu convexe, noir, laisant. Antennes d'un brunrouge; funicule plus clair. Front rugueusement ponctué, presque plan; strie fine, subsinuée et obsolète derrière l'épistome. Pronotum plus large que long, bisinué à la base, oblique sur les côtés, rélréci et échancré en devant, avec les angles obtus, ponctué, très finement sur le disque, plus fortement dans son pourtour, avec une impression latérale bien marquée, rugueuse; strie margina!e entière. Ecusson triangulaire, très petit. Elytres plus longues que le pronotum, de sa largeur à la base, légèrement dilatées à l'épaule, rétrécies et Iroites au borl apical, couvertes de points fins et peu serrés dans leur moitié postérieure; une tache jaune transversale, trilobéc ou comme composée de trois taches accolées; partant de la marginale interne et n'atteignant pas la suturale; stries dorsales raccourcies; 1-2 un peu au-delà diı milieu; 3 -4 vers lc milieu, rapprochées par paires; suturale entière, un peu raccourcie à la base, sans s'unir à la quatrième dorsale; humérale bien marquẻe; sublıumérales très courles; interne non distincte de l'humérale; marginale interne entière. Pygidium également ct densément ponctué. Prosternum assez étroit, à strieș entières, parallèles. Mésosternum ponctué, à strie 
marginale non interrompue. Pattes brunes; jambes antérieures 6-7 denticulées.

Russie méridionale, Kirglıises; Arabie ; Egypte et Algéric.

\section{S. interRteptus.}

Nigro-ctnens, nitidus; antemis pedibusque brunneis; fionte dense punctata, stria interrapta; monoto latcribus 4-foveolato basique punctato, stria vix abbrcviata ; clytris basi posticeque punctatis, macula pallida lata transversa utrinque ramosa, striis dorsalibus postice 1, 2 et 4 in medio $3^{\text {a }}$ ante medium, suturali untice abbreviatis; pygidio punctato; mosterno striis subparalletis; mesosterno stria interrupta; tibiis anticis 6-7 denticulatis. Long. 5 mill.; larg. 3 1/2 mill.

Histcr interruptus. Payk. Mon. Hist., 50, 37, pl. 12, 8 (1811).

Noir, luisant, un peu métalique. Antennes brunes; funicule rougeâtre. Front peu convexe, densément ponctué; strie fine, largement interrompue. Pronotum beaucoup plus large que long, bisinué à la base, avec un point antéscutellaire, oblique et sinué sur les côtés, rétréci et échancré en devant, avec les angles arrondis; imponctué sur le disque, densément ponctué dans son pourtour, avec quatre fovéoles bien marquées le long du bord latéral ; strie marginale un peu raccourcie à la base. Ecusson très petil, triangulaire. Elytres plus longues que le pronotum, de sa largeur à la base, légèrement dilatées sur les côtés, rétrécies el droites à l'extrémité, ornées d'une large tache pâle, trausversale, qui s'étend de la marginale interue à la suturale, placée aux deux tiers postérieurs, plus large en dehors, avec un rameau postérieur, et un antérieur plus grand, accompagné de deux plus petits de chaque coté; le disque est ponclué densément sur toute la tache et à la base, entre les stries 
dorsales ; strie suturale raccourcie en devant, dorsales raccourcies postérieurement, 1, 2 et 4 au milieu, troisième bien arant; humérale unie à la première dorsale el formant avec elle un angle fort ouvert; denx subhumérales très courtes; interne obsolète, réunie à l'humérale; marginales entières. Pygidium densément ponctué. Prosternum à stries bien marquées, entières, parallèles. Mésosternum ponctué; strie fine, largement interrompue. Pattes brunes; jambes antéricures 6-7 denticulées; postérieures garnies de deux rangs de rares spinules.

Inde ; Maradabad; Kurmaul.

\section{S. ERICHSONil.}

Ater, subnitidus; pedibus antemisque brunneis, clava rufa; fronte rugosa, stria interrupta; pronoto muctato, lateribus fortius, foveolatoque; clytris rugoso-munctatis, humeris, apice, macula sculellari alinque minuta $2^{\mathrm{i}}$ interstitii lavibus, apice bipartito flavo; striis dorsalibus cequaliter dimidiatis, suturali abbreviata, submumerali interna brevi, cxterna mulla; pygidio pnuctato temiterque marginato; prosterno striis integris divaricatis; mesosterno punctato, marginato; tibiis anticis $7-8$ denticulatis. Long. 5 mill.; larg. 4 mill.

Uvale, peu conrexe, noir peu luisant. Antennes brunes; massue ferrugineuse. Front plan, rugueux; strie peu marquée, sinuée à l'épistome. Pronotum court, beaucoup plus large que long, bisinué à la base, avec un point antéscutellaire, oblique et cilié sur les côtés, rétréci et échancré en devant, avec les angles arrondis, légèrement impressionnés, couvert d'une ponctuation fine sur le disque, et forte dans son pourtour; stric marginale presque entière. Ecusson très petit, triangulaire. Elytres plus longues que le 
pronotum, dilatées à l'épaule, rétrécies et droites au bout; couvertes d'une ponctuation forte, serrée, rugueuse, avec les épaules, le bor'd apical, une plaque juxta-scutellaire arrondie, et une autre plus petite sur le deuxième interstrie, lisses; ornées d'une tache blanche apicale, bilobée en devant; stric suturale remontant jusqu'aux 4-5 antérieurs; 4-dorsales raccourcies au milieu, souvent la troisième plus courte et même obsolète; humérale parallèle à la première dorsale; subhumérale interne obsolète, courte, externe nulle; marginales entières. Pygidium allongé, bombé, densément ponctué, étroitement rebordé. Prosternum finement pointillé, un peu rétréci au milieu; stries bien marquées, entières, divergentes, réunies en devant. Mésosternum ponctué, entièrement rebordé. Pattes brunes; jambes antérieures garnies de 7-8 denticules espacés et assez forts.

Madagascar.

\section{S. Nitidus.}

Atro viridis, nitidus; antennis perlibusque brunneis; fronte punctulata, stria integra ; monoto punctulato, lateribus impresso subrugoso; stria basi abbreviata; elytris postice punctulatis, stria suturali integra dorsalibus 1 et 3 ante medium abbreviatis, 2a obsoleta humerali cum $1^{\mathrm{a}}$ dor'sali angulatim juncta, a subhumerali disjuncte; macula mediarotundata rufa; pygidio punctulato, apice sublavi; prosterno striis recurvis integris; tibiis anticis 8-denticulatis. Longueur 3 3/4 mill.; largeur $23 / 4$ mill.

Hister nitidus. Wiedem. Zool. Mag. Beng. Java, 2, 1, 29, 40 (1817).

? Saprinus amonulus. Fahr. in Bohem. Ins. Cafr., 1, 544, 593 (1851). 
Suborbiculaire, peu convexe, vert foncé noir, luisant. Antennes brunes; front peu convexe, finement pointillé; strie entière, bien marquéc. Pronotum beaucoup plus large que long, bisinué à la base, légèrement courbé sur les côtés, rétréci et échancré en devant, avec les angles arrondis; bordé de points dans son pourtour, plus marqués latéralement, avec une légèrc impression postoculaire; strie marginale un peu éloignée du bord, n’atteignant pas la base. Ecusson très petit, triangulaire. Elytres plus longues que le pronotum, de sa largeur a la base, curvilinéairement dilatées sur les côtés, rétrécies et droite au bout, couvertes d'une ponctuation fine et peu serrée remontant au milieu, près de la suture; tache rouge, arrondie, ne touchant ni à la suturale ni à la marginale; strie suturale entière; première et troisième dorsale atteignant à peine le tiers; deuxième olsolète, quatrième nulle; marginales entières ; humérale réunie à la première dorsale, un peu après la base, et formant un angle arec elle; subhumérale interne disjointe, externe courte, basale. Pygidium densément ponctué, presque lisse au bout. Prosternum rétréci au milieu; stries bien marquées, remontant et divergentes en devant. Mésosteruum finement ponctué et entièrement rebordé. Pattes brunes; jambes antérieures 7-8 denticulées.

Cap de Bonne-Espérance; C. des Aiguilles; Cafrerie.

10. S. EXTERNUS.

Niger, nitidus; antennis brunneis, clava rufa; macula flava parva laterali elytrorum; fronte punctulata, stria tenui subintogra; monoto basi punctato, lateribus impresso-rugosis; 
elytris striis 1-dorsalibus postice in medio, suturali antice abbreviatis; marginalibus integris, subhumerali utraque brevi; pygidio dense punctato; prosterno striis parallelis, subintegris; mesosterno marginato; tibiis anticis 7-denticulatis. Long. 7 mill.; larg. 4 1/2 mill.

Hister externus. Fisch. Ent. Russ., 2, 207, 9, pl. 25, f. 9 (1824).

Orale, peu convexe, noir, luisant. Antennes brunes, massue rousse. Front peu convexe, ponctué; strie fine, peu distincte en devant. Pronotum beaucoup plus large que long, largement bisinué et bordé de points à la base, oblique. sur les côtés, avec une impression profonde, ponctuée et rugueuse, rétréci et ćchancré en devant, avec les angles arrondis; strie marginale entière. Ecusson très petit, triangulaire. Elytres plus longues que le pronotum, de sa largeur à la base, à peine dilatées à l'épaule, rétrécies et droites au bord apical, couvertes dans leur moitié postérieure, de points fins peu serrés; ornées au milieu du bord latéral, d'unc tache jaune qui n'atteint pas la troisième dorsale; strie suturale assez raccourcie à la base, 1-4 dorsales, égales, ne dépassant pas le milieu; subhumérale externe courte; interne plus ou moins allongée, faisant suite à l'humérale; marginales assez rapprochées, entières, intervalle pointillé. Pyģidium densément ponctué. Prosieruum à stries à peine raccourcies en devant, divergentes à la base. Mésosternum ponctué, entièrement reborlé. Pattes brun de poix; jambes antérieures 7-8 denticulées.

-Russie mérilionale; Géorgie; Grande-Tarlarie; Arménie; Syrie; Perse occidentale.

\section{S. BigltTatus.}

Ater, nitidus; antennis pedibusque brunneis; fronte rugosopunctuta, stria interrupta; pronoto puncticulato, lateribus 
ciliato impresso punctatoque rugoso; elytris postice punctulatis, stria suturali subintegra, 1-4 dorsalibus dimidiatis, subhumerali utraque brevibus distinctis, humorali bifuda, macula parva rotunda rufa; pygidio dense munctato; prostcrno compresso, striis parallslis integris; mesostemo marginato; tibiis anticis 4-כ็ derticulatis. Long. 7 mill. ; larg. 4 1/2 mill.

Hisıer biguttatus. Steven, in Mém. Soc. Mosc., 1, 159 (1806). - Payk. Mon. Hist. 51. Note. - Fisch. Ent. Russ.. 2, 207, 8, pl. 25,8 .

Ovale, légèrement convexe, noir, luisant. Antennes brunes. Front à peine arrondi, densément et rugueusement ponctué ; strie fine, interrompue à l'épistome. Pronotum bisinué à la base, oblique et cilié sur les côtés, rétréci et échancré en devant, avec les angles obtus, couvert d'un pointillé fin sur le disque, de points plus forts le longr de la base, et d'une large bordure de points rugueux sur les côtés, arec une faible impression postoculaire. Ecusson petit, triangulaire. Elytres dilatées à l'épaule, rétrécies et coupées droit au bout, couvertes d'une fine ponctuation, qui remonte jusqu'au milien, et même plus loin dans le premier interstric ; strics subhumérales bien distinctes; interne disjointe; humérale très rapprochée de la première dorsale, bifide; suturale presque entière; dorsales atteignant le milieu, deuxième un peu plus longue; une ptite tache rouge au milieu de la moitié postérieure de l'élytre. Pygidium bombé, densément ponctué. Prosternum très étroit; stries rapprochées, presque parallèles, réunies en devant. Mlésosternum pointillé, entièrement rebordé. Pattes brunes; jambes antérieures garnies de quatre assez fortes dents, et d'une ou deux irès petites.

Russie méridionale; Turcomanic; Caucase; très rare ; dans le crottin de cheval. 


\section{S. Bi.ANCHARUI.}

Niger, nitidus; antennis rufo-brumeis; fionte rugosa, stria nulla; pronoto basi anguste, lateribus late impressis, rugosopunctatis; elytris postice disco munctatis, macula flavo-lutea transversa, antice sinuosa, striis marginalibus integris, dorsulibus 1-2 juxta, $3^{\mathrm{a}}$ interupta ultra et $4^{\mathrm{a}}$ ante medium abbreviatis; subhumerati extema subintegra; pygidio munctuto; prosterno striis antice recurvis, divergentibus, tibiis anticis 8-denticulatis. Long. 3 1/2 mill.; larg. 2 1/2 mill.

Saprinus ơnutus. Blanch. in d'Orbig. Toy. Amér. mér.

Noir, luisant, ovale, subconvexe. Antennes ferrugineuses; scape et massue plus bruns. Front peu convexe, rugueux; strie indistincte; épistome enfoncé. Pronotum plus large que long, légèrement bisinué à la base, courbé sur les côtés, rétréci et échancré en devant, avec les angles obtus, ponctué dans son pourtour, plus largement et rugueasement sur les bords latéraux, avec une légère impression postoculaire, presque lisse sur le disque; strie marginale entière. Ecusson très petit, triangulaire. Elytres plus longues que lc pronotum, de sa largeur à la base, dilatées à l'épaule, rétrécies et droites au bout, ponctuées à la base, sur les deux premiers interstries, et sur la moitié postérieure; stries dorsales raccourcies, 1-2 au milieu, troisième un peu au-delà et interrompue, quatrième avant, arquée à la base et réunic à la suturale; marginale entière bien marquée, bordée de points; humérale rapprochée de la première dorsale, s'en éloignant à l'épaule; subhumérales assez longues; interne faisant pour ainsi dire suite à l'humérale; tache jaune rougeâtre, large, transversale, allant de la marginale à la suturale, à bord postérieur presque droit; antérieur onduleux. Pygidium hombé, couvert d'une ponctuation serrée. Pro- 
sternum rétréci en devant, à stries divergentes, recourbées. Mésosternum ponctué, à strie interrompue. Pattes brunes; jambes antérieures 7-8 denticulées.

Patagonie; Chili.

\section{S. Bisignatus.}

Niger, metallicus, nitidus; fronte rugosa, stria tenui interrupta; pronoto luteribus ciliato et punctuto impresso; elytris macula mugna subrotundutu flava, in medio dense punctulata, stria subhumerali utraque brevibus, interna disjuncta, humerati et 1 a dorsali dimidiatis, approximatis, parallelis, 2avoviori, $3^{a}$ brevissima, $4^{a}$ vix incunte, arcu suturali juncta; mygidio punctatissimo; mesosterno munctis parcis, stria intorruptu; prostcrno striis valde ascententibus; tibiis anticis 9-10 denticulatis. Long. 4 mill. ; larg. 3 mill.

Hister bisignatus. Sol. in Gay, Hist. Chili. 377, pl. 8, f. 9 (184\%).

Saprinus bisignatus. Er. in Jahrb., 1, 177, 10 (1834).

Ovale court, peu convexe, noir, métalique, luisant. Antennes brunes. Front rugueusement et densément ponctué; strie fine, interrompue à l'épistome. Pronotum court, bisinué et étroitement bordé de points à la base, cilié, oblique, avec une impression rugueuse le long des côtés, rétréci et échancré en devant, avec les angles arrondis; strie marginale entière. Ecusson très petit. Elyties plus longues que de pronotum, de sa largeur à la base, dilatées à l'ćpaule, rétrécies et droites au bout, avec unc bande longitudinale de points serrés au milieu, terminée par une petite impression subapicale, et une tache jaune-paille médiane, subarrondie, entre les strıes marginale et suturale; strie subhumérale externe bien distincte, interne disjointe; humérale et première dorsale irès rapprochées, parallèles, raccourcies

3e Série, томе ин. 
vers le milieu; deuxième un peu plus courte; troisième tout à fait rudimentaire; quatrième qui est réduite à un arc basal qui la joint à la suturale : celle-ci entière, un peu plus distante de la suture an milieu qu'aux deux bouts. Pygidium couvert d'une ponctuation fine et serrée. Viésosternum avec quelūues gros points de chaque côté; strie marginale interrompue. Stries du prosternum fortes, très divergentes et relevées en devant. Jambes antéricures garnies de 9-10 petits denticules.

Bolivie ; Chili (Conception, S.-Iago, Coquimbo); La Plata (Tucuman).

\section{S. DECORATLS.}

Niger, ceneus nitidus; antennis pedibusque brunneis, funiculo rufo; fronte dense munctata, stria indistincta; pronoto ciliato lovi, lateribus late, basi anguste rugoso-punctato; elytris basi rugosis, discoque arcuatim donse puncticulatis, macula flava lata, transversa, basi scpius obscura, intus bisinuata, humero brunneo notato, striis suturali subintegra, dorsalibus 1, 2 et 4 in medio, $3^{3}$ longe ante medium abbreviatis, subhumerali utroque brcvibus; pygidio dense punctato; prosterno striis antice recurvis, tibiis anticis 9-10 denticulatis. Longueur 4 mill.; larg. 2 2/3 mill.

Saprinus decoratus. Er. in Jahrb., 176, 9 (1834).

Noir, mélallique, luisant. Antennes brun-rouge; massue foncée. Firont peu convexe, densément ponctué; strie indistincte. Pronotum plus large que long, subsinné à la base, oblique et cilié sur les côtés, rétréci et échancré en devant, avec les angles arrondis, lisse sur le disque, densément ponctué dans son pourtour, largement et presque rugueusement sur les côtés. Ecusson très petit, triangulaire. 
Elytres plus Iongues que le pronotum, de sa largeur à la base, saillantes et un peu dilatées à l'épaule, droites et rétrécies postérieurement, avec une légère impression transverse subapicale; couvertes à la base d'une bande de points rugueux, et sur le disque de points aciculaires serrés formant un espace yui s'élargit ct se recourbe vers la suture postérieurement; strie suturale presque entière, séparée de la suture par une striole bien marquée, presque aussi longue qu'elle ; dorsales raccourcies, 1, 2 et 4 vers le milieu; cette dernière sourent interrompue; troisième très courte; humérale parallèle à la première dorsale, très rapprochée d'elle; subhumérale externe courte, basale; interne assez longue, à peine séparée de l'humérale; marginales entières; une taclıe pâle, souvent obscure à la base, couvrant toute l'élytre, sauf l'extrémité postérieure et la suture où avec celle du côté opposé elle circonscrit une double tache arrondie, l'une plus grande, scutellaire, l'autre plus petite, postérieure; l'épaule est brune, ainsi qu'un trait médian souvent nul. Pygidium densément ponctué, avec une impression superficielle de chaque côté de la base. Dans l'un des sexes on remarque au bout une impression en forme de V. Mésosternum arec quelques points épars ; strie interrompue. Irosternum à stries recourbées en dehors et divergentes en devant. Pattes ferrugineuses; jambes antérieures garnies de 9-10 petits denticules épineux.

Pérou; Bolivie ; Chili.

\section{S. LEPIDIS.}

Ater, cencus; untennis pedibusque piccis; fronte rugosa, stria indistincta; pronoto riliato, rugoso-punctato, area media lovi 
nitida, stria integra; elytris antice posticeque brunneis, in medio undulate flavis, punctulatis; humero, margine apicali, area magna subscutellari aliuque parvu juxtu loovissimis, nitidis; striis dorsalibus a brevissima, 1, 2 et 4 in medio abbreviatis, humerali subgemina, subhumerali utrarpe brevibus, suturali integra: mygitio dense punctato: prostemo striis antice recurvis; tibiis anticis 6-denticulutis. Longneur 3 mill.; largeur $21 / 4$ mill.

Noir, métallique. Antennes brunes. Front peu convexe, rugueusement ponctué; strie indistincte. Pronotum plus large que long, à peine bisinué à la base, avec une bordure étroite de points serrés, rugueux, 3-sinué, légèrement courbé et cilié sur les côtés, rétréci et échancré en devant, avec les angles arrondis, couvert de points très serrés, plus rugueux latéralement, avec un espace médian, irrégulier, lisse, luisant; strie marginale entière. Ecusson très petit, triangulaire. Elytres beaucoup plus longues que le pronotum, de sa largeur à la base, dilatées et saillantes aux épaules, rétrécies et droites au bout, obtuses, courtes, l'une ponctuation fine, assez serréc, rugueuse à la base, avec l'épaule, le bord latéral et l'apical, une plaque large, scutellaire entre la suturale et la quatrième dorsale, et une autre petite arrondie, adjacente, entre la deuxième et la quatrième dorsale, lisses et luisantes ; ces deux plaques sont d'un noir-bronzé, tandis que le reste de la surface est d'un brun-jaunâtre, traversé par une tache pâle, ondulée, rétrécie en dedans et atteignant la strie sulurale; stries marginales entières ainsi que la suturale; dorsales raccourcies, 1,2 et 4 au milieu, troisième à la base, quatrième réunie à la suturale; humérale bien marquée, géminée; sublıumérales courtes, obsolètes. Pygidium plane, rugueusement ponctué. Mésnsternum avec quelques points épars, bordé 
d'une strie interrompue. Prostermum à stries recourbées et divergentes en devant. Pattes brunes; jambes antérieures 7-8 denticulées; postérieures garnies de deux rangs de rares spinules.

La Plata ; Tucuman.

\section{S. RUBER.}

Orbicularis, niger, nitidus; antemis neditusque rufis; fronte punctulata, stria integra; pronoto basi et lateribus tenuiter punctato; clytris rubris margine obscuro, postice punctulatis, stria suturali intrgra, $4^{\text {a }}$ dorsali versus medium abbreviata, 2a 3 a que versus apiccm, 1a suvintegra; humerali basim haud attingente, cum subhumerali interna juncta; mygidio munctato; mesosterno lovi prostorno striis temuibus subintegris; tibiis anticis 4-5 dentatis. Long. 3 mill.; larg. $21 / 5$

Ovale, orbiculaire, légèrement convexe, noir, luisant. Antennes d'un brun ferrugineux. Front peu convexe, pointillé; strie non interrompue. Pronotum plus large que long, bisinué à la base, oblique et cilié sur les côtés, rétréci et échancré en devant, avec les angles arrondis, peu densément ponctué dans soii pourtour, un peu plus fortement sur le bord latéral ; strie marginale entière. Ecusson triangulaire, très petit. Elytres plus longues que le pronotum, de sa largeur à la base, à peine dilatées à l'épaule, rétrécies et coupées droites au bout, finement pointillées postérieurement, rouges, avec la suture et le bord infléchi obscurs; stries dorsales bien marquées; 1re entière, recourbée en dedans, $2^{\mathrm{e}}$ et $3^{\mathrm{e}}$ raccourcies vers le bout, $4^{\mathrm{e}}$ au milieu, arquée à la base et réunie avec la suturale; humérale courte, ne partant pas de la base, continuée, sans interruption, par sa sublıumérale interne presque jusqu’à l'extrémité ; subhu- 
mérale externe basale, courte; marginales entières. Pygidium ponctué. Mésosternum lisse, bordé d'une strie entière. Prosternum rétréci en devant; stries fines et entières. Pattes d'un brun ferrugineux; jambes antérieures garnies de 6 à 7 denticules, quatre apicaux assez forts; postérieures de deux rangs de rares spinules.

Tripoli (M. Reiche).

\section{S. PLLChellis.}

Ovalis, viridi-ceneus, nitidus; antennis pedibusque rufis; fronte punclulata, stria integra; monolo lateribus impresso, plagiatim punctuto; clytris maculu mugna triangulari rubra, postice intus punctutis, stria suturali integra, 1./1 dorsalibus pone medium abbrevialis, humerali cum mima juncla; subhumorali interna brevissima, externa nulla; pygidlo punctulato; mesosterno punctuto marginutoque; prosterno striis integris parallelis; tibiis anticis 5-denticulatis. Long. 2 3/4 mill.; larg. $13 / 4$ mill.

IIister pulchellus. F. Ent. Suppl., 3S, 16 (179S). - F. S. EI. 1, 88, 21. - Pkl. Mon. Hist., 76, 60, pl. 13, f. 5.

Ovale, légèrement convexe, vert-métallique, luisant. Antennes brunes. Front peu convexe, finement pointillé; strie entière. Pronotum plus large que long, lẻgèrement bisinué à la base, avec une étroite bordure de points assez forts; oblique sur les côtés, arec d'étroites impressions ponctuées, rétréci et échancré en devant, avec les angles arrondis; bord antérieur ponctué, ainsi que quelques plaques sur le disque; strie marginale entière. Ecusson très petit, triangulaire. Elytres plus longues que le pronotum, de sà largeur à la base, dilatées à l'épaule, rétrécies et coupées droit au bout, finement ponctuées par derrière, jus- 
qu'au milicu ou près de la suture; tache rouge, triangulaire, assez bien limitée, couvrant tout le disque; stries dorsales 1-4 formant un crochet à la base, raccourcies vers le bout; première uiı peu plus courte ; quatrième recourbée et réunie avec la suturale; humérale joignant la première dorsale en formant un angle avec elle; subhumérale interne courte, disjointe, externe mulle; marginales entières. Pygidium densément pointillé. Prosternum à stries parallèles, entieres. Mésosternum ponctué, ertièrement rebordé. Pattes ferrugineuses; jambes antéricures garnies de cinq denticules; postéricures de quelques spinules disposées sur deux rangs.

Inde: Tranquebar.

B. Elytres sàns taches bien limitées (18-120).

C. Fossettes antennaires ne remontant pas jusqu'au bord antéricur du prosternum, et séparées par un large intervalle. - Strie suturale à peine raccourcie par derrière (18-118).

D. Strie suturale non réunie à la $4^{\mathrm{e}}$ dorsale par un arc basal (18-44).

\section{$2^{e}$ GROUPE.}

18. S. DISCOIDALIS.

Convexus, nigro-violaceus, nilidus; clava rufa; fronte rugosa, stria interrupta; pronoto ciliato, lateribus rugoso-punctato. angulis anticis acutis; clytris opacis punctatis, humeris interstitio $4^{\circ}$ late, $2^{\circ}$ que anguste politis, stria subhumerali juncta,

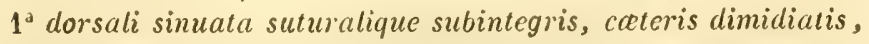
$3^{\circ}$ interrupta; pygidio punctatissimo; mesosterno marginato; 
prosterno angustuto, striis utrinque divergentibus; tibiis anticis ferrugineis, obtuse 7-Ilcuticulatis. Long. 7 mill.; larg. 5 1/2 mill.

Suprinus discoidalis. Le C. Hist Calif., v, 43, 6 (1851).

Ovale arrondi, convexe, noir-violet, assez luisant. Antennes brunes; massue ferrugineuse. Front plan, inćgal, avec un point sur le vertex, et une strie fine, obsolète à l'épistome. Pronotum très court, bisinué et bordé de points à la base, cilié et arqué sur les côtés, avec une impression et un large espace rugueusement ponctué, très rétréci et échancré en devant, avec les angles aigus; strie marginale fine, entière. Ecusson très petit. Elytres dilatées à l'épaule, rétrécies et subarrondies au bout, parcourues dans toute leur longueur par un espace obscur, cufoncé, ponctué, avec l'épaule, une petite plaque irrégulière sur le deuxième interstrie, et une grande bien limitée, occupant presque tout le quatrième, lisses et polis ; stries marginales entières, avec quelques rudiments d'une autre intermédiaire ; sublıumérale externe courte; interne longue joignant l'humérale; première strie dorsale sinueuse, entière; deuxième et quatrième dépassant le milieu; troisième plus courte, décomposée, pas d'arc basal entre la quatrieme et la suturale, quoique ces deux stries atteignent la base. Pygidium également et densément ponctué. Mésosternum large, entièrement rebordé, arec quelques points à peine visibles. Prosternum étroit ; stries entières, bien marquées, divergentes à chaque extrémité. Jambes antérieures ferrugineuses, garnies de sept denticules obtus.

Californie ( Vallecitas).

\section{S. VERSICOLOR.}

Soncer:us, nitidus, metallirus, aurco, viridi-rupreoversicolor; 
clava rufa; fronte punchutu, stria subintegra simuata; pronoto ciliato, lateribus strigoso impresso; clytris dense munctatis, striis dorsalibus 1-8 temibus dimidiatis, $4^{\mathrm{a}}$ multa, sutmali integra, subhumerali interna disjuncta; mygidio cequaliter dense rugoso punctato; mosterno lato, striis integris divergentibus; mesosterno stria integra, tibiis anticis valdè dilatatis, multi denticulatis. Long. 5 1/2 mill.; larg. 4 1/2 mill.

Ovale, arrondi, convexe, métallique, luisant, d'une teinte vert foncé en général, arec les élytres d'un bronze doré éclatant, le disque du pronotum cuivreux, les côtés bleus. Antennes rouges, scape foncé. Front plan, bosselé, ponctué; strie fine, entière, sinuée derrière l'épistome. Pronotum court, bisinué à la base, arqué et cilié sur les côtés, avec une large bordure de points rugueux, légèrement impressionnée, échancré et rétréci en devant, avec les angles arrondis ; strie marginale fine, complète. Ecusson très petit. Elytres un peu plus longues que le pronolum, de sa largeur à la base, très rétrécies et droites au bout, couvert d'une ponctuation serrée, rugueuse sur les interstries, fine en dedans, avec le voisinage de l'écusson lisse; strie humérale confuse, décomposée, subhumérale externe forte ; interne longue et disjointe; 1 -3 dorsales peu distinctes, dépassant le milieu; quatrième nulle; suturale entiere. Pygidium légèrement bombé, densément et également couvert de points rugueux. Mésosternum entièrement rebordé. Prosternum large ; stries entières, fort divergentes. Jambes antérieures brunes, garnies de douze à quinze fins denticules.

Cap de Bonne-Espérance.

\section{S. SEMIPUNCTATIS.}

Viridi-cyaneus, nitidus, metallicus; antennis fuscis: fronte 
punctata, stria tenui integra; pronoto ciliato lateribus impressis basique panctato; stria subintegra margini approximata; elytris postice pal ce punctulatis, interstitio $1^{\circ}$ strigoso, subhumerali externa distincta, interna disjuncta hamerali brevissima, dorsalibus 1-3 dimidlatis, $4^{2}$ utrinque, suturali basi, abbreviatis; myidio cequaliter punctato; proster no plano, striis parallelis; mesosterno marginato; tibiis anticis brunneis 6-denticulatis. Long 8 mill.; larg. 5 mill.

Hister semipunctatus. F. Ent. Syst. , 1,73, 4 (1792).-Syst. El., 1, 85, 10. - Duft. Fn. Austr., 1, 222, 17. - Sturm. Deuts. Fn., 1, 218, 16, pl. 17, c. - Illg. Mag. vi, 36, 10. - Payk. Mon. Ilist., 54,40, pl. 4, f. 8 .

H. cyanezs. Hbst. Nat. Syst., 4, 50, 22, pl. 36, 11 (1791). hossi, Mant. Fn. Eır., 1, 12, 19.

H. corulescens. E. H., 1, 73, 14 (1803). - - 2, 124.

Saprinus semipunctatus. Küst. Kæf, Eur., 7. 42.

Orale, allongé, pen convexe en dessus, d'un vert-bleu, métallique, luisant. Antennes brunes; funicule ferruginenx. Front bosselé, couvert de points inégaux, strigueux: strie fine, complète, sinuée derrière l'épistome. Pronotum assez court, bisinué ct bordé de points à la base, cilié, oblique, avec une impression rugueusement poncluée le long des côtés; rétréci et échancré en devant, avec les angles arrondis; strie maroinale forte, rapprochée du bord et presque entière. Ecusson très petit. Elytres un peu plus longues que le pronotum, dilatées à l'épaule, rétrécies et droites au bord apical; couvertes de points fins espacés dans leur moilié postérieure, et en dedans de la strie marginale, de strigosités obliques sur le premier interstrie; strie sublıumérale externe bien marquée; interne longrue, dis . jointe; humérale très courte; $\mathbf{1 - 4}$ dorsales alteignant le milieu; quatrième raccourcie à la base, ainsi que la sutu- 
rale. Ponctuation du pygidium égale, assez forte, peu serrée. Mésosternum paraissant lisse et entièrement rebordé. Prosternum plan; stries parallèles, complètes. Jambes antérieures brunes, garnies de six denticules obtus.

Cette espèce est fort répandue dans les collections. On la troure dans tout le bassin de la Néditerranée: Portugal; Espagne; France méridionale et Corse; Italie (Sardaigne, home ); Sicile; Allemagne; Autriche; Russie méridionale; Caucase; Sibérie ; Syric ; Egypte; Alger ; Tanger ; îles du Cap-Vert; quelquefois même au sénégal et au Cap de Bonne-Espérance.

\section{S. RASSELAS.}

Gyanco-violaceus, nitidus; antennis forrugineis; fronte pure tata, stria validu integra; pronoto lateribus impresso, late punctato; elytris postice dense munctatis, $1^{\circ}$ interstitio oblique strigoso; stria sublumerali extcrna distincta, interna ne!lla, dorsalibus 1-3 dimillatis, $4^{\text {a }}$ brevi sutureli integra; pygidio extus impresso, fortius quam in medio menctato; mesosterni strice interrupta; prostcmo pluno, striis paralletis; tibiis 6-clentirulatis.

Orale, peu convexe en dessus, vert-bleu métallique, violet sur les élytres, luisant. Antennes brunes. Front ruguensement ponctué, inégal ; strie entière, forte, arquée derrière l'épistome. Pronotum court, bisinué à la base, oblique sur les còtćs, rétréci et échancré en devant, avec les angles arrondis, largement et densément ponctué dans son pourtour, rugueux dans les impressions postoculaires; strie marginale forte, à peine raccourcie. Ecusson très petit. Elytres une fois et demie plus longues que le pronotum, do 
sa largeur à la base, rétrécies et coupées droit au bout, couvertes d'une fine ponctuation serrée, remontant sur les interstries, dout le premier est marqué de strigosilés obliques; strie marginale raccourcie à la base; subhumérale distincte; interne nulle ; lumérale courte; dorsales 1-3 raccourcies progressivement vers le milieu; quatrième n'atteignant pas la base; suturale entière. Pygidium impressionné de chaque côté, et plus fortement ponctué qu'au milieu. Mẻsosternum bordé d'une strie interrompue. Prosternum plan, à stries parallèles entières. Jambes antérieures brunes, garnies de six denticules assez forts.

Abyssinie.

\section{S. SPLENDENS.}

Viridi-ceneus, nilidus; antennis fuscis; fronte punctulata, stria integra; pronoto aureo, disco subtilissime puncticulato, lateribus punclatis anticeque impressis, stria abbrcviata; clytris dense punctalis, latcribus et circa scultllum sublovibus; $1^{\circ}$ interstitio oblique strigoso; striis suturali, $4^{\text {a }}$ dorsuli, humeralique basi, dorsalibush in medio postice abbreviatis; subhumerali interna nulla; pygidio impresso, grosse rugoso-punctato marginatoque; mosterno striis integris paralletis; tiliis anticis 7 denticulatis. Long. 8 mill. ; larg. 6 mill.

Hislor splendens. Payk. Mon. Hist., 53, 39, pl. 4, f. 7 (1811).

Saprinus splendens. Fahr. in Bohem. Ins. Calr., 1, 5ł0, 588.

Ovale, suborbiculaire, peu convexe; bleu verdatre métallique, assez luisant, doré sur le pronotum. Antennes brunes; funicule ferrugineux. Trete assez densément ponctuée; front presque plan; strie entière un peu sinucuse en devant. Pronotum beaucoup plus large que long, bisinué à la base, oblique et relevé sur les côtés, rétréri et échancré 
en devant, avec les angles arroudis ; couvert d'une ponctuation très fine sur ie disque, peu visible postérieurement, forte et même rugueuse dans une profonde impression le long des bords lateraux; strie marginale forte, raccourcie à la base. Ecusson très petit, triangulaire. Elytres plus longues que le pronotum, de sa largeur à la base, dilatées légèrement à l'épaule, rétrécies au bout, couvertes d'une ponctuation forte et assez serrée dans toute leur étendue, lisses sur les bords latéraux et dans le voisinage de l'écusson; premier interstrie sillonné de stries obliques; strie humérale droite, un peu raccourcic à la base, ainsi que la suturate et la ı̨uatrième dorsale; dorsale descendant jusqu'au milieu; subhumérale interne nulle; externe basale assez longue; marginales entières, avec leur intervalle ponctué. Pygidium rebordé, impressiontié à la base, de chaque côté, rugueusement et très fortement ponctué, élevé et moins fortement ponctué au bout. Prosternum à stries entières, presque parallèles. Mésosternum entièrement rebordé. Jambes antérieures brunes, garnies de sept dentelures assez fortes.

Cap de Bonne-Espérance; Cafrerie (Natal); Guinée.

\section{S. SPECIOStS.}

Viridiconeus, nitidus; antennis fuscis; fronte punctulata in medio impressa; pronoto lateribus anticis impresso, punctatis, stria abureviata; clytris postice interstitiisque punctutis $1^{\circ}$ strigoso, striis suturali, $4^{a}$ dorsali, humerali ct marginati antice, dorsalibus in medio postice abbrevintis; pygillio utrinque impresso rugoso punctato et marginuto; prosterno striis purallelis subintegris; rnesosterno stria interrupta; tibiis anticis 6-denticulatis. Long. 6 mill.; larg. $41 / 2$ mill.

Saprinus speciosus. Er. Jahr., 179, 16 (183/1). 
Ovale, peu convexe, vert-métallique, doré sur le pronotum et la tête, luisant. Antennes brunes. Tête ponctuée; front peu convexe, impressionnè au milieu; strie forte, entière, semi-circulaire; épistome bombé. Pronotum plus large que long, bisinué à la base, oblique et subsinué sur les côtés, échancré et rétréci en devant, avec les angles arrondis; couvert d'une ponctuation à peine risible sur le disque, forte latéralement, et même rugueuse au fond de l'impression occupant la moitié du bord antérieur; strie marginale forte, non interrompue en devant, s'éloignant un peu du bord latéral, et s'arrêtant aux deux tiers. Ecusson très petit, triangulaire. Elytres plus longues que le pronotum, de sa largreur à la base, dilatées à l'épaule, rétrécies au bout, couvertes d'une ponctuation assez forle et médiocrement serrée qui s'étend sur tous les interstries et sur le disque postérieur; stries dorsales s'étendant jusqu'au milieu, la quatrième est raccourcie à la base; la premièrc est accompagnée d'un trait; le premier iuterstrie sillonné de stries obliques assez serrées; suturale atteignant presque la base; humérale presque droite, commençant assez loin de la base, et descendant aussi loin que la première dorsale; subhumérale interne nulle; externe courte, basale; marginale interne un peu raccourcie. Pygidium rebordé et impressionné latéralement, fortenıent et même rugureusement ponctué, avec une bande longitudinale lisse. Prosternum à stries parallèles, presque entières. Mésosternum imponctué; strie marginale interrompue. Pattes brunes; jambes antérieures garnies de six dentelures

Inde (Pondichéry).

24. S. OVALis.

Viridi-ceneus; antennis pedibusque brunneis; fronte punctata 
stria integra; pronoto lateribus anticis profunde impresso punctato, stria marginali abbreviata; slytris punctatis, interstitiis rugosis, stria humerali $1^{a}$ que dorsali in medio abbrevial is, 2-3 confusis, $4^{a}$ mulla, suturali integra, subhumerali externa brevi, intcrna nulla; mygidio utrinque fortiter punctato; meso. terno marginato; prosterno striis subparallelis; tibiis anticis 6-denticulatis. Long. 6 mill, ; larg. $41 / 2$.

Ovale, peu convexe, d'un vert-métallique, Juisant, doré sur le pronotum. Antennes brunes. Front densément pointillé; strie entière. Pronotum court, bisinué et bordé de points à la base, oblique sur les côtés, avec une forte impression antérieure, rugueusement ponctuée; rétréci et échancré en devant, avec les angles arrondis ; strie marginale très raccourcie à la base. Ecusson très petit. Elytres un peu plus longues que le pronotum, de sá largeur à la base, rétrécies et coupées droit au bout; couvertes dans tout leur milieu de points assez serrés, rugueux sur les interstries; bord infléchi, pointillé; strie subhumérale externe très rapprochée de la marginale; interne nulle; humérale droite, descendant jusqu'au milieu de l'élytre, ainsi que la première dorsale, 2-3 confuses, un peu plus courtes; quatrième nulle ou obsolète; suturale à peine raccourcie. Pygidium rebordé, impressionné à la base, de chaque côté, et plus fortement ponctué dans l'impression que sur le reste de sa surface. Mésosternum entiirement rebordé. Prosternum plan, avec les stries subparallèles. Jambes bruries; antérieures garnies de six assez fortes dentelures.

Inde ; Chine.

\section{S. RLEGANS.}

Eneus, nitidus; antennis fuscis; fronte punctulata; pronoto lateribus antice impresso-rugosis, postice parum dense mune- 
tatis, stria abbreviata; clytris postice disco punctatis, $1 \cdot$ intter'stitio rugulis transversispurcioribus; dorsalibus striis postice in medio, 4" etiam antice, humerali, marginali suturalique abbreviatis; pygidio basi utrinque impresso, rugoso punclato marginatoque; mrosterno striis purallelis integris; mesosterno stria interrupta; libiis anticis 6-denticulatis. Long. 6 mill.; larg. 4 1/2 mill.

Hister elegans. Pkl., Mon. Hist., 57, 42, pl. v, f. 1 (1811).

Vert-métallique, brillant, bleuâtre sur les élytres, doré sur la tête et le pronotum. Antennes brunes. Front peu convexe, ponctué; strie entière. Pronotum plus large que long, bisinué à la base, oblique sur les côtés, rétréci et échancré en devant, arec les angles arrondis; marqué d'une impression latérale rugueusement ponctuée qui occupe la moiliê antérieure; strie marginale non interrompue, raccourcie à la base. Ecusson petit, triangulaire. Elytres plus longues que le pronotum, de sa largeur à la base, dilatées faiblement à l'épaule, rétrécies au bout; ponctuées postérieurement sur le disque, jusqu'au milieu des interstries; stric marginale interne raccourcie à la base, ainsi que la suturale, l'humérale et la quatrième dorsale; subhumémale externe basale, courte; interne nulle; dorsales finissant au milieu; première et troisième un peu plus courtes que les deux autres; premier interstrie sillonné de rides ob!iques bien marquées, peu nombreuses. Pygidium relordé étroitement, fortement ponctué, avec une impression de chaque côté de la base, rugrueusement ponctué. Prostcrnum à stries entières, parallèles. Mésosternum eutièrement rebordé. Jambes brun de poix ; antéricures garuies de six dentelures accompagnées vers la cuisse de quelques petils denticules.

Cap de Bonne-Espérance; Sénégal; Abyssinie. 


\section{S. CYANETS.}

Viridi-cyaneus, nitens; antennis fuscis; fronte vix punctulata, stria inlegra; pronolo cupreo, utrinque impresso rugoso, stria marginali haud abbreviata; clytris postice dense munctulatis, $1^{\circ}$ interstitio strigoso, stria suturali antice, 1-2 dorsalibus postice in medio abbreviatis, $3 \mathrm{a}, 4^{\mathrm{a}}$ arcnata, brevissimis, subhumerali externa distincta, interna subjuncta; mygidio hand impresso, dense ét cequaliter punctulato; mesosterno marginato; mosterno angusto, striis subparallelis; tibiis anticis 6-7 obtuse denticulatis. Long. 7 mill.; larg. 4 mill.

Hister cyanens F. Syst. Ent., 52, 3 (1775). - Spec. Ins., i, 60, 3. - Mant. 1, 32, 4. - Ent. Syst. 73,6 - Syst. El., 1, 86, 13. Oliv. Enl., 1, 8, 8, 6, p. 3,17 .

Saprimus cyaneus. Er. in Jah", , 1, 178, 14.

Ovale, allongé, peu convexe en dessus, vert bleu mélallique, cuivreux sur le pronotum, luisant. Antennes brunes. Front plan, à peine pointillé ; strie entière, bien marquée. Pronotum court, bisinué à la base, oblique sur les côtés, arec une impression rugueusement ponctuée, rétréci et échancré en devant, avec les angles arrondis; strie marginale entière. Ecusson petit. Elytres une fois et demie plus longues que le pronotum, de sa largeur à la base, rétrécies au bout; couvertes sur leur tiers postérieur de points fins et serrés, sur le premier interstrie, de fines strigosités; strie suturale raccourcie à la base; subhumérale externe distincte; interne longue, joignant presque l'humérale; jremière et deuxième dorsale raccourcie au milieu; troisième basale, ainsi que la quatrième qui est arquée vers l'écusson, très courte. Pygidium convexe, sans impression, densément et égalemeul pointillé sur toutesa surface. Mésosternum entièrement relordé. Prosternum plan, étroit; stries 3e Sórie, Tune III. 
entières, rapprochées, presque parallèles. Jambes antérieures garnies de six denticules obtus.

Nouvelle-IIollande (Port-Jackson; Swan-River); VanDiemen.

\section{S. TASMANiCLS.}

Nitidus, fronte punctulata; pronoto cneo, lateribus imeressorugoso, basi punctato; elytris ceruleis, postice, disco lateribusque punclulatis, stria sulurali antice, dorsalibus postice abbreviatis, $3^{a}$ multo breviori; mygidio dense munctato, area media levi; mostcrmo striis integris; mesosterno punctulato marginatoque. Long. 6 mill. ; larg. 4 1/2 mill.

Ovale, peu convexe, luisant, noir en dessous, bronzé sur la tête et le pronotum, bleu sur les élytres. Antennes brunes. Front densément pointillé, ainsi que l'épistome; strie entière, bien marquée, presque droite en devant. Pronotum plus large que long, largement bisinué et bordé de points à la base, oblique et subsinué sur les côtés, avec une assez profonde impression rugueusement ponctuée, qui commence derrière les yeus et s'étend presque jusqu'à la base, rétréci et échancré en devant, avec les angles arrondis; strie entière. Ecusson triangulaire, très petit. Elytres plus longues que le pronotum, de sa largeur ì la base, dilatées à l'épaule, rétrécies au bout; stries suturale raccourcie à la base; quatrième dorsale arquée vers la suturale, dépassant le milieu; deuxième aussi longue ; première phus courte; troisième encore plus; premier interstrie sillonné de stries obliques; humérale bien marquée, bifide; subhumérales assez longues; interne séparée; marginales entières, bordées de points fins, peu serrés, ainsi que la partie postérieure du disque. Pygidiurn densément ponctué, 
avec un espace lisse au milieu. Prosternum pointillé ; stries fortes, entières, se rejoignant en devant. Mésosternum ponctué, bordé d'une strie non interrompue. Jambes antérieures garnies de sept ou huit petiles dentelures; postérieures de deux rangées de rares spinules.

Tasmanie; Nouvelle-Hollande (MM. Guérin et de Laferté).

28. S. Cyayelus.

Viridi-metallicus, nitidus; antennis brunncis; fronte vixpunctulata, stria circulari integra; pronoto ceneo, lateribus retgoso impresso; clytris cyaneis, basi et apice punctatis, striis dorsalibus 1-2 pone modium, $3^{\text {a }}$ et humcrali in modio abbreviatis, $4^{\text {a }}$ brevi arcuata, suturali basim non attingente, subhumerali interna longa, disjuncta; pygidio requatiter punctato; mesosterno marginato; prosterno plano, striis validis subparallelis; libiis anticis 6-7 donticulatis. Long. 5 mill.; larg. 4 mill.

Ovale, allongé, peu conrexe, vert-métallique luisant, bronzé sur le pronolum et bleu sur les élytres. Antennes brunes. Front plan, à peine visiblement pointillé ; strie circulaire entière, bien accusée. Pronoturn court, bisinué et étroitement bordé de points à la base, oblique, imıressionné et forlement ponctué le long des côtés, rétréci et échancré en devant, avec les angles obtus. Ecusson très petit. Elytres plus longues que le pronotum, de sa largeur à la base, dilatées à l'épaule, rétrécies et droites au bout, couvertes de points le long de la strie marginale, à la base des interstries, et sur le tiers postérieur de la suture à la première dorsale ; subhumérale externe bien marquée; interne longue et disjointe; humérale partant de la base et atteignant le milicu, ainsi que la iroisième dorsale; premic̀re et deuxiome ın 
peu plus longues, tontes fortes et crénelées; quatrième réduite à un court are iransversal; suturale raccourcic. Pygidium plan, couvert de points également espacés et assez serrés. Mésosternum à peine ponctué latéralement, entièrement rebordé. Ironolum plan, étroit; stries fortes et entières, à peine sinuées. Jambes antérieures dilatées, et garnies de 6-7 denticules.

Australie.

\section{S. LETUS.}

Viridi-metallicus, nitidus; anternis brunneis; fronte puncticuluta, stria integra; monoto cupreo, lateribus impressis basique menctato; elytris postice dimidiato-punctatis, striis 1-4 clorsalibus pone medium, suturali antice abbreviatis, subhumerali interna longu cum humerali juncta; pygidio aqualiter et parnem dense punctato; mesostcrno marginato; prostcrno plano, striis integris ntrimque subdivergentibus; tibiis anticis, 6.7 denticulutis. Long. $41 / 2$ mill. ; Jarg. 3 1/4 mill.

Hister cyuneus. Payk. Mon. Hist., 56, 41, pl. 5, f. 2 (1811).

Suprimus letus. Er. in Jahr., 1, 1/9, 15 (1834).

Ovale, allongé, peu convexé, d'un vert-métallique, luisant, cuivreux sur la tête et le pronotum. Antennes d'un brun-ferrugineux; scape foncé. Front plan, assez densément pointillé; stric entière, bien marquée. Pronotum court, bisinué et étroitement bordé de points à la base; oblique sur les côtés, avec une impression longitudinale, marquée de points assez gros et presque rugueux, rétréci et échancré en devant, avec les angles arrondis; strie marginale presque cntière. Ecusson très petit. Elytres un peu plus longues que le pronotum, de sa largeur à la base, faiblement dilatées à l'épaule, rétrécies el droites au bout; 
couvertes d'une assez forte ponctuation peu serrée, de la suture à la première dorsale, remontant au-delà du milieu, dans le quatrième interstrie; stries fortes, crénelées; subhumérale externe bien marquée; interne longue et jointe à l'Jumérale; dorsales 1-3 dépassant le milieu; quatrième presque aussi longue, arquée à la base, vers l'écusson; suturale raccourcie à la base. Pygidium légèrement bombé, couvert de points espacés, uniformes. Mésosternum lisse, entièrement rebordé. Prosternum plan, assez large; stries entières, bien marqquées, un peu divergentes. Jambes antérieures élargies, garnies de 6-7 denticules assez forts.

Australie; Tasmanie.

30. S. subustus.

Nitidus, subtus niger, sumra pronoto obscure ceneo; elytris viridibus apice fulvis; antonnis pelibusque brumneis; fronte punctulata, stria integra; pronoto busi lateribusque munctatis, subimpresso, stria abbreviata; elytris sat dense punctatis, ad scutellun et humeros subtilius, stria sulurali subintegra, dorsalibusctualibus dimidiatis, humerali cum subhumeralicoennte; pygidio tenuitor punctato; prosterno striis utrinque divergentibus; tibiis anticis 7-S denticulatis. Longueur 4 1/2 mill.; larg. 3 mill.

Ovale allongé, légèrement convexe, luisant, noir en dessous. Pronotum cuirreux, obscur. Elytres d'un vert bleuâtre, avec le bord apical roux. Antennes brunes. Front légèrement convexe, couvert de points fins et assez serrés ; strie fine, entière. Pronolum beaucoup plus large que long, bisinué à la base, oblique sur les côtés, échancré et à peine oblique en devant, avec; les angles arrondis; ponctué sur les côtés et le long du bord postérieur, avec une faille im- 
pression postoculaire; strie marginale raccourcie à la base. Ecusson très petit, triangulaire. Elytres courtes, à peine plus longues que le pronotum, de sa largeur à la base, peu dilatées à l'épaule, et légèrement rétrécies au bout, couvertes en entier d'une ponctuation serrée, plus fine à la base, et sur les cotés ; strie suturale entière quoique affaiblie à la base, presque réunie avec la quatrième dorsale; toutes les dorsales à peu près d'égale longueur, dépassant le milieu; humérale jointe à la subliumérale interne, et formant un coude ou point de jonction; subhumérale externe courte, basale; marginales entières. Pygidium assez densément, mais finement ponctué. Mésosternum avec des points à peine distincts, entièrement rebordé. Prosternum large, l'étréci au milieu; stries divergentes de part et d'autre. Pattes d'un brun ferrugineux; jambes antérieures garnies de six a sept petits denticules épineux; postérieures de deux rangées de spinules.

Indes (MM. de Laferté, Deyrolle).

\section{S. A:RICOLLIS.}

Viridi cencus, nitidus; antennis brumeis; fronte punctata; stria integra; pronoto cupreo, lateribus anticis rugoso impressi.s basique punctulis; clytris fortiter ot parum dense undique punctatis, lateribus al cuque sculellari locibus; stria suturali antice, 4 torsalibnes postice pone medium ubbreviutis; humerati cum subhumerali juncta inegris ; pygidio sat elense punctato; mesostcrno nienginato sublevi; prosterno striis inlegris, subparallelis; libiis anticis 6 denliculalis. Longueur 5 1/2 mill.; larg. 3 1/2 mill.

Ovale allongé, convexe, luisant, métillique, cuivreux sur la tête et le pronotum, vert doré sur les élytres. Antenues 
brunes; funicules ferrugineux. Front plan, ponctué ainsi que l'épistome; stric entière, bien marquée, presque droite en devant. Pronotum beaucoup plus large que long, bisinué à la base et bordé étroitement de points, oblique, subsinué sur les côtés, avec une impression ponctuée, commençant derrière les yeux et ne dépassant guère le milieu, rétréci et échancré en devant, avec les angles arrondis; lisse sur le disque ; strie marginale entière. Ecusson petit, triangulaire. Elytres courtes, un peu plus longues que le pronotum, de sa largeur à la base, dilatées à l'épaule, rétrécies postérieurement; stries ponctuées, bien marquées; suturale raccourcie vers la base; dorsales s'étendant au-delà du milieu, 1 et 3 un peu plus courtes; quatrième arquée vers l'écusson; humérale jointe à la subhumérale interne et atteignant presque le bout; marginales entières; interne bordée de points; ponctuation des élytres peu serrée, mais forte, les couvrant en entier, a l'exception du bord latéral et d'un espace juxta-scutellaire lisses. Pygidium légèrement convexe, assez densément et uniformément ponctué. Prosternum à stries subparallèles, entières, réunies par devant. Mésosternum à peine visiblement pointillé, entièrement rebordé. Jambes d'un brun de poix ; antérieures garnies de six dentelures.

Iles Philippines.

\section{1 bis. S. PECUINCS.}

Niger, ceneus, nitidus, metallicus; antennis fuscis; fronte punctata, stria tenui interrupta; pronoto subimpresso, disco subtilius, basi et lateribus fortius punctato, stria marginati integra; elytris valide, substrigose punctatis, juxta scutellum et exterius tantum levibus, striis $1-4$ dorsalibus cequaliter dimi- 
diatis, subhumerali interna disjuncta, suturali abbreviata; pygidio dense, mesosterno submarginato parce, prosterno concavo subtiliter punctatis, striis valde divergentibus; tibiis brunneis, 6-7 denticulatis. Long. 5 mill. ; larg. $31 / 2$ mill.

Ovale, oblong, peu convexe, vert foncé, métallique, luisant. Arıtennes brunes. Frout légèrement bombé, densément et rugueusement ponclué; strie fine, sinuée et obsolète lerrière l'épistome. Pronotum court, bisinué à la base, oblique sur les côtés, rétréci et échancré en devant, avec les angles arrondis, légèrement impressionné derrière les yeux; couvert de points fius sur le disque, assez gros le long de la base et sur les côtés; strie marginale entière. Ecusson très petit. Elytres un peu plus longues que le pronolum, de sa largeur à la base, rétrécies et droites au bout, couvertes d'une ponctuation forle, assez serrée et comme strigneuse, ne laissant libre que le bord latéral et le voisinage de l'écusson; stries dorsales 1-4 forles, parallèles, progressirement raccourcies vers le milieu; suturale un peu raccourcie à la base; subhumérale csterne courte; interne disjointe; humérale décomposéc. Pygidium légèrement bombé, assez densément et uniformément ponctué. Mésosternum court, avec des points espacés, bien marqués, et une stric un peu interrompue. Prosternum pointillé, large, faiblement concave; stries entières, fortement divergentes, et un peu relevées en devant. Jambes brunes ; antérieures garnies de 6-7 denticules.

Chine (M. Buquet).

32. 5. FuLfibicolis.

Viridi reneus: nitidus, monoto rumpon iutilo, tihiis et an- 
tennis rufis; fronte rugoso punctata, stria integra; pronoto late. ribus impressis basique punctato, stria subintegra; elytris dense punctatis, versus humerum rugose; area scutellari iovi, stria suturali apicali, 2 et 4 dorsalibus brevibus, 1 et 3 suturalique mullis; marginali parum abbreviata; pygidio dense punctato; prosterno antice dilatato, bistriato, mesostcrnoque punctatis. Long. 6 mill. ; larg. 4 mill.

Ovale allongé, légèrement convexe, d'un vert doré luisant, avec le pronotum cuivreux, resplendissant. Antennes rouges; scape brun en dessus. Front inégal, rugueusement ponctué, ainsi que l'épistome; strie entière, avancée sur l'épistome. Pronotum plus large que long, bisinué et bordé de points à la base, légèrement courbé et couvert de points sur les côtés, avec une impression partant de la fossette postoculaire, presque rugueuse, n'atteignant pas la base; disque à peine distinctement pointillé; strie marginale presque entière. Ecusson très petit, triangulaire. Elytres courtes, à peine plus longues que le pronotum, de sa largeur à la base, dilatées à l'épaule, rétrécies au bout, entièrement couvertes d'une ponctuation serrée, rugueuses à la base, vers l'épaule, lisses latéralement, ainsi que sur un espace auprès de l'écusson; strie suturale à peine commencée; quatriène dorsale raccourcie au tiers postérieur ; deuxième beaucoup plus courte, ne partant pas de la base; première, troisième et lummérale nulles; subhumérales courtes, bien marquées; Inarginale interne raccourcie. Pygidium assez convexe et densément ponctué. Propygidium largement découvert et presque rugueux. Prosternum dilaté en devant, pointillé, bordé de deux stries entières, sinuées. Mésosternum avec des points épars, gros; strie non interrompue. Jambes ferrugineuses; antérieures garnies de six dentelures. 
Madlagascar. (Je n’ai vu, de cette magniíque espèce, que deux individus, l'un de la collection du Museum d'Histoire naturelle ; l'autre appartenant à 11 . Deyrolle.)

\section{S. penctatissimus.}

Sublus niger nitidus, supra anco-niger, rugoso punctatissimus; antentis brumeis; froute planu, striainlervrupta; pronoto lateribus subimpresso, marginato; elytris striis dorsalibus 1-4 vix dimidialis distinctis, sumurali antice abbreviata, subhumerali interna disjuncta; mesosterno marginalo parce, prosterno plano, angusto; clytris sublilius punctatis, striis subparallelis; pedibus rufo brumncis; tibiis anticis 5-dentatis. Long. 6 mill. ; larg. $31 / 2$.

Saprinus menctatissimus. Er. in Jahr., 1, 181, 19 (1834).

Ovale, court, presque carré, faiblement convexe, noir luisant en dessous, d'un bronzé métallique très sombre en dessus, avec une ponctuation très serrẻe et rugueuse, uniforme sur toute la surface. Antennes d'un brun ferrugineux. Front plan ; strie frontale se continuant sur l'épistome, interrompue. Pronotum court, bisincié à la base, arqué sur les côtés, un peu rétréci et échancré en devant, avec les angles très obtus. Ecusson très petit. Elytres un peu pius longues que le pronotum, le sa largeur à la base, saillantes à l'épaule, presque parallèles; stries dorsales 1.4 assez bien marquées, également raccourcies avant le milien; quatrième arquée vers l'écusson; suturale n'atteignant pas la base ; sublumérales bien marquées; interne disjointe. Pygidium bombé au bout. Prosternum étroit, plan, à stries presque parallèles, finement pointillé. Nésosternum entièrement rebordé, avec des points très espacés. Pattes d'un brun ferrugineux. Jambes antéricures asscz dilatées, garnies de cinq fortes dentelures.

Egypte. 


\section{S. LLGENS.}

Nigro-metallicus subnitidus, undique punctatissimus; pronoto lateribus impresso rugoso, disco lavi; elytris strigosis, spatio subscutellari humeroque lovi-politis, stria suturaliantice abbreviata, dorsalibus 1-4 temibus dimidiatis, subhumerali interna humerali juncta; mesosterno marginato marce, prosterno lato subtilissime mmctulatis, striis divergentibus; tibiis anticis 10-12 denticulatis. Long. \$-5 1/2 mill. ; larg. 6-4 mill.

Saminus lugens. Er. in Jahr., 1, 181, 20 (1834). - Le Conte, N. Anér., Hist. 4 1, 3, pl. 5, 4. - N. Coléop. Califor., 43, 8.

S. Galifornicus. Mannerh. in Bullet. Mosc., 2, 259, 185 (1843).

Ovale, oblong, peu convexe, noir-métallique. Front presque plan, densément ponclué ; strie fine, interrompue derrière l'épistome. Pronotum court, bisinué à la base, oblique sur les rôtés, rétréci el éclıancré en devant, avec les angles très obtus, et marqués d'une impression assez marquée, lisse et couvert de points très fins sur le disque, très gros et rugueux à la base et sur les côtés ; strie marginale entière. Ecusson très petit. Elytres un peu plus longues que le pronotum, dilatées à la base, à peine rétrécies au bout, entièrcment et rugueusement ponctuées, avec l'épaule et un espace juxta-scutellaire lisse et luisant, bien limité; strie suturale raccourcic à la base; dorsales fines, peu distinetes, dépassant le milieu; subhumérałe externe courte; interne longue, jointeàl'humérale. Pygidium bombé, couvert d'une ponctuation uniforme et très serrée. Mésosternum avec des points espacés et une margrinale entière. Prosternum large, pointillé; stries divergentes. Jambes antérieures dilatées, garnies de 10-12 denticules.

Californie ; Nouveau-Mexique (Santa-Fé); Orégon ; Etats-Unis (.Iissouri; Monts-Rocheux); Mexique (Mexico, ()rizaba); Guatemala. 


\section{S. DETERSUS.}

Niger, parum nitidus, supra punctatissimus, pronoti disco, area elytrorum sculellari lata aliaque minuta $22_{\mathrm{i}}$ interstitii lavibus, stria frontali interrupta; marginali pronoti integra, suturali antice, dorsalibus in medio postico, humerali subhumerali juncta ultru medium abbreviatis; mesosterno forticer prostcrnoque subtilissime punctatis, striis utrinque divergentibus. Long. 7 mill. ; larg. 4 1/2 mill.

Hister detersus. Illig., Mag., vi, 36, 11 (1807). - Ghl. Ins. Suec., 4, 265, 16-17.

Saprimus melas. Küist. Kæf. Eur., 17, 19 (1849).

Ovale, peu convexe, noir, médiocrement luisant en dessous, rugueusement et très densément ponctué, opaque en dessus, avec le disque du pronotum, une large tache subscutellaire entre la quatrième dorsale et la suturale, jusqu'au milieu des élytres, et une autre plus petite, entre les deuxième et troisième stries dorsales, séparée de la précédente, enfin le hord latéral et l'épaule lisses, luisants. Antennes brunes; funicule ferrugineux. Front presque plan; strie fine, obsolète ou interrompue derrière l'épistome. Pronotum beaucoup plus large que long, bisinné à la base, oblique et légèrement arqué sur les côtés, rétréci et échancré en devant, avec les angles très obtus; strie marginale entière, rapprochée du bord. Ecusson très petit, triangulaire. Elytres plus longues que le pronotum, de sa largeur à la base, dilatées à l'épaule, rétrécies au bout ; strie suturale raccourcie en devant, souvent interrompue avant l'angle sutural; dorsales ponctuées, atteignant le milieu; quatrième arquéc à la base, vers l'écusson; humérale moins forte, un peu plus ohlique, unie a la sublummérale interne. et ensemble dépassant la première dorsale; exterue courte, 
basale; marginales entières. Mésusternum ponctué, entièrement rebordé. Prosternum finement pointillé, rétréci au milieu; stries dirergentes aux deux extrémités et recourbées en devant. Pattes d'un brun de poix ; jambes antérieures garnies de 7-8 denticules épineux.

On troure cette espèce dans tout le littoral de la Méditerranée: le midi de la France; cn Portugal; Espagne; Sicile ; Grèce ; Oran ; Alger ; Sénégal. Gyllenlall le signale comme ayant été trouré en Suède (Smoland).

\section{S. OREGONEISIS.}

Niger, nitidus, metallicus; fronte mana, stria circulari integra; pronoto latcribus impressis basique punctato, stria marginali integra; clytris cxtus et postice, interstitiis usque in medio, dense punctatis, striis dorsalibus crenalis 1-4 validis dimidiatis, suturali antice abbreviata, subhumerali interna disjuncta; rygidio densissime, mesosterno marginato parce, prosternoque tenuissime punctatis, striis anterius divergentibus; libiis brumeis, anticis $8-9$ denticulatis. Long. 5 1/2 mill.; larg. 3 3/4 mill.

Saprinus Oregonensis. Le C., N.-Amér. Hist., 45, 11, pl, 5, 12 (1845). - Le C.. Calif. Col. 5, 43, 9 .

Ovale, oblong, peu convexe. noir, luisant. Front plan, paraissant à peine pointillé; strie bien marquée, entière. Pronotum court, bisinué et bordé de points à la base, oblique, avec une impression ponctuée le long des côtés, rétréci et échancré en devant, avec les angles obtus; strie marginale entière. Ecusson trìs petit. Elytres plus longues que le pronotum, de sa largeur à la hase, un peu saillantes a l'épaule, rétrécies au bout, couvertes postéricurement 
d'une ponchuation serrée, presque rugueuse, qui remonte jusque sur les interstries et le long de la marginale; stries dorsales 1-4 crénelées, fortes, parallèles, égales cutre elles, et raccourcies un peu au delà du milieu; quatrième arquée vers l'écusson; suturale n'alteignant pas la base; sublıumé. rales bien marquées; interne disjointe. Pygidium uniformément et très densément ponctué. Mésosternum avec des points espacés et une strie cntière assez éloignée de la marge. Prosternum sinué, finement pointillé ; stries divergentes et remontant en devant. Jambes antérieures brunes, garnies de 8-9 denticules.

Etats-Unis (Orégon); Culifornie (San-Francisco, Diégo); Nouveau-Mexique.

\section{S. Gavgeticus.}

Niger, nitidus, antennis pedibusque piccis; fronte subrugosa, stria interrupta; pronoto tateribus impresso-rngoso, basi munctato; clytris margine inflexo et disco nostico subtiliter punctulatis, stria suturali antice abbreviuta, dorsalihus versus medium abbreviatis humerali cum subhumerali interna juncta, marginali interna basint sequente, meso-prosternoque punctulatis, striis parallelis; tibiis anticis 7 denticulatis. Long. 8 mill.; larg. 5 mill.

Ovale allongé, assez convexe, noir, très luisant. Antennes noir de poix; massue brune. Front assez bombé, rugueusement ponctué; strie bien marquée, interrompuc à l'éfistome. Pronotum court, beaucoup plus large que long, finement pointillé, bisinué et bordé de points à la base, oblique sur les côtés, arec une large impression fortement rugueuse, très rapprochée du bor!, rétréci et échancré en devant, avec les angles arrondis; stric marginale euliere. 
Ecusson tris petit, trianguliare. Elytres plus longues que le pronotum, de sa largeur à la base, faiblement dilatées à l'épaule et rétrécies postérieurement, courertes sur le disque, à la partie postéricure, de points fins, peu serrés, ainsi que le bord infléchi ; premier interstrie légèrement sillonné de strioles obliques; strie suturale bien marquée, assez fine, ainsi que les autres, se continuant au hord apical, raccourcie vers la base; dorsales 1-2 atteignant le milieu, quatre plus courles et trois encore plus; humérale oblique, forte, bifide au bout, et joignant par une de ses brauches la subhumérale interne qui est presque entière; exterue basale; marginale non interrompue, suivant assez longtemps le bord basal. Pygidium bombé; ponctuation plus forte et un peu plus serrée que celle des élytres. Mésosternum entièrement rebordé, finement pointillé. Prosternum pointillé de même, subparallèle, plan; stries fortes, entières, se rejoignant en devant en formant un petit arc. Pattes noir de poix ; jambes antérieures garnies de sept denticules épineux, assez forts ; postérieures de denx rangées de rares spinules.

8. Profonde impression médiane sous le métasternum et le premier segment de l'abdomen.

Inde ; Syrie (Damas, Saïda).

\section{S. PHARAO.}

Piceus, nitidus; antemis "ufis tibiisque brumcis; fronte subrugoso-punctata, stria obsoleta simuata; pronoto lato, ciliato, timbo punctato biimpresso; clytris disco purce punctato, stria suturati antice abbreviuta, dorsulibus vix dimidiatis, alternatim paulo longioribus; lumeruli bifuda, subhumeruli interna mulla; pygidio clevato, aqualiter punctato; mesosterno sublavi, stria subinterrupta; prosterno attenuato, striis convergentibus, junctis; tibiis anticis 5 dentatis. I.0ng. 6-7 mill.; larg. 4-5 mill. 
Ovale allongé, assez convexe, brun de poix assez luisant. Antennes rousses; scape brun. Front assez bombé, couvert de points forts, peu réguliers, rugueux; strie obsolète en devant, formant une avance anguleuse sur l'épistome. Pronotum cilié, court, beaucoup plus large que long, bisinué à la base, à peine oblique sur les côtés, peu rétréci et échancré en devant, avec les angles larges et arrondis, biimpressionné derrière les yeux, largement couvert sur les côtés de points assez forts, espacés ; strie marginale entière. Ecusson très petit, triangulaire. Elytres courtes, plus longues que le pronotum, de sa largeur à la base, dilatées à l'épaule, rétrécies ensuite jusqu'au bout, courertes de points épars, lisses à l'épaule el autour de l'écusson; stries fines, irrégulières; suturale continuée au bord apical, remontant jusqu'au tiers antérieur; dorsales raccourcies un peu avant le milieu; 1-3 un peu plus longues que deux et quatre; humérale parallèle, divisée en deux branches; subhumérale interne nulle; externe courte; marginale forte, entiere. Pygidium bombé, couvert d'une ponctuation régulière, médiocrement serrée, assez forte, plus fine vers l'extrémité. Mésosternum à peine visiblement pointillé; strie subinterrompue. Prosternum plan, dilaté à la base, amincie insensiblement; stries assez rapprochées, et se réunissant en devant. Pattes brun-ferrugineux; jambes antérieures garnies de cinq lents fortes et espacées.

Dans l'un des sexes le bout du pygidium est très élevé st sans impression, dans l'autre, il est impressionné.

Egspte; Syrie (Damas, Saïda).

39. S. CONCINNES.

Niger, nitidus; antennis pedibusque brumeis; fromle muncu- 
lata; pronoto lateribus impressis busique grosse putctatis; elytris margine inflexo posticeque munctatis, stria suturali media, $3^{\mathrm{a}}$ que dorsali basali brevissimis, $1^{\mathrm{a}}, 2^{\mathrm{a}}$, $4^{\mathrm{a}}$ que ultra medium abbreviatis, hmmeruli cum subhumerali juncta; mygidio sat dense punctato marginatoque; libiis anticis 7-8 denticulatis. Long. 6 mill. ; larg. $41 / 2$ mill.

Saprinus concinnus. Mots, in Mosc. Mém., 3, 94, 5 (1849).

Ovale, très légèrement convexe, noir, luisant. Antennes brunes. Front peu convexe, pointillé; strie entière, bien marquée. Pronotum plus large que long, bisinué à la base, oblique sur les côtés, rétréci et échaucré en devant, avec les angles arrondis, ponctué à la base, creusé d'une impression rugueusement ponctuée le long du bord latéral; strie marginale entièıe. Ecusson triangulaire, très pelit. Elytres plus longues que le pronotum, de sa largeur à la base, dilatées à l'épaule, rétrécies au bout; ponctuation assez forte et médiocrement serrée, couvrant le tiers postérieur, depuis la première dorsale jusqu'à la suture, ainsi que le bord latéral infléchi, le long de la strie marginale interne qui est entière ; subhumérale externe courte, basale; interne assez longue, jointe à l'lıumérale; dorsales fortes, ponctuées; $1-2$ et quatre raccourcies au milieu; troisième très courte; quatrième arquée presque jusqu’à l'écusson ; suturale rudimentaire, médiane. Pygidium un peu bombé dans son milieu, à peine rebordé sur les côtés, assez densément et uniformément ponctué. Prosternum finement pointillé, rétréci au milieu; stries entières, divergentes de part et d'autre. Mésosternum couvert de points espacés, assez gros, rebordé. Pattes brun de poix; jambes antérieures garuies de sept ou huit denticules épineux; postérieures de deux rangées de spinules.

Russie méridionale; Caucase; Georgie; Sibérie.

3o Série, Tove 11 . 


\section{S. NITHDLLes.}

Niger, nitidus, metallicus; fronte pluna, punctulata, stria tenui antice sapius obsoleta; pronoto latcribus impressis rugoso, basi grosse munctato; elytris extus et postice parce punctatis, striis 1-4 dorsalibus crenatis dimidiatis, suturati antice abbreviala, sape obsoleta; subhumerali utraque brevi interna disjuncta; mygidio dense punctato; mesosterno punctis sparsis, stria integra; prostcrno sat lato, striis antice ascendemtibus divaricatis; tibiis anticis dilatatis 7-10 denticulatis. Long. $51 / 2$ 3 1/2 mill. ; larg. 4-2 4/5 mill.

IIister nitidulus, Payk. Fn. Snec., 1, 45, 12 (1798). - Mon. Hist., 58, 43, pl. 5, 3. - F. Syst. El., 1, 85, 7. - Panz. Fn. Germ., 93, 1. - Sturm, Deuts, Fn., 1, 221, 17. - Duft. Fn. Austr., 1, 222, 18. - Gyll. Fn. Suec., 1, S8, 17. - Steph. Illust. Brit. Ent., 3, 153, 22.

II. semistriatus. Hbst., 4, 306, pl. 35, 6 (1791). - Illig. Kæf., Pr., 1, 59, 12. - E. H., 1, 77, 15, et 2, 125.

H. acuminatus. F. Ent. Suppl., 37, 4, 5 (1798). - Syst. El., $1,86,11$.

II. incrassatus. Fald. Fn. Trans., 211 (1836).

Saprinus nitidulus. Er. in Jahr., 1, 179, 17. - Kae. Brandt., 1, 670, 1. - Herr, Fn., Helvet., 1, 460, 1. - Küst. Kæf. Eur., 7, 43. - Redt. Fn. Austr., 237. - Bach. Fn. Pr., 1, 307, 1.

S. niger, Turcomanicus, subattenuatus, lateralis, planiusculus, sparsipunctatus, Uralensis; Motsch. in Mosc. Mem. (1849), p. $9,1-9$.

Ovale, court, peu convexe, d'un noir luisant, métallique. Autennes brunes; funicule ferrugineux. Front plan, inégalement ponctué; strie fine, orlinairement obsolète derrière l'épistome, rarement complète. Pronotum court, bisinué ì la base, oblique et assez fortement inipressionné le long des côtés, rẻtréci et échancré en devant, avec les angles obtus, 
assez grossièrement ponctué dans son pourtour, surtout dans l'impression latérale; stric marginale entière. Ecusson très petit. Elytres un peu plus longues que le pronotum, de sa largeur à la base, à peine dilatées à l'épaule, rétrécies et droites au bout, couvertes le long de la marginale, et sur leur partie postérieure, de la suture au premier interstrie, de points espacés ; stries dorsales crénclées; première raccourcie an milieu, les autres au-delà; troisième souvent très raccourcie; quatrième arquéc vers l'écusson; suturale n'atteignant pas la base, plus ou moins courte, quelquefois entièrement nulle; subhumérale petite; interne disjointe. Pygidium convexe, uniformément et assez lensément ponctué. Mésosternum entièrement rebordé, colıvert d'assez gros points espacés. Prosternum assez large, en carène très obtuse, concave; stries fortes, entières, remontant et très divergentes en derant. Jambes brunes; antérieures dilatées, garnies de 7 à 10 denticules.

Cette espèce est fort commune et trìs répandue dans toute l'Europe; dans le nord de l'Afrique ( Maroc, Algérie, Tripoli, Tunis, Egypte). En Sibérie, dans les régions caucasiennes et en Syrie; on la retrouve jusqu'aux Indes Orientales. Elle vit dans le fumier, les bouses, les charognes, etc.

Elle présente une foule de variations dans les stries sutu . rale, troisième dorsale et frontale, dans la ponctuation, soit du pronotum et des élytres, soit du mésosternum; enfin dans les denticules des jambes antérieures. M. de Motschulsky dans un travail inséré dans les Mémoires de Moscou (1849), 'T. 3, p. 94, a divisé cette espèce en neuf autres (S. niger, Turcomanicus, suballenuatus, lateralis, concinnus, planiusculus, incrassutus, sparsipunctatus, Uralensis); encore s'occupe-t-il exclusircment d'un petit rayon de la Russic. 
En suivant les traces de cet auteur, on pourrait faire du $S$. nitidulus une centaine d'espèces. Ses descriptions courtes et vagues s'appliquent toutes à certains individus; le $S$. planiusculus est le seul dont j'aie vu un type dans la collection de M. Chevrolat. Il m'a été impossible d'y remarquer des différences plus tranchées que celles que je rencontre entre deux individus eertainement de la même espèce. Peut-être y a-t-il, en effet, plusieurs espèces dans ce groupe hétérogène? Mais après un examen répété sur un nombre considérable d'individus de toutes les provenances, je n'ai découvert aucun caractère constant, et j'ai dû renoncer à débrouiller ce clıaos.

\section{S. StBnitidus.}

Nigro-ceneus, nitidus; antennis pedibusque piceis ; fronte dense punctulat, , stria interrupta; pronoto lateribusrugoso-impressis basique punctato; clytris subtiliter transverse dimidiato punctatis, stric suturali 1-2 dorsalibus versus medium, 3-4 paulo ante abbreviatis; subhumerali utraque brevi, interstitio $1^{\circ}$ strigoso; pygidio dense aqualiter punctato; mosterno striis antice subparallelis; tibiis anticis 9-10 denticulatis. Long. 5 1/2 mill.; larg. 3 1/2 mill.

Ovale, peu convexe, vert métallique foncé, luisant. Antennes brun-obscur. Front légèrement convexe, densément ponctué, rugueux sur l'épistome; strie interrompue. Pronotum beaucoup plus large que long, bisinué a la base et bordé de points ; subarqué sur les côtés, avec une impression longitudinale qui s'étend jusqu'aux $5 / 6$ de la base, rugueusement ponctuée; rétréci et échancré en devant, avec les angles obtus; strie marginale entière. Ecusson triangulaire, très petit. Elytres plus longues que le pronotum, de sa lar- 
geur à la base, dilatées à l'épaule, rétrécies ensuite jusqu'au bout, couvertes dans leur moitié postérieure d'une ponctuation assez peu serrée et faible, dont la limite antérieure est presque droite, sans sinus, ainsi que sur le bord infléchi; strie suturale bien marquée, non interrompue au bord apical, un peu raccourcie à la base, et n'atteignant pas tout à fait la quatrième dorsale; premier interstrie sillonné obliquement de quelques stries irrégulières; $\mathbf{1 - 2}$ stries dorsales raccourcies vers le milieu; 2-3 un peu avant; humérale fine, oblique, bifide; subhumérale interne courte, disjointe; externe basale; marginale entière. Pygidium également, assez densément et fortement ponctué. Mésosternum ponctué, entièrement rebordé. Prosternum plan, assez étroit, paraissant lisse; stries entières, réunies en devant, et à peu près parallèles. Pattes brunes; jambes antérieures garnies de huit à dix petits denticules épineux, serrés.

${ }^{*}$. Métasternum profondément impressionné au milieu, avec la pointe du pygidium un peu relevée et plus lisse que le reste.

Cette espèce, confondue avec le. $S$. nitichulus, me paraît distincte et se reconnaît à ses stries prosternales parallèles en derant, sa ponctuation fine et à bord antérieur droit.

Elle se rencontre daus le midi de la France et en Espagne. J'en ai vu un exemplaire de Grèce, et un de Russie.

\section{S. Algericus}

Brunneus, nitidus; antemnis rufis; fronte punctulata, stria obsoleta: mronoto basi et lateribus punctato, stria integra; elytris postice punctatis, stria suturati antice abbreviata, 1-4 dorsalibus dimidiatis, humcrali cum subhumerali junctu lon- 
giori; pygidio punctuluto; prosterno striis integris utrinque divergentibus. Long. $33 / 4$ mill ; larg. $23 / 4$ mill.

Hister Algericus. Payk. Mon. Hist., 60, 44, pl. 5, 4 (1811).

Ovale, légèrement convexe, d'un brun de poix luisant. Antennes rouges. Front convexe, pointillé; strie nulle. Pronotum plus large que long, bisinué à la base, oblique sur les côtés, rétréci et échancré en devant, avec les angles arrondis, ponctué dans son pourtour, un peu plus fortement et largement sur les côtés, à peine distinctement impressionné; strie marginale entière. Ecusson très petit, triangulaire. Elytres beaucoup plus longues que le pronotum, de sa largeur à la base, curvilinéairement dilatées sur les côtés, rétrécies au bout, couvertes de points assez peu serrés dans leur moit:é postérieure, et plus fins le long de la strie marginale; dorsales égales, raccourcies au milieu; humérale réunie avec la sublıumérale interne, et descendant plus bas que les dorsales; 4-dorsale arquée vers la suturale ; celle-ci raccourcie en devant, un peu plus éloignée de la suture à son milieu qu’à ses extrémités. Pygidium légèrement convexe, couvert d'une ponctuation assez serrée. Mésosternum avec quelques points épars, entièrement rebordé. Prosternum dilaté à la base; stries entières, fortes, divergentes. Paltes brun plus clair; jambes antérieures garnies de pelits denticules peu serrés et peu nombreux.

Algérie; Espagne; Portugal; Sardaigne.

\section{S. Fulvis.}

Metallicus, niger, nitidus; antemis pedibusque rufis; fronte plana dense munclata, stria intermupta; pronoto lateribus immessis basifue munctatis; elytitis strigose el dense munctatis, 
humeris et area scutellari lavibus, striis 1-4 dorsalibus dimitiatis, suturali antice abbreviata, subhumerali intcrna vix disjuncta; mygidio dense munchulato; mesosterno marginalo; prosterno plano, striis vix divergentibus; tibiis anticis 7-8 denticutatis. Loug. 4 mill. ; larg. $23 / 4$ mill.

Saprinu furvus. Er. in Jahrb., 1, 180, 18 (1834).

Ovale, court, peu convexe, d'un noir métallique, luisant. Antennes rousses; scape brun. Front plan, densément pointillé: strie fine, interrompue derrière l'épistome. Pronotum court, bisinué à la base, courbé et impressionné le long des côtés, rétréci et échancré en devant, avec les angles obtus, couvert de points fins et serrés dans son pourıur; strie marginale entière. Ecusson très petit. Elytres à peine plus longues que le pronotum, de sa largeur à la base, dilatées à l'épaule, rétrécies et droites au bout, couvertes d'une ponctuation fine et serrée, rugueuse sur les interstries, ne laissant de libre que l'épaule et un espace mal limité dans le voisinage de l'écusson; stries dorsales fines, également raccourcies vers le milieu; quatrième recourbée vers la suture; suturale raccourcie; subhumérale externe petite; interne joignant presque l'humérale. Pygidium bombé, uniformément et densément pointillé. Mésosternum entièrement rebordé, avec des points épars. Prosternum plan, peu élargi; stries presque parallèles, un peu divergentes en devant. Pattes ferrugineuses; jambes antérieures dilatées, garnies de $7-8$ petits denticules.

France méridionale (Marseille); Portugal; Espagne; Alger; Trị̂oli ; Egypte; Grèce.

14. S. IMMUNDES.

Suborbicularis, miger, supra rugoso-punctatus, obseurus, 
pronoti disco, slytrorum humeris apice, geminayue scutellari area lcvibus, nitidis; fronte stria temu subintegra; antennis pedibusque brumeis; elytris stria suturali antice, dorsalibus 1, 2

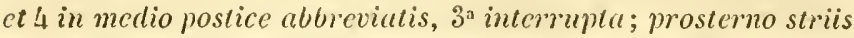
divergentibus; mesosterno munctato stria intermupta; tibiis anticis 4-5 denticulatis. Long. $33 / 4$ mill. ; larg. 2 3/4 mill..

Hister immendus. Ghl. Ins. Suec., 4, 266, 17-18 (1827).

Saprinus immundus. Er. in Jahr., 1, 182, 22. - Kief. Brand., - Redt. Fn. Austr., 789. - Bach. Kæf. Prus., 1, 307, 3.

Suborbiculaire, légèrement convexe, noir luisant en dessous, obscur et ponctué densément en dessus, avec le lisque du pronotum, l'épaule, le bord apical des élytres lisses, luisant, ainsi qu'une tache subscutellaire, large, occupant le tiers antérieur, entre la deuxième dorsale et la sulure, et divisée en deux inégales par la quatrième dorsale ; l'extérieure la plus petite est entamée à la base par la surface rugueuse. Antennes brunes; funicule ferrugineux. Front légèrement convexe; strie fine, entière. Pronotum plus large que long, bisinué à la base, obiique sur les côtés, rétréci et échancré en devant, avec les angles arrondis, et marqué en dessus d'une légère impression ; strie marginale entière. Elytres courtes, plus longues cependant que le pronotum, de sa largeur à la base, dilatées à l'épaule, rétrécies en arrière ; strie suturale remontant vers le milieu de l'espace lisse; quatrième dorsale forte, ponctuée, raccourcie vers le milieu, arquée à la base, jusqu'à l'écusson ; troisième interrompue; deuxième et première fines, plus courtes que la quatrième ; lumérale rapprochée de la dernière; sublıumérales courtes; interne disjointe. Pygidium ì peine bombé, sans rebord, moins rugueusement ponctué que les élytres. Mésosternum à points épars; strie interrompuc. Plosternum 
à stries fines, divergentes aux deux bouts. Pattes brunes; jambes antérieures garnies de 4-5 denticules épineux.

Cette espèce, peu répanduc, se rencontre en France (Calais); Belgique; Suède; Autriche; Allemagne; Caucase.

\section{S. Figuratus.}

Subtus nitidus, supra opacus, dense rugoso-punctatus, 3 ovatis pronoti scutellique magna arcis lavibus nitidis, antennis brunneis; stria frontali mulla, stria suturali intcgra, dorsalibus et subhumerali interna mullis; prosterno striis subparallelis; mesostcrno munctato, marginato; libiis anticis 6-dcnticulatis. Long. 3 1/2 mill,; larg. $23 / 4$ mill.

Ovale, suborbiculaire, peu convexe, noir brun, assez luisant en dessous, opaque en dessus à cause de la ponctuation. Antennes brunes; massue ferrugineuse. Front presque plan, densément et finement pointillé; strie obsolète. Pronotum court, bisinué à la base, oblique sur les côtés, rétréci et échancré en devant, avec les angles arrondis; strie marginale entière; une assez grande tache ovalaire au milieu, bien limitée, flanquée de deux autres posées obliquement, plus petites, toutes lisses et luisantes; le reste de la surface densément et rugueusement ponctué. Ecusson triangulaire, très petit. Elytres larges, plus longues que le pronotum, de sa largeur à la base, dilatées à l'épaule, rétrécies postérieurement; couvertes d'une poncluation rugueuse, très serrée, plus fine sur le bord infléclii, avec les angles, le bord apical, et un long espace lisse qui s'étend jusqu'aux deux tiers; strie suturale entière, conme rejoignant en forme d'arc la quatrième dorsale qui semble limiter la place lisse, et est à peine visible, ainsi que les autıes; lıméralc obsolète; 
subhumérale interne nulle; externe basale ; marginale forte, entière. Pygidium également et assez densément ponctué, plus finement au bout. Mésosternum entièrement rebordé, avee des points espacés, assez forts. Prosternum à peine élargi en devant; stries bien marquées peu divergentes. Pattes brun de poix; jambes antérieures garnies de 5-6 denticules épineux.

Alger; Tunis ; Syrie.

46. S. LUBRICUS.

Eneus, nitidus, pedibus rufis; fronte, pronoto ciliato, limbo, clytrisque punctato rugosis, his humeris areaque scutellari magna lavissima, stria suturati integra, antice ar'cuatim juncta, dorsalibus dimidiatis, subhumerali interna disjuncta, externa nulla; pygidio dequaliter, mesosternoque marginato fortius munctatis; mosterno carinato, striis ascendentibus; tibiis anticis 7-denticulatis. Long. $31 / 2$ mill. ; larg. 2 1/2 mill.

saprinus lubricus. Le C. Gol. Calif., v, 4º 45, 20 (1851).

Ovale, légèrement convexe, bronzé luisant. Antennes brunes; funicule rougeâtre. Front assez convexe, densément et rugueusement pointillé; strie obsolète. Pronotum cilié, plus large que long, bisinué à la base, oblique sur les côtés, rétréci et échancré en devant, avec les angles arrondis, couvert, dans son pourtour, de points denses, rugueux, disque lisse; stric marginale entière. Ecusson triangulaire, très petit. Elytres plus longues que le pronotum, de sa largcur à la base, dilatées à l'épaule, rétrécies postérieurement, densément et rugueusement ponctuées, épaule et bord apical lisses, ainsi qu'un grand espace subscutellaire, entre la quatrième dorsale el la suturale, étendue 
au-delà du milieı; strie suturale entière, réunie à la base par un arc à la quatrième dorsale; toutes les dorsales raccourcies au milieu, fines et à peu près d'égale longueur ; humérale oblique; subhumérâle interne disjointe; externe nulle; marginale entière. Pygidium couvert d'une ponctuation égale et serrée. Hésosternum entièrement rebordé, avec de gros points épars. Prosternum caréné, un peu concave; stries fortes, remontant et divergentes. Pattes rousses; jambes antérieures garnies de sept petits denticules épineux.

Californie (San-Francisco, Diégo).

\section{S. SPECULIFER.}

Eneus, nitens; antennis pedibusque brunneis; fronte punctulata, stria internupta; pronoto lateribus impresso rugoso, basi punctato, stria integra; elytris dense rugoso punctatis, humeris, macula magna sculellari aliaque minuta lavissimis politis, stria suturali integra, antice arcuation comexa, $4^{\text {a }}$ dor. sali in medio abbreviata, cateris mullis, humorali obsoleta, subhumerali interna minuta, extcrna basali, marginati valida; pygidlio mesosternoque marginato punctatis; prosterno striis medio paululum propioribus; libiis anticis 7-8 denticulatis. Long. 3 3/4 mill. ; larg. $23 / 4$ mill.

Hister speculifer. Latr. Gener. Ins., 2, 48, 2 (1807). - Payk. Act. Holm., 229, pl. 7, f. 2. - Pkl. Mon. Hist., 70, 54, pl. 6, f. 4. - Gyll. Ins. Suec., 4, 267, 21, 22.

I. pulcherrimus. Web., Obs. Ent., 37, 1 (1801). - Steph, Illust. Brit. Ent., 3, 183, 23.

II. personatus. Illig. Mag., 6, 39, 13 (1807).

Saprimus speculifer. Er. in Jahr, 1, 182, 23. - Kæ.. Brancl., 1. 613, 4. - Heer, Fn. Helvet. 1, 461, 2. - Redt. Fn. Austr., 237.Kïst. Kæf. Eur., 8, 70, - Bacl. Kif. Prus., 1, 308, 5. 
Ovale, assez convexe, métallique luisant en dessus, plus obscur en dessous. Antennes brunes; funicule rougeâtre. Front peu bombé, densément pointillé ; strie interrompue derrière l'épistome. Pronotum beaucoup plus large que long, bisinué et étroitement bordé de points à la base, oblique sur les côtés, avec une large bande légèrement enfoncée, densément et rugueusement ponctuée, touchant le bord; rétréci et échancré en devant, avec les angles arrondis ; stric marginale entière. Ecusson triangulaire, très petit. Elytres beaucoup plus longues que le pronotum, de sa largeur à la base, dilatées à l'épaule, rétrécies au bout, couvertes de points très serrés, fins sur le bord infléchi, rugueux sur le disque, dans toute sa longueur, avec les épaules, le bord latéral, le postérieur, et deux taches scutellaires très lisses et luisantes; l'une interne beaucoup plus grande, s'étend entre la stric suturale et la quatrième dorsale, jusqu'aux deux tiers de l'élytre; l'autre externe petite, arrondie, en dehors de la quatrième dorsale, au milieu de la grande, souvent séparée par un étroit canal rugueux, d'autres fois par la strie dorsale seule, encore quelquefois est-elle interrompue en cet endroit, et la petite tache semble être un sinus de la grande; stric suturale entière, rejoignant la quatrième dorsale à la base; celle-ci s'étend jusqu'au milieu, les autres dorsales nulles; humérale fine, obsolète ; subhumérale interne très courte; externe basale; marginale forte, entière. Pygidium peu densément ponctué. Mésosternum entièrement rebordé, ponctué. Prosternum rétréci au milieu; stries légèrement divergentes aux deux extrémités. Pattes brunes; jambes antérieures garnies de 7-8 denticules épineux.

8. Légère impression médiane au bord postérieur du métasternum, aver un tubercule terminal unique. 
Cette espèce vit dans les cadavres et les bouses: $\Lambda$ ngleterre; Suède; France; Suisse; Allemagne; Autriche ; Espagne ; Portugal ; Italie ; Grèce ; Afrique septentrionale (Alger, Maroc, Tripoli, Egypte) Syrie.

48. S. ENEUS.

Nigro-cencus nitidus; antennis pedibusque piceis ; fronte punctulata, stria intcrupta; pronoto tateribus impresso rugoso, basique punctata, stria subintegra; clytris dense rugoso punctatis, margine areaque scutellari usque ad $2^{\mathrm{am}}$ dorsalem lavi. stria suturali integra, antice arcuatim coeunte cum $4^{\text {a }}$ dorsali dimidiata, 3" brevi 1-2 dimidiatis, humerali tenui, subhumerali internu brevissima disjunctu; pygidio dense, mesosternoquc grosse punctatis; prosterno striis utrinque divergentibus; tibiis anticis 6-7 denticulatis. Long. 4 mill.; larg. 3 mill.

Hister ceneus. F. Syst. Ent., 53,9 (1775). - Spec. Ins. , 1, 62, 9. - Mant., 1, 33, 12. - F. Ent. Syst., 1, 76, 19. - F. Syst. El., 1, 88, 25. - Oliv. Ent. 1 , 8, 12. 12, pl. 2, 10. - Hbst. Nat. Syst., 4, 29, 5, pl. 35, 5. - Payk. Fn. Suec., 1, 46, 14. - Mon. Hist., 62, 58, pl. 6, 6. - Illig. Kæf. Prus., 1, 59, 13. - Panz. Ent. Germ. 1, 24, 21. - Fn., 93, f. 2. - E. H. 1, 79, 16. - Sturm. Deuts. Fn., 1, 223, 18. - Duft. Fn. Austr., 1, 223, 19. lllg. Mag., 6, 39, 14. - Gyll. Ins. Suec, 1, 89, 18. - Steph. Illust. Ent. Brit., 3, $154,25$.

Saprinus aneus. Er. in Jahr,, 1, 182, 24. - Kæf. Brand., 1, 673, 5. - Heer, Fn., Helvet., 1, 461, 3. - Küst. Kæf. Eur., 7, 44. - Redt. Fn. Austr., 237. - Bach. Kæe. Pruss., 1, 309, 6.

Ovale, légèrement convexe, noir métallique luisant. Antennes brun de poix. Pronotum court, beaucoup plus large que long, bisinué à la base et bordé de points, oblique sur les côtés, avec une large bande longitudinale couvrant le bord, rugueuse et densément ponctuée, légèrement impres- 
sionnée; rétréci et largement échancré en devant, avec les angles arrondis; strie marginale un peu raccourcie à la base. Ecusson triangulaire, très petit. Elytres plus longues que le pronotum, de sa largeur à la base, dilatées à l'épaule, rétrécies au bout, ponctuées sur le bord infléchi, plus densément et rugueusement sur le disque; bords apical et latéral et une grande place scutellaire étendue entre la suture et la deuxième strie dorsale, jusqu'aux deux tiers de l'élytre, lisses, luisantes, divisée par la quatrième dorsale; stries ponctuées; suturale entière (quelquefois un peu interrompue), réunie en forme d'arc basal avec la quatrième dorsale : celle-ci dépassant le milieu ; première et deuxième à peu près de même longueur; troisième basale courte, confuse; humérale fine, rapprochée de la première dorsale; subhumérale interne disjointe, petite; externe basale; marginale entière. Pygidium densément et également pointillé, biimpressionné à la base. Mésosternum entièrement rebordé, couvert de points forts et peu serrés. Prosternum rétréci au milieu; stries divergentes de part et d'autre. Pattes brunes; jambes antérieures garnies de 7-8 denticules.

6. Une très superficielle impression médiane à la partie postérieure du métasternum.

Très commun dans les bouses et les charognes, par toute l'Europe; Syrie (Beyrouth, Saïla, Damas).

\section{S. PRASINTS}

Viridi-ceneus, nitidus; antennis pedibusque piceis; fronte rugoso-punctulata, stria obsoleta; pronoto basi anguste', latcribusque rugoso impresso late punctato, stria integra; clytris dense strigoso-punctatis, humeris, margine apicali, muculacnue 
scutellari interstriam 2 an dorsalem et suturalem ad medium lavi, stria suturali integra antice arcuatim coeunte, dorsalibus 1, 9 et 4 in medio, $3^{\mathrm{a}}$ mox abbreviatis, subhumerali interna brevissima disjuncta; pygidio dense cequaliter punctato; prosterno striis paralletis; tibiis anticis 5-denticulatis. Long. 3 3/4 mill.; larg. $23 / 4$ mill.

Saprinus prasimus. Er. in Jahr., 182, 25 (1834).

Ovale, assez convexe, vert-métallique, luisant. Antennes brunes. Front plan, rugueux, densément ponctué; strie obsolète. Pronotum beaucoup plus large que long, bisinué et bordé étroitement de points à la base, oblique sur les côtés, avec une impression longitudinale, rugueuse et fortement ponctuée jusqu'au bord, rétréci et échancré en devant, avec les angles arrondis; strie marginale entière. Ecusson triangulaire, très petit. Elytres beaucoup plus longues que le pronotum, de sa largeur à la base, dilatées à la base, rétrécies au bout, finement ponctućes sur le bord infléchi, très densément et rugueusement sur le disque, avec l'épaule, le bord apical lisses, ainsi qu'une grande tache scutellaire, entre la suture et la deuxième dorsale, jusqu'audelà du milieu, formée de deux taches divisées par la quatrième dorsale, l'une interne, plus grande, l'autre externe, plus petite, raccourcie à la base; stric suturale entière, réunie en arc avec la strie la plus voisine $; 1.2$ et quatre dorsales raccourcies au milieu; troisième courte, basale, confuse; humérale oblique, rapprochée de la première dorsale; subhumérale interne très courte, disjointe; externe basale; marginale entière. Pygidium également et assez densément ponctuć. Mésosternum avec quelques points espacés, entièrement rebordé. Prosternum dilaté seulement à la base; stries fortes, parallèles exactement en devant. 
Pattes d'un brun de poix; jambes antérieures garnies de 5-6 denticules épineux; postérieures de deux rangées de spinules.

ه. Une très légère impression au milieu du bord postérieur du métasternum.

Syrie; Italie.

\section{S. PSEUDOCYANEUS.}

Brunneus, metallicus, nitidus; fronte puncticulata, stria interrupta; pronoto basilateribusque impressis punctato; elytris margine inflexo discoque postico rugoso-punctatis opacis, interstitio $1^{\circ}$ partim punctato, striis 1-2 dorsalibus dimidiatis,

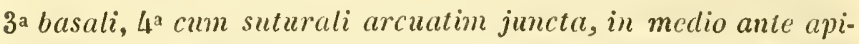
cem arca politce abbreviata, subhmmerati interna disjuncta, externaque brcvibus; pygidio dense, mesosterno marginato parce punctatis; prosterno plano, angusto, striis parallelis; pedibus brunncis, tibiis anticis 6-denticulatis. Long. $43 / 4$ mill.; larg. $31 / 4$ mill.

Saprinus pseudocyaneus. White, Voy. de l'Ereb. et Terror, Ins. N.-Zélande, 95 (1846).

Ovale, oblong, brun-noir, métallique, luisant. Antennes brunes ; funicule ferrugineux. Front plan, densément pointillé; strie bien marquée, interrompue derrière l'épistome. Pronotum court, bisinué et bordé de points à la base, oblique, arec une étroite impression ponctuée le long des côtés, laissant la marge libre, rétréci el échancré en devant, avec les angles assez obtus; strie marginale entière. Ecusson très petit. Elytres plus longues que le pronotum, dilatées à la base, rétrécies au bout, couvertes sur le repli latéral et la partie postérieure du disque, d'une ponctuation forte, serrée et rugueuse, qui remonte dans le premier interstrie, et en- 
clos un large espace lisse et poli, bien linité, étendu jusqu'aux deux tiers de la longueur et jusqu'au premier interstric; 1-2 dorsales crénelées, atteignant le milieu; troisième très courte, basale; quatrième de la longueur des premières, mais n'atteignant pas l'extrémité de l'espace poli, réunie à la suturale par un arc basal; subhumérales courtes; interne disjointe. Pygrilium bombé, densément ponctué, long au bout. Mésosternum entièrement rebordé, avec des points fins et espacés. Prosternum plan, comprimé; stries rapprochées, parallèles. Pattes brun-ferrugiıcux; jambes antérieures assez dilatées, garnies de quitre dents accompannées le trois à quatre petits denticules.

Nouvelle-Zélande.

\section{5ั1. \$. IUGIPENNIS.}

Niger, nitidus, metallicus; elytris, untemis, pedibus pugilioque apice rufo-brunneis; fronte punctulata, stria antice obsoleta; pronoto lavi, angulis anticis prominulis, later ibus et basi anguste punctutis; clytris rugoso punctatis, humero et area ma!na junctu sculellari usyue ud $2^{\text {an }}$ strium dorsulcm politis, stria suturali incegra cum $\uparrow^{\text {a }}$ dorsali ultra medium extensa coennte, $\mathbf{1}^{\text {a }}$, 2a que paulo hrevioribus, $3^{3}$ brevi busali, humerali et subhumerali externa tenui, interna disjuncta; pygidio dense punctato; mesosterno marginato parce punctato; prosterno medto subdilutato, striis sinuatis antice convergentibus; tibiis anticis 5-denticulutis. Long. ä 1/2 mill. ; larg. 2 1/2 mill.

Ovale, peu convexe, noir-métallique luisant. Antennes brun de poix ; funicule ferrugineux. Front plan, pointillé; strie entière, anguleuse sur l'épistome et un peu obsolète. Pronotum court, beaucoup plus large que long, bisinué à la base, arec un point antéscutellaire, arqué sur les côlés,

3. Série, TowE 111. 
rétréci et échancré en devant, avec les angles assez prononcés, lisse, subimpressionné en devant, avec une bordure étroite de points qui part derrière les yeux et longe tout le bord latéral, sans le courrir, et se continue sur la marge postéricure, jusqu'à l'écusson; strie marginale entière, bien marquée. Elytres rouge-brun, plus longues que le pronotum, de sa largeur à la base, dilatées à l'épaule, rétrécies par derrière, avec une impression subapicale, rugueusement et densément ponctuées, avec l'épaule et un large espace subscutellaire s'élendant jusqu'au tiers postérieur de l'élytre, et en dehors, jusqu'à la deuxième strie dorsale, lisses, polis; strie suturale entière, arquée à la base, et réunie à la voisine; dorsales ponctuées; quatrième raccourcie au milieu; deuxième à peu près de la même longueur; troisième très courte, rudimentaire; première peı accusée, plus courie que la deusième; humérale confuse ; subhumérale interne assez longue; externe basale confuse; marginales entières. Pygidium densément ponctué, avec l'extrémité rouge. Mésosternum avec des points latéraux, pcu nombreux, enticrement rebordé. Prosternum légèrement dilaté, et bombé vers le tiers antérieur; stries fortes, sinueuses, rapprochées et réunies en devant. Paltes d'un brun-rouge; jambes antérieures armées de cinq denticules, les quatre derniers, grands.

Amérique probablement.

\section{S. DIPTYCHCS.}

Suborbicularis, convexiusculus, brunneo-cheus, nitidus, pedibusque ferrugineis; fronte rugoso-punctata, stria obsolcta; pronoto ciliato, circum rugoso; elytris rugoso-punctutis, margine, humero, maculo scutellari et parva $2^{a}$ interstitii, lovibus, 
stria suturali integra, 1-4 ilor'salibus dimidiatis, subhumerali interna brevi, disjunctu, externu mulla; mgidio dense munctato; prosterno striis valde divergentibus; mesosterno marginato parce punctato ; tiviis anticis 5-6 denticulatis. Longneur 2 mill. ; larg. $11 / 2$ mill.

Suborbiculaire, assez convexe, d'un brun-métıllique, luisant. Antennes brunes. Front rugueux, plan, non distinct de l'épistome; strie obsolète, interrompue. Pronotum court, bisinué et bordé de points à la base, arqué et cilié sur les côtés, rétréci et échancré en devant, arec les angles arrondis, largement bordé de points rugneux dans son pourtour. Ecusson très petil, triangulaire. Elytres plus longues que le pronotum, de sa largeur à la base, dilatées à l'épaule, rélrécies et droites au bout, courertes d'une poncluation fortc, rugueuse au milieu, arec l'épaule, le bord, un espace bien limité occupant la moitié antérieure du quatrième interstrie, et un autre plus vague sur le deuxième, lisses et très luisants ; stries bien marquées; marginale entière, profonde; subhumẻrale externe confondue avec elle à la base; interne courte, disjointe; humérale oblique; 1-4 dorsales raccourcies au milieu; les premières un peu plus longues; sıturale entière réunic avec la quatrième; interstrie sutural parcouru par une striole. Pygidium densément ponctué. Prosternum en carène arrondie, élargi à la base; stries divergentes et très ascendantes, non réunies en devant. Mésosternum rebordé, avec des forts points espacés. Pattes ferrugineuses; jambes antérieures garnies de 5-6 denticules; postérieures de quelques spinules sur deux rangs.

Yucatan (M. Pilate). 
$e^{\prime}$. Elytres plus ou moins ponctuées, sans espace lisse, juxta-scutellaire, nettement limité. (53-118.).

$f$. Une troisième strie marginale ou une cinquième (Jorsale. (53-54).

\section{S. Patagonicls.}

Niger, nitidus; antice subtus fulvo ciliato; fronte rugosa, stria profunda integra, in clypeo angulatu prominente; pronoto lateribus anguste impressis rugoso muctatis, stria valida integra; clytris rugoso punctulis, lateribus ar eaque antice suturali lavi; striis ì marginalibus, 2 subhusteralibus, interna disjuncta; dorsalibus 1-2 versus medium, 3-4 ante-abbreviatis, $4^{\text {a }}$ cum suturali subjuncta; pygidio grosse punctato, circum subsulcato; mesosterno marginali; prosterno acute cavinato, striis ascendentibus divergentibus; tibiis anticis 5-6 dentatis. Long. 7 mill.; larg. 5 mill.

Ovale, peu convexe, noir, luisant. Antennes brunes; funicule ferrugineux. Front rugueux, marqué d'une impression en $\mathrm{V}$, très superficiclle ; strie bien marquée, entière, formant, sur l'épistome, une anse très saillante et profonde. Pronotum beaucoup plus large que long, bisinué à la base, arec une bordure de petits points, oblique sur les côtés, rétréci et échancré en devant, avec les angles arrondis, bordé de cils fauves dans tout son pourtour; lisse sur le disque, avec une étroite impression latérale, ponctuée, rugueuse dans toute la longueur; strie marginale forte, entière, se continuant un peu à la base. Ecusson très petit, triangulaire. Elytres plus longues que le pronotum, dilatées dès la base et fort saillantes à l'épaule, rétrécies au bout, entièrement couvertes de points serrés, rugueux, avec l'épaule, le 
bord latéral et un assez grand espace juxta-scutellaire lisse, lequel envoie un étroit prolongement jusqu'à la deuxième strie dorsale; interstrie marginal sillonné par une marginale intermédiaire, forte, entière; humérale fine, rapprochée de la première dorsale; sublıumérale externe basale ; interne courte, disjointe; $\mathbf{1 - 2}$ dorsales raccourcies au milieu; troisième un peu plus, interrompue à l'espace lisse; quatrième ne dépassant pas le tiers, arquée vers la suturale, quelquefois interrompue; celle-ci entière, bien marquée, séparée de la suture par une striole obsolète. Pygidium couvert de gros points médiocrement serrés, plus fins au bout, entouré d'un sillon peu profond. Mésosternum entic̀rement rebordé, peu densément pointillé. Prosternum en carène aiguë, élargi à la base; stries divergentes et remontant sur les côtés. Jambes antérieures garnies de cinq dents assez fortes et de quelques faibles denticules.

Patagonic (Rio-Negro); Bolivic.

\section{S. LaCordiarei.}

Nigro-brumeus, obscurus; antennis rufis; fronte rugosopunctata, stria integra in clypeo angulatim valde producta; pronoto ciliato, disco vix distincte, lateribus late rugoso punctulato, antice biimpresso; stria integra; elytris disco opaco dcnse punctulato, lateribus et juxta scutcllum levvibus; stria subhumerati interna sinuosa humeralijuncta; dorsalibus ultra medium productis 1-3 longioribus, $4^{2}$ cum suturali conjuncta, $5^{\text {a }}$ basi abbreviata; suturali integra à sutura in medio magis distanti; mygidio dense punctato, circum sulcato; mesosterno marginato muctulato; prosterno striis utrinque divergentibus; tibiis anticis 8-9 denticulatis. Long. 4 1/2 mill.; larg. 3 1/3.

Orbicu'aire, assez convexe, noir-!run, pen luisant. An- 
tennes ferrugineuses; massue plus clinire. Front légèrement convexe, densément et rugueusement ponctué; strie entière, assez bien marquée, s'avançant en anse aigu sur l'épistome. Pronotum court, beaucoup plus large que long, bisinué à la base, arec une légère impression antéscutellaire, oblique sur les côtés et très étroitement rebordé, rétréci et échancré en devant, avec les angles arrondis, cilié de fauve ; couvert d'une ponctuation très fine et peu visible sur le disque, dense et rugueuse le long du bord latéral, jusqu'à la base, avec une fossette postoculaire peu profonde; strie marginale fine, entière. Ecusson très petit, triangulaire. Elytres courtes, plus longues que le pronotum, de sa largeur à la base, dilatées à l'épaule, rétrécies au bout, obscures, ponctuées sur le disque, lisses sur les côtés et dans le voisinage de l'écusson ; stries fines, bien marquées; marginale interne recourbée et suivant la base; humérale fine, quelquefois raccourcic ou confuse; subhumérale externe courte ; interne réunie, longue, contournée; dorsales 1-3 dépassant le milieu, 2.4 un peu plus courtes; quatrième arquée vers la suture et réunie à la suturale; une cinquième dorsale bien distincte, un peu raccourcie à la base, l'en sépare; suturale entière, plus éloignée de liı suture au milieu qu'aux extrémités, l'intervalle qui l'en sépare est creusé en gouttière. Pygidium également et densément ponctué, bombé, entouré d'un sillon assez profond. Mésosternum finement pointillé, rebordé, très rétréci en devant. Prosternum rétréci aı milieu; stries divergentes. Pattes brunes; jambes antérieures garnies de $\mathbf{8 - 9}$ denticules épincux.

Bolivia; La Mata (Tucuman); Patagonie. 
f'. Pas de cinquième strie dorsale, ni de troisième marginale aux élytres. (55-118.)

g. Jambes antérieures crénelées; postérieures simples. (55-117.)

h. Pygidium entouré d'un sillon semicirculaire. (55-62.)

\section{S. AZC̈RESCENS.}

subtus niger, fronte medio impressa rugosa, stria nulla; pronoto obscure metallico, disco sublavi, lateribus et basi punctato, utrinque impresso, lugoso; elytris nigro caruleis, undique dense et fortiter punctatis, humer is et juxta scutellum sublavibns; stria suturali, antice cum $4^{\mathrm{a}}$ dorsali arcuatim convexa; huc el $3^{\text {a }}$ ante medium, $2^{a}$ ultra, $1^{\text {a }}$ ad apicem abbreviatis; subhumerali interna disjuncta; externa distincta; pygidio grosse punctato, circum sulcato; mesosterno parce punctato; prosterno striis valde divergentibus; tibiis anticis multidenticulatis.Long. 6 mill.; larg. 4 mill.

Orale, légèrement convexe, luisant, noir de poix en dessous. Pronotum d'un métallique obscur. Elytres d'un bleu très foncé. Antennes brunes; funicule ferrugineux. Front convexe, ponctué, avec une impression médiane rugueuse, prolongée sur l'épistome; strie nulle, si ce n'est par derrière. Pronotum plus large que long, bisinué à la base, avec un point antéscutellaire, oblique sur les côtés, rétréci et échancré en devant, avec les angles arrondis, lisse sur le disque ou à peine distinctement pointillé, avec une bordure étroite à la base, large sur les côtés, de points plus forts, et avec une impression rugueuse qui s'étend de l'angle 
antẻrieur, jusqu'au milieu du pronotum; stric marginale enticre. Ecusson très petit, triangulaire. Elytres plus longues que le pronotum, de sa largeur à la base, dilatées à l'épaule, rétrécies an bout, couvertes, dans toute leur étendue, d'une ponctuation assez forte, assez égale, serrée, plus finement pointillées et presque lisses à la base et le long des côtés ; stries fortes, ponctuées, bien marquées; humérale fine, oblique, séparée de la subhumérale interne; première dorsale presque entière; deuxième dépassant le milieu ; troisième et quatrième raccourcies au tiers ; suturale entière, un peu interrompue au bout, réunie à la base, avec la quatrième dorsale. Pygidium bordé d'un rebord élevé, tranchant, séparé par un profond et assez large sillon, couvert de gros points serrés. Mésosternum ponctué, entièrement rebordé. Prosternum finement pointillé, droit, assez large, convexe; stries fortes, ascendantes et très divergentes en devant. Pattes brunes; jambes antérieures garnies d'un bon nombre de petits denticules serrés; postérieures de quelques spinules disposées sur deux rangs.

8. Extrémité du pygidium, bombée, lisse.

†. Plane, impressionnée.

Brésil; Nouvelle-Grenade; Vénézuéla.

\section{S. ENEICOLLIS.}

Subtus niger; untcnnis pedibnsque piccis ; fronte punctato-impressa, stria mulla; monolo metallico, disco puncticulato, lateribus impresso-rngosis basiqne pumctatis, stria integra; elytris distincte punctulutis, postice intus fortiter punctatis, lincis 5 distinctis stria suturali utrinque subinterrupta, 1-2 dorsulibus nlla $4^{\mathrm{a}}$ ante medium abbreviatis, 3a basuli; subhumerali interna obsoleta; mygialio grosse, mesostermo marginato minus 
dense prunctatis; prosterno subrecto, striis antice ascendentibus ct divaricatis; tibiis anticis denticulatis. Largeur 5 1/2 mill.; larg. 4 1/2 mill.

Ovale, peu convexe, d'un noir de poix en dessous, avec les antennes et les pattes brunes ; luisant en dessus, métallique-obscur sur le pronotum, et bleu sur les élytres. Front convexe, assez densément ponctué, aver une impression médiane plus profonde, et rugueuse au point de jonction du front arec l'épistome; strie nulle. Pronotum plus large que ĩong, bisinué à la base, avec un point antéscutellaire; oblique sur les côtés, rétréci et échancré en devant, avec les angles arrondis, finement, mais visiblement pointillé sur toute sa surface, bordé de points plus forts à la base et sur les côtés, impression latérale peu profonde, rugueusement ponctué, s'étendant jusqu'au milieu ; strie marginale entière. Ecusson très petit, triangulaire. Elytres plus longues que le pronotum, de sa largeur à la base, dilatées à l'épaule, rétrécies au bout, couvertes de points fins, mais très distincts, sur toute leur surface, et par derrière, de points assez forts, médiocrement serrés ; de cet espace ponctué partent des lignes régulières de gros points, dont trois remontent vers les stries dorsales, et deux dans l'interstrie juxta-scutellaire, le plus près de la suture est large et un peu confus, mais distinct de celui qui en est le plus rapproché; stries fortes, ponctuées; suturale un peu interrompue à ses deux extrémités; quatrième dorsale n'atteignant pas le milieu, arquée vers l'écusson à la base, et se dirigeant à la rencontre de la suturale; troisième très courte, basale; deuxième dépassant le milieu; première encore un peu plus longue; humérale fine; subhumérale interne obsolète; externe courte: marginales entières. Pygidium densément 
et fortement ponctué, entouré d'un sillon profond, entier, et d'un rebord élevé. Mésosternum fortement ponctué, entièrement rebordé. Prosternum droit, finement pointillé; stries entières, fortement relevées et divergentes en devant. Jambes antérieures garnies de nombreux denticules.

๑. Extrémité du pygidium bombé, presque lisse.

o presque plane, légèrement impressionnée.

Mexique.

\section{S. AZURELS.}

Niger, nitidus; antennis pedibusque brunneis; fronte impressa rugosa, stria obsoleta; pronoto aneo, lateribus antice impressis basique punctato; elytris cyancis apice punctis cerfualibus vittisque irregularibus punctorum $4^{\mathrm{a}}$ distinctis. striis dorsalibus $2^{\text {a }}$ dimidiata, $1^{\text {a }}$ longiori valida, $3^{\text {a }}$ brevissima basali, $4^{\text {a }}$ brevi cum suturali connexa, subhumerali utraque brevi, interna disjuncta; mygidio ctuatiter et dense rugoso; mesosterno marginato parce punctatis; prosterno recto striis ascendentibus; tibiis anticis 7-8 denticulatis. Long. 6 mill.; larg. 4 mill.

Hister azureus. Sahlb. Peric. Ent., 4, 2 (1823).- Thon. Arch., II, 1, 13, 2.

Saprinus azureus. Er. in Jahr., 1, 184, 34.

Ovale, assez convexe, noir, luisant, bronzé sur le pronotum, bleu sur les élytres. Antennes brunes; massue un peu ferrugineuse. Front assez bombé, ponctué, rugueux et impressionné vers l'épistome, avec un gros point sur le vertex, strie marquée seulement par derrière. Pronotum court, largement bisinué à la base, avec une borlure de points, un peu arqué sur les côtés, avec une impression ponctuée, très rétréci et échancré en devant, avec les angles obtus; strie marginale entière. Ecusson très petit. Elytres un peu 
plus longues que le pronotum, de sa largeur à la base, dilatées à l'épaule, rétrécies au bout, couvertes de points égaux, peu serrés, sur leur quart postérieur, jusqu’à la deuxième dorsale; de cette ponctuation s'élèvent quatre à cinq bandes étroites, irrégulières, tous les extérieures vont rejoindre les stries, et les deux intérieures sont placées dans le quatrième interstrie ; stries dorsales assez bien marquées; première plus forte, raccourcie au-delà du milieu; deuxième un peu arant; troisième dès la base; quatrième au tiers, réunie par un arc basal à la suturale, qui est entière, mais un peu plus fine au niveau de l'écusson et à l'angle sutural; subhumérales courtes; interne disjointe. Pygidium rugueusement et densément ponctué, entouré d'un sillon profond, entier. Nésosternum entièrement rebordé, avec des points espacés. Prosternum droit, convexe; stries fortement remontêes sur les côtés. Jambes antérieures dilatées, garnies de 7 -8 denticules.

Brésil.

Les espèces 55-59 ont entre elles les plus intimes rapports, on peut les reconnaitre aux caractères suivants : le $S$. Bonariensis de couleur plus noire, est le seul qui ait l'impression du pronotum arrondie, bien limitée; chez les autres, elle s'étend le long du bord latéral; le $S$. azurescens diffère par ses élytres d'un bleu-foncé, ponctuées plus également sur une plus grande étendue et sans bandes de points, par la troisième strie dorsale un peu plus longue, et par la strie suturale non interrompue en devant, réunie à la quatrième dorsale par un are basal; le $S$. violaceipennis se distingue des deux autres par ses élytres blenes, sans reflet violet: par sa surface plus distinctement pointillée; 
par la ponctuation latérale du pronotum plus large; par l'espace postérieur des élytres ponctué plus fortement et plus étendu; par la bande de points juxta-suturale plus élargie; et par la sublıumérale interne obsolète; enfin le $S$. azureus se distingue du $S$. violaceipennis par la taille plus grande, le front plus fortement, les bords latéraux de son pronotum plus largement ponctués, et par les points des élytres plus gros.

\section{S. VIOLACEIPENNIS.}

Fronte subimpressa parum dense munctata; antennis fuscis; pronoto obscure ceneo, subtilissime punctulato, tateribus anticis punctato impressis, stria integra; clytris violaceis postice punctulatis, stria suturali utrinque subinterrupta, dorsulibus 1-2 pone medium $4^{\text {a }}$ unte, $3^{\text {a }}$ basi abbrcviatis, lineis ipunctorum 5 distinctis; pygidio sat dense, mesosterno marginato, parce punctatis; mrosterno subrecto, striis valde antice uscendentibus, tibiis anticis 5-denticulatis. Long. 5 mill. : larg. $33 / 4$ mill,

Ovale, légèrement convexe, noir ell dessous, luisant en dessus; tête et pronotum d'un bronzé-obscur. Elytres d'un bleu-foncé violet. Antennes et pattes brunes. Front convexe, sans strie, si ce n'est par derrière, avec un point enfoncé sur le vertex, d'où part une impression médiane qui s'avance sur l'épistome. Pronotum court, beaucoup plus large que long, bisinué à la base, avec un point antéscutellaire, oblique sur les côtés, rétréci et échancré en devant, arec les angles arrondis, très finement pointillé sur toute sa surface, avec une impression latérale, fortement ponctué, qui s'étend de l'angle antérieur jusqu'au milieu du bord latéral, et une rangéc de points à la base ; strie marginale entière. Ecusson petit, triangulaire. Elytres plus longues que le pronotum, 
le sa largeur à la base, dilatées à l'épaule, rétrécies au bout, presque lisses sur la plus grande partie de leur disque, (mais courertes réellement de très petits points espacés), finement et peu densément pointillées au bout; de cet espace ponctué partent cinq lignes de points, dont trois vont rejoindre les trois stries dorsales internes, et deux s'élèvent dans l'interstrie juxta-sutural; strie suturale interrompue plus ou moins distinctement aux deux extrémités; prenière dorsale s'étendant jusqu'aux trois quarts de l'élytre; deuxième un peu plus courte, troisième rudimentaire, basale; quatrième raccourcie avant le milieu, mais arquée à la base, et marchant à la rencontre de la suturale ; liumérale fine et très oblique; subhumérale interne disjointe; externe basale; marginales entières. Pygidium couvert d'une ponctuation serrée, un peu rugueuse. Mésosternum couvert de points réguliers assez gros, peu serrés; strie entière. Prosternum finement pointillè, peu bombé; strics fortement divergentes et remontant. Jambes antérieures garnies de cinq ou six denticules épineux.

$c^{\star}$. Pygidium avec l'extrémité lisse et bombée.

\& plane, impressionnée.

Cette espèce a étẻ rapportée par M. Sallé, du Vénézuéla, et par M. Goudot, de la Nouvelle-Grenade.

\section{S. BoNARIENSIS.}

Ovalis, niger, nitidus; fronte punctata, longitudinaliter rugosis impressa, striu obsoleta; pronoto distinctius lateribus punctulato, utrinque foveola rotunda; elytris stria suturali utrinque abbreviata, 4' dorsali basi arcuatim recurva, postice in medio $3^{\mathrm{a}} \operatorname{mox}, 2^{\mathrm{a}}$ ultra medium, $1^{\text {a }}$ versus apirem abbreviatis, 
taniis punctorum continuatis postice confusis; humerali obsoleta brevi, subhumerali externa disjuncta, externa vix distincta, pygidio dense punctuto, sulcato alte marginato; prosterno convexo, striis antice valde recurvis; mesosterno parce punctu. lato marginatoque; tibiis anticis multidenticulatis. Longueur 5 1/2 mill.; larg. $31 / 2$ mill.

Ovale, peu convexe, noir, luisant. Antennes brunes; massue d'un ferrugineux-obscur. Front convexe, ponctué, avec une impression rugueuse, longitudinale, se prolongeant sur l'épistome; strie nulle en devant. Pronotum plus large que long, bisiuué à la base, avec un gros point antéscutellaire, oblique et un peu sinué sur les côtés, rétréci et écliancré en devant, avec les angles arrondis, finement et peu distinctement pointillé, plus visiblement sur les côtés , avec quelques points le long du bord postérieur, creusé de chaque côté, en devant, d'une fossette arrondie, bien marquée ; strie marginale entière. Ecusson très petit, triangu. gulaire. Elytres plus longues que le pronotum, de sa largeur à la base, à peine dilatées à l'épaule, rétrécies au bout; suturale un pen raccourcie aux deux extrémités, séparée de la quatrième dorsale qui se recourbe vers elle à l'écusson; celle-ci ponctuée, forte, raccourcie au milieu; denxième un peu plus longue; première la dépassant de beaucoup; troisième très courte, rudimentaire; de chacune de ces stries et du quatrième interstrie, partent des bandes de points distinctes, qui vont se réunir au bout en un assez vaste espace ponctué; la bande juxta-suturale est plus large et touche la suturale; humérale fine, obsolète; subhumérale interne disjointe, bien marquée, ainsi que l'exterue; marginales entières; interne ponctuée. Pygidium densément ponctué, avec l'extrémité presque lisse, entouré d'un sillon 
profond qui forme un rebord élevé. Mésosternum ponctué, bordé d'une strie entière. Prosternum bombé en devant, à stries raccourcies, ascendantes et divergentes en devant. Jambes antérieures garnies d'une foule de petites dentelures épincuses; postérieures de quelques spinules sur deux rangées.

đ. Extrèmité du pygidium très hombée, assez lisse.

f plane, avec une légère impression médiane.

Buenos-Ayres; Moutévidéo.

60. S. ASsimilis.

Ater, niticlus; antennis pedibusque piceis; fronte punctulata, stria nulla; pronoto latcribus impresso-punctato; elyt is postice grosse punctatis, striis 1-2 dorsalibus ultra, $3-4$ versus medium abbreviatis, validis, $4^{\text {a }} \mathrm{cum}$ suturali antice cocunte, hac postice subintcrupta; humerali obliqua, subhumerali interna disjuncta, externa sape mulla; mygidio dense punctato, apice breviter circum sulcato; mesosterno marginato prosternoque subtiliter punctatis, striis ascendentibus; tibiis anticis multicrenatis. Long. 5 mill.; larg. $33 / 4$ mill.

Hister assimilis. Pkl. Mon. Hist., 68, 47 , pl. v, f. 7 (1811).

H. extrancus. Kn. Illig. Mag., 6, 36, note (1807).

Saprinus assimilis. Le Conte, Mon. Hist. N.-Amér., 42, 5, pl. 5. f. 6 .

Suborbiculaire, légèrement convexe, noir, peu brillant. Antennes brunes. Front assez convexe et assez également pointillé; strie nulle. Pronotum beaucoup plus large que long, bisinué à la base, avec un point antéscutellaire, subarqué sur les côtés, très rétréci et échancré elı devant, avec les angles arrondis, bordé de poirts dans tout son pourtour, plus largement sur le bord latéral, creusé d'une impression; 
disque presque lisse et à peine visiblement pointillé; strie marginale entière. Ecusson très petit, triangulaire. Elytres courtes, un peu plus longues que le pronotum, de sa largeur à la base, dilatées à l'épaule, rétrécies au bout, couvertes dans leur tiers postérieur de gros points médiocrement serrés, jusqu'à la première strie dorsale, dont quelques-uns remontent le long des stries dorsales, et se prolongent jusqu'au milieu, le long de la suture; moins fortement, mais plus densément ponctuées à la base, sur l'épaule et le long de la strie marginale interne; stric subhumérale externe sourent confondue avec cette dernière; interne disjointe; humérale obsolète vers la base; dorsales très fortes, crénelées et profondes ; 1-2 descendant bien audelà du milieu; troisième plus ou moins courte; quatrième raccourcie au milieu, arquée à la base et réunie avec la suturale; celle-ci interrompue à l'angle sutural. Pygidium assez densément et fortement ponctuć, ceint postérieurement d'un court sill n semicirculaire. Mésosternum grossièrement ponctué, rebordé. Prosternum à peine visiblement pointillé; stries divergentes et remontant. Pattes brun de poix ; jambes antérieures fincment crénelées.

$\sigma^{*}$. Extrémité du pygidium bombée, avec deux élévations lisses, sillon souvent interrompu.

†. Pygidium plan, subimpressionné.

Cette espèce est répandue dans toute l'Amérique septen. trionale, dans les mèmes conditions que le $S$. Pensylı'anicus.

\section{S. CONNECTENS.}

Niger, cencus, motallicus, nitidus; antemris pedibusyue brunneis; fronte menctulata, stria intermpta; monoto utrinque 
subimpresso latcribus el basi punctato; stria marginali abbreviata, a margine distanti; clyuris nostice dense munctulatis, stria subhumcrali crterna mulla; dorsalibus, 1a longe ultra medium, 2a adnuc longius, to basi, abbreviatis, $4^{a}$ brevissima curn suturali connexa; mygidio striu scmicirculari brevi dense, mesosterno marginato parce punctalis; prosterno subrecto, striis ascendentibus; libiis anticis 8-10 denticulatis. Longueur 4 mill. ; larg. 3 mill.

IIister connectens. Payk. Mon. Hist., 35, 25, pl. 4, 6 (1811).

Orale, assez convexe, noir, bronzé, luisant. Antennes brunes. Front plan, très densément pointillé, avec un point sur le vertex; strie fine, interrompue. Pronotum court, lar«ement bisinué à la base, courbé sur les côtés, rétréci et échancré en derant, avec les angles arrondis, marquées d'une petite fovéole, étroitement bordé de points latéralement; strie marginale forte, raccourcie, éloignée du bord. Ecusson très petit. Elytres beaucoup plus longues que le pronotum; de sa largeur à la base, curvilinéaires sur les côtés et très rétrécies au bout, finement et densément pointillées sur leur tiers postérieur; strie marginale grosse; subhumérale externe presque accolée à elle; interne nulle; dorsales très fortes; première raccourcie bien au-dela du milieu; deuxième encore plus loin ; troisierre réduite à un point basal; quatrième très courte, réunic à la suturale par un are basal. Pronotum bombé, couvert d'une ponctuation très serrée et terminé par une courte strie semicirculaire. Mésosternum entièrement rebordé avec des points espacés. Prosternum presque plan, en carène arrondie ; stries remontant et divergentes. Pattes brunes; jambes antérieures dilatées, garnies de 8-10 petits denticules.

Brésil (Bália; Rio-Janeiro ; Montévidéo).

3e Série, Tone III. 


\section{S. ERYTIROPTERIS.}

Niger, nitidus; antenmis, pedibus elytrisque rufo-brunneis; fronte subtilissime pmotulatu, striu subiutegra antice angulata; pronoto busi mnetato, fuscia subringoso impressa laterali, angusta, valde a margine remota, stria integra; elytris apice sparse punctutis, stria sutureli vix abbreviata cum $4^{\text {a }}$ dor'sali coeunte, $3^{\mathrm{a}}$ stubintegra, $2^{\mathrm{a}} \mathbf{1}^{\mathrm{a}}$ que sensim brevioribus, humerali temui, subhumeralibus nullis; mgidlio dense panctato, apice breviter circum sulcato; mesosterno pmetuto; prosterno striis ascendentibus; tibiis anticis 6-7 denticulatis. Long. 3 1/2-4 mill.; larg. 2-2 1/2 mill.

Ilister erythropterus. Pkl. Mon. Hist., 73, 57, pl. 13, f. 4 (1811).

Saprinus erythropterus. Blanch. in Voy. Ann. m. de d'Orbig.

Ovale, assez convexe, noir luisant. Antennes brunes: funicule ferrugineux. Front presque plane, très finement pointillé; strie assez bien marquée, formant en devant un angle avancé sur l'épistome, et là pas toujours distinctement fermée. Pronotum court, beaucoup plus large que long, bisinué à la base, avec une étroite bordure de points et une petite impression antéscutellaire, oblique sur les côtés, avec une étroite bande rugucuse, poncluée, distante du bord, rétréci et échancré en devant, avec les angles arrondis; stric marginale entière. Ecusson très petit, triangulaire. Elytres beaucoup plus longues que le,pronotum, de sa largeur à la base, peu dilatées à l'épaule, fortement rétrécies au bout, courertes postéricurement de points assez gros, peu serrés, qui ne dépassent pas la troisième strie; toutes les stries fortes, ponctuées; suturale un peu raccourcie au bout, arquéc et réunic à la quatrième dorsale; celle-ci raccourcie vers le milieu; troisième dorsale presque 
entière; deuxième et première de plus en plus courtes; humérale très fine, oblique; subhumérales nulles; marginales entières. Pygidium légèrement bombé, densément ponctué, points plus fins au bout, avec un sillon arqué, court. Mésosternum couvert de gros points peu serrés, entièrement rebordé. Prosternum assez large; stries entières, remontant et fort divergentes en devant. Pattes brunes; jambes antérieures garnies de 6-7 denticules épineıx.

Brésil (Rio-Janciro ; Montévidéo, Maldonado); Bolivie ; La Plata (Buénos-Ayres); Patagonie.

h. Pygidium sans sillon semicirculaire an bout. (63-117.) $i$. Stries prosternales à peu près dans le plan du prosternum. (63-85.)

\section{S. Pensylyanicus.}

Viridi-ceneus, nitidus; antemnis pedibusque brunneis; fronte subplana, punctulata, stria tenui, subintegra; pronoto basi lateribusque impressis punctato; elytris dimidiata parte postica intus valide munctatis, striis crenatis, dorsalibus 1, 2 et 4 in medio, $3^{\text {a }}$ ante medium abbreviatis, $4^{3}$ cum suturali arcuatim connexa, subhumerali externa vix distincta, interna longa disjuncta; pygidio dense, mesosterno marginato parce punctatis; prosterno simuato lato, striis divergentibus; tibiis anticis 8-10 denticulatis. Long. 6 mill.; larg. 5 mill.

Hister Pensylvanicus. Payk. Mon. Ilist., 62, 46, pl. 5, 6 (1811).

Saprimus Pensylvanicus. Le Conte, Nouv.-Amér., Hist. 41, 4, pl. 5,5 .

Ovale arrondi, convexe, d'un vert-métallique, luisant, 
bronzé sur le pronotum. Antennes brunes. Front à peu près plan, densément pointillé ; strie fiue, à peine interrompue à l'épistome. Pronotum court, largement bisinué et étroitement bordé de points à la base, arqué sur les côtés, arec une légère impression ponctuée, rétréci et échancré en devant, avec les angles obtus; strie marginale entière. Ecusson très petit. Elytres un peu plus longues que le pronotum, de sa largeur à la base, un peu dilatées à l'épaule, très rétrécies au bout, poncluées assez fortement sur leur dernière moitié, jusqu'au premier interstrie ; stries crénelées ; 1, 2 et 4 dorsales raccourcies au milieu; troisième un peu avant; quatrième réunie à la suturale par un are basal; humérale fine, accostant la première dorsale; subhumérale interne droite, longue, disjointe; externe à peine distincte de la marginale. Pygidium couvert d'une ponctuation serrée et uniforme; o l'extrémité bombée, avec deux surfaces ovalaires élevées, lisses. Mésosternum entièrement rebordé, avec des points espacés. Prosternum arrondi, sinué, assez large; stries fortes, à peu près dans le plan du prosternum, divergentes en devant. Jambes brunes ; antérieures dilatées, garnies de cinq denticules assez forts, et au-dessus des cinq ou six autres très petits.

Cette espèce a été trouvée par M. Sallé, à la NouvelieOrléans, en septembre, dansles charognes. Elle est répandue dans les Etats-Unis (Gcorgie, Alabama, Pensylvanie, Louisiane, Texas).

\section{S. PSEUDOHICOLOR.}

Viridi-cheus, nitidus; antemis brumneis, clava testacea; fronte plana, dense munctulata, stria integra; monoto cuprco- 
violacco, ciliuto, lateribus strigose, limboque luto punctulato; clytris dense munctulatis, extus et circa scutellum loxvibus, striis dorsalibus 1-2 dimidiutis, aliis basalilues brevissimis, 4a $\mathrm{cum}$ suturali connexa, subhumerali externa brevi, interna disjuncta pygidio a'qualiter punctulato; mesosterno maryinato; prostorno lato, subplano, striis antice divergentibus, pedibus ferrugincis; tibiis anticis 7-8 denticulutis. Long. 3 1/2 mill ; larg. 3 mill.

Ovale, arrondi, peu convexe, d'un vert-métallique, plus brillant sur les élytres, d'un cuivreux-violet sur la tête et le pronotum. Antennes brunes; massue testacée. Front plan, finement et densćment pointillé; strie semicirculaire, bien marqué, entière. Pronotum court, largement bisinué à la base, arrondi et cilié sur les côtés, très rétréci et échancré en devant, avec les angles peu saillants, couvert d'un pointillé serré, plus fort à la base et sur les côtés, lisse sur la partie postérieure du disque; strie marginale entière. Ecusson très petit. Elytres plus longues que le pronotum, de sa largeur à la base, curvilinéaires sur les côtés, rétrécies au bout, couverles d'une ponctuation très fine et assez serrée sur toute leur surface, excepté à l'épaule et dans le voisinage de l'écusson; stries fines; première dorsale raccourcie au milieu; deuxième au-delá; troisième et quatrième à la base; celle-ci réunie à la suturale par un arc basal; humérale courte, très oblique; subhumérale externe presque accolée à la marginale; interne assez longue, disjointe. Pygidium bombé, couveri de points uniformes et espacés. Nésosternum lisse, entièrement rebordé. Prosternum presque droit, assez large; stries entières dans son plan, divergentes en devant. Pattes ferrugineuses; jambes antérieures dilatées, garnies de 7.8 denticules.

Cap) de Bonne-Espérance. 


\section{S. OPTABILIS.}

Nitidus, nigro-viridis metallicus; antennis pedibusque brunneis, clava forruginea; fronte panctata, stria interrupta; pronoto coneo, angulis anticis impressis, lateribus et basi sat fortiter, limbo reliquo subliliter punctuto; stria subabbreviata; elytris viridi-cyaneis, sat dense munctatis, postice aciculatis, circa scutellum humeroque lavibus, interstitio $1^{\circ}$ strigoso; striis dorsalibus plusquam dimidiatis, $4^{\mathrm{a}}$ cum suturali cornexa, subhumerali externa vix à murginali separata, interna longa cum humerali juncta, aliaque intermedia basali; pygidio dense, mesosterno marginato parce punctatis; prosterno subrecto; striis divergentibus ; tibiis anticis 6-7 denticulatis. Long. 6 mill.; larg. 4 mill.

Ovale allongé, peu convexe, d'un vert-foncé, métallique, luisant, bronzé sur la tête et le pronotum, d'un vert-bleu sur les élytres. Antennes brunes: massue ferrugineuse. Front presque plan, ponctué assez densément, arec un gros point sur le vertex; strie fine, interrompue en devant. Pronotum court, largement bisinué à la base, oblique et bisinué sur les côtés, rétréci et échancré en devant, avec les angles arrondis et une fossette postoculaire, ponctué dans tout son pourtour, avec des points plus gros à la base et sur les côtés; strie marginale bien marquée, un peu raccourcic. Ecusson très petit. Elytres un peu plus longues que le pronotum, de sa largeur à la base, dilatées à l'épaule, rétrécies au bout, couvertes sur toute leur surface d'unc ponctuation assez serréc, aciculaire par derrière, et strigueuse sur le premier interstric; stries dorsales fortes, dépassant le milieu; deuxième un peu plus longue; quatrième réunie à la suturale par un arc basal; huméralc courte, très oblique, subhumérale interne longue, jointe à l'humérale; externe accolée à la marginale; une troisième subhumérale 
intermédiaire à la base, sur le calus huméral. Pygidium bombé, ponctuation égale et assez serrée. Mlésosternum entièrement rebordé, couvert de points espacés. Prosternum large, presque droit; stries fortes, à peu près dans le même plan, très divergentes en devant. Pattes brunes; jambes antérieures dilatées, garnies de 6-7 denticules.

Inde (Kurmaul). - (MM. de Laferté et Deyrolle).

66. S. BICOLOR.

Nigro-ceneus, nitidus, fronte punctata, stria integra; pronoto basi et lateribus punctato, stria marginali abbreviata; elytris viridi-cyancis, dense aciculato punctatis, extus et circa scutellum positis, striis dorsalibals nltra medium abbreviatis, $4^{\text {a }}$ cum suturali comexa, subhumerali interna cum humerali juncta, parallela externa brevi, pygidlio dense, mesosterno mar. ginato subtiliter punctatis; prosterno plano, striis parallclis vix antice divergentibus; tibiis anticis 8-10 denticulatis.

Hister bicolor. Fab. Syst. El., 1, 86, 14 (1801). - OI. Ent., 1, 8, 13, 13, pl. 3, 20. - Payk. Mon. Hist., 64, 48, pl. 5, 8.

Saprinus bicolor. Fahr. in Bohem. Ins. Cafr., 1, 541, 589.

Ovale, allongé, peu convexe, d'un noir métallique luisant, bronzé sur le pronotum, et d'un vert-bleu foncé sur les élytres. Antennes brunes: funicule ferrugineux. Front presque plan, couvert de points serrés; strie entière. Pronotum court, bisinué à la base, curvilinéaire sur les côtés, rétréci et échancré en devant, avec les angles obtus, et une impression postoculaire, ponctué assez fortement à la base et sur les côtés; strie marginale un peu raccourcie à la base. Ecusson très petit. Elytres plus longues que le pronotum, de sa largeur à la base, à peine dilatées à l'épaule, uu peu 
rétrécies au bout, couvertes de points serrés, fins, aciculaires, lisses autour de l'écusson et le long du bord latéral; stries bien accusées; dorsales raccourcies bien au-delà du milieu, progressivement plus courtes de 1 à 4, la dernière réunie avec la suturale par un arc basal ; liumérale très profonde, continuée par la subhumérale interne, formant comme une cinquième dorsale, parallèle aux autres, et un peu plus longues qu'elles; sublıumérale externe accolée à la marginale, et à peine distincte. Pygidium bombé, couvert d'une poncluation assez forte et assez serrée, un peu plus fine au bout. Mésosternum rebordé et faiblement pointillé. Prosternum plan, étroit; stries parallèles, à peine divergentes en devant. Pattes brunes; jambes antérieures dilatées, garnies de huit à neuf petits denticules.

Cap de Boune-Espérance; Cafrerie (Natal); Arabie (Djidda).

\section{S. VIRESCENS.}

Viridi-cencus, nitens, undique punctatus, circa scutellum Iavis; antennis tibiisque brumeis; fronte plana, stria subinterrupta; pronoto lateribus hand impresso rugoso; elytris striis dorsalibus versus medium abbreviatis, 1-3 sensim tongioribus, $4^{a}$ cum suturali connexa, subhumerati interna disjuncta, cxterna bievi; mesosterno marginato, parce punctato; prosterno striis divergentibus; tibiis anticis 7-denticulatis. Long. 4 mill.; l arg. 3 mill.

IIister virescens. Payk. Fn. Suec., 1, 48, 16 (1798). - Mon。 Hist., 69, 53, pl. 6, 7. - Gyll. Ins. Suec., 1, 91, 21, 3, 67h, 21. -Steph. Ill. Ent. Brit., 3, 157, 31.

II. viridlis. Duft., Fn. Austr., 1, 29/, 20 (1805).

?H. gemimus. Duft. Fn. Austr, 1, 224, 21 (1805). 
Suprimus viresccus. Er. in Jahrb., 1, 184, 31. - Fn. Brand., 1, 674, 6. - Heer, Fn. Helvet., 1, 461, 4. - Redt. Fn. Mustr., 237. - Bach, Fn. Prus., 1, 309, 7.

Ovale, arrondi, assez convexe, d'un vert-nútallique, luisant. Front bombé, arec de gros points serrés; strie obsolète derrière l'épistome. Pronotum court, largement bisinué à la base, arrondi sur les côtés, rétréci et échancré en devant, avec les angles obtus et abaisés, couvert de points espacés sur le disque, gros et rugueux latéralement; strie marginale entière. Ecusson très petit. Elytres plus longues que le pronotum, dilatées à l'ćpaule, rétrécies postérieurement, ponctuées assez fortement, mais peu deusément sur toute leur surface, lisses à l'épaule et darıs le voisinage de l'écusson; stries fortes; dorsales raccourcies vers le milieu; 1.3 progressivement plus longues; quatrième un peu moins que la troisième, réunie à la suturale par un arc basal; subhumérales bien distinctes; interıe disjointe. Pygidium bombé, couvert de points serrés, uniformes. Mésosternum entièrement rebordé, avec des points épars. Prosternum presque droit; stries dans le même plan, divergentes en derant. Jambes antérieures brunes, dilatées, garnies de sept denticules.

Cette espèce, assez rare, se trouve dans la plupart des contrées de l'Europe.

Angleterre; Suède; France (P. Lyon, St-Valery-surSomme, Nantes); Allemagne ; Suisse; Autriche; Espagne; Russie méridionale; Caucase.

68. S. Distivguendet.

Viger, nilidus, melullicus; fronle dense punclula, slria 
interrupta; pronoto lateribus impressis et basi rugose, disco tenuiter punctato, stria marginali integra; clytris rugoso-punctatis, humero ct area parva juxta scutellum lavibus, stria subhumerali cum humerali juncta, dorsalibus tenuibus dimidiatus, $4^{\text {a }}$ suturati connexa; pygidio annaliter et dense, mesosterno parce punctatis; prosterno punctulato, subsimuto, striis antice divergentibus; tibiis anticis 6-7 denticulatis. Long. 4 1/2 mill.; larg. 3 mill.

Ovale oblong, peu convexe, noir-métallique, luisant. Antennes brunes. Front plan, densément pointillé; strie obsolète derrière l'épistome. Pronotum court, largement bisinué à la base, oblique sur les côtés, rétréci et échancré en devant, avec les angles arrondis, couvert de points fins sur le disque, forts et serrés dans son pourtour, surtout dans l'impression latérale, où ils sont rugueux; strie marginale entière. Ecusson très petit. Elytres plus longues que le pronotum, de sa largeur à la base, dilatées à l'épaule, rétrécies au bout, rugueusement ponctuées, avec l'épaule et la base du quatrième interstrie lisses ; stries fines ; dorsales égales, raccourcies au milieu; quatrième réunie à la suturale par un arc basal; subhumérale externe distincte; interne assez longue, descendant plus bas que la première dorsale, jointe à l'humérale. Pygidium légèrement bombé au bout, densément et également ponctué. Mísosternum entièrement rebordé, avec des points épars assez forts. Prosternum pointillé, subsinué; stries fortes dans son plan, divergentes en devant. Pattes brun de poix; jambes antérieures dilatées, garnies de 6-7 denticules.

Etats-Unis.

69. S. CRibellatus.

Eneus, nitidus, antennis rufo-brunncis; fronte rugosu, stria 
antice obsoleta; pronoto subtilissime disco, lateribus rugosomunctato; stria integra; elytris dense punctatis, macula oblonga scutcllari lavi; striis 1-4 dorsatibus versus medium abbreviatis, suturali integra cum $1^{\text {a }}$ dorsali cocunte, subhumerali utraque brevi, intema disjuncta; mgidio dense munctato; mesosterno prosternoque punctatis, striis subparalletis; tibiis anticis 8-9 denticulatis. Long. 5 mill. ; larg. $31 / 2$ mill.

Ovale, assez convexe, noir-métallique, luisant. Antennes rousses; scape brun. Front densément et rugueusement ponctué; strie obsolète en devant. Pronotum court, beaucoup plus large que long, largement bisinué, avec une bordure étroite de points plus forts, oblique, subimpressionné, rugueusement ponctué sur les côtés, jusqu'au bord, rétréci et échancré en devant, avec les angles arrondis; le reste de sa surface couvert de points fins; strie marginale entière. Ecusson triangulaire, très petit. Elytres beaucoup plus longues que le pronotum, de sa largeur à la base, dilatées et saillantes à l'épaule, rétrécies postérieurement, couvertes sur toute leur surface, sur le bord infléchi, comme sur les interstries, d'une ponctuation forte et médiocrement serrée, une plaque lisse entre la suturale et la quatrième dorsale, jusqu'au-delà du milieu; strie suturale entière, arquée à la base et réunie à la quatrième dorsale ; celle-ci, ainsi que les trois autres, atteint le milieu, cependant 2 et 3 sont un peu plus longues que 1 et 4 ; humérale oblique, aussi forte que les autres; subhumérales ordinaires; interne descendant plus bas que la première dorsale, disjointe; externe basale; marginale entière. Pygidium densément ponciué, plus finement au bout, plus fortement à la base. Mésosternum entièrement rebordé, ponctué. Prosternum pointillé, parallèle, ainsi que les stries qui se réunissent en devant. Pattes brunes; jambes antérieures 
garnies de 8-9 denticules épineux; postérieures de deux rangs de spinules.

Russie méridionale; Crimée ( $\mathbf{I}$. de Laferté ).

70. S. STRIGIL.

Niger, ceneus, nitens; antennis pedibusque rufis; fronte punctuluta, stria postice tantum conspicua; pronoto utrinque pone oculos foveolato, undique punctulato latcribus rugoso, stria inlegra; clytris dense aciculato-punctalis, extus et circa sculellum lavibus, striis dorsalibus aquuliler dimidiatis, $4^{\mathrm{a}} \mathrm{cum}$ suturali comnexa, humerali obsoleta, subhumerali externa distincta, interna disjuncta brevi; pygidtio dense, mesosterno marginato parce munchulatis; prosterno subsinuato, striis divergentibues; tibiis anticis $8-10$ denticulatis. Longueur 3 mill.; larg. 2 mill.

Ovale, arrondi, faiblement convexe, noir-bronzé, luisant. Antennes ferrugineuses. Front un peu bombé, couvert de petits points serrés; strie obsolète, visible seulement par derrière. Pronotum court, largement bisinué à la base, arqué sur les côlés, rétréci et échancré en devant, avec les angles obtus et une foréole arrondie très marquée, couvert sur toute sa surface de points lins et espacés sur le disque, plus forts à la base, rugueux latéralement; strie marginale entière. Ecusson très petit. Elytres plus longues que le pronotum, de sa largeur à la base, faiblement dilatées à l'épaule, rétrécies au bout, couvertes de points aciculaires, serrés, arec l'épaule et le voisinage de l'écusson lisse, luisant; stries dorsales fines, toutes égaleınent raccourcies au milieu; quatrième réunic à la suturale par 111 arc basal; humérale indistincte; subhumérale externe courte, distincte 
de la marginale; interne disjointe, ne descendant pas audessous le la première dorsale. Pygidium bombé, finement et densémeut pointillé. Mésosternum entièrement rebordé, avec des points espacés. Prostermum subsinué; stries dans son plan, divergentes en devant. Pattes ferrugineuses; jambes antérieures dilatées, garnies de huit denticules.

Abyssinie.

\section{S. Cilalcites.}

Aincus nitidus; antemis pedibusque rufo-brunneis; fronte munctulata, stria mulla; pronoto antice biimmesso punctulato disco postico sublevi, stria parmm abbreviata; elytris parum dense punctalis, lateribus areaque scutellari magna lavibus, interstitio $1^{\circ}$ strigoso, stria suturali integra cum propiore juncta, 1-4 dorsalibus dimidiatis, humerali et subhumerali interna disjunctis brevibus; mygidio sat dense punctulato; prosterno striis utrinque divergentibus; tibiis anticis 8-9 denticulatis. L. 2-3 1/2 mill. ; larg. 1 1/2-2 mill.

IIister chalcites. Illig. Mag., 6, 40, 15 (1807).

I. affinis. Pkl. Mon. Hist.. 76, 59, pl. 7, f. 2 (1811).

H. rufipes. Ghl. Ins. Suec., 1, 9), 19 (1807).

Orbiculaire, légèrement convexe, bronzé luisant. Antennes brun-rouge : massue plus claire. Front presque plan, densément pointillé; strie nulle. Pronotum court, beancoup plus large que long, bisinué à la base, oblique sur les còtés, rétréci et échancré en devant, avec les angles arrondis, couvert d'une ponctuation fine et espacéc; disque presque lisse, avec ure impression postoculaire bien marquée de chaque côté; strie marginale, fine, un peu raccourcie à la base. Ecusson triangulaire, très petit. Elytres 
courtes, un peu plus longues que le pronotum, de sa largeur à la base, dilaté à l'épaule, rétrécies postérieurement; ponctuées assez finement et assez peu densément pour ne pas dissimuler la couleur du fond; épaules, bord latéral lisses, ainsi qu'une grande plare juxta-scutellaire qui s'étend jusqu'à la deuxième dorsale; premier interstrie sillonné de strioles obliques; strie suturale entière, arquée à la base et réunie à la quatrième dorsale; celle-ci et la deuxième raccourcies au milieu; première et troisième un peu plus longues ; humérale courte, obsolète; subhumérale interne également courte, disjointe; externe basale; marginales entières. Pygidium également et assez densément ponctué. Mésosternum ponctué entièrement rebordé. Prosternum rétréci au milieu, recourbé au bout antérieur; stries rapprochées au milieu, divergentes à la base comme en devant. Pattes d'un rouge-brun, métallique sur les cuisses ; jambes antérieures garnies de nombreux denticules épineux (8-9).

$\sigma^{*}$. Métasternum avec une légère excavation au milieu du bord postérieur, limitée par un petit tubercule saillant de chaque côté.

Diffère du cupreus Er., surtout par la ponctuation des élytres, qui est moins serrée et laisse apercevoir le fond de l'élytre, et par ses jambes antérieures garnies d'un plus grand nombre de denticules.

Cette espèce est répandue dans toutes les parties méridionales du bassin de la Méditerranće; Portugal; Espagne; France méridionale; Corse; Italic; Sicile; Autriche; Grèce; Russie méridionale; Turquie d'Asie ; Syrie (Beyrouth, Saïda, Damas); Arabie; Egypte; Tripoli ; Algérie; Maroc; Sénégal; Madère. 


\section{S. AREOLATUS.}

Nigro-cencus, nitens; antemnis pedibusque brunneis; fronte subtiliter rugulosa, stria intervupta; pronoto punctulato lateribus rugnloso, stria abbreviata; elytris dense aciculato-punctalis, cxtus et juxta scutellum lavibus, striis temuibus, dorsalibus 1-4 dimidiatis, sensim brevioribus, $4^{\text {a }} \mathrm{cum}$ suturali connexa, subhumerali utraque brcvi, interna disjuncta, humerali indistincta; pygidio dense, mesosterno marginato parce punctatis; prosterno plano, striis antice modice divergentibus; tibiis anticis 6-7 denticulatis. Long. $23 / 4$ mill.; larg. 2 mill.

Saprinus arcolatus. Fahr. in Bohem. Ins. Cafr., 1, 542, 591 (1851).

Ovale, arrondi, noir-métallique, luisant. Antennes brunes. Front peu convexe, densément et rugueusement ponctué; strie fine, obsolète derrière l'épistome. Pronotum court, largement bisinué à la base, arqué sur les côtés, rétréci et échancré en devant, avec les angles obtus, et sans impression postoculaire marquée, couvert de points fins, peu serrés, plus forts sur le limbe et rugueux latéralement. Ecusson très petit. Elytres plus longues que le pronotum, de sa largeur à la base, dilatées à l'épaule, à peine rétrécies au bout, couvertes d'une poncluation serrée, circulaire arec l'épaule et un espace juxta-scutellaire à la base du quatrième interstrie, lisses et polis ; stries fines; dorsales raccourcies au milieu, mais 1-4 progressivement plus courtes; quatrième réunie à la suturalc par un arc basal: humérale courte, oblique, indistincte; subhumérales courtes: externe séparée de la ınarginale; interne disjointe, ne dépassant pas la première dorsale. Pygidium peu convexe, densément et également ponctué. Mésosternum entièrement rebordé, avec de petits points espacés. Prosternum presque plan, 
assez étroit, stries dans son plan, presque parallèles, un peu divergentes en devant. Paltes d'un brun-ferrugineux; jambes antérieures dilatées, garnies de 6-7 denticules.

Cafrerie (Natalj.

\section{S. CîpRELS.}

Aneus nitidus; antemis pedibusque rufo-piccis; fronte dense punctulata, stria intervupta; pronoto pone oculos impresso punclato, medio lavi, stria subabbreviata; elytris alcuse rugoso punctatis, margine latcrali posticoque ct urea juxte-scutcllari lata lcevi, stria suturali integra cum $1^{a}$ dor'sali cocunte, hac in molio abbreviata 1-3 scnsim longioribus, humerali mulla, subhumerali internu longiori, externa brevi; pygidio alcuse munc. tato; mosterno striis utrinque divergentibus; tibiis anticis 6-7 denticulatis. Long. 3 3/4 mill.; larg. 2 1/2 mill.

Saprinus cupreus. Er. Jahr, , 182, 27 (1834). - Fahr. in Bohem. Ins. Cafr., 1, 541, 590 .

Ovale, court, assez convexe, noir-métallique luisant. Antennes rouges: scape brun. Front faiblement convexe, densément pointillé, avec un point enfoncé sur le vertex; strie interrompue derrière l'épistome. Pronotum beaucoup plus large que long, bisinué à la base, oblique sur les côtés, fortement rétréci, échancré en devant, avec les angles arrondis, couvert de points assez serrés, fius, un peu plus forts dans le pourtour, et presque lisse sur le disque postérieur, avec une légère impression postoculaire; strie marginale presque entière. Ecusson petit, triangulaire. Elytres courtes, cependant plus longues que le pronotum à la base, dilatées à l'épaule, rétrécies au bout, couvertes d'une ponctuation dense et serrée, avec le bord latéral et postérieur lisse, ainsi qu'un grand espace juxta-scutellaire qui s'étend postérieu- 
rement jusqu'au milieu, et en dehor's, jusqu'à la deuxième dorsale; strie suturale cutière, arquée à la base et réunie avec la quatrième dorsale; l'humérale parait nulle; subhumérale interne droite, longue et remontant très haut; externe courte, très rapprochée de la marginale; dorsales descendant vers le milieu, première beaucoup plus longue; quatrième bien plus courte que les autres. Pygidium densément et également ponctué. Mésosternum entièrement rebordé, couvert de points espacés, peu profonds. Prosternum lisse, assez large ; stries entières, divergentes aux deux extrémités. Pattes brun de poix; jambes antérieures garnies de cinq denticules épineux.

đ. Présente à l'extrémité du métasternum une petite excavation étroite, bordée latéralement par deux tubercules assez saillants.

Cafrerie; Cap de Bonne-Espérance; Benguela.

\section{S. BRUNIVESTIS.}

Nigro-ceneus nitidus; antennis, pedibus elytrisque rufo-brumneis; fronte punctulata, striaobsoleta; monoto punculato, disco lavi, antice bïmpresso, stria integra; elylris dense rugoso punctatis, lateribus, areaque scutcllar i lavibus, stria suturali integra antice cum $4^{\circ}$ elorsali coeunte, hac et 1-3 dorsalibus ullea medium productis, humerali obsoleta, subhumerali interna recta longiori; mygidio aqualiter punctuleto; mrosterno striis utrinque divergentibus; tibiis anticis cremulatis. Long. 3 mill.; larg. 2 mill.

Suborbiculaire, convexe, noir-bronzé luisant. Antennes, pattes, élytres d'un brun-rouge. Front peu convexe, densément pointillé; strie obsolète en levant. Pronotum court, 3е Série, томЕ 
beaucoup plus large que long, bisinué à la base, oblique sur les côtés, échancré et rétréci en devant, avec les angles arrondis, couvert de points très fins, presque lisse sur le disque postérieur, avec une échancrure postoculaire de chaque côté; strie marginale entière. Ecusson très petit, triangulaire. Elytres courtes, cependant plus longues que le pronotum, de sa largeur à la base, dilatées à l'épaule, rétrécies au bout, couvertes d'une ponctuation serrée, rugueuse, avec le bord latéral lisse, ainsi qu'un assez large espace juxta-scutellaire, étendu en dehors, jusqu'à la deuxième dorsale; strie suturale entière, arquée à la base et réunie à la strie voisine; dorsales 1-4 parallèles, d'égale longueur, dépassant le milieu; humérale obsolète ; subhumérale interne longue, droite; externe courte, basale; marginales entières. Pygidium assez densément et également ponctué. Mésosternum avec de petits points espacés, entièrement rebordé. Prosternum rétréci au milieu; stries rapprochées au milieu, s'éloignant en devant et s'arrondissant pour se rejoindre. Jambes antérieures dilatées et arrondies vers les deux tiers, garnies de 7-8 denticules épineux.

§. Mésosternum arec une impression médiane, et de chaque côté un petit tubercule peu élevé, placé presqu'au milieu et non au bord apical.

Sénégal.

\section{S. FRONTISTRICS.}

Nigro-ceneus, nitidus; antenmis pedibusque ferrugineis; fronte punclulata, stria semi-circulari integra; pronoto marginato pone oculos impresso, undique muctato, disco subtilissime; clytris rugoso-dense punctatis, extus et area subscutellari usque ad $1^{\text {um }}$ interstitium extensa polita, striis $1 . /$ dorsalibus dimi- 
diatis, $4^{\text {a }}$ cum suturali arcuatim comexa, subhumerali externa indistincta, interna integra angulatim cum humcrali juncta; mygidio aqualiter dense; mesosterno marginato parce; prostcrmo subtiliter punctulatis, striis subdivergentibus; tibiis anticis S-denticulatis. Long. $23 / 4$ mill. ; larg. 2 mill.

Orbiculaire, assez convexe, noir-bronzé, luisant. Antennes ferrugineuses. Front bombé, finement pointillé; strie circulaire, entière, bien marquée. Pronotum court, largement bisinué à la base, oblique sur les cotés, rétréci et échancré en devant, avec les angles obtus et creusés d'une fossette postoculaire, couvert de points très fins sur le disque, assez forts et rugueux latéralement; strie marginale entière. Ecusson très petit. Flytres courtes, un peu plus longues que le pronotum, de sa largeur à la base, curvilinéaires sur les côtés, rétrécies au bout, couvertes d'une ponctuation rugueuse, serrée, remontant sur le premier interstrie, et sur le bout du deuxième et du troisième, laissant le pourtour de l'élytre libre, ainsi qu'un espace lisse, juxta-scutellaire, étendu jusqu'au milieu de la longueur, et jusqu'au premier interstrie, assez bien limité; stries fortes; dorsales 1-4 raccourcies au nilieu; quatrième réunic à la suturale par un arc basal; subhumérale externe confondue avec la marginale; interne entière, rencontrant angulairement l'humérale qui accoste obliquement la première dorsale. Pygidium peu bombé, également et densément ponctué. Mésosternum entièrement rebordé, avec de petits points espacés. Prosternum pointillé, presque droit ; stries dans son plan, un peu divergentes en devant. Pattes ferrugineuses; jambes dilatées, garnies de huit petits denticules.

Chili. 


\section{S. Cavaluerr.}

Suborbicularis, piceus nitidus; antennis pedibusque brumneis; fronte puncticulata, stria interrupta; pronoto antice subrugoso, biimpresso, limbo punctato; clytris postice parce subtiliter punclatis, stria sulurali antice subinterrupta; $4^{\mathrm{a}}$ dorsali versus scutcllum arcuata $3^{\text {a }}$ que dimidialis, 1-2 longioribus, subhumerali interna longa vix disjuncta; pygidio aqualiter et minus profunde punctato; prosterno striis antice junclis subparallelis; tibiis anticis 7-S denticulatis. Long. 3 mill.; larg. 2 1/2 mill.

Suhorbiculaire, peu convexe, noir de poix, assez luisant. Antennes brunes: scape obscur. Front presque plan, également pointillé; strie fine, interrompue. Pronotum beaucoup plus large que long, bisinué à la base, étroitement bordé de points serrés, légèrement arqué sur les côtés, largement et densément ponctués, avec une impression antérieure un peu rugueuse, rétréci et échancré en devant, avec les angles arrondis, lisse sur le disque; strie marginale entière. Ecusson triangulaire, très petit. Elytres courtes, larges, un peu plus longues que le pronotum, de sa largeur à la base, dilatées à l'épaule, un peu rétrécies postérieurement, couvertes sur leur moitié postérieure de points peu serrés et peu profonds; stric suturale se continuant sans arrêt avec l'apicale, un peu interrompue vers l'écusson, puis cnvoyant un arc sur la quatrième dorsale; celle-ci, ainsi que la troisième, raccourcie vers ce milieu ; 1-2 plus longues; luumérale fine, oblique, presque réunie angulairement, avec la subhumérale interne, qui est longue; externe très courte, basale; marginale entière. Pygidium également et assez densément pouctué. Mésosternum entièrement rebordé, avec quelques points. Prosternum légèrement concave; stries presque parallèles et droites, réunies en devant, en 
s'arrondissant. Paltes rouge-brun; jambes antérieures garnies de 7-8 denticules épineux.

Cuba, dans les bouses, en arril.

Se distingue du Sapr. Cnymenens, arec lequel il a les plus grands rapports, par sa taille plus petite, sa forme moins convexe, sa ponctuation moins forte, moins profonde et moins serrée; la massue des antennes est aussi plus obscure.

\section{S. GuYanetsis.}

Suborbicularis, niger nitidus; antemis rufis; fronte punctulatu, stria obsoleta, intcrupta; pronoto punctulato, lutcribus late impressis rugosis, margine baseos punctuta, stria integra; clytris postice punctalis, stria suturuli integra, antice arcuatim cum $4^{\text {a }}$ dorsali juncta, 3-4 dorsalibus versùs medium, 1-2 ultra abbreviatis, subhumerali interna angulatim cum humcrali continuata; pygidio dense munctato; prostcrno striis vix divergentibus, antice junctis; tibiis anticis 7-8 denticultutis. Long. 4 mill, ; larg. 3 mill.

Suborbiculaire, peu convexe, noir, luisant. Antennes rousses; scape brun. Front assez bombé, densément pointillé ; strie obsolète. Pronotum beaucoup plus large que long, bisinué à la base, arec une bordure de points très serrés, oblique et un peu sinué sur les côtés, rétréci et échancré en derant, avec les angles arrondis, finement pointillé sur le disque, plus fortement en devant et sur les côtés, arec une large impression rugueuse qui s'étend de l'angle antérieur, jusqu'au milieu, en s'affiiblissant; strie marginale entière. Ecusson triangulaire, très petit. Elytres larges, courtes, plus longues que le pronotum, curvilinéairement dilatées sur les côtés, rétrécies au bout, couvertes 
postérieurement de points assez forts et peu serrés, qui remontent à la suture, au-delà du milieu et sous le bord infléchi de points plus fins; strie suturale entière, continuée sans interruption, avec l'apicale, arquée à la base et réunie avec la quatrième dorsale; première et deuxième égales, dépassant de beaucoup le milieu; premier interstrie en partie ponctué, et en partie obliquement strigueux; troisième et quatrième d'égale longueur et beaucoup plus courtes; humérale oblique, bien marquée, réunie à la subhumérale interne, qui est longue et droite; externe courte, basale ; marginale entière. Pygidium bombé, densément et également ponctué. Ilésosternum entièrement rebordé, assez fortement ponctué. Prosternum faiblement dilaté de part et d'autre; stries peu divergentes et réunies en devant en forme de cercle. Pattes brunes; jambes antérieures garnies de sept ou huit denticules épineux.

Cuba ; Cayenne ; Brésil ; Para.

\section{S. Blissonir.}

Suborbicularis, parum convexus, nigro-picens subnitidus ; antennis pedibusque rufo-brunneis; fronte dense punctuiata, stria obsolcta; monoto biimpresso lateribus et basi punctato; clytris dimidia parte postica parce punetulatis, stria suturali integra, arcuatim antice juncta, dorsalibus 3-4 dimidiatis, 1-2 paulo longioribus, humerali cum interna subhumerali, subintegra; pygidio aqualiter dense punctulato; prosterno striis utringue subdivergentibus; tibiis anticis 6-7 denticulatis. Long. 3 mill. ; larg. 2 1/2 mill.

Suborbiculaire, peu convexe, noir de poix, assez luisant. Antennes brunes. Front peu bombé, densément pointillé; strie obsolète. Pronotum plus large que long, bordé de 
points dans tout son pourtour, plus forts et presque rugueux vers les angles antérieurs, surtout au fond de l'échancrure postoculaire, bisinué à la base, légèrement arqué sur les côtés, rétréci et échancré en devant, avec les angles arrondis; strie marginale entière. Ecusson très petit, triangulaire. Elytres courtes, un peu plus longues cependant que le pronotum, de sa largeur à la base, dilatées à l'épaule et rétrécies au bout, couvertes de points peu serrés et légers sur leur moitié postérieure, à peine visiblement pointillées sur le bord infléchi; strie suturale entière, se continuant sans interruption le long du bord apical, et se réunissant à la base par un arc à la quatrième dorsale; celle-ci raccourcie au milieu, ainsi que la troisième; première et deuxième un peu plus longues; humérale oblique, bien marquée; subhumérale interne, longue, réunie angulairement avec l'humérale; externe courte, basale ; marginale entière. Pygidium densément et également ponctué. Mésosternum entièrement rebordé, légèrement ponctué. Prosternum un peu rétréci au milieu; stries entières, bien marquées, un peu divergentes. Pattes brun-roussâtre; jambes antérieures garnies de 6-7 denticules épineux.

Cetle espèce, découverte par M. Sallé, se trouve dans la vallée de Caracas (Vénézuéla), sous les bouses, en juin.

\section{S. EgYPTIACUS.}

Nigro-piceus, nitidus; antemis pedibusque brunneo-ferrugineis; fronte rugulosu stria subintegra; pronoto ciliato, dense punctulato, basi et lateribus lata rugosis, stria marginali subabbreviata; elytris dense et fortiter punctatis, area juxta-scutellari et humero lavibus, striis dorsalibus subcequatibus dimidiatis, $4^{\mathrm{a}}$ basi cum suturali connexa, subhumerali externa 
distincta, iuterna lonya cum humerali juncta; pygidio apice convexo dense, mesosterno marginato parce punctatis; prosterno plano, striis modice convergrntibus; tibiis anticis 5-dentatis. Long. 5 mill. ; larg. 3 4/5 mill.

Ovale, arrondi, assez convexe, d'un brun de poix, luisant. Antennes ferrugineuses. Front plan, densément et rugueusement ponctué ; strie à peine interrompue. Pronotum court, largement bisinué à la base, courbé et bordé de cils jaunes sur les côtés, profondément échancré et rétréci en devant, avec les angles arrondis, et une faible fossette postoculaire, couvert de points fins sur le disque, forts à la base et rugueux latéralement; strie marginale à peine raccourcie. Ecusson très petit. Elytres plus longues que le pronotum, de sa largeur à la base, un peu dilatées à l'épaule et rétrécies au bout, couvertes d'une ponctuation forte et rugueuse sur toute leur surface, avec un espace lisse et luisant autour de l'écusson, lequel s'étend même sur le milieu des deuxième et troisième interstries; stries fortes, bien marquées; dorsales à peu près égales, raccourcies au milieu; quatrième réunie à la suturale par un arc basal; subluumérale externe bien séparée de la marginale; interne longue', joignant anguleusement l'humérale. Pygidium bombé à l'extrémité, densément et fortement ponctué. Mésosternum avec des points espacés, entièrement rebordé. Prosternum étroit, plan; stries dans son plan, convergentes. Pattes d'un brun-ferrugineux : jambes antérieures dilatées, garnies de trois forres aents et ac aeux aenticules.

Egypte (M. Deyrolle).

\section{S. GILVICORNIS.}

Pirens, nilidns: autenmis pedibusque? rufo-brumuris; fronte 
rugulosa, stria tenui subintegra; pronoto ciliato, utrinque foveolato, latcribus basique rmgoso-punctato; clytris disco tcnuiter parce muctato, striis validis, dorsali $1^{\text {a }}$ subintegra, ccteris sensim brcvioribus, $4^{\text {a }}$ cum suturali conncxa, subhumerali cxtcrna brevi, intoma juncta humcrali completa; mgidio convexo, valide ac parce punctato; mesosterno murginato; prostcrno plano, angusto, striis convergcntibus; tibiis anticis 5-denticulatis. Long. 4 1/2 mill. ; larg. 31/2 mill.

Saprinus gilvicornis. Er. in Jalı., 1, 184, 29 (1834).

Suborbiculaire, bombé, brun de poix, luisant. Antennes d'un brun-roux. Front court, ruguleux; strie fine, presque entière, épistome très étroit. Pronotum court, largement bisinué à la base, arqué et cilié sur les côtés, rétréci et ćchancré en devant, avec les angles ohtus et une fossette postoculaire, couvert de points forts et rugueux à la base et sur les côtés. Ecusson très petit. Elytres à peine plus longues que le pronolum, de sa largeur à la base, peu rétréeies au bout, couvertes sur le disque de petits points superfieiels, peu serrés, stries fortes et bien marquées; première dorsale presque entière, les autres progressivement plus courtes; quatrième réunie d la suturale par un arc basal ; subhumérale externe séparée de la marginale; interne jointe à l'humérale presque sans angle et atteignant le bout. Pygidium bombé, couvert d'assez gros points, avec une impressjon subapicale, particularité sexuelle probablement. Mésosternum lisse, entièrement rebordé. Prosternum droit, étroit; stries dans le mème plan, convergentes. Pattes d'un brun-ferrugineux; jambes antérieures dilatées, garnies de cinq denticules.

Egypte. 
80. S. TENUistrils.

Nigro-piceus nitidus; antennis pedibus clytrisque fulvis; fronte punctulata, stria obsolctu; pronoto punctuluto latcribus profunde impresso rugoso punctato, stria tenuissimia, subabbreviata; elytris suturati integra, dorsalibus 4 in medio abbreviatis, sublumerali cum humerali coeunte; pygidio punctato; prosterno striis divergentibus; tibiis anticis 5-6 denticulatis. Long. 4 mill.; larg. $31 / 4$ mill.

Suborbiculaire, peu convexe, noir de poix luisant. Antennes rousses, massue plus claire. Front légèrement convexe, finement et assez densément ponctué; strie nulle. pronotum plus large que long, bisinué à la base, oblique et relevé en bourrelet sur les côtés, rétréci et éclıancré en devant, avec les angles arrondis, couvert de points très fins sur le disque, plus forts le long de la base, rugueux sur les côtés, une longue et profonde impression s'étend du bord antérieur, jusqu'à la base ; strie marginale très fine, dans le bord même, un peu raccourcie. Ecusson petit, triangulaire. Elytres brunes, courtes, cependant un peu plus longues que le pronotum, de sa largeur à la base, dilatées à l'épaule, rétrécies postérieurement, couvertes de points assez fins, serrés et comme rugueux sur les interstrics, avec les côtés, et le pourtour de l'écusson lisse; strie suturale entière, arquée à la base et réunie avec la quatrième dorsale; cellesci, ainsi que les trois premières, raccourcies au milieu; humérale fort oblique formant un coude à sa jonction avec la subhumérale interne; marginale forte, entière, bordée de points. Pygidium bombé, couvert de points médiocrement serrés. Mésosternum peu distinctement ponctué, entièrement rebordé. Prosternum rétréci au milieu; stries diver- 
gentes. Pattes ferrugineuses; jambes antérieures garnies de cinq ou six denticules épineux.

Diffère de l'Égyptiacus, par son front ponctué, non rugueux, à strie obsolète, par la strie du pronotum, fine dans l'arête même, par la ponctuation des élytres fine, moins serrée, rugueuse sur les stries, par le pygidium moins fortement ponctué, les jambes antérieures à petits denticules, et les stries prosternales divergentes en; devant; du gilvicornis, en outre par le pronotum non cilié, et par la strie subhumérale disjointe.

Egypte. (Un seul individu appartenant au Musée de Paris.)

\section{S. LAUTIS.}

Niger nitidus; antemis pedibusque rufo-piceis ; fronte punctulata, stria subinter rupta; pronoto punctulato, basi lateribusque subimpressis fortius, stria integra ; elytris postice sparsini punctatis, stria subintegra, cum $4^{\text {a }}$ dorsali cocunte, 2-4 dorsalibus versus medium abbreviatis, $1^{\text {a }}$ paulo breviore, stria subhumerali brevi disjuncta; pygidio sat dense et fortiter punctato; mesosterno punctato; prosterno striis parallelis; tibiis anticis 6-denticulatis. Long. 4 mill.; larg. 3 mill.

Saprinus lautus. Er. Kæf. Brand., 1, 675, 7 (1839). - Austr,, 782. - Bach. Kæf. Prus., 1, 309, 8.

Ovale, suborbiculaire, assez convexe, noir de poix luisaní. Antennes brunes : funicule ferrugineux. Front peu convexe, ponctué; strie interrompue derrière l'épistone. Pronotum beaucoup plus large que long, bisinué à la base, légèrement arqué sur les côtés, rétréci et échancré en devant, avec les angles arrondis, finement pointillé sur toute la surface, arec une étroite bordure de points plus forts à la base, et une impression latérale presque rugueuse et grossièrement 
ponctué ; strie marginale entière. Ecusson triangulaire, très petit. Elytres plus longues que le pronotum, de sa largeur à la base, dilatées à l'épaule, ensuite rétrécies jusqu'au bout, couvertes dans leur moitié postérieure de points assez espacés, jusqu'à la deuxième strie dorsale; suturale entière, réunie à la base, avec la quatrième dorsale par un are; 2-4 dorsales dépassant un peu le milicu; première un peu plus courte et plus forte; humérale fine, très oblique; subhumérale interne courte, disjointe; externe basale; marginale entière ; bord infléchi, ponctué. Pygidium couvert d'une ponctuation assez forte et serrée. Mésosternum entièrement rebordé, ponctué. Prosternum finement pointillé ; stries entières, parallèles. Pattes brunes ; jambes antérieures garnies de six denticules épincux et crénelées, finement vers la cuisse.

France (Fontainebleau); Allemagne; Autriche.

\section{S. Postilunus.}

Niger nitidus; antennis pedibusque brunncis; fronte muncticulata, stria obsoleta; pronoto limbo menctulato, ante scutellum impresso; clytris postice parce punctatis, stria suturati subintegra, dorsalibus 2-4 xqualibus ultra medium abbreviatis, $1^{\text {a }}$ longiori, subhumerali interna disjuncta, cxterna distincta; mygidio cequaliter punctulato; mosterno striis parallelis convergcnlibus; Libiis anticis 6-denticulutis. Longueur 4 mill.; larg. $23 / 4$ mill.

Ovale, assez convexe, noir luisant. Antennes brunes: funicule rouge. Front à peine bombé, densément pointillé; strie obsolète. Pronotum beaucoup plus large que long, bisinué à la base, avec une impression antéscutellaire, et une 
bordure de points, oblique sur les cotés et largement pointillé, rétréci et échancré en devant, avec les angles arrondis; strie marginale entière. Ecusson triangulaire très petit. Elytres plus longues que le pronotum, de sa largeur à la base, dilatées à l'épaule, rétrécies postéricurement, couvertes sur leur moilić postérieure de points peu serrés, jusqu'à la première strie dorsale; toutes les stries assez fortes et poncluées; suturalc à peine raccourcie au bout, arquée à la base et réunie à la quatrième dorsale ; 2 -4 égales entre elles, dépassant un peu le milieu; première plus longue, un peu contournéc au bout ; lıumérale oblique; subhumérale interne assez longue, disjointe ; externe basale, assez distincte; marginale entière. Pygidium également couvert de points assez serrés. Mésosternum entièrement rebordé, couvert d'une ponctuation assez forte. Prosternum étroit, plan; stries parallèles, dans le mème plan, convergentes. Pattes brun-rouge; jambes antérieures garnies de 6-7 denticules épineux.

Etats-Unis.

\section{S. Blanchu.}

Eneus nitidus; antennis pedibusquerufis; fronte subtilissime puncticulata, stria interrupta; pronoto basi et lateribus punctato, biimpresso, stria integra; elytris intus postice punctatis, stria suturali integra, antice arcuatim juncta, dorsalibus 1-4 in medio abbreviatis, sensim longioribus, subhmmerali interna brevi obsoletu, externa nulla; pygidio basi punctato; mrosterno parallelo striis antice junctis, subapproximatis; tibiis anticis 6-denticulatis. Long. 3 1/2 mill.; larg. $21 / 2$ mill.

Orale, assez convexe, métallique, bronzé luisant. Antennes rousses. Front peu bombé, très finement pointillé ; strie bien 
marquée, interrompue derrière l'épistome Pronotum beaucoup plus large que long, bisinué et bordé de points assez forts à la base, oblique sur les côtés, avec une fossette arrondie, superficielle, d'où part une étroite bande de points qui ne touchent pas le bord, rélréci et échancré en devant, avec les angles arrondis, couvert sur le reste de la surface de points imperceptibles; stric marginale entière. Ecusson triangulaire, très petit. Elytres assez allongées, plus longues que le pronotum, de sa largeur à la base, dilatées à la base, rétrécies au bout et couvertes de points assez forts, dont quelques-uns remontent le long des stries dorsales; suturale ponctuée, entière, réunie en arc basal, avec la quatrième dorsale; 1-4 dorsales raccourcies vers le milieu, allant en augmentant de longueur; humérale oblique, divisée; subhumérale interne courte, obsolète, disjointe; externe nulle; marginale entière. Pygidium finement et également pointillé, presque lisse au bout. Mésosternum entièrement rebordé, à peine visiblement ponctué. Prosternum subparallèle, à stries assez rapprochées, un peu sinueuses, et se joignant en devant. Pattes rouges; jambes antérieures garries de six denticules épineux, les trois extrêmes très grands.

Syrie (Smyrne, Beyrouth, Damas, Saida); Egypte.

\section{S. TRIANGULIFER.}

Niger, nitidus; antonnis pedibusque rufo-brumneis ; fronte punctulata, stria tenui, clypeo angulata integra; monoto limbo omni punctato, lateribus latius, stria subintcgra; elyliris dimidia parte postica valide el parce punclatis, striis dorsalibus

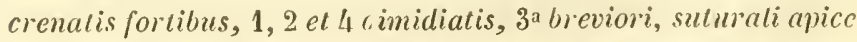
abbreviata, basi cum $4^{\mathrm{a}}$ dorsali conncxa, subhumerali utraque 
mulla; mygidio ctqualiter dense, mesosterno marginato parce punctatis; prosterno triangnlari, plano, striis angulatim punctis; tibiis anticis 7.8 denticulatis. Long. 2 1/2 mill.; larg. 2 mill.

Suborbiculaire, légèrement convexe, noir, luisant. Antenues brunes. Front arrondi, presque plan, densément pointillé; strie fine, entière, avancée en anse sur l'épistome. Pronotum court, largement bisinué et bordé de points à la base, avec une impression antéscutellaire, arqué sur les côtés, avec une large bordure de points assez forts, rétréci et échancré en devant, avec les angles obtus; strie bien marquée, à peine raccourcie. Ecusson très petit. Elytres un peu plus longues que le pronotum, de sa largeur à la base, curvilinéaires sur les côtés, rétrécies au bout, couvertes d'assez gros points espacés sur leur moitié postéricure, jusqu'au premier interstrie; stries crénelées, fortes; dorsales raccourcies au milieu; troisième un peu avant; suturale raccourcie au bord apical, réunie ả la quatrième dorsale par un arc basal; humérale oblique, assez forte; subhumérales nulles. Pygidium bombé, également ponctué, avec un double o sculpté au bout $\sigma^{*}$. Mésosternum rebordé, avec des points épars. Prosternum en triangle très allongé, avec les stries réunies angulairement. Pattes ferrugineuses; jambes antérieures dilatées, bordées de 7-8 denticules.

Yucatan (II. Pilate).

\section{S. PASTORALIS.}

Brunneus, nitidus; ore, antennis, elytris pedibusque rufis; fronte strigosula, stria obsoleta; monoto disco levissime, limbo fortius munctuiato, stria marginali integra; elytris apice et intus usque ad basim tennissime punctulatis, striis subhume. rali utraque disjuncta, dorsalibus 1 et 4 in medio, 2-3 pone 
abbreviatis, $4^{\text {a }}$ cum suturali connexa; pygidio dense aqualiter, mesosterno marginato parce punctutis; prosterno angusto, plano, striis subparallelis, convergentibus; tibiis anticis 8-10 denticulatis. Long. 2 1/2 mill.; larg. $14 / 5$ mill.

Saminus pastoralis. J. du V. in Soc. Ent. (1852), 704.

Suborbiculaire, convexe, brun de poix, luisant. Mandibules, bouche et antennes rouges. Front bombé, ruguleux; strie fine, obsolète derrière l'épistome. Pronotum court, largement bisinué à la base, arqué sur les côté, rétréci et échancré en derant, avec les angles abaissés, obtus, couvert d'une ponctuation plus forte à la base, et surtout latéralement. Ecusson très petit. Elytres ferrugineuses, beaucoup plus longues que le pronotum, de sa largeur à la base, dilatées à l'épaule, peu rétrécies au bout, ponctuation très fine, étendue sur toute la moitié postérieure, et jusqu’à la base du quatrième interstrie; stries fines, bien distinctes; 1 et 4 dorsales raccourcies au milieu; 2-3 au-clelà; quatrième réunic à la suturale par un arc basal; sublıumérales courtes, l'une et l'autre disjointe. Pygidium convexe, également et assez densément ponctué. Mésosternum entièrement rebordé, pointillé. Prosternum étroit, plan; strie dans le mème plan, presque parallèles, un peu convergentes en devant. Pattes ferrugineuses; jambes antérieures dilatées, garnies de 8-10 denticules fins.

France inéridionale (Montpellier).

i. Stries prosternales remontant en devant, sur les côtés du prosternum. (86-117.)

\section{S. INNUBUS.}

Dibicularis, niger nitidus; renemnis rufis pelibusque forru- 
gineis; fronte rugoso menctatu, cruciatim impressa, stria mulla; monoto late et sat fortiter ad latera punctato, ante scutellum impresso, striu integra; clytris postice munctis validis parum densis, striu snturali postice sububbreviata, untice cum $4^{2}$ dorsali juncta, hac ante medium, $3^{\text {a }}$ interrupla prius, 2 a $3^{\text {a }}$ que ultra medinm abbreviatis, sublnmerali incrue brevi disjuncta; pygidio menchuto; mostemo striis vulde divergentibus; tibiis anticis 7-lenticulatis. Long. 4 mill. ; larg. 5 mill.

? S. imiressifrons. Sol. in Gay, Hist. Chili, 379, 4 (1849).

Saprimus immbus. Er. Jalı., 187, 38 (iS34).

Orbiculaire, légèrement conrese, noir luisant. Antennes ferrugineuses, massue pâle. Tète densément et rugueusement ponctuée, arec une impression longitudinale au milieu et une autre transverse entre les antennes, se coupant en croix. Pronotum beaucoup plus large que long, bisinué à la base, courbé sur les côtés, rétréci fortement et échancré en devant, arec les angles arrondis, couvert de points peu serrés, très fins sur le disque, et assez forts latéralement, avec une très légère impression antéscutellaire; strie marginale entière. Ecusson très petit, triangulaire. Elytres plus longues que le pronotum, de sa largeur à la base, rurvilinéairement dilatérs sur les côtés, rétrécies au bout, couvertes dans leur moitié postérieure de la suture à la premiere strie dorsale d'une poncluation forte, assez espacée ; strie suturale entière, un peu raccourcie au bout, réunie à la base arec la première dorsale; celle-ci atteignant à peine le milieu; deuxième réduite à un point basal, séparé d'une courte ligne qui en est la suite; première arrivant aux deux liers; deuxième ung peu plus courte; humérale oblique, rapprochée de la première dorsale; subhumérale interne courte, di:jointe; externe courte, basále; marginales entières; interne forte, bordée de points. Pysidium 3e Séric, Tone un. 
bombé, également, mais peu densément ponetué. Prosternum large, finement pointillé; stries très divergentes en devant. Mésosternum ponctué, entièrement rebordé. Pattes ferrugineuses ; jambes antérieures garnies de 6-7 denticules épineux, peu serrés.

Brésil (Para); Bolivie (Santa-Cruz); Chili (Conception, Araucania).

La seule différence qui sépare le $S$. impressifrons du $S$. inmubus Er., du moins autant qu'on en peut juger par la description de cet auteur; c'est que la troisième dorsale est presque nulle, et que la subhumérale interne l'est entièrement; mais cette différence ne paraît pas fondamentale, car dans le seul individu qu'il m'a été donné d'examiner et qui est le type de la description de l'impressifrons, la sublumérale interne est on ne peutplus courte, et en ne tenant pas comple du court prolongement de la troisième dorsale, on peut dire qu'elle est presque nulle.

\section{S. RUSSATLS.}

Brumco-piceus, nilidus; antennis pedibusque ferrugineis; fronte rngosula, stria antice obsoleta; pronoto ciliato, basi et lateribus punctulato; elytris postice dense punctutis, sub apicem impressis, striis crenutis, dorsulibus dimidiatis, 4a cum suturali connexa, subhumerali ulraque brevi, disjuncta, myidio cequaliter et sut valile punctato; mesosterno marginato, tavi; mrostcrno anguste carinato, striis valde ascendentibus; tibiis anticis 7-8 denticulatis. Long. 3 mill.; larg. 2 mill.

Ovale, peu convexe, d'un brun de poix, luisant. Antennes ferrugineuses. Front légèrement bombé, densément et ruguleusement pointillé; strie fine, obsolète derrière l'épi- 
stome. Pronotum cilić, court, largement bisinué à la base, courbé sur les côtés, rétréci et échancré en devant, avec les angles arrondis, couvert de points étroitement a la base, et sur une assez grande étendue latéralement; strie marginale entière. Ecusson très petit. Elytres un peu plus longues que le pronotum, dilatées à l'épaule, rétrécies au bout, couvertcs de points assez serrés, mais non rugueux, remontant un pen sur les interstries, avec une impression superficielle au bord apical; stries crénelées, bien marquées; 3-4 dorsales raccourcies au milieu; 1 et 2 plus bas; quatrième réunic à la suturale par un are basal; humérale fine, parallèle, à la première dorsale; subhumérales courtes, bien disjointes. Pygidium bombé, assez fortement ponctué. Mésosternum lisse, entièrement rebordé. Prosternum en carène tranchante, un peu sinué; stries remontant très fortement sur l's côtés du prosternum. Patles ferrugineuses; jambes antérieures dilatées, garnies de 7-8 denticules très fins.

Egypte?

\section{S8. S. CEBACOLA.}

Niger nilidus; fronte punctata, stria obsolcta; pronoto antice biimpresso, lateribus mmetato, stria integra; clytris strigoso punctulis, humcris areayue scutelluri marva hevibus, striis 4 dorsulibus brevibus puulo obsoletivribus, suturali antice subabbreviata; mygidio sat dense punctato, pulvinato; mesostcrno parce punctato; mosterno striis divaricatis; peditus brunncis; tibiis anticis cr cmulatis. Long. 4 1/2 mill.; larg. 3 1/2 mill.

Ovale, légèrement convexe, noir luisant. Antennes brunes, funicule ferrugineux. Front assez convexe, densément ponctué; strie nulle. Pronotum beaucoup plus large que long, bisinué à la base, avec quelques points marginaux, 
oblique sur les côtés et largement ponctué, rétréci et échancré en devant, avec les angles antérieurs arrondis, marqués chacune d'une légère impression peu étendue; strie marginale entière. Ecusson très petit, triangulaire. Elytres plus longuesque le pronotum, le sa largeur à la base, dilatées à l'épaule, rétrécies au bout, couvertes d'une ponctuation serrée, rugueuse, assez furte, plus fine postérieurement, bords latéraux trés fimement pointillés, presque lisse, ainsi qu'un petit espace scutellaire; strie suturale un peu raccourcie en devant; dorsales obsolètes; 1-2 atteignant le milieu, les deux autres beaucoup plus courtes, troisième surtout; quatrième recourbée vers la suture, et allant retrouver la suturale; humérale très fine, oblique; subhumérale interne courte, disjointe; externe basale; marginales entières. Pygidium légèrement convexe, assez densément et également ponctué. Mésosternum couvert de points assez gros, espacés; strie forte, entière. Prosternum lisse, parallèle; stries fortes, entières, divergentes en devant. Pattes brun de poix ; jambes antéricures garnies de cinq ou six petits denticules épineux.

ơ . Rxtrémité du pygidium un peu plus bombée. - Poitrine peu distinctement impressionuće.

Ile de Cuba.

\section{S. vinulets.}

Niger viridis, miticlus; antennis pedibusque piceis; fronte dense munctata, stria obsoleta; monoto sub-biimpresso, munctulato, lateribus et basi fortius; stria integra, clytris strigose munctatis, humeris et rirca scutellum subtovibus, stria sulurali integra antice arcuatim juncta; 1-4 dorsalibus dimidiatis, subhumerali incrua brevi disjuncta ; mygidio aerualiter munctulato; 
prosterno striis utrinque divergcntibus; libiis anticis 6-7 denticulatis. Long. 4 mill.; larg. $23 / 4$ mill.

Orale, assez convexe, vert-foncé luisant. Antennes bruncs. Front légèrement bombé, densément ponctaé ; strie obsolète. Pronotum beaucoup plus large que long, bisinué à la base, avec une borlure étroite de points plus forts que sur le disque, oblique sur les côtés, avec une impression large, superficielle, couverte de points serrés, rugueux jusque sur le bord, rétréci et échancré en devant, avec les angles arrondis; strie marginale entière. Elytres beaucoup plus longues que le pronotum, de sa largeur à la base, dilatées à l'épaule, racc urcies au bout, courertes d'une ponctuation serrée et presque rugueuse sur les premiers interstries, épaule et place subscutellaire presque lisse; strie suturale entière, réunie par un arc basal à la quatrième dorsale; 1-4 dorsales égales entre elles, atteignant le milieu; humérale oblique, rapprochée de la prenière dorsale; subhumérale interne courte, disjointe; externe basale; marginale entière. Pygidium également et assez densément ponctué. Mésosternum entièrement rebordé, avec des points peu scrés. Prosternum rétréci au milieu; stries divergentes aux deux extrémités. Pattes brun de poix; jambes antérieures garnies de 6-7 denticules épineux.

$\checkmark$ avec une impression bien marquée au milieu postérieur du métasternum.

Inde (Kurmaul).

90. S. Syriaces.

Ovalis, niger subnitidus; antonnis pedibusque piceis; fronte sublitissime muctulata, stria temui inteyra; pronoto lateribus 
impresso-rugoso; elytris dense puncticulatis, circa scutellum vix sublrevibus, stria suturuli integra, dorsulibus in medio abbreriatis, subhumerali ntrapue brevi intcrna disjuncta; mygielio dense, mesostemo parce at fortius munctutis; prosterno striis subparallelis; tibiis anticis 6-denticulutis. Long. 3 1/2 mill. ; larg. 2 1/4 mill.

Orale, légèrement convexe, noir, peu luisant. Antennes brun-olsscur. Front presque plan, densément pointillé ; stric obsolète, entière. Pronotum plus large que long, bisinué à la base, oblique sur les côtés, rétréci et échancré en devant, avec les angles arrondis, couvert d'une ponctuation très fine et très légère, avec des points plus forls le long de la lase, et une impression latérale rugueusement ponctuée, peu profonde. Eeusson très petit, triangulaire. Elytres assez allongées, beaueoup plus longues que le pronotum, de sa largeur à la base, dilatées a l'épaule, rétréeies postérieurement, également couvertes de points fins serrés, rugueux sur les interstries, avee le pourtour de l'écusson à peu près lisse; strie suturale entière, réunie en arc à la base, avec la quatrième dorsale; celle-ci et la deuxième descendant à peu près jusqu'au milieu; première et Iroisième à peine plus courtes ; humérale très fine, très rapprochée de la première dorsale; sublumérales courtes; interne disjointe; externe basale; marginale entière. Pygidium couvert d'une ponctuation assez forte, égale et serrée. Mésosteruum avec des gros points espacés; strie entière, anguleuse, éloignée du bord au milicu. Prosternum à peine rétréci au milieu; stries entic̀es, peu divergentes. Pattes brun de poix; jambes antérieures garnies de six denticules épineux ; postérieures de deux rangs de spinules.

Syrie ( M. de Iaferté). 


\section{S. CANalisticis.}

Orbicuteris, niger, nitidus; antennis brumncis, clava rufa; fronte munctata, subimpressa, stria integra, antice oblongo-angulata; monoto ante scutcllum impresso, munctulato, lateribus fortius; clytris postice parce punclatis; stria $1^{\text {a }}$ dorsali velida mofundu subintegra, 2-4 multo tenuioribus, sensim brevioribus, suturali subintegra, antice arcuatim cum $4^{\mathrm{a}}$ dorsali cocunte, humerali obliqua, subhumerali utraque mulla; mygidio dense punclalo, ulrinque impresso; prosterno pronincnle, striis valde ascendentibus divergontibus; tibiis anticis 4-denticulatis. Long. $31 / 2$ mill. ; larg. $21 / 2$ mill.

Orbiculaire, légèrement convexe, noir, luisant. Antennes rousses: scape brun. Front fortement ponctué, avec une légère impression longitudinale au milieu; strie entière, avancée en angle assez aigu sur l'épistome. Pronotum beaucoup plus large que long, faiblement bisinué à la base, avec une impression antéscutellaire, d'abord droit, puis arqué sur les côtés, rétréci et largement échancré en devant, avec les angles arrondis, couvert d'une ponctuation très fine sur le disque, plus forte latéralement; strie marginale entière. Ecusson triangulaire, très petit. Elytres larges, plus longues que le pronotum, de sa largeur à la base, curvilinéairement dilatées sur les côtés, rétrécies au bout, finement pointillées, avec la moitié postérieure interne couverte de points plus gros, assez espacés; première strie dorsale très forte, profonde, à peine raccourcie au bout; 1-3 beaucoup moins fortes et plus courtes, mais graduellement; suturale un peu raccourcie au bout, entière et réunie en arc à la base, arec la quatrième dorsale; humérale fine, oblique; subluumérales nulles; marginale forte, eutière. Pygidium bombé, assez fortement ponctué, biimpressionné à la base. Mésosternum 
entièrement rebordé, avec d'assez gros points. Prosternum en carène bombée en devant; stries divergeant de bonne heure et remontant. Pattes d'un brun-ferrugineux; jambes antérieures garnies de $4-5$ petits denticules épineux; postérieures de quelques spinules sur deux rangées.

Cayenne? ( M. de Laferté).

\section{S. ERYTHROPLEURUS.}

Oblongo ovatus, niger mitidus; pedibus clytrisque latcralitcr fermgincis; fromte llense puncticulata, stria mulla; pronoto laleribus punctatis, stritu intcgra; clytris postice punctulatis, stria suturali apice subabbreviata, antice arcuatim cum $4^{a}$ dorsali coennte, 1 et 4 in molio, 2 et 8 pone medinm abbreviatis, humerali temissima, subhumerali interna mulla; pygidio cequeliter et dense munctulato; mesosterno mencticulato; prostcrmo striis divaricatis abbreviatis; tibiis anticis 6-denticnlat is. Long. 4 mill.; larg. $23 / 4$ mill.

Ovale, un peu allonge, peu convexe, noir de poix luisant. Antennes brunes, funicule ferrugineux. Front presque plan, densément et finement pointillé; strie nulle. Pronotum court, beaucoup plus large que long, sub-bisinuć à la base, avec une impression antéscutellaire, et des points marginaux, légèrement arqué sur les côtés, rétréci et largement échancré en devant, avec les angles arrondis, lisse sur la surface, arec unc bande latérale ponctuée, et au tiers une très petite foréole à peine sensible; strie marginale entière. Ecusson très petit, triangulaire. Elytres beaucoup plus longues que le pronolum, de sa largeur à la base, à peine dilatées à l'épaule, rétrécies postérieurement, couvertes dans le tiers postérieur d'une ponctuation fine, serrée, peu étendue sur les côtés; stries bien marquées, profondes, 
ponctuées; suturale à peine raccourcic au bout, réunic en arc à la base avec la quatrième dorsale; celle-ci, et la première dorsale, égales entre elles, atteignant le milieu; deuxième et troisième égales et plus longues que les deux autres; humérale très fine, oblique à la première dorsale; subhumérale interne nulle; externe basale, presque confondue avec la marginale, qui est forte et entière. Pygidium médiocrement bombé, densément et finement ponctué. Mésosternum entièrement rebordé, avec une très fine ponctuation. Prosternum assez large; stries divergeant de bonne heure et raccourcies. Pattes d'un rouge-brun; jambes antérieures garnies de six denticuies épineux, asse\% longs.

Le seul individu que j'aie pu voir, et de ma collection, présente à l'extrémité du pyggidium, deux petits sillons en spirale adossés; sans doute c'est un caractère sexuel, et probablement de la \&. J'ignore sa patrie.

\section{S. IYYPOCRITA.}

Ovalis, nigro-piceus; antennis pedibusque rufis; fronte punctulata, stria obsolcta; pronoto disco subtilissime, lateribus fortius pumctulatus, stria integra; elytris lateribus ct basi sublilissime, postice sat for liter el parum dense punctatis, striis validis dorsalibus 1-2 ultra medium, 3-4 minus abbreviatis. sulurali paululum abbrcviala, basi arcuatim cum $4^{a}$ coeunte, subhumeralibus obsoletis; mygidio punctulato; prosterno striis divergentibus ascendentibus; tibiis anticis 8-denticulatis. Long. 4 mill.; larg. 3 mill.

Ovale suborbiculaire, noir de poix, luisant. Antennes rousses, scape brun. Front presque plan, également ponctué, avec un gros point enfoncé sur le vertex; strie 
obsolète. Pronoium court, beaucoup plus large que long, subsinué à la base, avec une impression antéscutellaire, oblique sur les côtés, rétréci et largement échancré en devant, avec les angles arrondis, finement ponctué, plus fortement dans son pourtour; strie marginale entière. Ecusson triangulaire, très petit. Elytres beaucoup plus longues que le pronotum, de sa largeur à la base, dilatées à l'épaule, rétrécies au bout, couvertes d'une ponctuation fine et espacée dans leur première moitié, plus forte, et un peu rugueuse dans leur dernière ; stries fortes, bien marquées, ponctuées ; 1-2 dorsales égales, dépassant le milieu ; 3-4 égales, un peu plus courtes; suturale à peine raccourcie postérieurement, réunie en arc avec la quatrième dorsale; hımérale assez forte, très rapprochée de la première dorsale; subhumérales obsolètes; marginales entières. Pygidium bombé, finement et également ponctué. Mésosternum entièrement rebordé, ponctué de même. Prosternum concave, a stries fortement divergentes et ascendantes. Pattes d'un brun-ferrugrineus; jambes antérieures garnies de 7-8 denticules épincux; postéricures de deux rangées de rares spinules.

Un des sexes présente à l'extrémité dı pygidium une double impression petite et supericielle.

Buenos-Ayres. (Maldonado.)

\section{S. Campechiancs.}

Niger, nitidus; antennis brumeis, pedibus fermgineis ; fronte mgulosa, stria obsolcta; pronoto latcribus et basi menctulato; elytris intus postice parce muctutis, striis validis crenatis, dorsalibus 1-3 subcequalibus longe pone medium abbreviatis, $4^{\text {a }}$ paulo minus, cum sulurali connexu, hac apice abbreviata, 
subhumerali utraque mulla; pygidio valide, me`osterno marginato marce punctatis; prosterno subrecto, striis ascendentibus; tibiis unticis 6-7 denticulatis. Long. $23 / 4$ mill. ; larg. 2 mill.

Ovale arrondi, convexe, noir de poix , luisant. Antennes brunes. Front bombé, rugueusement ponctué en devant, ainsi que l'épistome; strie obsolète. Pronotum court, largement bisinué à la base, avec une légère impression ponctuée, antéscutellaire, courbé sur les côtés et bordé de points, rétréci et à peine échancré en devant, avec les angles abaissés et arrondis; strie marginale forte, entière. Ecusson très petit. Elytres plus longues que le pronotum, de sa largeur à la base, curvilinéaire sur les côtés, rétrécies au bout, couvert d'assez gros points espacés, qui ne dépassent pas la deuxième strie dorsale et le tiers postérieur; stries fortes; dorsales 1-3 raccourcies aux trois quarts; quatrième un peu plus courte, réunie à la suturale par un arc basal; celle-ci obsolète à l'angle sutural; subhumérales nulles. Pygidium bombé, arec de gros points peu serrés. Mésosternum entièrement rebordé, couvert de points épars. Prosternum droit; stries ascendantes. Pattes ferrugineuscs; jambes antérieures dilatées, garnies de 6-7 denticules.

Yucatan (Campêche). (M. Pilate).

\section{S. BLANDLS.}

Oralis convexiusculus, ceneus; entennis nedibusque rufis; fronte punctulala, stria nulla; prothorace transverso, cequali, antice angustato, lateribus rotundato, punctulato, versus latera fortius, stria marginali integra; chytris brevibus, basi latioribus, postice muctatis, stria submarginali integra, laterali mulla, humerali tenui, dorsalibus 4 ver'sus medium productis, $4^{a}$ breviori untice arcuatim cum suturali coeunte, sat versus upicem sub- 
altemuata; pygidlo munctulalo, apice 6 lincis profunde exciso ; tibiis anticis cremulatis, 4 posticis spinutosis. Long. 3 mill.; larg. 2 mill.

Saprinus blandus. Er. in Jahrb., 1, 188, 40 (1834).

Ovale, assez convexe, d'un noir métallique luisant. Antennes d'un brun de poix. Front finement et densément ponctué, sans strie. Prothorax plus large que long, légèrement bisinué à la base, arrondi sur les còtés, rétréci en devant, avec les angles peu marqués, et l'échancrure céphalique peu profonde, sans impressions latérales, finement pointillé, avec des points plus marqués sur les côtés; strie marginale entière. Ecusson punctiforme. Elytres beaucoup plus larges que longues, dilatées à la base, rétrécies à l'extrémité, ponctuées postérieurement; strie submarginale entière; latérales nulles; humérale fine, très rapproclıée de la première dorsale; celle-ci et la deuxième dépassent le milieu; la troisième l'atteint; la quatrième est plus courte, arquée à la base, et se continue avec la suturale, qui ne va pas tout à fait jusqu'à l'extrémité. Pygidium assez densément et finement ponctué, arec six lignes profondes, courtes, convergentes à l'extrémité. Paltes d'un brun-ferrugineux ; jambes antérieures crénelées ; intermédiaires et postérieures épineuses.

+. Pygidium sillonné de six courtes stries au bout.

Nouvelle-Grenade (Cartlıagène). (Para). Brésil.

\section{S. NILIUM.}

Ferrugineus, nitens; fronte punctulata, stria tenui integra; pronoto basi anguste, lateribus impressis rugose punctatis, stria integra; elytris postice intus punctulatis, striis crenatis, 
$1^{3}$ dorsali ultra medium abbreviata, 2a longiori, 3, it sensim breviou ibus, $4^{\text {a }}$ cum suturaliconnexa, sublumeraliutraque mulla; pygidlo dense et cequaliter; mesosterno murginato, parce munctulatis; mosterno carinato, striis uscenulentibus; tibiis anticis 7-8 denticulutis. Long. $13 / 4$ mill, ; larg. 1 mill.

Ovale, oblong, assez convexe, luisant, entièrement ferrugineux. Tête plus obscure. Front arrondi, presque plan. densément pointillé; strie fine, entière. Pronotum court, largement bisinué et bordé de points à la base, arqué et bordé de petits points sur les côtés, avec une impression longitudinale, étroite, de points plus gros, rétréci et faiblement échariçé en devant, avec les angles arrondis; strie marginale entière. Ecusson très petit. Elytres un peu plus longues que le pronotum, de sa largeur à la base, curvilinéaires sur les côtés, rétrécies au bout, ponctuées en dedans, sur leur quart postérieur; stries crénelées, fortes ; dorsales raccourcies bien au-delà du milieu ; 2-4 progressivement plus courtes; première plus courte que la deuxième; celle-ci réunie à la suturale par un arc basal; sublıumérales nulles. Pygidium bombé, assez densément et égale. ment pointillé. Mésosternum entièrement rebordé, et couvert de points espacés. Prosternum en carène un peu sinuéc; strie remontant sur les côtés du prosternum. Jambes antérieures dilatées, garnies de 7.8 petits denticules.

Nouvelle-Grenade.

\section{S. MODESTIS.}

Niger, nitidus; antemis pedibusque brunneis; fronte convexiuscula, puncticulata; mronoto medio impresso; pronoto marginato, latcribus foveoluto, limbo sut dense punctulato; 
elylris postice dense subtiliter menctatis, striis validis, crenatis, 2-4 none mealinmi abbreviatis, $1^{2}$ longior $i, l^{2} \mathrm{cum}$ suturali sul, apicen cessunte arcuatim comnexa, sublumerali externa cum marginati confusa, interna brevi disjuncta; pygidio aqualiter dense, mesosterno marginuto vix munctulatis; prosterno subrecto, striis ascendentibus; tibiis anticis multidentalis. Long. $3 \mathrm{~J} / 2$ mill. ; larg. $21 / 2$ mill.

Saprinus modeslus. Er. in Jahr., 187, 38 (1S34).

Ovale, oblong, assez convexe, noir de poix luisant. Antennes bruncs. Front bombé, très finement pointillé, avec un gros point au milieu du vertex; strie fine, obsolète derrière l'épistome. Pronotum court, arrondi au milieu et faiblement bisinué en dehors, courbé sur les còtés, arec une foréole au premier tiers, rétréci et peu échancré en devant, avec les angles arrondis, couvert de points fins et serrés, un peu plus forts latéralement; strie marginale entière. Ecusson très petit. Elytres plus longues que le pronotum, de sa largeur à la base, curvilinéaires sur les côtés, rétrécies au bout, ponctuées de petits points fius et un peu aciculés sur le tiers postérieur en dedans, avec une légère impression subapicale; stries fortes, crénelées; dorsales 2-4 raccourcies, un peu au-delà du milieu; première beancoup plus longue et plus profonde; suturale réunie i la quatrième par un arc basal, et n'atteignant pas le bout; subhumérale externe accolée à la marginale et confondue arec elle; interne courte et très distante de l'humérale. Pygidium bombé, densément et également pointillé, avec denx fovéoles à l'extrémité, dans l'un des sexes. Mésosternum entièrement rebordé, avec des points ì peine visibles. Proslernum droit, assez larges; stries remontant sur les côtés. Pattes brunes; jambes antérieures dilatées, garnies de nombrcux denticules.

Brésil (Para, Maldonado); Uruguay. 


\section{S. FULVOPTERUS.}

Niger nitidus; antemis, pedibus elytrisque rufo-brumeis; fronte subtilissime muctulutu, stria subintegra temui; pronoto margine basali munctutu, fusciu luterali immesso rugosa, stria integra; chtris postice punctatis, stria suturali subabbrcviata, cum $4^{\text {a }}$ dorsali cocunte; $2^{a}$ vix apice abbreviata, $1^{\text {a }} 3^{*}$ que requalibus, pauto ante, $4^{\mathrm{a}}$ allhuc breviori, subhumerati interna longa, disjuncta, exterma nulla; pygidio cerpaliter et dense punctato; prosterno striis valde divergentibus; tibiis anticis 7-8 denticulatis. Long. 4 mill.; larg. 3 mill.

Ovale un peu allongé, faiblement convexe, noir luisant. Antennes brunes: funicule ferrugineux. Front peu convexe, finement pointillé; strie fine, entière, mais un peu confuse en devant. Pronotum beaucoup plus large que long, bisinué à la base, avec un rebord étroit, ponctué, un peu arqué sur les côtés, avec une bande longitudinale enfoncée de points rugueux, ne touchant pas au bord, rétréci et échancré en devant, arec les angles arrondis; strie marginale entière. Ecusson triangulaire, très petit. Elytres beaucoup plus longues que le pronotum, de sa largeur à la base, dilatées à l'épaule, rétrécies postéricurement, brunes, rouges latéralement, ponctuées finement à l'extrémité sur une petite étendue; stries bien marquées, assez fortes, ponctuées ; suturale à peine raccourcie au bout, arquée à la base et réunie à la quatrième dorsale; deuxième dorsale presque entière; première et troisième un peu plus courtes et égales entre elles; quatrième encore un peu plus raccourcie; humérale fine, oblique ; subhumérale interne assez longue, disjointe; externe nulle; marginale interne entière, forte, recourbée à la base. Pygidium lombé, couvert de points bien marqués, peu serrés. Mésosternum entièrement re- 
bordé, ponctué de même. Prosternum à stries divergeant dìs la base. Pattes roussâtres; jambes antéricures garnies de sept ou huit denticules épineux.

Bolivie ; Maldonado ; Montevideo; Patagonie.

\section{S. SubVicints.}

Niger, nilidus; antennis vedibusque brumeis; fronte munctulata, stria obsoleta; pronoto murginato, limbo punctuto, antice utrinupe foveolato, latcribus anguste rugoso; chytris intus apice punctatis, striis validis crenatis, 1-3 dor'salibus subcruatibus tonge pone medium abbreviatis, $4^{\text {a }}$ mevimi arcuatim cum suturali apice abbreviata juncta, subhumerali externa nulla, interna brevi disjuncta; mygillio aqualiter punctato; mesostcrno marginato; prostcrno recto, striis ascendentibus; tibiis unticis 6-7 denticulutis. Long. 3 mill.; larg. 2 mill.

Ovale, convexe, noir, luisant. Antennes brunes. Front à peu près plan, finement pointillé; stric fine, obsolète en devant. Pronotum court, arrondi au devant de l'écusson, subsinué de part et d'autre à la base, avec une étroite bordure de points, arqué sur les côtés, avec une ligne étroite de points rugueux, commeriçant dans une fovéole placée à l’angle, rétréci et à peine éclıancré en devant, arec les angles arrondis; strie marginale entière. Ecusson très pelit. Elytres un peu plus longues que le pronotum, de sa largeur à la base, curvilinéaires sur les côtés, rétrécies au bout, couvertes en dedans, sur leur tiers postérieur, de points assez serrés et assez forts, stries fortes, crénelécs; dorsales 1-3 égales, raccourcies aux $3 / 4$; quatrième plus courte, réunie par un are basal à la suturale qui n'alteint pas le bord apical ; strie subhumérale externe confondue avec la marginale; interne courte, très disjointe. Pygidium densément et également ponctué. Mésosternum entièrement rebordé. Prosternum 
droit, assez large; stries remontant sur les cotés. Pattes brunes; jambes antérieures dilatées, garnies de 6-7 denticules.

Amérique méridionale ; Amazones ; Santana.

\section{S. Granatensis.}

Suborbicularis, nigro-cencus, nilidus; antennis pedibusque rufo-brunncis; fronte sublevi, stria integra obsoletu; pronoto lateribus impresso-punctuto; elytris postice panctatis, striis

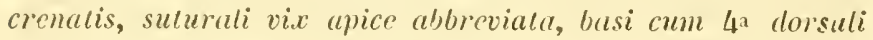
junctu, hac dimidiata it $3^{a}$ magis distanti, 1-3 tongioribus subcequalibus; interstitio $1^{\circ}$ postice, $2^{\circ}$ amtice angustioris, $3^{\circ} \mathrm{ll}$ tiori; subhumerali intcrna brevissimu, cxtcrna nulla; pygillio dense munctato; mesostemo tenuiter ptunctulato maryinatoque, prostcrno striis divergentibus el ascendentibus; tibiis anticis 7-8 denticulatis. Long. 2 1/2 mill.; Jarg. 1 1/2 mill.

Suborbiculaire, peu convexe, noir-métallique, luisant Antennes brunes. Front presque plan, si légèrement ponctué qu'il parait lisse ; strie entière, mais fort obsolète en devant. Pronotum beaucoup plus large que long, subbisinué et bordé de points à la base, légèrement arqué sur les côtés, avec une impression ponctuée, étroite, éloignnée du bord, rétréci et largement échancré en devant, avec les angles arrondis; stric marginale entière. Ecusson triangulaire, très petit. Elytres plus longues que le pronotum, de sa largeur à la base, dilatées à l'épaule, rétrécies au bout, assez fortement ponctuées dans le tiers postérieur, quelques points re. montent le long des stries; strie suturale forte, un peu raccourcie an bout, arquée et réunic à la base, avec la quatrième dorsale; celle-ei forte, ponctuée, raccourcie au milieu; 1-3 égales entre elles, beaucoup plus longues que 3c Série, Tone II. 
la quatrième, non parallèles; humérale fine, oblique; subhumérale interne disjointe, très courte; externe nulle; marginale entière; troisième interstrie beaucoup plus large que les autres; premier rétréci postérieurement ; deuxième élargi. Pygidium assez bombé, égalenent pointillé ; extrémité rouge. Mésosternum rebordé d'une strie entière, parallèle au bord, avec des points peu serrés et peu profonds. Prosternum convexe, à stries entières, divergentes, remontant un peu. Pattes rouge-brun; jambes antérieures garuies de 7-8 denticules épineux; postérieures de deux rangées de rares spinules.

Carthagène.

\section{S. PAVIDUS.}

Suborbicularis, niger nitidus; antemnis, pedibus elytrisque apice rufo brumeis; fionte munctuluta, stria obsolcta; mronoto puncticulato, luteribus rugoso impressis, striu integra; elytris postice munctatis, striis suturali vix upice abtreviata, antice arcuatim cum mopiore junctu, lorsulibus uitra medium abbre-

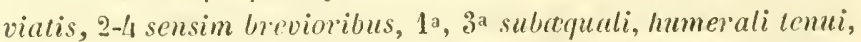
sublumerali interna longa vix lisjuncta, cxterna nulla; pygitio dense punctuto; mosterno striis divergentibus; tibiis anticis 6-denticulntis. Long. $31 / 2$ mill. ; larg. 2 1/2 mill.

Suprinus pavidus. Er, in Jahr., 187, 39 (1834).

S. piceus. Blanch. in d'Orbig. Amér. mér.

Ovale, suborliculaire, assez convexe, noir luisant. Antennes brun-rouge. Front peu convexe, finement ponctuć; stric fine, obsolète. Pronotum beaucoup plus large que long, bisinuc à la base et bordé de points, oblique sur ies cotés, avec une impression longitudinale étroite, rugueusement 
ponctuée, ne touchant pas le bord, rétréci et largement échancré en devant, arec les angles arrondis, couvert d’une ponctuation tres fine, et peu visible sur le disque; strie marginale entière. Ecusson triangulaire, très petit. Elytres d'un brun-rouge, plus longues que le pronotum, de sa largeur à la base, dilatées a l'épaule, rétrécies au bout; moitié postérieure couverte de gros points peu serrés, jusqu’a la deuxième dorsale; stries fortes, ponctuées; suturale à peine raccourcie au bout, réunie à la base arec la quatrième dorsale; deuxième la plus longue, dépassant de beaucoup le milieu; première et troisième un peu plus courtes; quatrième encore plus ; humérale fine, oblique, presque continuée par la subhumérale interne, qui est assez longue; externe nulle ; marsinale forte, entière. Pygidium également et densément ponctué. Mésosternum entièrement reborlé, ponctué. Prosternum finement pointillé; stries fortement divergentes. Pattes rouges; jambes antérieures garnies de six dentelures assez fortes.

Brésil ; Corientes (République Argentine).

\section{S. ATRONITIDEs.}

Ovalis, picco-nitidus; antemis pedibusque rufo-brumeis; froute punctulata, stria integra; pronoto margine punctato, utrinque foveoluto, stria integra; ctytris postice intus punctat is, striis dor salibus $2-4$ sensim decrescentibus suturatique postice abbreviatis, subhumerali externa mulla, irterna vix disjuncta; pygidio dense munctato; prostemo striis antice divaricato attingentibus; tibiis anticis $8-9$ denticulatis. Long. 4 mill.; largeur 21/2 mill.

Saprinus atronitidus. Blanch. in d'Orbigny, voy. Amér. mér.

Ovale assez convexe, noir de poix luisant. Antennes 
brunes. Front bombé, pointillé; strie fine, non interrompue. Pronotum beaucoup plus large que long, rétréci en devant. arec les angles fort arrondis, légèrement pointillé sur le disque et plus fortement à la base et le long des bords latéraux, avec une fossette superficielle de chaque côté; strie marginale entière et assez bien marquée. Ecusson ponctiforme. Elytres plus longues que le pronotum, de sa largeur à la base, curvilinéairement dilatées sur les côtés, rétrécies et droites au bord apical ; ponctuation assez forte, régulière, remontant à peine jusqu'au milieu, contre la suture, et ne dépassant pas en dehors la deuxième strie dorsale; strie marginale forte, entière; sublsumérale externe nulle ; interne assez longuc, à peine séparée de l'lumérale; dorsales fortes, crénelées; dcuxième presque entière; première et troisième égales entre elles, un peu plus courtes; quatrième raccourcic vers le milieu, et réunie avec la suture, la quille ne se continue pas aı bord apical. Propygidium et pygidium densément et fortement ponctués. Mésosternum ponctué, entièrement rebordé. Prosterıum assez étroit, à peine concave; stries divergentes et remontées en derant. Paltes rouge-brun; jambes antérieures garnies de huit à dix petits denticules.

Brésil (Goya).

103. S. CoNformis.

Ovalis, atcr, nitidus; antonnis pedibusque brunncis; fronte punctulata; stria mulla; pronoto lateribus et basi sat donse punctalo, ante scutcllum inupresso; clyte is dimidio postico grosse et rarum dense mnctuto, stria suturali antice cum proxima coeunte, postice abbreviata, 1-2 dorsalibus versus apiceme abbrevialis, $3-4$ sensim brovioribus, basi intus uncinatis; humerali 
el subhumerali interna disjunctis; pygidio dense et cequaliter punctulato; mesostcrno sat dense munctato marginato; mo= stermo, striis divergentibus ascendentibus; tibiis anticis 6-7 denticululis.

Sapr inus conformis. Le Conte, N.-Amér. Hist., 42, 6, 1. 5, 7 (1845).

Ovale, assez convexe, noir, luisant. Antennes brunes. Front légèrement bomlé, densément pointillé ; stric obsolète. Pronotum plus large que long, bisinué à la base, avec une impression antéscutellaire, légèrement arqué sur les côtés, rétréci et échancré en devant, avec les angles arroudis; strie marginale eutiére, couvert d'une ponctuation fine et presque imperceptible sur le disque, assez forte à la base et plus élendue sur les cotés. Ecusson très petit, triangulaire. Elytres plus longues que le pronotım, de sa largenr à la base, dilatées a l'épaule, fortement rétrécies au bout, couvertes de points fins sur les côlés, de gros et médiocrement serrés sur la moitié postérieure, l'espace ponctué remonte au-delì du milieu, à la suture et moins ell dehors, vers la deuxième dorsale qu'il ne dépasse pas ; stries fortes, ponctuées; suturale arquée à la base, vers la quatrième dorsale, raccourcie à l'extrémité ; première dorsale plus enfoncée que les autres, dépassant de beaucoup le milien, ainsi que la deuxième : troisième raccourcie vers le milieu; quatıième un peu avant; lıumérale fine. rapprochée de la prenière dorsale; sublıumérale interne courte, fort disjointe ; externe basale à peine distincte; marginale entière. Pygidium hombé, égalenent et densément ponctué. Nétasternum lisse, avec une bande subterminale de points espacés. Mésosternum entièrement rebordé, couvert de points assez serrés. Prosternum en carèue arrondie; stries fortement 
divergentes en devant, remontant peu et ne se rejoignant pas. Pattes brunes; jambes plus ferrugineuses, garnies de 6-7 denticules épineux ; postérieures de quelques spinules disposées sur deux rangs.

Amérique boréale.

Nola. J'ai vu dans la collection Dejean, des individus appartenant au $S$. conformis, Le Conte, sous le nom de II. sphuroides, Dej., et des II. sphceroiles, sous le nom de II. conformis, I)j., provenant de I. Le Conte lui-mème. Puisque cet auteur eite Dejean, il y aura eu sans doute une transposition de noms.

104. S. Minetus.

Niger nilidus; antennis pedibusque piceis; fronte puncticulata, stria obsoleta; monoto limbo munctulato; elytris postice fortiter panctatis, stria sulurali postice sububbreriata, clorsalibus 1 ultra medium, 2-3 in medio, ot $4^{\text {a }}$ anle abbreviatis, subhumerali interna disjunctu, externa mulle; mgidio mesostorno punctato; prosterno striis divergentibus; tibris anticis 5-denticulutis. Long. 4 mill.; larg. 2 1/2 mill.

Saprimus mimulus. Le Conte, Mon. Ilist. Amı. „1, 43, 8, pl. 5, 9 (1845).

Ovale, assez convexe, noir luisant. Antennes brunes: funicule rougeatre. Front presque plan, finement et également pointillé; strie obsolète. Pronotum plus large que long, bisinué à la base, arqué sur les côtés, rétréci et échancré en devant, avec les angles arrondis, lisse sur le disque, finement ponctué daus son pourtour, un peu plus fort à la base; strie marginale entière. Ecusson triangulairn, très petit. Elytres courtes, plus longues que le pro- 
notum, de sa largeur à la base, dilatées à l'épaule, très rétrécies au bout, convertes de gros points assez peu serrés dans leur moitié postérieure, jusquià la deuxième dorsale, en dehors; stries fortes, ponctuées; suturale un peu raccourcie au bout, réunie par un are basal arec la voisine; dorsales 2-3 raccourcies au milieu; première plus langue; quatriène plus courte; humérale fine, oblique ; subhumérale interne assez longue, non réunie, externe nulle; marginale entière. Pygidium également et assez densément ponctuć. Mésosternum heaucoup moins densément, entièrement rebordé. Prosternum assez large, finement pointillé; stries remourtant et divergentes, terminées dans une petite cavité antérieure. Pattes brun-rouge; jambes antéricures garnies de cinq denticules épincux.

Etats-Unis, dans les bouses.

\section{S. ARROGANS.}

Ovalis, piceus, nitidus; antennis pedibusque rufis; fronte subtilissime munctulata, stria obsoleta; pronoto lateribus et basi distinctius; elytris postice punctulatis, stria suturali antice arcuatim juncta, postice subabbreviata, dorsalibus in medio, 1-4 sensim breviatis, 3. decomposita, subhumerali intorna disjuncta, externa nulla; mygidio mesosternuque marginato punctatis ; mosterno striis divergentibus ascendentibus; tibiis anticis 7-8 denticulatis. Long. 2 1/2 mill.; larg. $11 / 2$ mill.

Ovale, suborbiculaire, assez convexe, brun-métallique, luisant. Antennes et pattes roussatres. Front légèrement convexe, densément pointillé; strie obsolète. Pronotum plus large que long, bisinué à la base, avec une bordure de points assez forts, un peu arqué sur les cottés, 
avec une ponctuation plus marquée encore que sur le disque, rétréci et largement échancré en devant; les angles arrondis; strie marg̣inale entière, bien marquée. Ecusson très petit, triangulaire. Elytres plus longues que le pronotum, de sa largeur à la base, dilatées à la base, rétréries postéricurement, couvertes sur leur moitié postérieure de gros points peu serrés, à la base et sur les côtés d'un pointillé très fin et presque lisse; stries fortes, ponctuées; suturale réunie en arc à la hase, avec la quatrième dorsale, un peu raccourcie au bout; dorsales peu obliques; première dépassant assez le milieu; les trois autres graduellement plus courtes; troisième deux fois interrompue; lıumérale plus fine, bien marquée, très oblique; subhumérale interne courte, disjointe; externe nulle; marginale entiere. Pygidium densément et également ponctué. Mésosternum entièrement, mais très finement rebordé, assez densément pointillé. Prosternum presque parallèle; stries fort divergentes et remontantes. Pattes rouges; jambes antérieures garnies de 7-8 denticules épineux assez serrés.

Cumana (Venezuela). (M. Laferté).

106. S. vescrs.

Niger, nitidus; antennis pedibusque brunncis; fronte punctulata, stria antice internutu; pronoto limbo dense menctulato, stria integra; slytris intus ad minus dimidio postico comualiter munctatis, striis crenatis valielis, dorsalibus 1-4 sensim brevioribus none medium abbreviatis, suturali apice cvan'scente basi cum $1^{2}$ connestl, $1^{\circ}$ interstitio catcris angustiori, $1^{\circ}$ mimus lato; subhumerali externa mulla, intoma brevi disjuncta; pygitio dense aqualiter, mesosterno marginato parce munctulatis; 
prosterno subrecto, striis ascendentibus; tibiis anticis 7-8 denticulatis. Long. 3 mill.; larg. 1 1/2 mill.

Orale, oblong, peu convexe, noir luisant. Antennes brunes. Front arrondi, presque plan, finement pointillé; strie fine, obsolète derrière l'épistome. Pronotum court, arrondi au devant de l'écusson, puis faiblement sinué, et rebordé de points à la base, courbé sur les côtés, rétréci et échaneré en devant, avec les angles obtus, abaissés, couvert de points fins et serrés dans son pourtour; strie marginale entière. Ecusson très petit. Elytres une demi-fois plus longues que le pronotum, de sa largeur à la base, curvilinéaires sur les côtés, rétrécies et coupées droit au bout, couvertes au bout de points assez gros, qui remontent sur les interstries, jusque au-delà du milieu; stries fortes, crénelées ; 1-4 dorsales progressivement raccourcies, descendaut jusqu’aux deux tiers; suturale réunie à la quatrième dorsale par un arc basal, et n'atteignant pas le bord apical; quatrième interstrie moins large que d'habitude; premier plus étroit, surtout au bout, que les deux suivants; subhumérale externe confondue dans la base de la marginale; interne courte, disjointe. Pygidium convexe, finement et également ponctué. Mésosternum entièrement rebordé, avee de petits points épars. Prosternum presque droit; stries remontant sur les côtés. Pattes brunes; jambes anté-. ricures dilatées, garnies de $7-8$ denticules.

Texas (M. Pilate).

\section{S. rebricilus.}

Fevrugineus, nitidus; antemis brumeis ; fronte muncliculata. stria obsoleta; pronoto undique aqualiter et parm dense 
punctulato, stria integra; elytris intus dimidio postico parce punctato, striis dorsalibus $2-4$ in medio sensim magis abbreviatis, $1^{a}$ longiori, $4^{\text {a }}$ arcuatim cum suturali connexa, hac apice et juxta scutcllum obsoleta, subhumerali cxter na mulla, interna brevi disjuncta; pygitio etqualiter et sat dense, mesosterno marginato parce punctulatis; prosterno subrecto, striis ascendentibus; tibiis anticis obtuse 5-6 denticulatis. Long. 2 1/5 mill.; larg. 2 mill.

Ovale oblong, peu convexe, brun-ferrugineux. Antennes plus foncées. Pattes plus claires. Front peu bombé, finement et densément pointillé ; strie obsolète. Pronotum court, arqué à la base, courbé sur les cotés, sans impression, échancré et un peu rétréci en devant, avec les angles obtus, couvert sur toute sa surface d'une ponctuation égale et peu serrée; strie marginale entière. Ecusson très petit. Elytres plus longues que le pronotum, de sa largeur à la base, à peine dilatées à l'épaule, un peu rétrécies an bout, couvertes de points assez forts, espacés, sur leur moitié postérieure, remontant sur les interstries et au-delà du milieu; stries dorsales bien marquées, crénelćes; prenière beaucoup plus longue que les autres; 2 -4 raccourcies vers le milieu, de plus en plus courtes; la suturale raccourcie au bout et continuée par des points au niveau de l'écusson, réunie par un are basal à la quatrième dorsale; subhumérale interne courte et disjoinie; externe nulle. Pygidium bombé, avec une ponctualion ẹ́ale et assez serrée. Nlésosteruum entièrement rebordé, arec des points espacés. Prosterıum en carène droite; stries remontant sur ses côtés. Jambes antéricures dilatées; garnies de 5-6 denticules obtus.

Amérique? 


\section{S. NEGLECTIS.}

Breviter ovalis, comvexiusculus, niger, nitidus; amemis pedibusque brummeis; froute puncticulata, stria obsoleta; pronoto limbo sat dense punctato, stria marginali integra; elytris postice intus sut valide et parce punctatis, interstitiis trevibus, striis valialis crenatis, dorsulibus $2-3$ pone medium, $1^{\text {a }}$ vix, $4_{a}$ cum suturali apice obsoleta urcuatim juncta ante abbreviatis, subhumerali externa nulla, interna brevi; pygidio et mesosterno marginato parm. dense muctatis; prosterno striis ascendentibus, tibiis anticis b̆-6 denticulatis. Long. 2 4/5 mill.; larg. 2 mill.

Ovale arrondi, assez convexe, noir, luisant. Antennes brunes. Front presque plan, très finement et densément pointillé ; strie obsolète. Pronotum court, largrement bisinué à la base, courbé sur les côtés, très rétréci et à peine éclıancré en devant, avec les angles obtus et abaissés ; sans impression latérale, mais entouré d'une ponctuation assez serrée ; strie narg̣inale bien marquée, entière. Ecusson très pelit. Elytres un peu plus longues que le pronotum, de sa largeur à la base, curvilinćaires sur les côtés, et rétrécies au bout, couvertes sur leur moitié postéricure d'assez gros points peu serrés, qui ne dépassent pas en dehors de la deuxième strie dorsale, mais ne remontant pas dans les interstries; stries fortes, crérelées; 2-3 dorsales raccourcies aux deux tiers; première p'us longue; quatrieme plus courte, réunie par un arc basal à la suturale, qui est un peu raccourcie au bout; subhumérale interne conrte, disjointe ; externe nulle. Pygidium bombé, couvert d'une ponctuation égale, serrée Vésosternum entiòrement rebordé, avec des points espacés. Prosternum en carène, droit; stries remontant sur les côtés du prosternum. Patles brunes; jambes antérieures dilatées, garnies de $7-8$ denticules.

Amérique boríale. 
109. S. INSTLARIS.

Ovalis, convexiusculus, piceus, nitidus; antennis pedibusque ferrugincis; fronte denss punctulata, stria obsoleta; pronoto undique punctulato, lateribus et basi fortius; elytis postice parlius, mox rugose punctatis, stria suturali basi arcuation juncta, 1-4 dorsalibus versus medium sensim abbreviatis, subhumerali interna disjuncta; mygidio mesosternorpe marginato munctatis ; prosterno carinato striis valde ascendentibus; tibiis anticis obtuse denticulatis. Long. 2 1/2 mill.; larg. 2 mill.

Ovale court, assez convexe, noir de poix, luisant. Antennes ferrugineuses. Front bombé, assez densément pointillé; strie obsolète. Pronotum plus large que long, légèrement bisinué à la base, arqué sur les côtés, rétréci et échancré en devant, avec les angles arrondis, couvert d'une ponctuation fine, serrée, mieux marquée dans son pourtour; strie marginale entière. Ecusson petit, triangulaire. Elytres un peu plus longues que le pronotum, de sa largeur à la base, dilatées à l'ćpaule, rélrécies au bout, couvertes de points dans leur moitié postérieure, d'abord espacés, puis serrés, rugueux; stries dorsales crénelées, raccourcies vers le milieu, mais graduellement dans cet ordre, 1, 2-3 et 4; suturale n'atteignant pas le bord apical, réunie à sa base avec la plus proche; subhumérale interne longue, droite, non réunie à l'humérale; externe nulle; marginale forte, entière. Pygridium assez densément pointillé. Mésosteruum couvert de gros points, entièrement rebordé. Prosternum en carène amincie; stries trìs remontées et divergentes en devant. Pattes rouge-brun; jambes antérieures dilatées et arrondies au bout, arec quelquis dentelures obtuses; postérieures garnies de deux rangées de spinules.

Guadeloupe (M. Chevrolat). 


\section{S. MODESTIOR.}

Niger nitidus; antemis pedibusque brumeis; fronte puncticulutu, stria mulla; pronoto lateribus atqualiter punctuto, striu integra; elytris postice subtiliter muctatis; stria suturati postice deficionte $\mathrm{cum} 4^{\text {a }}$ dorsuli arcuatim juncta, 1-3 dorsalibus subctpuliter pone medium abbreviatis, $4^{\text {a }}$ breviore; humerali sat mofunde, subhumerati interna brevissima disjuncta; pygidio cequaliter subtiliterque punctato; mesosterno sublavi; prosterno striis divergentibus; tibiis anticis 10-denticulatis. Long. 4 mill, ; larg. 3 mill.

Ovale, légèrement convexe, noir luisant. Antennes brunes: funicule ferrugineux. Front faiblement bombé, finement poiutillé, avec un point enfoncé sur le vertex; strie obsolète. Pronotum court, beaucoup plus large que long, bisinué à la base, oblique sur les côtés, avec une ponctuation large et régulière, sans impression, rétréci et largement éclancré en devant, avec les angles arrondis, presque lisse et à peine distinctement pointillé sur le disque; strie marginale entière. Ecussou triangulaire, très petit. Elytres élargies, plus longues que le pronotum de sa largeur à la base, dilatées à l'épaule, rétrécies au bout, très finement pointillées sur leur tiers postérieur; strie suturale disparaissant à l'extrémité, réunie en arc avec la quatrième dorsale; celle-ci atteignant le milieu: 1-3 un peu plus longues, presque d'égale longueur; humérale irrégulière, assez marquée, oblique, rapprochée de la première dorsale; subhumérale interne courte, très distante; externe basale; marginale entière. Pygidium bombé, couvert d'une ponctuation très fine, régulière. Mésosternum entièrement rebordé, très finement pointillé. Prosternum à stries en- 
tières, divergentes. Pattes brunes; jambes antérieures garnies de neuf on dix denticules épineux.

Sainte-Catherine (Brésil).

\section{1t1. S. CONVEXITSCELIS.}

Suborbicularis, convexus, brumneus, nitidus; antonnis pedibusque rufis; fronte subtilissime mencticulata, stria antice angulata subintegra; pronoto lateribus et basi punctulatis; elytris postice tenuiter, stria suturali integra antice arcuatim juncta; elorsalibus 1-3 nltra medium abbreviutis, $4^{\text {a }}$ paulo breviore, sublumerali intorna disjuncta, externa nuller; pygidio munctulato; mosterno striis divergentibus et ascendentibus; tibiis anticis 1-8 denticulatis. Long. 3 mill.; larg. 2 mill.

Suborbiculaire, convexe, brun, luisant, un peu bronzé sur les élytres. Antennes rouge-brun. Front plan, densément pointillé, mais peu visiblement; strie entière, fine, formant un angrle sur l'épistome. Pronotum beaucoup plus large que long, à peine bisinué à la base, bordé de points fins, oblique et ponctué de même sur les côtés, rétréci et échancré en devant, avec les angles arrondis; strie marginale fine, entière. Ecusson triangulaire, très petit. Elytres plus longues que le pronotum, de sa largeur à la base, à peine dilatées à l'épaule, rétrécies postérieurement, finement pointillées en dedans, sur le tiers postérieur; strie suturale entière, réunie à la quatrième dorsale par un arc à la base; celle-ci peu oblique, raceourcie un peu au-dela du milieu; 1-3 égales, plus longues; humérale fine, très oblique, sublumérale interne courte, disjointe; externe nulle; margrinale entière. Pygidium également et assez densément pointillé. Mésosternum entièrement rebordé, faiblement ponclué. Prosternum en carène un peu concave; 
stries légèrement divergentes et relevées en devant. Paltes rousses; jambes antérieures garnies de 8 -9 denticules épineux; postérieures de deux rangées de spinules.

Amérique boréale. (M. de Laferté.)

\section{S. Fimbriatis.}

Encus nitidus; antennis pedibusque rufo-brunncis; fronte subrugosa, stria intcrupta; pronoto ciliuto biimpresso limbo muctato; elytris parmm dense munctatis margine apicali, humeris arerufue subscutclluri lcevibus ad 2am torsalem; stria suturali iutegruantice arcuatim juncta; dorsalibus 3-4 in medio, 1-2 ultra abbreviatis; 3 internis lineis lavigatis continuatis, subhumerali interna juncta, externa nulla; pygidio dense cequaliter, mesosterno parce punclato; prosterno carinato, striis ascondentibus divaricatis; tibiis anticis 7-8 denticulatis. Long. $31 / 4$ mill. ; larg. 21/4 mill.

Saprinus fimbriatus. Le Conte, Ins. Calif., 5, 45, 17 (1851).

Ovale assez convexe, bronzé luisant. Antennes brunes. Front assez bombé, rugueusement pointillé; strie interrompue. Pronotum court, beaucoup plus large que long, bisinué à la base, et bordé de points avec une impression antéscutellaire, oblique, cilié sur les còtés, rétréci et échancré en devant, avec les anğles arrondis, marqués d'une petite impression, largement ponctué dans tout son pourtour, stric marginale entière. Ecusson très petit, triangulaire. Elytres courtes, plus longues que le pronotnm, de sa largeur à la base, dilatées à l’épaule, rétrécies postérieurement, couvertes de points peu serrés; épaule, bord apical et place subscutellaire, jusqu'à la deuxième dorsale, en dehors, lisses; stric suturale entière, réunie par un arc basal à la quatrième dorsale; $3-4$ raccourcies au milieu; 
1-2 un peu au-delá; les trois internes continuées par une ligne lisse au milieu de la ponctuation; humérale oblique, réunie à la sublımérale interne; externe nulle; marginale entière. Pygidium également et lensément ponctué. Mésosternum entièrement rebordé, avec des points épars. Prosternum caréné, droit; stries remontant un peu, divergentes. Pattes d'un rouge-brun; jambes antérieures garnies de sept ou huit denticules épineux.

Amérique boréale; Californie.

\section{S. IGNOTES.}

Suborbiculuris, ceneo-nitidus; antennis pedibusque rufo brunncis; froute subtiliter punctulata, stitu obsoletu; pronoto ciliato lateribus basique subrugoso munctuto; elytris dense et fortiter rugoso punctutis, areu scutelluri tevi, stria suturuli integra antice junctu; dorsulibus 1-1 dimidiatis, subhumer ali interna disjuncta, externa nullu; pygidio dense aqualiter munctulato; prosterno striis valde divergentibus; tibiis anticis 10-denticulatis. Long. 2 1/2 mill.; larg. $13 / 4$ mill.

Suborbiculaire, assez convexe, bronzé-obscur luisant. Antennes rousses. Front plan, finement et densément pointillé, stric obsolète. Pronotum cilié sur les bords, beaucoup plus large que long, bisinué à la base, arec une étroite bordure de points serrés, oblique sur les côtés, et largement couvert d'une ponctuation un peu rugueuse, rétréci et échancré en devant, avec les angles arrondis : strie marginale cntière. Ecusson triangulaire, très petil. Elytres courtes, plus longues que le pronotum, de sa largeur à la base, dilatées à l'épaule el rétrécies postérieurement; couvertes d'une forte ponctuation serrée, avec une place lisse, arrondie autour de l'écusson, s'étendant jusqu'au milieu des élytres, 
et en dehors, jusqu'i la deuxième on troisième strie dorsale ; le bord latéral est très finement et à peine visiblement ponctué ; strie suturale entire, réunie à la quatrièarc dorsale par un arc basal ; dorsales raccourcies vers le milieu, a peu priç ézales; deuxieme et troisiène un peu plus lorigues né.ımoins ; humérale assez forle, oblique, pllus confuse que les autres; subhumérale interne courte, disjointe; externe nulle; marginale forle, entière. Pygidium également, assez. densément et peu profondément pointillé. Nísosternum: entièrement rebordé, couvert de points forts, espacés. Prosternum en carène, peu dilaté aux extrémités; stries fortement divergentes des la base. Pattes rouges; jambes antérieures garnies de dis denticules épineux, très petits et seriés.

Mexique; Nouvelle-Grenade.

\section{S. ORBICLLATUS.}

Brunneus, nitichus; antennis pediuunque rufis; fronte rugulosa, siria antice obsolcta; monoto ciliato, limbo yunctulato, lateribus validius; elytris extus et dimidio postico parce punetatis, striis 1-4 dorsalibus crenatis sensim magis in madio

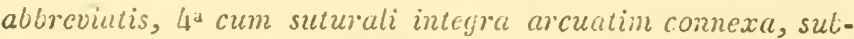
huncrali cxterna cum marginali coalescente, interna disjuncta marginem non attingente; pygidio aqualiter, mesosterno marginato parcius punctatis; prosterno carinato, sinuato, striis ascondontibus; tibiis anticis multidentatis. Longueur 3 mill.; larg. 2 mill.

Arrondi, assez convexe, d'un brun-ferrugineux, luisant. Antennes rousses. Front bombé, assez rugulcusement ponctué ; strie fiuc, obsolète derrière l'épistone. I'ronotum court, largement lisinué à la hase, oblique et cilié sur les 3e Sirie, tone II. 
côtés, rétréci et échancré en devant, arec les angles abaissés, oblus, courert de petits points sur la plus grande partie du disque, plus forls sur la marge postéricure, et rugueux latéralement; strie marginale fine, entière. Ecusson très petit. Elytres un peu plas longues que le pronotum, de sa largeur à la base, dilatées à l'épaule, rélrécies au bout, couvertes de points ausez ésaux, saus ètre fort serrés sur leur tiers postéricur et le long de la strie marginale; iulerstries libres; stries dorsules crínclées, raccourcies vers le milieu ; 1-4 progressivement plus courtes; quatrième réunie par un are basal à la suturale qui alteint le bord apical; lumérale fine, oblique; sublumérale interne disjointe, ne touchant pas le hord; externe confondue avec la marginale, quoique distincte au boul. Pygidium bombé, avec des points égaux, peu serrés. Mésosternum entièremeut rebordé, avec des poiuts épirs. Prosternum en carène, sinué; stries remontant sur les cotés. Pattes ferrugineuses : jambes antérieures dilatées, garnies de nombreux denticules.

Etats-Unis ; Texas (M. Pilate).

\section{S. VAFER.}

Ovalis convexiusculus, ancus nitidus; antennis pedibusque rufis; fronte subrugosa, stria integra; pronoto ciliato basi et lateribus punctato; clytris postice parce et tenuiter punctatis, stria suturali subintegra, 1-4 dorsalibus dimidiatis, subhumerali interna disjuncta, externa nulla; pygidio punctato; pro. noto anguste curinato, striis va!de divergentibus; tibiis anticis 7-8 denticulatis. Long, 3 mill.; larg. $13 / 4$ mill.

Ovale, assez convexe, bronzé luisant. Antennes brun. ferrugineux : funicule plus clair. Front presque plan, ru- 
gucusement ponctué; stric fine, entière. Pronotum plus large que loner, bisinué et élroitement bordé de points à la Jase, courbé el subrugueusement ponctué sur les colés. rétréci et échancré en devant, avec les angles arrondis, cilié; strie marginale enlière. Erusson très petit, triangulaire. Elytres plus longues que le pronolum, de sa largeur à la base, dilatées à l'épaule, très rétrécies postérieurement, courerles d'unc ponctualion ćparse, peu profonde, sur leur moilié postéricure; strie suturale cutiere, réunic en arc à la base arec la quatrieme dorsale: celle-ci interrompue, raccourcie an milieu, de même longueur que les trois autres; humérale très fine, oblique, trés rapproshce de la premiere dorsale; sublıumérale iutcrne courle, à peine disjointe; externe nulle; marginale entiere. Pygidiun tombé, couvert d’une poncluation égale et médiocrement serrée. Mésosternum entierement rebordé, avec quelques points épars. Prosternum en carc̀ne élroite, éargi à la base ; strics fortement divergentes en devant. Paltes rongeâtres; jambes antéricures garnies de ienticules épineus, serrés.

Vera-Cruz (Mexique). (M. Géhin).

\section{S. viaton.}

Brunneus, nitidus; antennis peditusque rufis; fronte dense punctata, stria obsolcta; pronoto ciliuto, limbo prosertim latcrali rugose punctato, stria intcgra; clytris parce extus et dimidio postico punctatis, striis crenatis per paria approximatis, dimidiatis, $l^{\mathrm{a}} \mathrm{cum}$ suturali completa connexa, subhumerali externa indistincta, interna disjuncta, interstitio inter humeralcm et $1^{\mathrm{am}}$ clorsalcm strigoso; pygidio cequaliter, mesosterno marginato parce punctatis;prostcino recto, striis ascendentibus; tibiis anticis 6.7 denticulatis. Long. $21 / 4$ mill. : larg. $13 / 4$ mill. 
Orbiculaire, peu convexe, brun-noir, luisant. Antennes rouges. Front assez bombé, ruguleusement pointillé; strie obsolète. Pronotum court, rilié, largement bisinué à la base, arqué sur les cótés, rétréci et échancré en devant, avec les angles abaissés, obtus, couvert de points fins sur le disque, un peu plus forts a la marge postérieure, rugueux latéralement; strie marginale entière. Ecusson très petit. Elytres larges, un peu plus longues que le pronolum, dilatées à l'épaule, rélrécies au bout, moilié postérieure couverte de points peu serrés; stries dorsales crínelées, et comme composées de lignes de points enchainés, rapprochées par paires, raccourcies au milien; $1-2$ plus lon:ues que trois et quatre; suturale complète, réunie à la plus voisine par un arc basal; sublumeérale externe confondue avec la marginale; externe disjointe; internalle entre la premiere dorsale et l'hu mérale obliquement strigueux. l'ygidium jeu bombé, également courert de points assez serrés. Mésosternum enlièrement rebordé, arec dés points épars. Prosternum en carène presque droite; stries remontant sur les côtés. Pattes ferrugineuses; jambes antérieures dilatées, garnies de 6-7 denticules.

Antilles (Cuba).

\section{S. CHulieNsis.}

Rufo-brunneus, nitidus; antennis brunneis, pedibus ferrugincis; fronte rugulosa, stria obsolcta; monoto ciliato, limbo punctato, stria marginuli integra; clytris dimidio postico sat dense punctatis, striis 3-4 in medio, 1-2 u!tra abbreviatis, $3^{2}$ arcu tenui cmn suturali integra conncra, subhumcrali extcrna cum murginati coalescente, interna disjuncta; pygidio oqualiter punctulato; mesosterno lovi, marginato; prosterno 
striis ascendentibus; tibiis anticis $8-9$ denticulatis. Long. 21/4 mill. ; larg. 1 1/2 mill.

Ovale cotirl, arrondi, peu convexe, d'un brun, plus ferrugineux sur les élytres et les côtés du pronotum. Antennes brunes. Front assez hombé, ruguleusement posuctué ; strie obsolète. Pronotum counl, largement bisinué à la base, courbé et cilié sur les côtés, rétréci et échancré en devant, avec les angles obtus et abaissés, entouré d'une fine ponctuation, plus forte et un peu rugueuse sur les côtés; strie marginale entière. Ecusson très putit. Elytres larges, un peu plus longues que le pronolum, de sa largeur à la base, dilutées à l’épanle, rélrécies au bout, convertes sur leur moitié posterreure d’une ponctuation, assez serrée et un peu aciculaire au bout, remontantau-dela du milieu, jusque sur les interstries: intervalle entre l'lıunérale et les lorsales obliquement strigueux; stries dorsales fines, raccourcies 3-4 au miiieu; 1 el 2 un peı au-flelà; troisic̀me réunie par un arc basal, avec la suturale qui atteint le bord apical; subhumérale esterne accolée à la marginale ; interne assez lon:ue, disjointe. Pygillum bounbé, assez Jensément ponctuć. Mésosternum lisse, entièrement rebordé. Prosternum en carèue sinuée; stries remontant sur les côtés. Palles ferrugineuses; jambes antérieures garnies de $\mathbf{8 - 9}$ pelits denticules.

\section{Chili.}

$g^{\prime}$. Jambes antérieures fortement tridentées ; postérieures densément et longuement ciliées.

\section{S. TRIDENS.}

Ferrugineus, nitidus; clava testacea; fronte loni, stria in 
tervupta; pronoto et subtus longius fulvo ciliuto, undique inctualiter et temui punctuluto; chytris postice in $4^{\circ}$ interstitio vage munctatis, striis valilis, crenatis, dorsulibus 1-'́ integris, apice arcutim approximutis, $\mathbf{1}^{\text {a }}$ cum suturuli inegra basi comexa, subhumerali intrrna disjuncta, exterma mullu; pygidio conecxo deu me metato; mesosterno marginato; prosterno carinito simuato, striismox coalest cntibus; tibiis anticis 3-dentatis, posticis longius spinosis. Long. 3 mill. ; larg. 2 mill.

Saprinus tridens. J. du Val, in Soc. Ent. (1852), 704.

Ovale oblong, convexe, ferrugineux, luisant, garni en dessous, latéralement, et surtout au pronotum, de longs poils jaunes serrés. Antennes plus pales. Front lisse, peu convexe; strie interrompue derrière l'épistome. Pronolum conrt, arqué à la base, oblique sur les còtés, rétréci et échancré en devant, arec les angles ohtus, abaissés, couvert de points un peu plus forts à lia base et latéralement; strie marginale entière. Ecusson très petit. Elytres plus longues que le pronutum, dilatẻes a l'épaule, rétrécies au bout, avec une ponctuation éparse, irrégulière dans le premier interstrie; stries crénclées; dorsales entières, fort obliques, arquées et rapprochées au bout; quatrième jénnie par un arc basal à la sulurale, qui est entière el plus rapprochée de la suture en arrière qu'en levant; sublumérale externe nulle; interme disjointe, assez courte, quoique abordant la marginale. Pygidium très incliné, bombé, couvert de points égaux, nssez forts. Mésosternum imponclué, entiirement rebordé. Prosternum en carine tranchante, sinuée; stries réunies de bonne heure, enfermées par les stries externes. Jambes antéricures armées de trois forles dents; postérieures garnies de longues épines ferrugineuses.

France; Montpellier, dans le sable des bords de la mer. 
c'. Fossettes antennaires remontant jusqu'au bord antérieur dı proslernum, et séparćes par une lame étroite. - Strie suturale nulle ou fort riccourcie par derrière.

\section{GROOPE (119.120).}

\section{S. RotcNDatus.}

Piceo-nitidus parce et fortiter punctatus; mgidlioque subtilius et densius; fronte haud striat.u; antennis pedibusque ferrugineis; pronoto stria int'gra, ante scutellum subimeresso; cly'ris stria suturali valde abbreviata, postice busi simuatin juncta; $1^{2}$ clor. salijuncta, scepius subinte:-ra, 2-4 panto pone medium abbreviatis, subhumerali interna longa disjunctu, 3 marginatibus; prostcrno antice valcic attenuto, striis convergentibus; tibiis anticis 5-dcnticulatis. Long. $3 \mathrm{~J} / 2$ mill. ; larg. $2 \mathrm{~J} / 2$ mill.

Hister rotundatus. Illg. Kxf., pl. 1, 61, 16 (1798). - F. Syst. El., 1, 90, 33. - Ent. Hefte, 1, 87, 20, pl. 1, 10 et 11. - Sturm. Deuts. Fn., 1, 2:92, 29.-Gylı. Ins. Suec., 1, 93, 23. - Pkl. Mon. Hist., 77, 61, pl. 7, f. 3. - Sieph. Ill. Brit. Ent., 3, 158, 32.

H. punctatus. Pkl. Fn. Suec., 1, 49, 17 (1798). - Duft. Fn. Austr., 1, 226, 23.

H. conjugulus. Illig. Mag., 6, 42, 19 (1807).

Saprinus rotundatus. Er. in Jahr., 1, 175, 1. - Kæf. Brand., 1, 675, 8, - Hée:, Fn. Helv., 1, 461, 5. - Le Conte, N.-Amér. Hist., 40, 1, pl. 5, 2. - Redt. In. Austr., 237. - Bach. Kxf. Prus.

S. deletus, Le Conte. N.-Amér. Hist., 4', 11, pl, 5, 11.

Taille très variable, ovale, peu convexe, brun de poix luisant plus ou moins foncé. Massue ferrugineuse: scape brun. Front légèrement bombé, finement poiutillé, sans strie. Pronotum beaucoup plus large que long, bisinué à la base, avec une impression antéscutellaire, oblique sur te 
côtés, rétréci et échancré cn devant, avec l'angle arrondi, également ponctué sur toute sa surface, mais peu densément : strie marginale entiere. Ecusson triargulaire, très petit. Elytres assez allongées, beancoup plus lonoues que le pronotum, de sa larggeur à la base, dilalées à l'épaule, puis réfrécies postérieurement, couvertes de points forts, peu serrés, plus fins à la base et sur les cotés; strie suturale fort raccourcie en arrière, souvent interrompue, el quelquefois réduite à une courte stric basale; rudiment fort court, d'une rinquieme strie dorsale, qui relie la qualrième avec la sulurale par un are sinué et deux fois interrompu ; première dorsale ordinairement continuée jusqu’à l'extrémité, mais plus fine à partir du milieu ; 2 -4 laccourcies a milieu; humérale bien marquée, oblique, rapprochée de la premièe dorsale; subhumérale interne longue, disjointe; cxlerne basale; trois marginales peu distinctes. Pygidium régulièrement pointillé. Mlésosternum entièrement rebordé, avec des points fins et peu serrés. Prosternum finement piointilié, large, plan, fortement rétréci en devant et resscré entre Ies denx fossettes antennaires; stries forles, entieres, bien marquées, se réunissant en devant en angle aigu. Pattes brun-ferrugincux; jambes antéricures garnies de cinq denticules épineux, arec un intervalle plus considérable entre le deuxieme et le Iroisième.

Anglelerre; France (P., Nantes, Rouen, Calais, Ie Mans, Marseille, Landes ); Suisse.

Cetle petite espèce se rencontre dis le premier printemps, sous les écorces, dans les charogries, dans le suc des arbres, dans presque toute l'Europe (Suede; Finlande; Allemagne, Italie; Styrie; Autriche) : dans le nord de l'Afrique (Alger. Egypte). et même dans le nord de l'Amériquze. 
120. S. PICETS.

Orbiculuris, gibbosus, rnfus, lavissimus subnitidus; fronte haud strialu; chytris stria lavissimis, suturali nulla la dorsali ultru medium, 2-4 sensim brevioribus, hrmerali ob:olcta, subhumerali interna nulla, cxterna subintegra; prostorno antice acuminato, striis angulatim convergontibus; tiliis anticis, lineuribus, ri.x spinulosis. Long. 2 1/5 mill.; larg. 2 mill.

Hister piceus. Pkl. Acta Holm. (I80?), 23,1 , pl. 7, f. 4. - Pkl. Mon., S1, 65, pl. 7, f. 7. - Ghl. Ins. Suec., 4, 270, $25-26$. - Stcph. 111. Brit. Ent., 3, 160, 5.

Saprinus piceus. Er. Kæx. Brand., 1, 676, 9. - Redt. Fn. Austr., 237. - Bach, Kæi. Prus., 1, 307, 2.

Orbiculaire, tris bombé, brun-rouge peu luisant, imponclué. Antennes ct palles plus pâles. Front légèrcment élevé, sans strie. Pronotum court, large, subsinué à la base et arancé ell pointe sur l'écusson, arqueé sur les côtés, très rètréci ct profondément échancré en devant, avec les angles aigus et assez avancés; strie marginale entière. Ecusson triangulaire, très pelit. Elytres deux fois au moins plus longues que le pronotum, de sa largeur à la base, curvilinéairement dilatées sur les côtés, forlement rétrécies au bout; strie suturale nulle; dorsales très fines et peu visibles; première dépassant le milieu ; $2-4$ de plus en plus raccourcies ; la dernière moins Inngue à la base; humérale très neu distincte, sans subhumérale interne; externe bien marquée, partant de la base et alleignant presque le bout; deux marninales entières. Pygillium très finement pointillé. Mésosternum entierenıent rehordé, paraissant lisse. Prosternum saillant, étroit, terminé en poinle, très étroite entre les fossettes antennaires: stries hien marquées, se 
joignant, à angle très aigu. Jambes antérieures étroites, avec quelques rares petites épines.

Angleterre ; Irance; Suède ; Allemagne; Autriche.

Cetle rare espèce se rencontre dans les fourmilières; clle a été omise daus la révision des llistérides, d'Erichson, dans le Juhrbücher. Elle a un faciès tout différent des autres $S a$ prinus, on dirait un Tribalus ou un Dendrophilus; mais aucun caractère de valeur ne la sépare de ce genre, si nom. breux en espèces. 


\section{ESSAI MONOGRAPHIQUE SUR LA FAMILLE DES HISTERIDES.}

(Suite) (1).

Par M. S.-A, de MARSEUL.

(Séance du 9 Février 1853.)

XXXIII. SAPRINUS (Suite).

Soc. Ent. 3 e série. T. 3 (1855), pl. 16 à 20. - Mon. pl. 15 à 19. Genre XXXIII.

A'. Front séparé de l'épistome par une carène (121-163).

B. Front sans sillon transversal en forme de chevron ou d'accolade.

5e GROUPE (121-139).

C. Front lisse ou ponctué (121-129).

\section{S. SERRIPES.}

Ovalis, convexus, brunneus, nitidus, antennis pedibusque rufis, subtus flavo-pilosus; fronte sublcevi, stria integra, carina recta; pronoto undique strigoso; elytris intus apice rude punctatis, in $4^{\circ}$ interstitio biserialim strigosis, striis validis punc. tatis, suturali integra, postice obsolescente, untice arcuatim

(1) Voyez 3 e Série, T. I (1853), p. 131 et 4'77; T. II (1854), p. 161, 525 et 671 ; et T. 111 (1855), p. 83 et 327. 
juncta, dorsalibus 1-4 integris apice valde convergentibus, subhumerali interna subintegra, externa nulla; mygidio punctulato; prosterno acule carinato striis brevibus junctis; tibiis anticis fortiter $8 \cdot d c n t a t i s$, posticis longius spinulosis. Longueur 3 mill.; larg. 2 mill.

Ovale allongé, fort bombé, brun-ferrugineux, assez luisant. Antennes rouge-pâle. Front peu bombé, transversal, lisse; strie entière, carène mince derrière l'épistome, droite. Pronotum assez court, beaucoup plus large que long, à peine bisinué à la base, oblique sur les côtés et bordé le longs cils jamuâtres, rétréci et échancré en devant, avec les angles arrondis; couvert de rides confuses sur toute sa surface, plus fortes latéralement; strie marginale entière. Ecusson triangulaire, très petit. Elytres très courtes, un peu plus longues que le pronotum, de sa largeur à la base, dilatées à l'épaule, très rétrécies postérieurement, couvertes au bord apical et le long de la suture de gros points irréguliers, formant dans le qualrième interstrie deux stries irrégulières; stries fortes, ponctuées; sulurale entière, réunie à la base par un arc avec la voisine, devenant plus fine et presque obsolète au bout; clorsales $\mathbf{1 - 4}$ formant un crochet interne à la base, eutières, très rapprochées les unes des autres vers lo bord apical; humérale fine, oblique, rapprochéc de la première dorsale, subhumérale interne longue, di-jointe, externe uulle; marginale entière. Pygidium également et assez densément ponctué. Mésosternum entiirement rebordé, paraissant imponctué. Prosteinum fortement rétréci au milieu en carène mince; stries courles, fines. réunies en angle dès la base, externes se rejoignant derrière le bord antérieur. Dessous couvert de longs poils jaunes sur les rôtés. Piottes rouges; jambes antérieures armées de trois 
fortes dents ; postéricures garnies de longues épines serrées, disposées sur deux rangées confuses.

France méridionale (Nîmes); Sicile; Turquie.

\section{S. MEDIOCRIS.}

Suborbicularis, piceus, nitidus, antennis pedibusque rufis; fronte puncticulata, carina transiersalevi; pronoto biimpresso, punctato basi fortius, disco postico lavi; elytris postice dense ct sat fortiter punctulatis, suturali stria antice subinterrupta, dorsalibus in medio abbreviatis, subhumerali interna brevissima disjunctu, erterna nulla; pygidio cequaliter punctato; prosterno striis parallelis antice junctis, tibiis anticis 6.7 denticulatis. — Long. 3 mill. ; larg. 2 mill.

Ovale arrondi, brun de poix, luisant en dessus. Antennes roussâtres, scape obscur. Front presque plan, arrondi, très finement pointillé ; strie entière, carène fine, régulièrement arquée. Pronotum beaucoup plus large que long, bisinué à la base, avec une bordure de points forts et assez serrés; oblique sur les côtés, rétréci et échancré en devant, avec les angles arrondis, légèrement impressionné de chaque côté; couvert de points répartis par places, le disque postérieur, un petit espace de chaque côté et le bord latéral paraissant lisses; strie marginale entière. Ecusson triangulaire, très petit. Elytres plus longues que le pronotum, de sa largeur à la base, dilatées à l'épaule, rétrécies postérieurement, couvertes dans leur moitié postétieure jusqu’à la deuxième dorsale, de points assez forts et assez serrés; strie suturale subinterrompue en devant, obsolète vers l'angle sutural postérieur; quatrième dorsale arquée vers l'écusson, 1, 3 et 4 raccourcies au milieu, deuxième un peu plus longue ; humérale fine, oblique; subhumérale interne très courte. 
disjointe, externe nulle ; marginale entière. I'ygidium également mais assez peu densément ponctué. Mísosternum entièrement rebordé, paraissaul lisse. Prosternum assez peu large, horizontal; slries fortes, subparallèles, réunies en devant. Pattes rouges; jambes antérieures garnies de 7.8 denticules épineux; postérieures de quelques spinules sur deux rangées.

France méridionale.

\section{S. FULViPES.}

Suborbiculuris, niger, nitidus, antennis brunneis, podibus rufis; fronte subtilissime muctata, stria integra, carina arcuata; pronoto disco tenuissime, letcribus basique fortius, clytrisque postice munctulatis, stria suturali antice arcutatim juncta, postice abbreviata; ilor salibus $1^{\text {a }}$ prope, 2a versus, :3-4 ultra medium productis; subhumeruli interna nulla; mggidio aqualiter sat dense, mesosterno fortius punctatis; rosterno carinuto striis valde angulatim apmroximatis, tibiis anticis 5-6 ılenticulatis. - Long. 2 3/4 mill. ; larg. 2 mill.

Suborbiculaire, lé èrement convexe, noir, luisant. Antennes brunes. Front à peine bounbé, très finement pointillé, strie entière, carène transversale de l'épistome arquéc, fine. Pronotum finement pointillé, presque lisse sur le disque postéricur, beaucoup plus large que long, bisinué à la base, avec une bordure de points assez forts, lígèrement courbé sur les côtés, largement et assez fortement ponctué saus impression, rétréci et échancré en devant, avec les angles arrondis; strie marginale un peu raccourcie à la base. Ecusson triangulaire, très petit. Elytres plus longues que le pronotum, de sa largeur à la base, curvilinéairement dilatées sur les côtés, rétrécies postérieure- 
ment ; ponctuation apicale assez fine, peu serrée, s’étendant presque jusqu'au milicu, et en dehors jusqu'á la deuxième strie dorsale; stries ponctuées, bien marquées; suturale réunie à la base par un arc avec la plus rapprochée, raccourcie à l'extrémilé, sans strie apicale, troisième et quatrième dorsales égales, dépassant le milieu; deuxième et première progressivenent plus courtes; humérale oblique rencontrant la première dorsale; subhumérale externe forte, courte, basale, interne nulle; marginale entière. Pygidium également et assez densément pointillé. Mésosternum entièrement rebordé, couvert de points espacés, assez forts. Prosternum en carène tranchante, élargi à la base; stries fort rapprochées, formant un angle très aigu. Pattes ferrugineuses; jambes antérieures garnies de 5 -6 petits denticules épineus; postérieures de quelques spinules sur deux rangées.

Espagne. (MM. de Laferté et Chevrolat.)

\section{S. A 1 ENTS.}

Ovalis, viridi-obscurus, nitidus, antemis pedibusque brunneis; fronte obsolete biimpressa, punctulatı, stria intcgru, carina transversa subrecta; monoto subtilissime lateribus inipresso subrugoso basique punctato; clyıris apirc punctulis, stria suturali integra antice arcuatim juncta, dorsalibus 1-4 sensim longioribus, 1a dimidiata; subhumerali interna disjuncta, externu nulla; pygidio cqualiter minus dense punctulato; mosterno striis approximatis antice junctis; tibiis anticis 5.dentatis. - Long. $31 / 4$ mill. ; larg. 2 1/4 mill.

saprinus amcenus Er. in Jahr., 190, 46 (1834).

Ovale, assez convexe, d'un vert foncé, luisant. Antennes brunes, massue faure. Front faiblement bombé, finement 
pointillé, avec une double impression à peine sensible, strie entière, carène transversale entre lui et l'épistome légère et un peu arquée. Pronotum finement pointillé, beaucoup plus large que long, bisinué à la base, arec une bordure de points plus forts; oblique sur les côtés, avec une étroite bande de points non contiguë au bord, impressionnce et un peu rugueuse antérieurement; rétréci et éclıancré en devant, avec les angles arrondis; strie marginale entière. Ecusson triangulaire, très petit. Elytres beaucoup plus longues que le pronotum, de sa largeur à la base, dilatées à l'épaule, rétrécies postéricurement, avec lc bord apical rougeâtre, ponctućes sur le quart postérieur en dedans de la deuxième strie dorsale, avec deux petites lignes peu régulières de points remontant sur le quatrième interstrie; stries fortes, ponctućes; suturale entière réunic à la base par un are avec la plus voisine; dorsales 1-4 graduellement plus-longues, première raccourcic vers le milieu ; lumérale fine, oblique, subliumérale interne courte, disjointe, externe nulle ; marginale entière. PJgidium couvert d'une ponctuation égale, peu scrrée et assez fine. Mlésosternum entièrement rebordé, peu visiblement pointillé. Prosternum assez étroit dès la base, horizontal; stries parallèles, rapprochées, réunies en devant. Pattes brunes; jambes antérieures garnies de cinq denticules épineux assez forts; postérieures de quelques spinules sur deux rangs.

Espagne; Portugal ; Autriche ; Russie.

\section{S. SPRETLLUS.}

Niger metullicus nitidus, amemis pedibusque brumeis; fronte subtilissime puncticulata, stria integra car ina subarcuata; pronoto tateribus late subrugoso, basi anguste punctalo; elytris 
intus postice parum alcnse punctutis; stria suturati integra, untice arcuatim junctu; dorsulibus 2-? sub apicem, 1 versus medium abbreviatis, subhumerali nuraque nullu, marginali secundum basim tontirututa; prostcrno striis parallelis; tibiis anticis 6-tenticulatis. - Long. $23 / 4$ mill. ; larg. $13 / 4$ mill.

Saprimus sprectulus Er. in Jahr., 192, 49 (1834).

Ovale assez convexe, noir métallique luisant. Antennes brunes. Front peu bombé, transverse, très finemont pointillé; strie entière, carène derrière l'épistome subarquée, nince. Pronotum couvert d'une ponctuation très fine, arec une bordure de points plus forts, plus large que long, bisiluué à la base, oblique sur les côtés, rétréci et échancré en devant, avec les angles arrondis; strie marginale $\mathrm{cn-}$ iière. Ecusson très petit, triangulaire. Elytres beaucoup plus longues que le pronotum, de sa largeur à la base, curvilinéairement dilatées sur les côtés, rétrécies au bout, ponctuation apicale assez fine et peu serrée, s'étendant jusqu'au milieu de la longneur, et en dehors jusqu'à la deuxième dorsale environ; stries ponctuées, bien marquées, suturale entière, arquée à la base et réunic avec la plus voisine; dorsales 2-4 dépassant de beaucoup le milieu, première moins longue; humérale fine, oblique, très rapprochée de la première dorsale; subhumérales nulles; marginale cutière, continuée le long de la base. Pygidium également pointillé. I'ésosterumm entièrement rebordé, avec des points espacés, peu profonds. Prosternum un peu rétréci en devant, stries fines, subparallèles, un peu raccourcies. Paltes brunes; jambes antérieures garnies de six denticules épineux, apicaux assez forts.

Portugal ; Alger ; Tanger. 


\section{S. Lovgistrius.}

Suborbicularis, nigro-piccus, nitidus; untennis pedibusque. rufis; fronte dense punctulata, stria integra, carinu elevatiori; pronoto basi sat fortiter, lateribus subrugose, disco subtiliter, clytrisque intus postice punctulatis, stria suturali integra, untice arcuatim juncta, dorsalibus $2-4$ sub apicem, $1^{\text {a }}$ paulo ante abbreviatis, subhumerali intcrma tonga, externa nuila; pygidio aqualiter puncticulato; proster no striis paralletis; tibiis anticis 6-denticulatis. Long. 2 1/2 mill. ; larg. 1 1/2 mill.

Ovale, suborbiculaire, légèrement convexe, noir de poix, luisant. Antennes rouges. Front peu bombé, très finement, un peu rugueusement pointillé ; strie entière, carène derrière l'épistome , mince, sinueuse, tranchante et assez saillante. Pronotum beancoup plus large que long, subsinué à la base, oblique sur les côtés, rétréci et échancré en devant, avec les angles arrondis ; finement ponctué sur le disque, presque lisse postérieurement, avec une bordure de points plus forts, large et rugueuse latéralement, étroite au bord postérieur; strie marginale entière. Ecusson trianģulaire, très petit. Elytres assez courtes, un peu plus longues que le pronotum, de sa largeur à la base, curvilinéairement dilatées sur les côtés, rétrécies au bout; ponctuation fine, peu serrée, couvrant le tiers postérieur, jusqu'à la deuxième strie dorsale; stries fines, ponctuées, bien marquées ; suturale entière, réunie à la base par un arc avec la plus voisine; dorsales dépassant de beaucoup le milieu, égales; première et qualrième un peu plus courtes; humérale fine, oblique; subhumérale interne longue, joignant presque l'humérale, externe nulle; marginale enticre. Pygidium couvert d'une ponctuation fine, assez serrée, égale. Mésosternum entièrement reborlé, avec des points espacés peu 
profonds. Prosternum étroit, à stries subparallèles, assez. distantes. Pattes rouges; jambes antérieures garnies de 6-7 denticules épineux; postérieures de denx rangées de spinules.

Autriche; IIongrie. (M. de Laferté).

\section{2i. S. PRECOX.}

Brnumeus, nitens, untemnis peulilusque mfis; fronte carinatu, cemissime muncticulata, stria integra; monoto disco leviter, lateribus sat dense et fortiter menctulalo, stria marginali integra; elytris postico dimidio munctutis, stris dorsulibus $1^{\text {a }}$ apice, 2-4 in medio abbreviatis, suturali integra arcuutim connexu, subhumerati externa nulla, internu disjuncta; pygidio cequaliler munctulato; mesosterno marginato; mosterno carinato, striis convergentibus subparallelis; tibiis anticis 6-denticulatis. Long. 1 1/2 mill.; larg. 1 mill.

Samirus precox Er. in Jahr, 1, 193, 52 (1834).

Ovale-oblong, peu convexe, brun, luisant. Antennes rousses. Front transversal très fincment et peu visiblement pointillé, bordé d'une carène bien marquée derrière l'épistome et d'une strie entière. Pronotum court, arqué à la base, oblique sur les côtés, rétréci et faiblement échancré, avec les angles abaissés et arrondis, couvert d'une ponctuation assez serrée, plus forte sur les côtés, et très fine sur le disque; strie marginale entière. Ecusson très petit. Elytres un peu plus longues que le pronotum, de sa largeur a la base, rétrícies au bout, plus ferrugineuses que le reste, couvertes sur leur moitié postérieure de petits points peu serrés, qui ne dépassent pas en dehors la deuxième dorsale et ne remontent pas sur les interstries; stries crénelées, bien accuscées; première dorsale à peine raccourcie an 
bout, 2 et 4 n'atteignant pas tout à fait le milieu, troisième un peu plus longue, quatrième réunie par un arc basal à la suturale qui est complete ; subhumérale externe nulle; interne disjointe, courte. Pygidium bombé, également pointillé. Mlésosternum entièrement rebordé. Prosternum en carène étroite; stries très rapprochées, convergentes, quoique à peu près parallèles. Pattes rouges; jambes antérieures peu dilatées, garnies de six denticules, dont les trois ou quatre derniers sont assez forts.

Egypte.

\section{S. METALLESCENS.}

Eincus nitidus, antemmis pedibusque rufis; fronte puncticulata, stria integra, carina temui subrccla; pronotolimbo panctulato, stria integra antice ab angulo discedentc; etytris intus prostice punctatis, stria suturalintegra, antice arcuatim juncta, clorsalibus 1-4 parum abbreviatis, subhumarali utraque nulle; mygidio tenuissime punctulato; mosterno strits approximatis, subparalletis; tibiis antiris 5-6 tenticulatis. Long. 2 mill. ; larg. $11 / 2$ mill.

Suprinus metallescens Er. in Jahr., 192, 50 (1S34).

Orale un peu allongé, peu convexe, bronzé luisant. Alltennes brunes. Front presque plan, à peine visiblement pointillé; strie entière, carène transverse derrière l'épistome, peu saillante, arquée. Pronotum beaucoup plus large que long, oblique sur les côtés, rétréci et échancré en devant, avec les angles obtus; pointillé sur tout son pourtour, et bordé étroitement de points un peu plus gros à la base; strie marginale entière, s'éloignant du bord à l'angle antérieur. Ecusson très petit, triangulaire. Elytres assuz allongés, beaucoup plus longues que le pronotum, de sa 
largeur à la base, légèrement dilatées à l'épaule, rétrécies postérieurement, à ponctuation fine, peu serrée, peu étendue en dehors, mais remontant dans le premier interstrie un peu au-delà du milieu; stries ponctuées, assez lortes; suturale eutière, réunic à la base par un arc arec la plus rapprochée; dorsales presque entières, mas variant un peu de longueur; humérale fine, oblique, rej ignant la premìre dorsale; subhumérales nulles; marginale entière. Pygi-dium couvert d'une ponctuation fine, assez serrée, égale. Mésosternum entièrement rebordé, faiblement ponctué. Prosteruum à stries assez rapprochées, entières, parallèles. Pattes brunes; jambes antérieures garnies de cinc ou six petits denticules épineux.

France méridionale; Sardaigne; $\mathbf{A}$ gger ; Syrie (Beyroulh).

\section{S. AnLLCS.}

Subceneo-piceus, nitidus, antemis pedibusque o ufo-brumeis ; fronte subtilissime puncticulala, carina transvorsa tenui subrecta; mronoto limbo clytrisque margine apicali punctulatis; stria suturali antice, dorsatibus 1 , 3 et 4 sub apicem, $2^{2}$ prius abbreviatis; subhumerali interna brcvissima, externa mulla; pygidio muclulato apice sublevi; prosterno striis valde approximatis; tibiis anticis 5-6 denticulatis. Long. 21/4 mill.; larg. 1 1/2 mill.

Hister cemulus Illg. Mag., v, 42, 18 (1807).

Ovale-allongé, assez convexe, noir le poix, un peu métallique, luisant en dessus. Antennes brun-rouge. Front à peine boubé, très finement pointillé, avec une strie culière, sćparé de l'épistome par une rarène fine, légèrement arquée. Pronotum plus large que long. à peine bisinué à la 
base, oblique sur les côtés, rétréci el échancré en devant, avec les angles arrondis, couvert d'une ponctuation très fine, avec le disque postérieur lisse ; strie marginale entière. Ecusson triangulaire, très petit. Elytres allongées, beaucoup plus longues que le pronotum, de sa largeur à la base, à peine dilatées à l'épaule, très rétrécies postérieurement; bord apical densément pointillé, précédé de quelques points très espacés; strie suturale raccourcie presque an milieu; quatrième dorsale arquée vers l'écusson, atteignant les trois quarts, ainsi que la troisième et la première, deuxième plus courte; humérale oblique accostant à la base la première dorsale; subhumérale interue courte, disjointe, externe nulle; marginale entière. Pygidium assez densément pointillé, presque lisse au bout. Mésosternum entièrement rebordé, marqué de quelques points peu visibles. Prosternum devenant très étroit dès la base; stries très rapprochées, n’atteignant pas le bord antérieur et enclavées par les stries extérieures qui so réunissent. Pattes rouges; jambes antérieures garnies de 5-6 denticules épineux.

vrance méridionale (Marseille, Beziers); Porlugal.

c'. Front rugneusement ponctué (130-139).

\section{S. Consic's.}

Ovalis, convexiusculus, ceneus, nitidus; antemnis pedibusque brumne is; fronte strigosa, stria integra; mronoto subrugosomunctato area posticu lavi; plytris postice muctatis, stria sutuvali mella, 2-4 in medio abbreviatis, $4^{\text {a }}$ basi arcuata, $1^{\text {a }}$ punlo longiori; subhumerali interna ferejuncta, cxterna mulla; mygidio dense muncliculato; mosterno striis valde amproximatis; tibiis anticis 5-rlentatis. Longueur 2 milliur.; largeur 1 1/2 mill. 
Ovale, un peu arrondi, assez conrexe, métallique, luisant. Intenues brunes. Front transversal, plane, couvert de strigosilćs lortes et serrées; strie entière, séparée de l'épistome par une carène un peu sinuéc. Pronotum beancoup plus large que long, bisinuć à la base, oblique sur les côtés, rétréci el échancré en devant, avec les angles arrondis, cotivert d'une ponctuation assez forte dans tout son pourtour, rugueuse et large sur. les côtés, étroite à la base; strie marginale entière, un peu interrompue derrière les yeux. Ecusson triangulaire, trés petit. Elytres plus longues que le pronotum, de sa largeur à la base, a peine dilatées à l'ípaule, rétrécies postérieurement; ponctuation fine, assez. serrée, comvrant presque la moitié postérieure jusqu'à la deuxiène strie dorsale; suturale nulle; 2 -3 dorsales raccourcies vers le milieu, première au-delà, quatrième un peu avant, recourbée en arc vers l'écusson ì la base ; humérale fine, oblique, rapprochée de la première dorsale; subhumérale interne assez longue, presque jointe à l'lıumérale; externe nulle; marginale entière. Pygidium également et densément pouctué. Mésosternum entièrement rebordé, avec quelques points à peine visibles. Prosternum très rétréci peu après la base; stries très rapprochées, terminéeşun peu avant le bord antérieur, entourées par les stries externes, qui se réunissent en avant. Pattes brunes; jambes antérieures garnies de cinq dents, les apicales assez fortes; postérieures de quelques spinules sur deux rangées.

Corse (I. Reiche).

131. S. HERBEIS.

Ovaíis, convexus, rufo-piceus, submetallicus, nitidus; carina subsinuata, fronte strigosa; monoto basi ct laterihus rugoso3e sérir, TOME II. 
punctato; elytris postice intus subtilissime punctulatis, striu suturali antice interrupta, dos:salibus paulo pone medium abbreviatis, 1a appendiculata; subhumerali interma disjuncta, externa nulla; pygidio dense aqualiter muncticulato; mesostemo sublavi; mostemo striis valde approximatis; tibiis anticis 4-dentatis, Long. 2 1/2 mill.; larg. 1 1/2 mill.

Ovile, assez convexe, brun, métallique, luisant. Autennes roussatres. Front plan, transversal, couvert de points rendus ronfus par des strioles transterses, entièrement ceint d'une strie forte et bien marquéc, séplaré de l'épistome par une petite carène un peu sinuce au milieu. Pronotum plus large que loug, bisinué à la base et borlé de points serrés, oblique sur les côtés, rétréci et échancré en devant, avec les angles arronlis, largement bordé dans son pourtour de points strigueux peu serrés; strie marginale entière. Ecusson trianguiaire, très petit. Elytres plus longues que le pronotum, de sí largeur à la base, un peu dilatées à l'épaule, fort rétrécies et plus rougeâtres postéricurement; poncluées très fiuement et assez densément sur la moitié postérieure, jusqu’à la troisième strie dorsale; strie suturale un peu interrompue en levant; quatrieme dorsale raccourcie an milieu, arquée vers l'écusson et parais. sant vouloir rejoindre la suturale; $1-3$ un peu plus longues, première augmentéc d'un appendice qui la continue jusqu'an bord apieal; humérale fine, oblique; subhumérale interne disjointe, externe nulle; marginale entière. Pygidium également et très finement ponctué. Mésosternum entièrement rebordé, ì peiue distinctement pointillé. Pro sternum trés étroit presque dlès la base; stries fort rapprochées, subparallèles. Pattes roussatres; jambes antéricures armées de quatre fortes dents, postérieures de deux rangées de spinules.

Hongrie (M. de Iaferté). 


\section{S. AREMARILS.}

Ovalis, converus, rufu-piccus, nitidus; untennis pedibusque rufis; frontc strigosu, stria integra, carina rectu; pionote puncticulato lateribus impresso subrugoso; clytris nostice subtilitermunctatis, striu suturati integret, untice arcuatim junctu, dorsalibus 2-4 pone malium abbroviatis, 1a longiori; subhumerali interna longa subjuncta, externa nulla; mygidio cequaliter puncliculato; prosterno curinato, striis valde apmoximatis; tibiis anticis 5-denticulatis. Long. 2 mill.; larg. 11/2 mill.

Ovale, un peu arronli, assez convexe, brun de poix luisant, plus rouge sur les élytres. Antennes rouges, massue plus pâle. Front transversal presque plane, densément pouctué, finement rugueux ; strie entière, carène derrièro l'épistome, tranclıante, arquée, assez saillante. Pronotum? beaucoup plus large que long, à peine bisinué à la base, oblique sur les côtés, rétréci et échancré en devant, avce les angles arrondis, très légèrement impressionnés, cunvert d'une ponctuation très fiue, assez serrée, un peu plus forte et rugueuse latéralement; stric marginale entière. Ecusson petit, triangulaire. Elytres courtes, un peu plus longues que le pronotum, de sa largeur à la base, dilatées à l'épaule, rétrécies postérieurement; ponctuation fine, assez serrée. occupant presque toute la moilié postérieure, jusqu'à la deuxième strie dorsale; stries fines, ponctuées; suturale entière, réunie en arc à la base asec la plus rapprochée: dorsales 1-4 graduellement plus courtes, première simuée ef presque entière, troisième et quatrième rapprochées au bout, dépassant le milicu; humérale fue, oblique, très voisine de la première dorsale; subhumérale interne assez longue, à peine disjointe, externe nulle; marginale entière. Pygilium également ct trés fuement pointillé. Hésosternum 
enlièrement rebordé, paraissant lisse. Prosternum en carène étroite, stries fort rapprochées par devant. Pattes rouges; jambes autérieures garnies de cinq ou six denticules épineux, postérieures de longues spinules sur deux rangées.

Autriche ( 11. de Laferté).

\section{S. RUFIPES.}

Aneus vitidus, antomis pedibusque rufis; fronte rugulosa, stria integra, carina transver'sa subrecta; pronoto dense punctulato, disco postico lavi; elytris dimidia parte postica punctatis, stria suturali integra, antice arcuatim juncta, dorsalibus 2-4 plusquam dimidiatis, 1 a subintegra sinuata, subhumerali interna longa, externa nulla; mygidio subtilissime puncticulato; prosterno carinato, striis valde approximatis; tibiis anticis 6-denticulatis. Long. 2 mill. ; larg. 1 1/2 mill.

Histcr rufipes Payk. Fn. Suec. 1, 50, 18 (1798). - Mon. Hisı, 75, 58, pl. 7, 1. - Duft. Fn. Aust. 1, 228, 27. - Gyll. Ins. Suec., $4,268,22,23$.

Saprinus rufipes Heer Fin. Helv., 1, 462, 7. - Redt. Fn. Aust., 238. - Bach Kæf. Prus. 1, 311, 14 .

S. rubripes Er. in Jahr. 1, 191, 48 (IS34).

Ovale, suborbiculaire, légèrement convexe, bronzé-luisant. Antennes brun-rouge plus ou moins clair. Front plan, transverse, finement ridé; strie entière, carène derrière l'épistome tranchante, presque droite. Pronotum assez court, heaucoup plus large que long, couvert d'une ponctuation serrée, bien marquée, avec le disque postérieur lisse, à peine bisinué à la base, oblique sur les côtés, échancré et rétréci en devant, avec les angles arrondis; strie marginale entière. Ecusson triangulaire, très petit. Elytres larges, un peu plus longues que le pronolum, de sa largeur à la hase, dilatées à l'épaule, rétrécies postérieurement: 
ponctuation assez serrée, couvrant la moitié postérieure jusqu'à la deuxième dorsale; stries assez fines, ponctuées ; suturale entière, arquée à la base et réunie avec la plus proche, non continuée au bord apical; $2-4$ dorsales raccourcies un peu au-delà du milieu. première sinuée au lout, presque entière; humérale fine, oblique; subhumérale interne longue, presque jointe; externe nulle; marginale entière. Pygidium également et densément pointillé. Mésosternum entièrement rebordé, avec des points espacés, peu marqués. Prosternum en carène très mince; stries fort rapprochées, réunies en devant en angle très aigu. Pattes rougeâtres; jambes antérieures garnies de six denticules épineux.

Suède; France (Marseille, Calais), Suisse; Allemagne; Autriche; Espague; Portugal ; Alger; Sénégal.

\section{S. GRANARIUS.}

Rotundatus, ceneus, nitidus; antennispedibusque rufo-brunneis; fronte ruguloso-carinata, stria integra; pronoto limbo omni dense punctulato, lateribus rugulose; stria integra; elytris postice intus subtilissime puctulatis, dorsali $\mathbf{1}^{\text {a }}$ arcuata subintegra, 2-4 pone medium sensim abbreviatis, 4a cum suturali postice obsoleta comnexa; sublumerali interna angulatim humerali adnexa, externa nulla; pygidio subtilissime cequaliter puncticulato; mesosterno marginato; prosterno sinuatim car $i$ nato; striis subintegris valde approximatis; tibiis anticis 5-denticulatis. Long. 1 1/2 mill. ; larg. 1 1/4 mill.

Saprinus granarius Er. in Jahr. 1, 191, 48 (1834). - Redt. Fn. Austr. 783.

Orbiculaire, convexe, d'un bronzé métallique, luisant. Antennes rousses. Front transversal, plan, rugueusement ponrtué, avec une carène bien accusée derrière l'épistome, 
et une strie entière. Pronotum très court, arqué à la base, oblique sur les côtés, rétréci et échancré en devant, avec les angles très saillants, arrondis; couvert dans son pourtour d'un pointillé assez serré, plus fort et rugueux latéralement; strie marginale entière. Ecusson très petit. Elytres un peu plus longues que le pronotum, de sa largeur à la base, dilatées à l'épaule, rétrécies au hout, couvertes sur leur liers postérieur de très petits points également serrés, qui ne dépassent pas le deuxième interstrie ; stries dorsales fines et bien marquées, première sinueuse au bout et presque complète, 2-4 raccourcies progressivement au-delà du milieu, quatrième réunie par un arc basal à la suturale, qui disparaît postéricurement; sublumérale externe nulle, interue longue ef attcignant presque la marginale, jointe angulairement à l'humérale. Pygidium bombé, densément et également pointillé. Mésosternum entièrement rebordé. I'rosternum en (arène sinuée : stries convergentes, adossées et s'arangant parallèlement presque jusqu'au bout. Pattes d'un brun plas ou moins ferrugineux ; antérieures peu dilatées, garnies te cinq denticules, dont les trois derniers sont assez forts.

France méridionale.

\section{S. CONJUNGENS.}

Niger subceneus, nitidus; antemis pedibusque piccis; fronte iriangulari rugosa impre ssione carina transversali, retrorsum subanguluta; pronoto lateribus et busi sat fortiter anguste punclato; elytris postice breviter punctatis, stria suturali apice subaburcviuta, antice arcuatim juncta, dorsalibus

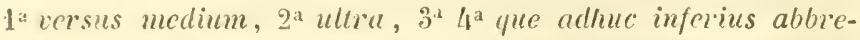
viatis, subhumerali internn obsoleta, extorna nulla; pygidio manm dense aizualiter muctulo: mosterno striis in medio 
valde approximatis, antice coëuntibus; tibiis anticis 4-dentatis. Long, 3 mill. ; larg. 2 1/4 mill.

IIister conjungens Payh. Fn. Suec., 1, 44, 11 (1799). - Mon. Hist., 65, 49, pl, 6, 1. - E. H., 1, 82, 18, pl. 1, 8. - Sturm Deuts Fn. 1, 228, 20. - Duft. Fn. Aust., 1, 227, 26. - Gyll. Ins. Suec., 1, 87, 16. - Steph. 1ll. Brit. Ent., 3, 155, 26.

H. 10-striatus Rossi, Mant., 1, 15, 22 (1792).

Saprinus conjungens Er. in Jahr., 1, 190, 45. - Kæf. Brand., 1, 677, 10. - Heer Fn. Helvet., 1, 462, 6. - Redt. Fn. Austr., 238. - Bach Kæf. Pruss., 1, 311, 13. - Küst. Kæf. Eur., 17, 31.

Ovale, assez convexe, noir métallique luisant. Antennes brunes. Front plane, pointillé, avec une profonde impression rugueuse, triangulaire; strie entière, carène transverse, mince, formant un petit angle rentrant au milieu. Pronotum plus large que long, bisinué à la base et étroitement bordé de points, un peu arqué sur les côtés, avec, une étroite bande de points non contiguë au bord, rétréci et échancré en devant, avec les angles arrondis; strie marginale entière. Ecusson triangulaire, très petit. Elytres plus longues que le pronotum, de sa largeur à la base, à peine dilatées à l'épaule, rétrécies postérieurement, assez fortement ponctuées au bord apical, avec des bandes de points remontant vers les denxième, troisième et quatrième dorsales et le long de la suturale; cette derniere souvent en forme de strie; stries fortes, ponctuées; suturale à peine raccourcie au bout, réunic à la base par un arc avec la voisine ; pre. mière dorsale raccourcie au milieu, deuxième un peu audelà, 3-4 encore un peu plus longues: humérale fine, oblique; sublumérale interne courte, obsolète; externe nulle; marginale entière. Pygidium assez fortement, mais pas très densément ponctué. Mésosternum entièrement rebordí, arec des points espacés. Prosternum resserré au 
milieu; stries entières, rapprochées, puis un peu divergentes et réunies en devant. Pattes brun de poix; jambes antérieures garnies de quatre denticules épineux assez forts.

Angleterre ; Suède; France (P., Rouen, Calais , Nantes, Le Mans, Iletz, Marseille); Suisse; Allemagne ; Autriche; Espagne; Italie; Afrique boréale.

\section{S. Buqueti.}

Ovalis, convexus, niger subnitidus; antonis pedibusquerufis; fronte rugosa, stria parum distincta; pronoto ciliato, biimpresso, lateribus strigoso; clytris rugoso-punctatis, humeris et juxta scutellum sublcevibus; stria suturali integra, arcuatim basi cum $4^{\mathrm{a}}$ dorsali dimidiata coeunte, 2-3 paulo longioribus, 1" subintegra, humerali cum subhumerali continua; pygidio dense punctato; mesosterno sublcevi; prosterno striis approximatis ; tibiis anticis 5-denticulutis, Long. 4 mill.; larg. 3 mill.

Ovale, assez conıexe, noir assez íuisant. Antennes rousses, scape brun. Front peu bombé, transverse, rugueusement ponctué; strie obsolète en devant; épistome fort étroit. Pronotum cilié, beaucoup plus large que long, bisinué à la base et bordé de points, oblique et un peu sinué sur les côtés, avec une ponctuation rugueuse, rétréci et échancré en devant, avec les angles arrondis et marqués d’une large impression. Ecusson triangulaire, très petit. Elytres beaucoup plus longues que le pronotum, de sa largeur à la base, dilatées à l'épaule, rétrécies postérieurement, entièrement couvertes d'une ponctuation serrée, rugueuse; épaules et région de l'écusson presque lisses; stries peu distinctes au milieu de cette surface chagrinée; uturale entière réunie en arc à la base, avec la quatrième 
dorsale; celle-ci s'arrêtant au milieu; deuxième et troisième un peu plus longues, première atteignant presque le bord apical ; lumérale ne partant pas tout à fait de la base, se continuant sans déviation ni interruption avec la subhumérale interne jusqu'au bout, parallèle à la première dorsale, externe basale ; marginale entière. Pygidium bombé, assez fortement, densément et également ponctué. Mésusternum presque lisse, entièrement rebordé. Prosternum étroit; stries bien marquées, rapprochées et réunies en devant. Pattes d'un brun-rouge; jambes antérieures garnies de quatre dents assez fortes.

Sénégal; Cap de Bonne-Espérance.

\section{1.)7. S. SCULPTURIFER.}

Ovalis, convexus, cupreus nitidus, ant mis pedibusque rufis; fronte rugosa, stria i tegra, carina recta prominula; monoto iliato elytrisque rugoso-punctatis, areis lavibus tessellatis, illo 4 parvis anterioribus, 1 magna, 4 basalibus, his 2 in unoqnoque 2-4 interstitiorum, stria suturali integra, antice arcuatim juncta; dorsalibus ultra medium productis, subhumerali interna valde disjuncta, externa mulla; pygidio punctato, medio sublcevi; prosterno carinuto, striis subadunatis; mesosterno punctato marginatoque; tibiis anticis 4-denticulatis. Long. ? 1/2 nill.; laıg. 1 1/4 mill.

Ovale allongé, assez convexe, cuivreux, luisant. Antennes rouge-pâle; scape brun. Front transrersal plane, densément et finement rugueux; stric entière, carène derrière l'épistome, mince, droite, saillante. Pronotum plus large que long, très arrondi et à peine bisinué à la base, avec une faible impression au devant de l'écusson, obliq̣ue et cilié sur les côtés, rétréci et échancré en devant, avec les angles arrondis, couvert de points serrés, rugueux, aver des espaces 
lisses, luisants, assez bien limités, nombreux : une rangée antérieure de quatre ou six très petits, irréguliers, une de quatre plus gros à la base et au milieu un plus fort entre les deux rangées; strie marginale entière. Ecusson très petit, triangulaire. Elytres courtes, à peine plus longues que le pronotum, de sa largeur à la base, dilatées à l'épaule, rétrécies postérieurement, ponctuées comme le pronotum, avec leux larges espaces lisses carrés sur le quatrième interstrie, avec une toute petile trace d'un troisième postérieur, deux petits sur le troisième, an niveau des deux postéricurs de la rangée précédente, deux sur le deuxième, l'antérieur fort long , le postérieur très petit; stries bien marqućes; suturale entière, arquée et réunie à la base avec la plus rapprochée; dorsales à peu près d'égale longueur, dépassant le milieu; humérale fine, oblique, un peu confuse; subluumérale interne loin d'atteindre l'humérale, externe nulle; marginale entière. Pygidium densément ponctué, lisse au milicu, biimpressionné à la base. Mésosternum entièrement rebordé, couvert de points assez forts, espacés. Prosternum en carène très mince; stries se rapprochant beaucoup et se confoudant bientôt. Pattes rouges; jambes antéricures garnies de quatre denticules épineux, postérieures de deux rangs de spinules.

Indes N.O. (II. de Laferté).

\section{S. ELEGANTULLS.}

Picco-reneus, subnitidus, polibus antcnnisque rufo-brunneis, clava flava; fronte donsc rugosula, stria integra, carina promimula; pronoto chyerisque mesos-pmonctatis, illo arca triangulari postica mediu, his oblonga $4^{\mathrm{i}}$, minima $3^{\mathrm{i}}$, binis $2^{\mathrm{i}}$ insterstii, humeris margineque apicali lavibus nitidis, stria suturali inteara, striola a sutura separatu, basi arcuatim juncta, dorsu- 
libns 1-4 pone medium dequaliter abbreviutis, subhumerali interna disjunctu, externa mulla; mygidio dense punctulo medio levi; mosterno striis vulde approximatis; tibiis anticis 5-denliculutis. Long. 2 3/4 mill.; larg. 1 1/2 mill.

Orale, assez convexe, noir cuivreux, luisant. Antennes brunes; massue rouge-pallc. Front plan, transverse, couvert d'une ponctuation rugueuse très fine el très serrée; strie entière, carène derrière l'épistome mince, saillante. I'ronotum beaucoup plus large que long, bisinué à la base, oblique sur les côtés, rétréci et échancrẻ en devant, avec les angles arrondis, couvert d'une ponctuation très serrée, rugueusc, arce un large espace triangulaice sur la partie jostérieure du disque, flanquée de deux autres très petits ; sric Inarginale entic̀re. Ecusson triangulaire, très petit. Nitres plas longues que le pronotum, de sa largour à la hase, dilaties ì l'épaule, rétrécies postéricurement, foncluées de la même manière, arec l'épaule, le bord apical et plusieurs espaces lisses, luisants: un allongé sous l'écusson, occupant tout le quatrième interstrie jusqu'aux deux tiers de l'élytre, un très petit sur le troisième au has du premier, deux sur le deuxième à la base ct au niveau du précédent, tant soit pen plus graní que lui; stries hien marquées, suturale entière, séparće de la suture par une strie internédiaire, arquée à la base et réunie avec la strie wisine; dorsales $1-4$ à peu près égales, dépassant le milicu; liumérale très oblique; subhumérale interne presque jointe, externe nulle; marginale entière bien marquée. Pygidium densément ponctué, avec une bande méđiane lisse, luisante. Nésostemum entièrement rebordé, ponctué. Prosternum assez étroit, légèrement concave; stries irès rapprochées, réunies en devant, enclavées par la. 
réunion des externes. Pattes brunes; jambes antérieures garnies de cinq denticules épineux plus forts, et au-delà de plusieurs très petits, serrés.

Indes $\mathbf{N} .0$.

\section{S. SPECILLUM.}

Eneus, nitidus, antennis pedibusque rufo-brunneis; fronte rugulosa, carinata, stria integra; pronoto marginato, donse rugulose punctato, disco triangulari polito; clytris densissime opace punctatis, margine extus et apice, dimidia basi $2^{\mathrm{i}}$ et $4^{\mathrm{i}}$ interstitii politis; stria dorsali $1^{\mathrm{a}}$ sinuata vix, $2-4$ in medio sensim abbreviatis, 4" cum suturali arcuatim connexa, subhumerali cxterna nulla, interna longa, disjuncta; pygidio dense; mesosterno marginuto parce punctulatis; prosterno triangulari, striis convergentibus; tibiis anticis 5-6 denticulatis. Long. 2 1/2 mill. ; larg. $12 / 3$ mill.

Ovale, peu convexe, d'un bronzé métallique, luisant. Antennes ferrugineuses. Front plan, transversal, rugueux, avec une carène derrièrc l'épistome et une stric cutière. Pronotum court, courbé à sa base, oblique sur les côtés, rétréci et échancre en devant, avec les angles arrondis, saillants, couvert d'une ponctuation très serrée, rugueuse, plus opaque latéralement, laissant sur son disque postérieur un espace triangulaire poli, assez bien limité; strie marginale entière. Ecusson très petit. Elytres larges, un peu plus longues que le pronotum, de sa largeur à la base, faiblement dilatées à l'épaule, un peu rétrécies au bout, couvertes d'une ponctuation si serrée et si régulière qu’elle forme une sorte de tissu opaque, le pourtour latéral et apical luisants, avec un espace juxta-scutellaire arrondi à la base du quatrième interstrie, et un autre en carré long à la 
base dn deuxième, bien limités, polis, luisants; stries assez hien marquées, première dorsale sinuce an bout, presque complète, les antres progressivement raccourcies vers lo milieu, quatrieme réunic par un arc basal arec la suturale ıui est entière; subhumérale cxterne nulle, interne longue, lisjointe. Pygidium bombé, également et densément pointillé. llésosternum entièrement rebordé, arec des points épars. l'rosternum en triangle allongé, à peine sinué ; stries entières, convergentes. Pattes d'un brun-ferrugineux; jambes antérieures médiocrement dilatées, garnies de 5-6 denticules, dont les quatre derniers assez forts.

Capp de Bonne-Espérance.

B'. Front avec un ou deux sillons en forme de chevron ou d'accolade.

$$
6^{\text {e }} \text { GROUPE }(140 \cdot 163) \text {. }
$$

C. Elytres couvertes d'une ponctuation aciculaire serrée, opaque. (140-144.)

\section{S. FRATERNUS.}

Nigro-cupreus, opacus, subtus piceus nitidus; fronte rugosa, sulco angulato gemino, carina transversa recta, prominula; pronoto strigoso, area levi nitida transversa baseos; elytr is aci. culatis, area subscutellari, humeris margineque inflexo lcovibus nitidis, stria suturali integra, antice arcuatim juncta, dorsali 1a apice undulata integra, 2-4 valde abbreviatis, subhurnerali interna subjuncta, externa mulla; pygidio cequaliter dense punctulato; mesosterno punctis parcis; prosterno striis approximatis; tibiis anticis 7-8 denticulatis. Long. 5 mill.; larg. 3 mill.

Hister fraternus Say in Soc. Phil., 5, 140, 12 (1825).

Saminus fraternus Le Conte N. Amér. Hist., 47, 16, pl., 6, १. 
Ovale, convexe, noir cuivreux, opaque ell dessus, noir de poix luisant en dessous. Antennes noires de poix. Front plar, transierse, rugueux au milieu, avec un double chevron un peu confus; strie entic̀re, carène derrière l'épistome droite, saillante. Pronotum plus large que long, faiblement bisinué à la base, oblique et un peu sinué sur les côtés. rétréci et fortement échancré en devant, arec les augles arrondis, coivert de points confluents, strigueux, avec un espace lisse, luisant au milieu du disque postérieur; strie marginale entière. Ecusson triangulaire, très petit. Elytres plus longues que le pronotum, de sa largeur à la base, un peu dilatées à l'épaule, rétrécies par derrière, densément aciculées, un espace arrondi subsculellaire à la base du quatrième interstrie lisse, luisant, ainsi que l'épaule et le bord infléchi; stries fines, suturale entière, réunie en are à la base avec la quatrième dorsale ; $\mathbf{2 - 4}$ dorsales progressivement plus courtes, raccourcies vers le milieu; première entière, ondulée et arquée en dedans; humérale oblique rapprochée; subhumérale interne entière, presque jointe ; externe nulle; marginale entière. Pygidium couvert d'une ponctuation égale, très serrée. Mésosternum entièrement rebordé, avec des points espacés. Prosternum rétréci ('n devant et un peu concave; stries rapprochées, un peu raccourcies, enclavées par les externes qui se réunissent en devant. Pattes brun de poix ; jambes antérieures garnies de 7-8 denticules épineux.

$\sigma^{*}$. Une impression médiane postérieure sur le métasternum; mésosternum presque lisse.

Cette espèce, qui a beaucoup d'analogic avec notre $S$. 4-striatus, varie dı noir au bronzé cuivreux plus ou moins obscur, et beaucoup pour la taille. Elle se rencontre aux 
Etats-lnis, sur les bords de la mer, dans les fucus et les matières régétales et animales en décomposition.

\section{S. 4-STRINTUS.}

Niger corulescens, subopacus; antemnis perlibusque piccis; fronte rugosa bisulcata, carina transversa recta; pronoto strigoso area transversa postica lavi; elytris dense rugoso-punctatis, area scutellari ovatu, apice humcrisque levibus, stria suturali antice arcuatim juncta, dorsabbus parum distinctis, sublumerali interna suljuncta integra; mygidio dense tequatiter puncticulato; mosterno striis valde apmoximatis; tibiis anticis 6-denticulatis. Long. 3 3/4 mill.; larg. 3 mill.

Hister 4-striatus Ent. IIefte, 1, 85, 19, pl. 1, f. 9 (1803). Gyl. Fu. Suec., 1, 90, 20. Paykl. Mon. Hist., 71, 55, pl. 6, f. 5. Steph. Illıst. Brit. Ent., 3, 154, 24. - Sturm Deuts. Fn., 1, 230, 24.

H. rugiceps Duft. Fn. Aust., 1, 225, 22 (1805).

Saprinus 4-strialus Er. in Jahr., 1, 194, 5/. - Kief. Brand., 1, 677, 11. - Heer, Fn. Helv., 1, 462, S. - Redt. Fn. Aus!., 2อ38. Bach Kief. Pruss. , 1, 310, 10. - Küist。 Kæf. Eur., 17, 32.

Ovale élargi, assez peu convexe, noir ou noir-bleuâtre, peu luisant. Antennes brun de poix. Front transverse, plan, rugueux, chevron double, confus; strie entière, carène lerrière l'épistome droite, saillante. Pronotum beaucoup plus large que long, bisinué à la base, oblique et un peu sinué sur les còtés, échancré et légèrement rétréci en devant, avec les angles antérieurs arrondis, rugueusement ponctué sur toute sá surface, avec un espace transverse sur' le disque postérieur, lisse, luisant ; strie marginale entière. Ecusson triangulaire, très petit. Elytres plus longues que le pronotum, de sa largeur à la base, dilatées à l'épaule, rétrécies posićrieurement, densément et rugueusement ponc- 
tućes, arec un espace ovale lisse el luisant auprès de l'écusson daus le quatrième interstrie, circonscrit par l'arc qui réunit la quatrième dorsale el la suturale, ainsi que le bord postérieur, l'épaule et le bord infléchi; stries peu marquées; suturale obsolète postérieurement; dorsales courtes, plus ou moins confuses, première interrompue et continuée par un appendice arqué au bout; humérale oblique mieux marquée ; subhumérale interne presque jointe, prolongée jusqu'au bout, externe courte, basale; marginale entière. Pygidium également couvert d'une ponctuation fine et très serrée. Mésosteruum entièrement rebordé, avec quelques faibles points. Prosternum en carèıe étroite, un peu concave; stries très rapprochées, presque réunies, enclavées daus les externes qui se réunissent en devant. Pattes noir de poix : jambes antérieures garnies de six denticules épineux, apicaux assez longs.

Cette espèce se rencontre en France (Nantes, Orléans, Calais, Le Havre, Lyon); Angleterre; Suède ; Belgique; Suisse ; Bavière : Saxe; Autriche: Italie, et dans les provinces du Caucase.

Elle ne paraît commune nulle part.

\section{S. SPECLLARIS.}

Metallicus, fronte sulco confuso, supra densissime rugosipunctatus, pronoto area geminatu elytrisque subscutellari rotunda polita nitida, his stria suturati antice abbreviata, dorsalibus, subhumerali utraque obsoletis brevibus ; mygidio dense aqualiter munctulato; mosterno striis attenuatis approxima. tisque; tibiis anticis 6-denticulatis. Longueur 4 mill.; larg. $23 / 4$ nill.

Ovale élargi, peu convexe, cuiıreux assez luisant. An- 
tennes noires. Front plan, transverse, lugueux, chevron un peu confus; strie entière, carène derrière l'épistonıe droite, assez saillante. Pronotum court, beaucoup plus large que long, bisinué à la base, avec une légère impression au devant de l'écusson, un peu oblique et subsinué sur les côtés, rétréci et échancré en devant, avec les angles arrondis, rugueusement ponctué sur toute sa surface, avec une large bande lisse transverse, divisée en deux par une faible impression ponctués; strie marginale entière. Ecusson petit, triangulaire. Elytres larges, plus longues que le pronolum, de sa largeur à la base, un peu dilatées à l'épaule et rétrécies postérieurement, poncluées rugueusement comme le pronotum, un peu opaques, avec le bord infléchi, l'apical, l'épaule et une petite tache arrondie subscutellaire à une petite distance de la base lisses, luisantes; stries peu distinctes, suturale raccourcie à la base, dorsales indistinctes, subhumérales courtes, interne disjointe, externe basale, marginale entière. Pygilium couvert d'une ponctuation serrée, mais non rugueuse. Ilésosternum entièrement rebordé, avec quelques fiibles points. Prosternum très étroit; stries fines se rapprochant beaucoup et raccourcies en devant, enclarées dans les externes, qui se rejoignent. Pattes noires; jambes antérieures garnies de six denticules épineux.

L'un des sexes présente une profonde impression au milieu du métasternum.

Cette espèce, très voisine du S. 4-striatus, s'en distingue aisément par sa couleur plus cuivreuse, moins bleu foncé, ses stries plus obsolètes, son espace lisse du pronotum plus large et divisé, celui des élytres plus petit, exactement 
circulaire, un peu éloignẻ de la base, et par ses stries pro. sternales moins rapprochćes.

Allemagne; 'Turquie; Autriche.

Trouvé sous une pierre, dans un torrent desséché.

\section{S. Maxcus.}

Niger, subtus nitidus, supra aciculato dense punctatus obscurus; antemnis brunneis; fronte marginata, carinata, sulco angulari; pronoto stria marginali integra; clytris lateribus et juxta scutellum sublcevibus, striis postice obsoletis, $1^{\text {a }}$ dorsali sinuata complcta, 2-4 sensim in merlio abbreviatis, suturali arcuatim comnexa, postice obsoleta, sublumcrali externa distincta, interna disjuncta; pygidio cequaliter dense, mesosterno marginato obsolete punctulatis; prosterno curinato, sinuato, striis approximatis, convergentibus; tibiis anticis 5̆-6 denticulatis, Long. 3 1/2 mill.; larg. 2 1/2 mill.

Hister mancus Say, in Soc. Pliil., v, 41, 13 (1825).

Saprinusmancus Le C., N. Amér. Hist., 56, 5.

Ovale, oblong, assez convexe, noir, luisant en dessous, obscur et ruguleusement ponctué en dessus. Antennes brunes. Front transversal, ruguleusement pointillé sur la partie postérieure, avec une carène derrière l'épistome, une strie entière et un chevron bien arreté, qui circonscrit un petit espace lisse. Pronotum court, subbisinué à la base, oblique sur les côtés, rétréci et échancré en devant, avec les angles arrondis, saillants; ponctuation très dense et rugueuse latéralement, un peu effacée sur le disque; strie marginale entière. Ecusson très petit. Elytres plus longues que le pronotum, de sa largeur à la base, rétrécies au bout, plus densément et aciculairement ponctuées, ne laissant de libre que les cotés et un petit coin du quatrième interstrie 
à la base et encore très mal limité; stries dorsales obsolètes au bout, et peu distinctes an milieu de la ponctuation; première sinuée, presque entière; 2 -4 raccourcies vers le milieu, celle-ci réunie par un arc basal à la suturale, qui disparait de bonne heure; subhumérale esterne courte; interne disjointe. Pygidium bombé, également et densément pointillé. Mésosternum entièrement rebordé, avec quelques petits points effacés. Prosternum en carène, droit et rétréci jusqu'aux trois quarts, puis rabattu; stries rapprochées, cessant à la sinuosité; jambes antérieures dilatées, garnies de 5-6 denticules assez forts.

Etats-Unis.

\section{S. BIGEMMEUS.}

Niger ceneus, nitidus, antennis pedibusque brunneis; fronte carinata, subangulatim sulcata, strigosa, stria integra; pronoto lateribus rugose, catero limbo tenuiter munctato, disco postico lavi, marginato; elytris densissime strigoso-aciculatis, ceneo-aureis, cxtus, apice et area rotundata basi $4^{\mathrm{i}}$ interstitii politis; striis indistinctis, suturali cum $4^{\text {a }}$ dorsali arcuatim connexa, antice distincta; subhumerali externa mulla, interna disjuncta; pygidio dense, mesosterno sparsim tenuissime punctatis; prosterno sinuato valde compresso, striis mox coalescentibus ; tibiis anticis $6-7$ denticutatis. Long. 3̊ mill. ; larg. 2 mill.

Saprinus bigemmeus Le Conte, Col. Calif. v, 46, 22 (1851).

Ovale oblong, peu convexe, noir bronzé, luisant, doré sur les élytres. Antennes brunes. Front plan, transversal, confusément ponctué, avec un chevron mal limité, carène saillante derrière l'épistome; strie entière. Pronotum court, à peine bisinué à la base, oblique sur les côtés, rétréci et échancré en devant, avec les angles arrondis, saillants; cou- 
vert dans son pourtour d'une ponctuation serrée, rugueuse latéralement, lisse sur la partie postérieure du disque; strie marginale entière. Ecusson très petit. Elytres courtes, un peu plus longues que le pronotum, faiblement dilatées à l'épaule, rétrécies au boul, si finement et si densément aciculées qu'elles paraissent soyeuses, lisses sur les côtés et au bord apical, avec un petit espace arrondi, poli, très brillant à la base du quatrième interstrie; stries confuses, peu visibles surtout les dorsales; quatrième réunie à la suturale par un arc basal; subhumérale externe nulle, interne disjointe. Pygridium bombé, densément et également ponctué. Mésosternum entièrement rebordé, couvert de petits points obsolètes. Prosternum en carène comprimée, concave; stries très rapprochées, adossées au milieu. Jambes brunes; antérieures dilalées, garnies de 6-7 denticules.

Californie.

c'. Elytres moins densément ponctuées, ordinairement lisses sur leur partie antérieure (145-163).

d. Un seul chevron sur le front (145-151).

\section{S. CoNspitus.}

piceo-metallicus, nitidus, aniennis pedibusque rufis; fronte sulco subangulato regulari, postice subtilissime puncticulata; pronoto areu parva antica utrinque punctata; elytris postice intus parce punctatis, stria suturali subintegra antice arcuatim juncta, dorsalibus dimidiatis, subhumerali interna disjuncta, externa nulla; pygillio lavi limbo punctulato; mesosterno punctato; prosterno striis mox confluentibus ; tibiis anticis 6-7 denticulatis. Long. 3 1/2 mill. ; larg. 2 3/4 mill.

Orale très bombé, d'un brun mélallique luisant, plus 
rouge sur les élytres. Antennes rouge-brun; scape plus foncé. Front transverse, peu convexe, très finement pointillé, un seul chevron à peine anguleux, bien dessiné; strie entière, carène derrière l'épistome droite, saillante. Pronotum assez court, beaucoup plus large que long, à peine bisinué à la base, oblique sur les côtés, rétréci et profondément échancré en devant, avec les angles arrondis, lisse avec une étroite bordure de points le long du bord postérieur, et un espace ponctué mème un peu confusément derrière les yeux, avec quelques points rares le long du bord latéral; strie marginale entière. Ecusson triangulaire, très petit. Elytres assez courtes, plus longues que le pronotum, de sa largeur à la base, fortement dilatées à l'épaule, très rétrécies postérieurement; ponctuation espacée remontant jusqu'au tiers antérieur, et ne dépassant pas en dehors la troisième strie dorsale; suturale un peu raccourcie à la base; dorsales fortes, ponctuées, raccourcies vers le milieu, à peu près égales, troisième un peu plus longue; humérale oblique, très rapprochée à la base de la première dorsale; subhumérale interne courte, isolée; externe nulle; marginale forte, entière. Pygidium pointillé dans son pourtour, lisse au milieu. Mésosternum entièrement reborlé, couvert de points très espacés. Prosternum en carène mince, concave; stries confluentes, enclavées dans l'angle très aigu des externes. Pattes d'un brun-rouge; jambes antéricures garnies de quatre dents assez fortes et de plusieurs petites, dont deux seulement visibles à la loupe.

Mexique (Vera-Cruz, Mexico).

\section{S. JaVETI.}

Ovalis, converus, viridis, nitidus; antennis tibiisque ferru- 
gineis; fronte angulatim uni striata; pronoto basi, lateribus tractim, elytris intus sat fortiter punctatis, stric suturali integra, arcuatim juncta, dorsalibus 1-4 dimidiatis subcrqualibus, subhumerali brevi disjuncta, externa mulla; pygidlo punctulato; mostcrno carinato concavo, striis proximis ; tibiis anticis 4-dentatis. Long. 3 mill.; larg. 2 mill.

Ovale, convexe, vert métallique, luisant. Antennes ferrugineuses. Front large, paraissant lisse, séparé de l'épistome par une strie semi-circulaire et une forte carène arquée, creusé d'un seul chevron nettement „dessiné. Pronotum court, faiblement bisinué et rebordé de gros points à la base, sinué sur les côtés, rétréci et échaneré en derant, avec les angles arrondis, une trainée irrégulière de points en devant el de chaque côté, assez éloignée du bord. Ecusson très petit, triangulaire. Elytres plus longues que le pronotum, de sa largeur à la base, dilatées à l'épaule, rétrécies et rougeâtres au bord apical, couvertes d'assez forts points espacés ell dedans, presque jusqu’à la base, postérieurement jusqu'au niveau de la troisième dorsale; stries crénelées, fortes ; marginale entière; subhumérale externe nulle; interne courte, disjointe; dorsales s'étendant jusqu'au milieu; première un peu au-delà ; suturale entière et réunie à la base avec la plus voisine. Pygidium bombé, assez densément pointillé. Mésosternum entiẻrement rebordé, couvert de points très espacés. Prosternum en carène étroite, concave; stries fort rapprochées, réunies en devant. Jambes ferrugineuses; antérieures garnies de quatre dents et de quelques denticules; postérieures de deux rangées d'assez longues spinules.

Amérique boréale. 


\section{S. PATREELIS.}

Viridi-ceneus nitidus, antcmis pedibusque brunneis; fronte sublcevi, sulco angulato profundo, carina prominula recta; pronoto basi ct ad angulum anticum munctalo; elytris dimidia parte postica ad $3^{+m}$ dorsalem parce punctatis, stria sulurali integra, antice arcuatim juncta, 1-4 dorsalibus punctatis, validis, vix medium atlingentibus; subhumerali interna brevi clisjuncta, externa nulla; myidio aqualiter punctulato; prostcrno carinato, striis valde approximatis; tibiis anticis 5-denriculatis. Long. 4 mill. ; larg. 3 mill.

Saprimus patmelis Le Conte, N. Amér. Hist., 46, 14, pl. 6, f. 2 (1845).

Ovale allongé, convexe, vert métallique luisant. Antennes lorunes, funicule rougeâtre. Front très faiblement bombé, lisse; chevron fort et nettement dessiné, strie entière, carène transverse derrière l'épistome, droite, saillante. Pronotum beaucoup plus large que long, bisinué à la base, avec une étroite bordure de points, oblique et un peu sinué sur les côtés, rétréci et fortement échancré en devant, avec les angles arrondis, lisse, avec un petit espace ponctué de chaque côté en devant; strie marginale forte, entière. Ecusson triangulaire, très petit. Elytres plus longues que le pronotum, de sa largeur à la base, rétrécies postérieurement, assez fortement et peu densément ponctuées dans leur dernière moitié jusqu’à la troisième strie dorsale ; stries fortes, bien marquées, ponctuées; suturale entière, continuée au bord apical, réunie à la base par un arc avec la quatrième dorsale; 1 - 4 dorsales égales, atteignant à peine le milieu; humérale fine, très oblique; subhumérale interne très courte, fort disjointe, externe nulle; marginale entière. Pygidium finement, densément et également ponctué, mésosternum entièrement rebordé, avec des points espacés. 
Prosternum étroit, caréné, un peu concave; stries fort rapprochées, enclavées dans les externes, réunies par devant en un angle très aigu. Pattes brunes; jambes antérieures garnies de cinq denticules épineux assez forts, et de quelques autres très petits et très scrrés.

Amérique horéale, avec le $S$. dimidiatipennis.

\section{S. FERRUGINETS.}

Ferrugineus, nitidus; fromle lavi, angulution sulcula, carinata, stria integra; pronoto marginato lateribus et basi anguste punctulato; elytris postice intus parce munctulatis, stria dorsali $1^{\text {a }}$ in medio, 2-3 pone, $4^{\text {a }}$ ante abbreviatis, suturali nostice intermuta, arcuatim connexa, subhumerali externa mulla, interna disjuncta; mygidio subtitissime, mesosterno marginato sparsim muncticulatis; tibiis anticis 5-6 denticulatis. Longueur 2 1/4 mill. ; larg. 1 1/2 mill.

Ovale oblong, peu convexe, l'un rouge ferrugineux, lnisant. Front lisse, un peu bombé, avec un chevron, une carène derrière l'épistome et une strie entière. Pronotum court, arqué à la base, oblique sur les côtés, rétréci et échancré en devant, avec les angles arrondis, couvert d'un pointillé fin le long des côlés et de la base; strie marginale entière. Ecusson très petit. Elytres un peu plus longues que le pronotum, de sa largeur à la base, rétrécies au bout, avec de très petits points espacés en dedans, sur le tiers postérieur; stries crénclées, bien marquées; première dorsale raccourcie au milieu, 2-3 un peu au-delà, quatrième avant, réunic à la suturale par un arc basal, celle-ci interrompue postérieurement; subhumérale externe nulle, interne disjointe. Pygidium bombé, très finement pointillé. Mésosternum entièrement rebordé, avec de tres petits poiuts 
éfars. Prosternum en carène sinuée; stries très rapproclées. Jambes antéricures dilatées, garuics de 5.6 denticules, dont les quatre derniers sont assez forts.

Amér. bor., Texas. (II. Pilate.)

\section{S. DHMIDIATIPENNIS.}

Ovalis, convexus, niger, nitidus; antennis pedibusque brunncis; fronte lavi sulco angulato profondo, carina prominula subrecta; pronoto lavi, basi punctato; elytris diagonaliter rubris intus postice punctatis; stria suturati integra, basi arcuatim juncta, 1-4 dorsalibus dimidiatis, humerali levissima, subhumerali intrrna brevi disjuncta, externa mulla, marginali profunda integra; pygidio parce menctato; prosterno acute carinato, striis mox conflucntibus, mesosterno marginato; tibiis anticis 4-5 tenticulatis, posticis 3-4 seriatim spinosis. Long. 5 mill. ; larg. $31 / 2$ mill.

Saprinus dimiliatipennis Le Conte in Ant. Lyceum N. Hist. New-York, T. I (1824). - N. Amér. Hist. 45̆, 12, pl. 6, fig. 1 (1845).

S. palmatus Le Conte N. Amér. Hist. 46, 13, pl. 6, 1.

Hister palmatus Say in Soc. Phil. v, 42, 14 (1825).

Orale allongé, convexe, lisse, luisant. Antennes brunes, funicule ferrugineux. Front large, lisse, avec un simple chevron bien imprimé; strie semi-circulaire, séparée de l'épistome par une carène presque droite. Pronotum assez court, beaucoup plus large que long, bisinué et bordé de points à la base, oblique sur les côtés. avec une tache rouge peu distincte, rétréci et fortement échancré en devant, avec les angles arrondis; strie marginale assez forte, entière, se continuant un peu a la base. Ecusson très petit, triangulaire. Elytres beaucoup plus longues que le pronotum, de sa largeur à la base, dilatées à l'épaule, rétrécies postérieurement, ponctuces assez fortement sur le quatrième inter- 
strie par derrière, couvertes d'une grande tache rouge triangulaire, dont le côté interne s'étendant de l'épaule à l'angle sutural, coupe l'élytre en deux parties à peu près égales; stries fortes, bien marquées; suturale entière, réunie à la base arec la quatrième dorsale par un arc; dorsales 1-^́ égales, raccourcies au milieu, avec un crochet interne à la base; humérale fine, oblique; subhumérale interne courte, très disjointe; marginale forte, profonde, bordée de quelques points, se continuant un peu le long de la base. Pygidium peu densément pointillé. Mésosternum entièrement rebordé, avec des points espacés. Prosternum en carène très mince, légèrement concave; stries bientôt réunies. Pattes brunes; jambes antérieures garnies de trois denticules épineux, forts, et de deux autres plus petits; postérieures de trois ou quatre rangées d'épines.

Amérique boréale (New-York), au bord de la mer, dans des poissons en putréfaction.

\section{S. SAbULOSCS.}

Piceus nitidus, antennis rufis; frontc lavi, sulco angulato valido, obsolete gcmino; pronoto margine basali ct parcius pone oculos punctulato; clytris $4^{\circ}$ interstitio grosse irr egulariterque punctato, stria suturali integra antice arcuatim juncta; dorsalibus munctatis, 1, 2 et 4, 3 sensim pone medium abbrcviatis; humerali duplicata, subhumerali interna subjuncta, cxlerna basali; pygidio ctqualiter punclato; prosterno carinato, striis mox comiventibus; tibiis anticis 6-denticulatis. Long. 4 1/2 nill. ; larg. 3 mill.

? Hister maritim us Steph. Illust. Brit. Ent. II, 155, 27 (1830).

Saprinus sabulosits Fairm. in Soc. Ent. (1852), 688, 3.

Ovale allongé, très convexe, noir de poix luisant. Antennes rousses, scape brun. Front peu bombé, lisse, chevron 
profond, bien dessiné en are de cercle, accompagné d'un deuxième très obsolète, réduit à trois points enfoncés; strie entière, carène élerée, transverse. Pronotum plus large que long, bisinué à la base, oblique sur les côtés, peu rétréci et fort échancré en devant, avec les angles arrondis, lisse avec la marge basale et un petit espace postoculaire ponctué; strie marginale entière. Ecusson triangulaire, petit. Elytres courtes, plus longues que le pronotum, de sa largeur à la base, dilatées à l'épaule, rétrécies postérieurement, ponctuées sur le quatrième interstrie, assez densément par derrière, irrégulièrement par devant ; stries fortes, larges, ponctuées; suturale entière, réunie à la quatrième dorsale par un arc basal, quatrième dorsale dépassant le milieu, première de la même longueur, 1-3 progressivement plus longues; humérale fine, très oblique, souvent accompagnée d'un petit appendice parallèle sur l'épaule; subhumérale entière, presque jointe, avec deux appendices courts; marginale forte, entière. Pygidium également ponctué. mésosternum entièrement rebordé, indistinctement pointillé. Prosternum en carène étroite, concave ; stries bientôt réunies, séparées ensuite et enfin jointes derrière les externes qui se rencontrent en devant. Pattes brunes; jambes antérieures garnies de trois fortes dents épineuses et de trois plus petites.

$c^{*}$. Impression métasternale.

Cette espèce vit dans le sable', sur les côtes septentrionales de France et de Belgique, et en Angleterre.

\section{S. DESERTORUM.}

Piceo-brunneus, nitidus, antemnis forrugincis; fronte lavi, carinata, stria integra, sulco angulato; pronoto hasi anguste 
de Marseul, - Mislérides.

punctato, stria marginali integra valida; elytris dimidio postico intus sat dense punctatis, striis crenatis, 1-4 dorsalibus dimidiatis, $1 \mathrm{et} 4$ paulo brevioribus, $4^{\mathrm{a}} \mathrm{cum}$ suturati integra antice arcuatim juncta, sublumerali externa mulla, interna disjuncta; pygitlio dequaliter sat dense, mesosterno marginato parce tenuiter punctutis; prosterno acute carinato, striis mox confluentibus; tibiis anticis 3 validis et 3 temibus denticutis armatis, posticis triplici serie spinosis. Long. 3 3/4 mill.; larg. 2 1/2 mill.

Ovale allongé, convexe, brun de pois, luisant. Antennes ferrugineuses. Front bombé, lisse, bordé d'une strie entière, avec une carène forte et droite derrière l'épistome, et un chevron bien marqué. Pronotum court, à peine bisinué et bordé de points à la base, oblique sur les côtés, rétréci et fortement échancré en devant, avec les angles arrondis, saillants; strie marginale très forte, entière, et même recourbée à l'angle basal. Ecusson très petit. Elytres plus longues que le pronotum, de sa largeur à la base, dilatées à l'épaułe, très rélrécies au bout, couvertes de points assez serrés, qui ne dépassent pas le deuxième interstrie, mais remontent un peu au-delà du milieu; stries fortes, crénelées; marginale formant un fort sillon; suturale entière, réunie à la quatrième dorsale par un arc basal; dorsales raccourcies vers le milieu, 2-3 un peu plus longues que 1 et 4; subhumérale externe nulle; interne courte, disjointe. Pygidium bombé, assez densément et également ponctué. Mésosternum entièrement rebordé, avec de petits points espacés. Prosternum en carène très tranchante, concave, stries bientôt réunies. Pattes brunes; jambes antérieures dilatées, munies de trois forts denticules et de trois petits; postéricures garnies d'une triple rangée de longues épines ferrugineuses.

Amérique boréale, monts Rocheux. 
d'. Deux chevrons sur le front. (152-163.)

\section{S. CRASSIPES.}

Piceus nitidus, antennis pedibusque rufis; fronte lavi sulcis 2, antico transverso, postico angulato, curina prominula; pronoto strigoso lateribus et disco lavi, elytris dimidio postico purctutis, striu suturali integra, antice arcuation juncta, dorsalibus 1-L dimidiatis, subhumerali interna subjuncta, externa nulla; pygidlio cequaliter munctato; prosterno angusto, striis conflucntibus; tibiis anticis obtuse 4-dentatis. Long. 3 3/4 mill. ; larg. 2 1/2 mill.

Saprinus crassipes Er. in Jahr., 195, 5\$ (1934).

Ovale fort convexe, brun de poix luisant, plus ou moins foncé. Antennes rouges, massue plus pâle. Front à peine bombé, lisse, avec deux chevrons bien marqués, l'antérieur transverse, largement arqué, le postérieur anguleux, en forme de circonflexe ou d'accolade, avec un point enfoncé à l'angle sur le milieu du vertex; strie entière, carène derrière l'épistome droite, saillante. Pronotum beaucoup plus large que long, bisinué à la base, oblique sur les cótés, avec un sinus assez marqué, rétréci et fortement échancré en devant, avec les angles arrondis, bordé de points à la base, et couvert de stries confluentes, laissant le bord externe, le disque postérieur et quelques petits espaces irréguliers, lisses, luisants ; strie margiıle entière. Ecusson très petit, triangulaire. Elytres plus rougeâtres que le reste de la surface, beaucoup plus longues que le pronotum, de sa largeur à la base, dilatées à l'épaule et rétrécies postérieurement, couvertes dans la derrière moitié de points assez réguliers, presque jusqu'à la deusième strie dorsalc; strie suturale entière réunie à la quatrième dorsale par un arc basal ; dorsales rarcourcies au milieu, à peu près égales entre 
elles, première un peu plus courte ; humérale fine, oblique; subhumérale interne à peine disjointe, externe nulle ; marginale entière. Pygidium également et assez densément ponetué. Mésosternum entièrement rebordé. Prosternum en carène tranchante, un peu concave; stries rapprochées beaucoup et enclavées dans les externes qui se rejoignent en devant. Pattes rouges; jambes antérieures garnies de quatre à einq larges dents obtuses ; postérieures larges, fortement épineuses.

Cette espèce varie pour la taille. Elle diffère du S. grossipes, avec lequel elle a été confondue, par le bord latéral du pronotum non cilié, visiblement sinué, par la ponctuation confuse et moins étendue, par ses chevrons frontaux moins mêlés de strioles, et par ses jambes moins fortes et leurs dents antérieures moins saillantes.

France méridionale (Landes); Allemagne; Espagne et Portugal; Italie; Hongrie.

\section{S. GROSSIPES.}

Rufo-brunneus, nitidus, antennis pedibusque rufis; fronte sulcis 2 angulatis substrigosis, carina prominula; pronoto ciliato, sat dense et fortiter punctato, disco postico sublavi; elytris ultra medium in $4^{\circ}$ interstitio irregulariter punctatis., stria suturali integra, antice arcuatim juncta, dorsalibus 1-4 dimidiatis, subhumerali interna vix disjuncta, externa nulla; pygidio punctulato ; prosterno carinato, striis subconniven. tibus; tibiis anticis late $4-5$ dentatis. Long. 3 mill.; larg. $13 / 4$ mill.

Ovale, très bombé, brun rouge luisant. Antennes d'un rouge pâle. Front légèrement convexe, ehevrons forts, pro fonds, un peu mêlés de strioles; antérieur en arc, postérieur 
en forme d'accolade; strie entière, carène derrière l'épistome droite, saillante. Pronotum cilié, beaucoup plus large que long, bisinué à la base, légèrement courbé sur les côtés, rétréci et échancré en devant, avec les angles obtus, couvert de points un peu rugueux latéralement, avec un espace presque lisse sur la partie postérieure du disque; strie marginale entière. Ecusson petit, triangulaire. Elytres courtes, un peu plus longues que le pronotum, de sa largeur à la base, dilatées à l'épaule, rétrécies postérieurement, ponctuation peu régulière, assez forte le long de la suture jusqu'au-delà du milieu, mais ne sortant pas du quatrième interstrie ; stries fortes, bien marquées, ponctoées; suturale entière, réunic par un arc à la base avec la plus rapproclıée; dorsales $1-4$ raccourcies vers le milieu, d'égale longueur, la troisième cependant un peu plus longue; humérale fine et très oblique; subhumérale interne à peine disjointe, externe nulle ; marginale entière. Pygidium également et finement ponctué. Mésosternum entièrement rebordé, pointillé. Prosternum en carène très étroite, concave; stries se rapprochant de manière à se confondre, enclavées par les stries externes qui se rencontrent en devant. Pattes fortes et robustes, rouges; jambes antérieures garnies de larges dents, dont les deux dernières sont assez saillantes; postérieures dilatées, fortement épineuses.

Espagne ; France, Bayeux, Marseille.

\section{S. SPIIXROIDES.}

Niger, metallicus, nitidus, untennis brunneis; fronte carinata, stria integra, sulco angulato gemino; pronoto punctato, lateribus rugoso, disco nostico levi, stria marginali completa; 
elytris postice intus dense punctulutis, striis dorsalibus $1^{*}$ integra, 2-4 parum abbreviatis, $4^{a}$ cum suturali arcuatim connexa, subhumerali externa mulla, intorna longa humcrali juncta; pygidio aqualiter et subtilissime punctato; mesosterno marginato parce punctato ; prosterno carinato sinuato, striis approximatis; tibiis anticis 5-6 denticulatis. Longueur $33 / 4$ mill.; larg. 21,4 mill.

Saprinus spharoides Le Conte N. Amér. Hist., 48, 17, pl. 6, f. כ (1845).

S. bigener Le Conte N. Amér. Hist., 47, 15, pl. 6, f. 3 (1845).

Ovale élargi, assez convexe, d'un noir métallique, luisant. Antennes brunes. Front légèrement bombé, lisse, avec une carène élevée derrière l'épistome, une strie entière et un chevron géminé et doublé de deux traits. Pronotum court, arqué et bordé de points serrés à la base, oblique sur les côtés, rétréci et échancré en devant, avec les angles saillants, arrondis, couvert de points rugueux latéralement, avec la partie postérieure du disque imponctuée; strie marginale entière. Ecusson très petit. Elylres plus longues que le pronotum, de sa largeur à la hase, curvilinéaires sur les côtés, rétrécies au bout, couvertes en dedans, sur leur tiers postéricur, de points serrés et fins en triangle; stries bien marquées; première dorsale sinueuse, complète, 2-4 égales, raccourcies seulement au quart postérieur, quatrième réunie à la suturale par un arc basal, celle-ci un peu interrompue au bout; humérale oblique, décomposée; subhumérale externe nulle; interne longue se joignant à l'humérale anguleusement. Pygidium bombé, couvert de pelits points fins, serrés. Mésosternum entièrement rebordé, avec des points épars. Prosternum en carène sinueuse; stries très rapprochées. Pattes brunes; jambes antérieures dilatées, garnies de 5-6 denticules. 
Etats-Unis, dans les poissons en putréfaction, sur les bords de la mer.

\section{S. RUGIFRONS.}

Obscurc virili-cenens, antennis pedibusque piccis; fronte sulcis 2 ungulatis sepe strigosis, carina recta prominula; monoto rugoso disco postico lavi; elytris dimidia parte postica sat fortiter punctutis, stria suturali integra, antice arcuatim comexa, dorsalibus $1-4$ dimidiatis, subhumerali interna juncta; pygidio dense punctulato; prostcrno striis approximatis subparallelis; tibiis anticis 6-denticulatis. Long. 4 mill; larg. $21 / 2$ mill.

Itister rugifrons Payk. Fn., Suec., 1, 47, 15 (1778).

II. metallicus Ent. H., 1, 81, 17 (1803). - Sturm, Deuts. Fn., 1, 225, 19. - Payk. IIon. Hist., 67, 51, pl. 6, f. 3. - Gyll. Fn. Suec. 1, 92, 22 .

Saprinus rugifions Er. in Jahr., 1, 195, 57. - Kxf. Brandt., 1, 678, 12. - Heer Fu. Helv, , 1, 462, 9. - Redt. Fn. Aust. 237. Bach, Kæf. Prus., 1, 310, 11. - Kü̈st. Kæf. Eur., viII, 72.

Orale allongé, convexe, vert sombre luisant. Antennes brunes. Front légèrement bombé, lisse sur le vertex, avec deux chevrons bien marqués, anguleux, souvent leur intervalle ridé transversalement; strie entière, carène transverse derrière l'épistome droite, sai!lante. Pronotum beaucoup plus large que long, bisinué et bordé de points à la base, oblique sur les côtés, rétréci et fortement échancré en devant, avec les angles arrondis, couvert de strigosités fortes et irrégulières, avec la partie postérieure du disque luisant et lisse; strie marginale entière. Ecusson très petit, triangulaire. Elytres plus longues que le pronotum, de sa largeur à la base, dilatées à l'épaule, rétrécies postérieurement; ponctuation assez forte et assez serrée, couvrant plus de la

3e Série, TOM II 
moitié postérieure, jusqu'à la deuxième strie dorsale ; stries fortes, ponctuées; suturale entière, réunic à la plus rappro. chée par un arc basal; 1.4 dorsales à peu près égales, dépassant un peu le milieu; humérale fine, un peu confuse, oblique et rapprochée de la première dorsale ; subhumérale interne jointe, externe courte, basale; marginale entière. Pygidium densément ponctué. Mésosternum entièrement rebordé, avec quelques points peu distincts. Prosternum assez étroit, concave; stries rapprochées, parallèles, enclavées par les externes réunies en devant. Pattes brun de poix ; jambes antérieures médiocrement dilatées, garnies de six denticules épineux de plus en plus faibles.

Cette espèce est répandue dans toute l'Europe (Angleterre, Suède, Be!gique, Allemagne, Trance, Espagne, Italie, Autriche, Russie, Grèce), et dans l'Algérie. Elle varie beaucoup de taille et de couleur (vert, bleu-violacé, noir), on l'a prise pour le $\boldsymbol{H}$. metallicus de Fabricius, non seulement dans les collections, mais dans plusieurs ouvrages.

\section{S. NETALLICLS.}

Ovalis, convexus, obscure viridis, nitidus, antennis pedibusque rufo-piceis; fronte sulco utroque irregulari haud angulato, postice strigosa, carina recta prominula; pronoto strigoso disco postico lcevi; elytris postice intus punctulatis, stria suturali integra, antice arcuatim juncta, clorsalibus $2-4$ dimidiatis, $1^{\text {a }}$ undulata subinlegra, subhumerali interna vix disjuncta, externa nulla; pygidio puncticulato; prosterno striis mox subconfluentibus; titiis dilatatis, valide 4-dentatis. Longueur 3 mill.; larg. 2 mill.

IIister metallicus Herbst Nat. Syst., iv, 32, 7, pl. 35, 7 (1791). - Illg. Kæf. Prus., 1, 60, 14. - F. Syst., El. , 1, 89, 26. - Steph. III. Brit. Ent., 3, 156, 29. 
Saprinus metallicus Er. in Jahr., 1, 195, 56. - Kx. Brand., 1, 679, 13. - Redt. Fn. Austr., 238. - Bach Kxf. Pruss., 1, 310, 12. - Küst. Kæf. Eur., rıII, 71.

Ovale un peu raccourci, assez convexe, vert métallique obscur, luisant. Antennes brunes, massue ferrugineuse. Front plan, transiersal; premier chevron sans angle rentrant, peu distinct, deuxième perdu au milieu de la rugosité; strie entière, carène derrière l'épistome droite, assez saillante. Pronotum court, beaucoup plus large que long, bisinué à la base, avec une étroite bordure de points serrés, oblique sur les côtés, rétréci en devant et fortement échancré, avec les angles arrondis, couvert de strioles confuses, arec la partic postérieure du disque et quelques petits espaces lisses; strie marginale entière. Ecusson très petit, triangulaire. Elytres larges, plus longues que le pronotum, de sa largeur à la base, rétrécies postérieurement, finement ponctuées dans leur tiers postérieur, jusqu’à la troisième strie dorsale; suturale entière, réunie à la quatrième dorsale par un arc basal; dorsales fines, bien marquées, ponctuées; 2.4 égales dépassant un peu le milieu, première entière, ondulée; humérale rapprochée de celie-ci, parallèle et fine; subhumérale interne à peine disjointe; externe nulle; marginale forte, entière. Pygidium densément et également pointillé. Mésosternum entièrement rebordé, à peine visiblement ponctué. Prosternum en carène étroite; stries parallèles, très rapprochées. Pattes brunes; jambes antérieures fort dilatées, garnies de quatre dents épineuses, dont les trois dernières sont fortes ; postérieures de deux rangs de spinules.

Cette espèce, confondue avec le $S$. rugifrons Payk., s'en distingue par sa forme plus raccourcie, moins bombée, le 
front rugueux derrière l'unique ehevron qui soit distinct, la ponctuation des élytres plus fine et moins étendue, la première dorsale presque entière, et surtout les jambes antérieures plus dilatées et armées de quatre dents beaucoup plus fortes.

Angleterre; Suède; Allemagne; Belgique ; France, dans les dunes de la Manche (Calais); Autriche; Portugal; Italie, peu répandue dans les collections.

\section{S. RADIOSLS.}

Viridi-ceneus, nitidus; antennis pedibusque brumneis ; fronte carinata strigosa radiata, sulco angulato striaque integra; pronoto rugose-munctato, disco postico lcevi, stria completa; elytris clense punctatis, extus et area scutcllari lavibus, striis dorsalibus 1-3 in medio, $4^{\text {a }}$ ante abbreviutis, $3^{a}$ cum suturati integra arcuatim connexa, subhumerali externa tenui, interna disjunctu; mygidio dequalier dense, mesosterno suutiliter munctatis; mostemo carinato striis approximatis; tibiis anticis 5-denticulatis. Long. 3 mill.; larg. 2 1/3 mill.

Ovale raccourci, convexe, vert métallique, luisant. Antennes brunes. Front transversal, plan, rugueux, marqué d'un chevron et de lignes irrégulières radiées, arec une carène derrière l'épistome ct une strie entière. Pronotum court, à peine bisinué et bordé de gros points à la base, oblique sur les côtés, rétréci et échancré en devant, avec les angles arrondis et abaissés, couvert d'une ponctuation strigueuse, partie postérieure du disque imponcluée; strie marginale entière. Ecusson très petit. Elytres larges, plus longues que le pronotum, de sa largeur à la base, rétrécies au bout, couvertes d'une ponctuation forte et serrée, avec la marge latérale et apicale et un espace juxta-scutellaire luisants; 
stries crénelées, bien marquées ; dorsales 1-3 raccourcies au milieu, quatrième un peu avant; suturale entière, réunie à la troisième dorsale par un are basal; subhumérale externe fine, courte; interne disjointe. Pygidium hombé, densément et également pointillé. Mésosternum entièrement reborlé, avec de très petits points obsolètes. Prosternum en carène sinuée; stries très rapprochées. Pattes brunes ; jambes antérieures dilatées, garnies de cinq denticules.

France (Marseille).

\section{S. APRICARIUS.}

Eneus, nitidulus, antemis rufis, pedibus brunneis; fronte sulco gemino angulato, stria integra, carina prominula; pronoto strigoso, disco postico tevi; elytris dense punctut is, humeris; margine inflexo, areaque subscutellari icevibus, stria suturati integra antice arcuatim juncta, dorsalibus 3-4 in medio, 1-2 paulo prost abbreviatis, subhumerali interna disjuncta, externu mulla; pygidio aqualiter munctulato; mosterno striis valde approximatis; tibiis anticis 6-denticulatis. Long. 3 1/2 mill.; larg. $21 / 2$ mill.

Saprinus apricarius Er. in Jahr., 194, 55 (1834).

Ovale oblong, peu convexe, bronzé assez luisant. Antennes rouges, massue plus claire. Front peu bombé, imponctué, chevron double, bien marqué, peu nettement dessiné, à angle très élargi ; strie entière, carène transverse derrière l'épistome droite, saillante. Pronotum plus large que long, bisinué à la base, oblique sur les còtés, avec un léger sinus médian, rétréci et échancré en devant, avec les angles arrondis, couvert de strigosités irrégulières peu serrées, bordé étroitement de points à la base, avec un espace lisse, luisant sur la partie postérieure dı disque; strie marginale entière. Ecusson petit, triangulaire. Elytres 
un peu plus longues que le pronotum, de sa largeur à la base, dilatées à l'épaule, rétrécies postérieurement, couvertes de points serrés, presque aciculés; les trois premiers interstries sont ordinairement ponctués aussi densément que le reste du disque, mais on trouve tous les passages, depuis une ponctuation plus éparse, jusqu'au lisse et au luisant; épaule, bord infléchi et un espace arrondi à la base du quatrième interstric lisses, luisants; strie suturale entière réunie à la quatrième dorsale par un arc basal, troisième et quatrième dorsales raccourcies au milieu, 1-2 un peu au-delà, celle-ci un peu plus longue; humérale oblique, bien distincte; subluumérale interne disjointe, externe nulle; marginale entière. Pygidium également et assez densément ponctué. Mésosternum entièrement rebordé, avec quelques points peu profonds. Prosternum étroit, caréné, concare; stries très rapprochées, un peu sinueuses antérieurement, enclavées par les externes réunies en devant. Pattes brunes; jambes antérieures garnies de six denticules épineux.

Sicile; Corse ; tout le nord de l'A frique, depuis Gibraltar jusqu'en Egypte. M. Lucas l'a trouvée très abondamment en juin, aux environs d'Alger.

\section{S. BrasilueNSIS.}

Eneus, nitidus, antennis rufis, pedibus brunncis; fronte bino sulco angulato, stria integra, carina rectu prominula; pronoto strigoso punctato, area postica lavi; elyuris parum dense aciculatis, area subscutellari, humeris et murgine inflexo lavibus, stria suturali integra, antice arcuatim juncla, dor'salibus 1-4 versus medium sensim abbreviatis, subhumerali imterna disjuncta, caterna nulla; mygidio requaliter punctulato; mo- 
sterno striis approximatis, subparallelis; tibiis unticis 6-denticulatis. Long. 4 mill. ; larg. $21 / 2$ mill.

Hister Brasilicnsis Payk., Mon. Hist., 66, 50, pl. 6, f. 2 (1811).

Orale allongé, assez convexe, bronzé assez luisant. Antennes rousses, scape un peu obscur. Front peu bombé, presque lisse, chevron peu fortement anguleux, entier, double, à bords déchirés, peu nets; strie entière, carène transverse derrière l'épistome droite, assez saillante. Pronotum plus large que long, bisinué à la base, oblique sur les côtés, rétréci et échancré en devant, avec les angles arrondis, bordé étroitement par derrière de points serrès, ridé sur toute sa surface, avec un espace lisse, transverse sur la partie postérieure du disque; strie marginale entière. Ecusson très petit, triangulaire. Elytres plus longues que le pronotum, de sa largeur à la base, dilatées à l'épaule, rétrécies postérieurement, ponctuées densément et un peu aciculées, avec le bord infléchi, l'épaule et un espace subscutellaire et la base du quatrième interstrie lisses, luisants; stries fortes, ponctuées ; suturale entière, réunie à la base par un arc avec la quatrième dorsale; $\mathbf{1 - 4}$ dorsales raccourcies vers le milieu, de plus en plus courtes; humérale fine, oblique, rapprochée de la première dorsale, mal dessinée, subhumérale interne assez longue, disjointe, externe nulle; marginale entière. Pygidium également couvert de points serrés. Mésosternum entièrement rebordé, pouctué. Prosternum étroit, caréné; stries rapprochées, presque parallèles, enclavées dans les stries externes réunies en devant. Pattes rouge-brun; jambes antérieures garnies de trois denticules épineux plus forts et de trois plus petits et plus serrés.

Montevideo: République d'Uruguay. 
160. S. DENTIUES.

Ovalis, subconvexus, obscure coneus, subnitidulus, antennis pedibusque brunneis; fronte levi sulcis 2 , antico arcuato, postico .3-sinuato; pronoto rugoso, mar gine basali munctorum 1-seriato, disco postico lavi; elytris dimidiatim punctulatis, stria suturali integra antice arcuatim juncta, dorsalibus 1.4 paulo pone mediur abbreviatis, subaqualibus, subhumerali interna disjunctu, externa nulla; pygidio aqualiter parce punctulato; mesosterno lavi marginuto; mosterno striis subparallelis; tibiis anticis 6-denticulatis. Long. 4 mill.; larg. $23 / 4$ mill.

Ovale élargi, peu convexe, bronzé obscur, peu luisant. Antennes brunes, funicule rouge. Front presque plan, lisse; deux chevrons profonds, un peu irréguliers, antérieur semi-circulaire, postéricur à trois courbures; strie entière, carène transverse derrière l'épistome droite, saillante. Pronotum court, beaucoup plus large que long, á peine bisinué à la base et bordé d'une ligne d'assez gros points, oblique sur les côtés, rétréci et échancré en devant, avec les angles arrondis, couvert de points rugueux, forts, assez peu serrés, partie postérieure du disque lisse ; strie marginale entière. Ecusson très petit, triangulaire. Elytres courtes, plus longues que le pronotum, de sa largeur à la base, un peu dilatées à l'épaule rétrécies postérieurement, ponctuation assez fine, peu serrée, opaque, s'étendant vers le milieu et en dehors, jusqu'à la deuxième strie dorsale; strie suturale forte, entière, réunie à la plus rapprochée par un arc basal; dorsales ponctuées, un peu irrégulières, à peu près d'égale longueur, raccourcies au milicu; lıumérale fine, oblique, très rapprochée de la première dorsale; subhumérale interne courte, isolée; externe nulle; marginale entière. Pygidium également courert de points peu serrés. 
Hésosternum lisse, entièrement rebordé. Prosternum en carène un peu concave; stries subparallèles, enclavées par les stries externes réunies en devant. Pattes brunes ; jambes antérieures garnies de six denticules; postérieures de deux rangées d'épines.

Mexique. (M. Chevrolat).

161. S. BISTRIGIFRONS.

Brunneo-ceneus nitidus, antennis pedibusque rufis; fronte 2 sulcis subarcuatis; pronoto punctato subrugoso, disco postico lcevi; clytris postice dimidio sat dense punctnlato, stric suturali integra, antice arcuatim juncta, dorsalibus 1-4 sersim brevioribus dimidiatis, subhumerali interna disjuncta; pygidio punctulato; prosterno striis approximatis; tibiis anticis b̆-denticulatis. Long. 2 1/2 mill.; larg. $13 / 4$ mill.

Ovale peu allongé, légèrement convexe, brun-bronzé luisant. Antennes roussâtres. Front peu bombé, lisse', avec un point sur le vertex, deux sillons bien dessinés, parallèles, plus en arc qu'en chevron; strie entière, carène transverse derrière l'épistonie droite, assez saillante. Pronotum court, beaucoup plus large que long, à peine bisinné à la base, oblique sur les côtés, rétréci et échancré en devant, avec les angles arrondis, couvert de points forts, un peu rugueux a l'angle, plus forts à la base, avec la partie postérieure du disque lisse; strie marginale entière. Ecusson triangulaire, très petit. Elytres courtes, à peine plus longues que le pronotum, de sa largeur à la base, légèrement dilatées á iépaule, rétrécies postérieurement; poncluation fine, assez serrée, s'étendant au delà du milieu et en dehors, jusqu'à la deuxième strie dorsale; stries fines, ponctuées; suturale 
entière, réunie avec la plus rapprochée par un arc basal ; dorsales 1-4 progressivement plus courtes, dépassant le milieu; humérale fine, très oblique, rapprochée de la première dorsale; subluumérale interne à peine disjointe ; externe nulle ; marginale forte, entière. Pygidium également et densément pointillé. Mésosternum lisse, entièrement rebordé. Prosternum ètroit, un peu concare; stries assez rapprochées, divergentes. Pattes brun-rouge; jambes antćrieures garnies de six denticules.

Mexique.

\section{S. DIMIDIATOS.}

Eneus nitidus, antennis pedibusque rufis; fronte lcevi, sulco angulato forti; pronoto lavi; clytris dimidia parte postica parum dense punctatis, stria suturali integra antice arcuatim juncta, 1-4 dorsalibus subequalibus versus medium abbreviatis, subhumerali interna vix disjuncta, externa nulla; pygidio puncticulato; mesostcrno levi; prosterno carinato striis sub. confluentibus; tibiis anticis 5-denticulatis. Long. 3 1/2 mill.; larg. 2 mill.

Hister dimidiatus Illg., Mag., vi, 41, 17 (1807). — Payk., Mon. Hist., 73, 56, pl. 6, f. 8.

H. semi-coneus Brullé Exp. Morée, 1, 157, 248 (1822).

Saprinus dimidiatus Er. in Jahrb., 1, 195, 59. - Küst. Kæf. Eur., 18, 31.

Ovale allongé, assez convexe, bronzé luisant. Antennes roussâtres. Front transverse, légèrement bombé, imponctué ; chevron assez fort, nettement dessiné, en forme d'accolade, avec une trace d'un chevron postérieur à peine visible; strie entière; carène derrière l'épistome droite, saillante. Pronotum lisse, court, beaucoup plus large que long, à peine bisinué à la base, avec quelques points peu 
serrés le long de la marge, oblique, subsinué sur les côtés, rétréci, échancré en devant, avec les angles arrondis; strie marginale entière. Ecusson très petit, triangulaire. Elytres allongées, beaucoup plus longues que le pronotum, de sa largeur à la base, sans dilatation sensible aux épaules, rétrécies postérieurement, ponctuées peu densément sur leur moitié postérieure, jusqu’à la deuxième strie dorsale; suturale entière, réunie avec la plus rapprochée par un arc basal; dorsales mal limitées, raccourcies vers le milieu ou au-delà; quatrième ordinairement un peu plus courte ; humérale fine, oblique, rapprochée de la première; subhumérale interne, à peine disjointe; externe nulle; marginale forte, ponctuée, entière. Pygidium assez égalenuent couvert de petits points peu serrés. Niésosternum entièrement rebordé, lisse. Prosternum en carène un peu concave; stries très rapprochées, enclavées par les externes réunies en devant. Pattes rouges; jambes antérieures garnies de trois dents épineuses assez fortes et de deux plus petites.

$\sigma^{\pi}$. Métasternum impressionné.

Cette espèce varie beaucoup pour la taille et pour la couleur (du noir au bronzé plus ou moins doré). On la trouve assez communément dans le midi de la France. Espagne; Portugal; Italie; Hongrie, et dans le nord de l'Afrique (Tripoli, Alger, Oran).

\section{S. DISJUNCTUS.}

Nigro-piceus, aneus nitidus, lavis, antennis pedibusque rufobrumeis; fronte sulcis 2 rugulosis; pronoto subtilissime antico margine purctulato; elytris striis subtilibus, suturali in medio antice, dorsalibus postice, 1-3 ante medium abbreviatis, subhumerati interna obsoleta disjureta; mygidio puncticulato; pro- 
sterno striis subparallelis; tibiis anticis 5-denticulatis. Longuenr 2 1/2 mill.; larg. 1 1/2 mill.

Ovale, court, légèrement convexe, d'un noir de poix, brun sur les élytres, bronzé luisant, lisse, avec les bords du pronotum, la partie postérieure des élytres et le pygidium couverts de points très fins et peu distincts. Antennes brunes; massue roussâtre. Front plan, 2 chevrons anguleux bien marqués; strie entière, carène transverse derrière l'épistome, légèrement arquée, peu saillante. Pronotum beaucoup plus large que long, oblique sur les cotés, rétréci et échancré en devant, avec les angles arrondis; strie marginale entière. Ecusson triangulaire, très petit. Elytres courtes, un peu plus longues que le pronotum, de sa largeur à la base, légèrement dilatées à l'épaule, rétrécies postérieurement; stries fines et peu marquées; suturale remontant à peine jusqu'au milieu; dorsales obliques, raccourcies au tiers; quatrième quelquefois nulle ou très courte; humérale oblique, fort rapprocliée de la première dorsale; sublıumérale interne courte, obsolète, isolée ; externe nulle; marginale entière. Mésosternum entièrement rcbordé, lisse. Prosternum assez étroit; stries médiocrement rapprochées au milieu. Pattes brun-rouge; jambes antérieures garnies de cinq denticules.

Iles de Madagascar et de Mayolte.

Espèces que je n'ai pas vues.

Vo 133' S. Antiquulus IIlg. Mag., 6, 43 note (1807). (Hister.)

Aneus; fronte untice marginata; elytris striis 5 apice abbreviatis, suturali integra, pedibus rufis, tibiis anticis spinosis. Long. 2 mill. 
Entièrement de la structure du $S$. chalciles, mais seulement de 2 mill. de long, bronzé, avec les pattes et les antennes d'un brun-ronge, fort luisant. Front séparé par un rebord, de l'épistome rétréci, finement ponctué comme le pronotum. Elytres polies, finement ponctuées au bout; stries raccourcies un peu avant le bord apical; suturale liée avec la voisine par un arc basal. Jambes antérieures garnies d'épines au bord externe.

\section{Autriche.}

IIIo 46' S. Rrgifer Payk. Act. Holm. (1809) 230, pl. 8, 3. (Hister.) - Mon. Hist., 61, 45, pl. 5, 5.-Gyll. Ins. Suec., il, 3, 19. - Er. Brand. Fn., 1, 672, 3.-Redt. Fn. Austr., 782. - Bach Kæl. Irus., 1, 308, 4.

S. 4.Strintus Payk. Fn. Suec., 45, 13 (1798).

Niger, punctatissimus; pronoti disco parcius punctato; elytris macula minuta subscutellari sublcevi. Long. 6 mill.

De la taille et de la forme du $S$. nitidulus, noir, peu luisant, poli sur le milieu du pronotum. Antennes brun-rouge; scape et massue noirs. Front assez densément ponctué, points plus fins et plus espacés sur le vertex. Pronotum rétréci par devant, peu arrondi sur les côtés et très fort aux angles antérieurs, ponctué finement et peu densément sur le milieu, limbe, latéralement surtout, fortement et très densément ponctué, avec une faible impression de chaque côté. Elytres fortement et assez densément ponctuées, les intervalles finement ridés, l'épaule et un seul petit espace scutellaire lisses; strie suturale entière, les quatre dorsales descendent jusque au-delà du milieu, à peine reconnaissables dans la ponctuation rugueuse, ainsi que les subhu- 
mérales raccourcies par derrière. Propygidium et pygidium très densément et assez fortement ponctués, limités l'un et l'autre par un fin rebord. Jambes antérieures comme dans le $S$. nitidulus.

Suède; Allemagne; Autriche; très rare.

IIo 40’ S. Godet Brullé Exp. Morée, 157, 246, pl. 36 (1822). (Hister.)

Niger, nitidus, crebre punctatus; pronoti disco, scutello, ely. trorum basi ct marginibus lavigatis; elytris lateribus longitudinaliter bistriatis, in disco striis 4 abbreviatis impressis, quarum interna basi recurva, sutura undique in elytrorum plusquam dimidia parte postica striga marginata. Longueur 4 mill.; larg. 3 mill.

D'un noir très brillant. Tête assez fortement ponctuée; labre transversal, échancré au milieu, et marqué d'un gros point de chaque côté de l'échancrure. Pronotum médiocrement échancré, arrondi aux angles antérieurs, élargi en arrière, un peu avancé vers l'écusson, parsemé sur tout son disque de points enfoncés très petits, qui grossissent ì mesure qu'ils s'approchent des bords, sur les bords latéraux principalement ces points sont très gros et très serrés. Ecusson extrêmement petit et lisse. Elytres plus longues que le pronotum, couvertes de points enfoncés assez gros et assez serrés qui disparaissent à la base et sur les côtés; chaque élytre présente en outre une strie longitudinale, sinueuse près du bord latéral, une deuxième plus intérieure et un peu arquée, qui part de la base en dedans de l'angle externe, et se rend vers l'extrémitc, près de la strie externe, puis quatre stries intérieures parallèles (dorsales) à la précédente, mais qui n'occupent que les deux tiers au plus de 
la longueur des élytres, la plus intérieure de ces stries se recourbe à la base et se rapproche de la suture; le long de la suture, on voit une autre strie dans les deux tiers postérieurs; un petit bourrelet assez large borde les élytres sur les cotés et en arrière, à cette dernière partie ce bourrelet est un peu rougeâtre. Pygidium entièrement couvert d'une ponctuation assez grosse et serrée; côtés du ventre et de la poitrine grossièrement ponctués. Pattes très finement ponctuées ; les antérieures au contraire assez fortement ; jambes antérieures garnies de plusieurs rangées d'épines assez serrées, plus longues aux intermédiaires; les épines sont plus grêles et plus rares aux postérieures. Les pattes et plus particulièrement les tarses, présentent une teinte d'un brunrougeâtre à peine sensible.

Morée.

S. Semistriatys Steph. IIl. Brit. Ent., 3, 156, 28 (1830).

\section{(Hister).}

Convexus, ater, obscurus; pronoti clisco postico lavi; elytrorum basi impunctato, striis 5 abbreviatis, apice interno punctato; tibiis anticis subundulatis. Long. $31 / 2$.

Convexe, noir, obscur. Front poli, avec une ligne longitudinale imprimée. Pronotum très finement ponctué sur les bords latéral et antérieur, avec une bordure étroite de points à la hase, et un espace poli sur la partie postérieure du disque. Elytres à strie suturale entière, arquée à la base et unie à la quatrième dorsale, qui s'étend obliquement vers le milieu, 1-3 équidistantes, dont la première la plus longue; premier interstric rugueux; humérale fine, très approchée de la voisine; la dernière moitié des élytres, excepté le bord apical et un étroit espace en dehors, for- 
tement et plus densément ponclué. Pattes et antennes d'un noir de poix.

Angleterre; Bristol, un seul individu.

S. violacers Steph. Ill. Brit. Ent., 3, 157, 29 (1843). (Hister.)

Violaceus, pronoto toto punctato; elytris basi striis 5 recurvis, apice punctatis. Long. $51 / 4$ mill.

Ovale, violct. Pronotum entièrement ponctué, pas lisse. Elytres avec cinq stries recourbées à la base, ponctuées au bout.

Il se distingue du S. virescens, dont le pronotum est entièrement ponctué, par sa taille plus grande, par ses stries dorsales plus distinctes. Il paraît n'en être qu'une forte et large variété.

Angleterre (Suffolk).

II ${ }^{\circ} 67^{\prime}$ S. Subvirescens Fald. Fn. Transcauc., 1, 314 (1836). (Hister).

Atro-virens, subquadratus, punctatissimus; elytris antice 5-striatis, apice rufescentibus. Long. 3 1/4 mill.; larg. 2 1/3 mill.

Tête inclinée, arrondie, d'un vert luisant, un peu convexe, très obsolètement, très finement et densément ponc-. tuée; front convexe. Antennes noir de poix. Pronotum presque deux fois plus large que long, plus étroit antéricurement, tronqué au bout ou légèrement échancré, avec les angles obtus, légèrement bisinué à la base, lisse et luisant sur le disque, ponctué assez densément, mais d'une manière obsolète sur les côtés, et étroitement en devant et par 
derrière. Ecusson très petit, triangulaire, luisant. Elytres grandes, carrées, peu convexes, noir-vert, postérieurement d'un rouge de poix, ponctuées densément, mais obsolètement sur les côtés et au bout, avec un petit espace lisse et luisant avant le milieu en dedans; cinq stries très raccourcies à la base, l'extérieure un peu plas longue; suturale entière réunie par un arc basal à la quatrième dorsale. Corps épaissi en dessous, d'un noir olivacé, couvert de gros points nombreux. Pattes ferrugineuses; jambes antérieures un peu dilatées, armées de quatre petits denticules aigus.

Caucase.

40 119' S. procerults Er. in Jahr., 1, 175, 2 (1834).

Parallelus, depressus, nigro-piceus, munctutus. Longuemr $31 / 2$ mill.

Egypte.

3o 73' S. ERatus Er. in Jahr., 1, 183, 28 (1834).

Supra fusco-ceneus, nitidus; pronoto foveoluto, lateribus ciliatis; elytris parcius punctatis, stria suturati integra. Long. 4 mill.

Très semblable au $S$. chalcites. Dessous noir, dessus brun métallique très luisant. Tête finement et densément ponctuée; strie frontale interrompue au milieu. Antennes couleur de poix; scape plus foncé. Non loin de l'angle antérieur, les bords latéraux du pronotum forment un angle obtus, à partir duquel ils sont droits jusqu'à l'angle postérieur; surface ponctuée partout, finement et rarement au milieu, densément et plus fortement sur les côtés; fossette 3e Série, Towe III. 
de l'angle antérieur profonde; repli latéral garni de poils courts, qui font paraître la marge ciliée. Elytres couvertes de points assez serrés, qui laissent libre une place autour de l'écusson, et qui deviennent très fins aux bords latéraux ; la strie suturale est entière et réunie en arc avec la dernière oblique, cette dernière n’atteint pas le milieu de l'élytre. mais 1-3 descendent plus bas; la sublumérale interne n'atteint ni la strie humérale, ni le bout. Pygidium densément ponctué, ainsi que le propygidium, plan, avec les bords relevés, un peu convexe vers le bout. Pattes brunrouge; cuisses plus foncées, d'un luisant presque métallique. Jambes antérieures pour ainsi dire sans dents, garnies seulement de iaibles denticules.

Buchara.

$3^{\circ} 57^{\prime}$ S. Aterrimus Er. in Jahrb., 1, 185, 35 (1834).

Ater, nitidus; fronte subimpressa; pronoto plaga angusta laterali punctata; elytris ad apicem punctatis, stria suturali integra, marginalibus mullis. Long. 6 mill.

De la taille du $S$. azureus, noir foncé, luisant. Tête ponctuée; front avec une large, mais très faible impression, dans laquelle les points sont plus gros et plus serrés, et se confondent par-ci par-là; strie frontale nulle. Antennes noirâtres. Pronotum très poli ct luisant; bords latéraux un peu relevés en bourrelet; en dedans desquels une étroite bande de points au fond d'une légère dépression s'éteni du bord antérieur au postérieur. Elytres également unies et luisantes, couvertes seulement dans leur quart postérieur de forts points serrés, qui cependant montent jusqu'au bout de la quatrième et de la deuxième dorsale, au niveau 
de laquelle ils cessent en dehors; la strie suturale entière se réunit par un arc basal à la quatrième dorsale oblique: celle-ci, ainsi que la première, dépasse le milieu de l'élytre, on ne remarque qu'un rudiment de la troisième; stries sublıumérales nulles; marginales entières, supérieure très profonde, inférieure très fine; l'intervalle qui les sépare est large et couvert de points trìs fins et espacés. Propygidium assez large, pygidium plus petit que d'habitude, très convexe, densément ponctués l'un et l'autre. Pattes noir de poix ; tarses bruns; jambes antérieures fortement dilatées au milieu, édentées, garnies seulement de très petits denticules.

Brésil.

3o 95’ S. placidrs Er. in Jahr., 1, 189, 41 (1834).

Niger, nitidus; antennis pedibusque piceis; pronoto cequali lateribus punctulato; elytris postice profunde punctatis, stria suturali postice abbreviata. Long. 3 mill.

Petite espèce noire, luisante, assez convexe. Tete finement ponctuée; front marqué d'un point plus gros, sans strie. Antennes brun de poix. Pronotum rétréci par devant, légèrement arrondi sur les cotés, un peu convexe, couvert de points très fins et épars, et de points plus gros et plus serrés le long du bord latéral. Elytres assez convexes, lisses, avec leur moitié postérieure fortement ponctuée; strie suturale entière, réunic par un arc à la base avec la quatrième dorsale; celle-ci et les deux précédentes s'étendent jusqu'au milieu, la première atteint le bout des élytres; toutes sont très grossièrement et profondément ponctuées; les deux stries subhumérales manquent; les 
deux marginales sont entières, la supérieure grosse, l'inféférieure très fine. Propygidium fortement et densément ponctué ainsi que le pygidium. Pattes d'un brun de poix rougeâtre; jambes antérieures dentées.

Amérique boréale.

3o 95" S. venustus Er. in Jahr., 1, 189, 42 (1834).

Piceus, niticlus; pronoto elytrisque lincis tuberculisque elevatis; antermis pedibusque rufis. Long. 3 1/2 mill.

Très élégante petite espèce, d'un brun de poix foncé, très luisant. Tète très finement pointillée; front un peu impressionné au milieu, avec une strie fine, interrompue en devant. Antennes rouges; massue plus claire. Pronotum rétréci par devant, légèrement arrondi sur les côtẻs, très légèrement convexe, finement pointillé, avec la partie postérieure marquée de quatre lignes longitudinales élevées, raccourcies de part et d'autre, dont les deux externes sont plutôt de petits boutons en relief que des lignes. Elytres assez planes, également poncluées; strie suturale nulle, à la place de la cinquième dorsale, qui d'ailleurs manque dans toutes les espèces de ce genre, on voit quatre petits tubercules; 1 -4 dorsales paraissent être autant de lignes élevées, qui s'étendent de la base jusqu'au-delà du milieu des élytres, et dont les deux internes sont çà et lả interrompues ; strie subhumérale interne nulle; externe entière, profonde; narginales entières, supéricure profonde; l'intervalle qui les sépare, enfoncé, poli. Pygidium et propygidium brun-rouge, finement ponctués. Dessous fortement ponctué. Abdomen brun-rouge au bout. Pattes rouge-brun; jambes antérieures ohtusément dentelées.

Bahia (Brésil). 
3o 95"' S. nutilus Er. in Jahrb., 1, 190, 43 (1834).

Breviter ovalis, convexiusculus, rufo-castaneus, nitidus; elytris stria suturali $4^{2}$ qae dorsali antice abbreviatis, subhumerali exteriore integra. Long. 3 1/4 mill.

Egypte.

$2^{\circ} 11^{\prime}$ S. Ixcisus Er. Fn. V. Diemen, 152 1812).

Niger, nitidus; pronoto punctato; elytris postice crebre, antice parce subtiliterque punctatis, stria suturali integra, obliquis interioribus medio, externa infra medium abbreviatis; mrosterno interrupto. Long. 4 mill.

Forme absolument du $S$. virescens, noir, luisant. Antennes noir de poix. Front très légèrement convexe, sans strie, ponctué. Pronotum rétréci en devant, légèrement arrondi sur les côtés, faiblement convexe, égal, couvert d'une ponctuation fine et espacée sur le disque, plus forte et plus serrée vers les bords. Elytres ponctuées peu densément et finement avant le milieu, et assez densément au-delà; strie suturale entière, non réunie à la quatrième dorsale; celle-ci ct troisième raccourcies au milieu; deuxième avant et première au-delà; subhumérale nulle. Ponctuation du pygidium fine et très serrée. Dessous très densément ponctué. Prosternum bordé, impressionné de chaque coté, avant le milieu, et sillonné profondément entre les impressions. Pattes brunes; jambes antérieures à peine crénelées, légèrement épineuses en dehors. - o avec une impression sur la poitrine, couvert d'une fine pubescence jaune.

Y. Diemen. 
$3^{\circ}$ '4 ' S. INTricates Er. Beitr. Zur Ins. Fir. Angola, $226,44(1843)$.

Obscure ceneus; pronoto disco parce, lateribus crebre punctuto, nitido, elytris opacis, confertissime punctato-rugulosis, spatio circa scutellum levissimo. Long. 4 mill.

Angola.

$2^{\circ} 18^{\prime}$ S. alienus Le C. Col. Calif. v. $4^{\circ} 43,7$ (1851).

Elargi, noir bronzé, luisant; front finement rebordé. Pronotum impressionné, très ponctué sur les côtés. Elytres avec des stries égales raccourcies au milieu, avec un espace arrondi, étendu jusqu'au bout, les épaules et une plaque sur le troisième interstrie lisses, très luisants, le reste de la surface étant ponctué, opaque. Prosternum comprimé, lisse; stries à peine divergentes en devant. Jambes antérieures 6-denticulées.

Californie.

40 119' S. interceptus Le C. Coléop. Calif. v. $4^{\circ}$ 42, 5 (1851).

Ovale-oblong, noir, luisant. Pronotum moins densément ponctué. Elytres ponctuées, pointillées à la base; stries inégales, externes plus longues; suturale très courte; basale séunie à la quatrième dorsale. Prosternum convexe, à stries parallèles. Jambes antérieures garnies environ de six dents. - Long. 3 mill.

San-Diego (Calif.). - Un seul individu.

S. interstitialis Le C. Col. Calif. v, 40 42, 1 (1851).

Allongé, bronzé. Pronotum largement ponctué sur les 
cotés, pointillé sur le disque. Elytres à stries parallèles, raccourcies un peu au-delá dı milieu; deuxième strie dorsale géminée, interstries et un espace apical commun transversal ponctués. Prosternum convcxe, sans strie; jambes antérieures 5-dentées. - Long. 3 1/5 mill.

San-Francisco, très rare dans le fumier.

3o S. obscurcs Le C. Col. Calif. v, 40 42, 2 (1851).

Orale, noir, luisant. Pronotum ponctué, plus densément sur les côtés. Elytres couvertes de points espacés, fins, assez fortement ponctuées sur leur dernière moitié ; stries externes plus longues; marginale distincte. Prosternum convexe, ponctué; stries parallèles. Jambes antérieures 6-denticulées. - Long. 5 mill.

San-Francisco (Californie), très rare.

$3^{\circ}$ S. pectoralis Le C. Col. Calif. v, $4^{\circ} 42,3$ (1851).

Ovale, noir, luisant. Pronotum densément ponctué sur les côtés, pointillé ;sur le disque. Elytres couvertes de points peu serrés; stries externes plus longues; marginale nulle. Prosternum ponctué, convexe ; stries rapprochées, parallèles; jambes autérieures 6-denticulées. - Long. 4 5/6 millim.

San-Diego (Californie), moins commun.

$3^{\circ}$ S. Peminosts Le C. Col. Calif. v, 4042,4 (1851).

Ovale, noir, luisant. Pronotum ponctué sur les côtés, pointillé sur le disque. Elytres peu densément pointillées, ponctuation plus forte postérieurement ; stries externes plus 
longues; marginale nulle. Prosternum convexe, à peine pointillé; stries éloignées, parallèles; jambes antérieures 6-denticulées. - Long. 3 1/5 mill.

Var. Strie marginale très courte.

San-Francisco (Californie).

20 36' S. IMPERfectus Le C. Mon. Hist. 40, 2, pl. 5, f. 3 (1845)

Fronte impressa; mronoti disco elytrisque antice impunctatis, stria suturali utrinque abbreviata; tibiis anticis crenato-dentatis, Long. 6 mill.

Noir, luisant. Tête ponctuée; front rebordé; palpes et antennes rousses; massue plus obscure. Pronotum impressionné en devant, lisse sur le disque, largement ponctué sur les côtés, étroitement à la base. Elytres densément ponctuées sur leur moitié postérieure, toutes les stries dorsales ponctuées, raccourcies par derrière, troisième plus courte, quatrième recourbée vers la suturale; celle-ci raccourcie aux deux bouts; premier interstrie couvert de strioles obliques; humérale distincte, avec denx subhumérales raccourcies, réunies à l'humérale; épipleures ponctuées, deux stries marginales. Abdomen ponctué au bout de chaque segment sur les côtés. Pattes d'un rouge-brun; jambes antérieures crénelées.

Pensylranic.

3० 76' S. mpressus Le C. Mon. Hist., 44, 9, pl. 5, 10 (1845).

Pronoto antice utrinque grande et profunde impresso, disco lavi, marginibus punctatis; elytris postice et lateribus mu:tatis ; libiis anticis dentato-spinosis, Long. 5 mill.

Noir, luisant. Tete poneţ่̧e. Pronotum avec une grande 
et profonde impression en devant de chaquue côté, lisse sur le disque, ponctué largement en devant et sur les côtés, étroitement à la basc. Elytres imponctuées sur leur moitié antérieure, ponctuées postéricurement et sur les côtés; toutes les strics dorsales raccourcies par derrière, quatrième un peu plus courte, réunie à la suturale par un arc basal; subhumérale interne jointe à l'humérale. Prosternum avec unc ligne de points au milieu; stries parallèles, divergentes en devant. Mésosternum ponctué. Pattes brun de poix; jambes antérieures garnies de dentelures épineuses.

Etats-Unis (Géorgie), rare.

3076 " S. infatstus J.-L. Le C. Classif. Méth. Hist., p. 41 (1852).

S. piceus Le C. Mon. Hist., 43, 7, pl. v, 8 (1845).

Nigro-piceus; pronoto antice lateribusque punctato, medio postice lavissimo; tlytris punctatis, macula magna basali prope suturam lavi; tibiis anticis crenatis. Long. 3 mill.

Noir de poix, luisant. Tête ponctuéc. Pronotum arec une impression de chaque còté, couvert d'une ponctuation très étendue en devant et sur les côtés et étroite à la base, lisse sur le disquc. Elytres ponctuées avec un grand espace basal imponctué de la troisième strie dorsale à la suture; toutes les dorsales raccourcies postérieurement, de plus en plus courtes à partir de la première; suturale entière réunie à la précédente par un arc basal; humérale distincte; subhumérale disjointe. Prosternum à stries parallèles. Segments inférieurs de l'abdomen ponctués, excepté le dernier. Pattes brun de poix; jambes antérieures crénelées.

Etats-unis, très rare, aux bords de la mer. 
3o S. Insentus J.-L. Le C. Ins. Calif., v, 40 43, 10 (1851).

Ovale, convexe, noir-bronzé. Pronotum couvert de points fins, serrés. Elytres pointillées, avec des points plus forts au-delà du milieu; stries externes plus longues ; subhumérale distincte; jambes antérieures crénelées. - Longueur $31 / 2$ mill.

Californie (San-Francisco).

30 S. obductus J.-L. Le C. Hist. Calif. v, 40 44, 11 (1851).

Ovale, convexe, d'un noir-bronzé. Pronotum densément et finement ponctué. Elytres pointillées, aciculées au-delà du milieu; stries à peu près égales, raccourcies un peu au-delà du milieu; subhumérale distincte; jambes antérieures crénelées. - Long. 4 3/4 mill.

Nord de la Californie.

30 S. Ciliatus J.-L. Le C. Hist. Calif. v, 40 44, 12 (1851).

Large, bronzé. Pronotum très densément ponctué, disque postérieur pointillé, bordé de longs cils. Elytres aciculées, avec un petit espace juxta-scutellaire couvert de petits points espacés; stries intéricures plus longues, s’étendant au-delà du milieu; subhumérale distincte ; suturale obsolète en devant. Jambes antérieures garnies de nombreux denticules. Prosternum convexe, avec une fossette de chaque côté; stries divergentes, un peu moins distantes que dàns $S$. obductus. - L, 2 1/3 mill.

Californie (Colorado).

30 S. vinctus J.-L. Le C. Col. Calif., v, 4o 44, 13 (1851). Arrondi, noir, luisant, assez densément ponctué. Elytres 
à stries à peu près égales; suturale entière; sublıumérale assez longue, ponctuation plus fine vers la base. Prosternum convexe; stries éloignées, divergentes. Jambes antérieures créuelées. - Long. 2 1/3 mill.

Californie, San-Diego. Un seul exemplaire.

3o S. Laridus J.-L. Le C. Col. Calif. v, 4o 44, 14 (1851).

Arrondi, noir, luisant. Pronotum avec des points espacés. Elytres couvertes de points peu serrés, plus fins à la base; stries subparallèles, ponctuées, raccourcies au milieu; subhumérale distincte. Prosternum convexe; stries éloignées, divergentes ; jambes antérieures crénelées. -- Long. 2-2 1/3 mill.

Var. Strie suturàie obsolète antérieurement.

San-Diego, dans le fumier.

$3^{\circ}$ S. scissus J.-L. Le C. Col. Calif. V, $4^{\circ} 44,15$ (1851).

Arrondi, noir . luisant. Pronotum peu densément ponctué. Elytres couvertes dans leur moitié postérieure de points espacés; stries obliques, imponctuées, raccourcies au milieu, première plus courte; suturale n'atteignant pas la base; subhumérale distincte. Prosternum convexe; stries éloignées, divergentes. Jambes antérieures crénelées. - Long. 2 1/3 mill.

San-Diego, dans les fucus en putréfaction.

3o S. vestitus J.-L. Le C. Col. Calif. v, 40 44, 16 (1851)。

Arrondi, noir, opaque, densément ponctué; stries des élytres égales, raccourcies au-delà du milieu; subhumérale 
indistiucte. Prosternum en carène comprimée, à stries divergentes. Jambes antérieures très crénelées. - Longueur 2 1/3 mill.

Californie (San-Jose), un seul exemplaire.

3o S. Plenus J.-L. Le C. Col. Calif. v, 40, 45, 18 (1851).

Large, bronzé, luisant. Pronotum ponctué sur les côtés, lisse sur le disque; stries des élytres égales raccourcies au milieu, subhuınérales plus longues; surface aciculée avec un grand espace juxta-scutellaire lisse, les épaules peu ponctuées. Prosternum en carène comprimée, à stries divergentes; jambes antérieures crénclées. - Très semblable au $S$. fimbriatus, il ne s'en distingue que par les points des élytres plus serrés, aciculés, son prosternum plus ponctué et par les côtés du pronotum garnis de cils plus courts et moins serrés. - Long. 3 mill.

Californie (Colorado).

$3^{\circ}$ S. vitıosis J-L. Le C. Col. Calif. v, 40, 45, 29 (1851).

Large, bronzé, luisant; côtés du pronotum ponctués. Elytres aciculées, avec un grand espace juxta-scutellaire et le bord apical lisses et polis; bords latéraux faiblement ponctués; stries égales; quatrième dorsale nulle. Prosternum comprimé en carène; stries divergentes. Jambes antérieures crénelées. - Long. 3 mill.

Californie (Colorado), moins commun.

30 S. coenulescens J.-I. LeC. Col. Calif. v, 40, 45, 21 (1851).

Large, bleuâtre, densément ponctué, un peu plus fine- 
ment à la base des élytres et du pronotum; stries externes des élytres plus longues. Prosternum en carène comprimée; stries divergentes. Jambes antérieures crénelées. Massue des antennes très grande. - Long 3 1/2 mill.

Californie (San-Diego), un seul individu dans une charogne.

$6^{\circ} 158^{\prime}$ S. Lucidulus J.-L. Le C. Col. Calif. v, 4º, 45, $22(1851)$.

Oblong, noir de poix, luisant; front bordé par devant. Pronotum ponctué, moins densément au milieu. Elytres à stries égales, allongées ; subhumérale plus longue, espace ponctué postéricur s'étendant presque jusqu’à la marge ; stries du prusternum presque accolées; jambes antérieures garnies de cinq dents. - Voisin du S. patruelis, dont il dilfère par son pronotum ponctué. -- Long. 3 mill.

Californie (San-Francisco), un seul exemplaire.

\section{3o $125^{\prime}$ S. SABtLETJ.}

Nigro-subceneus, nitidus; fronto marginata, dense subtilissime punctata, prothoracis limbo elytrisque postice punctatis, his stria suturali inteyra, obliquis infra medium abbreviatis, tibiis anticis 5-dentatis.

Saprimus sabuleti Rosenh. Beit. Ins. Eur., $1^{\circ}$ (1847).

Assez convexe, luisant, noir métallique; très semblable au $S$. conjungens Payk. pour la forme et pour la taille, il se distingue facilement par une ponctuation extrèmement fine et serrée sur le front, lequel ne montre pas d'enfoncement léger au bord antérieur, en outre tout le bord antérieur du prothorax et presque la moitié postérieure des élytres sont ponctués. Tête très finement et densément ponctuée, fine- 
ment rebordée. Antennes d'un brun-rouge; massue noirâtre. Pronotum rétréci par devant, assez arrondi sur les côtés, avant le milieu, finement ponctué près des côtés, dans le sens de la longueur, étroitement et fortement à la base, largement au bord antérieur, de sorte que la moitié postérieure seulement paraît lisse. Ecusson très petit, triangulaire. Elytres presque entièrement ponctuées sur leur moitié postéricure; les points s'avancent jusqu'à la troisième strie oblique; stries toutes profondément et fortement ponctuées; la suturale est entière; les trois premières strics obliques laissent libre le dernier tiers des élytres (elles sont aussi beaucoup plus courtes quedans le $S$. conjungens); quatrième encore plus courte que celles-ci; la deuxième qui manque, ainsi que la subhumérale, sont indiquées par des points. Propygidium et pygidium densément et finement ponctués; cuisses noires; tarses et jambes rouge-brun: celles-ci 5-dentées.

Varie quelquefois pour la couleur, souvent aussi les dents des jambes sont plus fortes et plus pointues.

Allemagne, Erlangen.

5o S. PILles.

Breviter ovalis, piceus; fronte marginata rugulosa; pronoti lateribus rugoso-punctatis; elytris apice punctatis; his stria suturali antice, obliquis infra medium abbreviatis, tibiis 4-dentatis. Long. 2 1/3 mill.; larg. 2 mill.

Saprinus pullus Rosenl. Beit. Zur Ins. Faun. Eur. $2^{\circ}$ (1847).

En ovale un peu raccourci, médiocrement convexe, peu brillant, d'un brun de poix ; bouche, antennes, pointe des élytres et tarses rouge-brun. Il se rapporte au groupe des Suprinus à front rebordé et ridé; il ressemble aux plus 
petits individus du S. metallicus, mais il s'en distingue par la couleur, plus particulièrement par la strie suturale interrompue et par les quatre dents des tibias antérieurs. Tête légèrement ridée; front bordé. Antennes rouge-brun. Prothorax rétréci par devant, arrondi sur les côtés, peu avant le milicu, fortement aux angles antérieurs, densément rugueux le long des còtés, très finement au bord antéricur; dos lisse dans une plus grande étendue; à la base il y a une ligne de points distincte, simple, qui au-dessus de l'écusson paraît un peu enfoncée et plus dense. Ecusson petit, triangulaire, brun. Elytres lans leur tiers postérieur finement et densément ponctuées, à la suture jusqu'au milieu et par en delıors, jusqu'à la deuxième strie oblique. Stries toutes profondes, finement ponctuées; suturale très fine, interrompue par devant, les trois premières stries obliques s'étendent un peu au-delá du milieu, la quatrième jusqu'au devant du bord apical, et la subhumérale paraît être une suite de l'humérale. Les deux derniers segments postérieurs de l'abdomen sont densément et très finement ponctués. Pattes rouge-brun; jambes antérieures 4-dentées, l'avant dernière dent la plus grande.

Allemagne, Erlangen.

\section{5o S. CURTIS.}

Breviter ovalis, niger, supra viridi-aneus nitidus; fronte leviter marginata, rugosa; pronoto toto elytrisque pone medium punctatis, his stria suturali antice, obliquis infra medium abbreviatis, pedibus rufo-piceis, tibiis anticis acute serratis Long. 2 mill. ; larg. 1 1/4 mill.

Saprinus curtus Rosenl. Beitr Ins. Eur. $\quad 3^{\circ}$ (1847).

Petit, en ovale court, médiocrement convexe, noir 
brillant, d'un vert foncé métallique en dessus. Antennes. pointe des élytres et tarses ronge-brun; encore plus petit que les plus petits individus du S. metallicus, fort voisin du S. pullus, il se distingue aisément de l'un et de l'autre par son pronotum entièrement ponctué, densément ridé, son front légèrement rebordé et ses jambes antérieures très dentées.

Tête densément rugueuse, finement ponctuée. Front très légèrement rebordé. Antennes d'un brun-rouge. Pronotum un peu rétréci en derant, peu arrondi sur les côtés et fortement aux angles antérieurs, finement et densément ponctué sur les côtés, un peu moins au milieu. Ecussoı petit, triangulaire. Elytres finement et densément ponctuées jusqu'au milieu et en dehors jusqu’a la troisième strie oblique, toutes profondes, légèrement ponctuées; strie suturale extrêmement fine, et marquée seulement par des points, raccourcie par devant, les trois premières stries obliques s'étendent à peine au-delà du milieu, quatriènıe presque jusqu'à l'extrémité ; la strie subhumérale paraît ètre un prolongement de l'humérale, et ne dépasse pas le milieu. Propygidium et pygidium finement et densément ponctués. Pattes rouge-brun; jambes antérieures élargies en arc et avec 8-9 petites dents pointues.

Hongrie.

\section{$3047^{\prime}$ S. BIPARTITIS.}

Niger, nitidus, punctatissimus, humeris maculisque lavissimis, nitidissimis, altera suturali biloba, altera minuta inter strias 2 el 3 sita; pronoto punctulato, lateribus creberrime punctatis; elytrorumi striis punctatis, abbreviatis, aquilongis, $\mathbf{5}$; tibiis anticis extrorsum dense denticulatis; antenuarum arti- 
culo $1^{\circ}$ clavaque nigro-piceis, capilis linea impressu integru. Long. 5 mill. ; larg 4 mill.

Saprinus bipartitus Motsch. in Bul. Hosc. 1849, p. 98.

Un peu plus large que le $S$. milidulus, se rapprochant du $\$$. rugifer en grande lartic par sa pouctualion, qui cependan! n'est pas opaque; il s'en distingue par la tache luisantes entre la deuxième el la troisième stries. Tête peu convexe et distinctement ponctuée, ligne frontale peu interrompuc au milieu. Pronotum rétréci antérieurenıent; bords latéraux arqués; base très étroitement ponctuée; strie marưinale non interrompue an milieu. Ecusson bien distinct, triangulaire, lisse. Elytres plus larges que le pronotum, carrées, un peu dilatées avant le milieu, fortement poncluées sur les borls, laissant libre une grande tache bilöbée ou en cœur sur la suture et au-delà de l'écusson, et une autre petite de chaque côté, entre la deusième et la troisiène stries; angle huméral également lisse; stries dorsales toutes de même longueur; suturale se réunissant en arc avec la première. Abdomen et dessous du corps mnins fortement ponctués que les élytres. Jambes antérieures élargies et denticulées. Antennes noirâtres avec les arlicles du milieu roussâtres.

Carthagène.

\section{13 ' S. CRENATIPES.}

Ovuis, niger nifidus; monoto levi, lateribus et basi dense punctato; dytris lavibus, apice dense punctatis, obscuris mrope humeros striis 3 obliquis, irregularibus notatis, uroque macula magna sinuata rubra, stria suturali punctutata, ventre levi; mesosterno punctuto. Long. 3 mill.; larg. 3 mill.

Hister crenatipes Sol. in Gay, Hist Fis y pol. de Chile (1849), ए. 378,2 .

¿e Série, ToME IH. 
Corps court, comparativement au $S$. bisignatus, auquel il ressemble, plus ovale, d'un noir très brillant, légèrement métallique au bout, mais d'un noir pur à la base. Tête obscure et ponetuée. Dos du pronotum lisse, avee les bords latéraux couverts d'une ponctuation très serrée, formant une bande, et la base ponctuée de même, mais très étroitement. Elytres lisses, présentant vers les angles huméraux trois stries courtes, obliques, irrégulières, entremêlées de diverses rides et de quelques points à la base. Sur chaque élytre, on voit une strie suturale finement ponetuée, atteignant la base sans arc antérieur et s'oblitérant dans la ponctuation de l'extrémité; on voit aussi une grande tache rouge anguleuse qui touche au bord latéral, ses extrémités sont marquées par une bande de points serrés qui les rendent obscures en eet endroit; ees points s'avaneent beaucoup plus vers la tache que vers la suture. Ventre lisse, avec le mésosternum très ponctué.

Chili, r. Copiapo.

\section{3o 86 ' S. SPINOLA.}

Vix ovatus, subparallclus, niger nilidus ; pronoto lcevi; clytris lavibus, postice laxe punctulatis, mope humeros striis 3 obliquis incequalibus notatis, stria interna longiore, stria suturati profunda, basi obliterala, intus incurvata et utrinque prope suturam fossulu oblonga, postice notatis; ventre lavi; mesosterno laxe punctulato et muncto magno mediano notato; metasterno in medio profunde sulcato, sulco antice et postice oblitcrato. Long. 4 mill. ; larg. $21 / 3$ mill.

Ilister Spinole Sol. in Gay, Hist. fisica y polit. de Chile, p. 379, $3(1849)$.

Corps à peine ovale, subparallèle, d'un noir très brillant. Tète luisante et finement ponctuée. Dos du pronotum en- 
tièrement lisse. Elytres unies, mais finement et vaguement ponctuées à leur extrémité et marquées vers les angles huméraux de stries obliques et inégales; les deux externes plus courtes et l'interne atteignant le milieu de l'élytre; strie suturale profonde, mais oblitérée au bout et à la base, oú elle se coude un peu en dedans, parallèlement à la base; ventre lisse. Mésosternum finement et lachement ponctué, mais marqué au milicu d'un gros point enfoncé. Métasternum présentant au milieu un sillon profond qui n'atteint ni le bord antérieur, ni le postérieur. En outre, on remarque divers points enfoncés à la base et sur le bord antérieur du premier segment de l'abdomen. Jambes antérieures très larges.

Chili.

2042 ' S. puncticollis Küst. Kæf. Eur., 17, 30 (1849).

Obscure ceneo-viridis, nitidus; fronte immarginata, irregnlariter rngulosa; mronoto confertim punctato; elytris postice punctutis, antice medio, tevibus, stria suturali antice abbreviuta, laterati integra; antennis pedibusque fusco-rufis, tibiis anticis muilidentatis. Long. $21 / 5$; larg. 1 mill.

Espèce très distincte par la conformation du front et des jambes antérieures, ainsi que par son pronotum également ponctué. Corps légèrement convexe, luisant, d'un vert bronzé foncé. Antennes testacées; massue un pea plus claire, grise. Tête large, plane, rebordée des deux côtés, formant un angle distinct à l'insertion des antennes, finement et confusément rillée. Bouche ferrugineuse. Pronotum une fois et demie aussi large que long, légèrement échancré en devant, avec les angles arrondis, arrondi légèrement et rétréci par devant sur les côtés, se dirigeant obliquement 
en dehors postérieurement, de sorte que la base est plus large, très légèrement arquée, non échancrée, et formant dans le milieu un angle très obtus; la surface est légèrement convexe, densément et finement ponctiés en entier, mais près des bords latéraux, il n’y a que de très petits points épars. Ecusson à peine visible, triangulaire. Elytres très légèrement arrondies sur les côtés, coupées droit au bout, finement et densément ponctuées jusqu'au-dessus du milieu, assez luisant; épaule, bords latéral et apical polis; la partie antérieure des élytres polie a seulement moins d'éclat; la strie suturale, ponctuée comme toutes les autres, est un peu raccourcie en devant; les stries dorsales 2-4 dépassent le milieu; la première atteint presque l'extrémité ; la subhumérale est entière ainsi que la marginale. Dessous noirâtre, finement ponctué. Pattes rouge-brun; jambes antérieures garuies de 9-10 denticules fins et aigus.

Sardaigne (Cagliari); Espagne (Carthagène).

3o 73' S. Natalensis Fahr. in Bohem. Ins. Cafr. 1, 543, 592 (1851).

Brevissime subovalis, obscure aneus, capite migro; pronoto elyurisque cupreo tinctis, illo antice lateribusque punctato, intra apicem utrinque foveola impressa, his punctatissimis; area commuri baseos levi, dor so striis 5 obliquis postice abbre. viatis, $4^{\text {a }}$ antice cum striu suturali comnexa, interstitis exterioribus antice strigosis; clava antennarum pedibusque ferrugineis, tibiis anticis multidentatis. Long. 2 1/2 mill. ; larg. 2 1/8 mill.

Très ressemblant au $S$. cuprcus, il paraît cependant distinct. Tete rétrécie en devant, noire, luisante, densément ponctuée. Autennes courtes, ferrugineuses, noir de poix à 
la base. Pronotum deux fois plus large yue long a la base, rétréci peu à peu cu devant, légèrement bisinué à la base, échancré en devant, avec les angles arrondis, médiocrement convexe en dessus, bifovéolé, bronzé-cuivreux, luisant, ponctué densément dans son pourtour, à peine sur le disque. Ecusson très petit, triangulaire, de même couleur. Elytres étroitement appliquées au pronotum, curvilinéairement dilatées, tronquées au bout, avec l'angle externe arrondi, deux fois plus longues que le pronotum, peu convexes en dessus, bronzé-cuivreux, luisant; stries dorsales 1-4 obliques dépassant le milicu, quatrième réunie avec la suturale par un arc basal, de plus une striole discoïdale de chaque coté, qui n'atteint ni la base, ni le bout, et sur les côtés une petite strie entière; surface dorsale très densément ponctuée, laissant un espace commun, lisse à la base, qui occupe la moitié de la longueur de l'élytre et de la suturale à la quatrième dorsale. Pygidium obtus, noirbronzé, très densément ponctué. Dessous d'un bronzé obscur, luisant, ponctué un peu plus densément sur les côtés. Pattes comprimées, ferrugineuses ; jambes antérieures multidentées.

Natal.

$3^{\circ} 73^{\prime}$ S. Breviusculus Jahr. in Bohem. Ins. Cafr., 1, 544, 594 (1851).

Subrotundatus, niger, nitidissimus; antennarum apice pedibusque ferrugineis; pronoto aquali, parce punctato; clytris striis 7 , vix punctatis; suturali cum $3^{\text {a }}$ connexa, $2^{\text {a }}$ et $7^{\text {a }}$ antice abbreviatis, interstitiis lavibus; tibiis omnibus spinulosis. Hab. in tractibus fluvii Limpoponis. Long. 21/2 mill.; larg.2 1/4 m.

Tête inclinée, rétrécie antérieurement, noire, luisante, à peine ponctuée; strie semi-circulaire distincte. Antennes 
courtes, ferrugineuses; scape obscur. Pronotum transversal, à peine long de la moitié de la largeur de la base, très rétréci en devant et échancré, avec les angles abaissés, avancé au milieu de la base, presque tronqué obliquement de chaque côté; égal et médiocrement convexe en dessus, noir, luisant, un peu métallique, ponctué peu densément en devant et sur les côtés, la partie postérieure du disque à peu près lisse, excepté la bordure de points. Ecusson triangulaire, de la couleur du fond. Elytres curvilinéairement dilatées, et fortement appliquées contre le pronotum, chacune olstusément arrondie au bout, deux fois plus longues que le proıotum, légèrement convexes en dessus, noires, très luisantes, rouges au bord apical, avec sept stries; suturale réunie à la troisième dorsale par un arc basal: deuxième très raccourcie antérieurement, septième s'étendant du bout jusqu'au milieu à peine, toutes les autres entières, lisses ainsi que les interstries. Pygidium très convexe, infléchi au bout, noir, luisant, peu densément ponctué. Dessous convexe, noir, luisant, lisse au milieu, ponctué sur les cotés. Pattes comprimées, couleur de poix ; tarses ferrugineux; jambes armées de 8-10 spinules.

Cafrerie. 


\section{ESSAI MONOGRAPHIQUE SUR LA FAMILLE DES HISTERIDES.}

(Suite) (1).

Par M. S.-A. de MARSEUL.

(Séance du 9 Février 1853.)

XXXIV. PACHYLOPUS.

( $\pi \alpha \chi v \lambda$ ós, épais ; $\pi 0 \tilde{u} 5$, pied).

Soc. ent. , 3e Série, T. 4 (1856), pl. III.-Mon., pl. XXI. Genre XXXIV.

Er. in Jahrb. I, 196, XVI (1834).

Caput retractile; fronte transversa, marginala, a clypeo abrupte distincta; antennis ad mandibularum basim inter oculos et clypentm insertis.

Prostermu valde compressum, antice parum prominulum. subacutum, pectoris margine utrinque inciso, fossa antennali juxta coxas insculpta; mesosternum subsinuatum marginatumque.

Pronotum convexum, antice profunde emarginatum, angulis rotundatis, stria marginali unica integra.

Elytra convexa striis obsoletis, humerali, suturali et laterali exceptis.

(1) Voyez $3^{\circ}$ Série, T. I (1853), p. 131 et 4'47; T. II (1854) p. 161,525 et 671 ; et T. III (1855), p. 83 et 327.

3e Série, Tone IV. 
Abdomen 10 segmento valde elongato; pygidio perpendiculari.

Tibice anlice bidentula, postice tumidee extus dense strigillate, femoribus crassis.

Corps ovaie, convexe, lisse ou ponctué, plus on moins luisant, de couleur brune ou métallique.

Tête (f. $1 c$ ) assez forte, inclinée en devant et peu enfoncée dans le prothorax. Front transversal entouré d'une strie profonde complète et marqué d'un chevron en devant. Epistome assez étroit et bien distinct du front ; labre court, subtrilobé dans l'espèce que je regarde comme le type du genre; mandibulesfortes, saillantes, surmontées d'une carène. Antennes courtes, insérées à la base des mandibules, sous te rebord du front, entre les yeux et l'épistome; scape courbé, renflé au bout; premier article du funicule assez grand, obconique, les autres petits et serrés les uns contre les autres; massue globuleuse.

Menton (f. 1 b) quadrangulaire, sinué en devant; lèvre avancée, presque cornée, avec les paraglosses courtes, arrondies, frangées en dedans. Palpes labiaux assez épais; deuxième article obconique, troisième plus long, cylindrique, tronqué au bout. Mâchoires (f. $1 c$ ) épaisses, à lobes fortement garnis en dedaus de poils serrés; palpes maxillaires épais; deuxième article très gros, troisième un peu plus petit, quatrième de la longueur des deux précédents révnis, subcylindrique, atténué vers le bout.

Prosternum (f. $1 a$ ) en carène très mince, un peu élargie et sinuéc à la base, relevée en devant et terminéc par une pointe fine, qui ne dépasse pas les angles antérieurs du pronotum; bord pectoral entaillé pour le passage de l'antenne, dont la massue vient se loger dans une fossette peu 
profonde et peu nettement accusée, au devant des hanches, adosséc au prosternum; la portion entre les deux rainures a la forme d'une accolade. Hésosternum assez étroit, rebordé dans son pourtour, paraissant sinué en devant, mais envoyant une petite pointe qui s'enfonce dans la base du prosternum ct s'y eache.

Pronotum convexe, transversal, rebordé d'une seule strie, avec une profonde échancrure pour la tête et les angles antérieurs arrondis. Ecusson très petit. Elytres serrées contre le prothorax, de sa largeur à la base et plus longues que lui, élargies à l'épaule, arec une strie suturale et une subhumérale entières et bien marquées.

Abdomen de cinq segments; premier très allongé; les autres très courts et serrés l'un contre l'autre. Propygidium court. Pygsidium triangulaire rabattu perpendiculairement.

Pattes robustes; cuisses, surtout les postérieures, fortement renflées; jambes antérieures triangulaires, amincies, armées de deux fortes dents externes et creusées d'une rainure tarsale droite; postérieures très épaisses garnies en dehors de dents mousses serrées ce qui leur donne l'apparence d'une carde; tarses de 5 articles garnis de soies en dessous et terminés par deux crochets.

Le genre Pachylopus a été créé par Erichson en 1834 sur un insecte du Cap de Bonne-Espérance, aux formes bizarres et remarquables. Il a beaucoup des Saprinus, surtout de ceux des derniers groupes : l'insertion des antennes; le prosternum en carène, sans lobe; les jambes épineuses; la tête et surtout le front; le pronotum avec sa strie marginale unique. Mais il a les cuisses postérieures bien plus renflées, les jambes de la dernière paire comme tuméfiées, couvertes de fortes épines mousses serrées et en forme de carde ou de 
brosse; la structure du bord pectoral antérieur n'est plus éga lement la même. Enfin les élytres, dans l'un des sexes, présentent, ainsi que le premier arceau ventral de l'abdomen, une particularité qui n'a pas d'analoguedans toute la famille. Ces parties s'appointissent, se prolongent bien au delà de l'abdomen en se courbant vers un point commun et semblent vouloir se rejoindre. Le pygidium perpendiculaire comprime fortement les autres segments qui disparaissent presque entièrement, et lui-même se laisse voir avec peine sous les trois pointes formées par les élytres et le premier segment ventral. Les trois individus que j'ai pu voir appartiennent au même sexe; l'autre sexe m'est inconnu.

J'ai réuni, quoique à regret, à cette espèce le Saprinus sulcifrons de Mannerheim, comme l'avait fait M. J.-L. Le Conte, qui a bien voulu m'en donner un individu. II n'a pas la différence sexuelle que nous venons de signaler dans le $\boldsymbol{P}$. dispar, mais il en a tous les autres caractères. Il devrait peut-être former une coupe intermédiaire entre les Saprinus et les Pachylopus.

\section{P. Dispar.}

Brunneus, nitidus, antennis, tibiis clytror umque apice rufoferrugineis; fronte lavi marginala, stria triangulari antice exarata; pronoto stria marginali vix basi interrupta; clytris stria suturali et subhumerali integris, humerali tenui; pygidio impunctato; tibiis anticis valide bidentatis. Longueur 5 mill.; larg. 3 mill.

Pachylopus dispar, Er. in Jahr., I, 197, pl. II, f. 4 (1834).

Brun noir, luisant, lisse en dessus et assez fortement ponctué latéralement en dessous. Front peu convexe, transversal, entouré d'une forte strie entière, avec un faible che- 
vron en devant. Epistome étroit, brusqueneut séparé du front, bordé sur les côtés. Labre court, trilobé en devant. Mandibules avec une forte carène longitudinale. Pronotum bombé, fortement échancré en devant avec les angles arrondis, presque droit sur les côtés, légèrement arqué à la base, avec les angles pcu marqués : strie marginale bien marquée, entière, à peine interrompue à la base vers le milieu et vers les angles. Écusson très petit. Ẻlytres convexes, fortement appliquées contre le pronotum, de sa largeur à la base, un peu dilatées à l'ẻpaule, rétrécies postérieurement, déhiscentes au bout et terminées en pointe acérée dans l'un des sexes; strie suturale forte et rejoignant presque la subhumérale qui est également bien marquée; liumérale fine, les autres nulles; la couleur des élytres devient plus rougeâtre au bout, et, dans les individus pris par Erichson pour type de l'espèce, elles sont rousses avec un espace triangulaire commun noir au milieu. Jambes ferrugineuses, garnies de poils roussâtres.

Cap de Bonne-Espérance.

\section{P. sulcifrons.}

Convexus, subquadratus, nigro-concus, subniticlus; fronte marginata, cum striola angulari media; pronoto stria marginali haud interrupta, basi punctato; elytris ruguloso-punctatis, exlus lavibus, stria humerali et 1-3 clorsalibus obsoletis, subhumerali et suturali postice junctis; pygidio dense punctato; tibiis anticis bidentatis. Long. 5-6 mill.; larg. 3-4 mill.

Saprinus sulcifrons, Manh. in Bullet. Mosc. 1843, 11, 259, 186. Pachylopus sulcifrons, J. L. Le Conte, New. Spec. of Californ. Col. in An. Lyc. of Nat. Hist. N.-Y, v, 4, 41, 1.

Convexe, en carré oblong, d'un noir métallique peu luisant. Front à peine distinctement pointillé, presque plan, 
entouré d'une forte strie entière et marqué en devant d'un chevron obsolète. Eistome bien séparé, sans rebord. Labre subsinué. Pronotum court, bombé, fortement échancré en devant avec les angles arrondis, presque droit sur les côtés, un peu élargi postérieurement, subarqué et bordé de points à la base avec les angles obtus; strie marginalc forte et sans interruption. Ecusson très petit. Elytres larges, un peu convexes, serrées contre le pronotum, de sa largeur à la base, avec les épaules saillantes et lisses, rétrécies postérieurement et coupées droit au bout ; strie suturale bien marquée, rejoignant d'une part la subluumérale par l'extrémité et de l'autre la troisième dorsale par un arc basal, humérale et 1-2 dorsales courtes et irrégulières, bord infléchi ponctué.Pygidium bombé, couvert d'une ponctuation serrée et assez forte. Dessous ponctué latéralement. Jambes antérieures armées de deux fortes dents externes et d'une petite un peu au dessus.

Californie, à San-Diégo, sur les bords de l'Océan.

Espèces que je n'ai pas vues et qui doivent probablement se réunir au genre Saprinus.

¿’'P. Serrulatus J.-L. Le Conte, N. spec. Calif. Coléopt., 41, 2. in An. Lyc.nat. 1.ist. N.- Y.T.V., 41, 2 (1851).

Noir, oblong, pronotum étroitement couvert de points à la base et sur les côtés postérieurement. Elytres densément ponctuées, avec les épaules et un espace apical lisses ; stries dorsales raccourcies au milieu, suturale entière réunie por un are basal à la dorsale voisine. Jambes antérieures dentées en scie et garnics d'épines. I.ong. 4 mill.

Il se trouve avec le $P$. sulcifrons, mais moins communé- 
ment, à San-Diego, en Californie, sur les bords de l'Océan ; sa tête est sculptée de même. Ses élytres varient du noir au marron.

2" P. Gaudens. J.-L. Le Conte, New spec. Calif. col., 41, 3 (1851).

Oblong, noir bronzé, luisant; tête rebordée et marquée en devant de chaque côté d'une ligne oblique. Pronotum bordé de points à la base. Elytres couvertes de points espacés au delà du milieu, avec les côtés entièrement lisses, strie marginale très courte, dorsales raccourcies au milieu, suturale entière réunie avec la dorsale voisine par un arc basal. Jambes antérieures tridentées avec la dent apicale bifide. Long. 4 mill.

Un seul individu, trouvé avec le P. scrrulatus.

\section{TRYPANAUS.}

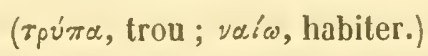

Soc. Ent. 3e Série. Tome IV (1856), pl. II. Mon. pl. XX.

\section{Genre XXXV.}

Esch. Zool. Atl. I. p. 10, pl. IV, f.\{ 7. (1831). - Er. in Jahrb. I. 198.

Bostrichus F. S. El. II, 385 (1801).

Hister Payk. Mon. Hist. (1811).

Corpus elongatum, cylindricum, nitidum.

Caput magnum exsertum, rostro acuto, valde prominulo mandibulas et oris partes excedente; antennis brevibus sub frontis margine ante oculos insertis, clava orbiculari com. yressa, fossa antemali nulla.

Prosternum mesosternumque angustatq, óistriala, lobo an. isco nullo. 
Pronotum parallelum, elytris longius, utrinque marginatum scutellum dissimulans, antice haud vel vix emarginatum; $p a-$ rapleuris conspicuis.

Elytra haud striata, postice arcuata. Pygidium conicum, oblusum vcl acuminatum.

Pedes robusti, libiis anticis intus basali dente armatis extusque dentatis, posticisque villosis versus apicem dilatatis; tarsis elongatis, articulo ulimo biungulato valde elongato.

Corps (f. 1, 1 a) allongé, cylindrique, terminé en pointe, noir luisant, quelquefois avec une tache jaune sur les élytres.

Tête grosse, saillante, se prolongeant en museau fortement saillant au delà de la bouche; front ordinairement excavé et sans ligne de démarcation qui le sépare de l'épistome. Yeux très distants, petits, globuleux.

Antennes (f. $1 d$ ) courtes, insérées sous un rebord du front à l'origine du rostre, au devant des yeux; scape assez grand, renflé au bout, villeux; premier article du funicule plus long et plus gros que les suivants, ceux-ci serrés, courts, grossĩssant progressivement; massue 4-articulée, orbiculaire, velue, comprimée, libre, saus fossette antennaire distincte.

Mandibules courtes, courbées, à pointe acérée et unidentées en dedans. Mâchoires (f. $1 c$ ) à deux lobes cornés, barbus en dedans, l'externe dépassant de beaucoup l'interne. Palpes maxillaires courts de quatre articles, premier très ténu, deuxième et troisième obconiques, ce dernier un peu moins ong, subovalaire. Menton plus large que long, largement et profondément échancré; lèvre (f. 1 c) saillante, bifide, à paraglosses membraneuses, ciliées en dedans. Palpes labiaux de trois articles, er court, $2^{\mathrm{e}}$ allongé, renflé au bout, der"o nier ovalaire un peu plus court. 
Pronotum plus long que les élytres, parallèle, bordé d'une strie sur les cotés, à peine échancré en devant, et un peu angulcux sur l'écusson qui disparaît presque entièrement. Elytres laissant entre elles et le pronotum un espace angulaire occupé par les parapleures, élargies au milieu, tronquécs au bout avec l'angle externe arrondi.

Prosternum (f. $1 a, 19 e, 21 \mathrm{~g}$,) étroit, élevé, bordé d'un sillon, plus ou moins avancé vers la bouche, ne dépassant pas les angles prothoraciques. Mésosternum un peu plus large que le prosternum, rebordé commelui, en pointe obtuse. Métasternum très allongé, de sorte que les hanches postérieurcs sont très distantes des hanches intermédiaires, avec un sillon médian longitudinal.

Pattes robustes; cuisses avec une coulisse sur le coté intcrne; jambes antérieures (f. $1 b$ ) non dilatées en devant, sans fossette tarsale bicn accusée, terminées par un crochet court, armées en dedans à la base d'une dent forte, et en dehors de quatre a cinq assez aiguës; intermédiaires munies de longues épines; postérieures dilatées au bout, denticulées et ciliées en dehors. Tarses minces, allongés, 1-4 articles égaux, 5e terminé par deux crochets, de la longueur au moins des deux précédents réunis.

Abdomen de cinq segments, premier assez allongé, dcuxième et troisième à peu près égaux, courts, quatrième encore plus court, cinquième semi circulaire. Pygidium oblique, obtus ou en pointe aiguë.

Eschscholtz, dans son Zoological Atlas, 1re partie, p. 11 (1831), a fondé le genre Trypanceus, qui depuis a été adopté par Erichson dans le Jahrbucher der Insectenkunde de Klug, 1, p. 198, mais changé en Tryponceus sans doute par erreur typographique. Il y réunit deux espèces, déjà publiées avant lui par Fabricius dans son Systema Eleutheratorum, t. II, 
p. 385 (1801), Bostrichus"proboscideus et B. thoracicus, les décrit et donne la figure de la première. Paykull, dans sa Monographie (1811), décrit et figure de nouveau la même espèce sous le nom de Hister proboscideus.

Aux deux espèces de Fabricius, Erichson en ajoute deux nouvelles, $T$. volvulus et $T$. bimaculatus.

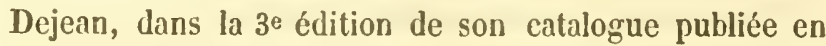
1837, adopte le genre Trypanceus, énumère les quatre espèces déjà connues, mais sous des noms différents et sans citer le travail d'Erichson, et en ajoute cinq autres, ce qui porte le nombre des espèces de ce genre à neuf. J'ai pu en décrire vingt-une et il est probable que bientôt le nombre s'accroîtra encore, lorsque l'attention des entomologistes se sera portée sur ces insectes curieux et généralement ignorés.

Fabricius avait décrit encore une autre espèce, le Bostrichus bipustulatus, méconnu des auteurs cités plus haut, et qui doit se rapporter au $T$. bimacnlalus Er. ou au T.pictus, mais je n'en suis pas bien sûr, n'ayant pour guide que la description, laquelle s'adapte également à l'un et à l'autre.

Ces insectes vivent sous les écorces dans le continent de l'Amérique, depuis le Mexique jusqu'au Brésil. On ne sait rien sur leurs mœurs, ni sur leurs transformations.

Ce genre étrange a quelques points de contact avec les Terelrius, les Xiphonotus et les Cylistus; on y retrouve la forme allongée et cylindrique qui les caractérise, la dent interne de la base des jambes antéricures que nous avons vue dans les premiers genres et qui se retrouve dans les $\mathrm{Cy}$ listus; la tete est libre comme dans les Hololepıa, mais les mandibules, au lieu d'être saillantes, sont cachées et très courtes. Mais on les reconnaîtra au premier abord à ce museau saillan qui depasse de beaucoup le labre et la bouche, à la longueur exorbitante du prorintum et aux élytres sans stries. 

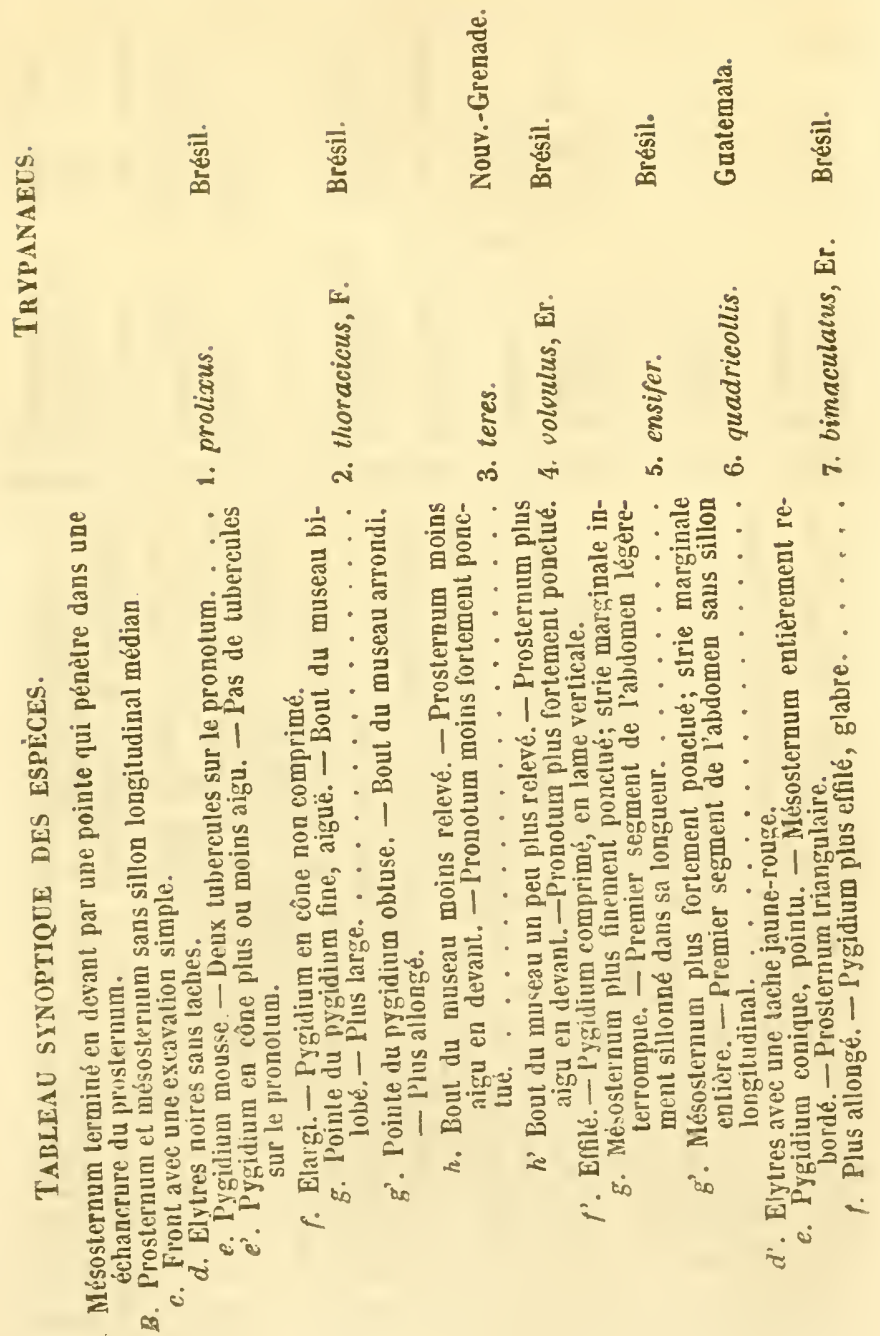


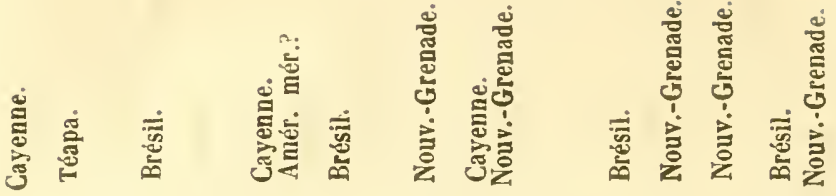

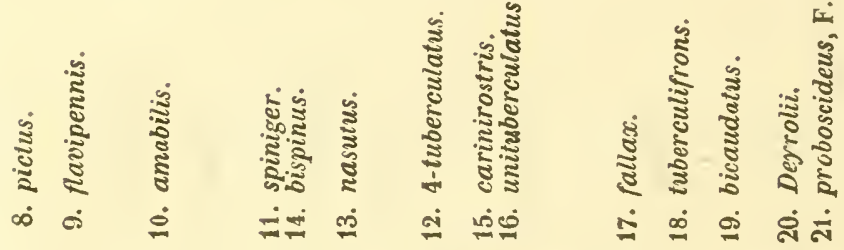

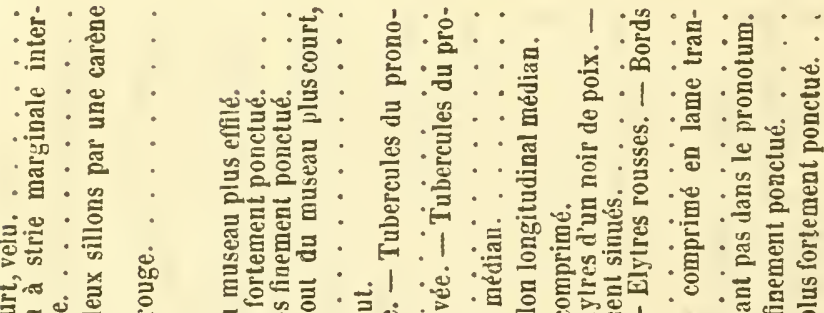

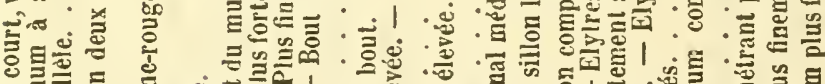
몷 可出. .

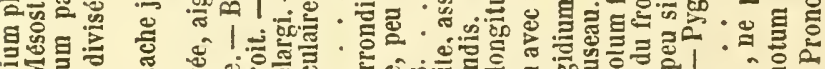
릴 Ð

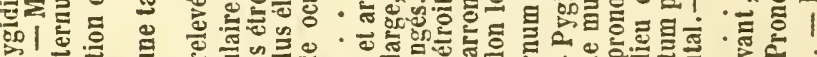

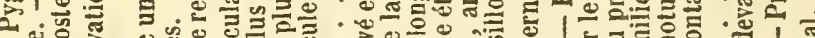
1 议 ङ 的 년 ๘ घ 㖊目

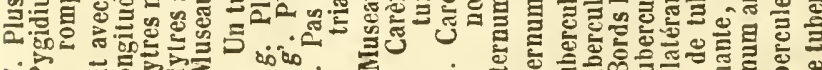

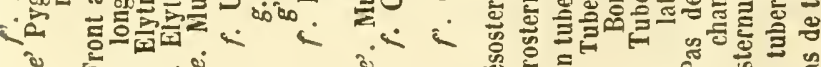

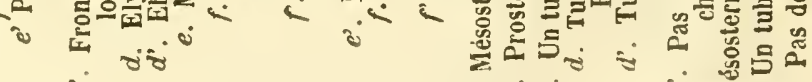

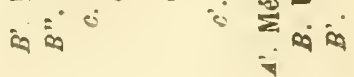


A. Mésosternum terminé en devant par une pointe qui pénètre dans une échancrure du prosternum (1-16).

B. Prosternum et mésosternum sans sillon longitudinal médian (1-15).

C. Front avec une excavation simple (1-9).

\section{T. Prolixus.}

Ater, nitidus, latas; fronte profunde excavata, rostri apice acute rotundat a; pronoto antice utrinque exciso, ibi grosse punctato, bituberculato, postice lcevi; pygidio obluso, punctatissimo pilosoque; prosterno subparallelo antice obtuso marginato, mesosterno stria obsoleta, planis, vix punctulatis; tibiis anticis 5-dentatis. Long. 10 mill.; larg. 2 1/2 mill.

Allongé, cylindrique, assez épais, d'un noir luisant. Front creusé d'une excavation profonde, rugueuse, à bords relevés; museau en pointe arrondie et légèrement relevée. Antennes brunes avec le funicule ferrugineux. Pronotum en carré allongé, plus long que les ély tres, avancé en pointe sur l'écusson qui est à peine visible, avec les angles postérieurs arrondis; dilaté sur les côtés au quart postérieur, légèrement échancré en devant, avec trois excavations, une petite médiane limitée par deux tubercules et deux plus larges marquées de gros points aux angles antérieurs, qui sont arrondis et peu saillants; le reste de la surface est parsemé de points peu serrés et très fins ; strie marginale bien marquée jusqu’à l'angle antérieur. Elytres dilatées au milieu des bords latéraux, arrondies à l'extrémité, avec la suture légèrement relevée en arrière, finement et plus densément ponctuées que le pronotum. Pygidium obtus et garni au bout de longs poils, densément et assez fortement ponctué ainsi que le propygidium. Prosternum et mésosternum plans, à peine ponctués, 
bordés sur les côtés d'une strie marginale obsolète; métasternum presque lisse, avec quclques points vers l'extrémité. Pattes de la couleur du corps, arec les tarses d'un brun ferrugineux; jambes antérieures munies de cinq dents espacées, intermédiaires de six, postérieures dilatées au bout, denticulées et villeuses.

Brésil, Sainte-Catherine.

\section{T. THORACICUS.}

Ater, nitidus latus; fronte leviter excavata, rostro brevi apice bilobo; pronoto parce tenuissime, antice vero rude punc. tato, tripliciter at parum profunde impresso; stria marginali antice continuata; pygidio punctulato, acuto; prosterno antice angustato, mesostcrno plano, stria marginali interrupta; tibiis anticis 5-(lentatis. Long. 9 mill.; larg. $21 / 2$ mill.

Bostrichus thoracicus F. Syst. El. II, 3̊85. 4 (1801).

Trypancus thoracicus Escl. Zool. Atl. I, 10. T. 1v. f. 7 (1829). - Perty, Del. Anim. art. I, 35. T. 7, f. 14 (1833).

Cylindrique, assez épais, d'un noir luisant. Front à peine impressionné; museau court, plan, à bords non relevés, bifide au bout; yeux arrondis, saillants, bruns. Antennes brunes, funicule ferrugineux. Pronotum plus long que les élytres, avancé en pointe sur l'écusson, arrondi aux angles postérieurs, élargi sur les côtés aux 3/4 postérieurs, bordé d'une strie marginale à peine interrompue en devant; couvert d'une ponctuation épaisse et superficielle, mais assez forte et assez dense à la partie antérieure, avec trois impressions superficielles. Elytres dilatées vers le milieu et arrondies à l'extrémité; ponctuation très fine, plus visible et plus serrée vers la suture à l'extrémité. Pygidium finement et densément ponctué, prolongé en pointe aiguë. Prosternum 
en triangle allongé entièrement rebordé. Mésosternum plan, presque lisse, avec une strie marginale interrompue. Métasternum assez distinctement ponctué postérieurement. Pattes d'un brun plus ou moins ferrugineux; jambes antéricures armées de cinq dents, intermédiaires de six plus longues et plus aiguës, postérieures denticulées vers le bout et garnies de poils.

Brésil, Sainte-Catherine.

\section{T. TERES.}

Niger nitidus; fronte tcvitcr impressa, rostro brevi apice rotundato; pronolo supra punctato, antice nec impresso, nec tuberculato, stria marginali vix interrupta; elytris tenuissime punctulatis; pygidio conico, mudo; prostcrno subparallelo mesosternoque marginatis; metasterno punctato, postice densius; tibiis anticis 4, intermediis 5-dentatis Long. 8 mill.; larg. 2 mill.

Cylindrique, un peu atténué postérieurement, d'un noir luisant. Front pointillé, à impression fort superficielle, sans rebords élevés; museau court arec la pointe un peu élevée et arrondie.Yeux petits, bruns, globuleux. Antennes brunes. Pronotum bisinué à la base, avancé en pointe sur l'écusson, avec les angles arrondis; dilaté aux trois quarts postérieurs sur les côtés et bordé d'une strie marginale qui s'arrête aux angles antérieurs, largement et peu profondément échancré en devant, sans tubercules ni impressions, également et assez fortement ponctué sur toute sa surface. Elytres plus courtes que le pronotum, dilatées au milieu, arrondies au bord apical, très finement ponctuées sur touteleur surface. Pygidium conique, densément et finement ponctué, sans poils. Prosternum à côtés presque parallèles, obtus en devant, bordé d'une strie marginale entière et bien marquée, ainsi que le 
mésosternum; celui-ci ponctué, mais moins densément et moins fortement que le métasternum. Pattes de la coulcur du corps, avec les tarses brun-ferrugineux; jambes antérieures armées de 4 dents, intermédiaires de cinq.

Un peu plus grand que le $T$. volvulus Er. dont il est très voisin, il a le museau moins relevé au bout, la ponctuation moins forte et le prosternum moins rétréci en devant.

Nouvelle-Grenade.

\section{T. volvulos.}

Ater, nitidus; fronte leviter impressa, rostro apice rotundato elevato; pronoto fortiter et subctqualiter, elytris densius et subtiliter punctatis; pygidio conico nudo; prosterno antice attemuato mesostcrnoque marginatis; metasterno dense punctato; tibiis 4 anterioribus 5-dentatis. Long. $61 / 2$ mill.; larg. 2 mill.

Trypancus volvulus Er. in Jahrb., I, 200, 2 (1834).

Cylindrique, d'un noir luisant. Front légèrement impressionné ; museau en pointe obtuse, arrondie et relevée. Yeux arrondis, médiocrement saillants. Antennes brunes, funicule rouge. Pronotum une fois et demi plus long que les élytres, à base prolongée en pointe sur l'écusson, bisinuée, arrondie aux angles postérieurs, dilaté sur les côtés au trois quarts postérieurs, bordé d'une strie marginale qui cesse aux angles antérieurs, à peine échancré en devant, assez fortement ponctué sur toute sa surface, mais plus densément en devant. Elytres dilatées au milieu, obtusément arrondies au bout, très finement ponctuées; ponctuation plus serrée et plus visible le long de la suture et du bord apical. Pygidium conique, nu, ponctué. Prosternum bordé d'une strie marginale entière, assez rétréci et obtus en devant; mésosternum couvert de quelques points avec une 
strie margninale interrompue en devant. Métasternum couvert de points plus forts et plus serrés postérieurement. Pattes brunes, avec les tarses plus clairs ; jambes antérieures armées de cinq dents, ainsi que les intermédiaires.

Brésil, Sainte-Catherine.

\section{T. ENSIFER.}

Ater nitidus; fronte excavata, rostro brevi acuto, apice elevato; pronoto cylindrico, cequali, dense fortiterque, elytsis densius et subtilius, metasterno crebre et valide, mesosterno parce punctatis stria intervuta; $1^{\circ}$ abdominis segmento sulcato; pygidio acute compresso. Long. 5 1/2 mill.; larg. 1 3/4 mill.

Cylindriqne, allongé, d'un noir luisant. Front assez profondément impressionné, avec un petit tubercule à l'angle interne de chaque œil et les bords un peu relevés; museau court, relevé en pointe obtuse. Antennes brunes. Yeux assez saillants, bruns. Pronotum une fois et demi plus long que les élytres, paraissant cylindrique, mais réellement élargi aux trois quarts sur les côtés, prolongé en pointe au-dessus de l'écusson; angles postérieurs arrondis, antérieurs peu saillants; ponctuation forte et serrée surtout vers la base ; strie marginale se continuant le long du bord antérieur. Elytres dilatées latéralement, obtusément arrondies au bout, plus finement et plus densément pointillées. Pygidium ponctué, comprimé en pointe large et mince. Prosternum en triangle fort allongé, avec une strie marginale bien marquée, rugueux ; mésosternum légèrement ponctué, avec unc strie interrompue; métasternum densément et fortement ponctué. Pattes de la couleur du corps avec les tarses d'un brun-ferrugineux.

Brésil. (M. de Laferté).

3e Série, Tome iv. 


\section{T. QUAURICOLLIS.}

Niger, nitidus, fliformis; fromte excavata, rostro apice acuto reflexo; pronoto sul densc et fortiter punclato; pygidio carinato et acute compresso; metasterno dense fortiter punctato, stria haud interrupta; tibięs anticis 4, intermediis 5-dentatis. Long. 5 1/4 mill.; larg. 1 1/4 mill.

Très allongé, cylindrique, d'un noir luisant. Front excavé ; museau court, relevé en pointe obtuse. Antennes brunes, avec le funicule plus clair. Yeux assez saillants, bruns. Pronotum une fois un quart plus long que les élytres, prolongé en pointe saillante sur l'écusson, arroudi aux angles postérieurs, à côtés paraissant parallèles en dessus, mais réellement dilatés aux trois quarts postérieurs, faiblement échancré en devant, égal et couvert d'une ponciuation forte et assez serrée, surtout vers la base; strie marginale longeant le bord antérieur. Elytres bordées de brun, élargies au milieu, arrondies au bout, un peu relevées posté rieurement à la suture; très finement et plus densément ponctuées, surtout vers le bord apical. Pygidium ponctué, comprimé en lame verticale et tranchante. Prosternum en triaugle allongé, bordé d'une strie marginale, et fort aigu en devant; mésosternum bordé également d'une strie non interrompue, assez fortement ponctué, mais moins densément et moins fortement que le métasternum. Paltes de la couleur du corps, avec les tarses ferrugineux; jambes antéricures armées de quatre dents, intermédiaires de cinq.

LeT' quadricollis est difficile à distinguer de l'ensifer; on le reconnaîtra surtout à la ponctuation du mésosternum plus forte et plus serrée, à la strie marginale non interrompue en devant, à l'élévation un peu plus grande de l'extrémité du museau, enfin à l’absence du sillon longitudi- 
ual médian sur le premier segment ventral de l'abdomen.

M. Sallé a trouvé cette espèce en mai sous les écorces, dans le Guatemala. Il se rencontre aussi dans la Nouvelle-Grenade.

\section{T. BHACULATLS.}

Elongatus, ater, nitidus; fronte impressa ; rostro brevi rotundato; pronoto grosse punctato; elytris punctulatis, maculu pallida notatis; mygidio conico subelongato, subacuto compresso; metasterno dense et rugose punctato, mesosterno prosternoque triangularibus, marginatis; tibiis anticis 5-dentatis. Long. 5 mill.; larg. 1 mill.

Trypances bimaculatus, Er. in Jahr. 201, 3 (1834).

Allongé, cylindrique, assez étroit, d'un noir luisant. Tète finement ponctuée; excavation du front légère, prolongée sur le museau, qui est court et relevé en pointe.Yeux arrondis, assez saillants, bruns ainsi que les antennes. Pronotum une fois et demie plus long que les élytres, avancé en pointe sur l'écusson, dilaté sur les côtés un peu avant les angles postérieurs, à peine échancré en devant avec les angles peu saillants, sans impressions ni tubercules, densément et fortement ponctué sur toute sa surface; strie marginale non interrompue. Elytres courtes, ponctuées finement, mais plus distiuctement vers la suture, noires avec une grande tache d'un jaune ferrugineux, triangulaire, sinuée en arrière; dila. tées au milicu du bord latéral, puis rétrécies et olstusément arrondies au bout; partie postérieure de la suture légèrement relevée. Pygidium allongé, conique, terminé en pointe comprimée. Prosternum et mésosternum bordés d'une strie, ponctués, en triangle allongé; métasternum très densément et rugueusement ponctué. Pattes brunes ; tarses ferrugineux; jambes antérieures 5-dentées.

Brésil, Sainte-Catherine. 


\section{T. PICTUS.}

Oblongus, niger nitidus; fronte subimpressa, rostro apice vix reflexo, subbilobo; pronoto punctato, elytris macula media triangulari rufa, punctulatis ; pygidio brevi conico piloso; mesosterno triangulari dilatato prosternoque attenuato marginatis; metasterno punctato; tibiis anticis 4-dentatis. Long. 5 mill.; larg. 1 1/2 mill.

Assez allongé, noir luisant. Antennes brunes. Front très légèrement impressionné, museau à peine relevé au bout et légèrement bilobé. Pronotum beaucoup plus long que les élytres, dilaté sur les côtés au tiers postérieur, avancé en pointe sur l'écusson, légèrement échancré en devant, ponctué sur toute sa surface, un peu plus fortement au milieu; strie marginale entière et bien marquée le long du bord antérieur. Elytres finement pointillées, un peu plus densément le long de la suture et du bord apical, marquées d'une tache rouge triangulaire, à angles arrondis, sans sinuosité au côté postérieur. Pygidium ponctué, conique, assez court, peu comprimé, couvert de poils courts et fins. Prosternum en triangle aigu; mésosternum plus élargi, avec quelques points; l'un et l'autre bordés d'une forte strie entière. Métasternum assez fortement mais peu densément ponctué. Pattes noires, tarses ferrugineux, jambes antérieures armées de quatre dents, intermédiaires de cinq.

Plus large et plus grand que le $T$. bimaculatus Er., il a en outre le pygidium velu, moins long et non comprimé; le mésosternum à peine pointillé, en triangle plus dilaté; le métasternum assez fortement, mais moins densément ponctué et nullement rugueux.

Cayenne 


\section{T. FLA VIPENNIS.}

Cylindricus, niger nitidus; fronte excavata, rostro apice reflexo rotundato; pronoto punctato antice bituberculato; elytris macula magna triangulari flava; pygidio obtuso piloso; prosterno parallelo, mesosterno stria interrupta; antennis pedibusque rufis, tibiis anticis 5.dentatis. Long. 3 1/5 mill.; larg. 5/6 m.

Cylindrique, effilé, noir luisant. Antennes rousses, massue brune. Front largement excavé à rebord élevé, museau large, relevé et arrondi au bout. Pronotum beaucoup plus long que les élytres, prolongé en pointe sur l'écusson, avec les angles de la base arrondis; légèrement dilaté sur les côtés, largement et peu profondément échancré en devant, avec les angles bien marqués, bituberculé un peu avant le bord antérieur ; strie marginale forte, interrompue en devant; ponctuation grosse, peu serrée. Elytres courtes, dilatées à l'épaule, arquées au bord apical, finement pointillées, bordées de roux avec une large tache triangulaire flave qui n'atteint pas la base. Pygidium densément ponctué, en cône très obtus, garni de poils au bout. Prosternum parallèle, ferrugineux, tronqué en devant, entièrement rebordé. Mésosternum lisse, strie marginale interrompue ; métasternum profondément tuberculé, sans points. Pattes rouges ; jambes antérieures garnies de cinq petites dents.

Mexique, Téapa. (M. Pilate).

C'. Front avec une excavation divisée en deux sillons par une carène longitudinale (10-15).

\section{T. AMABILIS.}

Cylindricus, elongatus, ater nitidus; ronte trispinosa, bisulcrta, rostro longo, apice attenuato, erecto; pronoto antice in 
medio vulde 'retuso et 1-tuberculato, supra dense el fortiter punctato; elytris subtilissime punctulatis, nigris margine brunneis, macula magna rufo-pallida; pygidio obtuso apice piloso; metasterno punctatissimo; prosterno mesosternoque angustis marginatis; tibits anticis 4-dentatis. Long. 3 1/4-2 mill.; larg. 1 1/4 m.

? Bostrichus bipustulatus, F. Syst. El. II, 385, 6. (1801).

Allongé, cylindrique, d'un noir luisant. Tête surmontée de de trois épines, une sur le milieu du vertex et une de chaque côté à l'angle interne des yeux, une crête saillante relie la première avec chacune des deux autres; excavation du front divisée en deux sillons par une carène saillante longifudinale, prolongée sur le museau; celui-ci allongé, relevé en pointe tronquée au bout. Yeux bruns, arrondis, assez saillants. Antennes brunes avec le funicule ferrugineux. Pronotum beaucoup plus long que les élytres, prolongé en pointe au dessus de l'écusson, dilaté un peu au devant des angles postérieurs, ce qui ne l'empêche pas de paraître cylindrique en dessus, peu échaneré en devant avec une impression médiane, surmonté d'un tubercule peu saillant; ponctuation serrée et forte, plus faible en devant; strie marginale non interrompue. Elytres courtes, finement pointillées, plus densément vers la suture, rétrécies et obtusément arrondies au bout, noires arec les bords bruns et une grande tache jaune triangulaire sinuée postérieurement. Pygidium conique, ponctué, obtus, rugueux et garni de poils au bout. Prosternum triangulaire à sommet arrondi, bordé d'une forte strie entière. Mésosternum allongé, fortement bordé, rugueux; métasternum densément et fortement ponctué. Pattes brunes; tarses ferrugineux; jambes antérieures garnies de quatre petites dents.

Ce n'est qu'avec doute que je rapporte a celle espèce ir: 
Bostrichus bipustulatus de Fabricius. Une description comme relle du Systema eleutheratorum, est bien insuffisante pour se fixer avec certilude sur l'espèce que l'anteur a voulu décrire.

Brésil, Sainte-Catherine.

11. T. SPINIGER.

Etongatus cylindricus, niger nitidus; fronte bisulcata, in medio carinata, utrinque spinosa, rostro oblongo, apice acuto reflexo; pronoto fortiter punctato, antice bituberculato; elytris brumneis; pygidio punctato obtuse conico, piloso; metasterno in medio longitudinaliter sulcato, mesosterno lato, prosterno angusto, trianguluribus, marginutis; tibiis anticis 4 , intermediis 5-dentatis. Long. 5 2/3 mill.; larg. 1 1/3 mill.

Allongé, cylindrique, presque filiforme, très voisin du T. quadricollis pour la forme, d'un noir luisant. Front creusé d'une excavation profonde, divisée en deux sillons par une carène longitudinale fine, se prolongeant sur le museau, lequel s'allonge en pointe aiguë et relevée; avec une épine de chaque côté à l'angle interne de l'œil.Yeux bruns. Antennes de même couleur, avec le funicule ferrugineux. Pronotum presque deux fois aussi long que les élytres, bisinué à la base, avancé en pointe sur l'écusson, arrondi aux angles; à côtés parallèles vus en dessus, mais en effet dilatés un peu avant la base; angles antéricurs assez marqués, échancrure céphalique peu profonde, surmontée au milieu d'une paire de tubercules. P'onctuation forte et peu serrée; strie marginale ne suivant pas le bord antérieur. Elytres d'un brun plus clair sur les bords, finement pointillées, dilatées vers le milieu et arrondies au bord apical. 'Jygidiurn obtus, ponctué, garni d'une touffe de poils au bout. Prosternum en triangle 
fort allongé, à base profondément échancrée pour recevoir le mésosternum et à sommet aigu, bordéd'une strie bien marquée. Mésosternum large, rugueux, avec une strie marginale interrompue en devant. Métasternum assez densément ponctué et sillonné longitudinalement au milieu. Pattes d'un brun ferrugineux, avec les tarses plus clairs ; jambes antérieures garnies de quatre dents, intermédiaires de cinq ou six.

Nouvelle-Grenade.

\section{T. 4-TUBERCULATUS.}

Cylindricus, clongatus, niger-nitidus; fronte rostroque elevuto-bisulcatis; pronoto munctulato, antice retuso, 4-tuberculato; pygidio dense punctulato, obtuso, piloso; prosterno plano, parallelo, haud marginato; tibiis anticis 5-dontatis, Long. 7 1/2 mill. ; larg. 3 mill.

Allongé, cylindrique, d'un noir luisant. Tête ponctuée. Yeux arrondis assez saillants. Excaration frontale divisée en deux sillons par une carène médiane large, peu élevée, prolongée sur le museau, qui est assez allongé, aplati au bout et relevé en pointe arrondie. Antennes brunes. Pronotum d'un quart plus long que les élytres, avancé en pointe sur l'écusson, à côtés paraissant parallèles en dessus, mais dilatés un peu avant la base, taillé obliquement en devant avec quatre tubercules disposés par paires sur le bord antérieur, ceux du milieu rapprochés et représentant deux petites carènes parallèles, les deux autres sont fort petits ; la ponctuation est peu serrée et beaucoup moins forte vers la base que dans le voisinage des tubercules; les stries marginales cessent aux angles antérieurs. Elytres dilatées au milieu, arrondies nu bout, relevées sur la suture, courertes d'une ponctuation. 
fine et assez serrée, surtout sur le long de la suture et du bord apical. Pygidium densément et fortement ponctué, en cône obtus et garni de poils au bout. Prosternum plan en dessous, sans strie marginale, presque parallèle, tronqué èn devant. Mésosternum lisse et bordé d'une strie peu marquée; métasternum très finement ponctué. Pattes brunes avec les tarses plus clairs; jambes antérieures armées de ciuq dents espacées.

Nouvelle-Grenade.

\section{T. NASUTUS.}

Elongatus cylindricus, ater nitidus; fronte bisulcala, in medio carinata, rostro apice trigono erectoque; pronoto punctato, antice haud retuso, bituberculato; pygidio brevi, punctato, obtuso, piloso; prosterno parallelo marginato; metasterno lato puncticulato; tibiis anticis 4-,intermediis 5-dentatis. Long. 6 1/2 mill.; larg. 1 1/2 mill.

Allongé, cylindrique, d'un noir luisant. Front lisse avec une excavation divisée en deux sillons bien marqués par une carène longitudinale qui commence plus tard que dans le précédent et se continue de même sur le museau, dont la pointe est triangulaire et fortement relevée. Antennes brunes avec le funicule ferrugineux. Yeux assez saillants, bruns. Pronotum une fois et demi plus long que les élytres, paraissant cylindrique en dessus, mais dilaté un peu au devant des angles postérieurs, prolongé en pointe sur l'écusson ; bord antérieur légèrerement échancré, couvert de points forts et peu serrés ; strie marginale s'arrêtant aux angles antérieurs. Il présente au milicu vers le bord antérieur une paire de tubercules, mais sans dépression semicirculaire. Elytres courtes, finement ponctuées, plus visiblementle long du bord apical arrondi et 
de la suture qui est relcvée. Pygidium court, densément ponctué, obtus et garni de poils au bout. Prosternum parallèle, tronqué en devant, de la longueur du mésosternum et bordé comme lui d'une strie bien marquée, entière ; ces deux segments ponctués, ainsi que le métasternum. Pattes noires, avec les tarses ferrugineux; jambes antérieures garnies de quatre dents, intermédiaires de cinq.

Brésil, Sainte-Catherine.

\section{T. BISPINUS.}

Elongatus, postice subattenuatus, niger nitidus; fronte bisulcata bispinosa, rostro apice acuto elevatoque; pronoto punctato antice bituberculato; elytris punctulatis; pygidio obtuso pilosoque; prosterno antice acuto, metasternoque valide punctatis. Long. 5 21/2 mill. ; larg. 2 mill.

Allongé, subcylindrique, un peu plus étroit postérieurement, d'un noir luisant. Tête ponctuéc; front avec une excavation divisće en deux sillons étroits par une carène bien marquée et prolongée sur le museau, qui est assez allongé, avec la pointe aiguẻ et relevée; les bords latéraux des sillons s'élèventà l'angle interne des yeux en une épine forte et saillantc. Antennes brunes, ainsi que les yeux. Pronotum une fois et demic plus long que les élytres, avancé en pointe à la base sur l'écusson avec les angles arrondis; côtés paraissant parallèles en dessus, mais dilatés au-devant des angles postérieurs; borl anterieur peu profondément échancré, avec les angles assez saillants, obtus et une paire de tubercules au milieu ; ponctuation assez forte et peu serrée; surtout postéricurement; strie marginale indistincte au bord antéricur. Elytres courtes, dilatées au milica, rétrécies cısuite, arrondies au bout, un peu relevées sur la suture postérieurement, 
légèrement pointillées. Pygidium ponctue, court, obtus et garni de poils au bout. Prosternum en triangle allongé, bordé d'une strie ainsi que le mésosternum; ce dernier ponctué mais beaucoup moins densément et moins fortement que le métasternum. Pattes noires, avec les tarses bruns.

La patrie de cet insecte m'est inconnue; il vient probablement d'Amérique, et fait partie de la collection de M. de Laferté.

\section{T. CARINIROSTRIS.}

Niger nitidus; antice paulo latior; fronte bisulcata, rostro apice rotundato, fortiter reflexo; pronoto antice retuso, 4-tuberculato, undique sat fortiter punctato; pygidio dense punctato, aprice obtuso piloso; prosterno marginato. Long. $81 / 2$ mill. ; larg. $21 / 2$ mill.

Cylindrique, un peu plus étroit postérieurement, d'un noir luisant. Excavation frontale profonde, continuée sur le museau, divisée en deux sillons bien dessinés par une carène longitudinale étroite et forte; muséau allongé, aplati et relevé fortement en pointe obtuse au bout.Yeux assez saillants, bruns. Antennes noires avec le funicule brun. Pronotum avancé en pointe sur l'écusson, arrondi aux angles de la base, élargi un peu au-devant sur les côtés, un peu plus large en devant qu'en arrière, peu échancré, couvert d'une ponctuation peu serrée, mais assez forte, la partie antérieure offre une dépression semicirculaire avec quatre petits tubercules placés trausversalement sur le bord et à distances égales; stric marginale cessant aux angles antérieurs. Elytres finement pointillées, élargies au milieu du bord latéral, obtusément arrondies aı bout et légèrement relevées postérieurement le Iong de la suture. Pygidinm en cône obtus, den- 
sément et fortement pouctué, garni de poils au bout. Prosternum allongé, à peine rétréci en devant, bordé, ainsi que le mésosternum, d'une strie marginale bien marquée non interrompue, celui-ci et le métasternum ponctués, le dernier plus densément. Pattes brunes, avec les tarses plus clairs.

Guyane, Cayenne.

B' Mésosternum avec un sillon longitudinal médian.

\section{T. UNITUBERCULATUS.}

Elongatus, cylindricus, niger nitidus; fronte bispinosa bisulcataque carina longitudinali antice bifila, rostro acuto reflexo; pronoto fortiter satque dense punctato, antice unituberculato; mygidio punctato obtuso pilosoque; prosterno trigono, convexo marginato; mesosterno immurginato in medio sulcato; tibiis 4 anterioribus 6-dentatis. Long. $81 / 2$ mill. ; larg. 2 mill.

Allongé, cylindrique, un peu atténué postérieurement, d'un noir luisant, Tête ponctuée; front creusé d'une légère impression, sans rebords élevés, divisée en deux sillons par une carène d'abord très fine, puis formant au-dessus du museau un tubercule birameux; à l'angle interne des yeux, on voit de chaque côté une épine saillante; museau terminé en une pointe relevéc aiguë. Antennes et yeux bruns. Pronotum plus long que les élytres, bisinué à la base avec les angles arrondis, paraissant cylindrique, mais dilaté légèrement aux trois quarts postérieurs, peu profondément échancré en devant, avec un seul tubercule médian et les angles assez saillants et marqués d'une légère impression. Ponctuation forte et assez serrée, surtout en devant et au milieu oủ elle est presque rugueuse. Strie marginale indistincte au bord. antérieur. Elytres finement pointillées, dilatées au milieu, 
obtusément arrondies au bout. Pygidium ponctué, obtus et velu au bout. Prosternum triangulaire, convexe, à sommet aigu, bordé d'une strie marginale, mais sans sillon médian. Mésosternum sans strie marginale, pointillé et divisé en deux par un sillon médian profond qui se continue sur le métasternum; ce dernier segment assez densément ponctué et plus fortement au milieu. Pattes d'un brun ferrugineux avec les tarses plus clairs; jambes à six dents ; dent basilaire interne des intermédiaires à peine sensible, tandis qu'elle est très saillante aux antérieures.

Nouvelle-Grenade.

B" Prosternum avec un sillon longitudinal médian, ainsi que le mésosternum (17-19).

\section{T. FALLAX.}

Cylindricus, niger, nitidus; fronte plana, rostro brevi acute elevato supra tuberculato; pronoto fortiter punctato, angulis anticis prominulis; elytris densius punctulatis, brunneis, margine pallido; pygidio conico; prosterno in medio longitudinaliter sulcato, rugose punctato; pedibus brunneo-ferrugineis. Long. $41 / 4$ mill. ; larg. $11 / 4$ mill.

Cylindrique, d'un noir de poix luisant. Front uni; museau peu allongé, terminé en pointe relevée, surmontée d'un tubercule; antennes ferrugineuses. Yeux bruns. Pronotum une fois et demi plus long que les élytres, avancé en pointe sur l'écusson, dilaté sur les côtés au-devant des angles postérieurs, largement échancré en devant, avec les angles très saillants: strie marginale ne longeant pas le bord antérieur; ponctuation forte et assez serrée. Elytres brunes avec les bords ferrugineux, rétrécies et oblusément arrondies au 
bout, densément et finement ponctuées. Pygidium ponctué, conique, terminé en pointe courte et obtuse. Prosteruum arrondi en devant, sans strie marginale, rugueux et sillonné d'une strie médiane ainsi que les deux segments suivants, Pattes d'un brun ferrugineux; tarses plus clairs.

Brésil.

\section{T. TCBERCULIFRONS.}

Cylindricus, atro-brunneus, nitidus; fronte 1-tuberculata, rostro brevi impresso murginato apice aculo; pronoto valide punctato; clytris brunneis, subtiliter punctulatis; pygidio conico; sterno marginato longitudinaliter sulcato punctatissimoque; pedibus obscure ferrugineis; tibiis 4 anterioribus 6 denticulatis. Long. 4 mill. ; larg. 1 1/4 mill.

Assez allongé, cylindrique, d'un brun noir plus clair sur les élytres, luisant. Front ponctué, avec un petit tubercule médian entre les yeux; museau court, relevé en pointe aiguë, creusé, rebordé; antennes ferrugineuses, massue brunc. Yeux bruns. Pronotum plus long et un peu plus large que les élytres, avancé en pointe sur l'écusson, élargi sur les côtés au-devant des angles postérieurs, légèrement échancré en devant avec les angles assez saillants; strie marginale non interrompue; ponctuation forte et assez serrée. Elytres courtes, rétrécies et arrondies au bout, d'un brun plus ou moins foncé, finement pointillées. Pygidium ponctué, en cône assez pointu. Sternum sillonné dans son milieu d'une strie forte, et couvert d'une ponctuation serrée, presque rugueuse. Prosternum et mésosternum bordés d'une stric marginale complète et bien marquée. Pattes d'un brun ferrugineux plus clair aux jambes et surtout aux tarses; jambes antérieures armées de six lents.

Nouvelle-Grenade. 


\section{T. HiCAUdATUS.}

Cylindricus, parum elongatus, aler, nitidus; fronte subimmessa, rostro brevi, obtuso; pronoto minus elongato, dense sat fortitcr munctato, pygidio acute compresso, apice bifido; sterno in medio longitudinaliter sulcato, punctulissimo; mesostorno marginato; pedibus rufo-brunneis, tibiis anticis 5-dentatis. Long. 4 mill. ; larg. $11 / 4$ mill.

Cylindrique, peu allongé, d'un noir luisant. Front légèrement impressionné; museau court, à pointe obtuse, non relevée. Yeux bruns, assez saillants. Antennes brunes, avec le funicule plus clair. Pronotum plus long que les élytres, un peu plus large à la base, avancé en pointe sur l'écusson, élargi sur les côtés un peu avant les angles postérieurs, échancré en avant arec les angles peu saillants; strie marginale non interrompue; ponctuation assez forte, plus serrée que dans les autres espèces de ce genre. Elytres courtes, finement pointillées, d'un brun ferrugineux sur les bords, rétrécies et arrondies au bout. Pygidium (f. $19 e$ ) ponctué, comprimé an bout en une lame tranchante, bifide. Sternum (19f) densément ponctuée, sillonnée dans toute sa longueur par une forte strie médiane. Prosternum triangulaire sans strie marginale; mésosternum bordé d'une strie bien marquée. Pattes d'un brun ferrugineux; jambes et tarses plus clairs, jambes antérieures 5-dentées.

Nouvelle-Grenade.

A' Mlésosternum arrondi en devant, ne pénétrant pas dans une échancrure du prosternum (20-21).

20. T. DEXroLII.

Cylindricus, niger nilidus, antemis pedibusque rufo-brunneis; 
fronte leviter impressa 1 -tuberculata, rostro apice obtuso reflcxo; pronoto subquadrato lateribus parallelis parum dense punctato; elytris tenuissime puncticulatis, pygidio brevi convexo; sterno sublctvi, marginato; tibiis anticis 5-dentatis. Long. 5 mill.; larg. $11 / 4$ mill.

Cylindrique, raccourci, un peu plus large en devant, noir luisant. Antennes d'un brun ferrugineux. Front légèrement excavé avec un petit tubercule médian; museau court, en pointe relevée, arrondie. Pronotum presque carré, largement et faiblement échancré en devant avec les angles saillants, abaissés; à peine élargi sur les côtés, arrondi aux angles de la base, avancé en pointe sur l'écusson; ponctuation peu forte et peu serrée; strie marginale entière. Elytres presque de la longueur du pronotum, élargies sur les côtés, arrondies au bout avec la marge roussâtre, finement pointillées. Pygidium assez densément ponctué, court, convexe. Prosternum parallèle, rebordé en entier; mésosternum large, arrondi en devant, ne pénétrant pas dans la base du prosternum, strie marginale non interrompue. Tout le dessous du corps presque lisse. Pattes rousses; jambes antérieures armées de cinq dents.

Brésil, Sainte-Catherine.

\section{T. PROBOSCIDEUS.}

Cylindricus, niger, nitidus; rostro marginato apice veflexo fronteque impressis, pronoto parallelo marginato, parce at grosse punctato; elytris subtiliter, pygidio conico densc punctulatis; prosterno parallelo marginato, mesosterno antice late rotundato; pedibus ferrugineis tibiis anticis 5-dentatis. Long. 2 mill.; larg. 1 mill.

Bostrichus proboscideus, F. Syst. Eleut. II, 385, 5. (1801). Hister proboscideus, Payk. Mon. Hister. 88, 72, pl. vin, f. 4. Trypanceus proboscidens, Esch. Zool. Atl. 1, 11. 
Cylindrique, noir, luisant, un peu atténué postérieurement. Tête épaisse; yeux saillants; antennes brunes; front excavé, ainsi que le museau, sans tubercule ; celui-ci rebordé et terminé en une pointe obtuse et un peu relevée. Pronotum à côtés parallèles fortement rebordés, un peu dilaté en devant avec les angles arrondis, assez saillants, presque sans échancrure, avancé un peu à la base sur l'écusson ; couvert d'une ponctuation forte espacée. Elytres un peu plus courtes que le pronotum, élargies au milieu du bord latéral, arrondies au bout, couvertes de points fins et plus rapprochés, brunes, rousses dans leur pourtour. Pygidium en cône très obtus, densément et régulièrement ponctué. Prosternum (f. $21 \mathrm{~g}$ ) plan, fortement rebordé, à peine atténué en devant; mésosternum large, arrondi en devant et ne pénétrant pas dans la base du segment précédent, strie marginale interrompue ; métasternum sillonné longitudinalement, peu fortement ponctué. Pattes d'un brun ferrugineux ; jambes antérieures armées dc cinq dents; postérieures garnies de poils serrés.

Nouvelle-Grenade, Carthagène.

\section{TERETRIUS.}

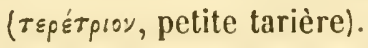

Soc. Ent. 3e Série. T. iv (1856), pl. III.-Mon., pl. XXI, G, XXXVI.

Hister, F. Syst. Ent. (1792).

Teretrius, Er in Jahrb. 1, 201, XVIII (1834).

Corpus cylindricum, breve, obtusum.

Caput latum, receptum, fronte convexa, a clypeo haud divisa, stria nulla.

Antennce in fronte anteoculos insertce, scapo contorto, funiculo 3e Série, томе IV. 
7-articulato, clava ovali, fossa antennali ante coxas sub margine laterali parum profunda.

Mentun trapezoülale antice emarginatum. Palpi maxillares elongati, labiales articulo $2^{\circ}$ crassiori.

Pronoturn transversum convexum, stria marginali tenui: scutellum parvum, paraplenris vix conspicuis; clytra pronoto vix longiora apice truncata, striis mullis.

Prostcrnum latum, basi incisum, antice latius obtusum, parum prominens, lobo nullo; mesosternum antice acuminatum receptum, marginatum.

Abdomen 5-articulatum, articulo 10 magno, pygidio semicirculari, inflexo.

Tibice antice spatulaformes dilatate extus denticulata, posteriorcs 4 subcylindrice, extus parce spinosie.

Corps court, cylindrique, obtus.Tête assez grosse, s'enfoncant dans le prothorax; front convexe, sans strie ni impression qui le distingue de l'épistome ; labre court, transversal, arrondi au bord antérieur; mandibules fig. $4 c, 4 d$ ) larges, en pointe aiguë, recourbée, 1-dentées au côté interne; yeux ovales, transverses, non saillants.

Antennes (fig. $4 \mathrm{~g}$ ) insérées sur le front en dedans des yeux; scape coudé, épaissi au bout, logé dans une coulisse des côtés de la tête; funicule filiforme de sept articles serrés, de plus en plus courts; massue ovalaire allongée, de quatre articles peu distincts, velus. Fossette antennaire (f. 1 a) bien marquée au milieu des bords latéraux du prothorax au-devant des hanches; le bord pectoral antérieur est entaillé profondément de chaque coté pour le passage de l'antenne.

Máchoires ( $\mathrm{f} .4 \mathrm{e}$ ) cornées à deux lobes garnis de poils, l'externe plus long. Palpes maxillaires de quatre articles; premier court, mince ; deuxième allongé, obconique ; troi- 
sième cylindrique plus court que le deuxième, troisième conique deux fois plus long que le précédent. Menton (f. 4 f) trapézoïde, rétréci et échancré en devant; languette nulle, paraglosses membraneuses, courtes, arrondies. Palpes labiaux courts, de trois articles, deuxième court, renflé, fort gros; troisième plus long et terminé en pointe.

Pronotum quadrangulaire, un peu plus large que long, convexe, abaissé en devant, légèrement arqué à la base, sinué sur les côtés, échancré au bord antérieur avec les angles arrondis; une strie marginale fine. Parapleures peu visibles en dessus. Ecusson ponctiforme. Élytres convexes, courtes, faiblement arrondies au bout; élargies sur les côtés, sans stries.

Prosternum (f. 1 a) saillant, souvent bistrić longitudinalement, profondément échancré à la base, élargi en devant, en pointe plus ou moins droite ou mème lẻgèrement sinuée, sans lobe. Mésosternum large, court, terminé antérieurement par une pointe saillante enfoncée dans la base du prosternum.

Pattes assez allongées, celles de la première paire rapprochées à leur insertion; celles de deux autres très distantes, à peu près également. Cuisses dilatées, comprimés et creusées d'une coulisse pour loger les jambes. Jambes antérieures (f. $4 i, 6 l$ ) aplaties, dilatées au milieu en forme de spatule; denticulées au bord externe et creusées en dessus d'une fossette tarsale peu marquée ; postérieures (f. $4 k, 4 j$ ) légèrement élargies au bout, garnies en dehors d'une série de denticules; terminées par deux épines inégales. Tarses de cinq articles, quatre premiers courts, cinquième allongé, terminé par deux crochets.

Abdomen (f. $1 b$ ) de cinq articles dont le premier segment 
inférieur occupe à lui seul presque toute la surface ventrale, les quatre autres étant serrés l'un contre l'autre. Propygidium presque triangulaire, oblique; pygidium arrondi au bout, fortement infléchi.

Ce genre, créé par Erichson dans sa Revue des Histérides du Musée de Berlin, en 1834, ne comprenait pour cet auteur qu'une petite espèce connuc depuis longtemps et propre à l'Europe, le Hister picipes de Fabricius et de Paykull. Tout récemment $M$. Fahræus vient d'en décrire une deuxième sous le nom de T. punctulalus, découverte par Wahlberg en Caffrerie (H. Boheman, Insecta Caffraria, pars. I, fasc. 2(1851). J'ai pu en ajouter cinq nouvelles, dont deux du Cap de Bonne-Espérance, une de Madagascar et deux d'A mérique que je dois à l'obligeance de M. A. Sallé. L'espèce de Fahræus, qui m'est inconnue, semble tenir le milieu entre les $T$. pilimanus et le T. latus, qui proviennent des mêmes contrées que lui.

Ces insectes vivent sous les écorces des arbres pourris; ils paraissent rares et leurs premiers états sont inconnus. 
XXXVI. Teretrius.

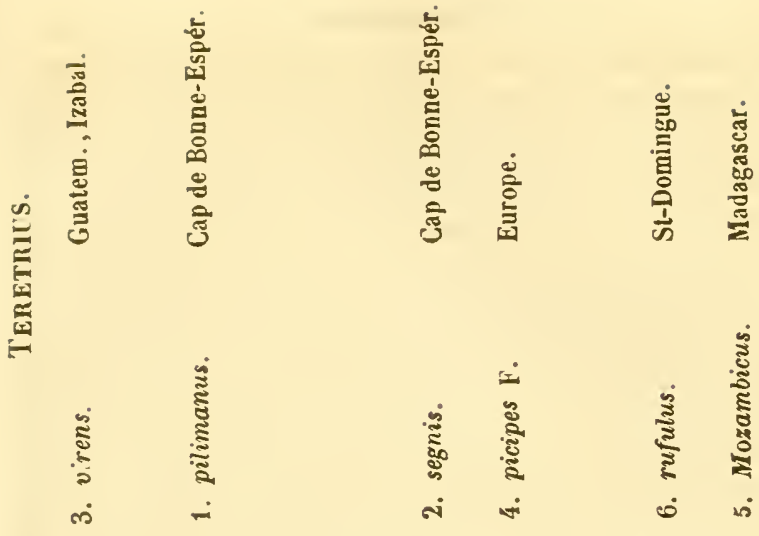

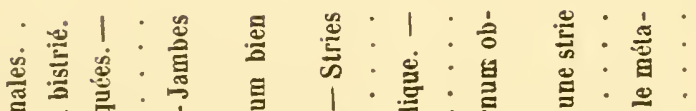

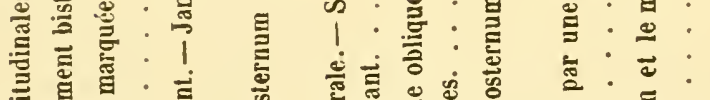

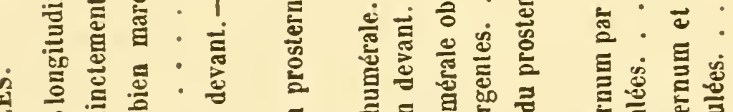

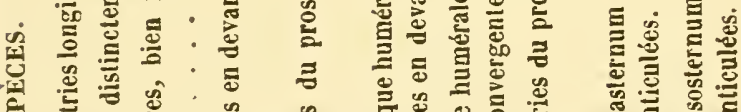

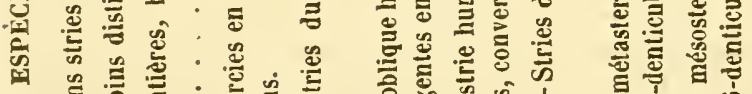

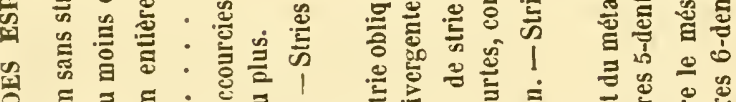

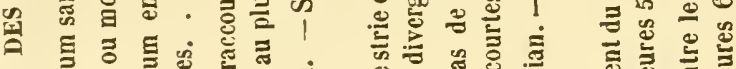

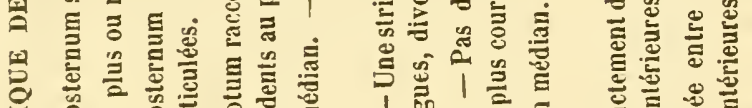

9

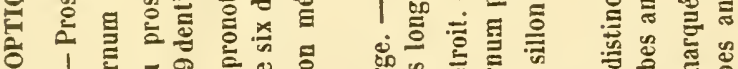

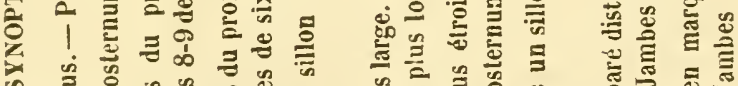

क

क

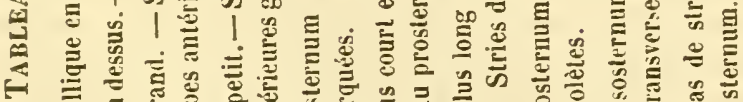

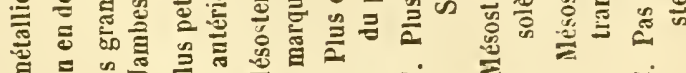

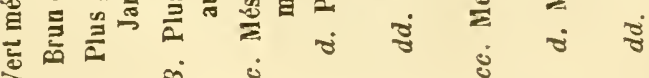

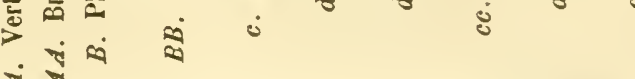




\section{T. PILHands.}

Nigro-brumnens, nitidus, dense punctatus; prosterno slriis integris subparallelis; clytris tuberculo humerali lavi; pedibus brunneo-ferrugineis tibiis anticis intus ciliatis, extus 8-10, intermediis 8 , posticis 6-spinosis. Long. 4 mill. ; larg. $21 / 4$ mill.

Cylindrique, court et large, d'un brun noir luisant avec le bord latéral des élytres, les anternes et les pattes plus ferrugineuses. Tête large, finement ponctuèe; front convexe sans strie qui le distingue de l'épistome; labre court, arrondi en devant. Pronotum en carré plus large que long, assez convexe, arqué à la base, sinué sur les côtés, échancré en devant, avec les angles arrondis et abaissés, fnement et densément ponctué sur toute sa surface; strie marginale bien marquée, non interrompue au bord antérieur. Ecusson très petit, ponctiforme. Elytres de la largeur du pronotum et un peu plus longues que lui, légèrement convexes, un peu élargies sur les côtés, arrondies au bout, de manière à former un angle sutural rentrant; plus fortement et un pen moins densément ponctuées, surtout vers les bords, avec un espace huméral lisse. Pygidium finement ponctué , presque vertical. Prosternum allongé, saillant, bistrić dans toute sa longueur, rétréci à la base et fortement échancré, concave, légèrement élargi et sinué en devant, bordé d'une strie; plan sur sa surface et assez fortement ponctué. Mésosternum large, court, avec une pointe antérieure pénétrant très avant dans la base du prosternum, bordé d'une strie entière; métasternum sillonné au milieu dans sa longueur; ces deux segments ponctués, ainsi que j’abdomen. Pattes ferrugineuses; jambes antérieures dilatées en spatule, avec de longs poils en dedans et 8 à 10 denticules en dehors; intermédiaires garnies de huit, postérieures de six denticules.

Cap de Bonne-Espérance. (M. Chevrolat). 


\section{T. SEGNIS.}

Brevis, niger, nitidus; pedibus ferrugineis; undique puncta. tus; elytris stvia humerali obliqua, sutura elevata; prosterno basi haud impresso, 2 striis abbreviatis ; mesosterno a metasterno huted distincto; tibiis anticis 6, mediis 4, posticis 1-spinosis. Long. 3 mill. ; larg. 1 2/3 mill.

Subcylindrique, plus large, à peine une.fois et demie plus long que large, d'un noir luisant, ponctué sur toute sa surface. Tête large, saillaute ; front convexe, finement ponctué; yeux aplatis, ovalaires. Antennes brunes. Pronotum peu convexe, beaucoup plus large que long, légèrement avancé sur l'écusson; angles postérieurs coupés droit, à bords latéraux parallèles; à peine rétréci en devant avec une échancrure peu profonde, et les angles antérieurs peu saillants et très abaissés ; couvert d'une ponctuation uniforme assez forte et peu serrée; strie marginale entière. Ecusson triangulaire très petit. Elytres de la largeur du pronotum à la base, un peu plus longues que lui, légérement dilatées au milieu du bord latéral, coupées droit au bout; légèrement convexes, plus fortement ponctuées que le pronotum, avec une strie humérale oblique et la suture relevée en carène. Pygidium légèrement convexe, perpendiculaire, finement ponctué. Prosternum assez saillant, avec deux stries longitudinales, raccourcies en devant et un peu divergentes ; fortement échancré à la base, plan et ponctué sur toute sa surface. Mésosternum large, en pointe saillante, enfoncée dans la base du prosternum, fortement ponctué et sans strie qui le sépare du métasternum. Pattes d'un brun ferrugineux; jambes antérieures dilatées en spatuie, garnies en dehors de six denticules, les intermédiaires de quatre et les postérieures d'une seule dent apicale.

Cap de Bonne-Espérance. (M. Cherrolat). 


\section{T. VIRENS.}

Viridis metallicus, undique sat dense et fortiter punctulatus; antennis pedibusque rufis; clytris transversim basi impressis; prosterno haud bistriato, mesosterno stria marginali interrupta, a metasterno haud distincto; tibiis anticis intermediisque 6-denticulatis. Long. 2 mill. ; larg. 1 mill.

Cylindrique, court, assez large, d'un vert métallique luisant en dessus, noir de poix en dessous, assez densément et fortement ponctué sur toute sa surface. Antennes rousses, scape garni de longs poils flaves. Front convexe, épistome rétréci à son origine. Pronotum bombé, presque carré, à peine prolongé à la base au devant de l'écusson, sinué sur les côtés, légèrement échancré en devant avec les angles peu saillants; strie marginale bien marquée, entière. Ecusson triangulaire très petit. Elytres de la longueur du pronotum et de sa largeur à la base, curvilinéairement dilatées sur les côtés, à peine rétrécies au bout; avec un sillon transverse le long du bord antérieur. Pygidium plus finement ponctué que le reste du corps. Prosternum large, arrondi, sans stries; mésosternum couvert de gros points ocellés, à strie marginale un peu interrompue en devant; sans sillon longitudinal médian, ni strie transverse qui le sépare du métasternum. Pattes rouges; jambes antérieures garnies de six denticules, ainsi que les intermédiaires.

Un individu trouvé par M. Sallé, en mai, sous les écorces à Izabal, village du Guatemala.

\section{T. PICIPES.}

Cylindricus, subelongatus, nigro-brunneus ; pedibus ferrugineis; undique punctatus, elytris parcius et fortius; prosterno leviter bistriato, basi impresso, mesosterno stria transversa 
terminato ; tibiis anticis extus 6-, mediis 5-posticisque 2-spinosis. Long. 2 1/2 mill.; larg. 1 1/5 mill.

Hister picipes, F. Ent. Syst. 1, 77, 21 (1792). - F. Syst. El. 1, 92, 42. - Ent. Hefte 1, 104, 26. - Illig. Mag. vi, 46, 22. - Gyl. Ins. Suec. 1, 95, 26. - Payk. Mon. Hist. 89, 73, pl. viı, f. 5.

Dendrophilus picipes, Steph. III. III, p. 161.7 (1830).

Terctrius picipcs Er. Kæf. d. Brand. I, 680.1 (1839). - Heer, Fn. Helv. I, 463, 1. - Le C. N. Amér. Hist. 49, 1. T. vı, f. 6. Redt. Fn. Austr. 238. - Bach, Fn. Prus. I, 311, 1.

Cylindrique, assez allongé, d'un brun noir, avec la bouche, les pattes et les antennes, les bords du pronotum et des élytres ferrugineux. Tête grusse, saillante, densément et assez finement ponctuée; front convexe; yeux ovalaires, peu saillants. Pronotum peu convexe, beaucoup moins long que large, couvert d'une ponctuation forte et assez peu serrée ; légèrement bisinué à la base, parallèle sur les côtés, à peine rétréci en devant, avec une faible échancrure et les angles abaissés peu saillants; strie marginale dépassant les angles antérieurs, mais interrompue en devant. Ecusson très petit, triangulaire. Elytres peu convexes, plus longues que le pronotum, de sa largeur à la base, légèrement dilatées au milieu et rétrécies à l'extrémité qui est coupée droit; ponctuation comme celle du pronotum; suture un peu relevée. Pygidium finement ponctué et plus densément que le pronotiun et les élytres. Prosternum saillant, entaillé profondément à la base, impressionné un peu avant, stries longitudinales dépassant un peu le milieu et convergentes, arec quelques points seulement comme sur le mésosternum, ce dernier pénétrant très avant dans la base du prosternum, fortement rebordé et séparé du métasternum par une strie transverse. Jambes antérieures contournées, dilatées au bout en forme de spatule, garnies en dehors de six dentelures, les intermediaires de cinq et les postérieures de deux seulement. 
Il se distingue du 7. segnis par sa taille plus petite, surtout par les élytres plus allongées par rapport au pronotum; par l'absence de strie humérale, la ponctuation des élylres un peu moins forte et plus serrée, l'impression basale du prosternum, la briéveté des stries latérales, la strie transverse qui sépare le mésosternum du métasternum, enfin le nombre des dentelures des jambes.

Cette espèce vit sous les écorces, dans le bois des vieux saules (Erichson) et se trouve, mais assez rarement, dans plusieurs contrées de l'Europe: Suède, Angleterre, France, Allemagne, Autriche, Portugal.

\section{T. Mozanibicus.}

Subelongatus, piceus, antennis pedibusque brunneis, dense et sat fortiter punctatus; elytris sutura elevata; prosterno indistincte bistriato, mesosterno in medio sulcato, stria transversa a metasterno disjuncto; anticis tibiis 5-dentatis. Long. 1 2/3 mill.; larg. $3 / 4$ mill.

Assez allongé, cylindrique, d'un noir de poix, avec la la bouche, les antennes, les pattes et la marge des élytres brunes. Tête grosse, légèrement convexe, penchée, enfoncée dans le prothorax; front ponctué, sans strie qui le sépare de l'épistome. Pronotum convexe, un peu plus large que long, arqué à la base, légèrement sinué latéralement, aussi large antérieurement qu'à la base; bordé sur les côtés d'une strie marginale entière, couvert d'une ponctuation forte et assez serrée. Elytres un peu plus longues que le pronotum, aussi larges que lui, parallèles, obtuses au bout, relevées sur la suture, sans stries, mais couvertes l'une ponctuation plus serrée et ąussi forte que ìe pronotum. Pygidium vertical, finement jorictué. Prosternum allongé, assez saillant, ponctuè, un peu élargi antérieurement, profondément échan- 
cré à la base, saus impression bien marquée, avec deux courtes stries obsolètes; mésosternun terminé en devant par une pointe qui s'enfonce dans la base du prosternum, avec une strie marginale et un sillon médian longitudiual qui se continue sur le métasternum. Patles d'un ferrugineux testace. jambes antérieures fortement dilatées, garnies de cinq dents aiguës sur le coté externe; quatre postérieures denticulées.

Cettc espèce diffère du $T$. picipes par sa taille plus petite, un peu plus svelte, sa poncluation plus forte, ses pattes moins pâles et surtout par son prosternum sans impression basale ef par le sillon médian de son mésosternum.

Madagascar.

\section{T. RUFULUS.}

Brunneus, antennis pedibusque rufis, sat dense punctulatus; prosterno obsolete striato, mesosterno integre marginato, in medio sulcato, stria transversa postice a metasterno distincto, grosse punctatis; tibiis anticis 5-, intermediis 3-, posticis apice denticulatis. Long. 1 1/2 mill. ; larg. 3/4 mill.

Cylindrique, un peu moins bombé que les autres; brun roussâtre sur les élytres, finement et àssez densément pointillé sur toute sa surface. Antennes rousses. Pronotum presque droit sur les côtés, légèrement échancré en devant avec les angles peu saillants; strie marginale entière. Ecusson triangulaire très petit. Elytres de la longueur du pronotum, de sa largeur à la base, parallèles; un peu plus finement ponctuées que le pronotum. Prosternum échancré à la base pour recevoir l'avance du mésosternum, peu visiblement bistrié postérieurement, assez fortement ponctué. Mésosternum entièrement rebordé, distinctement sillonnć au unilieu, 
séparé du métasternum par une forte strie transversale, plus fortement ponctué que le segment précédent. Pattes rouges; jambes antérieures garnies de poils en dedans vers le bout, armées de cinq denticules, les deux apicaux rapprochés; intermédiaires 3-denticulées; postérieures seulement avec quelques épines apicales.

Izabal dans le Guatemala, sous les écorces, en mai.

Espèce que je n'ai pas vue.

T. punctulatus. Fahræus in Bohem. Ins. Caffr. I. Pars 2a. 546,596 (1851).

Subcylindricus, niger, nitidus, punctatissimus, antennis pedibusque ferrugineis, pronoto tenuiter marginato, postice medio leviter producto; elytris areola humerali lcevi, absque striis, tibiis spinosis. Long. 3 mill.; larg. 1 1/2 mill.

In tractibus fluvii Gariepis superioribus.

Tout noir, excepté les antennes et les pieds, luisant. Tête infléchie, rétrécie en devant, très finement pointillée. Antennes assez courtes, ferrugineuses, massue arrondie, flavescente. Pronotum presque carré, un peu avancé au milieu postérieurement, légèrement échancré en devant, avec les angles abaissés, également et médiocrement convexe en dessus, très finement rebordé en devant et sur les côtés, toute la surface distinctement et assez densẻment ponctuée. Ecusson à peine visible. Elytres de la largeur dı pronotum, sublinéaires, bord latéral néanmoins dilaté au milicu, mais rabattu, ensemble légèrement sinuées en devant, posterieurement très obtusément arrondies séparément, à peine de moitié plus longues que le pronotum, également convexes en dessus, ponctuées de toutes parts comme le pronotum, ̀̀ 
l'exception d'un petit espace oblong lisse de chaque côté au bord huméral. Pygidium convexe, arrondi, infléchi au bout, pointillé de toutes parts. Corps convexe en dessous, ponctué plus distinctement sur les côtés, moins densément et plus finement au milieu. Pattes assez robustes, un peu comprimées. ferrugineuses; jambes antérieures armées de 8-10 spinules ou denticules, postérieures de 5-7.

\section{XIPHONOTUS.}

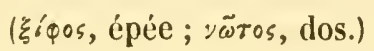

Soc. Ent. 3e Série, T. 3 (1855); pl. III. -Mon., pl. XXI. G XXXVII.

Corpus cylindricum, elongatum, postice truncatum.

Caput parvum, retractum, rotundatum; fronte plana, stria nulla; mandibulis crassis uni-dentatis, cxtus tuberculatis.

Antenne in frontis margine insertce, foveola anternali in pectore medio ante coxas, lala, margine pectoris inciso.

Prosternum bistriatum, basi incisum, lobo indistincto; mesosternum antice receptum, marginatum.

Pronotum elytris longius, anterius constrictum, valde super caput prominens, elytraque haud striata.

Propygidium transversum, breve, pygidium semicirculare, oblique resecta.

Tibice antice dilatatce, fossa tarsali vaga, denticulata, intus inermes, postica dentibus extus uni-seriatim parvis armat(e; tarsis ultimo articulo 1-unguiculato.

Corps allongé, cylindrique, atténué en devant, tronqué par derrière.

Tête (f. $1 b, c)$ petite, arrondie, s'enfonçant profondément dans le prothorax; front plan, sans strie; épistome 
resserré entre les antennes, assez long; labre arrondi; yeux ovalaires peu saillants. Mandibules (f. $1 d$ ) épaisses, courtes, arrondies, presque entièrement cachées, 1 -dentées en dedans, et surmontées d'un fort tubercule en dehors.

Antennes insérées sur le front, en dedans des yeux, logées dans une coulisse creusée sous la tête, passant par une profonde échancrure du bord pectoral antérieur, pour se loger dans une large fossette placée au devant des hanches.

Mâchoires (f. $1 d$ ) cornées à deux lobes barbus au bout. l'externe beaucoup plus long que l'interne. Palpes maxillaires de quatre articles; premier petit, deuxième obconique, troisième court, quatrième ovalaire, obtus. Menton (f. 1 e) court, échancré antérieurement, garni de longs poils; lèvre membraneuse, paraglosses en lobes courts, ciliées; languette échancrẻe. Palpes labiaux de trois articles; deuxième gros, globuleux; troisième ovalaire, plus mince.

Pronotum allongé, convexe, légèrement arqué à la base, parallèle, sans stries, rétréci en devant, en une lame re. bordée, obtuse, avancée au-dessus de la tête et la couvrant comme un capuchon. Ecusson très petit, distinct. Elytres plus courtes que le pronotum, parallèles et droites au bout; sans stries. Prosternum élevé, étroit, bistrié, profondément incisé à la base, dilaté et un peu rabattu antérieurement, sans lobe distinct. Mésosternum assez large, rebordé, avec une pointe médiane qui pénètre dans la base du prosternum. Métasternum très long, assez étroit, sillonné longitudinalement au milicu.

Pattes assez longues, antérieures rapprochées à leur insertion, postérieures trìs éloignées des intermédiaires. Cuisses 
renflées au milieu. Jambes antérieures (f. 1 g) creusées d'une fossette superficielle, dilatées et denticulées; postérieures $(f .1 h, i)$ avec une seule arête externe garnie de quelques dents espacćes. Tarses de cinq articles, 1-4 triangulaires, égaux, biciliés en dessous; cinquième long, armé d'un seul crochet.

Abdomen de cinq anneaux; premier segment ventral long, bistriẻ; $2-4$ très pressés, souvent difficiles à distinguer an milieu; cinquième assez long, rabattu. Propygiỏium court, transversal; pygidium semi-circulaire, taillés obliquement.

Le type du genre Xiphonotus est une jolie petite espèce nouvelle du Cap de Bonne-Espérance ( $X$. Chevrolati), dont la forme est presque aussi singulière que celle des Trypanæus. Elle ressemble à un Terctrius; mais l'avance du pronotum sur la tête, le dernier article des tarses armé d'un seul crochet, le tubercule externe des mandibules, la troncature de l'abdomen, les fossettes antennaires bien marquées; les jambes antérieures inermes en dedans; l'épistome sans museau laissant voir le labre, forment autant de caractères tranchés et exclusifs.

\section{Xiphonotus Cinevrolati.}

Cylindricus, brunneo-nitidus, tenuissime punctulatus; fronte planiuscula ab epistomo haud distincta, labro antice arcuato ciliatoque; pronoto antice constricto, lamina proninula margine striata; elytris haud striatis; tibiis dilatatis, anticis extus 6-denticulatis, intermediis 4-, posticis 3-dentatis. Long. 2 mill.; larg. 4/5 mill.

Allongé, cylindrique, d'un brun ferrugineux luisant, densément et très finement ponctué sur toute sa surface. Tête 
médiocre, s'enfonçant dans le prothorax, restant visible en dessous, mais entièrement cachée en dessus. Front large, plan, sans strie qui le distingue de l'épistome; ce dernier peu avancé, large et légèrement échancré au bout; labre court, arrondi, cilié. Mandibules épaisses, saillantes, courbées, muries d'une dent interne vers le bout, et en dehors d'un fort tubercule médian. Yeux subovalaires, peu saillants. Antennes insérées dans une fossette, sur le front, en dedans des yeux. Pronotum sans stries, cylindrique, rétréci en devant et projetant sur la tête une lame allongée, rebordée et tronquée au bout. Ecusson très distinct, quoique petit, triangulaire. Elytres parallèles, de la largeur du pronotum, un peu plus courtes, coupées droit au bout, sans stries. Propygidium et pygidium entaillés, obliques, l'un transverse, l'autre semi-circulaire. Prosternum assez saillant, dilaté en devant, bistrié longitudinalement, profondément échancré à la base. Mésosternum large, en pointe saillante enfoncée dans la base du prosternum, distinct du métasternum par une strie transversale fine; ce dernier long, sillonné dans sa longueur par une strie médiane ę deux latérales. Pattes assez allongées, ferrugineuses, deuxième paire rapprochée de la première et fort éloignée de la troisième. Cuisses renflées au milieu; jambes antérieures dilatées, garnies extérieurement de six ou sept denticules, les intermédiaires de quatre, les postérieures de trois, le dernier bifide.

Cap de Bonne-Espérance. 


\section{ESSAI MONOGRAPLIYUE SUR LA FAMILLE DES HISTERIDES.}

(Suite) (1).

Par M. S.-A. de MARSEUL.

(Séance du 9 Février 1853.)

XXXVIIl. PLEGADERUS.

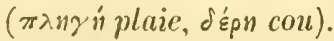

Soc. Ent. 3e série, IVe vol. (1856), pl. xı. - Mon. pl. xxir. Genre XXXVIII.

Hister F. Panz. Rossi; Say.

Plegaderus Erich. in Jalır). 1, p. 203, xix (1834). - Fn. Brand 1, 682, - Heer, Fn. Helv. I, 463, Ix (1841). -- Le Conte, N. Amér. Hist. (1845), 49. - Redt., Fn. Austr. 239 (1849). - Bach, Fn. Prus. I, 311 (1849).

Ovalis, parum convexus ; capul parvum retractum, fronte a clypeo land distinctum.

Antennce in fronte ad oculos inserta', scapo clongato, funiculo 7-articulato, -2 longioribus, celeris minutis, clava roI undata 4-urticulata; fovcole profunde medio in latere ante coxas sita, pectoris margine antico exciso.

Pronotum margine laterali incrassato striato sulcaloque, scepius sulco transverso bipartilo. Elytra striis obsolctis.

(1) Voyez $3^{\circ}$ Série, T. I (1853), p. 131 et 4'17; T. II (185亿), p. 161, 525 et 671 ; 'T. III (1855), p. 83 et 327 , et T. IV (1S56), p. 97. 
Pygidium scmi-circulare, verticale.

Prosternum latum, longiludinaliter bisulcatum costa media serpins interrupta, lobo antico nullo; mesostermum antice emarginatum foveolatumgue, postice haud a metasterno distinctum.

Peles elongati, tibiis anticis apice dilatatis denticulatisque, posticis lincaribus ciliatis, tarsis 5 articulis brevibus, ultimo oblongo, biungulato.

Corps ovalaire, peu convexe.

Tête (fig. $3 g$ ) petite, enfoncée dans le prothorax; front sans strie qui le distingue de l'épistome; labre court, trapézoïdal, obtus au bout; mandibules (fig. 3 h) larges, courtes, bifides ; yeux arrondis, médiocrement saillants.

Antennes (fig. $3 g$ ) insérées sur le front, tout près du bord interne de l'œil; scape renflé au bout, assez long; funicule de 7 articles; $1^{\text {er }}$ et $2^{\mathrm{e}}$ à peu près de même longueur, obconiques, l'un beaucoup plus gros que l'autre; 3-7 courts, moniliformes, égaux ; massue ovalaire, courte, un peu comprimée, de 4 articles garnis de poils. Fossette antennaire (fig. $8 d$ ) profonde, bien dessinée, pratiquée au milieu des côtés de la poitrine, un peu au-devant des hanches; l'antenne y pénètre par une coulisse pratiquée dans le bord pectoral antérieur.

Máchoires (fig. $3 e$ ) cornées, à deux lobes membraneux, ciliés, l'externe plus long, courbe ; l'interne mince, presque droit. Palpes maxillaires de quatre articles, premier très petit, deuxième,renflé au bout, allongé, troisième court cylindrique, quatrième ovalaire, obtus au bout. Menton (fig. 3 f) transverse, coupé droit à la base; languette membraneuse; paraglosses dépassant la languette et terminé en lobe arrondi. Palpes labiaux de trois articles, premier petit, 
deuxième obconique renllé, le troisième un peu plus long, ovalaire, obtus au bout.

Pronotum en trapèze rétréci par devant, à base bisinuée, à côtés plus ou moins arqués, avec une strie marginale et un bourrelet élevé, bordé en dedans par un sillon profond, large, quelquefois coupé en deux par un sillon transverse. Ecusson triangulaire, petit. Elytres rétrécies et tronquées postérieurement, plus ou moins bombćes au milieu; ordinairement ponctuées, avec quelques stries rudimentaires obliques à la base.

Prosternum médiocrement saillant, arrondi à la base, coupé droit en devant, bordé de chaque còté par un rebord élevé, sinueux, rétréci au milieu, souvent partagé en deux parties par une excavation garnie d'une houppe de poils. Mésosternum échancré en devant, sans ligne de démarcation du côté du métasternnm; avec trois sillons longitudinaux profonds continués sur les deux segments.

Pattes (fig. $2 a, b, c$ ) assez allongées, à peu près également distantes à leur insertion. Cuisses subcylindriques, un peu épaissies; jambes antérieures terminées par une brusque dilatation, denticulées au bord extérieur; postérieures presque linéaires, de la longueur des cuisses, repliées contre elles dans le repos. Tarses libres, non repliés sur les jambes, filiformes, de cinq articles; les quatre premiers égaux entre eux, moniliformes ; cinquième pius long, armé de deux crochets.

Abdomen de cinq segments; premier aussi long que les quatre suivants réunis; ceux-ci égaux et courts; propygidium court, oblique; pygidium semi-circulaire, ver¿ical. 
Le genre Plegaderus, établi par Erichson en 1834 dans le Jahrbücher de kilug, forme un petit groupe d'espèces très homogènes, de faciès uniforme, et distinct de tous les autres histérides par des caractères saillants et nombreux. La structure du prosternum est surtout des plus remarquables, et on ne trouve rien dans toute la famille qui en approche tant soit peu. Joignez à cela la position des fossettes antennaires larges et arrondies, au milieu des côtés de la poitrine, au devant des hanches, dans lesquelles les antennes pénètrent par une profonde coulisse pratiquée dans le bord pectoral antérieur, et vous ne pourrez confondre ce genre avec ceux qui auraient avec lui quelque ressemblance fort éloignée.

A l'époque de cette heureuse découverte, on connaissait déjà cinq espèces de Plegaderus : P. casus $\mathrm{F}$., pusillus Rossi, vulncratus Panz., saucius, confondu par Sturm et Gyllenhal sous le nom de vulneratus avec le précédent, et Iransversus Say. Depuis, Erichson lui-même, dans sa Faune de la province de Brandebourg, a décrit les $P$. dissectus et discisus; et M. Truqui le P. sunalus, dans les Annales de notre Société. Je ne puis y ajouter que deux espèces, l’une des Etats-Unis, P. Sayi, faisant partie de la collection de 11 . de la Ferté, et l'autre découverte en France dans le départemerit du Var.

Elles sont toutes propres a l'Europe ot aux Etats-Unis; elles vivent toutes dans des circonstances analogues. Les larves sont carnassières et se tiennent dans les galeries des xylophages, dont elles dévorent la progéniture. Elles y éclosent au printemps, s'y développent en quelques mois, s'y métamorphosent en nymphes, et arrivent en automne à l'état d'insecte parfait

L'insecle parfait se rencontre souvent en abondance sous les écorces des tronc's d'arbres pourris, dans le terreau hımide qui s'y forme. 

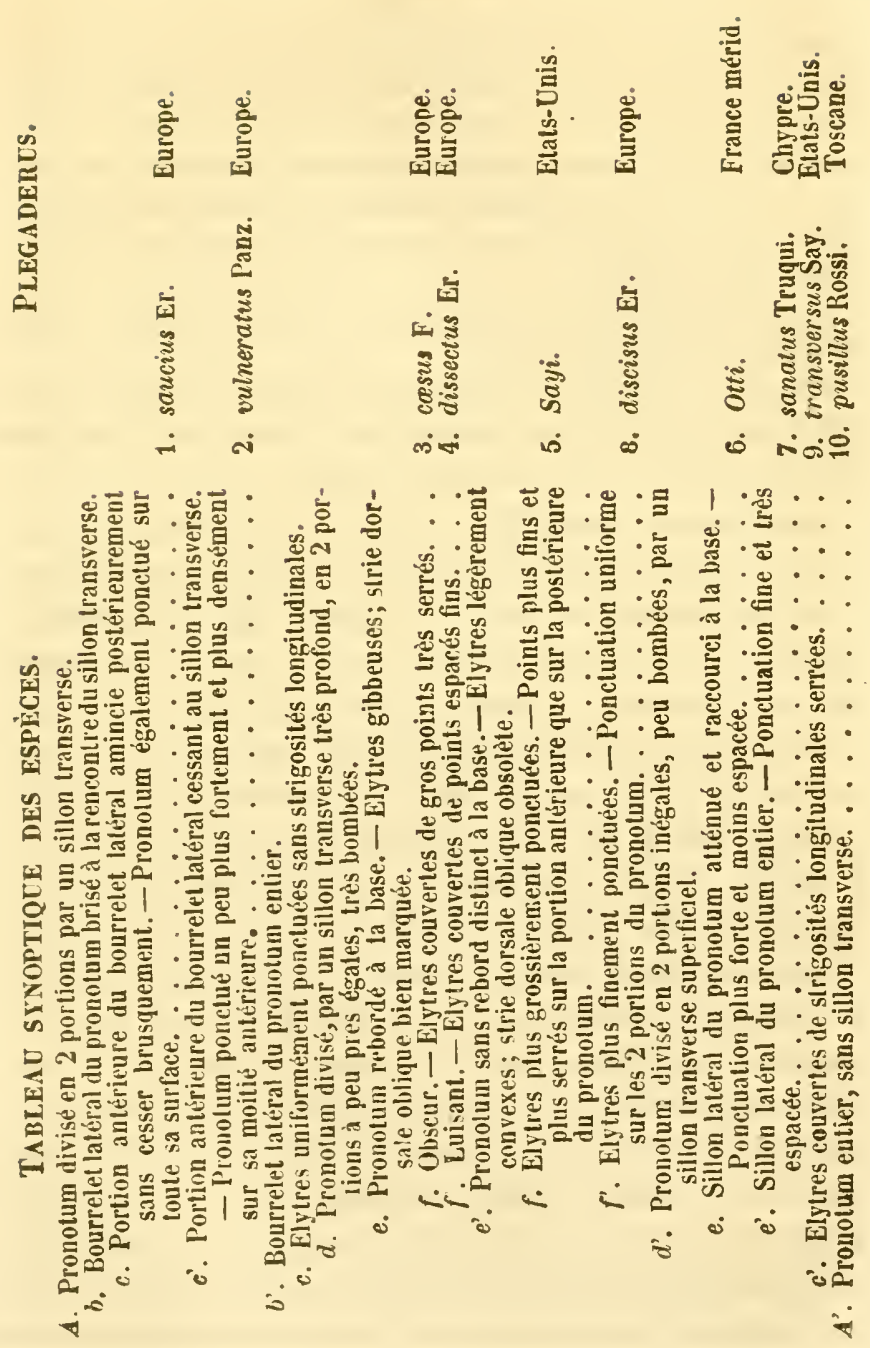


\section{i. Y. SALCIUS.}

Subcylindricus, piceus, nitilus, antennis pedibusque rufobrunneis; fronte in medio alepressa punctulata; mronoto coqualiter parce munctato, antice marginali striu, lateribus incrussatis sulco longitudinali profundo postice bifido, transversali paulo ante medium; clytris strigosis, stvia mumerali obsoleta; prosterno profumle bisulcuto, costa media vix interrupta. Long. 2 mill. ; larg. 1 mill.

II ister vulnerutus Sturn, Deutsch. fı. I, 258, 37 (1805).-Gylh. Fn. Suec. 1 , 97, 29 (1808).

Plegaulerus saucius Er. in Jahrb. 204, 2 (1S34).-Kæl. Brand $\boldsymbol{I}_{\text {, }}$ 682, 2 (1839). - Heer, Fn. Helv. I, 464, 3.-Redt. Fu. Austr. 240 (1849). - Bach, Fn. Prus. I, 313, 2 (1849).

Ovale-oblong, assez épais et un peu cylindrique; noir de poix luisant. Antennes brunes, massue ferrugineuse. Front légèrement déprimé au milieu, un peu élevé de chaque côté au-dessus des yeux; finement et densément ponctué. Pronotum beaucoup plus large que long, assez convexe et couvert de points espacés également sur toute sa surface, divisé par un sillon transversal placé un peu avant le milieu en deux portions inégales, coupé droit à la base, avec les angles aigus, un peu sinué postérieurement sur les côtés et arrondi en devant, étroitement reboudé au bord antérieur, assez fortement échancré au milieu et encadrant bien la tête avec ses angles obtus et abaissés; de chaque côté la marge est épaissie en un bourrelet entier, qui s'amincil subitement au niveau du sillon transversal; ce bourrelet est limité en dedans pa! un profond canal bifurqué au même point el enfermant entre ses branclıes un large pli triangulaire. Ecusson très petit, linéaire. Elytres plus longues que le pronotum et de sa largeur à la base, convexes et couvertes de gros points 
rugueux çà et là, relevées à la suture, saillantes à l'épaule, avec une ou deux stries obliques obsolètes, à peine rétrécies et tronquées au bout; bord infléchi avec une carène étroite dans sa moitić antérieure qui semble la continuation du bourrelet prothoracique. Pygidium assez densément et uniformément ponctué. Prosternum large, un peu rétréci au milieu, bordé de chaque côté d'une carène et d'un sillon large et profond; la partie médiane s’élargit en devant et n'est que très brièvement interrompue aux deux tiers postérieurs. llésosternum presque lisse avec un sillon au milieu et deux latéraux qui se prolongent sur le métasternum; ce dernier couvert de points faibles et espacés. Pattes grêles, d'un brun rougeâtre; jambes antérieures spatuliformes, avec quelques denticules en dehors; intermédiaires et postérieures linéaires, ciliées.

Suède; France; Suisse; Allemagne; Autriche; assez rare.

\section{P. VELNERATLS.}

Ovatus, convexus, niger nitidus, ore, antennis pedibusque rufobrunncis; fronte punctulata, ad oculos prominula; pronoto sulco transverso in 2 incequalcs partes diviso, antice fortius, poslice parcius et subtilius punctato; margine latcrali incrassato interrupto, clytris pasce et tenue punctatis; prosterno utrinque sulcato, costa media latiori versus basim interrupta, cxcavata, dense flavo holosericca. Long. 1 3/4 mill. ; larg. 1 mill.

IIister vulncratus Panz. Fu. Germ. 37, 6 (1792).- Illig. Kæf. Prus. 62, 18 (1798). - Duft. Fn. Aust. I, 229, 28 (1805). - Sturm Deutsch. Ins. I, 258, 37 (1805). - Payk. Mon. Hist. 95, 79. T. xI, f. 6 (1811).

Plegaderus vulneratus Er. Jahrb. 1, 204, 3 (1834). - Kxf. Brand. I, 682, 1 (1839). - Heer. Fn. Helv. 1, 463, 1 (1841). - Redt. Fn. Aust. 240 (1849). - Bach, Fn. Prus. I, 313, 1 (1849). 
Ovale-oblong, assez convexe, tronqué aux deux extrémités, noir de poix luisant. Antennes rouge-brun avec la massue plus claire. Front légèrement impressionné, un peu saillant de chaque côlé au devant des yeux, finement ponctué. Pronotum plus large que long, divisé en deux portions par un sillon transverse bien marqué, l’antérieure plus petite, beaucoup plus fortement et plus densément ponctuée que la postérieure; un peu arqué à la base, avec les angles aigus; sinué à peine sur les côtés; rétréci en devant, avec une large échancrure et les angles obtus, abaissés, encadrant bien la tête; bourrelet latéral paraissant entièrement interrompu au niveau du sillon transverse, et comme divisé en deux bourrelets, limités en dedans par un sillon latéral profond, l'antérieur plus court et plus étroit, le postérieur s'élargissant vers la base et bordé d'une strie en dehors. Ecusson petit. Elytres plus longues que le pronotum, de sa largeur à la base, bombées, couvertes de points assez espacés et légers; suiure élevée; épaule saillante avec une strie oblique; bord infléchi avec une carène faisant suite an bord du pronotum, disparaissant au-delà du milieu. Pygidium couvert d'une ponctuation égále et assez serrée. Prosternum subsinué sur les côtés, profondément sillonné de chaque côté, renflé au unilieu; renflement large antérieurement, interrompu par une forte excavation garnie d'une houppe de longs poils jaunes serrés qui s’étend dans la partie adjacente des sillons longitudinaux. Mésosternum échancré en devant, 3-canaliculé ainsi que le métasternum, qui est à peine visiblement pointillé. Pattes (fig. $2 a, b, c$ ) ferrugineuses; jambes intérieures élargies au bout en spatule, garnies d'épines en delıors; 4 postérieures linéaires, intermédiaires épincuses. 
Voisin dı précédent pour la forme du corps; il faut avoir égard, pour les distinguer, surtout à la ponctuation du pronotum et des élytres, à la structure du bourrelet latéral et du prosternum.

Il se rencontre sous l'écorce des arbres pourris, daus les ordures et les detritus. Il est répandu dans diverses contrées de l'Europe : Suède, Finlande, Russie. France, Suisse, Allemagne, Autriche.

\section{P. Casus.}

Subgibbosus, ovatus, piceus subopacus, antennis rufis, pedibus rufo-brunneis; fronte impressa punctatuque; pronoto dense munctulato, basi et apice unguste marginato, lateribus late incrassutis, sulco lateruli transversoque profundis, in duas partes melvinalus aquales diviso; elytris grosse el dense punctatis, sutura elevata, versus humerum breviter oblique bistriatis; prosterno carina media late interrupta, mesosterno trifoveolato. Long. 1 2/3 mill.; larg. 3/4 mill.

Hister ceesusHerbst, Natursyst. Iv, 40, 14, T. xxxvi. f. 3 (1791).F. Ent. S. 1, 77, 22 (1792). - Thunb. Ins. Suec. 65 (1794).-1llig. Kief. Pruss. I, 61, 17 (1798). - Payk. Fn. Snec. 1, 53, 22 (1798).F.S. Eleut. I, 92, 43 (1S01).-Ent. Hefte I, 114, 31 (1803). - Sturm, Deuts. fn. x, 256, 36, pl. xix, f. $c(1805)$. -Duft. Fn. Austr. I, 229, 29) (1805). - Gyll. Ins. Suec. I, 96, 28. (1S08). - Payk. Mon. Hist. 94,78, T. xI, f. 5 (1811).

Plcgaderus casus Er. Kær. Brand. I, 684, 4 (1839).-Heer, Fu. Helv. 1, 464, 3 (1841). - - Redt. Fn. Austr. 240 (1849).-Bach, Fn. Pruss. $1,313,4$ (1849).

Ovale, bombé, gibbeux sur les élytres, d'un brun plus on moins obscur. Antennes ferrugineuses. Front (fig. $3 e, f$, y, h) impressionné au milicu, fortement relevé au-dessus de l'insertion du scape, pointillé. Pronolam courl, beaucoup 
plus large que long, un peu arqué et rebordé à la base, curvilinéaire sur les côtés avec un large et fort bourrelet entier entre la strie marginale et un profond sillon latéral, rétréci et échancré en devant avec les angles assez saillants, ponctué assez densément et finement sur toute sa surface, divisé en deux partions égales, bombées, par un sillon transverse très enfoncé. Ecusson triangulaire très petit. Elytres courtes, plus longues que le pronotum, à peu près de sa largeur à la base, fort dilatées sur les côtés, rétrécies et tronquées au bout, couvertes de gros points serrés et également distribués; suture et épaules saillantes, deux courtes stries dorsales obliques. Propygidium et pygidium avec une ponctuation assez serrée. Prosternum largement et profondément interrompu; mésosternum trifovéolé. Pattes brunferrugineux; jambes antérieures spatulées, denticulées en dehors; postérieures sublinéaires, ciliées en dehors.

Suède, France, Suisse, Allemagne, Autriche.

\section{P. Dissectus.}

Ovalis, convexus, nigro-piceus, ore, antennis pedibusque ferrugineis, supra parce aqualiter punctulatus; fronte plana; pronoto utrinque profunde sulcato, margine late incrassato, sulco transverso in 2 partes aquales pulvinatas diviso; elytris pulvinatis, humero suturaque valde prominulis, 2 striis obliquis validis; prosterno profunde utrinque bisulcato, costa media excavato-interrupta, mesosterno basi 3-foveolato, metasterno fortiter el parce punctato. Long. 1 1/2 mill. ; larg. 2/3 mill.

Plegaderus dissectus Er. Kxf. Brand. I, 684, 5 (1839). - Bach, Fn. Pruss. r, 314, 5 (1849).

Ovale allongé, assez convexe; noir de poix luisant; couvert en dessus d'une ponctuation également espacée et légère. Bouche et antennes rousses, massue plus claire. Front plan. 
Pronotum plus large que long, légèrement arqué et rebordé à la base avec les angles aigus, sinué postérieurement sur les côtés et de là arrondi, rétréci et fortement échancré en devant avec les angles abaissés, très saillants et encadrant bien la tete; divisé par un sillon transverse profond en deux portions d'égale dimension, très bombèes; bourrelet latéral, large et épais, sans interruption au milieu; limité en dehors par une fine strie et en dedans par un large et profond sillon. Ecusson très petit. Elytres courtes, de la largeur du pronotum à la base, fortement bombées, à suture et épaules saillantes, très rétrécies postérieurement; sillonnées d'une strie humérale et d'une dorsale oblique forte et longue; strie marginale cessant au milieu du bord infléchi. Prosternum bordé d'une strie en devant et d'une carène de chaque côté, bicanaliculé; côte médiane renflée en devant, ponctuée, interrompue par une prolonde et large excavation. Mésosternum échancré en devant, fortement 3-fovéolé. Métasternum couvert de gros points assez espacés. Pattes ferrugineuses; jambes antérieures élargies au bout en spatule, garnies de denticules en dehors; intermédiaires denticulées et postérieures ciliées, linéaires.

Sous les écorces des troncs d'arbres pourris; France, Fontainebleau; Belgique; Allemagne.

\section{P. SAYi.}

Ovalis convexus, br ameo-piceus, nitidus, ore, antennis pedibusque fulvis, fronte improssu; pronoto in duas partes incequales sulco transverso profundo diviso, utrinque incrassato margine integro inter striam et sulcum, sat dense fortiter punctato; clytris pulvinatis sutura valde clevata, ad basim striis obliquis validis brevibus, punctis gro sis haud confluentibus. Long. 1 1/2 mill.; larg. 3/4 mill. 
Ovale allongé, assez convexe, d'un brun luisant, avec la . bouche, les antennes et les pattes ferrugineuses. Tête densément ponctuée; front avec une impression bien marquée. Pronotum plus large que long, rétréci en devant, divisé en deux portions inégales, bombées, par un profond sillon transverse, situé avant le milieu, couvertes de points assez serrés, plus gros vers la base; sans rebord basal; côtés relevés en un bourrelet épais, serré entre la strie marginale et un sillon latéral. Ecusson très petit. Elytres un peu plus longues que le pronotum, de sa largeur à la base, fortement rétrécies postérieurement, bombées sur le disque, couvertes de gros points assez serrés et confluents, à suture fortement relevée; stries rudimentaires de la base bien marquées. Pygídium densément ponctué. Prosternum bordé de chaque côtẻ d'un profond et large sillon; côte médiane arec quelques points épars, interrompue par une profonde excavation. Mésosternum et métasternum fortement et assez densément ponctués, avec trois sillons longitudinaux commençant par une fossette plus profonde. Pattes grêles, allongées. Jambes sans épines; antérieures élargies en spatule au bout; quatre postérieures linéaires.

Il diffère du P. transversus Le C. par le sillon transvorsal prothoracique plus enfoncé, les deux portions du pronotum plus convexes et plus fortement ponctuées, les élytres plus bombées, à points plus forts, moins confluents, lia suture plus relevée, et le métasternum plus grossièrement ponctué.

J’ai dédié cette espèce au célèbre entomologiste Th. Say, qui le premier a étudié les IIstérides des Etats-Unis. La collection de M. de Laferté en renferme deux exemplaires. 


\section{6. Р. OтT1.}

Oblongus, subconvexus, miger nitidus, antennis pedibusque rufis; fronte impressa punctulata; pronoto tenuiter et parce punctato, sulco levi transverso incqualiter diviso, lateribus valde incrassato, sulco longitudinali basi abbreviato; clytris munclis parcis sat validis, margine inflexo ruguloso ; prosterno pone medium rufo penicillo interrupto, mesosterno profunde trisulcato melasternoque lovibus. Long. $12 / 3$ mill.; larg. 1 mill.

Oblong, assez convexe, noir luisant. Antennes rousses. Front légèrement impressionné au milieu, relevé sur l'insertion du scape, pointillé. Pronotum moins long que large, convexe, finement et peu densément ponctué, divisé en deux portions inégales par un faible sillon transverse, un peu arqué et non rebordé à la base, presque droit sur les côtés, un peu rétréci, étroitement rebordé et échaneré en devant avec les angles fortement arrondis, bourrelet latéral très fort, entier, circonscrit par la strie marginale en delıors et par le sillon latéral en dedans ; celui-ci est profond, atténué et un peu raccourci à la base. Eeusson triangulaire très petit. Elytres une fois et demie plus longues que le pronotum, à peu près de sa largeur à la base, dilatées à l'épaule puis graduellement un peu rétrécies, tronquées au bout; suture relevée, ponctuation espacée, assez forte, égale sur toute la surface, bord infléchi rugueux. Propygidium et pygidium densément ponctués. Prosternum avec la crête médiane largement interrompue et garnie de touffes épaisses de poils jaunes. Mésosternum profondément trisillonné, lisse et imponctué comme le milieu du métasternum. Pattes rouges; jambes antérieures élargies en spatule, denticulées en delırs, postérieures ciliées étroites.

Cette jolie espèce, découverte dans le département du Var, m'a été communiquée par M. Ott, de Strasbourg, qui a bien voulu m'en sacrifier un exemplaire. 


\section{P. Sanatus.}

Oblongo-ovatus, undique parce punctulatus, nigro-piceus, subnitidus, antennis pedibusque brumeis, clava rufa; pronoto laterali margine integra inter striam marginalem et sulcum lateraiem constricta, sulco transverso obsolcto; elytris postice ciliatis, 2 striis obliquis; mesosterno impunctato, in medio bisulcato.

Plegaderns sanatus Truqui, Soc. Ent. (1852), 64, pl. 11, n. 2, f.3.

Ovale allongé, noir de poix, assez luisant, couvert en dessus de points espacés, un peu plus forts sur les élytres, d'où sortent des poils courts faciles à détruire. Antennes brunes, massue testacée. Front légèrement concave, élevé au-dessus des yeux. Pronotum un peu plus large que long, à peine arqué à la base, échancré en devant, sinué sur les côtés avec un bourrelet entier, large, resserré entre une petite strie marginale qui se continue le long du bord antérieur et un profond sillon latéral, arrondi vers l'angle antérieur; disque peu convexe, divisé en dẹx parties inégales par un faible sillon transversal. Ecusson petit, triangulaire. Elytres plus longues que le pronotum, de sa largeur à la base, arrondies sur les côtés, tronquées au bout, relevées à la suture, légèrement bombées sur leur disque, avec deux stries courtes, obliques. Prosternum bisillonné de chaque côté avec une cavité garnie d'une touffe de poils fauves; mésosternum imponctué, échancré en devant, 4-sillonné et impressionné au milieu. Pattes brunes. Jambes antérieures dilatées au bout et garnies de denticules, ainsi que les postérieures.

Chypre (M. Fairmaire).

\section{P. DISCISUS.}

Oblongo-ovatus, parum convexus, piceus, nitidus, ore, anecnnis pedibusque rufo-brumneis; pronolo cequaliter punctato, 
sulco transwerso paulo ante medium, margine value incrassato haul interrupto striam inter marginalcm et sulcum lateralcm; elytris fortius punctutis, sutura et humero clcvatis, striis obliquis 2 obsolctis; prostcrno luto profunde bicanaliculato, costa media excavalione pilifera intermuta; mesosterno metasternoque 3-sutcatis, valite munctatis. Long. 1 1/4 mill. ; larg. 2/3 mill.

Plegaderus discisus Er. Kief. Brand I, 683, 3 (1539). - Redt. Fn. Austr. 240 (18/9). - Bach, Fn. Pruss. 313, 3 (1849).

Ovale oblong, peu convexe, noir de poix luisant. Bouche et antemnes brun-ferrugineux, massue fauve; front pointillé, déprimé au milieu et anguleuscment saillant au devant des yeux. Pronotum plus large que long, couvert également sur toute sa surface de poinis espacés, à peine arqué à la base. avec les angles aigus, courbé sur les côtés et bordć d'un épais bourrelet entier, enfermé entre une strie marginale et un sillon latéral, rétréci et échancré en devant avec les angles abaissés, saillants, formant un encadrement parfait à la tête; divisé en deux portions inégales par un sillon transverse bien marqué, placé un peu avant le milieu. Ecusson très petit. Elytres un peu plus longues que le pronotum, de sa largeur à la base, un peu bombées au milieu, élevées à la sulure et à l'épaule, rétrécies et tronquées au bout, avec quelques stries obliques rudimentaires, bordées d'une strie marginale sous le bord infléchi dans leur première moitié, couvertes d'une ponctuation assez forte et assez serrée. Pygidium densément pointillé. Prosternum assez large, sinuć latéralement, profondément bi-canaliculé, côte mé. diane épaisse en devasit, interrompue par une profonde excavation, garnie d'une lıouppe de poils jaunes. Mésosternum échancré en devant, trisillomé, aiısi que le métaster- 
num, qui est couvert d'assez gros points serrés. Pattes brunes, grêles. Jambes antérieures élargies en spatule au bout et garnies en dehors de rares épines; postérieures à peine dilatées et inermes.

Le $P$. discisus se trouve dans presque toute l'Europe. II est très commun sous les écorces pendant toute l'année. surtout en hiver. Au mois de mai, lorsque le Crypturgus pusillus établit ses galeries, la femelle vient y déposer ses œufs, qui éclosent au scin de la famille du xylophage; sa larve s'y nourrit des larves et des nymphes de son hôte, s'y développe rapidement et se métamorphose dans une coque formée des débris. La durée de son existence parait être d'environ 5 mois, et l'insecte parfait éclot en septembre ou octobre.

Mon savant ami, M. Edouard Perris, vient de publier les mœurs et le développement de cette espèce. Je ne puis mieux faire que de reproduire la description et la figure qu'il donne de la larve et de la nymphe. Cet observateur judicieux sait joindre la clarté à l'exactitude scrupuleuse des détails :

LARVE (fig. $8 \mathrm{j}$ ).

Long. 3 millim.; larg. 1/2 millim.

Un peu aplatic, charnue, linéaire.

Tete plate, ferrugineuse, cornée, luisante et en carré long, ayant quelques poils sur les côtés, longitudinalement concave en dessus et marquée de quatre sillons dont les deux intermédiaires longs et les deux autres courts; bord antérieur un peu prolongé au milieu et dentelé. Mandibules 
(fig. 8 i) ferrugineuses, semblables à celles de la larve du Platysoma oblongam avec la dent interne plus forte et arrondie en dessus et quelques soies au bord externe. Machoires (fig. $8 n$ ) très longues, cylindro-coniques; de deux articles dont le premier présente intérieurement, près de la base, une échanerure et au-dessous une sorte de talon surmonté de longues soies, et le deuxième, plus étroit à la base qu'i l'extrémité, porte un lobe papilliforme terminé par un poil. Palpes maxillaires droits, de quatre articles, dont le premier plus court que les autres qui sont égaux; le dernier grêle et surmonté d'un poil. Lèvre (fig. $8 l$ ) un peu arrondie à l'ex. trémité, plus large à la base, à côtés sinueux. Palpes labiaux droits de trois articles, premier très court, les deux autres égaux, surmontés de petits poils. Antennes (fig. $8 \mathrm{~m}$ ) semblables à celles de la larve du Platysoma, sauf que le deuxième article est presque droit en dedans et un peu renflé en dehors et que l'article supplémentaire est un peu plus grand. Tous ces organes sont roussâtres, avec l'extrémitć des antennes plus claire. Yeux nuls ou non apparents.

Prothorax moins arrondi que dans les larves précédentes, roussâtre surtout antérieurement; les deux autres segments du thorax plus courts et d'un blanc un peu livide.

Pattes comme ci-dessus, sauf que la cuisse ne paraît avoir qu'une soie en dessus, sans aucun cil en dessous, et que le tibia est dépourvu de soies.

Abdomen d'un blanc un peu livide, de neuf segments, dont les huit premiers à peu près égaux, revêtus latéralement et en-dessous de poils longs el mous, entremêlés de poils courts et raides, ayant de chaque côté un bourrelet et sur le dos des plis transversaux comme les larves précédentes; neuvième segment velu, déclive postérieurement, 
pourvu, ì la naissance de la déclivité, de deux appendices subconiques, ob'us, divergents, biarticulés, hérissés de longss poils. En dessous un mamelon pseudopode rétractile. Tout l'abdomen est recouvert de petites spinules droites, très rapprochées, visibles seulement à un fort grossissement.

Stigmates comme dans les larves de la même famille.

Elle ressemble à s'y méprendre à celle du Platysoma, dont elle diffère cependant par quelques caractères importants : le nombre des articles des palpes plus élevé d'une unité que dans celle-ci; la forme raccourcie et conique des appendices du dernier segment; enfin le développement du mamelon anal.

NYMPHE (lig. $8 k$ ).

Blanche, ovoïde, déprimée; vertex, bords et face dorsale du prothorax et côtés des segments de l'abdomen munis de petites soies roussâtres; des soies beaucoup plus courtes sur le dos des mêmes segments ; dernier segment terminé par 2 papilles qui servent à la nymphe à s'attacher à la peau de la larve agglomérée à l'extrémité du corps, ou, quand la dépouille a été tout à fait refoulée, à se retourner dans sa cellule en s'appuyant sur le plan de position. Ces papilles sont en forme de crochets convergents, et leur moilié postérieure est roussatre et sétiforme. Sternum découvert comme dans la nymphe du Platysoma, à cause de la brièveté des pattes; vu au microscope, tout le corps paraît couvert de spinules extrêmement petites et très serrées. 


\section{P. Transversus.}

Oblongo-ovalus, convexiusculus, nigro-piceus, nitidus, ore clavaque rufis, pedibus antennisque brunneis; pronoto transverse incequaliter divisus, parce aciculato-punctato, margine crasso inter striam sulcumque profundum; elytris sutura humeroque subelevatis, striis obsoletis obliquis, punctis grossis dense strigosis; prosterno bicanaliculato, costa media lata excavatione flavo fasciculata interrnpta; mesosterno trisulcato, metasterno sparse punctato. Long. 1 1/4 mill. ; larg. 2/3 mill.

Hister transversus Say in Acad. Philad. v, 45, 20 (1825).

Plegaderus transversus Le Conte, N. Amér. Mon. Hist. 50, 1, T. vI, f. 7 (1845).

Ovale oblong, assez convexe, noir de poix, luisant. Bouche roussâtre. Antennes brunes, massue ferrugineuse. Front impressionné au milieu, anguleusement saillant au devant des yeux, parcimonieusement et faiblement ponctué. Pronotum beaucoup plus large que long, arqué et sans rebord à la base, avec les angles aigus, à peine courbé sur les côtés, avec la marge formant un large et épais bourrelet, entier, resserré entre une strie marginale et un sillon latéral profond, largement échancré, rétréci et étroitement rebordé en devant avec les angles saillants, abaissés, encadrant étroitement la tête; divisé en deux portions inégales par un sillon transverse profond, placé un peu avant le milieu; couvert de points aciculés peu serrés. Ecusson très petit. Elytres courtes, de la largeur du pronotum à la base, dilatées à l'épaule, curvilinéaires sur les côtés, rétrécies et tronquées au bout; suture ún peu élevée; bord infléchi rugueux avec une strie marginale disparaissant vers le milieu; ponctuation serrée, grosse, aciculaire, confluente. Pygidium et propygidium assez fortement et assez densément ponctués. Prosternum large, rebordé sur les côtés, et bicanaliculé; partic médiane élargie en devant avec quel- 
ques points, interrompue par une profonde excavation garnie d'une houppe de poils jaunes brillants. Mésosternum échancré en devant, trisillonné et rarement ponctué ainsi que le métasternum. Pattes brunes; jambes denticulées en dehors et ciliées; antérieures élargies au bout en spatule; postérieures linéaires.

Etats-Unis.

\section{P. PUSilles.}

Oblongo-ovatus, convexiusculus, piceus, nitidus, supra grossis piliferis punctis tectus, ore, antennis pedibusque rufis; pronoto basi marginato, lateribus valde incrassatis, stria sulcoque laterati, transversali nullo; elytris sutura subelevatu, striis 2 obliquis; prosterno lato parallelo, punctato, houd cxcavato, bisulcalo; mesosterno antice emarginalo metusternoque 3-sulcatis fortiter punctatis; tibiis anticis abrupte spatkulatis. Long. 1 m.; larg. 1/2 mill.

IIister pusillus Rossi, Nant. Ins. I, 15, 26 (1792). - Payk. Mon. Hist. 96, 80, T. xı, 4 (1811).

II. ceesus, var. Payk. Fn. Suec, 1. 53, 22 (1798).

Plegaderus pusillus Er. in Jahrb. I, 204, 4 (1834). - ? Le Ca N. Amér. Mon. Hist. 50, 2, T. vi, f. 8 (1845).

Ovale oblong, médiocrement convexe, d'un brun de poix luisant, couvert en dessus, sur toute sa surface, de gros points pilifères assez rapprochés. Bouche et antennes rousses, massue plus claire. Front déprimé au milieu, relevé angulairement au devant des yeux. Pronotum beaucoup plus large que long, bombé, coupé droit et rebordé à la base, avec les angles bien marqués, légèrement arqué sur les côtés avec un épais bourrelet entre une strie marginale et un profond sillon latéral, échancré en devant avec les angles avancés et abaissés, encadrant étroitement la tête. Pas de sillon transversal. Ecusson très petit. Elytres beau- 
coup plus longues que le pronotum, de sa largeur à la base, dilatées à l'épaule, fortement rétrécies et tronquées au bout; suture relevée; deux strics obliques bien marquées, la dorsale assez longue. Prosternum large, parallèle, rebordé latéralement avec deux sillons longitudinaux profonds; intervalle large, ponctué, peu saillant, sans rétrécissement ni excavation profonde. Mésosternum échancré en devant, tricanaliculé et ponctué, ainsi que le métasteruum. Pattes ferrugineuses, tarses roussâtres; jambes antérieures terminées par une spatule abrupte, garnies de denticules; postérieures grêles, épineuses et ciliées.

Sardaigne, Toscane.

\section{GLYMMA.}

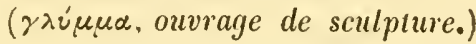

Soc. Ent. 3e série, tome IV (1856), pl. 11. - Mor. pl. xxı, Genre XXXIX.

Corpus ovatum, ferrugineum, nitidum.

Caput valde retractum, fronte transversa, utrinque angulata, margine elevalo, a clypeo distincta; antemis in margine ante oculos insertis, clava orbiculari, fossa antennali in prothoracis angulo excisa.

Prostermum bistrialum, basi sinuatum, lobo antico latissimo prominente; mesosternum utrinque foveolatum.

Pronotum transversum, costatum; clylra pronoto arcte junctu costis setosis, intervallis biseriatim punctatis.

Propygidium breve, transicrsum detectum ; pygidium semicirculare, prorsus inflexum; segmento primo ventrali transversim multifoveolato.

Pelles tenues; tibiis sublinearibus, utrinque ciliatis; anticis extus denticulatis; tarsorum 5 articulis subcqualibus, ultimo biungulato. 
Corps (fig. 1, 1 a) ovale oblong, peu convexe, plus élargi par devant, rouge-ferrugineux luisant.

Tète fortement enfoncée dans le prothorax; front transverse, en demi-cercle, avec un angle de chaque côté, bordé dans son pourtour d'une carène très élevée, arquée par derrière, en zigzag par devant, envoyant de claque côté un prolongement sur l'épistome et se repliant au milieu jusqu'à l'arc postérieur, de manière à diviser le front symétriquement; épistome transverse, légèrement rebordé; labre court. Yeux ovalaires, déprimés, cachés par le rebord latéral du front et invisibles en dessus.

Antennes (fig. 16 ) insérées en devant, dans un pli du bourrelet frontal, entre l'angle et l'origine des mandibules, au-dessus des yeux; scape long et robuste, obconiqne; premier article du funicule court, globuleux; les six autres beaucoup plus petits, serrés; massue arrondie, 4-articulée, pubescente, avec quelques granils cils autour de chaque article; elle va se loger dans une petite fossette peu profonde, creusée daus l'angle antérieur même du prothorax; la coulisse par laquelle elle pénètre est taillée si obliquement que le bord pectoral paraît entier en devant.

Mandibules rétractiles courbées en pointe aiguë. Máchoires insérées en dehors du menton, cornées, bilobées; palpes maxillaires (fig. $\mathbf{t} c$ ) de quatre artieles : premier très petit; deuxième ovale allongé, renflé au bout; troisième court, obconique; quatrième aussi long que le premier, atténué à l'extrémité. Menton arrondi en devant. Palpes labiaux (fig. $1 d$ ) de trois articles, premier très petit, deuxième et troisième à peu près égaux.

Pronotum court, transverse, droit sur les côtés, légèrement arqué à la base, subsinué en devant avec les angles 
tronqués, rebordé dans son pourtour et sillonné de côtes longitudinales. Ecusson à peine visible. Elytres fortement serrées contre la base du pronotum, un peu plus larges que lui, subparallèles dans leur première moitié, curvilinéairement rétrécies postérieurement, et tronquées au bout, avec la suture et des côtes longitudinales garnies de soies courtes, séparées par une double rangée de points; bord infléchi, étroit, faiblement sillonné dans sa longueur.

Prosternum (fig. 1 a) assez large, bistrié et rebordé latéralement, sinué à la base ; mentonnière longue, fortement avancée sur la bouche, occupant tout le bord pectoral antérieur; on remarque à sa base de chaque côté du prosternum, une série de fossettes irrégulièrement quadrangulaires. Mésosternum court, bisinué et rebordé en devant, avec une profonde impression de chaque còté; métasternum long, sillonné et fortement impressionné au milieu.

Pattes assez grêles; jambes (fig. 1 e) antérieures un peu élargies, arquées et terminées par un crochet, garnies de cils et en dehors de denticules espacés, sans fossette tarsale bien accusée; intermédiaires et postérieures (fig. $1 f$ ) un peu dilatées au bout, garnies de cils des deux côtés, et en dehors de quelques soies plus fortes. Tarses libres de cinq articles, coniques, à peu près égaux, garnis au bout de deux assez longues soies, le dernier un peu plus fort garni de deux crochets.

Abdomen de cinq anneaux courts, serrés; premier segment ventral avec une série transversale de fovéoles profondes, bordé au bout d'une rangée de points ainsi que les quatre autres. Propygidium court, transversal, découvert. Pygidium en demi-cercle entièrement rabattu, avec une bosse au milieu. 
Ce genre curieux est établi sur une petite espèce, découverte à Liége (Belgique), dans une couche à melons, par M. le $\mathrm{d}^{\mathbf{r}}$ Candèze. J'en dois la connaissance à M. Boïeldeu, qui a eu l'amabilité de m'en donner un individu. Je ne sais rien de ses mœurs, encore moins de ses métamorphoses; mais il y a lieu de croire qu'elles se rapprochent beaucoup de celles des Plegaderus, dont il est très voisin. Il vient naturellement se placer entre ce genre et les Onihophilus. Il joint à la forme du premier, les côtes et plusieurs caractères des seconds, tels que la disposition des jambes antérieures, celle du pygidium et du propygidium et l'articulation du prosternum avec le mésosternum; mais il n'a pas la forme arrondie de ce dernier, et il est très distinct de tous deux par sa large et longue mentonnière et par la position de la fossette antennaire.

\section{G. CandeziI.}

Ovalis, ferrugineus; fronte utrinque angulata, carina mu:ginali postice arcuata, antice 3-angulata et totidem appendiculata; pronoto transverso, longitudinalibus costis 6 , parce setosis, interstitiis profundis lavibus; elytris sutura, margine externo 3-que costis setosis, interstitiis bi-seriatim punctatis; prosterno bistriato, basi sinuato, lobo latissimo, mesosterno utrinque, metasterno in medio, $1^{\circ}$ ventris segmento seriatim impressis. Long. $11 / 2$ mill. ; larg. 2/3 mill.

Ovale, oblong, ferrugineux, assez luisant, bouche plus claire. Tête profondément enfoncée dans le prothorax à l'état de repos: front transverse, fortement anguleux de chaque côté derrière les antennes; rebordé entièrement d'un bourrelet tranchant, arqué postérieurement, en zigzag antéricurement, et formant trois plis et par conséquent trois 
angles, deux antérieurs de chacun desquels part un appendice qui s'avance sur l'épistome, et un postérieur émettant un autre appendice qui va rejoindre le bord postérieur et divise le front en deux portions égales. Epistome bien distinct, transverse, avec le bord relevé. Pronotum beaucoup plus large que long, peu convexe en dessus, arqué faiblement et bordé de points à la base, presque droit sur les côtés, sinué en devant avec les angles écornés; marge et six cotes longitudinales parallèles garnies de courtes soies, séparées par de larges et profonds sillons. Ecusson très petit, à peine visible. Elytres étroitement appliquées contre la base du pronotum, à peine plus larges que lui, presque parallèles dans leur première moitié, curvilinéaires et rétrécies postérieurement, avec l'extrémité tronquée; parcourues dans toute leur longueur par trois côtes tranchantes, garnies de soies courtes; suture et bord externe relevés; intervalles larges, bisérialement ponctués; bord infléchi sillonné. Prosternum assez large, bistrié, sinué à la base ; mentonnière très large et très avancée, limitée sur les côtés de la poitrine par un collier de fossettes subquadrangulaires, irrégulières. Mésosternum court, rebordé en devant, profondément impressionné de chaque côté entre les hanches. Métasternum avec une strie longitudinale médiane, au fond d'une forte impression. Propygidium court, transverse, relevé et tronqué au bout; pygidium en demi-cercle, avec une élévation au milieu. Pattes grèles; jambes ciliées, antérieures garnies de denticules espacés.

Belgique, Liége; dans les couches à melons.

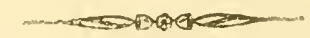


, 


\section{ESSAI MONOGRAPHIQUE SUR LA FAMILLE DES HISTERIDES.}

(Suite) (1).

Par M. S.-A. de MARSEUL.

(Séance du 9 Février 1853.)

Xle Genre, Oxthophuls.

(o\% \%os, fumier; фìos, ami).

Soc. Ent. $3^{\text {e }}$ série, T. 4 (1856), pl. xı. - Mon. pl. xxıI, Genre XL.

Hisler F. Ol Rossi, Herbst, Illig. Duft. Sturm.

Onthophilus Leach, Zool. Miscel, II, p. 76 (1817).-Erichson, in Jahrb., 204, $\mathbf{x x ~ ( 1 8 3 4 ) . ~ - ~ K a e f . ~ B r a n d . ~ 1 , ~} 680$ (1839). - Heer Fn. Helv. I, 463, viı (1841). - Le C. N. Amer. Hist. 50 (1845). - Redt. Fu. Aust. 239 (1849).-Bach, Fn. Prus. I, 312 (1849).

Corpus subglobosum, supra depressum. Capul parvum retractum.

Intenna: in fromle ante oculos inserlae, scapo crasso, funiculo arliculo 10 crasso 20 que longioribus, clava ovali; fossa antemali sublus pone angulum anticum rotunda profunde exarala.

Pronotum Iransversum costatum; elytra planiuscula multicarinalu, apice truncata; stulcllum minutum triangulare.

Prosternum latum, basi simnatum, antice lobo brevissino ; mesosternum bisinuatum transversum.

(1) Voyez $3^{\text {e }}$ Série, T. I (1853), p. 131 et 41'17; T. II (1854), p. 161,525 et $671 ;$ T. III $(1855)$, p. 83 et 327 , et T. IV (1S56). p. 97 et 259 . 
Propygidium trape semiovatum reflexum.

Pedes clongati, gracilcs, tibiis lincaribus anticis extus denticulatis, sulco tarsali distincto, posticis ciliatis; tarsis 5-articulatis, posterioribus liberis, articulo 10 longiore, 2-4 requalibus, hoc dimidio minoribus, 50 magno biungulato.

Corps globuleux, peu convexe en dessus.

Tête petite, peu enfoncée dans le prothorax; front excavé au milieu, fortement relevé en crête au-dessus des yeux, sans strie transverse ; épistome bombé, distinct; labre court, arrondi au bout; mandibules courtes, terminées par une pointe courbée aiguë, munie en dedans d'une petite dent. Yeux placés sur les côtés, en ovale allongé.

Antennes (fig. $1 d$ ) insérées sur le front au devant des yeux ; scape dilaté au bout, comprimé, courbé; funicule allongé de 7 articles, premier obconique, épais, plus long que le deuxième; ‘elui-ci étroit, aussi long que les deux suivants réunis; les autres deviennent successivement plus courts et plus larges; massue de quatre articles, en ovale terminé en pointe, un peu comprimée. Fossettes antennaires (fig. 1 a) profondes, arrondies, sous l'angle antérieur du prothorax, libres au dessus du bord pectoral qui est cntaillé obliquement pour le passage de l'antenne.

Jâchoires (fig. I $c$ ) cornées, à deux lobes membraneux, barlus en dedans, l’interne plus étroit et plus court, l'externe beaucoup plus long et plus large. Palpes maxillaires allongís, grêles: de quatre articles; premier petit obconique: deuxième assez long, renflé au bout, courbé; troisième court; fuatrième trois fois plus long, subcylindrique, obtus au bout. Menton (fig. $1 b$ ) corné, large et court, presque droil en devant; languette échancrée, paraglosses mem- 
braneuses, arrondies, garnies de poils. Palpes labiaux de trois articles: premier obconique, deuxième court, troisième un peu plus long, ovalaire.

Pronotum court, bisinué à la base, fortement rétréci et échancré en devant avee les angles arrondis, couvert de côtes. Ecusson petit, triangulaire. Elytres larges à la base, peu convexes, arrondiessur les côtés, rétrécies postérieurement, couvertes de cỏtes longitudinales plus ou moins élevées. Prosternum assez saillant, court, large, bistrié, sinué à la base, coupé droit en devant avec un rebord en forme de lobe très court. Mésosternum court, transverse, bisinué en devant; bien distinct du métasternum.

Pattes allongées, grèles, assez distantes à leur insertion, les postérieures un peu plus. Cuisses à peine renflées, avec une coulisse pour logrer les jambes. Jambes cylindriques grêles, garnies de cils en dedans et en dehors d'un rang de petites épines; au bout, de deux courtes épines; antérieures (fig. 1 c) creusées d'une coulisse pour loger le tarse. Tarses grêles, allongés, libres dans le repos, excepté les an. térieurs, de einq articles triangulaires; premier plus long que les trois autres; cinquième égal au premier et armé de deux crochets.

Abdomen de cinq anneaux; premier segment ventral assez long, bistrié; quatre suivants très serrés. Propygidium hexagonal, presque perpendiculaire; pygidium en demi ovale, entièrement retourné.

Ce genre, établi par Leach dans le Zoological Miscellany en $181 \%$, a été adopté généralement par tous les auteurs qui en ont parlé depuis. Il a un faciès si remarquable et des allures tellement à lui, qu'il ne pent être confondu avec 
aucun autre. Ses principaux caractères, en outre de la sculpture du prothorax et des élytres, consistent dans l'insertion des antennes sur le front, la fossette antennaire profonde et arrondie, creusée presque au bord pectoral externe un peu au-delá de l'angle antérieur, le prosternum, large, sinué à la base et muni en avant d'une très courte mentonnière, le pygidium long et retroussé, les jambes grêles et les tarses allongés.

Il se compose de petites espèces d'un noir profond luisant, qui vivent dans les bouses et dans les matières en décomposition. Sur sept espèces que j’ai vues, quatre sont européennes, deux des Etats-Unis, un seul est originaire du Sénégal, encore ce dernier a-t-il un faciès un peu différent des autres espèces. Les premiers états sont inconnus. 

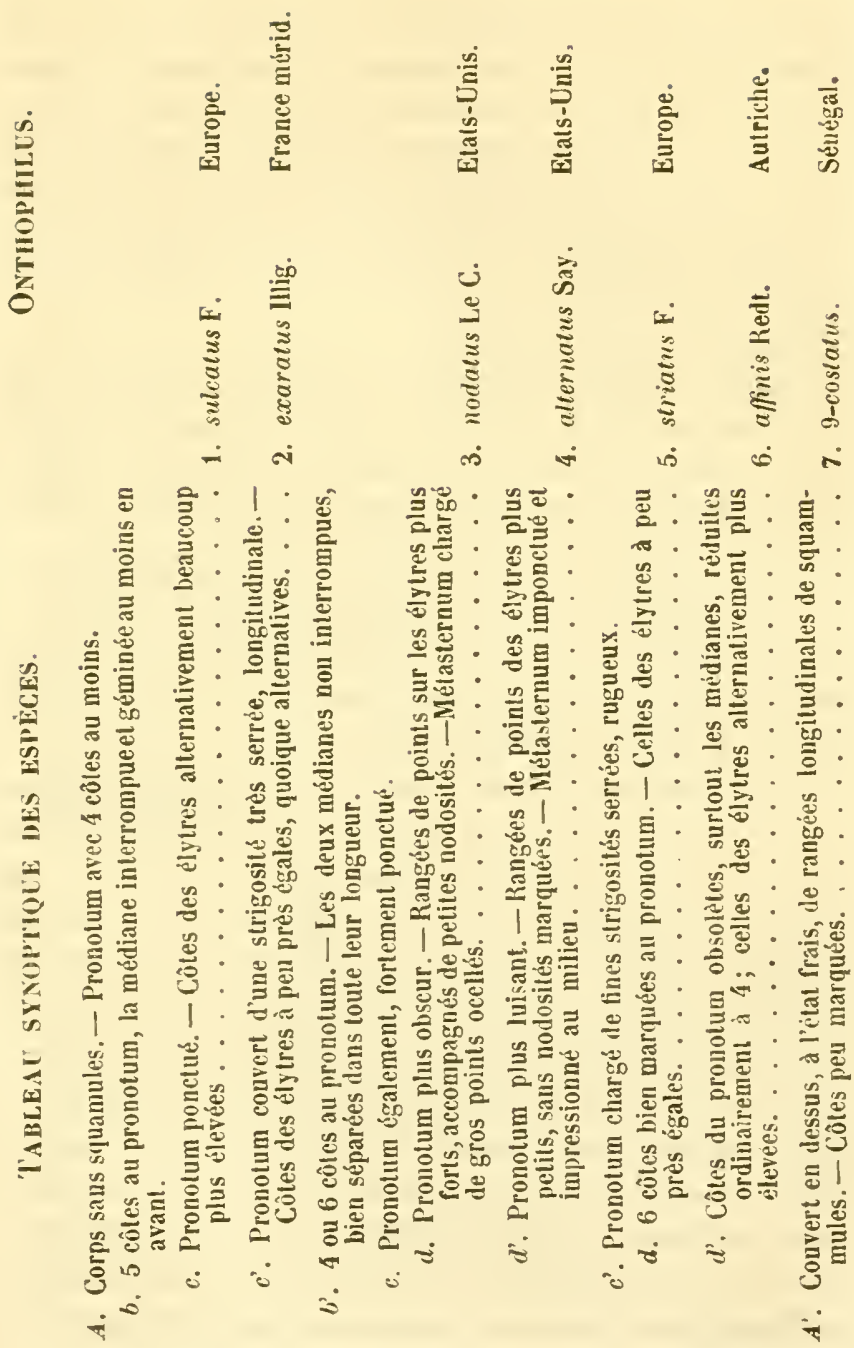


\section{O. SULCATLS.}

Ovatus, supra depressiusculus, niger nitidus, antennis pedibusque brunneis; fronte valule supra clypeum elevata; pronoto punctuto, margine laterali elevato costisque 5 longitudinatibus, intermedia intermupta et autice gemina; elytris margine laterali, sutura et 3 carinis validis, intervallis 5-carinulutis et biseriatim crenatis; mropygidio obsolete trituberculato, pygidio circum foveolato, punctulato, metasterno grosse occllato-punctato. Long. 3 1/2 mill.; larg. 2 1/2 mill.

IIister sulcatus F. Ent. Syst. I, 74, 12 (1792). - Syst. El. I, 89, 31 (1801). - Panz. Faun. Germ. S0, 5 (1792). - Ent. Germ. I, 21, 10. - Illig. Kixf. Pruss. 1, 51, 1 (1798). - Creutz. Eut. Verzeitn. 82, 1 (1799). - Fint. Hefte, I, 116, 32 (1803). -Dufts. Fu. Aust. 1, 234, 36 (1805). - Sturni, Deuts. Faun. I, 260, 38 (I805). - Payk. Mon. Hister. 99, 83, t. x, 8 (1811).

H. globulosus Ol. Ent. I, g. S, 16, 19, pl. IJ, lig. 15 (17S9).

II. striatus Herbst, Nat. Syst. IV, 38, 12, t. xxxvi, f 1 (1791).

Onthophilus sulcutus Er. Faum. Braud. 1, 6\$0, 1 (1839).-Steph. Illust. Brit. Eut. JII, 143, 2 (1830). - Redt. Faun. Aust. 259 (1849). - Bacli, Faun. Pruss. 1, 3̋12, 1 (1849).

Ovale, suldéprimé en dessus, noir luisant. Antennes brunes. Front formant en arant une carene transversale, concave, relevé fortement de chaque côté à l'insertion des antennes, brusquement séparé de l'épistome, vertex un peu déprimé, ponctué, avec un très petit tubercule au milicu. Prountum court, élargi postéricurement, avec la base en augle obtus, faiblement arqué sur les còtés avec le bord relevé, très rétréci et échancré en devant avec les angles obfus et médiocrement avancés ; couvert sur toute ln surface de gros points également espacés, chargé de cinq còtes longitudinales sinueuses, n’atteignant pas tout à fait le bord antérieur, exterues plus courtes. intermédiaire moins marquée, sillonnée postérieurement; interrompue au milieu, géıninée 
en devant. Ecusson petit, triangulaire. Elytres au moins deux fois plus longues que le pronotum, plus larges à la base; épaules saillantes, se rétrécissant gradnellement jusqu'au bout, oủ elles sont très étroites et tronquées; sillonnées dans toute leur longueur, de nombreuses carènes très serrées entre la suture et le bord externe qui sont élevés; entre ces carènes, il y en a trois beaucoup plus fortes, alternant avec celles du pronotum, l'intermédiàire un peu enfoncée au tiers antérieur; l'intervalle qui les sépare, présente cinq carinules très minces, crénelées par une rangée de points enfoncés, excepté l'intermédiaire qui est entière et à peine plus sailante; on remarque avant l'extrémité des élytres une dépression transverse; bord infléchi bisillonné et rugueusement ponctué. Propygidium ponctué avec trois tubercules obsolètes. Pygidium densément pointillé et entouré de légères fovéoles. Prosternum ponctué, sans strie marginale, métasternum avec de gros points ocellés; pattes brunes.

Angleterre, France, Allemagne, Autriche, Espagne, Italie, Algérie.

\section{O. EXARATUS.}

Ovalis, supra depressiusculus, niger, subopacus, antennis pedibusque piccis; fronte rugoso-punctatu, supra oculos et in medio biluberculata; monolo dcnse strigoso, margine roflexo, 5̆-costulato, intermedia gemina, interrupta, cateris plas minusve abbreviatis; elytris sutura humeroque elevatis, costis 6 alternatim paulo clevatioribus, inlervallis bi-crenato-carinulatis, margine inflexo rugoso-punclato sulcalo; pygidio incequali, prosterno gibbo. Long. 2 1/3̈-3 1/3 mill.; larg. 2 mill.

llister exarutus Illig. Mag. VI, 4S, 25 (1807).

Ovale, légèrement déprimé en dcssus, ıoir, presque opa- 
que. Antennes brun de poix. Tête rugueusement et densément ponctuée; front relevé au dessus de l'insertion des antennes, terminé en devant par un bourrelet triangulaire et non séparé de l'épistome par un enfoncement transverse profond, un tubercule entre les yeux et un autre plus petit derrière. Pronotum beaucoup plus large que long, saillant à la base en angle obtus sur l'écusson, arqué sur les côtés avec un faible rebord, très rétréci, échancré en devant avec les angles assez marqués, couvert d'un réseau de petits points aciculaires allongés, ou de strigosités serrées, et sillonné de cinq côtes longitudinales faibles, raccourcies, les externes encore plus faibles et très courtes, celle du milieu, interrompue et géminée. Ecusson triangulaire petit. Elytres deux fois et demie plus longues que le pronotum, plus larges à la base, légèrement cuvilinéaires sur les côtés, avec l'épaule saillante, le bord infléchi rugueusement ponetué et parcouru par un sillon ponctué, rétrécies et tronquées au bout, avec une faible dépression transversale un peu avant; suture élevée, six côtes longitudinales faibles, inégales dans leur parcours, alternativement un peu plus élevées, intervalles avec deux petites carinules crénelées. I'ropygidium densément rugueux, obtusément tritubercu. leux. Pygidium bosselé et rugueux. Dessous entièrement rugueux. Prosternum gibłeux en devant, mentonnière séparée par un profond enfoncement. Pattes noires de poix; jambes grêles denticulćes et ciliées en dehors; tarses ferrugineux.

France méridionale (Marseille); Portugal.

3. O. NODATIS.

Sub-orbicularis, supra gibbosus, niger sub-opacus, antemis 
pedibusque brunneo-ferrugineis; fronte variolosa triangulariler carinala; monoto parum dense grosse panctato, margine laterali valde arcuato clevato, costis 6 validis, extornis tantum abbreviatis; clytris suturu, laterali murgine, costisque 6 alternatim valde elevatioribus, intervallis bicarinulatis, biseriatim gross munctatis nodulosisque; mopygidio grosse punctuto tritubcrculuto; pygidio sculpto; meso-et metusterno occltulo-punctatis. Long. 2 1/2 mill. ; larg. $13 / 4$ mill.

Onthophilus nodutus Le Conte, N. Amér. Hist. Plil. Soc. V. ๖3, $3(1845)$.

Arrondi, gibbeux en dessus, noir, opaque, un peu luisant sur le pronotum. Antennes bruues. Tête variolée; front élevé au-dessus de l'insertion des antennes, terminé en devant par une carène mince, anguleuse et non séparé abruptement de l'épistome, avec une courte et faible carène médiane. Pronotum beaucoup plus large que long, avancé en angle obtus au milieu de la base, arqué et fortement rebordé sur les côtés, très rétréci et échancré en devant avec les angles obtus ; couvert d'assez gros points espacés, avec six côtes très saillantes, minces, quatre intermédiaires un peu sinuées, également distantes, eutières, externes plus rapprochées du bord et raccourcies en devant. Ecusson petit, triangulaire. Elytres deux fois plus longues et beaucoup plus larges que le pronotum à la base, dilatées à l'épaule, curvilinéaires sur les côtés, fortement rétrécies et tronquées au bout, avec une impression transverse subapicale. Suture et bord latéral élevé, avec le bord infléchi rugueuscment ponc. tué, parcouru par un sillon profond ponctué, limité en dehors par une carène sinueuse (1); six carènes longitudinales

(1) J'ai toujours considéré le repli latéral ou hord infléchi comme limité en haut par le rebord saillant qui semble faire suite au bord latéral du pronotum; alors le sillon ponctué et la carèue qui lui sert 
alternativement beaucoup plus saillantes, intervalle rempli par deux petites carinules, séparées par une série de gros poiuts qui s'avancent sur elles et les entaillent. Propygidium grossièrement ponctué tricaréné. Pygidium ponctué également et présentant une petite carène longitudinale interrompue et une espèce de W en relief. Prosternum séparé de la mentonnière par un profond enfoncement transversal, couvert de gros poiuls, mesosternum, metasternum et premier segment ventral, avec des poiuts ocellés encore plus forts et plus espacés. Pattes grêles, brun ferrugineux obscur; jambes ciliées et munies de quelques spinules en dehors.

Etats-Unis, Géorgie.

\section{O. A:TERATtS.}

Suborbicularis, supra gibbosus, niger nitidus, antennis pedibusque ferrugineo-piceis: cupite punctato, fronte triangular iter cavinata, tuberculo minuto medio; pronoto punctis oblongis, margine arcuato tenui reflexo, costisque 6 ; clytris basi apiceque transversim impressis, 3 carinis elevalis, intervalis 5 carinulis, incermedia integra, caleris serie punctorum bina dissectis, murgine inflexo curinato sulcutopuc; propygidio 3̈-curinato, pyyidioque trunsver:so circumflexo elevato sculpto punctutis; mosterno mesosternoque parce punctatis, met isterno medio foveolato punctulato. Long. 2 1/2 mill.; larg. 1 2/3 mill.

Hister alternatus Say in Soc. Philad. V, I, 46, 21 (1S25).

Onthophilus allernatus Le Conte, N. Amér. Hister. Bon. 52, 2, pl. vı, fig. 9 (1845).

Arrondi, gibbeux en dessus, noir foncé, luisant. Anten-

de limite en fait partie; on pourrait également bien regarler celte carène comme la limite de la face supéricure des élyıres, alors le bord intléchi serait simple et uni. 
nes brun ferrugineux sombre. Tête fortement ponctuée, front non brusquement séparé de l'épistome, élevé sur l'insertion des antennes, terminé en devant par un bourrelet triangulaire, impressionné au milieu avec un très petit tubereule. Pronolum court, large, obtusément anguleux au milieu de la base, arqué et rebordé sur les côtés, très rétréci et échancré en devant avec les angles obtus; couvert de points allongés, inégalement espacés, assez grands, quatre côtes assez fortes entières, un peu raccourcies et plus distantes entre elles à la base, et de chaque coté une autre plus courte, plus oblique et plus rapprochée du bordque de la côte intermédiaire. Ecusson triangulaire petit. Elytres deux fois plus longues et plus larges que le pronotum à la base, bombées au milieu et impressionnées transversalement ì la base et à l'extrémité, très dilatées à l'épaule, de là graduellement rétrécies sur ies côtés, avec le bord infléchi sillonné sinueusement d'un canal ponctué et bordé d'une petite carène en bas; rétrécies et tronquées au bout, suture et bord latéral un peu élevés; trois côtes très saillantes parallèles, égales, séparées par des intervalles remplis de cinq carinules fines, l'intermédiaire continue, les quatre autres décomposées par deux séries de gros points placés entre elles et empiétant sur elles. Propygidiun assez densément ponctué et tricaréné. Pygidium couvert d'une ponctuation régulière assez forte et chargé à la base d'un circonflexe en relief. Prosternum faiblement séparé de la mentonnière, avec des points espacés. Métasternum fovéolé au milieu finement pointillé et entouré de quelques gros points épars. Pattes grèles, ferrugineux bruı; jambes ciliées et garnies de rares denticules.

Cette espèce ne peut etre confondue avec l'O. nodatus 
Le C. Elle est plus petite, plus luisante; les bords de son pronotum sont moins fortement arqués et moins relevés, son pygidium est plus également ponctué et n'a pas le même dessin. Enfiu son mélasternum et son prosternum affectent une forme et une ponctuation très différentes.

Cette description est faite sur un individu que m'a donné M. le docteur Le Conte, comme appartenant à l'espèce de Say, et qu'il tenait de Zimmermann. La collection de l'illustre savant américain ayant été entièrement détruite et n'ayant plus que quelques rares débris, il m'a été impossible d'en étudier les types, comme j'ai pu le faire pour ceux du Major Le Conte.

Cette espèce est rare aux États-Unis, et je n’ai pu réussir à l'y trouver. Elle habite de Pensylvanie en Caroline.

\section{O. STRIATIS.}

Breviter ovatus, subtus dense rugoso-punctatus, supra par um convexus, niger subnitidus, antemis pedibusque brunneis; monoto subtiliter et dense strigosus, margine elevato et costis 6 , extcrnis tuntum abbreviatis; elytris sutura et costis 6 subequalibus, interstitiis 3-striatis, uni-seriatim punctatis ; mropygidio tricarinato pyyidioque incequali. Long. 22/3-2 mill. ; larg. 1 3/1-1 mill.

Hister sulcatus 01., Ent. I, (i. 8, p. 17, 20), t. I, lig. 6 (1789). Rossi, Fn. Etr. I, 30, 70, t. I1, fig. 3 (1790). - Mant. Ins. I, 14, 24 (1792).

11. striatus F. S. Eleut. I, 90,32 (1801). - Illig. Mag. I, 36, 1-2 (1801). - Ent. Hefte, I, 117, 33 (IS03). - Sturm, Dents. Fu. I, 26/, 39, pl. xix, fig. al (1S05). - Duft. FI. Ausi. I, 234, 37 (1805). - Payk. Molı. Hister. 100, 84, pl. xı, 1 (1811).

Onthophilus striutus Steph. Ill. Brit. Ent. III, 148, 2 (1830). Lr. Kæf. Brand. I, 681, 2 (1839). - Heer, Fu. Helv. I, 44 3, 1 (1841). - Redt. Faun. Austr. 239 (1849). - Bach. Faun. Pruss. I, 312, 2 (1849). 
Ovale arrondi, peu convexe en dessus, d'un noir peu luisant. Tête densément et finement ponctuée, rugueuse; front creusé d'une impression triangulaire avec une crête médiane et un tubercule de chaque còté alu dessus des yeux. Antennes allongées, d'un brun rouge avec le scape noir. Pronotum beaucoup plus large que long, bisinué à la base, relevé et arrondi sur les côtés, fortement rétréci et échancré en devant avec les angles aiğus, couvert de points aciculaires serrés, formant une fine réticulation, avec six côtes fines saillantes, les quatre du milieu entières, également distantes, rapprochées en devant; les externes raccourcies en devant et plus près du bord latéral que de la côte voisine. Ecusson petit, triangulaire. Elytres deux fois plus longues que le pronotum, plus larges à la base, avec les épaules saillantes, rétrécies et abaissées au bout, avec la suture carénée et six côtes à peu près également saillantes, si ce n'est la deuxième et la quatrième ; intervalles striés finement avec une série de points enfoncés dans la strie du milieu. Propygidium et pygidium densément ponctués; l'un tricaréné, l'autre avec une carène longitudinale obsolète croisée par une autre à la base. IJessous du corps lensément et rugueusement ponctué. Prosternum plan sans stries marginales et à peine distinct de son lobe antérieur. Pattes brunes; jambes étroites, antérieures garnies de quelques spinules.

Commun dans les bouses au printemps et en automne. On le rencontre dans toute l'Europe.

\section{0 . AFFINIS.}

Sub-orbicularis, convexiusculus, niger sub-nitidus, antennis pedibusque ferrugineis; fronte rugoso-punctal a antice triungu3e Série, тон上 1 y. 
lariter supra clypeum producta; pronoto dense rugoso-punclato, 6 carinulis abbreviatis sapius partim obsoletis; elytris sutura, margine extcrno costisque 6 alternatim elevatioribus, intervallis bi-carimulatis bi seriatimque punctatis; propygidio tri-tuberculato pygidioque inarquali munctatis; prosterno punctulato, lobo haud abrupte distincto, mesosterno et metasterno grosse punctutis. Lòng. 2 mill.; larg. $11 / 3$ mill.

Onthophilus affinis Redt. Fn. Austr. 239 (1849).

Suborbiculaire, assez convexe, noir luisant. Antennes brun ferrugineux. Tête densément ponctuée, front impressionné au milieu sans tubercule, relevé sur les yeux et se prolongeant sur l'épistome en bourrelet angulaire. Pronotum beaucoup plus large que long, en angle obtus au milieu et bisinué sur les côtés de la base, arrondi sur les côtés avec le rebord élevé, rétréci et échancré en devant avec les angles obtus, couvert d'une ponctuation serrée et rugueuse, mais non en manière de stries aciculées, carènes longitudiuales très fines, paraissant réduites à quatre, intermédiaires parallèles rapprochées, peu distinctes, les autres plus marquées, lines cependant, se rapprochant en devant; c'est à peine si l'on aperçoit de chaque côté un court vestige de celle qui avoisine le bord latéral. Ecusson très petit, triangulaire. Elytres plus de deux fois plus longues que le pronotum, plus larges que lui à la base, bombées, curvilinéaires sur les côtés, rétrécies et tronquées au bout; suture et bord latéral élevés, six côtes, dont trois beaucoup plus fortes; intervalles tristriés ou bicarinulés avec une série de points enfoncés qui débordent sur les cariuules; bord infléchi silIonné-ponctué avec une petite carène sinueuse, au-dessous de laquelle il est fortement ponctué. Propygidium trituberculé, ponctué, ainsi que le pygidium qui présente une élévation cruciale. Prosternum ponctué avec la mentonnière 
distincte sans brusque séparation; méso-et métasternum converts de gros points ocellés médiocrement serrés. Palles lerrugineuses.

Il ressemble au premier abord an $U$. striatus, il est de la taille des plus petits indivilus; mais on le distingnera aisément à son pronotum ponctué différemment et à côtes obsolètes, aux carènes des ély tres plus fortes et plus inégalement saillantes, enfin à la ponctuation plus forte et plus espacée de son sternum.

Autriche.

\section{O. 9-costatis.}

Ovalis, convexus, niger, nitidus, ore, antennis pedibusque rufo-brunncis; fronte impressa, margine elevata, medio carinata; pronoto parce punctato, setario, margine laterali carinaque parallela fortiter elcvatis; elytris sutura, margine laterali costisque 3 elcuatis setosis, interstitiis bi-lineatim punctatis, pygidio brevi, rugoso ; prosterno concavo, mesosterno bisinuato; tibiis anticis extus denticulatis. Long. 2 1/4 mill.; larg. 1 3/4 mill.

Orale, convexe, noir, assez luisant. Tête ponctuée; front avec une impression triangulaire à bords tranchants, et divisée par une carène médiane. Antennes rousses. Pronotum convexe, couvert de points peu serrés et peu profonds, et hérissé de petites écailles qui se détruisent aisément; beancoup plus large que long, subhisinué à la base, arqué et fortement relevé sur les côtés, rétréci légèrement el échancré en tlevant avee les angles arrondis; une forte carène parallèle au bord latéral de chaque côté; au milieu du bord antérieur on apergoit, mais avec peine quelques traces des còtes de ses congénères. Ecusson très petit. Elytres bombées une fois et demie plus longues que le pronotum, à 
peine plus larges a la base, curvilinéaires sur les cotés et fortement rétrécies au bout, relevées sur la suture et sur le bord latéral plus fortement, avec trois côtes saillantes garnies d'une série de soies écailleuses; intervalles, surtout en dehors, relevés en cotes larges, lisses, obsolètes, avec deux lignes de points espacés. Propygidium court et rugueusement ponctué ainsi que le pygidium, l'un et l'autre sans carène. Prosternum large, triangulaire, sinué à la base, creusé et rugueux ; mésosternum bisinué, non rebordé. Pattes rouge-brun; jambes antérieures armées en dehors de quelques denticules irréguliers.

Sénégal (M. de La Ferté).

Espèces que je n'ai pas vues,

3'. Oxthophllus pleneostates.

Le Conte, N. Amér., Hister. Mon. 51, 1 (1845).

Thorace lineis 6 elcvatis (costis), 1a untice, 3a postice paulo abbreviatis; elytris costis 14 elevatis. Long. 3 mill.; larg. 2 mill.

Noir, opaque. Tête ponctuée, avec un rebord élevé et l'angle saillant près des yeux; front marqué d'un tubercule central oblong; antennes de poix, massue obscure. Pronotum ponctué, rebord élevé, courbé, six côtes : première (externe) raccourcie en devant, deuxième subsinuée entière, troisiène raccourcie postérieurement, toutes convergentes en devant. Elytres arec quatorze côtes entières, alternatirement un peu moins saillantes, intervalles striés avec une simple série de points qui interrompent les carènes. Pygidium et propygidium grossièrement ponctués, celui-ci avec trois lignes longitudinales élevées, celui-là oborale, avec une ligne élevée au milieu; segments du ventre 
étroits, ponclués, le premier plus large, avec une série en devant de gros points plus profonds.

Géorgie, très rare.

\section{7'. OxthophiLus hispints.}

Payk., Mon. Hist. 98, 82, 1. x1, fig. 2 (1811) (Hister).

Niger, hispiclus, pronoto utrinque bi-sulcato; clytris lineis 5 clevatis longitudinatiter. Long. $12 / 3$ mill.

Noir, opaque, de la taille de l'O. strialus. Tête avec cinq lignes élevées longitudinales; celle du milieu et les deux latérales plus longues que les autres, toutes munies de larges poils gris très courts; massue des antenues ferrugineuse. Pronotum à peine deux fois plus large que long en devant, et presque trois fois à la base, avec deux sillons de clıaque côté, provenant de la marge et de deux lignes longitudinales élevées, milieu convexe; de toute la surface et surtout des lignes élevées s’élèvent comme de courtes écailles. Elytres un peu plus de moitié plus longues que le pronotum à la base et beaucoup plus larges au milieu, cinq lignes longitudinales élevées, d'oủ sortent de courtes écailles, interstries internes avec deux séries. externes avec une série de points. Dessous profondément ponctué; propygidium et pygyidium Irès rugueusement ponctués. Pattes d'un noir de poix; jambes postérieures à peine dilatées, garnies de très petites épines; antérieures un peu plus larges, très faiblement 4-denticulées.

Indes-Orientales.

\section{7". O. costipennis.}

Fähr. in Bohem., Insecta Caffraria, I, 549, 601) (1851).

Subrotundatus, ater, amtennarum clava flavescente; capite 
rugoso, medio carinato; thorace dorso rugoso punctato, utrinque bisulcuto; clytris 5-costatis, interstitiis dorsalibus seriatim menctatis; tibiis subcrenulatis, pone medium denticulo munitis. Long, 2 mill. ; larg. 1 2/3 mill.

Habitat in tractibus fluvii Gariepis superioribus.

Tout noir, exepté le bout des antennes, peu luisant. Tête inclinée, carénée longitudinalement au milieu, calleuse et rugueuse des deux côtés, peu densément ponctuée. Antennes assez courtes obscures à la base, massuc flavcscente. Pronotum deux fois plus large à la base que sa longueur, rétréci en devant, arrondi et un peu avancé à la base, légèrement échancré au bout, peu convexe en dessus, bisilionné de part et d'autre vers les côtés, interstice et bord formant des côtes, profondément, mais moins densément ponctué sur le dos, avec quelques rides longitudinales élevées au bout. Ecusson à peine visible. Elytres deux fois plus longues que le pronotum et lui adhérant étroitement, brièvement élargies derrière l'épaule, ensuite rétrécies, bord latéral infléchi; subtronquées au hout, médiocrement convexes en dessus, avec cinq côtes suberénelées en dehors de la suture, s'étendant de la base à l'extrémité, élevées, l'externe latérale flexueuse se réunissant aver sa voisine avant l'extrémité, les quatre interstries du dos sérialement ponctués, les trois plus rapprochés de la suture, formant deux séries de points, le quatrième une seule (les points des interstries intermédiaires sont plus grands); euviron dix ou douze par rangée. Pygidium obtus, infléchi au boul, rugueusement ponctuć partout. Dessons du corps médiocrement convexe, assez lisse au milicu, limbe ruguensement ponctué. Pattes assez grêles, d'un noir de poix, jambes extéricurement "u pen dilatées an milieu, subcréne!ées, un deuticule à delà du milieu plus distinct. 


\section{XLIe Genre BACANIUS.}

(Báxø:\%о, graine de rave.)

Soc. Ent. 3e série, T. 4 (1856), pl. xiv. - Mon. pl. x xı11. Genre XLI.

Abraeus Aubé.

Bacanius L. Le Conte, Proceed. Acad. Phil. (1853), 291.

Corpus ovale, convexum. Caput retractum, mandibulis retractis, fronte a clypeo haud distincto.

Antennce inter oculos in fronte inserte, scapo apice valde incrassato, funiculi articulo $1^{0}$ sat lato parum elonguto, 20 tenui magis elongato, 3-7 breviusculis, clava ovali 1-articulata; fossa antennali sub margine laterali ante coxas, pectore antice inciso.

Pronotum basi multo latius, stria tenui marginali; scutellam mullum. Elytra marginali stria distincta, cateris usque fere nullis.

Prosternum trunsversum, basi sinualum, lateribus narginalum lobo lato antico.

Tibice antice in medio rotundale, posteriorcs plus mimusve apiccm versus dilatate: tarsi omnes 5-articulati, supra tibiarum in fovcola occulti.

Propygidinm brevissimum obtectum, mygidium trigonum revulsum.

Corps ovale, convexe.

Tête (fig. $3 \mathrm{c}$ ) arrondie, rentrant dans le prothorax; front bombé, formant une légère saillie au niveau des yeux, non séparé de l'épistome, soit par une strie, soit par un enfoncement transverse; labre arrondi. Mandibules rétractiles, en pointe aiguë. Yeux ovalaires peu saillants. 
Antennes (fig. $3 e$ ) insérées sur une saillie du front, en dedans des yeux; scape courbé et très renflé au bout, logé à l'état de contraction dans une fossette large creusée de chaque côté de l'épistome: funicule de sept articles, premier épais, peu allongé, deuxième plus long, plus étroit, égal en longueur aux trois suivants réunis, un peu élargi au bout, $3-7$ petits, serrés, moniliformes, 3 et 5 moindres que 4 et 6 ; massue abrupte, ovalaire, comprimée, de quatre articles serrés pubescents et garnis de cils, Fossette antennaire large, mal limitẻe, creusée sous le bord latéral au devant des hanches; l'antenne y pénètre par une coulisse étroite du bord pectoral antérieur.

Mâchoires cornées à deux lobes garnis de poils. Palpes maxillaires de quatre articles, premier très petit, deuxième assez long renflé au bout, troisième cylindrique plus court, quatrième en pointe obtuse plus long que le précédent. Menton en trapèze, corné ; palpes labiaux courts à premier article très petit, deuxième assez grand renflé au bout, troisième plus nince, terminé en pointe obtuse.

Pronotum bombé avec une seule strie marginale fine, qui se continue ordinairement en devant, un peu avancé en angle obtus au milieu de la base, oblique sur les côtés, très rétréci en devant, avec les angles obtus, abaissés, assez saillants, et faiblement échancré en devant. Ecusson non apparent. Elytres ordinairement bombées, beaucoup plus longues que le pronotum, de sa largeur à la base, fortement rétrécies et tronquées au bout, avec une fine strie marginale, qu'on l'aperçoit qu'en obliquant l'insecte, une seule des espèces que j'ai sous les yeux présente une strie dor. sale presque entière.

Prosternum (fig. 36 ) couri, plan, parallèle et bordé sur 
les côtés, sinué à la base, muni antérieurement d'une large mentonnière légèrement arrondie en devant, distincte par un pli transversal du prosternum et à peu près aussi longue. Mésosternum plus large, pénétrant nu peu dans la base du précédent, bisinué, rebordé sur les côtés.

Pattes (fig. $3 b$ ) comprimées, distantes à leur insertion. Jambes antérieures (f. $2 a, 3 d$ ) aplaties, dilatées curvilinéairement au milieu, garnies de petits denticules très courts, et ciliés en dedans; postérieures plus ou moins élargies au bout, triangulaires. Tarses de cinq articles, dernier plus long et bi-ongulé, se repliant dans le repos dans une large fossette creusée à la partie supérieure de toutes les jambes.

Abdomen de cinq segments; premier grand bistrié longitudinalement entre les jambes; 2.5 très courts, serrés fortement quand l'abdomen se replie. Propygidium court, masqué par le bout des élytres, très oblique; pygidium en triangle arrondi peu convexe, entièrement renversé.

II. L. Le Conte a créé ce genre, en 1853, dans les P'roccedings de l'Académie de Philadelphie, pour deux petites espèces nouvelles des Ėtats-Unis, que j'ai pu voir dans son intéressante collection du pays. Mais n’ayant eu i ma disposition qu'un seul individu de l'une d'elles, il ne m'a pas été possible d'étudier les parties de la bouche, comme je l'aurais voulu. J'y ai réuni l'Abraeus punctiformis, qui a la plus grande ressemblance avec les deux autres espèces et qui se trouve dans le mème pays; ainsi qu'une nouvelle espèce de Caracas (Venezuela); enfin j’ai cru devoir y comprendre l'Abr. rhombophorus de M. Aubé, de sorte que le genre compte un représentant en Europe. Toutes ces espèces forment un genre très homogène, non seulement par le faciès, mais aussi pour l'ensemble des caractères. Voisins des Acritus 
pour la forme et la manière de vivre, ils en diffèrent essentiellement par la structure du prosternum et par leurs tarses postéricurs. Les rapports qu'ils ont également avec certains Tribalus ne sont que superficiels : la fossette et le point d'insertion des antennes sont fort différents.

Ces insectes, dont les métamorphoses sont encore inconnues vivent, comme les espèces d'Acritus et d'Abrcus, dans les détritus et les matières en décompositlon. L'espèce d'Europe a été trouvée dans la tannée des serres du Jardin-desPlantes, celles d'Amérique sous les écorces des troncs d'arbres pourris dans le terreau qui se forme entre elles et le bois.

A. Lisse en dessus.

\section{B. HUMICOLA.}

Ovalis, convexus, brunneus, levigatus, nitens, antennis pedi. busque ferrugineis, clava oreque flavis, monoto antice et late. ribus marginato, scutello mullo; prosterno mesosternoque stria marginali; tibiis anticis dilatatis, cxtus uni-llenticulatis versus apicem. Long. 1 1/4 mill.; larg. 3/4 mill.

Ovale, fortement convexe surtout en dessus, d'un brun très luisant, entièrement lisse sur toute sa surface. Antennes rouges, massue pâle ainsi que la bouche. Front arrondi. Pronotum court, faiblement anguleux au milieu de la base, oblique sur les côtés, très rétréci en devant, avec les angles obtus et fortement déprimés, strie marginale entière. Ecusson nul. Elytres beaucoup plus longues que le pronotum, de sa largeur à la base, curvilinéairement dilatées âl milicu sur les côtés avec une très fine strie mar- 
ginale, très rétrécies et tronquées au bout. Propygidium recouvert. Pygidiuın entièrement rabattu, peu convexe. Prosternum sinué il la base, rebordé latéralement, avec une large mentonnière; mésosternum bisinue en devant, strie marginale interrompue. Paltes rousses; jambes antérieures aplaties dilatées, ciliées sur les côtés, avec un denticule subapical en dehors; postérieures triangulairement élargies au bout.

Venezuela (Caracas).

A' Plus ou moins fortement ponctué en dessus.

B. Une ligne de points encliainés enclosant un espace rhomboïdal à la base du pronotum.

\section{B. RHOMBOPHORTS}

Ovalis, convexus, rufo-castanens, supra sat parce punctulatus nitidus, antennis pedibusque r.ufis; fronte punctulata; pronoto stria marginali vix antice interrupta, linea paucorum punctorum angulata, in medio baseos, rhombeum spatium includente; scutello mullo; elytris stria marginali tenui; mostcrno subquadrato, marginato, basi simuato, lobo lato punctato; mesosterno stria marginali antice interrupta ad angulos a)cuaia; tibiis anticis latis contortis, extus parce brevi-denticulatis; posticis triangularibus. Long. 1 1/4 mill.; larg. 3/4 mill.

Abræeus rhombophorus Aubé in Soc. Ent. 1843 , p. 75, pl. I, $4^{\circ} 2$. - Küst. Kæf. Eur. XIV, 46 (1848). - Bach, Faun. Pruss. I, 316, 6 (1849).

Ovale. convexe, roux marron plus ou moins foncé, luisant. Têtc arrondie, front convexe, relevé sur les yeux, avec queliues petits points. Antennes ferrugineuses, massue pâle ainsi que les palpes. Pronotum court, avancé en angle obtus au milicu de la base, oilique et rebordé sur les 
côtés, très rétréci et légèrement échancré en devant, avec les angles oblus et forlement abaissés; couvert d'une ponctuation fine et peu serrée, avec une ligne de gros points enchaînés peu nombreux, formant au milieu de la base uu angle obtus enserrant un espace rhomboïdal. Ecusson nul. Elytres une fois et demie aussi longues que le pronotum, de sa largeur à la base, curvilinéaires sur les côtés, fortement rétrécies et tronquées au bout, couvertes de points espacés et très fetits, strie marginale très fine. Propygidium très court eaché; pygidium lisse entièrement retourné. Prosternum presque carré, rebordé sur les côtés, simué à la base, avec me mentonnière large, ponctuée. Mésosternum plus large que le prosternum à la base, bordé d'une strie marginale qui se replie en arc aux angles antérieurs, et est interrompue en devant. I'attes ferrugineuses. Jambes antérieures (fig. 2 a) contournées un peu comme dans les Paromalus, dilatées, aplaties, garnies en dehors de très courts denticules très distants ; postéricures en triangle faiblement élargi au bout.

Cet insecte, décrit pour la première fois par II. Aubé, m'a beaucoup embarassé. Ses pattes antérieures contournées et denticulées en dehors, son prosternum échancré à la base et recevant le mésosternum, pourvu en devant d'une mentonnière large et un peu rabattue, me semblaient en contradiction avec sa forme d'Abraeus, et longtemps je me sentis porté à le séparer en un genre particulier. Néanmoins je n'avais pu me décider à cette innovation, et à l'exemple de l'éminent entomologiste qui l'a découverte et qui connaît si bien les petites espèces, et de tous ceux qui en ont parlé depuis, je l'avais laissé dans le genre Abracus. Cette particularité d'organisation n'élait à mes yeux qu'une preuve de 
plus que la nature se joue des bornes étroites dans lesquelles nous voulons la circonscrire et que Dieu dans la création ne va point par sauts et par bonds, mais que tout s'y lic et s'enchaîne dans un admirable tableau.

Ce n'est que depuis mon royage aux États-Unis, après avoir étudié le genre Bacanius, créé par le docteur L. Le Conte qui me l'a communiqué, que j'ai vu les rapports intimes qui lient notre Abr. rhombophorus à ce nouveau genre et que j’ai résolu de débarrasser les Abraeus de cette espèce si disparate.

France, environs de Paris; Allemagne; on le trouve daus la tannée, les matières en décomposition; il est rare.

B' Pas de ligne de points à la base du pronotum.

C. Une strie humérale; ponctuation moins forte et moins rugueuse.

\section{B. MISELLIS.}

Ovalis, convexus, rufo-ferrugineus, supra parce punctulatus nitidulus; antennis pedibusque rufis, clava pallida; pronoto stria marginali tenui haud interrupta; elytris stria humerali integra, antice magis a margine distanti; prosterno lato, basi sinuato, labo lato panctulato, mesosterno lato stria marginali sinuata integra; tibiis unticis rotundato-dilatatis, extus vix denticulatis, posticis apice latioribus. Long. 1 mill.; larg 2/3̊ mill.

Bacanius misellus L. Le Conte, in Proceed. Acad. Phil. 1853, p. 291 .

Orale, assez convexe, rouge ferrugineux, assez luisant. Front convexe pointillé. Antennes (fig. $3 e$ ) rouges, massue pâle. Pronotum court, transrerse, faiblement arqué à la base, à peine anguleux au milieu, oblique sur les côtés, très rétréci et peu échancré en devant, avec les angles obtus 
abaissés, ponctuation espacée et fine, strie marginale fine. Ecusson uul. Elytres beaucoup plus longues que le pronotum, de sa largeur à la base, dilatées et arroudies sur les côtés, avec une sirie dorsale. entre la petite strie ordinaire, fine, plus avancéc en dedans à la base, se rapprochant du bord vers le bout et presque entière, très rétrécies et tronquées au bout, bombées et couvertes de points espacés et un peu plus forts que ceux du pronotum. Propygidium court, et pygidium triangulaire entièrement retourné, lisses. Prosternum plus large que long, rebordé sur les cotés, sinué à la base, muni d'une large mentonnière pontillée. Pattes rouges; jambes applaties; antérieures (fig. 3 d) curvilinéaire. ment dilatées, garnjes de petits denticules très courts et à peine visibles; postérieures médiocrement élargies au bout, ciliées en dehors.

États-Unnis, sous les écorces des arbres pourris.

C' Pas de strie humérale aux élytres. Ponctuation plus forte, plus rugueuse.

\section{B. PINCTIFORMIS.}

Ovalis, convexus, rufus, undique punctatus, elyiris rugosis, parun nitidus, antennis pedibusque ferrugineis, pronoto elytrisque marginatis, prostcrno lato, basi sinuato, lateribus rectis marginalis, tobo antico latiori, mesosterno dimidiatim hex. . gono, stria marginali antice interrupta melasternoque excavalis; tibiis anticis valde medio, posticis leviter apiccm versus dilatatis. Long. 2/3-3/4 mill.; larg. 1/2 mill.

Abrceus punctiformis L. Le Conte in Proceed. Acad. Philad. 1853 , p. 288.

Ovale, convexe, rouge ferrugineux, peu luisant. Antennes rouges, massue plus claire. Tête arrondie; front plan, 
un peu avancé sur les yeux, pointillé. Pronotum court, légèrement arqué à la base, oblique sur les côtés, Irès rétréci et peu échancré en devant, avec une strie marginale fine, et une ponctuation fine assez espacée. Ecusson nul. Elytres beaucoup plus longues que le pronotum, de sa largeur à la base, dilatées à l'épaule, rétrécies postérieurement, tronquées au bout, avec la suture relevée, une strie marginale fine et une ponctualion forte et rugueuse. Propygidum court, caché en dessus, pygidium en triangle arrondi, ponciué. Dessous fortement, parfois rugueusement ponctué. Prosternum en carré, large, rebordé sur les côtés, sinué à la base, muni d'une mentonnière large et presque droite au bout. Mésosternum et métasternum for-mant une large excavation commune terminée par un bourrelet latéralement; le premier en demi-hexagone avec une strie marginale interrompue en devant. Pattes ferrugineuses; jambes aplaties; antérieures curvilinéaires et dilatées au milieu, postérieures faiblement triangulaires au bout.

J'ai trouvé cette espèce sous les écorces des arbres pourris au milieu du terreau humide formé par la décomposition, en juin et juillet, dans le nord des Etats-Unis; il se rencontre aussi sans doute dans les autres parties de l'Union.

Espèces que je n'ai pas vues.

\section{Bacayius tantillus.}

L. Le Conte, in Proceed. Acad. Philad. 1853, p. 291.

Rotundatus, convexus, rufus, nitidus, minus subtiliter punctatus, elytris stria marginali antice abbreviata, pygidio punctulato. Long. 2/i' mill. 
Etats du milieu et du sud, sous les écorces et dans les champignons.

Corps convexe, rond, presque globuleux, rouge brunâtre, luisant; tète finement el rarement pointillèe. Pronotum pas densément, mais distinctement ponctué. Elytres plus grossièrement ponctuées que le pronotum, avec des traces de stries obliques, près de la base; strie marginale distincte, mais ne s'étendant pas au devant du milieu; épipleures vaguement ponctuées, avec des traces indistinctes d'une ligne latérale. Pygidium fortement infléchi, finement ponctué. Corps grossièrement ponctué en dessous; jambes’antérieures uu peu subitement et largement dilatées.

\section{BaCANILS? MaRginates.}

L. Le Conte, in Proceed. Acad. Philad. vi (1853), p. 292.

Rotundatus, modice convexus, niger, subnitidus, dense grosse punctutus, elytris margine laterali acuto, pygidio munctulato. Long. 1 1/5 mill.

Un individu de l'illinois.

Corps arrondi, légèrement et régulièrement convexe, formant un petit segment de sphère, noir, un peu luisant. Tête densément pointillée. Pronotum densément ponctué, bord latéral longitudinalement impressionné. Elytres grossierement ponctuées, avec de légers vestiges de stries externes obliques à la base ; bord exterue brusquement limité; stric marginale obsolète ; épipleures larges, unies, bistriées Pygidium perpendiculaire, finement ponctué; dessous ponctué. Pattes rousses; jambes antérieures courbées en dedans, légèrement dilatées; jambes postérieures très minces. 


\section{XliIe Genre Abrateus.}

(¿ispòs, délicat, beau).

Soc. Ent. 3e série, t. $1 v(1856)$, pl.14. - Mon. pl. xxıı.

Genre XlII.

Ilister Creutz. Ent. hefte. Payk. Sturm. Duft. Gyll.

Abrenes Leach, Zool. Misc. III (1817), p. 76. - Erichs. in Jahrb., 206, Xxi (1834); in Fn. Brand. 1, 685 (1839). - - L 0 Conte, N. Amér. Hist. 53 (1815). - Heer, Fn. IIelv. 1, 464, x (1841). - Redt., Fu. Austr. 240, 231 (1849). - Bach, Fn. Prus., 1, $314(1849)$.

Corpus comvexum suborbiculare. Caput retractum mandiInlis aequalibus, retractis, fronte stria a clypeo haud distincta.

Antenme inter oculos in fronte inserte, scapo longo, funiculi articulo 10 brcvi crasso, 20 duplo longiori, magis temi, reliquis brevibus, clava compressa, ovali; foveola molio in pectoris latere ante coxas mediocri.

Pronotum basi multo lalins, stria temi marginali. Scutchlum minimmm. Elylra striis obsoletis, marginali nulla, apice angustata.

Prosternum transversum basi truncutum latum bistriatum, lobo nullo; mesostermum stria marginali.

Pedes temues, tibiis anticis plus mimusve dilatatis; tarsis ommibus 5-urliculatis.

Pygidium subinflexum; propygidium latius inclinatum.

Corps suborbiculaire convexe.

Tête (fig. $6 p$ ) légèrement convexe, enfoncée dans le prothorax; front sans strie ni dépression qui le sépare de l'épistome; labre arrondi au bout, assez long; mandibules ré3e Série, Toue iv. 
tractiles, légèrement courbées en pointe aiguë avec une dent interne; yeux ovalaires peu saillants.

Antennes (fig. 1 b, 3 f) insérées sur le front en dedans des yeux, à une petite élévation; scape logé dans une cavité large et assez profonde, long, légèrement courbé et dilaté au bout; funicule de sept articles; premier très court, plus épais que les suivants, quelquefois aussi large que le scape, deuxième plus grêle, long et un peu épaissi au bout, 3-7 courts égaux serrés ; massue ovalaire, comprimée, de quatre articles serrés garnis de poils. Fossette antennaire assez grande, creusée sous le prothorax non loia du bord au devant des hanclıes; le bord pectoral est à peine entaillé pour le passage de l'autenne.

Machoires (fig. $6 \mathrm{~m}$ ) cornées, à deux lobes membraneux garnis de poils au bout, l'externe beaucoup plus long et plus large que l'interne. Palpes maxillaires de quatre articles, premier très petit, deuxième obconique, troisième court, quatrième allongé ovalaire. Menton (fig. $6 n$ ) corné, large, transverse, avec une double échanciure de chaque côté; lìvre membraneuse; paraglosses courtes, arrondies. Palpes abiaux renflés, de trois articles, premier un peu plus court, moins gros que les autres, deuxième court, gros, troisième très épais ovalaire.

Pronotum bombé, sans autre strie qu'une marginale parallèle au bord latéral et se continuant rarement antérieurement, arqué à la base, arrondi sur les côtés, fortement ré.. tréci en devant, avec une faible ćchancrure et les angles bien marqués abaissés. Ecusson très petit, indistinct. Elytres plus ou moins convexes, arrondies sur les côtés, tronquées au bout, ponctuées, sans strie marginale, ni aucun autre, si ce n'est quelques restiges d'une dorsale oblique. 
Prosternum (fig. $2 d, 4 h, 5 j, 6 \eta, 7 s, 8 t$ ) court, plan, beaucoup plus large que long, fortement appliqué à la base contre le mésosternum, tronqué droit ou un peu arrondi, élargi plus ou moins en devant, avec les angles antérieurs assez saillants mais souvent relevés, sans mentonnière. Mésosternum large, tronqué en devant, quelquefois sinué, rebordé sur les côtés, rarement dans tout son pourtour.

Pattes (fig. $6 l$ ) allongées, distantes à leur insertion, surtout les postérieures; cuisses subcylindriques, les antéricures creusées d'une coulisse pour loger les jambes, toutes bordées postérieurement. Jambes antérieures (figg. $1 a, 2 c, 3 e, 4 g, 5 i, 6 o, 7 r)$ dilatées, aplaties, creusées en dessus d'une fossette tarsale vague sans bords arrêtés; postérieures linéaires un peu élargies au bout, garnies de cils. Tarses (fig. 5 k) de cinq articles, premier plus ou moins long, 2-4 égaux serrés, subcylindriques, terminés par deux soies, cinquième assez long, biongulé. Les antérieurs logés sur les jambes, les postérieurs libres.

Abdomen (fig. $6 l$ ) de cinq segments; premier grand, long, avec deux stries sinuées, 2-5 très courts, plus ou moins serrés, quand l'abdomen se replie. Propygidium fortement incliné, large; pygidium bombé, en ogive, entièrement renversé.

Leach a créé le genre Abrueus dans le Zool. Iliscel. en 1817 pour des espèces d'llister de très petite taille, noires ou brunes et souvent globuleuses. Leur faciès particulier ne permet de les confondre avec aucun autre genre, si ce n'est peut-être avec certains Tribalus dont les élytres poncluées n'ont que des rudiments de stries obliques. Mais la disposition des antennes et du prosternum est si différente qu'on n’hésitera pas un instant; les antennes insérées sur le front 
en dedans des yeux à un pelit tubercule, les deux premiers articles du funicule toujours différents des suivants, les fossettes antennaires creusées largement sous le milieu du bord pectoral au devant des hanches, le prosternum subtronqué à la base, dépourvu de mentonnière, le pronotum sans sillon, les élytres sans stries bien marquées, et les pattes antérieures plus ou moins dilatées, tandis que les postérieures sont grêles, constitueıt autant de caractères qui les distinguent de tous les autres genres.

Erichson, dans le Jahrbücher (1834) adoptant cette roupe de l'entomologiste anglais, y comprend cinq espèces : Ilister globnlus Creutz., globosus E. H., nigricomis E. I., mimutus F. et une nouvelle espèce Abrous exiguns, dont il donne la description. Dans sa faune de la Murche de Bromlebonrg (1839), il y ajoute l'A. grumulum. Après lui, divers auteurs ont publié successivement quelques nourelles espèces d'Abra'us: M. Le Conte, dans sa Monographie des Mistérides de l'Amérique du Nord (1845); A. aciculalus, simplex, obliquns et fimetarius; et son fils le docteur J. L. Le Conte, dans ses insectes de Californie (1851), A. maritimus et basatis; M. Aubé, dans nos Annales (1842-1851), A. parvulus, atomurius, munctum, rhombophorus et consobrimu; M. Küster (1818), A. semimulum; enfin M. Fahraeus dans les Insectes de Caffrerie de M. Bohemann (1851), A. sclulosns, curmulus et misellus.

Mais dans cet ensemble d'espèces d'apparence si homogène, il y a néanmoins deux formes bien distinctes et séparées par des caractères tranchés. L'une orbiculaire, globuleuse a le lobe maxillaire sans crochet corné, les élytres saus strie marginale, le propygidium long, oblique, le pygidium entièrement retourné, et les tarses postéricurs 5-ar- 
ticulés; l'autre plus ovalaire, moins convexe, a le lobe maxillaire terminé par un crochet corné, les élytres bordées d'une strie marginale, le propygidium plus court et le pygidium moins incliné, enfin les tarses postérieurs 4-articulés, les deux premiers s'étant soudés et formant un article toujours plus long. La premiere lormera le genre Abreus proprement dit; la seconde est le genre Acritus de M. J.L. Le Conte.

Notre genre Abrueus ainsi réduit et lébarrassé de tous les éléments étrangers, se trouve composé d'espèces réparties dans les quatre parties du monde, mais d'une manière fort inégale : quatre en Europe, deux en Afrique, un dans les Indes-Orientales et un dans la Nouvelle-Grenade.

Ces inscctes vivent sous les écorces des arbres jetés par terre, dans le terreau pourri qui s'y forme, dans les matières en décomposition, les fumiers, les champignons, quelquefois sous les pierres et dans les bouses. Leurs larves et leurs transformations n’ont pas encore été étudiées. 

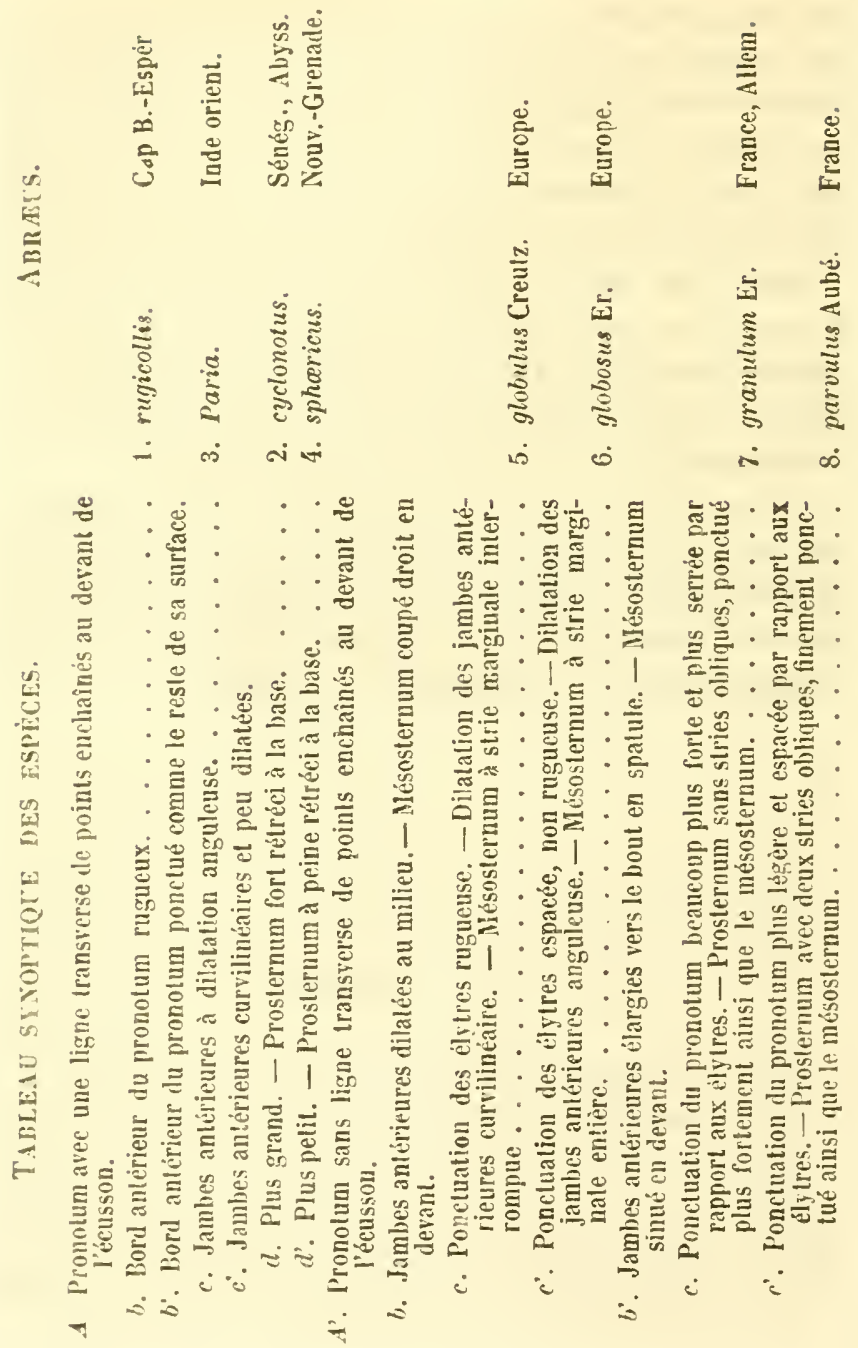
A. Pronotum bordé à la base d'une ligne transverse de points enchainés (1-4).

\section{A. RUGICOLLIS.}

Orbiculuris, subglobosus, niger subobscurus, undique sat dense punctutus, antennis pedibusque rufo-brunneis, funiculi articulo $1^{\circ}$ brevi magno, $2^{\circ}$ elongato tenui; pronoto yibboso antice rugoso, ante scutellum punctorum linea arcuata; elytris striis obsoletis; prosterno brevi, lato, bistriato, postice simuato; mesosterno stria interrupta, tibiis unticis rotundato-dilatatis. Long. 2 mill. ; larg. 1 1/2 mill.

Orbiculaire, globuleux, noir peu luisant. Antennes (fig. 1 b) d'un brun ferrugineux; premier article du funicule court trìs gros, deuxième obconique beaucoup plus long. Tète rugueusement ponctuée sur le vertex, creusée de chaque côté d'une fossette pour l'insertion des antennes, ce qui rend le front élcvé triangulaire. Pronotum bombé, très large, bisinué à la base, avec une ligne de gros points serrés en arc à convexité antéricure, au devant de l'écusson, et avec les angles postéricurs très aigus, sinué et rebordé sur les côtés, très rétréci et échancré en devant avec les angles courts abaissés; gibbeux derrière l'échancrure antérieure, et s'abaissant à partir de ce point; ponctué fortement et assez densément, avec le pourtour rugueux en devant. Ecusson petit triangulaire. Elytres bombées, plus Iongues que le pronotum, de sa largeur à la base, curvilinćairement dilatées sur les côtés, rétrécies et arrondies au bord apical, couvertes de points assez forts et serrés, rugueux sur le bord infléchi; strie dorsale oblique assez longue et peu marquée. Pygidiun plas fortement ponctué ainsi que le dessous. Prosternum court, large, replié en devant de cha- 
que côté, ce qui le fait paraitre plus étroit que postéricurement, quoi(qu'il soit réellement un peu plus large, obscurément bistrié sur les côtés, échancré à la base; mésosternum court, arrondi en devant arec une strie marginale interrompue. Paltes d'un rouge ferrugineux. Jambes antéricures (fig. 1 a) fortement dilatées et arrondies au milieu.

Cap de Bonne-Espérance (H. Chevrolat).

\section{A. CYCLONOTUS.}

Dvato-y!obosus, piccus, nitidus, densissime munctalus; fronte convexa; antennis pedibusque forrugineis, articulis funiculi $1^{\circ}$ brevi crasso, 20 clongato, clava ovali acmminata; pronoto basali linea munctorum iransicrsa; ciyıris suluice subclevala, striu oblipur obsoleta, mosterno antice latiori, busi lmancato, mesosterno striatutcrupta, punctutis; libiis anticis in madio rotundo-dilutatis. Long. 1 mill. ; larg. $11 / 4$ mill.

Ovale globuleux, d'un brun de poix luisant. Tête pelite, vertex rugueux; front convexe, relevé en triangle entre les yeux. Antenues ferrugincuses; scape allongé, épaissi au bout; premier article du funicule court et gros; lleuxième flus mince et deux fois plus long, les autres courts, serrés, moniliformes; massue abrupte cn ovale allongé pointu. Pronotum convexe, hisinué à la base, arqué el rebordé sur les côtés, fort rétréci en devant avec les angles abaissés, couvert d'une ponctuation serrée, uniforme et assez forte; arec une ligne de points transversale presque droite et rapprochée du bord. Ecusson à peine visible. Elytres plus longues que le pronotum, de sa largeur à la base, forleinent rétrécies au bout, couvertes d'une ponctuation serrée, culrmíle de points plus gros; quelques rudiments de strie oblique rudimentaire; suture relevéc postérieurement. Pygidium bombé, finement ponctué. Pronotum (lig. $2 d$ ) 
beaucoup plus large que long, paraissant plus étroit antérieurement et cependant l'étant moins que la base, coupé droit a la base, fortement appliqué contre le mésosternum et comme soudé, échancré en devant. P'attes d'uu rouge ferrugineux; jambes antéricures (fig. 2 c) fortement dilatées et arrondies au milieu.

Sénégal. Abyssinie.

3. A. 'MAMA.

Suborbicularis, convexus, niyer, nitidus, sut dense muictatus; antemnis peclibusque rufo-brumeis; fronte trianguluri: monolo besi arcuatim menctis lineato; elytris stric elorsuli obsoleta maryinalique abbreviatis; prosterno bievi antice latiori, bistriato; mesosterno stria interrupta; libiis anticis angulaviler in medio dilatatis. Long. $14 / 5$ mill.; larg. $11 / 2$ mill.

Suborbiculaire, convexe, noir luisant. Antennes (fig. $3 f$ ) rouge-brun, massue testacéc; premier article du funicule court, obconique; deuxième obconique, plus long et moins épais que le premier. Front bombé triangulaire, creusé de chaque còté de fossettes profondes pour l'iusertion des antennes, finement pointillé. Pronotum court bisinué à la base avec une ligne de points arquée au devant de l'écusson, les angles très aigus, oblique et rebordé sur les côtés, rétréci et échancré en devant ávec les angles abaissés, peu saillants, assez densément pointillé. Ecusson triangulaire. Elytres plus longues que le pronotum, de sa largeur à la base, curvilinéairement dilatées sur les côtés, rétrécies et arrondies au bout arec un angle sutural bien marqué; couvert de points assez serres el plus gros que ceux du pronotum; repli latéral pointillé arec une strie marginale raccourcie, dorsale oblique obsolete. Pygidium pointillé comme le des- 
sous. Prosternum court, large, un peu rétréci à la base et paraissant plus étroit en devant, tronqué de chaque côté, bistrié. Mésosternum à strie interrompue. Pattes rouge ferrułrineux. Jambes antérieures (fig. $3 e$ ) angulairement dilatées au milieu.

Maradabad (Indes-Orientales).

\section{A. SPHenices.}

Sphoroides, nigro-picens, obscurus, dense ct fortiter munctatus, antemis pedibusque rufis; funiculi articulo $1^{\circ}$ globoso, $2^{\circ}$ obconico longiori, clava ovali acuminata; pronoto basali magnorum munctorum linea arcuata; elytris postice rugulosis, stria obliqua ; mosterno breviter rectangulo, bistriato; tibiis anticis in medio rotundato-dilatatis. Long. $11 / 2$ mill.; larg. 1/5 mill.

Sphérique, moins luisant, noir de poix, couvert partout de gros points serrés. Tête grosse, vertex rugucux, front relevé sur les yeux. Antennes rousses, massue testacée; scape obconique, allongé ; premier article du funicule subglobuleux très gros, court; deuxième obconique plus long, les autres courts, égaux, moniliformes; massue en ovale allongé, acuminée. Pronotum bisinué à la base, avec une ligne de gros points peu nombreux, arquée, au devant de l'écusson, fortement arrondi sur les côtés et rétréci en devant. Ecusson ponctiforme. Elytres un peu plus longues que Ic pronotum, de sa largeur à la base, fortement rétrécies au bout et arrondies sur les côtés avec des rudiments de stries obliques í la base, suture relevée, ponctuation très forte rugucuse dans le pourtour. Prosternum (fig. $4 \mathrm{~h}$ ) beaucoup plus large que long, couné droit à la base, appliqué contre le mésosternum, légèrement échancré en devant et replié aux angles, ce qui le fait paraitre plus étroit, 
quoiqu'il soit en rectangle plus large que long et couvert de gros points espacés. Mésosternum court, ponctué de mème, bordé d'une strie interrompue et séparé du métasternum parr une strie sinueuse. Pattes rouges; jambes antéricures (fig. $4 \mathrm{~g}$ ) dilatées fortement et arrondies au milieu.

Carthagène (Nouvelle-Grenade).

A' Pronotum sans ligne transverse de points enchainés le long de la base (5-8).

\section{A. Globulus.}

Globosus, piccus, parum nitidus, donse munctatus, clytris strigosis, seriatim albosetosus, antemis pedibusque rufis, prosterno brevi postice angustiori; libiis anticis in medio iotundatoditatatis. Long. $11 / 2$ mill.; larg. $11 / 5$ mill.

Ilister globulus Creutz. Ent. Vers. 83, 5, pl. 1, 12 (1799). Ent. hefte 1, 112, 30 (1893). -- Sturm, Deut. F1. I, 255, 35, (1895). - Duft. Fn. Austr. 1, 235, 38 (1805). - Payk. Mon. Hist. 85, 69, t. v1ı, f. 8 (1811). - Gyll. Ins. Suec. 4, 271, 29 (1827).

Abrcous globulus Er. Kaf. Brand. 1, 685, 1 (1839). - Heer Fn. Helv. I, 464, 1 (1841). - Küst. Kæe. Eur. 14, 43 (1848). - Redt. F11. Austr. 241, 1 (1849). - Bach, Prus. Fn. I, 315,1 (184!).

Suborbiculaire, globuleux, noir de poix, peu luisant, densément et assez fortement ponctué sur toute sa surface, parsemé en dessus de petites soies blanches renflées au bout, écartées et disposées en séries. Antennes brunes, massuc rougeâtre, premier article du funicule cylindrique. allongé, aussi long que les trois suivants réunis. Têtc arrondie; front concave, relevé au devant des yeux. Pronotum court, avancé à la base sur l'écusson, sans ligne de points, mais avec un faible sillon, arqué sur les côtés, rétréci et 
échancré en devant avec Ies angles abaissés, obtus et peu avancés; ponctué assez deusément et d'une manière uniforme. Ecusson poucliforme. Elytres plus longues que le pronotum, de sa largeur à la base, dilatées à l'épaule, fort rétrécies au bout avec un angle sutural bien marqué, relcvées en carêne à la suture; ponctuation plus forte et plus serrée que celle du pronotum, confluente sur le bord infléchi et dans la partie postérieure; stries à peine visibles Prosternum (fig. 5 j) ponclué, court, plus large en devant, mais relevé sur les côlés, et cette disposition le fait paraittre plus étroil. Pattes ferrugineuses; jambes antérieures (fig. 5 i) dilatées fortement et arrondies au milieu.

lirance, Allemagne, Autriche, Suède, Suisse; sous les détritus et les bouses à moitié desséchées. Assez rare.

\section{A. Globosus.}

Ovalus, globosus, parce punclulatus, rufo-brumens, nitidus, antcnnis redibusque rufis, clava testacea; mostcrno brevi, basi sinuato, antice latiori; tibiis anticis in modio angulato-dilatutis. Lomg. $11 / 4$ mill.; larg. 1 mill.

Hister globosus Ent. Hefte, I, 110, 29, 1. II, f. 1 (1803). Sturm, Deul. Fu. 1, 255, 34. (1805). - Gyll. Ins. Succ. 1, 98, 30 (1808). - Payk. Mon. Hist. 86, 70, t. v111, f. 2 (1811).

Abrecus globosus Er. Kae. Brand. I, 686, 2 (1839). - Heer, Fn. Helv. I, 464, ㄹ (1841). - Küst. Kee. Enr. 11, 44 (1848). - Bach, Irus. Fn. I, 315, 2 (1849). - Redt. Fn. Austr. 241, 2 (1849).

Ovale globuleux, brun plus ou moins ferrugineux, luisilut, couvert de points espacés, assez fins, arec des points trés petits dans l'intervalle. Antennes ferrugineuses, massue pâle; premier arlicle du funicule beaucoup plus large que 
long, plus court que le suivant. Front (lig. 6 p) plan, légè rement sailiant sur les yeux. Pronotum court, subarrondi a la base, oblique sur les côtés, rétréci et échancré en devant avec les angles très abaissés et peu saillants. Ecusson ponctiforme. Elytres plus longues que le pronotum, de sa largeur ì la base, courbées sur les côtés, rétrécies au bout avec un angle sutural bien marqué; bord infléchi rugueux, strie dorsale oblique un peu plus visible. Prosternum (fig. $6 \eta, l$ ) court, sinué à la base, élargi en devant, mais un peu relevé de chaque côté; strie marginale du mésosternum entière. Pattes ferrugineuses. Jambes antérieures (fig. 6 o) fortement élargies au nilieu et en triangle très marqué.

Suède, France, Allemagne, Autriche, Suisse, Italie. Assez rare, sous les écorces pourries. M. Blisson l'a trouvé dans un vieux tronc d'arbre pourri en compagnic de petites fourmis qui y avaient établi leur séjour, dans la forêt de Perseigne (Sarthe).

\section{A. GRANULTH.}

Ovalus, convexus, brunneus, pronoto, antemnis, ore pedibusque rufis, dense el fortiter punctatus; mesosterno stria marginali interrupta; elytris basi striatis; tibiis anticis versus apicem subito dilutatis. Long. 1 5/5 mill.; larg. 4/5 mill.

Abrceus gramulum Er. Kæ. Brand. 1, 686, 3 (1839). - Heer, Fn. Helv. 1, 464, 3 (1841). - Bach, Prus. Fu. I, 315, 3 (1849). Redt. Fus. Aust. 241 (1849).

Ovale, assez convexe, d'un brun plus roussître sur le pronotum, à la bouche, aux antennes et aux pattes. Front convexe, saillant sur les yeux, sans strie qui le sépare de l'épistome, densément et fortement ponctué ainsi que le pronotum. Celui-ci convexe, bisinué à la base, terminé en pointe 
au devant de l'écusson, arqué sur les bords, fortement rétréci et échancré en devant; strie marginale forte et non interrompue en devant. Ecusson ponctiforme. Elytres une fois et demie plus longues que le pronotum, de sa largeur à la base, rétrécies vers le bout, encore plus densément et plus fortement ponctuées que le pronotum; avec une strie oblique assez forte au milieu et une autre plus fine a l'épaule. Pygidium assez densément ponctué. Prosternum (fig. 7 s) aussi long que large, rebordé, bisinué à la base, coupé à peu près droit et un peu plus large en avant. Mésosternum couvert de gros points espacés, strie marginale interrompue. Pattes rougeâtres; jambes antérieures (fig. $7 r$ ) d'abord très étroites jusqu'au milieu, puis subitement et fortement dilatées jusqu'au bout.

Il a la forme et la couleur du précédent; mais il est moins luisant, plus densément et plus fortement ponctué; il se distingue en outre par son mésosternum plus fortement ponctué, non entièrement rebordé, par la strie des élytres bien distincte et surtout par la dilatation tibiale qui est fort différente.

France, Allemagne, Autriche, Suisse.

\section{A. parvulus.}

Ovatus convexus, picco-fervugineus, ore, antennis pedibusque dilntioribus, subniliulus; pronoto pares et lenuissime, elyuris dense el forliler munclatis; rroslcrno 2 striis obliyuis, mesosterno stria interruplu; libiis anticis apre subilo dilatatis. Long. 1 mill.; larg. 3/4 mill.

Abrcus parvulus Aubé, Soc. Ent. (1842) 232.

Ovalaire, convexe, d'un brun de poix ferrugineux. Tếte finement pointillée, luisante; front saillant sur les yeux. 
Antennes ferrugineuses, massue testacée. Pronotum ferrugineux, luisant, couvert de petits points espacés et très fins; subarrondi a la base et avancé en pointe sur l'écusson, arqué sur les côtés, fortement rétréci et échancré en devant; strie marginale très fine. Ecusson à peine visible. Elytres plus longues que le pronotum, de sa largeur à la base, fortement rétrécies au bout, convexes, relevées à la suture, ternes, couvertes de gros points très serrés et quelquefois rugueux. Pygidium firement ponctué. Prosternum (fig. $8 t$ ) létréci postérieurement avec deux stries obliques partant de la base et se dirigeant l'une vers l'autre. Mésosternum à strie margrinale interrompue. Pattes ferrugineuses; jambes antérieures d'abord étroites, puis dilatées au bout assez fortement et subitement.

Cette espèce intermédiaire pour la taille à l'A. globosus et à l'A. gramulum, semblable au premier pour la ponctuation du pronotum el au deuxième pour la dilatation des jambes antérieures, se distingue aisément de celui-lì par ses élytres plus fortement et plus densément ponctuées, par la dilatation apicale subite et arrondie des jambes antérieures, et par la strie du mésosternum interrompue; de celui-ci par la ponctuation du pronotum et du mésosternum, et par les deux stries obliques du prosternum.

France, Allemagne, dans le bois pourri.

Espèces que je n'ai pas vues.

1' Abreus curtules Fahr. in Boh. Ins. Caffi. 1, 548, 598 (1851).

Subrolundatus, niger, nitidus, crebre concinne punctatus, pronoti lateribus tenniter marginatis, elytris striis 2 dorsali- 
bus, ohliquis, postice abbreviatis, obsoletis; mutemis pedibusyue forruyineis, libiis tenuissime serrulatis. Long. 2 mill.; larg. $13 / 4$ mill.

Noir, luisant, glabre. Tète abaissée, densément et finement ponctuée; front obliquement creusé en devant depuis l'insertion des antennes. Celles-ci un peu plus longues que la lìte, d'un brun ferrugineux; massue ovalaire, acuminée an bout, plus pâle. Pronotum deux fois plus large que long à la base, très étroit en devant, dilaté et arrondi sur les côtés, étroitement rebordé, légèrement bisinué par derrière, assez avancé au milieu, faiblement échancré antérieurement avec les angles abaissés, régulièrement convexe, assez densément et finement ponctué. Ecusson nul. Elytres étroitement serrées au pronotum, arrondies et dilatées, avec les côtés infléchis, arrondies au bout séparément, deux fois plus longues que le pronotum, régulièrement convexes en dessus, ponctuées comme le pronotum, avec deux stries obliques, raccourcies au delà du milieu, peu distinctes, et une petite stric postérieure oblique raccourcie de part et d'autre. Propygidium obtus, densément et plus fortement ponctué. Pygidium infléchi. Dessous du corps convexe, assez profondément ponctué. Pattes assez grẻles, d'un brun ferrugineux; jambes antérieures comprimées el dilatées, toutes faiblement cilićes en dehors.

Sur les bords du fleuve Limpoponis (Caffrerie).

2' A brals Setulosis Fahr. in Bohem. Ins. Caffr. I, 547, 597 (1851).

Subrolundetus, ater, opacus, confertissime rugutoso-punctulus, supra selulis crectis flavescentibus obsitus, fronte impressa, 
pronoti latcribus tenuiter murginatis, margine crenulato, antennis medibusque ferrugineis, tibiis tenuissime serrulatis. Long. $12 / 3$ mill. ; larg. 1 1/2 mill.

Noir, obscur, couvert de toutes parts d'une ponctuation serrée et rugueuse. Tête subtriangulaire, avec quelques petites soies flaves, front fovéolé. Antennes un peu plus longues que la tête, couleur de poir, massue ovalaire, ferrugineuse. Pronotum presque deux fois plus large que long à la base, beaucoup plus étroit en devant, arrondi sur les côtés, légèrement avancé à la base, peu échancré en derant, avec les angles aigus, abaissés, uniformément convexe en dessus, assez densément garni de soies flaves dressées, faiblement crénelé sur les bords latéraux. Ecusson invisible. Elytres étroitement appliquées au pronotum, uı peu élargies à l'épaule, et se rétrécissant bientôt, avec le bord latéral infléchi, arrondies au bout, à peu près deux fois plıs longues que le pronotum, régulièrement convexes en dessus, parsemées de soies flaves dressées, et pour l'ordinaire en séries. Propygidium convexe avec de rares soies; pygidium très infléchi. Dessous du corps convexe, glabre. Pattes grêles, d'un ferrugineux foncé. Jambes finement ciliées en dehors; antérieures aplaties, dilatées.

Natal.

2" Abrets Monilis Fahr. in Boh. Ins. Caffr. 1, 549, 599 (1851).

Subrotundatus, niger, nitielus, elytris fusco-castancis, disco antico menctis majoribus spursis, pronoto tenuiter marginato, untennis pedibusque forrugincis. Long. 1 2/3 mill.; larg. $11 / 3$ mill.

3e Série, TOME IV. 
Tete perpendiculaire, noire, pointillée; front convexe. Antennes assez grêles, ferrugineuses, scape plus obscur, massue ovaic oblongue pubescente grise. Pronotum deux fois plus large que long à la base, très rétréci en devant, étroitement rebordé et un peu curvilinéairement dilaté sur les côtés, légèrement bisinué à la base, peu échancré en devant, avec les augles abaissés, régulièrement convexe en dessus, densément et finement pointillé, noir, luisant. Ecusson invisible. Elytres étroitement serrées contre le pronotum, arrondies et dilatées, avec les bords latéraux inlléchis, séparément arrondies au bout, deux fois plus longues que le pronotum, convexes en dessus, d'un marron foncé, luisantes, finement pointillées avec des points plus gros sur la partie antérieure du dos. Propygidium convexe, infléchi au bout, densément pointillé, noir, luisant. Pattes assez grêles, ferrugineuses. Jambes finement ciliées en dehors; antérienres aplaties, dilatées.

Mème localité que le Curlulus.

3' Abrai's Exilis Payk. Mon. Hist. 84, 67, pl. и, 8 (1811) (Hisier).

Niger, convexo-ovatus, fronte plana prominula, pronoto marginato, clytris supra striis nullis, libiis inermibus. Long. $12 / 3$ millim.

Un peu plus grand l'A. globulus, de la taille du T. capeusis, noir luisant, finement ponctué de toutes parts. Frout plan, saillant de chaque côté sur les yeux. Antennes rousses, massue plus claire. Pronotum à peine aussi large que long en devant, mais deux fois plus à la base, convexe, étroitement rebordé. Elytres de moitié plus longues au moins que le pronotum, de sa largeur à la base, dilatées au milieu, rétrécies postérieurement, peu convexes, stries ter- 
minale et marginale entières, les autres nulles. Abdomen dépassant de fort peu les élytres. Pattes rouges, jambes inermes, intermédiaires et postérieures subfiliformes, antérieures peu dilatées. - Indes-Orientales.

Très voisin de l'A.Paria, si toutefois ce n'est pas la même espèce.

\section{XLIIIe GENRE. Acritus.}

(ä́xpıtos, non séparé, conlondu).

Soc. Ent. 3c série, T. 4 (1856), pl. xiv. - Mon. pl. xxil Genre XLIII.

Hister F. Creutz. Ent. Hefte; Payk. Sturm. Gyll.

Abrceus Leach. Erichs. Aubé; J. Le Conte; Redt.

Acritus J. L. Le Conte, Proceed. of the Acad. of Philad. III, p. 288 (1853).

Compus ovatum, convexiusculum. Caput retrachmm mandibulis uqualibus retractis, fronte u clypeo stria haul distincta.

Antenna inter oculos in fronte inserial, scapolongo, funiculi articulo $1 " 2^{\circ}$ duplo longiori, ceteris brevibus, clava ovali compressa, foveola medio in pectoris latere ante coxas lata.

P'ronotum basi latius, stria tenui marginali, scutellum minimum, clytra striis dorsalibus obsoletis, marginali tonui distincta.

Prosternum utrinque truncatum subparallelum marginatum, lobo mullo; mesosternum stria marginali.

Pedes tennes, tibiis anticis versus apicem parum dilatatis; tarsis posticis 4-articulatis.

Propygidium breve; pygidium oblique flexum, iriangulare. 
Corps ovale, légèrement convexe, luisant.

Tete convexe, enfoncée dans le prothorax jusquau milieu des yeux. liront sans strie ni dépression transversale qui le distingue de l'épistome; labre allongé arrondi au bout. Mandibules rétractiles, légèrement courbées en pointe aiguë, précédée d'une dent interne; yeux ovalaires peu saillants.

Antennes (fig. $11 n, 12 \%, 13$ s) insérées sur le front en dedans des yeux à une petite élévation; scape long, légèrement courbé et renflé au bout, logé dans une cavité large et bien marquée; funicule de sept articles; premier un peu plus gros et beaucoup plus long que le suivant; deuxième plus grêle et plus court, cependant dépassant les troisième et septième qui sont petits, assez serrés, presque égaux, terminés par des poils; massue ovalaire de quatre articles serrés pubescents. Fossette antennaire large peu nettement accuséc, sous le milieu du bord latéral au devant des hanclıes, l'antemne y pénètre par une légère incision du bord pectoral antéricur.

Màchoires cornées à deux lobes membraneux ciliés, interne terminé par un crochet corné, plus court que l'exferne. Palpes maxillaires (fig. $13 u$ ) de quatre articles; premier petit, deuxième obconique, troisième court, quatrième allongé, alténué et obtus au bout. Henton corné, transverse, bisinué en devant; languette membraneuse, paraglosses courtes obtuses; palpes labiaux de trois articles; premier court, deuxième et troisièmc épais, subglobuleux.

Pronotum beaucoup plus large que long, arqué à la base, curvilinéaire sur les cotés, fortement rétréci et peu échancré en devant avec les angles obtus, très abaissés, strie marginale fine, suivant le bord mais s'arrondissant un peu 
plus loin de l'angle antérieur. Ecusson très petit, triangulaire. Elytres plus ou moins convexes, arrondies sur les côtés, tronquées au bout, étroitement jointes au pronotum et de sa largeur à la base, bordées latéralement d'une petite strie marginale, et marquées quelquefois d'une courte strie dorsale oblique a la partie antérieure.

Prosternum (fig. $1 a, 2 b, 3 c, 4 c, 5 \int, 6 g, 7 k, 8 j, 9 l$, $10 \mathrm{~m}, 11 o, 12 \mathrm{p}, 13 \mathrm{l}, 14 x, 15 \mathrm{y}, 16 \approx, 17 \%, 185,19 \%$, 20 o, 21 \&, $22 \zeta, 23$ n) plan, parallèle, bordé d'une strie qui ne se continue pas ì la base, tronqué aux deux bouts, un peu rétréci au milieu, sans mentonnière; tantôt long et étroit, tantôt plus large et comme carré. Mésosternum plus ou moins large, avec une strie marginale souvent complète, le plus ordinairement séparée de l'épistome par une ligne de points, affectant des formes diverses.

Pattes allongées grêles, jambes antérieures (fig. 8 i) faiblement dilatées vers le bout, garnies de cils, postérieures grrèles ; tarses antérieurs de cinq articles repliés sur la jambe; intermédiaires de cinq articles également; postérieurs (fig. $3 d, 13 v$ ) de quatre seulement, libres.

Abomen de cinq segments, premier grand, bistrié entre les hanches posférieures ; deuxième à cinquième courts serrés, rentrant lorsque le pygidium se replie. Propygidium transrerse, court. Pygidium en triangle peu convexe, fortement incliné, mais non entièrement retourne.

M. J. L. Le Conte, dont les nombreux travaux sur les coléoptères des kitats-Unis, annoncent un entomologiste distiıgué, a constitué ce genre dans un article, publié en 1853 dans les Proccedings de l'Acatémie des sciences de Philudelphie. Son coup d'oeil sùr a saisi les différences essentielles qui séparent les Acrilus du reste des Abrous. Cependant 
M. Redtenbacher (Fn. Aust. p. 211) avait reconnu la composition des tarses de certaines espèces sans songer à les séparer. Cette anomalie, due à la réunion des deux premiers articles en un seul, qui est toujours plus long que les autres et conserve pour ainsi dire une trace de cette soudure, est si remarquable dans cette famille si homogène et dans laquelle toutes les autres espèces ont tous les tarses 5-articulés, qu'elle suffirait à elle seule pour l'établissement de cette nouvelle coupe. Niais un ensemble de caractères, que je ne répéterai pas, la forme générale scule, suffit pour les faire reconnaître au premier abord.

Ce genre renferme un fort grand nombre d'espèces, d'une taille très petite, vivant dans les mêmes circonstances que les Abraus. Ils sont répandus partout, disséminés dans toutes les parties du monde. Parmi les vingt-trois que jai étudiés en nature, cinq se trouvent en Europe, douze aux États-Unis, six dans les parties de l'Amérique méridionale baignćes par le golfe du Mexique. 
XIIII. Acritus.

ร99

$\underset{3}{\Xi}$

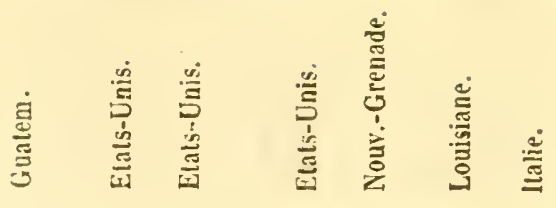
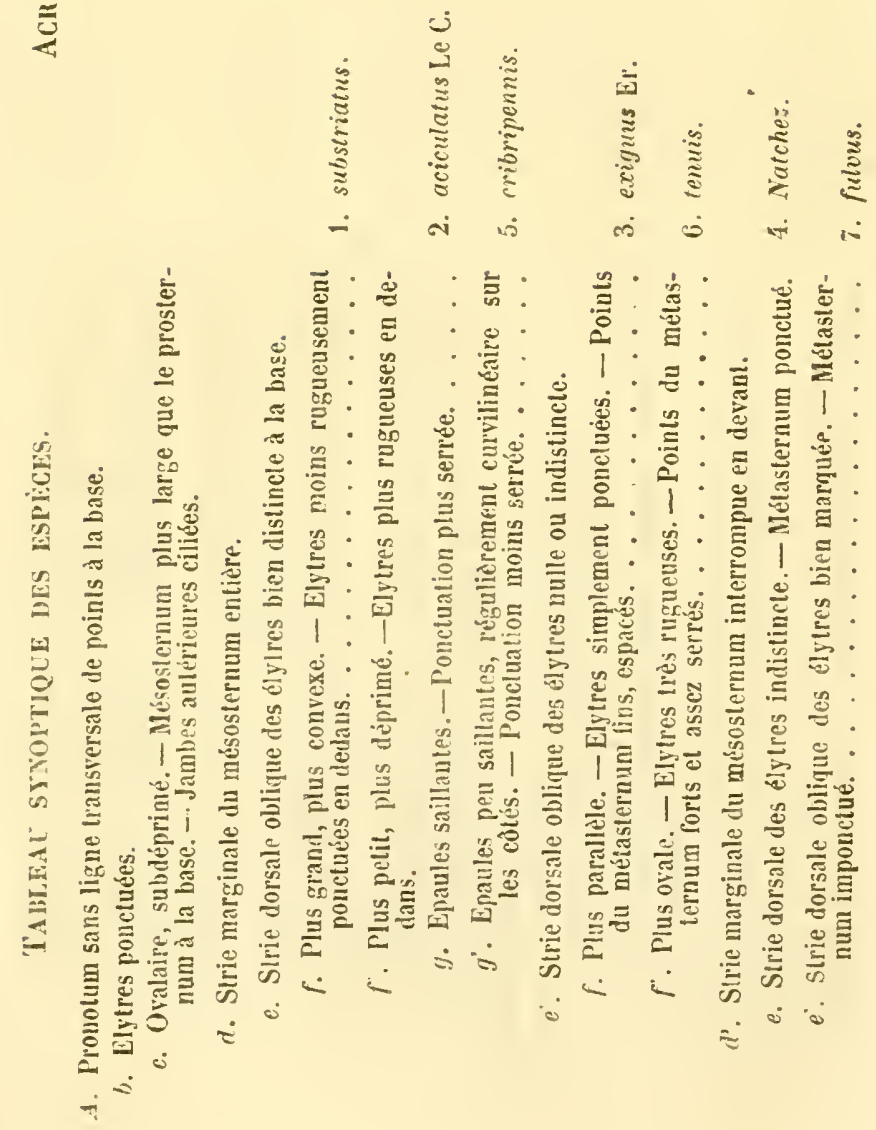

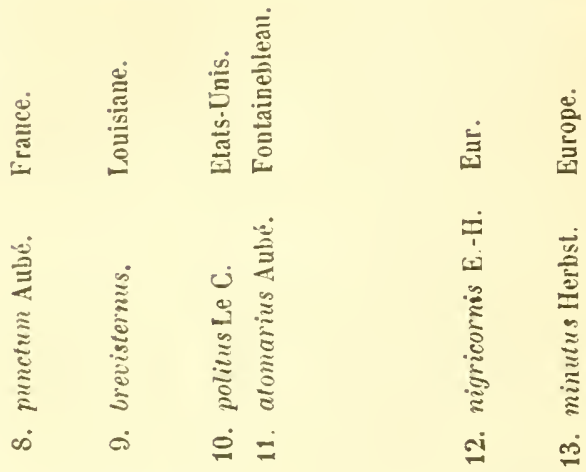

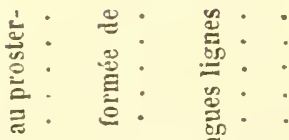

Е

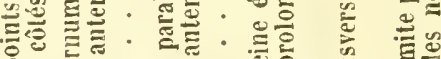

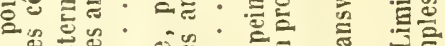

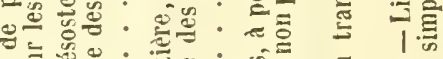

ॠ. छ:

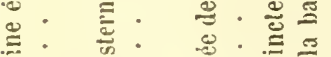
ह

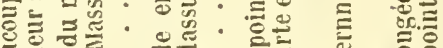

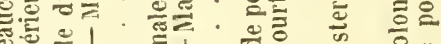

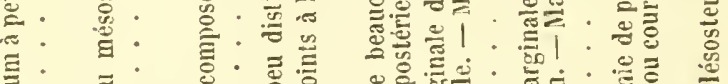

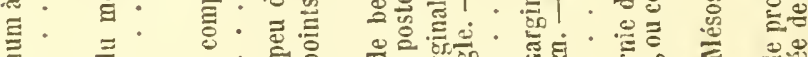

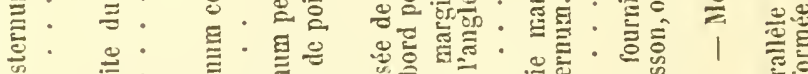

.

.

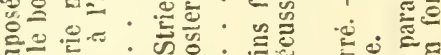

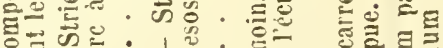

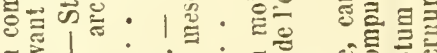
回芯 ¿.

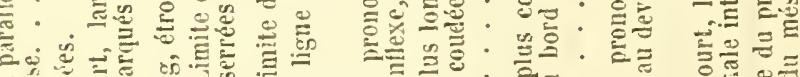

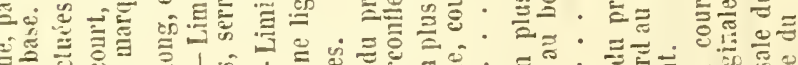

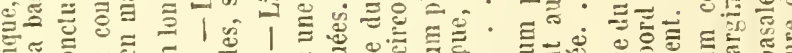

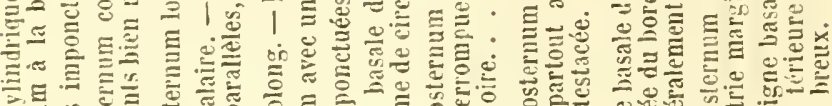
른

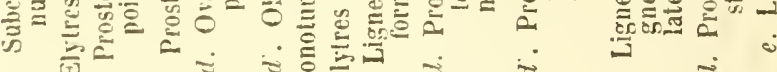


XLIII. Acritus.

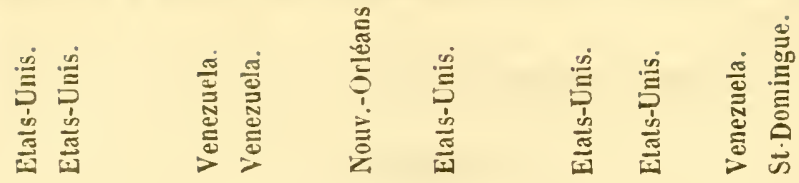

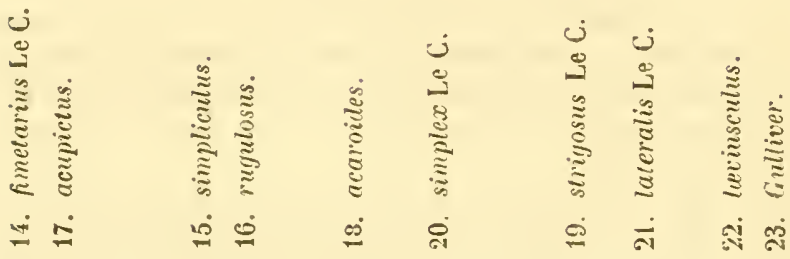

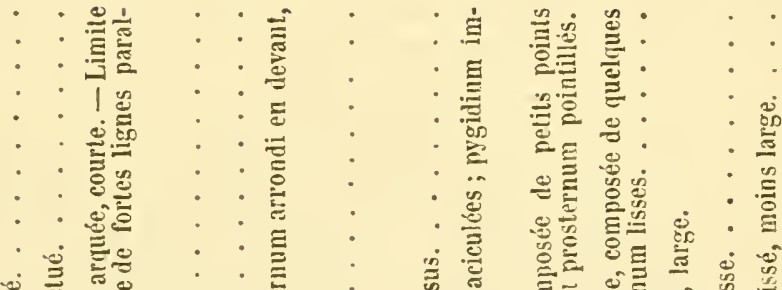

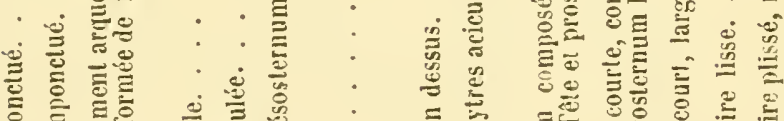

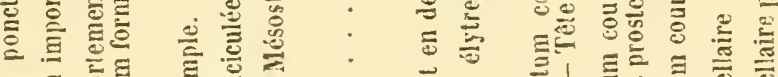

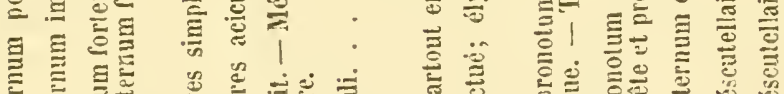

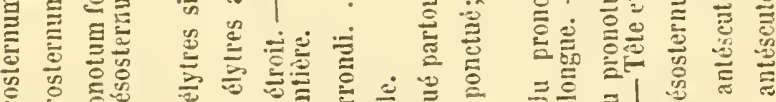

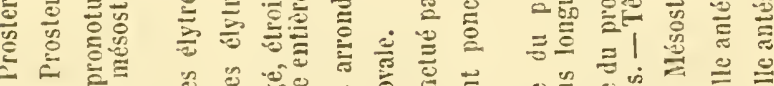

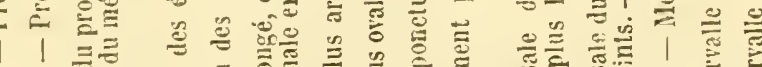

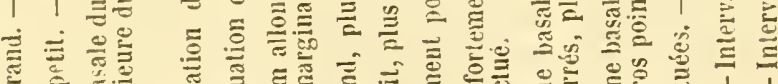

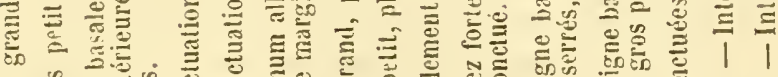

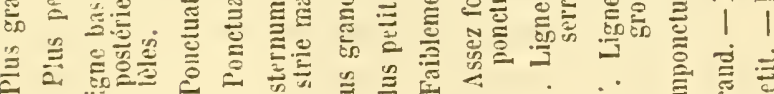

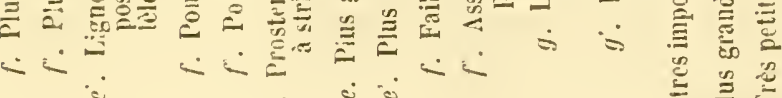
密点是 
A. Pronotum sans ligne transversale de points à la base (1-11).

b. Elytres ponctuées (1-8).

\section{A. SUBSTHITLS.}

Ovalis, convexiusculus, niger, nitidus, antennis pedibusque 'ufis ; rronoto parce, elytris parcius postice substrigoso-punctatis; mostemo bistriato, mesosterno antice subcequali stria inteyr'l, impunctatis; tibiis anticis parum apice dilatatis. Long. 1 mill.; larg. 112 mill.

Ovale, un peu convexe, noir luisant. Antennes ferrugineuses, massue testacée. Front bombé, un peu saillant sur les yeux, pointillé. Pronotum couvert de points espacés, bisinué á la base et bordé de points plus gros sur la marge même, sans ligne de points transversale, arqué sur les côtés, rétréci et échancré en devant avec les angles abaissés obtus. Ecusson ponctiforme. Elytres plus longues que le pronotum, de sa largeur à la base, curvilinéairement dilatées sur les cotés, rétrécies et droites au bord apical; strie oblique dorsale asse $z$ marquée, partant de la base et accompagnée d'un court rudiment externe; ponctuation plus forte, trìs espacée, avec quelques rides par derriére le long de la sutnre. Prosternum (fig. 1 a) assez long, bistrié, imponclué, rétréci au milieu, tronqué aux deux extrémités. Nésosternum subarrondi cu devant et un peu plus large que la base du pronotum; strie marginale entière. Patles ferruginenses. Jambes antérieures ciliées, ct un peu ćlargies au bout.

Guatemala. 


\section{A. ACicilatis.}

Ovalis, subdepressus, brumncus nitidus, pedibus fermugincis, cleva testeceu; fronte pygidioque punctulatis, pronoto punctis sat densis ante scutellum rugulosis; clytris humeris valde promimulis, sulura elevata, grosse muctutis, stria dorsali valida, (1)pendice auctu; prosterno longo, mesosterno murginato, stria posticu arcuata, merum crenulata. Long. 1 mill.; larg. 2/3̈ mill.

Abrceus uciculatus. Le C. N. Amér. Hist. p. 54, 1, t. vi, f. 10 (1845).

Ovale, déprimé, brun luisant. Antennes brunes, massue testacée. Front légèrement pointillé. Pronotum transverse, arrondi sur les côtés, rétréci en devant, bordé d'une strie marginale; peu convexe, couvert de points assez forts, plus serrés et ruguleux au devant de l'écusson, sans ligne transversale. Elytres courtes, un peu plus longues que le pronotum, de sa largeur à la base, fortement dilatées à l'épaule, subitement rétrécies au delá, couvertes d'une ponctuation beaucoup plus forte et plus serrée que sur le pronotum, ruguleuse vers le inilieu près de la suture qui est élevée, strie humérale oblique, très forte, touchant la base et accompagnée d'un court appendice externe. Pygidium finement ponctué. Prosternum (fig. 2 b) long, parallèle, un yeu rétréci au milieu, bordé d'une strie. Mésosternum plus large, entièrement rebordé, séparé du métasternum par une ligne arquée en devant, peu crénelée. Pattes ferrugineuses.

Sous les écorces, en juin et juillet, dans le terreau des troncs d'arbres pourris, dans le nord des Etats-Unis.

3. A. Exigles.

Picco-brunncus, nitidus, ovato-oblongus, parum depressus; 
ancunis, we pedibusque rufis; fronte mygidioque tenuissime, monolo purce, clylrisque sat dense ct fortius punctulatis; mumcris furum mominulis, striis dorsalibus indistinctis, sulura clcvatu; prostorno oblongo, mesosterno maryinato, stria postica subcrenala, impressa. Long. 1 mill. ; 2/3 mill.

Abre('us caxiguus Er. in Jahrb. 1, 208, 5 (18å4).

Brun de poix plus ou moins rougeâtre; légèrement convexe, ovale, oblong. Bouche et antennes rousses. Front faiblement pointillé, ainsi que le pygidium. Pronotum courl, arrondi et rebordé sur les côtés, rétréci en devant, couvert de points médiocres, peu serrés, un peu plus notables au milieu du bord postérieur. Elytres beaucoup plus íngues que le pronotum. de sa largeur à la base, peu dilatées aux épaules, plus densément et plus fortement ponctuées surlout au milieu vers la suture, qui est élevée. Prosternum (fig. $3 c$ ) allongé, tronqué et d'égale largeur devant et derrière, rítréci au milieu; mésosternum plus large, rebordé, séparé du métasternum par une strie crénclée au fond d'une impression transversale. Pattes ferrugineuses (fig. $3 d$ ).

Etats-Unis.

\section{A. Natriez.}

Oralis, demressiusculus, nigor, nilidus, sul grosse munctulalus; antemis pedibusyue rufo-lmrmucis; clytris obsolele striatis, sulura elevalu; prosterno bistrato, lrevi; mesosterno stria in. temmpla; metasterno punctato; tibiis anticis ciliatis, avice subdilatulis. Long. 1 mill.; larg. $1 / 2$ mill.

Ovale, lépriné, noir luisant. Antennes ferrugineuses, massue testarce, premier article du funicule plus long que le deuxième. Front un peu convexe, à peine distinctement pointillé, un peu saillant sur les yeux. l'ronotum court, ar- 
rondi à la base, sans ligne de points transversale, arqué sur les cotés, rétréci et échancré en devant avec les angles obtus abaissés, couvert de points espacés, fins, un peu plus forts au milieu. Ecusson ponctiforme. Elytres un peu plus longues que le pronotum, de sa largeur à la base, arrondies sur les côtés, tronquées au bout, couvertes de points assez forts en dedans et de quelques rides vers la suture; stries obliques obsolètes. Prosternum (fig. 4 e) plus long que large, rétréci au milieu, tronqué aux deux bouts, bistrié, lisse. Mésosternum subsinué, rebordé d'une strie interrompue; métasternum ponctué. Pattes ferrugineuses; jambes antérieures ciliées légèrement et insensiblement dilatées au bout.

Louisiane (États-Unis).

\section{A. CILIBRIPENNIS.}

Ovalis, subdepressns, niger, nitilus, grosse et parnm dense punctnlatns, antennis pedibnsque infis; elytris striu obliqna distincta; mosterno bistriato, levigato; mesostcrmo stria haud interrupta; tibiis anticis sensim subdilatatis. Long. 4/5 mill.; lirg. 1/3 mill.

Ovale, un peu déprimé, noir luisant. Antennes ferrugineuses, massue testacée. Front lisse, convexe, un peu saillant sur les ycux. Pronotum court, bisinué à la base, sans ligne de points transversale, laiblement arqué sur les côtés, rétréci et échancré en devant avec les angles obtus abaissés, couvert d'une ponctuation forte, espacée, régulière. Lcusson ponctiforme. Elytres un peu plus longues que le pronotum de sa largeur à la base, arrondies sur les côtés, fortement rétrécies au bout, avec l'angle sutural peu marqué, criblé de points plus gros et plus espacés encore que le pronotum, 
avec quelques rides longitudinales; suture un peu relevée; strie oblique bien marquée et forte. Prosternum (fig. $5 \mathrm{f}$ ) assez long, lisse, bistrié, rétréci au milieu, tronqué aux deux bouts. Mésosterıum arrondi en devant et bordé d'une strie entière. Pattes rousses; jambes antérieures ciliées, faiblement et insensiblement élargies au bout.

États-Unis.

\section{A. TeNuis.}

Ovatus, convexiusculus, niger nitidus, antennis pedibusque ferrngineis ; pronoto basi fortius, elytris intus validius subrugoseque parce punctatis, stria dorsali obsolela; prosterno subluvi bistriato, basi latiori, mesostemo stria integra; metasterno dense et valide menctato, tibiis anticis sensim apice dilatatis. Long. 4/5 mill. ; larg. 1/2 mill.

Ovale, faiblement convexe, noir, luisant. Antennes brunes, massue testacée. Pronotum court, arrondi à la base sans ligne de points, arqué sur les côtés, rétréci et échancré en devant, avec les angles abaissés obtus, couvert sur toute sa surface d'une ponctuation assez lorte, peu serrée, un peu plus forte vers la région scutellaire. Elytres ponctuées de même, avec quelques rides longitudinales en dedans; plus longues que le pronotum, de sa largeur à la base, curvilinéairement dilatées sur les côtés, rétrécies et tronquées au bord apical; strie dorsale oblique obsolète; suture élevée. Prosternum (fig. $6 \mathrm{~g}$ ) assez large, rétréci en devant, bistrié, à peine distinctement pointillé, tronqué aux deux extrémités. Mésosternum droit en devant et beaucoup plus large que la base du prosternum, bordé d'une strie marginale fine, non interrompue, et postérieurement d'une forte strie transversale crénelée. Métasternum couvert de 
points forts et assez serrés. Pattes ferrugineuses; jambes antérieures ciliẻes, et insensiblement élargies au bout.

Venezuela (Caracas), Nouvelle-Grenade (Carthagène).

\section{A. FCLVis.}

Ovalis subconvexus, sat dense punctulatus, rufo-brumneus nitidus, ore, antemnis pedibnesque testaccis; clytris stria dorsali obliqua distincta; prostcmo clongato bistriato, mesostcrno stria interrupta metasternoque lavigatis; tibiis anticis apice vix dilatutis, crtus ciliatis. Long. 1 mill. ; larg. 2/3 mill.

Ovale, médiocrement convexe, d'un rouge brun luisant, assez densément ponctué. Tête pointillée; front convexe, sans strie qui le sépare de l'épistome. Antennes et bouclıe testacées. Pronotum convexe, faiblement arqué à la base, arrondi sur les côtés, rétréci et échancré en devant avec les angles abaissés et obtus; strie marginale fine et entière. Ecusson ponctiforme. Elytres un peu plus longues que le pronotum, de sa largeur ì la base et lui adhérant étroitement, convexes, assez fortement ponctuées surtout en dedans, régulièrement curvilinéaires sur les côtés, fortement rétrécies et tronquées au bout; strie dorsale oblique bien marquée. Pygidium et propygidium ponctués. Prosternum (fig. 7 k) allongé, un peu rétréci vers le milicu, bistrié, plus étroit que le mésosternum, imponctué, ainsi que les deux segments suivants; mésosternum à strie interrompue. Pattes d'un testacé pâle; jambes antérieures (fig. 7 h) à peine dilatées au bout, assez densément ciliées en dehors.

Italie.

\section{A. penctum.}

Oblongoovatus, subparallelus, convexiusculus, rufo-brun- 
nens nitidus, ore, antemis pelibusque testaceis, supra sparsim et tcmuiter munctalus; clytris busi oblique striatis; prosterno clonyalo, busi angustiore, mesosterno latiludine cequali, lavigato, striis moryinatibus comiventibus; libïs anticis cxtus ciliatis, apice sensim parum dilutatis. Long. 1 mill.; larg. 1/2 mill.

A'rous punclum Aubé, Soc. Ent. (1S4Z) 232.

Tribalus minimus Aube, Soc. Ent. (1850) 324.

Ovale allongé, subcylindrique, médiocrement convexe, d'un rouge brun luisant. Tête finement pointillée; front conrexe, saillant sur les yeux. Antennes d'un testacé pàle; scape allongé un peu renllé au bout; premier article du funicule deux fois plus long que le suivant; deuxième encore un pen plus long que chacun des autres. Pronotum plus court que large, presque droit à la base, à peine arqué sur les côtés avec une strie marginale fine et entière; éclıancré et médiocrement rétréci en devant, avec les angles abaissés obtus; couvert de points fins épars. Ecusson ponctiforme. Elytres beaucoup plus longues que le pronotum, de sa lar.geur à la base, peu convexes, pouctuées comme lui, presque parallèles, rétrécies et tronquées au bout, plus rougeâtres, avec la suture élevée et une strie dorsale oblique bien marquéc à la base. Pygidium et propygidium très finement ponctués. Prosternum (fig. 8 j) beaucoup plus long que large, rétrèci à la base et légèrement sinué, iisse; strie marginale entière et non interrompue aux deux extrémités. Mésosternum arrondi en devant de la largeur du prosternum à peine, entièrement rebordé. Pattes d'un testacé pâle; jambes antérieures (fig. 8 i) ciliées faiblement et insensiblement dilatées vers le bout.

France méridionale; Italie.

L'llister minimus Rossi (Fu. Etrusc. I, 30, 71, 1790) doit- 
il se rapporter à l'Abreus globosus comme le pensait Paykull, ou bien est-ce le Tribalns minimus, selon qu'Erichson l'établit (Jahrb. p. 165 note) avec une assurance qui le ferait supposer entièrement fixé sur l'espèce de la Faune toscane? C'est une question que je n’oserais trancher qu'après l'inspection du type. M. Aubé, dans une petite note rectificative (An. de la Soc. Ent. 1S50, p. 324) dit qu'il a décrit le Tribalus minimus de Rossi sous le nom d'Abreus punctum. Je ne sais si son espèce est identique à celle d'Erichson ou si elle en diffère. Dans tous les cas, le type de l'Abriens puncıum Aubé, que j'ai pu voir dans plusieurs collections, u'est certainement pas un Tribulus. Quoi qu'il en soit, je m'en tiens provisoirement à l'opinion de l'auteur allemand, et je considère l'Abrusus punctum comme une espèce distincte.

B'. Elytres imponctuées $(9-11)$.

\section{A. BREVISTEIRUS.}

Ovalis, convexiusculus, miceus nilidus, Levissimus, antemnis redibustue rufo-leslacris; clytris stria ohsoleta; prostcrno longiludine latiori, bistriato; mesostcrno antice arcualo, stria interrupta, a metastcrno linea punctorum valida distinclo; libiis anticis ciliatis, paululum apice dilatatis. Long. 4/5 mill.; larg. $1 / 2$ mill.

Ovale, légèrement convexe, noir de poix luisant, très lisse et sans points. Antennes ferrugineuses, massue testacée; premier article du funicule plus long que le deuxième. Pronotum arrondi à la base, sans ligne transversale de points, arqué sur les côtés, rétréci et échancré en de-

3e Série, тоне 1 
vant, avec les angles obtus et abaissés. Ecusson à peine visible. Elytres plus longues que le pronotum, de sa largeur à la base, curvilinéairement arrondies sur les côtés, rétrécies et tronquées au bout; strie dorsale oblique obsolète. Prosternum (fig. $9 l$ ) court, beaucoup plus large que long, un peu resserré au milieu, tronqué en devant, subsinué à la base, bistrié. Mésosternum arrondi en devant, à peine plus large que le prosternum au point de contact, séparé du métasternum par une ligne de points assez forts, bordé d'une strie marginale interrompue. Pattes testacées; jambes antérieures ciliées, un peu dilatées au bout.

États-Unis (Louisiane).

\section{A. Molitus.}

Ovatus, converiusculus, piceus nilidus, lavigatus, cutennis pedibusque rufo-brunneis; prostcmo elongato, bistriato, mesosterno untice rotundato, stria interupta, a metasterno seric linearum tongitudinalium separato; tibiis anticis scnsim apice subdilutatis. Long. 1 mill. ; larg. $1 / 2$ mill.

Acritus politus J. L. Le C. Acad. Phil. (1853), p. 289.

Ovale, court, légèrement convexe, noir de poix luisant, imponctué. Antennes d'un brun ferrugineux. Pronotum court, arrondi à la base, sans ligne de points transversale, arqué sur les côtés, rétreci et échancré en devant avec les angles oblus, abaissés. Ecusson à peine visible. Elytres plus longues que le pronotum, de sa largeur à la base, curvilinéairement dilatées sur les côtès, rétrécies et tronquées au bord apical. Prosternum (fig. $10 \mathrm{~m}$ ) beaucoup plus long que large, bistrié, tronqué au deux bouts. Mésosternum arqué en devant, à peu près de la largeur du prosternum à sou point de contact, séparé du métasternum par une série 
transverse de lignes enloncées longitudinales; strie marginale interrompue. Pattes ferrugineuses; jambes antérieures ciliées, dilatées légèrement au bout.

Entièrement lisse et sans points comme les deux espèces voisines, il se distingue aisément de l'A. brevisicrnus par la longueur relative de son prosternum, et de l'A. atomurius par sa forme arrondie et non parallèle, ainsi que par la ligne de démarcation entre le mésosternum et le métasternum.

États-Unis.

\section{A. Atoharics.}

Oblongo-ovalis, parum convexus, brumncus, nitidus, lovvissimus, ore, antennis pedibusque ferrugincis; elytris subparallelis; prosterno bistriato, elonguto; mesostorno stria intern upta, “ metasterno vix distincte separato; tibiis anticis cilictis vi.c apice dilatatis. Long. 3/4 mill.; larg. 1/3 mill.

Abrceus atomarius Aubé, Soc. Ent. (1842), p. 231.

Ovale, un peu allongé, très faiblement convexc, d'un brun plus ou moins ferrugineux, très luisant, sans trace de points, si ce n'est quelques-uns à peine visibles au devant de l'écusson. Tète petite; front légèrement convexe, saillant sur les yeux. Antennes (fig. 11 n) ferrugineuses avec la massue d'un testacé pale; scape assez long, dilaté au bout; premier article du funicule beaucoup plus long et plus fort que le deuxième; les autres d'égale épaisseur décroissant progressivement en longueur. Pronotum trausversal faiblement bisinué à la base, arrondi sur les còtés; rétréci et échancré en devant avec une strie marginale fine. Ecusson à peine visible. Elytres deux fois plus longues que le pronotum, de sa largeur à la base, peu rétrécies au bout, 
sans stries ni points. Prosternum (fig. 11 o) moins large que long, bistrié, légèrement sinué à la base. Mésosternum arrondi en devant, bordé d'une strie marginale interrompue, à peine distinctement séparé du métasternum. Pattes grêles; jambes antéricures ciliées, à peine dilatées au bout.

Cette rare et jolie petite espèce, découverte dans la forêt de Fontaineblean dans les vieux troncs d'arbres pourris, est facile à distinguer de toutes nos espèces l'Europe par l'absence de points. On la reconnaîtra de toutes celles qui sont lisses comme elle parmi les exotiques, par son pronotum dépourvu de ligne de points anté-scutellaire, par sa forme allongée, presque parallèle, son prosternum allongé, sa strie mésosternale interrompue ct la limite antérieure de soll mélasternum.

A' Pronotum avec une ligne transversale de points à la base (12-23).

B. Elytres ponctuées (12-21).

12. A. Nigriconvis.

Ovalis convexus, subtilissime menctulatus, picens nitidus; antemuis cleva nigricante; pronoto line basuli c multis punctis composita, in medio arcuata, secus marginem continuala; prostcrno bistriato longiori, mesostcrno stria interrupla, ad anyulos utrinfuc fructa, parce punctulatis; libiis anticis versus apiccm dilatutis.

Hister niyricomis Ent. IIefte, II, 127 (1803). - Sturm, Deuts. Fn. 1, 253, 33 (1805). - Gyll. Ins. Suec. 1v, 272, 31 note (1827).

H. minutus Payk. Mon. Hist. 87, 71, 1. v11, f. 1 (1811). yll., Ins. Suec. I, 99, s11 (1808). 
Abrctus nigricornis Er, in Jahrb. 1, 207, : (1834); - Kxr. Brantl. I, 657, 4 (1839). - Ilecr, Fn. Helv. 1, 465, 4 (1S41). Küisı, Kixf. Eur. x1r, 45 (1848), --- Redt., Fn. Austr. 241 (1849). - Bach, Fu. Prus. I, 315, 4 (1849).

Orale, convexe, d'un noir de poix luisant, très finement ponctué sur la tête et le pronotum, plus distinctement sur les élytres, à peine visiblement sur le pygidium. Tete petite; front convexe, relevé sur les yeux. Antennes (fig. $12 q$ ) brunes; scape allongé; premier article llu funicule beaucoup moins épais, de la longueur des quatre suivants réunis; massue ovalaire noirâtre. Pronotum convexe, plus large que long, subbisinué à la base, arrondi sur les côtés, très rétréci et échancré en devant avec les angles abaissés obtus; strie marginale fine; ligne basale autéscutellaire, composée d'un grand nombre de points serrés, arquée au milieu, non anguleuse, suivant longtemps le bord vers les côtés. Ecusson très petit. Elytres un peu plus longues que le pronotum, de sa largeur à la base, arrondies sur les côlés, rétrécies et tronquées au bout, sans rudiment de strie dorsale oblique. Prosternum (fig. $12 p$ ) très allongé, bistrić, subparallèle, subsinué à la base; mésosternum plus large que lui, distinct du métasternum, bordé d’une strie se coudant en arc à l'angle et interrompue en devant, couvert, ainsi que le prosternum de quelques points très fins; métasternum un peu plus distinctement pointillé. Pattes ferrugineuses; jambes antérieures légèrement et insensiblement dilatées vers le bout, postérieures filiformes.

Cette espèce, beaucoup moins commune que la suivante, vit arec elle dans les charognes desséchées, dans le fumier, les détritus, les plaies des arbres, sous les écorces.,. Elle est répandue dans une grande partie de l'Europe: Suède, Angleterre, France, Suisse, Allemagne, Autriche, Italic. 
Ces deux espèces ont les plus grands rapports et ne peuvent se distinguer l'une de l'autre sans un examen attentif de certains caractères, qu'il est assez difficile d’apprécier dans des insectes si petits. La forme du mésosternum et du prosternum et la couleur des antennes sont les plus importants.

\section{A. Mistets.}

Ovalis parum convexus, picens nilidus, sat dense munctulatus, antemarum cliva lestecea; pronoto linea munctorum multorum basali, in medio arcuata secus margines continuala; prosterno mimus elongato, bistriato, hasi truncato, mesostcrno stria integru, ad angulos haud fracta; tibiis anticis vix apice dilatalis. Long. 1 mill. : larg. 2/3 mill.

llister mimulus Herlsst, Nat. Syst. Iv, 41, 15, 1. xxxvı, f. 4 (1791). - F. Syst. Eleut. 1, 90, 3/ (1S01). - Ent. Hefte, I, 109, 28 (1S(1) . - Sturm, Deuts. Fu. I, 252, 32 , 1. xix, f. B (1805).-Duft., Fil. Aıstr. 1, 280, 30 (1805). — Gyll., ins. Suec. 1, 99. 81 (1808).

Abrates minulus Er. in Jahrb. I. 208, 4 (1834) ; - Kaf. Brant. I, 697, 5 (1839). - Kïst., Kref. Eur. yv, 47 (1848). - Redt., Fr. Austr. 242 (18/9). - Bach, Fu. Prus. I, 316, 5 (1849).

Ovale, peu convexe, d'un noir de poix luisant. T'ête petite; l'ront convexe, saillant sur les yeux, firement pointillé. Antennes (figr. 13 s) brunes; scape allongé, peu renflé au bout; premier article du funicule de la longueur des (qualre suivants réunis, deuxiòne un peu plus large que les autres qui sont Ienticulaires; massue abrupte, ferruegrineuse. Pronotum beaucoup plus large que long, subbisinué ¿ la base, arrondi sur les côtés; fortement rétréci et échanrré en devant avec les angles abaissés obtus; densément et très fincment ponctué; strie marginale fine; ligne transversale de la base composée de points serrés nombreux, arquéc sans angle au milicu, suivant le bord sur les côtés. 
Ecusson peu visible. Elytres une fois et demie plus longues que le pronotum à la base, arrondies sur les côtés, rétrécies au bout, couvertes d'une ponctuation fine, serrée à la base, plus lâche vers le bout; quelques rudiments de stries dorsales obliques à la base. Pygidium lisse. Prosternum (fig. $13 t$ ) plus long que large, bistrié, presque parallèle, tronqué aux deux extrémités; mésosternum rebordé d'une strie entière, cotoyant régulièrement la marge, séparé du métasternum par une ligne transverse de points bien marquée; ponctuation du sternum faible et très espacée. Pattes ferrugineuses; jambes (fig. $13 r, v$ ) grêles, ciliées.

Il se trouve par toute l'Europe, dans les matières en décomposition. Je l'ai pris en abondance dans le fumier d'étable entassé dans les terres labourables pour servir à la préparation des ensemencés, de septembre en novembre.

\section{A. Fumetarits.}

Ovalis, subconvexus, piccus, nitidus, punctulutus, untennis pedibusque forrugineis; pronoto punctorum line maryini apmoximala antice concuva; clytris stria obliqua, muctis aciculatis; mesterno muctalo bistriato, brevinsculo; nesosterno munclato, antice rolumduto, stria intervepta, punctorum linca transversuli a metusterno distincto; tibiis articis ciliatis, apice dilatatis. Long. 1 mill.; larg. 1/2 mill.

Abrceus fimeturius Le C. N. Amér. Hist. 54, 4 (1845).

Ovale, légèrement convexe, brun de pois, luisant. Antennes ferrugineuses, massue testacée. Pronotum bisinué à la base, arrondi sur les côtés, rétréci et éclıancré en devant avec les angles abaissés obtus; couvert de petits points espacés ; ligue de points le long de la base, longue, fort rapprochée du bord et l'accompagnant peu de temps, arquée à convexité postérieure. Ecusson à peine distinct. Elytres 
plus longues que le pronotum, de sa largeur à la base, curvilinéairement dilatées sur les côtés, rétrécies et tronquées au bord apical; suture élevée; strie oblique bien accusée; poncluation fine assez peu serrée, aciculaire au milieu. Prosternum (fig. $14 x$ ) un peu plus longr que large, sinué à la base, bistrić, arec quelques points légers. Mésosternum arrondi en devant, rebordé d'une strie interrompue, distinct du métasternum par une ligne transverse de points nombreux, couverts l'un et l'autre d'assez forts points peu serrés. Pattes ferrugineuses; jambes antérieures ciliées, dilatées au bout.

Nouvelle-Orléans (Louisiane); Géorgic, dans le fumier.

\section{A. SHMpliculus.}

Ovalis, monum convexus, picens nitidus, parce muncticulatus, "untenuis pedibusque rufis; pronoto tinea punctorme catenuta arcuald brevi ante scutellum; clytris stria obliqua obsolelissima; prosterno bistriato, subquadralo; mesosterno latiori, stria marginati interrupta, linea punctorum oblongorum a metastemo distincto; libiis anticis ciliatis apice dilatatis. Long. 3/4 mill. ; larg. 1/3 mill.

Ovale, peu convexe, brun de poix, assez luisant. Antennes ferrugineuses, massue testacée, premier article du funicule court, quoique plus long que le deuxième; front bombé. Pronotum bisinué et hordé de longs points à la base, arrondi sur les cotés, rétréci et échaneré en devant avec les angles obtus, abaissés; couvert de petits points fort espacés; ligne de points antéscutellaire arquée, convexe en devant, courte, cnchainée. Ecusson à peine distinct. Elytres plus longues que le pronotum, de sa largeur à la base, curilinéairement dilatées sur les côtés, rétrécies et tronquées 
au bout, peu densément pointillées, sans rides; suture élevée, strie dlorsale oblique, obsolète. Prosternum (figg. 15 y) à peine plus long que large, bistrié, tronqué aux deux louts, presque rectangulaire. Mésosternum beaucoup plus large que le pronotum, séparé du métasternum par une ligne droite de points oblongs, peu nombreux; strie marginale interrompue. Pattes ferrugincuses; jambes antérieures cilićes, légèrement dilatées au bout.

Caracas (Venezuela).

\section{A. Rugulosus.}

Ovalis, convexiusculus, piccus, nilidus, antomnis pedibusque rufis; îronoto parce puncticulato, linea arculu brevi u scutello distunte; elytris dor'so aciculato-rugosulis; prosterno brevi bistriato, subquadrato, mesosterno stria interruptc oblongorum punctorum scrie transversa a metusterno distincto; tibiis unticis apice parum dilatatis, ciliatis. Long. 3/4 mill.; larg. 1/3 mill.

Ovale, légèrement convexe, brun de poix, luisant. Antennes ferrugincuses. massue testacće, premier article du funicule plus long que le deuxième. Front bombé, saitlant sur les yeux. Pronotum bisinué à la base, arqué sur les còtés, rétréci et échancré en devant avec les angles obtus abaissés, couvert de très petits points rares; ligne arquéc au devant de l'écusson, courte, formée de points longs, assez distante du bork. Ecusson ponctiforme. Elytres plus longues que le pronotum, de sal largeur à la base, curvilinéairement dilatées sur les côtés, rétrécies el tronquées au bout, très superficiellement pointillées, et ridées lonģitudinalement sur le dos. Prosternum (fig. 16 s) court, tronqué aux deux bouts, presque carré, un peu resserré au milicu, bistrié. Mésosternum plus large au point de contact, sé- 
paré du métasternu n par une ligue droite de points oblongs ; bordé l'une strie interrompue. Pattes ferrugineuses. Jambes antérieures un peu dilatées au bout, ciliées en dehors.

Caracas (Veuczula).

\section{A. AcUpiCTUS.}

Ovalis, mfo-brunno'us, antennis palibu que pullidis; monoto parce, clytris aciculatim, tonuiter punctulatis, linca punctorum basuli subrcctu; capite pygidioque lavibus; prostcrno marginato quadrato, mesosterno tato, punctutato, stria marginali interrupta postice linea menctoram recta. Long. 1 mill.; larg. 3/4 mill.

Ovale, peu convexe, brun ferrugineux luisant. Front lisse. Antennes rouges, massue pâle. Pronotum légèrement arqué à la base, courbé sur les côtés et rétréci en devant avec une strie marginale fine, couvert de points fins et espacés; ligne basale à peine arquée au milieu, composée de points scrrés réunis, l'intervalle postérieur plissé. Elytres déprimées, de la largeur du pronotum à la base, curvilinéaires sur les côtés, rétrécies et tronquées au bout, aciculairement et finement pointillees. Propygidium et pygidium lisses. Prosternum (fig. 17 a) presqu’en carré, rebordé, imponctué. Mésosternum large, avec des points faibles épars, séparé du mélasternum par une ligne droite le points peu allongés, strie marginale interrompue en devant. Pattes rousses.

États-Unis, sous les écorces des arbres pourris.

\section{A. ACAROIDES.}

Dvalis, convexus, piceus, nitidus, untennis pedibustne ferrugincis; momoto punctuluto, lineu punctorum busali anlice con- 
cava margini approximata; elytris aciculatis siria obliqua tenui; prosterno bistriuto, postcrius angustiori, mesostcrnoque marginato munctatis; tibiis anticis ciliatis, apice dilatatis. Long. 1 1/5 mill.; larg. 2/3 mill.

Ovale, convexe, brun de poix, luisant. Antennes ferrugineuses, massue testacée. Pronotum bisinué à la base, arrondi sur les côtés, rétréci et échancré en devant avec les angles abaissés obtus, couvert de points fins et assez serrés; ligne basale de points fort rapproclıée du bord, arquée à convexité postérieure. Ecusson ponctiforme. Elytres beaucoup plus longues que le pronotum, de sa largeur à la base. curvilinéairement dilatées sur les côtés, rétrécies et tronquées au bout; strie dorsale oblique obsolète; ponctuation espacée, aciculaire dans la partie postérieure. Prosternum (fig. $18 \beta$ ) bistrié, un peu plus long que large, rétréci postérieurement et tronqué à la base, couvert de points espacés. Mésosternum de la largeur du pronotum à la base, ponctué de même et entièrement rebordé. Pattes ferrugineuses; jambes ciliées, antérieures dilatées au bout.

Géorgie, Caroline et Louisiane (États-Unis).

\section{A. STRIGos!'s.}

Ovalis, convexiusculus, brumeus, nitidus, antemnis pedibusque ferrugincis; fironte tenuissime, clytris aciculution pronotoque parce sal fortiter muctatis, hoc munctorum linea basali subrect, illis stia humcrali abbreviala; mopygidio punctato, mysidio subgranuloso; mosterno clongato mesosternoquc anlice rotumdato puretutis maryinutisque. Long. 1 mill.; larg. 1/2 mill.

Acritus strigosus J. L. Le Conte, I'roceed. Acad. Philad. 1853, p. 259 . 
Orale, assez convexe, brun luisant. Antennes ferrugineuses, massue lauve. Front légèrement pointillé. Pronotum large, transversal, arqué à la base, curvilinéaire sur les côtés arec une strie marginale, rétréci et à peine échancré en devant, couvert de points espacés assez notables; ligne basale presque droite formant un sillon crénelé, composée de beaucoup de points. Elytres beaucoup plus longues que le pronotum, de sa largeur à la base, légèrement dilatées sur les côtés, rétrécies et tronquées au bout, fortement aciculées, c'est-à-dire couvertes de points espacés, notables, prolongés en devant par une fine strie comme une pointe d'aiguille; suture élevéc, strie humérale courte, oblique, distincte. Propygidium arec quelques points. Pygidium paraissant à un très fort grossissement couvert de très fines granulations sans points distincts. Prosternum (ijg. $19 \gamma$ ) allongé, étroil, subparallèle; mésosternum arrondi en devant, séparé lu métasternum par une série de points peu marqués ; l'un et l'autre rebordés et pointillés. Pattes rousses.

Etats-Unis.

20. A. SIMPLEx.

Ovalis, subconveazus, mifo-brunens, nitulus, antemis padibusque mpis; perce punctulutns, monoto distinctius, basali punctorum linere brevi subrecta, olytris stria hmerali distincta sutura slevata; mostcrno clongato, Irevi, marginato; mesostcrno stria maryinali integra, antice arcuuto, postice serie munctorum simbuta a mctasterno distincto. Long. 1 mill.; larg. $1 / 2$ mill.

Acritus simplex Le Conte, N. Amér. Ilist. 1845, p. 54, 2, 1. $11,1.11$. 
Ovale, légèrement convexe, rouge-brun luisant. Antennes ferrugineuses, massue jaune. 'Tete convexe, avee des points très fins disséminés. Pronotum légèrement arqué à la base, fortement sur les côtés arec une stric marginale fine, très rétréci et à peine échancré en devant, avec les angles abaissés; ponctuation éparse, assez légère, ligne basale de points assez forts enchaînés, presque droite, courte. Elytres beaucoup plus longues que le pronotum, de sa largeur a la base, curvilinéaires sur les côtés, très rétrécies et tronquées au bout, suture relevée, strie humérale courte, oblique; ponctuation très faible et très espacée surtout à la base. Pygidium avec quelques petits points. Prosternum (fig. 20 خे) allongé, rebordé; mésosteruum arrondi au bout, séparé du métasternum par une ligne sinueuse d'assez forts points, entièrement rebordé. Pattes rouges.

Etats-Unis.

\section{A. Lateralis.}

Ovalis, convexiusculus, piceus, nitidus, antennis pedibusque rufis; fronte lavi, mygidio subgramuloso; pronoto, linea basuli brevi recta punctorum pancorum, parce munctulato, elytris sutura elevata, punctis parcis, breviter aciculutis; prosterno longo, marginato lavique; mesosterno punctalo, recta serie punctorum a metasterno disjuncto, stria narginali haud interrupta. Long. $5 / 6$ mill. ; larg. 1/2 mill.

Ovale, assez convexe, noir luisant. Front lisse, antennes rousses. Pronotum large, arqué à la base, arrondi et rebordé sur les côtés, fortement rétréci et à peine échancré en devant, avec les angles très abaissés; couvert de points fins; ligne basale courte, droite, composée de gros points isolés en petit nombre. Elytres beaucoup plus longues que 
Ie pronotum, de sa largeur à la base, curvilinéaires sur les côtés, rétrécies et tronquées au bout, couvertes de points assez forts espacés, brièvement aciculés; suture relevée. Pygidium imponctué, finement granulé. Prosternum (iig. 21 s) allongé, presque parallèle, lisse, rebordé; mésosternum à peine plus large en devant que le prosternum, entièrement rebordé, distinctement ponetué, séparé du métasternum par une série de points assez forts désunis, en ligne droite transversale. Pattes ferrugineuses.

Etats-Unis.

B'. Elytres lisses et imponctuées (22-23).

\section{A. LAVILSCILUS.}

Ovalis, subconvexus, piceus, nitidus, ore, antennis nedibusque testaceis; fronte convexa; rronoto parcius puncliculato, linea munctorum basali calenalu arcuala; tytris lavissimis, siria obliqua, apice tenuissime reticulatis; prosterno subqualrato, bistriato; mesosterno stria interrupta linea cblongorum punctorum a metasterno distinclo; libiis anticis, apice vix dilalatis. Long. 2/3 mill. ; larg. $1 / 3$ mill.

Ovale, peu convexe, noir de poix luisant. Têle lisse; front élevé au dessus des yeux. Antennes testacées; scape allongé, courbé el dilaté au bout, premier article du funicule plus long et plus fort que le suivant; massue abrupte ovalaire, terminéc en pointe. Pronotum plus large que long, fortement rétréci en devant, bisinué à la base et en angle oblus au milieu, légèrement arqué sur les côtés, avec quelpues pelits points très fins, très écartés; ligne de gros points enchaînés au devant de la base arquée. Ecusson a peine vi- 
sible. Elytres beaucoup plus longues que le pronotum, de sa largeur à la base, légèrement rétrecies vers le bout, relevées sur la suture, entièrement lisses avec deux strics obliques rudimentaires a la base, ct une fine réticulation visible au microscope vers le bout. Prosternum (fig. 22 ऊ) bistrié, un peu plus long que large, coupé droit en devant comme à la base; mésosternum court, appliqué contre la base du prosternum, rebordé seulement sur les côtes, séparé du métasternum par une ligne transversale droite de gros points oblongs. Pattes grêles; jambes antérieures à peine élargies.

Diffëre de l'A. alomarius, avec lequel il a les plus grands rapports, par la ponctuation du pronotum, la ligne de gros points qui longe sa base, la réticulation du bout de ses élytres et l'existence des stries dorsales; enfin la ligne de points oblongs qui sert de limite antérieure au métasternum.

Caracas (Venezuela).

\section{A. Gulliver.}

Oblongo.ovalis, parum convexus, piceus, nitidus, lavissinus, antemis pedibusque rufo-testaccis; pronoto linea muctorum basali arcuata, spatium trigonum plicatum inchudente; mosterno bistriato subquadrato; mesosterno stria interrupta, linca transversali munctorum recta a metasterno distincto; tibiis anticis ciliatis, apice dilatatis. Long. 2/3 mill.; larg. 1/3̈ mill.

Ovale, un peu oblong, faiblement convexe, brun de poix luisant, lisse el imponctué. Antennes rouge-testacé. Pronotum bisinué à la basc, arrondi sur les côtés, rétréci et échancré en devant avec les angles abaissés obtus; ligne basale de points courte, arquée et assez forte, circonscri- 
vant un espace triangulaire plissé. Ecusson à peine visible. Ejytres beaucoup plus longues que le pronotum, de sa largenr à la base, courbées sur les côtés, rétrécies et tronquées au bout. Prosternum (fig. 23 n) un peu plus long que large, bistrié, tronqué aux deux extrémités. Mésosternum séparé du métasternum par une ligne droite de points oblongrs, strie marginale interrompue. Pattes testacées; jambes antérieures ciliées, dilatées au bout.

Cel insecte, le plus petit du genre et de toute la famille, a quelques rapports avec l'A. alomarius dont il se distingue par la ligne de points qui longe la base du pronotum. On ne peut pas le confondre davantage avec l'A. leviusculus qui est plus grand, plus convexe, et dont le corselet est visiblement ponctué et la strie dorsale oblique des élytres mieux accusée.

Il a élé trouvé en juillet sous les écorces des arbres morts en décomposition, à Santo-Domingo (Haïti).

Espèces douteuses ou que je n'ai pas vnes.

\section{(a) Acritus Seminulum,}

Küst. Kæf. Eur. xv, 27 (1818) (Abreus).

Convexiusculus, subliliter punctalus, piceus, nilidus; antennis ferrugincis, pronoto postice linea transversu, impressu; tibiis anticis simplicibus. Long. 1 1/4 mill.; larg. 2/3) mill.

'I'rès voisin des A. Whombophorus et mimulus, il se distingue du premier par les jambes simples, et du deuxième par la ligne transversale enfoncéc à la base du pronotum. Corps un peu convexe, très luisant, d'un brun de poix rougeâtre; antennes en culicr d'un jaune ferrugineux, un peu plus 
longues que la tète; massue en ovale courl, presque ronde, couverte d'un duvet gris. Tête courte, arronlie, abaissée, presque plane, finement ponctuée. I'ronotum une demifois aussi large que long, profondément échancré en devant. ì peine arrondi sur les côtés, rétréci par devaut, angles postérieurs droits, surface très finement et vaguement ponctuće; au devant de la partie anguleuse de la base se trouve une ligne transversale composée de points serrés plus grands, qui s'infléchit de part et autre et se continue quelque temps le long du bord postérieur, oủ enfin elle devient une bordure de gros points. Ecusson invisible. Elytres de la largeur par devant de la base du pronotum, un peu élargies au dessous de l'épaule, et se rétrécissant de là jusqu'au bont, qui est tronqué, lessus finement et peu densément ponctué, avec quelques stries obliques à la base; les points sont toujours plus fins dans la partie postérieure et disparaissent entièrement an bord apical; strie marginale élevée et disparaissant vers le milieu dans le bord latéral. Propygidium et pygidium légèrement convexes, très finement ponctués, d'un brun de tan. Dessous luisant, poitrine finement ponctuée latéralement. Pattes jaune-ferrugineux, jambes antérieures à peine élargies an bout, postérieures grêles et minces.

Monténégro.

(b) Acritrs consobrincs Aubé, Soc. Ent. (1850), 323, 32 (Abreus).

Picous, nitidus, valde sparsim munctatus; tibiis anticis tonue rotundatim ampliatis. Long. 1 mill.

II a la plus grande analogie avec le gramulum, dont il dif3e Série, TONE IV. 
fère cependant par la taille un peu plus petite, la ponctuation un peu plus làche, un corselet plus court, et principalement par la forme des jambes antérieures qui sont moins fortement dilatées, régulièrement arrondies en dehors; en outre, la dilatation naît et finit insensiblement de l'articulation de la cuisse à celle de la tarse, tandis que, dans le gramulum, la jambe est brusquement élargie.

Batoum en Iméritie.

(c) Acritus obliques Le C., N.-Amér., Hist. 54, 3. Pl. VI, 12 (1845) (Abraus).

Punctatus; elytris stria basali obliqua, abbreviata. Long. $11 / 3$ mill.

Noir ou couleur de poix, luisant, ovale, légèrement convexe, ponctué. Pronotum à peine échancré en devant, étroitement rebordé postérieurement. Elytres à strie basale oblique, raccourcie par derrière, placée près des bords latéraux: lleux stries marginales profondes. Pattes rougebrun. Pygidium ponctué.

Caroline (Eiats-Unis).

(d) Acritus maritimus J. L. Le C. Gol. Calif. 46, 1 (1851) (Abraus).

Oblongus, mimus convexus, niger, pronoto parce munctato, basi immarginuto, elytris minus dense punctatis, stria obliqua dimidiata notatis, myidio impunctato. Long. 4/5 mill.

San-Diego (Calilornie). Dans les fucus en putréfaction.

\section{(e) ACritus basalis,}

J. L. Le C., loc. cit. 46, 2 (1851) (Abreus).

Oblongus, subdepressus, piccus, marce subtiliter punctatus, 
pronoto basi striolato, medio marginato, clytris striola mella dorsali inuressis, haterali temi ; humeris lateribusque lavibus, pygidio parce punctulato. Long. $2 / 5$ mill.

Sous les écorces, près des bords du R. Colorado et du Gila (Californie).

Cette espèce me semble devoir se rapporter à l' $A b$. rugulosus, mais je noserais l'affirmer. Dans un genre comme les Abreus, une simple diagnose est insuffisante, et pour reconnaître l'espèce d'une manière certaine, il serait nécessaire de confronter les types.

(f) Acritus niscus J. L. Le C., Proceed, Acad. Philad. vi (1853), p. 289.

Rotundatus, minus convexus, nigro-piceus, thorace subtilissime, elytris subtiliter sat dense punctatis, illo basi murginato; pygidio lctvi. Long. 1 mill.

Deux individus sous les écorces, dans la Géorgie supérieure.

Corps rond, moins convexe que de coutume, noir de poix luisant. Tête très obsolètement pointillée. Pronotum très finement pointillé, avec une ligne transverse distincte au milieu de la base. Elytres finement et assez densément ponctuées, très légèrement aciculées. Epipleures larges, finement pointillées; strie latérale profonde. Pygidium imponctué. Dessous finement ponctué. Pattes rousses; jambes antérieures, très légèrement dilatées graduellement.

(g) Acritus conformis J. L. Le G. Proceed. Acad. Philad. (1854), p. 289.

Rotundatus, convexus, vix ovalis, piceus vel rufo-piceus, 
thorace subliliter punctululo, basi medio marginato; elytris punctatis, postice subrugosis, lateribus lavibus, stria laterali profunula, mgidio impunctato. Long. 1/2 mill.

Géor gie, sous les écorces.

Semblable pour la forme à l'A. fimetarius, mais seulement moitié aussi grand et un peu moins globuleux; varie en cunleur du noir de poix ou roux-brunâtre. Pronotum très finement ponctué ; milieu de la base distinctement rebordé. Elytres plus finement, pas densément ponctuées; points postérieurement plus petits et mêlés d'égratignures, les côtés et les épipleures sont polis, la strie latérale profonde. Pygidium imponctué ; postpectus distinctement couvert de points épars; jambes antérieures légèrement dilatées.

(h) Acritus analis J. L. Le C., Proc. Acad. Philad. (1853), 290.

Piceus, modice convexus, leviter ovalis, thoruce punclulato, busi melio marginuto, elytris punclutis et postice subrugosis lateribus levibus, stria laterali profunda, pygidio subtiliter punctuluto. Long. 1/2 mill.

Un exemplaire de Cuba.

(i) Acritus atomes.

J. I. Le C. Proc. Philad. (1853), vi, p. 291.

Rotundutns, fere depressus, rufus, thorace elyırisque aciculuto-punctutis; mygidio vix punctulalo. Long. 4/5 mill.

Lin exemplaire de Cuba.

Corps circulaire, déprimé, luisant, roux. Tête finement poinlillée. Pronotum et élytres grossièrement et deısément ponctués, poncluation quelque peu aciculée. Pygidinn finement el olssolètement pointillé; jambes antérieures non dilatées. 


\section{ESSAI MONOGRAPHIQUE \\ SUR LA FAMILLE DES HISTERRIDES}

(Suite) (1).

Par M. S.-A. de MARSEUL.

(Séance du 9 Février 1853.)

Mon Essai Monographique sur la Famille des IIistérides touche à son terme. J'ai passé successivement en revue la série des genres et des espèces. La Société Entomologique, arec un empressement qui m'honore, a poursuivi sans relâche la publication de ce travail: chaque uuméro de nos Annales, depuis 1853, a fourni son contingent; et cependant il n'a pas fallu moins de $\mathbf{4}$ ans pour le compléter. Il contient, en effet, la description détaillée de plus de 700 espèces, réparties dans $\mathbf{4 3}$ genres, et la figure d'après nature de toutes les espèces, avec de nombreux détails génériques ou spécifiques, dans 23 planches tellement chargées qu'elles renferment plus de six fois la matière des planches ordinaires.

Lorsque j’offrais à la Société ces prémices de mes études entomologiques, j’étais loin de prévoir toute l'étendue de ma tåche. Depuis lors, l'attention s'étant portée sur celte famille, de nombrcux matériaux m'ont été fournis. M. le Docteur John L. Le Conte, de Philadelphie, a mis à ma

(1) Voyez $3^{\text {e }}$ séric, T. 1 (1853), p. 131 et 447; T. II (1854), p. 161, 525 et 671 ; T. Ill (1S55), p. S3 et 327 , et T. IV (1856), p. 97, 259 el 549 .

3e Série, tone v. 
disposition sa riche collection de Coléoptères des Etats-Unis, avec un aimable et généreux empressement; M. Andrew Murray, d'Elimbourg, m'a communiqué des espèces curieuses du Vicux Calabar; MII. Asa Fitch, des Etats-Unis, Wollaston de Londres, m'ont été d'un grand secours; je les en remercie publiquement. Cette accumulation suceessive a pu contrarier l'unité du plan, mais elle a cnrichi mon travail et l'a rendu plus utile et plus complet.

Il ne me reste plus maintenant qu'à coordonner tous ces éléments; à donner quelques idées sur l'ensemble de la famille, son organisation, ses mœurs, sa distribution géographique; à disposer systématiquement dans un tableau clair et méthodique, les genres dont elle se compose, comme je l'ai fait pour les espèces de chaque genre: ainsi j'aurai rempli ma promesse.

Nalgré les nombreuses espèces nourelles que j’ai décrites, il en est encore beaucoup que je n'ai pas connues en temps opportun; et une révision complète de mon travail pourrait offrir déjì de l'intérêt. Mais ce serait peut-être aujourd'hui une entreprise hasardeuse et, prématuréc. Le nombre des nouvelles espèces ira croissant rapidement, les observations et les critiques que j'appelle de tous mes vœux, me metlront sur la voie des améliorations à introduire, la communication des types me permeltra de reconnaître certaines espèces des auteurs qui me sont restées inconnues. Alors ce sera le moment d'entreprendre quelque chose de sćrieux ê de réellement profitable à la science. Je sens, d'ailleurs, que ce serait abuser de la complaisance de mes collègues; ct j'ai hàte de laisser libre à d'autres le champ que j'occupe depuis trop longtemps. Je me bornerai done à exposer l'une manière concise: 
10 Les caractères distinctifs de la famille;

$2^{2}$ Les variations de forme qu'affectent les principaux organes externes dans les tribus et les genres.

L'anatomic intérieure le ces insectes n’a été le sujet d'aucun traité spécial; le peu que nous en savons, est dù au savant Entomotomiste M. L. Dufour, qui en a dit quelque clrose incidemment dans un ménoire publié par l'Acadénie des sciences. Je ne me sens pas en mesure de combler cette lacune. Ces études sortent de mon cadre et exigent une publication ì part.

$3^{\circ}$ Les métanorphoses et les mœurs; la distribution géographique.

$4^{0}$ L'histoire des travaux publiés sur cette famille; les développements successifs qu'elle a reçus;

$5^{\circ}$ Le tableau synoptique des tribus et des genres que j'ai adoptés ;

$6^{\circ}$ La description des espèces que je n’ai pu reconnaître dans les auteurs et qui m'avaient échappé lors de la publication de leurs genres respectifs; le signalement plus complet de celles que j'ai pu me procurer depuis; enfin un genre nouveau fort intéressant et quelques cspèces remarquables.

Ces généralités seront closes par une table alphabétique de toutes les espèces citécs dans la Monographie. Chaque espèce est précédée de l'initiale lu genre el du no d'ordre qu'elle y occupe; elle est suivie du nom abrégé de l'auteur et de la date de sa publication, du volume et de la page où elle se trouve citce dans la monographie.

Un catalogue systématique des tribus, des genres et les espèces, présentera une vue complète de la famille 
et remédiera aı défant d'ensemble. Il me permettra également d'éviter ces longues listes si fastidieuses et sans intérêt, connues sous le nom d'errala, corrections. Il contiendra plusieurs rectifications de noms, résultat d'erreurs typographiques ou autres. Quant aux fautes sans importance, je m'en remets à la sagacité du lecteur et compte sur son indulgence.

Convaincu de l'importance du principe de n'employer qu'une seule fois le mème nom spécifique dans chaque groupe, j'ai cru devoir l'appliquer dans la famille des Histérides. Je propose donc un nouveau nom pour les espèces formant double emploi, mais seulement lorsque ces noms sont de mon fait; car je respecte ceux des autres. En un mol, j'étends au groupe le droit de priorité admis généralement pour le genre, et j'espère que la Socićté voudra bien admettre ce principe et le consacrer.

Eufin je donne dans ce catalogue la synonymie des espéces du Catalogue Dejean, dont j’ai vu tous les types dans la collection de M. le Mis de la Ferté-Sénectère; ce n'est pas que j’attribue un droit de priorité aux noms de collection ou de catalogue, système qui a jelé beaucoup de confusion dans la science; mais comme cet ouvrage a servi longtemps de régulateur dans le classement des collections, ce rapprochement facilitera la reconnaissance des espèces aux amateurs qui les conservent sous ces noms.

\section{Caracteires distinctifs de la fanille}

\section{jes Histérines.}

Antenne fractix, retractiles, scapo elongato, funiculo 7-articulato, clava solida, 
Mandibule validx, arcuat $x$, acuminate.

Maxille cornex, malis 2 membraneis, apice cilialis; palpis filiformibus 1 -articulatis.

Menum corneum, ligula brevi paraglossisque membraneis, palpis filiformibus 3-arliculatis.

Pronotum antice emarginatum, basi clytris arcte applicatum.

Elytra abdomine breviora, apice truncata, sutura recla, alas penitus tegentia.

Prosternum prominens mesosterno arcte connexum.

Pedes retractiles, coxæ anticæ transversæ, posteriores ovata magis inter se, ab intermediis valde distantes.

Tarsi 5-articulati. (Acritus tantum apud genus postici 4-articulati).

Abdomen 5 segmentis, $3^{\circ}$ parte ventrali supra producta, pone dorsalem adnexa, 40 et $5^{\circ}$ (Propygidio et Pygidio) supra corneis, detectis.

Les Histérides ont les antennes insérćes au devant des yeux, rétractiles, brisées; le scape est allongé, ordinairement contourné, épaissi au bout, et logé dans une coulisse pratiquée à la partic inféricure de la tète entre les ycux et le menton; le funicule est composé de 7 articles serrés, ordinairement courts; la massue est compacte, ordinairement pubescente, de 3 articles avec un appendice en manière de $4^{\mathrm{e}}$ article, presque toujours distincts, si ce n'est dans les genres Hetcrius et Erctmotus où elle parait formée d'un seul article cylindrique, tronqué, glabre. Celle massue est souvent logée dans une fosselte creusée sous le prothorax, dont la position et la forme fournissent l'excellents caractères génériques. 
La lète a le labre court et sans mouvement bien visible; elle est armée de mandibules fortes, sailiantes, recourbées en pointe aiguë. Ies mâchoires sont eornées, avee les lobes membraneux, inégaux, barbus. Le menton est corné, la languetie courte, membraneuse, ainsi que les pariglosses.

Les palpes sont filiformes, si ec n'est dans le genre $\boldsymbol{P}_{\text {si- }}$ loscelis où ils sont sécuriformes, les maxillaires de 4 articles, les labiaux de 3.

Le prothorax est échancré en devant pour recevoir la tête; le pronotum est étroitement appliqué contre la basc des élytres, et le prosternum contre le mésosternum.

Les élytres embrassent l'abdomen sur les côtés, cachent complétement les ailes au repos, s'ouvrent largement dans le vol, jusqu'à s'opposer base à base au-dessus du pronotum. 'Tronquées au bout (1), elles laissent à découvert les deux derniers segments dorsaux de l’abdomen (propygidium et pygidlinm), qui sont toujours cornés. La suture est droite, ni imbriquée, ni déhiseente.

Le prosternum est toujours saillant entre les hanches, rétréci, plus ou moins arancé sur la bouche. Les banches antérieures sont transversales, assez rapprochées à leur insertion ; les autres ovalaires. Les postéricures sont très distantes ertre elles, et fort éloignées des intermédiaires. Les trochanters en forme de virgule sont soudés à la cuisse et ne font qu'un avec clle.

Les tarses sont toujours de 5 articles dans les 2 sexes, excepté dans le genre Acrilus, où les 2 premiers des postérieurs s'étant soudés, il n'en reste que 4 de mobiles.

L'abilomen se compose toujours de 5 anneaux s'embồ-

(1) Le I'achylopus dispar a les élytres terminées en pointe dépassitut l'abdomen. 
tant les uns dans les autres: le premier segment veutral est beaucoup plus long que les suivants; le troisieme ne s'articule pas sur le coté dı troisième segment dorsal, mais à sa partie postérieure; s’avançant derrière les élytres, il forme une espèce de triangle sur les côtés du propygidium.

Les téguments sont durs, épais, comés, luisants.

D'un faciès particulier, qui les fait distinguer au premier abord, les IIstérides ont cependant de nombreuses affiniés.

Les élytres courtes et tronquées se retrouvent dans toute la famille des Braclélytres. Ordinairement beaucoup plus courtes encore, dépassant même à peine la poitrine et laissant à nu presque tous les segments dorsaux de l'abdomen, cornés à cet effet, dans la grande majorité des espèces de cette dernière famille, elles s'allongent dans quelques-unes, telles que les Omalides, et laissent dépasser à peine les derniers segments abdominaux. Elles sont également unies au repos par une suture droite, et recouvrent entièrement les ailes. Mais les segments de l'abdomen toujours au moins au nombre de 6 , sont semblables et articulés sur les côtés. Le pronotum n'adhère pas lortement ì la base des élytres, et la poitrine est dépourvue de saillie prosternale. Les antennes ne sont point brisées, ni terminées par une massue compacle.

Les Pselaphes partagent encore cette disposition; ils y joigneut une massue antennaire, et, à l'exceptiou des $E u$ plectus, un abdomen de 5 segments cornés en dessus. Mais ils sont moins rapprochés par tout l'ensemble de leur forme; leur tête est grosse et toujours sortie du prothorax, leurs antennes à massue peu serrée et sans coude, leur abdomen dépasse toujours de beaucoup les élytres, leur pronotum 
est beaucoup plus étroit que la base des élytres, leurs tarses 3-articulés et leurs laanches postérieures contiguës les sćparent plus qu’il n’est besoin.

Les Nitidulaires ont plusicurs points d'organisalion communs arec les Histérides. Souvent leurs élytres sont abrégúes et tronquées en arrière; leur abdomen est saillant et les derniers segrments sont cornés dessus. Leur tête s'en. fonce dans le prothorax, échancré en devant à cet effet, et leurs antennes coudées, sont terminées par un bouton de 3 articies qui se loge sous le bord inférieur du prothorax. Les élytres sont ordinairement de la largeur du pronotum à la base. Le prosternum prolongé audelà des hanches antérieures, s’applique étroitement au mésosternum; mais il n'est saillant qư a la hase et toujours dépourva de mentonnière. Tues màchoires, toujours bilobées chez les Histérides, sont pour la plupart l'entre eux réduites à un seul lobe. Les segments de l'abdomen sont mobiles, presqu'égaux entre eux; l'arceau ventral est articulé latéralement et non à la partie postérieure de l'arceau dorsal, de sorte qu'il est tout entier invisible en dessus. Le pygidium n'offre rien de remarquable, et n'affecte pas toutes ces formes singulières et variées qu'offre celui des Histérides. Le pronotum et les élytres sont également dépourvus de ces dessins réguliers qui forment leur livrée, de ces stries dont la disposition constante et pour ainsi dire géonétrique, aide si puissamment à les classer et à les distinguer.

Je ne pousserai pas plus loin les rapprochements. Les Trichoptérides aux élytres encore raccourcies et dépassées par l’abdomen, n’ont qu'unc ressemblance fort éloignéc. Leurs antennes capillaires de 11 articles, hérissées le poils, terminées par une massue lâche de 3 articles, 
leurs hanches antéricures contiguës, leurs tarses de 3 articles et leurs téguments pubescents, constituent des caractiores trop tranchés pour permettre une méprise quelconque.

Certains silphales malgré la disposition de leur abdomen et de leurs élytres, se distinguent aisément à leurs antemes de dix articles à massue ovale bi-articulée, à leurs hanches postérieures contiguës, et à leurs trochanters sällants.

Le Sphorites glabraus ressemble tellement à un Hister au premier coup d'ocil, que Fabricius l'avait placé dans ce genre. C'est le seul élément étranger qui se soit iutroduit daus la famille; tant elle est homogène!

\section{Anatonie, variations de Formes.}

Corps ovalaire court, épais.

Allongé, presque parallèle, plus ou moins aplati (IIololepıa, Phylloma, Lioderma, Macrostcmus, Platysoma, Carcinops, Puromalus).

entièrement cylindrique (Cylistix, Trypanaus, Xiphonotus, Teretrius).

arrondi, presque globuleux (Hetcrius, Nototoma, Erel. molus, Dendrophilus, Tribalus, Onthophilus, Bacanius, Abrcus, Acritus).

Noir lisse et luisant, rarement avec des laches rouges.

brun, plus ou moins rouge (Notodoma, Hetcerius, Glymma).

métallique, vert ou bleu, rarement avec des taches rouges on jaunes (Saprinus, Pachycrarus, Phelisler, Teretrius, Cyplurus).

Tête ordinairement petite, arrondie. grosse (Oxysternus, certains IIister). assez large et aplatic (Ilololepla, Phylloma, Lioderma). 
Libre, se redressant lorsqu'on les inquiète, ne s'enfoncant pas dans le prothorax de manière à disparaître en dessous, cachée par le prosternum, Hololeptiess, Trypaneeus,

mais ordinairement rétractile et invisible en dessous dans l'état de contraction, s'inclinant en devant.

Front souvent séparé de l'épistome par une strie, un rebord ou un sillon transversal,

épistome ordinairement faisant suite au front sans ligne de démarcation aucune, rétréci graduellement et tronqué en devant,

prolongé en un long muscau, en pointe plus ou moins obtuse, sarançant sur la bouche (Trypanceus).

Labre court, transverse, horizontal, coupé droit en de. rant ou légèerement sinué, ou enfiu un peu arrondi ;

perpendiculaire, paraissant échancré en dessus, triangrulaire fortement escavé en devant, fermant la bouche et s'appliquant exacte ment à l'échancrure du menton : HocoLEPTIENS ;

prolongé en lobe médian, ou élargi ou conique, relevé dans le $\sigma^{x}$ (deuxième groupe du genre Ilister).

Ícux placés verticalement de chaque côté de la tête, au dessous d'un rebord saillant, séparés de la base des mandibules par la coulisse des antennes, déprimés el enfoncés en lout ou en partie dans le prothorax,

en croissant plus ou moins ćlargi,

exactement arrondis et saillants (Trypanceus).

Mandibules fortes, arqueés en dedans, terminées en pointe asser aiguë ;

igales, cependant quelquefois la gauche est plus forte et plus longue (Oxystermus, of de certains Hister); 
munies quelquefois d'une ou plnsieurs petites dents, d'autres fois inermes,

croisées, la gauche sur la droite dans l'état de contraction, excepté dans les HoLoleptiers;

saillantes et avancées : Hololeptiens,

plus ou moins enfoncées, et quelquefois entièrement couvertes soit par le labre, soit par le inuseau (Trypanceus),

Bouche ordinairement étroite, resserrée entre les mandibules, quelquefois f'ermée exactement par le labre et le menton, dans ceux qui, à l'état de contraction, se liennent la tête redressée: dans les autres, ces parties sont protégées en dessous par la mentonnière, en dessus par les mandibules et le labre.

Mlenton corné, large, transverse, rétréci et sinué ou échancré en devant.

Lèvre membraneuse avec les paraglosses lobulaires, allongées, ciliées en dedans, la languette nulle ou peu saillante.

Palpes labiaux filiformes, de 3 articles $; 1^{\text {er }}$ petit, $2^{\text {e }}$ et $3^{\mathrm{e}}$ allongés, à peu près d'égale longueur, l'un obconique, l'autre fusiforme,

élargis et tronqués au bout (Psiloscelis).

Mâchoires insérées derrière le menton (IIololepla, Liorlerma, Oxystermus),

de chaque côté ordinairement,

en partic derrière et latéralement (Phylloma),

cachées dans une coulisse des mandibules ou derrière le menton, au moins en partie; cornées, à deux lobes membraneux ciliés au bout el en dedans, arrondis, peu sail-

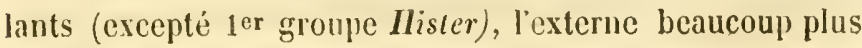
long que l'interne. 
Palpes maxillaires filiformes de 4 articles : 1 er petit, $2^{\mathrm{e}}$ long obconique, 3e court, obconique ou cylindrique, 4e fusiforme aussi long que le 2 e, - renflé et tronqué au bout (Psiloscelis).

Antcunes assez courtes, reployées sous la tête à l'état de contraction, brisćes.

Scape allongé, courbé, renflé au bout, inséré sous un rebord du front, entre les yeux et la base des mandibules, a une grande distance l'un de l'autre ; quelquefois ce point d'insertion remonte un peu entre les yeux et parait en dessus, de manière que les antennes sont placées sur le front (Xiphonolus, Plegaderus, Onthophilus, Bacanius, Abrceus, Acritus). Il est logé dans une coulisse plus ou moins profonde, pratiquée entre les yeux et la base des mandibules,

large sur les côtés de l'épistome (Abrous, Plegaderus),

étroite el profonde (IIister, Hololepta, Saprinus).

Funicule de 7 articles, pelits, serrés, glabres, avec quelques cils : 1er plus long et un peu plus fort; plus gros et plus court que le suivant (Abreus); - 2e quelquefois plus allongé que les suivants (Onthophilus, Abraus, Bacanius, $\boldsymbol{A}$ crinus); - les autres courts, à peu près d'égale longueur, s'élargissant souvent vers la massue.

Massue velue de 4 articles très serrés, mais distincts, coupés droil ou angulairement entaillés (1).

les articles tout à fait indistincts (Monoplius),

d'un seul arlicle sans trace des soudures (Hetcrius, Erelmolus).

Arrondie, en pointe plus ou moins obtuse, quelquefois courle, obtuse (Tribalus), - cylindrique, tronquée (Ilelerius Eictmotus), - renflée progressivement, implantée sur l'axe

(1) M. Lacordaire considère le dernier article comme un appendice du $3 ٌ$, mais je le trouve séparé comme les autres articles. 
même du funicule; - abrupte (Tribalus, Trypanaens, Onthophilus, Notodoma); - ovale, transverse, implantée obliquement (Monoplius).

Fosselles antennaires de la forme de la massue, plus ou moins marquées, pratiquées au dessus du bord pectoral,

dans l'angle même, ne paraissant pas autre chose que la jonction de la lame dorsale et de la lame pectorale: Glyntma, Cylisus.

sous l'angle antérieur entre deux plis du bord pectoral dont l'interne laisse une coulisse oblique pour le passage de l'antenne, et l'autre est entier: Platysoma, Omalodes, Margarinotus, Monoplius, Epicrus.

creusées au dessous du bord pectoral qui est entaillé d'une coulisse pour le passage de l'antenne,

tantôt au milieu du flane: Plegaderus,

tantôt sur le côté, un peu au-delà de l'angle antérieur, bien limitées, profondes, arrondies; le bord ayant l'air continu et seulement très étroitement entaillé obliquement: Onthophilus, Spherosoma,

tantôt adossées au prosternum: Saprinus, Pachylopus,

tantôt larges et placées au devant des hanches : $X i$ phonotus, Teretrius, Carcinops, Puromalus, Bacanius, Dendrophilus.

Elles sont nulles dans les HoLoleptiens et les TrrypaNÉExs; il en est de même dans beaucoup d'espèces du ğenre Hister; la massue se loge entre la tête et le bord interne du prothorax; le scape seul entaille un peu le bord pectoral.

Pronotum serré à la base contre les élytres; arqué (Oxysternus, Plasius, Placodes), ou bisinué avec le milieu un peu avancé sur l'écusson (Hister, Trypanceus, Omalodes) Angles postérieurs lien marqués, obtus, - tout à fait 
arrondis (Trypanceus, Oxysternus) - assez aigus, Plegaderus, Sruprinus;

laissant ordinairement un intervalle plus ou moins étendu, orcupé par une partic triangulaire des épimères du mésothorax (Oxysternus, Trypancens, Omalodes);

plus large que long, convexe transversalement, quelquefois plan (Iololepta, Phylloma, Macrostermus, Plalysoma, Paromalus), - cylindrique, plus long que large (Cylistus, Trypanceus ;

abaissé et rétréci en devant, avec les angles antérieurs obtus, et une échancrure large semi-circulaire, enclosant la tête; - avec une avance en forme de lame au-dessus de la tète: Xiphonotus; - garni ou dépourvu de poils sur les cotés, lisse ou finement ponctué avec une strie marginale, presque toujours interrompue en devant et à la base, une lutérale, et rarement une $2^{\mathrm{e}}$, suivant les côtés et mème le bord antérieur (Ilister, Omalodes, Platysoma),-tuberculeux (Margarinotus), - bordé d'un bourrelet latéral (Hetcerius, Plegaderus), - marqué de côtes longitudinales (Onthophilus, Glymma).

Ecusson petit, triangulaire; - rarement indistinct (Trypanceus).

Elytres formant ensemble un trapèze plus ou moins allongé (depuis IIololepıa jusqu’à Cylisıus), échancré en devant, un peu rétréci par lerrière;

rarement parallèles: Cylistus, Hololeptiens, Trypa NÉENS,

droites au bout: Plcesius, Onıhophilus, Paromalus, Epiems, Platysoma, Placoles, Aulacosternus, - arrondies et laissant un petit angle sutural rentrant : Cypturus, Monoplius, Triptencus, Abreus, - tronquées obliquement de dehors en dedans et laissant un angle sutural large, plus ou 
moins marqué : Liodermu, Macrostcrnus, - prolongées en en pointe suturale dans le o du Pachylopns dispar.

replićes sur les côtés et formant un bord infléchi, ordinairement anguleux à l'épaule, avec une fossette dans certains Hister, sillonné de stries marginales.

Le dos des élytres est plan (IIololepta, Macrosternus, PlaIysoma, Paromalus) - convexe transversalement(Oxystermus, Cypturus, Pachycrerus, Hister, Dendrophilus, Abraus, Trypanaus, Cylistus),一bombé (Monoplius, Scapomegas, Heterius).

Il est parcouru par des stries dont la distribution est assez constante, les extérieures presque toujours plus marquées que celles qui avoisinent la suture, depuis l'humérale avec les subhumérales, les dorsales et la suturale; chaque genre affecte une disposition spéciale des stries; ainsi le système n'est pas le mème dans les IIister que dans les Saprinus, dans les Epierus que dans les Platysoma ou dans les Carcinops, et encore moins dans les Hololeptiens et les Omalodes.

Rarement la surface est tuberculeuse (Margarinous); costiforme (Onthophilus, Glymma, Pelorus).

La face sternale est très remarquable par ses formes variées. On y trouve d'excellents caractères génériques, non seulement dans la fossette antennaire, mais encore dans la formedu prosternum et dans sa jonction avec le mésosternum. Les trois segments forment ensemble une espèce de surlace triangulaire dont le sommet est l'extrémité antérieure du prosternum et la base le bord postérieur du métasternum. Ce dernier est beaucoup plus long que le prosternum; le mésosternum est court, soudé au métasterıum dont il est cependant presque toujours distinct par une ligne transversale.

Le prosternum forme toujours une saillic plus ou moins étroite, entre les lıanches antérieures; - très saillant et 
étroit (Oxysternus, Hister), - large, peu saillant (Hololeptu, Macrostermus, Pleguilerus, Eretmotus); avec ou sans stries marginales;

coupé droit à la base et juxtaposé sur la partie antérieure du mésosternum (Ilister, Saprinus, Pachylopus, Bacanius, Abre'us, quelques Acritus), - ou un peu sinué (Sphyracus, Notodoma, Epierus, Sccupomegas, Ilcterius, Eretmolus, Tribulus, Onthophilus, certains Abreus et Acritus), - ou en. taillé et pénétré par une pointe du mésosternum : Monoplius, Trypanueus, excepté deux, Teretrius, Xiphonotus, Pelorus, Glymma,-ou arrondi et s'enfonçant dans une échancrure du mésosternum : IIololeptiess, Plasius, Placoles, Aulacosternus, Platysoma, Cylistus, Cypturus, Pachycroms, Phelister, Omalodes, Margarinolus, certains IIister, Carcinops, Paromalus, Denulrophilus, Plegalerus, Psiloscelis, Contipus, Rhyjpochares, - sinué et pénétrant néanmoins dans le mésosternum : Macrostermus.

Tantot sans mentonnière (Saprinus, Pachylopus, Trypaneeus, Plegallerus, Acrilus, Abrceus, Xiphonotus),

ou avec une mentonnière trèsin distincte: HoLOLEPTiens, Hetcrius, Eretmotus, Pelorus, Notodoma,

avec une mentonnière courte : Cypturus, Phelister, Sphyracus, Omalodes, Spharosoma, Margarinotus, Hister, Epierus, Carcinops, Ilonoplius, Scapomegas, Dendrophilus, Tribulus, Teretrins, Ontophilus, Bacanius, Psiloscelis, Contipus, Rhypochares, ou longue, dépassant quelquefois les angles antéricurs du prothorax: Plcesins, Placodes, Aulacosternus, Macrosternus, Platysoma, Cylistus, Pachycrarus, Paromalus, Glymma.

Le mésosternum est ou droit antérieurement, ou en pointe, ou entaillé quelquefois jusqu'à la base: Oxysternus ; bordé d'une strie, ordinairement interrompue en devant. 
Les palles sont rétractiles, sans être reçues dans des enfoncements particuliers ; la première paire est très rapprochée de la deuxième à son insertion, la troisième est fort éloignée de celle-ci; l’intervalle qui sépare les pattes de la même paire, est plus considérable postérieurement qu'antérieurement.

Les hanches sont transversales, antérieures plus longues, arrondies en dedans. - Les trochanters en forme de virgule joints à la base de la cuisse.

Cuisses courtes, épaissies au milieu, borlées dans le sens de la flexion d'un sillon en dessous et d'un canal en dessus pour loger les janıes; - beaucoup plus renflées : Trypanceus, Cylistus, Pachylopus.

Jambes antérieures élargies en triangle, comprimées, rebordées en dedans, terminées au bout par deux épines inégales; souvent dentées plus ou moins fortement ( Plaiysoma, Hololepla, Lioderma, Hister, Monoplins), quelquefois ciliées ou denticulées (Saprinus, Epierus, Phelister); fortement dilatées (Dendrophilus, Eretmotus, Saprimus), grêles Onthophilus);

creusćes en dessus d'une fossette tarsale dont la configuration varie, caractère dont Erichson s'est servi fréquemment, tantòt sinuée et bien entaillée : Hololepta, Oxysternus, Placodes, Plcesius, Aulacosternus; tantôt droite et peu nettement accusée : IIister, Saprinus.

Les jambes postérieures plus régulièrement triangulaires, bordées en dedans, terminées par deux épines inégales, ciliées en dehors, dentées ou denticulées sur un ou deux rangs, - quelquefois grêles (Pleyaderus, Ontophilus, Abrcus, Bacanius), - d'autre fois très élargies (Erctmolus, Dendrophilus, Hetcrius), - rarement renflées en forme de carde : Pachylopus.

3e Séric, TONe v. 
ordinairement semblables, cependant les intermédiaires sont dentées, et les postérieures ciliées et courbées (Trypanceus).

Tarses de cinq articles, excepté dans les Acritus, où les postérieurs sont de quatre seulement, jamais dilatés, comprimés, petits, de nême longueur, seulement le deuxième quelquefois plus long que les suivants; le dernier armé d'un double crochet, excepté dans les Xiphonolus.

Abdomen de cinq anneaix. Le premier segment ventral est toujours le plus grand, bistrié entre les hanches, prolongé en pointe dans le Pachylopus dispar; les autres sont courts, serrés les uns contre les autres, surtout dans la contraction; le troisième et le quatrième se voient en dessus; les deux derniers segments dorsaux sont visibles ordinairement daus toute leur étendue : le quatrième, ou propygidium, est en lexagone court, iucliné plus ou moins fortement; le cinquieme, ou pygidium, en triangle curviligne plus ou moins allongé, affecte différentes positions : ordinairement oblique, il est quelquefois perpendiculaire : Scapomegas, Eretmotus, d'autrefois eutièrement tourné en bas : Monoplius, Cypturus, Pachylopus, Onthophilus; quelquefois en pointe simple ou bifide, plus ou moins aiguë ou tranchante: Trypanceus.

\section{Métamorploses et Mogurs; Distrubution gÉOGRAPHLUE.}

Les premiers états des Histérides sont encore peu connus, malgré la multiplication considérable des espèces. Les seules larves publiées jusqu'à ce jour sont celles des Hisler merdarius, décrite par Paykull (Mon. Hist., pl. 1, fig. 1), 
que j'ai reproduite d'une manière plus exacte , $\boldsymbol{H}$. cadaverinus, observée par Iatreille (Dict. d'Hist. nat., x, 429), du Platysoma oblongum, du Paromalus flavicomis et du Plegalerus discisus, étudiées par M. Eol. Perris dans ses Insectes du Pin marilime (Soc. 1854, p. 85-97), découvertes précieuses dont j'ai pu enrichir mon travail. Ce nombre d'observations est trop restreint pour en déduire une doctrine satisfuisante sur les métamorphoses de la famille en général.

A en juger par celles que nous connaissons, les larves ont d'intimes rapports avec celles des Brachelytres et des Silphides. Allongées, charnues, linéaires, elles sont composées de treize segments. La tête est plate, cornée, l'épistome et le labre sont soudés, le bord autérieur dentelé, les stigmates nuls. Les antennes, relativement assez longues, sont composées de quatre articles ; le premier, très court et rétractile; deuxième a!longé, renflé en dedans vers le bout; troisième, tronqué et muni en dehors d'un très petit appendice et d'une courte spinule, et, en dedans, d'une autre spinule très petite ; quatrième étroit, cylindrique, tronqué et surmonté de trois petites soies. La cavité buccale est petite, la languette manque, le menton, à deux lobes divergents, porte les palpes labiaux de deux articles, sauf dans les Plegaderus, où il y en a trois. Les mâchoires très longues, étroites, cylindriques, de deux pièces, dont l'une, qualre fois plus longue que l'autre, est munie en dedans d'un long pinceau de poils, et l'autre d'un lobe grêle, court, papilliforme, surmonté d'une petite soie. Palpes maxillaires de trois articles, (de quatre dans les Plegaderus). Les mandibules sont très longues, falciformes, acérées, et munies en dedans, vers le milieu, d'une forte dent saillante, surmontée d'une apophyse dans quelques-uns. 
Le thorax est de la largeur de la tête, et muni de poils rares sur les côtés. Le prothorax, beaucoup plus grand que les deux autres segments, est corné en dessus.

Les pattes sont courtes et grêles, de quatre articles, terminées par un seul crochet petit et subulé.

L'abdomen composé de neuf segments égaux au prothorax et à peu près égaux entre eux, excepté le dernier qui est un peu plus grand et terminé par deux longs appendices biarticulés.

Il y a neuf paires de stigmates placées sur les côtés du mésothorax et des huit premiers segments abdominaux.

La forme des organes buccaux dénote des habiludes carnassières. Il est probable que les larves des Histérides sont toutes dans cette catégoric, même celles qui vivent dans les bouses; et toutes celles dont on a étudié les mœurs le sont réellement. Ainsi, comme je l'ai décrit (1853, p. 252) d'après les observations de mon ami M. Ed. Perris, le Platysoma oblongum à l'état de larve vit aux dépens des larves el des nymphes du Tomicus stenographus, de meme que le Paromalus flavicornis; le Plegaderus discisus, de celles du Crypurgus pusillus.

Le développement est assez rapide, et ne dure qu'environ cinq mois. Quand le moment de la métamorphose est venu, les larves se construisent une coque à parois lisses avec les débris des substances dont elles ont vécu. La nymphe n'offre d'autre particularité que deux appendices divergents à l'extrémité de l'abdomen.

Les habitudes des Histérides à l'état parfait sont les mêmes que celles des Staphylins et des Silpliales. Il vivent dans les cadavres, les excréments, les détritus des végétaux et sous les écorces des arbres morts. Quelques-uns ont été rencontrés 
dans les fourmilières (V. Mærkel, Insectes myrmecophiles, Germ.Zeit.t.v, p. 345). Ils sont communs au printemps et en automne. Ils volent assez bien. Leur démarche est peu agile, et ils se contractent quand ils veulent échapper au dangrer qui les menace.

\section{Distribution gÉograpiroue.}

Le nombre des espèces d'Histérides que j'ai décrites et figurées est de 620 ; celui des espèces qui ne me sont connues que par la description des auteurs, de $\mathbf{1 2 6 .}$

Elles sont répandues sur tout le globe, mais inégalement réparties : 92 appartiennent à l'Europe; 107 à l'A frique ; 64 à l'Asie ; 294 aux deux Amériques, et 16 seulement à l'Océanie.

13 sont communes à l'Europe et à l'Afrique,10 à l'Europe, et à l'Asie, 4 à l'Afrique et à l'Asic; 12 se retrouvent dans tout l'ancien continent, et 8 à la fois dans l'Ancien et dans le Nouveau-Monde.

Des 43 geures que j'ai admis, les suivants : Hololepta Platysoma, Saprimus, ont des représentants dans tout l'univers; Paromalus, Teretrius, Onthophilus et Abrceus, répandus dans toutes les parties de l'ancien continent, Contipus, Epicrus, Carcinops, Hetcerius, Dendrophilus, Tribalus, Pachylopus, Plegaderus, Bacanius et Acritus, dans quelques-unes seulement, se rencontrerit également dans le nouveau continent. Un assez grand nombre sont purement américains : Phylloma, Lioderma, Oxystemus, Cylistix, Phelister, Sphyracus, Omalodes (à l'exception d'une espèce douteuse des iles Marquises ), I'siloscelis, Scapomegas et Trypanans. Glymma est Européen; P'lacodes, Maerosicmus, Pachycrierus, Rihypochares, Monoplius, Pclorus, Erenotus, Sphorosoma et Xi- 
phonous sont africains; Plesius, Cypturus ct Notodoma sont asiatiques. Enfin Aulacosternus est commun à l'A frique et à l'Océanie, et Margarinotus répandu sur les plages méditerranéennes, soit en Espagne, soil en Afrique.

\section{Histoine ves travaux sUR tes Histérides.}

1735. Linné réunissait dans un mème groupe les 6 espèpèces d'Histérides qui lui étaient connues. Ce genre, sous le nom d'Hister, adopté par les auteurs qui vinrent après lui, vit grossir peu à peu le nombre de ses espèces. Tabricius en décrit 10 dans son Systema Entomologice (1775); Olivier, 24 dans le premier volume de son Entomologie (1;89); Herbst, 30 dans son Natursystem (1791); Fabricius, dans son Entomologia systematica en décrit le mème nombre, en y comprenant celles du supplément (1792), et plus tard, en 1811, dans son Systema Eleutheratorum, il en porte le nombre à 43. C'est dans cet ouvrage qu'il décrit trois espèces du genre Trypanceus, en les réunissant au genre Bostrychus.

1803. Le premier ouvrage spécial sur ce groupe est la monographie des espèces des anciens départements de Donnersburg, de Saar et de Rhein und Mosel, publice à Francfort-sur-Mein dans les Cahiers d'Entomologie de Joffmann, Koch, Müller et Linz, connus sous le nom d'Entomologische IIefte. Les limites restreintes de ce travail ne l'empèchent pas d'etre fort utile. Le groupe y est distribué en 9 familles, d'après la disposition des stries du pronotum et des élytres, que tous les auteurs ont employées après eux avec succès. 34 espèces y sont décrites avec soin; des figures, un peu grossičres encore, mais reconnaissables, limitent bien cerlaines especes nouvelles ou litigieuses. (1805) Sturm, dans 
sa Faune d'Allemagne et Duftschmilt, dans celle d'Autriche, déerivent clacun 38 ou 39 espèces', mais sans apporter aucun jour nouveau, et sont loin de valoir le précédent. (1808) Gyllenlıal fait bien connaittre les espèces de Suède.

1811. La principale monographic générale, celle de Paykull, divise les Histérides en denx genres Hisler et Hololepta, décrit d'une main de maitre et représente, par des figures au trait d'unc grande exactitude, 93 espèces. Voici le tableau de ses divisions et subdivisions :

\section{Genre Histelk.}

Is Sectio : prothorax longitudinaliter striatus.

Ia Tribus : prothorax lateribus bistriatus.

1a Familia : elytra stria marginali efpèces. nourelles.

$2^{\text {a }}$ Familia : elytra absque stria marginali. 6 II Tribus : prothorax lateribus unistriatus.

$1^{\text {a }}$ Familia : ely tra absque stria marginali. 4

2 Familia : elytra stria marginali unica. 5

II Sectio: prothorax longitudinaliter haud strialus.

Ia Tribus : corpus ovatum.

$1{ }^{\text {a }}$ Familia : elytra striis 5 dorsalibus. . . 5

$2^{3}$ Familia : elytra striis dorsalibus 4 vel paucioribus.

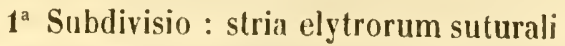

a 4 a dorsali distante. ...... 9 4

2a Subdivisio : stria suturali antice cum $4^{\text {a }}$ dorsali connexa. ...... 17

$3^{2}$ Subdivisio : stria suturali nulla. . 4 
3. Familia :

espèces. nourelles.

II Tribus : corpus oblongum.

$1^{\text {a }}$ Familia : elytra lıaud striata. .... 2

$2^{\text {a }}$ Familia : elytra striata. ...... 4

III ${ }^{a}$ Sectio : Pronotum sulcatum.

I Tribus : pronotum utrinque longitudinaliter uni-sulcatum. . . . . . 4

II Tribus : pronotum longitudinaliter pluri-

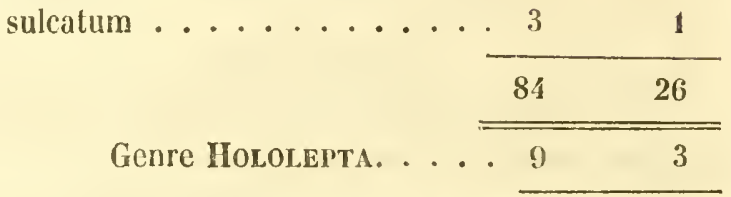

Toutes ces espèces sont bien définies à peu d’exceptions près : les divisions quelque systématiques qu'elles soient, ne s'éloignent pas trop de l'ordre naturel. L.es caractères sur lesquels elles s'appuient sont tranclıés et d'un usage facile. Paykull est le premier qui ait fait connaître la larve d'une espèce, l'Hister merdarius.

Dans les années qui suivent jusqu'en 1834, un grand nombre d'auteurs publient des espèces nouvelles dans des ouvrages isolés ou dans des Faunes locales : Wiedeman, 4 (1817); Germar, 6 (1813, 1817, 1824); Kirby, 4 (1817, 1827); Fischer de Waldheim 3 (1823); Sahlberg, 2 (1817, 1823); Say, 22 (1825); Stephens, 4 (1830), et Brullé, 3 (1832).

Leach, dans le tome HI $^{\mathrm{e}}$ du Zoological miscellamy (1817), sépare dı groupe les 4 genres Platysoma, Dendrophilus, Onthophilus et Abreus, ụui sont bien établis et ont été conscrvés. Eschscholtz, daus le Zoological allas (1829), crée le 
genre Trypanacus, qui avait jusqu’ici passé inaperçu des entomologistes, et qui s'est enrichi dans mon travail de tant d'espèces nouvelles.

1834. Erichson, de regrettable mémoire, dans le seul volume du Jahrbücher publié par Klug, en étudiant la collection du Musée de Berlin, a formé une famille de ce groupe et l'a remanié tout entier d'une manière très méthodique et rationnelle. Il l'a répartic en 21 genres, que j'ai fous adoptés, et il a fait connaître bon nonbre d'espèces nouvelles. Voici le tableau de sa classification :

Ier Groupe : Tête saillante (prosternum sans mentonuiere) :

IIololepta, Pk., Phylloma (IIol. corticalis Pk.), et Oxysternus (Dj.).

IIe Groupe : Tête s'enfonçant dans le prothorax, et reçue par une mentonnière ou prolongement antérieur du prosternum.

A. Fossettes pour la réception de la massue des antennes, situéc au bord antérieur du dessous du prothorax.

a. Fossette des jambes antérieures pour loger les tarses nettement limitée des deux côtés :

Plasius (N. G.), Placodes (N. G.), Platysoma Leach., Omalodes (Dej.), Cyptuirus (N. G.).

b. Fossette des jambes antérieures pour loger les tarses effacéc au moins d'un côté :

Hetcrius (Dej.), Epierus (Hister fulvicornis F.), Tribalus (IIst. capensis Payk.).

B. Fossettes des antennes situées au milieu du dessous lu prothorax :

Dendrophilus Leach., Paromalus (IIist. Ravicornis F.). 
IIIe Groupe: Tète se retirant dans le prothorax; mentonnière uulle, bouche appuyée immédiatement sur le bord antérieur du prosternum.

1. Antennes insérées sous le bord du front:

Saprinus (Hist. nilidulus), Pachylopus (N. G.), Tryponceus Esch..

B. Intennes insérées sur le front même :

Teretrius (Hist. picipes F.), Plegaderus (Hist. cresus F.), Onthophilus Leach., Abraus Leach..

Plus tard dans sa Faune de la province de Brandebourg (1839), dans le voyage de Wagner en Algérie (1840), dans la Faune de Yan Diémen et dans eelle d'Angola (1842), il a fait connaìtre un certain nombre d'autres espèces.

Plusicurs autres auteurs ont ajouté successivement quelques nouvelles espéces; parmi lesquels je citerai MM. Aubé, le Comte de Mannerheim, Le Guillou, Rosenhauer, de Motschulsky, Lucas, Solier, Léon Fairmaire, Blanchard, Vähræus, Truqui et Reiche.

Miais en terminant eette revue historique, je ne puis passer sous silence M. le Major J. Le Conte et son fils, le docteur J.-L. Le Conte, dont les travaux ont jeté une si grande lunière sur les Histérides des États-Unis d'Amérique. Le premier en a donné une Monographie complète en 1845. Les espèces y sont groupées d'après les genres d'Erichson; toutes sont figurées au trait et reconnaissables; 37 sont nouvelles.

Le second, en 1851, décrit environ 40 nouvelles espèces de Californie, provenant dı périlleux voyage que son dévouement à la seience a pu seul lui inspirer. En 1852, le même auteur, dans un travail intitulé : Hinds towarils a 
natural classification, discute le système d'Erichson, rejelle les genres Omalodes, Platysoma, Pliesius, Placodes, qu'il fait rentrer dans le genre Hister, subdivisé en 15 sections. Il réunit également au genre Saprinus, le genre Pachylopus, d'Erichson, dont il n'a pas comnu le type et auquel il avait rapporté, peut-être ì tort, beaucoup d'espèces californiennes dans son travail précédent. Ce genre est distribué en neuf catégories. Il fonde ponr deux espèces assez disparates, inconnues à Erichson, le genre Corostermus, que j'ai préféré réunir aux Tribalus.

Voici le tableau synoptique des gemres qu’il a conservés :

1. Caput porrectum antice non lobatum.

Mandibulæ edentatæ. .... Hololepta Pk.

- dentalx; prosternum latum planum. ... Oxysternus Er. (Exot.).

- dentatæ; prosternum elevatum subacuminatum. ....... Phylloma Er. (Exot.).

B. Caput retractum; prosternum antice valde lobatum.

a. Scrobiculi antennales antici.

1. Tarsiantici unguiculo unico. Cypturus Er. (Exot.).

2. - biunguiculati.

Mandibulæ porrectie, antennæ sub frontis margine insertæ, capitulo 3.articulato. ..... Hister L.

(Ce genre comprend Omalodes Er., I'latysoma Leach; Pliesius, Er.; Placodes Er.) 
- porrectx; antennæ sub frontis margine insertæe, capitulo solido truncato....... Hetcrius Er.

-- retracta; antennæ in frontis margine insertac, capitulo 3 -articulo rotundato. . . . E. Epierus Er.

- retractx; antennx in frontis margine insertie, capitulo $3 \cdot$ articulato, truncato. . . . Tribalus Er.

6. Scrobiculi antennales medii

laterales. antennæ articulo $8^{\circ}$ latiore. Dendrophilus Leach. - $\quad$ - non latiore. Paromalus Er.

C. Caput retractum; prosternum antice non lobatum.

a. Antennæ sub frontis margine inserta. Mandibula exserta; scrobiculiantennales antici. Corostemus N. G.

- exserta; scrobiculi antennales medii . . Saprinus Er.

- clypeo obterta . . Tryponaus Er. (Exot.).

b. Antenna in frontem inserta. Scrobiculi antennales medii, laterales, prosterno subproducio ....... Teretrius Er.

- ad prosterni latera siti. . Plegaderus Er. 
- antici ........ Onthophilus Leach.

- medii, laterales, prosterno

truncato. . . . . . Abraus Leach.

Enfin, dans un dernier mémoire (1853), il fonde les genres Bacanius et Acrilus, qui méritent bien d'ètre séparés du genre Abrceus.

\section{Autecrs cités.}

AÜB́ (Ch.).

Description de deux Coléoptères nouveaux des genres Plitium et Hister. V. Société Entom. de France 1833, pag. 94-96.

Notes sur quelques Coléoptères nouvcaux. V. Soc. Ent. 1842, p. 225-237.

Description de deux Coléoptères nouveaux appartenant à la Faune parisienne. V. Soc. Ent. 1843, p. 73-76.

Description de quelques insectes Coléoptères appartenant à l'Europe et à l'Algéric. V. Soc. Ent. 1850, p. 299. 346.

\section{BACH (II.).}

Kaferfauna der Preussischen Rheinlande mit hesonderer Kücksicht auf Nord-und Mitteldeutschland, 4 vol. 1849-1854.

Blanchard (Emile).

$V$. Voyage dans l'Amérique méridionale, par II. d'Orbigny, 1850, p. 68-73.

BoHeman (Carolus-H).

Insecta Caffrariæ annis 1838-1845 à J.-A. Wahlberg collecta, amici auxilio suffultus descripsit, 1er vol. Iol$\operatorname{mix} 1851$. 
Brtllé (Auguste).

Expédition scientifique de Morée : animaux articulés, tom. III, $1^{\text {re }}$ partie, 1832.

Creutzer.

Entomologische verzuche. Wien in-80 1799.

Duftsciundot (Gaspar).

Fauna Austria oder Beschreibung der Osterreichischen Insecten, Linz 1805-1825, 3 rol.

Evtonologiscie Hefte.

$V$. Hoffman.

Erichson.

I)ie Käfer der Mark Brandenburg, 1 vol. Berlin 18371839.

Uebersicht der Histeroides der Sammlung. V. Jahrbücher der Insectenkunde von $D^{\mathbf{r}}$ Fr. Klug, 1er vol., Berlin 1834, p. 83-208, pl. 11 .

Beiträge zur Insecten Fauna von Van Diemen, 1842.

Beitrïge zur Insecten Fauna von Angola, 1843.

Insect. Berber. $V$. Wagner Reise, 1840.

\section{Esciscinoltz.}

Zoologischer Atlas, enthaltend und Beschreibungen neuer Thierarten, Berlin 1829 et suiv.

Fabricies.

Systema entomologiæ, 1 vol. in-8, 1775.

Species insectorum, Hamburgi, 2 vol. in-8 $8^{\circ}, 1781$.

Mantissa insectorum, Hafnix, 2 rol. in-80, 1787.

Entomologia systematica, IIafnia, 4 vol. in-80, 17921798.

Supplementum Entomologix systematicx, Hafnix, 1 vol. int-8 ${ }^{\circ}, 1798$.

Systema Eleutheratorum, Hafniæ, 2 vol. in-8º, 1801. 
Fahraus.

V. Boheman, Iusecta Caffrariæ, p. 529.557, Holniæ 1851.

Fairuatre (Léon).

Essai sur les Coléoptères de la Polynésie.

$V$. Guériı-Méneville, Revue zoologique 1849 , p. 410 411.

\section{Fairmaire et Laboulbène.}

Faune entomologique française ou description des insectes qui se trouvent en France; Coléoptères, Paris, 1854-1856.

Description de quelques Coléoptères nouveaux d'Europe et de France.

V. Soc. Ent. 1819, p. 419-427.

Excursion entomologique dans la baie de la Somme.

V. Soc. Ent. 1852, p. 663-691.

\section{Falderman.}

Fauna entomologica transcaucasica, 3 vol. in- $4^{\circ}$.

V. Mémoires de la Société des naturalistes de Moscou, 1836-1838.

\section{Fischer de Waldhein.}

Entomographia imperii rossici, 3 vol. in $-4^{\circ}$, avec planches, 1820-1828.

\section{FCesLy.}

Verzeichniss der ilıne bekannten Schweitzerischen Insekten, in-40 Zürich 1775.

Magazin für die Liebhaber der lintomologie, 2 vol. in So, Zürich 1778-1779.

Neues Magaziı...., 3 vol in-80, Zürich 1782-1786. 
Gexí.

De yuit)usdam insectis Sardiniæ novis aut minus cognitis, 2 fasc.

$V$. Memorie della reale academia delle scienze di Torino, 1 re série, tom. $x \times x ı x(1838)$ et $2^{\circ}$ série, tom. $\mathbf{I}^{\text {er }}(1839)$.

Germar.

Reise nach Dalmatien et in das Gebiet von Ragusa, in$8^{\circ}, 1817$.

Species insectorum novæ aut minus cognitæ descriptionibus illustrata, in-8 ${ }^{0}$, IIalle. 1824.

Magazin der Entomologie, Ire année, 1re partie, IIalle 1813.

\section{Gringer.}

Ilister ruficornis, nov. spec.

$V$. Entomologische zeitung von dem Entomologischen Vereine zu Stettin 1852, p. 221.

Gú̉rin-Míneville.

Insectes de Nouvelle-Zélande, 1846.

$V$. White, voyage de l'Erebus et 'Terror.

Revue et Magasin de zoologie, 1838 et suiv.

Gyllenital.

Insecta suecica, 4 vol., Scaris et Leipsig, in-80, 18081827.

\section{HEER.}

launa Coleopterorum helvetica, 1 vol., T'urin, 18411842.

IIER BST.

Natursystem aller bekannten in-und Ausländischen Insecten Porgesetzt von J.-F.-W. Herbst : Küfer, IV theil, 1 er Heft, t. 4, in-80, Berlin 1791. 
IIofFMn, Koch, MüLLeR, LiNz.

Monographic der in d. Departemente von Donnersburge und der Angrenzende Gegende des depart. V. d. Saar und V. Rhein und Mosel einheimisch beobacteten Slutzkafer.

Entomologische Hefte I, Francfort 1803.

\section{ILLIGER.}

Verzeichniss der Kafer Preussens entworfen V. Kugellan, in-8 ${ }^{\circ}$, Halle 1798.

Magazin fur Insectenkunde, 6 vol. 1807.

Portugiesische Kiæfer, tom. 6e, p. 29-49.

JaCQUELIN DU VAL.

Description de deux genres nouveaux et de plusicurs espèces nouvelles de Coléoptères propres à la Faune francaise.

V. Soc. Ent. 1852, p. 695-718.

KLUG.

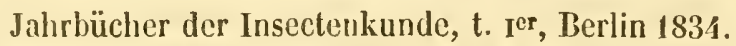
ḰIRBY.

Centuric d'insectes. $V$. Transact. soc. Lin. Lond., t. xu (1817), Paris, Lequien 1834.

Fauna borcali-americana by Richardson assisted by Swainson and Kirby, in-4 ${ }^{\circ}, 1837$.

KolendTI.

Meletemata entomologica; insecta Caucasi, ve fasc., 1846.

KR INICKI.

Enumeratio Coleopterorum Rossiæ meridionalis et præcipue in Universitatis Cesarea Charkoviensis circulo obveniensium.

3e Sírie, Tone r, 
V. Bullet. Soc. Natural. Moscou, I. v (1833).

El. Lequien, p. 167-186.

Kugeldan.

Verzeichniss der in einigen Preussens bis jezt endeckten Kiefer-Arten, 1er vol. p. 252-306 et Ive 477-582.

$V$. Schncider, Neuestes Magazin fur die Liebhaber der Entonologie, 5 vol. in-80, 1791-1794.

lïster.

Die Kæfer Luropa's nach der Natur besclıreilen, 28 liv. , Nïrnberg $1844 \cdot 1854$.

\section{Latreille.}

Genera Crustaceorum et insectorum secundum ordinem naturalem in familias disposila, 4 vol. in- $\$^{\circ}$, Paris 1806 1809.

\section{Leacir el Nodder.}

Zoological Miscellany, 3 vol., Lond. 1814-1817.

Le Conte. (John).

Monograplyy of the north american IIisteroides, ext. Boston journal of natural history, t. v, 1845.

Le Covte (I)r J.-L.).

Descriptions of new species of coleoptera from California.

Extr. Annals of the Lyceum of natural history of NewYork, t. v, 1851.

Ilinds towards a natural classification of the family IIistrini of Coleopterous Insects.

$V$. Proceedings of the Academy of natural sciences of Philadelplia, 1852.

$V$. Proceedings of the $\Lambda$ cad. Philad., t. v1 (1853). 
Le Guillou.

Description de vingt insectes Coléoptères, recueillis pendant le royage de l'Astrolabe et la Zélée.

V. Guérin-Méneville, Revue zoologique 1844, p. 220-225. LiNNÉ.

Systema naturæ, 1 re édit. $1735 ; 12 \mathrm{e}, 3$ vol. 1766-1768.

Fauna suecica, 1746.

LuCAS.

Exploration scientifique d'Alger, Animaux arliculés, 1849.

Mannerueim (comte de)

Coléoptères de la Sibérie orientale.

V. Bullet. Soc. Nat., Mosc. 1852.

Y. Mémoires Soc. Natur., Mosc. 1843.

Mévétriés.

Catalogue raisonné des objets de zoologie recueillis dans un voyage au Caucase, in-4 ${ }^{\circ}$, Petersl. 1832.

Motscimulsky. ( Victor de)

Remarques sur la collection des Coléoptères russes de M. de Motchulsky. - V. Buli. Soc. Natur. Mose. 1845, 1, p. 55.

V. Bullet. Soc. Natur. Mosc., 1849, II, p. 94, 98.

Mulder (O-Tr.).

Fauna insectorum fridrichsdalina sive methodica descriptio insectorum agri fridriclssdalensis.... Hafnix et Lipsix, in-80, 1764.

Zoologixe Daniæ prodromus, etc. IIafnix, in-8o, 1776. MULSANT.

Opuscules entomologiques, 6 vol. $1852 \cdot 1855$. 


\section{Olivier.}

Entomologie ou Ilistoire naturelle des insectes, 6 vol. itl-4 ${ }^{\circ}, 1789-1810$.

Palisot de Bauvois.

Insectes recucillis en $\Lambda$ frique et en Amérique, ainsi que dans le Royaume d'Oware et de Benin, à Saint-Domingue et dans les Etats-Unis, in-fo, Paris 1805.

Panzer.

Entomologia germanica seu Deutschlands Insecten Fauma oder Eutomologisches Taschenbuch, Nuremberg, in-12, 1795.

Fauna insectorum Germaniæ, Nuremberg 109 fasc., 1796-1805.

Pavkule (Gust. de).

Fauna suecica, 3 vol. in-8n, Upsal 1798-1800.

Kiongl. Svenska vetenskaps Academiens IIandlingar, Stockolm, in-80, 1809.

IIonographia histeroidum, in-80, upsal 1811.

Perris.

Histoire des insectes du Pin maritime.

V. Soc. Ent. 1854-1856.

Preyssler.

V. Hayer : Sammlung Physikalischer Aufsatze besonders die Boehmische Naturgeschichte. 4 vol. in-8o, I'rague 1791-1794.

Verzeichniss Bohmischer Insecten in-8o, Prague 1799.

\section{Quensel.}

Descriptions de quelques IIistérides.

$V$. Schouherr, Synonymia insectorum, t. I (1806). 
Redtenbacier (Ludwig).

Fauna austriaca : Dic Kæefer, in-8o, Vienne 1819.

ReICIIE.

Voyage en Abyssinic, dans les provinces du 'Tigré, du Samen et de l'Amhara, par Ferret et Galinier, in-fo, 1851, atlas in-fo, Paris 1847.

Roseninuer.

Beitræge zur Insecten Fauna Europa's.

In-80, Erlangen 1817.

Rossi.

Fauna etrusca sistens insecta qua in provinciis florenlina et pisana præsertim collegit, in-40, Livourne 1790.

Mantissa insectorum exhibens species nuper in Etruria collectas, 2 vol. in-40, Pise 1792-1794.

SAIILBERG.

Dissertatio entomologica insecta fennica enumerans, in-8 ${ }^{\circ}, 1817$.

Periculi entomologici, species insectorum nondum descriptas proponens, in-80, Aboæ, 1823.

SAY.

Descriptions d'espèces nouvelles d'Hister et d'Hololepta des Etats-Unis.

V. Annales Soc. Pliilad., t. v, p. 32-47 (1825).

SCHNEIDER.

Magazin. 5 vol. 1791-1794.

Schoenher.

Synonymia insectorum. 3 vol. in- $8^{\circ}$, Stockholm 1806 1817. 
ScIInAvK.

Enumeratio Insectorum Austrix indigenarum. In-80, Augusta Vindel., 1781.

Fauna Boica. 6 vol. in-8 ${ }^{\circ}$, Nuremberg el Ingolstadt 1798-1804.

Scruba.

Journal für die Liebhaber der Entomologie. In-8, Francfort 1790.

Beitrege zu der Insecten gesichte. In-4º, Francfort, 3 Ilefte 1790-1793.

SOLIER.

V. Gay, Historia fisica y politica de Chile, Paris 1849. STEPIENS.

Illustrations of British entomology : Mandibulata. 5 vol. $1827-1835$.

STEVEN.

V. Mémoires de Moscou, 1806, No 1. Sturir.

Deutschlands fauna in Abildungen nach der Natur mit Beschreibungen, ve abtheilung, Kafer 22 vol. Nuremberg 1805-1853.

Catalogue 1843.

Thunberg.

Dissertatio entomologica sistens insecla Suecia. 9 part. Upsal 1784-1795.

Truqui.

Novæ Histerinorum et Cryptocephalorum species.

V. Soc. Ent. 1852, p. 61-68.

Weber.

Observationes entomologica, in- $\AA^{\circ}$, Kiel 1801. 
W IITE.

Insectes de Nouvelle-Zélande, 1846.

Voyage de l'Erebus et Terror.

\section{WIEDEMAN.}

New Kæefer Bengal et Java.

V. Zoological Magazin, 2 vol., 1817-1823.

V. Germar, Magazin der Entomologie. T. Iv (1821).

\section{Classification.}

De toutes les difficultés inhérentes à mon sujet, je n'en ai pas trouvé de plus grande que celle de distribuer la famille des Histérides en tribus; c'est-à-dire de répartir les genres en groupes naturcls, tranchés et faciles à reconnaitre les uns des autres par des caractères simples et saillants. Après maints essais infructueux, je me suis arreté à la méthode suivante, qui est loin de me satisfaire pleinement, mais qui renferme au moins quelques bonnes coupes dont les Entomologistes pourront tirer parti, comme les tribus des Hololeptiens, des Trypaníens, des Ilétériens et des $\mathrm{S}_{\boldsymbol{A}}$ Priniexs. Celle des Histériens a besoin d'être subdivisće; elle est composée d'éléments trop nombreux et peu homogènes. Jusqu’ici mes efforts ont échoué; j’en laisse le suceès à des mains plus habiles ou plus heureuses.

Dans certains genres, à forme allongée, aplatie ou cylindrique, vivant toutes sous les écorces dans des conditions identiques, la tête reste toujours avancée et saillante, sans se retirer dans le prothorax à l'état de contraction; ces geures formeront une première division composée de deux tribus,

dont l'une est composée d'espèces aplaties, à mandi- 
bules longues et saillantes, à tête grosse et large, à épistome tronqué et laissant le labre à nu, à pygidium court et rabattu, à mésosternum large et peu saillant. . . Hololeptiens. et dont l'autre l'est au contraire d'espèces cylindriques, à mandibules courtes, couvertes ainsi que le labre par un long prolongement de l'épistome, en forme de museau, à pygidium conique, en pointe plus ou moins aiguë, et à mésosternum eomprimé et très élevé. . . . . Tr. Tryanéens.

Daus les autres genres, la tête se retire dans le prothorax pendant la contraction. Reçue par le prosternum ou par son prolongenent ou mentonnière, elle est invisible en dessous. La forme est plus ordinairement ovalaire ou arrondie.

Les uns ont le prosternum muni d'une mentonnière;

soit que la massue des antennes, arrondic ou ovalaire, ait quatre articles distinets serrés, pubeseents. . Histériexs. soit qu'elle paraisse d'un seul article lisse, cylindrique, tronqué au bout; la soudure des articles ne laissant aucune

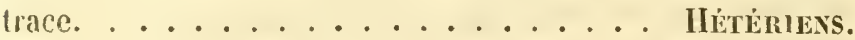

Les autres ont le prosternum dépourvu de mentonnière. Iis forment deux tribus:

ceux dont les antennes sont insérées sous un rebord latéral du front, et dont les fossettes antennaires sont adossées au prosternum. ........ SA Priniens. et ceux dont les antennes sont insérées sur le front et les fossettes antennaires situées au milieu du bord pectoral ou au devant des hanches. .......... Abitiexs. 


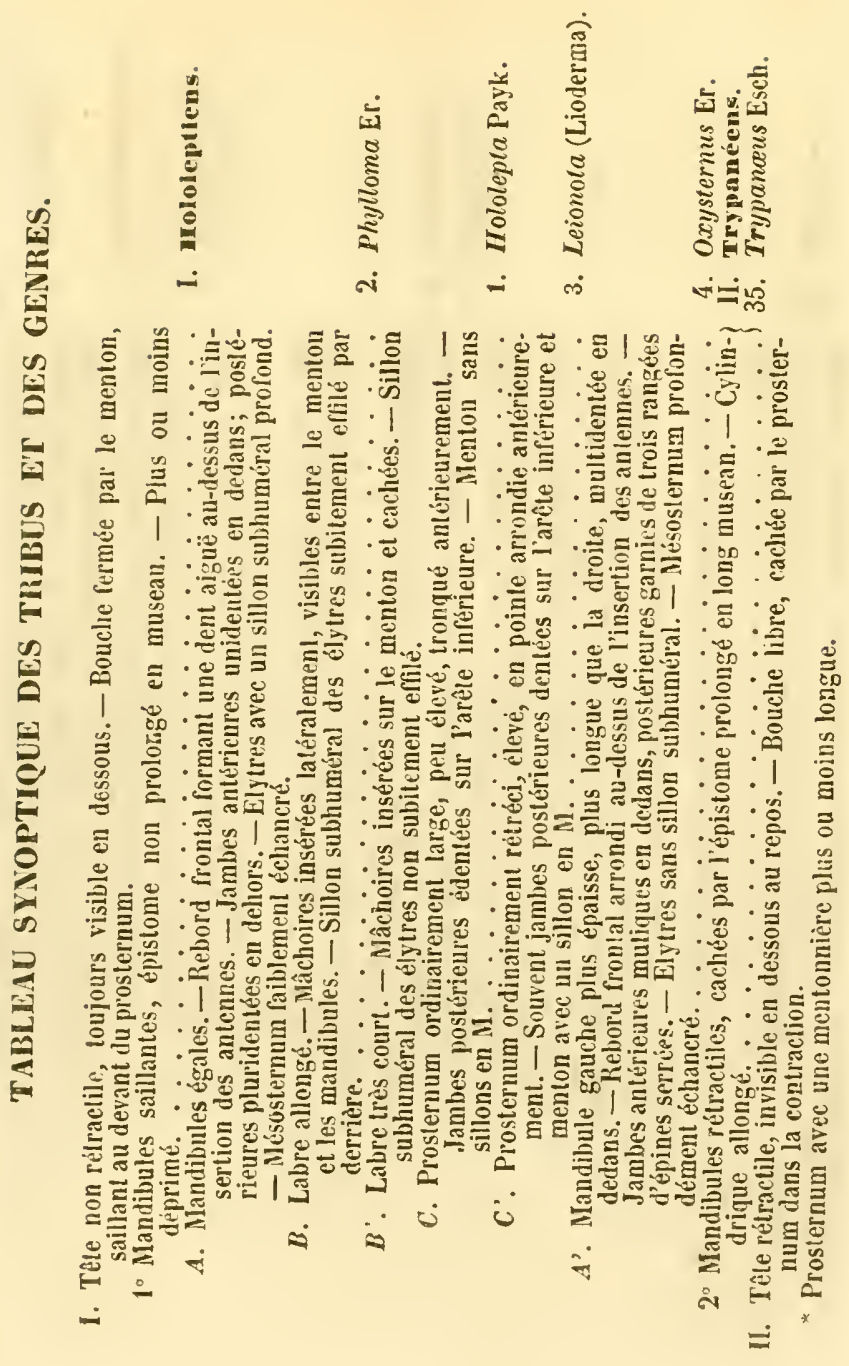



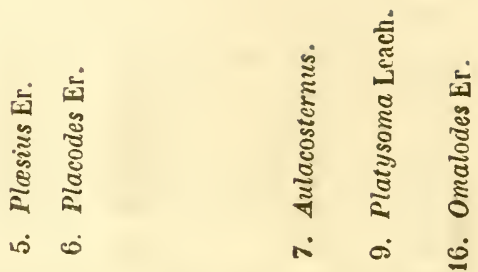

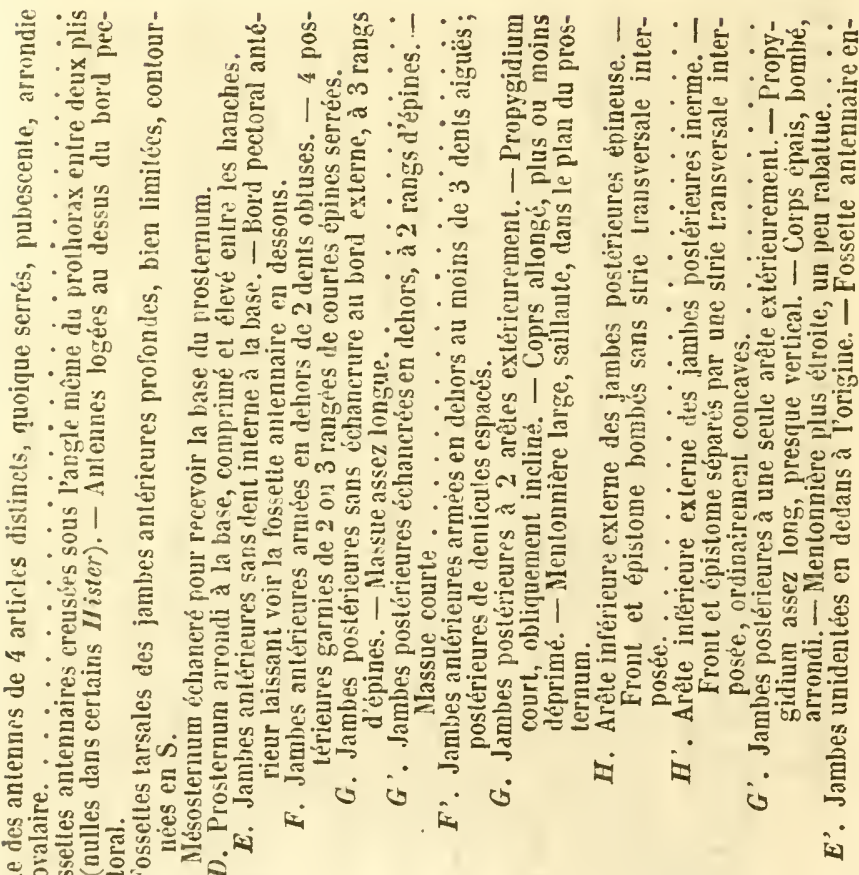

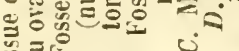

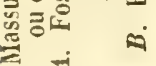



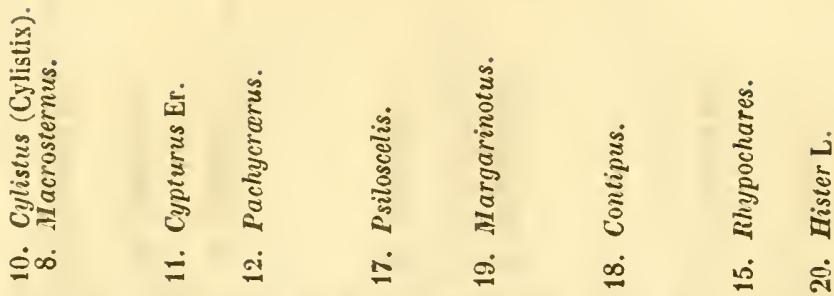

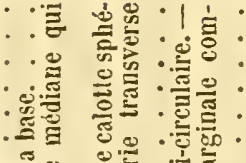

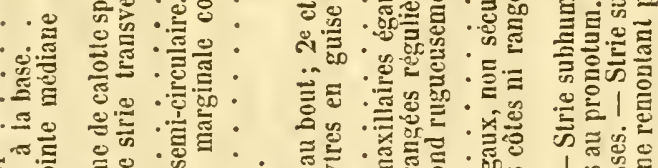

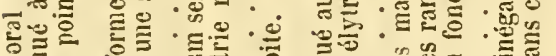

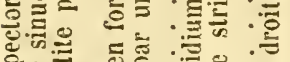

证。

㱒

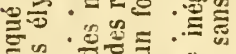

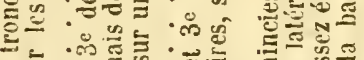

\&.:

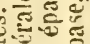

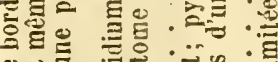

Q0

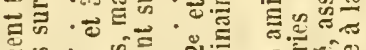

ปั้

है

क्ठ․

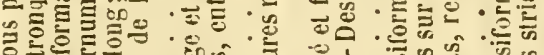

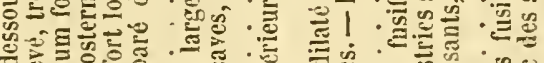

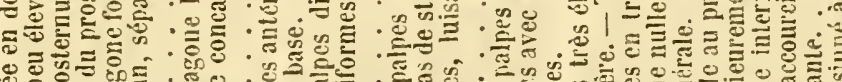

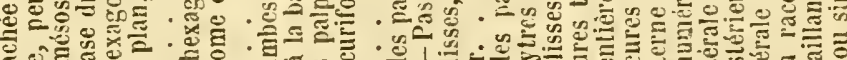
ए人

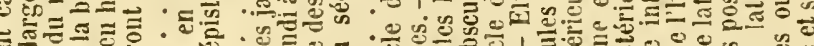

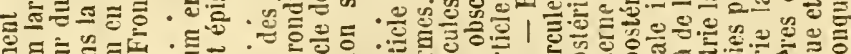

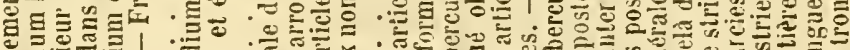

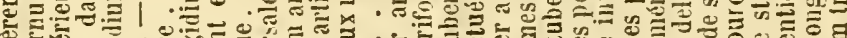

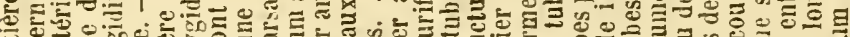
फ

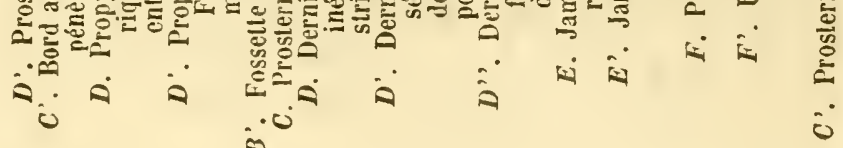




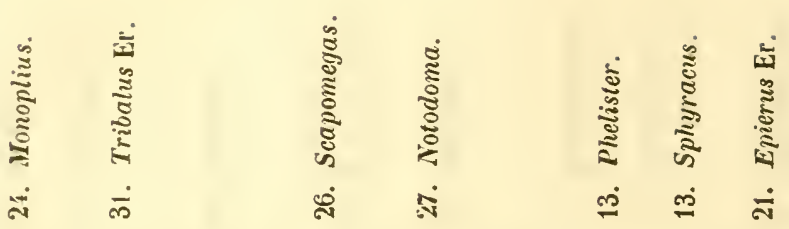

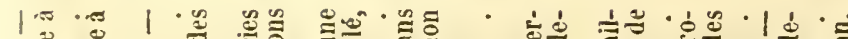

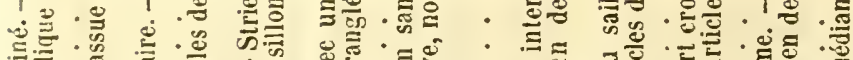

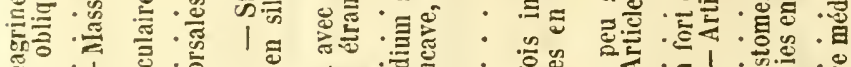

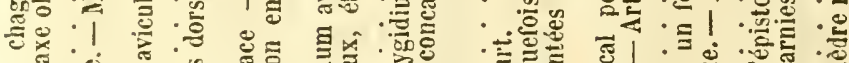

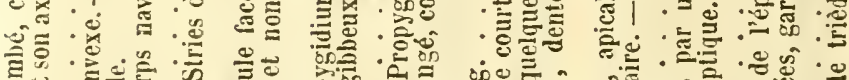

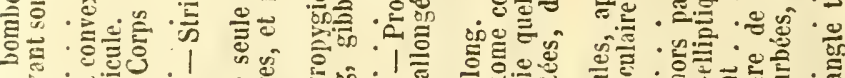
:

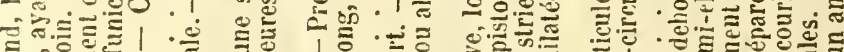

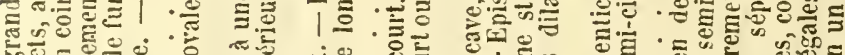

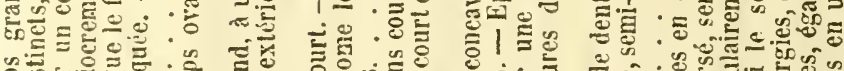

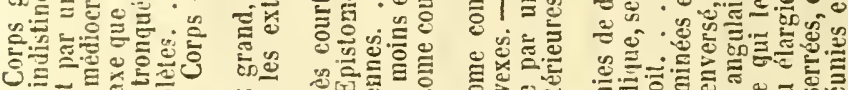

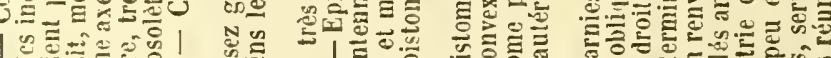

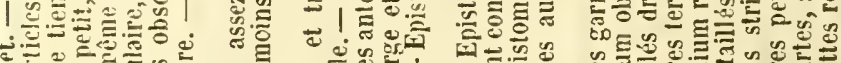

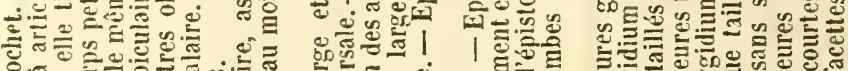

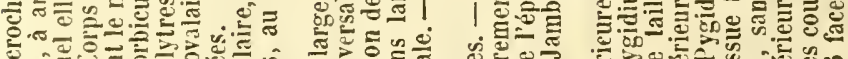

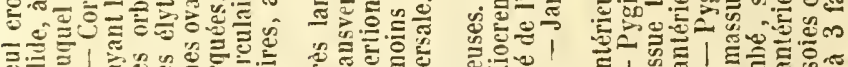

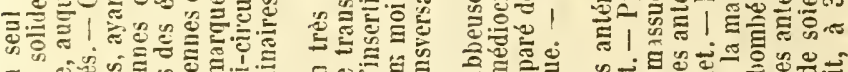

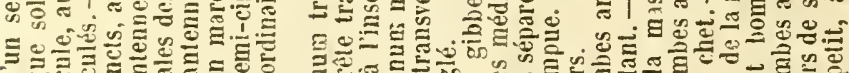
三引

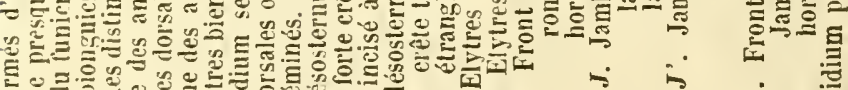

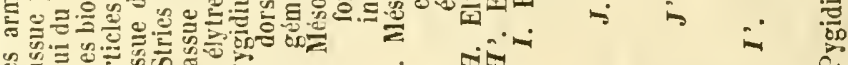

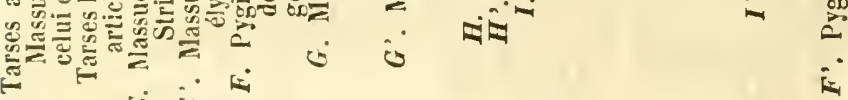
$\dot{\theta} \dot{0}$ i i 


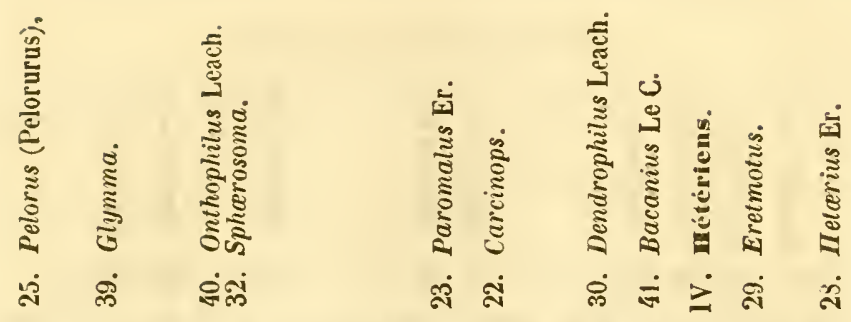



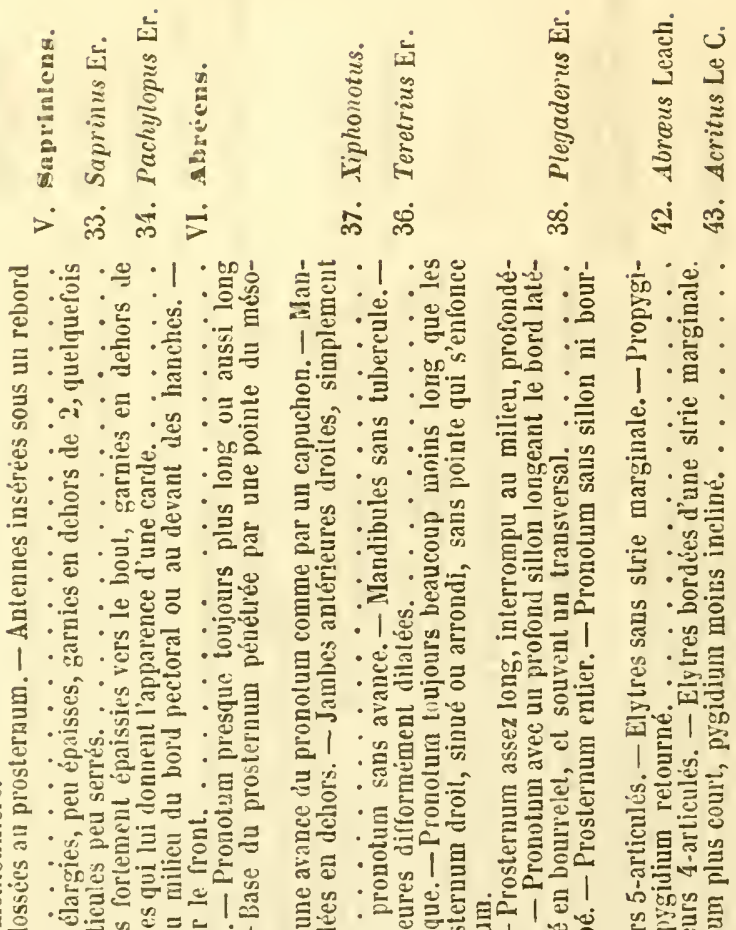

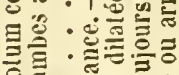

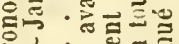

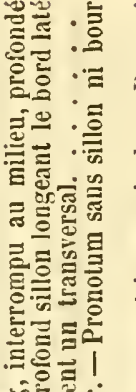
का

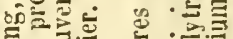
을율

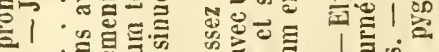

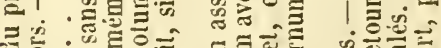

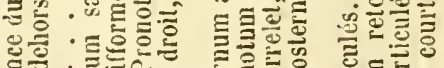

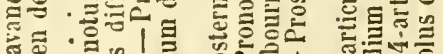

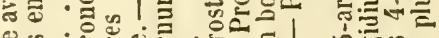

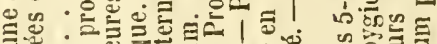

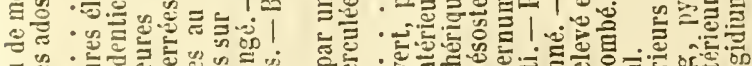

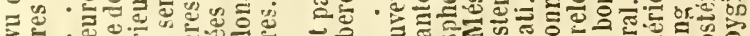

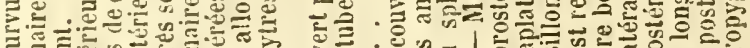

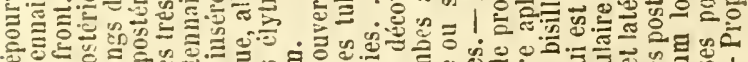

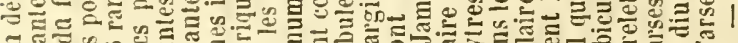

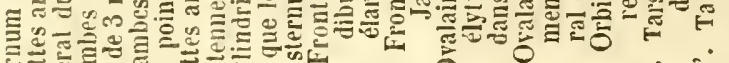

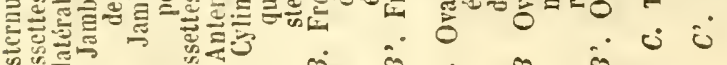
के ; $\therefore$ \& 


\section{SPECIES AUCTORUM INVISE ET OBLIT E.}

\section{Hololepta flageliata.}

Kirby, Cent. d'insect.Trans. Soc. Lin. de Lond., XII, 395, 27 (1817) Edit. Léq., 20, 27.

Atra, elytris bistriatis, abdomine segmento penultimo (propygidio) utrinque sulcato. Long. 12 mill.

Corps ovale oblong, déprimé, luisant, lisse, noir, côtés ponctués en dessous. Tête avec des mandibules saillantes relevées. Pronotum marqué de chaque côté d'un sillon marginal. Elytres obliquement tronquées au bout, avec l'angle externe arrondi, tristriées ; stric intérieure entière, intermédiaire raccourcie à la base, exterue à l'extrémité. Toutes les jambes quadridentées. Propygidium ponctué de chaque coté et bisillonné; sillons formant un angle obtus à ouverture latérale. Pygidium ponctué, infléchi. - Australie.

\section{Hololepta glabra.}

Fahr. in Bohem. Insect. Cafr. I, 556 608, (1851).

Depressissima, nigra, nitida antennis ferrugineis, fronte lavi, pronoto antice utrinque marginato, strigis punctorum obsoletiorum in medio bascos lateribusque; clytris striolis 2 humeralibus obliquis, pygidio segmento $1^{\circ}$ horizontali, apice utrinque punctulato, basi stria marginali utrinque; tibiis anterioribus dentibus 4, posticis 3 armatis. Long. 6 mill., larg. 2 2/3 mill.

IIab. in tractibus fluvii Garicpis superioribus.

Tout noir, excepté les antennes et les tarses, très luisant. Téte subtransversale, presque plane, légèrennent impressionnée en devant; éclancrée de partí dî́ d’autre au-dessus des antennes, lisse; mandibules saillantes, de la longueur de la lête, médiocrement arquées, acuminées. Antennes plus longues que la tête, ferrugineuses, massue d'un flave soyeux. Pronotum postéricurement, presque deux fois plus 
large que sa longueur, subtronqué au milieu de la base, avant les angles postérieurs qui sont arrondis, linéaire au delà du milieu, alors bientôt rétréci, distinctement échancré au bout, avec les angles saillants; très déprimé en dessus, côtés rebordés seulement en avant, marqué de quelques points au-devant de l'écusson, et de strioles de points assez obsolètes sur les côtés, ailleurs très lisse. Ecusson très petit, ponctiforme. Elytres de la largeur du pronotum, à peine plus longues que lui en dedans, sublinéaires, presque tronquées à la base, triangulairement sinuées au bout conjointement, avec les angles postérieurs subarrondis; déprimées en dessus, très lisses, à l'exception de deux strioles de chaque côté en dedans des épaules, obliques, bientôt raccourcies, et d'un sillon dans le côté même. Pygidium ample, segment basal plan, marqué d'une stric marginale de chaque côté, raccourcie après le milieu, limbe postérieur couvert de points épars, le reste de la surface lisse, segment apical très court, infléchi, presque lisse. Dessous du corps très déprimé, lisse; côtés de la poitrine et du ventre ponctués seulement à la base.Pattes très courtes, mais robustes, jambes antérieures et intermédiaires munies chacune de 4 dents, postérieures seulement de trois, tarses d'un ferrugineux obscur.

\section{Platysoma castaneum.}

Ménétr., Cal. rais. 171 No 713 (Hololepta) - Fald., Fn. Transc. I, 215 (1836).

Castancum, nitidum; capite discoque thoracis nigro; elytris utrinque profunde 6-striatis, striis omnibus integris; libiis anticis late dentatis. Long. 1 3/4 mill.; larg. 1 mill.

Stature en quelque sorte de l'Hololepta deplanata Gyll. Cependant deux fois plus grand et surtout plus élargi. 
Tete courte, saillante, médiocrement convexe ; très obsolètement mais très densément pointillée; front légèrement impressionné; épistome ferrugineux, très saillant, luisant. Pronotum grand, carré, un peu rétréci en devant; arrondi à la base avec les angles obtus; côtés très étroitement rebordés; profondément et largement échancré au bout, avec les angles saillants aigus; marge apicale un peu plus obscure; médiocrement convexe en dessus, lisse, noir au milieu du disque, brun marron vers les côtés; en dedans lu bord latéral, deux stries étroites entières de chaque côté. Ecusson triangulaire lisse, déprimé en dessus, brun marron. Elytres de la largeur du pronotum, et à peine plus longues que lui, parallèles, subquadrangulaires, brunes, marquées de noir, réfléchies sur les cơtés, tiès aplanies elı dessus, six stries entières pointillées, rémnies sur chacune à la base et à la marge; interstries lisses, luisants, imponctués. Dessous du corps d'un marron clair, luisant, un peu rembruni, rudement ponctué. Pattes fortes, brunes, luisantes, garnies le quelques soies roides, testacées, éparses; janbes antérieures très dilatées, quatre larges denticules dont les deux externes plus grands.

\section{Hister (PIIELISTER) NANUS.}

Le Conte, N. Amér., Ilist. 31, 29, T. Iv, fig. 4, (1845).

Pronoto stria marginali subintegra, antice non ambiente. Elytris striis dorsalibus integris, $5^{\mathrm{a}}$ introrsum arcuata. Tibiis anticis serrato-dentatis. Long. 21,4 mill.

Noir de poix, luisant. Tête ponctuéc, front concave, sans impression; antennes rousses. Pronotum ponctué, mais davantage sur les côtés, strie rapprochée du bord, courbéc 
en lıaut à l'angle et s’éloisgnant de la marge, non continuée en devant. Blytres rousses en dehors à l'extrémité, stries dorsales entières, cinquième arquée en dedans à la base, réunie à la suturale, suturale ordinairement entière, mais quelquefois un peu raccourcie à la base: humérale distincte, deux latérales, supéricure raccourcie en devant après le milieu, inférieure entière. Pattes rousses, jambes antérieures finement dentelées.

Etats-Unis.

\section{7' HISTER LABIATUS}

Mols. Bull. Mosc. 1845; I, p. 55, 150 Sibérie.

Deux fois plus grand que le $I$. incequalis, ct facile ì reconnaître par le prolongement du labre daus la + ; du reste, il ressemble au Hister incequalis.

Steppes des Kirguises.

88' IIISter atranentarius.

Suffr. in Stet, Zeit. 1855, 1). 142.

Oblongo-ovalis, niger nitidus, thorace lateribus bistriato, elytris striis dorsalibus tribus interioribus obsoletis, marginali abbrcviata; tibiis anticis 3-dentatis. Long. 8 mill.

Cette espèce atteint la taille des plus grands individus du II. unicolor, lient pour la forme le milicu entre lui et le 11. tcrricola Germ., et ressemble aux deux par la surface polie, mais non vernissée, comme dans les $\boldsymbol{H}$. cadaverinus et merlarius, du corps qui est d'un noir uniforme, par les jambes antérieures fortement tridentées, par le pronotum bistrié sur les côtés et par la sculpture des élytres dont les trois stries externes sont entières et les trois internes raccourcies, et dont la deuxième est réduite à un rudiment 
obsolète. Elle se distingue des deux par la disposition de la strie prothoracique externe, qui se rapprochant toujours davantage du bord externe et placée enfin presque sur lui, touche presqu'à l'externe au bord postérieur, par la massue d'un rouge de rouille, et par la disposition des stries latérales des élytres, dont l'interne manque, tandis qu'il n'y a de visible qu'un court, mais bien distinct rudiment de l'externe, vers le bout de la strie humérale, comme dans le $I$. stercorarins. Quanta la forme, il n'est pas aussi arrondi latéralement que le $\boldsymbol{H}$. unicolor, mais plus que le II. terricolu: il ressemble davantage an 11 . merdarins, et se rattache au II. unicolor, comme le II. merdarius au II. cadaverinus. Le pygidium est grossièrement et densément ponctué, avec les intervalles très finement ponctués et rendus mals par cette ponctuation; sur le propygidium, la ponctuation est encore plus grossière, mais plus espacée, et celle des intervalles moins serrée; le fond est plus luisant surtout au milieu du bord postérieur où les gros points s'affaiblissent peu à peu et disparaissent presque entièrement. La fossette subluunérale du bord infléchi n'est pas ponctuée, les stries marginales sont distinctes.

Lac Baikal.

108' Hister Ruficonvis, Grim. in Stet. Zeit. (1852). 221.

- II. myrmecophilus Muls. Opusc. II, 97 (1853).

Ater, nitidus; elytrorum stria marginali externa basim non attingente, $1^{\text {a }}$ et prosertim $2^{a}$ antice abbreviatis; pygidio propygidioque fere aqualiter et sat fortiter munctatis; mrothorace subtriangulari, postice arcuato, latcribus unistriato, punctulato; mesosterno cmarginato; tibiis anticis 4-vel 5-denticulatis. Long. 4 1/5 mill., larg. $29 / 10$ mill.

Corps d'un noir brillant. Front uni; superficiellement 
pointillé; marqué d'une ligne peu profonde, en demi-cercle, presque tronqué en devant. Labre en demi-cercle, plus long que large. Mandibules une fois et demie à deux fois plus longues que le labre; convexes en dessus ; pointillées. Antennes noires, à bouton rouge, d'un tiers environ plus long que large. Prothorax élargi en ligne un peu courbe sur les côtés, peu ou point émoussé aux angles postérienrs ; faiblement alquué en arrière à la base; lisse, rayé près des bords antérieurs et latéraux, d'un seul trait finement ponctué; chacun des latéraux à peu près en ligne droite, et sensiblement recourbé en dedans à son extrémité postérieure. Elytres sensiblement élargies dans leur milieu; à stries finement ponctuées; la première nulle dans son tiers antérieur ou un peu plus; la deuxième dépassant à peine les deux cinquièmes postérieurs de la longueur ; la marginale u’atteignant pas la base ; la troisième presque aussi longue que les autres qui sont à peu près entières, ordinairement marquée en derant de son extrénité antérieure de deux points obliquement dirigés en dedans. Fossette latérale densément ponctuée, extérieurement bornée par un bord lisse et imponctué. Pygidium et propygidium couverts de points aussi rapprochés et à peu près aussi gros et aussi marqués. Dessous du corps noir; densément poncuué sur les côtés. Prosternum triangulairement élargi dans son tiers postérieur ou un peu jlus; visiblement pointillé et rayé d'une strie de chaque côté de cette partie; arqué à son bord postérieur. Mésosternum échancré, lisse, ainsi que les parties suivantes du milieu du corps. Pieds d'un rouge ferrugineux un peu obscur ou d'un rouge brun. Jambes de devant armées ordinairement de cinq, quelquefois de quatre petites dents a peu près égales. 
Patrie : le département lu khône, dans les troncs de chène en compagnie de li Formica fuliginosa.

Cette espèce a tout le faciès de l'II. corvinus, dont elle se distingue par ses mandibules convexes en dessus; par son labre plus long que large; par la strie margimale du prothorax ordinairement plus droite; par l'existence de la strie marginale des élytres; par le pygidium à peu près aussi fortement ponctué que le propygidium; par son prosternum arqué à son bord postérieur, pointillé sur sa surface, strié latéralement; par son mésosternum visiblement échancré. Elle doit ètre placée entre les H.carbonarius et purpurascens; elle diffère du premier par sa taille toujours moindre, par la troisième strie des élytres toujours presque entière; par les première et deuxième moins oblitérées; par son prosternum plus triangulaire, plus visiblement ponctué, strić latéralement. Ce dernier caractère lu prosternum, la strie du front sans sinuosité en devant, celle du prothorax plus droite, ses élytres sans tache, etc......, la distinguent sans peine de l'Ilisicr purpurascens.

\section{7" Hister parallelogramits.}

Fald. Fauna Entom. Transe. I, 2 \{2 (1836).

Truncato-ovatus, subdepressus, atcr nitidus; clytris sublincaribus angustatis lincis 3 integris, profunde impressis et 4 dimidiatis obsoletissimis; tibiis anticis denticulis 5 simplicibus. Long. 21/6-2 2/3 lin., larg. 1 1/4-2 lin.

Voisin pour la stature du $\boldsymbol{H}$. sicrcorarius Payk.

Tète petite, abaissée, plane, glabre, strie semi-circulaire bien marquée; front un peu impressionné. Antennes ferrugineuses, avec le dernier article noir. Ironotum transverse, 
presque deux fois plus large que long, un peu plus étroit cu devant, très lisse, luisant, médiocrement convexe; largement et assez profondément échancré au bout; còtés sublinéaires, épaissis au bord. Ecusson petit, triangulaire, déprimé. Elytres courtes, de la largeur da pronotum, un peu dilatées au milien; médiocrement convexes sur le dos; quatre stries entières, crénelées, peu obliques, profondes; externe beancoup plus courte, les suivantes unies à la base et au bout sur chaque élytre; on observe des rudiments obsolètes de strie suturale, interstries très lisses, luisants. Pygidium très saillant, densément et profondément ponctué. Dessous du corps épaissi, densément couvert de points plus grands; abciomen brun. Paltes plus épaisses, très glabres, noir de poix, luisantes; jambes antérieures à cinq denticules; tarses roux.

$V a r$. Presque deux fois plus petit, la plupart du temps surtout plus étroit.

\section{7 " Hister parallelus.}

Ménétr. Cat. rais. p. 171, 707. - Fald. Fauna transe. I, 213 (1836).

Ater nitidulus; clytris subparallclis, striis 3.extcrnis intcgris, intornis 3 antrorsum abbreviatis; tibiis anticis 4-dentatis. Long. $23 / 4$ lin., larg. $11 / 3$ lin.

Stature et taille du II. parallelogrammus, mais un peu plus grand; distinct par ses élytres pour l'ordinaire plus dilatées et par ses jambes antérieures quadri-denticulées.

Téte petite, un peu enfoncée, lisse, avec une strie semicirculaire profonde; frout à peine impressionné, très obsolïtement pointillé; épistome glabre incliné. Autemes enlierement d'un noir de poix. Pronotum grand, de moitić 
plus large que long; arrondi a la base, largement et profondément échancré an bout, et lì avec les anghles aigus. Convexe en dessus, très lisse, épaissi a la marge, et une strie marginale profonde de chaque coté; en outre une petite fovéole arrondic, basale, profonde audessus de l'écusson. Ecusson petit, triangulaire, lisse. Elytres carrées, de la largeur du pronotum ; ensuite dilatées un peu au milieu, subparallèles; très lisses en dessus, convexes ; six stries extérieures entières, parallèles; intérieures très raccourcies, unies à la base et n'atteignant pas le milicu du disque, fond des stries ponctué. Jessous du corps noir, rudement ponctué. Pattes de poix, jambes antérieures très dilatées, quatre denticules larges acuminés.

\section{0' Hister arcuatus.}

Kolenat. Melet. Ent. V, 60, 262 (1846).

Subovalis niger nitidissimus, pronoli lateribus subbistriatis, stria interiore medio flexa, extcriore brevissima, clytris stria dorsali $1^{\mathrm{a}}$ abbrcviata, $2^{\mathrm{a}}$, $3^{\mathrm{a}}$ que nulla, macula semilunaris extcrna rubra. Long. 5 mill., larg. 4 mill.

Tête avec une stric marginale, ponctuée. Pronotum trìs finement et rarement pointillé, 3-fovéolé postérieurement, une fossetie médiane et deux latérales, strie latérale externe finissant au milicu, interne coudée eı dedans en angle obtus au milieu; élytres noires avec une tache externe réniforme rouge, première strie dorsale courte s'étendant au milicu de l'élytre, deuxième et troisiène unlles, deuxième formant uue trace de points jusqu'au milieu, troisième marquée de même sur toute l'élytre, les trois autres stries externes entières, quatrième droite, cinquième très coudéc en dehors, sixième un peu en dedans, rapprochéc de la cin- 
quième; ces trois stries externes, pointillées postérieurement, interstries vaguement pointillés le long de la suture; antennes et pattes d'un roux de poix; abdomen variolé.

Karabaga, au delà du Caucase.

\section{Hister DistaNs.}

Fisch. Entom. Ross. I, 205, 2 (1823).

Noir, stric extérieure du corselet très courte; élytres it cinq stries dont l'extérieure très courte ct l'intéricure interrompue. Long. 4 lin, larg. 2 1/2 lin.

Daurie.

\section{1' Carcinops, Dendropiefus melicatclus.}

Führs. in Bohem. Insect. Caffr. I, 350, 601 (1851).

Breviter ovalis, niger, nitidus capite thoraceque punctulatis; clytris 9-striatis, striis 2 intimis approximatis, antice cvanescentibus, reliquis integris, 3-8 dorsalibus, cequaliter arcuatis, 9" laterali; antemis ferrugineis, pedibus piceis, tibiis dilatatis, anticis medio subscrrulutis. Long. 1 1/2 mill., larg. 1 mill.

Ilabilat in tractibus fluvii Garicpis superioribus.

Noir dessus et dessous, luisant. Tète transverse pointillée, front terminé en devant par une ligne semi-circulaire élevée. Artennes courtes, ferrugineuses, plus obscures il la base. Pronotum deux fois plus large que long a la base, rétréci en devant, peu échancré au bout, angles abaissés aigus; obtu. sément arrondi postérieurement, peu convexe en dessus, finement pointillé, faiblement rebordé sur les côtés. Ecusson très petit, ponetiforme. Elytres conjointement échancrées à la base et là de la iargeur de la base du pronotum, légèrement arrondies et dilatées avant le milieu, rétrécies de nouveau postérieurement et tronquées au bout, presque trois 
fois plus longues que le pronotum, médiocrenent convexes en dessus, sillonnées de neuf stries pointillées, deux rappro. clées près de la suture, n'atteignant pas la base, les autres entières, 3-8 dorsales également arquées, neuvième sur le bord latéral même, fléchie avant le milieu; interstries lisses. Pygidium presque perpendiculaire, arrondi, presque lisse. Dessous du corps peu convexe, lisse au milieu, ponctué sur les côtés. Pattes médiocres, de poix, jambes dilatées, comprimées; antérieures munies en dehors vers le bout de quelques denticules obsolètes.

\section{DeNDROPHLes minutus.}

Fahr. in Bohem. Insect.Caffr. I, 551, 602 (1851).

Ovalis, niger, nitidus, capite pronotoque punctulatis, elytris alorso 6-striatis, stria suturali antice cvancscente, reliquis distinctioribus, integris, punctatis, antice introrsum flexis, margine laterali inflexo, stria crenata insculpto; antennis pedibus. que forrugincis, clava illar um flavescente, tibiis anticis dilatutis, extus bidentatis, 4 posterioribus bispinosis. Long. 2 mill., larg. $11 / 4$ mill.

II abitat in tractibus fluvii Gariepis superioribns.

Tout noir, excepté les antennes et les pattes, très luisant. Tete subtriangulaire déprimée, densément et très finement pointillée, front très faiblement rebordé. Antennes un peu plus longues que la tête, ferrugineuses, massue flavescente. Pronotum deux fois plus large à la base que sa longueur, et là obtusément arrondi, médiocrement rétréci en devant, cotés étroitement rebordés, angles antérieurs acuminés; peu convexe en dessus, très linement et densément pointillé avec des points épars plus distincts sur les côtés. Ecusson très petit, ponctilorme. Elytres à la base de la largeur du 
pronolum, et étroitement serrées contre lui, un peu dilatées i la base, mais bientôt légèrement rétrécies, plus de deux fois phis longues que le pronotum, tronquées au bout, avec les angles extérieurs arrondis; peu convexes en dessus, sillonnées de six stries dorsales ponctuées, suturale raccourcic par devanl, les autres entières, fléchies en dedans antérieurement, interstries pointillés; en outre sur le bord infléchi mème, une strie subcrénelée entière, avec deux autres stries fines, obsolètes, imponctuées, adjacentes en haut. Pygidium fléchi à la base, ponctué, segment apical subinlléchi, arrondi, lisse; dessous du corps médiocrement convexe, presque lisse au milieu, ruguleusenent ponctué sur les côtés. Pattes médiocres, ferrugincuses; jambes antéricures comprimées et dilatées, bidentées en dehors, quatre postérienres munics de deux spinules plus distinctes, l'une au milieu, l'autre au bout.

\section{1'Dendrol'hlus sulcatos.}

Mots. Bull. Mose. 1845, I, p. 55, 149.

Beaucoup plus petit que le D. munclatus, et facile à reconnaître par les stries fortement imprimées qui traversent ses élytres et qui sont entièrement ponctuées.

Mingrelie.

SAPRivis estriates Le Conte.

Camut antice marginatum, prostermum striis valde approximatis, postice divergentibus, antice non divergentibns. Prostcrmum compressum, striis anticis antice convergentibus.

If. le Dr Le Conte dans son tableau des Saprinus, place cette espece entre le mancus et le bigcmmeus dans son se groupe; mais il n'en donne pas les caracteres. L'a-l-il décrite ailleurs? 


\section{Hister (saprinus) curratis.}

Kolen. Melet. Ent. v, 62, 276 (18i6).

Viridi-cupreus; fronte glabra, stria marginali; elytris postice punctatis, striis ad dimidium vergontibus; antennis pedibusque rufis. Long. 2, 4; larg. 1, 9.

Pronotum très finement ponctué, bisérialement ponctué transversalement à la base, strie antérieure courte, côtés du pronotum pointillés. Elytres à cinq stries, pouctuées sur leur moitié postéricure, strie suturale entière et réunie par devant en arc avec la troisième, deuxième nulle, les quatre autres obliques et graduellement plus courtes, ne dépassant pas le milieu de l'élytre, stries obsolètement ponctuées ; marge postérieure des élytres roussâtre. Abdomen ponctué.

Karabagh (Arménie).

Hister (saprines) Krynickit (Fald.)

Krynk, in Bul. Mosc. Ed. Léq. I, 174, 32.

Ovatus, niger, sum nigro-cencus, nitidus; thorace antice utrinque foveolato; elytris antice lavibus; striis 5 obliquis abbreviatis, capitulis antennarm tarsisgne piccis, tibiis anticis paupere denticulatis. Long. $21 / 2$ lin., larg. $13 / 4$ lin.

Charkow, dans les cadavres.

\section{6' Saprinus Flextoso-Fasciatus}

Motsc. Bull. Mosc. 1845, p. 55, 148.

Très jolie espèce l'Astrabad. De la taille et de la forme des grands exemplaires du $S$. Eneus, mais avec une bande transversale d'un blanc jaunâtre un peu siunée sur le milieu des élytres. 



\section{ESSAI MONOGRAPHIQUE}

\section{SUR LA FAMILLE DES HISTERIDES}

(Suite) (1).

Par M. S.-A. de MARSEUL.

(Séance du 9 Février 1853.)

\section{Description D'un genre nouveau et DE Plusieurs} ESPÈCES NOUVELLES.

Pl. xxiv et xxv. (Supplément).

1'. Hololepta Perraudieri.

parallelo-ovalis, depressus, niger, nitidus, lcevis; fronte lata haud striata, mandibulis validis in medio uni-dentatis, labro bilobo; pronoto lateribus marginatis; clytris striis 2 dorsalibus brevibus, sulco subhumerali utrinque abbrcviato; propygidio extus parce punctato; prostcrno lato antice subrotundato; tibiis extus infra inermibus, anticis supia 4-, posterioribus 3-dentatis. Long. 10 mill., larg. 7 mill.

Ovale oblong, parallèle, déprimé ; noir luisant très lisse.

(1) Voyez $3^{\text {e }}$ série, T. 1 (1853), p. 131 et 447; T. II (1854), p. 161, 525 et 671 ; T. III (1855), p. 83 et 327 , et T. IV (1856), p. 97. 259 et 549 . 
Tête large, front plan, sans strioles ni tubercules, avec une petite dent oculaire; labre court bilobé. Mandibules fortes, saillantes, peu arquées, épaissies à la base, un peu recourbées au bout et armées en dedans d'une petite dent médiane. Pronotum transversal, court, subbisinué à la base, avec une légère strie médiane, occupant la moitié postérieure, et les angles obtus; légèrement arqué sur les côtés et bordé d'une forte strie marginale qui se continue à la base et se termine dans une profonde fossette ơ ovale à l'angle antéricur, qui est arrondi et présente une faible entaille; largement échancré au devant. Ecusson très petit. Parapleures visibles. Elytres de la largeur du pronotum à la base, à peine plus longues que lui, presque parallèles, obliquement tronquées au bout avec les angles externes arrondis et parsemés de quelques petits points; bord infléchi lisse avec quelques points le long de la stric marginale; sillon subhuméral profond, sinueux, raccourci aux deux extrémités; première dorsale bien marquéc atteignant le tiers, deuxième très courte. Propygidium entouré de points assez gros, très épars. Pygidium imponctué. Echancrure du menton très profondément entaillée o ${ }^{*}$. Prosternum court, large, faiblement arrondi en devant. Mésosternum tronqué en devant, bordé sur les côtés. Jambes incrmes à l'arête inférieure; antéricures 4 -dentées à l'arête supérieure, postérieures 3 -dentées.

J'ai dédié cette intéressante espèce au jeune et savant voyageur, M. Henri de la Perraudièı’e, qui l'a découverte à Ténériffe. Elle vient se placer en tête des espèces de la deuxième division, dont elle se distingue par ses mandibules dentées. 


\section{9'. Hololepta Baulny,}

Oblongo-ovalis, nigra nitida, funiculo tarsisque brunncis; fronte ad oculos dentata, pronoto latcribus striato parceque punctulato; clytris margine inflexo lavi, sulco subhumerati in medio dilatato, basi subintegro, dorsali $1^{a}$ appendiculata ante medium abbreviala, 2a brevissima; propygidio grosse et parce circum, mygidio dense rugoso-punctatis; tibiis anticis 4-, posti cis 3-dcntatis. Long. 15 mill., larg. 7 mill.

Ovale allongé, subdéprimé, noir luisant. Funicule brun. Tête arrondic un peu transverse; front plan, lisse, avec unc fovéole derrière les ycux et une dent devant; labre court, échancré. Mandibules assez saillantes. Pronotum court, large, bisinué à la base avec une striole médiane à peine visible audevant de l'écusson, et les angles arrondis, courbé sur les côtés avec une fine strie marginale entière, longée par des points fins, espacés; fortement échancré en devant avec les angles bien marqués obtus. Ecusson très petit; parapleures visibles. Elytres à peine plus longues à la suture que le pronotum, de sa largeur à la base, droites sur les côtés, formant un angle sutural très profond postérieurcment; bord infléchi lisse, sillon subhuméral large et profond au milieu, finement aiguisé vers la base qu'il atteint pour ainsi dire; première strie dorsale forte, du tiers de la longueur, avec un appendice apical aussi long qu'elle, deuxième très courte. Propygidium entouré de points variqueux plus ou moins rapprochés. Pygidium densément et rugueusement ponctué. Jambes antérieures armées de quatre dents obtuses, et postérieures de 4 aiguës, sur l'arête externe.

Un peu plus grand que le IIol. indica, auprès duquel il vientse placer, il en diffère par la ponctuation du pronotum; 
celle de son propygidium pius forte et plus étendue, son sillon subhuméral atteignant la base et moins brusquement terminć.

Indes-Orientales (collection de M. Javet).

\section{LIOdERMA CACTI.}

Niger, nitillus, elongato-parallelus, convexiusculus; caput magnum fronte utrinque brevi-striata, mandibulis magnis; pronoto tateribus intervupte marginato, antice fovcolato, extus punctuto; clytris striis 2 dor salibus, $1^{\text {a }}$ punctis continutata, 2 a subintegra, sulco subhumerali hinc inde abbrcviato; propygidio circum parce, pygidio marginato obscure munctatis; tibiis anticis 4-, posterioribus 3-dentatis, carina inferiori celentata. Long. 13 mill., larg. 7 mill.

Ilololepta cacti L. Lec. Calif. (1851) p. 38.- Mars. Mon. Hister III, 1, p. 220 (1853).

Noir luisant, allongé, parallèle, convexe en dessus transversalement. Tête grosse ; front large ì peinc bombé, lisse, avec une courte strie au fond d'une fovéole de chaque côté, un sillon et une courte épine en dedans des yeux ; mandibules arquées, très longues; menton échancré en devant avec une crête longitudinale de chaque côté. Pronotum court, large, avec une légère strie médiane visible postirieurement, subbisinué a la base, avec les angles arrondis, droit sur les côtés, bordé d'une strie interrompue continuée un peu à la base, et terminée en devant dans une profonde cavité creuséc sur l'angle antéricur qui est obtus; largement échancré en devant. Sur les bords de la strie marginale, on voit des inégalités rugueusement ponctuées. Elytres 
de la largeur du pronotum à la base, presque droit sur les cotés avec l'angle postéro-externe arrondi, couvert de petits points espacés, et un angle sutural profond; deux stries dorsales bien marquées, interne atteignant l'extrémité, mais brièvement interrompue, l'externe raccourcie au quart el continuée par une ligne de points ; sillon sublıuméral atténué et raccourci devant et derrière; bord infléclii triangulaire,' un peu creusé et parsemé de quelques points. Propygidium un pen convexe, transversal, lisse au milieu, couvert de points épars dans son pourtour. Pygidium obscur, peu distinctement pointillé, limité par un rebord élevé saillant. Prosterıum saillant comprimé avancé en pointe vers la tète. Mésosternum assez profondément échancré avec une strie marginale iuterrompue. Jambes inermes à l'arête inféricure, armées à la supérieure, antérieures de quatre dents et postérieuresside trois.

Ne connaissant pas cette espèce, qui vient de Californic, lors de la publication des Hololeptiens, je m'étais borné à reproduire la courte diagnose du Docteur J.-L. Le Conte; je puis en donner une description détaillée sur un individu que je dois à son obligeance.

Elle doit se placer à la suite du Liodcrma strigicollis.

\section{8' Trypaneus breviculus.}

Cylindricus, brevis, niger, nitidus; fronte subimpressa, rosvo lato, apice rotundato; pronoto parce et grosse punctato, lateribus marginato, elytris munctulatis, macula magna triangulari rufo-flava, mygidio conico obtuso; prostcrno angustato marginato, basi subinciso, mesosterno lato plano stria marginali interrupta; tibiis anticis 5-dentatis. Long. 3 nill., larg. 1 $1 / 3$ mill.

Cylindrique court, noir, luisant. Tête large; yeux sail- 
lants; front légèrement impressionné ; rostre large, arrondi au bout. Antennes brunes. Pronotum plus long que large, beaucoup plus long que les élytres, paraissant parallèle, mais réellement élargi aux quatre cinquièmes postérieurs, fortement rebordé sur les côtés, et à peine échancré en devant, avancé en pointe sur l'écusson, couvert de points forts et peu serrés. Elytres finement pointillées, élargies latéralement vers le milieu, arrondies au bout, et marquées d'une tache d'un jaune fauve, triangulaire ou ovalaire, s'élargissant vers la suture. Pygidium conique, peu convexe et couvert d'une ponctuation très serrée. Prosternum presque parallèle et entièrement rebordé, obtus et un peu rétrèci en devant, sinué à la base; mésosternum plan, élargi, pénétrant légèrement dans la base du segment précédent, bordé d'une strie un peu interrompue; métasternum sillonné au milieu, finement ponctué. Pattes brunes, jambes antérieures armées de cinq dents; postérieures dilatées et velues.

Il se rapproche du $T$. pictus par sa forme et sa couleur; mais il est encore plus court; le museau est plus large, le pygidium moins bombé; le prosternum moins triangulaire et les jambes antérieures ont cinq dents, tandis qu'il n'y en a que quatre dans son congénère.

Il vient du me̊me pays, c’est-à-dire de Cayenne.

\section{1'. Trupaneus Cartiagenus.}

Cylindricus, niger, nitidus; fronte leviter impressa, tubercutala, rostro apice obtuso reflcxo; pronoto parce punctato, latcribus purallelo, antice subbituberculato; pygidio punctulato obtuso conico; prosterno narallelo utrinque obtuse truncato, subconcavo lateralique margine clcvato; mesostermo antice rotundato lato, intorrupte marginato; pedibus brunncis, tibiis anticis 4-dentatis. Long. 2 mill., larg. 1 mill. 
Cylindrique, court, noir luisant. Front légèrement concave avec les bords latéraux un peu élevés et un petit tubercule médian; museau large terminé en pointe obtuse et relevée. Antennes et pattes brunes. Pronotum court, un peu plus long que large, parallèle et rebordé sur les côtés, un peu avancé en pointe sur l'écusson, tronqué droit au bord antérieur avec deux très faibles tubercules rapprochés; couvert de points assez forts, très espacés. Elytres beaucoup plus courtes que le pronotum, élargies au milieu, arrondies au bout, :brunes avec le pourtour rougeâtre. Pygidium en cône obtus densément pointillé. Prosternum parallèle et même un peu plus élargi en devant, concave avec les bords latéraux élevés, tronqué aux deux extrémités. Mésosternum plus large, arrondi en devant et ne pénétrant pas dans la base du prosternum, bordé d'une strie interrompue. Jambes antérieures armées de quatre dents obtuses.

Il vient se placer près du $T$. proboscidens, dont il se distingue surtout par les tubercules de son front et de son pronotum.

Nouvelle-Grenade, Carthagène.

\section{3' Platysoma Murrayi.}

Oblongo-ovatus, depressus, niger, nitidus; fronte plana, stria iransversa integra, pronoto stria laterali haud intervipla, ely. tris striis dorsalibus 1-3 integris, $4^{a}$ dimidiala; pygidio marginato, ocellato-punctato; mesosterno simuato marginatoque; tibiis anticis 4-dentatis, intermediis 4-, posticis 3-spinosis. Long. 7 mill., larg. 3 mill.

Ovale, oblong, déprimé, noir luisant. Front transverse, 
plan, bordé en devant d'une strie entière, repliée sinueusement en dedans des yeux; épistome concave; mandibules fortes, arquées, uni dentées en dedans. Pronotum beaucoup plus large que long, presque droit à la base, parallèle sur les côtés, largement échancré eu devant avec les angles obtus; strie latérale forte non interrompue en devant. Ecusson petit triangulaire. Elytres de la largeur du pronotum à la base, une fois et demie plus longues, retrécies et tronquées an bout; stries dorsales 1-3 entières, quatrième occupant le tiers postérieur et se recourbant au bout vers la cinquième, représentée seulement par quelques points; stric subhumérale entière, ainsi que les marginales; bord infléchi lisse. Propygidium court transverse couvert ainsi que le pygidium de gros points ocellés; ce dernier triangulaire et entouré d'un rebord élevé. Prosternum étroit avec une mentonnière avancée et rebordée, arrondi à la base. Mésosternum large, sinué en devant et bordé d'une stric entière. Jambes antérieures 4-dentées; intermédiaires munies de 4 épines, postérieures de 3.

Cette espèce, provenant du Vieux-Calabar, m’a été communiquée par notre savant collègue, M. Andrew Murray, á qui je suis lıcureux de la dédier. Elle vient se ranger entre les $P l$. atrutum et lucifugum; elle présente la forme aplatie et le pygidium rebordé du dernier, mais elle a trois stries entières, la quatrième courte et la cinquième nulle.

\section{9'. Platysoma Confucir.}

Ellipticus depressus, niger, nitidus, antennis pedibusque rufobrunneis; fronte marginata, clypeo concavo; pronoto stria latcrali a margine distanti, anterius interrupta; elytris striis clorsalibus 1-3 integris, 4-5 dimidiatis; propygidio grosse at parce, pygidio anterius punctulis; mosterno lobo valde promi- 
nenti, mesostcrno interrupte marginato; tibiis anticis 4-dentatis, posterioribus 4-vel 3-spinosis, Long. 4 mill., larg. 1 3/4.

Ovale, subparallèle, déprimé, lisse, noir luisant en dessus, brun rouge en dessous, avec les antennes et les pattes ferrugineuses. Front transverse, entouré en devant et sur les côtés d'une forte strie; épistome concave. Pronotum beaucoup plus large que long, tronqué droit à la base, parallèle sur les côtés, largement échancré en devant, avec les angles obtus; strie latérale distante de la marginale, forte et un peu sinuće, interrompue en devant. Ecusson petit, triangulaire. Elytres une fois et demie de la longueur du pronotum, de sa largeur à sa base, parallèle sur les côtés, retrécies et arrondies à l'angle postérieur et tronquées au bout; stries dorsales profondes, imponctuées, droites, 1-3 entières, 4-5 égales, raccourcies au milieu; subhumérale entière, abaissée, bord infléchi lisse, assez étroit. Propygidiun: court marqué de gros points espacés. Pygidium triangulaire, bombé, lisse postérieurement et grossièrement ponctué à la base. Prosternum étroit, arrondi à la base, muni d'une mentonnière très avancée et rebordéc ; mésosternum échancré en devant, et bordé d'une strie sur les côtés. Jambes antérieures 4 -dentées, les autres garnies d'épines, dont l'extrême est double, intermédiaires de 3 , postéricures de 2.

Cette espèce, de Chine, vient se placer à la suite du $\mathrm{Pl}$. Pangami; c'est en petit le $P \boldsymbol{l}$. Luzonicum, sauf la forme du pygidium.

24'. Platysoma gracile J. Le C., Mon. Hister, 11, 5, t. 1, fig. 7 (1845). - Mars. Mon. Hister. (1853),

$$
\text { Ix, 27, pl. Iv, pag. } 283 .
$$

Cylindricus, clonyatus, nigro-brunneus, punctulatus, pectore 
rentennis pedibusque forrugineis; fronte stria scmicircularipa. rum profunda, clypeo concuvo; pronoto stria laterali margini approximata, haud interrupta; elytris striis dorsulibus 1-4 integris, $5^{\text {a }}$ et suturali plus minusve basi abbreviatis; propygidio ocellato, pygidio basi parce punctatis; prosterno valde prominenti, mesosterno emarginato, stria integra; tibiis anticis 5dentatis, posterioribus 3-vel bispinosis. Long. 2 1/2 mill., larg. 1 mill.

Allongé subcylindrique, un peu déprimé, noir brun, surtout aux élytres et en dessous, avec les antennes, les pattes et la poitrine ferrugineuses. Front transverse un peu convexe, pointillé, bordé d'une strie semi-circulaire peu nettement accusée ; épistome concave. Pronotum presque carré, ponctué sur toute sa surface, avec une bordure de plus gros points à sa base, qui est tronquée, et des points plus forts et moins serrés latéralement; parallèle sur les côtẻs, largement écliancré en devant avec les angles obtus; strie latérale fort rapprochée du bord et non interrompue. Ecusson triangulaire très petit. Elytres une fois et demie plus longues que le pronotum, de sa largeur à la base, parallèles sur les côtés et tronquées au bout, couveries d'une fine ponctuation assez serrée; stries dorsales bien marquées, 1-4 entières, cinquième complétée par une ligne basale de points, suturale ne partant pas tout à fait de l'extrémité et n'atteignant pas la base, mème avec la ligne de points; subhumérale un peu abaissée, distante de la première dorsale. Propygidium oblique, assez long, couvert de gros points ocellés peu serrés. Pygidium bombé, perpendiculaire, avec des points espacés à la base. Prosternum très étroit, arrondi à la base, avec une mentonnière très saillante; mésosternum assez étroit, fortement échancré en devant et bordé d'une strie entière, ponctué comme le mélasterıum. Jambes antérieures à cinq 
lents; postérieures garnies de deux ou trois épines, la dernière géminée.

Cette description est faite sur un type, des Etats-Unis, que m'a donné M. le Docteur J.-L. Le Conte. Il est plus étroit que le $\mathrm{Pl}$. parallclum, sa ponctuation moins forte et plus serrée, différente sur le pygidium, ses stries internes moins complètes. Il diffère aussi du $P l$. coarctatum par son pronotum plus allongé, les deux stries internes des élytres continuées par des points et la ponctuation de son pygidium plus forte et mieux marquée.

\section{1*. Hister costatus, Mon., pl. xxiv (sup.).}

Oblongo-ovatus, parum convexus, vix nitidus; fronte plana stria integra; mandibulis canaliculatis, intus dentatis; monotolacvi laleribus bisulcato, striis 2 latcralibus, interna haud interrupta, impressione basali mulli-sinnata; elytris gramulatopunclutis, sutura basi costisque 7 alternis tuberculatis clevatis, margine inflexo lavi sulcato; propygidio margine laterali, carina media, tuberculis que 2 elevatis, pygidioque basi grosse munctatis; prosterno marginato; mesosterno emarginato striis 2, postica haud interrupta; tibiis anticis obtuse tridentatis; poslicis biseriatim spinosis. Long. 8 mill., larg. 5 mill.

Mister costatus J.-L. Le Conte, Proceed. of the Acad. of Nat. Sciences of Philad. vi (1854), p. 37.

Ovale oblong, peu convexe, d'un noir mat, un plus luisant sur le pronotum. Antennes brun de poix. Front plan, transverse, séparé de l'épistome par une strie semi-hexagonale plus profonde en dedans des yeux. Mandibules fortes, arrondies en pointe au bout, légèrement canaliculées, fortement dentées au dedans. Pronotum court, transverse, un 
peu arqué au milieu de la base, avec les angles obtus, courbé sur les côtés, échancré et retréci en devant avec les angles arrondis, deux sillons longeant le bord latéral; ils sont limités en dehors par les stries latérales à bord tranchant, dont l'interne n'est pas interrompue en devant et l'externe se termine près des yeux; le sillon interne est large et profond; il s'étend le long de la base, et il est limité en devant par la surface qui forme des festons en relief; audevant de l'écusson, s'élève une crête entre deux cavités. Ecusson petit, triangulaire, enfoncé. Parapleures visibles en dessus. Elytres un peu plus longues que le pronotum, de sa largeur à la base, à peine courbées sur les còtés, avec le bord infléchi, lisse, sillonné, rétrécies et tronquées droit au bout, avec un petit angle sutural. Elytres rugueusement ponctuées, avec six côtes représentant les stries dorsales, 1, 3 et 5 entières à la base et continuées par des tubercules, la dernière se réunissant par un arc ì la base de la suture, qui est élevée; 2,4 et 6 commençant par deux ou trois tubercules et continuées par une longue crête granulée; l'épaule est marquée par un tubercule qui se continue d'une part avec l'arête de la marge et de l'autre avec la première côte ; une côte sublıumérale, composée comme cette dernière d'une ligne de tubercules, longe le bord externe. Base du pygidium et propygidium couverts de gros points espacés; ce dernier bifovéolé, relevé sur les cotés, caréné au milieu et tuberculé de chaque côté.

Prosternum arrondi à la base, retréci au milieu, bordé d'une strie entière, mentonnière courte, un peu inclinée, largement rehordée. Fossette antennaire sous l'angle anlérieur du prothorax, mais mal limitée. Mésosternum échan- 
cré en devant, bordé d'une strie entic̀re profonde et d'une autre plus fine et interrompue, séparé du métasternum par une stric transverse; ces deux segments concaves. Jambes antérieures dilatées en triangle court, armées de trois dents obtuses; postérieures assez étroites, peu épaisses et allongées, garnies d'une double rangée de spinules. Tarses courts, dernier article armé de 2 courts crochets.

Cette remarquable espèce a été trouvée par M. Aug. Sallé dans le sable éboulé d'une berge du chemin sur la Cordillère, près du village de Tenejapam (Mexique), pendant le mois de mai. J'en ai vu deux autres individus provenant de la Californic, dans la collection du Docteur J.-L. Le Conte, qui l'a mentionnée sous le nom de $I$. costatus, en 1854 , sans la décrire, et qui en fait son quatrième groupe.

Elle s'éloigne entièrement pour l'aspect des autres espèces du genre IIister, dont elle conserve tous les autres caractères. Ses élytres á côtes tuberculeuses, son propygidium la feraient prendre pour un énorme Onthophilus. Peut-ètre devrait-elle former un nouveau genre dans le voisinage des Psiloscelis? Mais en attendant que de nouvelles recherches m’aient fait découvrir des caractères plus importants, je la placerai dans une division à part en tête du genre.

\section{1' Hister Assamensis.}

Ovalis subconvexus, niger nitidus; fronte plana lata, stria scmicirculuri subrecta, mandibulis canaliculatis pronoto ciliato, striis 2 luteralibus postice apmoximutis, interna interrupta; clytris striis validis, punclatis, subhumerali interna humerum attinqente, 1-3 dorsalibus integris, $4^{\mathrm{a}}$ basis et apicis rudimento lineaque munctormm composita, fossa mumerali unisulcata, mropygidio bifovcolato mygidioque punctulatis; mesos- 
terno simuato marginatoque; tibiis anticis 3-dentatis, posterioribus biseriatim spinosis. Long. 7 mill., larg. 5 mill.

Ovale, assez convere, noir, luisant. Tête forte; front large, plan, séparé de l'épistome par une strie semi-circulaire presque droite; labre court, légèrement impressionné; mandibules canaliculées, fortement dentées en dedans. Antennes brunes, massue grisâtre, pubescente. Pronotum court, subbisinué à la base arec les angles arrondis, oblique sur les côtés, écharcré et très retréci en devant, avec les angles obtus, abaissés et saillants, cilié de fauve dans son pourtour ; strie latérale externe fine, rapprochée du bord, presqu'entière, cessant à l'angle antérieur; interne beaucoup plus forte, rapprochée de l'externe à la base, interrompue au milieu du bord antérieur. Ecusson triangulaire très petit. Parapleures saillantes. Elytres une fois et demi plus longues que le pronotum à la base, arrondies sur les côtés, retrécies et tronquées obliquement au bout avec l'angle externe arrondi, et l'angle sutural très obtus; fossette subhumérale sans ponctuation distincte, limitée par un seul sillon entier; stries fortes, ponctuées; subhumérale interne atteignant l'épaule, 1-3 dorsales entières, inégalement distantes entre elles, quatrième formée de deux strioles l'une basale, l'autre apicale, lićes par une ligne de points; cinquième et suturale nulles. Propygidium bifovéolé, transverse, couvert de points peu serrés; pygidium plus terne, peu convexe, avec des points fins et espacés. Prosternum étroit, arrondi à la base, mentonnière ne dépassant pas les angles prothoraciques; mésosternum sinué et entièrement rebordé. Jambes antérieures fortement tridentées, postérieures garnies d'une double série d'épines brunes.

Indes-Orientales. 


\section{7'. Hister lamacola.}

Ovalis, concexiusculus, niger nitiches; fronte plana, stria subsimuata, mandibulis canaliculatis; monoto ciliato,'strialaterali externa dimidiata, interna haud interrupta; clytris nargine inflexo bisulcato, stria subhumerali interna unica, 1-3 dorsalibus

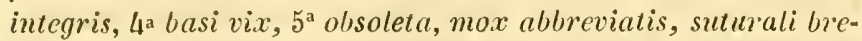
vissima; propygidio basi, mygidio toto, parce punctulatis; me. sosterno sinuato marginatoque; tibiis anticis 3-dentatis. Long. 11 mill., larg. 7 mill.

Ovale, assez convexe, noir luisant. Antennes brunes. Front plan, transversal, entouré d'une strie forte semi hexagonale, subsinuée en devant; mandibules robustes, creusées légèrement en gouttière. Pronotum court, transverse, bisinué à la base, avec les angles arrondis, arqué et cilić sur les côtés, fortement échancré et très retréci en devant avec les angles abaissés, bien marqués; stric latérale externe fine, raccourcie au milieu, interne presque entière, avec une légère fossette au tiers antérieur, non interrompue en devant. Ecusson très petit, visible ainsi que les parapleures. Elytres plus longues que le pronotum, de sa largeur à sa base, dilatćes à l'épaule, rétrécies et coupées droit au bout; bord infléchi bisillonné, ponctué, sans fossette profonde; strie humérale fine oblique, subhumérale externe nulle, interne forte entière; dorsales ponctuées; 1-3 fortes entières, quatrième un peu raccourcie à la base, faible; cinquième courte, obsolète; suturale réduite à un court et faible rudiment. Propygidium avec quelques points épars assez petits en devant. Pygidium plan, couvert entièrement d'unc ponctuation fine et peu serrée. Prosternum étroit, arrondi à la base, muni d'une mentonnière aussi allongée que les angles antérieurs du prothorax; bord pectoral antérieur 
profondément sinué, sans fossette. Mésosternum écliancré et bordé d'une strie entière. Pattes de poix ; jambes antérieures armées de trois dents obtuses; postérieures garnies de nombreuses paires de denticules.

On dirait au premier aspect un petit 1 . Memnonius, mais la strie latérale externe du pronotum raccourcie, ainsi que la quatrième et cinquième dorsales, la ponctuation du pygidium moins forte, celle du propygidium moins étendue, le distinguent aisément de cette dernière espèce, habitant d'ailleurs des contrées bien différentes. Les mêmes différences l'éloignent du $I$. luctuosus.

Indes orientales (M. Andrew Murray).

\section{9' Hister Tinbetanes.}

Ovalis convexus, niger nitidus; fronte plana stria semicirculari antice rectc; pronoto striis 2 lateralibus integris, interna haud interrupta; clytris postice impressis, striis dorsatibus 1-3 integris punctutis, $4^{\mathrm{a}}$ et $5^{\mathrm{a}}$ ad apiccm vix brcviter notatis, sublutmerali interna integra, fossa humerali lavi, bisulcata; pro. mygidio bifoveolato mygidioque parce punctatis; mesosterno sinuato marginatoque, tibiis anticis 3-dentatis. Long. 8 mill., larg. 6 mill.

Ovale, convexe, noir luisant. Tête médiocre; front arrondi transversalement, plan et imponctué, entouré d'une strie semi-circulaire bien marquée, interrompue postérieurement; labre court, mandibules fortes, convexes en dessus, sans rebord, terminées par une pointe aiguë recourbée, et garnies en dedans, la gauche d'une dent, la droite de deux. Antennes brunes, ainsi que les palpes, menues et courtes, massue arrondic, fosselte antennaire peu profonde. Pronotum lisse 
beaucoup plus large que long, arqué à la base, oblique sur les cotés, rétréci et fortement échancré en devant, avec les angles abaissés et très obtus; deux stries latérales bien accusées, rapprochées et arrivant à la base, l'interne coudée latéralement, non interrompue en devant, externe accompagnant sans la joindre l'interne à l'angle antérieur jusqu'au niveau des yeux; on aperçoil là entre elles un court rudiment de strie. Ecusson petit, triangulaire. Parapleures visibles. Elytres de la largeur du pronotum à la base, arrondies et dilatées sur les côtés, arquées et un peu rétrécies au bout avec ur petit angle sutural et une légère impression subapicale; strie subluumérale interne bien marquée; dorsales 1-3 entières, arquées, parallèles et ponctuées, quatrième et cinquième signalées par quelques points à l'extrémité, suturale nulle; bord infléchi creusé sous l'épaule d'une fossette lisse et parcourue de deux sillons, l'externe entier. Propygidium bifovéolé ponctué, un peu moins densément et régulièrement que le pygidium, d'un noir mat comme lui. Prosternum saillant, presquehorizontal, arrondi à la base, muni d'un lobe étroit arrondi, rebordé et saillant; mésosternum sinué et rebordé en devant. Jambes antérieures fortement tridentées, postérieures garnies d'une double rangée de nombreuses épines.

Assam (M. Andrew Lurray).

\section{3'. Hister montands.}

Ovatus convexiusculus, niger, nitidus; fronte plana, stria semi-circulari valida semi-hexagona; pronoto stria laterali interna integra, externa dimidiata; clytris striis temuibus, subhumerali interna hancrum attingente, 1-3 dorsalibus integris, 
4-5 brovissimis apricalibus, sulurali amerius abbreviatu, fossa subhumerali bisulcala, impunctale; propygidio parce, pygidio dense munclatis; mosterno loho brevi, mesostemo subsinuato a marginato; libiis antiris 5-dentatis, posterioribus biscriatim spinosis. Long. 7 mill., larg. 6 mill.

Ovale, assez convexe, noir luisant, lisse. Front arrondi, plan, bordé d’us fort sillon suni-hesagonal; labre court. mandibules courtes, édentées, convexes en dessus, terminécs en pointe arquée. Antennes noires, massuc grise, pubescente; lossette antennare peu nettement accuséc. Prowotum court, bombé, tronqué droit à la base avec les ancrles obtus, arrondi sur les côtés, échancré en devant avec les angles peu aigus et abaissés; strie latérale cxterne fine, n'atteignant pas le milieu, arquée à l'angle et rapprochée de l'interne, qui est plus coudée ; celle-ci est plus forte, entière et un peu sinueuse. Ecusson très petit, triangulaire, Parapleures visibles. Elytres une fois et demie plus longues que le pronotum, de sa largeur à la base, arrondies sur les côtés, légèrement arquées au bout, avec un tout petit angle sutural; fossctte subhumérale imponctuée, bisillonnée; stries assez fines porsctuées, subhumérale interne atteignant l'é. paule, 1-3 dorsales entieres; 4-5 très courtes apicales, suturale raccourcie au tiers antéricur. Propygidium oblique, en demi hexagone transverse, biimpressionné, et couvert de points espacés entremècés de plus fins. Pygidium bombé, presque vertical, densément pointillé. Prosternumn étroit, arrondi à la base, avec une courte mentonnière. Mésosternum large, à peine sinué en devant et cntièrement rebordé. Jambes antérieures 5-dentées; postéricurea garnies d'une double série d'épines noires.

Abyssinie. 


\section{0' Hister Calamaricus.}

Ovalis, parum convexus, niger, nilidus, amtemnis pedibusque brumeis; fronte plana stria semicirculari subrecta, mandibulis canaliculatis; pronoto stria taterali catema brevi, interna integra; elytris fossa subhumerali lavi bisulcala, stria subhumerali interma ad lumerum producta, 1-3 dorsalibus integris, 4-5 apicalibus, suturali dimidiata; mropygidio pygidlioque basi patce punctatis, utrinque foveolatis; mesosterno cmarginato stria integla; tibiis anticis 3-dentatis, posticis dense biseriatim spino. sis. Long. 7 mill., larg. 5 mill.

Ovale, peu convexe, d'un noir très luisant ; antennes et paltes brunes. Front large plan, entouré d'une strie semicirculaire bien marquée, droite par devant; labre très petit. Mandibules larges, creusées en dessus, arquées en pointe aiguë au bout et bidentées en dedans. Pronotum court. tronqué droit à la base avec les angles obtus, oblique sur les côtés, échancré et rétréci en devant arec les angles abaissés obtus; strie latérale interne entière, non interrompue en devant, un peu sinuée sur les côtés, externe courte et moins forte. Ecusson triangulaire. Parapleures visibles. Elytres une fois et demie plus longues que le pronotum, de sa largeur à la base, curvilinéaires sur les côtés, arquées au bout avec un angle sutural étroit; fossette subhumérale imponctuée, bisillonnée. Stries fortes, crénelées; sublıumérale interne atteignant l'épaule; 1-3 dorsales entières, plus rapprochées au bout, quatrième et cinquième courtes apicales; suturale arquée, un peu raccourcie en devant. Propygidium court, bifovéolé, couvert de points espacés en devant. Pygidium mat et ponctué antérieurement avec deux très légères impressions, lisse et luisant au bout. Prosternuin étroit, arroudi a la base, muni d'une mentonuière rebordée et dépassant les angles protho. 
raciques. Mésosternum échancré et rebordé. Jambes courtes el larges; antéricures 3-dentées; postérieures garnies de nombreuses épines disposées sur deux rangées.

Vieux-Calabar; communiqué par M. Andrew Murray.

\section{9'. Hister coelestis.}

Orbicularis, convexiusculus, niger, nitidus, untennis rufis ; fronte latu stria semi-circulari subsinuata; pronoto utrinque menctalo immessorpe, stria laterali internu line inde ubbreviatn; clytris brrvibus margine inflcro unisulcato, striis dorsulibus crenatis validis, 1-4 intcgris postice archutis, 5a et suturrali antice abbreviatis, subhumerali interna brevissima; propygidio basi punctuluto; mesosterno marginato vix simunto, tibiis anticis obtuse 4-dentatis. Long. 2 1/2 mill., larg. 1 1/3 mill.

Orbiculaire, légèrement convexe, noir, luisant. Antennes ferrugineuses. Front large, peu convexe, ceint d'une strie semi-circulaire subsinuée, avec un point sur le vertex. Labre petit. Mandibules en pointe arquée au bout. Pronotum court, presque droit à la base, arqué sur les côtés, rétréci et échancré en devant avec les angles arrondis; marqué de chaque côté d'une faible impression au milieu d'un espace pouctué; de cetle impression part une courte strie latérale qui n'atteint pas la base. Ecusson triangulaire. Parapleures visibles. Elytres très courtes, de la largeur du pronotum à la base, dilatées à l'épaule, rétrécies et tronquées au bout, avec un petit angle sutural; fossette subhumérale unisillonnéc; stries fortes, crénelées; subhumérale interne réduite à ın point oblong placé audessus de l'épaule, 1-3 dorsales entières arquées au bout en dedans; troisième atteignant presque la suture; quatrième également entière; cinquième et suturale raccourcies vers la base. Propygillum en hera- 
gone incliné, couvert en devant de points peu serrés. Pygidium bombé, verlical, lisse. Prosternum court en rarêne, avec une étroite mentonuière rebordée. Mésosternum rebordé et à peine sinué en devant. Jambes antérieures armées de quatre petites dents obtuses, la dernière saillante et bifide; postérieures légèrement épineuses.

Cette espèce, provenant de Chine, le Cóleste-Empire, ne peut être confonduc arec aucune autre espèce; ses stries dorsales et la strie latérale de son pronotum offrent un aspect insolite.

\section{2'. Hister Jekeli.}

Ovalis, convexus, niger, nitidus; fronte plana stria scmicirculari integra; mronoto utrinque grosso punctuto, stria laterali externa nulla, iulerna integra margini approximala; elytris striis validis crenatis, 1-4 dorsalibus integris, $5^{\mathrm{a}}$ et suturali abbreviatis, subhumrrati extus arcu aucta; fossu subhumerali bisulcuta punctula; propygidio mygidioupue dense et yrosse punctalis; mesostermo sinualo marginatoque; tibiis anticis ठ̀-dentatis, posticis biseriatim purce punctutıs. Long. 9 mill., larg. 7 mill.

Ovale, assez convexe, noir, luisant. Tête médiocre; front plan, eutouré d'une forte strie semi-circulaire erénelée; labre court; mandibules convexes en dessus, édentées et terminées en pointe arquée. Antenues à massue brune, pubescente, logée dans une large fossette assez marquée audessous de l'angle antérieur. Pronotum court, droit et bordé de points à la base avec; les angles arrondis, arqué sur les côtés, échancré en devant avec les angles obtus et abaissés, bordé de chaque côté de gros points assez serrés et légèrement impressionné en devant; strie latérale externe nulle, interne crénclée cutière, fort rapprochće lu bord 
Leusson petit, triangulaire; parapleures visibles. Elytres une fois et demie plus longues que le pronotum, de sa largeur ì la base, dilatées à l'épaule, rétrécies et arrondies au bout, avec un angle sutural étroit et une impression transverse subapicale; fossette subhumérale ponctuée et bisillonméc; stries fortes, crenclées, 1-4 dorsales entières, cinquième et snlurale raccourcies un peu avant le milieu; strie subhuınérale interue, presque réduite à une ligne de points, avec un appendice arqué de subhumérale externe. Propygidium assez fortement ponctué ainsi que le pygidium, qui est bombé. Prosternum arı́ondi à la base, avec une courte mentonnière. Mésosternum fortement échancré et entièrement rebordé. Jambes élargies ponctućes; antérieures tridentées, postérieures garnies d'épines peu nombreuses, disposées sur deux séries.

Shangai ; dédiée à M. Jekel, si connu pas ses études spéciales sur les Curculionites, qui me l'a communiqué.

\section{0'. Hister Kundistanus.}

Oblongus, comvexus, nigro-picens nilidus, anlemnis, clytris pedibusque mifis; fronte stria forti anterius recta, mronoto stria laterati interna haud interrupta, externa brevi antice; clytris margine inflexo subbisulcalo, huad excavalo, striu subhumerali cxtcrna valida integra, sucurali el dorsalibus 1-4 integris, $5^{\text {a }}$ busi vix abbreviala ; mropygidio mygidioque dense ocellato-munclatis; mesosterno sinualo marginato que, libiis anticis 4-llentatis, posticis 4-fariam spinosis. Long. 5 mill., larg. 2 2/3 mill.

Oblong, convexe, noir de poix luisant; élytres d'un ferrugineux olscur, ainsi que le ventre. Antennes rousses. Front transversal peu convexe, entouré d'une strie semi- 
circulaire profonde, droite en devant avec un petit onglet médian. Mandibules sans gouttière. Pronotum beaucoup plus large que long, à peine arqué et bordé de points à la base, avec les angles arrondis, peu courbé sur les còtés, échancré et retréci en devant, avec les angles obtus et abaissés, couvert de quelques points peu distincts; strie lalérale interne bien marquée, entière, parallèle au bord latéral, non interrompue en devant, externe réduite à un court tron çon vers l'angle antérieur. Parapleures saillantes. Ecusson petit, triangulaire. Elytres une fois et demie plus longues que le pronotum, lle sa largeur à la base, un peu dilatées à l'épaule, à peine retrécies et arrondies au bout, bord infléchi lisse, sans fossette subhumérale bien marquée, longé d'un fort sillon, flanqué d'un rudiment peu visible vers le milieu; strie subhumérale externe unique entière, arquée à l'épaule; humérale oblique, assez marquée; dorsales ponctuées entières, troisième un peu coudée, cinquième à peine raccourcie et interrompue, suturale entière. Propygidium et pygidium bombés, couverts de points ocellés très scrrés. Mésosternum bordé d'une strie entière, profondément sinué. Prosternum court, élargi à la base, avec une mentonnière très courte. Pattes ferrugineuses. Jambes courtes, larges, triangulaires, antérieures garnies de quatre dents obtuses, postérieures de quatre masses spinifères.

Cette espéce vient se placer immédiatement avant le $\boldsymbol{H}$. Smyrnazs, dont il n'a pas le faciès. Il est épais au lieu d'être aplati, la strie subhumérale est entière, au lieu d'ètre très courte, et la latérale externe du pronotum raccourcie au lieu d'être entière; le mésosternum très échancré an lieı d'être presque droit.

1. Cherrolat a regi cette espèce comme renant du hurdistan. 
101'. Histele Peyloni.

Ovalis, subdenresus, nigro-piceus, nitidus, antomis perlibnsque rufis; fronte subbifoveolata, stria marginali antice rectu; pronoto tcmuiter punctulato, stria latcrali extcrna integra, inter na huad intermpta postice simuala, approximalis; clytris 5 dorsalibus integris, suturati vix antice ubbreviata, sublumerali cxterna brevissima al humerum; margine inflexo əs-sulcato; mropygidio valide pygidioque temniter parce punctatis; mesosterno vix subsimuato maryinato; tibiis anticis 4-dentatis. Long. 3 1/2 mill., larg. 1 2/3 mill.

Ovale subdéprimé, d'un noir de pois luisant. Antennes brunes, scape ferrugineux. Front transversal, peu convexe, finement pointillé avec deux petites fovéoles à peine visibles, entouré d'une strie fine bien marquée, entière, droite en devant. Mandibules creusées en gouttière. Pronotum un peu plus large que long, légèrement arqué à la base, avec les angles arrondis, presque parallèles sur les côtés, un peu rétréci et fortement échancré en devant avec les angles abaissés, saillants et obtus, couvert d'une très fine ponctuation sur tout son disque; strie latérale externe très rapproclsće du bord, u'atteignant pas l'interne en devant, celle-ci entière, nou interrompue antérieurement, plus forte, très distante en devant du bord externe, coudée vers la base et s'en rapprochant beaucoup. Ecusson petit, triangulaire. Elytres un peu plus longues que le pronotum, de sa largeur à la base, parallèles sur les cotés, à peine rétrécies, taillées obliquement en dedans au bout et d'une couleur plus claire; stries fortes, dorsales entières parallèles; suturale un peu raccourcie à la base; humérale obsolète; subhumérale externe, uniọue réduite à un arc placé audelà de l'épaule; bord infléchi avec trois sillons dont l'inférieur est rudimentaire. 
Propygidium couvert liassez forts points espacés; pygidium d'un pointillé très fin. Mésosternum à peine sinué en devant avec une strie entière et de petits points peu visibles. Prosternum court, étroit, obsolètement bistrié, mentonnière étroite. Pattes rouges; jambes antérieures 4-dentées; postérieures garnies de six ou huit paires de denticules.

Cette espèce vient des mèmes contrées que le $\boldsymbol{H}$. Snıyrneus, avec lejuel il m'est impossible de le comparer. La seule différence est la forme de la strie latérale interne du pronotum et le raccourcissement de la suturale. N'ayant connu qu'un seul individu de chacune de ces espèces et ne les ayant étudiés que séparément à plusieurs années d’intervalle, je n'oserais certifier qu'elles soient bien distinctes.

\section{1'. Hister cognatus.}

Ovalis, convexus, niger, nitidus; fronte plana, stria semi-circulari; pronoto stria laterali integra, utrinque late punctato; elytris stria subhumerali externa, 1-4 dorsalibus integris, hac basi versus sculellum arcuata, $5^{\text {a }}$ dimidiata, suturuli parım abbreviala, margine inflexo unisulcalo; propygidio pygidioque sat dense defualiter punctalis; prosterno sat lato; mesosterno subsinuato marginatoque; libiis anticis 6-llenticulatis, posticis parce spinosis, Long. 4 mill., larg. 3 mill.

Hister cognatus Le C. N. Amér. Hister. 28, 23, pl. III, fig. 10 (1845).-Mars. Mon. Hist. (1854), xx, bo 114' p. 548.

Ovale, alrondi, convexe, noir, luisant. Tête petite; front arrondi, plan, bordé d'une strie semi-circulaire bien marquée; labre très petit. Mandibules convexes, à peine arquées au bout. Antennes brunes. Pronotum court, arqué à la base, oblique sur les côtés, très retréci et échancré en devant; stric latérale interne un peu raccourcie á la base, non inter- 
rompue, largement bordée en dedans d'une ponctuation forte, peu serrée. Ecusson triangulaire petit. Parapleures visibles. Elytres bombées, une fois et lemie plus longues que le pronotum, de sa largeur à la base, curvilinéairement dilatées sur les côtés, rétrécies eı tronquées au bout; bord inlléchi sans fossette, parcouru d'un profond sillon; strie subhumérale externe entière; dorsales bien marquées, 1-4 entières courbées, quatrième recourbée en arc vers l'écusson; cimpuième raccourcie vers le milieu, suturale un peu raccourcie à la base. Propygidium en hexagone transverse, oblique, couvert d'une forte ponctuation assez égale. Pygidium bombé, presque vertical, égralemeut et densément ponctué. Prosternum court, assez large, arrondi à la base, muni d'une mentonnière petite, abaissée; fossette antennaire petite, bien accusée. Nésosternum légèrement sinué et rebordé. Jambes antérieures armées de six denticules, postérieures bisérialement épineuses.

Cette espèce, des Etats-Unis, qui ne m'était connue que par la description de M. Le Conte, ressemble extrêmement à l'II. marginans pour la forme et la disposition générale des stries; mais elle s'en éloigne à la première vue par le bord infléchi des élytres, la ponctuation du pygidium et du propygium, etc.

\section{9’. Hister Sennevilli.}

Ublongo-ovatus, convexns, miger, nitidus, sublus lateribus lnteo villosis; untemis mis; fromte pluna, stria semi-circnluri rectu; monote striis 2 latcralibus integris; clylris rulris, anire maculurpe scntellari trapezoidali nigris, margine inflexo uni-sulcalo; striis dorsulibus 1-3 integris, creteris et sublume- 
rali interna brovibus obsolctis; promygidio pygitioque purce forliter munclatis; mrosterno lobo brevi, mesosterno exciso muryimutnque; tibiis anticis bidentatis, posticis multi-spinosis. Long. 6 mill., larg. 4 mill.

Ovale allongé, convexe, noir, luisant, garni en dessous sur les côtés de longs poils jaunes. Tête grosse ; front large, plan, bordé d'une strie transverse, droite en devant. Labre petit. Mandibules convexes, arquées au bout en pointe, sans dents internes. Antennes à funicule et massue ferrugineus. Pronotum finement pointillé, court, tronqué droit à la base, arec les angles obtus; légèrement arqué sur les côtés, retréci et largement échancré en devant, avec les angles abaissés et arrondis. Stries latérales bien marquées, rapprochées à la base, entières, séparécs par un assez large intervalle présentant d'assez nombreuses gerçures. Ecusson triangulaire. Parapleures visibles. Elytres rouges vers l'extrémité et une tache en trapèze autour de l'écusson noires, une fois et demi plus longues que le pronotum, de sa largeur à la base, dilatées à l'épaule, fort rétrécies postérieurement avec le bout arqué et marqué d'une impression transverse; angle sutural assez aigu; fossette subhumérale lisse, bisillonnée; stries dorsales 1-3 entières, bien marquées, 4-5 ainsi que la suturale et la subhumérale interne raccourcies et représentées par des lignes de points obsolètes. Frosternum arrondi à la base, en carène étroite, muni d'une mentonnière rebordée très courte; fossettes antennaires vagues. Mésosternum rétréci en devant, fortement échancré et rebordé d'une strie entière. Jambes antérieures larges fortement bidentées; postérieures épaisses, garnies de cinq ou six tranches garnies chacune de trois ou quatre épines mousses.

Cette jolie espèce californienne a des rapports frappants de formes avec l'H. arcualus et l'H. biplanialus. In l'ai dórlise 
à l'un de mes jeunes élèves, M. Gaston de Semneville, qui déjà depuis plusieurs années se livre avec ardeur à l'élude des Coléoptères.

\section{7'. HISTER PRATERMISSIS.}

Ovalis, convexiusculus, niger nitidus; ore antcunisque $\mathrm{m}$. fis, fronte stria integra antice recta; pronoto stric laterali unica haud interrupta; clytris margine inflexo rugoso bisulcato, striis subhumerali mulla, dorsalibus 1-4 integris, $5^{\text {a }}$ in medio, suturali uttra abbreviatis; propygidio bifoveotato mygidioque acnse arquatiter punctatis; mesosterno antice recto marginato. tibiis anticis 4-denticulatis. Long. $51 / 2$ mill., larg. $32 / 3$ mill.

Hister pretermissus Peyrón, Soc. Ent. $3^{\text {e }}$ série, t. iv, p. 727 (1856).

Ovale, assez convexe, noir luisant, imponetué sur la tête, le pronotum et les élytres. Palpes et antennes roussâtres. Front élargi, assez plan, avec de légères traces d'une paire de fossettes en devant, entouré d'une strie semi-circulaire entière bien marquée, un peu sinuée de chaque côté, droite en devant. Pronotum court, arqué à la base, avec les angles droits et les parapleures à peine visibles, arrondi sur les côtés, échaneré et retréei en devant avec les angles abaissés, assez saillants et peu aigus; strie marginale bien visible, interrompue au niveau des yeux, latérale interne unique, entière, forte et parallèle au bord externe. Ecusson triangulaire petit. Elytres une fois et demie plus longues que le pronotum, de sa largeur à la base, un peu dilatées à l'épaule, retrécies et droites au bout; stries subluumérales nulles; 1-1 lorsales entières, bien marquées, surtout les première et troisième, parallèles, seulement cclle-ci un peu coudée, les autres raceourcies; cinquième n'atteignant pas le milien, suturale la dćpassant en devant, mais commencant plus loin du bord postérieur; bord infléchi marqué d'une los. 
sette peu profonde, rugueuse, bisillonnće. Propygidium bi fovéolé, assez densément, igalement et distinctement ponctué, ainsi que le pygidium. Prosternum droit à la base, rétréci, court, avec une mentonnière peu avancée; fossettes antérieures faibles. Mésosternum droit en devant, bordé d'une strie entière. Pattes d'un noir de poix. Jambes courtes en triaugle assez large, antérieures garnies de quatre denticules, apical bifide; postérieures d'un double rang d'épines serríes.

Cette espèce, découverte au bord de l'étang de Berre, Inon loin de Rognac, sous une pierre, par M. Peyron, se place auprès du 11 . corvinus avec lequel elle a les plus grands rapports. Elle est plus grande, son bord subinfléchi est ponctué rugueusement; son propygidum est bifovolé et plus densément et également ponetué ainsi que le pygidium. M. Peyron croyait d'abord devoir le rapporter au II. nigrita de Stephens.J'avoue que la courte description de l'auteur anglais lui va passahlement, si l'on en excepte toutefois ces caractères a antennes et bouche noircs, jambes antéricures garnies de cinq dentelures, einquième dorsale du liers de la sulurale", que je ne retrouve pas dans le type que j'ai sous les yeux.

Mais je préfere le regarder comme une espèce nouvelle et attendre que j'aie pu voir le type de Stephens pour m'édifier sur l'espèce qu'il a voulu décrire. Cet entomologiste est trop sujet à caution pour qu'on ne soit pas en droit de croire qu'il n'a peut-être décrit qu'une des espèces déjà connues, et dès lors ce serait prématurément changer le nom d'Erichson.

Depuis M. Peyron a décrit cette espèce, comme distincte, sous le nom de $I I$. pretermissus, que je substitue à celui de gallicus que j’avais adopté dans ce supplément, présenté depuis longtemps à la Société. 


\section{Carcinops corticalis.}

J.-I. Le Conte, N. Sp. Calif. Col. in Lyceum N. Y. r, $4^{\circ}, 39,2$ (1851).

Urale aplati, noir luisant. Front pointillé, bordé d'une légère strie. Pronotum à peine distinctement pointillé, bordé d'une stric marginale. Elytres à cinq stries dorsales, cinquième raccourcie aux deux ticrs, suturale au tiers; une sublıumérale très courte à la base; une deuxième entière ì la narge. Propygidium ponctué; pygidium paraissant lisse. Prosternum rebordé. Mésosternum échancré avec une strie marginale, séparé du métasternum. Jambes antéricures dilatées contournées, avec deux leats externes espacées. Long. 2 mill., larg, 1 1/2 mill.

Peu commun sur les bords du Rio Colorado, Californie, (II. Le Conte.)

$$
\begin{aligned}
& \text { Xxiv bis. Coelocraera. } \\
& \text { (xoinas, creux; upaipa, tête). }
\end{aligned}
$$

Mon. Hister. pl. xxiv, Suppl. genre xxiv bis.

Corpus ovulum, convexum.

Capul retratile; fiomle in medio foveoluta. striu a clypeo haud distincta, margine clevato; antennis sub maryine amte oculos inscrtis, scapo contorto clava parva ovali; mandibulis edemutis.

Prostcinum compressum, sulcatum, basi incisum, lobo mrominulo incurva, fossa antcmali sub angulo prothoracis. MesosLermum hrere amlice acmmimatum, sielco marginatum, postice sulco mofmudo a metasterno alistinctum.

Pronolum antice emarginutum, angustius, lateribus valde re 
flexis, stries mullis. Elytu aprice truncala mulli-costala, margine inflero bisulculo.

Propygidium hexagonum declive; mygidium semiciculare inflexum.

Tibia compressa, anlice ovales, cxlus denliculule, fossa tarsali obliqua cxarata, posticce subparallela, cxlus patre spinoset tarsis-arlicululi, ungulis binis.

Corps épais, bombé, ovale, raccourci.

Tètc petite, arrondie, s'enfonçant dans le prothorax et s'inclinant en devant. Front réuni à l'épistome sans stric qui l'en sépare, hexagonal, creusé d'une profonde cavité, entouré d'une strie marginale interrompue seulement par derrière, et d'un rebord étroitement élevé. Veux ovalaires, peu saillants. Labre court irausverse, sinué. Mandibules (fig. f) fortes, recourbées e! pointe aiguë, sans dents.

Antennes (fig. $e$ ) insérées sous un rebord du front entre les yeux et la base des mandibules; scape fort contourné, épaissi au bout; funicule ténu, de sept articles; premier obovale aussi long que les trois suivants, les autres 2-; courts, presque d'égale longueur, mais s'élargissant graduellement : massue ovalaire, pubescente, à articies à peine distincts, presque de la largeur du dernier article du funicule. Fosselte antennaire bieı marquée sous l'angle antérieur du prosternum, l'anteune vient s'y loger sans entailler le bord pectoral antérieur.

Menton (fig. c) corné, presque carré, quoique un peu élargi à la base, languette courte et étroite, paraglosses membraneuses longues, terminées en serpette, ciliées en dedans. Palpes labiaux cornés, support assez long cylindrique, premier article court, deusième obconique, troisième fusiforme d'égale longueur. 
Màchoires (fig. l) cornées, à deux lobes, garnis en dedans de longues franges, l'externe de beaucoup plus long que l'interne ; palpes maxillaires de quatre articles, premier petit, deuxième obconique, peu allongé, troisième cylindrique encore plus court. quatrième plus long que les autres réunis, en fuseau à peine renflé.

Pronotum plus large que long, convexe, obtusément angulaire à la base, oblique avec un rebord élevé et tranchant, bordé en dedans par une large rigole sur les côtés, retréci, abaissć et échancré en devant, avec les angles obtus; stries latérales nulles, marginale fine, non interrompuc. Ecusson triangulaire très petit. Elytres plus larges que longues, convexes, exactement serrées contre le pronotum et uı peu moins larges que lui à la base, arrondies sur les côtés, avec le bord infléchi sans fossette subhumérale, bisillonnées, retrécies et tronquées au bout; chargées de six côtes très saillantes, sans y comprendre la suture et le bord latéral. Prosterıum (fig. b) saillant, étroit, un peu retréci en devant, bisillonné, échancré à la base, muni en devant d'un lobe rabattu, arrondi el médiocrement avancé. Mésosternum court, rebordé d'un profond sillon qui se continue sur les côtés du mésosternum, et séparé de celui-ci par un autre arqué, terminé en devant par une pointe qui pénètre dans la base du prosternum.

Pattes (fig. $g, h, i)$ médiocres, antérieures courtes, postéricures fort distantes à lcur insertion, cuisses fusiformes, rebordées en dedans; jambes aplaties, ciliées en dedans, antéricures fortement dilatées en dedans, garnies en dehors de courts denticules, creusées en dessus d'une étroite fossette tarsale assez bien limitée, oblique; postérieures allongées, faiblement dilatées au bout, et garnies en dehors de 
rares épines; tarses de einq articles, atténués au bout, terminés par deux crochets.

Abdomen rle cinq segments; premier assez long, bisillonné de chaque côté an niveau des hanches postérieures; les quatre autres beaucoup plus courts, allant en diminuant de longueur. Propygidium hexagonal, assez grand, convexe, abaissé; pygidium en triangle sphérique à angles très obtus, convexe et fortement incliné.

Ce genre, dont le nom rappelle une des singulières particularités de sa conformation, est itabli sur un insecte remarquable du Vicux-Calabar, qui m’a éié communiqué par 11. André Mluriay, mais trop tard pour être compris dans mon Essci sur les Histérides. II pent ètre placé alans le petit groupe de genres à formes bizarres, des Monoplius, Pelorus, Scapomegas, etc.; non qu'il ait avec eux un air de parenté, et qu'un ensemble de caractères tranchés et importants lie ces genres en une division digne de former une tribu particulière et en exclue tous les autres, mais parce qu'il a plus d'analogie qu'avec tout autre genre. Leur corps est épais et convexe, il est vrai ; la fossette antennaire, le lobe prosternal et l'articulation sternale sont disposés chez eux d'une manière uniforme; mais qucl est celui de ces caractères qui ne se retrouve dans un genre ou dans un autre, et que de différences dans la forme de leurs téguments, dans la configuration de leur tête et de leur abdomen, comme dans la structure des jambes.

Il serait superflu de le rapprocher des autres genres pour en faire ressortir les rapports et les dissemblances. Il suffit de jeter les yeux sur son front crensé d’une fosselte profonde étendue sur l’épistome, qui rappelle un peu certains Omalodes, et sur ses élytres à côtes saillantes, pour le reconnaitre 
à l'instant. Les Onthophilus sont les seuls qui affectent quelque disposition analogue dans les élytres, mais la ressemblance n'est que superficielle. D'ailleurs à côté que de différences saillantes dans la tête, le pronotum, la fossette antennaire et les pattes.

Je ne sais rien des mœurs et des premiers états de ce nouveau genre.

B'. Fossettes tarsales droites.

C'. Prosternum tronqué ou sinué à la base.

D'. Tarses bionguiculés. Corps petit, médiocrement convexe. - Massue à articles distincts, de même axe que le funicule.

* Front fovéolé. - Elytres couvertes de côtes... 24 bis. Coclocrera.

** Front bombé. - Elytres striées. - E et E'.

\section{Coelocriers costifers.}

Ovalis, corvexus, nitidus, niger, ore antennis pedibusque fusco-fcrrugincis; fronte punctulata, foveolata marginataque; pronoto rugose punctato, margine laterali clevato, ad angulum. bifoveolato; elytris sutura, margine cxterna 6que costis integris, nuargine inflexo bisulcato; mopygidio pygidioque alcuse muctulatis; metasterno in medio sulcato $1^{\circ}$ que ventris segmento grosse muctutis; tibiis anticis latis extus multi-dcnticulatis, posticis versus apicem parce spinosis. Long. $31 / 2$ mill, larg. $21 / 2$ mill.

Ovale assez court, convexe; noir luisant. Intennes et bou- 
che d'un brun ferrugineux. Front arrondi, pointillé, réuni à l'épistome, sans ligne de démarcation, creusé d'une profonde fossette arrondie, entouré d'un rebord éleré et d'une strie marginale interrompue postérieurement. Mandibules épaisses, sans rebord, recourbées en pointe aiguë. Pronotum convexe, en angle obtus à la base, oblique sur les côtés avec un étroit rebord très élevé, limité en dedans par une rigole assez large; abaissé, rétréci et échancré en devant avec les angles obtus et largement bifoveolés, couvert en dessus d'une poncluation serrée, rugueuse. Parapleures non apparentes. Ecusson triangulaire, très petit. Elytres convexes, plus longues que le pronotum, pas tout à fait de sa largeur à la base, étroitement serrées contre lui, arrondies sur les côtés, rétrécies et coupées droit au bout; suture et hord externe formant des carènes saillantes, entre lesquelles on voit six côtes longitudinales fortes, un pen arquées, entières, parallèles, séparées par die larges sillons lisses; repli latéral bisillonné sans fossette sublumérale. Propygidium en hexagone, bombé et densément pointillé ainsi que le pygidium. Prosternum étroit, saillant, bisillonné, échancré à la hase, rétréci en devant, muni d'un lobe rabattu arrondi. Mésosternum court, bisinué en devant, terminé par une pointe qui pénètre dans la base du prosteruum, bordé d'un fort sillon, prolongé sur les côtés du métasternum, dont il est séparé par un autre sillon profond arqué; ce dernier ponctué sur toute sa surface, grossièrement par derrière; premier segment ventral bisillonné entre les hanches, couvert de points très forts et traversé en devant, d'une ligne de longues fossettes. Pattes brun ferrugineux. Jambes aplaties, ciliées en dedans; antérieures courtes, larges, dilatées au milieu, brièvement denticulées en dehors; posiérieures 
allongées, à peine élargies, avec deux ou trois épines vers le bout.

Vicux-Calabar, côte d'Afrique.

xxvi. Hetznius Er. Mon. Suppl. pl. xxv, Genre 28.

\section{IIeterios punctulatos.}

Breviter ovatus, convexus, brunnco-fermgineus; fronte punetulata concava, margine clevato; pronoto lateribus punc. tulato, margine incrassato, basi latiori, suleo vix distincto, angulis anticis obtusis reflexis; clytris punetulatis, striis subhumerali, 1-3 dorsalibus terctibus postice plus minusve abbreviatis, scriatim fulvo-pilosis; propigilio parce piloso; prosterno impresso, lateribus marginato simutoque, meso-et metasterno profunde excavatis. Long. 2 mill., larg. 1 1/5 mill.

Hetcrius penctulatus Luc. Soc. Ent. 3 e sćrie, t. 11I, page iv (1855)

Suborbiculaire, convexe, d'un brun rouge, luisant. Front concave, ponctué, entouré d'une fine strie et d'un rebord élevé. Pronotum court, transverse, ponctué latéralement, presque lisse aı milieu, bisinuć à la base, cilié, oblique et bordé d'une strie fine sur les côtés, un peu sinué vers l'angle intérieur qui est obtus, creusé d'une fosselle antennaire, un pen relevé et formant comme une oreille, rétréci et largement échancré en devant; le bourrelet latéral est nu, élargi à la base, mal limité en dedaus, surtout au milieu. Le sillon profond qu'on remarque dans les deux autres espèces est remplacé par un pli qui n'est bien visibie qu'à la base. Ecusson très petit. Elytres lornbées, deux lois plus longues que 
le pronotum, de sa largeur à la base, dilatées à l'épaule, rétrécies et tronquées au bout; stries fines, sublumnérale et première dorsale entières; deuxième et troisième un peu raccourcies vers le bout; bord infléchi sans sillon bien marqué, un peu concave sous l'épaule; surface couverte de poils jaunes peu serrés, disposés en six séries. Propygidium couvert d'une semblable villosité. Prosternum large, échancré à la base, creusé au milieu, ponctué, rétréci au milieu, rebordé, avec une courte mentonnière. Mésosternum et métasternum̃ sans ligne de séparation, profondément et largement excavés. Jambes très dilatées à partir du milicu, garnies de courtes épines en dehors.

Cette espèce, découverte en Algérie par l'auteur de l'entomologie de notre belle possession africaine, M. Lucas, et décrite par lui dans nos Annales, est remarquable entre toutes par la profonde excavation dn sternum et par la forme de son pronotum. Elle tient le milieu entre le $\boldsymbol{H}$. sesquicornis et le brmipemis.

Le genre Hetcrius, qui ne m'était connu que par l'espèce d'Europe, est aujourd'hui composé de trois espèces, bàties sur un plan uniforme et vivant toutes dans les memes conditions. On peut les classer dans l'ordre suivant : $1^{\circ} \mathrm{H}$. punctulatus, qu'on ferait mieux de nommer eavisternus, afin d'éviter la confusion qui scra le résultat de ce nom, déjà tant de fois employé dans la famille des Histérides; $2^{\circ} \mathrm{H}$. brunipennis; $30 \mathrm{H}$. sesquicornis.

\section{Hetarius brunNipenNis.}

Ovatus, convexus, rufo-brunneus, nitidus fronte concuve 
margine clevato; pronoto utrinque oblique sulcato, maryine cresso holosericeo; elytris scrialim selnlosis, humero elcvalo, 1-3 striis dorsalibus subhumeralique integris; mygilio convexo; mostcrno coarctato basi planato, fossa antennali exarata; mesosterno in medio elevalo, utrinque profunde impresso; libiis a medio al apiccm dilatatis, cxtus denticulatis. Long. 2 mill., larg. 1 1/2 mill.

Ovale, convexe d'un rouge uniforme tirant sur le brun, lisse et luisant. Front triangulaire, concave, entouré d'une stric et d'un rebord élevé. Fossette antennaire étroite, bien limitée à l'angle même du prothorax. Pronotum beaucoup plus large que long, tronqué droit à la base, oblique sur les côtés, rétréci et largement échancré en devant avec les angles peu saillants; bord latéral épaissi, limité en dedans par un fort sillon oblique, couvert d'une brosse de poils jaunes, courts, dressés, avec une petite impression vers le milieu de la marge; espace médian lisse, en forme de trapèze, avec une houppe de poils de chaque côté. Ecusson petit, triangulaire. Elytres une fois et demie plus longues que le pronotum, de sa largeur à la base, dilatées à l'épaule, arquées sur les côtés, rétrécies et coupées droit au bout; suture enfoncée, bordée d'une strie fine; sillonnées de soies fauves dressées, disposées par séries; strie subhumérale fine et entière, abaissée vers le bord infléchi qui présente une légère fovéole à l'épaule; strics dorsales 1-3 entières, fines, plus rapprochées à la base. Propygidium d'un ferrugineux plus clair, hexagonal, lisse, incliné. Pygidium bombé, entièremient tourné en bas. Prosternum comprimé, aplati entre les hanches, échancré à la base, avec une courte mentonnière. Mésosternum élevé en devant et resserré entre deux profondes fossettes. Jambes aplaties, élargies à partir du tiers, 
garnies de fines épines en dehors. Tarses logés dans une coulisse creusée sur la jambe.

Cette espèce, des États-Unis, vit avec d'assez grandes fourmis, d'un noir fuligineux uniforme, avec les antennes, les jambes et lles tarses roussâtres. Je dois un individu de cet Hctcerius et de la fourmi, dont il est le parasite, à M. le Docteur J.-L. Le Conte.

xxx. Devirophules Leach. Mon. Suppl. pl. xxv, g. 30 .

\section{1'. Dendrophllus punctulatus.}

Ovalis, convexus, subnitidus, niger, antennis pedibusque brunneis, undique dense punclatus; fronte plana; pronoto brevi, ante scntellum impresso myoso, stria marginali integra; elytris margine inflexo bistriato, striis dorsalibus 4, interna postice abbreviata, ceteris mullis; tibiis mox abrupte dilatalis compressis extus parce breviter denticulatis. Long. 3 1/2 mill., larg. 2 mill.

Hister punctulatus Say, in Philad. Acad. v, 45, 19 (1825).

Dendrophilus punctulatus Le C. N. Amér. Hist., 35 1, t. IV, f. 8 (1845).

Ovale allongé, convexe, noir, à peine luisant sur le dos, mat sur le reste de la surface. Front plan, à peine visiblement pointillé. Antennes brunes. Pronotum court, anguleux au devant de l'écusson avec une impression rugueuse au milieu et les angles postérieurs droits, légèrement arquué sur les côtes, rétréci et largement échancré en devant, avec les angles abaissés et médiocrement saillants; également et 
densément pointillé sur toute sa surface. Stric marginalc fine, rapproclice du bord, entière. Ecusson ponetiforme. Elytres bombées, deux fois et demie plus longues que le pronotum, et un peu plus larges à la base, curvilinéaires sur les côtés et un peu élargies avant le milieu, rétrécies et tronquées au bout, couvertes d'une ponctuation assez serrée, peu régulière, un peu rugucuse postérieurement; relevées à la suture. Stric humérale oblique obsolète; dorsales bien marquées, parallèles; 1-3 entières; quatrième un peu raccourcie par derrière; cinquième et suturale nulles; un sillon subhuméral entier longeant le bord externe, et une strie marginale sous le bord infléchi, dont la partie supérieure est rugueuse. Propygidium court, presqu'entièrement couvert par les élytres. Pyğidium presque plan, triangulaire, densément et également ponctué, avec une petite impression dc chaque côté à la base. Dessous du corps ponctué sur les côtés. Prosternum étroit, bistrié, arrondi et un peu élargi à la base. Mentonnière courte, rabattue. Mésosternum court, ponciué, échancré en devant, sans rebord, bien limité postérieurement par une strie crénclée transverse. Pattes brun ferrugineux. Jambes très dilatées, amincies, dès la base, garnịes en dehors de fins et courts denticules.

Etats-Unis.

Je dois à M. le Docteur L. Le Conte un exemplaire de cette espèce depuis la publication du genre Denulrophilus.

Il est très voisin du D. punclatus, mais sa taille est un peu plus grande, ses élytres surtout proportionnellement plus allongées; sa ponctuation est plus serrée, plus fine, son front plus plan, la suture de ses élytres élevée et ses stries différentes pour le nombre et la longucur relative. 
xxx1. Tribalts Er. Mon. Suppl. pl. xxv, genre 31 .

\section{1'. Tribalus mixtus.}

Ovalus, convexus, nigro-brumneus, nitidus, punctulaus, antennis pedibus anoque ferrngineis; fronte plana ul orulos clevata utrinque striata; pronoto stria tomi marginali; clytris stria subhumerali demissa, 1-3 dorsalibus et sunurali integris, margine inflexo bisulcato; prosterno lato bistriato, basi simnato, lobo brevissimo; mesosterno tenuiter marginato; tibiis parmu dilatatis, anticis cxtus denticulatis, posticis spinosulis. Long. 3 mill., larg. $12 / 3$ mill."

Ovale, convexe, d’un noir brun assez luisant, densément pointillé sur toute sa surfice; antennes ferrugineuses, ainsi que les pattes et l'anus; fossette antennaire bien arrètée, creusée daus l'angle mème du prothorax; front arrondi, peu convexe, élevé au devant des yeux, avec une petite strie de chaque côté, non distinct de l'épistome; labre court, mandibules assez fortes. Pronotum beaucoup plus large que long, obtusément anguleux au milieu de la base, légèrement arqué sur les côtés, très retréci et échancré en devant avec les angles obtus et abaissés; une seule strie marginale fine complète. Elytres une fois et demie plus longues que le pronotum, de sa largeur à la base, curvilinéaires sur les côtés, rétrécies et tronquées droit au bout; bord infléchi sans fossette, bisillonné; strie sublumérale abaissée, fine, entière; 1-3 dorsales et suturale entières, fines, mais assez bien marquées; les autres nulles. Propygidium en hesagone très allongé, incliné. Pygidium en ogive bombée, rabattu entièrement. Prosternum assez large, bistrié, impressionné entre les hanches antérieures, échancré à la base, muni en devant d'une très petite mentonnière. Mésosternum la!ge, 
bisinué en devant, fincment rełordé. Jambes antẻreures ninces, légèrement dilatées au milieu, garnies de petits denticules; postérieurcs à peine élargies au bout, garnies de spinules.

Cette espèce, du Cap de Bonne-Espérance, tient le milieu pour la taille et le faciès entre les $T$. agrestis ct Capensis. Sa couleur n'est ni anssi noire que dans celui-là, ni métallique comme dans celui-ci; sa ponctuation est très serrée, fine et uniforme, et ses stries beaucoup mieux accusées que dans l'un et l'autre.

xxxil. Saprivus Er. Mon. Suppl. pl. xxv, genre 33.

\section{0'. Saprinus Turcicus.}

Ovalis, subconvexus, piceus niliclus, antennis, pedibus elytrisyue rufo-brumncis; fronte dense puncliculala, latcribus marginala; pronolo stria laterali brevi; elytris intus postice pumclulatis, striis punctalis, suluruli integra, basi arcuutinu juneta, postice apicem sequente, dorsalibus 1-4 sensim longioribus pone medium abbreviatis, humerali parallela, sublumerali utraque elistinela, interna disjuncta; pygidio aqualiter punctulato; prosterno plano, striis antice subparallelis; mesosterno parce punclato marginalo; libiis anlicis 5-denticulatis, posterioribus parce spinosis. Long. 5 mill., Jarg. $23 / 4$ mill.

Ovale, assez convexe, noir de poix luisant, avecla bouche, les antennes, les élytres et les pattes rouge brun. Front densément pointillé, à peine convexe, bordé latéralement d'une fine stric. Pronotum court, assez fortement convexe, bisinué et bordé de points à la base avec les angles droits, arrondi sur les côtés antérieurement, retréci et échincré en 
đevant arec les angles obtus et abaissés; strie marginale fine entière, une assez courte latérale arquée, comme un pli. Parapleures et écusson à peine visibles. Elytres beaucoup plus longues que le pronotum, de sa largeur à la base, un peu dilatées à l'épaule, retrécies el tronquées au bont, couvertes en dedans sur leur tiers postérieur de fins points peu serrés; stries ponctuées; suturale entière, réunie à la base avec la dorsale voisine, suivant le bord apical; dorsales 1-4 raccourcies progressivement de la moitié aux deux tiers postérieurs environ ; humérale distincte, parallèle à la première dorsale, subhumérale interne assez longue disjointe, externe courte distincte de la marginale. Pygidium bombé couvert de points fins, peu serrés. Prosternum plan, étroit, un peu dilaté à la base, stries se rejoignant en devant et presque parallèles dans le même plan. Mésosternum entièrement rebordé avec quelques points épars. Jambes antérieures garnies de cinq denticules, postérieures de rares épines.

Cette espèce vient de Turquie. M. Cherrolat en a reçu plusieurs individus de M. Baudi. Elle vient se placer dans le voisinage du Saprinus lautus Er.

\section{3'. Saprinus 'Trries.}

Nigro-metallicus, nitidus, antemnis pedibusque brumeis; fronte alense puncticulate, stria temi interrupta, carina mulla; pronoto tenuiter, versus latera fortius 'punctulato, striga laterali brevi; clytris postice intus parce punculatis, stria sulurati integra cum $4^{\text {a }}$ dorsali basi juncta, $1^{\text {a }}$ in medio, $2^{\mathrm{a}} 4^{\mathrm{a}}$ que requalibus ultra, $3^{\text {a }}$ sub apicem abbreviatis, simuosis; humerali valida, subhumerali interna parva; pygidio dense, 
mesosterno marginato parce punctalis; prosterno augustato stria recta, libiis anticis 5-6 denticnlatis. Long. 3 1/2 mill., larg. 2 mill.

Ovale convere, noir métallique lıisant; antennes brunes. Front plan, finement et densément penctué, bordé d'une strie fine, interrompue en devant, sans carène qui le sépare brusquement de l'épistome. Pronotum beaucoup plus large que long, bisinué à la base avec les angles droits, oblique sur les côtés, retréci et échancré en devant avec les angles arrondis et abaissés; strie marginale fine entière; ponctuation fine couvrant presque toute la surface, un peu plus forte vers les côlés, formant une courte strie ou pli bien marqué. Ecusson ponetiforme; élytres plus longues que le pronotum, de sa largeur à la base, dilatées à l'épaule, arquées sur les côtés, rẻtrécies et droites au bout: stries ponctuées, suturale un peu rapprochée postérieurement de la suture, atteignant le bord apical, mais sans le suivre, réunie avec la quatrième dorsale par un arc basal; première dorsale raccourcie au milieu, deuxième et quatrième égales entre clles descendant encore plus bas, troisième les dépassant un peu, toutes trois sinueuses; hunérale forte, oblique; subhumérale interne très courte et très fine; externe confondne avec la marginale; ponctuation fine et espacée occupant le dernier tiers, en dedans de la deuxième dorsale. Pygidium bombé, densément ponctué. Mésosternum avec des points plus forts moins serrés, bordé d'une strie cntière. Prosternum plan, pointillé, un peu rétréci en devant, avec les stries dans le mème plan, allant se réunir en angle très aigu. Jambes brunes, antérieures garnies de cind ou six dentelures dont les trois externes plus fortes, postérieures d'un double rang d'épines rousses. 
Syric.

Voisin du S. Blanchei, il n'en diffère que par la disposition et la longueur relative des stries dorsales, les plis latéraux du pronotum et par le prosternum s'avangant en pointe à còtés droits, sans légère dilatation antéricure.

\section{3" SAPRINos Mersive.}

Ovalis convexus, nigro-metallicus nitidus, antennis pedibusque rufo-brunneis; fronte subrugosa, stria tenu interrupta; pronoto disco tennissime, circum valide versus latera rugulose punctulato; clytris dimidia postica parte punctulatis; stria suturali postice subinterrupta, basi arcuatim juncta, $1_{a}$ dorsali $4^{\text {a } q u e ~ v e r s u s ~ m e d i u m, ~ 2 a ~ p o n e, ~} 3$ a inferius abbreviatis, humerali temi, subhumerali interna subadnexa longa, externa nulla; pygillio dense; mesosterno vix punctulatis; prosterno concavo striis convergentibus, haud ascendentibus; tibiis anticis 4-denticulatis. Long. 4 mill., larg. 2 1/2 mill.

Ovale convexe, noir métallique brillant. Antennes brunes. Front légèrement convexe, subrugueusement ponctué avec une fiue strie uarginale interrompue. Pronotum court bombé, à peine arqué à la base, arrondi sur les côtés, échancré et retréci en devant avec les angles obtus et abaissés; couvert en dessus d'une ponctuation fine sur le dos, plus forte dans son pourtour et rugueuse vers les côtés; strie marginale fine non interrompue. Ecusson ponctiforme. Elytres plus longues que le pronotum, de sa largeur à la base, dilatées à l'épaule, obliques sur les côtés, retrécies et tronquées au bout avec les angles postérieurs arrondis; courertes dans leur moitié postéricure interne de petits 
points un peu oblongs, assez espacés; stries sans points bien distincts; snturale fine, rapprochée de la suture, un peu interrompue et plus obsolète au bout, réunie à la base par un arc à la dorsale voisine; première dorsale dépassant un peu le milieu; deuxième un peu plus longue, troisième encore davantage, quatrième plus courte que la première, humuérale oblique, très fine; subhumérale interne assez longue à peine disjointe; externe confondue avec la marginale. Pygidium bombé, entièrement et densément ponctué. Mésosternum avec une strie non interrompue, couvert de quelques yoints épars. Prosternum étroit, concave, rétréci en devant, stries dans son plan, un peu convergentes. Pattes brun ferrugineux; jambes antérieures garnies de quatre à cinq denticules, dont les trois derniers plus forts; postérieures garnies de deux rangs de longues épines rousses.

Vient se placer auprès du $S$. Blanchii, avec lequel il n'a que peu de rapports, et dont il s’éloigne surtout par son prosternum et sa ponctuation.

Syrie.

\section{S'. SApRINUS DESERTORU.}

Ovalis, convexus, wneus, nitens, antennis pelibusque ferrugineis; fronte dense punctula stria nulia; pronoto extus ciliato, laleribus late megoso, basique punctato; elytris lateribus el postice punctalis, stria sublumerali cxlerna disincla, intoma humerali connexa, 1-4 dorsalibus dimiliatis 1 "t 3 brevioribus, f" arcu basali cum sulurali juncla; piggidio dense punctato; mesosterno marginato punctis parcis, prosterno striis untice divergentibus el ascendentibus; tibiis anticis purce demiculalis. Long. 3 1/2 mill., larg. 2 mill. 
Ovale oblong, assez convexe, d'un bronzé luisant, avec les antennes et les pattes d'un brun rouge. Front arrondi, hombé, couvert d'une ponctuation serrée, sans strie qui le distingue de l'épistome. Pronotum court, arrondi et étroitement bordé de points à la base, oblique, puis arrondi en devant sur les côtés, très rétréci et peu échancré en devant avec lesang les abaissés obtus; cilié latéralement et largement bordé de points serrés et rugueux, finement pointillé au milieu; strie marginale fine, entière. Écusson très petit. Élytres presque deux fois aussi longues que le pronotum, de sa largeur à la base, dilatées à l'épaule, rétrécies et tronquées au bout; bord infléchi avec un sillon bordé de points. Strie subhumérale externe distincte et bien marquée, interne longue et joignant l'humérale, qui est un peu confuse; dorsales ponctuées, raccourcies au milieu; première et troisième un peu en avant, quatrième réunie par un arc basal à la suturale qui est entière; ponctuation médiocrement serrée, occupant la moitié postérieure et remontant sur le premier interstrie. Pygidium densément et fortement ponctué, avec un petit espace lisse au bout. Mésosternum entièrement rebordé avec quelques points très espaccés. Prosternum assez conrt, peu concave, arec les stries divergeant et remontant en devant. Jambes antérieures dilatées et garnies en dehors de sept à huit denticules, postéricures épincuses.

J'ai publié, t. 1II, p. 715, No 151, de cette monographie, sous le nom de Saprinus desertorum, une toute autre espèce qui m’avait été donnée par M. Th. Lacordaire comme le type de M. le Docteur Le Conte. Mais celui-ci étant le vrai desertorum de cet auteur, puisque j'en tiens un individu directement de lui, lo premier prendra le nom de $S$. deserticolit. 


\section{8'. SAPRINCS PLACIDES.}

Suborbicularis convexus, niger nitidus, antennis pedibusque piceis; fronte dense punculula, pronoto basi ct lateribus punclato; clytris postice intus parce punctatis, striis validis, 1-4 ulursalibus versus medium intequaliter abbrevialis, sumrali postice abbreviata arcu basali $4^{\text {x }}$ dorsali connexa; subhumerali intema brevi disjuncta, externa mulla; pygialio subtiliter, mesosterno parce et grosse punctatis: prosterno striis uscendemibus; libiis anticis denticulutis. Long. 2 mill., larg. 1 1/2 mill.

Saprimus placilus Er. in Jahrb, 189, 41 (1834).- Le C., Mon. Hister., 56, 4 (1845), - J.-L. Le C., classif.

Suborbiculaire, noir luisant. Antemnes et pattes noires de poix. Front bombé, couvert d'une ponctuation fine et serrée. avec un point sur le vertex. Pronotum court, avancé en angle obtus au milieu de la base avec une étroite bordure de gros points; arrondi sur les côtés, très rétréci et échancré en devant, avec les angles obtus et abaissés; couvert dans son pourtour d'une ponctuation serrée, un peu rugueuse sur les côtés ; strie margrinale entière et bien marquéc. Ecusson très petit. Elytres une fois et demie plus longues que le pronotum, de sa largeur à la base, dilatées à l'épaule, rétrécies et tronquées au bout, couverles de points espacés et assez forts en dedans à la partie postérieure; bord infléchi lisse; strie marginale forte ct eıtière; subhumérale externe nulle, interne courte et séparée de l'humérale; dorsales fortes et ponctuées, raccourcies, première au delà du milieu, deuxième et troisième égales, un peu plus, quatrième au 
milicu, réunie par un arc basal à la suturale, qui n’atteint pas l'extrémité. Pygidium convexe, ponctué également, ainsi que le propyşidium. Mésosternum à peine sinué en devant, rebordé et couvert de points espacćs. Prosternum presque plan, à stries divergentes et remontantes. Jambes antérieures 6-denticulées, postérieures épineuses.

Cette espèce, des Etats-Unis, qui ne m'était connue, lors de la publication des Saprinus, que par la description d'Erichson et de M. Le Conte, doit se ranger à la suite du $S$. neglectus Le C. J'en donne ici la description d'après un type qui me vient du Docteur J.-L. Le Conte. Elle s'accorde de tous points arec celle d'Erichson que javais reproduite.

\section{$127^{\circ}$. SAPRines FugaX.}

Ovalis, convexiusculus, piceus nitidus, pedibus. elytris antemisque rufis; /ronte dense punctata, a clypeo stria transversa distincta; pronoto un lique aqualiter parce elytrisque punctalis, stria suturati iniegra basi areuatim juncta, $1^{a}$ dor. sali multo longiori, 2-4 sensim brevioribus, subhumerali externa nulla, interna brevi disjuncta; pygidio elense punclalo; prosterno concavo striis valde approximatis; tibiis anticis 6-dentatis. Long. 2 mill., larg. $11 / 4$ mill.

Ovale, médiocrement convexe, brun de poix luisant. Antennes, pattes, élytres et extrémité de l'abdomen roussâlres. Front transverse, presque plan, densément pointıllé, séparé brusquement de l'épistome par une assez forıe strie. Pronotum beaucoup plus large que long, arrondi à la base, avec une faible impression au-dessus de l'écusson, arqué sur les còtés, échancré el rétréci en devant arec les angles obtus el

3e Série, тonk v. 
abaissés, bordé d'une fine strie marginale non interrompue, couvert sur toute sa surface d'une ponctuation espacée assez forte, plus grosse le long de la base. Elytres ponctuées de même, moins distinctement à la base, plus lonigues que le pronotum, de sa largeur à la base, dilatées à l'épaule, rétrécies et fronquées au bout; stries dorsales ponciuées, raccourcies postérieurement, la première beaucoup plus longue que les trois autres, $2-4$ raccourcies graducllement; suturale eutière réunie avec la dorsale voisine par un arc basal; humérale fine très oblique, accompagnée d'une courte subhumérale interne disjointe, externe nulle. Pygidium peu convexe, densément et également pointillé. Mésosternum sinué en devant, rehordé, avec quelques points épars. Prosternum étroit, concave, avec deux strics très rapprochées vers le milieu. Jambes antérieures munies de six denticules dont les plus externes assez forts; postérieures, d'épines peu nombreuses.

Indes orientales (coll. Javet, Murray).

Celte espèce vient se placer auprès du S. preceox, auquel elle ressemble beaucoup par la couleur, la ponctuation et la forme. Les stries dorsales seules sont d'une grandeur relative différente.

\section{2'. Saplinus Boduista.}

Ovalus, convexiusculus, aencus nitillus, antennis rufis, pcdibus brunneis; fronle aciculata, transversin striata carinataque; pronoto latcribus ciliato, marginato, undique punctato, circum fortius; elytris postice subrugose punctatis, stria subhumerali externa nulla, interna cun humerali con- 
linua, longa, 1-4 dorsalibns aqualiter subintegris, $4^{\mathrm{a}}$ (un snturali integra basi aruatim juncta; pygidio convexo, sat valide munctito; prosterno concavo, striis mox coalescentibus; tibiis anticis extus 4-dentatis. Long. 2 mill., lary. 1 mill.

Ovale oblong, assez convexe, bronzé luisant. Antennes rousses. Front transverse plan, rugueusement aciculé, bordé en devant d'une strie et d'une carène, qui le sépare brusquement de l'épistome. Pronotum arqué à la base, oblique et cilié sur les côtés, échancré et rélréci en devant avec les angles abaissés, arrondis; bordé d'une strie marginale entière, et couvert en entier de points assez forts peu serrés, beaucoup plus gros à la base et vers l'angle antérieur. Ecusson très petit. Elytres plus longues que le pronotum, de sa largeur à la base, dilatées à l'épaule, rétrécies et tronquées au bout; stries fortes; 1-4 dorsales presquentières et à peu près d'égale longueur, suturale entière, réunie à la base par un arc à la quatrième dorsale; humérale oblique continuée sans interruption par la subhumérale interne qui est assez longue, externe nulle; ponctuation forte, presque ruguense, occupant sculement le tiers postérieur, mais remontant un peu vers la suture et vers le premier interstrie. Pygidium bombé, également et bien sensiblement ponctué. Prosternum étroit, concave. Stries réunies vers le milieu. Mésosternum avec de gros points espacés et entièrement rebordé. Pattes brunes. Jambes autérieures fortement dilatées, armées de quatre dents distinctes; postérieures, de quelques épines.

Indes orientales (coll. Javet, Murray). 


\section{6'. S.PHLUS BARPLES.}

Conc'xus, oblongus, piceus, subrilidus, ore, ancmis pedibusque rufis, fronte transuersa, anlice acule marginata, sulco arcualo medio; pronoto mgoso, angulis anticis rotuntais ; clylris postice dimidiatim strigoso-punctalis, striis dorsalibus $2^{\mathrm{a}}, 1^{\mathrm{a}}$ it $3^{\mathrm{a}}, 4^{\mathrm{a}} \mathrm{cum}$ sumrali arcualim connexa, sensim. brevioribus, nlla medium nbbrevialis, subhumerali imerna junctu; propygidio mygidiogue dense punctalis: prosierno carinato, striis approximatis; tibiis anticis 5-6 dentalis, poslerioribus longius cilialis. Long. 2 mill., hagg. 1 1/2 mill.

Saprinus lucidulus L. Le C., Col. Calif. (1851).

Ovalc oblong, très convexe, assez luisant, brun de poix. Antennes rousses. Scape dvec de longs cils ferrugincux. Bowhe rougeatre. Front en demi-cercle, plan et lisse en dessus, séparés de l'épistome par une arête aiguë transverse et mesque droite, avec un chevron large arqué. Pronotum conrt, à peu près tronqué à la base, droit sur les côtés, un pou rétréci, largement et profondément échancré en devant avec les angles arrondis et abaissés; strie marginale entière; ponctuation rugueuse, un peu afrablie au milieu. Ecusson très petit, triangulaire. Elytres courtes, un peu plus longues que le pronotum, de sa largeur à la base, peu arqué sur les côtés, rétrécies et coupées droit au bout, densément strigueuses et inégales dans leur moitié postérieure interne; stries dorsales fines; première et troisième atteignant les quatre cinquièmes de la longueur; deuxième un peu plus longue; quatrième un peu plus courte, réunie par un arc basal à la suturale, qui suit le bord postérieur des élytres et va se réunir 
à la strie marģinale qui est très forte; strie humérale réunie à la subhumérale interne, qui est accompannée de deux strioles; subhumérale externe nulle. Propygidium couvert d'une ponctuation forte et serrée; pygidium convexe, plus finement ponctué. Mésosternum lisse et rebordí. Prosternum en carène, concave, avec deux stries très rapprochées, entières, adossées au milieu. Pattes rouges. Jambes antérieures dilatées, armées de cinq à six dents, dont les trois dernières plus fortes; postérieures garnies de longs cils ferrugineux.

Californie (coll. A. Murray).

Cette espèce, que je crois être le $S$. lucidulus de I. Le C., dont le type m’est inconnu, vient se placer à côté du $S$. sabulosus, qu'elle figure en petit.

xxxvil. Plegaderis Er. Mon. Suppl. pl. xxv, G. 38.

\section{6'. Pleggaderus Barany.}

Ovalis connexinsculus, picens, nitidus, antennis pedibusque rufis; pronoto sulco tenui transverso incequaliter diviso, vix distincte punctulato, margine crasso integro, intus sulco basim allingente terminato; clytris parce sed sat fortiter punctulo, striis 2 obliquis basi sutura clevala; prosterno bisulcalo, costa medic lale interrupta fulvo-holosericen, mesosterno trisulcato. Long. 1 1/2 mill., larg. 4/5.

Ovale oblong, bombé, d'un brun de poix, luisant. Antennes et pattes rousses. Front pointillé, déprimé, relevé au devant des yeux. Pronotum presque carré, bisinué à la base, légèrement convexc sur les côtés, avec un bourrelet entier assez étroit, un peu abaissé au delà du milieu, bordé d'une 
strie de chaque côté, et en dedans d'un siilon profond atteianant la base, un peu rélréci et légèrement échancré en levant avec les angles arrondis; couvert sur sa surface d'une fine ponctuation très espacée, un peu plus visible vers la base, divisé en deux portions inégales faiblement bombées par un sillon transverse peu profond. Ecusson très petit, enfoncé. Elytres un peu plus longues que le pronotum, de sa largeur à la base, dilatées à l'épaule, rétrécies et tronquées droit au bout, couvertes d'assez forts points peu serrés, uniformément espacés, bombées, avec la suture très élevée, et deux stries obliques basales courtes. Pygidium finement pointillé. Prosternum profondément bisillonné avec une côte médiane, largement interrompue et une houppe de poils fauves au fond de la cavité. Mésosternum séparé du métasternum, profondément trisillonné.

Cette espèce, découverte à Toulon par M. Beriont, m'a été communi(juée par notre collègue, si zélé et si obligeant, II. de Baran, auquel je suis heureux de la dédier. Elle a beaucoup de rapports avec le $\boldsymbol{P}$. Oulii, découvert par M. Capiomont dans les mêmes contrées. Elle est un peu plus petite, moins ponctuée, en particulier sur le pronotum. Le bourrelet latéral un peu abaissé au niveau du sillon transverse, moins élargi à la base, et le sillon qui lui sert de linite en dedans, atteignant la base, me la font regarder comme fort distincte. 


\section{TABLE ALPIIABETIQUE}

\section{DES GENRES ET DES ESPICGLS.}

42. Abratus Leach. 1817. IV 577

16. Omalodes Er. 183 1. I 498

43. Acritus L. Le C. 1853. IV 595

40. OnthophilusLeach. 1817. IV 549

7. Aulacosternus.

I 234

4. Oxysternus Ei. 183í.

I 220

41. Bacanius L. Ie C. 1853 . IV 567

12. Pacliycraerts.

1 447

31. Carosternus L. Le C.

34. Pacilylopus Er. 1834. IV 97 1852.

23. Paromalus Er. 1834.

III 100

22. Carcinops. III 83

25. Pelorurus ou Peloris.

II) 125

24'. Crelocrara. Sщ!l. V 426

13. Phclister.

I 462

18. Conlipus.

I 543

2. Phylloina Eı². 1834.

I 191

10. Cylistix on Cylisıs.

1287

6. Placodes $\mathrm{Er}^{2} .1831$.

1229

11. Cypturus Er. 1831.

I 290

5. Plresius El. 183 .

I 224

30. Dendropliilus Leac. 1817 . III 146

9. Plalysoma Leach. 1817. I 2 亿8

21. Epierus Er. 1834.

II 671

38. Plegaderus Er. I83\%. IV 259

29. Eretmotus.

III 141

17. Psiloscelis.

I 539

39. Glymma.

IV 279

13. Rihypochares.

I 49 年

28. Helærius Er. 1S3i. III 137

33. Saptinus Er 183\%. Ili 327

20. 1lister L. 1735.

I1 161

26. Scapomegas.

II] 129

1. Hololepla Payk. 1811. I 135

32. Splieı osoma.

III 162

3. Lioderma on Lionola.

$1 \mathbf{1 9 6}$

14. Spliyracus.

1489

8. Macroslermus.

I 239

36. Terelrius Er. $183 \%$.

IV 129

19. Margarinolus.

1549

31. Tribalus Er. 1834.

III 151

24. Monoplins.

III 122

35. Trypanaus Esclı. 1834

IV 103

27. Notorlensa

III 133

37. Xiplıonolıs.

IV 141 


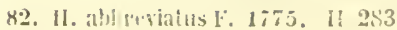

1. D. abbrevialus liossi.

1790.

2. I'lat. abruptum Fir. 183 i. I 257

39. 1I. Abyssinicus.

II $22: 2$

18. Acr. acaloiles.

IV 618

2. Acr.aciculatus I.c. 18 i5. IV 603

8. I'hel. acopostermus.

I 475

40. S. acuminatus F. 1798. III 40:2

17. Acr'. acupiclus.

IV 618

24. S. advena. v. ovalis. III 382

78. S. Egypliacus.

III 455

129. S. aemulus llg. 1807. IlI 687

56. S. aneicollis.

III 42 '

1. Сyp. anescens Er. 1834, I 293

48. S. aneus I. 1775 III 413

2. Par. áqualis Say. 1825. Ill 108

5. Hol. opualis Say. 1825. I 147

43. II. æerualorius.

Il 227

148. I1. aeruistrins.

II 5.59

73'. S. Aeratus Er. 1834. III 737

24. HI. Etliops IIcer. 1811. II 204 Il.? afel Payk. 1811. II 592

71. S. affuis Payk. 1811. IIl 415

1. Par. allinis Le C. 1845 . III 107

6. Onl. affuis fiedt. 1849. IV 561

1. 'Tr. agre'stis.

III 155

42. S. AIgericus Payk. 1811. III 405

12. Platysom. Algericum Luc. 18.49.

1267

18'. S. alienus I. Le C. 185 !. Ill 742

4. Ont.alternalus Say.1825. IV 558

15. Ep. alulaceus.

II 694

10. Tryp. anuabilis.

IV 117

5. Trib. Americanns Le C. 1845.

III 159

138. H.Americanus Payk.18\1. II 575

4. Pacliyc. anetleyslimus. I 455

9. S. umanules Fah. 1851.11! 361
12\%. 5. amouas ki. 1831. III 681

26. Il. amplicullis Er. 1840. II 208

(h) Acr. analis H, I $e^{2}$ C. 1853. IV 628

3. Om. angulatus F. 180I. I 508

21. Plat, angustialum E. II. 1803.

I 278

20. Plat. angustatum Payk. 1811. I 276

26. Om. anthracinus. I 533

21. Ep. Antillarım. II $\mathbf{7 0 0}$

133'. S. Antiquulus $1 \mathrm{lg} .1807$. III 732 112. II. apicatus Sclirank. 1798.

11582

158. S. apricarius El'. 1834. III 725

66. 11. Arabicus.

II 263

23. IIoI. aradilinunis Er. I831. I 181

17. Hol. arcilera.

I 159

5. Hi.arciger.

II 68 \%

62. II. arcualus Say. 1825. II 258

120'. 11. a:cuatus kolen. 1846 Silpl.

V 163

132. S. arenarius.

III 691

72. S. areolatus Fahı'. I851. III 4 i7

105. s. arrogans. III 487

II'. I1. Assamensis. Supt. V $\mathbf{4 0 9}$ 60. S. assimilis Payk. 1811. III 431 57 '. S. alerrinus Er. 1834. III 738 11. Acr, alomarius Aubé. 1813.

IV 611

2. $1 \mathrm{cr}$, atomos Riossi, 1792. IV 612

(i) Acr. atomus L. Le C. 1853. IV 628 $8 S^{\prime \prime}$. H. a!rameularius sinffr.

I855. V $\mathbf{4 5 8}$

3. P'al, atralum Er. 1831. I 259 102. S.atronilidus Bl. 1852. IlI 483

21. IIUl. altenuala Bl. 1852. I 182 25'. Plat, allentalun I.e C.

1815.

I 281

31. 5. aulicullis.

III 390 

1. Sicap. aurilus.
III 132
4. Ilol, Auslialica.
I 146
III 423

55. 5. azluriscens.

57. S. azmeris Sahll, 1823. III 426

19. II. Baconi.

11198

6'. I'I. Barani. Sup?.

$\checkmark 449$

$150^{\prime}$. S. barluips. Supt.

V 418

13. Lioul. Bari.r. punctulata. I 216

(c) ACr. lasalis L. Le C. IS51. IV 626 9'. ilol. Baulnyi. Supl. V 399

5. II. Bengalensis Wied. 1821. II 182

19. Tisp.licaudatus. IV 127

66. S. Jicolor 01.1789. III 439

14. Ilol. Jidenlala, I 156

83. I1. bifidus Say. 1825. II 284

5. Om. lifoveolalus. I 510

116. H. Jifrons. II 545

144. S. Jigemmeus 1 . Le $C$. 1851.

III 707

154. S. bigener Le C. 1845. 111719

11. S. ligultalus SLev. 1806. III 366

442. H. binaculatus L. 1735. II 582

7. Tryp. Jimaculatus Er.

$$
\text { 1834. IV } 115
$$

96. II. Jinotalus Er. 1834. II 303

47 . S. Liparlilus Mols. 1849. III 752

119. Il. biplagialus Le C. 1845. 11552

16. Phel. bipulvinatus. I 484

121. II. bipunclalus. Payk. 1811.

I] 555

102. H. bipustulatus 01 . 1789.

1I 528

141. IJ. bipustulatus F. 1798. II 581

10. Tryp. bipustulatus F. 1801

IV 117

8. Ep. Jisbistrialus.

II 68:

13. ‥ Jisizualus El , 183', Jll 369
14. Tryp. bispinus.

IV 122

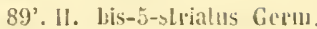
1813.

II 309

136. 11. bissexstrialus F. 1804 . II 572

145. IS. bissexstrialus Dufl.

$$
\text { 1805. II } 586
$$

8. Par. 1istriatus Er. 1834. Ill 11 i

161. S. listrigifrons. 111729

12. \$. Blanchardi. III 368

83. S. Blancliii. I11 461

95. S. blandus E1*. 1834. I1I 475

77. s. Blissoni. 1454

5. l'acliyc. Bocandei. I 456

26. Hol. Begotana. 1184

51. II. Bolivianus. 11235

59. S. Bonariensis. 111429

1. Om. borealis Le C. 1815. I 506 132'.S. Boudista. supl. \446

7. Pliel. borinus. 1474

15. Hol. Jractea $\mathrm{El}^{\circ} .183$ I. I 157

7. On. Brasilianus. I 513

159. S.Brasiliensis Payk.1811. III 726

8'. 'Tryp. hreviculus. Supl. V 401

28. Hol.blevis. v. curtu. I 187

9. Acr. brevisleruus. IV 609

17. PheI. Inevistrius. I 485

73'.5. breviusculus Fahı. 1851 .

III 757

1. Pel. bрuchoices.

109. II. Grunneus Ilerist. 1791. II 536

87 H. brunneus Ilg. 1798. $\quad 11291$

18. Ep.brunnipennis.v. I'ufipennis. $\quad 11697$

2. Ilet.brunnipennis. Sup'. V 433

77. 11. brumnipes Er. 1831. II 277

74. \$. brunnivestis. III 449

136. s. Burueli. III 696 
5'. Liod. cacti l.. I. C. 1851. I 220 el supt.

$\checkmark 400$

87. H. cadlaverinus F. II 1803.

II 29 !

3. Pleg. citsus F. 1775. IV 267

110I. Calfril Er.183í. 1219

2. Milc. Caffur Er.183\%, I 233

10. II. Caffer Er. 1834. II 188

8. H. Caffer Falır. 1851. II 186

46. 11. Calabarieus. Suph. V 415

113. II. Califormicus. Il 5 í

34. S. Californicus Mamn. 1843.

III 395

98'.11. Caliginosus Steph. 1830 . II 311

94. S. Campechianus. Ill 474

91. S. canalistrius. III 47 I

1. Glym. Candczii. IV 282

11. Plat.Capense Wied. 1821, I 266

2. Tribal. Capensis Payk. 1811.

III 156

37. 11. Capieola.

II 220

107. 11. Carionarius tlliger. $1798 . \quad$ II 534

15. Tryp. carinirostris. IV 123

14. Plat. Carolintim Payk.

$1811 . \quad 1269$

21'. Tiyp. Carthagenus. Supt. V 156 plat. castaneum Mnt. 1832. SuIt.

Y 402

18. I'lat. castanipes.

1271

109. II. castanipes sleph.

$$
1830 \text {. }
$$

II รั36

75. S. Cavalieri.

III 452

69. 11. cavifirons.

Il $26 \pi$

I. Hel. cavisteruts, v. puncIulitlus.

Y $\{32$

22. HeI Cayemunemis.

I 180

i. Liud. cerdo.
71. S. chalcites Illir. 1807. III its

2. Pacluye, chalybeus Falı. 1851.

I 453

1. Xiph. Chevrolali.

IV 143

117. S. Chiliensis.

IIl 500

12. Il. Chinensis Qnens, 1806. II 190 S. cilialus L. I.e C. 1851. III 746

6. P'hel. circulifrous. 134. II. civilis Le C. 18 15. II 570

25. Plal. coarctatum le $\mathrm{C}$. 1845.

I 282

59'. H. cxlestis. Sup'. V $\$ 16$

76. 11. cœenosus Ër. 183i. II 276

20. S. cœrulescens E. II. $1803 . \quad 111377$

S. coriulescens L. Le C. 1851.

III 748

111'. H. cognahus Le C. 1845. II 548 et 111' Supt. V 421

12. Ilol, Colombiana. I 154

3. Par. complanatus Illig. 1798.

III 109

2. Par. complanatus Pal. 1805.

20. Ep. comptus lllig. 1807. II 699 39. S. concinmus Hols. 1849. 111400

58. II. confinis Er. 1834. Il 250

57. H. conformis Er. 1834. II 249 103. S. conformis Le C. 1845. III 48 i

(g) Acr. conformis L. Le C. 1853.

IV 627

9'. Plat. Confucii. Supl. V 40 .

3. Liod. confusa. 1205

12. Om. conicicollis. I 519

119. S. conjugatus $1 \mathrm{lg} .1807 .111503$

2. Carc. conjunclus Say. 1825. III 8 ?

135. S. conjungens Ph.17\$18. 111694

61. S. connecleus layk.1811.111 $43: 2$ 
10m+ jlage

108. S. Connori. v. neglectus III 491

20. On. consanguineus. I 527

(b) Acr. Consobrinus Aubé. 1850.

IV 625

1. Carc. consors I. Le C. 1851.

$\begin{array}{ll}\text { III } 88 & 8\end{array}$

145. II. consputus.

III 708

47. H. contemptus.

II 231

111. S. convexiusculus.

III 494

11. Par. convexus

III 118

2. Dend. Cooperi Steph. 1830.

III 150

4. Ep, coproides.

Il 682

42. II. coprophilus Reiche 1851.

II 226

100. II. Colacinus Er. 183i. II 307

130. S. Corsicus.

III 688

1. Pllyl, corticale F. 1801. I 193

1. Dend. corticalis Payk. 1798.

III 148 Carc. corticalis L, Le C. 1851. Supt.

V 426

147. H. corvinus Germ. 1817. II 588

* II. costalus, Le C. 185 f́. Supt.

V 407

1. Cœl. costifera. Supt. V 430

7". Ont. costipennis Fahr. 1851.

IV 565

152. S, crassipes Er. 1834. III 717

13'. S. crenatipes Sol. 1849. IIl 753

69. S. cribellatus.

III 442

5. Acl' cribripennis. IV 605

45. H. cribrurus. II 229

1. S. crucialus F. 1792. III 354 24'. II. crurnlus Er. 1834. II 242

88. S. Cubacola.

III 467

19. IIol. Cubrnsis Er. 1834. I 178

3. Phel. Cunaneusis. 1470

s cupralus Kolru, 18 \$6. tome page

supt.

V 167

73. S. cupreus Er. 183\%. III $\mathbf{4 4 8}$

28. Hol.curta, voy. hrevis, I 187

S. curlus Rosenlı. 1847. III 751

73. II. curtitus L.e C. 1815 . II 272

1'. AJr' curtulus Falı. 1851. IV 591

65. H. curvalus Er. 1834. II 262

28. S. cyanellus. III 387

7, Pacliyc, cyanescens Er.

1834.1458

26. S. cyaneus F. 1775. III 385

20. S. cyaneus IIerb.1791. III 377

29. S. cyaneus Payk.1811. III 388

9'. Pachyc. cyanipenuis Fal.

1851. I 460

2. Abr. cyclonotus. IV 584

1. Cyl. cylindricus Payk. 1811. I 289

23. Plat, cylindroides. I 280

22. Plat. Dalmatinum Küst. 1850.

135. S. decemstriatus Rossi. 1792.

III 69 ?

22. Ep. decipiens L, Lc C. 1851.

Il 702

76 H.decisus Le C. 1845 . II 276

14. S.decoratus Er. 1834. Ill 370

119. S. deletus Le C. 1845 . III 503

11'. Carc. delicatulus Falır. 1851. Supl.

V 161

160. S. dentipes.

III 728

16. Plat. deplanatum Gyl. 1808.

I 27 I

30. On. depressistermus. I 537

16. Plat. depl'essum F, 1787. I 271

17. Plat. depressum Le $\mathrm{C}$. 1815.

74. H. depuralor Say, 1825. II 274 
151. S. deserticula. voy. desertorum.

88'.s. desterlonum le C. 1851 . supl.

1432

6. Pachye. desidiosus.

1457

35. Sidclersus 11g. 1807. 111396

9. Litud. devia.

I 211

20. 'Tryp. Deymoli.

IV 127

i2 i. 11. diadema.

II 559

1. Conl. dislymoslrius.

5. J'ar. dislynus.

1546

2. Cunt. digilalus.

III 111

I 5.47

149. ง. dimidialipenuis Je C. 1821.

III 713

162. S. dimidlialus IIlig. 1807 . III 730

52. S. diplychus.

III 418

8. Pleg. discisus EI', 1839), IV 272

18. S. discoidalis L, Le C. 1851.

111375

(f) Aer, diseus L. LeC, 1853. IV 627

163. S. disjunclus.

III 731

1. Pacliyl. dispar El. 1834. IV 100 129'. H. dispar Le C. 18 15 . II 576

1. Pleg. disseclus Er. 1839. IV 268 H. distaus Fis. 1823 . Sujl, V 164

93. Il. distiuctus Er. 1834. II 300 68. s. dislinguendus. 111 141 16. 11. distou'sus Illig. 1807. II 195 10. Calc. Dominicanus. III 97 79. แ1. dubius.

145. I1.12-sluiatussinu. 1781. I1 586 107. H. 12-strialus 1. 1801. II 534 80. 1]. Aluphicatus. 11280

22. Ou, clenninus Er.1834. 1529

2. Aıl. Erlwardsii. I 237

12. Ihluel. egcuis. 1 i80

25. 5. vlegaus Payk, 1811, II\} 383

f:38. ר. risgaululus

(I) 695
2. J'axs, (1liplicis. I 227

31. Hol. elongala Ev'. 1834. I 190

19. Plat. elongalum oliv. 1789.

1275

15. II. elongatulus. II 194

29. I1. encauslus. II 211

5. Tryp. ensifer. IV 113

4. S. cuncstris Ev, 1843. III 358

8. S. Ericlssonii. III 363

92. S. erylhropleurus, II! 472

62. S. erytluoplerus Payk. 1811.

III 431

142. II. erylhopterus F. 1798.

II 582

81. II Eschischolizii.

II $28 \%$

$143^{\prime}$. S. estriatus Ise C. 1851 . Supl.

V 166

2. Onllı. exaratus $I 1 \mathrm{~g} .1807$. IV 555 $117^{\circ}$.H exaratus I.e C. 1845. II 549

6. Ilul. excisa. 11 is

3. Acr. exiguแs Er. 1831. IV 603 Få. exiguus Falır. I851. Iil 121 3'. Afr', cxilis Payk. 1811. IV 59 A 10. S.externus Fisch, 1823. JII 365 21. Om. extoris.

I 528

60. S. extraneus IIg. 1807. III 431

8. On. exul.

1514

17. Tryp. fallax.

IV 125

9. Om. lauslus Er. 1834. I 515

148 \$. ferrugineus. $\quad 11 \mathrm{712}$

1. Het. ferrugineus Oliv. 1789.

III 140

45. S. figuralus. III 409

22. 'lal, filiforme Er. 1834. I 278

112. S. fimbriatus L. Le C. 1851111.495

102. II. finclarius II risst. โร91

1) 528 
14. Aeril. timetarims Le $\mathrm{C}$.

$$
1845 \text {. }
$$

IV 615

IIol, flagellata hill, 1817.

$$
\text { Supt. }
$$$$
\text { Y } 155
$$

10. Par. flavicornis Llerlost.

$$
1791 .
$$

III 117

9. Tryp. flavipennis.

IV 117

(i. S. flexuosofasciatus Mls.

$$
\text { 1845. Supt. V } 167
$$

88. Il. foelatus Le C. 1845 . II 292

3. Mac. foliaceus Pay k. 1811. I 245

2. Itend. formicetorum.

$$
\text { Auhé. } 1833 .
$$

III 150

131. II, fossor Er. 1834.

II 566

5. Ilol. fossularis Say. 1825 . I 147

11. Om. foveola Fr.1834. I 517

11. Ep. firater.

II 690

I 10 . S fralermus Say. 1825. III 701

13. Plał. frontal Payk.1798. I 268

27. Platys. fromtale Say. 1825.

I 283

7'.s. fronlistrins.

III 450

127 '. S. fugax, Supt.

V 475

32. s. fulgidicollis.

III 392

26. Ep. fulvicornis F. 1801 , Il 706 123. s. fulvipes.

III 680

98. S. fulvopteris.

III 479

7. Acr. fulvus.

IV 607

135. II. funeslus.

II 571

97. II. furcipes.

II 304

43. S. linvuts Er.1834, III 406

24. H. gagates llig. 1807. II 204

23. 11. gagatirius Reiche.

\section{1.}

II 202

37. S. Gangeticus.

III 398

2". Pacliyl. gautens I. I.c C. 1851.

IV 103

99. I1. Gehinit.
59. II. geminus Er. 1834. II 251

67. S. geminus Duft.1805. III 440

2. scap. giblus.

III 132

1. II. gigas Payk.18!1 11170

7. Carc. Gilensis L. Le C.

$1851 . \quad$ III 9 I

79. S. gilvicornis Er. 1834. Jll 456 Ilol. glabra Fahr. Supt. V 155

1. Not. globatum. III 136

15. Pluel, glohiformis. I 483

6. Alr. globosus E. H. 1803 . IV 588

1. Onth. globulosus oliv.

$1789 . \quad$ IV 554

5. Abr. holulus Creulz. 1799. IV 587

40'. S. Godet Brul. 1832. III 734

144. II. Goulotii. II 585

27. Plal. gracile Le C. 18亿j. I 283 24' Supt. V 405

103. II. Græecus Brul. 1832 . II 529

134. s. granarius Er. 1831. III 693

100. S. Gramatensis. III 481

2i. II. grandicollis IIg. 1807. II 209

5. H.graudis Gern.1824. II 182

2. Liod. grandis. I 204

7. Alsr.gramulum Er. 1839. IV 589

95. Il. graliosus Man. 1852. II 302

3. II. gravis Fahlr. 1851 . II 172

153. S. grossipes. III 718

15. Om. grossus. I 522

43'. II. Guinensis Payk. 1811. 11246

23. Acr, Gulliver. IV 623

76. S. Guyanensis. III 453

9. Phıl.hæmorrhöus. I 476

18. Om. Ilaĭliants. I 525

92. II. IIarrisii Kirb. I837. II 299

1. Psil. IIarrisii Le C. 1850 . I 542

6. Ep. luaslatus, II 685 
Iom" page

32. II. AeInis Truq. 1852. II 214

11. Mlat. IIenningiisturm. 184:3.

1266

131. S. lierluels.

III $6 \times 9$

12'. II. Leros Er, 1812.

II 242

II $2 \% 8$

78. H1. IIipponensis.

7'. Ont. lispridus Payk. 1811. IV 565

3. Pachyc. histroüdes. 1 $\mathbf{4 5}$

40. H. Hullentola Er. 1834. 11223

120. 11. humeralis Fiscl.

$$
18: 3 .
$$

II 553

1. Bac. luumicola .

IV 570

6. Plat. Imunile Er.183í. 1261

20. 110I. Inmilis Payk.1814. I 1;9

9.3. s. Hypocrila.

III 473

30'. Il. ignavus Fabr. 1851. II 2 亿3 106. II. ignobilis.

II 532

113. S. ignolns.

111496

102. H. Illigeri Duft.1805. II 528

4í. S. immundus Gyl. 1827. 111407

91'. II.inmunis Er.1834. II 310

36 '. Il.imperfeclus Le C. 18 \$5. Ill 744

68. 11. impressifrons.

I1 266

86. S. impressifrons Sol.

\section{9}

III 464

87. H. impressus F. 180 I. II 291

76 '. S.implessus Le C. 1845. JII $7 \div 4$

7. Il. intermalis 01.1789. I1 181

2. Ep. Incas.

II 681

70. 11. incerlıs.

11 269

67'.S. incisus Er. 183 i. III 741

87". 11. incisus Er.1812. II 241

11. S. incognilus.

(I) 289

40. S. incrassatus Fald. 1836.

III 402

23. Ep incullus.

II 703

10. Ilol. Indica Er.1831. 1152

137. II. indislinclus Say. 18:5. II 573
76 ". S. infaustus $\mathrm{I}$, Le C. 1852.

III 745

6. Par infimus.

III 112

1. Hon. inflatus.

Il] 124

12. AJr. iunolatus Le C. 1815 .

86. S.imnulus Er.1834. 111 164

S. insorlus L. Le C. 1851. II] 746

109. $S$ instlaris. Jil 492

119 '. S interceptus L. Le C. $1851 . \quad$ II1 742

12. Ep. intermedius. $\quad 11691$

11. Liod. interrupla. voy. ruplistria. 1214

90. 11. inlcrruptus Pal 1805. 11295

7. S.inlereruptus Pay. 1811. III 362

6. S. interruptus Fisch. $18 \div 3$.

III 360

S, interstitialis $\mathrm{L}$. Le C. 1851.

III 712

4'.S.iulricatus Er. 18\$3. III 742

9. Ep.Italicus layk. 1811. Il 688

22. II. Japonicus.

II 201

123. Il. Javanicus Payk. 1811. 11557

1. Plas. Javanus Er. 1834. 1226

146. S. Javeli. IIJ 709

62'. I1. Jekeli. Supt. V 417

8. Pachyc jucundus. I $\mathbf{4 5 9}$

110. H. Lïrbyi Steph, 1830.

S. Krynichii Kryn.1829. Supt.

100'. 11. Kurdislanus. Supt. V 418

7'. Il. Iabiatus Nols. 1845. Supt.

V 158

2. Om. laceralus. $\quad 1507$

54. S. Lacorlailii. III 421

29. S. lectus. Er. 183i. III 388 
tome pige

8. Plal, leve.

I 263

29'. Plat. levicolle Kust. 1850 I 28 '

23. Om: levigalus Qums. 1806.

6. Tribal. levigalus Payk. 1811.

III 161

24. Omal. laevigatus Er. 1834.

I 531

3. Plas.lavigatus.v. preliosus.

I 228

25. Om. levinolus,

I 532

49. Il. levipes Germ. 1821. II 233

6. Trib. lavissimus L. Le

C. 1852 .

III 161

22. Acr. lacriusculns.

IV $62 \%$

7. H. larvus Rossi. 1790. II 184

1. Macr. Laferlei. I $\mathbf{2 4 3}$

17'. H. Lamecola. Supt. V 411

29. Hol. launina Payk. 1811. I 188 S. laridus L. LeC. 1851. III 747

12. Liod. lata.

1215

3. S. lateral is llig. 1807. III 357

40. S. lateralis Vols, 1819. III $\mathbf{4 0 2}$

21. Acr. lateralis.

IV 621

7. Plat. latisternum.

I 262

36. II. latobins.

II 219

81. S. laulus Er. 1829. III 459

104. S. Leachii Stepl. 1830 . II 530

17. Plat, Leconli.

I 273

129. H. lentulus Er. 1834. II 564

140. H. Ienlus.

11 580

15. S. lepidus.

III 371

7. Ep. levistrius.

11 686

127. II. limbalus Truq. 1852. II 562

20. Plat.lineare Er.183i. 1276

2. H. lissopyga.

I 144

75. H. lissurus.

II 275

52. II. Loandx.

II 236

61. II. longicollis.

II 257
126. S. longislrins.

tome page

24. Ep. longulus II 70 4

46. S. lubricus L.LeC. 1851. III 410

1. Eret. Lucasi. 111144

10. Ep. Hucens. II 689

16. Lip.lucidulus Er.1834. II 695 158'.S. lucidulus I. I.e C. 1851. voy. HII 749

150'. barlsipes. Supl. V $\mathbf{4} 48$

4. Om. Incidıs Er. 1831. I 509

18. IIol. lueida Le C. 1845. I 177

4. Plat, lucilugum. I 259

18. H. lucluosus, $11 \mathbf{1 9 7}$

34. S. lugens Er. 183i. III 395

125. 11. lugubris Truq. 1852. II 560

2\%. II. lunatus Rossi. 1790. Il 20 ?

6. 1I. lutarius Er. 1834. II 183

10. Plat. Luzonicum Er. 1834. 1265

2. S. maculalus Rossi. 1792. III 355

12. Car'c. Madagascariensis, III 99

4. H.majol L. 1735. $\quad 11 \mathbf{1 7 3}$

16. H, major Herlst. 1791, II 195

143. S.mancus Say. 1825. III 706

3. Phyl. mandibulare, I 195

3. Nol. Manillensis. I 145

111. Il. marginatus $\mathrm{Er}, 1834$. II 539 Bac. marginatus 1. Le $\mathrm{C}$. 1853.

IV 576

11. IIol. marginepunctata. 1153

113. Il. marginicollis Le $C$. 1845.

I! 512

150. S. maritimus Sleplens. $1830 . \quad$ III $\mathbf{7 1 4}$

(d) Acr. marilimus L. Le C. 1851.

IV 626

6. Om. Marquisicus. I 512

24. II. Marshami Sleph. 
3. Trib.ulauritanicusLue.

$$
1849 \text {. }
$$

III 157

3ก. 11. Yiulllls.

II 212

1. Ox.marullosusni.1789. I 223

1. 0x, maximus L. 1735 . I 223

1. II. maririlus 01.1789. I] 170

122. S. mediocris.

III 679

13. Il. melanarius Fr. 1834. II 191

35. S. meles Kïst. 1819. III 396

91. II. Hemonius Say. 1825.

1I 297

17. II. Memnouins El'.183亿, II 196

91. Il. merslarius E. II. 1803. II 297

25. Hol. Meridima.

] 184

\$3". s. Mersinæ. suppl.

V 411

125. S. metallescens Er. 1 E3 . lii 686

156. S. metallicus Herbst. 1791.

III 7202

155. S. metallicus E. II. 1803.

III 721

7. Liot. Mexicana.

I 209

96. S. milium.

III 476

4. Trib. minimus fiossi. 1790.

III $15 \mathrm{~S}$

3. Carce ninimus Aulé. 1850.

III 90

8. Aer. minimus subé. 1850.

IV 608

13. Nat minor Rossi. 1792 .

25. Ep. minor le C. 1845. II 705

13. Arril mimuliss Herbst. 1791.

IV 611

12. Acrit, minutus Payk. 1811.

I) 612

14. Lind. minula Er', 1834. 1217

10 i. Ł. minulus I.e C. 1815 , III is6

¡), minulus Ial]r. $18:, 1$. Silp. $\checkmark 165$

3. Bac, miscllts 1., If C.
1853.

II 573

8. Carc.misellus.v.miser. IIl 95

8. Carc.miser. v.misellus. III 95

1'. Trib. mixlus. Sinp'. V 437 110. 5. moleslior. III 493

97. S,modeslus Er, 183í. III \$77

128. H. moer ns El'.1834. II 563

13. Om, monilifer. I 520

2'. Abr. monilis Falı . 1851. IV 593

33'.11.monlamus. supl. V 413

5. Ter. Mozanbieus. JV 138

1. Ep. mundus Er.1834. II 680

3'. PI. Murrayi. Smp. V 403

108'. II. myrmecophilus Mul. 1853. Supl.

V 159

Phel. nanus Le C. 1845. supe.

V 157

3. Par. nassatus Janz. 1792.

III 109

13. 'Грур. nasulus. IV 121

73'. ¿. Nalalensis Fahr, 1851. II 756

4. Acr. Nalchez. IV 60 i

112. II. navis. II 541

104. If. negleclus Germ. 1813. If 530

108. S. neglectus.v. Connori. Ill 491

110. H. nigetlatus Germar.

1824.

40. S.niger Mols.1849. JII 402

13. Ep. nigrellus Say. 1825. II 692

12. Acr. Migricornis E. II. 1803.

IV 612

35. II. nigrimus Fahr. 1851 . II 218

147"'. H. nigrita steph. 1830. II 591

8. H. nigrila Er. 1834. II 186

S. nigrita Blanch. 1850. Supl.

53. II. Niloticus.

II 237

40. S. nitiduhus Payk. 1798. III 402

9. S. nilitus Wied. 1817. HI 36 i 
3. onth, uodatis Le $C$. 1845.

IV 556

33. II. nomas Er. 1834. II 216

7. Ontl. novemeoslatus. IV 563

17. Omı. novis.

I 524

S. obduclus L. Le C. $185 \mathrm{I}$.

III 746

132. H. obesus Fahr. 1851. II 568

142. H.obliquus Say 1825. II 582

(c) $\mathrm{Acr}$. obliquus Le C. 1815. IV 626

2. Plıyll.oblitum.

I 194

19. PIat. oblonģim Payk. 1778.

I 275

20. Plat.oblongum IIg.1798. 1276

8. II. obscura.v. Pizari. I 150 S. obscurus L. LeC. 1851. III 743

3. $\boldsymbol{H}$. obscurus Reiclie. 1851.

II 172

90. I1. oblusatus Harr. 1845. 11295

4. Par. oceanitis.

111110

i. Spliyr, omalodellus.

I 492

1. Om,omega Kirb. 1817.1506

65. S. optabilis.

IIl 438

Carc, opuntia L. Le C. 1851.

HII 100

114. S. orbiculalus.

III 497

36. S. Oregonensis Le $\mathrm{C}$. 1845 .

III 397

14. H.orientalis Payk. 1811. II 193

6. Pleg. Olli.

IV 271

6. S. ornalus Er. 1834.

III 360

12. S. ornatus BI. 1852. III 368

24. S. ovalis. v. advena, III 382

4. Macr. Oras

I 245

44. H. ovatulus.

II 228

1. Plat. ovalum. Er. 1831. I 257

1. Sphar. ovum.

III 164

S. paminosus L. Le C. 1851.

III 7.13

3c Sirie, TOME I.
149. S. palmatus Say. 1825. III 713

50. H. Panamensis.

II $2: 34$

117 ". H. parallelograminus Fald. 1836. Supl.

V 161

9. Par. parallelipipedus Ilbst. 1791.

III 116

24. PIat. parallelum Say. 1825.

1281

$117^{\prime \prime \prime}$.H.parallelus Vutr.1832. Supt

V 162

3. Abr. Paria.

IV 585

10. Par. parvulus Rossî, 1792.

18. Phel. parvulus Er. 1834. 1 486

8. Abr. parvulus Aubé. 1842.

IV 590

136. II.parvus GyII. $\$ 808$. Il 572

85. S. pastoralis Jacr. Buy. 1852.

III 463

53. S. Patagonieus.

III 420

147. S. patruelis Le C. 1845 . 111711

9. Plat. Paugami Le Guil. 1844.

I 264

101. S. paridıs Er. 1834. III 482

7' H. Paykulli Kirby. 1837. II 286 S. pectoralis L. Le $C$. 1851.

III 743

3I'. S. Pecuinus

III 391

63. S. Peusylvanicus Payk. 1811.

III 435

5. S. perinleriuptus.

III 359

1'. HoI.Perraudieri.Supt. V 397

2. S.personatus Fis. 1823. III 355

47. S. personatus Ilg. 1807. III 411

101'. H. Peyroni. Supt. V 420

38. S. Pliarao.

III 399

118. H. Philippinensis. II 547

120. S.piceus Payk. 1809. III 505 76. S. piceus I.e C. 1845 III 745 
101. S. piceus Blanch. 1852. III 482

4. Ter. picipes F. 1792 . IV 136

10. Par. picipes Payk.1798. III 117

9. Par.picipes Stur. 1805. Ill 116

2. Trib. picipes Falı.1851. III $156^{\circ}$

8. Tryp. piclus IV 116

1. Ter. pilimanus. IV 134

8. Ilol. Pizari. vo obscura. 1150

95'. S. placidus Er. 1834. III 739 108'. Supl. V 444

19. Om. planifrons. I 526

1. Psil.planipes J.1. Le C. $1852 . \quad$ I 542

40. S. planiusculus Mols. $1849 . \quad$ III 402

22. Ep. planulus Er'.1834. Il 702

1. IIol, plana Luesly.1775. I 143

10. Liod. plcitysma Er. 1834.

1212

11. Carc. plebejus.

III 98

S. plenus L. Le C. 1815. III 748

3 '. Ont. pluricostatus Le C. 1845.

IV 564

19. Acr. politus L. Le C. 1853 . IV 610

6. Liod.polita. voy. pumicata.

I 208

2. $\boldsymbol{H}$. ponderosus Fahr. 1851.

II 17 I

15. Hol. populnea L. Le C. 1851.

I 157

82. S. posthumus.

III 460

127. S. præcox Er. 1834. III 685

147'.II. præelermissus Peyr. 1856. Supl.

V 424

49. S. prasinus Er. 1834. III 414

3. Plas. preliosus, v. lavigalus.

I 228

21. Trypan. proboscideus $\mathrm{r}$. 1801.

IV 128
119 '. S. procerulus Er.1834. III 737

30. Hol.procera Er. 1834. I 189

7. Par. productus.

III 113

1. Tiyle prolixus. IV 109

64. S. pseudobicolor. III 436

50. S.pscudocyancus White. 1846.

III 416

17. S. pulchellus F. 1798. III 374

47. S. pulcherrimus WeLer. 1801. III 411

25. Ep. purlicarius Er. 1834. II 705

33'. 1I. pullalus Er. 1834. 11244

S. pullus Rosenh, 1847. III 750

14. Om. pulvinatus Er. 1834. I 521

6. Liod. pumicala. v. polita. I 208

4. Car. pumilio Er. 1834. III 91

17. Phel.pumilus Er. 183 f. I 485

33. S. punctatissimus Er. 1834. III 394

1. Dend. punclalus Herbst. 1791

III 148

119. S. punctatus Pk. 1798. III 503 147\%. II. puncticollis Heer.

$$
1841 . \quad \text { II } 591
$$

42'. S. punclicollis Küst.1849. $11 \mathrm{I} 755$

147'. Il. puncticollis Rdt. 1849. Il 590

67. II. punclifer Payk. 1811. II 265

4. Bac. punctiformis $L_{\text {s. }} \mathrm{LCC}$. 1853.

IV 574

10. Om.punclistrins. 1516

111. H. puncliventer. II 543

Teret. punctulatus Fahr. $1851 . \quad$ IV 140

13. Liod, menctulata. v. Bari.

I 216

60. II. puuctulalus Wied. $1817 . \quad$ II 256

1'. Dend, punchulalus Say. 1825. Supe.

V. 435 
1. Het. punclulalus Luc. 1855. Supt.

8. Ac. punctum Aubé. 18 \$2. 1V 607 109. H. purpurascens Ilerbst. 1791. II 536

10. Pleg. pusillus Ros. 1792. IV 278

5. Phel. pusio.

$14: 2$

25. II. pustulosus Géné. 1838. II 206

71. H. putridus Er, 1834. 11270

2. Dend. pyginæus L. 1735. III 150

1. Dendr. pygmaus $\mathrm{F}$. 1775.

III 148

1. Hei. quadratus Kugel. 1794. v. sesquicornis. 111140

6. Tryp. quadricollis. IV 114

9. Liod.quadridentata Er. 1834.

10. Liod, quadridentata F. 1792.

27. Hol. qualriformis.

3. S. quadriguttatus $\mathrm{F}$. 1798.

III 357

24. 11. quadrimaculatus L. 1735.

I1 204

122. H. quadrimaculatus
0l. 1789.
II 556

122. 11, quadrinotatus Scrib. 1790.

11 556

4. Phel, quadripunctulus. I $\mathbf{4 7 1}$

141. S. 4-striatus E. H. 1803 . III 703 $466^{\prime}$. S. quadristriatus Payk. 1798.

111733

12. Try. quadrituberculatus. IV 120

56. H. 1\%-slrialus Gyl.1808. II 218

104. H. quisquilius Stepll. 1830.

1l 530

157. S. radiusus.

III 721
21. S. hasselas. 111379

31. II. reclisternus. $\quad 11213$

48. II. rectirvus. Il 232

9. H. reflexilabris. $\quad \mathbf{1 8 7}$

8. Liorl. Reichii. 1210

24 II. reniformis 01. 1789. II 204 $90^{\prime}$. II. repletus Le C. 18 is. II 310

9. Ep. relusus lllig. 1897. II 688

2. Bac. rliombopliorus Aub. 1813.

IV $5 \pi 1$

26. Plat. rimarium Er, 1834, I 283

15. Liod. rimosa. I 213

3. II. l'obusius Er. 1834. II 172

119. S. rotundatus 11lig. 1798. 111503

20. Phel. Rouzeti Fairm.1849, 1488

27. Ep. I'ubellus Er. 1834. II 707

10. Plicl. l'ubens. 1477

16. S. ruber. III 373

107. S. rubriculus. III 489

133. S. rubripes Er. 183'. III 692

24. Om. ruficlavis. I 53 I

108'. H. ruficornis Grim. 1852. V 159

18. Ep. rufipennis. v. brunnipennis. $\quad 11697$

71. S. rufipes Gyll. 1808. III 445

133. S. rufipes Payk, 1798. III 692

6. Ter. rufulus. IV $\mathbf{1 3 9}$

141. S. rugiceps Duft. 1805. III 703

1. Abr. rugicollis. IV 583

46'. S. rugifer Payk. 1809. III 733

155. S. rugifrons Payk. 1798.111 721

51. S. rugipennis. $\quad 114 \mathbf{4 1 7}$

16. Aer. I'ugulosns. IV 617

11. Liod. ruptistria, v. interrupta.

87. s. I'ussatus.

III 466

19. Ep. Russicus. 11698

95"'.s. rutilus Er. 1834. III 741 
125'. S. sabutrli Rosenlı, 18 亿7. Ily 7 i9

150. S. saluulosus Fair. 1852. III 71 '

I 13. II. Sallei.

II 58 i

7. Pleg. sanalns Truq. 1852. IV 272

13. Plıel. sanguinipennis. I 481

1. Rityp. saprinuides Lr. 1534.

1. Pleg. saucius Er. 183 \% IV 261

5. Pleg. sayi.

IV 269

1. Varg. scalled F. 1787. I 552

11. H. scevola Er. 1831. $\quad 11 \quad 189$

3. Trib. seaphidiformis $\mathrm{Il}$. 1807.

III 157

55. I1. scissifrons.

II $2 ! 0$

S. scissus L. Le C. 1851. III 747

30. Plalys. sculpium Fahr. 1851.

I 285

157. S. scuIplurifer.

III 697

139. Il. scutellaris Er. 1834. II 579

84. II. 16-slrialus Say. 182 . II 28 š

2. Ter segnis.

IV 135

162. S. semianeus Br.1822. 111730

16. 11ol. semicincta.

1159

28. I1. semigranosus.

II 210

12. Par. seminulum Er.183\%. $111 \quad 120$

(a). Acr. seminulum Küst. 1818.

IV 623

5'. II. semiplanı:

11239

20. S. senipunc!alus F.1792. 111377

40. S. semipunctatus Ilbst. 1791.

III 4 ti2

40. S. semistriatus llerbst. 1791.

III 102

S. semistriatus Steph. 1830.

III 735

1. Plac. Senegalensis Payk. 1811.

I 232

119'. 11. Srunerillei. Sup'. V $\mathbf{1 2 2}$

130. II. sepuIchualis Er. 183i, II 565
29. Om. serenus Er. 183\%. I 536

121. S, espripes.

III 677

2'. Pach. Serrulalus L. Le C. 1851.

IV 102

126. Il. seprus Er. 1834. II 561

1. llet. sesquicornis Preysil.

1790.voy. quad̄ratus. J11 140

10. H. severus Falır. 18.51. II 188

2'. Abr. selnlosus Fah, 1851. 10 592

86. 11. sexstriatus l. l.e C.

1851.

I1 290

\section{Dend. Sheppardi Curt.} 1830.

III 150

98. H. Sibiricus. II 305

13. Ino! sinilis.

1155

20. Acr. simplex I. C. $18 \%$. IN 620

15. Acr. simpliculus.

IV $6: 6$

28. (m). sinuaticollis.

I 535

21. II. sinuatus Thunb. 1784 .

Il 203

102. H. simuatus F. 1792 . II 528

120. 11. sinnalus llig. 1798. II 553

101. 11. Smyrneus. 11308

27. Om. solvinus Er. 1834. I 534

11. Platys. sordilum siy. 1825.

I 269

136'. H. sordillus Aubé. 1859. II 577

40. S. sparsipunctatus Mol. 1819.

III $\mathbf{4 0 2}$

139. s. specillum.

III 700

23. S.speciosus Er. 183\%. IIl 381

1:2. S. specularis. III 704

47. S. speculifer Lalr. 1807. III 411

4. A)r. spltericus. IV 586

151. S. spliœroides LeC. 1815 . Iil 719

20. II. spinipes. $11 \quad \mathbf{1 9 9}$

11. Tiyp. spiniger. IV 119

86'.S. Spinol:e Sol, 1819. III 75 i

22. S. splemdens Payk, 1811. 11 1380 
tome page

123. S. sprelulus lir. 183\%. III 682

72. If. spretus Le C. 1845 . II 271

123'. H. squalidus EP. 1834. II 576

117. I1. stercorarius E. II.

$1803 . \quad$ II 546

5. Mac. striatellus. I 246

15. Plat. striutiderum. voy. slrialicolle. I 270

9. IIoI. sl riatidera.

1151

1. Ont. striatus IIerbst. 1791.

IV 55 i

5. Ont. strialus Crentz. 1799.

IV 560

5. Liod. strigicollis.

I 207

70. S. strigil.

III 414

19. Acr. strigosus L. Le C. 1853.

IV 619

87. II. striola Sahlb, 1817 . supt.

21. II. striolatus.

II 200

94. II. Slygicus Le C. 1815. II 301

40. S. subatlenuatus Mots. 1819.

III 402

21. Hol. sublıumilis.

1179

7. Hol. sublucida.

I 149

41. S. sulmilitus.

III 404

3. Cont. subquadratus.

I 518

19. Phel. subrotundus Say. 1825.

I 487

1. Acr, substriatus.

IV 602

38. 11. subsulcalus.

II 221

30 . S. subustus.

III 389

99. s. subricinus.

III 480

67'.3. subvirescens Mlénétr. 1832.

III 736

5. Onth. sulcatus 01.1789. IV 560

1. Ont. sulcalus F. 1 1 92. IV 55 4

I'. Dendr. sulcalus Molsch 18 \{. Supt.

v 166
2. Pach, sulcifrons Mianner.

$$
1813 .
$$

IV 10 I

90. S. Syriacus.

III $\$ 69$

2. Macr, taciturnus.

1214

Bac. lantillus L. Le C.

$$
1853 .
$$

IV 575

6. Carc.tantillus.v.Iristis. III 93

27. S. Tasmanicus. III 386

14. Phel. Teapensis. I 482

7. Carc. tenellus Er. 183i. III 94

6. Acr.tenuis. IV 606

80. S. tenuistrius. III 458

3. Tryp, teres. IV 111

89. H. terricola Germ. 1824. II 294

3. Ep. lersus Er.1834. II 682

63. H. teter Truq. 1852 . II 259

16. $0 \mathrm{~m}$. Texanus. I 523

29', 11. Thibetanus. Supt. V 412

2. Tryp. thoracicus F. 1801 . IV 110

26'. H. thoracicus Payk, 1811. II 243

146. II. torqualus. II 587

46. H. lorridus. II 230

87. $\boldsymbol{H}$. transversalis Duft. 1805. II 291

9. Pleg. transversus Say. 1825.

IV 277

81. S. triangulifer. III 462

118. S. hidens J. Duv, 1852. III 501

6. Carc. trislis. voy, tantillus.

III 93

133. II. tristrialus, $\quad$ II 569

5. Carc. Iroglodytes Payk. 1811.

III 92

34. II. tropicalis.

11 217

41. II. tropicus Payk. 1811. II 225

18. Tryp. tuberculifrous. IV 126

42. II. tumidus Fahr, 1851, II 226

8ก'. ४. Turcicus. sul. \ 138 
40. S. Turcomanicus Mots. $18 \lcm{49}$.

III 402

83'.S. Tyrius. Supt.

$\mathrm{V} \quad \mathbf{4 3 9}$

120. H. uncinatus Illig. 1807.

II 553

2. Spliyr. uncipes.

I 493

105. H. uncostriatus.

II 532

64. IJ, unicolor L, 1735.

II 261

16. Tryp. uniluberculatus. IV 121

40. S. Uralensis Mots. 1849. III 402

5. Plat. Urvillii Le Guil. 18 个.

1260

115. S. vafer.

III 498

2. H. validus Er.1834. II 171 108. H. ventralis. II 535

95". S. venuslus. Er. 1834. III 740

1. Pliel. venustus Le $\mathrm{C}$. 1845.

I 168

11. Plicl, vernus Say. 1825. I 478

19. S. versicolor. III 376

106. S. vescus. III 488

S. vestitus L. Le C. 185̌1. III 7 亿7

116. S. viator. III 499

Jhol. vicina L. L,e C. 1851. I 220

14. Ep, vicinus L. Le C. 185 I. II 693

45'. Il. viduus Fahr. 1851. II 247
36 '. H. vilis Falır. 1851 II 245

S. vinctus L. Le C. 1851. III 746

58. S. violaceipeunis. III 428

S. violaceus Steplı. 1830. III 736

2. Phel, violaceus, voy, violaris.

I 409

2. Phel, violaris. voy, violaceus. I 469

3. Ter, virens. IV 136

67. S. virescens Payk. 1798. IIl 440

9. Carc. vinidicollis. III 96

67. S. viridis Duft. 1805. III 440

1. Pacliyc. virjus. I 452

9. S. viridulus. IJI 468

S. vitiosus L. Le C. 1851. III 748

4. Tryp. volvulus Er. 1834. IV 112

2. Pleg. vilneratus lanz. 1792.

IV 265

1. Pleg. vulneratus Slur. 1805.

IV 264

2. II. Walkeri Rejch. 1851. II 171

17. Ep. Waterhousii. II 696

1. Liod. Yucaleca. I 203

1. Aul. Zelandicus. $\quad 236$ 


\title{
GATALOGUE
}

DES

\section{TRIBUS, GENRES ET ESPÈCES}

\author{
DE LA FAMILLE DES HISTERIDES.
}

Tribu : HOLOLEP'TIENS.

I1. Phyllomi Er. Jahr. 96, 2, 1834.

1. Corticale F. S. El. I, 91, 38, 1801. Dj. Guyane, Brésil.

2. Oblitum.

Nouv. Gren.

3. Mandibulare.

Guyane.

1. Hololepta Payk. Mon. 101, 1811.

1. Plana Fuess. Vers. 5, 68. 1775. Dj. Eur. Canc.

1'. Perraudieri. Sup.

Ténériffe.

2. Lissopyga.

Bengale.

3. Manillensis.

Manille.

4. Australica.

Australie.

5. Fossularis (1) \& Say, Phil. v, 47, 2. 1825. Etats-Unis, Equatis ? id. id. 1.

Id.

(I) 5. Hol, bifoveata Dj. 
6. Excisa (1).

7. Sublucida.

8. Pizarri.

Obscura.

9. Striatidera (2).

9’. Baulnyi. Sup.

10. Indica Er. Jahr. 90, 3. 1834. Dj.

11. Marginepunctata $\mathbf{D j}$.

12. Colombiana.

13. Similis.

14. Bidentati.

15. Bractea Er. Jahr. 91, 4. 1834.

Populnea L. Le C. Calif. 39, 3. 1851.

16. Semicincta.

17. Arcifera.

18. Lucida Le C. Mon. 7, 2. 1845.

19. Cubensis Er. Jahır. 93, 8. 1834.

20. Iumilis Payk. Mon. 109, 7. 1811. Dj.

21. Subhumilis.

22. Cayennersis.

23. Aradiformis Er. Jahr. 93, 9. 1834.

24. Attenuata Blanch. d'Orb. 68, 246. 1852 .

25. Meridana.

26. Bogotana (3).

27. Quadriformis Dj.

28. Brevis.

Curta

(1) 6. Lucida Dj.

(2) 9. Hottentota $\mathrm{Dj}$,

(3) 26. Consimilis $\mathrm{D} \mathrm{i}$.
Cap.

Ind. or.

Java.

Nouv.-Gren.

Venez.

Nouv.-Gren.

Venez.

Id.

Californic.

Sénégal.

Id.

Et.-Un.

Cuba. Haïti.

Brésil.

Nexique.

Guyanne.

Guyan. Brés.

Bolivie.

Yucat.

Guatem. Ven.

Brésil.

Nouv.-Gren. 
29. Lamina Payk. Mon. 108. 1811.

Amér.

30. Procera (1) Er. Jahr. 91, 5. 1834́.

Java.

31. Elongata Er. Jahr. 92, 6. 1834.

li.

\section{LIODERMA.}

(Lionola Dj. Déjả employé.)

1. Yucateca.

2. Grandis.

3. Confusa.

4. Cerdo Dj.

5. Strigicollis.

5'. Cacti L. Le C. Calif. 38, 1. 1851. Sup.

6. Pumicata. Polila.

7. Mexicana.

8. Reichei.

9. Devia.
Yucat.

Mexique.

Id.

Guyane.

Mexique.

Californie.

Mexique.

Id.

Guyane.

Guyane. Brés.

4-dentata Er. Jahr. 95, 12. 1834. Dj.

10. 4-dentata (2) F. E. S. I, 74, 11. 1792. Dj. Et.-Un. Hlaïti, N.-Gren. Venez. Guyane, Brés. Bol.

Plalysma Er. Jalır. 95, 111834.

?Surinamensis Herbst, Nat. IV, 51, 24. 1791.

11. Ruptistria.

Cuba.

Interrupta.

12. Lata.

Brésil.

13. Bari (3).

Guyane, Brés.

(1) 30. Subarmata Dj.

(2) 10. Liod. 9 brevicollis.

(3) 13. Lamina Dj. 
menctulata.

14. Minuta Er. Jahr. 96, 13. 1834.

Bresil.

15. Rimosa.

Cuba.

Invisa auctorum species.

Caffra Er. Jahr. 94, 10. 1834.

Cafrerie.

Glabra Fahr. Bohem. Cafr. 1, 556, 608. 1851. Sup.

Id.

Vicina L. Le C. Calif. 38, 2. 1851.

Calif.

Flagellata Kirb. Soc. Lin. XII, 395, 27. 1817.

Australie.

IV. Oxusternus Er. Jahr. 98, 11I. 1834. 1)j.

1. Maximus L. S. N. II, 566, 1. 1735. Guyane, Brés. Bol. Maxillosus Oliv. Ent. I, G. 8, 5, 1. 1789. Dj.

\section{Tribu : TRYPANÉENS.}

XXXV. TrYpaneus Esch. Zool. Atl. I, 10. 1831. Dj. (Bosirichus E. S. El. II, 384, 151. 1801.)

1. Prolixus (1).

Brésil.

2. Thoracicus (2) F. S. El. II, 385, 4. 1801. Id.

3 . Teres. Nouv.-Gren.

4. Volvulus (3) Er. Jahr. 200, 2. 1834. Brésil.

5. Ensifer (4).

Id.

(1) 1. Tryp, clongatus Dj.

(2) 2. Cylindrus Dj.

(3) 4. Decipiens Dj.

(1) 5. Proboscideus Dj. 
6. Quadricollis.

Guat. N.-Gr.

7. Bimaculatus (1) Er. Jahr. 201, 3. 1834. Brésil.

8. Pictus (2).

Guyane.

8'. Breviculus. Sup.

Cayenne.

9. Flavipennis. Mexique.

10. Amabilis Brésil.

? Bipustulatus F. S. El. II, 385, 6. 1801.

11. Spiniger.

12. 4-tuberculatus.

13. Nasutus Dj.

14. Bispinus.

15. Carinirostris.

16. Unituberculatus.

17. Fallax Dj.

18. Tuberculifrons.

19. Bicaudatus.

20. Deyrolii.

N.-Gren.

Id.

Brésil.

Amér. mér.

Guyane.

N.-Gren.

Brésil.

N.-Gren,

Id.

Brésil.

21. Proboscideus (3) F. S. El. II, 385, 5. 1801.

Colombie.

21’ Carthagenus. Sup.

Carthagène.

\section{Tribu : HISTÉRIENS.}

V. Plasius (4) Er. Jahr. 101, IV. 1834.

1. Javanus (5) Er. Jahr. 102, 1.

Java.

(1) 7. Concinnus Dj.

(2) 8. Amabilis Dj.

(3) 21. Pauperculus Dj.

(4) V. Plasius Er. (Platisuona Dj.).

(5) 1. Plirs, Orthogonium $\mathrm{Dj}$. 
2. Ellipticus.

Java.

3. Pretiosus.

Id.

Levigatus.

VI. Pracopes Er. Jahr. 103, V. 1834.

1. Senegalensis Payk. Mon. 13, 5. 1811. Sénég. Guin. Invisa species.

Caffer Er. Jahr. 105, 1. 1834.

Cafr.

VII. Aulacosternus.

1. Zelandicus.

N.-Zél.

2. Edwardsii.

Madag.

VIII. Macrosternus.

1. Lafertei.

2. Taciturnus $\mathrm{Dj}$.

Sénég. Port.

3. Foliaceus Payk. Mon. 106, 3. 1811.

Madag.

4. Ovas.

5. Striatellus.

Sénég.

Madag.

ld.

IX. Platysona Leach. Zool. Misc. III, 76. 181\%. Dj.

1. Ovatum (1) Er. Jahr. 108, 3. 1834. Dj. Java.

2. Abruptum (2) Er. Jahr. 109, 4. 1834. Id.

3. Atratum (3) Er. Jahr. 110, 6 (1834. Coromand,

(1) 1. Platys. planatum Dj.

(2) 2. Cavifrons Dj.

(3) 3. Parallelipipedum $\mathrm{Dj}$. 
3'. Mlurrayi. Sup.

V. Caliabar.

4. Lucifugum.

I. Philip.

5. Urvillii Le Guil. in Rev. Zool, 184', $223,12$.

6. Ilumile Er. Jalır._109, 5. 1834.

Taïli. Varao.

7. Latisternum.

8. Live.

Java.

v. Diem.

9. Paugami Le Guil. Rev. Zool. 1844, 223, 13.

I. Aroë.

9. Cunfucii. Sup.

Id.

10. Luzonicum Er. Jahr. 111, 7. 1834. Dj. I. Philip.

11. Capense Wied. in Germ. Mag. IV, 12\%, Chine. 32. 1821. Cap, Nat.

IIcmingii Sturm, Cat. 62, pl. 1I, f. 11. 1843.

12. Algiricum Luc. Algg. 231, 606. $1849 . \quad$ Algérie.

13. Frontale Payk. Fn. I, 40, 7. 1798. 1)j. Europe.

? Minor Rossi, Hant. I, 13, 21. 1792.

14. Carolinum Payk. Mon. 45, 32. 1811. Dj. Etats-Unis. Sordidum Say Phil. V, 44, 17. 1825.

15. Striaticolle. Manille.

Striatiderum.

16. Depressum F. Mant. 1, 32, 8. 1787. Dj. Europe.

Var. deplanatum Gyll. Fn. I. 85, 13. 1808. Dj.

17. Le Conti.

Etats-Unis.

Depressum Le C. Mon. 10, 2. 1845.

18. Castanipes.

Sénég.

19. Oblongum F, Ent. S. I, $75,13.1792$. Dj. Eur. Elongatum OI. Ent. I, G. S, 16, 18. 1789.

20. Lineare Er. Jahr. 113, 11. 1834. Eur. 
Oblongum Illig.. I'russ. I, 63, 22. 1798.

Angustatum Payk. Mon. 92, 76. 1811.

21. Angustatum Ent. Hefte, I, 102, 25.

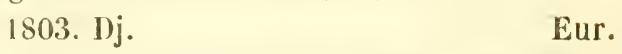

22. Filiforme Er. Jahı. 114, 13, 1834. France mér. Port. Dalmatinum Iï̈st. Kof. XX, 5. 1850. Dalm. Volhyn. 23. Cylindroides. Mexique.

21. Parallelum Say. Phil. V, 42, 15. 1825. Dj. Etats-Unis. 24. Gracile Le C. Mon. 11, 5. 1845, et Sup. Id. Frontale Say Pliil. V, 43, 16. 1825.

25. Coarctatum Le C. Mon. 11, 4. 1845. Id.

Invise auclorm species.

Rimarium Er. Jahr. 112, 9. 1834. Ind. or.

Attenuatum Le C. Mon. 12, 7. 1845. Etats-Unis.

Lavicolle Küst. Kæf. XX, 2. $1850 . \quad$ Sard.

Sculptum Fahr. in Boh. Cafr. I, 554, 605. 1851.

Cafr.

Castaneum Ménét. Cat. 171, 713.1832. Cauc.

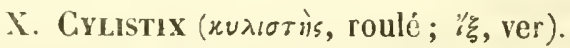
(Cylistus Dej. Déjà employé.)

1. Cylindricus Payk. Mon. 91, 75. 1811. Etats-Unis.

XI. Crptures Er. Jahr. 125, VIII. 1834.

1. Enescens Er. Jahır. 126, 1. 1834. Indoust. 
XII. Pachycraris (1).

1. Viridis.

Hotlent.

2. Chalybæus Fahr. in Boh. Cafr. I, 553, 604. 1851.

Natil.

3. Histeroides.

Sénég.

4. Amethystinus (2),

Guin.

5. Bocandei.

Sénég.

6. Desidiosus Dej.

Id.

7. Cyanescens (3) Er. Jahr. 155, 72. 1834. Sén. Guin. Caf.

8 . Jucundus.

Bissag.

Invisa species.

Cyanipennis Fahr. in Boh. Cafr. I, 586 . 1851.

Cafr.

Xili. Pielister (4).

1. Venustus Dej. Le C. Mon. 56, 6. 1845. Carol. Géorg.

2. Violaris. N.-Gren.

Violaceus.

3. Cumanensis,

Id.

4. 4-punctulus.

Venez.

5. Pusio.

Bahia.

6. Circulifrons.

Sénég.

7. Boviuus.

Venez.

(9) Xli. Paciuycrients (Hister et Platisona Dj.).

(2) 4. Pachyc. Westermanni Dj.

(3) 7. Chalybxum Dj.

(4) Xili. Phelister (Dexdrophilus Dj.). 
8. Acoposternus.

N.-Gren.

9. Hæmorrhoüs.

Ital.??

10. Rubens (1).

N.-Gren.

11. Vernus (2) Say, Phil. V, 40, 11. 1825. Etats-Unis.

12. Lgenus 1)ej.

N.-Gr. Ven.

13. Sanoruinipennis.

1.4. Teapensis.

15. globiformis.

16. Bipulvinatus.

17. Brevistrius.

Guyane.

Mex.

Venez.

N.-Grell.

Brés.

? Pumilus Er. Jahr. 155, 74. 1834.

18. Parvulus Er. Jahr. 156, 75. 1834,

N.-Gren.

19. Subrotundus (3) Say, Phil. V, 39, 10. 1825. Et.-Un. N.-Gren. Venez.

20. Rouzeti Fairm. Soc. Ent. 1849. 421. Bondy près Paris?

\section{Invisa species.}

? Nanus Le C. Mon. 31. 29. 1845.

Et-Un.

XIV. Sphyracus.

1. Omalod lius.

Venez.

2. Uıcipes.

Boliv.

\section{RHypochares.}

1. Saprinoides Er. Jahr. 146, 48. 1834. Cap.

(1) 10. Phel. parvulus Dj.

(2) 11. Pedicularius Dj.

(3) 19. Cranarius Dj. 
XVI. Onalones Dej. Er. Jahr. 114. VII. 1834.

1. Omega (1) Kirby Cent. 20, 26. 1817. Brés. ? Borealis Le C. Mon. 14, 1. 1845. N.-Orl.

2. Laceratus.

Brés.

3. Angulatus F. S. El. I, 85, 8. 1801 Guyane, Brés.

4. Lucidus Er. Jahr. 120, 4. 1834. Brés.

5. Bifoveolatus. Guyane.

6. Marquisicus. I. Marquises.

7. Brasilianus. Brésil.

8. Exul. Guyane.

9. Faustus (2) Er. Jahr. 124, 10. 1834. Guyan. Brés.

10. Punctistrius.

11. Fovcola Er. Jahr. 120, 5. 1834. Guyan. Brés.

12. Conicicollis.

13. Monilifer.

Id.

Niexique.

14. Pulvinatus (3) Er. Jahr. 123, 9. $1834 . \quad$ Guyan. Brés.

15. Grossus.

Mex.

16. Texanus.

Texas.

17. Novus.

18. Haïlianus.

N.-Gren.

19. Planifrons.

20. Consanguineus.

21. Extorris.

Haïti.

Brés.

N.-Gren.

Guyane.

22. Ebenninus (4) Er. Jabr. 118, 2. 1834. Chili, Montev.

Tuc.

(1) Dejean confoud avec Omal. omega, angulatus, foveola, lucidus et lævigatus, sous le nom de Schönherri, lævigatus et lævinotus.

(2) 9. Cayeunensis Dj.

(3) 14. Cognatus Dj.

(4) 22. Aterrimus Dj.

3e Série, томг V. 
23. Lævigatus Quens. in Sch. Syn. I, 90, 15. Haïti.

24. Ruficiavis. Mex. Cuba, Haïti.

Levigatus Er. Jahr. 121, 6. 1834.

25. Lavinotus.

Guadel.

26. Anthracinus. N.-Gren. Ven.

27. Sobrinus (1) Er. Jahır. 122, 7. 1834.

28. Sinuatocollis.

29. Serenus Er. Jahr. 123, 8. 1834.

30. Depressisternus. Mex.N.-Gren. Ven. Boliv. Brés. Guyane, Brés. Guyane.

XVII. Isiloscelis.

1. IIarrisii Le C. Mon. 14, 2. 1845. Planipes L. Le C. Classif. 1852, 39.

Pensylv.

\section{Contipus.}

1. Didymostrius.

Sénég.

2. Digitatus Dej. Id.

3. Subquadratus. Yucat.

\section{XiX. Margarinotus.}

1. Scaber F. Mant. I, 32, 3. 1787. Port. Esp. Alg. XX. Hister L. S. N. II. 1735.

* Costatus Le C. Phil. 1854, 37. Calif.

(1) 27. Mexicanus Dj。 
ler Groupe.

1. Gigas Payk. Mon. 9, 1. 1811. 1)j. Sénég.

Maximus Ol, Ent. I, gre 8, 5, 2. 1809.

2. Validus Er. Jahr. 130, 2. 1834. Cafr. Sénég. Sennaar. Walkeri Reiche, Abyss. 298, 1. 1851.

Ponderosus Falır. in Boh. Cafr. I, 529, 573.1851.

3. Robustus Er. Jahr. 130, 3. 1834. Cap. Cafr. Abyss.

Obscums Reiche, Abyss. 300, 2.1851.

Gravis Fahr. in Boh. Cafr. 1, 532, 575.

1851.

4. Major L. S. N. II, 566, 2. 1735. Dj. Eur. Afr. Syrie.

$2^{\text {e Groupe. }}$

5. Bengalensis (1) Wiedm. in Germ. Mag.

IV, 126, 31. 1821 .

Bengale.

Grandis Germ. Spec. 86, 14\%. 1824.

6. Lutarius (2) Er. Jahr. 133, 10. 1834. Ind, or.

7. Inæqualis Ol. Ent. I, 8e gre, 7, 4.1789.

Dej.

Eur. Cauc. Afr. bor.

Levvus Rossi, Fn. I. 28, 63. 1790.

8. Nigrita Dj. Er. Jahr. 131, 7. 1834. Sénég. Guin. Nat. Caffer Fahr. in Boh. Cafr. I, 531, 575. 1851.

9. Reflexilabris.

Malab.

10. Caffer (3) Er. Jahr. 132, 8. 1834.

Cap. Cafr.

(1) 5. Medius Stm. Dej.

(2) 6. Indus, \& Inequidens Ltr. Dej.

(3) 10. Dregei. Dej. 
Severus Fahr. in Boh. Cafr. I, 531, 576. 1851.

11. Scævola Er. Jahr. 134, 12. 1834.

Indoust. Chin.

11'. Assamensis. Sup. Ind. or.

12. Chinensis Quens. in Sch. Syn. I, 88,5 . 1506. Dj.

Chine, Ind. Manil.

13. Melanarius Er. Jahr. 135, 15, 1834. Indoust.

14. Orientalis Payk. Mon. 17, 8. 1811. Dj. Ind. Chine.

15. Elongatulus. Ind. or.

16. Distorsus Illig. Mag. VI. 29, note. 1807. Corom. Major Herbst, Nat. IV, 48, 21. 1791.

17. Memnonius Er. Jahr. 134, 11. 1834. Abyss. Nub.

17'. Lamacola. Sup.

18. Luctuosus Dj. Ind. or.

19. Baconi. Nubie.

20. Spinipes. Ind. bor.

21. Striolatus Dj.

22. Japonicus. Sénég. Id.

23. Gagatiuus Reiche, Abyss. 301, 3. 1851. Abyss.

24. 4-maculatus L. S. N. II, 567, 6. 1735. Eur. Alg. Syr. Reniformis Ol. Ent. I, Se g. 10, S. 1789.

Lunatus Rossi, Fu. I, 28, 64. 1790. Dj. Simuatus Herbst, Nat. IV, 43, 18. 1791. Gagates Illig. Mag. VI, 31, 3, 180\%. Marshami Steph. Illustr. III, 144, 1. 1830.

Ethiops Heer, In. Helv. I, 453, 4. 1841.

25. Pustulosus Gené, Acad. Tur. 1838, 61. Sard.

26. Amplicollis Er. in Wagn. Alg. 169. 1840. Algrer. Esp. 
27. Grandicollis Illig. Nag. VI, 30, 2. $180 \%$.

$$
\text { Dej. }
$$

28. Semigranosus.

99. Encaustus.

29'. Thibetanus. Sup.

30. Maurus Dej.

31. Rectisternus.

32. Helluo (1) Truq. Soc. 1852, 61, 1.

33. Nomas Er. Jahr. 13\%, 23. 1834.

33. Montanus. Sup.

34. Tropicalis.

35. Nigrinus (2) Fahr. in Boh. Cafr. I, 533, 578.1851.

36. Latobius.

37. Capicola.

38. Subsulcatus Dej.

39. Abyssinicus.

40. Hottentota Er. Jahr. 136, 17. 1831.

41. Tropicus Payk. 19, 9. 1811.

42. Coprophilus Reich. Abys. 302, 4. 1851. Abys. Cafr. Tumiclus Fahr. in Boh. Cafr. I, 537, 584. 1851.

43. Equatorius.

44. Ovatulus.

45. Cribrurus.

46. Torridus.

46'. Calabaricus. Sup.

1\%. Contemptus.

(1) 32. Nigerrimus $\mathbf{B j}$.

(2) 35. Alratus Dij.
Portug.

Ind. or.

Indoust.

Assam.

Sénég.

Id.

France, Piém. Abyss. Cap. Nat.

Abyss.

Sénég.
Cap. Cafr.

Cap.

Id.

Sénég. Cap.

Abyss.

Ab. Cap. Caf.

Guin. Nub.
Guin. Sénég.

Cap.

Sénég.

Id.

V. Calabar.

Cap. 
48. Recurvus.

Madag.

49. Lævipes (1) Germ. Spec. 87, 148. 1824. Et.-Un. Mex. Brés.

50. Panamensis. Yuc. Panam.

51. Bolivianus.

52. Loandæ.

53. Niloticus.

54. Semiplanus.

55. Scissifrons. Bolivie. Guin. Angol. Abyss. Sénég. Indoust.

Invisce auctorum species.

7’. Labiatus Mots. Mosc. 1845, I, 55. Sup. Kirguises. 11’. Incisus Er. Jahr. 134, 13. 1834. Amér. bor.

12'. Heros Er. Fn. Angol. 226, 42. 1842. Angola. 24'. Cruentus Er. Jahr. 137. 21. 1834. Cafr. 26. Thoracicus Payk. Mon. 20, 11. 1811. Amér. bor. 30’. Ignavus Fahr. in Boh. Cafr. I, 533, 579. 1851. Cafr. 33'. Pullatus Er. Jahr. 138, 24. 1834. Ind. or. 36'. Vilis Fahr. in Boh. Cafr. I, 536, 582. 1851. Cafr. 43’. Guinensis Payk. Mon. 26, 15. 1811. Guin. 45. Viduus Fahr. in Boh. Cafr. 1, 535, 581 . 1851.

Cafr.

3e Groupe.

56. 14-striatus Gyll. Fn. I, 83, 11. 1808. Dej. Sued. Finl. Ras.

(6) 49. Simplirimanus $D j$. 
5\%. Conformis (1) Er. Jahr. 153, 68. 1834. Cap.

58. Confinis Er. Jahr. 154, 69. 1834, Cuba.

59. Geminus Er. Jahr. 154, 70. 1834.

Cap.

59'. Cœlestis. Sup.

Cline.

- ie Groupe.

60. Purnctulatus Wied. Zool. Mag. I, 162,

$$
\text { 8. 1817. Dj. }
$$

Beng. Java.

61. Longicollis.

Nat.

62. Arcuatus Say, Phil. V, 34, 3. 1825.

Et.-Un.

62'. Jekeli. Sup.

Shanghaï.

63. Teter Truq. Soc. 1852, 62, 2.

Suis. Piém.

64. Unicolor L. S. N. Il, 567, 3. 1735. Dej. Eur.

65. Curvatus Er. Jalır. 139, 26. 1834.

Brés.

66. Arabicus.

Arab.

67. Punctifer Payk. Mon. 25, 14. 1811.

68. Impressifrons Dej.

Brés. Bol.

69. Cavifrons.

\%. Incertus.

Guyane.

Et.-Un. Vén.

Et.-Unis.

71. Putridus Er. Jalır. 140, 28. 1834.

Brés.

72. Spretus Le C. Mon. 23, 14. 18

Georg. Louis.

73. Curtatus Le C. Mon. 24, 15. 1845.

Et.-Unis.

74. Depurator (2) Say, Phil. V, 33, 2. 1825. Id.

75. Lissurus.

Brés.

76. Cœnosus (3) Er. Jahr. 140, 30. 1834.

Decisus Le C. Mon. 21, 11. 1845.

Et.Un. Cuba, Haï. Nicar.

77. Brunnipes Er. Jahr. 141, 31. 1834. Mex.

(1) 57. Africanus Stm. Dj.

(2) 74. Anthracinus Dj.

(3) 76. Melanarius Dj. 
78. Hipponensis.

79. Dubius.

so. Duplicatus.

81. Eschscholtzii Dej.

82. Abbreviatus (1) F. S. Ent. 53, 6. 1775. Et.-Un.

83. Bifidus Say, Phil. V, 34, 4. 1825.

84. 16-striatus (2) Say, Phil. V, 36, 6. 1825.
Alg.

Brés. Montev.

Beng.

Sib. Kamsch.

Id.

Id.

\section{Invisa species.}

71'. Paykulli Kirby, Fn. Bor. Amér. 123, 172. 1837.

Amér. bor.

\section{$5^{\ominus}$ Groupe.}

85. Incognitus.

Ind. or.

86. 6-striatus L. Le C. Calif. 39, 1. 1851. Calif. Et.-Un.

87. Cadaverinus Ent. Hefte, I, 34, 2. 1803.

$$
\text { Dej. }
$$

Eur.

Brumeus F. S. Lnt. I, 75, 4. 1775.

Impressus F. S. El. 85, 6. 1801.

Tremsversalis Duft. Fn. I, 214, 8. 1805.

Var. Striola Sahlb. Fn. III, 25, 3. 1817.

s8. Fœdatus Le C. Mon. 20, 9. 1845.

Et.-Un.

89. Terricola Dej. Germ. Spec. 87, 149. 1824.

Suisse, Allem.

90. Interruptus (3) Pal. Beauv. 180. 1805. Et-Un. Obıusatus Harris, Soc. Hartf. no 1.

(1) 82. Striatopunctatus $\mathrm{Dj}$.

(2) 84. Exaratus D).

(3) 90 . Morin Dj. 
91. Merdarius Ent. Heft. I, 39, 3. 1803. Dj. Eur. Et.-Unis, Memenonius Say, Phil. V, 32, 1.1825. Natal.

92. Harrisii (1) Kirby Fn. Bor. Amér. IV,

$$
\text { 124, 173. 183\%. Et.-Ũll. }
$$

93. Distinctus Dej. Er. Jahr. 143, 41. 1834. Suisse, Allem.

94. Stygicus Dej. Le C. Mon. 18, 5. 1845. Et.-Un.

95. Gratiosus Manh. Mosc. 1852, IV, 296,

40.

Mlongol.

96. Binotatus Dej. Er. Jahr. 145, 45. 1834. France mér., Esp. Suisse.

97. Furcipes. Ind. or.?

98. Sibiricus Dej.

Sibér. Daour.

99. Gehini (2).

Sénég.

100. Coracinus Er. Jahr. 146, 47. 1834.

Indoust. 100'. Kurdistanus. Sup.

Kurdistan.

101. Smyrnæus.

Syrie.

101'. Peyroni. Sup.

Id.

\section{Invise anclorum species.}

89'. Bisquinque-striatus Germ. Mag. 1, 120, S. 1813.

Amér.

90'. Repletus Le C. Mon. 19, 7. 1845.

Et-Unis.

91'. Immunis Er. Jahr. 143, 39. 1834.

Amér. bor.

98'. Caliginosus Steph. Ill. III, 152, 21. 1830.

Londres.

(1) 92. Ambiguus Dj.

(2) 99. Gagatinus Dj. 
6e Groupe.

102. Fimetarius Herbst, Nat. IV, 27, 3. 1791.

Dej.

Eur.

Sinuatus F. Ent. S. I, 75, 15. 1792.

!Illigeri Duft. Fn. 1, 213, 6. 1805.

Bipustulatus 01. Ent. I, Se g. 10,9.

1809.

103. Gracus Brul. Mlor. 157, 242. 1829. Dej. Bords de la Méditér.

101. Neglectus Germ. Mag. I, 120, \% 1813. Eur. Alg. Ind. Sibér.

Leachii Steph. IIl. III, 150, 15. 1830.

Quisquilius Steph. III. III, 151, 17. 1830.

105. Uncostriatus.

106. Ignobilis.

Esp. Port.

10\%. Carbonarius Illig. Prus. I, 53, 3. 1798.

Dej.

Eur.

12-striatus F. S. El. I, 85, 5. 1801.

108. Ventralis.

Id.

108'. Ruficornis Grim. Stet. 1852, 221.

Id.

Myrmecophilus Muls. Op. II, 97. 1853.

109. Purpurascens IIerbst, Nat. IV, 42, 17. 1791. Dej.

Eur.

Castanipes Steph Ill. 1II, 152, 20. 1830. Brunneus Herbst, Nat. IV, 35, 10. 1791.

110. Nigellatus Germ. Spec. s8, 150. 1824. France, All.

111. Marginatus Er. Jahr. 1任 43. 1834. Fr. 1ll. Suis. 
112. Narus.

Ind. Syr.

113. Marginicollis Dej. Ie C. Mon. 28, 24. 1845.

N.-Orl.

114. Punctiventer.

Mex.

115. Californicus.

Calif.

116. Bifrons.

Ind. or.

117. Stercorarius Ent. IIeft. I, 57, 11. 1803. Dej.

Eur.

118. Philippinensis.

I. Philip.

Invise auctorum species.

114'. Cognatus Le C. Mon. 28, 23. 1845. 111' Sup.

N.-Orl.

117'. Exaratus Le C. Mon. 29, 25. 1845. Georg. Carol. 117". Parallelogrammus Fald. 212. 1836. Transcauc. 117'”. Parallelus Mntr. Cat. 171, 70\%. 1832. Id. 7e Groupe.

119. Biplagiatus Dej. Le C. Mon. 25, 17. 1845 .

Et. -Un.

119'. Sennevillii. Sup.

Calif.

120. Sinuatus Illig. Prus. 57, 9. 1798. Dej. Eur. Alg. Cauc.

Uncinatus Illig. Mag. VI. 32, 5. 180\%.

IItmeralis Fisch. Ent. I, 205, 3. 1823.

121. Bipunctatus Payk. Mon. 2\%, 10. 1811. Dej.

122. 4-notatus Scrib. Beit. I, 47, 12. 1790. Eur. \{-maculatus Ol. Ent. I, se g. 9.7. 1789. Dej. 
123. Javanicus P'ayk. Mon. 30, 10. 1811. Dej. Corom. Java. 124. Diadema. Guyane, Bol.

125. Lugubris Truq. Soc. 1852, 63, 3. Piém. Nantes.

126. Servus Er. Jahr. 117, 51. 1834. Cuba, IIaïti.

12\%. Limbatus Truq. Soc. 1852, 6-1, 4. Liban. 128. Mœrens Er. Jahr. 150, 5\% 1834. Istrie, Alger. 129. Leutulus (1) Er. Jahr. 149, 55. 1834. Cap. 130. Sepuchralis (2) Er. Jahr. 149, 56. 1831. Hongr. 131. Fossor (3) Er. Jahr. 148, 54. 1834. Dej. Sénég. 132. Obesus Fahr. in Boh. Cafr. I, 537, 583. 1851.

Guin. Cafr.

133. Tristriatus. Cap.

131. Civilis Le C. Mon. 25, 18. 1845. Pensyl. Mass.

135. Funestus Er. Jahr. 151, 58. 1834. France, Autr.

Dalm. Esp.

136. Bissexstriatus (4) F. S. El. I, 84, 4, 1801. Dej. Eur.

Parvus Gyl. Fn. I, 79, 7. 1808.

12-strialus, var b., Ent. Hefte, I, 59. 1803.

137. Indistinctus Say, Phil. V, 35, 5. 1825. El.-Un. 138. Americanus Payk. Mnn. 31, 20. 1811. Dej. Id. Invise auclorum species.

123'. Squalidus Er. Jahr. 148, 53. 1834. Chine.

(1) 129. Caffer Dj.

(2) 130. l'olitus Dhl. Dj.

(3) 131. Ebenimus Dj.

(1) 136. Sermarius Sim, Doj. 
129'. Dispar Le C. Mon. 27, 21. 1845. Géorg. 136'. Sordidus Aubé, Soc. 1850, 322, 30. Espag. 120'. Arcuatus Kol. Melet. V, 60, 262. 1846. Cauc.

(Déjà employé.)

$$
\text { 8e Groupe. }
$$

139. Scutellaris. Er. Jahr. 151, 62. 1834. Dej Sic. Dal. Syr. 140. Lentus. Sénég.

141. Bipustulatus F. Ent. S. Sup. 38, 16-17.

$$
\text { 1798. Dej. Ind. or. }
$$

142. Bimaculatus L. S. N. II, 567, 5. 1735.

Dej. Eur. Alg. Syr. Ind. Amér. bor. Eryehropterus F. Ent. Sup.3S, 16. 1798. Obliquus Say, Phil. V, 37, 7. 1825. Apicalus Schranck, Fn. Boic. 1, 11, 452. 1798.

243. Sallei.

Venez.

144. Goudoti. Madag.

145. 12-striatus Schranck, Enum. 39, 70. 1781. Dej.

Eur. Alg. Syr. Dissextriatus Duft. Fn. I, 215, 9. 1805. 146. Torquatus. Ind. or.

147. Corvinus Germ. Reise, 185, 37, $181 \%$. Dej. Eur.

147'. Prætermissus P. Soc. 727 (1856). Sup. France mér. 148. Aquistrius. Madag.

Invisce auctormm species. 
147"”. Puncticollis Ileer, Fn. Helv. I, 457, 19. $1841 . \quad$ Suisse.

$147, "$, . Nigrita Steph. Ill. III, 149, 12.1830. Londres.

Incerte scdis.

Afer Payk. Mon. 12, 4. $1811 . \quad$ Guin.

Punctatus Sahl. Fn. Fen. 31. 181\%. Finl.

Distans Fsch. Ent. II, 205, 2. 1823. Daurie.

XXI. EpIerus (1) Er. Jahr. 158, XI. 1834.

1. Mundus Er. Jahr. 160, 2. 1834.

2. Incas.

3. Tersus (2) Er. Jahr. 161, 3. 1834.

4. Coproides.

5. Arciger.

6. Hastatus.

7. Levistrius.

8. Bisbistriatus.

9. Reiusus Illig. Mag. VI, 36. 1807. Italicus Payk. Mon. 47, 35. 1811.

10. Lucens.

11. Frater.

12. Intermedius Dej.

13. Nigrellus Say, Phil. V, 38, 8. 1825.

14. Vicinus L. Le C. Calif. 40, 2. 1851.
Guyane, Brés.

Venez.

Brés.

Amér. bor.

N.-Gren.

Id.

Id.

Brés.

Toscane, Syr.

Venez.

Mex. Et.-Un.

Guat.

Et.-Unis.

Calif.

(1) XXI. Epierus Er. (Dendiophious Di.).

(2) 3. Lucidulus Dj. 
15. Alutaceus.

N.-Gren.

16. Lucidulus (1)Er. Jahr. 161, 4. 1834. Mex. Nicar. N.-Gr. Venez. Brés.

17. Waterhousii. Haïti.

1S. Rufipennis. N.-Gren. Brumipennis.

19. Russicus. Géorg.

20. Comptus (2) Illig. Mag. VI, 36, note. 1807.

Autr.

21. Antillarum.

Cuba, Porto-Rico, Haili.

22. Planulus Er. Jahr. 162, 8. 1831. Calif. Mex. Venez. Decipiens L. Le C. Calif. 40, 1. 1851.

23. Incultus.

Mex.

24. Longulus. Yucat.

25. Pulicarius Er. Jahr. 162, 5. 1834. Dej. Et.-Un. Minor Le C. Mon. 33, 2. 1845.

26. Fulvicornis F. S. El. I, 90, 35. 1801. N.-Gren.

2\%. Rubellus Er. Jahr. 163, 9. $1834 . \quad$ N.-Gr. Brés.

\section{Carcinops (3).}

1. Consors L. Le C. Calif. 40, 2. 1851. Calif. Mex.

2. Conjunctus (4) Say, Phil. V, 38, 8. 1825. Et.-Un. Ven.

3. Minimus Dej. Aubé, Soc. 1850.322, 31. Eur. Alg.

4. Pumilio Er. Jahr. 169, 1. 1834. Fr. Esp. Alg. Egypte, Et.-Unis.

(1) 16. Similis et Ellipticus Dj.

(2) 20 . Italicus $\mathrm{Dj}$.

(3) XXII. Carcinors (Dendrophiluts Dj.).

(4) 2. Nanus Dj. 
5. Troglodyles (1) Payk. Mon. 46, 34.

1S11. Dej.

6. Tristis.

Taurillus.

7. Tenellus Er. Jahr. 170,3. 183亿. Calif. N.-Gren. Ven. Gilensis L. Le C. Calif. 40, 3. 1851.

8. Miser.

Misellus Dej.

9. Viridicollis.

10. Dominicanus.

11. Plebejus Dej.

12. Madagascariensis.
Cuba, Haïti, N.-Gren. Ind.

Venez.
Guatem.

Mex.

Haïti.

Cap.

Madag.

Invise auctorum species.

Opuntia L. Le C. Calif. 40, 1. 1851. Calif. 11'. Delicatulus Falır. in Boh. Cafr. I, 550, 601. 1851. Sup.

Corticalis L. Le C. Calif. 32, 2. 1851 . Sup.

Cafr.

Colorado.

XXII. Panomalus Er. Jahr. 167, xiv. 1834.

1. Affinis Le C. Mon. 37, 2. 1845.

Et.-Unis.

2. Equalis Say, Phil. V, 44, 18. 1825.

Id.

3. Complanatus Illig. Prus. I, 64, 24. 1799.

Dej.

Eur.

Nassalns Panz. Fu. Germ. 67, 8.

4. Oceanitis (2).

Manille.

(1) 5. Tantillus Dj.

(2) 4. Par, micros Dj. 
5. Didymus.

Venez.

6. Infimus Dej:

id.

7. Produclus.

Cuba, N.-Gr.

8. Bistriatus Er. Jahr. 171, 7. 183-́.

Et.-Un. Mex.

9. Parallelipipedus Ilerlist, Nat. IV, 37, 11. 1791.

Eur.

Picipes Sturm. Fn. I, 247, 30, 1805.

10. Flavicornis IIerbst, Nat. IV, 40, 13. 1791. Dej. Id.

Picipes Payk. Fn. I, 52, 21. 1798.

Parvulus Rossi, Mant. I, 14, 25. 1792.

11. Convexus.

Venez.

12. Seminulum Er. Jahr. 171, 8. 1834. Et.-Un. Mex

\section{Invisu species.}

Exiguus Fahr. in Boh. Cafr. I. 552, 603. 1851.

Nat.

XXIV. Monoplits Dej.

1. Inllatus (1).

Cap.

XxiV bis. Coelocrara. Sup.

1. Costifera Sup.

V. Calabar.

(2) 1. Mon, obesus Dj.

ze Série, TOME r. 
XXY. Pelondres ( $\pi \varepsilon \lambda$ cop, monstrueux; oupa, queue). (Pelorus.)

1. Bruchoides.

Sénég.

XXVI. SCAPOUEGaS.

1. Auritus.

Guyane.

2. Gibbus.

Brésil.

xxVII. Notonona.

1. Globatum.

Indoust.

XXX. Dexdropmuts Leach. Zool. Misc. III, 76. 1817. Dej.

1'. P'unctulatus Say, Phil. V, 45, 19. 1825. Sup. Pensyl.

1. Punclatus Herbst, Nal. IV $41,16.1791$.

Dej. Eur.

Abbrevialus Rossi, Fn. Etr. I, 30, 69. 1790.

Pygmaens F. S. Ent. I, 53, 5. 1775. Corticalis Payk. Fn. 150, 19.1798.

2. Pygmaus L. S. N. II, 567, 4. 1735. Dej. Eur. Formicelorum Aubć, Soc. 1833. 95. 
Sheppardi Curt. Brit. Ent. 11I,131.1830.

Cooperi Steph. III. III, 159. 2. 1830. !

Invisee species.

Minutus Fahr. in Boh. Cafr. I, 551, 602. 1851. Sup.

Cafr。

1'. Sulcatus Mots. Mosc. 1845, I, 55, 149.

Sup.

Mingrélie.

XXXI. Trimalus (1) Er. Jahr. 164, xir. 1834.

A.

1. Agrestis.

1'. Mixtus. Sup.

2. Capensis Payk. Mon. 80, 53. 1811.

Picipes Falur. in Boh. Cafr I. 545. 595. 1851.

3. Scaphidiformis Illig. Nag. VI, 47, 24.<smiles></smiles>

Manritanicus Luc. Alg. 230, 603. 1849.

4. Minimus (2) Rossi, Fu. I, 30,71. 1791. Tosc. Dalmat. Suisse.

(1) XXXi Tribalus Er. (ABReus Dj.).

(2) 4. Trib. nitens Dj.
Sénég.

Cap b. Esp.

Cap. Cafr.

Port. Alg. 
B. Conrosternus 1. Le C. Classif. Phil. 1852, 39.

5. Americanus (1) Le C. Mon. 34, 1. 1845. Et-Unis.

6. L.rigatus (2) Payk. Mon. 84. 68. 1811. E.-Un. Yucat.

N.-Gren. Venez. Cuba, Haïti.

L.xerissimus L. I.e C.C.Cassif.40, 2. 1852.

\section{Spherosona.}

1. Ovum.

Madag.

Tribu : HÉTÉRIENS.

XXVIII. Нет,eru's Dej. Er. Jahr. 156, x. 1834.

1. Cavisternus.

Alg.

Punctulatus Luc. Soc. 1855. 3' Sup.

2. Brunnipennis. Sup.

Et.-Unis.

3. Sesquicornis Preysst. Mayer. Saml. Aufs. 3. 1792.

Eur.

Quadratus Kugel. in Schneid. Mag. IV, 519, 21. 1794. Dej.

Ferrugineus Ol. Ent. I, Se g. 19, 24 1789.

(1) 5. Erythrocerus Dj.

(2) 6. Orbiculatus J)j. 


\section{X.XIX. ËeThotes.}

1. Lucosi.

Ager.

\section{'Tribu: SAPRINIENS}

XXX1ll. SAPRINUS Er. Jahr. 172, 15. 1834.

1er Groupe.

1. Cruciatus 1F. Ent. S. I, 75, 16. 1792.

Dej.

Alg. Trip. Mar. Seneg.

2. Maculatus (1) Rossi, Mant. I, 12, 20.

1792.

Médit. Cauc. Sibér.

Personatus Fisch. Ent. 1, 206, 5. 1823.

3. 4-guttatus F. Ent. Sup. 39. 18-19.1798. Indoust.

Yar. Laterulis Illig. Mag. VI, 36, note.

1407.

4. Equestris Lr. Beitr. Angol. 226, 43.

1813.

5. Perinterruptus.

6. Ornatus Er. Jahr. 176, 4. 1834 . Interruptus Fiscl. Ent. 1, 20\%, \%. 1823. Egypt Alg.

7. Interruptus Payk. Mon. 50, 37. 1811.

$$
\text { Dej. }
$$

1) 2. Sap. cruciatus (15. Dj.
Angol. I. Cap-Vert.

Sén. Id.

Rus.m. Arah.

Ind. or. 
8. Erichsonii (1).

Madag.

9. Nitidus Wiedm. Zool. Mag. II, 1, 29, 40. $181 \%$. Cap. Cafr.

?Amoenulus Fahr. in Boh. Cafr. I, 544. $593.185 \%$ ?

10. Externus Fisch. Ent. I, 207, 9. 1823. Dej. Rus. Tart. Syr., Perse.

11. Biguttatus Stev. Mem. Mosc. I, 159. 1806. Dej.

12. Blanchardi. Russ. m. Turcom. Ornatus Blanch. in d'Orbigny, 1852?

13. Bisignatus Er. Jahr. 17\%, 10. 1834. Dej. Bol. Chili, Tucum.

14. Decoratus Er. Jahr. 176, 9. 1834. Pérou, Bol. Chili.

15. Lepidus Dej. La Plata, 'Tucum.

16. Ruber. Tripol.

17. Pulchellus F. Ent. Sup. 38, 16. 1798. Tranquebar.

Invise spccies.

6. Flexuoso punctatus Mots. Mosc. 1845 , I, 55. Sup. Astrabad.

13'. Crenatipes Sol. in Gay, Chili, 379, 3. 1849.

Chili.

2e Groupe.

18. Discoidalis L. Le C. Calif. V, 43, 6.1851. Calif.

(1) 8. Kingii Dup. Dj. 
19. Versicolor.

Cap.

20. Semipunctatus F. Ent. S. I, 73, 4. 1792.

Dej.

Médit. Sénég. Cilp.

Cyomeus IIerhst, Nat. IV, 50, 22. 1791.

Corulescens Ent. IIefte, 173, 14. 1803.

21. Riasselas.

Abyss.

22. Splendens (1) Payk. Mon. 53, 39. 1811. Guinće, Cap,

Cafr.

23. Speciosus (2) Er. Jahr. 179, 16. 1834. Ind. or.

24. Ovalis (corr. atvena dans les planches). Ind. or. Chin. 25. Elegans (2) Payk. Mon. 57, 42. 1811. Sén. Abys. Cap. 26. Cyaneus (3) F. S. Ent. 52, 3. 1775. Austr. V. Diém. 2\%. Tasmanicus (4).

Tasman. Austral.

28. Cyanellus. Austral.

29. Lætus Er. Jahr. 179, 15. 1834. Austral. Tasinan. Cyaneus Payk. Mon. 56, 41. 1811. Dej.

30. Subustus.

Ind. or.

31. Auricollis.

I. Philip.

31'. Pecuinus.

Chine.

32. Fulgidicollis.

Madag.

33. Punctatissimus Er. Jahr. 181, 19. 1834.

Dej.

Egypte.

34. Lugens Er. Jahr. 181, 20. 1834.

Califor. Orég. Californicus Dej. Manh. Mose. II, 259. 185. 1843.

Mex. Guat.

(1) 22. Capicola Dj.

(2) 23-25. Splendens Di.

(3) 26. Speciosus DJ.

(4) 27. Australis Di. 
35. Detersus (1) Illig. Mag. VI, 36, 11.

1807. Médit. Esp. Port. Sicil. Grèc. Alg. Sénég. Detrilus Rossi, Fn. I, 29, 67. 1790.

Melas Kust. XVII, 19. 1849.

36. Oregonensis Le C. Mon. 45, 11. 1845. Orég. Calif.

37. Gangeticus. Ind. Syr.

38. Pharno. Egyp. Syr.

39. Concinuus Mots. Mosc. 1849, III, 96, 5. Rus. m. Cauc. Sibér.

40. Nitidulus Payk. Fn. 1, 45, 12. 1798.

Dej. Eur. Afr. b. Sibér. Syr. Ind. or. Semipunctatus et Semistriatus Herbst, Nat. IV, 306. 1791. Acuminatus F. Ent. Sup. 37, 4-5. 1798. Incrassalus Fald. Transc. I, 211, 1836. Niger 1lots. Mosc. 1849, III, 95, 1. Tarcomanicus Mots. Mosc. id. 2. Subattenualus id id. 3. Latcralis id. jd. 4. Planiusculus id. $97,5$. Sparsipunclatus id. id. 6. L'ralensis id. 98,9 . Tripartitus id. id. 10.

41. Subnilidus. Europe.

42. Algericus Payk. Mon.60, 44.1811. Dej. Esp. Portug. Sard. Alg.

13. Furvas (2) Er. Jahr. 180, 18, 1834. Fr. m. Espar. Portug. Grèce, Alger, Trip. Egypte.

(1) ว่อ. Intricatus I,\{1. 1) j.

(2) 4ir. Massiliensis Di, 
44. Immundus (1) Gyl. Fn. IV, 266, 17-18. 1827.

Eur. b. Cauc.

Invise anclorum species.

18'. Alienus L. Le C. Calif. V, $4^{\circ}, 43,7$. 1851.

Calif.

36'. Imperfectus Le C. Mon. 42, 2. 1845. Pensylv.

40'. Godet Brul. Mor. 157, 246. $1822 . \quad$ Morée.

42’. Puncticollis Küst. XVII, 30. 1849. Sard. Esp.

3e Groupe.

45. Figuratus.

Alg. Tun. Syr.

46. Lubricus L. Le C. Calif. V, 40 $45,20$. 1851.

Calif.

47. Speculifer Latr. Gen. II, 48, 2. $180 \%$.

Dej.

Eur. Afr. b. Syr.

Pulcherrimus Web. Obs. 37, 1. 1801.

Personutus Illig. Mag. VI. 39, 13. 1807.

48. Aneus F. S. Ent. 53, 9. 1775. Dej. Eur. Syr.

49. Prasinus Er. Jahr. 182, 25. 1834. Syr. Ital.

50. Pseudocyaneus White, N.-Zel.95. 1846. N.-Zél.

51. Rugipennis.

Amér.

52. Diptychus.

Yucat.

53. Patagonicus.

Patag. Boliv.

54. Lacordairei Dej.

Bol. Tuc. Patag.

(1) 4\%. Cancasicus Dj. 
55. Azurescens (1).

N.-Gren. Venez. Brés.

56. Aneicollis.

Nex.

57. Azureus Sahlb. Peric. IV, 2. 1823. Dej. Brés.

58. Violaceipennis.

N.-Gr. Ven.

59. Bonariensis Dej.

Montevid. B.-Ayr.

60. Assimilis Payk. Mon. 63, 47.1811. Dej. Amér. b.

Extraneus Illig. Mag. VI, 36, note. 1807.

61. Connectens Payk. Mon. 35, 25. 1811. Dej.

Brés. Mlontev.

62. Erythropterus (2) Payk. Mon. 73, 5\%. 1811.

Brés. Bol. Patag.

63. Pensylvanicus Payk. Mon. 62, 46. 1811.

Dej.

64. Pseudobicolor.

65. Optabilis.

66. Bicolor OI. Ent. I, se g., 13, 13. 1789.

Dej.

67. Virescens Payk. Fu. I, 48, 16. 1798.

Dej.

Viridis Duft. Fn. I, 224, 20. 1805.

? Geminus Duft. Fn. I, 224, 21. 1805.

68. Distinguendus.

69. Cribellatus Dej.

70. Stricril.

7). Chalcites (3) Illig Mag. VI, 40, 15. $180 \%$.

(1) 55. Bonariensis $10 \mathrm{j}$.

(2) 62. Caralistrius, confondu avec VErythropterus.

(3) 7I. Alliuis et Ruficornis Dj.
Et-Unis.

Cap.

Ind. or.

Cap, Nat. Arab.

Eur. Cauc.

Et.-Unis.

Rus. m.

Abyss.

Eur. Asie, Alr. 
Affinis Payk. Mon. 76. 59. 1811. Dej.

Rufipes Gyll. Fn. I, 90, 19. 1808.

72. Arcolatus Fahr. in Boh. Cafr. I, 542,

$$
\text { 591. } 1851 \text { Nit. }
$$

73. Cupreus Er. Jahr. 182, 27. 1834. Cafr. Cap, Benguel.

74. Brunnivestis.

74 . Frontistrius.

Sénég.

75. Caralieri.

Chili.

76. Guyanensis Dej.

Cuba.

7\%. Blissonii.

78. Egyptiacus.

79. Gilvicornis Er. Jahr. 184, 29. 1834

Cuba, Cuyan. Brés.

Venez.

Esypite.

80. Tenuistrius.

Id.

80'. Turcicus. Sup.

Id.

81. Lautus Er. Fn. I, 675, 7. 1839.

Turquie.

82. Posthumus.

Fr. Allem.

83. Blauchii.

83'. Tyrius. Sup.

Et.-Unis.

Syr. Egyp.

Syrie.

83". Mersina. Sup.

84. Triangulifer.

Id.

Yucat.

85. Pastoralis J. Duv. Soc. 1852, 704 .

France in.

86. Iunubus Er. Jahr. 186, 37. 1834.

Brés. Chili.

! Impressifrons Sol. in Gay, Chili, 379, 4. 1849 .

8\%. Russatus.

88. Cubrecola.

Egypte.

Cuba.

88'. Desertorum Le C. 1851. Sup.

Mts-Rocheux.

89. Viridulus.

Indoust.

90. Syriacus.

Syrie.

91. Canalistrius.

Guyane?

92. Erythropleurus.

N. 
93. Hypocrita Dej.

94. Campechianus.

95. Bliudus (1) Er. Jahr. 188, 40. 1834.

96. Milium.

97. Modestus Er. Juhr. 187, 38. 1834.
98. Fulvopterus.

99. Subvicinus.

100. Granatensis (2).

101. Pavidus (3), Er. Jahr. 187, 39. 1834. Brés.

Piceus Blanch. in d'Orb. Voy, 1852?

102. Atronitidus Blanch. in d'Orb.

103. Conformis (4) Le C. MIon. 42, 6. 1845. Amer. b.

104. Minutus (5) Le C. Mon. 43, 8. 1845. Et.-Unis.

105. Arrogans.

106. Vescus.

107. Rubriculus.

108. Connori

Neglectus. Brés. Boliv. Mlonter. Patag.

Brés.

N.-Gren.

N.-Gren.

Texas.

Amér. ?

Amér. b.
Brésil.

Campêche.

N.-Gr. Brés.

N.-Gren.

Brès. Urug.

108'. Placilus Er. Jahr. 189, 41. 1834. Sup. Et.-Unis.

109. Insularis.

Guadel.

110. Modestior.

Brésil.

Amér. b.

111. Convexinsculus (6).

112. Fimbriatus L. Le C. Calif. V, 47, 17. 1851.

Amer. b. Calit.

(1) 95. Lebasii $\mathrm{Dj}$.

(2) 100. Viciulis IJj.

(3) 101. Difficilis 0j.

(4) 103. Splhæroides Dj.

Confondu arec les Vedincris, Spretulus, Apricarius el Blancbii.

(a) 10\%. Pitruelis $1 \mathrm{j}$.

(6) 111. Convexus Dj. 
113. Ignotus.

11'. Orbiculatus.

115. Vafer.

116. Viator.

117. Chiliensis.

118. Tridens J. Duv. Soc. 1852, 704.
Mex. N.-Gr.

Et-Lnis.

Vera-Cruz.

Cuba.

Chili.

France.

Invisce auctorum species.

44'. Inlricatus. Er. Fn. Angol. 226, 44. 1843.

Angola.

46". Rugifer Payk. Act. Holm. 1809. 230. Suèd. Allem. 4-striatus Payk. Fn. I, 45, 13. 1798.

47'. Bipartitus Mots. Mosc. 1849, $98 . \quad$ N.-Gren.

57'. Aterrimus Er. Jahr. 185, 35. 1834. Brés.

67'. Subvirescens Ménét. Cat. 171, 710.

67'. Incisus Er. Fn. V.-Diem. 152. 1842. V.-Diem. 1832.

Cauc.

73'. Eratus Er. Jahr. 183, 28. 1834.

Buchara.

73". Natalensis Fahr. in Boh. Cafr. 1, 5 i3, 592. 1851 .

Natal.

73"'. Breviusculus Fahr. in Boh. Cafr. I, 545, 594. 1851.

Calr.

76'. Impressus I. Le C. Mon. 4ł, 9. 1845. Géolg. 76". Infaustus L. Le C. Class. 1852, 41. El.-Unis.

Picens Le C. Mon. 43, 7. 1845.

86'. Spinolæ Sol. in Gay, Chili, 18 17, 379, 3. Chili.

95’. Venustus Er. Jahr. 189, 42. 1834. Brés.

95”. Rutilus Er. Jahr. 190, 43. 1834. Egypte.

1843.

Arigol.

Obscurus L. I.e C. Calif. V, 40, 42, 2. 1851 .

Cialiforn. 
Pecturalis L. Le C. Calif. V, 40, 42, 3. 1851.

Californ.

Pæminosus L. Le C. Calif. V, 40, 42, 4. 1851.

ld.

Insertus Le C. Calif. V, 40, 43, 10. 1851. Id.

Obductus

id. 44,11. id. Id.

Giliatus

iú. 12. id. Id.

Vinctus

id. 13. id. Id.

Laridus

id. 44,14. id. Id.

Scissus

id.

15. id. Id.

Vestitus

id.

16. id. Id.

Plenus

Vitiosus

Cœrulescens

id.

id.

45, 18. id. Id.

id.

19. id. Id.

21. id. Id.

4c Groupe.

119. Rotundatus (1) Illig. Prus. I, 61, 16. 1799.

Eur.

Punctalus Payk. Fn. 1, 49, 17. 1798.

Var. Conjugatus Illig. Mag. VI, 42, 19.

$180 \%$.

Deletus Le C. Mon. 44, 11. 1845.

120. Piceus Payk. Act. Holm. 1809, 23, 1. Eur.

Invisa species.

119'. Procerulus Er. Jahr. 175, 2. 1831. Egyple.

(1) 119. Dendr. rotuudatus Dj. 
119”. Interceptus I. I.e C. Calif. V, 40, 42, 5. 1851 .

Cúlif.

5e Groupe.

121. Serripes.

12.2. Mediocris.

123. Fulvipes.

124. Amœenus (1) Er. Jahr. 190, 46. 1834.

125. Spretulus Er. Jahr. 192, 49. 1834. 126. Longistrius.

127. Præcox Er. Jahr, 193, 52. 1834.

127'. Fugax. Sup.

128. Metallescens (2) Er. Jahr. 192, 50.1834.

129. Amulus Illig. Mag. VI, 42, 18. 1807.

130. Corsicus.

131. Herbeus (3).

132. Arenarius Dej.

132'. Boudista. Sup.

133. Rufipes (4) Payk. Fn. I, 50, 18. 1798. Eur. Alg. Sén. Rubripes Er. Jahr. 191, 51. 1834.

134. Granarius Er. Jahr. 191, 48. 1834. Fr.m.

(1) 124. Ereus Dj.

(2) 128. Sardeus Dj.

(3) 131. Virens Dj.

(4) Dejean confond Fulvipes et Longistrius avec Rufipes.
Fr. Sic. 'Turq.

France $\mathrm{m}$.

Espagne.

Esp. Por. Aut.

Russie.

Port. Alg. Mar.

Autr.

Egypte.

Ind. or.

Sar.

Alg. Syrie.

Col'se.

Autr.

Id.

Ind. or. 
135. Conjungens l'ayk. Fu. I, 14, 11. 1798. Dij.

Eur. Afr. b.

10-striutus liossi, Mant. I, 13, 22. 1792.

136. Buqueti Dej.

13\%. Sculpturifer.

Sénég. Cap.

138. Elegantulus.

Indoust.

139. Specillum

Cap.

Id.

Invisa auclorum species.

125'. Sabuleti Rosenh. Beit. I, 1847.

Allem.

133'. Antiquulus Illig. Mag. VI, 43, note. $180 \%$.

Pullus Rosenh. Beit. I, 20. 1847.

Autr.

Curtus Rosenh. Beit. I, $3^{\circ} .1847$.

Allem.

Hongrie.

(je Groupe.

140. Fraternus (1) Say, Phil. V, 40, 12.1825. Et.-Unis.

141. 4-striatus Ent. Hefte, I, 85, 19. 1803.

Dej.

Eur. Cauc.

!Dctritus Rossi. Fn. 1, 29, 87. 1790.

Var. Rugiceps Duft. Fn. I, 225, 22. 1805.

142. Specularis (2).

Allem. Turq.

143. Mancus Say, Phil. V, 41, 13. 1825. Et.-Unis.

144. Bigemmeus L. Le C. Calif. V, 46, 22. 1851.

Caiif.

(1) 140. Aciculatus Dj.

(2) 142. 4-Striatus $\mathrm{Dj}$. 
1 1 亿o. Consputus.

146. Javeti.

147. Patruelis Le C. Mon. 16, 11. 1845.

14.8. Ferrugineus.

149. Dimidiatipennis Le C. Lyc. N. I. I. Dej. Et.-Unis. Palmalus Say, Phil. V, 42, 14. 1825.

150. Sabulosus Dej. Fairm. Soc. 1852,688. 3. Anglet. Belg.

? Marilimus Steph. Illust. III, 155, 27. 1830.

150'. Barbipes.

Lucidulus L. Le C. Calif. I, 4, 4르, 1. 1851. Sup.

151. Deserticoli. Sup. Fr. Port.

Calif.

Mex.

Amér. b.

Id.

Texas.

Desertorum (confondu avec celui de Le C.).

152. Crassipes 1) Er, Jahr. 195, 58. 1834.

$$
\text { Dej. }
$$

153. Grossipes.

154. Sphæroides (2) Le C. Mon 48, 17. 1845. Et.-Unis.

Bigener Le C. Mon. 47, 15. 1845.

155. Rugifrons (3) Payk. Fn. I, 47, 15. 1798. Eur. Aig. Metallicus Ent. Hefte, I, 81, 17. 1803

156. Metallicus (4) Herbst, Nat. IV, 32, 7.

$$
\text { 1791. Dej. }
$$

Eur.

(1) 152. Latipes Dj.

(2) 154. Conformis Dj.

(3) 155. Metallescens I)j.

(4) 156 . Corynthius Dj. 
157. Radiosus.

France $m$.

158. Apricarius Er. Jahr. 194, 55. 183.1. Sic. Cors. Afr. b. 159. Brasiliensis Payk. Mon. 66, 50. 1811. Montev. 160. Dentipes. Mex.

161. Bistrigifrons.

162. Dimidiatus Illig. Mag. V1, 41, 17. 1807. Dej.

Eur. m. Afr. b.

Semiceneus Brul. Mor. I, 457, 248. 1822.

163. Disjunctus.

Miadag. Mayotte.

Invisa anctomem species.

143'. Estriatus Le C. 1851.

Et.-Unis.

Incerte sedis.

Semistriatus Steph. III. III, 156, 28. 1830.

Bristol.

Violaceus Steph. III. III, 157, 29. 1830. Suffolk.

Interstitialis I. Le C. Calif. V, 4o, 42, 1. 1851 .

Calif.

Cupratus Kolem. Melet. V, 62, 276. 1846.

Armén. Cauc.

Erythropus Blanch. d'Orb. 71, 258. Amér. m.

Nigrita Blauch. d'Orb. 70, 256.

Id. 
XXXiV. Pachinopus Er. Jahr. 196, xvi. 1834.

1. Dispar Er. Jahr. 197, 1. 1834.

Cilp.

2. Sulcifrons Mannerh. Mosc. 1843, II, $259,186$.

Calif.

Invisce anctorum species.

2'. Serrulatus L. Le C. Calif. 1851, 41, 2. Id.

2". Gaudens L. Le C. Calif. 1851, 41, 3. Id.

\section{Tribu : ABRÉENS}

XXXVI. Tenethus Er. Jalır. 201, xvi1. 1834.

1. Pilimanus.

2. Lalus.

3 . Virens.

4. Picipes F. Ent. S. I, 77, 21. 1792. Dej. Eur.

5. Goudotii.

6. Rufulus.

Haïti.
Cap.

Id.

Guatem.

Madag.

\section{Invisa spcries.}

Punclulatus Falur. in Boh. Cafr. I, 546. 596.1851 .

Cafr. 
XIXVII. Ximovotes.

1. Chevrolati

Cill.

XXXVIII. Plegadercs Er. Jahr. 203, xix. 1834.

1. Saucius Er. Jahr. 204, 2. 1834.

liur.

Vulncralus Sturm, Fn. 1, 258, 37. 1805.

2. Vulneratus Panz. Fn. Germ. 37, 6. 1792. Dej.

Eur.

3. Cæsus F. S. Ent. 1, 92, 43. 1755. Dej. Id.

4. Dissectus Er. Fn. I, 684, 5. 1839. Fr. Belg. Allem.

5. Sinyi. Amér. b.

6. Otti.

Var.

6'. Barani. Sup.

'Toulon.

7. Sinatus Truq. Soc. 1852. 64.

Chypre.

8. Discisus Lr. Fn: I, 683, 3. 1839. Fr. Allem.

9. Transversus Say. Phil. 45, 20. 1825. El.-Unis.

10. Pusillus Rossi, Mant. I, 15, 26. 1772. Sard. Tosc.

XXXlX. GLuma.

1. Candezii.

Beler: 
X1. Oxthophus Leach. Misc. III, 76. 1817. 1)ej,

1. Sulcatus I. Ent. S. I, 7 1, 12. 1792. Dej. Eur. Alg. Siriatus IIerbst, Nat. IV, 38, 12. 1791.

Globulosus Ol. Ent. I, ge g. 16, 19. 1789.

2. Exaratus Illig. Mag. VI, 48, 25. 180\%. Fr.m. Port.

3. Nodatus Le C. Non. 53, 3. $1845 . \quad$ E.-Un. Géorg.

4. Alternatus Say, Phil. V, I, 46, 21. 1825. Pensyl. Carol.

5. Striatus Crtz. Verz. 83, 2. 1799. Dej. Eur.

Silcaus liossi, Fn. I, 30, 70. 1790.

6. Affinis Redt. Fı. 239. 1849.

Autr.

7. 9-costatus Dej. Sénég.

Invisa auclorum species.

3'. Pluricostatus Le C. Mon. 51, 1. 1845. Géorg.

7'. Hispidus Payk. Mon. 93, 82. 1811. Ind. or.

7". Costipennis Fahr. in Boh. Cafr. I, 549. $600,1851$.

Cafir.

XLI. Bacanirs L. Le C. Phil. 1853, 291.

1. Hunicola. Venez.

2. Rhombophorus Aubé Soc. 1843, 75. Fr. Allem.

3. Misellus L. Le C. Phil. 1853. $291 . \quad$ Et.-Unis,

4. Punctiformis L. Le C. Plit. 18.03. 288, Id. 
Tantillus L. Le C. Phil. 1853, $291 . \quad$ Id.

? Marginatus L. Le C. Plıil. 185̃3, 291'. Id.

Consobrinus Aubé, Soc. 323, 32. 1850. Batoun.

XLII. Abnius Leach. Misc. 181\%, III, 7(). Dej.

1. Rugicollis.

2. Cyclonotum.

3. Paria.

4. Sphæricus (1).

5. Globulus Crtz. Verz. 83, 3. 1799. Dej. Eur.

6. Gilobosus (2) Ent. Hefte, I, 110, 29. 1803. Dej.

7. Granulum Er. Fn. I, 686, 3. 1839.

\$’. Parvulus Aubé, Soc. 1812, 232.

Invisce anctormm species.
Cap.

Sénég. Abyss.

Indoust.

N.-Gren.

Il.

Eur.

Fr. Allem.

1'. Curtulus Fahr. in Boh. Cafr. I, 548, 598. 1851.

Calir.

2'. Setulosus Fahr. in Boh. Cafr. I, 547, 597.1851.

Nat.

(1) 4. Abr. exiguus 1)j.

(2) 6. Catemulatus vj. 
2". Monilis Fahr. in Boh. Cafr. I, 519, 599. 1851 .

Cafr.

3. Exilis Payk. Mon. 84, 6\%. 1811.

Ind. or.

Xlili. Acritus L. Le C. Phil. III, 288. 1853.

1. Substriatus.

2. Aciculatus Le C. Mon. 54, 1. 1845.

3. Exiguus Er. Jahr. I, 208, 5. 1834.

4. Natchez.

5. Cribripennis.

6. Tenuis.

7. Fulvus.

8. Punctum Aubé, Soc. 1842, 232.

9. Brevisternus.

10. Politus L. Le C. Pliil. 1853. 289.

11. Atomarius Aubé, soc. 1842, 231.

12. Nigricornis Ent. Hefte, II, 12\%, 28-29. 1803.

Atomos Rossi. Mant. 15, 27. 1792.

Minutus Payk. Mon. 87, 71. 1811.

13. Minutus F. S. El. I, 90, 34. 1801. Dej. Id.

14. Fimetarius Le C. Mon. 54, 千. 1845. Louis. Géorg.

15. Simpliculus.

16. Rugulosus.

17. Acupictus.

18. Acaroides.

19. Strigosus L. Le (¿. Phil. 1853, $289 . \quad$ Et.-Unis.
Guatem.

Géorgs. Carol.

Et.-Unis.

Id.

Id.

N.Gr. Venez.

Ital.

Ital. Fr. m.

Louisiane.

Et.-Unis.

Fontainebl.
Eur. Venez.

Id.

Et.-Unis.

Louis. Géorg. Carol. 
20. Simplex Ie C. Mou. 1845, 54, 2.

21. Lateralis.

22. Laeviusculus.

23. Gulliver.

Géorg. Carnl. El. Unis.

Venez.

St-Doming.

Invise auctorum species.

Maritimus L. Le C. Calif. 46, 1. 1851. Calif.

Basalis id. id. 2.1851. Id.

Obliquus Le C. Mon. 54, 3. 1845. Carol.

Discus L. Le C. Phil. 1853. 289. El.-Unis.

Conformis id. id. 289 . Id.

Analis id. id. 290. Cuba.

Atomus id. id. $290 . \quad$ Id.

Seminulum Küst. XV, 27. $1848 . \quad$ Montenegro. 


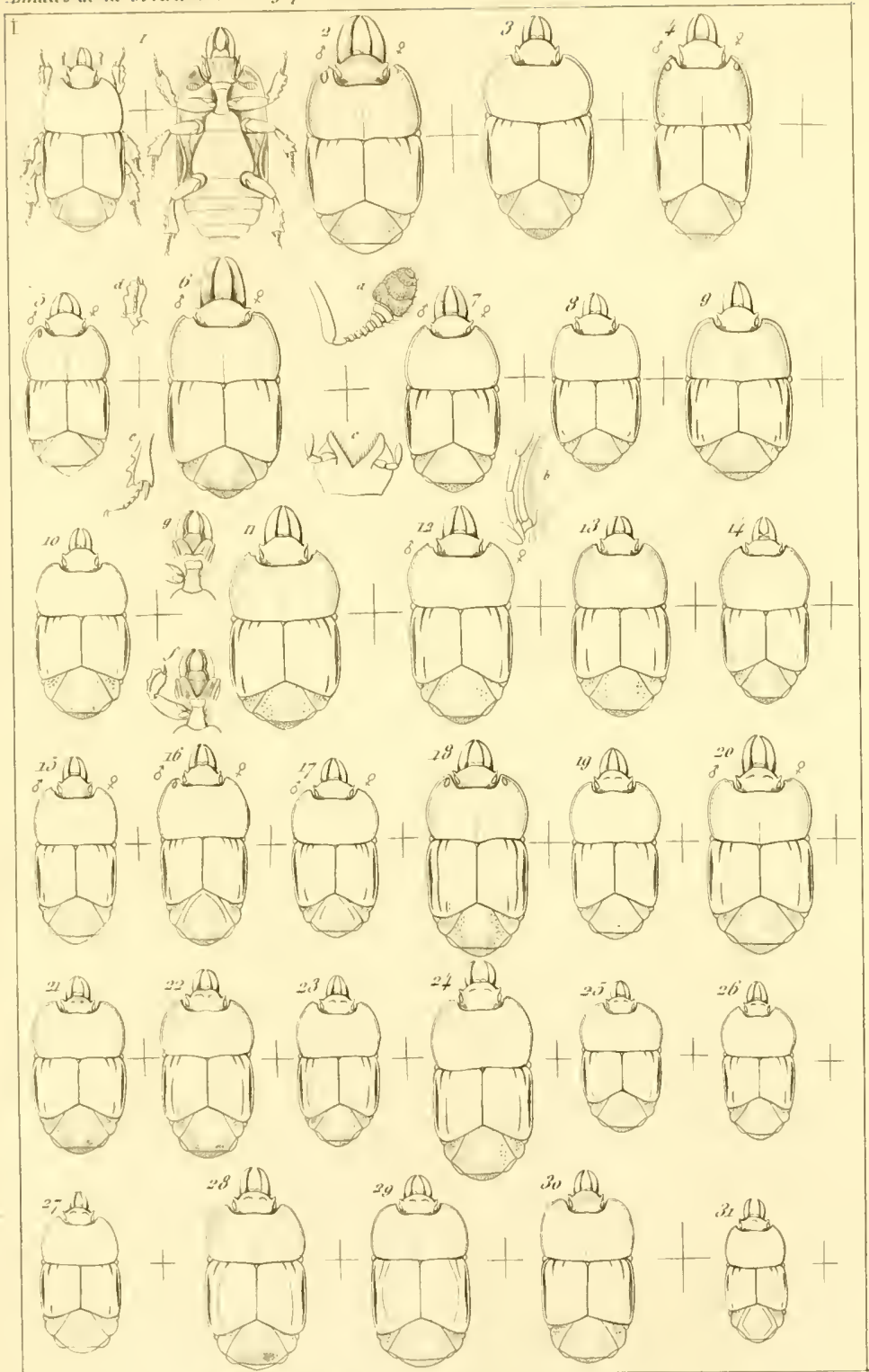

de Morsendel Misterrides Ml Mre

1. li. Helolepter. 



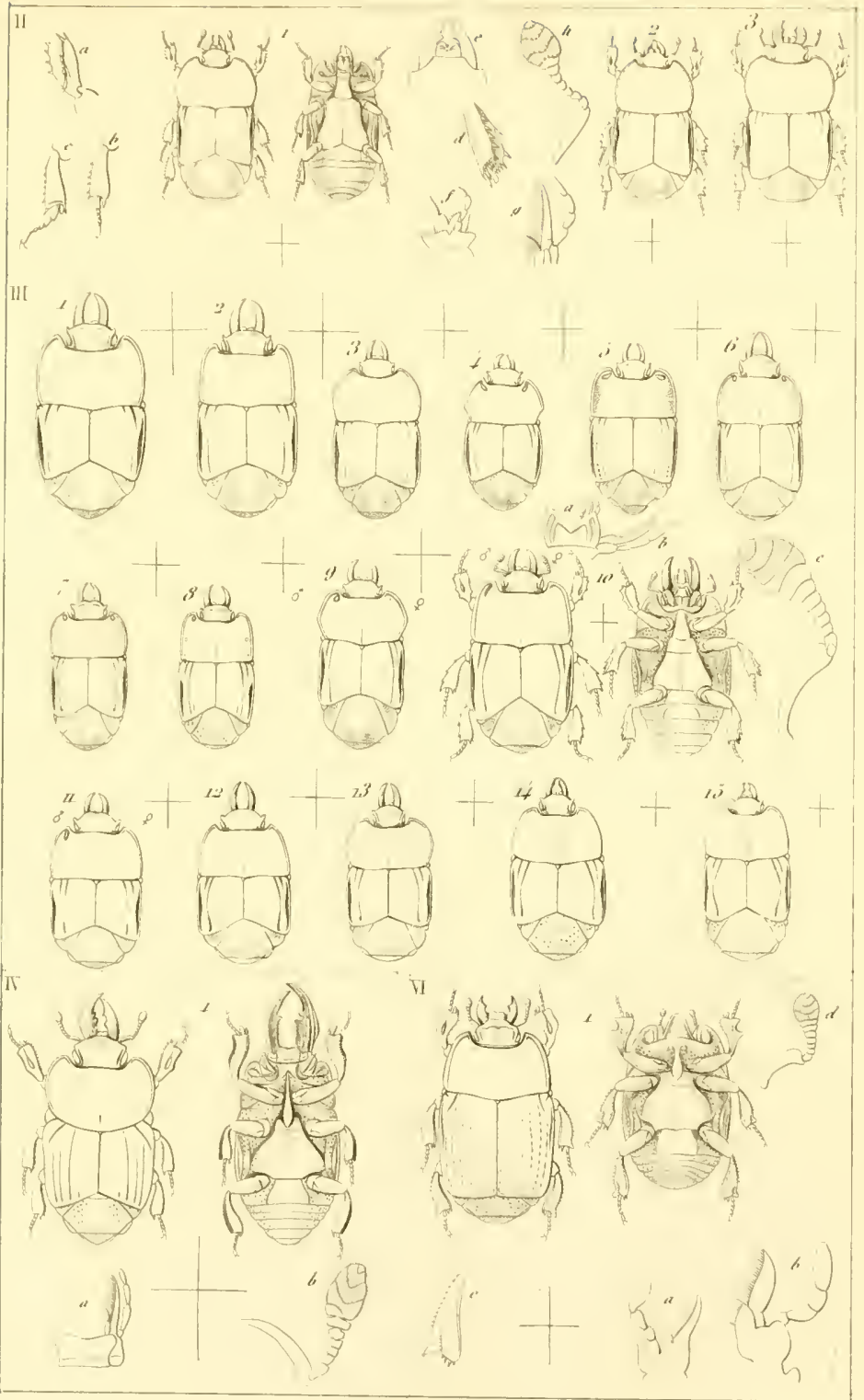

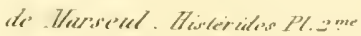

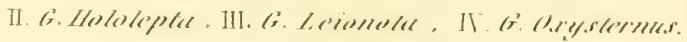
II. G. Pleseredes: 


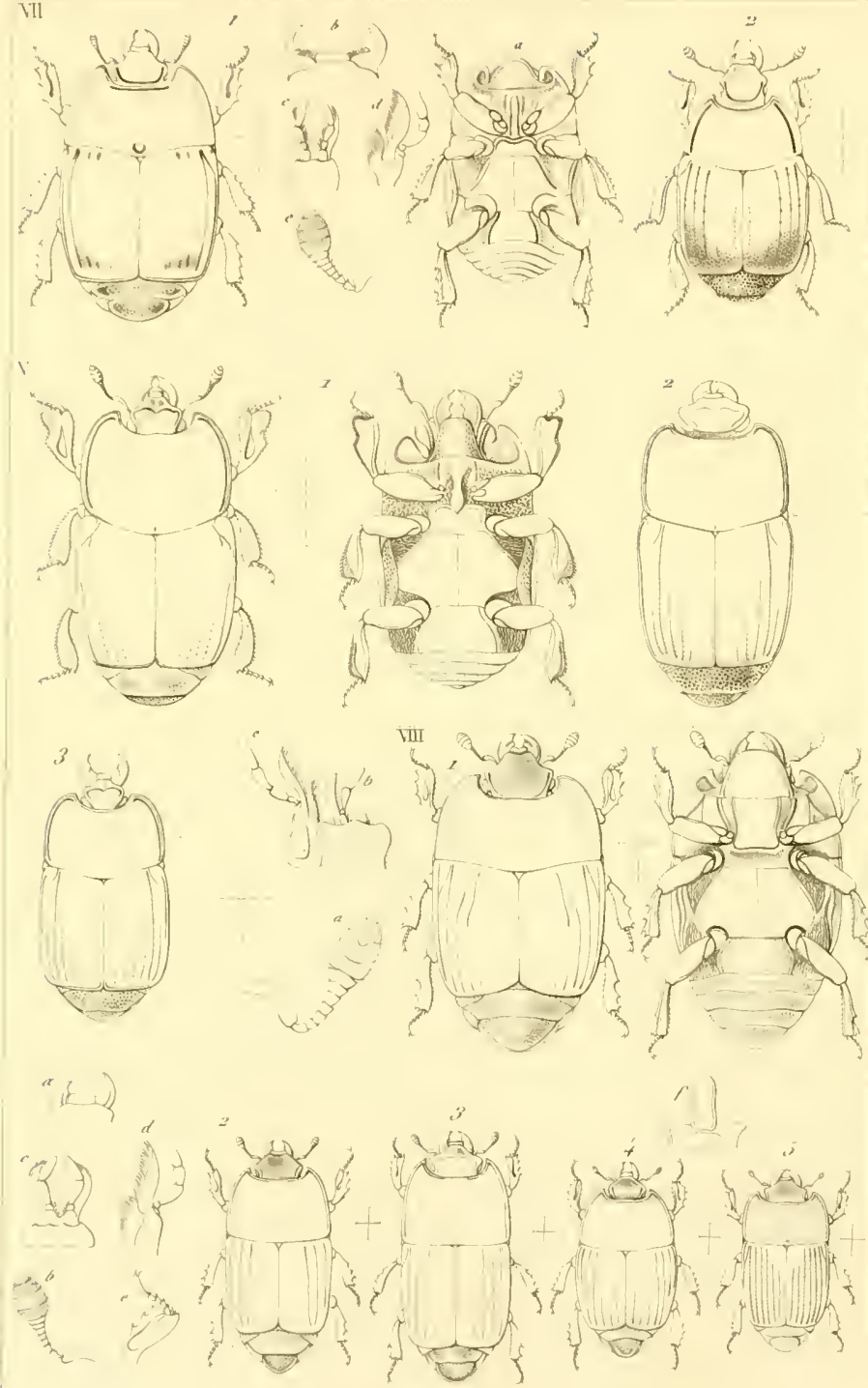

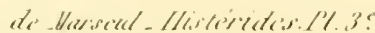

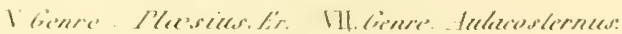

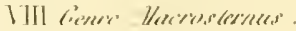





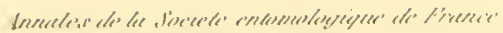

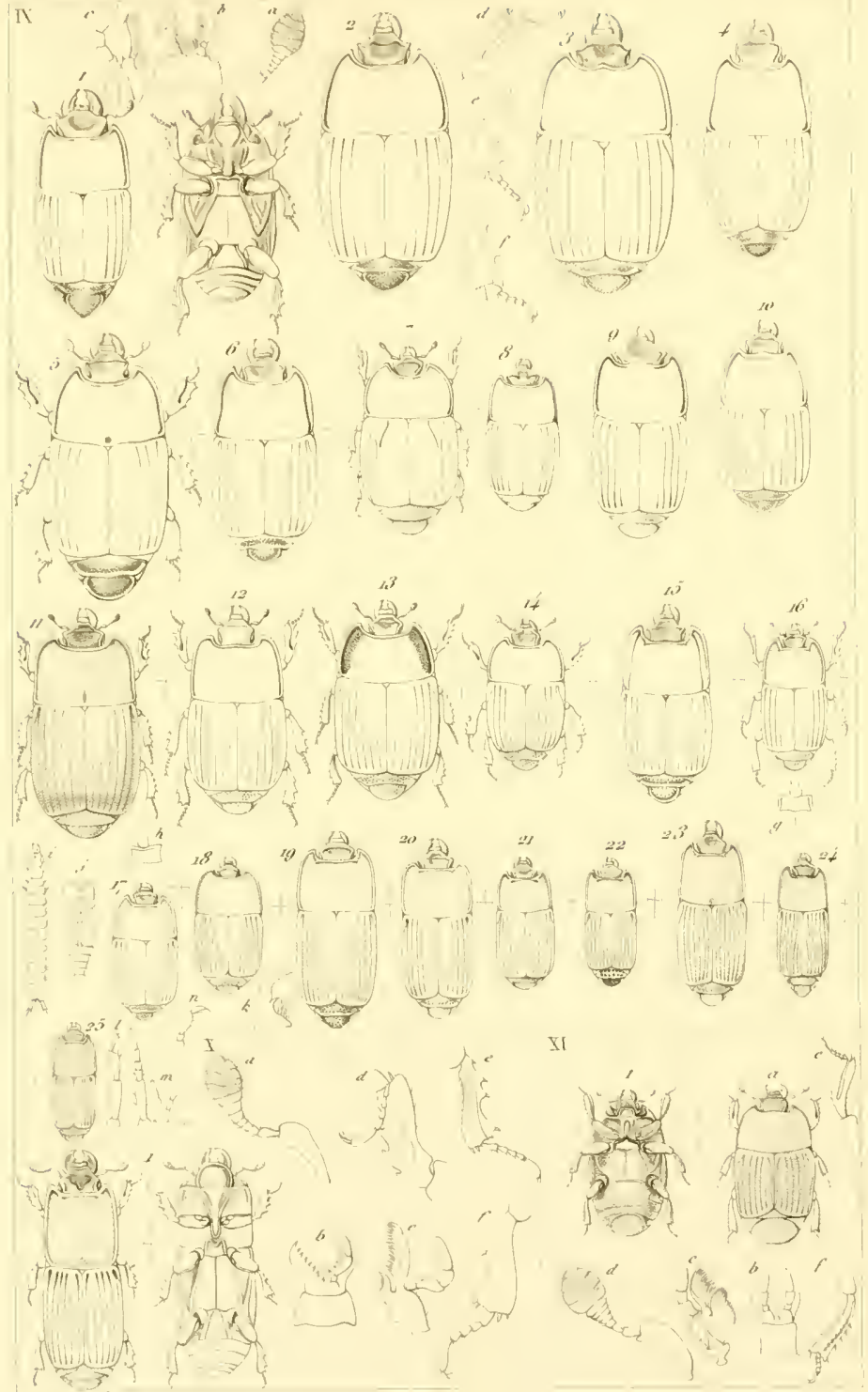

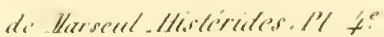

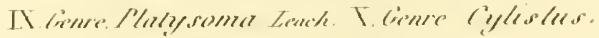

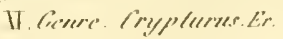





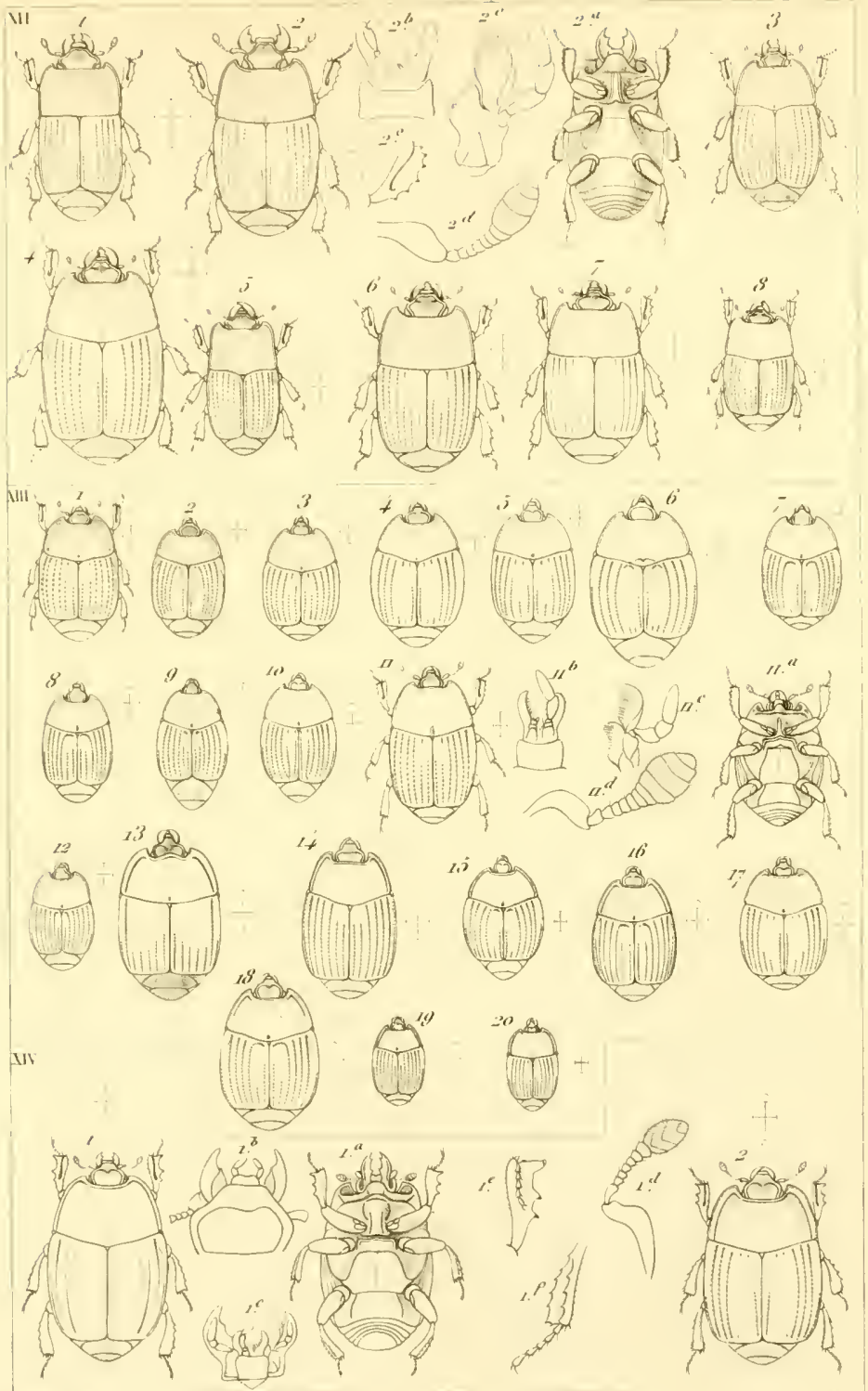

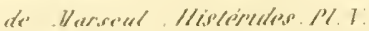

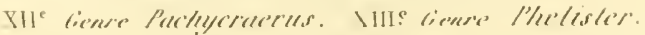

Alve lienere spliygerens. 


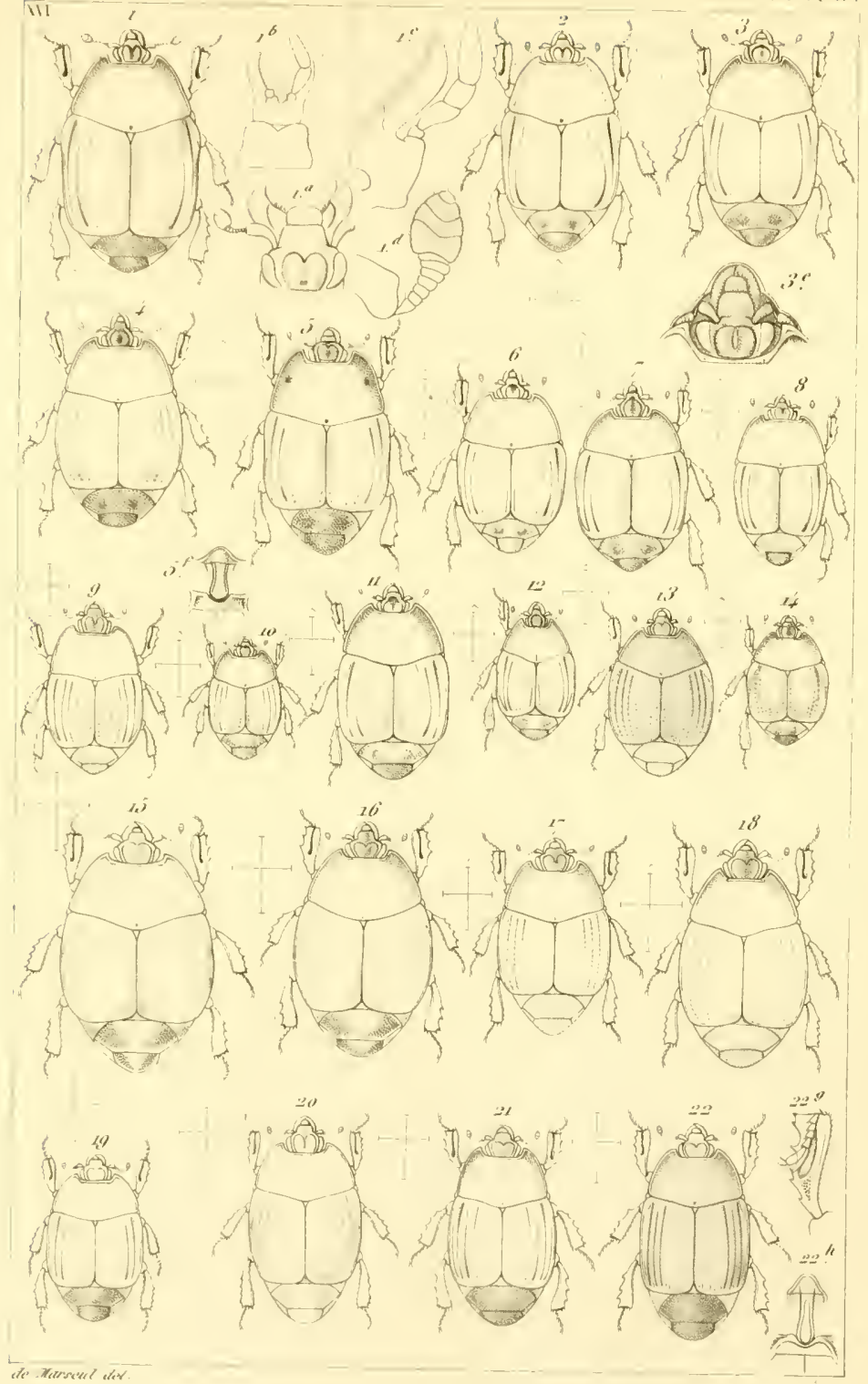

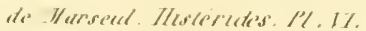

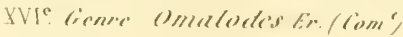





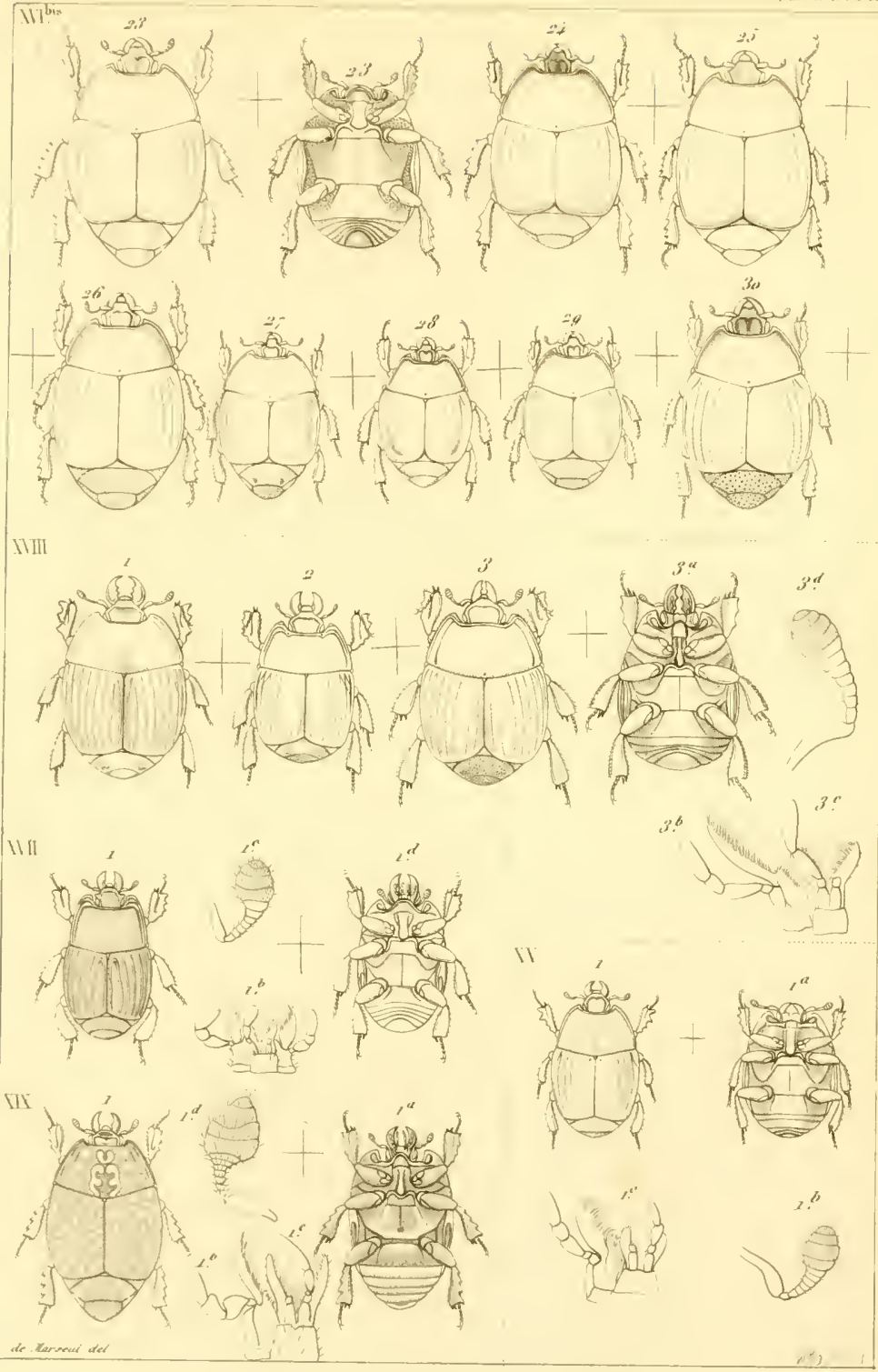

de Harsent. Hesterteres. PZ. II/

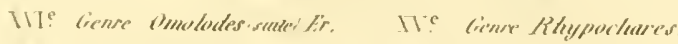

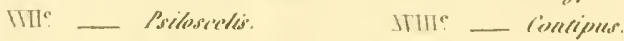

$17 \mathrm{C}^{2}$ - Haryurimutus. 


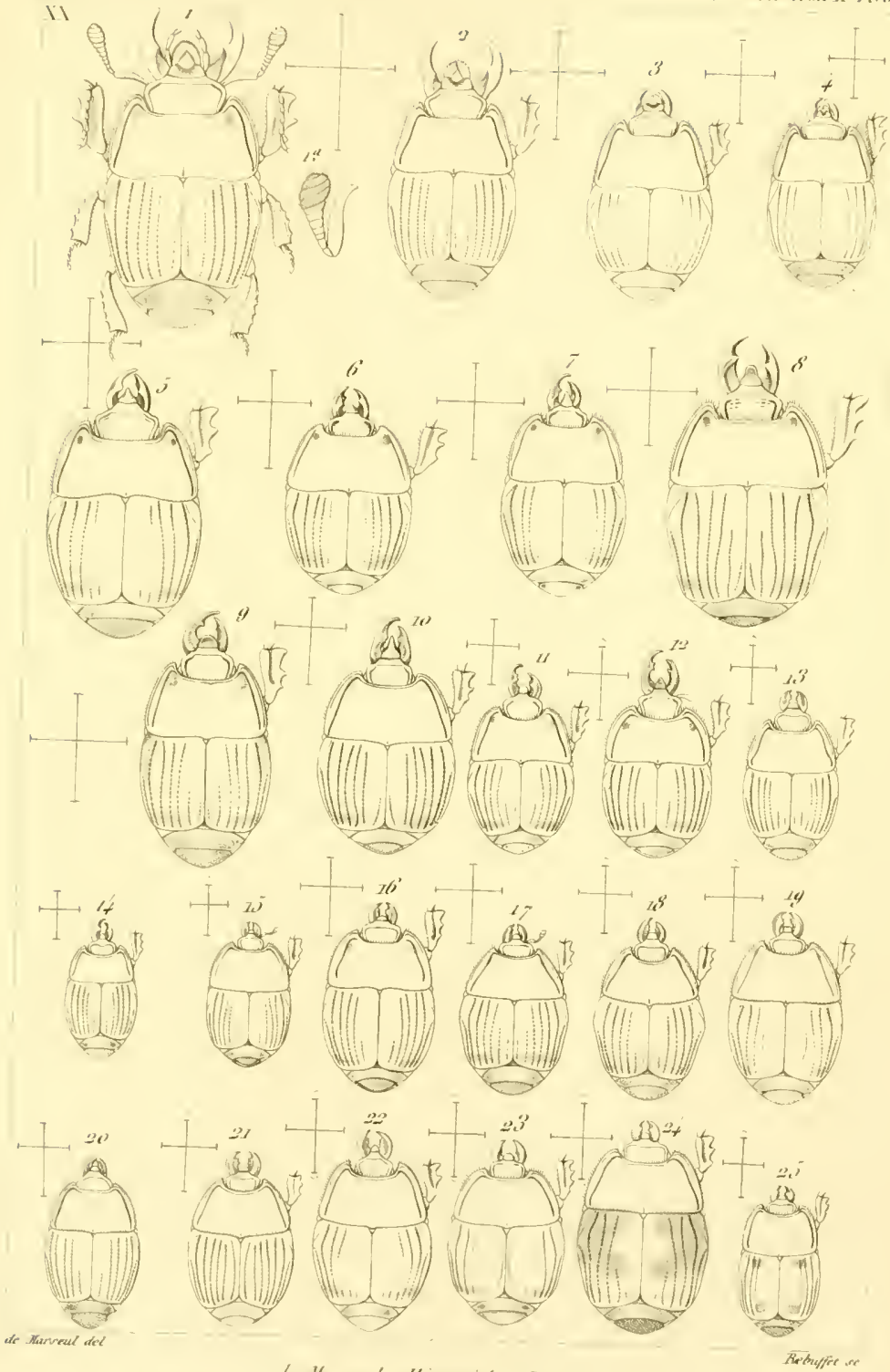

de Harsoul. Hosterietes. PI. IIII.

110 lichere Mister /., /1) 


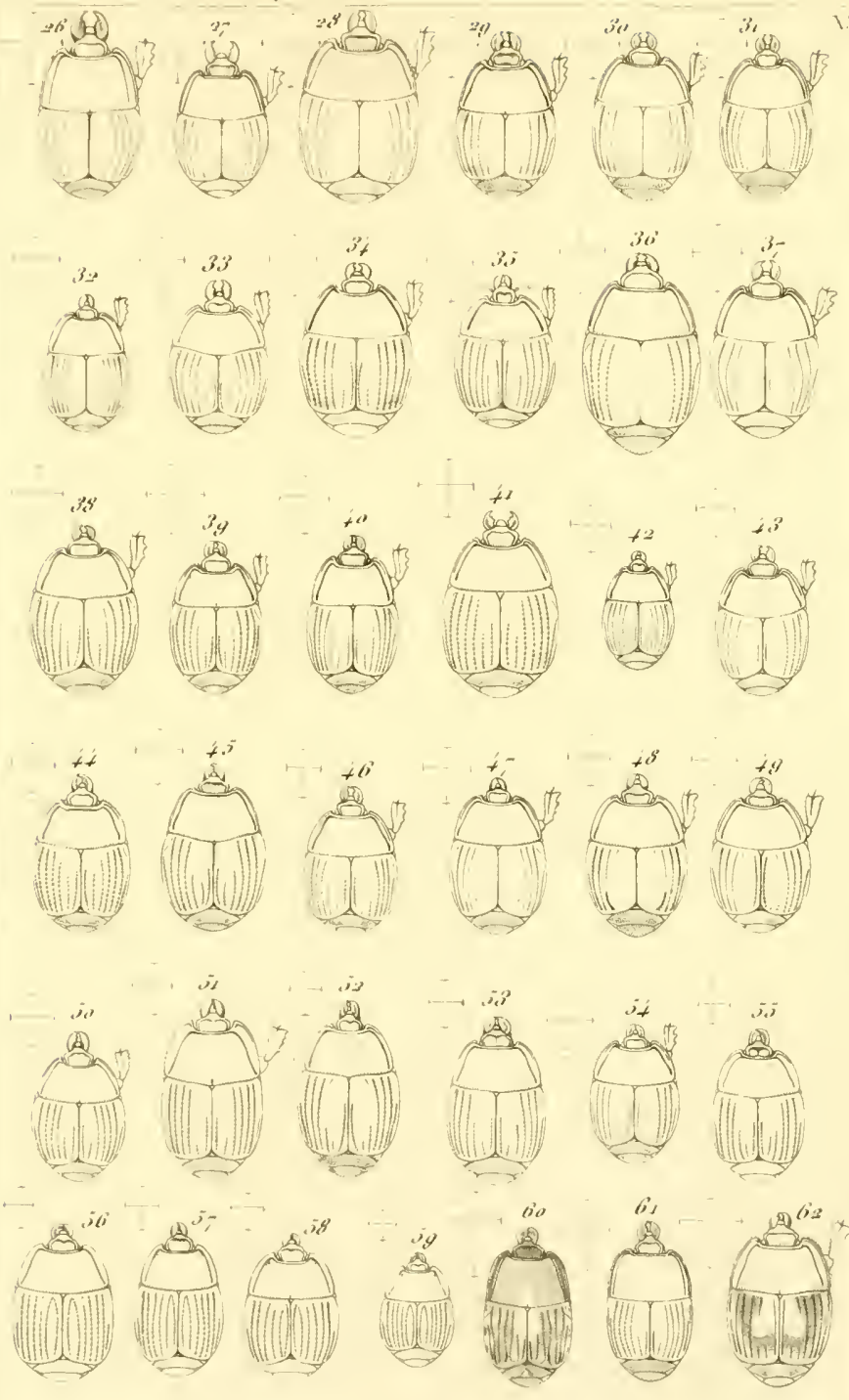

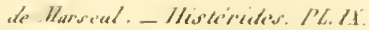

II. Genre . Vister L. 2) 


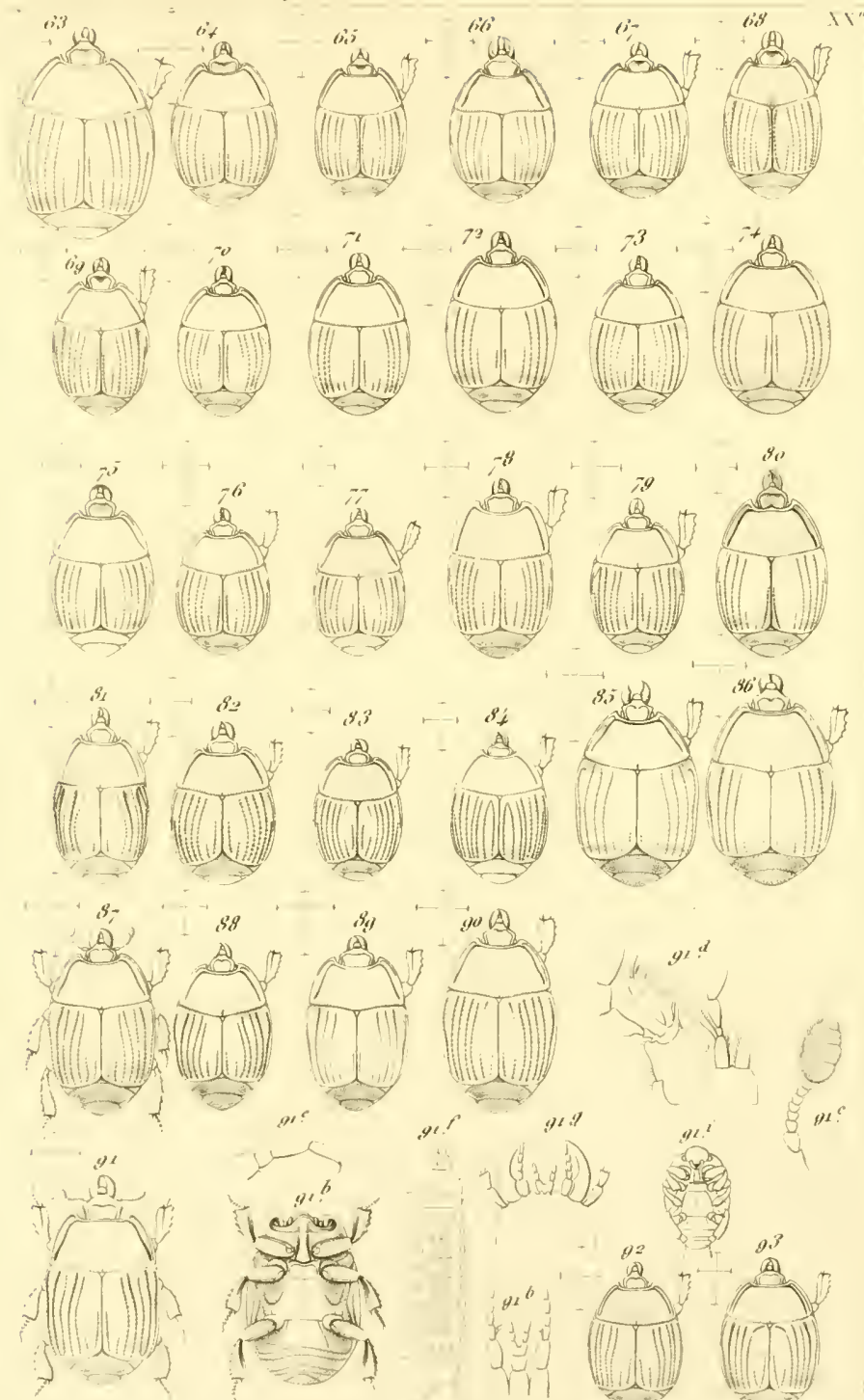

de latruteal dad
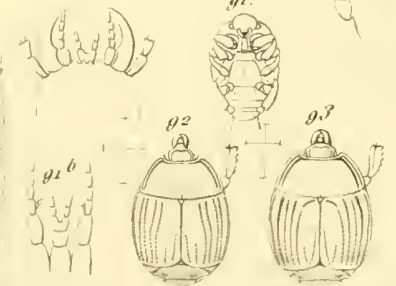

Ifothesitic

de Hurseul. - Meslerisless PM 1

II. (ienere. Hislere. L. (3) 


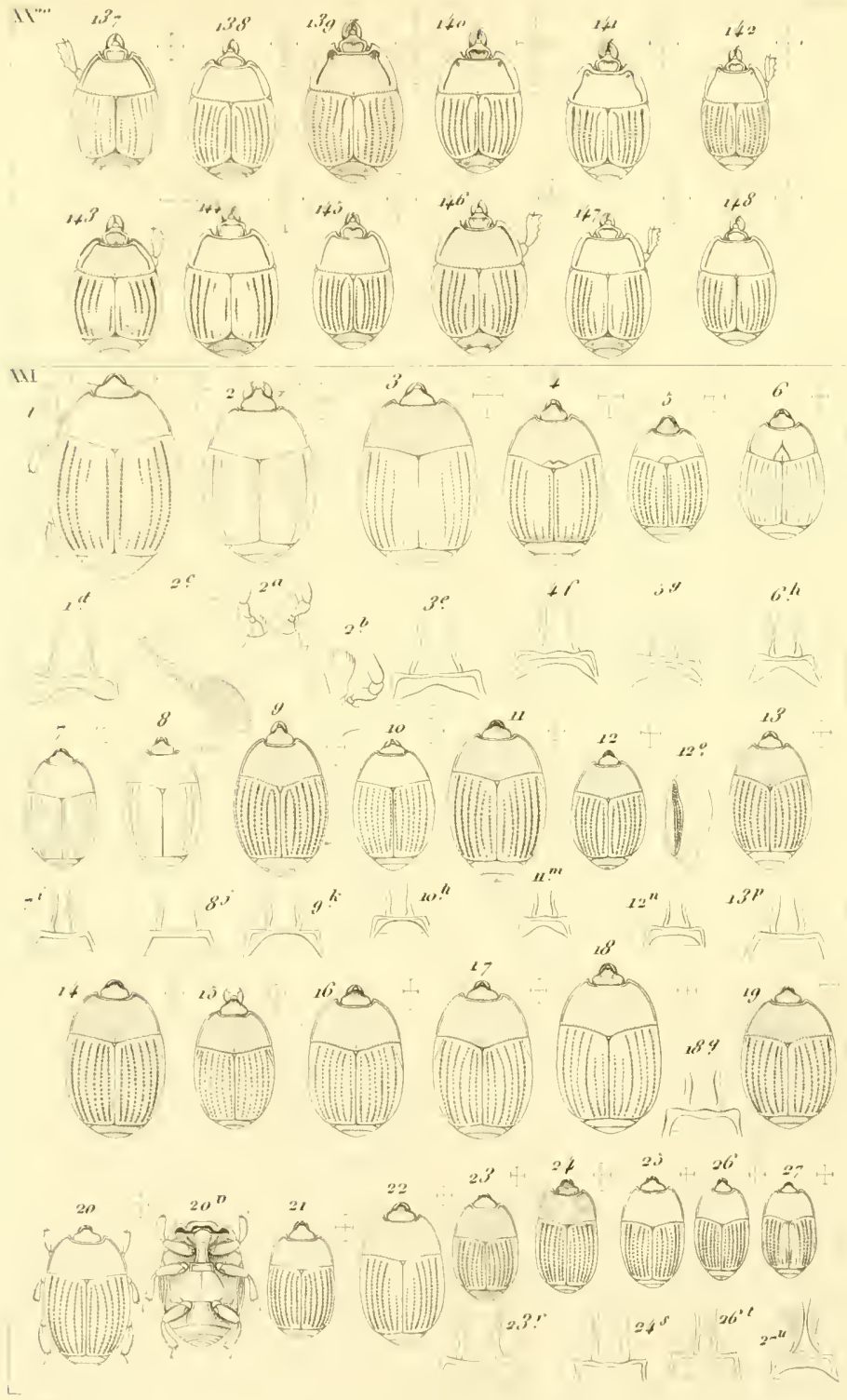
Ile. Warveul ded?

The Marseul Misterides'. PIIII.

Bsibuter wo

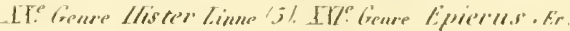





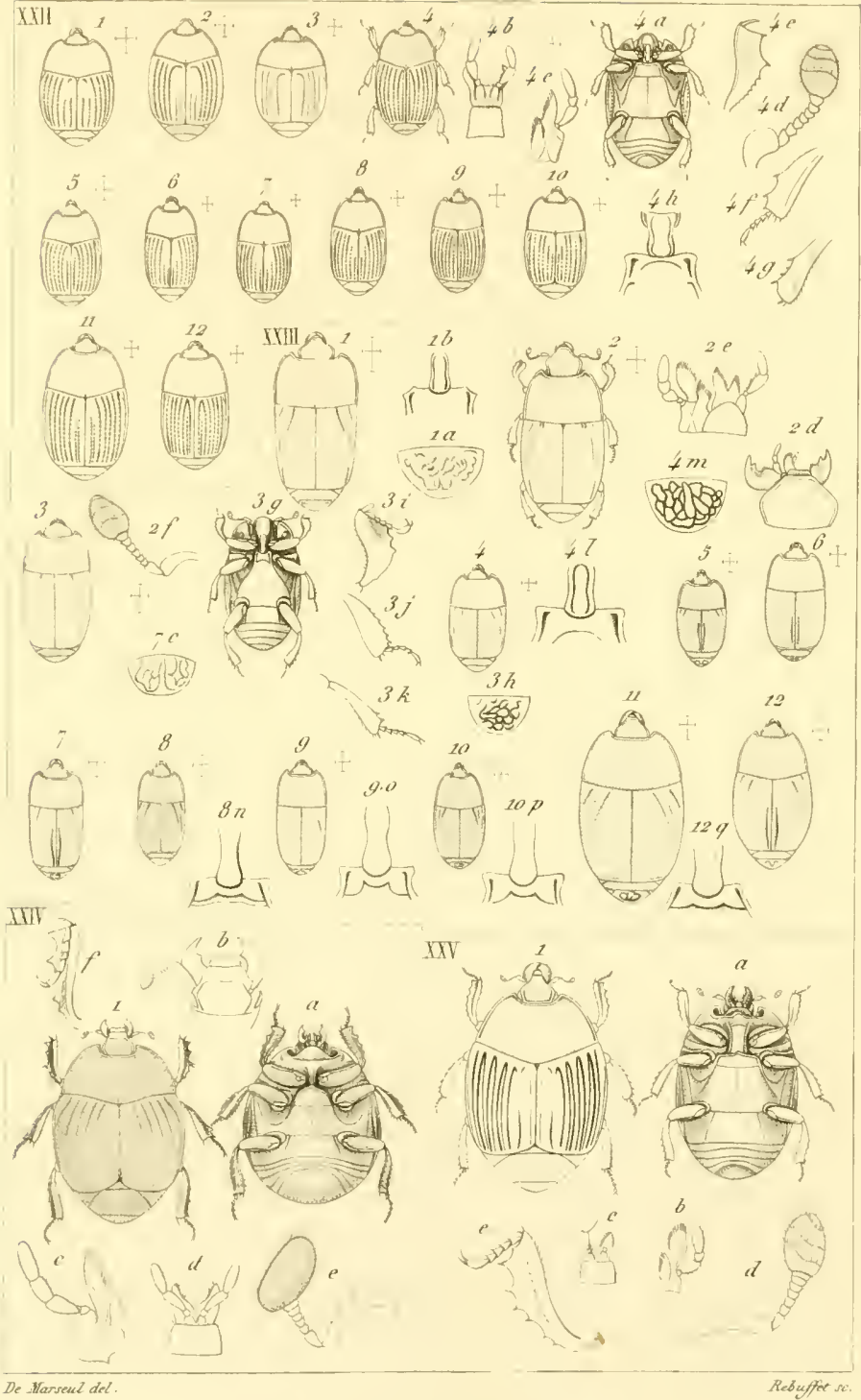

De Marsent Histerides PZ. IIII

XXII Gene Carcinus DXII Gene Honoplius

IXIII - Paromalus Er. HT - Pelorns 


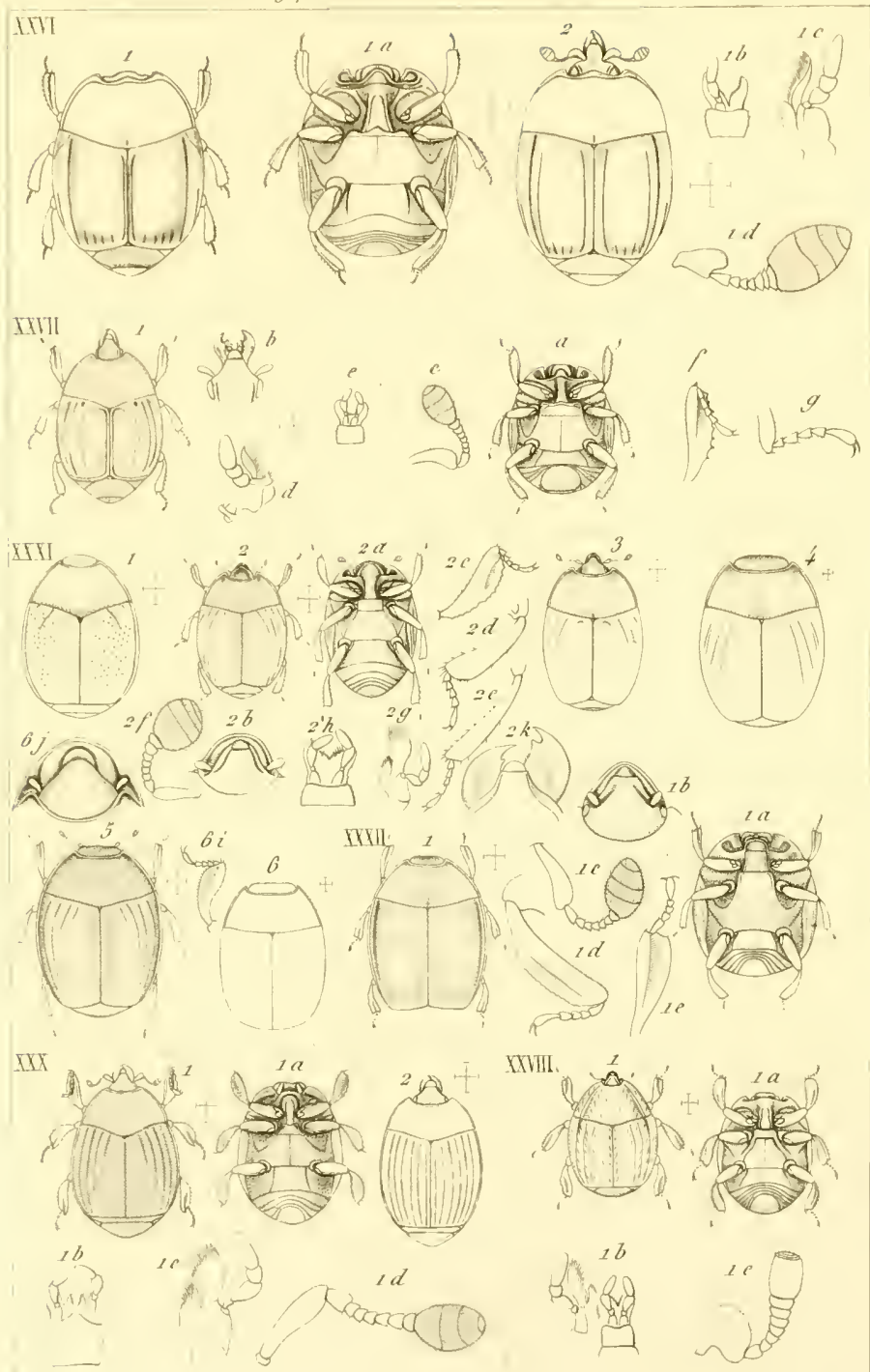

De Harreul del.

Rebuffer ac

De Marseul Histerides Pl. YTI

X117 Genee Scapomegas IIY Genre Dendrophilus Leach.

IITII - Totodoma IXXI_Tribalus Er.

IIIII - Hetarius En. IITll _ Spharosoma 



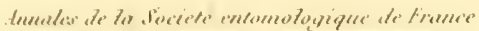

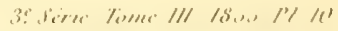
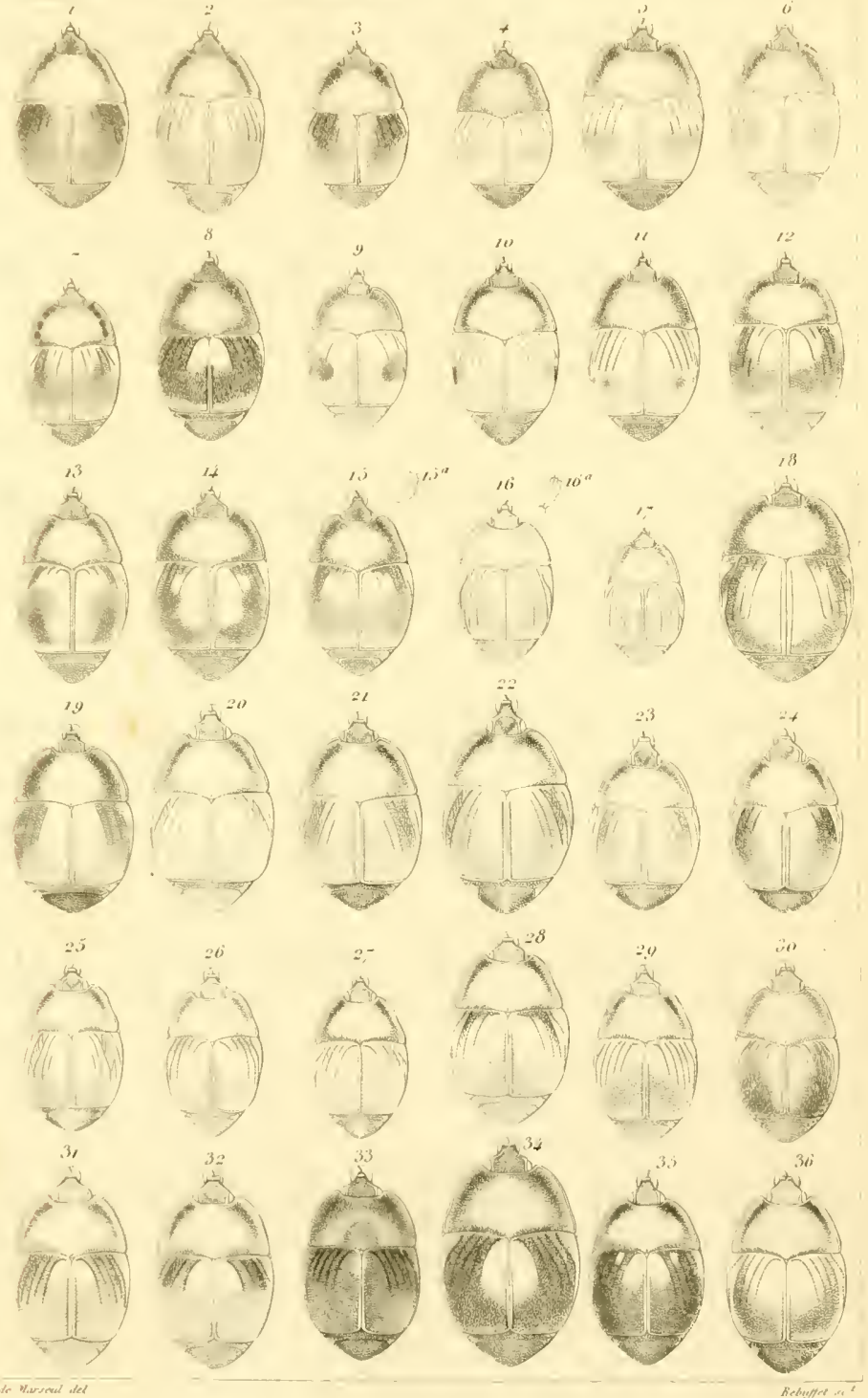

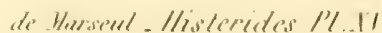

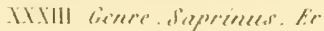

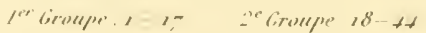





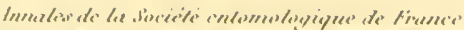

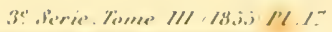
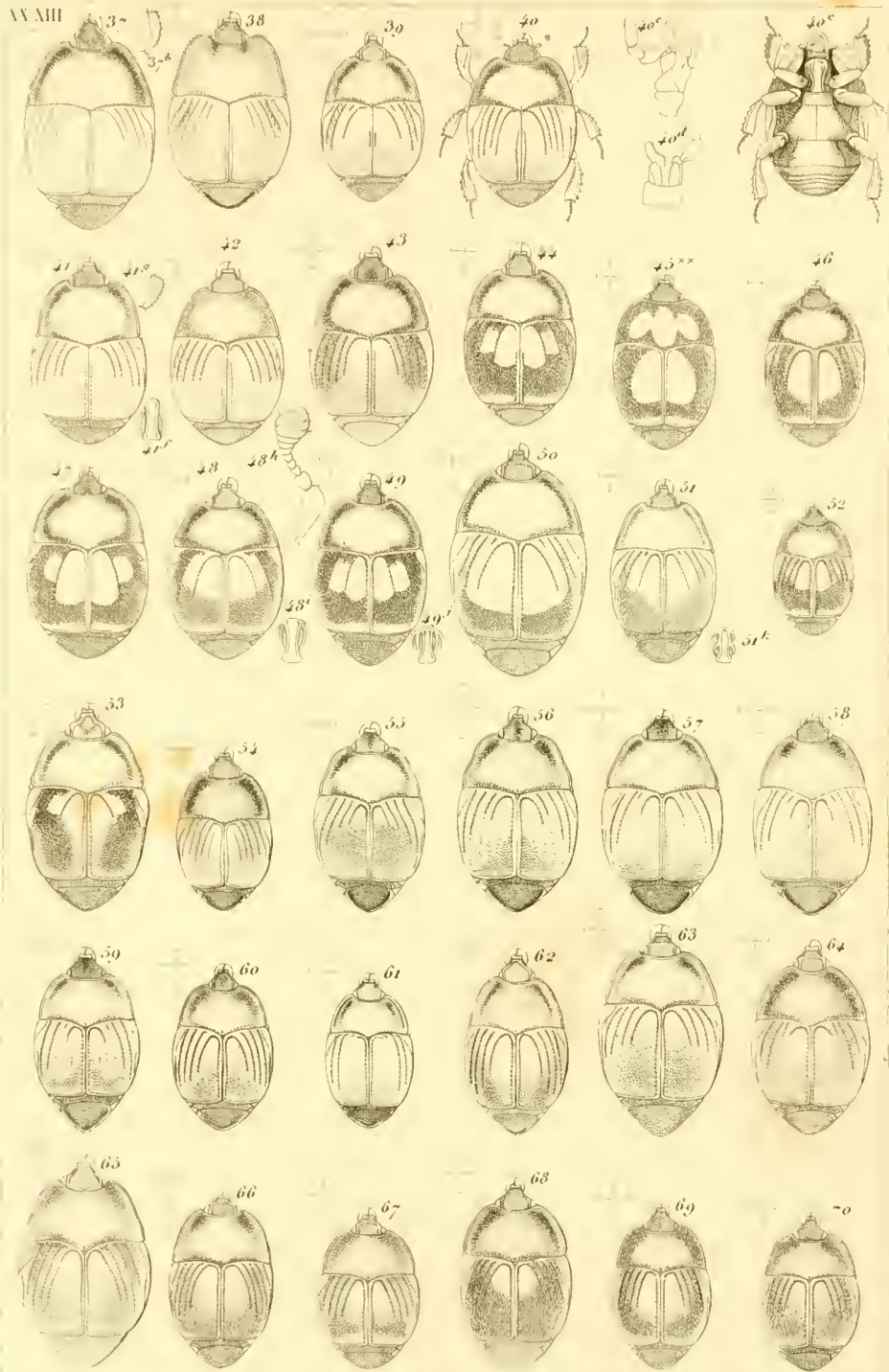

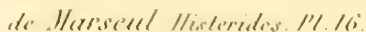

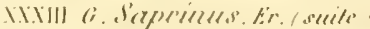
$\because$ Ciroupe li -46 .
3c (imupe $4.5-1 / 8$. 


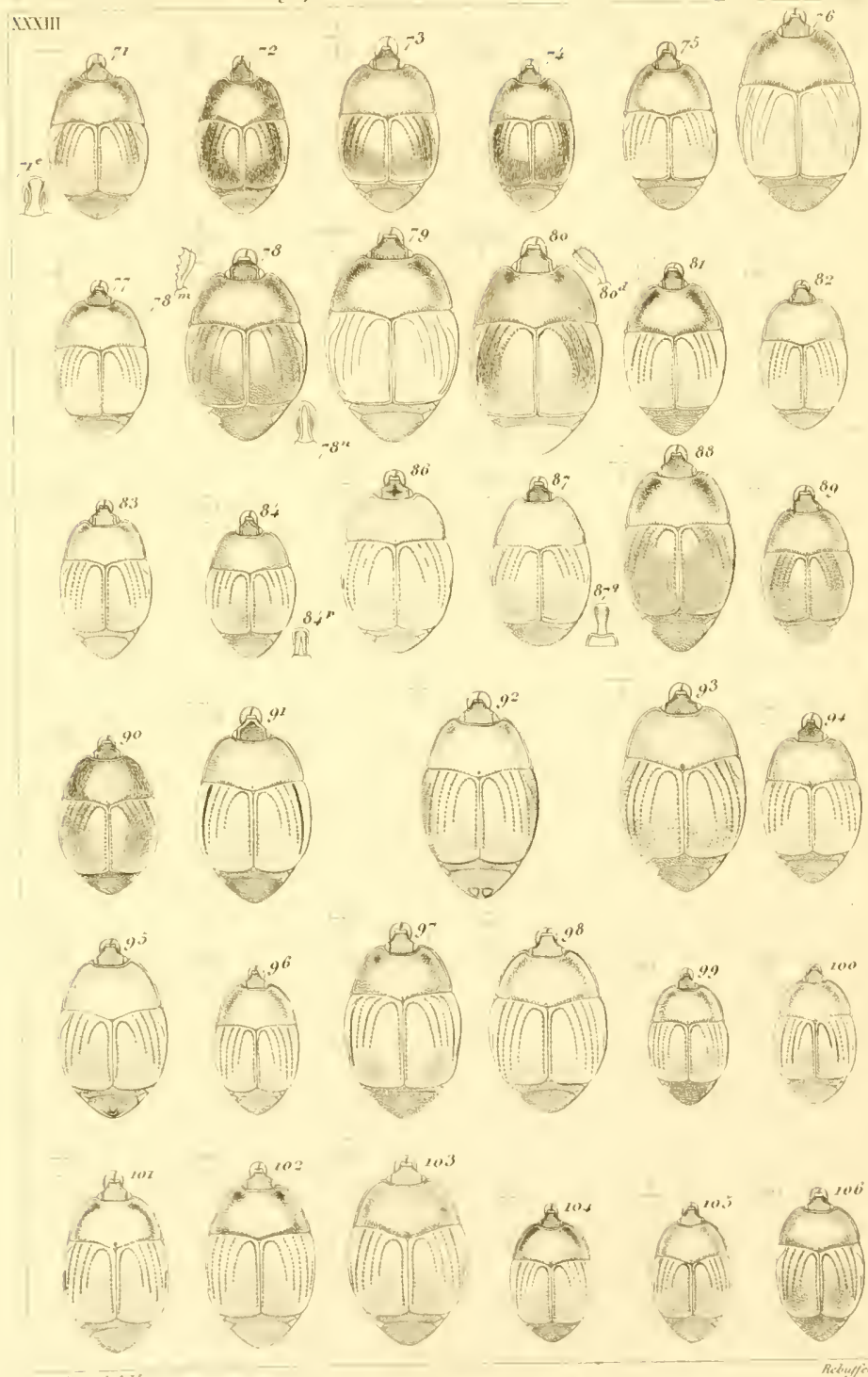

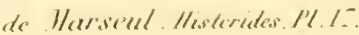

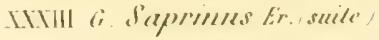

3e Giroupe ti-l/s. 



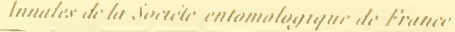

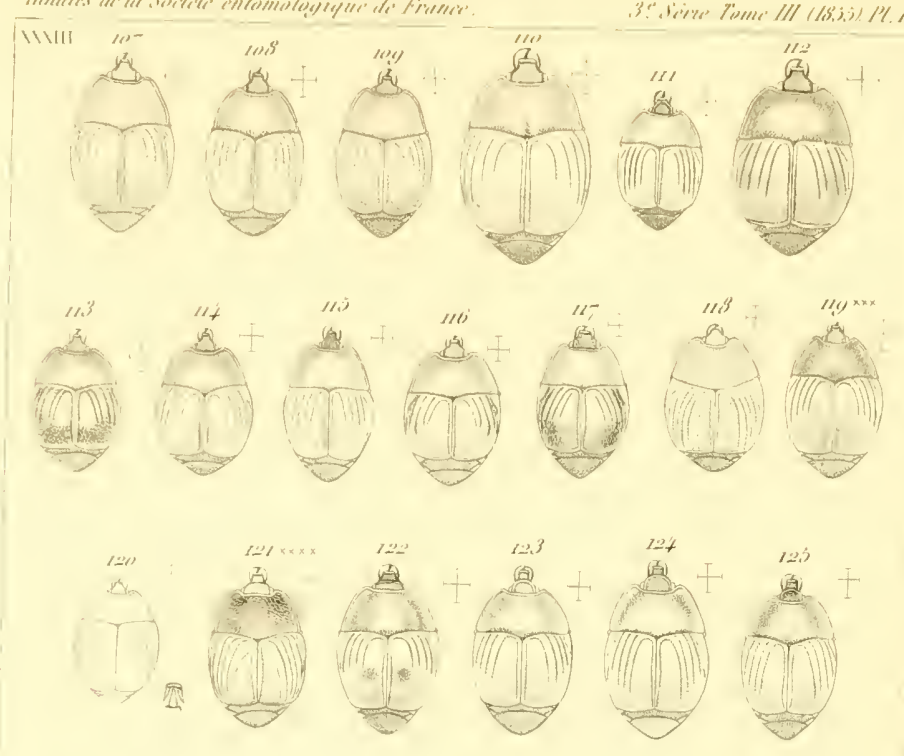

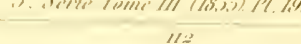
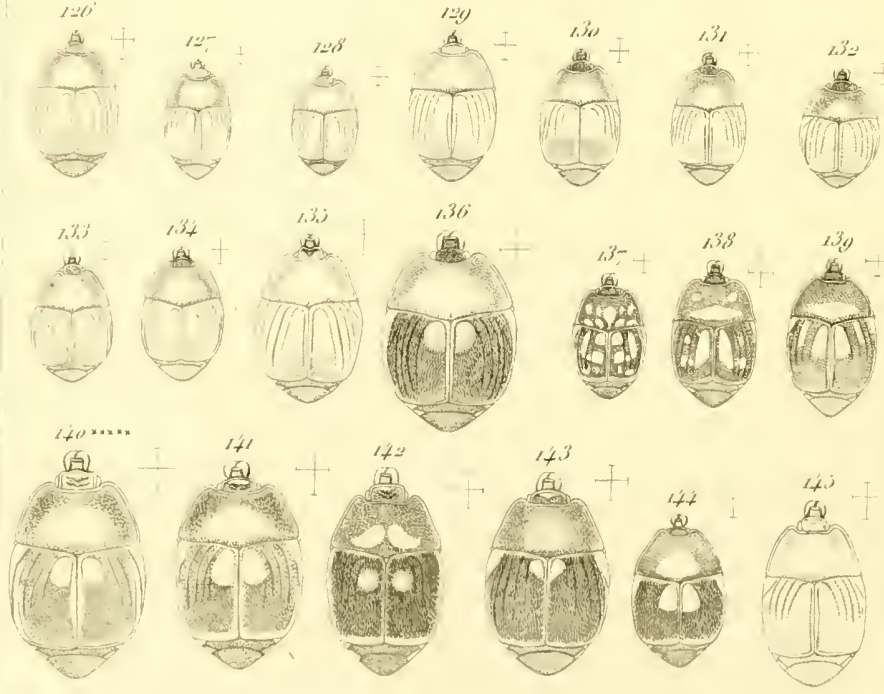

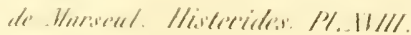

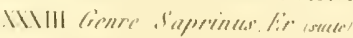

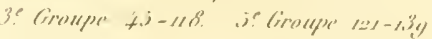

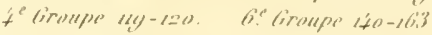



IIXII
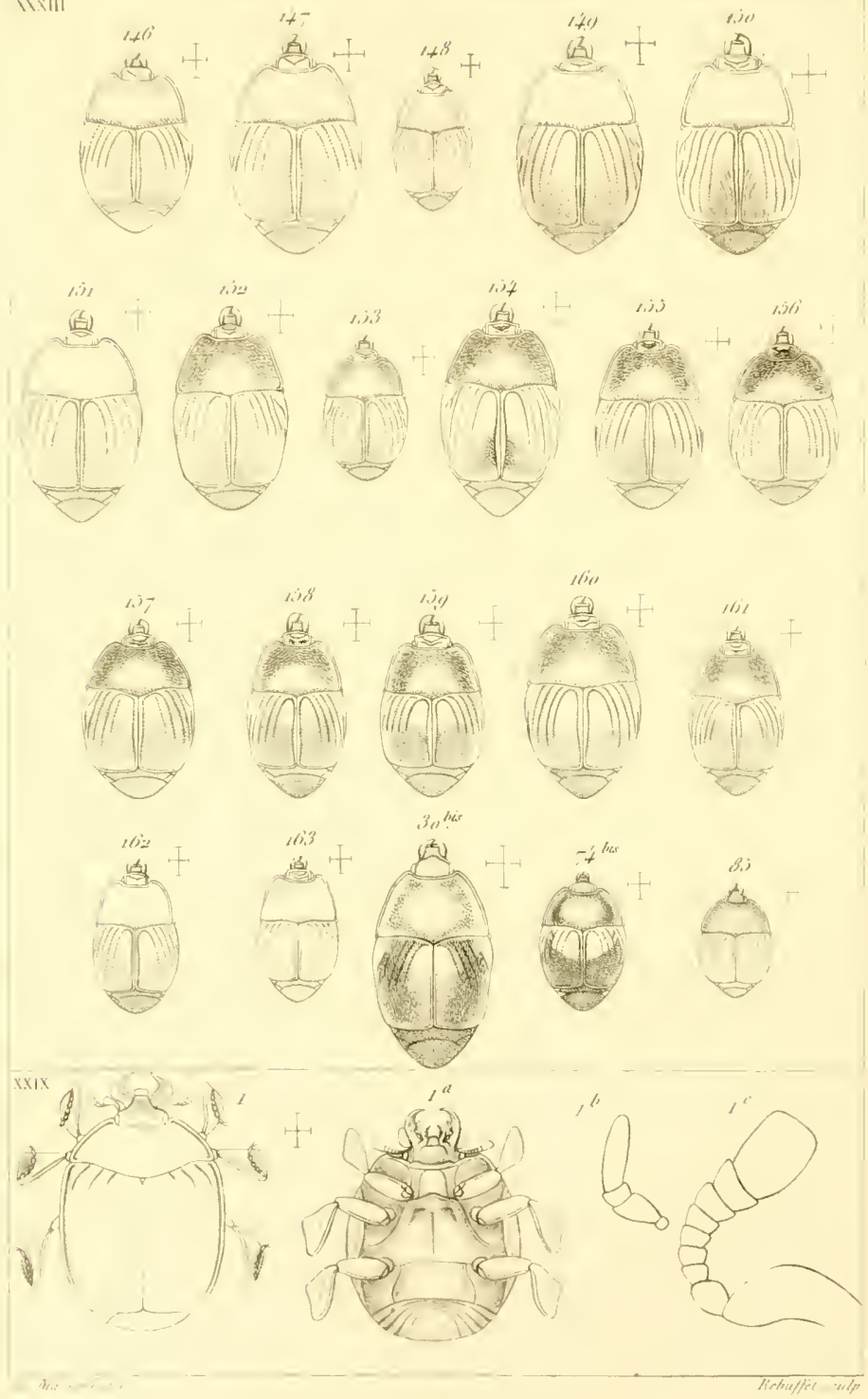

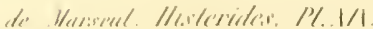

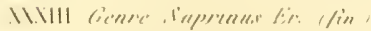

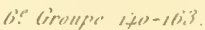

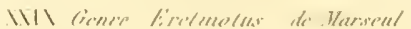





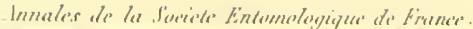

3." Sirvi Teme $I V(18,50)] \% 2$.

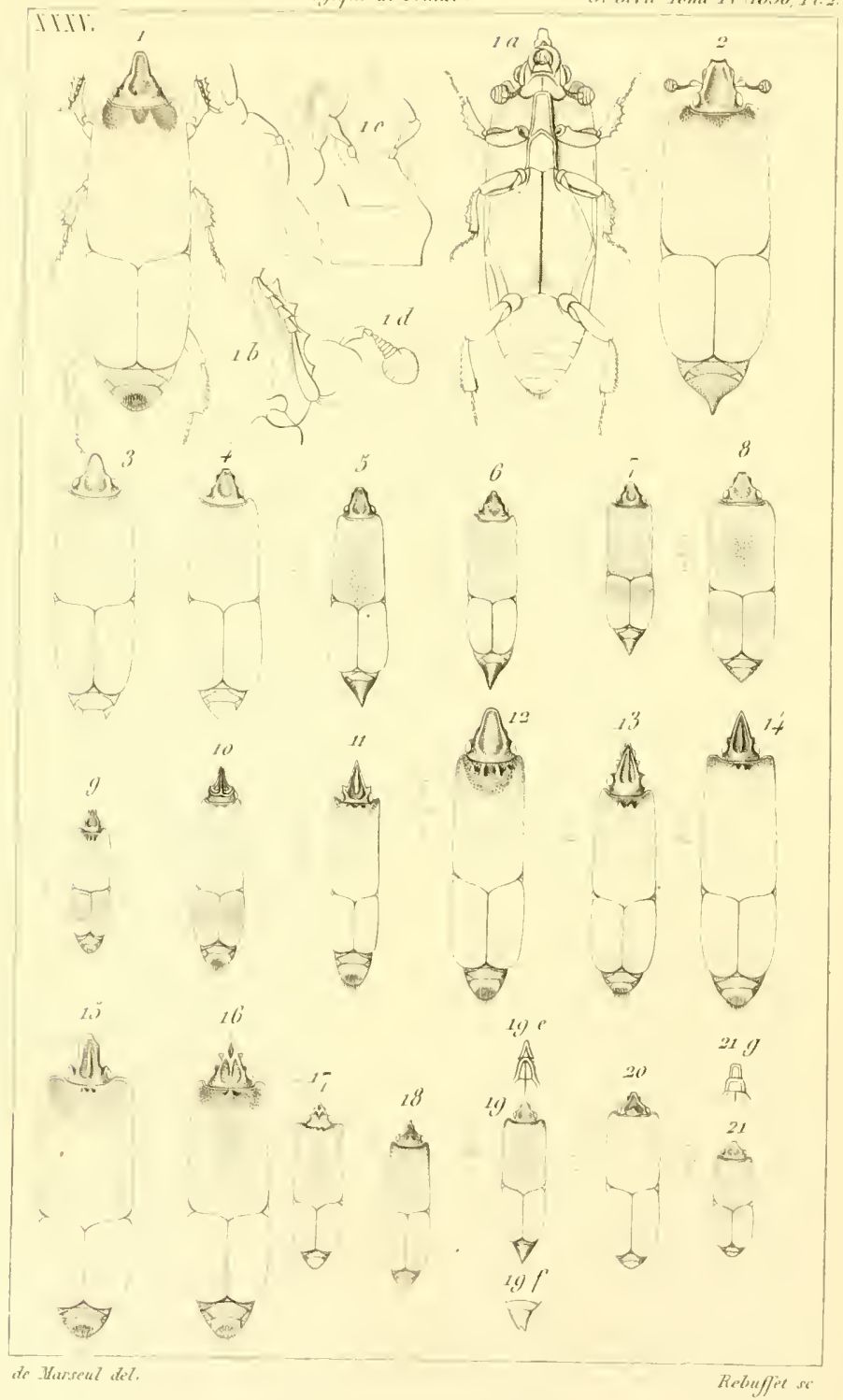

de Marseul. Histeridtes PI. DA.

I.11. Gieme Trypunatus Essh. 



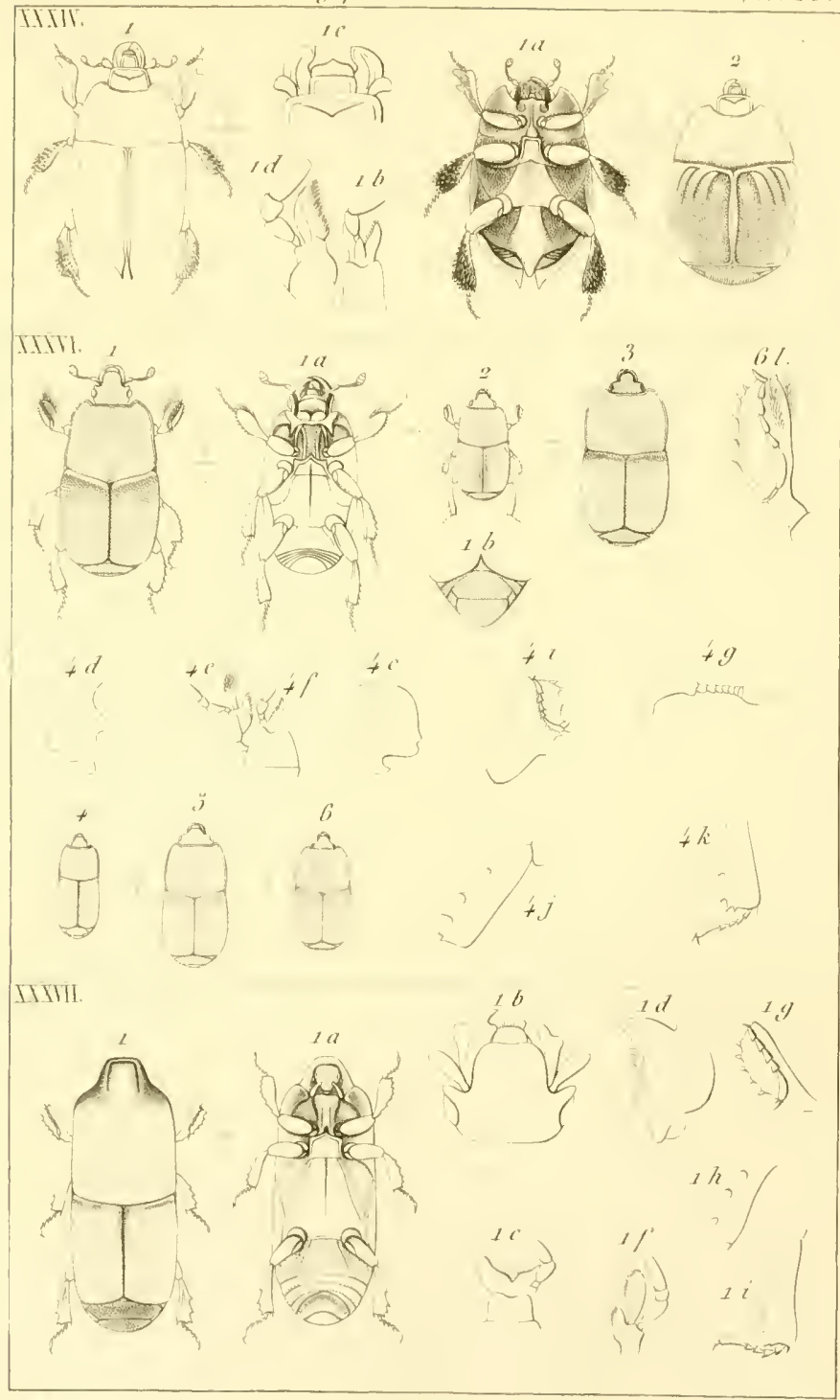

de llarseul tel.

Rebujfel sc.

de Marseul Histervites I'l. nil.

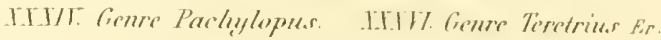
frill lisure fiphonolus 



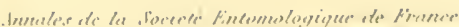

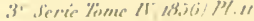

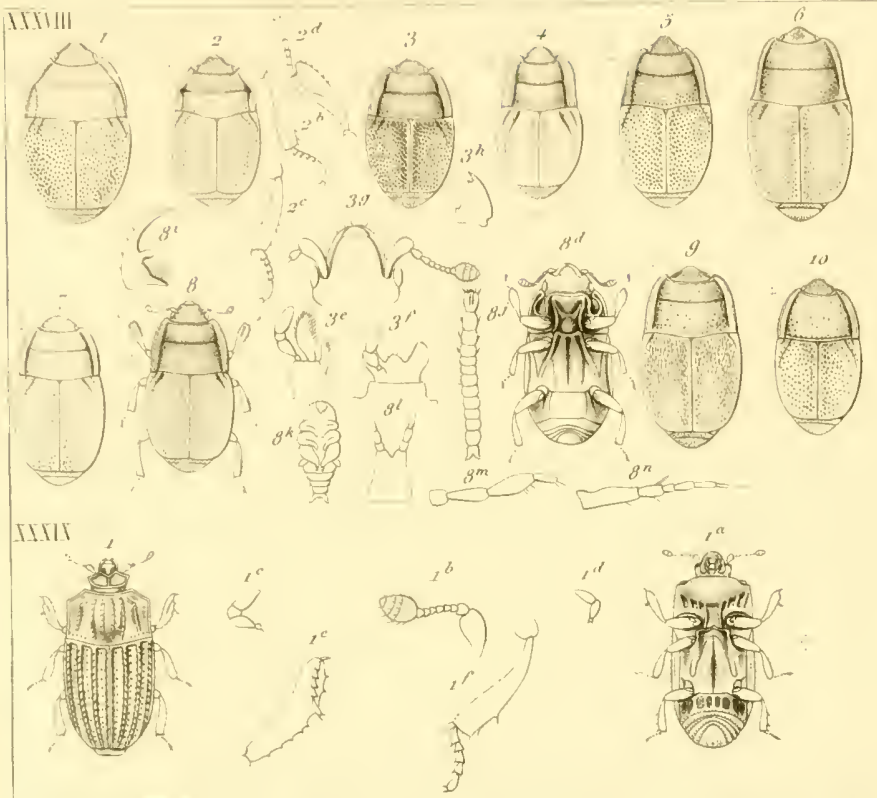

II

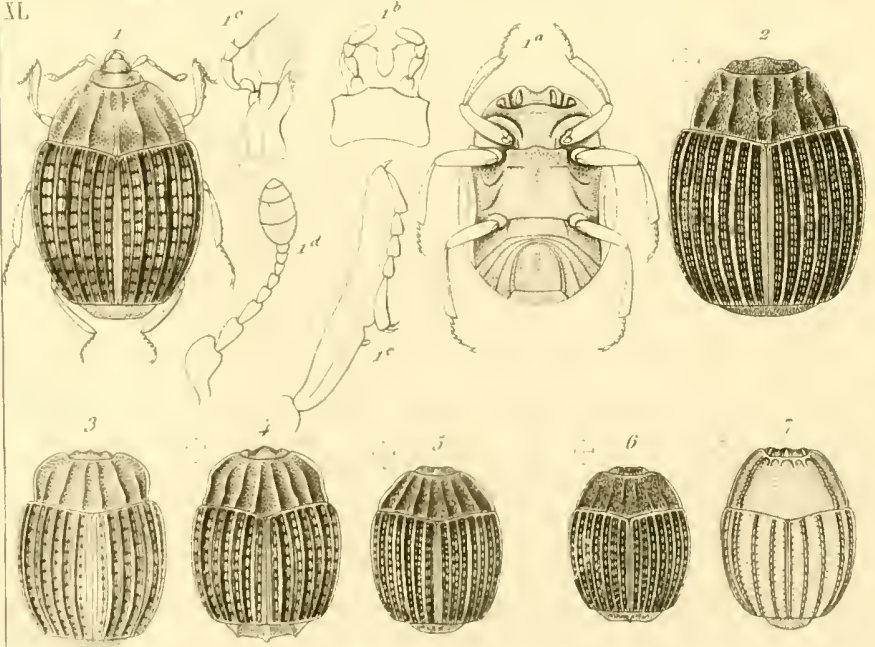

de thusend dit

Relonflict se

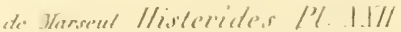

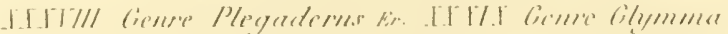

1\%. (iemere (),elhophlulus beach 



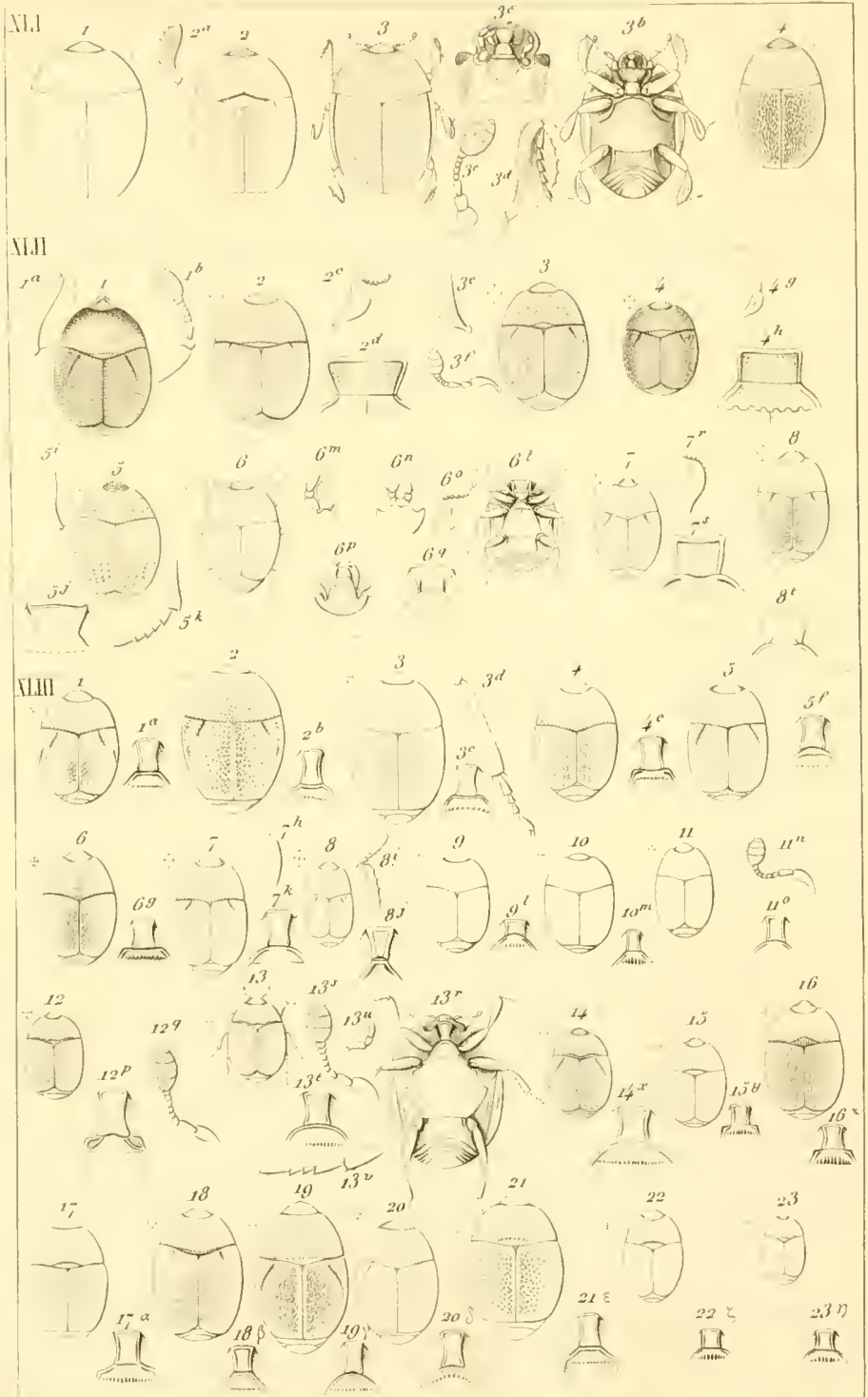

de Marseul del

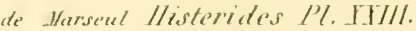

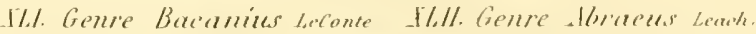
ILIII. Cienre Acrilus Lecime 



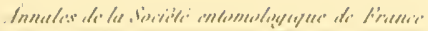

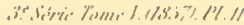

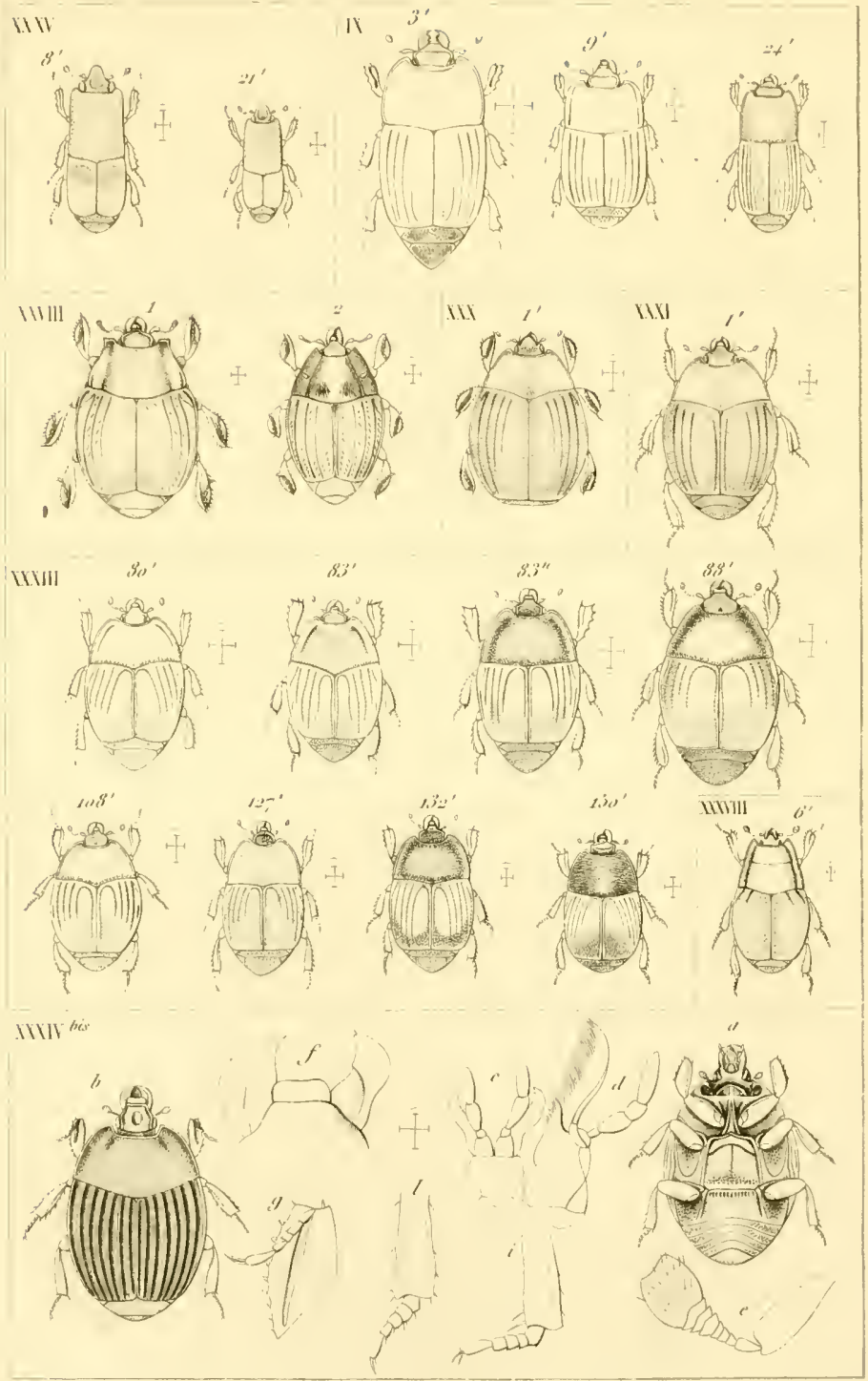

Michuflit:

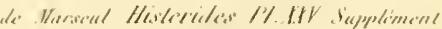

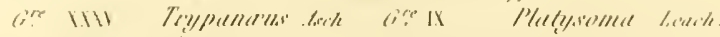

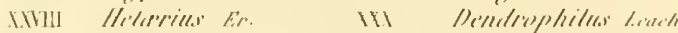

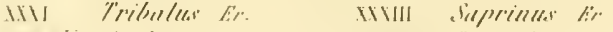

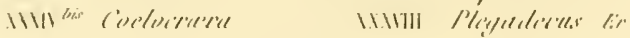








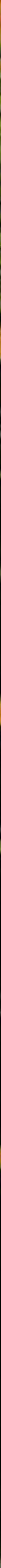

